\section{ARPO}

XXXIV

\section{congireso}

Nacional de

Riegios

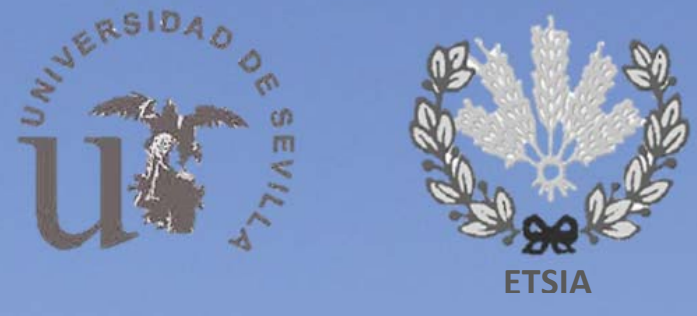

7-9 de junnio de 2016

Sevilla

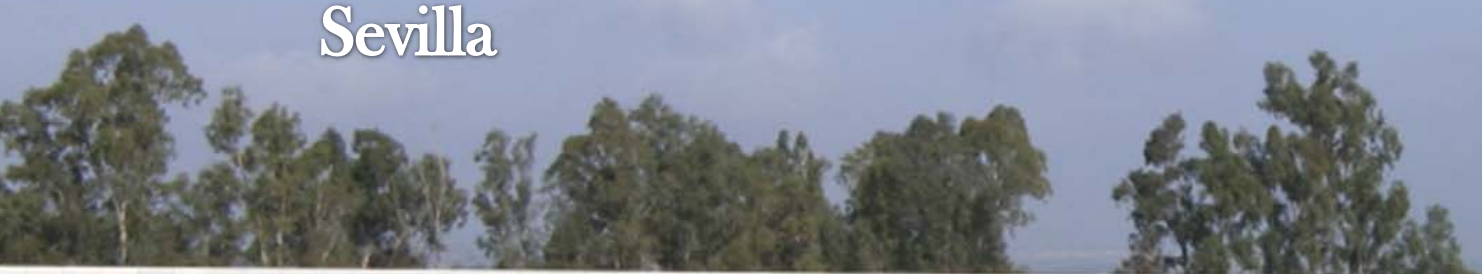


Editor:

Luis Pérez Urrestarazu

Edita

E.T.S. de Ingeniería Agronómica. Universidad de Sevilla ISBN: 978-84-608-6982-5 
XXXIV Congreso Nacional de Riegos

Sevilla, 7-9 de junio de 2016

ENTIDADES ORGANIZADORAS

ASOCIACIONESPAÑOLA DE RIEGOS Y DRENAJES - AERYD

COMITÉ ESPAÑOL DE RIEGOS Y DRENAJES - CERYD

ESCUELA TÉCNICA SUPERIOR DE INGENIERÍA AGRONÓMICA

UNIVERSIDAD DE SEVILLA

CONSEJERÍA DE AGRICULTURA, PESCA Y DESARROLLO RURAL

DIRECCIÓN GENERAL DE DESARROLLO RURAL Y POLÍTICA FORESTAL-MAGRAMA

GRUPO TRAGSA

SOCIEDAD ESTATAL DE INFRAESTRUCTURAS AGRARIAS-SEIASA

CONFEDERACIÓN HIDROGRÁFICA DEL GUADALQUIVIR

INSTITUTO DE INVESTIGACIÓN Y FORMACIÓN AGRARIA Y PESQUERA-IFAPA

FEDERACIÓN NACIONAL DE COMUNIDADES DE REGANTES-FENACORE

INSTITUTO DE RECURSOS NATURALES Y AGROBIOLOGÍA-IRNAS-CSIC

CONSEJO GENERAL DE COLEGIOS OFICIALES DE INGENIEROS AGRÓNOMOS

COLEGIO OFICIAL DE INGENIEROS AGRÓNOMOS DE ANDALUCÍA

COLEGIO OFICIAL DE INGENIEROS TÉCNICOS AGRÍCOLAS DE ANDALUCÍA OCCIDENTAL 


\section{COMITÉ ORGANIZADOR}

Presidente:

Prof. D. José Manuel Quintero Ariza

Director de la Escuela Técnica Superior de Ingeniería Agronómica - Universidad de Sevilla

\section{Secretarios:}

Central: Dña. Pilar Ortiz y Ruiz del Castillo - AERYD

Local: D. Luis Pérez Urrestarazu - Subdirector de Innovación Docente y Movilidad ETSIA- Universidad de Sevilla

\section{Secretarios Adjuntos:}

D. José María de Miguel Pérez, Presidente de AERYD

D. José Antonio Ortiz Fdz.-Urrutia - AERYD-CERYD

\section{Vocales:}

D. José Antonio Baso López, Subdirector de Análisis y Estudios del Grupo Tragsa Dña. Raquel Bravo Rubio, Dirección Gral. Desarrollo Rueral y Política ForestalMAGRAMA

D. José Manuel Castillo Blesa, Gerente Operaciones de Andalucía y Extremadura del Grupo Tragsa (Suplente)

D. Rafael Cuevas Navas, Consejería Agricultura, Pesca y Desarrollo Rural - Junta de Andalucía

D. Antonio Díaz Espejo, Instituto de Recursos Naturales y Agrobiología IRNAS-CSIC

D. José Fernández de Heredia Moreno, Represenante FENACORE, Presidente de la Comunidad de Regantes de la Margen Izquierda del Bembézar

D. Pedro Gavilán Zafra, Investigador IFAPA

D. Javier Gistas Fernández, Colegio Oficial de Ingenieros Agrónomos de Andalucía

D. Manuel Enrique Grosso Casalini, Jefe Área Explotación Confederación Hidrográfica del Guadalquivir

D. Álvaro Gutiérrez Valle, Jefe de Obras, Explotación y Proyectos de SEIASA

D. Antonio F. Vergel Román, Presidente del Colegio Oficial Ingenieros Técnicos Agrícolas Andalucía Occidental 


\section{COMITÉ CIENTÍFICO}

Dña. Raquel Bravo Rubio

Subdirección Gral. Regadíos y Economía delAgua-DGDRPF-MAGRAMA

D. Javier J. Cancela Barrio

Ingeniería Agroforestal - EPS Campus de Lugo - Univ.Santiago Compostela

Dña. Idoia Ederra Gil

Instituto Navarro de Tecnologías e Infraestructuras Agrarias-NTIA, Navarra

D. Gregorio Egea Cegarra

Escuela Técnica Superior de Ingeniería Agronómica, Universidad de Sevilla

D. Antonio Franco Salas

Escuela Técnica Superior de Ingeniería Agronómica, Universidad de Sevilla

D. Sergio Lecina Brau

Dr. Ing. Agrónomo e Ing. de Montes - Investigador, Zaragoza

D. Manuel López Hernández

Grupo TRAGSA, Madrid

D. David Lozano Pérez

IFAPA, Córdoba

D. Victoriano Martínez Álvarez

Ing. Alimentos y Eq. Agrícola. E.T.S.I.Agronómica Univ. Ptc.Cartagena

D. Francisco José Pérez Latorre

Campus Científico Tecnológico, Mecánica de Fluidos, Universidad de Jaén

D. Ángel Martínez Romero

Investigador del CREA, Universidad de Castilla-La Mancha, Albacete

D. Francisco Ramírez de Cartagena Bisbe

Ingeniería Hidráulica - Escuela de Ingeniería Agraria - Univ. Gerona

Dña. Ma del Carmen Rocamora Osorio

Escuela Politécnica Superior de Orihuela, Univ. Miguel Hernández, Alicante

D. Juan Antonio Rodríguez Díaz

Agronomía - E.T.S.I. Agrónomos y Montes - Univ. Córdoba

D. Álvaro Royuela Tomás

Investigador del CVER, ETSIAMN, Universidad Politécnica de Valencia

D. Ángel Ruiz Padín

Ingeniería del Riego - E.S.y T.Ingeniería Agraria -Univ. de León

Dña. Ma del Carmen Ruíz Sánchez

Investigadora del CEBAS-CSIC-Murcia

D. Antonio Jesús Zapata Sierra

Departamento de Ingeniería Rural, Universidad de Almería 


\section{GRUPO TEMAS A: Agrohidrología. Hidrología del riego}

Relaciones agua-suelo-planta-atmósfera. Necesidades hídricas de los cultivos. Balance de agua. Coeficientes de cultivo. Estrategias de riego en áreas con escasez de agua. Respuesta de los cultivos a riegos deficitarios. Nuevos métodos y tecnologías de medición del agua de riego, herramientas de cálculo y modelos de simulación. 
A-01

\title{
ET。 ESTANDARIZADA EN EL SUR DE ESPAÑA. ¿CUÁL DEBE SER LA REFERENCIA?
}

\author{
Gavilán, ${ }^{1}{ }^{1}$, Estévez, $\mathrm{J}^{2}$, Berengena, $\mathrm{J}^{3}$ \\ ${ }^{1}$ Investigador Titular. IFAPA Centro Alameda del Obispo, Apdo. 3092, 14080 Córdoba, \\ pedrod.gavilan@juntadeandalucia.es \\ ${ }_{2}^{2}$ Profesor contratado doctor. Área de Proyectos de Ingeniería. Universidad de Córdoba. \\ Carretera Nacional IV Km. 396, 14014. Córdoba. jestevez@uco.es \\ ${ }^{3}$ Investigador Principal. IFAPA Centro Alameda del Obispo, jubilado
}

\section{Resumen}

La evapotranspiración de referencia $\left(E T_{0}\right)$ cuantifica la demanda evaporativa del aire y es necesaria para el cálculo del uso consuntivo de agua de los cultivos. Las redes de estaciones agrometeorológicas proporcionan esta información, utilizando diferentes versiones de la ecuación de Penman-Monteith, realizando cálculos horarios o diarios. Este trabajo pretende arrojar luz sobre la controversia que existe en la utilización de ambos tiempos de cálculo, realizando una comparación a escala local y regional entre las versiones FAO56 y ASCE de esta ecuación. La comparación se realizó en 31 localizaciones de Andalucía, calculando los valores diarios mediante suma de horarios. Además, se comparó la estimación diaria de $\mathrm{ET}_{\text {o }}$ de la ecuación FAO56-PM con la medida en un lisímetro de pesada en Córdoba. Los resultados de la comparación entre valores medidos y estimados usando ambas ecuaciones estandarizadas indican que los métodos más precisos para estimar los valores diarios de la ETo fueron FAO56-PM en base diaria y ASCE-PM en base horaria. Ambos mostraron una precisión similar cuando se compararon con los valores medidos en un lisímetro de pesada. La ecuación FAO56-PM en base horaria mostró una menor precisión, con subestimaciones del $5 \%$. A escala regional, la ecuación FAO56-PM en base horaria subestimó los valores diarios de $\mathrm{ET}_{0}$ calculados mediante la misma ecuación estandarizada en su versión ASCE hasta un $6 \%$, produciéndose una subestimación media del $4 \%$. Esta diferencia fue debida al uso de un mayor valor de $r_{c}\left(70 \mathrm{~s} \mathrm{~m}^{-1}\right)$ en la ecuación FAO56-PM, en relación con el valor de $50 \mathrm{~s} \mathrm{~m}^{-1}$ aplicado en la ecuación estandarizada ASCE durante las horas diurnas.

\section{Summary}

The most practical way to quantify water consumption by the crops is by using the concept of reference crop evapotranspiration ( $\mathrm{ET}_{\mathrm{o}}$ ). Agrometeorological networks provide daily $\mathrm{ET}_{0}$ values using the Penman-Monteith equation on a daily or hourly basis. Up till now, the $E T_{0}$ methods are being used mainly for computation with a 24-h timestep because hourly meteorological data are not readily accessible for the users to apply $\mathrm{ET}_{\text {o }}$ procedures on an hourly basis. This work quantifies the differences associated with using two different timesteps (hourly and daily basis) for computing $\mathrm{ET}_{\mathrm{o}}$ using two standardized PenmanMonteith equations (ASCE and FAO56) under different climatic conditions in Andalusia. Hourly $E T_{0}$ was measured in Córdoba, southern Spain, using a precision weighing lysimeter. Close to the lysimeter, an automatic weather station was located to register hourly meteorological variables. Penman-Monteith equation to estimate $\mathrm{ET}_{\mathrm{o}}$ was evaluated for hourly and daily estimates. ASCE and FAO-56 standardized ET。 equations were also compared using data from 31 meteorological stations in Andalusia. Comparisons were made 
between daily $\mathrm{ET}_{0}$ obtained by summing hourly standardized ASCE-Penman-Monteith estimations and calculated from the addition of hourly FAO56-Penman-Monteith estimations and daily $\mathrm{ET}_{0}$ estimated on a daily basis. On an hourly basis, the FAO-56 version estimated lower than the ASCE version as $6 \%$ in some locations, with a difference of $4 \%$ on the average, mainly due to the higher surface resistance $\left(70 \mathrm{~s} \mathrm{~m}^{-1}\right)$ used in the FAO-56 version during daytime periods, as opposed to the $50 \mathrm{~s} \mathrm{~m}^{-1}$ value used by the ASCE version. The level of agreement improved when the two computational time steps (hourly and daily) were compared, because differences were lower ( $2 \%$ on the average).

\section{1- Introducción y objetivos}

Andalucía es una región semiárida con veranos muy cálidos y secos. Cuenta con más de un millón de hectáreas de regadío, que representan alrededor del $32 \%$ de la superficie cultivada, el $76 \%$ de la producción final agrícola y el $63 \%$ de la producción final agraria y el empleo agrario. El uso consuntivo de agua de la agricultura es elevado y la ausencia de lluvias limita el desarrollo de los cultivos y la producción de cosechas durante los periodos de sequía. Esta situación requiere actuaciones para un eficiente uso del agua, entre ellas la estimación precisa de la evapotranspiración de los cultivos $\left(E T_{c}\right)$.

El método generalmente usado para estimar el uso consuntivo de agua por parte de los cultivos es el propuesto por la FAO en su Manual de Riego y Drenaje $n^{\circ} 24$ (Doorenbos y Pruitt, 1977). Está basado en la cuantificación de la demanda atmosférica, mediante el cálculo de la evapotranspiración del cultivo de referencia $\left(E T_{0}\right)$, y la posterior aplicación de un coeficiente de cultivo $\left(\mathrm{K}_{\mathrm{c}}\right)$, que tiene en cuenta las características del mismo. El producto de esos dos componentes proporciona una estimación de la $\mathrm{ET}_{\mathrm{c}}$. El cultivo de referencia fue definido como una superficie extensa de gramíneas, de altura uniforme entre 8 y $15 \mathrm{~cm}$, en crecimiento activo, con cobertura total y bien abastecida de agua (Doorenbos y Pruitt, 1977). Este cultivo de referencia ha sido posteriormente redefinido en el Manual de Riego y Drenaje $\mathrm{n}^{\circ} 56$ como un cultivo hipotético con una altura asumida de $0.12 \mathrm{~m}$, una resistencia de la cubierta $\left(r_{c}\right)$ fija de $0.70 \mathrm{~s} \mathrm{~m}^{-1}$ y un albedo de 0.23 (Allen y col., 1998).

La mayoría de las redes de información agrometeorológica y de los servicios de asesoramiento al regante proporcionan diariamente valores de $\mathrm{ET}_{\mathrm{o}}$ en las localizaciones de sus estaciones meteorológicas. Estos son calculados generalmente aplicando la ecuación estandarizada de Penman-Monteith, usando para los cálculos datos meteorológicos medios diarios. En algunos casos se realizan cálculos intradiarios, usando datos meteorológicos horarios o semihorarios, que posteriormente son sumados para obtener el valor de $E_{\text {o }}$ diario. Hace algunos años, los cálculos de la $\mathrm{ET}_{0}$ se realizaban siempre en base diaria debido a la falta de disponibilidad de datos meteorológicos intradiarios. Las redes de estaciones meteorológicas automáticas han permitido el cálculo de $\mathrm{ET}_{0}$ en base horaria $\mathrm{o}$ semihoraria.

Muchos trabajos indican que existe una mejora de la precisión de las estimaciones de $E_{0}$ cuando se usa la versión estandarizada por la American Society of Civil Engineers (ASCE) de la ecuación de Penman-Monteith (ASCE-PM) y se realizan los cálculos en base intradiaria (Lecina y col., 2003; Berengena y Gavilán, 2005; Allen y col., 2006). El cálculo horario tiene en cuenta los efectos de los cambios súbitos que ocurren durante el día en la velocidad del viento, la temperatura del aire o el déficit de presión de vapor (Irmak y col., 2005; Itenfisu y col., 2003). Esta ecuación, aplicada en base horaria, utiliza una resistencia de la cubierta $\left(r_{c}\right)$ de $50 \mathrm{~s} \mathrm{~m}^{-1}$ durante los periodos diurnos y de $200 \mathrm{~s} \mathrm{~m}^{-1}$ durante los nocturnos. La versión FAO56 (FAO56-PM) utiliza un único valor de $r_{c}$ igual a $70 \mathrm{~s} \mathrm{~m}^{-1}$. Por tanto, una comparación entre ambas versiones de la ecuación, con diferentes tiempos de cálculo (horario y diario), sería aconsejable en las condiciones semiáridas del sur de 
España, para aclarar las ventajas e inconvenientes del uso de cada una de ellas. Esto es lo que se pretende con este trabajo.

\section{Material y métodos}

\subsection{Medida de la evapotranspiración de referencia}

La comparación entre los valores de $\mathrm{ET}_{0}$ medidos y estimados fue realizada en la estación lisimétrica del Centro IFAPA Alameda del Obispo en Córdoba (37ํำ $\mathrm{N}, 4^{\circ} 51^{\prime} \mathrm{W}$, $110 \mathrm{~m}$ sobre el nivel del mar), en el valle medio del Guadalquivir. Los datos experimentales fueron recogidos durante el año 2004 sobre una parcela de festuca (Festuca arundinacea) de 1.3 ha aproximadamente que fue usada como superficie de referencia. En total, se usaron para el análisis 266 días. La $\mathrm{ET}_{0}$ fue medida con un lisímetro de pesada localizado en el centro de la parcela, con una superficie de $3 \times 2 \mathrm{~m}^{2}$ y una profundidad de $1.5 \mathrm{~m}$. Está soportado por una plataforma contrapesada y es capaz de detectar variaciones de $0.1 \mathrm{~kg}$ (equivalente a $0.02 \mathrm{~mm}$ de $\mathrm{ET}_{\mathrm{o}}$ ). El peso del lisímetro fue medido usando una célula de carga conectada a un datalogger, programado para medir cada media hora. Dentro de la misma parcela, a $30 \mathrm{~m}$ del lisímetro, se ubica una estación meteorológica automática capaz de medir la humedad relativa y temperatura del aire, la radiación global, la velocidad y dirección del viento y la precipitación (Foto 1).

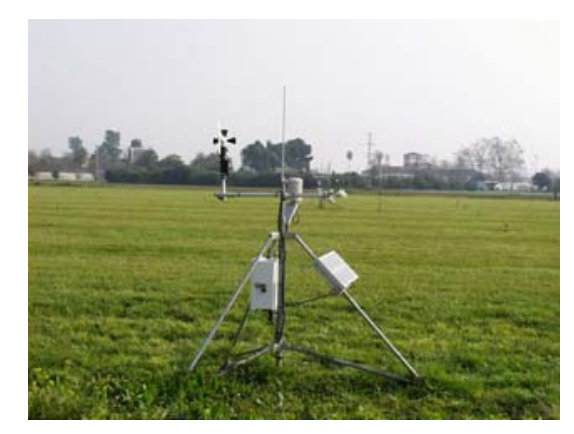

Foto 1. Estación meteorológica automática de la Red SIAR, usada para estimar la ETo.

\subsection{Datos meteorológicos. Análisis regional.}

Los datos meteorológicos usados en el análisis regional fueron obtenidos de las estaciones en Andalucía del Sistema de Información Agroclimática para el Regadío (SIAR) (Foto 1). Esta red cuenta en Andalucía con 100 estaciones meteorológicas automáticas y tiene como objetivo fundamental proporcionar valores de precipitación, ET o y otras variables meteorológicas para la estimación de las necesidades de agua de los cultivos. Los datos meteorológicos de las estaciones de Andalucía están disponibles en la dirección de Internet (www.juntadeandalucia.es/agriculturaypesca/ifapa/ria). Las estaciones están controladas por un datalogger programable y equipadas con sensores para la medida de la temperatura y la humedad relativa del aire, la radiación global, la velocidad y dirección del viento y la precipitación en forma de lluvia. Las estaciones registran valores semihorarios y diarios. En el trabajo se usaron 31 estaciones, con diferentes condiciones climáticas, incluyendo estaciones costeras y de interior. Las elevaciones de las estaciones variaron entre 4 y 1212 $\mathrm{m}$ sobre el nivel del mar, la longitud entre $1.883 \mathrm{~W}$ y $7.018 \mathrm{~W}$ y la latitud entre $36.286 \mathrm{~N}$ y $38.255 \mathrm{~N}$. La precipitación media anual varió entre 265 y $727 \mathrm{~mm}$, la temperatura media entre 12.7 y $18.3^{\circ} \mathrm{C}$, la humedad relativa media del aire entre el 56 y el $71 \%$ y la velocidad media del viento entre 1.0 y $2.9 \mathrm{~m} \mathrm{~s}^{-1}$. En el estudio se usaron tres años de datos. 


\subsection{Estimación de la evapotranspiración de referencia}

La ecuación estandarizada ASCE-PM (ASCE-EWRI, 2004) fue fruto de un intento de simplificar la aplicación de la ecuación de Penman-Monteith en base horaria y diaria, usando una sencilla expresión válida para gramíneas $\left(E T_{0}\right)$ y alfalfa $\left(E T_{r}\right)$. Para gramíneas, cuando se realizan cálculos horarios, esta versión utiliza un valor de $r_{c}$ de $50 \mathrm{~s} \mathrm{~m}^{-1}$ para periodos diurnos y de $200 \mathrm{~s} \mathrm{~m}^{-1}$ para los nocturnos. Para cálculos diarios utiliza un único valor de $70 \mathrm{~s}$ $\mathrm{m}^{-1}$. La ecuación estandarizada FAO56-PM (Allen y col., 1998) utiliza una única resistencia $r_{c}$ igual a $70 \mathrm{~s} \mathrm{~m}^{-1}$ para cálculos horarios y diarios (Tabla 1). Se consideran valores diurnos aquellos en los que la radiación neta en un periodo semihorario es mayor que cero. Ambas versiones utilizan los mismos procedimientos de cálculo de $G, R n$ y los otros parámetros de la ecuación de Penman-Monteith (ASCE-EWRI, 2004). La ecuación estandarizada de Penman-Monteith en sus versiones FAO56 y ASCE adopta la siguiente forma:

$$
E T_{0}=\frac{0.408 \Delta\left(R_{n}-G\right)+\gamma \frac{C_{n}}{T_{a}+273} U_{2}\left(e_{s}-e_{a}\right)}{\Delta+\gamma\left(1+C_{d} U_{2}\right)}
$$

Donde $\mathrm{ET}_{\mathrm{o}}=$ evapotranspiración de referencia $\left(\mathrm{mm} \mathrm{h}^{-1}\right.$ ó $\left.\mathrm{mm} \mathrm{d}^{-1}\right) ; \Delta=$ pendiente de la curva de presión de vapor en saturación frente a la temperatura del aire $\left(\mathrm{kPa}^{\circ} \mathrm{C}^{-1}\right) ; \mathrm{R}_{\mathrm{n}}=$ radiación neta ( $M J \mathrm{~m}^{-2} \mathrm{~h}^{-1}$ ó $\left.\mathrm{MJ} \mathrm{m}^{-2} \mathrm{~d}^{-1}\right) ; \mathrm{G}=$ flujo de calor en el suelo ( $\mathrm{MJ} \mathrm{m}^{-2} \mathrm{~h}^{-1}$ ó $\mathrm{MJ} \mathrm{m}^{-2} \mathrm{~d}^{-}$ $\left.{ }^{1}\right) ; \gamma=$ constante psicrométrica $\left(\mathrm{kPa}^{\circ} \mathrm{C}^{-1}\right) ; \mathrm{T}=$ temperatura media horaria o diaria del aire $\left({ }^{\circ} \mathrm{C}\right) ; \mathrm{U}_{2}=$ velocidad del viento media horaria o diaria a $2 \mathrm{~m}$ de altura $\left(\mathrm{m} \mathrm{s}^{-1}\right) ; \mathrm{e}_{\mathrm{s}}=$ presión de vapor en saturación $(\mathrm{kPa}) ; \mathrm{e}_{\mathrm{a}}=$ presión de vapor actual $(\mathrm{kPa}) ; \mathrm{C}_{\mathrm{n}}$ y $\mathrm{C}_{\mathrm{d}}=$ constantes que dependen de la superficie de referencia (festuca o alfalfa) y el periodo de cálculo (Tabla 1). El valor de la resistencia $r_{c}$ está implícito en el denominador de la ecuación, concretamente en el factor $C_{d}$.

Tabla 1. Valores de $C_{n}$ y $C_{d}$ para las versiones estandarizadas FAO56 y ASCE de la ecuación de Penman-Monteith usando una gramínea como superficie de referencia.

\begin{tabular}{cccc}
\hline Método & Tiempo de cálculo & $\mathrm{C}_{\mathrm{n}}$ & $\mathrm{C}_{\mathrm{d}}$ \\
\hline FAO56-PM & Diario & 900 & 0.34 \\
& Horario & 37 & 0.34 \\
\hline \multirow{2}{*}{ ASCE-PM } & Diario & 900 & 0.34 \\
& Horario & 37 & $0.24 / 0.96^{\mathrm{a}}$ \\
\hline
\end{tabular}

${ }^{a}$ El primer valor es para periodos diurnos $\left(R_{n}>0\right)$ y el segundo para nocturnos $\left(R_{n}<0\right)$.

\subsection{Análisis de los resultados}

La comparación entre valores medidos y estimados se realizó utilizando como referencia los valores de $\mathrm{ET}_{0}$ medidos con el lisímetro. Para el análisis a escala regional se

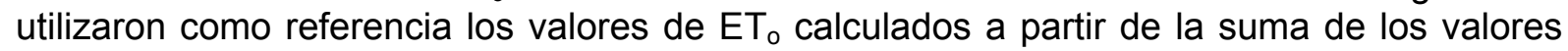
horarios obtenidos de la aplicación de la ecuación ASCE-PM. Este método ha sido seleccionado debido a que diferentes estudios realizados utilizando datos lisimétricos han mostrado su superioridad en las condiciones semiáridas de Andalucía frente a otras versiones (Berengena y Gavilán, 2005; Gavilán y col., 2007). En estos trabajos, los valores horarios y diarios de $\mathrm{ET}_{0}$, que se utilizaron como referencia, fueron medidos usando un lisímetro de pesada. 
En el análisis se determinó el error medio aritmético (MBE), la raíz cuadrada del error cuadrático medio (RMSE), el error relativo (RE) y la relación entre la media de los valores a comparar (R).

$$
\begin{gathered}
M B E=\frac{\sum_{i=1}^{n}\left(y_{i}-x_{i}\right)}{n} \\
R M S E=\sqrt{\frac{\sum_{i=1}^{n}\left(y_{i}-x_{i}\right)^{2}}{n}} \\
R E=\frac{M B E}{\bar{x}} \times 100 \\
R=\frac{\bar{y}}{\bar{x}}
\end{gathered}
$$

\section{Resultados y discusión}

\subsection{Comparación de las estimaciones de $\mathrm{ET}_{\mathrm{o}}$ frente a datos lisimétricos}

Durante el año 2004 se realizó en Córdoba la comparación entre los valores de ET。 medidos usando un lisímetro de pesada y los estimados aplicando la ecuación estandarizada FAO56-PM usando datos meteorológicos medios diarios. La Figura 1 representa los valores mensuales medios diarios medidos y estimados. El valor anual estimado de $\mathrm{ET}_{\mathrm{o}}$ fue de $1403 \mathrm{~mm}$, mientras que el medido en el lisímetro fue igual a 1401 $\mathrm{mm}$. Por tanto, la relación entre valores estimados y medidos fue prácticamente igual a 1. La raíz cuadrada del error cuadrático medio fue igual a $0.34 \mathrm{~mm} \mathrm{~d}^{-1}$, equivalente a un error relativo del $9.3 \%$. Puede considerarse que la ecuación ni sobrestimó ni subestimó, pues el error medio aritmético fue igual a $-0.05 \mathrm{~mm} \mathrm{~d}^{-1}$ (Tabla 2).

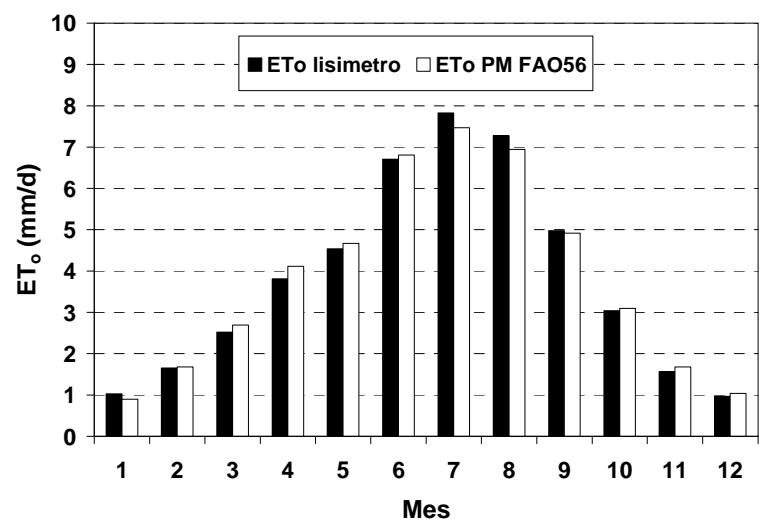

Figura 1. Comparación entre los valores mensuales medios diarios de $\mathrm{ET}_{\mathrm{o}}\left(\mathrm{mm} \mathrm{d}^{-1}\right)$ medidos mediante lisimetría y estimados a partir de datos meteorológicos medios diarios utilizando la ecuación estandarizada FAO56-PM. 


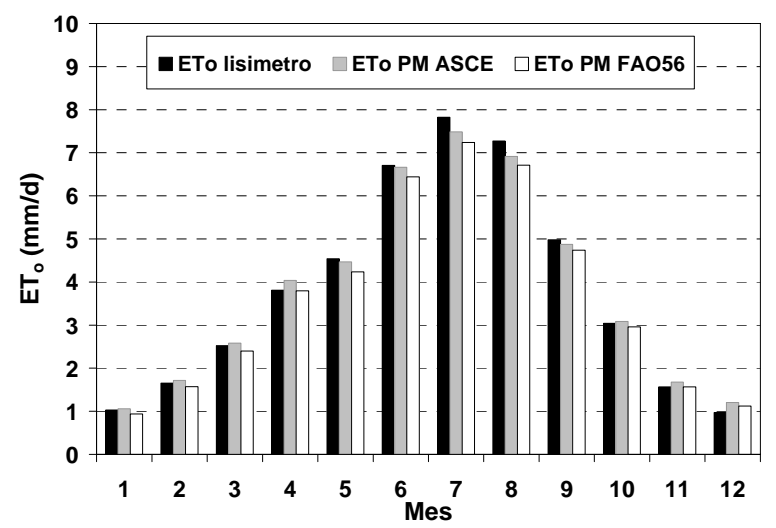

Figura 2. Comparación entre los valores mensuales medios diarios de $\mathrm{ET}_{\mathrm{o}}\left(\mathrm{mm} \mathrm{d}^{-1}\right)$ medidos mediante lisimetría y estimados a partir de datos meteorológicos horarios utilizando las ecuaciones estandarizadas ASCE-PM y FAO56-PM.

Tabla 2. Valores mensuales medios diarios y resultados de la comparación de los valores diarios de $\mathrm{ET}_{0}\left(\mathrm{~mm} \mathrm{~d}^{-1}\right)$ medidos con lisimetría y estimados utilizando las ecuaciones estandarizadas de Penman-Monteith en sus versiones FAO56 y ASCE, usando datos meteorológicos diarios y horarios.

\begin{tabular}{|c|c|c|c|c|}
\hline Mes & $\begin{array}{c}\mathrm{ET}_{\mathrm{o}} \text { lisímetro } \\
\left(\mathrm{mm} \mathrm{d}^{-1}\right)\end{array}$ & $\begin{array}{l}\mathrm{ET}_{\mathrm{o}} \mathrm{FAO56-PM} \\
\text { diarios }\left(\mathrm{mm} \mathrm{d}^{-1}\right)\end{array}$ & $\begin{array}{c}\mathrm{ET}_{\mathrm{o}} \mathrm{FAO56-PM} \\
\text { horarios }\left(\mathrm{mm} \mathrm{d}^{-1}\right)\end{array}$ & $\begin{array}{c}\mathrm{ET}_{\mathrm{o}} \text { ASCE-PM } \\
\text { horarios }\left(\mathrm{mm} \mathrm{d}^{-1}\right)\end{array}$ \\
\hline Enero & 1.03 & 0.90 & 0.94 & 1.06 \\
\hline Febrero & 1.65 & 1.68 & 1.57 & 1.72 \\
\hline Marzo & 2.52 & 2.69 & 2.40 & 2.58 \\
\hline Abril & 3.81 & 4.11 & 3.80 & 4.04 \\
\hline Mayo & 4.54 & 4.67 & 4.24 & 4.47 \\
\hline Junio & 6.71 & 6.81 & 6.44 & 6.66 \\
\hline Julio & 7.82 & 7.47 & 7.24 & 7.49 \\
\hline Agosto & 7.28 & 6.95 & 6.71 & 6.92 \\
\hline Septiembre & 4.98 & 4.91 & 4.74 & 4.87 \\
\hline Octubre & 3.04 & 3.10 & 2.96 & 3.08 \\
\hline Noviembre & 1.57 & 1.68 & 1.57 & 1.68 \\
\hline Diciembre & 0.97 & 1.04 & 1.12 & 1.21 \\
\hline Anual (mm) & 1401 & 1403 & 1334 & 1396 \\
\hline $\operatorname{MBE}\left(\mathrm{mm} \mathrm{d}^{-1}\right)$ & - & -0.05 & -0.17 & -0.01 \\
\hline RE (\%) & - & 9.3 & 10.6 & 7.3 \\
\hline $\operatorname{RMSE}\left(\mathrm{mm} \mathrm{d}^{-1}\right)$ & - & 0.34 & 0.39 & 0.28 \\
\hline Ratio (-) & - & 1.00 & 0.95 & 1.00 \\
\hline $\mathbf{R}^{2}$ & - & 0.99 & 0.99 & 0.99 \\
\hline
\end{tabular}

Además, se realizó la comparación entre los valores diarios de $\mathrm{ET}_{0}$ medidos y los estimados mediante las dos ecuaciones estandarizadas descritas, utilizando datos meteorológicos horarios (Figuras 2 y 3). Cuando se usó la ecuación FAO56-PM se produjo una subestimación de la $E T_{0}$ del $5 \%$, un RMSE de $0.39 \mathrm{~mm} \mathrm{~d}^{-1}$ (equivalente a un error relativo del $10.6 \%$ ) y un MBE de $-0.17 \mathrm{~mm} \mathrm{~d}^{-1}$ (Gavilán y col., 2007). Sin embargo la utilización de la ecuación ASCE-PM produjo subestimaciones inferiores al 1\%, con valores 
de RMSE de $0.28 \mathrm{~mm} \mathrm{~d}^{-1}$ (equivalente a un error relativo del $7.3 \%$ ) y MBE iguales a -0.01 $\mathrm{mm} \mathrm{d}^{-1}$ (Tabla 2). Estas diferencias pueden ser explicadas por los valores usados en la resistencia de la cubierta $\left(r_{c}\right)$ en ambas versiones de la ecuación cuando se realizan cálculos horarios. Durante las horas diurnas, en las que se producen elevados valores de la demanda evaporativa del aire, la versión ASCE utiliza valores de $r_{c}$ de $50 \mathrm{~s} \mathrm{~m}^{-1}$, valor que se incrementa hasta $200 \mathrm{~s} \mathrm{~m}^{-1}$ durante las horas nocturnas. En la versión FAO56 la resistencia de la cubierta usada en el cálculo permanece constante durante todo el día $\left(r_{\mathrm{c}}=70 \mathrm{~s} \mathrm{~m}^{-1}\right)$. Berengena y Gavilán (2005) calcularon los valores de esta resistencia a lo largo del día en una pradera de festuca en Córdoba, observándose que durante las horas centrales del día este valor ronda los $50 \mathrm{~s} \mathrm{~m}^{-1}$ y se eleva hasta los $200 \mathrm{~s} \mathrm{~m}^{-1}$ durante la noche (Figura 4). Esto demuestra que la hipótesis del valor constante de $r_{c}$ no es en rigor aceptable y que los valores mínimos de $r_{c}$-inferiores a $70 \mathrm{~s} \mathrm{~m}^{-1}$ - se dan en las horas de máxima demanda evaporativa. Otros estudios han demostrado igualmente que durante las horas diurnas $r_{c}$ es menor de $70 \mathrm{~s} \mathrm{~m}^{-1}$ para una cubierta de gramíneas de $12 \mathrm{~cm}$ de altura y que valores menores proporcionaron estimaciones más precisas de $\mathrm{ET}_{\text {。 }}$ (Allen y col., 1996; Ventura y col., 1999; Todorovic, 1999; Wright y col., 2000; Lecina y col., 2003; Allen y col., 2006).

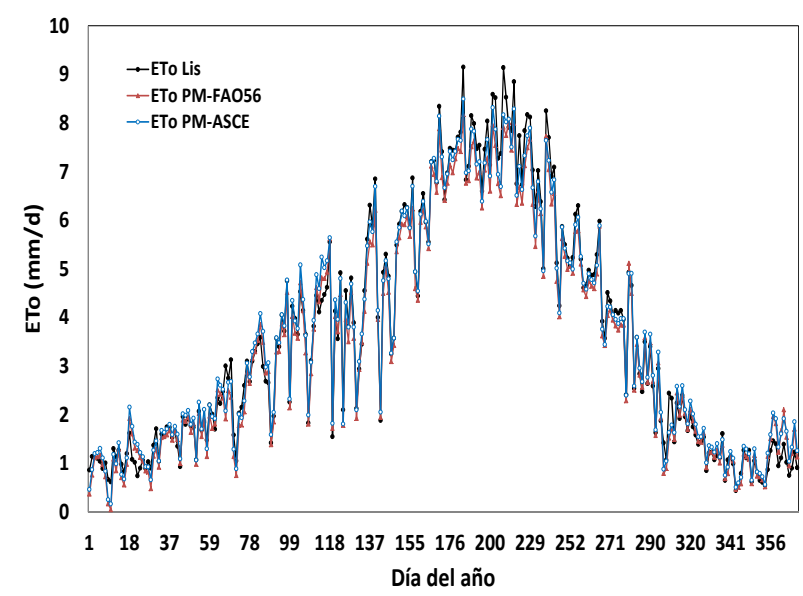

Figura 3. Evolución de los valores medios diarios de $E T_{0}$ ( $\left.\mathrm{mm} / \mathrm{d}\right)$ durante el año 2004 medidos mediante lisimetría y estimados a partir de datos meteorológicos horarios utilizando las ecuaciones estandarizadas ASCE-PM y FAO56-PM.

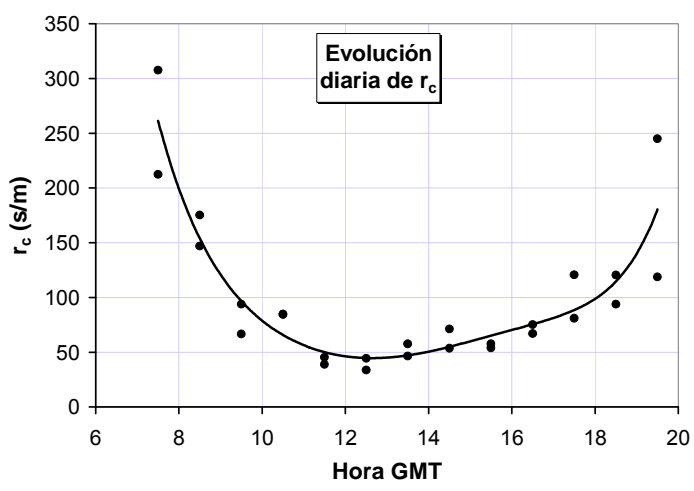

Figura 4. Evolución diaria media de la resistencia de la cubierta $\left(r_{c}\right)$ de referencia durante la estación de riegos medidos sobre una pradera de festuca en Córdoba. 


\subsection{Comparación a escala regional entre los valores diarios de $\mathrm{ET}_{\mathrm{o}}$ obtenidos de la suma horaria de los valores estandarizados FA056-PM y ASCE-PM}

Es difícil disponer de datos medidos de $\mathrm{ET}_{0}$ en diferentes localizaciones. En concreto, en Andalucía existe un único lisímetro de pesada. Sin embargo, se puede realizar la comparación entre dos ecuaciones estandarizadas utilizando como referencia una de ellas, a ser posible la que se haya mostrado más precisa al compararla con valores medidos. Para este trabajo se ha usado como referencia la ecuación estandarizada ASCEPM en su versión horaria.

Los valores de $\mathrm{ET}_{0}$ obtenidos a partir de las sumas horarias de las ecuaciones estandarizadas FAO56 y ASCE en las 31 estaciones meteorológicas analizadas mostraron una alta correlación $\left(R^{2}>0.99\right)$ (Figura 5 ) y bajos valores de RMSE (variaron entre 0.09 y $0.25 \mathrm{~mm} \mathrm{~d}^{-1}$ ), bajo las condiciones semiáridas de Andalucía. Sin embargo, la versión FAO56 de la ecuación de Penman-Monteith en base horaria subestimó los valores de la versión ASCE-PM entre un $2 \%$ y un $6 \%$, produciéndose una subestimación media del $4 \%$ de la versión FAO respecto a la ASCE (Tabla 3). Esto significa que la primera subestimó los valores de la versión ASCE en todas las localizaciones. El valor negativo del error medio aritmético, que varió entre -0.06 y $-0.20 \mathrm{~mm} \mathrm{~d}^{-1}$, corrobora esta afirmación. Por tanto, estos resultados sugieren que el uso de la versión FAO56 para cálculos horarios en lugar de la versión ASCE produciría subestimaciones de $\mathrm{ET}_{0}$ a escala regional de hasta el $6 \%$. La diferencia fue menor del $2 \%$ en una sola localización y fue mayor del $5 \%$ en 15 localizaciones, el $50 \%$ de las estudiadas.

Tabla 3. Resultados de la comparación de las ecuaciones estandarizadas FAO56 y ASCE Penman-Monteith en base horaria para el cálculo de la $\mathrm{ET}_{0}$.

\begin{tabular}{|c|c|c|c|c|c|c|c|c|c|c|}
\hline & \multicolumn{5}{|c|}{$\begin{array}{c}\mathrm{ET}_{\mathrm{o}} \mathrm{FAO56-PM} \text { horario vs ASCE-PM } \\
\text { horario }\end{array}$} & \multicolumn{5}{|c|}{$\begin{array}{c}\mathrm{ET}_{\mathrm{o}} \text { ASCE-PM diario vs ET } \\
\text { horario }\end{array}$} \\
\hline & $\begin{array}{c}\mathrm{MBE} \\
\left(\mathrm{mm} \mathrm{d}^{-1}\right)\end{array}$ & $\begin{array}{l}\text { RE } \\
(\%)\end{array}$ & $\begin{array}{l}\text { RMSE } \\
\left(\mathbf{m m ~ d}^{-1}\right)\end{array}$ & $\begin{array}{c}\text { Ratio } \\
(-)\end{array}$ & $\begin{array}{l}R^{2} \\
(-)\end{array}$ & $\begin{array}{c}\mathrm{MBE} \\
\left(\mathrm{mm} \mathrm{d}^{-1}\right)\end{array}$ & $\begin{array}{l}\text { RE } \\
(\%)\end{array}$ & $\begin{array}{l}\text { RMSE } \\
\left(\mathbf{m m ~ d}^{-1}\right)\end{array}$ & $\begin{array}{c}\text { Ratio } \\
(-)\end{array}$ & $\begin{array}{l}R^{2} \\
(-)\end{array}$ \\
\hline Máximo & -0.06 & 6.7 & 0.25 & 0.98 & 1.00 & 0.05 & 10.5 & 0.38 & 1.01 & 0.99 \\
\hline Mínimo & -0.20 & 2.6 & 0.09 & 0.94 & 0.99 & -0.22 & 6.7 & 0.24 & 0.93 & 0.97 \\
\hline Medio & -0.14 & 4.7 & 0.17 & 0.96 & 0.99 & -0.05 & 7.9 & 0.29 & 0.98 & 0.98 \\
\hline
\end{tabular}
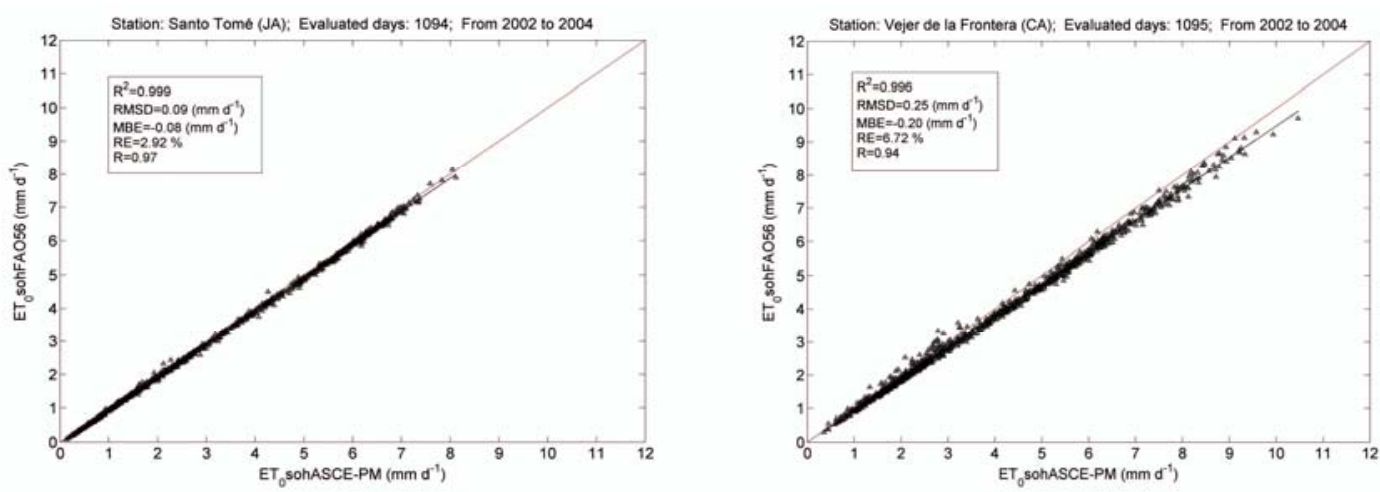

Figura 5. Comparación de los valores diarios de $E T_{0}$ obtenidos de la suma horaria de los

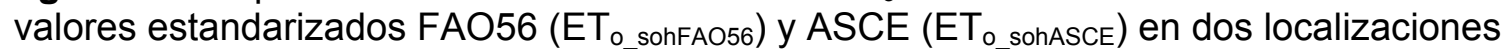
representativas de Andalucía durante los años 2002-2004. 


\subsection{Comparación a escala regional de los valores diarios obtenidos del cálculo diario de la ecuación estandarizada ASCE y los de su suma horaria}

El acuerdo entre los cálculos de $\mathrm{ET}_{\mathrm{o}}$ en base diaria y horaria de la ecuación estandarizada ASCE-PM fue muy razonable en todas las localizaciones, con una alta correlación $\left(R^{2}>0.97\right)$ (Figura 6$)$. Los valores de RMSE fueron mayores que en el caso anterior, variando entre 0.24 y $0.38 \mathrm{~mm} \mathrm{~d}^{-1}$, con un valor medio de $0.29 \mathrm{~mm} \mathrm{~d}^{-1}$. Sin embargo, la subestimación de los valores procedentes del cálculo diario con respecto a la suma diaria de los valores horarios fue menor, en concreto se produjo una subestimación media inferior al $2 \%$, con un $60 \%$ de estaciones en las que no hubo subestimación alguna (Tabla 3). Las pequeñas diferencias entre ambos tiempos de cálculo pueden ser atribuidas a la incapacidad del cálculo en base diaria de tener en cuenta los rápidos cambios a lo largo del día de la velocidad del viento, la temperatura del aire y el déficit de presión de vapor. Sin embargo, los resultados demuestran que la robustez de la ecuación de PenmanMonteith en su versión ASCE cuando se utilizan diferentes tiempos de computación es superior a la de la versión FAO56-PM.
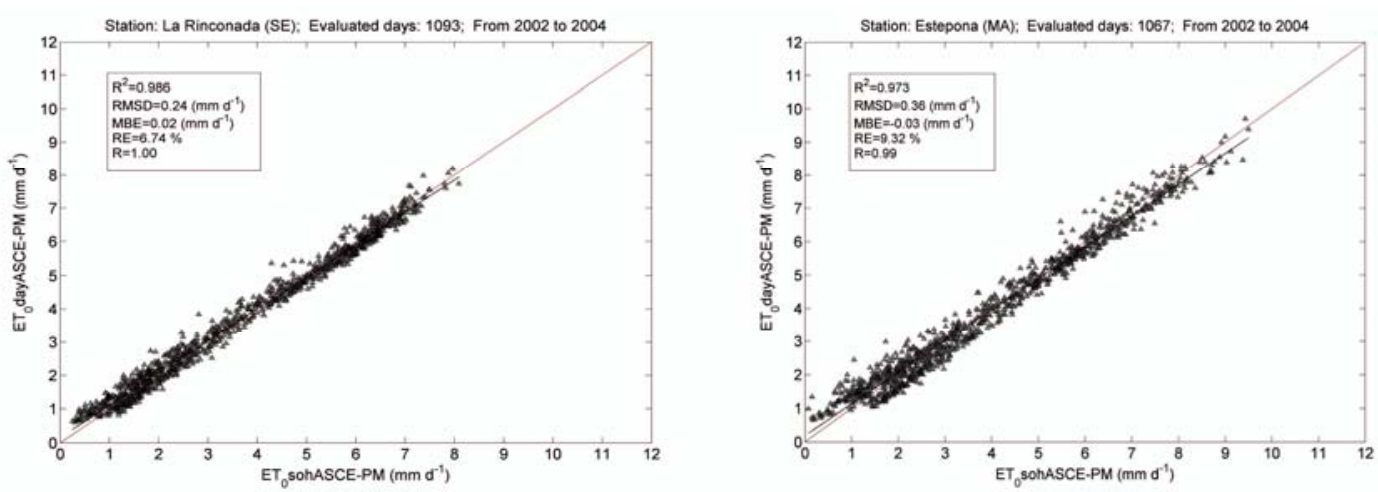

Figura 6. Comparación de los valores diarios de $\mathrm{ET}_{\mathrm{o}}$ obtenidos del cálculo diario de la ecuación estandarizada ASCE (ET O dayASCE) y de la suma horaria de la misma ecuación (ET o_sohASCE$_{\text {) }}$ en dos localizaciones representativas de Andalucía durante los años 20022004.

\section{Conclusiones y recomendaciones}

Los resultados de la comparación entre valores de $\mathrm{ET}_{0}$ medidos mediante lisimetría y los estimados usando las ecuaciones estandarizadas ASCE-PM y FAO56-PM indican que los métodos más precisos para estimar los valores diarios de la $\mathrm{ET}_{0}$ en el valle medio del Guadalquivir fueron el de Penman-Monteith FAO56 en base diaria y la versión ASCE de la misma ecuación en base horaria. Ambos mostraron una precisión similar cuando se compararon con los valores medidos en un lisímetro de pesada. Sin embargo, la ecuación FAO56-PM en base horaria mostró una menor precisión, con subestimaciones de $\mathrm{ET}_{0}$ del $5 \%$. A escala regional, la ecuación FAO56-PM en base horaria subestimó los valores diarios de $\mathrm{ET}_{\mathrm{o}}$ calculados mediante la misma ecuación estandarizada en su versión ASCE hasta un $6 \%$, produciéndose una subestimación media del $4 \%$ en 31 estaciones meteorológicas de Andalucía. Esta diferencia fue debida principalmente al uso de un mayor valor de $r_{c}\left(70 \mathrm{~s} \mathrm{~m}^{-}\right.$ ${ }^{1}$ ) en la ecuación FAO56-PM, en relación con el valor de $50 \mathrm{~s} \mathrm{~m}^{-1}$ aplicado en la ecuación estandarizada ASCE durante las horas diurnas. Por tanto, para el cálculo de los valores diarios de $\mathrm{ET}_{\circ}$ se aconseja la utilización de la ecuación estandarizada PM-ASCE en base horaria o bien la de PM-FAO56 en base diaria. Sin embargo, no resulta aconsejable el uso de la ecuación estandarizada de PM-FAO56 en base horaria por los motivos que han sido 
expuestos en este trabajo. Finalmente, para el cálculo de los valores horarios o semihorarios de $\mathrm{ET}_{\mathrm{o}}$ se aconseja el uso de la ecuación estandarizada ASCE-PM con dos resistencias, 50 y $200 \mathrm{~s} \mathrm{~m}^{-1}$, para las horas diurnas y nocturnas, respectivamente.

\section{Bibliografía}

Allen, R. G., Pruitt, W. O., Businger, J. A., Fritschen, L. J., Jensen, M. E., Quinn, F. H., 1996. Evaporation and transpiration. ASCE handbook of hydrology, Wootton et al., eds., Chap. 4, ASCE, New York, 125-252.

Allen, R.G., Pereira, L.S., Raes, D., Smith, M., 1998. Crop evapotranspiration. Guidelines for computing crop water requirements. FAO Irrigation and Drainage Paper 56. FAO, Roma.

Allen, R.G., Pruitt, W.O., Wright, J.L., Howell, T.A., Ventura, F., Snyder, R., Itenfisu, D., Steduto, P., Berengena, J., Baselga, J., Smith, M., Pereira, L.S., Raes, D., Perrier, A., Alves, I., Walter, I., Elliott, R., 2006. A recommendation on standardized surface resistance for hourly calculation of reference $\mathrm{ET}_{\text {。 }}$ by the FAO56 Penman-Monteith method. Agricultural Water Management, 81, 1-22.

ASCE-EWRI, 2004. The ASCE standardized reference evapotranspiration equation. Standardization of Reference Evapotranspiration Task Committee Final Report. Reston, Va.: ASCE Environmental and Water Resources Institute.

Berengena, J., Gavilán, P., 2005. Reference evapotranspiration estimation in a highly advective semiarid environment. Journal of Irrigation and Drainage Engineering, 131(2), 147-163.

Doorenbos, J., Pruitt, W.O., 1977. Las necesidades de agua de los cultivos. Manual FAO de Riego y Drenaje $\mathrm{n}^{\circ} 24$. Roma.

Gavilán, P., Berengena, J., Allen, R.G., 2007. Measuring versus estimating net radiation and soil heat flux: Impact on Penman-Monteith reference ET estimates in semiarid regions. Agricultural Water Management, 89, 275-286.

Gavilán, P., Estévez, J., Berengena, J., 2008. Comparison of standardized reference evapotranspiration equations in southern Spain. Journal of Irrigation and Drainage Engineering, 134(1), 1-12.

Irmak, S., Howell, T.A., Allen, R.G., Payero, J.O., Martin, D.L., 2005. Standardized ASCE Penman-Monteith: impact of sum-of-hourly vs.24-hour timestep computations at reference weather stations sites. Transactions of ASAE, 48(3), 1063-1077.

Itenfisu, D., Elliott, R. L., Allen, R. G., Walter, I. A., 2003. Comparison of reference evapotranspiration calculation as part of the ASCE standardization effort. Journal of Irrigation and Drainage Engineering, 129(6), 440-448.

Lecina, S., Martínez-Cob, A., Pérez, P.J., Villalobos, F.J., Baselga, J.J., 2003. Fixed versus variable bulk canopy resistance for reference evapotranspiration estimation using the Penman-Monteith equation under semiarid conditions. Agricultural Water Management, 60, 181-198.

Todorovic, M., 1999. Single-layer evapotranspiration model with variable canopy resistance. Journal of Irrigation and Drainage Engineering, 125(5), 235-245.

Ventura, F., Spano, D., Duce, P., Snyder, R. L., 1999. An evaluation of common evapotranspiration equations. Irrigation Science, 18, 163-170.

Wright, J.L., Allen, R. G., Howell, T. A., 2000. Conversion between evapotranspiration references and methods. Proc., 4th Decennial National Irrigation Symp., Phoenix, ASAE, St. Joseph, Mich., 251-259. 
A-02

\title{
USO DE IMÁGENES TÉRMICAS AÉREAS EN REMOLACHA AZUCARERA (Beta vulgaris) PARA PROPUESTA DE RIEGO DE PRECISIÓN
}

\author{
Quebrajo Moya, L. $^{1}$, Egea, G. $^{2}$, Pérez-Ruiz, M. ${ }^{2}$, Pérez-Urrestarazu, L. ${ }^{2}$
}

\author{
${ }^{1}$ Técnico apoyo a la Investigación. Departamento Ingeniería Aeroespacial y Mecánica de \\ Fluidos. ETSIA. Universidad de Sevilla. Ctra. Utrera km.1, 41013. Sevilla. E-mail: \\ lquebrajo@us.es. \\ ${ }^{2}$ Profesor. Departamento Ingeniería Aeroespacial y Mecánica de Fluidos, Área de Ingeniería \\ Agroforestal, ETSIA. Universidad de Sevilla. Ctra. Utrera km.1, 41013. Sevilla. E-mail: \\ gegea@us.es, manuelperez@us.es, Iperez@us.es
}

\section{Resumen}

Para un manejo adecuado del riego es necesario tener información disponible de una manera rápida y sencilla. Gracias a los avances tecnológicos, esto es posible. En este trabajo se han utilizado imágenes captadas mediante una cámara térmica montada sobre un vehículo aéreo para evaluar el estado hídrico de un cultivo de remolacha azucarera en una parcela con una gran variabilidad espacial en las propiedades del suelo. Los resultados se han comparado con mediciones puntuales de la humedad del suelo. No se ha percibido una relación directa entre el estado hídrico del suelo y del cultivo. Por otro lado, sí se advierte una tendencia decreciente en la producción en relación al estrés hídrico detectado en el cultivo gracias a las imágenes térmicas. Se observan claramente las diferencias entre los distintos tipos de suelo, de modo que queda patente la conveniencia de llevar a cabo estrategias de riego diferenciales en función de la distribución de los mismos, especialmente en parcelas muy heterogéneas.

\section{1.- Introducción y objetivos}

El sector agrícola se enfrenta actualmente a cambios radicales en la forma en que se recopila, analiza y utiliza la información para optimizar los procesos productivos. En los últimos años ha crecido el interés por la agricultura de precisión (AP) a nivel de explotación, y será cada vez más común que los agricultores tengan a su disposición terabytes de información sobre cuestiones tan específicas como el tamaño, el peso y el estado de los frutos, producción exacta en cada unidad de superficie o el estado de humedad y el nivel de nutrientes de planta y suelo. Precisamente el gran reto es sacarle partido a toda esa información generada.

Las particularidades de la agricultura de regadío en zonas áridas y semi-áridas ponen de relieve la necesidad de desarrollar técnicas para utilizar los recursos hídricos disponibles de manera muy eficiente, aplicando la cantidad justa de agua a la planta en el momento adecuado. Es por ello por lo que las técnicas de riego de precisión se convierten en una herramienta muy útil para mejorar la eficiencia del uso del agua. Una de las posibilidades que abre el uso de sensores remotos es, precisamente, el manejo adecuado del agua a escala de parcela, pudiendo seguir diferentes estrategias de riego atendiendo a la variabilidad espacial del suelo y al estado de los cultivos. Debido a esa variabilidad, las necesidades hídricas reales de los cultivos pueden cambiar dentro de una misma parcela. En este caso, el reto del riego de precisión consiste en desarrollar metodologías que posibiliten delimitar zonas de manejo uniformes dentro de las parcelas de cultivo y validar 
protocolos que permitan una programación precisa del riego en las distintas sub-unidades establecidas.

Igualmente, es muy importante que la obtención de información y análisis de datos se realice en el menor tiempo posible, de manera que se pueda determinar el estado hídrico de las plantas para poder actuar rápidamente sobre ellas. Muchas de las características de la fisiología de las plantas responden directamente a los cambios en el estado hídrico en el tejido de la planta, por lo que pueden ser utilizados como indicadores precisos para la programación del riego (Jones, 2004). Dicho estado se mide comúnmente en términos de potencial hídrico (Jones, 1992), para el cálculo del cual se ha utilizado tradicionalmente la cámara de presión (Scholander et al., 1965). De este modo, el déficit de agua se puede determinar a partir del potencial hídrico de las hojas. Aunque este método es una medida fiable del estado hídrico de la planta, es muy lento y laborioso y requiere un análisis continuado que lo hace poco operativo (Cohen et al., 2005).

Desde hace más de 30 años se acumulan las evidencias sobre el potencial y utilidad que presenta la medida de la temperatura del cultivo para monitorizar el estado hídrico del mismo. Por ello, la medición de la temperatura de la cubierta ha sido propuesta como una alternativa a la medida del potencial hídrico. Cuando se induce el estrés hídrico, los estomas de la hoja se cierran, la tasa de transpiración se reduce y su efecto refrigerativo disminuye, lo cual hace que la temperatura de la hoja se eleve. Idso et al. (1981) y Jackson et al. (1981) propusieron el índice de estrés hídrico del cultivo (Crop Water Stress Index, CWSI) como un indicador de estrés hídrico de la planta. Se ha demostrado que la detección de la temperatura de una cubierta vegetal usando sensores o imágenes infrarrojas puede ser aplicada para el cálculo de CWSI y estimar así el estado hídrico del cultivo para establecer una adecuada programación del riego en multitud de cultivos, como por ejemplo el algodón, el maíz, vid, y los pistachos (González-Dugo et al., 2006; Payero et al., 2006; Moller et al., 2007; Testi et al, 2008). Las imágenes térmicas captadas desde un micro-UAV presentan grandes ventajas frente al uso de termómetros de infrarrojos manuales (mucho trabajo y poca representatividad de las medidas) e imágenes térmicas satelitales (resolución espacial y temporal insuficiente para la mayoría de aplicaciones de riego). Para parcelas de pequeña/mediana extensión, estas plataformas pueden representar también una ventaja competitiva frente a plataformas aéreas de mayores dimensiones/autonomía, como pueden ser los aviones tripulados de gran envergadura portando sensores remotos.

El presente trabajo tiene como objetivo evaluar el uso de imágenes térmicas procedentes de una cámara portada sobre un UAV para conocer el estado hídrico del cultivo con el fin de que puedan utilizarse como herramientas de ayuda a la decisión en la gestión eficiente del riego en remolacha azucarera.

\section{2.- Materiales y métodos}

\subsection{Parcela experimental}

El trabajo se llevó a cabo durante la campaña 2014/2015 en una parcela comercial de remolacha azucarera (Beta vulgaris L.) situada en la provincia de Cádiz, y con una alta variabilidad espacial de las propiedades físico-químicas del suelo $\left(36,6965397^{\circ} \mathrm{N}\right.$, $\left.6,3184375^{\circ} \mathrm{W}\right)$. La variabilidad del suelo se caracterizó por la recogida aleatoria y análisis de muestras de suelo tomadas a distintas profundidades. Este análisis fue realizado en los laboratorios del CITIUS (Universidad de Sevilla) y los parámetros analizados fueron pH, conductividad eléctrica (CE), carbono orgánico oxidable (C orgánico), materia orgánica (MO), capacidad de intercambio catiónico (CIC) y contenido en arcillas, limo y arenas. Se realizó un muestreo sistemático, que consiste en dividir la parcela en zonas manteniendo una distancia fijada entre cada dos puntos muestreados (red o malla). Todas las muestras fueron georreferenciadas por un receptor DGNSS (Differential-Global Navigation Satellite System), lo que permitió obtener con la ayuda de un sistema de información geográfica (FarmWorks) los mapas de distribución de las diferentes propiedades del suelo mediante técnica de krigeado. 
El mapa de variabilidad del suelo permitió delimitar dentro de la propia parcela una zona de suelo arcilloso y otra de suelo arenoso (Figura 1). En el suelo arcilloso se establecieron dos sub-parcelas y otras dos en el suelo arenoso. Todas las sub-parcelas fueron equipadas con dos tubos de acceso para la monitorización del contenido de humedad del suelo en profundidad (sonda PR-2, Delta-T Devices Ltd., Cambridge, UK). La sonda PR2 fue calibrada para los suelos de las dos zonas de estudio. Para ello, durante varios días al final del ciclo de cultivo se tomaron muestras de suelo inalteradas en las proximidades de los tubos de acceso. Simultáneamente a la recogida de muestras de suelo, se tomaron lecturas de humedad con la sonda PR-2. Las muestras de suelo se llevaron a laboratorio para determinación de densidad aparente y contenido volumétrico de humedad. Las medidas de humedad realizadas con la sonda PR-2 y las obtenidas en laboratorio se utilizaron para determinar las curvas de calibración para cada tipo de suelo.

Con el objetivo de poder comparar las dinámicas de humedad del suelo en ambas localizaciones, las medidas de humedad en el perfil $0-100 \mathrm{~cm}$ del suelo se normalizaron mediante el cálculo de la fracción de agua extraíble relativa (REW):

donde $R$ es el contenido de humedad real y $R_{\max }$ y $R_{\min }$ los contenidos de humedad a capacidad de campo y punto de marchitez, respectivamente, determinados con funciones de pedotransferencia.

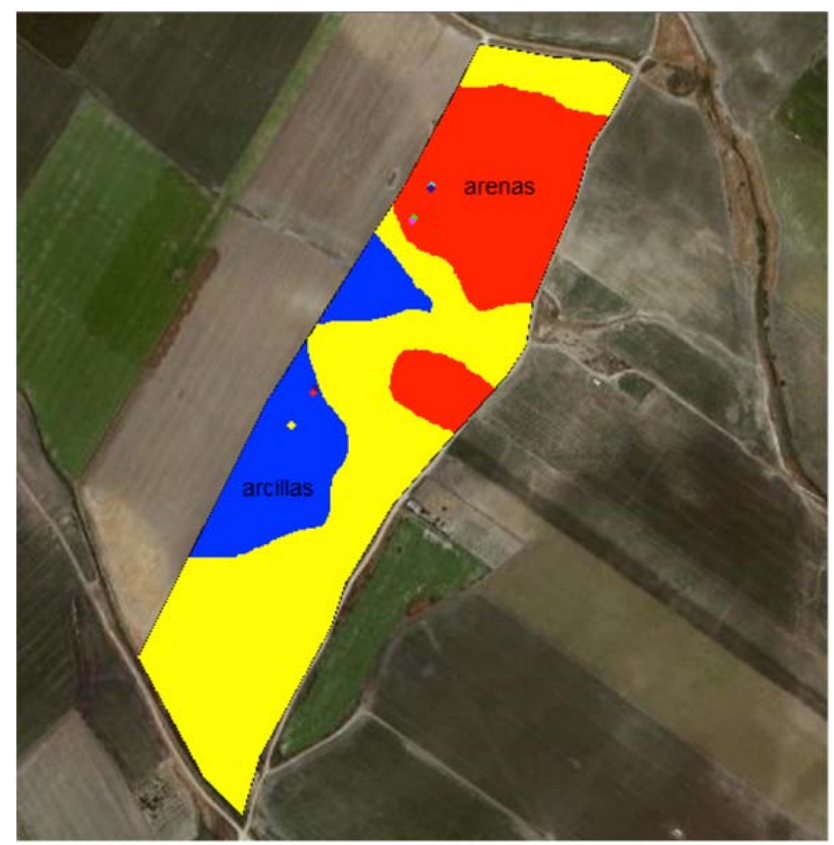

Figura 1. Varibilidad del suelo en la parcela. En rojo, zona de textura arenosa; en azul, zona de textura arcillosa; y en amarillo, zona de textura franco arenosa y franco-arcillo arenosa.

\subsection{Cámara térmica y plataforma de vuelo (UAV)}

Durante la estación de riego y con frecuencia semanal/quincenal se realizaron vuelos con UAV (Unmanned Aerial Vehicle) equipado con cámara termográfica (Tau 2 324, FLIR, Oregon, USA).

EI UAV empleado, modelo Phantom 2 (SZ DJI Technology Co., Ltd.), tiene una autonomía de vuelo de 25 minutos y 1.000 metros de alcance de comunicación en espacios abiertos y va equipado con un receptor GNSS. La cámara se instaló con una orientación vertical en la mitad de la parte inferior del UAV, lo que permitió la grabación de imágenes de video y el ajuste de umbrales isotérmicos para colorear zonas de interés térmico partiendo 
de imágenes en escala de grises. Los ajustes y calibración de la cámara se realizaron cada día que se hicieron medidas de temperatura en campo. Los principales parámetros usados fueron la emisividad de la superficie de cultivo y la altura de vuelo.

Las imágenes térmicas se tomaron a medio día solar, por presentar ese periodo las condiciones más idóneas para ello (Bellvert et al. 2014), a una altura de $30 \mathrm{~m}$ y en días soleados. Posteriormente, se analizaron con un software de segmentación de imágenes escrito en $R$ ( $R$ Development Core Team, 2015) que permite discriminar los pixeles correspondientes a vegetación de los píxeles correspondientes a suelo desnudo o mezclado con vegetación así como determinar la temperatura media del dosel vegetal. Para el mosaicado de imágenes, se usó un software específico (Agisoft PhotoScan, Agisoft LLC).

La evaluación del estado hídrico del cultivo se realizó a partir de la diferencia entre la temperatura media de la cubierta vegetal y la temperatura del aire $(\Delta T)$. Los valores de $\Delta T$ fueron asimismo utilizados para determinar la integral de estrés durante el periodo de medida, para lo que se utilizó una expresión análoga a la propuesta inicialmente por Myers (1988):

donde $t$ es el número de medidas de $\Delta T, \Delta T_{i, i+1}$ es la media de $\Delta T$ para cualquier intervalo $\mathrm{i}$, $\mathrm{i}+1, c_{i, i+1}$ es la media del menor valor de $\Delta \mathrm{T}$ para cualquier periodo $\mathrm{i}, \mathrm{i}+1 \mathrm{y} \mathrm{n}$ es el número de días en el intervalo. Los valores de $c$ se obtienen a partir de la línea de referencia en condiciones de no estrés (NWSB, de sus siglas en inglés: Non water-stress baseline) utilizada para el cálculo de CWSI (Bellvert et al., 2014):

donde DPV representa el déficit de presión de vapor y $a$ y $b$ son dos parámetros obtenidos de forma empírica para cada especie y para unas condiciones ambientales determinadas. En este trabajo han sido utilizados los valores de $a$ y $b$ determinados por Idso (1982) para remolacha azucarera en días soleados: $a=2.50 ; b=-1.92$. Los datos de DPV se obtuvieron de una estación agroclimática de la Junta de Andalucía próxima a la parcela de estudio.

\subsection{Estrategia de riego}

En cada zona de estudio (correspondientes a los dos tipos de suelo estudiados, arcilloso y arenoso) se estableció una sub-parcela en la que se practicó el riego de acuerdo con el criterio del agricultor (siglas WW en adelante) y otra en la que se aplicaron dos periodos de déficit hídrico mediante el cegado de boquillas de los aspersores colindantes (siglas WS en adelante). El primer ciclo de déficit tuvo una duración de 24 días, al cual siguió un ciclo de recuperación de otros 24 días, para terminar con un último ciclo de estrés.

\subsection{Datos de producción}

Al final del ciclo de cultivo (principios de julio) se llevó a cabo la recolección manual de la remolacha procedente de las cuatro sub-parcelas de estudio. Las muestras recogidas se enviaron al laboratorio para el análisis de rendimiento, contenido de azúcar ( $\mathrm{t} / \mathrm{ha}$ ), índice económico para el agricultor valorando los ingresos en remolacha tipo de $16^{\circ}$ (IEA, $t /$ ha $\left.16^{\circ}\right)$, pureza $(\%)$, etc.

\section{3.- Resultados y discusión}

La dinámica de humedad en el suelo para las cuatro sub-parcelas se muestra en la Figura 2. En la misma, se observa que el tratamiento WW de la zona de arena permitió mantener valores de REW próximos a 1 (condiciones de capacidad de campo) durante todo 
el periodo de estudio. En cambio, el tratamiento WW de la zona de arcilla no consiguió mantener los valores de REW próximos a la unidad durante la estación de riego, sino que se observó una caída de REW hasta valores próximos a 0.6 durante el período comprendido entre los días 80 y 125 aproximadamente. A pesar de haber recibido la misma programación de riego (dosis y frecuencias), las diferencias existentes en las condiciones de humedad del suelo en arcilla_WW y arena_WW ponen de manifiesto la importancia de adaptar los sistemas de riego a la heterogeneidad del suelo. Las diferencias existentes en velocidad de infiltración del agua, capacidad de retención del suelo e incluso en la estructura del sistema radicular en cada tipo de suelo van a condicionar sobremanera la eficiencia de aplicación del riego.

Tan solo una correcta delimitación de las áreas que requieren un manejo uniforme, acompañado del establecimiento de protocolos basados en la monitorización de variables hídricas como el estado hídrico del suelo y/o del cultivo permitirá garantizar una gestión eficiente del riego.

La dinámica de REW en las sub-parcelas arcilla_WS y arena_WS fue similar a lo largo del periodo de estudio, si bien arcilla_WS siempre mostró un valor de REW $15-20 \%$ inferior al observado en arena_WS (Figura 2). La restitución del riego al finalizar el primer ciclo de déficit hídrico en los tratamientos WS no permitió que los valores de humedad del suelo alcanzasen los niveles de los tratamientos WW en ninguna de las zonas de estudio. Este hecho se debe a que el agricultor aplicaba dosis de riego acordes a la evapotranspiración acumulada durante el período entre riegos, claramente insuficiente para recargar las reservas de agua del suelo tras un período de déficit prolongado.

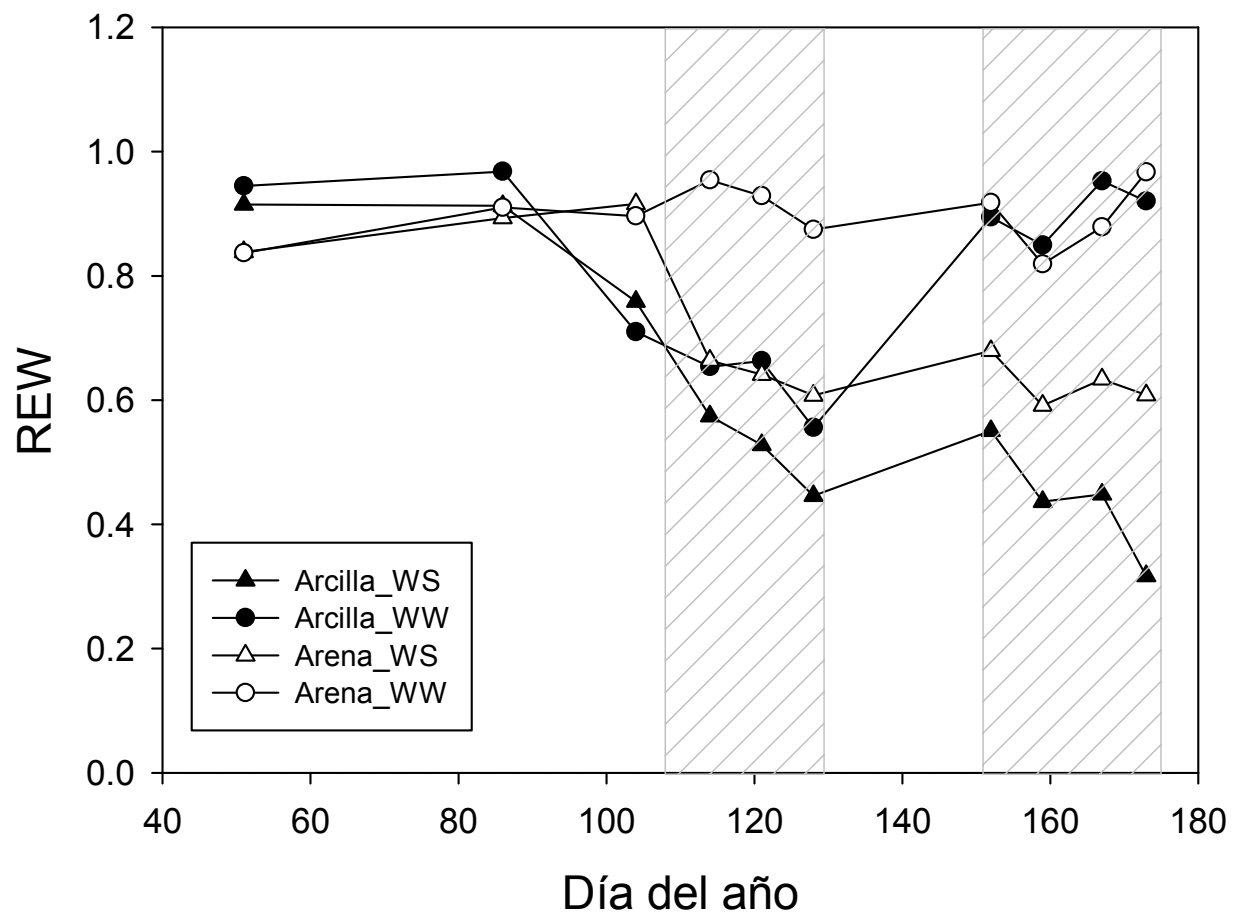

Figura 2. Evolución de la fracción de agua extraíble relativa (REW) en el perfil $0-100 \mathrm{~cm}$ para las cuatro zonas de estudio. Cada punto es la media de dos medidas realizadas en sendas localizaciones de cada zona de estudio. El área rayada delimita los períodos en los que se suprimió el riego en las zonas Arcilla_WS y Arena_WS.

En la figura 3 se muestra un ejemplo de 4 imágenes térmicas obtenidas el mismo día y a la misma hora en las 4 sub-parcelas de estudio. A partir de la escala de color, se puede apreciar las grandes diferencias de temperatura existentes entre unas zonas y otras. La captura de imágenes térmicas debe acompañarse de un procesado de datos posterior que 'filtre' todos aquellos pixeles que no corresponden al objeto deseado, en este caso el dosel vegetal del cultivo. En la figura 4 se presenta, de igual forma, un ejemplo del proceso de 
segmentación de imágenes que debe realizarse para determinar las temperaturas medias del cultivo en una zona determinada.
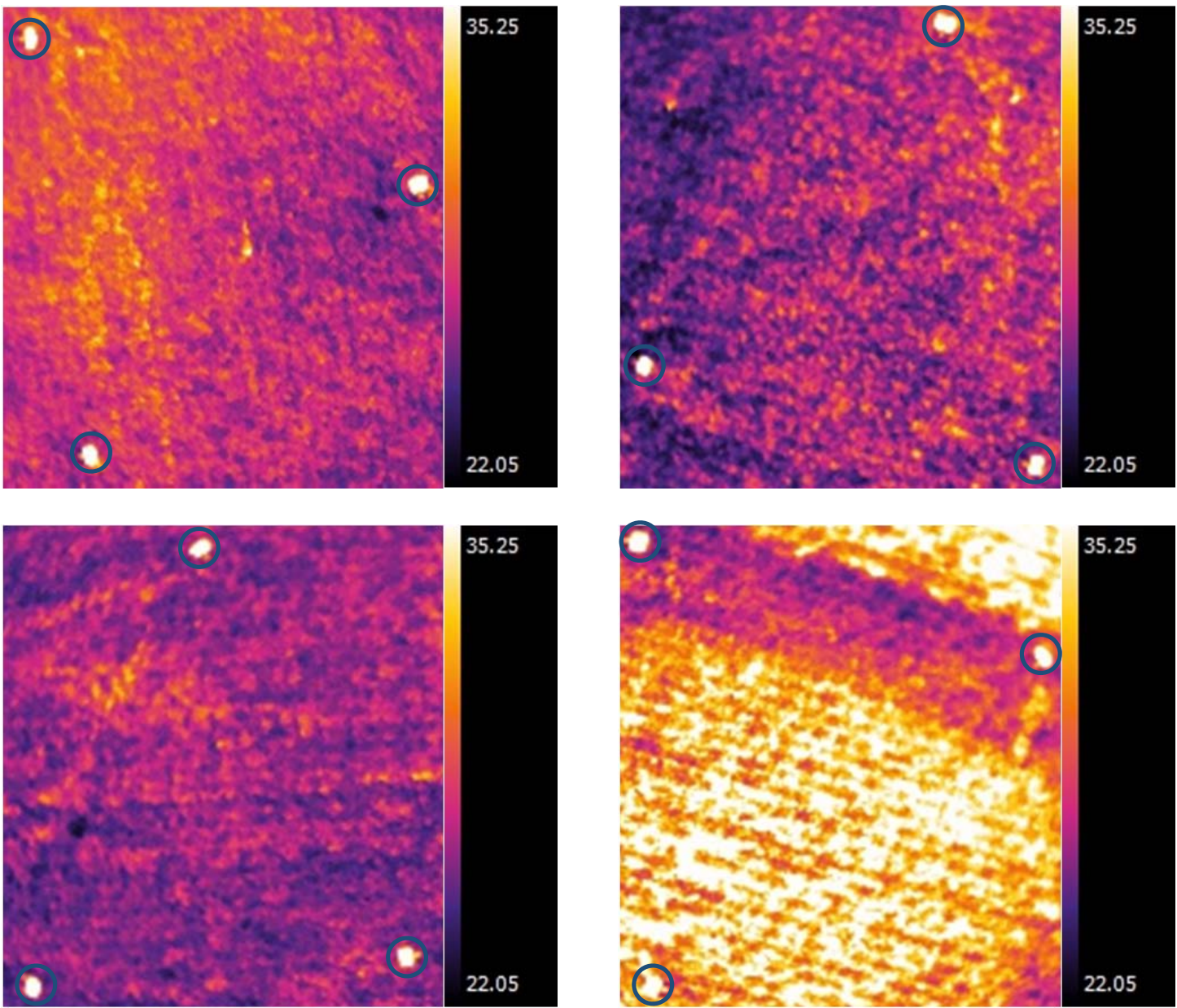

Referencia caliente delimitando la zona de estudio

Figura 3. Imágenes térmicas en falso color determinadas desde UAV para las cuatro zonas de estudio el día 08/05/15 a medio día solar. Arcilla WW (arriba izda.); Arcilla WS (arriba dcha.); Arena WW (abajo izda.); Arena WS (abajo dcha.).
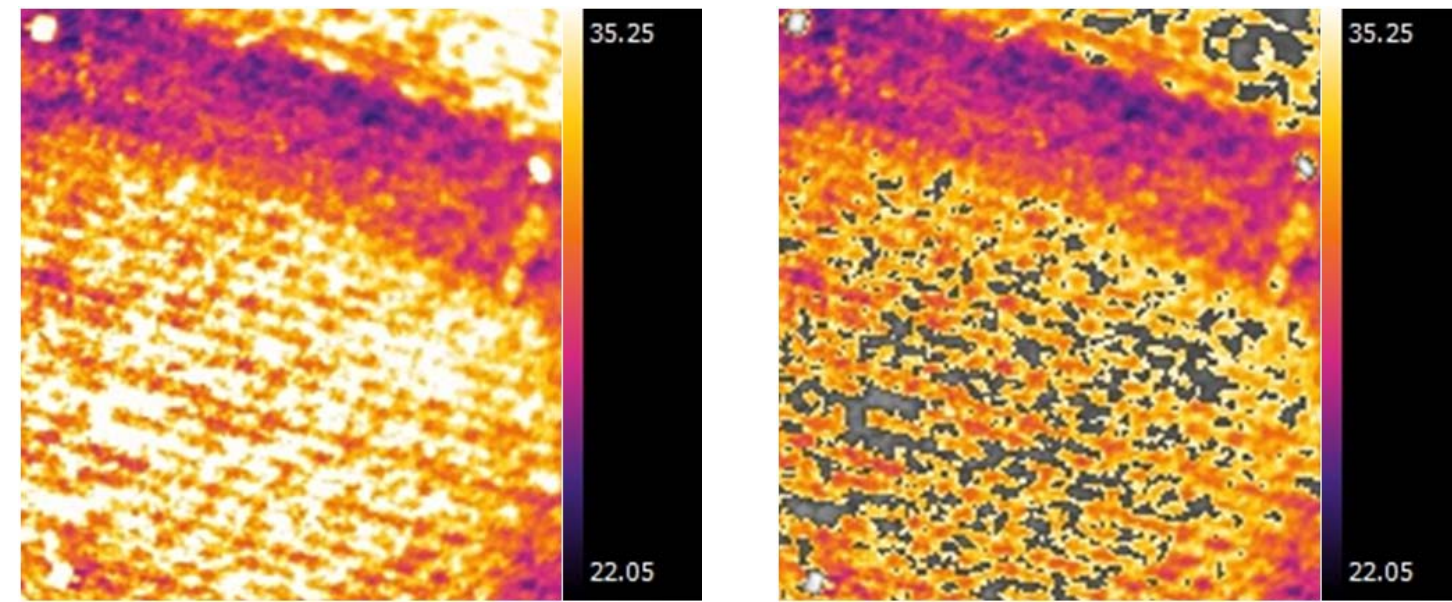

Figura 4. Imagen térmica de zona Arena WS determinada el día 08/05/15 a medio día solar a una altura de vuelo de $30 \mathrm{~m}$. En la imagen de la derecha se observan en color gris los pixeles identificados por el algoritmo de segmentación como suelo desnudo y/o mezcla de suelo desnudo/vegetación. 
Una vez realizado el procesado de imágenes térmicas para las cuatro sub-parcelas y todos los días de medida, las diferencias de temperatura cultivo-aire $(\Delta T)$ fueron calculadas a lo largo del periodo de estudio y se presentan en la Figura 5. La comparación de la dinámica de $\Delta T$ con REW revela que no existe una clara similitud entre las dinámicas del estado hídrico del suelo y del cultivo. El día 86, por ejemplo, no se observaron apenas diferencias en REW, si bien $\Delta T$ fue sensiblemente superior en Arcilla_WS con respecto al resto. El día 114, los contenidos de humedad en Arcilla_WS y Arcilla_WW fueron relativamente parecidos (Figura 2), coincidiendo con los valores de $\Delta \mathrm{T}$ obtenidos (Figura 5). Sin embargo, para el mismo día, los valores de REW en Arena_WS y Arena_WW mostraron una reducción en el contenido de humedad del primero con respecto al segundo, aspecto que no se tradujo en un incremento de $\Delta T$ en Arena_WS como se hubiese esperado. Lo que se observó a nivel de cultivo es que, ese día (114), las sub-parcelas de la zona de arena presentaron un estado hídrico del cultivo similar y más favorable que el de las zonas de arcilla. A partir del día 114, el cultivo de la sub-parcela Arena_WS incrementa los valores de $\Delta T$ con respecto al resto de sub-parcelas. Atendiendo a la dinámica de REW (Figura 2), dado que Arcilla_WS mostró valores inferiores de REW con respecto a Arena_WS, se habría esperado que ambos tratamientos hubiesen mostrado valores similares de $\Delta T \mathrm{o}$, incluso, superiores en Arcilla_WS.

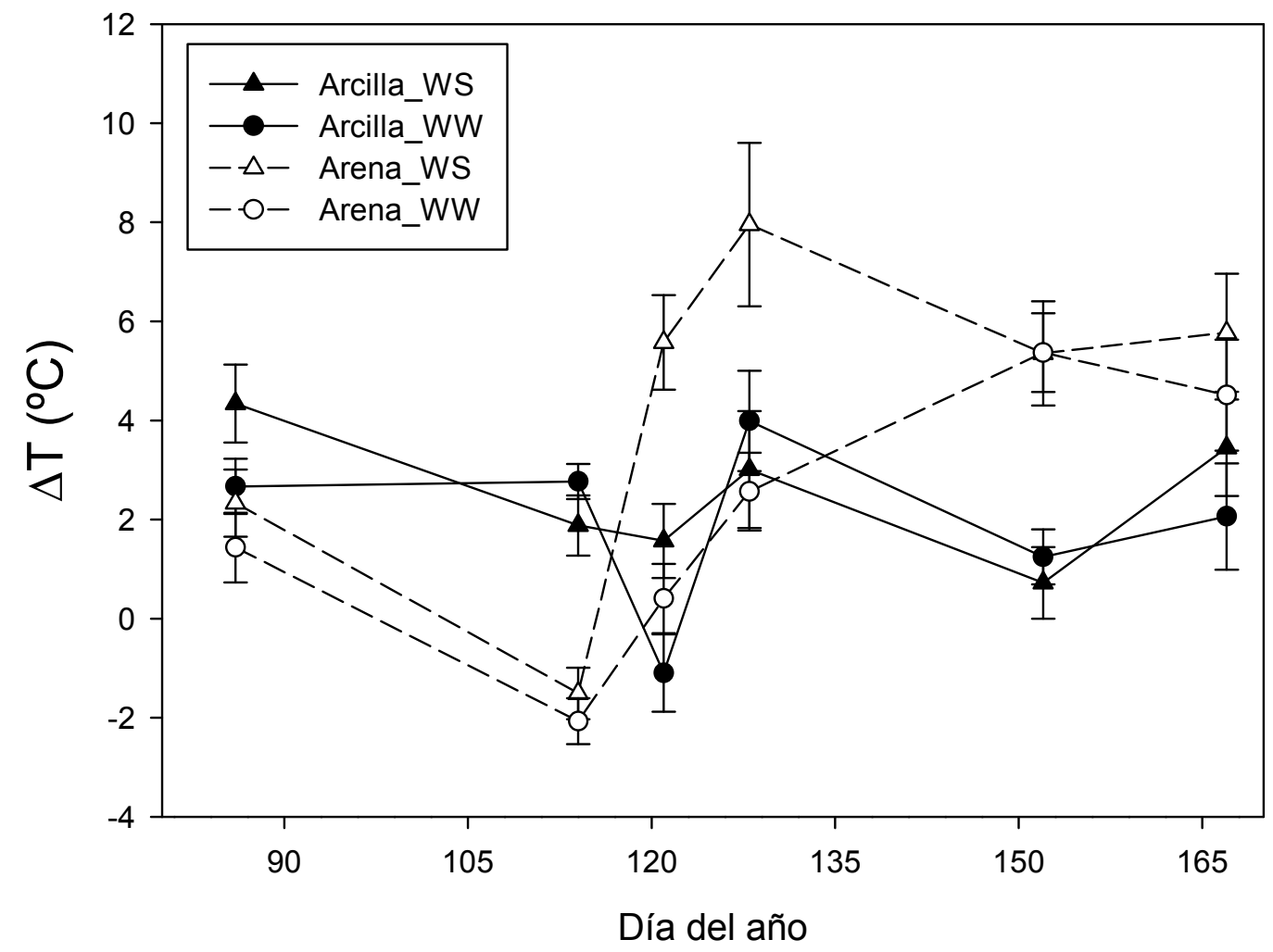

Figura 5. Evolución de la diferencia de temperatura entre la cubierta vegetal determinada con UAV y la temperatura del aire $(\Delta T)$ para las cuatro parcelas de estudio. Las barras de error indican el error estándar de la media.

La interpretación de estos resultados arroja dos conclusiones claras. En primer lugar, $\Delta \mathrm{T}$ determinada a partir de imágenes térmicas tomadas desde un micro-UAV permiten identificar variaciones en el estado hídrico del cultivo debidas a una gestión del riego diferente o a la variabilidad natural de las propiedades físico-químicas del suelo. En segundo lugar, se observa que la dinámica del contenido de humedad del suelo determinada en un número limitado de puntos de muestreo (dos por sub-parcela en este estudio), no permite representar adecuadamente la variación del estado hídrico del cultivo. Las limitaciones de la 
monitorización del estado hídrico del suelo como herramienta de ayuda para la gestión del riego ya han sido puestas de manifiesto en muchos trabajos de investigación. Este trabajo añade más evidencias a esta problemática y destaca el potencial de herramientas como la termografía infrarroja que permiten muestrear toda la superficie de cultivo, evitando de esta forma disponer de una información muy sesgada a nivel espacial.

En un intento de integrar el estrés hídrico acumulado por el cultivo en las distintas sub-parcelas para el período de medida, se utilizó la expresión de Myers (1988) originalmente desarrollada para cuantificar la integral de estrés a partir de medidas de potencial hídrico foliar. La relación obtenida entre la integral de estrés hídrico determinado por métodos térmicos $\left(\mathrm{S}_{\Delta \mathrm{T}}\right)$ con respecto a la producción total de remolacha y la producción normalizada atendiendo a criterios económicos para el agricultor (IEA) se presenta en la Figura 6. Se puede observar que la producción mostró una tendencia linealmente decreciente con $S_{\Delta T}$, si bien el tratamiento que menor producción mostró a pesar de no ser el que mayor $S_{\Delta T}$ tuvo fue Arcilla_WS. Sin embargo, la IEA obtenida en Arcilla_WS fue similar a la obtenida en las parcelas $\mathrm{WW}$, por lo que la relación IEA vs $S_{\Delta T}$ mostró una tendencia decreciente a partir de un cierto umbral de $S_{\Delta T}$, por encima del cual el indicador IEA no se vio afectado.

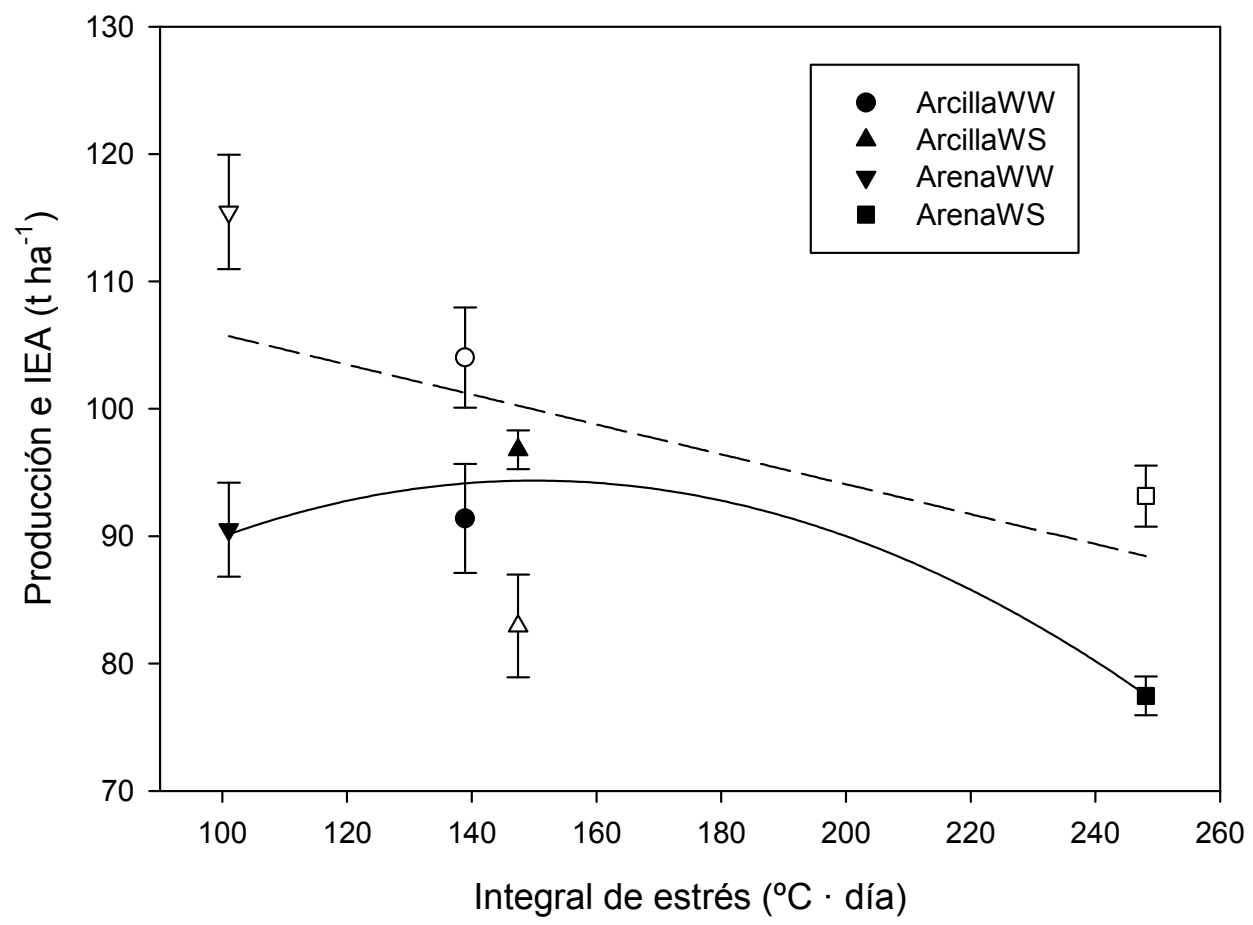

Figura 6. Relación entre la producción (símbolos blancos) e IEA (símbolos negros) con la integral de estrés determinada a partir de la temperatura de cubierta vegetal tal y como se ha descrito en la metodología. Línea discontinua: regresión entre producción e integral de estrés. Línea continua: regresión entre IEA e integral de estrés.

\section{4.- Conclusiones}

La medida de la temperatura del cultivo determinada de forma remota mediante UAV ha demostrados ser una medida eficaz para determinar el estado hídrico del cultivo en remolacha azucarera. Asimismo, se observa cómo no existe una relación directa en el tiempo entre el estado hídrico del suelo y del cultivo, por lo que se refuerza la hipótesis de que la medida de la humedad del suelo mediante unos pocos sensores distribuidos por la parcela puede no ser la mejor estrategia, aunque ciertamente ayuda a realizar ajustes en la programación de los riegos, especialmente en parcelas con características del suelo uniformes. Los ensayos realizados han permitido comprobar que las parcelas de remolacha 
azucarera con alta heterogeneidad espacial del suelo requieren de un manejo del riego que atienda a las particularidades de cada zona. Tanto las sub-parcelas regadas según el criterio del agricultor como aquellas que fueron deliberadamente sometidas a periodos de déficit hídrico mostraron patrones de respuesta hídrica diferentes en función del tipo de suelo. La producción de remolacha en las zonas con limitación de riego fue inferior a la obtenida en las zonas sin alteración del riego, siendo la reducción más acusada en la zona con textura arenosa.

Estos resultados confirman la necesidad de establecer programas de riego adaptados a la variabilidad espacial del terreno en las parcelas de remolacha altamente heterogéneas, especialmente bajo condiciones de riego deficitarias donde las mermas productivas pueden ser más acusadas en unas zonas que en otras.

\section{5.- Bibliografía}

Bellvert, J., Zarco-Tejada, P.J., Girona, J., Fereres, E. (2014). Mapping crop water stress index in a 'Pinot-noir' vineyard: comparing ground measurements with termal remote sensing imagery from an unmanned aerial vehicle. Precision Agric 15, 361-376.

Cohen Y, Alchanatis V, Meron M, Saranga Y, Tsipris J (2005) Estimation of leaf water potential by thermal imagery and spatial analysis. J Exp Bot 56, 1843-1852.

Gonzalez-Dugo, M. P., Moran, M. S., Mateos, L., \& Bryant, R. (2006). Canopy temperature variability as an indicator of crop water stress severity. Irrigation Science, 24, 233-240.

Idso, S.B., Jackson, R.D., Pinter, P.J., Reginato, R.J., Hatfield, J.L. (1981). Normalizing the stress-degree-day parameter for environmental variability. Agric Meteorol 24, 45-55.

Idso, S.B. (1982). Non-water stressed baselines: a key to measuring and interpreting plant water stress. Agric Meteorol 27, 59-70.

Jackson, R.D., Idso, S.B., Reginato, R.J., Pinter, P.J. (1981). Canopy temperature as a crop water-stress indicator. Water Resour Res 17, 1133-1138.

Jones, H.G. (1992). Plants and microclimate, 2nd edn. Cambridge: Cambridge University Press

Jones, H.G. (2004). Irrigation scheduling: advantages and pitfalls of plant-based methods. J Exp Bot 55, 2427-2436.

Moller, M., Alchanatis, V., Cohen, Y., Meron, M., Tsipris, J., Naor, A., Ostrovsky, V., Sprintsin, M., Cohen, S. (2007). Use of thermal and visible imagery for estimating crop water status of irrigated grapevine. J Exp Bot 58, 827-838.

Myers, B.J. (1988). Water stress integral-a link between short-term stress and long-term growth. Tree Physiol 4, 315-323.

Payero, J.O., Tarkalson, D. e Irmak, S. (2006). Corn yield response to different irrigation depths with subsurface drip irrigation, Annual meeting of the ASCE-EWRI. ASCEEWRI, Omaha, Nebraska.

Scholander, P.F., Hammel, H.T., Bradstreet, E.D., Hemmingsen, E.A.. (1965). Sap pressure in vascular plants. Science 148, 339-346.

Testi, L., Goldhamer, D.A., Iniesta, F., Salinas, M. (2008). Crop water stress index is a sensitive water stress indicator in pistachio trees. Irrig Sci 26, 395-405. 


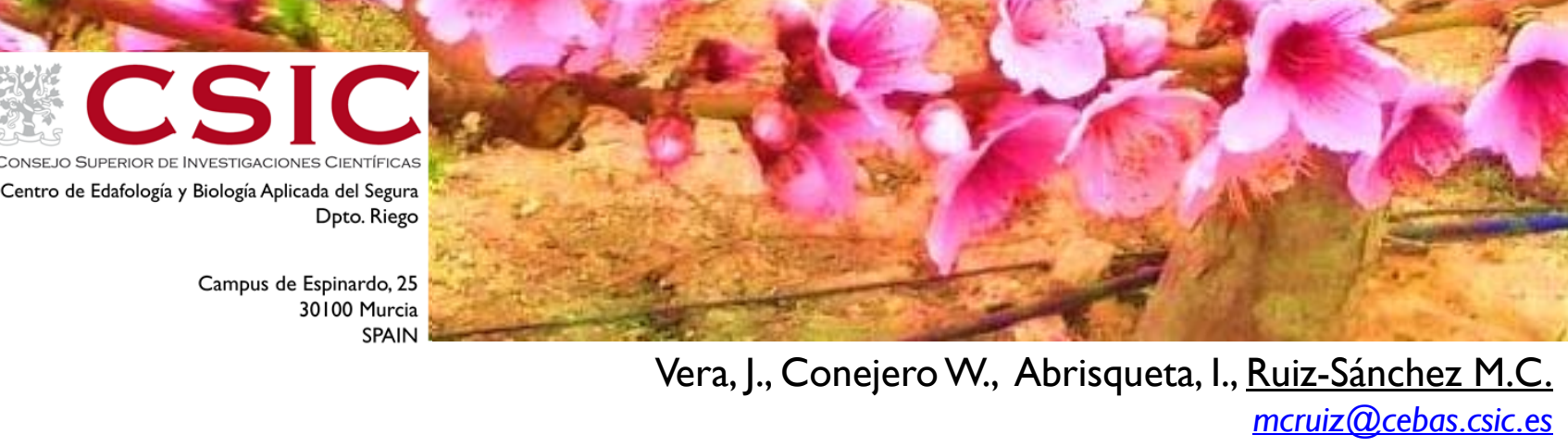

\section{I - Introduceión y Objetivos}

Las variedades frutales de maduración temprana, media estación y tardía van asociadas a rendimientos y necesidades hídricas crecientes. La limitada disponibilidad de agua para la agricultura en España y las mejores oportunidades de mercado, justifican el notable incremento experimentado en los últimos años del cultivo de variedades de fruta temprana en zonas meridionales de la cuenca mediterránea. En este escenario la eficiencia de los recursos hídricos y energéticos empleados debe orientarse claramente a la sostenibilidad.

La programación de riego más utilizada sigue la metodología FAO que estima los requerimientos hídricos del cultivo $\left(E T_{C}\right)$, en base a la evapotranspiración del cultivo de referencia $\left(E T_{0}\right)$ y coeficientes específicos de cada cultivo $\left(K_{C}\right)$, obtenidos mediante balance hídrico (Allen et al., 1998).

Este trabajo describe una metodología simple, práctica y precisa para obtener un factor de riego $(\mathrm{K})$ que permite estimar las necesidades hídricas de nectarinos extratempranos en clima Mediterráneo con riego localizado.

\section{2- Materiales y Métodos}

El estudio se realizó durante 2015, en una parcela de nectarinos (Prunus persica (L) Batsch, cv. Flariba) de maduración extratemprana, injertados sobre $\mathrm{GxN}-15$, con un marco de $6.5 \mathrm{~m} \times 3.5 \mathrm{~m}$. El sistema de riego fue por goteo con un lateral por hilera de árboles y 4 goteros de $4 \mathrm{~L} / \mathrm{h}$. Las labores de cultivo incluyeron control fitosanitario, empleo de herbicidas, aclareo manual de frutos y poda invernal.

El contenido de agua en el suelo se monitorizó en continuo con sondas de capacitancia FDR y el riego con un contador volumétrico con salida de pulsos. La finca dispone de estación agro-meteorológica automática

(http://www.cebas.csic.es/general_spain/est meteo.html).

El riego se automatizó a fin de cubrir las necesidades hídricas del cultivo, para lo que se establecieron unos límites de agotamiento de agua disponible ( $\alpha$ ) en la zona radicular $(0-50 \mathrm{~cm})$ para el inicio del riego del $10 \%$ hasta la postcosecha inicial $(15$ junio) y del $30 \%$ en adelante.

Paralelamente se realizó un seguimiento del estado hídrico de la planta con medidas a mediodía solar de potencial hídrico de tallo $\left(\Psi_{\text {tallo }}\right)$, con cámara de presión, y de intercambio gaseoso con LICOR-6400, así como del grado de desarrollo del dosel de árbol mediante fotografía cenital.

\section{3- Resultados y Discusión}

Como se observa en la Figura 1, la variación del contenido de humedad a $70 \mathrm{~cm}$ de profundidad no fue significativa, por lo que el drenaje quedó limitado a los periodos de lluvia. Además, en el caso en que la lluvia se produjera simultáneamente al riego, el automatismo lo detiene cuando el contenido de agua en el suelo alcanza el nivel de capacidad de campo. Por consiguiente, el drenaje correspondiente al riego puede asumirse como despreciable.

Los valores estacionales de $\Psi_{\text {tallo }}$ fueron superiores a los umbrales de déficit hídrico (Abrisqueta et al., 2012), lo que confirmó el cumplimiento de la condición de riego (Figura 2). Los niveles correspondientes al intercambio gaseoso -conductancia folia $\left(g_{s}\right)$ y fotosíntesis neta $\left(F_{n}\right)$ - mostraron valores crecientes desde el inicio de la estación hasta la cosecha, momento a partir del cual la actividad fotosintética tuvo una tendencia decreciente. Por ello, la relación 'Riego/ET,', en los periodos sin lluvias, se correspondería con un factor K (Figura 3), que combina los coeficientes de cultivo, de localización y de eficiencia de aplicación.

La evolución del factor $\mathrm{K}$ demostró una estrecha relación con el desarrollo de la cobertura del árbol (Figura 3). Se observa que el mayor uso consuntivo de agua (hasta el $90 \%$ de las necesidades anuales) en esta variedad sucede tras la cosecha. Es a partir de este periodo cuando aparecen importantes diferencias con otras fuentes citadas en la bibliografía (FAO-56, Haifa Chemicals Ltd., Ayars et al., 2003), lo que demuestra la necesidad de realizar ensayos locales para una mayor precisión del riego.

Los valores medios mensuales del factor de riego $\mathrm{K}$ (Tabla 1) sitúan las necesidades hídricas anuales para nectarino extra-temprano en unos $660 \mathrm{~mm}$ en la zona agroclimática de Santomera (Región de Murcia), con intervalos de riego de 1 a 6 días según el periodo fenológico.

\section{4- Gonclusiones}

Se proponen factores de riego mensuales ajustados para nectarinos extra-tempranos en condiciones edafo-climáticas mediterráneas, sin limitación hídrica en el perfil de suelo correspondiente a la máxima densidad radicular, a partir de un balance hídrico en suelo automatizado.

\section{5- Bibliografía}

Abrisqueta, I., Abrisqueta, J.M., Tapia, L.M., Munguía, J.P., Conejero, W., Vera, J., Ruiz-Sánchez, M.C. 2013. Agricultural Water Management 121: 158-163.

Abrisqueta, I., Vera, J., Tapia, L.M., Abrisqueta, J.M., Ruiz-Sánchez, M.C. 2012. Agricultural Water Management 104: 62-67.

Allen, R. G., Pereira, L. S., Raes, D., Smith, M. 1998. FAO Irrigation and Drainage paper 56, Roma.

Ayars, J.E., Johnson, R. S., Phene, C.J., Clark, D.A., Mead, R.M. 2003. Irrigation Science 22: 187-194.

Girona, J., del Campo, J., Mata, M., Lopez, G., Marsal, J. 2011. Irrigation Science 29:55-63.

Girona, J., Fereres, E., Marsal, J., Goldhamer, D.A., Naor, A., Soriano, M.A. 2012. Crop Yield Response to Water. Irrigation and Drainage 66, FAO, Roma, 266-280.

\section{6- Agradecimientos}

Este trabajo ha sido financiado con el proyecto del Ministerio de Economía y Competitividadfondos FEDER (AGL2013-49047-C02-2R). Los autores son miembros del Grupo de Excelencia Científica de la Región de Murcia (Fundación Séneca 9903/GERM/15).
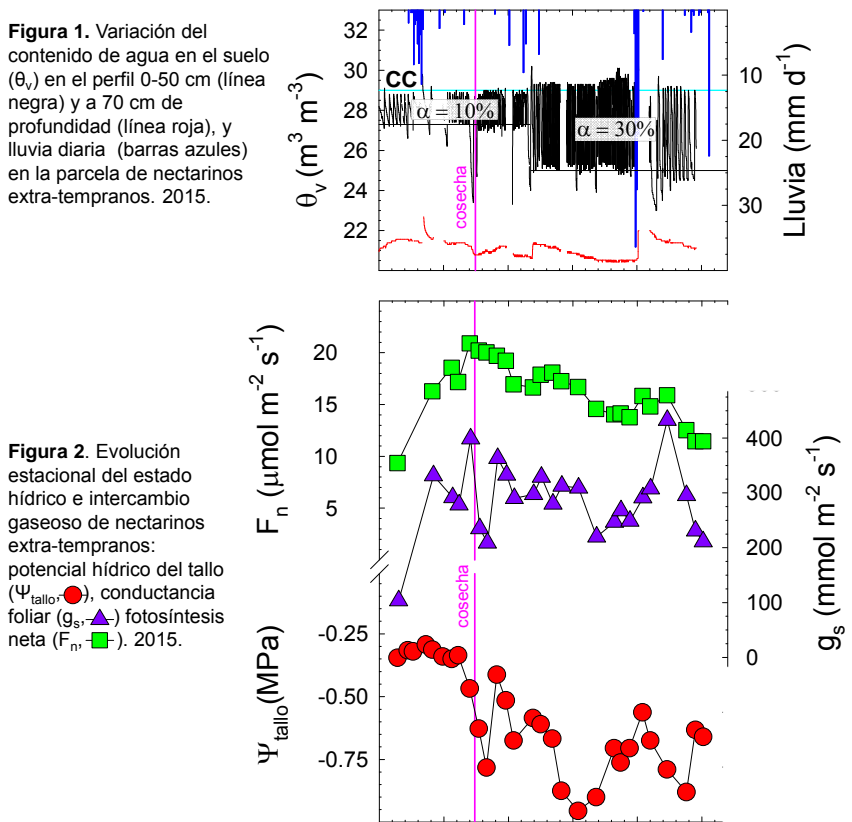

Figura 3. Evolución

estacional del factor de riego $(\mathrm{K}, *)$ y del dosel vegetal $(-)$ en nectarinos extratempranos. 2015.
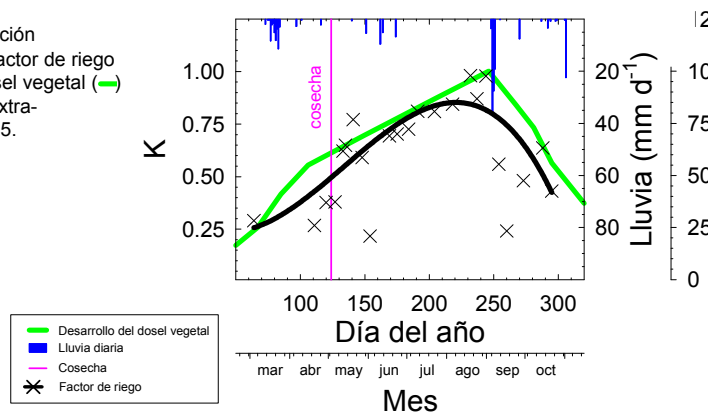

Mes

Tabla 1. Factor de riego $(\mathrm{K})$ para nectarino extra-temprano.

\begin{tabular}{|c|c|c|c|c|c|c|c|}
\hline Marzo & Abril & Mayo & Junio & Julio & Agosto & Septiembre & Octubre \\
\hline 0.31 & 0.41 & 0.57 & 0.72 & 0.83 & 0.86 & 0.77 & 0.51 \\
\hline
\end{tabular}




\title{
A-04
}

\section{ESTIMACIÓN DE LA EVAPORACIÓN/TRANSPIRACIÓN EN UN CULTIVO DE VIÑA MEDIANTE RADIOMETRÍA TÉRMICA}

\author{
Sánchez, J.M. ${ }^{(1)}$, López-Urrea, . $^{(2)}$, Caselles, $V^{(3)}$, Montoro, $A .{ }^{(4)}$, Martínez, $L .^{(5)}$, Doña,.$^{(6)}$ \\ 1 Profesor, UCLM, Dpto. Física Aplicada, EPC, Campus Universitario, 16071 Cuenca, \\ juanmanuel.sanchez@uclm.es \\ ${ }^{2}$ Director, ITAP-FUNDESCAM, Polígono Campollano, Avda. 2a-42 B, 02007 Albacete. \\ rlu.itap@dipualba.es \\ ${ }^{3}$ Catedrático, UV, Dpto. Física de la Tierra y Termodinámica, C/Dr. Moliner 50, 46100 \\ Burjassot, Vicente.caselles@uv.es \\ ${ }^{4}$ Investigadora, ITAP-FUNDESCAM, Polígono Campollano, Avda. 2a-42 B, 02007 Albacete. \\ meli.itap@dipualba.es
}

5 Técnica, ITAP-FUNDESCAM, Polígono Campollano, Avda. 2a -42 B, 02007 Albacete. Imm.itap@dipualba.es

${ }^{6}$ Doctoranda, UV, Dpto. Física de la Tierra y Termodinámica, C/Dr. Moliner 50, 46100 Burjassot, carolina.dona@uv.es

\section{Resumen}

La estimación precisa de la evapotranspiración de cultivo $\left(\mathrm{ET}_{\mathrm{c}}\right)$, así como su partición en las componentes evaporativa $(E)$ y transpirativa $(T)$, resultan fundamentales para mejorar la eficacia en la gestión del riego de cultivos en hilera en regiones áridas y semiáridas. El objetivo de este trabajo es contribuir a un mejor entendimiento de la partición E/T sobre viña llevando a cabo un balance de energía por separado para las componentes de suelo y de vegetación. En este trabajo se presentan los resultados de un experimento llevado a cabo en la finca de Las Tiesas, Albacete, de junio a octubre de 2013. Se instalaron un conjunto de radiómetros de infrarrojo térmico, apuntando directamente a las plantas y al suelo entre hileras. Se tomaron medidas de las cuatro componentes de la radiación neta, del flujo de calor en el suelo, además de variables meteorológicas y parámetros biofísicos. Todas las medidas se almacenaron en intervalos de 15 minutos, y se promediaron después a escala horaria y diaria. El valor medio observado de $\mathrm{ET}_{\mathrm{c}}$ fue de 3,1 $\mathrm{mm}$ día $^{-1}$. La evaporación se estimó en torno al $30 \%$. Los resultados presentados en este trabajo ofrecen una primera impresión de la partición E/T, y muestran el potencial de la caracterización térmica de la viña con este fin.

\section{Abstract}

An accurate estimation of crop evapotranspiration $\left(E T_{c}\right)$, and its partition into both components, soil evaporation (E) and canopy transpiration (T), is known to be critical for a more effective irrigation scheduling of row-crops in arid and semi-arid environments. Vineyards are the best example in Mediterranean countries. The aim of this work is to improve our understanding of the E/T partition in vineyards by establishing a separate energy balance for soil and canopy components. An experiment was conducted in Las Tiesas experimental farm, Albacete (Spain), from June to October of 2013. A set of thermal-infrared radiometers were assembled pointing directly to the plants and the soil between rows. Measurements of the four components of the net radiation over the canopy and soil heat fluxes, as well as meteorological variables and biophysical parameters were all collected and stored every 15-min. Hourly and daily averages were then computed and analyzed. An average daily $\mathrm{ET}_{\mathrm{c}}$ value of $3.1 \mathrm{~mm}^{\text {day }}{ }^{-1}$ was observed in both sites. Interrow soil evaporation 
reached as much as $30 \%$ of the total $\mathrm{ET}_{\mathrm{c}}$. These results provide a first insight into the partition $\mathrm{E} / \mathrm{T}$ and show the potential of the vine thermal characterization with this aim.

\section{1- Introducción}

Estimar de forma precisa la evapotranspiración real de cultivo $\left(E T_{c}\right)$ resulta fundamental para mejorar la gestión de los recursos hídricos, así como para lograr una programación del riego más eficiente. Mejorar nuestra comprensión de la partición de $\mathrm{ET}_{\mathrm{c}}$ en sus componentes evaporativa (E) y transpirativa ( $T$ ) contribuiría en gran medida, especialmente en cultivos no extensivos y en regiones áridas y semiáridas en las que la $E$ juega un papel importante. La viña es un claro ejemplo de cultivo en que se aprecian estas condiciones.

Recientemente se han aplicado y validado diferentes técnicas y métodos para estimar la $\mathrm{ET}_{\mathrm{c}}$ en viña. Shapland et al. (2012) obtuvieron la $\mathrm{ET}_{\mathrm{c}}$ en una viña utilizando la técnica surface renewal. Zhang et al. (2010) estudiaron la variación de $\mathrm{ET}_{\mathrm{c}}$ en una región árida del noroeste de China empleando el método de balance de energía Bowen Ratio. Ortega-Farias et al. (2009) evaluaron el modelo de Shutteworth y Wallace en una viña de la variedad Merlot en Chile. Miglietta et al. (2009) aplicaron una metodología basada en una formulación simplificada del flujo de calor sensible utilizando medidas aéreas en el suroeste de Francia. González-Dugo et al. (2010) comprobaron el funcionamiento del modelo de balance de energía de dos fuentes (TSEB) en una viña de riego por goteo empleando medidas de temperaturas radiométricas en la zona central de España. En la misma viña, Campos et al. (2009) estimaron $\mathrm{ET}_{\mathrm{c}}$ haciendo uso de la técnica del coeficiente de cultivo dual. En todos estos trabajos se obtuvieron resultados satisfactorios en términos de $E T_{c}$ total. Además, los modelos TSEB permiten la separación de $\mathrm{E}$ y $\mathrm{T}$ mediante el establecimiento de un balance por separado de las componentes de suelo y de vegetación (Colaizzi et al. 2012; Kustas et al. 2012); sin embargo, la partición entre E y T no es sencilla de validar, y muy pocos trabajos se han ocupado de esta separación de componentes. Algunos esfuerzos se han centrado en medir por separado ambas componentes empleando, por ejemplo, medidas de flujo de savia, instalando micro-lisímetros, o incluso sistemas eddycovariance bajo la vegetación (Wilson et al. 2001; Ham et al. 1990; Yunusa et al. 2004; Colaizzi et al. 2012; Evett et al. 2012). Las medidas de flujo de savia proporcionan una estimación de la transpiración de la planta, sin embargo la representatividad de estas medidas es bastante cuestionable. La instalación de varios micro-lisímetros para medir la evaporación del suelo es una buena solución, aunque bastante costosa. Tampoco se libra de ciertos problemas el uso de sistemas eddy-covariance cerca del nivel del suelo.

En este trabajo continuamos con el estudio iniciado en Sánchez et al. (2015). En dicho trabajo se comprobó el potencial del modelo STSEB (Sánchez et al. 2008, 2014) para estimar de manera aislada la transpiración en una viña de variedad Tempranillo en la zona centro de España. Siguiendo el procedimiento definido en Sánchez et al. (2014), se tomaron medidas de las temperaturas del suelo y de la vegetación, además de variables meteorológicas. Todos estos datos se registraron y almacenaron en intervalos de 15 minutos. En este trabajo se presentan los resultados de un experimento llevado a cabo durante la campaña de 2013 en una viña situada en la finca de Las Tiesas, Albacete.

\section{2- Materiales y métodos}

La nueva experiencia se llevó a cabo entre julio y octubre de 2013 en la finca experimental de "Las Tiesas" ( $2^{\circ} 5^{\prime} \mathrm{W}, 39^{\circ} 3^{\prime} \mathrm{N}, 695 \mathrm{~m}$ sobre el nivel del mar), Albacete (Figura 1). El clima es semiárido, continental con $320 \mathrm{~mm}$ de precipitación anual, principalmente concentrada en primavera y otoño. Los valores de temperatura promedios, máximos y mínimos son $13,7,24,0$ y $4,5^{\circ} \mathrm{C}$, respectivamente. 
Se empleó una parcela de $1500 \mathrm{~m}^{2}$ de viña adulta (Vitis vinífera L.) y el estudio se llevó a cabo sobre la cv. Airén, con un marco de plantación de 1,5 m entre plantas, y de $3 \mathrm{~m}$ entre hileras, con una orientación $165^{\circ}$ NO-SE. Durante todo el experimento, el cultivo se mantuvo sin restricciones hídricas mediante un sistema de riego por goteo.

Se instalaron 5 radiómetros Apogee SI-121 en un mástil situado en el centro de una hilera. Estos instrumentos están dotados de una banda ancha $(8-14 \mu \mathrm{m})$ y tienen una precisión de $\pm 0,2^{\circ} \mathrm{C}$ y un ángulo de visión de $18^{\circ}$. Dos de estos radiómetros apuntaban directamente a las hojas, por ambos lados de la planta, y otros dos apuntaban hacia el suelo a ambos lados de la hilera. Un quinto radiómetro, apuntando al cielo, registraba la radiación de onda larga descendente, necesaria para una adecuada corrección atmosférica de las medidas térmicas. Un sensor CNR4, situado a $4 \mathrm{~m}$ de altura, registraba la radiación neta, y gracias a un conjunto de platos de flujo HFP01SC, enterrados a $8 \mathrm{~cm}$ de profundidad, se midió el flujo de calor en el suelo. Además se realizaron medidas de temperatura del aire, humedad relativa, velocidad del viento, radiación solar, y temperatura y humedad del suelo. Todos los datos se almacenaron cada 15 minutos en un datalogger CR1000, y posteriormente se promediaron a escalas horaria y diaria. Asimismo, se midió semanalmente la proporción de vegetación $\left(P_{\mathrm{v}}\right)$ y la altura del cultivo $(\mathrm{h})$.

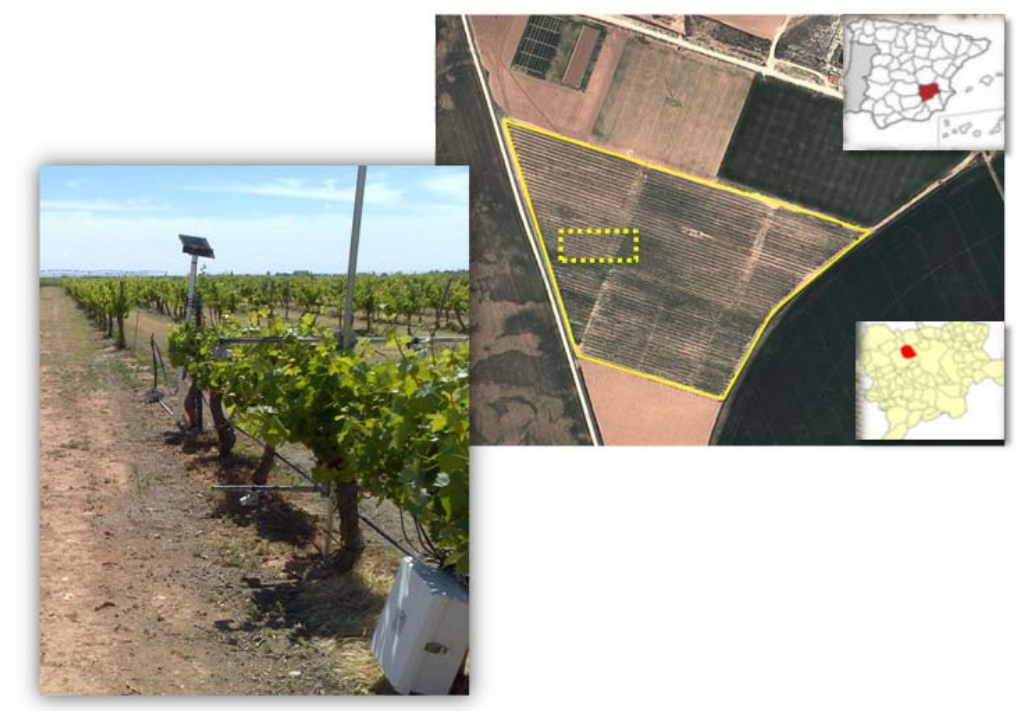

Figura 1. Localización de la zona experimental y fotografía de parte del montaje instrumental sobre la viña.

En este trabajo se aplicó el modelo simplificado de balance de energía de dos fuentes (STSEB) desarrollado por Sánchez et al. (2008) para el cálculo de la radiación neta, el flujo de calor en el suelo, el flujo de calor sensible, y la evapotranspiración. El esquema del STSEB permite, además, establecer un balance de energía por separado entre las componentes de suelo y de vegetación que conduce a una distinción entre evaporación y transpiración.

\section{3- Resultados y discusión}

Una vez corregidas de emisividad y efectos atmosféricos (Sánchez et al. 2008, 2014) los valores de temperatura de la planta $\left(T_{c}\right)$ y temperatura del suelo $\left(T_{s}\right)$, se combinaron con las variables meteorológicas y los parámetros biofísicos para obtener resultados de radiación neta $\left(R_{n}\right)$, flujo de calor en el suelo $(G)$, flujo de calor sensible $(H)$, y flujo de calor latente (LE), cada 15 minutos. Posteriormente los resultados se agregaron a escala horaria y diaria para el total de los 130 días correspondiente al periodo de estudio comprendido entre los días julianos 173 y 303, abarcando desde la floración hasta la senescencia. La figura $2 a$ 
muestra un ejemplo de evolución diurna de las cuatro componentes de temperatura medidas por los radiómetros instalados. Las medidas de temperatura de suelo y vegetación presentan diferencias importantes a ambos lados de la hilera, mostrando la necesidad de una adecuada caracterización térmica de la viña. A modo de ejemplo, y para la misma fecha, en la figura $2 \mathrm{~b}$ se presenta la evolución diurna de los distintos flujos energéticos en superficie.

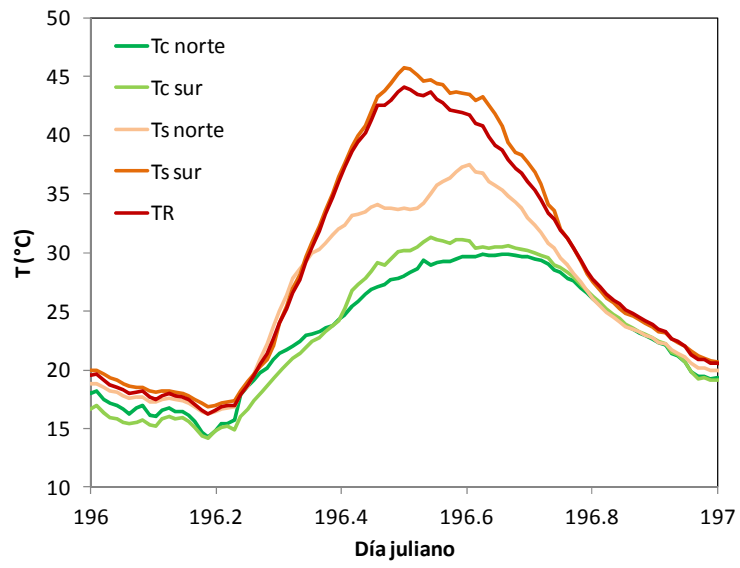

(a)

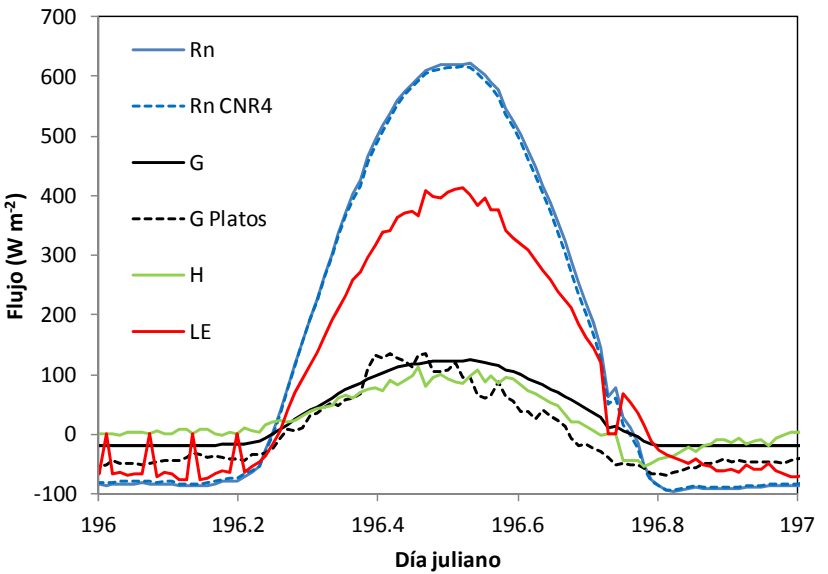

(b)

Figura 2. Ejemplo, correspondiente al día 196, de: (a) Evolución diurna de las cuatro componentes de temperatura ( $T_{c \text { norte, }}, T_{c \text { sur, }}, T_{s}$ norte, $T_{s \text { sur }}$, además de la temperatura del conjunto $\left(T_{R}\right)$, (b) Evolución diurna de los cuatro términos de la ecuación de balance de energía $\left(R_{n}, G, H\right.$ y $\left.L E\right)$, junto con las medidas in situ de $R_{n}$ y $G$.

Se observa un buen acuerdo entre los valores medidos y estimados de radiación neta (Figura 3), con un ajuste lineal muy próximo a la línea $1: 1$, y con un error cuadrático medio inferior a los $\pm 30 \mathrm{~W} \mathrm{~m}^{-2}$. La comparación entre los valores medidos y estimados de

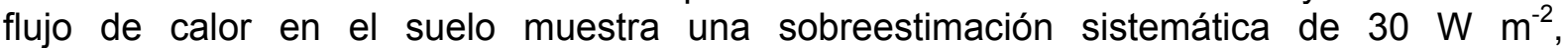
principalmente por la noche.
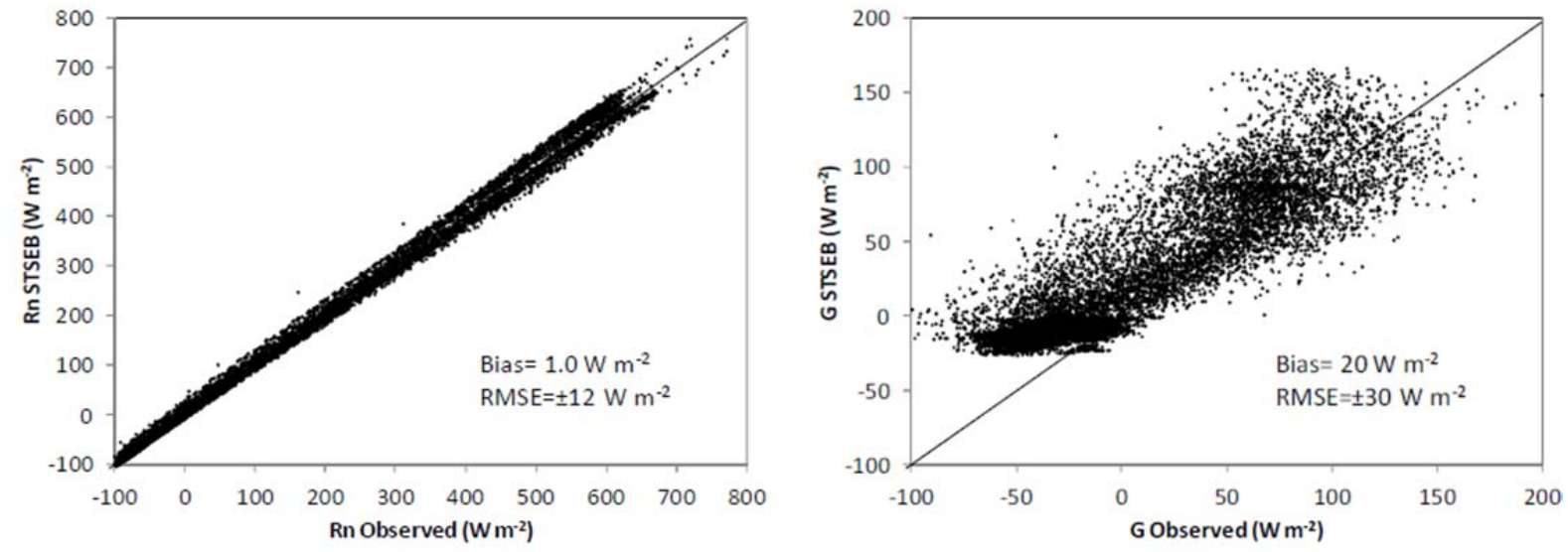

Figura 3. Comparación entre los valores medidos y estimados de radiación neta, $R_{n}$ (izquierda) y de flujo de calor en el suelo, G (derecha).

A escala diaria, la Tabla 1 muestra los valores promedio de $\mathrm{ET}_{\mathrm{c}}$ por meses entre julio y octubre. El valor máximo se alcanza entre julio y agosto, con una $E T_{c}$ de $3,9 \mathrm{~mm} \mathrm{~d}^{-1}$, 
debido a que hay una mayor demanda evaporativa y el cultivo llega al valor máximo de proporción de vegetación, descendiendo a partir de entonces.

Tabla 1. Promedio de los valores diarios de evapotranspiración de cultivo $\left(E T_{c}\right)$, y de su partición en evaporación (E) y transpiración $(T)$.

\begin{tabular}{ccccc}
\hline & Julio & Agosto & Septiembre & Octubre \\
\cline { 2 - 5 } $\mathbf{E T}_{\mathrm{c}}(\mathbf{m m})$ & 3.9 & 3.9 & 3.3 & 1.8 \\
$\mathbf{T}(\mathbf{m m})$ & $2.9(74)^{*}$ & $3.1(79)$ & $2.3(70)$ & $0.9(50)$ \\
$\mathbf{E}(\mathbf{m m})$ & $1.0(26)$ & $0.8(21)$ & $1.0(30)$ & $0.9(50)$ \\
\hline
\end{tabular}

Aplicando el balance de energía por separado al suelo y a la vegetación se obtienen los resultados de evaporación y transpiración. Los valores diarios de $\mathrm{E}$ se sitúan en torno a $1,0 \mathrm{~mm} \mathrm{~d}^{-1}$, y son bastante estables para toda la temporada, mientras que los valores diarios de $\mathrm{T}$ oscilan entre 0,9 y $3,1 \mathrm{~mm} \mathrm{~d}^{-1}$, alcanzando el máximo en agosto. En porcentaje, la transpiración supone más de un $70 \%$ del total de $\mathrm{ET}_{\mathrm{c}}$ entre julio y septiembre, llegando a alcanzar casi el $80 \%$ en agosto, coincidiendo con el estado fenológico de maduración de la uva. En términos de valores acumulados para toda la duración del experimento (130 días), del total de los $410 \mathrm{~mm}$ de $\mathrm{ET}_{\mathrm{c}}$ estimados, $290 \mathrm{~mm}$ correspondieron a transpiración de las plantas, y el resto $(120 \mathrm{~mm}$ ) a evaporación (Figura 4). Esto supone que un $30 \%$ del total de $\mathrm{ET}_{\mathrm{c}}$ en la viña corresponde a evaporación del agua del suelo. Si bien no se dispuso de medidas directas de evaporación y transpiración para validar, estos resultados dan una buena idea de la separación $\mathrm{E} / \mathrm{T}$ en viña, y ponen de manifiesto el alto porcentaje de la $E T_{\mathrm{c}}$ que se pierde en evaporación.

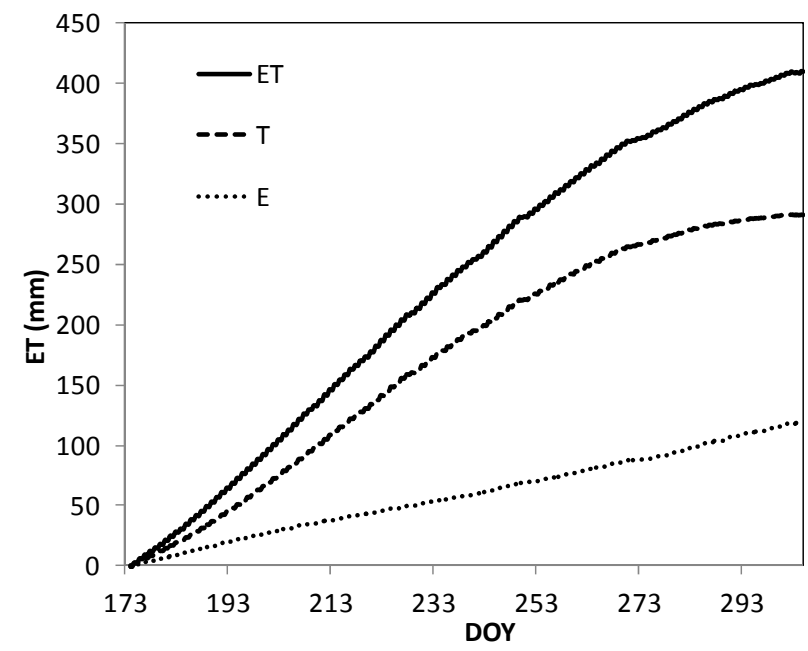

Figura 4. Evolución de los valores acumulados de evapotranspiración de cultivo (ET $)$, y de su partición en evaporación (E) y transpiración $(T)$, para toda la duración de la campaña.

\section{4- Conclusiones}

Las principales conclusiones que se pueden extraer de este trabajo son las siguientes. Las temperaturas radiométricas del suelo y de la vegetación, como parámetros de entrada en los modelos de dos fuentes, permiten obtener información de los flujos energéticos en superficie totales y realizar un balance por separado de las componentes del suelo y de la vegetación. Sin embargo, para disponer de una buena caracterización térmica en cultivos en hilera es fundamental un adecuado promediado de las partes soleadas y 
sombreadas de los distintos elementos. El valor promedio de $\mathrm{ET}_{\mathrm{c}}$ diario para el periodo de estudio resultó $3,1 \mathrm{~mm}$ día $^{-1}$, con un término de evaporación representando un $30 \%$ del total de $\mathrm{ET}_{\mathrm{c}}$ para toda la campaña. Estos resultados muestran el potencial de la caracterización térmica de la viña para una mejor programación y gestión de los riegos.

\section{Agradecimientos}

Este trabajo ha sido financiado conjuntamente por el Ministerio de Economía y Competitividad (proyectos CGL2013-46862-C2-1/2-P, cofinanciado con Fondos FEDER de la Unión Europea, y AGL2014-54201-C4-4-R), el Instituto Nacional de Investigaciones Agrarias (INIA) (proyectos RTA 2011-00100-C05-04 y RTA 2014-00049-C05-03), y la Generalitat Valenciana (proyecto PROMETEOII/2014/086).

\section{Bibliografía}

Campos, I., Neale, C.M.U., Calera, A., Balbontin, C., and González-Piqueras, J. (2010). Assessing satellite-based basal crop coefficients for irrigated grapes. Agri. Water Mgt.. 49, 211-224.

Colaizzi, P.D., Kustas, W.P., Anderson, M.C., Agam, N., Tolk, J.A., Evett, S.R., Howell, T.A., Gowda, P.H., and 'Shaughnessy, S.A. (2012). Two-source energy balance model estimates of evapotranspiration using component and composite surface temperatures. Adv. Water Res., 50, 134-151.

Evett, S.R., Kustas, W.P., Gowda, P.H., Anderson, M.C., Prueger, J.H., and Howell, T.A. (2012). Overview of the Bushland Evapotranspiration and Agricultural Remote Sensing Experiment 2008 (BEAREX08): A field experiment evaluating methods for quantifying ET at multiple scales. Adv. Water Res., 50, 4-19.

González-Dugo, M.P., González-Piqueras, J., Campos, I., Balbontin, C., and Calera, A. (2010). Estimation of surface energy fluxes in vineyard using meausurements of canopy and soil temperature. Proc. Remote Sensing and Hydrology Symposium, 27-30 September 2010, Jackson Hole, USA.

Ham, J.M., Heilman, J.L., and Lascano, R.J., (1990). Determination of soil water evaporation and transpiration from energy balance and stem flow measurements, Agri. Forest Meteorology, 52, 287-301.

Kustas, W.P., Alfieri, J.G., Anderson, M.C., Colaizzi, P.D., Prueger, J.H., Evett, S.R., Neale, C.M.U., French, A.N., Hipps, L.E., Chavez, J.L., Copeland, K.S., and Howell, T.A. (2012). Evaluating the two-source energy balance model using local thermal and surface flux observations in a strongly advective irrigated agricultural area. Adv. Water Res., 50, 120-133

Miglietta, F., Gioli, B., Brunet, Y., Hutjes, R.W.W., Matese, A., Sarrat, C., and Zaldei, A. (2009). Sensible and latent heat flux from radiometric surface at the regional scale: methodology and evaluation. Biogeosciences, 6, 1975-1986.

Ortega-Farias, S.O., Poblete-Echeverria, C., and Brisson, N. (2010). Parameterization of a two-layer model for estimating vineyard evapotranspiration using meteorological measurements, Agri. Forest Meterology, 150, 276-286.

Sánchez, J. M., Kustas, W. P., Caselles, V., and Anderson, M., (2008). Modelling surface energy fluxes over maize using a two-source patch model and radiometric soil and canopy temperature observations. Remote Sens. Environ., 112, 1130-1143.

Sánchez, J.M., López-Urrea, R., Rubio, E., and Caselles, V. (2011). Determining water use of sorghum from two-source energy balance and radiometric temperatures. Hydrol. Earth Syst. Sc., 15, 3061-3070.

Sánchez, J.M., Lopez-Urrea, R., Rubio, E., Gonzalez-Piqueras, J., and Caselles, V. (2014). Assessing crop coefficients of sunflower and canola using two-source energy balance and thermal radiometry. Agri. Water Mgt., 137, 23-29.

Sánchez, J.M., de la Cruz, F., Martinez, L., Montoro, A., and Lopez-Urrea, R. (2015). Testing the potential of two source surface energy balance to monitor plant transpiration in 
vineyards. Proc. 29th International Horticultural Congress, 17-22 August 2014, Queensland, Australia.

Shapland, T.M., Snyder, R.L., Smart, D.R., and Williams, L.E. (2012). Estimation of actual evapotranspiration in winegrape vineyards located on hillside terrain using surface renewal analysis. Irrig. Sci., 30 (6), 471-484.

Wilson, K.B., Hanson, P.J., Mulholland, P.J., Baldocchi, D.D., and Wullschleger, S.D. (2001). A comparison of methods for determining forest evapotranspiration and its components: sap-flow, soil water budget, eddy covariance and catchment water balance. Agri. Forest Meteorology., 106, 153-168.

Yunusa, I.A.M., Walker, R.R., and Lu, P., (2004). Evapotranspiration components from energy balance, sapflow and microlysimetry techniques for an irrigated vineyard in inland Australia. Agri. Forest Meteorology., 127, 93-107.

Zhang, B., Kang, S., Li, F., Tong, L., and Du, T. (2010). Variation in vineyard evapotranspiration in an arid region of northwest China. Agr.Water Mgt.., 97, 18981904. 


\title{
A-05
}

\section{¿ES POSIBLE MEJORAR LA EFICIENCIA EN EL USO DEL AGUA DE UN VIÑEDO MEDIANTE UN ACOLCHADO ORGÁNICO DEL SUELO?}

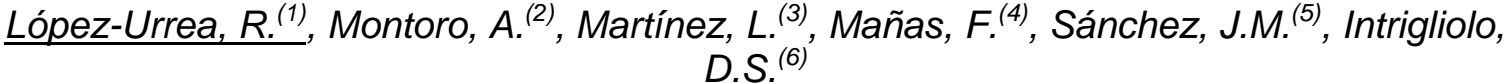

1 Director, ITAP-FUNDESCAM, Polígono Campollano, Avda. 2ª-42 B, 02007 Albacete. rlu.itap@dipualba.es

$\frac{2}{2}$ Investigadora, ITAP, Polígono Campollano, Avda. 22a -42 B, 02007 Albacete. meli.itap@dipualba.es

3 Técnica, FUNDESCAM, Polígono Campollano, Avda. 2a-42 B, 02007 Albacete. Imm.itap@dipualba.es

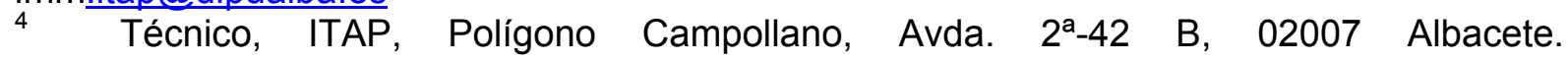
fmj.itap@dipualba.es

5 Profesor, UCLM, Dpto. Física Aplicada, EPC, 16071 Cuenca, juanmanuel.sanchez@uclm.es

${ }^{6}$ Científico Titular, CEBAS-CSIS, Campus Universitario de Espinardo. Espinardo, Murcia. E30100, dintri@cebas.csic.es

\section{Resumen}

El objetivo de este trabajo fue evaluar el efecto que un acolchado orgánico del suelo (restos de poda) puede tener sobre la evapotranspiración del cultivo $\left(E T_{c}\right)$ de la vid con el fin de mejorar la eficiencia en el uso del agua. El estudio se realizó durante la campaña de 2015 en la finca "Las Tiesas", Albacete (España). Las medidas se llevaron a cabo en un lisímetro monolítico de pesada ubicado en el centro de una parcela de vid (Vitis vinífera L., cv. Tempranillo) de 1 ha de superficie, y con cepas plantadas a un marco de 3 x 1,5 m y conducción en espaldera. Se llevaron a cabo tres ciclos de medidas, cada uno consistió en mantener el suelo desnudo durante los dos primeros días, los dos siguientes se cubrió la superficie del lisímetro con un acolchado orgánico (restos de poda de la vid) y los dos últimos días se cubrió el lisímetro con un acolchado inorgánico (lona de plástico). Los resultados indican que para la misma demanda evaporativa y fracción de cubierta vegetal, el acolchado orgánico redujo la $\mathrm{ET}_{\mathrm{c}}$ de la vid algo más de un $17 \%$, mientras que el plástico la redujo un $25 \%$. Los resultados obtenidos indican que con el acolchado orgánico sigue produciéndose una cierta evaporación de agua desde el suelo, pero se reduce considerablemente la $\mathrm{ET}_{\mathrm{c}}$ pudiéndose mejorar la eficiencia en el uso del agua.

\section{1- Introducción, Objetivos}

El cultivo de la vid ocupa grandes superficies de terreno en la cuenca Mediterránea, así como en otras regiones bajo condiciones climáticas áridas y semiáridas, en las cuales la evapotranspiración de este cultivo es una componente importante del ciclo hidrológico (Trambouze y Voltz, 2001). Castilla-La Mancha es la región que tiene una mayor superficie de viñedo para vinificación en el mundo con 437.072 ha en 2012 (MAGRAMA, 2013), representando algo más del $6 \%$ de la superficie mundial cosechada (FAOSTAT, 2012). Esta región produce 2,75 millones de toneladas de uva y la industria utiliza una parte muy importante de la mano de obra dedicada al sector agrícola en la región. 
En zonas con esta limitación, la prioridad para la agricultura es hacer un uso sostenible del agua, teniendo en cuenta una serie de consideraciones medioambientales, la viabilidad económica, así como ciertos aspectos tecnológicos y sociales (Guerra et al., 2015). Además, la actual escasez de recursos hídricos de muchas zonas de todo el mundo parece puede agravarse en el futuro debido fundamentalmente al cambio climático y la tendencia actual a cambios en la demanda de agua (Skura y Psaltopoulos, 2012).

El manejo del agua en el cultivo de la vid se considera una herramienta importante para mejorar el desarrollo de la planta y la calidad de la uva, así como para conseguir la estabilidad en la producción (Williams y Matthews, 1990). En aquellas zonas donde los recursos hídricos no son un limitante, se puede realizar una programación de riegos basada en producir un cierto estrés durante determinados periodos de tiempo para controlar el desarrollo vegetativo e incrementar la calidad de la uva (Schultz y Matthews, 1993; Jackson y Lombard, 1993). Sin embargo, en zonas áridas y semiáridas donde el agua es un recurso escaso y de gran valor, los viñedos están sometidos frecuentemente a un estrés hídrico muy severo, por lo que se hace necesario un manejo del riego preciso para conseguir una producción sostenible que resulte en una actividad económicamente rentable.

Estudios recientes llevados a cabo en La Mancha Oriental (López-Urrea et al., 2012; Sánchez et al., 2015) indican que la evapotranspiración del cultivo $\left(E T_{c}\right)$ de la vid, sin restricción hídrica, medida en un lisímetro de pesada o mediante medidas térmicas y balance de energía se sitúa entre 500 y $550 \mathrm{~mm}$ anuales, siendo la componente evaporativa del balance de agua un $20-30 \%$ del total de la $\mathrm{ET}_{\mathrm{c}}$ de la vid.

El objetivo de este trabajo fue evaluar el efecto que un acolchado orgánico del suelo (restos de poda) puede tener sobre la evapotranspiración del cultivo de la vid con el fin de mejorar la eficiencia en el uso del agua.

\section{2- Materiales y métodos}

El estudio se realizó durante la campaña agrícola de 2015 en la finca "Las Tiesas", Albacete (España). Sus coordenadas geográficas son: $2^{\circ} 5^{\prime}$ longitud Oeste, $39^{\circ} 3^{\prime}$ latitud Norte, y $695 \mathrm{~m}$ sobre el nivel del mar. El clima es semiárido, Mediterráneo templado con una precipitación media anual de unos $320 \mathrm{~mm}$, concentrada principalmente en primavera y otoño. Las temperaturas medias, máximas y mínimas son $13,7,24,0$ y $4,5{ }^{\circ} \mathrm{C}$, respectivamente. Para una descripción más detallada del clima de la zona ver López-Urrea et al. (2006).

El suelo de la parcela donde se realizó el estudio se cataloga como Petrocalcic Calcixerepts (Soil Survey Staff, 2006). La profundidad media del suelo de la parcela experimental es de $40 \mathrm{~cm}$ limitado por el desarrollo del horizonte petrocálcico que se encuentra más o menos fragmentado. La textura es franco-arcillo-limosa, con un $13 \%$ de arena, un $49 \%$ de limo y un $38 \%$ de arcilla, con un pH básico. El suelo es pobre en materia orgánica y en nitrógeno, y tiene un alto contenido en caliza activa y potasio.

Las medidas se llevaron a cabo en un lisímetro monolítico de pesada ubicado en el centro de una parcela de viñedo (Vitis vinífera L., cv. Tempranillo) de $100 \times 100 \mathrm{~m}$. La vid fue injertada en 1999 sobre patrón 110 Richter, con un marco de 3 x 1,5 m y conducción en espaldera. Las dimensiones del recipiente del lisímetro son de $3 \times 3 \mathrm{~m}$ de lado y 1,7 $\mathrm{m}$ de profundidad, con un peso total aproximado de 18,5 t. El tanque del lisímetro se apoya sobre un sistema de vigas y un contrapeso que contrarresta la carga muerta del suelo y el tanque del lisímetro, y reduce la carga en la báscula, con un factor de desmultiplicación de 1000:1. Un célula de carga (modelo SB2, Epelsa Ind., S.L., España) está conectada a la báscula. EI sistema permite medidas de la evapotranspiración $\left(E T_{c}\right)$ en el lisímetro con una resolución de $250 \mathrm{~g}$, lo que equivale a $0,03 \mathrm{~mm}$ de agua. En el interior del lisímetro se plantaron dos vides, ocupando cada una de ellas $4,5 \mathrm{~m}^{2}$, al igual que el resto de plantas de la parcela de protección, proporcionando una medida representativa de la $\mathrm{ET}_{\mathrm{c}}$ de la vid.

Las variables meteorológicas fueron medidas durante el experimento con una estación agrometeorológica automática, situada sobre una cubierta de césped y localizada a menos de $100 \mathrm{~m}$ del lisímetro de vid. Los sensores estaban situados entre 1,25 y $2 \mathrm{~m}$ de 
altura por encima de la cubierta de césped y se generaron registros cada quince minutos, horarios y diarios. Las variables medidas fueron: temperatura y humedad relativa del aire (MP100, Campbell Scientific Instrument, Logan, UT, USA), velocidad del viento (A100R, Vector Instruments Ltd., UK), radiaciones de onda corta (CM14, Kipp \& Zonen Delft, Holland), radiaciones de onda larga (CG2, Kipp \& Zonen Delft, Holland) y lluvia (ARG100, Campbell Scientific Instrument, Logan, UT, USA). Toldos los datos registrados se almacenaron en dos dataloggers (CR10X, Campbell Scientific Instrument, Logan, UT, USA). La evapotranspiración de referencia $\left(E T_{0}\right)$ se calculó utilizando la ecuación de PenmanMonteith FAO56 (P-M FAO56) (Allen et al., 1998). Los valores de coeficiente de cultivo $\left(\mathrm{K}_{\mathrm{c}}\right)$ se obtuvieron dividiendo la $\mathrm{ET}_{\mathrm{C}}$ medida en el lisímetro entre la $\mathrm{ET}_{0}$ calculada por el método de P-M FAO56.

Se llevaron a cabo tres ciclos de medidas en las siguientes fechas: del 12 al 17 de julio, del 26 al 31 de julio y del 9 al 14 de agosto. Cada ciclo consistió en mantener el suelo desnudo durante los dos primeros días, los dos siguientes se cubrió la superficie del lisímetro con un acolchado orgánico (restos de poda de la vid) y los dos últimos días se cubrió el lisímetro con un acolchado inorgánico (lona de plástico impermeable). Al inicio de cada periodo de 2 días se aplicó un riego de 3 horas (unos $5 \mathrm{~mm}$ ) a las 8:00h am (hora local). De esta forma, se pudo analizar la reducción que se produce en la evaporación (E) con el acolchado orgánico, así como evaluar si con los restos de poda se sigue produciendo algo de evaporación al compararlo con la lona de plástico (evaporación nula). En la Fig. 1 se presentan dos imágenes del lisímetro con los dos tipos de acolchado utilizado. Los valores de $\mathrm{ET}_{\mathrm{c}}$ de la vid se determinaron a partir de las pérdidas de masa en el lisímetro (por evaporación y transpiración) dividido por el área del lisímetro $\left(9 \mathrm{~m}^{2}\right)$. Los registros en que se produjeron ganancias de peso en el lisímetro (por riego), se eliminaron de los cálculos. En total se obtuvieron 462 registros de valores de $\mathrm{ET}_{\mathrm{c}}$ cada quince minutos para cada uno de los ciclos de medida y tipo de suelo (desnudo, restos de poda y plástico).
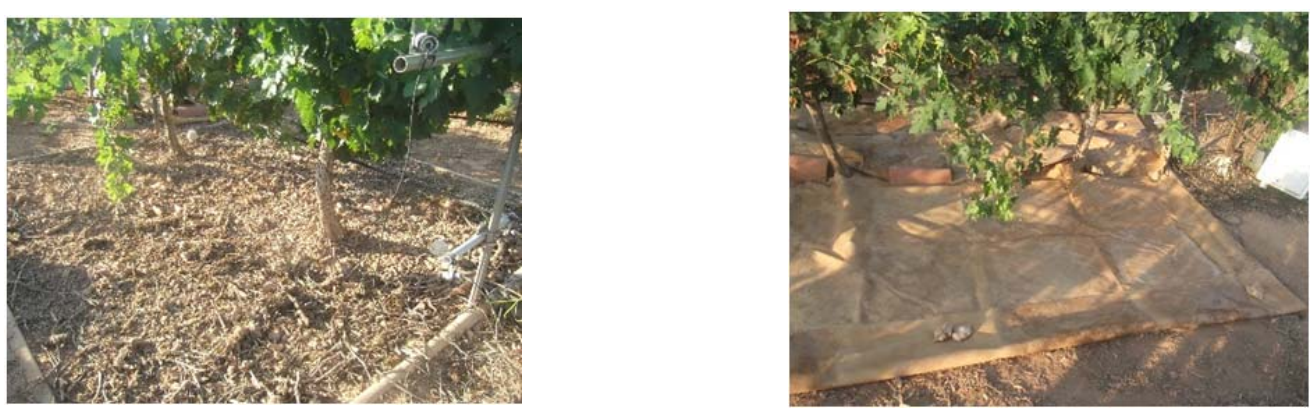

Figura 1. Suelo del lisímetro con restos de poda (izq.) y con una lona de plástico (drcha.).

Durante cada ciclo de medidas se llevaron a cabo una serie de determinaciones en el suelo y las plantas del lisímetro. Se midió de manera continua el contenido de humedad del suelo a 10, 40, 70 y $100 \mathrm{~cm}$ mediante sondas FDR (Frecuence Domain Reflectometry) (EnviroSCANTM, Sentek Pty Ltd., South Australia); los potenciales hídricos de hoja $\left(\Psi_{h}\right)$ y tallo $\left(\Psi_{t}\right)$ se midieron el primer día de cada uno de los tipos de cobertura del suelo (desnudo, restos de poda y plástico) durante los tres ciclos estudiados y a dos horas distintas (11:00 y 13:30 hora local), para lo que se utilizó una cámara de presión tipo Scholander (modelo 600, PMS Instrument Company, Albany, OR, USA); la fracción de suelo cubierta por vegetación $\left(f_{c}\right)$ se determinó diariamente a partir de la metodología clásica desarrollada por Cihlar et al. (1987), usando la técnica de la clasificación supervisada de imágenes con el algoritmo de máxima probabilidad, con el fin de asignar las diferentes clases de vegetación verde presentes en la imagen; la conductancia estomática $\left(g_{s}\right)$ se midió con un porómetro (modelo SC-1, Decagon Devices Inc., Pullman, WA, USA) los días indicados para las medidas de potencial hídrico y se llevó a cabo un seguimiento del estado fenológico del cultivo durante cada ciclo de medidas utilizando el código BBCH (Biologische Bundesanstalt, Bundessortenamt and CHemical industry) (Meier, 2001). 


\section{3- Resultados y discusión}

\subsection{Medidas de suelo y planta}

En la Fig. 2 se presenta la evolución del contenido de humedad del suelo a diferentes profundidades durante un ciclo de medidas (12-18 julio). Se observa como la sonda más superficial $(10 \mathrm{~cm})$ responde positivamente a cada uno de los riegos, obteniéndose un contenido de agua en el suelo similar durante todo el periodo estudiado, al igual que en los otros dos ciclos de medidas.

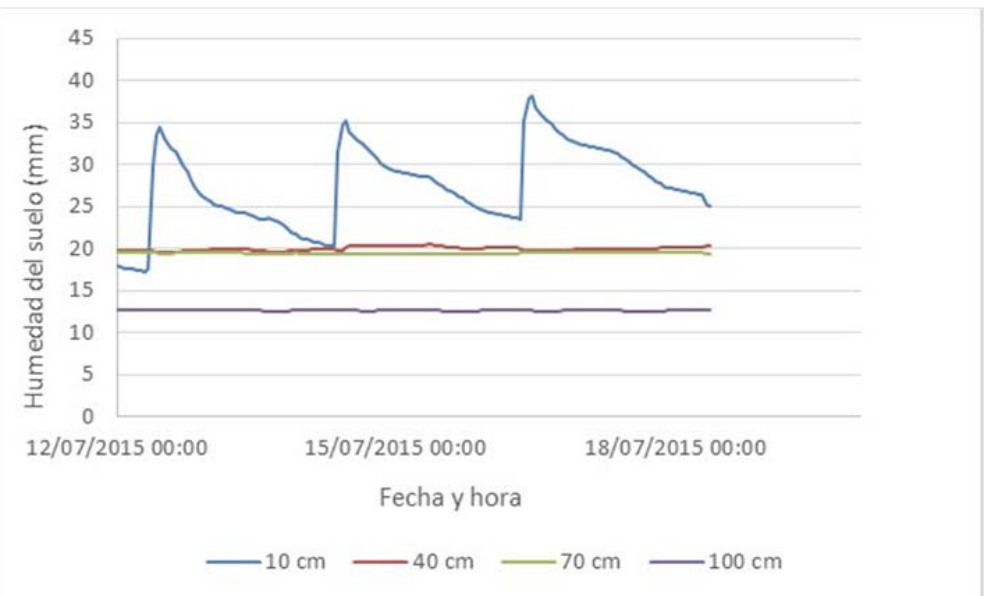

Figura 2. Evolución del contenido de humedad en el suelo a distintas profundidades durante el ciclo del 12 al 18 de julio.

En la Tabla 1 se presenta un resumen de los valores medios de los parámetros medidos en las plantas del lisímetro durante los ciclos estudiados. Los valores de los potenciales hídricos de tallo y hoja a las 13:30h (hora local) indican que las vides en general no padecían de un estrés hídrico acusado en ninguna de las tres condiciones de manejo del suelo. Existe una tendencia a menores valores de potencial hídrico en los días en los que el suelo se cubrió en particular con lona de plástico seguramente debido a la menor $E T_{c}$ (resultados mostrados a continuación) y por lo tanto mayor disponibilidad de agua en el suelo. Los resultados de potencial hídrico además sugieren que tanto la lona de plástico como la aplicación de restos de poda posiblemente no variaron notablemente el micro-clima de las cepas dado que los potenciales hídricos no se vieron afectados negativamente por la aplicación de las técnicas de manejo del suelo. La fracción de cubierta vegetal verde fue la misma en los tres ciclos de medidas, indicando que las plantas se encontraban en el mimo estado de desarrollo.

Tabla 1. Valores medios de potenciales de hoja $\left(\Psi_{\mathrm{h}}\right)$ y tallo $\left(\Psi_{\mathrm{t}}\right)$, conductancia estomática $\left(\mathrm{g}_{\mathrm{s}}\right)$, fracción de cubierta vegetal verde $\left(\mathrm{f}_{\mathrm{c}}\right)$ y fenología del cultivo. 


\begin{tabular}{|c|c|c|c|c|c|c|}
\hline Tipo cubierta & Fecha & $\Psi_{\mathrm{h}}(\mathrm{MPa})$ & $\Psi_{\mathrm{t}}(\mathrm{MPa})$ & $\mathrm{g}_{\mathrm{s}}\left(\mathrm{mmol} \mathrm{m} \mathrm{s}^{-2}\right)$ & $f_{c}$ & Fenología \\
\hline Suelo desnudo & 13-Julio & -1.62 & -1.03 & 343 & 0.32 & Cierre de racimos \\
\hline Restos poda & 15-Julio & -1.55 & -1.03 & 365 & 0.32 & Cierre de racimos \\
\hline Plástico & 17-Julio & -1.50 & -0.93 & 269 & 0.32 & Cierre de racimos \\
\hline Suelo desnudo & 27-Julio & -1.61 & -0.94 & 366 & 0.32 & Envero \\
\hline Restos poda & 29-Julio & -1.64 & -0.96 & 316 & 0.32 & Envero \\
\hline Plástico & 31-Julio & -1.32 & -0.86 & 446 & 0.32 & Envero \\
\hline Suelo desnudo & 10-agosto & -1.66 & -1.00 & 568 & 0.32 & Maduración \\
\hline Restos poda & 12-agosto & -1.66 & -0.84 & 557 & 0.32 & Maduración \\
\hline Plástico & 14-agosto & -1.56 & -0.80 & 375 & 0.32 & Maduración \\
\hline
\end{tabular}

\subsection{Medidas de evapotranspiración}

En la Fig. 3a se presenta la evolución de la $\mathrm{ET}_{\mathrm{c}}$ de la vid los días 9 de agosto (suelo desnudo), 11 de agosto (restos de poda) y 30 de julio (plástico) después de un riego $(5 \mathrm{~mm})$, teniendo el cultivo un desarrollo vegetativo similar $\left(f_{c}=0,32\right)$ y la misma demanda evaporativa en los distintos días de medida $\left(\mathrm{ET}_{\circ} \sim 5 \mathrm{~mm}\right.$ día $\left.{ }^{-1}\right)$. En la Fig. $3 \mathrm{~b}$ se presenta la $\mathrm{ET}_{\mathrm{c}}$ acumulada durante los tres ciclos de medidas para cada uno de los tipos de cubierta de suelo analizados. En ambas figuras se puede observar como los valores de $\mathrm{ET}_{\mathrm{c}}$ son superiores en condiciones de suelo desnudo.
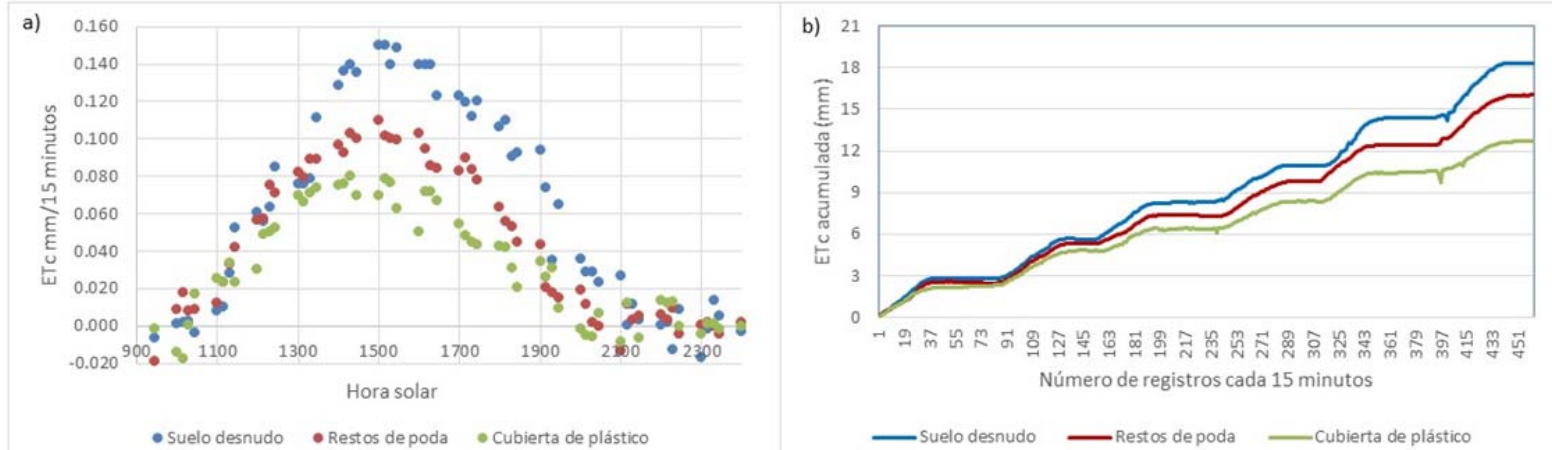

Figura 3. a) Evolución de la evapotranspiración del cultivo $\left(E T_{c}\right)$ cada quince minutos después de un riego; y b) $\mathrm{ET}_{\mathrm{c}}$ acumulada para cada tipo de cubierta de suelo durante el periodo experimental.

En la Tabla 2 se presentan los valores diarios y el total acumulado de $\mathrm{ET}_{\mathrm{c}}$ y $\mathrm{ET}_{\mathrm{o}}$ para los tres tipos de tipo de cubierta. Los resultados indican que para la misma demanda evaporativa y fracción de cubierta vegetal el acolchado orgánico redujo la $E T_{c}$ de la vid algo más de un $17 \%$, mientras que el plástico la redujo un $25 \%$.

Tabla 2. Valores de evapotranspiración de referencia $\left(E T_{0}\right)$ y de cultivo $\left(E T_{c}\right)$, así como sus correspondientes coeficientes de cultivo durante los tres ciclos estudiados. 


\begin{tabular}{lcccc}
\hline Tipo cubierta & Fecha & $\mathrm{ET}_{\mathrm{c}}\left(\mathrm{mm} \mathrm{dí}^{-1}\right)$ & $\mathrm{ET}_{\mathrm{o}}\left(\mathrm{mm} \mathrm{dia}^{-1}\right)$ & Coeficiente de cultivo \\
\hline Suelo & 12-Julio & 2.77 & 5.71 & 0.49 \\
desnudo & 13-Julio & 2.84 & 6.00 & 0.47 \\
& 26-Julio & 2.66 & 5.55 & 0.48 \\
& 27-Julio & 2.62 & 7.52 & 0.35 \\
& 9-Agosto & 3.46 & 4.78 & 0.72 \\
Total & 10-Agosto & 3.93 & 6.95 & 0.57 \\
\hline Restos de & & 18.28 & 36.51 & 0.50 \\
poda & 14-Julio & 2.53 & 6.00 & 0.42 \\
& 15-Julio & 2.81 & 7.09 & 0.40 \\
& 28-Julio & 2.01 & 5.98 & 0.34 \\
& 29-Julio & 2.45 & 7.53 & 0.33 \\
Total & 11-Agosto & 2.61 & 5.05 & 0.52 \\
Plástico & 12-Agosto & 3.62 & 7.05 & 0.51 \\
& & 16.03 & 38.70 & 0.41 \\
\hline & 16-Julio & 2.16 & 4.69 & 0.46 \\
& 17-Julio & 2.67 & 6.76 & 0.39 \\
& 30-Julio & 1.56 & 5.14 & 0.30 \\
& 31-Julio & 1.97 & 5.39 & 0.37 \\
& 13-Agosto & 2.02 & 6.35 & 0.32 \\
& 14-Agosto & 2.31 & 5.38 & 0.43 \\
& & 12.69 & 33.71 & 0.38 \\
\hline \multirow{4}{*}{ Total } & & & &
\end{tabular}

\section{4- Conclusiones y recomendaciones}

En conclusión, los resultados obtenidos indican que a pesar de seguir observándose una cierta evaporación de agua desde el suelo con un acolchado orgánico (alrededor de un $25 \%$ de la $\mathrm{E}$ obtenida con un suelo desnudo), se consigue una reducción de la $E T_{c}$ pudiéndose alcanzar una mejora importante en la eficiencia en el uso del agua (entorno al $20 \%$ ).

Se trata de resultados preliminares basados en un año de estudio, por lo que creemos necesario añadir más campañas experimentales al trabajo para obtener resultados más robustos y cuantificar con más solidez el efecto del acolchado sobre la $\mathrm{ET}_{\mathrm{c}}$ del viñedo.

\section{5.- Agradecimientos}

Los autores agradecen la financiación obtenida del Ministerio de Economía y Competitividad a través de los proyectos con co-financiación FEDER AGL2014-54201-C4-4R, RTA 2011-00100-C05-04 y RTA 2014-00049-C05-03

\section{6.- Bibliografía}

Allen, R.G., Pereira, L.S., Raes, D. Smith, M., 1998. Crop evapotranspiration. Guidelines for computing crop water requirements. FAO Irrigation and Drainage, paper $n^{\circ} .56, F A O$, Rome.

Cihlar, J., Dobson, M.C., Schmugge, T., Hoogeboom, P., Janse, A.R.P., Baret, F., Guyot, G., Le Toan, T., Pampaloni, P., 1987. Procedures for the description of agricultural crops and soils in optical and microwave remote sensing studies. Int. J. Remote Sens. 8, 427-439.

FAOSTAT, 2012. FAO Statistical Database (on line). Consulta: 1 de abril de 2016. http://faostat.fao.org/site/567/DesktopDefault.aspx?PagelD=567\#ancor

Guerra, E., Ventura, F., Snyder, R.L., 2015. Crop Coefficients: A Literature Review. J. Irrig. Drain. Eng., 10.1061/(ASCE)IR.1943-4774.0000983, 06015006. 
Jackson, D., Lombard, P., 1993. Environmental and management practices affecting grape composition and wine quality. A review. Am. J. Enol. Vitic. 44, 409-430.

López-Urrea, R., Martín de Santa Olalla, F., Fabeiro, C. and Moratalla, A. 2006. Testing evapotranspiration equations using lysimeter observations in a semiarid climate. Agric. Water Manage. 85:15-26.

López-Urrea, R., Montoro, A., Mañas, F., López-Fuster, P., Fereres, E., 2012. Evapotranspiration and crop coefficients from lysimeter measurements of mature "Tempranillo" wine grapes. Agricultural Water Management 112, 13-20.

MAGRAMA, 2013. Anuario de Estadística Agraria (on line). Consulta: 1 de abril de 2016. http://www.magrama.gob.es/estadistica/pags/anuario/2013/AE $201313 \quad 1103 \quad 01 . p$ $\mathrm{df}$

Meier, 2001. Growth stages of mono-and dicotyledonous plants. BBCH Monograph. Federal Biological Research Centre for Agriculture and Forestry, $158 \mathrm{pp}$.

Sánchez, J.M., López-Urrea, R., Cuxart, J., Montoro, A., Caselles, V., De la Cruz, F., Doña, C., Martínez, L., 2015. Thermal Remote Sensing Measurements as a Tool to Monitor Evaporation/Transpiration in Vineyards. VIII INTERNATIONAL SYMPOSIUM ON IRRIGATION OF HORTICULTURAL CROPS, Lleida (Spain).

Skuras, D., Psaltopoulos, D., 2012. A broad overview of the main problems derived from climate change that will affect agricultural production in the Mediterranean area." FAO/OECD Workshop: Building Resilience for Adaptation to Climate Change in the Agriculture Sector, FAO, Rome.

Schultz, H., Matthews, M., 1993. Growth, osmotic adjustment, and cell-wall mechanics of expanding grape leaves during water deficits. Crop Sci. 33, 287-294.

Soil Survey Staff, 2006. Keys to Soil Taxonomy, 10th ed. USDA-Natural Resources Conservation Service, Washington, DC.

Williams, L.E., Matthews, M.A., 1990. Grapevine. In: Stewart BA, Nielsen DR (eds) Irrigation of agricultural crops agronomy monograph no. 30. ASA-CSSA-SSSA, Madison, pp 1019-1055 


\section{A-06 \\ UMBRALES SOSTENIBLES DE ESTRÉS HÍDRICO DURANTE EL ENDURECIMIENTO DEL HUESO EN LA PRODUCCIÓN DE ACEITUNA DE MESA}

Corell, $M$ (1), Martín-Palomo, MJ (2), Girón, I (3), Torrecillas, A (4), Pérez-López, D (5), Moreno, $F(6)$, Moriana, A (7) ${ }^{1}$ Profesora, Universidad de Sevilla, Departamento de Ciencias Agroforestales,
mcorell@us.es
$\begin{aligned} & { }^{2} \text { Profesora, Universidad de Sevilla, Departamento de Ciencias Agroforestales, } \\ & \text { mjpalomo@us.es }\end{aligned}$

3 Técnico superior, Consejo Superior de Investigaciones Científicas, IRNAS, iggi@irnase.csic.es

${ }^{4}$ Profesor de Investigación,Consejo Superior de Investigaciones Científicas, CEBAS, atorreci@cebas.csic.es

${ }^{5}$ Profesor, Universidad Politécnica de Madrid, Departamento de Producción Vegetal:Fitotecnia, david.perezl@upm.es

${ }^{6}$ Profesor de Investigación,Consejo Superior de Investigaciones Científicas, IRNAS, fmoreno@irnase.csic.es

${ }^{7}$ Profesor, Universidad de Sevilla, Departamento de Ciencias Agroforestales, amoriana@us.es

\section{Resumen}

La programación del riego deficitario controlado (RDC) es una necesidad derivada de la escasez de agua disponible para el riego. La resistencia al estrés hídrico de los diferentes estados fenológicos en olivar está bastante bien documentada pero no así los niveles de estrés hídrico. El objetivo de este trabajo es sugerir en base a experimentos realizados en los últimos 7 años los niveles de estrés hídrico para el manejo del RDC en olivar.Los experimentos descritos en la presente comunicación se han desarrollado en la finca "La Hampa" propiedad del IRNAS (CSIC) en Coria del Río (Sevilla), en un olivar de 37 años cV "Manzanillo" y a un marco de $7^{\star} 5 \mathrm{~m}$. Los experimentos se establecieron con diferentes tratamientos de riego, aplicando condiciones de estrés hídrico durante endurecimiento de hueso y unas semanas antes de cosecha. Se discute los diferentes umbrales detectados y su efecto en cosecha, cantidad y calidad, y en la fisiología de la planta en el años en curso en el ciclo bianual del olivo.

\section{1.- Introducción}

El olivar es uno de los cultivos leñosos que ha sufrido un mayor cambio en las últimas dos décadas. Este cultivo ha pasado de ser tradicional de secano con una baja inversión, a un cultivo en el que aproximadamente un $20 \%$ de su superficie está en regadío (400.000 ha, Magrama, 2016) y con un aumento considerable en el número de árboles por hectárea y en la inversión realizada. Esta transformación supuso la aparición de un nuevo consumidor de agua sin apenas trabajos de investigación que permitan una optimización del riego.La programación de riego deficitario controlado (RDC) especialmente en cultivos leñosos es una necesidad derivada de la escasez de agua disponible para el riego. En el caso del olivar es aún más importante por la escasa dotación de agua y por su gran capacidad de resistencia al estrés hídrico. La resistencia al estrés hídrico de los diferentes estados fenológicos está bastante bien documentada en la mayor parte de los cultivos y el olivo no es una excepción (Goldhamer, 1999). Sin embargo, aunque en base a esta información se sugieren manejos, incluso para las nuevas plantaciones 
superintensivas(Fernández, 2014) se conoce muy poco acerca de los umbrales de estrés hídrico a los que puede someterse a la planta.EI RDC ha sido programado tradicionalmente en función de un porcentaje de la evaportanspiración del cultivo (ETc) en condiciones no limitantes. Sin embargo, la respuesta fisiológica de las plantas al estrés hídrico dificultad la modelización y estimación de la ETc. Desde los años 90 del pasado siglo se han desarrollado sensores que miden de forma continua diferentes indicadores de relaciones hídricas en las plantas. El desarrollo de la electrónica y las tecnologías de la información ha dado lugar a una gama cada vez más amplia de posibilidades. No obstante, a pesar de todo este espectacular avance, aún se sigue sin describir cuales son los límites a los que se puede someter a los árboles durante los periodos de déficit. El objetivo de este trabajo es sugerir en base a experimentos realizados en los últimos 7 años los niveles de estrés hídrico para el manejo del RDC en olivar.

\section{2.- Materiales y métodos}

Los experimentos se llevaron a acabo en la finca La Hampa propiedad del Instituto de Recursos Naturales y Agrobiología de Sevilla (IRNAS-CSIC) localizada en Coria del Río (Sevilla, España) $\left(37^{\circ} 17^{\prime} \mathrm{N}, 6^{\circ} 3^{\prime} \mathrm{W}, 30 \mathrm{~m}\right.$ altitud). Los experimentos se realizaron en un olivar de mesa (cv Manzanilla) de 37 años de edad al comienzo de los experimentos (año 2008) con un marco de $7 \mathrm{~m} \times 5 \mathrm{~m}$. El suelo es de tipo franco arenoso con unos $2 \mathrm{~m}$ de profundidad con un contenido en agua de $0.33 \mathrm{~m}^{3} \mathrm{~m}^{-3}$ a saturación, $0.21 \mathrm{~m}^{3} \mathrm{~m}^{-3}$ a capacidad de campo y $0.10 \mathrm{~m}^{3} \mathrm{~m}^{-3}$ en el punto de marchitez permanente. La densidad aparente es de $1.5 \mathrm{~g} \mathrm{~cm}^{-3}$. El riego se realiza habitualmente durante la noche o últimas hora de la tarde mediante el uso de goteo (5 emisores de $8 \mathrm{I} \mathrm{h}^{-1}$ por árbol) con una calidad de agua que no se considera limitante para el cultivo.

Los datos climatológicos se obtuvieron de una estación de una estación automática completa situada a $40 \mathrm{~m}$ de la parcela. La evapotranspiración de referencia (ETo) se calculó empleando la ecuación de Penman-Monteith (Allen et al., 1998).

El diseño experimental fue en bloques al azar con 3 o 4 bloques, dependiendo del periodo, y tres tratamientos diferentes de riego. Los tratamientos de riego tuvieron en consideración el estado fenológico del cultivo a la hora de aplicar las restricciones de riego. Las fases consideradas fueron:

- Fase I. Desde brotación hasta comienzo de endurecimiento del hueso. Esta fase engloba la plena floración (que suele tener lugar para el año medio a mediados de Abril) y es considerada la más sensible al estrés hídrico (Moriana et al., 2003).. El inicio de brotación habitualmente ocurre desde final de Febrero y el comienzo del endurecimiento masivo del hueso en la última semana de Junio. La determinación del comienzo del endurecimiento masivo se realizó según Rapoport et al (2013) que brevemente consiste en medir la longitud de la aceituna, cuando hay un cambio en la tasa de crecimiento se considera que ha comenzado este proceso. En el año medio durante este periodo las necesidades de riego suelen ser pequeñas por el régimen pluviométrico de la zona.

- Fase II. Desde endurecimiento masivo de hueso hasta la última semana de Agosto. Esta fase es la más resistente al estrés hídrico (Goldhamer, 1999) y es la que analizaremos en este trabajo. En todos los casos el final de esta fase es arbitrario y se ha seleccionado por la fecha de cosecha para asegurar un periodo de rehidratación suficiente. En el año medio esta fase coincide con una ausencia total de lluvias y una gran demanda evaporativa.

- Fase III. Desde la última semana de Agosto hasta cosecha. Esta fase se ha empleado como periodo de rehidratación habitualmente. La fecha media de cosecha es en torno al 15 de Septiembre. En el año medio puede iniciarse el periodo de lluvias otoñales aunque habitualmente de forma escasa.

- Postcosecha.

Los tratamientos realizados fueron: 
- Control. $100 \%$ de la Evapotranspiración del cultivo empelando para el cálculo los coeficientes de cultivo sugeridos por Fernández et al (2006) para la parcela ( $\mathrm{Kc}=0.7$ durante la fase de endurecimiento) y estimando un coeficiente reductor $(\mathrm{Kr})$ de 0.8. No se tuvo en consideración la humedad del suelo. Sin riego en postcosecha.

- Riego deficitario 2 (RDC-2). Restricción del riego durante la Fase II desde el año 2008 al 2013 estableciendo un umbral de riego alrededor a -2.5 MPa. El riego durante las Fases I y III se realizaba en función del umbral sugerido por Moriana et al (2012) de $-1.2 \mathrm{MPa}$ (en Fase I) y $-1.4 \mathrm{MPa}$ (en Fase II). Sin riego en postcosecha.

- Riego deficitario 12 (RDC-12). Restricción del riego en fase I y II desde el año 2008 al 2013 con umbrales similares al RDC-2.Sin riego en postcosecha.

- Riego deficitario controlado 2 semanas antes de cosecha (RDC- 2s). Riego como el control con un recorte de riego dos semanas antes de cosecha para obtener un nivel de estrés de $-2.0 \mathrm{MPa}$. Sin rehidratación ni riego en postcosecha. Aplicado sólo en 2014.

- Riego deficitario controlado 4 semanas antes de cosecha (RDC-4s). Como el anterior pero cuatro semanas antes de cosecha.

La aplicación del agua de riego en los tratamientos deficitarios fueron diarios cuando era preciso regary la estimación de las necesidades fue proporcional a la distancia de los valores medidos en planta al umbral considerado (Moriana et al 2012; Girón et al 2015). No realizando ningún riego cuando las plantas estaban mejor hidratadas que los umbrales fijados.

El estado hídrico de las plantas se determinó mediante la medida de potencial hídrico, conductancia estomática y dendrometría. Las medidas de potencial hídrico se realizaron al mediodía en hoja cubierta al menos una hora antes realizado con una cámara de presión (100, PMS). Las medidas de conductancia estomática se realizaron sobre las 10:00 am para estimar el máximo diario con un porómetro de régimen permanente (LICOR1600). Las medidas de dendrometría se realizaron con sensores de desplazamiento (LVDT, DF2.5, Solartrón) que obtenían datos cada 30 segundo y medias cada 15 minutos. El parámetro empleando en este trabajo es la tasa de crecimiento del tronco que se calcula como la diferencia entre dos máximos diarios consecutivos.

La cosecha se realizó de forma individual por cada árbol experimental estimando mediante muestreo el número de frutos por Kilo (escandallo) y la relación pulpa hueso.

\section{3- Resultados y discusión}

Los diferentes tratamientos de riego realizados entre los años 2008 al 2013 dieron lugar a niveles de estrés hídrico diferentes influenciados por la carga de frutapero sobre todo por la pluviometría. La Figura 1, muestra, a modo de ejemplo, dos años con un nivel de carga record y resultados muy distintos en cuanto al estado hídrico fruto de la abundancia de lluvias primaverales. En ambos casos la estrategia era de recorte durante el momento de endurecimiento del hueso y en ninguno de los casos se regó en ese periodo (entre las líneas verticales en la figura 1). El nivel alcanzado en el caso del año 2008 (Fig 1a) fue de un potencial hídrico mínimo alrededor de $-3 \mathrm{MPa}$, con una rehidratación casi completa al final de la estación. Por el contrario, en el año 2010 (Fig. 1b) el máximo nivel de estrés hídrico apenas si llegó a $-2 \mathrm{MPa}$. Es importante reseñar que en ambos casos los árboles Control, sin carencia de agua, llegaron hasta valores alrededor de -2 MPa. Este comportamiento está probablemente relacionado con la presencia del fruto que da lugar a una mayor traspiración de la planta (Martin-Vertedor et al., 2011).

La Figura 2 presenta los datos de conductancia estomática máxima diaria en los mismos años presentados en la Figura 1. Los niveles de potencial hídrico dieron lugar a un efecto en el intercambio gaseoso. Niveles de potencial por debajo de -2 MPa dieron lugar a un cierre estomático significativo en los árboles RDC (Fig 2a), mientras que los niveles de potencial por encima mantuvieron valores de conductancia foliar similares al control durante 
toda la estación (Fig. 2b). Moriana y Fereres (2002) describieron el intercambio gaseoso como un proceso menos sensible al estrés hídrico que el potencial hídrico. La no afección de la apertura estomática con valores superiores a -2 MPasugieren un primer nivel de estrés hídrico que podríamos catalogar como bajo, mientras que valores inferiores podrían ser moderados. Moriana et al (2002) presentan reducciones mucho más severas de la conductancia foliar con niveles de potencial hídrico por debajo de los $-3 \mathrm{MPa}$, lo que ya podría sugerir un nivel severo, al menos desde el punto de vista del estado hídrico del árbol.
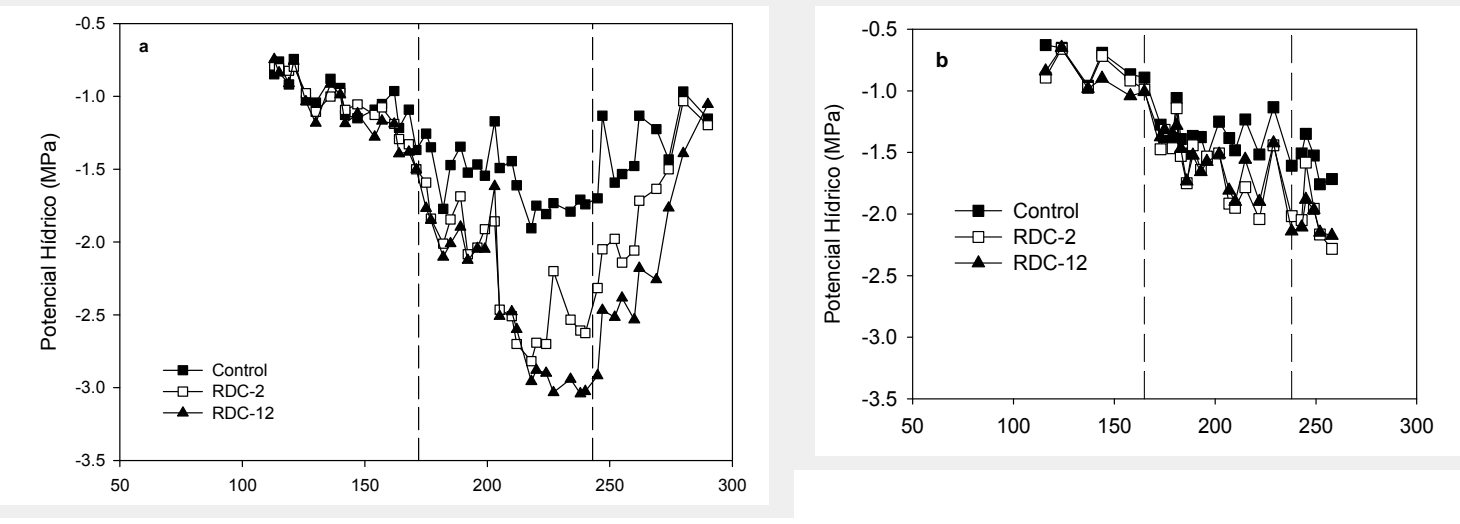

Figura 1. Evolución del potencial hídrico durante los años 2008 (a) y 2010 (b) con niveles de carga record para la media de la parcela (16.6 T ha ${ }^{-1}$ en 2008 y $16 \mathrm{~T} \mathrm{ha}^{-1}$ en 2010). Cada punto es la media de 6 árboles. Las líneas verticales indican el periodo de endurecimiento masivo del hueso, momento en el que se aplicó condiciones de RDC (Riego deficitario Controlado).

Estos niveles de estrés deben ser relacionados con el efecto en cosecha antes de considerarlos en la programación del riego. El efecto del estrés hídrico sobre la cosecha puede producirse a dos escalas, en el año en curso, afectando al número o tamaño de los frutos, y en la cosecha siguiente, disminuyendo el crecimiento o reducción el número de yemas inducidas a flor.
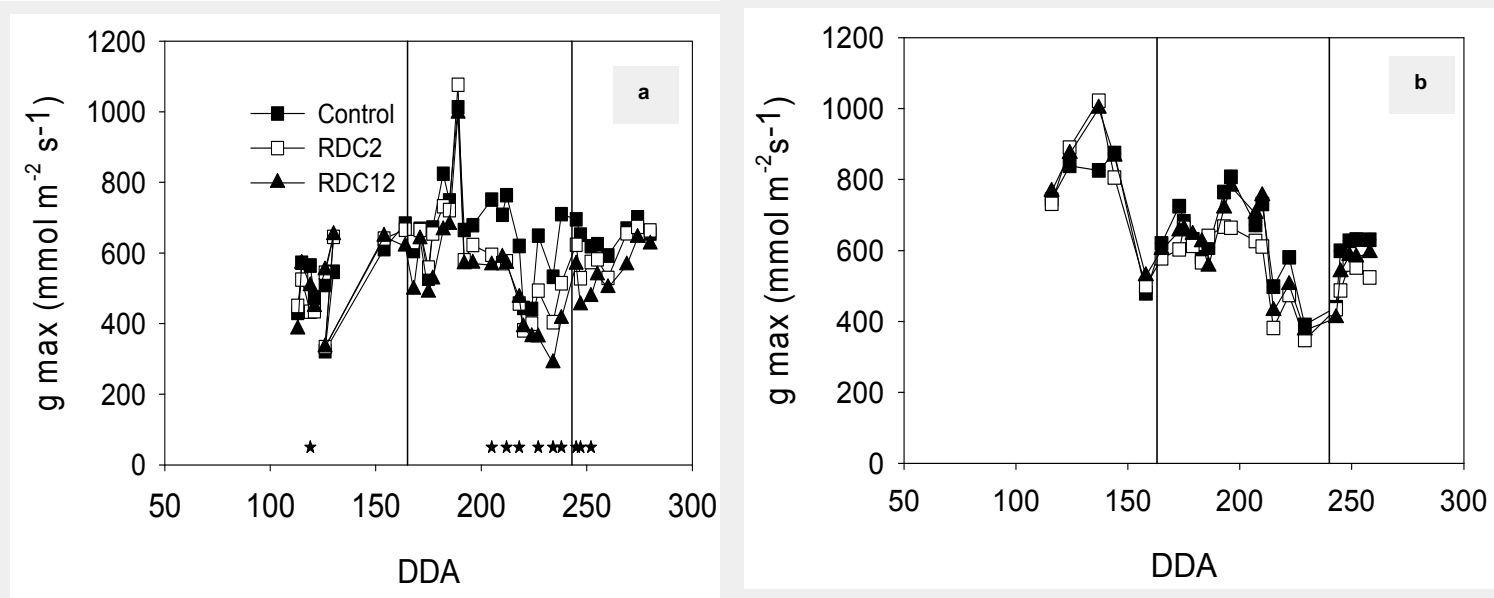

Figura 2. Evolución de la conductancia foliar máxima durante los años 2008 (a) y 2010 (b)con niveles de carga record para la media de la parcela (16.6 T ha-1 en 2008 y $16 \mathrm{~T} \mathrm{ha}^{-1}$ en 2010). Cada punto es la media de 6 árboles. Las líneas verticales indican el periodo de endurecimiento masivo del hueso, momento en el que se aplicó condiciones de RDC (Riego deficitario Controlado). Los asteriscos indican diferencias significativas en esa fecha $(p<0.05$. Test Tukey). 
La Figura 3a presenta la evolución del volumen de fruto en el año 2012, un año de carga media (alrededor de $6 \mathrm{~T} / \mathrm{ha}$ ), y nivel de estrés moderado con valores de potencial hídrico por debajo de $-2 \mathrm{MPa}$ al final de endurecimiento de hueso. Las diferencias significativas en el crecimiento del fruto sólo tuvieron lugar durante este periodo final en el que se detectó una disminución del potencial. El periodo de rehidratación, alrededor de 3 semanas, perimitó una recuperación completa tanto del estado hídrico como del tamaño del fruto. La Figura 3b presenta los datos de volumen de fruto en el año 2014, un año record de carga (alrededor de $15 \mathrm{~T} / \mathrm{ha}$ ) y en el que sólo se suprimió el riego unas semanas antes de cosechar sin rehidratar. Los valores de potencial hídrico estuvieron ligeramente por debajo de -2 MPa.No hubo diferencias significativas en el tamaño del fruto al final del experimento aunque se aprecia una parada de los tratamientos deficitarios que coincide con una tendencia, no significativa, a tener un mayor número de frutos por Kilo (datos no mostrados).

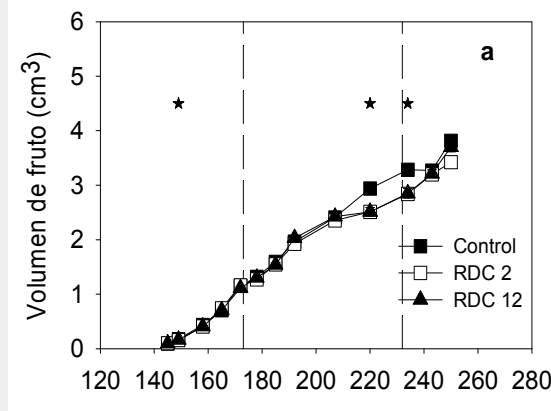

DDA

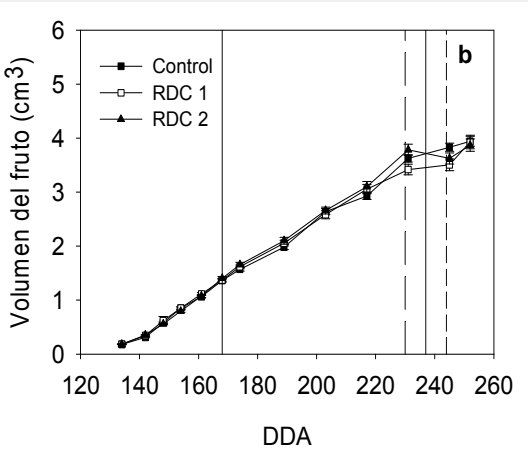

DDA

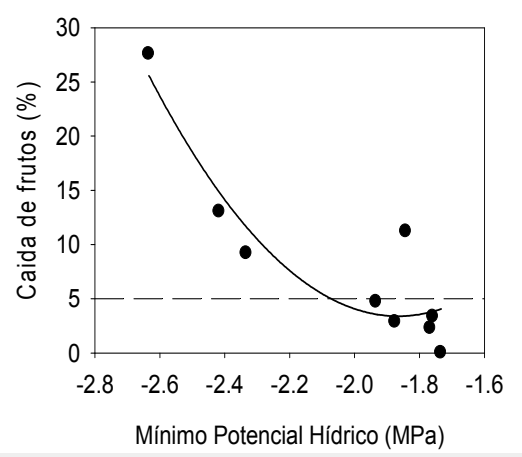

Figura 3. Evolución del volumen de fruto en el año 2012 (a) y 2014 (b). La figura 3c representa la relación entre la caid de frutos en brotes marcados y el potencial hídrico mínimo medido durante el endurecimiento del hueso entre los años 2011 al 2013. Cada punto es la media de 6 árboles. Las líneas verticales indican el periodo de endurecimiento masivo del hueso (a) o del recorte de agua antes de cosecha (b). La línea horizonatal de la figura $3 c$ indica un nivel asumible de caída de frutos. Los asteriscos indican diferencias significativas en esa fecha $(p<0.05$. Test Tukey).

La Figura 3c presenta la relación entre el número de frutos caídos entre los años 2011 al 2013 y el potencial mínimo obtenido durante la fase de endurecimiento de hueso. Los datos indican una clara tendencia a incrementar la reducción de frutos con la disminución del potencial hídrico. Asumiendo una caída del 5\% como económicamente viable, de nuevo, los niveles de estrés hídrico en torno a $-2 \mathrm{MPa}$ podrían ser adecuados durante este estado fenológico. A pesar de esta reducción tan clara en el número de frutos con el nivel de estrés (niveles que llegan hasta el $25 \%$ de los frutos por brote) está disminución no se vio trasladada en el mismo orden de magnitud en la cosecha obtenida (datos no mostrados). Esta falta de relación lineal podría estar relacionada con un efecto de muestreo y una caída diferencial dependiendo de la zona del árbol. Cherbity-Hoffman et al (2012) describe una distribución de la cosecha en los setos de olivar dependiente de la radiación que reciban.

La Figura 4 presenta los datos de la evolución de los diámetros máximos en dos años diferentes 2009 (año de descarga, Figura 4a) y 2013 (año de carga, Figura 4b). Durante el año 2009, los valores de potencial hídrico durante el endurecimiento de hueso disminuyeron hasta valores cercanos a $-2.5 \mathrm{MPa}$ lo que dio lugar, incluso a niveles de estrés hídrico inferiores, a una parada del crecimiento en los árboles RDC respecto al control. La rehidratación de los árboles permitió al final del crecimiento una tasa de crecimiento del tronco de nuevo cercana al control. Esta restricción del crecimiento tan evidente no afectó a la coseca del año siguiente en la que se obtuvieron valores del mismo orden que el control (15 T/ha en Control vs 19.2 T/ha en RDC, Moriana et al 2013). En los años en carga, el crecimiento se detiene durante la fase de endurecimiento (año 2013, Figura 4) por efecto de 
la mayor demanda de asimilados del fruto, por lo que el efecto en la cosecha está en el diferencial de crecimiento que tenga lugar durante la fase de brotación-floración (Fase I) en la que el fruto no actúa como limitante. En los datos mostrados en la figura los valores de potencial hídrico fueron similares y es necesario indicadores más precisos para controlar esta fase (pej. la variación del diámetro del tronco, Moriana y Fereres, 2002).
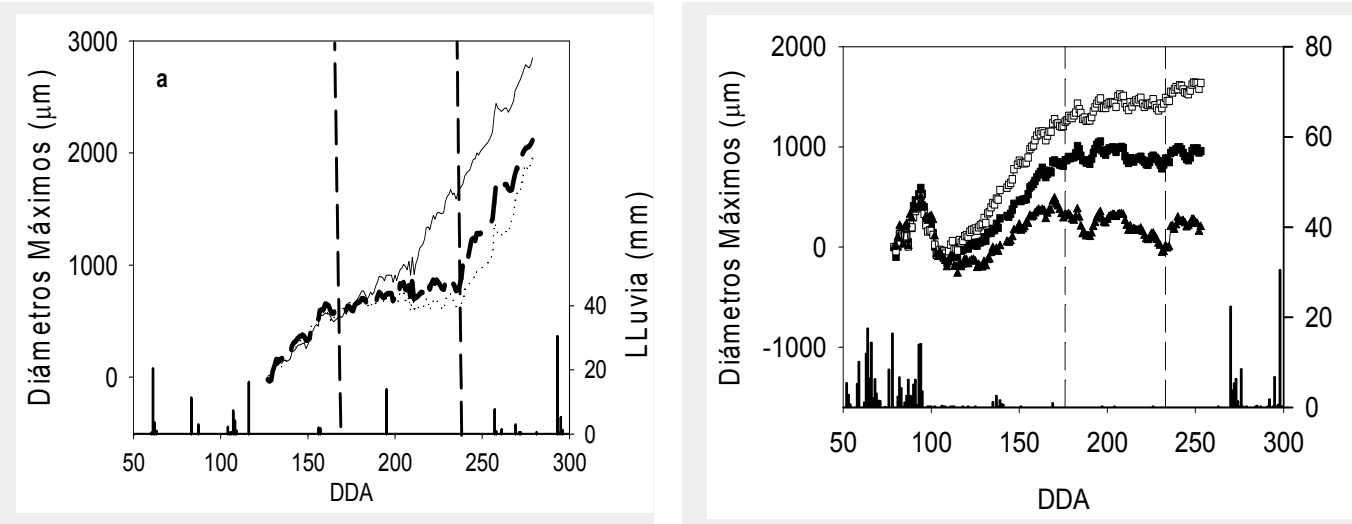

Figura 4. Evolución de los diámetros máximos durante un año de descarga (2009, a) y uno de carga $(2013$, b). La línea continua representa el tratamiento control y la discontinua los tratamientos deficitarios (Figura a). Los cuadrados rellenos representan el tratamiento control y los triángulos y cuadrados vacíos los tratamientos deficitarios (Figura b). En la parte inferior de la figura se representan la precipitación. Las líneas verticales indican la fase de endurecimiento del hueso.

La inducción floral del año siguiente es otro proceso que podría estar alterado con condiciones de estrés hídrico durante la fase de endurecimiento ya que algunos autores sugieren que el comienzo tiene lugar en esta época del año. Los experimentos realizados desde el año 2008 al 2013 muestran que el número de inflorescencias en el momento previo a plena floración nunca han estado afectadas. La evolución típica es la que se muestra en la Figura 5 correspondiente al año 2013 y en la que ya se ha descrito un estrés en el verano previo con niveles de -2.5 MPa. Los valores obtenidos al inicio y al final de la caída por cuajado son muy similares en todos los tratamientos lo que sugiere que no hubo un efecto del estrés del año anterior.

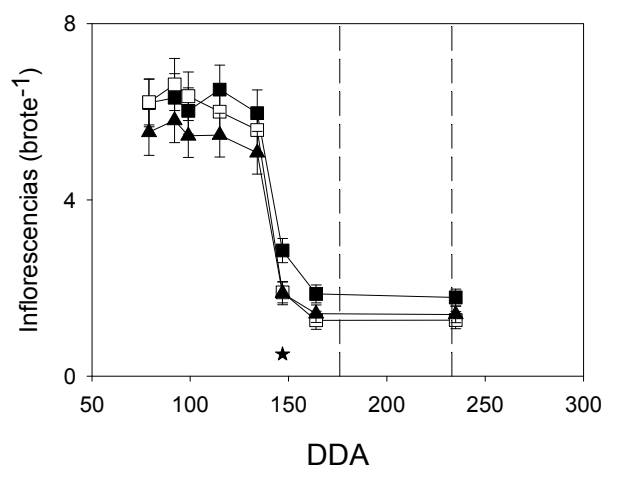

Figura 5. Evolución del número de inflorescencias durante el año 2013. Los cuadrados rellenos representan los datos Control, los cuadrados vacíos (RDC-2) y los triángulos (RDC12) los tratamientos deficitarios. Cada símbolo es la media de 60 datos. Las líneas verticales indican el periodo de endurecimiento del hueso.

La floración es un proceso muy sensible durante el año en curso (Moriana et al., 2003), aunque dado el régimen de lluvias de nuestras zonas olivareras no es habitual que tenga 
problemas. La inducción es un proceso poco conocido en su relación con el estrés hídrico pero no parece que los niveles a los que ha sido sometido vayan a comprometer la cosecha.

La Tabla 1 presenta los resultados en cantidad y calidad de cosecha del año 2008 al 2014. Nunca se obtuvieron diferencias significativas en cantidad de cosecha, aunque en muchas campañas ( 5 de las 7 presentadas) la cantidad de fruta fue superior a la de los tratamientos deficitarios.

Tabla 1.Cantidad y calidad en la cosecha del año 2008 al 2014. Letras diferentes en el mismo año indican diferencias significativas $(p<0.05$, Test de Tukey). Cosecha, T/ha; Escandallo, $\mathrm{n}^{\circ}$ frutos/ Kilo; Relación pulpa hueso; Riego, $\mathrm{mm}$.

\begin{tabular}{|c|c|c|c|c|c|}
\hline Año & Tratamiento & Cosecha & Escandallo & Pulpa/Hueso & Riego \\
\hline $\mathbf{2 0 0 8}$ & Control & $18.3 \pm 0.31$ & $308 \pm 14$ & $5.4 \pm 0.2$ & 619 \\
\hline & RDC-2 & $16.8 \pm 1.42$ & $379 \pm 29$ & $4.5 \pm 0.4$ & 119 \\
\hline & RDC-12 & $14.6 \pm 2.5$ & $358 \pm 22$ & $4.4 \pm 0.4$ & 45 \\
\hline $\mathbf{2 0 0 9}$ & Control & $2.3 \pm 0.51$ & $229 \pm 14$ & $5.7 \pm 0.2 \mathrm{ab}$ & 585 \\
\hline & RDC-2 & $1.4 \pm 0.52$ & $225 \pm 10$ & $4.2 \pm 0.6 \mathrm{~b}$ & 110 \\
\hline & RDC-12 & $0.8 \pm 0.17$ & $228 \pm 3$ & $6.0 \pm 0.3 \mathrm{a}$ & 63 \\
\hline $\mathbf{2 0 1 0}$ & Control & $15.0 \pm 1.7$ & $281 \pm 31$ & $4.8 \pm 0.14 \mathrm{a}$ & 710 \\
\hline & RDC-2 & $19.2 \pm 2.9$ & $284 \pm 5$ & $4.0 \pm 0.12 \mathrm{~b}$ & 160 \\
\hline & RDC-12 & $13.9 \pm 1.3$ & $288 \pm 11$ & $4.2 \pm 0.11 \mathrm{ab}$ & 38 \\
\hline $\mathbf{2 0 1 1}$ & Control & $2.5 \pm 0.5$ & $188 \pm 5 \mathrm{~b}$ & $6.2 \pm 0.1 \mathrm{a}$ & 299 \\
\hline & RDC-2 & $4.1 \pm 0.6$ & $206 \pm 5 \mathrm{a}$ & $5.7 \pm 0.1 \mathrm{~b}$ & 145 \\
\hline & RDC-12 & $2.9 \pm 0.6$ & $190 \pm 4 \mathrm{ab}$ & $6.1 \pm 0.1 \mathrm{a}$ & 115 \\
\hline $\mathbf{2 0 1 2}$ & Control & $6.6 \pm 0.7$ & $233 \pm 13$ & $4.1 \pm 0.1$ & 540 \\
\hline & RDC-2 & $5.0 \pm 0.8$ & $249 \pm 10$ & $4.1 \pm 0.2$ & 171 \\
\hline & RDC-12 & $5.9 \pm 0.7$ & $240 \pm 10$ & $4.4 \pm 0.2$ & 161 \\
\hline $\mathbf{2 0 1 3}$ & Control & $9.0 \pm 1.1$ & $229 \pm 13$ & $4.6 \pm 0.3$ & 369 \\
\hline & RDC-2 & $8.2 \pm 0.6$ & $209 \pm 7$ & $5.2 \pm 0.2$ & 207 \\
\hline & RDC-12 & $6.7 \pm 0.7$ & $208 \pm 11$ & $5.0 \pm 0.3$ & 106 \\
\hline $\mathbf{2 0 1 4}$ & Control & $14.7 \pm 1.6$ & $244 \pm 9$ & $4.6 \pm 0.1$ & 278 \\
\hline & RDC-2s & $12.2 \pm 2.4$ & $261 \pm 21$ & $4.6 \pm 0.2$ & 242 \\
\hline & RDC-4s & $12.0 \pm 2.4$ & $275 \pm 15$ & $4.4 \pm 0.2$ & 143 \\
\hline
\end{tabular}

Estas diferencias son más acusadas con el tratamiento RDC-12 y podrían estar relacionadas con el crecimiento de los árboles dando lugar a árboles Control con mayor volumen de copa. El manejo comercial de la poda es muy probable que elimine estas diferencias. Las tendencias estacionales presentan ciclos veceros en todos los tratamientos con una intensidad muy similar lo que de nuevo sugiere que no hay un efecto del estrés hídrico al largo plazo. Tampoco hay diferencias significativas en el número de frutos por kilo (escandallo), aunque de nuevo también hay una tendencia a mayores frutos (en 5 de los 7 años) en los árboles Control que en cualquiera de las estrategias RDC. No obstante, las diferencias no son superiores a un $15 \%$ obteniéndose habitualmente en todos los tratamientos valores en torno a 250 frutos por Kilo que son considerados de buena calidad. La relación pulpa hueso es un índice de calidad de gran importancia en la aceituna de mesa. En este parámetro sí hay, en algunos años, diferencias significativas (en 3 de 7) pero son entre el tratamiento Control y el deficitario que ha visto restringido su riego durante la fase de endurecimiento. Con los datos disponibles no hay una relación clara con los indicadores de estrés hídrico. La ausencia de diferencias con el tratamiento que, teóricamente, sufrió condiciones de estrés hídrico durante el cuajado podrían sugerir una disminución del tamaño del hueso que compensa la disminución en pulpa posterior. Sin embargo, las mediciones en hueso tampoco han dado diferencias significativas (datos no mostrados). Cuando el estrés 
hídrico se redujo en el año 2014 al último periodo previo a cosecha no hubo diferencias entre tratamientos aunque los niveles de estrés hídrico en el tratamiento de RDC 4s estuvieron ligeramente por debajo de -2.0 MPa. Finalmente lo que se ha obtenido es un ahorro de agua considerable respecto a los árboles Control. Las dotaciones de los tratamientos RDC estuvieron alrededor de las permitidas por las confederaciones hidrográficas para este cultivo, incluso en algunos años claramente por debajo. Es de destacar que la cantidad de agua empleada en los RDC fue muy variable y estuvo ligada al manejo del agua en función de los umbrales de estrés hídrico marcados.

\section{4.- Conclusiones y recomendaciones}

Un nivel de estrés hídrico superior a -2.0 MPa de potencial hídrico de tronco medido al mediodía durante la fase de endurecimiento del hueso no supuso una alteración de la cosecha del año en curso. Valores inferiores hasta niveles alrededor de $-3.0 \mathrm{MPa}$ afectaron al crecimiento del fruto pero el periodo de rehidratación fue suficiente para no detectar pérdidas significativas en el tamaño del fruto. Estos niveles de estrés hídrico, tras 7 años de experimentos, tampoco afectaron a la cosecha a medio plazo. Solamente se detectó una tenencia a perder cosecha en tratamientos en los que se restringió el riego durante cuajado por efecto, probablemente, de un menor tamaño de árboles. Sin embargo, es probable que el manejo de la poda en la explotación compense esta disminución. Estos dos umbrales de estrés pueden ser valores muy útiles para el manejo del riego deficitario en olivar de mesa que aseguren un uso sostenibles de los recursos con niveles de cosecha adecuados para el agricultor.

\section{5.- Agradecimientos}

Los datos presentados en este trabajo han sido financiados por sucesivos proyectos del MINNECO (AGL2007-66279-C03-00; AGL2010-19201-CO4-03; AGL2013-45922-C2-1R).Los autores agradecen la colaboración de todos los alumnos proyecto fin de carreara que han colaborado en este periodo y las ayudas de D. Antonio Montero y Pepe Rodriguez, técnicos del CSIC por su inestimable ayuda. Este trabajo se ha desarrollado gracias a la Unidad Asociada CSIC-US "Uso sostenible de suelo y agua en la agricultura".

\section{6.- Referencias}

Allen, R.G., Pereira, L.S., Raes, D., Smith. M., (1998).Crop evaportranspiration.Guideline for computing crop water requirements. FAO irrigation and drainage paper $n^{\circ} 56$. Roma. FAO.

Cherbiy-Hoffmann, S.U., Searles, P.S., Hall, A.J., Rousseaux, M.C. (2012). Influence of light environment on yield determinants and components in large olive hedgerows following mechanical pruning in the subtropics of Southern Hemisphere. ScientiaHorticulturae 137, 36-42.

Fernández, J. E. (2014). Understanding olive adaptation to abiotic stresses as a tool to increase crop performance. Environ.Exp. Bot. 103:158-179.

Fernández, J. E., Díaz-Espejo, A., Infante, J. M., Duran, P., Palomo, M. J., Chamorro, V., Giron, I. F., Villagarcía, L., (2006). Water relations and gas exchange in olive trees under regulated deficit irrigation and partial root zone drying. Plant Soil 284, 273-291.

Girón, I.F., Corell, M., Martín-Palomo, M.J., Galindo, A., Torrecillas, A., Moreno, F., Moriana, A. (2015). Feasibility of trunk diameter fluctuations in the scheduling of regulated deficit irrigation for table olive trees without references trees. Agricultural Water Management 161:114-126Goldhamer, D.A., 1999. Regulated deficit irrigation for California canning olives.ActaHortic. 474, 369-372.

Martín-Vertedor, A.I., Pérez-Rodríguez, J.M., Prieto, H., Fereres, E., (2011). Interactive responses to water deficits and crop load in olive (Oleaeuropaea L., cv. Morisca).Water use, fruit and oil yield. Agric. Water Manage. 98, 941-949.

Ministerio de Agricultura, Alimentación y Medio Ambiente (MAGRAMA) (2016). Anuario de estadísticaagraria.http://www.magrama.gob.es/es/estadistica/temas/publicaciones/anu ario-de-estadistica/2014/default.aspx 
Moriana, A. y Fereres, E.(2002). Plant Indicators for Scheduling Irrigation for Young Olive Trees. IrrigationScience 21,83-90.

Moriana, A; Villalobos, F.J.; Fereres, E. (2002). Stomatal and photosynthetic responses of olive (Oleaeuropaea L.) leaves to water deficits. Plant, Cell and Environment 25:395405

Moriana, A., Orgaz, F., Fereres, E., Pastor, M. (2003). Yield responses of a mature olive orchard to water deficits. J. Amer. Soc. Hort. Sci. 128,425-431.

Moriana, A., Pérez-López, D., Prieto, M.H., Ramírez-Santa-Pau, M., Pérez-Rodriguez, J.M. (2012). Midday stem water potential as a useful tool for estimating irrigation requirements in olive trees.AgriculturalWater Management 112:43-54

Rapoport, H.F., Pérez-López, D., Hammami, S.B.M., Aguera, J., Moriana, A. (2013). Fruit pit hardening: physical measurements during olive growth. Annals Applied Biology 163, 200-208. 


\title{
DESARROLLO DE UN ALGORITMO DE SOLUCIÓN DIRECTA PARA EL CÁLCULO DE DISTRIBUCIONES ÓPTIMAS DE CULTIVOS BAJO RIEGO DEFICITARIO CONTROLADO
}

\author{
López-Mata, $E .{ }^{1}(P)$, Orengo-Valverde, J.J. ${ }^{2}$, Tarjuelo, J.M. ${ }^{1}$, Martínez-Romero, $A .{ }^{1} y$ \\ Domínguez, A. $^{1}$
}

\begin{abstract}
${ }^{1}$ Investigador, Centro Regional de Estudios del Agua (CREA), Universidad de Castilla-La Mancha, Ctra. de Las Peñas, km 3.2 , 02071 Albacete (Spain), Eulogio.Lopez@uclm.es; Jose.Tarjuelo@uclm.es; Angel.MRomero@uclm.es; Alfonso.Dominguez@uclm.es

${ }^{2}$ Profesor, Departamento de Matemáticas, Área de Matemática Aplicada, Universidad de Castilla-La Mancha, Campus Universitario, s/n,02071, Albacete, (Spain), Jose.Orengo@uclm.es
\end{abstract}

\section{Resumen}

La adecuada gestión de un recurso natural cada vez más escaso, como es el agua, implica maximizar la eficiencia en su uso. Desde el punto de vista de una explotación agraria, es de la máxima importancia encontrar la distribución óptima de cultivos que maximice el margen bruto obtenido con el agua de riego disponible. Actualmente, los métodos de optimización disponibles para resolver este problema no lineal, recurren a métodos de optimización heurísticos de propósito general mucho más lentos y menos eficientes de lo que sería un algoritmo de optimización de solución directa, donde se conocen los mecanismos involucrados y las sinergias existentes entre los cultivos para la obtención de la solución óptima del problema. El objetivo del presente trabajo es desarrollar un algoritmo de solución directa capaz de determinar la distribución óptima de cultivos que sea compatible con el modelo MOPECO (Modelo de Optimización Económica del agua de riego). La solución óptima se consigue con sólo uno o dos cultivos, pero esta solución no es la más adecuada desde el punto de vista agronómico (p.e. rotación de cultivos, PAC, etc.), por lo que ha sido necesario adaptar el algoritmo desarrollado para manejar este tipo de situaciones. Para una hipotética explotación de 100 ha, considerando 10 cultivos diferentes y 11 escenarios de volumen de agua total disponible, se han comparado los resultados del algoritmo desarrollado con las soluciones ofrecidas por el software de optimización LINGO y los algoritmos genéticos. El algoritmo desarrollado consigue márgenes brutos un $0,5 \%$ inferiores a los de LINGO, y un 1,1\% mayores que los algoritmos genéticos, reduciendo el tiempo de cálculo entre $50-100$ y 2000 veces, respectivamente.

\section{1- Introducción}

El agua es un recurso escaso que debe ser gestionado de forma eficiente. Desde mediados del siglo XX se han desarrollado modelos complejos como Aquacrop, ISAREG, CROPSYS o WOFOST, que permiten simular el comportamiento de los cultivos bajo un amplio rango de condicionantes. MOPECO (Ortega et al., 2004) ha sido concebido para la optimización del margen bruto (MB) de las explotaciones de riego, en especial en zonas con escasos recursos hídricos y/o con altos costes de cultivo. Bajo condiciones reales, el sector productivo requiere de una herramienta que les asesore sobre cual es la superficie y el volumen de agua de riego, normalmente deficitario, que debe asignar a cada cultivo para maximizar la rentabilidad. Los datos requeridos para realizar esta tarea de optimización son las relaciones entre el margen bruto y la lámina de riego. Estas relaciones no son lineales, 
por lo que se deben de utilizar técnicas de optimización no lineal durante el proceso de optimización.

En la actualidad MOPECO utiliza los algoritmos genéticos para resolver este problema de optimización. Esta metodología presenta dos problemas. Por una parte, el resultado obtenido no es el óptimo absoluto. Y, por otro lado, el tiempo de cálculo requerido es muy elevado, lo que limita la posibilidad de generar una versión on-line del modelo para su utilización por los regantes y gestores de amplias zonas regables con un elevado número de usuarios.

El objetivo principal del presente trabajo es desarrollar una metodología capaz de determinar la distribución de cultivos que maximiza el margen bruto de una explotación, conocida la superficie regable y la cantidad de agua disponible, así como las funciones margen bruto vs. lámina de riego de cada cultivo, con bajos requerimientos de tiempo de cálculo. Los objetivos específicos son: i) Desarrollar un algoritmo de solución directa para el cálculo de distribuciones óptimas de cultivos bajo riego compatible con MOPECO; ii) Mejorar la eficiencia y velocidad en la resolución de problemas de distribución óptimas de cultivos respecto a los algoritmos genéticos; iii) Analizar los mecanismos y sinergias entre los cultivos para obtener la solución óptima.

\section{2- Materiales y métodos}

\section{1- Formulación del problema}

El problema de optimización de la distribución de cultivos en una explotación agraria bajo condiciones de estrés hídrico se puede formular de la siguiente manera:

A partir de una parcela de superficie $\left(S_{\text {total }}\right)$, una dotación de volumen de agua de riego $\left(V_{\text {total }}\right)$, unos cultivos de los que se conocen sus funciones margen bruto frente a la lámina de riego aplicada, se desean encontrar los valores de superficie $\left(S_{i}\right)$ y volumen de agua de riego $(\mathrm{Vi})$ que maximicen el margen bruto de la explotación ( $\left.\mathrm{MB}_{\text {total }}\right)$, expresión (1). Siendo: $\mathrm{n}$ el número total de cultivos a tener en cuenta en el problema y $\mathrm{f}$ la función que representa el margen bruto obtenido con respecto a la lámina aplicada (función MB/lam). La ecuación (1) está sujeta a las restricciones (2), (3), (4), (5) y (6):

$$
\begin{gathered}
\mathrm{MB}_{\text {total }}=\sum_{\mathrm{i}=1}^{\mathrm{n}} \mathrm{S}_{\mathrm{i}} \cdot \mathrm{f}_{\mathrm{i}}\left(\frac{\mathrm{V}_{\mathrm{i}}}{\mathrm{S}_{\mathrm{i}}}\right) \\
\mathrm{S}_{\text {total }} \geq \sum_{\mathrm{i}=1}^{\mathrm{n}} \mathrm{S}_{\mathrm{i}} \\
\mathrm{V}_{\text {total }} \geq \sum_{\mathrm{i}=1}^{\mathrm{n}} \mathrm{V}_{\mathrm{i}} \\
\mathrm{S}_{\mathrm{i}} \geq 0 \\
\mathrm{~V}_{\mathrm{i}} \geq 0 \\
\operatorname{lam}_{\mathrm{i}} \leq \operatorname{lam}_{\text {imax }}
\end{gathered}
$$

\section{2- "Funciones margen bruto / lámina"}

Las funciones MB/Lam dependen de las condiciones particulares de cada temporada (climatología, precio de venta de la cosecha, costes de cultivo, etc.). Siendo las mismas diferentes para cada año. Además, otros factores, como la aplicación de un adecuado 
calendario de riegos durante la etapa de crecimiento lo que afecta al MB final para una misma cantidad de agua aplicada al cultivo. López-Mata et al. (2010) simuló 146410 calendarios de riego del cultivo maíz modificando el déficit hídrico y la eficiencia del sistema de riego de forma aleatoria. Una línea de puntos denominada "Frontera de Pareto" (Darshana et al., 2011) representa el máximo MB posible por cada lámina suministrada al cultivo (Figura 1). En ésta línea, es imposible mejorar la variable MB sin perjudicar a la variable lámina de riego.

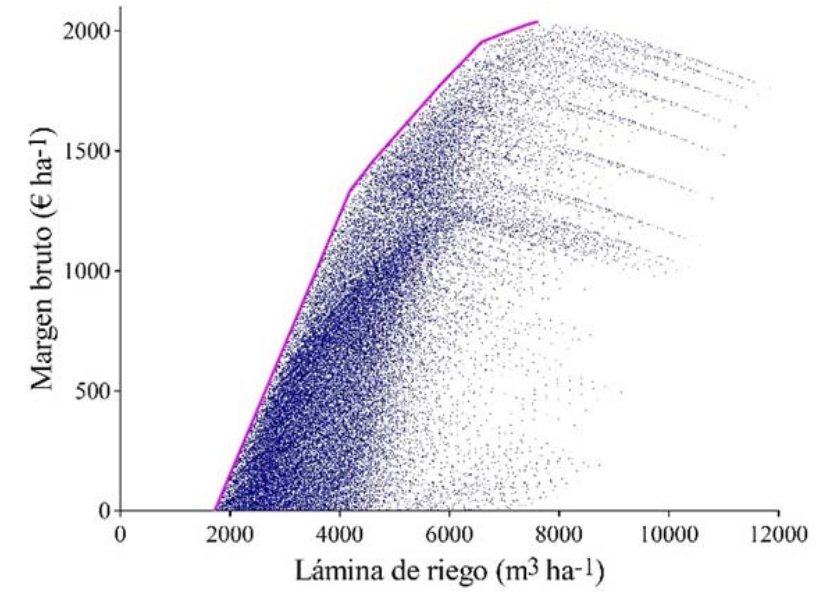

a

Figura. 1. a) Simulación de 146.410 calendarios de riego para el cultivo maíz. b) Algoritmo de recubrimiento.

Es inaceptable, en términos de tiempo de cálculo, simular una gran cantidad de calendarios de riego para obtener la frontera de Pareto del cultivo. Por ese motivo, MOPECO utiliza la metodología de riego deficitario controlado (ORDI) para determinar el calendario de riegos óptimo para una determinada cantidad de agua de riego (Domínguez et al., 2012a). La serie de datos climáticos utilizada por MOPECO es el año meteorológico típico (TMY) de la zona (Domínguez et al., 2013), consiguiendo de ésta forma una única función (MB/lam) por cultivo, teniendo en cuenta el valor medio de ciertos parámetros económicos.

\section{3- Algoritmo de optimización}

Se ha determinado matemáticamente que el óptimo margen bruto de la ecuación (1) con un solo cultivo con una función (MB/lam) positiva, creciente y cóncava (Figura 2a), denominada ideal en el presente trabajo, se obtiene cuando todo el volumen de agua es aplicado a toda la superficie disponible de la parcela $\left(\operatorname{lam}_{\mathrm{opt}}=\mathrm{V}_{\text {total }} / \mathrm{S}_{\text {total }}\right)$. Si se dispusiera de un volumen de agua superior a $S_{\text {total }} \cdot \operatorname{lam}_{M B m a x}$, la solución óptima sería $S=S_{\text {total }}$ y $\mathrm{V}=\mathrm{S}_{\text {total }} \cdot \operatorname{lam}_{\mathrm{MBmax}}$, regando con lam $=\operatorname{lam}_{\mathrm{MBmax}}$.

En los siguientes apartados, se desarrollarán una serie de transformaciones factibles donde se convertirá un problema con cualquier número de cultivos, con cualquier forma $\mathrm{MB} / \mathrm{lam}$ en una única función MB/lam ideal, con una respuesta de margen bruto mejor y cuyo óptimo ya se ha determinado anteriormente.

\subsection{Consideraciones sobre el reparto de agua}

Una misma dotación de agua se puede aplicar uniformemente a la totalidad de la parcela o se puede dividir en dos zonas de riego con diferentes láminas de agua aplicada, siendo el margen bruto medio por hectárea diferente. 
La figura (2b) muestra 3 funciones MB/lam que pasan todas ellas por dos puntos $\mathrm{P}_{1}$ y $\mathrm{P}_{2}$. Una misma lámina lam $_{\mathrm{opt}}$ obtendrá el valor más alto de margen bruto por hectárea con la función cóncava. Con la función convexa, la parcela puede ser dividida en dos superficies de riego diferentes con el mismo cultivo, una regada con la lámina $\operatorname{lam}_{1}$ (punto $P_{1}$ ) y la otra regada con la lámina $\operatorname{lam}_{2}$ (punto $\mathrm{P}_{2}$ ) elegidas de tal forma que la lámina media coincida con la lámina lam $_{\mathrm{opt}}$. De esta manera, el margen bruto por hectárea obtenido por la función convexa es igual al obtenido por la función lineal. Obteniendo las siguientes expresiones

$$
\begin{gathered}
\mathrm{S}_{2}=\mathrm{S}_{\text {total }} \cdot\left(\frac{\operatorname{lam}_{\mathrm{opt}}-\operatorname{lam}_{1}}{\operatorname{lam}_{2}-\operatorname{lam}_{1}}\right) \\
\mathrm{V}_{2}=\mathrm{S}_{2} \cdot \operatorname{lam}_{2} \\
\mathrm{~V}_{1}=\mathrm{V}_{\text {total }}-\mathrm{V}_{2} \\
\mathrm{~S}_{1}=\mathrm{S}_{\text {total }}-\mathrm{S}_{2}
\end{gathered}
$$

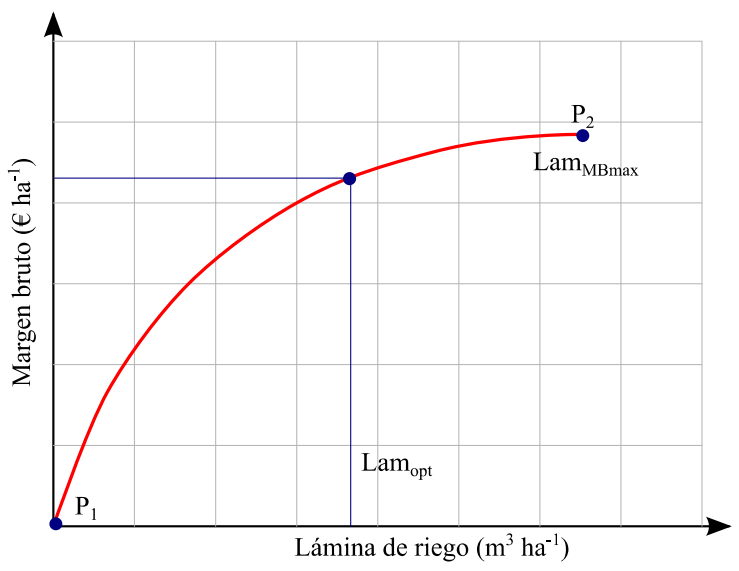

a

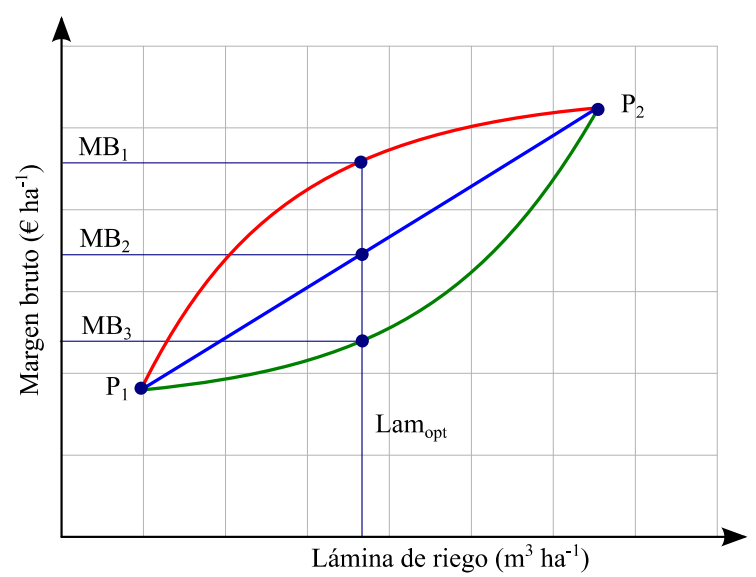

b

Figura 2. a) Función MB/lam "ideal”; b) Comparaciones entre funciones $M B / l a m$ cóncava, lineal y convexa que pasen por los mismos dos puntos.

\subsection{Transformación de funciones MB/Lam no cóncavas ni crecientes}

Si la función MB/Lam no es creciente y/o cóncava, la función se puede transformar detectando estas partes de la misma (p.e., la parte comprendida entre los puntos $P_{1}$ y $P_{2}$ de la figura 3a) y trazando una línea que una ambos puntos (Apartado 2.4). Esta línea será utilizada como nueva función $\mathrm{MB} / \mathrm{lam}$ entre los puntos $\mathrm{P}_{1}$ y $\mathrm{P}_{2}$ y está definida por las ecuaciones (7), (8), (9), y (10).

\subsection{Transformación de funciones MB/lam no siempre positivas}

Estas funciones pueden ser transformada de la misma forma que en la transformación anterior añadiendo un cultivo virtual con una función $\mathrm{MB} / \mathrm{lam}$ constituida por solo un punto (lam $=0 \mathrm{~m}^{3} \mathrm{ha}^{-1}$ y $\mathrm{MB}=0 € \mathrm{ha}^{-1}$ ) (Figura 3b).

\subsection{Transformación de $\mathbf{n}$ funciones MB/lam en una sola función}

Para el caso de dos cultivos (Figura 4a), el cultivo 1 responde mejor con láminas de riego bajas, mientras que el cultivo 2 responde mejor a láminas altas. Por lo tanto, la nueva función MB/lam estará formada, desde la lámina lam=0 hasta lam $_{1}$ por la función $\mathrm{MB} / \mathrm{lam}$ del 
cultivo 1, entre $\operatorname{lam}_{1}$ y $\operatorname{lam}_{2}$ por una línea tangente a las funciones de ambos cultivos, y desde $\operatorname{lam}_{2}$ la función MB/lam del cultivo 2. El procedimiento para encontrar el óptimo para cualquier número de cultivos es simplemente una generalización del procedimiento para dos cultivos (Figura 4b).

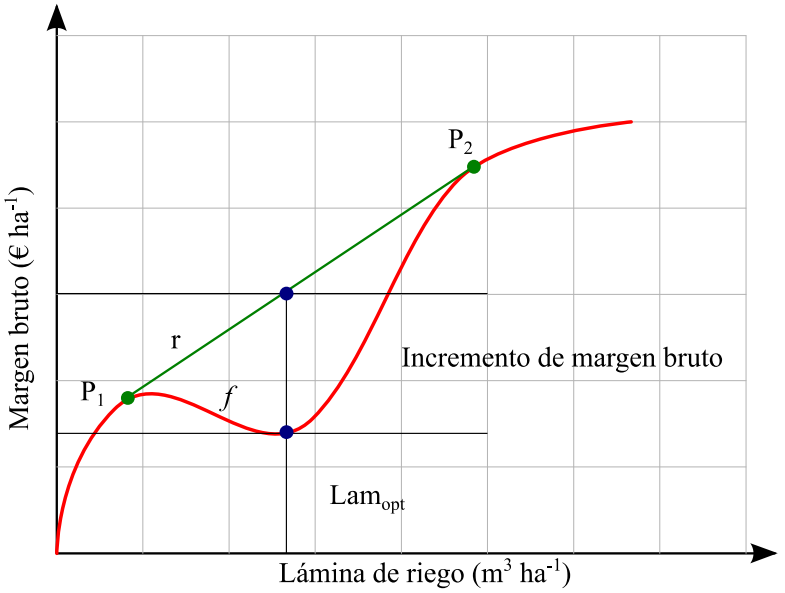

a

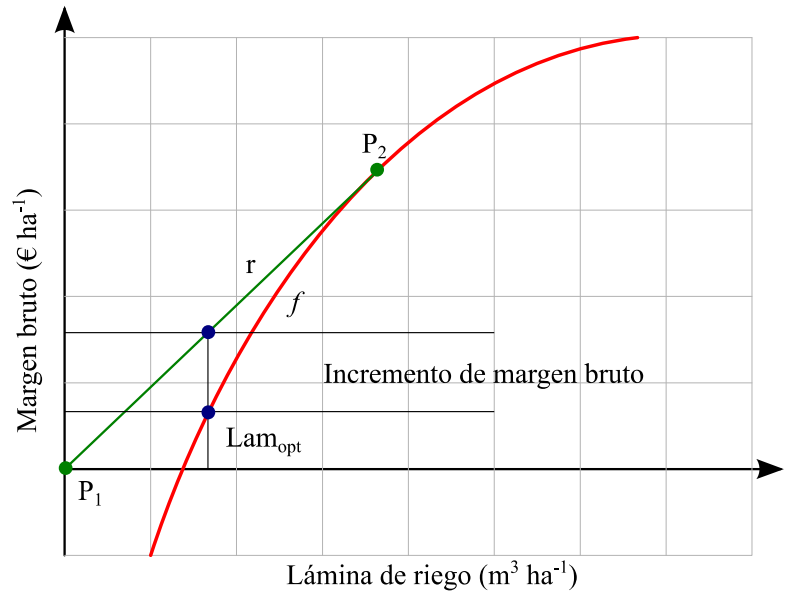

b

Figura 3. a) Transformación de una función MB/Lam no cóncava y no creciente; b) Transformación de una función MB/lam no siempre positiva.

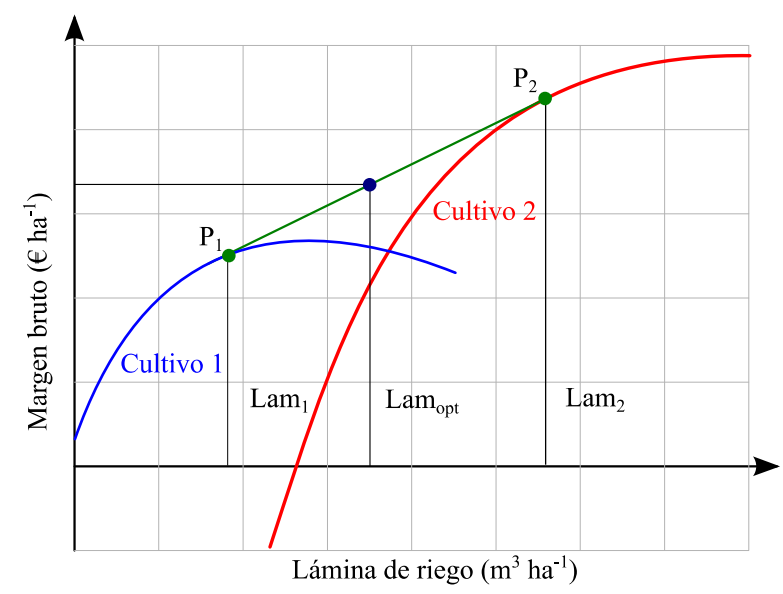

a

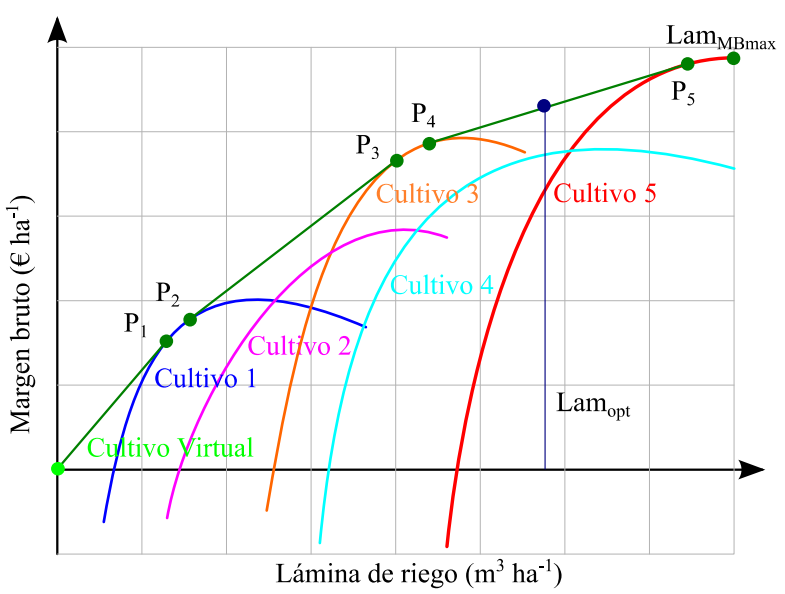

b

Figura 4. a) Transformación de las curvas MB/lam de dos cultivos en una sola curva MB/lam; b) Transformación de las funciones MB/lam de 5 cultivos en una sola función.

\subsection{Algoritmo de recubrimiento}

Para seleccionar únicamente los puntos pertenecientes a la "frontera de Pareto" de los cultivos y aplicar todas las transformaciones explicadas se ha desarrollado un algoritmo de recubrimiento, que lo procesa todo a la vez. El algoritmo ha sido diseñado para trabajar con listas de puntos.

Como primer punto de referencia se elige el primer punto de la lista ordenada de puntos, a continuación, se calculan las pendientes de los puntos que lo siguen con respecto al punto de referencia, eligiendo como segundo punto de referencia el punto de mayor pendiente positiva. Los puntos entre ambos puntos de referencia son eliminados. Este proceso es repetido sucesivamente hasta llegar al final de la lista, obteniendo una función cóncava (Figura 1b). 


\subsection{El proceso de optimización}

El proceso de optimización consta de dos procesos diferentes. El primer proceso determina la "Frontera de Pareto" de cada uno de los cultivos, y el segundo proceso determina la distribución óptima en términos de superficie y el volumen de agua para el conjunto de los cultivos considerados, siguiendo la metodología descrita en los puntos anteriores.

\subsection{Adaptación del algoritmo a la gestión real de explotaciones agrarias.}

Se ha demostrado, hasta este punto, que la solución óptima del problema de distribución de cultivos es o bien uno o dos cultivos. En la gestión de explotaciones agrarias reales, hay numerosos argumentos en favor de limitar la superficie máxima de un cultivo individual y adoptar la rotación de cultivos. Consecuentemente, la implementación de ésta metodología en el modelo MOPECO requiere que los usuarios puedan limitar la superficie máxima de cada cultivo. La manera de resolver éste problema es la siguiente:

Paso 1. Realizar la optimización siguiendo los pasos descritos en el apartado 2.9.

Paso 2. Si la superficie asignada para cualquiera de los cultivos de la solución obtenida es mayor a la máxima permitida por el usuario, el exceso de superficie y su correspondiente volumen de agua serán utilizados en una nueva optimización en la cual las funciones MB/lam de los cultivos que han alcanzado la superficie máxima son eliminadas. Este proceso debe ser repetido hasta que sea posible.

Paso 3. Es posible que una cierta cantidad de agua quede disponible al final de la última optimización. Éste volumen de agua es asignado al cultivo con el mayor incremento de margen bruto por unidad de agua suministrada (la función MB/lam con mayor pendiente positiva para la lámina determinada), pudiendo incluso ser asignado a varios cultivos.

\subsection{Evaluación de la metodología desarrollada.}

Se han utilizado diez cultivos ficticios para evaluar la distribución de cultivos que maximice el beneficio de una explotación agraria con el algoritmo desarrollado bajo dos escenarios: sin restricción de superficie a los cultivos (sin rotación), y siguiendo la metodología descrita en el apartado 2.10 considerando restricciones de superficie en los cultivos (rotación). En éste último caso, se ha considerado que la máxima superficie para cada cultivo sea $1 / 3$ de la superficie total de la explotación. Las funciones MB/lam utilizadas son funciones polinómicas, tal y como sugieren diferentes autores (English et al., 2002; Domínguez et al., 2012b,c) (Figura 5). Para este ejemplo, la superficie de riego total ha sido de 100 ha, y se han considerado 11 volúmenes de agua de riego. Los resultados con limitación de superficie en cultivos has sido comparados con los obtenidos por los algoritmos genéticos y el software de optimización LINGO (LINDO, 2015).

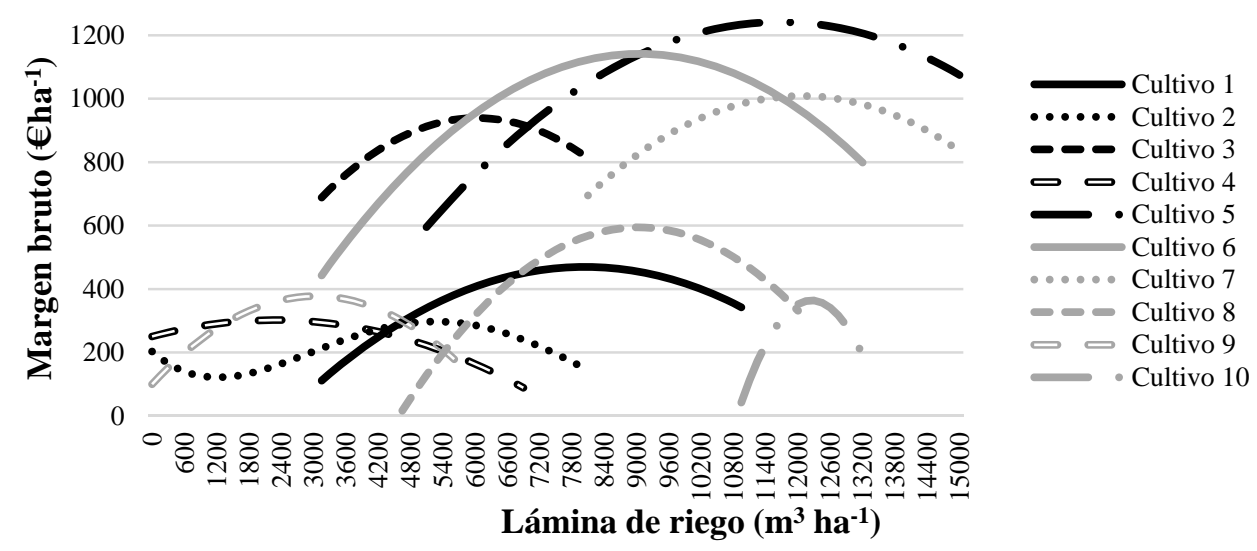


Figura 5. Funciones "MB/lam" de 10 cultivos ficticios.

\section{Resultados y discusión}

La principal diferencia entre las metodologías de optimización ha sido el tiempo de cálculo (Tabla 1). El algoritmo propuesto (AP) ha sido capaz de obtener los resultados 2000 veces más rápido que los algoritmos genéticos (AG), y entre 10-100 veces respecto a LINGO. Éste hecho es particularmente relevante para el desarrollo futuro de una versión online del modelo MOPECO para su utilización por agricultores. El margen bruto alcanzado por el " AP (rotación)" es siempre más bajo que el margen bruto alcanzado por el "AP (sin rotación)" (disminución media igual a $7,1 \%$ ), mientras que los requisitos de tiempo de cálculo fueron similares (Tabla 1).

Tabla 1. Resumen de los resultados de la comparación de los diferentes algoritmos.

\begin{tabular}{|c|c|c|c|c|c|c|c|c|}
\hline & \multicolumn{2}{|c|}{ AP (sin rotación) } & \multicolumn{2}{|c|}{ AP (rotación) } & \multicolumn{2}{|c|}{ AG (rotación) } & \multicolumn{2}{|c|}{ LINGO (rotación) } \\
\hline $\begin{array}{l}\text { Agua } \\
\left(\mathrm{m}^{3}\right)\end{array}$ & $\begin{array}{c}\mathrm{MB} \\
(€) \\
\end{array}$ & $\begin{array}{c}t \\
(s)\end{array}$ & $\begin{array}{l}M B \\
(€)\end{array}$ & $\begin{array}{c}t \\
(s)\end{array}$ & $\begin{array}{l}\text { MB } \\
(€)\end{array}$ & $\begin{array}{l}t \\
(s)\end{array}$ & $\begin{array}{c}\text { MB } \\
(\boldsymbol{E})\end{array}$ & $\begin{array}{c}t \\
(s)\end{array}$ \\
\hline 0 & 25000,0 & 0,02035 & 18428,4 & 0,02165 & 18428,4 & 26,21 & 18428,4 & 1 \\
\hline 130000 & 43436,0 & 0,02044 & 41703,4 & 0,02041 & 40698,8 & 41,56 & 41819,7 & 1 \\
\hline 260000 & 61871,9 & 0,02048 & 58050,5 & 0,02015 & 57903,9 & 52,72 & 58105,6 & 2 \\
\hline 390000 & 80173,8 & 0,02036 & 72909,2 & 0,02032 & 72005,7 & 44,41 & 73274,9 & 1 \\
\hline 520000 & 92287,3 & 0,02045 & 85939,2 & 0,02025 & 86106,5 & 46,53 & 86145,1 & 2 \\
\hline 650000 & 102002,4 & 0,02066 & 98331,0 & 0,02052 & 97142,4 & 46,53 & 99009,7 & 1 \\
\hline 780000 & 110976,4 & 0,02047 & 107491,8 & 0,02020 & 104185,6 & 40,78 & 108224,0 & 2 \\
\hline 910000 & 116422,7 & 0,02024 & 110264,0 & 0,020 & 10960 & 43,26 & 111118,0 & 2 \\
\hline 1040000 & 121752,5 & 0,02026 & 112204,3 & 0,02018 & 110926,9 & 51,11 & 112632,4 & 2 \\
\hline 1170000 & 124165,0 & 0,02014 & 113054,3 & 0,02029 & 111036,7 & 45,99 & 113059,6 & $<1$ \\
\hline 1300000 & 124165,0 & 0,02029 & 113054,3 & 0,02025 & 111709,9 & 53,07 & 113059,6 & $<1$ \\
\hline
\end{tabular}

Donde: MB: margen bruto; t: tiempo

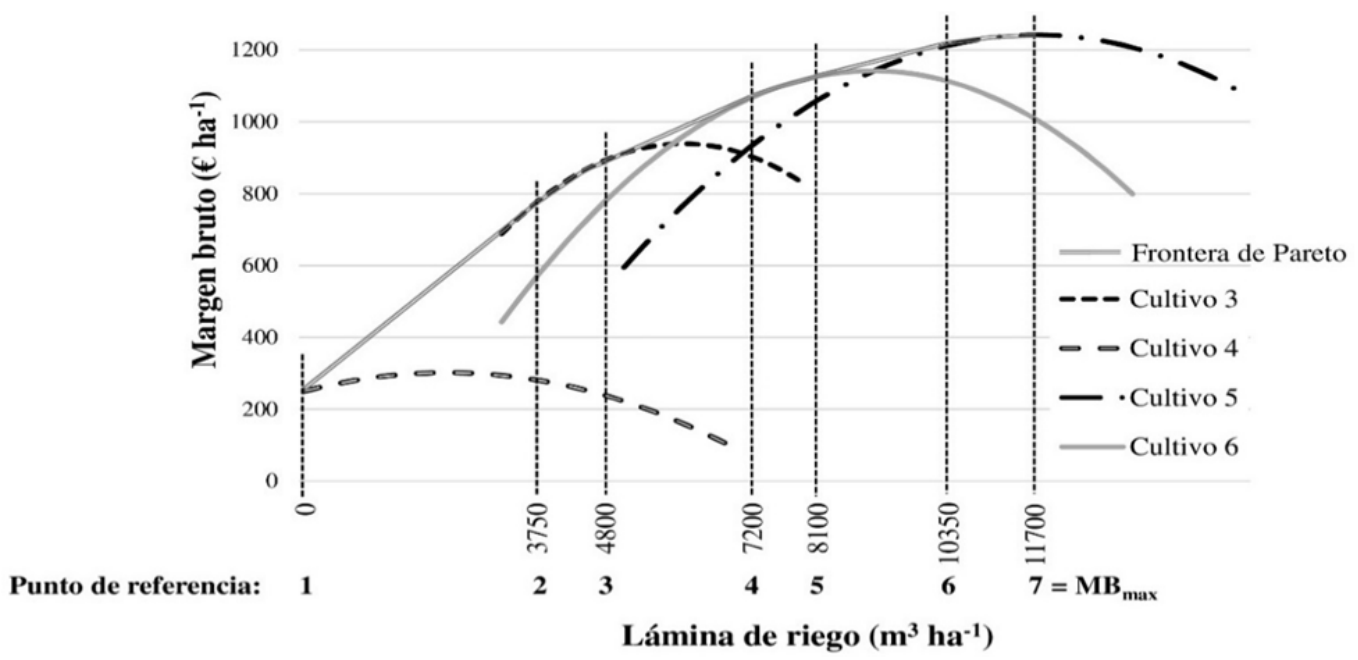

Figura 7. "Frontera de Pareto" y puntos de referencia obtenidos por el algoritmo desarrollado.

Los resultados del algoritmo propuesto con las restricciones de superficie "AP (Rotación)" se han comparado con los generados por "LINGO (Rotación)" y "AG (Rotación)", también con límites de superficie. En términos generales, las distribuciones de cultivos propuestas por las tres metodologías fueron muy similares en términos de cultivos seleccionados en la mayoría de los escenarios, difiriendo ligeramente en los valores de superficie y lámina asignados. Las diferencias en el uso de agua disponible aumentaron con 
la disponibilidad de agua, donde los AG dejaban recursos sin utilizar en cuatro escenarios. En todos los casos, se ha utilizado toda la superficie, mientras que en los dos últimos escenarios se ha dejado agua sin utilizar. LINGO ha sido la metodología que ha obtenido los valores más altos de margen bruto en todos los escenarios, aunque las diferencias entre ellos son pequeñas (inferiores a $3,9 \%$ para los AG y $2,2 \%$ para el AP, siendo la diferencia media del $1,5 \%$ y $0,5 \%$, respectivamente). Es necesario destacar que la adaptación del algoritmo propuesto para la gestión de una explotación con restricciones de superficie de cultivos puede no ser la óptima, lo que permite a los AG y LINGO lograr mejores resultados en algunos escenarios (Tabla 1). Por el contrario, el algoritmo sin restricciones de superficie (sin rotación) siempre obtiene la solución óptima global. En consecuencia, el algoritmo desarrollado genera resultados que son similares a los obtenidos por los otros dos métodos anteriormente probados. $A G$ es la metodología con los más altos requerimientos de tiempo de cálculo.

Otro resultado relevante es que, para cada cultivo, el algoritmo determina láminas de riego inferiores a la lámina de máximo margen bruto (Figura 7), excepto en los dos últimos escenarios debido a una alta disponibilidad de agua de riego. Este hecho pone de manifiesto la importancia del riego deficitario controlado en la gestión económica de las explotaciones de regadío con baja disponibilidad de agua, según lo recomendado por otros autores (English et al., 2002; Ortega et al., 2004; Georgiou and Papamichail, 2008).

La combinación del algoritmo de optimización propuesto con ORDI en el modelo MOPECO puede ayudar a los agricultores a mejorar la eficiencia del uso del agua y la rentabilidad de sus explotaciones. Este modelo también puede ayudar a los mismos a determinar distribución de cultivos más rentable y a aplicar estrategias de riego deficitario controlado a gran escala.

\section{Conclusiones y recomendaciones}

El algoritmo propuesto determina la superficie y la lámina de riego para un conjunto de cultivos seleccionados que maximiza el margen bruto de la explotación. La determinación precisa de estas funciones es crucial para obtener resultados fiables en condiciones reales.

En comparación con LINGO y con los algoritmos genéticos, el tiempo de cálculo y los recursos computacionales requeridos por el algoritmo desarrollado para la obtención de los resultados de los escenarios analizados son entre 50-100 y alrededor de 2000 menor, respectivamente.

Si no se limita la superficie máxima cultivable para cada uno de los cultivos, la solución óptima al problema de optimización es uno o dos cultivos. Tres o más cultivos nunca obtendrán el máximo margen bruto absoluto. Sin embargo, bajo condiciones de manejo para explotaciones de regadío, hay muchos argumentos a favor de la limitación de la superficie máxima ocupada por un cultivo individual.

La adaptación de la metodología propuesta para resolver esta limitación obtiene resultados adecuados, consiguiendo unos márgenes brutos alrededor del $0,5 \%$ inferior a LINGO, y un $1,1 \%$ más alto que los algoritmos genéticos para los casos de este estudio.

La mayor parte de los resultados obtenidos por el algoritmo proponen el manejo de los cultivos en condiciones de riego deficitario.

La velocidad de cálculo del algoritmo de optimización propuesto permite utilizarlo como parte de algoritmos de optimización más complejos que tengan en cuenta otros factores. Aún más importante que este hecho en la búsqueda de la distribución óptima de cultivos es la de sacar a la luz los mecanismos involucrados y cuáles son las sinergias entre los diferentes cultivos para la consecución de la solución óptima, permitiendo su conocimiento a los agricultores y técnicos desarrollar mejores estrategias de riego. En este sentido, el funcionamiento del algoritmo es fácil de entender y replicar, siendo posible hacerlo de forma manual. Esta metodología nace de la necesidad de optimización de la distribución de cultivos, pero es razonable pensar que puede ser aplicada en otros campos.

\section{Agradecimientos}


En este trabajo se ha desarrollado en el marco de dos proyectos europeos financiados por EC: FLOW-AID "Farm Level Optimal Water Management: Assistant for Irrigation under Deficit" $N^{\circ} .036958$ (GOCE), y DeSURVEY "A Surveillance System for Assessing and Monitoring of Desertification” (SUSTDEV-CT-2004-003950-2).

\section{Bibliografía}

Darshana, Pandey, A., Ostrowski, M., Pandey, R.P., 2011. Simulation and optimization for irrigation and crop planning. Irrigation and Drainage 61, 178-188.

Domínguez, A., Martínez-Romero, A., Leite, K.N., Tarjuelo, J.M., de Juan, J.A., López-Urrea, R., 2013. Combination of typical meteorological year with regulated deficit irrigation to improve the profitability of garlic growing in central Spain. Agricultural Water Management 130, 154-167.

Domínguez, A., de Juan, J.A., Tarjuelo, J.M., Martinez, R.S., Martinez-Romero, A., 2012a. Determination of optimal regulated deficit irrigation strategies for maize in a semi-arid environment. Agricultural Water Management 110, 67-77.

Domínguez, A., Jimenez, M., Tarjuelo, J.M., de Juan, J.A., Martinez-Romero, A., Leite, K.N., 2012b. Simulation of onion crop behavior under optimized regulated deficit irrigation using MOPECO model in a semi-arid environment. Agricultural Water Management 113, 64-75.

Domínguez, A., Martinez, R.S., de Juan, J.A., Martinez-Romero, A., Tarjuelo, J.M., 2012c. Simulation of maize crop behavior under deficit irrigation using MOPECO model in a semi-arid environment. Agricultural Water Management 107, 42-53.

English, M.J., Solomon, K.H., Hoffman, G.J., 2002. A paradigm shift in irrigation management. Journal of Irrigation and Drainage Engineering 128, 267-277.

Georgiou, P.E., Papamichail, D.M., 2008. Optimization model of an irrigation reservoir for water allocation and crop planning under various weather conditions. Irrigation Science 26, 487-504.

LINDO, 2015. LINGO. The modeling language and optimizer. User's manual. LINDO Systems Inc., Chicago, USA.

López-Mata, E., Tarjuelo, J.M., de Juan, J.A., Ballesteros, R., Domínguez, A., 2010. Effect of irrigation uniformity on the profitability of crops. Agricultural Water Management 98, 190-198.

Ortega, J.F., de Juan, J.A., Tarjuelo, J.M., López-Mata, E., 2004. MOPECO: an economic optimization model for irrigation water management. Irrigation Science 23, 61-75. 


\title{
A-08
}

\section{INFLUENCIA DEL RIEGO DEFICITARIO CONTROLADO PRECOSECHA SOBRE LA CALIDAD DE LA CEREZA 'PRIME GIANT'}

\author{
Blanco Montoya, $V^{1}{ }^{1}$, Domingo Miguel, $R .^{1}$, Artés Hernández $F^{2}{ }^{2}$, García Riquelme, M. ${ }^{1}$, \\ Pérez Pastor, A. ${ }^{1}$, Blaya Ros P.J. ${ }^{1}$, Torres Sánchez, R. $^{3}$
}

${ }^{1}$ Dpto. de Producción Vegetal. Universidad Politécnica de Cartagena (ETSIA-UPCT). Paseo Alfonso XIII, 48. 30203 Cartagena. victor.blanco@upct.es; rafael.domingo@upct.es; manuel.garcia@upct.es; alex.perez-pastor@upct.es; p.blaya18@gmail.com. ${ }^{2}$ Dpto. Ingeniería de los Alimentos y del Equipamiento Agrícola. Universidad Politécnica de Cartagena (ETSIA-UPCT). fr.artes-hdez@upct.es.

${ }^{3}$ Dpto de Ingeniería de Sistemas y Automática. Universidad Politécnica de Cartagena (ETSIIUPCT).roque.torres@upct.es.

\section{Resumen}

El uso de redes de sensores para el manejo del riego deficitario controlado (RDC) en cerezo puede incidir en la mejora de la productividad del agua, calidad de la fruta y en su comportamiento poscosecha, al permitir el conocimiento y control del estado hídrico del suelo y árbol en todo momento.

En el primer año de ensayo, el riego deficitario aplicado en precosecha para satisfacer el $85 \%$ de las necesidades máximas del cultivo $\left(\mathrm{ET}_{\mathrm{cg}}\right)$ permitió un ahorro de agua del $17 \%\left(380 \mathrm{~m}^{3} \mathrm{ha}^{-1}\right)$ respecto al tratamiento control, que se regó al $110 \%$ de la $\mathrm{ET}_{\text {cg. Este }}$ déficit hídrico ligero no afectó a la producción $\left(16,13 \mathrm{t} \mathrm{ha}^{-1}\right)$ e incluso mejoró la calidad del fruto. Así, en el momento de la cosecha $\left(t_{0}\right)$ los frutos bajo déficit ligero presentaron matices más rojos y mayor acidez que los de riego completo. Esta mayor acidez no afectó al índice de madurez debido a la compensación por sólidos solubles totales (SST). El carácter de mayor acidez perduró tras 30 días de conservación en frio $\left(\mathrm{t}_{1}\right)$ y 5 días de simulación de las condiciones de comercialización $\left(t_{2}\right)$. Igualmente, los frutos bajo déficit hídrico presentaron una tendencia a menores pérdidas de peso por deshidratación a finales de los periodos de conservación en frio y de simulación de la comercialización.

\section{1- Introducción}

La situación permanente de escasez de agua en la agricultura de regadío de las zonas semiáridas ha propiciado el uso y puesta a punto de nuevas tecnologías aplicadas al riego, mejorando la eficiencia en la distribución, transporte y aplicación del agua a nivel de parcela. Sin embargo, el ahorro de agua derivado de ellas sigue siendo insuficiente para satisfacer las necesidades de agua de sus sectores productivos. De ahí, la necesidad de desarrollar nuevas alternativas que redunden en la mejora de la gestión del agua. Una alternativa que puede contribuir a paliar esta situación de escasez en sector agrícola es el empleo de estrategias de riego deficitario controlado (Ruiz-Sanchez et al., 2010). Así, distintos estudios realizados en frutales y vid demuestran que algunas especies son capaces de tolerar déficits hídricos en determinados períodos del ciclo de cultivo sin mermas de producción ni de calidad, como es el caso del limonero (Domingo et al., 1994), almendro (Egea et al., 2012; Puerto et al., 2015), nectarina (De la Rosa et al., 2016), etc.

El empleo de este tipo de estrategias no sólo ha dado lugar a un aumento de la productividad del agua sino que en muchos casos han mejorado la calidad $y$ comportamiento poscosecha de los frutos; entre ellos del albaricoque (Pérez-Pastor et al., 2007), uva de mesa (Conesa et al., 2015) y melocotón (Falagán et al., 2015). 
Este trabajo se realizó en cerezo un cultivo prometedor por sus elevados precios de mercado, por ser una alternativa interesante a otros cultivos, ya que permite simultanear su manejo con el de otros frutales de la explotación. La cereza es un fruto no climatérico, muy perecedero, delicado y al mismo tiempo muy apreciado por el consumidor. Temperaturas próximas a $0^{\circ} \mathrm{C}$ y alta humedad relativa (90-95\%) permiten mantener su calidad, retrasando al máximo las pérdidas por deshidratación. Sin embargo, la refrigeración por períodos extensos puede provocar pérdida de color, acidez, aromas, y favorecer el desarrollo de enfermedades fúngicas.

El objetivo de este estudio fue evaluar la influencia de un déficit hídrico ligero en precosecha sobre la producción y las características físico-químicas de la cereza 'Prime Giant', una variedad de maduración media, en el momento de la cosecha, tras su conservación refrigerada y después de un periodo de simulación de las condiciones de comercialización.

\section{2- Materiales y métodos}

El ensayo se realizó durante 2015 en una parcela de 0,5 ha perteneciente a la finca comercial "Finca Toli" en Jumilla, Murcia (38 $8^{\prime} \mathrm{N} ; 1^{\circ} 22^{\prime} \mathrm{W}$ y $680 \mathrm{~m}$ de altitud). El suelo es de textura franco-arenosa y medianamente pedregoso, lo que le confiere unas propiedades de retención de agua medias. La plantación de 15 años de edad, constituida por cerezos [Prunus avium (L.)] cv. "Prime Giant", sobre patrón SL 64 y como polinizadores "Brooks" y "Early Lory", dispuesta a marco de plantación de $5 \mathrm{~m} \times 3 \mathrm{~m}$, está formada en vaso bajo con un área sombreada de aproximadamente el $55 \%$ y diámetro de tronco de $16,3 \mathrm{~cm}$. El diseño del sistema de riego por goteo fue de un único lateral por hilera de árboles con 3 goteros de $4 \mathrm{~L} \mathrm{~h}^{-1}$ por árbol. El agua de riego, de pozo, es de buena calidad y presentó una conductividad eléctrica de $0,8 \mathrm{dS} \mathrm{m}^{-1}$ y un contenido en sodio y cloruros de 79,1 y $120,5 \mathrm{mg}$ $\mathrm{L}^{-1}$, respectivamente. La evapotranspiración de referencia $\left(\mathrm{ET}_{0}\right)$ acumulada en el periodo 85$161 \mathrm{DDA}$ (día del año) fue $361,6 \mathrm{~mm}$, la $\mathrm{ET}_{0}$ media diaria en precosecha fue de 4,7 $\mathrm{mm}$, y la precipitación total $38,9 \mathrm{~mm}$. La temperatura media diaria tuvo un valor promedio de $16,5^{\circ} \mathrm{C}$, con un valor máximo de $28^{\circ} \mathrm{C}$ (DDA 134), ese mismo día se dio el valor máximo de déficit de presión de vapor (DPV) en precosecha, $2,31 \mathrm{kPa}$, aunque la media diaria para el periodo de estudio fue $0,92 \mathrm{kPa}$. Tanto la fertilización como el control fitosanitario se realizaron de acuerdo con las prácticas seguidas en la explotación. Los frutos se recolectaron en dos fechas, el día 3 de junio (DDA 154) y el 10 de junio (DDA 161) en base al color de la piel y siguiendo las prácticas comerciales habituales.

El ensayo constó de 3 tratamientos de riego : i) control, CTRL, regado para satisfacer el $110 \% \mathrm{ET}_{\mathrm{cg}}$ durante toda la campaña de riegos, ii) agricultor, AGR, programado de acuerdo con su experiencia y iii) riego deficitario controlado, RDC, programado al $85 \%$ de la $\mathrm{ET}_{\mathrm{cg}}$ durante precosecha, a excepción de los 7 días entre ambas recolecciones que se regó como CTRL. ET $\mathrm{cg}$ se determinó de acuerdo con la expresión propuesta por FAO:

$$
\mathrm{ET}_{\mathrm{cg}}=\mathrm{ET}_{\mathrm{o}} \times \mathrm{K}_{\mathrm{c}} \times \mathrm{K}_{\mathrm{r}}
$$

donde, $\mathrm{ET}_{0}$ es la evapotranspiración de referencia, $\mathrm{K}_{\mathrm{c}}$ el coeficiente de cultivo (Marsal et al. 2010) y $\mathrm{K}_{\mathrm{r}}$ un coeficiente corrector por localización dependiente de la superficie del suelo cubierta por las copas de los árboles (Fereres y Castel 1981) .

El diseño experimental fue de bloques al azar con 4 repeticiones de 7 árboles cada una. El volumen de agua aplicado se midió con contadores de pulsos (ARAD SF). El potencial hídrico de tallo a mediodía $\left(\Psi_{\mathrm{t}}\right)$ se controló semanalmente a partir de 2 hojas por repetición cercanas a la base del tronco y envueltas con plástico y papel de aluminio durante dos horas (Shackel et al. 1997), utilizando una cámara de presión Soil Moisture Equipment Corp., Model 3005, Santa Barbara,CA, USA).

En la madurez comercial de la fruta, se recogieron y pesaron los frutos provenientes de los 5 árboles centrales de cada repetición. Para ello, se realizaron dos recolecciones en los días del año, DDA, 154 y 161. Así mismo, se contaron los frutos existentes en muestras 
de $5 \mathrm{~kg}$ al objeto de conocer el peso unitario de la cereza. La calidad fisicoquímica de las cerezas de la primera recolección $(03 / 06 / 2015)$ se determinó tras la cosecha (tiempo $\left.t_{0}\right)$, tras un periodo de frigoconservación de 30 días a $0^{\circ} \mathrm{C}$ y $90 \%$ humedad relativa $(H R)\left(t_{1}\right)$, y tras un periodo adicional de simulación de la comercialización de 5 días a $15^{\circ} \mathrm{C}$ y $65 \% \mathrm{HR}\left(\mathrm{t}_{2}\right)$. Para ello, se tomaron muestras de 20 cerezas por repetición y en cuatro repeticiones por tratamiento y día de análisis $\left(t_{0}, t_{1}, y t_{2}\right)$. Los caracteres geométricos se midieron con un calibre digital, el color se determinó con un colorímetro Minolta CR 300 (Ramsey, NJ, EEUU), la firmeza con un analizador de textura LFRA 1500 (Middleboro, Brookfield, MA, EEUU) con una sonda de $2 \mathrm{~mm}$ de diámetro para rotura y una de 25,42 $\mathrm{mm}$ para compresión, los sólidos solubles totales con un refractómetro (Atago N1, Tokio, Japón) y la acidez titulable por valoración ácido-base.

El análisis de datos se realizó mediante ANOVA y regresiones lineales.

\section{3- Resultados y discusión}

Los volúmenes de riego aplicados en precosecha fueron $2.157,1.777$ y $2.751 \mathrm{~m}^{3} \mathrm{ha}^{-1}$ para CTRL, RDC y AGR respectivamente. El tratamiento AGR recibió un $27,5 \%$ de agua más que CTRL, mientras que la cantidad suministrada a RDC fue un $17,5 \%$ y $35,0 \%$ inferior a la de CTRL y AGR, respectivamente. El potencial de tallo a mediodía $\left(\Psi_{\mathrm{t}}\right)$ presentó valores medios $-0,51,-0,48$ y $-0,57 \mathrm{MPa}$ para $\mathrm{CTRL}$, RDC y $\mathrm{AGR}$, respectivamente. Se dieron diferencias significativas en 4 de los 6 días de medida (Figura 1), principalmente entre los tratamientos más regados (AGR y CTRL) y el deficitario RDC, lo que muestra la sensibilidad de $\Psi_{\mathrm{t}}$ para detectar estreses hídricos ligeros. Si se tiene en cuenta que durante todo el periodo precosecha $\Psi_{t}$ fue superior o igual a $-0,70 \mathrm{MPa}$ (Figura 1), valor por encima del cual consideran que no existe estrés hídrico en la variedad de cereza "Summit" (Marsal et al., 2010), podemos considerar que el estrés aplicado en RDC fue de intensidad ligera.

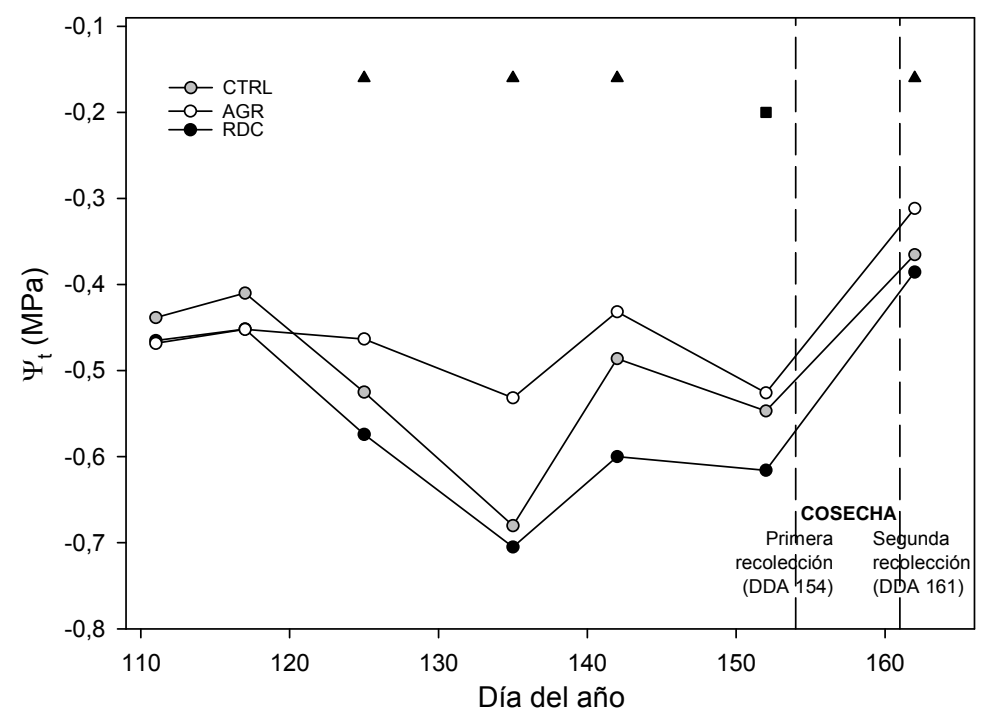

Figura 1. Evolución del potencial de tallo a mediodía en precosecha. Cada punto representa el valor medio de seis medidas. Las diferencias significativas entre tratamientos de acuerdo con el test de Duncan $(P>0,05)$ aparecen indicadas como: diferencias entre 2 tratamientos y $\boldsymbol{\Delta}$ diferencias de un tratamiento con los otros dos.

La tabla 1 muestra la producción total obtenida y la de cada una de las recolecciones. La producción comercial media para el conjunto de tratamientos fue de $15,5 \mathrm{t} \mathrm{ha}^{-1}$ y no hubo diferencias significativas de producción entre tratamientos en ninguna de las dos recolecciones ni en la total. Aunque el peso unitario del fruto fue similar en los tres tratamientos de riego, la tendencia fue a presentar valores más bajos en RDC, viéndose compensada la producción por el mayor número de frutos recolectados. Las producciones 
obtenidas pueden ser consideradas como medias-altas, máxime teniendo en cuenta los daños ocasionados por el granizo, 19 de mayo de 2015, los que fueron cifrados a nivel de parcela entre 1,5 y $2,0 \mathrm{t} \mathrm{ha}^{-1}$ de pérdidas.

Tabla 1. Peso unitario del fruto y producción de cereza por recolección y total.

\begin{tabular}{|c|c|c|c|c|c|}
\hline \multicolumn{2}{|c|}{ Parámetro } & \multicolumn{4}{|c|}{ Tratamiento } \\
\hline & & CTRL & RDC & AGR & \\
\hline Peso unitario fruto & $(g)$ & 11,07 & 10,63 & 11,77 & n.s. \\
\hline Recolección I & $\left(t \cdot h a^{-1}\right)$ & 8,86 & 10,43 & 8,17 & n.s. \\
\hline Recolección II & $\left(t \cdot h a^{-1}\right)$ & 6,72 & 5,71 & 6,67 & n.s. \\
\hline Cosecha Total I+II & $\left(t \cdot h a^{-1}\right)$ & 15,58 & 16,13 & 14,84 & n.s. \\
\hline
\end{tabular}

n.s. indica que no existen diferencias significativas entre tratamientos para ese parámetro de acuerdo al test de Duncan $(P>0,05)$.

La tabla 2 recoge los principales parámetros de calidad evaluados en las cerezas de la primera recolección en el momento de la cosecha $\left(t_{0}\right)$, tras 30 días en cámara frigorífica $\left(t_{1}\right)$ y tras el periodo de simulación de condiciones de comercialización $\left(t_{2}\right)$. En el momento $t_{0}$, se observaron diferencias significativas entre los tratamientos AGR y RDC en el matiz ( ${ }^{\circ}$ hue) y la acidez titulable (AT). La mayor concentración de ácido málico en RDC no influyó sobre el índice de madurez (IM), al ser ésta compensada por el ligero incremento de sólidos solubles totales (Tabla 2). Las diferencias encontradas en el matiz, pueden deberse a una mayor concentración de antocianinas en el tratamiento RDC, las que provocan un color más intenso. En firmeza no se observaron diferencias entre tratamientos tanto a nivel de compresión como de rotura, aunque sí se dio una relación directa entre la firmeza, especialmente la determinada a compresión, y el agua aplicada a cada tratamiento en precosecha (Figura 2). En cuanto al tamaño del fruto: volumen y diámetro ecuatorial, principales parámetros de calidad de la cereza, no hubo diferencias significativas entre tratamientos y tampoco en el peso unitario del fruto. Sin embargo, se observó una tendencia a mayores pesos unitarios, volumen y diámetro ecuatorial del fruto en los tratamientos más regados en precosecha. La alta correlación encontrada entre el volumen de fruto y el agua aplicada (Figura 2), podría explicar las diferencias encontradas en acidez titulable, y al mismo tiempo, la tendencia de RDC a presentar frutos más pequeños y mayores concentraciones de ácido málico y de antocianinas, relación descrito en uva por Castellarín et al. (2007).

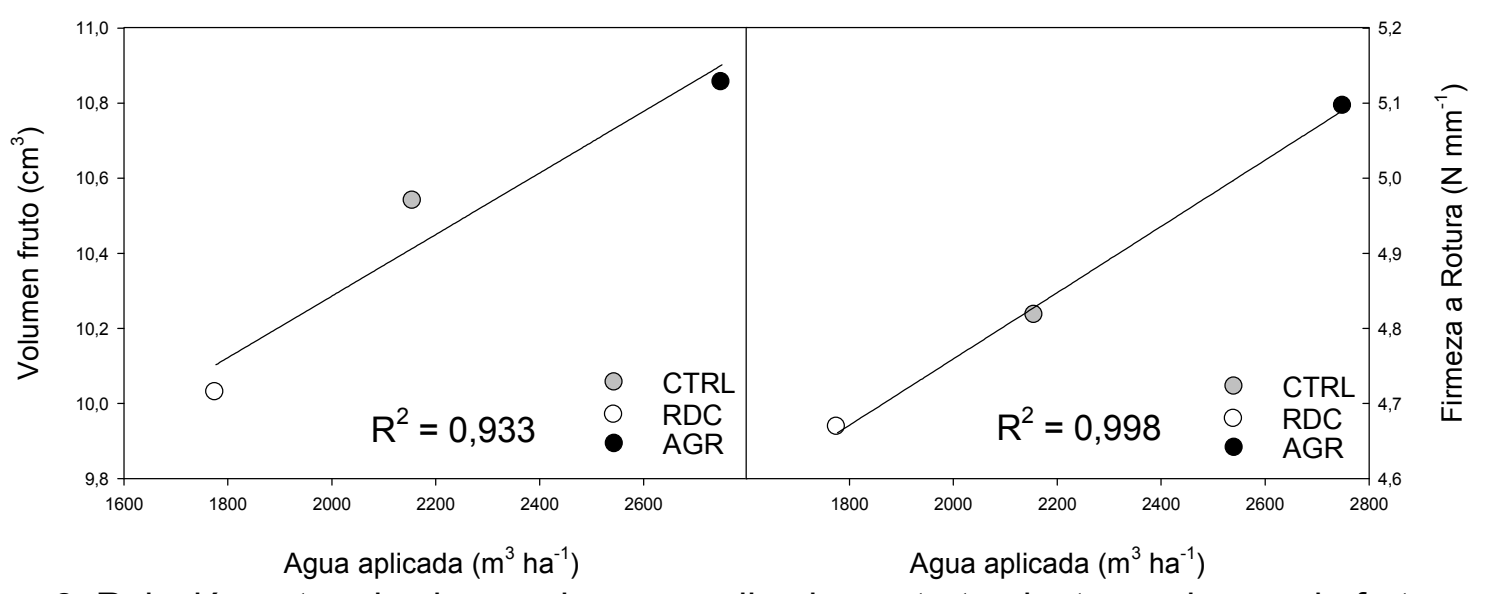

Figura 2. Relación entre el volumen de agua aplicado por tratamiento y volumen de fruto y firmeza a rotura $\left(\mathrm{N} \mathrm{mm}^{-1}\right)$. 
En $\mathrm{t}_{1}$, tras 30 días de almacenamiento en cámara frigorífica los parámetros físicos se mantienen constates, y aunque se presupone una pérdida de humedad en la fruta, ésta no ha sido suficiente para inducir un menor volumen o diámetro ecuatorial. Sin embargo, ha promovido un aumento de la concentración de sólidos solubles totales y por consiguiente del valor del índice de madurez. Las diferencias en matiz y acidez titulable que había entre AGR y RDC en el momento de la cosecha desaparecen, experimentando una bajada generalizada de sus valores. De igual modo, la firmeza tanto a compresión como a rotura desciende, particularmente a compresión que sufre una bajada del $22 \%$ de media frente al $14 \%$ a rotura. Ésta pérdida de firmeza tras el almacenamiento en cámara coincide con los resultados publicados por Diaz-Mula et al. (2009). Con respecto al color, la bajada de la saturación y del matiz se debe a un oscurecimiento de las cerezas debido al almacenamiento en cámara frigorífica, informada para la variedad Lapins por Drake y Elfving (2002). Aunque las pérdidas de peso entre tratamientos no fueron significativamente diferentes, se observó una propensión a valores inferiores en RDC (Tabla 2). En albaricoque "Búlida", Pérez-Pastor et al. (2007) informaron que eran los frutos RDC los que sufrían menores pérdidas de peso por deshidratación durante el periodo de frigoconservación.

En $t_{2}$, tras el periodo de 5 días de simulación de condiciones de comercialización los parámetros físicos presentaron valores parecidos a los $t_{1}$ y por tanto a los valores de cosecha. Sin embargo, la firmeza siguió descendiendo, de modo que a compresión se redujo en un $28 \%$ y $8 \%$ respecto a cosecha y frigoconservación, respectivamente. Similares reducciones tuvieron lugar a rotura, cifrándose en un $24 \%$ y $11 \%$ respecto a cosecha y frigoconservación, respectivamente. Aunque la caída de firmeza a compresión en $t_{1}$ parecía más pronunciada que la de rotura, en $\mathrm{t}_{2}$ se iguala, esto puede deberse a que en un principio la pérdida de humedad que ocurre tras el almacenamiento en frío puede endurecer el fruto y dar una sensación de menor pérdida de firmeza. En referencia al color no se encontraron diferencias en el matiz, el cual continuó descendiendo a matices más oscuros en todos los tratamientos. Contrariamente, sí se encontraron diferencias para la saturación entre AGR y los otros dos tratamientos CTRL y RDC. Este parámetro experimentó un considerablemente descenso durante los 5 días de vida comercial, un $30 \%$ de media respecto a $t_{1}$. Los valores de saturación $t_{2}$ corresponden a un rojo oscuro, consecuencia de la rápida pérdida de brillo. La saturación del color de las cerezas puede deberse a un aumento de los procesos de degradación propiciado por las condiciones de conservación, temperatura ambiente de $15^{\circ} \mathrm{C}$ y humedad relativa del $65 \%$. Esta degradación en el color ha sido igualmente observada en variedades de cereza como Van (Gonçalves et al. 2007). La evolución de los sólidos solubles y la acidez titulable presentó sentidos contrarios, propios de procesos degradativos (Serrano et al. 2009). Así, mientras que los primeros aumentaron, la acidez disminuyó de forma diferencial dando lugar a diferencias significativas entre tratamientos. RDC mantuvo durante el periodo de comercialización mayor nivel de acidez que CTRL y AGR. El índice de madurez (IM) aumentó considerablemente desde cosecha a comercialización en todos los tratamientos, debido principalmente al descenso de la acidez, comportamiento ya descrito en variedades como Brooks o Bing (Crisosto et al. 2002). Aunque la acidez fue superior en RDC, no dio lugar a diferencias en IM entre tratamientos, posiblemente por el ligero repunte experimentado en los sólidos solubles totales (Tabla 2). Aunque los tres tratamientos presentaron similares pérdidas de peso en $t_{2}$, fue RDC el tratamiento con menor porcentaje de pérdidas, como ya ocurriera en $t_{1}$. Esta propiedad, la cual es muy deseable, puede deberse a pequeños cambios en el fruto, tales como un mayor espesor de cutícula inducido por el déficit hídrico, que disminuirían las pérdidas de agua desde el fruto, Pérez-Pastor et al. (2007). 
Tabla 2. Resultados de los análisis de calidad físico-química de los frutos de la primera recolección.

\begin{tabular}{|c|c|c|c|c|c|c|c|c|c|c|}
\hline \multirow[b]{3}{*}{ Parámetro } & \multirow[b]{3}{*}{ unidad } & \multicolumn{9}{|c|}{ Momento de análisis } \\
\hline & & \multicolumn{3}{|c|}{$\operatorname{Cosecha}\left(t_{0}\right)$} & \multicolumn{3}{|c|}{ Frigoconservación $\left(t_{1}\right)$} & \multicolumn{3}{|c|}{ Comercialización $\left(t_{2}\right)$} \\
\hline & & CTRL & RDC & AGR & CTRL & RDC & AGR & CTRL & RDC & $\overline{A G R}$ \\
\hline Saturación & croma & 30,7 & 29,04 & 29,73 & 29,27 & 29,61 & 29,85 & $19,18^{b}$ & $20,09^{b}$ & $22,68^{a}$ \\
\hline Matiz & áng hue & $25,89^{a b}$ & $26,81^{a}$ & $25,49^{b}$ & 22,72 & 22,68 & 21,39 & 18,13 & 17,01 & 17,17 \\
\hline Diám. Ecuat. & $\mathrm{mm}$ & 29,59 & 29,13 & 29,95 & 29,52 & 29,22 & 30,00 & 29,43 & 29,25 & 29,25 \\
\hline Volumen & (cm3) & 10,54 & 10,03 & 10,85 & 10,54 & 10,36 & 10,97 & 10,56 & 10,46 & 10,31 \\
\hline Pérdida peso & $(\%)$ & & & & 0,70 & 0,44 & 0,81 & 2,23 & 1,50 & 2,41 \\
\hline Firm. Compr. & $\left(\mathrm{N} \mathrm{mm}^{-1}\right)$ & 12,21 & 12,23 & 12,23 & 9,25 & 9,22 & 10,13 & 8,76 & 8,84 & 8,96 \\
\hline Firm. Rotura & $\left(\mathrm{N} \mathrm{mm}^{-1}\right)$ & 4,82 & 4,63 & 5,10 & 4,02 & 4,13 & 4,41 & 3,74 & 3,59 & 3,79 \\
\hline SST & ("Brix) & 18,51 & 18,7 & 18,46 & 18,72 & 19,12 & 19,23 & 19,15 & 20,54 & 19,89 \\
\hline AT & $\left(\mathrm{g} \mathrm{L}^{-1}\right)$ & $9,34^{\mathrm{ab}}$ & $9,83^{a}$ & $9,13^{\mathbf{b}}$ & 7,97 & 7,97 & 8,35 & $6,81^{b}$ & $7,28^{\mathrm{a}}$ & $6,52^{b}$ \\
\hline IM & & 19,88 & 19,07 & 20,24 & 23,57 & 24,06 & 23,84 & 28,13 & 28,21 & 30,54 \\
\hline
\end{tabular}

Valores medios seguidos de letras diferentes en la misma fila indican diferencias significativas entre tratamientos para ese parámetro de acuerdo con el test de Duncan $(P>0,05)$. La ausencia de letras indica que no es significativo.

Crisosto et al. (2003) indicaron que las tres características principales de aceptación de la cereza eran el color, los sólidos solubles totales y la acidez titulable. El poder contar con una relación que englobe a los tres factores puede ser interesante de cara a estimar su comportamiento de mercado. En "Prime Giant" se encontró una relación polinómica entre el matiz, color de la piel de las cerezas, y la concentración de sólidos solubles totales y a su vez con la acidez titulable, siendo éstas de sentido opuesto (Figura 3). Estas relaciones, muy similares a las descritas por Yommi et al. (2012) para las variedades Lapins y Sweetheart, pueden resultar de interés para determinar el momento adecuado de la cosecha, así como la evolución de SST y AT en refrigeración, en función del color de las cerezas.

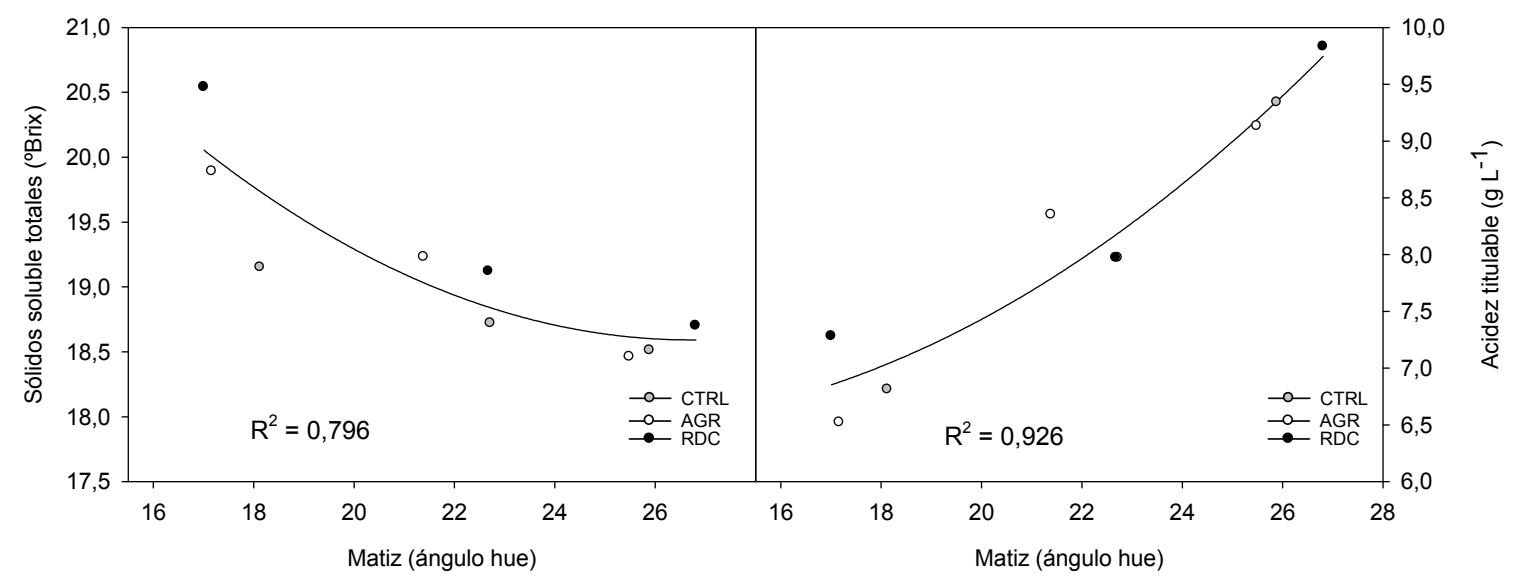

Figura 3. Relación entre el matiz (ángulo hue) y los sólidos soluble totales ( ${ }^{\circ} \mathrm{Brix}$ ) y la acidez titulable $\left(\mathrm{g} \mathrm{L}^{-1}\right)$.

\section{4- Conclusiones y recomendaciones}

El déficit hídrico ligero aplicado en precosecha no afectó negativamente a la calidad en ninguno de los tres momentos de evaluación: cosecha, frigo-conservación y comercialización. Incluso, en el momento de cosecha se dieron valores más altos de acidez 
titulable y matiz en RDC que en AGR. Independientemente de la inexistencia de diferencias significativas en volumen de fruto y firmeza, se observó una alta correlación entre ellas y el agua aplicada. Tanto los sólidos solubles totales como la acidez titulable presentaron buenas correlaciones con el matiz, las que pueden ser de interés de cara a determinar el momento de cosecha. Las pérdidas de peso durante la conservación no dieron lugar a diferencias entre tratamientos. Sin embargo, RDC presentó una tendencia a menores pérdidas de peso, característica que por su interés deberá ser comprobada en sucesivas cosechas. Ahorros de agua precosecha en RDC del $17 \%$ y $35 \%$ respecto a CTRL y AGR, respectivamente no afectaron a la producción de ninguna de las dos recolecciones ni a la total $\left(15,5 \mathrm{t} \mathrm{ha}^{-1}\right)$.

Teniendo en cuenta que son los primeros resultados obtenidos tras un único año de aplicación del déficit hídrico ligero en precosecha de "Prime Giant", es pronto para recomendar su aplicación a nivel comercial, de ahí el interés de poder validarlos en las siguientes campañas.

\section{5.- Agradecimientos}

Este trabajo fue financiado por el Ministerio de Economía y Competitividad (MINECO) y está encuadrado en el proyecto: 'Evaluación de la automatización del riego deficitario en frutales. Mejora de la gestión del agua para asegurar la productividad y sostenibilidad'. Referencia: AGL2013-49047-C2-1R.

\section{6- Bibliografía}

Conesa, M.R., De la Rosa, J.M., Artés-Hernández, F., Dodd, I.C., Domingo, R., Pérez-Pastor A. 2014. Long-term impact of deficit irrigation on the physical quality of berries in 'Crimson Seedless' table grapes. J. Sci. Food Agric. 95 (12), 2510-2520.

Crisosto, C.H., Crisosto, G.M., Ritenour M.A. (2002) Testing the reliability of skin colour as an indicator of quality for early season Brooks (Prunus avium L.) cherry. Postharvest Biology \& Technology, 24, 147-154.

Crisosto, C. H., Crisosto, G. M., Metheney, P. (2003) Consumer acceptance of "Brooks" and "Bing" cherries is mainly dependent on fruit SSC and visual skin color. Postharvest Biology \& Technology, 28, 159-167.

De la Rosa, J.M., Domingo, R., Gómez-Montiel, J., Pérez-Pastor, A. (2015). Implementing deficit irrigation scheduling through plant water stress indicators in early nectarine trees. Agricultural Water Management. 152, 207-216.

Díaz-Mula, H.M., Castillo, S., Martínez-Romero, D., Valero, D., Zapata, P.J., Guillén, F., Serrano, M. (2009) Organoleptic, nutritive and functional properties of sweet cherry as affected by cultivar and ripening stage. Food. Sci. Technol. Int, 15, 535-544.

Domingo, R., Ruiz-Sánchez, M.C., Sánchez-Blanco, M.J., Torrecillas, A. (1996). Water relations, growth and yield of Fino lemon trees under regulated deficit irrigation. Irrigation Sci. 16, 115-123.

Drake S.R. and Elfving D.C. (2002). Indicators of maturity and storage quality of 'Lapins' sweet cherry. Hort Technology. 12, 687-690.

Egea, G., Nortes, P.A., Domingo, R., Baille, A., Pérez-Pastor, A., González-Real, M.M. (2013). Almond agronomic response to long-term deficit irrigation applied since orchard establishedment. Irrigation Sci. 31, 445-454.

Falagán, N., Artés, F., Gómez, P.A., Artés-Hernandez, F., Conejero, W., Aguayo E. (2015) Deficit irrigation strategies enhance health-promoting compounds through the intensification of specific enzymes in early peaches. Journal of the Science of Food and agriculture, 96 (5), 1803-1813.

Fereres, E y Castel, J.R. (1981). Drip irrigation management. Division of Agricultural Sciences, University of California. Publicación Leaflet 21259. 
Gonçalves, B., Silva, A. P., Moutinho-Pereia, J., Bacelar, E., Rosa, E., Meyer, A. S. (2007) Effect of ripeness and postharvest storage on the evolution of color and anthocyanins in cherries (Prunus avium L.). Food Chem., 103, 976-984.

Marsal, J., López, G., del Campo, J., Mata, M., Arbones, A., Girona J. (2010). Postharvest regulated deficit irrigation in 'Summit' sweet cherry: fruit yield and quality in the following season. Irrigation Sci. 28, 181-189.

Pérez-Pastor, A., Ruiz-Sánchez, M.C., Martínez, J.A., Nortes, P.A., Artés, F., Domingo, R. (2007) Effect of deficit irrigation on apricot fruit quality at harvest and during storage. $J$ Sci Food Agric., 87, 2409-2415.

Ruiz-Sánchez, M.C., Domingo, R., Castel J.R. (2010) Deficit irrigation in fruit trees and vines in Spain: a review. Span. J. Agric. Res., 8 (S2), S5-S20.

Serrano, M., Diaz-Mula, H.M., Zapata, P.J., Castillo, S., Guillén, F., Martinez-Romero, D., Valverde Juan, M., Valero, D. (2009) Maturity stage at harvest determines the fruit quality and antioxidant potential after storage of sweet cherry cultivars. J. Agric. Food Chem., 57, 3240-3246.

Shackel K.A., Ahmadi H., Biasi W., Buchner R., Goldhamer D.A. et al. (1997) Plant water status as an index of irrigation need in deciduous fruit trees. Hort. Technol. 7, 23-29.

Yommi, A., Fernandez, V., Guerra, N., Cendoya, G., Quillehauquy, V. (2012) Skin colour changes in fruits of two sweet cherry cultivars, its heterogeneity and relationship with quality indices. Acta horticulturae, 934, 1055-1061. 


\title{
DESARROLLO DE UN SERVICIO EXPERIMENTAL DE TELEDETECCIÓN EN LOS RIEGOS DEL PORMA (LEÓN) PARA EL CÁLCULO AJUSTADO DE NECESIDADES HÍDRICAS Y MEJORA EN LA GESTIÓN DEL REGADÍO
}

\author{
Valdés Mora, I (1); Escudero Barbero, R (2); Rubio Melón, A (3); Fernández Pesado, P (4);
} Checa Alonso, MJ (5); Sanchez Hernández, B (6); Iglesias Gómez, S (7).

${ }^{1}$ Responsable Técnico de Proyecto OPTIREG1316, Gerencia de Ingeniería y Edificación (Tragsatec), Julián Camarillo 6, 28037 Madrid, ivm@tragsa.es

2 Jefe de Departamento de Teledetección, Gerencia de Sistemas de Información Geográfica (Tragsatec), Julián Camarillo 6, 28037 Madrid, reb@tragsa.es

${ }^{3}$ Coordinador de Obras (Tragsa), Cruz Roja de León 26 A. 24008 León, arubio@tragsa.es

${ }^{4}$ Analista (Tragsa), Cruz Roja de León 26 A. 24008 León, pfernand@tragsa.es

5 Jefe de Grupo de Actuaciones y Proyectos, Dpto de Teledetección, Gerencia de Sistemas de Información Geográfica (Tragsatec), Julián Camarillo 6, 28037 Madrid, mjc@tragsa.es ${ }^{6}$ Jefe de Actuaciones y Proyectos, Dpto de Teledetección, Gerencia de Sistemas de Información Geográfica (Tragsatec), Julián Camarillo 6, 28037 Madrid, bsh@tragsa.es ${ }^{7}$ Responsable de apoyo y supervisión de proyecto OPTIREG1316. Subdirección de I+D+i (Tragsa), Conde Peñalver 84, Madrid, siglesia@tragsa.es)

\section{Resumen}

El proyecto de innovación tecnológica OPTIREG Eficiencia Hídrica, impulsado por el Grupo Tragsa, tiene entre sus objetivos principales introducir el uso de la teledetección, como tecnología de apoyo a la gestión hídrica. Para ello se está desarrollando un servicio web gis experimental que servirá de repositorio único de imágenes y de sus productos derivados y que facilitará, tanto a los regantes, como a los gestores del riego, el seguimiento de los cultivos y de sus necesidades hídricas.

Diversos estudios científicos han demostrado la buena relación lineal existente entre el índice de vegetación normalizado (NDVI), derivado de las imágenes de satélite, y el coeficiente de cultivo, $\mathrm{K}_{\mathrm{c}}$ (Torres, 2010), utilizado en el cálculo de la evapotranspiración y las necesidades hídricas. Una primera evaluación de los resultados obtenidos en la campaña 2015 para los principales cultivos en regadío en la zona de estudio del Porma (León), indica que el $\mathrm{K}_{\mathrm{c}}$ calculado a partir del NDVI, se ajusta mejor que el de FAO. Por ello, se considera un sistema muy válido como referencia para ajustar no sólo la cantidad de agua, sino también para determinar el momento más adecuado de riego, que redundará en una mayor eficiencia hídrica.

\section{1) Introducción y objetivos}

Los planes de modernización de regadíos han sido el mecanismo más importante para la mejora de la gestión y el uso del agua, habiendo conseguido tanto una reducción del consumo como un aumento de la eficiencia en su uso.

La Teledetección es una de las tecnologías que hoy en día ofrecen mayor potencial de desarrollo para integrarse en los sistemas de telecontrol de riego, contribuyendo a conseguir una mayor eficiencia hídrica. Se trata de una tecnología que en los últimos años se ha beneficiado de las grandes inversiones realizadas en las misiones espaciales de 
observación de la Tierra, como es el caso en Europa, del Programa Copernicus y su constelación de satélites Sentinel.

El proyecto de innovación tecnológica OPTIREG Eficiencia Hídrica, impulsado por el Grupo Tragsa, tiene como uno de los objetivos principales introducir el uso de la teledetección como tecnología de apoyo en el ámbito de la gestión hídrica. Este proyecto está desarrollando un servicio de teledetección experimental, casi en tiempo real, que cubre de momento unas 17.000 ha de regadío pertenecientes a varias comunidades de regantes gestionadas por Tragsa en el Porma (León).

Distintos trabajos experimentales han derivado el coeficiente de cultivo $\left(\mathrm{K}_{\mathrm{c}}\right)$ a partir de índices de vegetación obtenidos con imágenes de satélite, como el de Calera et al, 2014. Con este estudio se pretende conseguir, un mayor ajuste de la curva de $\mathrm{K}_{\mathrm{c}}$ a lo largo del periodo de desarrollo fenológico, que el ofrecido en las tablas de cultivo del estudio de la FAO 56 de riegos y drenajes, empleadas tradicionalmente para el cálculo de la evapotranspiración del cultivo $\left(\mathrm{ET}_{\mathrm{c}}\right)$ y las necesidades hídricas.

\section{2) Materiales y métodos}

\subsection{Imágenes multiespectrales obtenidas por satélite}

Los sensores de observación de la Tierra han sufrido un enorme avance en los últimos años, optimizando sus características de:

- Resolución espacial, compitiendo en capacidad de captura y resolución espacial con las cámaras fotogramétricas, alcanzando los $50 \mathrm{~cm}$ de tamaño de pixel.

- Resolución espectral y radiométrica de algunos sensores, con mayor número de bandas espectrales y mayor sensibilidad (10 - 12 bits).

- Resolución temporal, con periodos de revisita cada vez más cortos, gracias a la existencia de constelaciones de satélites, como son el caso de las misiones Spot 6-7 o Pléiades $1 \mathrm{~A}-1 \mathrm{~B}$, empleadas en este proyecto.

Estas innovaciones tecnológicas, junto con la apertura de los archivos de imágenes de las agencias espaciales de NASA (http://earthexplorer.usgs.gov/) y ESA (https://scihub.copernicus.eu/dhus/\#/home), que ofrecen imágenes de libre distribución y media resolución espacial (30 metros de tamaño de pixel para Landsat y 10 metros para Sentinel2), al día siguiente de su captura, están dando un enorme impulso a las aplicaciones de la teledetección.

Además de las capacidades comentadas, la característica más importante de las imágenes multiespectrales obtenidas por satélite es que, gracias a su calibración radiométrica, es posible realizar conversiones a valores físicos de reflectividad, dotándolas de una homogeneidad que las hace perfectamente comparables entre sí en estudios multitemporales. Es decir, son susceptibles de ser procesadas mediante técnicas de teledetección para obtener parámetros biofísicos, a partir de los cuales se calculan índices de vegetación, como el NDVI (Normalized Difference Vegetation Index). Éste es un indicador probado de la actividad fotosintética de la planta y del que es posible derivar el coeficiente de cultivo $\left(\mathrm{K}_{\mathrm{c}}\right)$, utilizado en el ajuste de las necesidades hídricas de los cultivos dentro del modelo FAO56 (Allen et al, 1998).

En la campaña de 2015 se utilizaron imágenes Landsat8 OLI de libre distribución, combinadas con una programación específica de imágenes Pléiades y Spot, con el propósito tanto de trabajar con imágenes de mayor resolución espacial (50 cm y $1.5 \mathrm{~m}$, en la banda pancromática respectivamente), como de disponer de una imagen semanal, frecuencia que se ajusta de forma óptima a la programación automatizada del riego en el 
Porma. Los productos derivados y entregados en un periodo generalmente inferior a la semana son: imágenes RGB, NDVI y sus variables derivadas, $\mathrm{K}_{\mathrm{cb}}$ (coeficiente de cultivo basal) y $\mathrm{K}_{\mathrm{c}}$ (coeficiente de cultivo).

En la campaña 2016 se ha incorporado al servicio de imágenes las del nuevo satélite de la ESA Sentinel2 que cuenta con unas capacidades espaciales y espectrales mejores que las de Landsat8.

Las principales características técnicas de los tres tipos de imágenes a emplear en la campaña de teledetección OPTIREG 2016 se muestran en la Tabla 1.

Tabla 1. Principales características técnicas de los sensores empleados en OPTIREG.

\begin{tabular}{|c|c|c|c|c|}
\hline Satélite y sensor & $\begin{array}{c}\text { Ancho de pasada } \\
\text { (Swath) en Km }\end{array}$ & $\begin{array}{c}\text { Resolución } \\
\text { espectral (no de } \\
\text { bandas y rango } \\
\text { espectral) }\end{array}$ & $\begin{array}{c}\text { Resolución } \\
\text { espacial de las } \\
\text { bandas Ms y Pan }\end{array}$ & $\begin{array}{c}\text { Resolución } \\
\text { temporal }\end{array}$ \\
\hline LANDSAT 8 OLI & 185 & $\begin{array}{c}10 \text { bandas: } \\
\text { Visible, IRC, IRM }\end{array}$ & $\begin{array}{c}30 \mathrm{~m} \mathrm{Ms} \\
15 \mathrm{~m} \text { Pan }\end{array}$ & $\begin{array}{c}16 \text { días (8 en zona } \\
\text { de solape) }\end{array}$ \\
\hline SENTINEL 2A MSI & 290 & $\begin{array}{c}13 \text { bandas: } \\
\text { Visible, Borde del } \\
\text { Rojo, IRC, IRM }\end{array}$ & 10 a $60 \mathrm{~m}$ Ms & 10 días \\
\hline PLÉIADES & 20 & $\begin{array}{c}4 \text { bandas: } \\
\text { Visible, IRC }\end{array}$ & $\begin{array}{c}2 \mathrm{~m} \text { Ms } \\
0.5 \mathrm{~m} \text { Pan }\end{array}$ & $\begin{array}{c}\text { Programadas } 6 \\
\text { imágenes entre } \\
\text { Mayo y }\end{array}$ \\
\hline
\end{tabular}

Dadas las características de las imágenes empleadas, la prioridad para seleccionarlas será: Pléiades, Séntinel y Landsat, por este orden.

\subsection{Metodología aplicada para el cálculo de $\mathrm{K}_{\mathrm{c}}$}

La metodología aplicada en OPTIREG para el cálculo del $\mathrm{K}_{\mathrm{c}}$ a partir de las imágenes de satélite, es la seguida en la Universidad de Albacete y descrita en diversas publicaciones (Calera et al, 2014). Según esta metodología el coeficiente de cultivo $\left(\mathrm{K}_{\mathrm{c}}\right)$ se determina de forma directa a partir del NDVI derivado de las imágenes de satélite.

EI NDVI (Normalized Difference Vegetation Index) es un índice de vegetación con significado biofísico que informa sobre la actividad vegetativa de las plantas. Este índice se calcula a partir de las bandas roja (R) e infrarrojo cercano (IRC) del espectro electromagnético, donde las diferencias en los valores de reflectividad para la vegetación sana son mayores.

$$
N D V I=(I R-R) /(I R+R)
$$

Sus valores varían entre -1 y 1 , donde los valores más altos indican mayor actividad vegetativa.

En el cálculo del coeficiente de cultivo, $\mathrm{K}_{\mathrm{c}}$, se pueden distinguir dos componentes que reflejan la evaporación directa del suelo y la transpiración de la planta (Wright, 1982).

$$
\mathrm{K}_{\mathrm{c}}=\mathrm{K}_{\mathrm{cb}}{ }^{*} \mathrm{~K}_{\mathrm{s}}+\mathrm{K}_{\mathrm{e}}
$$




\section{Donde:}

$\mathrm{K}_{\mathrm{cb}}$, es el coeficiente de cultivo basal.

$\mathrm{K}_{\mathrm{s}}$, es el coeficiente de estrés. Éste varía entre 0 y 1 , tomando valores de 1 en ausencia de estrés, como ocurriría en los cultivos en regadío.

$\mathrm{K}_{\mathrm{e}}$, es el coeficiente evaporativo del suelo y expresa la reducción de transpiración que se produce en las plantas como consecuencia del déficit de agua en el suelo.

Para el cálculo de $\mathrm{K}_{\mathrm{c}}$ es necesario modelizar la componente evaporativa de la fracción de suelo desnudo, que está relacionada con la superficie efectivamente mojada, el sistema de riego y la frecuencia, las características del suelo, etcétera.

En la metodología propuesta por Calera et al, 2014, la ecuación lineal que relaciona el $\mathrm{K}_{\mathrm{c}}$ y el NDVI es:

$$
\mathrm{K}_{\mathrm{c}}=1.25 * \mathrm{NDVI}+0.1
$$

Según los autores, está simplificación de la ecuación, conlleva una serie de limitaciones que es importante tener en cuenta a la hora de aplicarla para el cálculo de la $E T_{c}$ y las necesidades hídricas de los cultivos de estudio. De manera que sólo se considera válida para cultivos herbáceos en regadío (con sistemas de riego tipo pivot o aspersión) que en su fase de máximo desarrollo alcanzan una cobertura completa del suelo. En la fase de nascencia o en el caso de cultivos como los ajos, cebollas, etcétera, donde en su fase de máximo desarrollo no alcanzan una cobertura completa del suelo, la componente evaporativa del suelo puede ser muy alta, y por lo tanto, este método tenderá a infraestimar el valor del $\mathrm{K}_{\mathrm{c}}$.

\subsection{Procesado de imágenes de satélite y generación de productos derivados}

El procesado de imágenes incluye los siguientes pasos:

- Selección y adquisición de las imágenes, conforme a la prioridad establecida: Pléiades (6 fechas programadas entre mayo y septiembre), Sentinel2 (cada 10 días) y Landsat8 (cada 16 días). El objetivo es disponer de una imagen semanal libre de nubes.

- Procesado de las imágenes de satélite. El procesado estándar de las imágenes consiste en una corrección geométrica y radiométrica de las imágenes que asegure la perfecta superposición de las mismas y las haga radiométricamente comparables entre sí, minimizando las diferencias derivadas de las distintas condiciones de iluminación durante la captura y las vinculadas al sensor.

Las imágenes Landsat8 y Sentinel2 se suministran ya georreferenciadas y en valores de reflectividad al techo de la atmósfera (TOA, Top Of Atmosphera). En el caso de las imágenes Pleiades y Spot6/7 es necesario realizar su ortorrectificación (usando puntos de control sobre el terreno y un modelo digital del terreno) y su transformación a valores de reflectividad TOA.

Además, con el fin de asegurar la congruencia de los valores de NDVI derivados de los distintos de sensores de la serie de imágenes de la campaña, se realiza un intercalibrado entre ellas, tomando como referencia el NDVI procedente de Landsat.

- Generación de la máscara de nubes y sombras, con el fin de eliminar éstas de las imágenes. Para crear la máscara de nubes se usa la banda de calidad de los 
sensores y las sombras se eliminan a partir de los valores de las bandas del rojo e infrarrojo cercano y medio.

- Elaboración de productos RGB para fotointerpretación. Para cada fecha de imagen se elaboran dos compuestos RGB, uno en falso color infrarrojo creado a partir de las bandas, verde, infrarrojo cercano y rojo y otro en color natural, utilizando las bandas, rojo, verde y azul, cuyos ejemplos se muestran en la Figura 1.
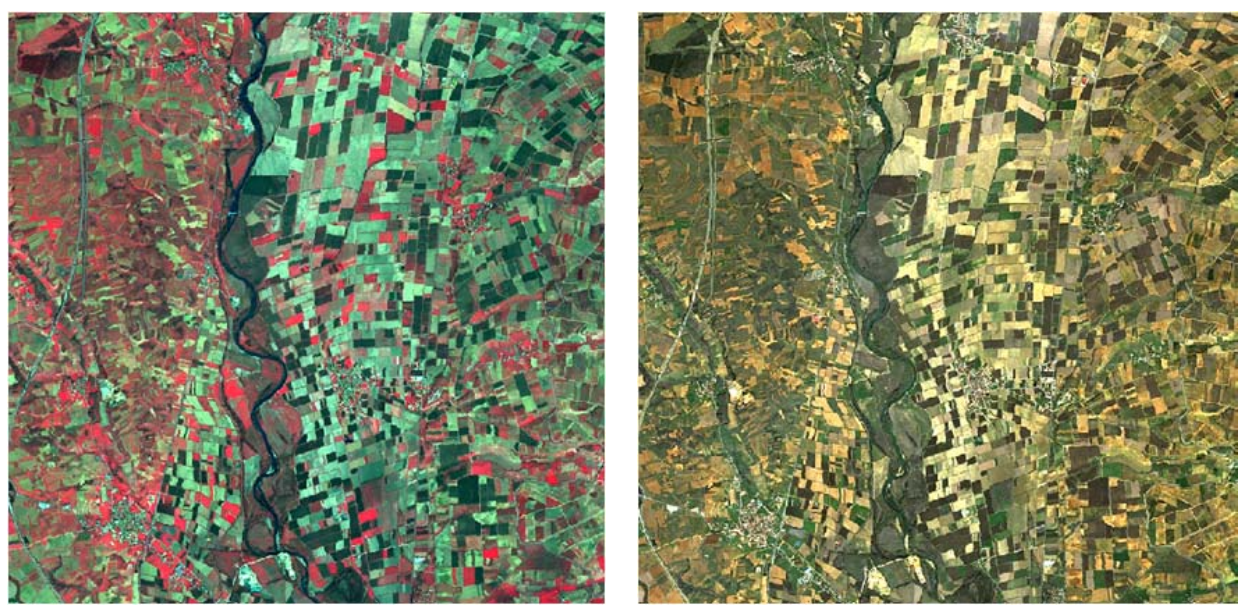

Figura 1. Compuesto RGB de una imagen Landsat8 en falso Falso Color infrarrojo (izquierda) y en color natural (derecha).

Para las imágenes que cuentan con banda pancromática, Landsat 8 y Pléiades, los compuestos RGB se generan empleando un algoritmo de Pansharpening que produce una imagen de fusión en color de máxima resolución espacial, conforme a las características de su banda pancromática (15 m en el caso de Landsat8 y $50 \mathrm{~cm}$ en el caso de Pléiades). Estas imágenes son óptimas para la fotointerpretación y el seguimiento de las explotaciones agrícolas por parte de los regantes.

- Generación del NDVI, a partir de las imágenes en valores de reflectividad TOA, y de los parámetros $\mathrm{K}_{\mathrm{cb}}$ y $\mathrm{K}_{\mathrm{c}}$, aplicando la fórmula de Calera et al, 2014, explicada anteriormente a la resolución espacial original de las bandas multiespectrales de cada sensor.

- Carga de imágenes y productos derivados en el servicio web de imágenes.

- Obtención de las curvas de $\mathrm{K}_{\mathrm{c}}$ por cultivo para cada unidad de riego y análisis de resultados. Contraste de los valores del $\mathrm{K}_{\mathrm{c}}$ derivado de teledetección y análisis de la evolución del NDVI- $\mathrm{K}_{\mathrm{c}}$ a partir de los datos de referencia disponibles, detección de anomalías, estudio de heterogeneidades, etcétera.

La Figura 2 muestra un flujograma con el protocolo de análisis de imágenes y productos de teledetección obtenidos. 


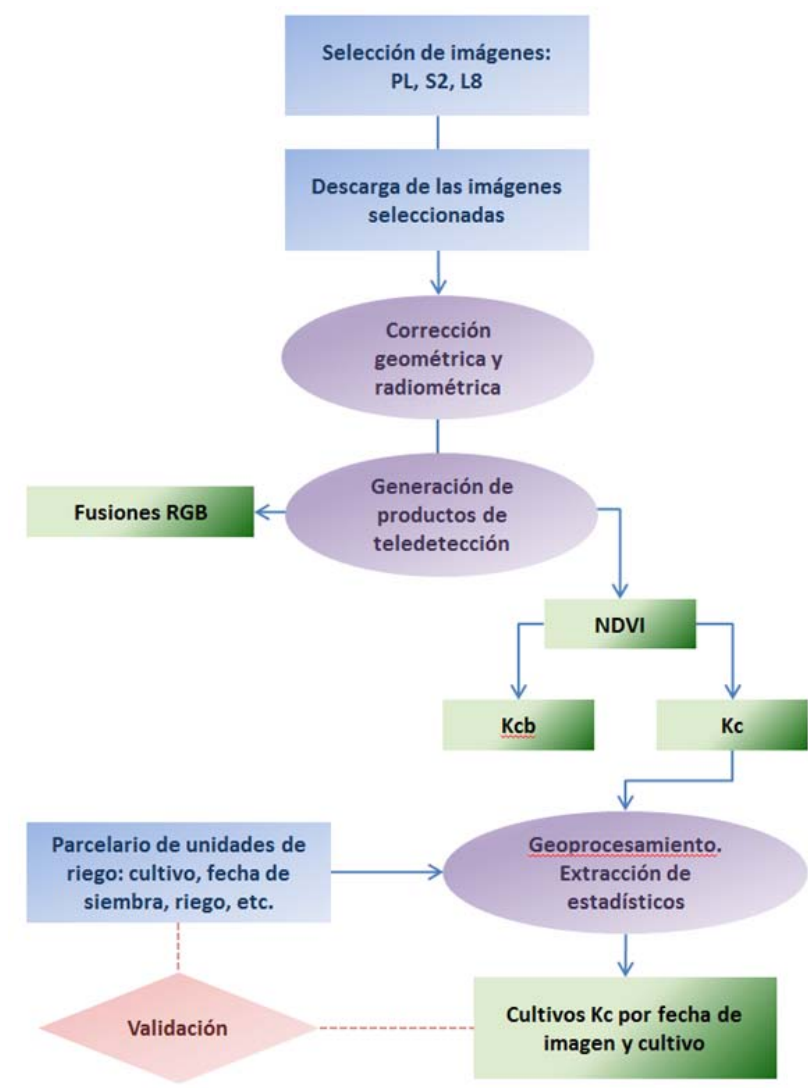

Figura 2: Protocolo de análisis de imágenes y generación de productos de valor añadido

\section{3) Resultados y discusión}

\subsection{Resultados y comparativa de coeficiente de cultivo}

El método de cálculo del coeficiente de cultivo más extendido es el de FAO56 (Allen et al 1998). En éste se fijan tres valores de $K_{c}$ para las cuatro fases de desarrollo del cultivo: inicial (desde la siembra al $10 \%$ de suelo sombreado), desarrollo (hasta el $70-80 \%$ de suelo sombreado), media (hasta el comienzo de la senescencia de las hojas) y final (hasta la maduración o recolección). Estos valores se fijan en función de cada cultivo, considerando la duración de cada etapa de crecimiento y la fecha de siembra.

El problema principal del método FAO es determinar correctamente la duración de las distintas fases de cultivo (condicionada por las variedades y las condiciones climáticas de cada región) y el $\mathrm{K}_{\mathrm{c}}$ que le corresponde a cada etapa.

La tabla adjunta describe las fechas de siembra y recolección de los principales cultivos de la zona, facilitados por las comunidades de regantes del Porma implicadas.

Tabla 2: Fechas de siembra y recogida de los cultivos principales.

\begin{tabular}{|l|l|l|}
\hline \multicolumn{1}{|c|}{ GRUPOS DE CULTIVOS } & \multicolumn{1}{|c|}{ SIEMBRA } & \multicolumn{1}{c|}{ RECOGIDA } \\
\hline Cereal & Noviembre & Junio-julio \\
\hline Girasol & Mayo-junio & Septiembre \\
\hline Maíz & Abril-mayo & Octubre \\
\hline Remolacha & Abril & Octubre \\
\hline
\end{tabular}


A partir de estas fechas se elaboró la curva $K_{c}$ según FAO 56 (Allen et al, 1998), atendiendo a la duración de las etapas de crecimiento establecidas en dicha publicación.

Por otro lado, se han obtenido las curvas $\mathrm{K}_{\mathrm{c}}$ derivadas por teledetección. Observándose que los valores del $\mathrm{K}_{\mathrm{c}}$ derivados de las imágenes, a lo largo del periodo de desarrollo de los cultivos, reproducen con mayor fidelidad la evolución de éste a lo largo de su ciclo fenológico.

En la figura $3 \mathrm{~A}$ a $3 \mathrm{D}$ están representadas las curvas del $\mathrm{K}_{\mathrm{c}}$ obtenidos por los dos métodos anteriormente citados, FAO y teledetección.

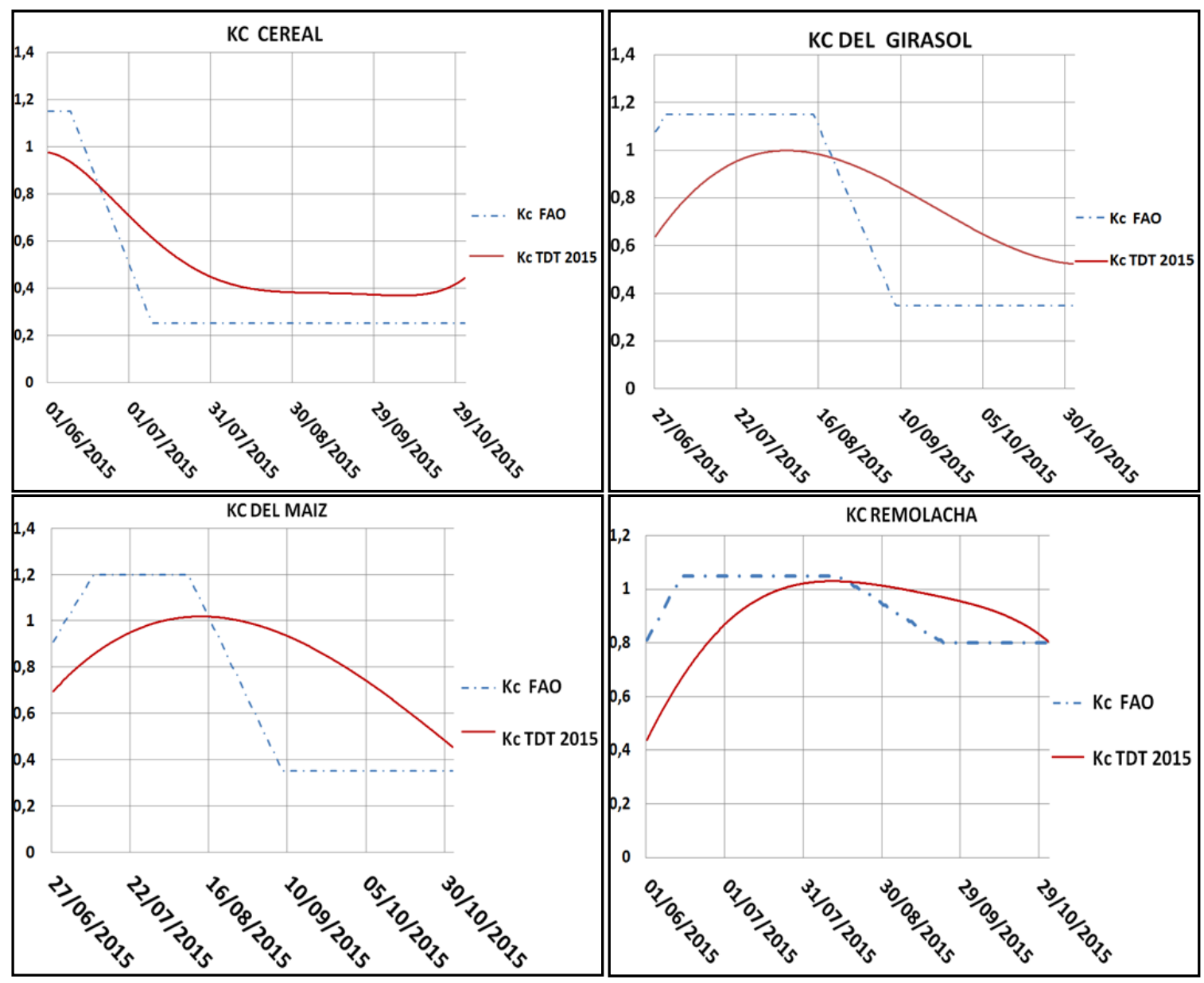

Figura 3: Comparativa de las curvas del $\mathrm{K}_{\mathrm{c}}$ obtenida por teledetección y curva $F A O$ para cereal $(A)$, girasol $(B)$, maíz $(C)$ y remolacha $(D)$.

- Cereal. Los datos suministrados por la comunidad de regantes solo incluyen datos a partir de mediados de julio, con dos poblaciones, una con valores de $\mathrm{K}_{\mathrm{c}}$ muy altos (próximos a 1) y otra con valores muy bajos (próximos a 0,25 ). Los valores de $\mathrm{K}_{\mathrm{c}}$ derivados de las imágenes de satélite presentan una evolución acorde con el ciclo fenológico de los cereales de invierno, presentando valores máximos desde principio de abril a principio de junio, coincidiendo con la fase de máximo desarrollo. Los valores a partir de julio corresponderían al cultivo ya cosechado.

- Cultivos de verano: girasol, maíz y remolacha. La evolución del $\mathrm{K}_{\mathrm{c}}$ derivado de las imágenes de satélite es congruente con su ciclo fenológico y con los valores de $\mathrm{K}_{\mathrm{c}}$ de referencia para las fases de desarrollo y máxima cobertura. Aunque la teledetección 
presenta valores máximos más bajos que la curva FAO, y ligeramente desplazados en el tiempo.

En líneas generales, la evolución del $\mathrm{K}_{\mathrm{c}}$ derivado de las imágenes de satélite es congruente con los valores de $\mathrm{K}_{\mathrm{c}}$ de referencia para las fases de desarrollo y máxima cobertura. En la fase de maduración y recolección, los valores de $\mathrm{K}_{\mathrm{c}}$ derivado de las imágenes reflejan con mayor fidelidad la verdadera evolución del cultivo. Como era de esperar, los mayores desajustes se observan en la fase inicial, cuando no existe una cobertura completa del suelo por el cultivo (limitación del método aplicado).

3.2 Cálculo de las necesidades hídricas a partir de los valores de Kc de teledetección y evaluación de resultados

Se compararon los valores de la Evapotranspiración del cultivo $\left(E T_{c}\right)$ calculados a partir de la $\mathrm{K}_{\mathrm{c}}$ de $\mathrm{FAO}$ con los calculados a partir de la $\mathrm{K}_{\mathrm{c}}$ de teledetección, para los distintos cultivos, aplicando la fórmula de cálculo de la $\mathrm{ET}_{\mathrm{c}}$ :

$$
\mathrm{ET}_{\mathrm{c}}=\mathrm{ET}_{\mathrm{o}}{ }^{*} \mathrm{~K}_{\mathrm{c}}
$$

La comparativa de las $\mathrm{ET}_{\mathrm{c}}$ acumuladas calculadas para los periodos vegetativos de los cultivos se recoge en el siguiente cuadro:

Tabla 4. Comparativa de las $\mathrm{ET}_{\mathrm{c}}$ acumuladas

\begin{tabular}{|c|c|c|c|c|}
\cline { 2 - 5 } \multicolumn{1}{c|}{} & $\begin{array}{c}27 \text { de Junio a } \\
31 \text { de Octubre }\end{array}$ & $\begin{array}{c}1 \text { de Junio a } \\
\text { 31 de Octubre }\end{array}$ & $\begin{array}{c}1 \text { de Junio a } \\
15 \text { de Julio }\end{array}$ & $\begin{array}{c}27 \text { de Junio a } \\
\text { 1os Septiembre }\end{array}$ \\
\hline & Maíz & Remolacha & Cereal & Girasol \\
\hline $\mathrm{ET}_{\mathrm{c}}\left(\mathrm{K}_{\mathrm{c}} \mathrm{FAO}\right) \mathrm{mm}$ & 369 & 586 & 171 & 359 \\
\hline $\mathrm{ET}_{\mathrm{c}}(\mathrm{Kc} \mathrm{tdt}) \mathrm{mm}$ & 391 & 525 & 190 & 340 \\
\hline $\begin{array}{c}\text { Diferencia } \mathrm{ET}_{\mathrm{c}} \\
\mathrm{mm}\end{array}$ & 22 & -61 & 19 & -19 \\
\hline
\end{tabular}

A partir de los datos de $E T_{c}$ y de datos meteorológicos y de campo, se calculan las necesidades brutas de agua por cultivo, a través de la fórmula siguiente:

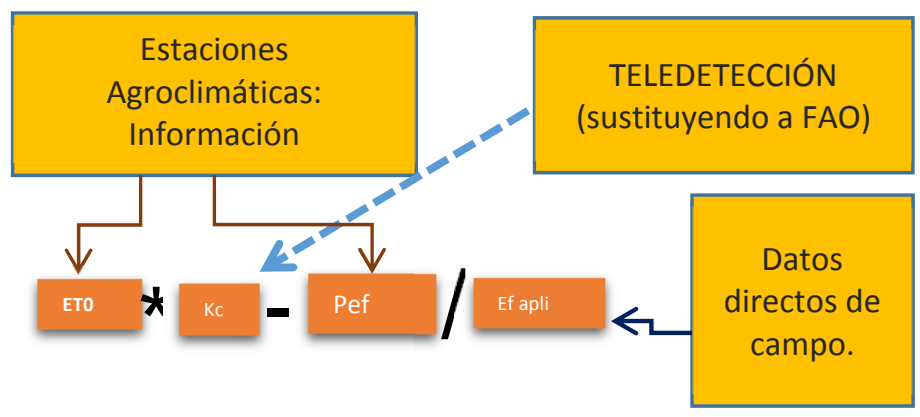

Figura 4: Fórmula de cálculo para las necesidades hídricas brutas y origen de los datos

En las tablas sucesivas se muestran los valores mensuales para cada cultivo estudiado: 
Tabla 5. Cálculo de las necesidades brutas mensuales del maíz (sobre 18 parcelas)

\begin{tabular}{|l|c|c|c|}
\cline { 2 - 4 } \multicolumn{1}{c|}{} & NNHHb FAO $(\mathrm{mm})$ & NNHHb Teledetección $(\mathrm{mm})$ & Diferencia (ahorro) $\mathrm{mm}$ \\
\hline Junio & 26 & 21 & -5 \\
\hline Julio & 146 & 138 & -8 \\
\hline Agosto & 138 & 122 & -16 \\
\hline Septiembre & 49 & 76 & 27 \\
\hline Octubre & 15 & 29 & 14 \\
\hline
\end{tabular}

El cálculo anual es similar por ambos métodos, pero las diferencias más importantes radican en la distribución de las necesidades hídricas mensualmente: menos dotación o riegos más espaciados entre junio y agosto y más dotación o riegos menos espaciados a partir septiembre.

Tabla 6. Cálculo de las necesidades brutas mensuales de la remolacha (sobre 9 parcelas)

\begin{tabular}{|l|c|c|c|}
\cline { 2 - 4 } \multicolumn{1}{c|}{} & NNHHb FAO $(\mathrm{mm})$ & NNHHb Teledetección $(\mathrm{mm})$ & Diferencia (ahorro) $\mathrm{mm}$ \\
\hline Junio & 119 & 85 & -34 \\
\hline Julio & 181 & 165 & -16 \\
\hline Agosto & 143 & 133 & -10 \\
\hline Septiembre & 82 & 96 & 14 \\
\hline Octubre & 39 & 41 & 2 \\
\hline
\end{tabular}

En el caso de la remolacha se necesitaría menos dotación en los meses de verano (junio a agosto) y algo más de dotación o riegos menos espaciados en el mes de septiembre.

Tabla 7. Cálculo de las necesidades brutas mensuales del cereal (sobre 13 parcelas)

\begin{tabular}{|c|c|c|c|}
\cline { 2 - 4 } \multicolumn{1}{c|}{} & NNHHb FAO $(\mathrm{mm})$ & NNHHb Teledetección $(\mathrm{mm})$ & Diferencia (ahorro) $\mathrm{mm}$ \\
\hline Junio & 60 & 62 & 2 \\
\hline Julio & 48 & 49 & 1 \\
\hline
\end{tabular}

En el caso del cereal tanto el cálculo anual como el de distribución mensual son valores muy similares. No obstante, hay que tener en cuenta que los cálculos disponibles son desde junio, que es la fase final del ciclo de cultivo, quedando sin calcular el periodo de máximo desarrollo vegetativo, por tanto se debería hacer el cálculo de fechas anteriores.

Tabla 8. Cálculo de las necesidades brutas mensuales del girasol (sobre 2 parcelas)

\begin{tabular}{|l|c|c|c|}
\cline { 2 - 4 } \multicolumn{1}{c|}{} & NNHHb FAO $(\mathrm{mm})$ & NNHHb Teledetección $(\mathrm{mm})$ & Diferencia (ahorro) $\mathrm{mm}$ \\
\hline Junio & 27 & 20 & -7 \\
\hline Julio & 134 & 111 & -23 \\
\hline Agosto & 139 & 134 & -5 \\
\hline Septiembre & 36 & 67 & 31 \\
\hline Octubre & 16 & 28 & 12 \\
\hline
\end{tabular}

Las cantidades obtenidas en los cálculos de necesidades hídricas anuales son muy similares. La diferencia radica en la distribución de los riegos: habría que aplicar menos dotación en los meses de junio y julio, pero se debe incrementar en septiembre y octubre. 


\section{4) Conclusiones y recomendaciones}

- Los resultados obtenidos hasta la fecha corroboran la hipótesis de partida de que a partir de los datos de teledetección es posible generar unas curvas de $\mathrm{K}_{\mathrm{c}}$ más ajustada que las de FAO para los cultivos principales de la zona: maíz, remolacha, cereal y girasol

- Pese a la diversidad de sensores utilizados, la coherencia y similitud de los valores del $\mathrm{K}_{\mathrm{c}}$, derivados de las imágenes de satélite, muestran la consistencia de los datos de teledetección, fruto de un procesado robusto y fiable.

- La metodología de cálculo de $\mathrm{K}_{\mathrm{c}}$ (Calera et al, 2014) arroja resultados consistentes para los cultivos analizados, aunque sería interesante profundizar en el estudio haciendo un análisis más detallado, con mayor número de parcelas de campo y con datos de primavera para el cereal.

- Las necesidades hídricas calculadas con este coeficiente de cultivo ajustado se pretenden utilizar como información de referencia, de manera que permitan mejorar la eficiencia hídrica, no sólo en la cantidad de agua, sino también en el momento adecuado para regar.

- En el análisis de las necesidades hídricas brutas, en principio no se obtienen diferencias significativas en cuanto a ahorro de agua (salvo en la remolacha) pero sí en cuanto a la distribución mensual de los riegos. Podría considerarse regar con menos frecuencia en los meses de junio a agosto, e incrementarse en septiembre. Esto podría repercutir tanto en un aumento de la productividad como en ahorro energético. Ambos aspectos pendientes de valoración.

\section{5) Bibliografía.}

Allen, R., Pereira, L.S., Raes, D., Smith, M., 1998. Crop evapotranspiration Guidelines for computing crop water requirements - FAO Irrigation and drainage paper 56. FAO, Roma, Italy.

Allen, R.G., 2011. Skin layer evaporation to account for small precipitation events-An enhancement to the FAO-56 evaporation model. Agricultural Water Management 99, 8-18.

Calera, A., Campos, I., Garrido, J., 2014. Determinación de las necesidades de agua y de riego mediante estaciones meteorológicas y series temporales de imágenes multiespectrales. Jornada técnica de innovación en gestión del regadío mediante redes agroclimáticas, teledetección y sistemas de información. CENTER, MAGRAMA.

Calera, A., Garrido, J., 2016. Un uso más eficiente del agua integrando Red SIAR, teledetección y SIG. Proyecto SPIDER-CENTER. CENTER, MAGRAMA.

Torres, E., 2010. El modelo FAO-56 asistido por satélite en la estimación de la evapotranspiración en un cultivo bajo estrés hídrico y suelo desnudo. Caso de estudio: Acuífero Mancha Oriental, España. Tesis Doctoral. Universidad de Castilla-La Mancha.

Wright, J.L., 1982. New Evapotranspiration Crop Coefficients. Journal of the Irrigation and Drainage Division 108, 57-74. 


\title{
UN NUEVO MODELO DE GESTIÓN DEL RIEGO DEL CULTIVO DE LA FRESA EN LA PROVINCIA DE HUELVA
}

\author{
Lozano, D. (1) (P), Ruíz, N. (2), Gavilán, P. (3) \\ ${ }^{1}$ Investigador contratado, IFAPA- Alameda del Obispo, david.lozano@juntadeandalucia.es \\ ${ }^{2}$ Técnico especialista, IFAPA- Alameda del Obispo, natividad.ruiz.baena@juntadeandalucia.es \\ ${ }^{3}$ Investigador titular, IFAPA- Alameda del Obispo, pedrod.gavilan@juntadeandalucia.es
}

\section{Resumen}

La producción de fresas en la provincia de Huelva tiene dos características principales: la generación de riqueza, se crean unos 80.000 puestos de trabajo por campaña, y la localización en una zona ambientalmente sensible, casi el $75 \%$ del total de la producción se sitúa en los alrededores del Parque Nacional de Doñana. Para acometer el reto de la gestión sostenible de los recursos hídricos empleados en la producción de fresas, el IFAPA ha realizado trabajos de experimentación en fincas comerciales durante las campañas 2012/2013, 2013/2014 y 2014/2015. Los trabajos han abordado el cálculo de las necesidades de riego de la fresa, el análisis de la influencia del caudal de la cinta de riego, el cálculo de la duración óptima de los pulsos de riego y la generación de calendarios de riego basados en el pronóstico meteorológico. El objetivo del trabajo fue generar y transferir un modelo de gestión del riego de la fresa que integre en la programación del riego los aspectos agronómicos locales y las características estáticas y dinámicas de los sistemas de riego, incluyendo a su vez un pronóstico de las variables meteorológicas que afectan al cálculo de las necesidades de agua de la fresa.

\begin{abstract}
Strawberry production in the province of Huelva has two main features: the generation of wealth, 80,000 jobs per season, and the location in an environmentally sensitive area, almost $75 \%$ of total production is located around the Doñana National Park. IFAPA has carried out experimental works on commercial farms during the campaign $2012 / 2013,2013 / 2014$ and $2014 / 2015$. The main objective was to address the challenge of sustainable management of water resources used in the production of strawberries. The works are related to calculation of strawberry water requirements, sensitive analysis of the irrigation tape flow, optimal duration of irrigation pulses and generation of irrigation schedules based on meteorological forecasts. The main aim of this study was to develop a management model that integrates into irrigation scheduling local agronomic parameters, static and dynamic characteristics of irrigation systems and a forecast of the meteorological variables that affect the calculation of strawberry water requirements.
\end{abstract}

\section{1- Introducción}

La fresa de Huelva genera mucha riqueza y empleo, pero la producción está localizada en su mayor parte en una zona de alto valor ecológico. El IFAPA, como organismo de I+D+F de la Junta de Andalucía, fue consciente desde hace años de que el futuro del sector fresero pasaba por una gestión sostenible y eficiente de los recursos hídricos empleados en la agricultura. Por ello, en estos últimos cinco años ha dedicado una importante cantidad de recursos humanos y económicos a la generación de conocimiento 
técnico que pueda ser transferido a los regantes para alcanzar una gestión eficiente del agua de riego (Gavilán et al., 2015; Lozano et al., 2016; Martínez-Ferri et al., 2015).

Para regar bien cualquier cultivo es necesario: 1) conocer sus necesidades de agua (cuánto regar), 2) conocer el funcionamiento y las potencialidades del sistema de riego (cómo regar) y 3) realizar una adecuada programación de los riegos (cuándo regar). Por tanto, cualquier modelo de gestión del riego basado en criterios racionales debe considerar estos tres aspectos de forma conjunta. Para calcular las necesidades de agua del cultivo, la metodología más ampliamente aceptada y utilizada es la desarrollada por la FAO (Doorenbos y Pruitt, 1977). Esta metodología permite conocer las necesidades de riego a través del cálculo la evapotranspiración del cultivo $\left(E T_{c}\right)$. La $E T_{c}$ es función de un indicador de la demanda evaporativa de la atmósfera, la evapotranspiración de referencia $\left(E T_{o}\right)$, y de una variable, el coeficiente de cultivo $\left(K_{c}\right)$, que integra el estado de desarrollo de la fresa y el sistema de cultivo. Además, para alcanzar un uso eficiente del agua se necesita un sistema de riego con un alto grado de control y flexibilidad en la aplicación del agua. El riego localizado tiene ambas potencialidades, por lo que, a priori, es el sistema de riego más eficiente. Sin embargo, a pesar de que la fresa en Huelva se riega en su totalidad con sistemas de riego localizado, el rango de aplicación de agua en el entorno del P.N. de Doñana varía entre 4.000 y $15.000 \mathrm{~m}^{3} \mathrm{ha}^{-1}$ (García-Morillo, 2015). El amplio rango de volúmenes de riego aplicado por los agricultores indica que el uso del riego localizado "per se' no es garantía de un uso eficiente del agua. Igualmente advierte de que hay regantes que no utilizan el agua de riego de forma eficiente. Por ello, el objetivo de este trabajo es generar y transferir un modelo de gestión del riego de la fresa de Huelva que integre en la programación del riego los aspectos agronómicos locales, las características estáticas y dinámicas de los sistemas de riego $\mathrm{y}$, a su vez, un pronóstico de las variables meteorológicas que afectan al cálculo de las necesidades de agua de la fresa.

\section{2- Materiales y métodos}

\subsection{Descripción del lugar de los ensayos}

Los ensayos se realizaron en cuatro fincas comerciales de fresa (Fragaria $x$ ananassa Duch.) de la provincia de Huelva: 'Corralizas', 'La Antena', 'Álamo' y 'Cuínes'. Todas ellas localizadas cerca de la Aldea de El Rocío (Almonte, Huelva) (longitud 6²9' Oeste, latitud $37^{\circ} 07^{\prime}$ Norte y 75 m s.n.m.) (Figura 1). El clima de la zona es Csa (clasificación de Köppen-Geiger) con un valor medio de lluvia anual de $467 \mathrm{~mm}$. Los valores medio, máximo y mínimo de temperatura anual son $17.8,36.5$ y $14.1^{\circ} \mathrm{C}$, respectivamente. Los suelos de las cuatro fincas comerciales tienen un alto contenido en arena (Tabla 1).

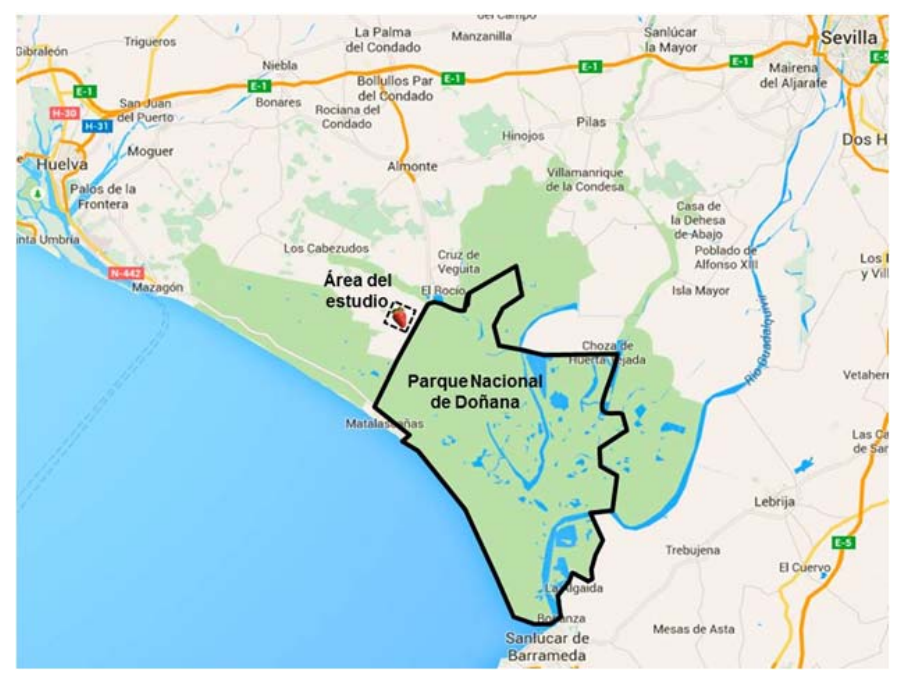

Figura 1. Localización de los ensayos de producción de fresa en el entorno del P.N. de Doñana, Almonte, Huelva. 
Tabla 1. Composición de los suelos en las fincas donde se realizaron los ensayos.

\begin{tabular}{lccc} 
Finca & $\begin{array}{c}\text { Arena } \\
(\%)\end{array}$ & $\begin{array}{c}\text { Arcilla } \\
(\%)\end{array}$ & $\begin{array}{c}\text { Limo } \\
\text { (\%) }\end{array}$ \\
\hline Corralizas & 90 & 10 & 0 \\
La Antena & 92 & 4 & 4 \\
Álamo & 90 & 5 & 5 \\
Cuínes & 92 & 4 & 4 \\
\hline
\end{tabular}

\subsection{Descripción de los ensayos.}

Toda la información referente a los años y las fincas donde se realizaron los ensayos, las variedades empleadas, las fechas de plantación, forzado del cultivo, inicio y fin de cosecha, así como la dimensión de los túneles invernadero, el número de lomos por túnel, la distancia entre lomos y entre plantas y los tratamientos, puede verse en la Tabla 2. Cada ensayo tuvo tres tratamientos y cada tratamiento tuvo cuatro repeticiones. Cada repetición se realizó en un túnel completo, lo que permitió comparar la producción del tratamiento con la producción de la finca. Todos los ensayos tuvieron dos filas de plantas por lomo y camas sobre las que se plantó la fresa de $0.6 \mathrm{~m}$ de base, $0.5 \mathrm{~m}$ en parte alta y $0.5 \mathrm{~m}$ de altura. A excepción del ensayo de cintas de riego, el caudal de la cinta de riego empleada en los ensayos fue de $5 \mathrm{I} \mathrm{h}^{-1} \mathrm{~m}^{-1}$. En todos los ensayos, salvo en el de fertilización (Finca 'Cuínes', 2014/2015), el agricultor decidió sobre todas las tareas agronómicas a realizar a excepción del riego, controlado en todos los ensayos por los autores de este trabajo.

Tabla 2. Características de los ensayos de las campañas 2012/2013, 2013/2014 y 2014/2015.

\begin{tabular}{|c|c|c|c|c|c|c|c|c|c|c|c|c|}
\hline \multirow[b]{2}{*}{ Año } & \multirow[b]{2}{*}{ Variedad } & \multirow[b]{2}{*}{ Finca } & \multicolumn{3}{|c|}{ Fechas de campaña } & \multicolumn{4}{|c|}{ Sistema de cultivo } & \multicolumn{3}{|c|}{ Tratamientos } \\
\hline & & & Plantación & Forzado & $\begin{array}{l}\text { Cosecha } \\
\text { Inicio Final }\end{array}$ & $\begin{array}{l}\text { Túnel } \\
\left(\mathrm{m}^{2}\right)\end{array}$ & $\begin{array}{l}\text { Lomos/ } \\
\text { Túnel }\end{array}$ & $\begin{array}{l}\text { Dist } \\
\text { Lomos } \\
(\mathrm{m})\end{array}$ & $\begin{array}{l}\text { Plantas } \\
(\mathrm{m})\end{array}$ & $\mathrm{T} 1$ & $\mathrm{~T} 2$ & T3 \\
\hline $12 / 13$ & Sabrina & Corralizas & $09 / 10$ & $10 / 11$ & 09/01 06/06 & $70 \times 6.6$ & 6 & 1.1 & 0.25 & $100 \mathrm{ET}_{\mathrm{c}}$ & $1.25 \mathrm{~T} 1$ & $1.5 \mathrm{~T} 1$ \\
\hline $12 / 13$ & Antilla & Antena & $15 / 10$ & $19 / 11$ & $20 / 0112 / 06$ & $51 \times 7.2$ & 6 & 1.2 & 0.25 & $100 \mathrm{ET}_{\mathrm{c}}$ & $1.25 \mathrm{~T} 1$ & $1.5 \mathrm{~T} 1$ \\
\hline $13 / 14$ & Sabrina & Corralizas & $11 / 10$ & $11 / 11$ & 08/01 14/05 & $70 \times 6.6$ & 6 & 1.1 & 0.25 & $5 \min$ & $10 \min$ & $15 \min$ \\
\hline $13 / 14$ & Sabrina & Antena & $12 / 10$ & $09 / 11$ & 16/01 15/05 & $51 \times 7.2$ & 6 & 1.2 & 0.27 & $5 \min$ & $10 \min$ & $15 \min$ \\
\hline $13 / 14$ & Antilla & Álamo & $22 / 10$ & $17 / 11$ & $02 / 0212 / 05$ & $51 \times 6.6$ & 5 & 1.2 & 0.25 & $2.5 \mathrm{l} / \mathrm{h} / \mathrm{m}$ & $3.8 \mathrm{l} / \mathrm{h} / \mathrm{m}$ & $5 \mathrm{l} / \mathrm{h} / \mathrm{m}$ \\
\hline $14 / 15$ & Fortuna & Cuínes & $12 / 10$ & $10 / 11$ & $18 / 1229 / 05$ & $56 \times 7.2$ & 6 & 1.2 & 0.27 & CEfinca & 1.25 T1 & $1.5 \mathrm{~T} 1$ \\
\hline $14 / 15$ & Victory & Álamo & $19 / 10$ & $18 / 11$ & $19 / 1226 / 05$ & $60 \times 6.6$ & 6 & 1.1 & 0.25 & $\begin{array}{c}\text { Gel } \\
60 \mathrm{~kg} / \mathrm{ha}\end{array}$ & $\begin{array}{c}\text { Gel } \\
40 \mathrm{~kg} / \mathrm{ha}\end{array}$ & Sin Gel \\
\hline $14 / 15$ & Victory & Corralizas & $16 / 10$ & $15 / 11$ & $17 / 1227 / 05$ & $70 \times 6.6$ & 6 & 1.1 & 0.25 & $\begin{array}{c}\text { Prono } \\
\text { Semanal }\end{array}$ & $\begin{array}{l}\text { Prono } \\
\text { Diario }\end{array}$ & $0.9 \mathrm{~T} 1$ \\
\hline
\end{tabular}

Campaña 2012/2013

Conocer las necesidades de agua de la fresa en las condiciones de cultivo de Huelva fue el objetivo principal de este primer año de ensayos. Para calcular las necesidades de riego de la fresa es necesario conocer la evapotranspiración del cultivo $\left(E T_{c}\right)$. Para obtener valores reales de $E T_{c}$ se realizaron dos ensayos. La $E T_{c}$ se obtuvo mediante un balance de agua en el suelo. El drenaje se midió usando lisímetros de drenaje. El cálculo de la $E T_{c}$ se realizó por diferencia entre el agua aplicada a través del riego y el agua drenada en los lisímetros. Los cálculos se hicieron con un balance quincenal. Se instaló un lisímetro de $1.4 \times 0.30 \times 0.62 \mathrm{~m}$ por tratamiento. Uno de los ensayos se realizó en la finca 'Corralizas', con la variedad Sabrina, y el otro en la finca 'La Antena', con la variedad Antilla. El primer tratamiento (T1_100ET C $_{\text {) }}$ aplicó una dosis de riego suficiente para satisfacer las necesidades de agua del cultivo. La dosis de riego a aplicar se obtuvo a partir de datos de $E T_{o}$ obtenidos de la Red de Información Agroclimática de Andalucía (Gavilán et al., 2008) y de coeficientes de cultivo tomados de la 
bibliografía existente (Hanson y Bendixen, 2004; Allen et al., 1998). El tratamiento T2_1.25T1 y el tratamiento T3_1.5T1 aplicaron un $25 \%$ y un $50 \%$ más que T1 respectivamente.

\section{Campaña 2013/2014}

Conocer la influencia del sistema y la programación del riego en la producción final de fresa fue el objetivo del segundo año de ensayos. Las características principales del sistema de riego son: el tipo de gotero, el caudal de la cinta de riego, la presión de trabajo, la topografía y el tamaño de la unidad de riego. Por otro lado, la programación del riego en cultivos hortícolas y suelos muy arenosos se ve condicionada en gran medida por la duración del pulso de riego, pues la duración del pulso de riego afecta a la uniformidad de distribución del agua y a la frecuencia de aplicación del riego (Lozano et al., 2014).

Para conocer la influencia del caudal de la cinta de riego en la producción de fresa se realizó un ensayo en la finca 'Álamo' con la variedad Antilla. El ensayo tuvo tres tratamientos con cuatro repeticiones cada uno. Cada tratamiento se regó con una cinta de riego de diferente caudal. El primer tratamiento $\left(T 1 \_2.5 \mathrm{lhm}\right)$ se regó con una cinta de riego de $2.5 \mathrm{I} \mathrm{h}^{-1}$ $\mathrm{m}^{-1}$, mientras que en el segundo (T2_3.81 $\mathrm{hm}$ ) y tercer tratamiento (T3_5lhm) se usaron cintas de 3.8 y $5 \mathrm{I} \mathrm{h}^{-1} \mathrm{~m}^{-1}$, respectivamente.

Para conocer la influencia de la duración del pulso de riego sobre la producción, se plantearon dos ensayos. Los tratamientos T1_5min, T2_10min y T3_15min regaron con pulsos de riego de 5, 10 y 15 minutos respectivamente. Todos los tratamientos aplicaron la misma dosis diaria de riego. La dosis de riego se calculó midiendo la cobertura del cultivo y utilizando la relación entre cobertura y coeficiente de cultivo obtenida el año anterior (Lozano et al., 2016). Las eficiencias de aplicación utilizadas garantizaron que el riego no fuera deficitario.

Además, en la finca 'Álamo' se realizaron evaluaciones de la uniformidad de distribución del agua de riego. La metodología empleada para la realización de la evaluación está descrita en Lozano et al. (2014). El indicador utilizado fue la uniformidad de distribución del menor cuarto,

(Merrian y Keller, 1978):

donde:

$\mathrm{V}_{25 \%}$ : media del volumen recogido en la cuarta parte de los goteros que aplican menos agua media del volumen recogido en todos los goteros evaluados

\section{Campaña 2014/2015}

Durante la campaña 2014/2015 se realizaron dos ensayos de producción para evaluar la programación del riego con pronóstico meteorológico en base semanal. Un ensayo tuvo lugar en la finca 'Álamo' y otro en la finca 'Cuínes'. En la finca 'Álamo' se ensayaron tres tratamientos para probar la efectividad del gel H-3 HIDROMAX@. En los tratamientos T1_Gel60 y T2_Gel40 se aplicó al suelo el gel H-3 HIDROMAX@ en concentraciones de 60 y $40 \mathrm{~kg} \mathrm{ha}^{-1}$ respectivamente. En el tratamiento T3_SinGel no se aplicó gel. En la finca 'Cuínes' se ensayaron tres tratamientos con diferentes dosis de fertilización basadas en conductividad eléctrica (CE). El primer tratamiento tuvo la misma CE que la finca (T1_CEfinca), el segundo tratamiento tuvo un $25 \%$ más CE que la finca (T2_1.25T1) y el tercer tratamiento tuvo un $50 \%$ más CE que la finca (T3_1.5T1).

Igualmente, durante la campaña 2014/2015, se realizó un ensayo de producción de fresa para evaluar el pronóstico meteorológico en base semanal frente a otras opciones de programación del riego. El primer tratamiento tuvo una programación del riego con pronóstico meteorológico en base semanal (T1_Semanal), el segundo tratamiento tuvo una programación del riego con pronóstico meteorológico en base diaria (T2_Diario) y el tercer tratamiento aplico un 90\% del agua programada para T1 (T3_0.9T1). 


\section{Productividad del riego}

La productividad del riego de los veinticuatro tratamientos planificados en los ocho ensayos de producción se evalúo utilizando el siguiente indicador (Pereira et al., 2012):

\section{Resultados y discusión}

\subsection{Campaña 2012/2013}

Los ensayos realizados durante la campaña 2012/2013 permitieron la determinación de las necesidades de riego de la fresa de Huelva con mayor precisión. En primer lugar, se probó con éxito la metodología para el cálculo de la $E T_{0}$ bajo plástico desarrollada por Fernández et al. (2010) para los invernaderos de Almería. En segundo lugar, se obtuvieron coeficientes de cultivo adaptados a las condiciones de Huelva, con valores máximos, 1.1, notablemente superiores a los descritos en la bibliografía a fecha del ensayo, 0.7 (Hanson y Bendixen, 2004), 0.85 (Allen et al., 1998). Así mismo, se calculó la $E T_{c}$ para las variedades Sabrina, $441 \mathrm{~mm}$, y Antilla, $352 \mathrm{~mm}$, en una campaña de 240 días utilizando lisímetros de drenaje. Por último, se estableció una relación entre el $K_{c}$ y el porcentaje de cobertura que permite el cálculo del coeficiente de cultivo en futuras campañas independientemente de la fecha de siembra o la variedad cultivada (Figura 2).

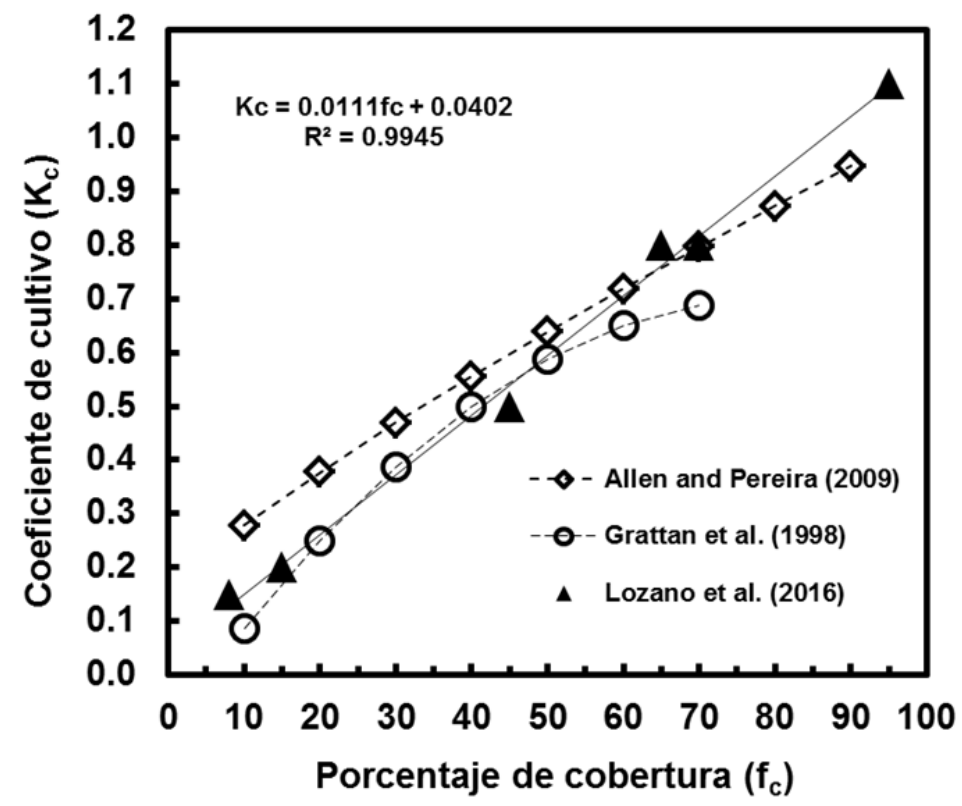

Figura 2. Relación entre el coeficiente de cultivo $\left(K_{c}\right)$ y el porcentaje de cobertura $\left(f_{c}\right)$ obtenido por Lozano et al. (2016), Allen y Pereira (2009) y Grattan et al. (1998).

Los resultados de los ensayos indican que el exceso de riego aplicado en los tratamientos T2_1.25T1 y T3_1.5T1 no tuvo ningún beneficio en términos de aumento de la producción (Figura 3a,b). De hecho, las producciones de todos los tratamientos de la campaña 2012/2013 alcanzaron el potencial de producción de la finca. La variedad Sabrina en la finca 'Corralizas' alcanzó producciones de $78 \mathrm{t} \mathrm{ha}^{-1}$ (Figura 3a). La variedad Antilla en la finca 'La Antena' alcanzó producciones de $50 \mathrm{t} \mathrm{ha}^{-1}$ (Figura 3b). Las diferencias de producción entre los dos ensayos fueron consecuencia, principalmente, de la diferente variedad empleada. Aunque la cosecha comenzó a mediados de enero, la duración de la campaña fue de 240 días (Tabla 2). Esta mayor duración hizo que los valores de producción máximos de Sabrina y Antilla se alcanzaran en la campaña 2012/2013. 

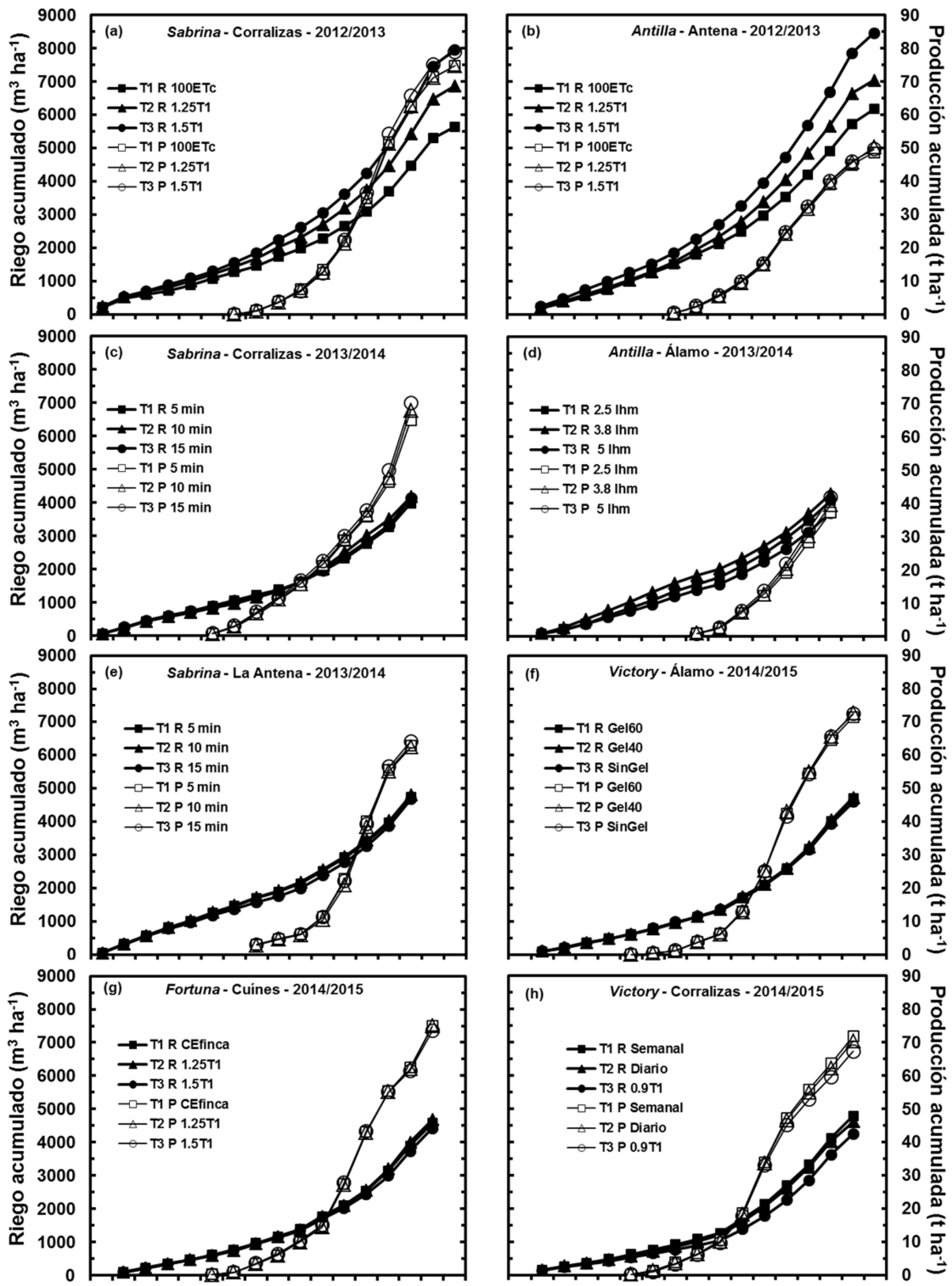

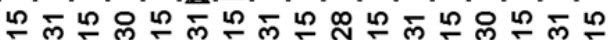

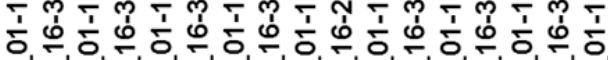

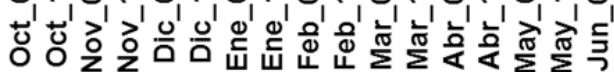

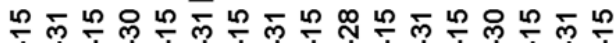

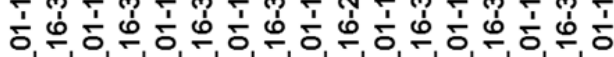

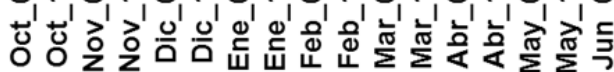

Figura 3. Riego $(R)$ y producción $(P)$ en base quincenal de los ocho ensayos realizados durante las campañas 2012/2013 (a,b), 2013/2014 (c,d,e) y 2014/2015 (f,g,h) 


\subsection{Campaña 2013/2014}

Los ensayos de producción de la campaña 2013/2014 se caracterizaron por emplear menores dosis de riego que en 2012/2013. Aunque la duración de la campaña 2013/2014 fue sensiblemente menor a la 2012/2013 (Tabla 2), la menor dosis de riego empleada en todos los tratamientos (Figuras 3c,d,e), se debió fundamentalmente a una mejora en la programación del riego fruto del conocimiento adquirido durante la campaña anterior. Sin embargo, estas menores dosis de riego alcanzaron los valores de producción potencial de las fincas en la campaña 2013/2014. La variedad Sabrina en la finca 'Corralizas' alcanzó producciones de $70 \mathrm{t}$ $\mathrm{ha}^{-1}$ (Figura 3c). La variedad Antilla en la finca 'Alamo' alcanzó producciones de $41 \mathrm{t} \mathrm{ha}^{-1}$ (Figura 3d). La variedad Sabrina en 'La Antena' alcanzó producciones de 64 t ha ${ }^{-1}$ (Figura 3e). Igualmente, las diferencias de producciones entre ensayos se debieron a las diferentes variedades y densidades de plantación (Tabla 2). Sabrina tuvo en ambas fincas producciones en torno a los $1000 \mathrm{~g}$ planta'. Sin embargo, la menor densidad de plantación en la finca 'La Antena' respecto a la finca 'Corralizas', hizo que en términos de producción por superficie plantada se alcanzarán mayores producciones en la finca 'Corralizas'.

Por otro lado, los ensayos realizados durante la campaña 2013/2014 permitieron determinar la influencia de la duración del pulso del riego y del caudal de las cintas de riego sobre la producción de fresas. La duración del pulso de riego óptimo en las condiciones de producción de Huelva está condicionada por los diferentes valores de uniformidad de distribución del agua de riego. A igualdad del resto de factores (presión, tamaño de la unidad de riego, topografía), cada cinta de riego tiene asociada una uniformidad de distribución del agua en función de la duración del pulso de riego. Esto es debido, fundamentalmente, a la influencia de los tiempos de llenado y vaciado de las tuberías. A menor duración del pulso de riego menor es la uniformidad de distribución, tal y como se ve en la Figura 4.

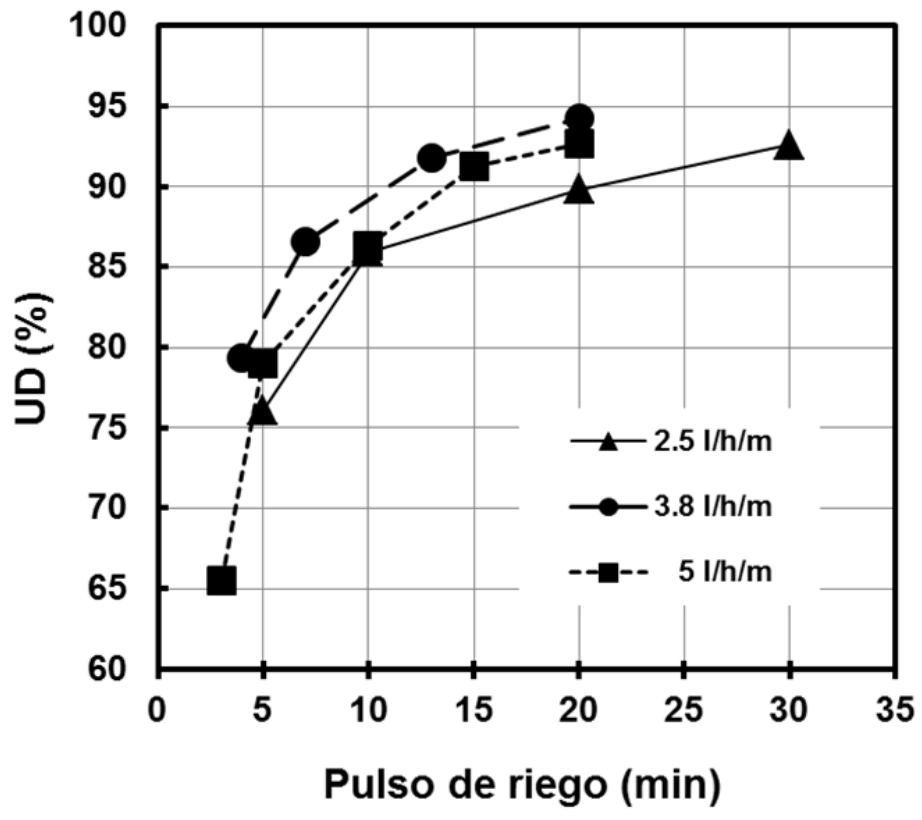

Figura 4. Uniformidad de distribución, UD (\%), en función de la duración del pulso de riego (min) para cintas de riego con caudales de $2.5,3.8$ y $5 \mathrm{I} \mathrm{h}^{-1} \mathrm{~m}^{-1}$

La evaluación de la UD en el ensayo de la variedad Antilla en la finca 'Álamo' durante campaña 2013/2014, ha permitido generar una herramienta de evaluación de la duración óptima del pulso del riego. La UD para un sistema de riego localizado se considera excelente si es superior al $95 \%$ y buena si está en el rango del $85 \%$ al $95 \%$, no siendo aceptables valores inferiores al $85 \%$. En todos los casos, un aumento del tiempo de riego supuso un incremento de la UD (Figura 4). Un tiempo de riego igual o superior a 10 minutos 
fue el umbral mínimo requerido para los tres tipos de cintas (UD > 85\%). Valores de UD superiores al $90 \%$ se obtuvieron cuando la duración mínima de los riegos para las cintas de $5,3.8$ y $2.5 \mathrm{I} \mathrm{h}^{-1} \mathrm{~m}^{-1}$ fue de 15,13 y 20 minutos respectivamente. Para tiempos de riego inferiores a 5 minutos, la UD descendió notablemente. A la vista de los resultados de la Figura 4, no parece razonable regar con pulsos de riego inferiores a 10 minutos, siendo recomendable una duración del pulso del riego en torno a 15 minutos. Una mayor duración del pulso de riego tiene poca o nula ventaja en términos de UD para cualquier tipo de cinta de riego y, sin embargo, aumenta notablemente el riesgo de drenaje de agua y fertilizante, especialmente en suelos arenosos como los de las fincas donde se realizaron los ensayos (Tabla 1).

Los valores medios de producción de los dos ensayos con tratamientos de diferente duración del pulso del riego, parecen confirmar la idoneidad del pulso de 15 minutos frente a menores duraciones. El ensayo de la variedad Sabrina en la finca 'Corralizas' tuvo pérdidas de producción, respecto al riego de 15 minutos, del $7 \%$ y $3 \%$ para los riegos de pulsos con duración de 5 y 10 minutos (Figura 3c). El ensayo de la variedad Sabrina en la finca 'La Antena' tuvo pérdidas de producción, respecto al riego de 15 minutos, del $2 \%$ y $3 \%$ para los riegos de pulsos de riego de 5 y 10 minutos respectivamente (Figura 3e). Las pérdidas de producción corresponden a valores medios obtenidos por tratamiento.

El ensayo de producción con cintas de riego de diferente caudal parece confirmar que la cinta de $5 \mathrm{I} \mathrm{h}^{-1} \mathrm{~m}^{-1}$, la más usada en Huelva, es la mejor opción, al menos, en suelos muy arenosos. El ensayo con cintas de diferente caudal se llevó a cabo con la variedad Antilla en la finca 'Álamo'. Los volúmenes suministrados a cada tratamiento no fueron todo lo similares que hubiéramos deseado (Figura $3 \mathrm{~d}$ ). El tratamiento que menos agua recibió fue el de la cinta de $5 \mathrm{I} \mathrm{h}^{-1} \mathrm{~m}^{-1}$. Sin embargo, fue este tratamiento el que alcanzó un mayor valor de producción final media (Figura 3d). El incremento en producción media respecto al tratamiento regado con cintas de $2.5 \mathrm{I} \mathrm{h}^{-1} \mathrm{~m}^{-1}$ fue de un $11 \%$, mientras que respecto al regado con la cinta de $3.8 \mathrm{I} \mathrm{h}^{-1} \mathrm{~m}^{-1}$ fue de un $5 \%$. Aunque en este trabajo no se presenta un análisis estadístico de significación, un descenso en la producción de más de un $10 \%$ habiendo aplicado una mayor dosis de riego, parece desaconsejar el uso de este tipo de cintas en, al menos, suelos muy arenosos, como es el caso de la finca 'Álamo' (Tabla 1).

\subsection{Campaña 2014/2015}

En esta campaña el objetivo principal fue validar un nuevo modelo de gestión del agua de riego de la fresa en la provincia de Huelva. Al conocimiento adquirido sobre el desarrollo de la fresa (Lozano et al., 2016) y el comportamiento del sistema de riego en función de la duración del pulso del riego, se le sumó en esta campaña un método de pronóstico meteorológico de los valores de $E T_{o}$ basado en los trabajos de Gavilán et al. (2015). Los datos necesarios para la realización del pronóstico meteorológico de $E T_{o}$ se obtuvieron de la página web de la AEMET (http://www.aemet.es).

Los tres ensayos de producción de la campaña 2014/2015 validaron la programación del riego basada en este nuevo modelo de gestión. Los dos ensayos que utilizaron la programación del riego con pronóstico meteorológico en base semanal, alcanzaron los valores potenciales de producción de la finca en la campaña 2014/2015. La variedad Victory en la finca 'Álamo' alcanzó producciones de $72 \mathrm{t} \mathrm{ha}^{-1}$ (Figura 3f). La variedad Fortuna en la finca 'Cuínes' alcanzó producciones de $75 \mathrm{t} \mathrm{ha}^{-1}$ (Figura $3 \mathrm{~g}$ ). En el ensayo de la variedad Victory se demostró que el gel H-3 HIDROMAX@, con supuestas propiedades de aumento de la capacidad de retención de la humedad en el suelo, no tuvo efecto alguno sobre la producción de fresas a dosis de riego de $4.500 \mathrm{~m}^{3} \mathrm{ha}^{-1}$ (Figura 3f). Igualmente, en el ensayo con la variedad Fortuna, el incremento de la dosis de fertilizante no tuvo ningún efecto sobre la producción (Figura 3g).

Finalmente, el ensayo de la variedad Victory en la finca 'Corralizas' mostró varios resultados interesantes. En primer lugar, el riego aplicado en el tratamiento que usó el pronóstico meteorológico en base semanal (T1_Semanal) fue superior en $150 \mathrm{~m}^{3} \mathrm{ha}^{-1}$ (un $3.5 \%$ ) al riego aplicado en el tratamiento con pronóstico meteorológico en base diaria 
(T2_Diario), teniendo ambos producciones similares en torno a las $70 \mathrm{t} \mathrm{ha}^{-1}$ (Figura $3 \mathrm{~h}$ ). Por tanto, para su aplicación en finca, la mayor dificultad en la programación y aplicación del agua de riego con pronóstico meteorológico en base diaria, parece no compensar el volumen de ahorro de agua. En segundo lugar, mostró el buen ajuste de los parámetros del modelo de programación del riego, pues el tratamiento deficitario que aplicó un $90 \%$ de la dosis de riego del tratamiento T1_Semanal (T3_0.9T1), sufrió una pérdida de producción del 6\% respecto a dicho tratamiento (Figura 3h). Esta caída en el rendimiento demuestra que el riesgo de incurrir en pérdidas de producción cuando disminuimos la dosis de riego por debajo de los cálculos realizados con el nuevo modelo de gestión es alto.

\subsection{Evolución del agua de riego aplicada}

Los volúmenes de riego aplicados en los ensayos se han ido ajustando a las necesidades reales de agua de la fresa a lo largo de los tres años de ensayos. Bien es verdad que el valor final del volumen de riego aplicado está condicionado en buena parte por la duración de la campaña de riego. No es igual terminar la campaña el 15 de mayo que el 15 de junio, pudiendo estos 30 días significar un incremento del riego de unos $1500 \mathrm{~m}^{3} \mathrm{ha}^{-1}$. Sin embargo, un indicador certero de esta evolución lo podemos encontrar en el riego aplicado hasta mediados de febrero. Hasta esa fecha, las necesidades del cultivo son bajas y muy parecidas, independientemente de la campaña y de la variedad de fresa. A fecha 15 de febrero, en la campaña 2012/2013 el agua aplicada en los ensayos fue de 1733 y $1955 \mathrm{~m}^{3}$ ha ${ }^{1}$, en la campaña 2013/2014 el agua aplicada en los ensayos fue de 1363, 1751 y $1825 \mathrm{~m}^{3}$ ha $^{-1}$ y en la campaña $2014 / 2015$, con el modelo de programación ajustado en todos sus parámetros, el riego aplicado a fecha 15 de febrero fue de 888,1131 y $1141 \mathrm{~m}^{3} \mathrm{ha}^{-1}$, lo que refleja una notable evolución en términos de ahorro del agua de riego aplicada.

Otro indicador que muestra la evolución de la gestión del riego hacia un uso más eficiente del agua es la productividad del riego. El valor de productividad del riego se ha incrementado campaña a campaña independientemente de la variedad de fresa, si bien Antilla tiene un menor potencial productivo que Sabrina, Fortuna y Victory (Figura 5).

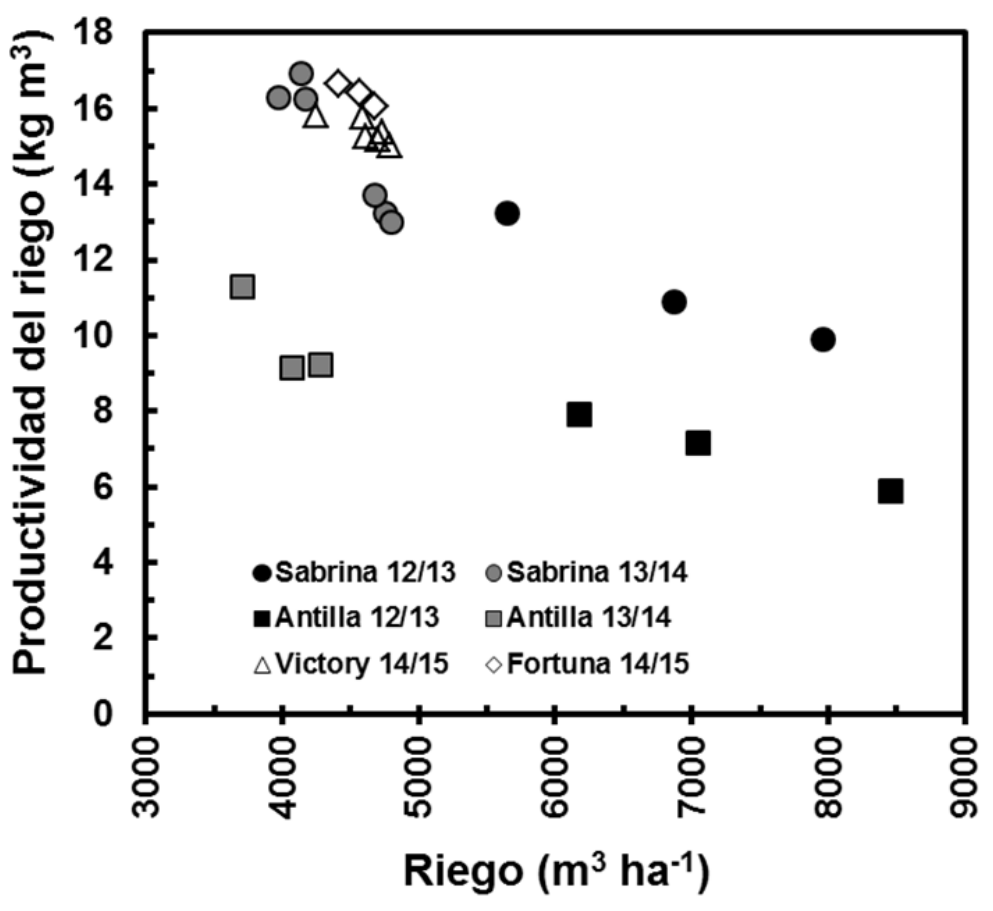

Figura 5. Productividad del riego $\left(\mathrm{kg} \mathrm{m}^{-3}\right)$ en las campañas 2012/2013, 2013/2014 y 2014/2015 en las variedades de fresa Sabrina, Antilla, Victory y Fortuna. 


\section{Conclusiones}

Los ensayos de producción del IFAPA en fincas comerciales han permitido desarrollar un nuevo modelo de gestión del riego de la fresa en la provincia de Huelva. Estos ensayos de producción han permitido conocer los valores de los coeficientes de cultivo de la fresa adaptados a las condiciones de Huelva, proponiendo una relación entre el grado de cobertura del cultivo y el valor del coeficiente de cultivo. Igualmente, la evaluación de la uniformidad de distribución del agua de riego en unidades de riego de fincas comerciales, así como la posterior validación de su efecto en ensayos de producción, ha permitido recomendar duraciones de pulso de riego en torno a 15 minutos. El ensayo de cintas de riego con distintos caudales parece confirmar que la elección mayoritaria de los agricultores, cintas de $5 \mathrm{I} \mathrm{h}^{-1} \mathrm{~m}^{-1}$ es acertada. Los ensayos de producción de la última campaña, 2014/2015, han descartado tanto la influencia del Gel H-3 HIDROMAX@ en el aumento de la producción de fresas, como la necesidad de aumentar la concentración de nutrientes en el fertirriego con respecto a lo tradicionalmente aportado por los agricultores de la zona. Finalmente, estos trabajos han incluido en la programación del riego todo el conocimiento generado en las dos campañas anteriores y, además, han validado un modelo de pronóstico de la evapotranspiración de referencia para el cálculo de las necesidades de riego de la fresa. EI IFAPA realiza actualmente labores de transferencia del conocimiento generado. Igualmente se encuentra en fase de experimentación de este nuevo modelo de gestión del riego a escala de finca comercial en varias explotaciones de la provincia de Huelva.

\section{Agradecimientos}

Estos trabajos han sido financiados por los proyectos TRANSFORMA PP.TRA.TRA2010.1 (Sistema de Asistencia al Regante), PP.TRA.TRA2013.1 (CONECTASAR), cofinanciados con fondos FEDER y por el proyecto P09-RNM5069 financiado por la Consejería de Innovación, Ciencia y Empresa de la Junta de Andalucía. Los autores agradecen la colaboración de las empresas Frutas Borja SL y Surexport Compañía Agraria SL.

\section{Bibliografía}

Allen, R. G., Pereira, L. S., Raes, D., Smith, M. (1998). Crop evapotranspirationGuidelines for computing crop water requirements. FAO Irrigation and drainage paper 56. FAO, Rome, Italy. 300(9), D05109.

Allen, R.G., Pereira, L.S. (2009). Estimating crop coefficients from fraction of groundcover and height. Irrigation Science, 28, 17-34

Doorenbos, J., Pruitt, W.O. (1977). Guidelines for predicting crop water requirements. FAO Irrigation and drainage paper 24. FAO, Rome, Italy, Hsiao. TC, 519-570.

Fernández, M.D., Bonachela, S., Orgaz, F., Thompson, R., López, J.C., Granados, M.R.,Gallardo, M., Fereres, E. (2010). Measurement and estimation of plasticgreenhouse reference evapotranspiration in a Mediterranean climate. Irrigation Science, 28, 497-509.

García-Morillo, J., Martín, M., Camacho, E., Díaz, J. R., Montesinos, P. (2015). Toward precision irrigation for intensive strawberry cultivation. Agricultural Water Management, 151, 43-51.

Gavilán, P., Estévez, J., Berengena, J. (2008). Comparison of standardized reference evapotranspiration equations in Southern Spain. Journal of Irrigation and Drainage Engineering, 134(1), 1-12.

Gavilán, P., Ruiz, N., Lozano, D. (2015). Daily forecasting of reference and strawberry crop evapotranspiration in greenhouses in a Mediterranean climate based on solar radiation estimates. Agricultural Water Management, 159, 307-317.

Grattan, S.R., Bowers, W., Dong, A., Snyder, R.L., Carrol, J.J., George, W. (1998). New crop coefficients estimate water use of vegetables row crops. California Agriculture, 52, 16-21. 
Hanson, B., Bendixen, W. (2004). Drip irrigation evaluated in Santa Maria Valley strawberries. California Agriculture, 58, 48-53.

Lozano, D., Ruiz, N., Gavilán, P. (2016). Consumptive water use and irrigation performance of strawberries. Agricultural Water Management, 169, 44-51.

Lozano, D., Ruiz, N., Gavilán, P. (2014). Evaluación en campo de cintas de riego por goteo de diferente caudal en un cultivo de fresa. Agricultura, 978, 778-781.

Martínez-Ferri, E., Soria, C., Ariza, M.T., Medina, J.J., Miranda, L., Domínguez, P., Muriel, J.L. (2015). Water relations, growth and physiological response of seven strawberry cultivars (Fragaria $\times$ ananassa Duch.) to different water availability. Agricultural Water Management, 164, 73-82.

Merriam, J.L, Keller, J. (1978) Farm Irrigation System Evaluation: A Guide to Management. Dept. Agricultural and Irrigation Engineering. Utah St. University, Logan, Utah.

Pereira, L. S., Cordery, I., lacovides, I. (2012). Improved indicators of water use performance and productivity for sustainable water conservation and saving. Agricultural Water Management, 108, 39-51. 
A-11

\title{
TRANSPIRACIÓN NOCTURNA EN VID
}

\author{
Montoro, A. ${ }^{(1)}$; López-Urrea, R. ${ }^{(2)}$; Mañas, F. ${ }^{(3)}$; Martínez, L. ${ }^{(4)}$; Sánchez, J.M. ${ }^{(5)}$
}

1 Investigadora, ITAP, Polígono Campollano, Avda. 2a -42 B, 02007 Albacete. meli.itap@dipualba.es

2 Director, ITAP-FUNDESCAM, Polígono Campollano, Avda. 2a -42 B, 02007 Albacete. rlu.itap@dipualba.es

${ }^{3}$ Técnico, ITAP, Polígono Campollano, Avda. 2a -42 B, 02007 Albacete.fmj.itap@dipualba.es 4 Técnica, FUNDESCAM, Polígono Campollano, Avda. 2a -42 B, 02007 Albacete. Imm.itap@dipualba.es

5 Profesor, UCLM, Dpto. Física Aplicada, E.U. Politécnica de Cuenca, 16071 Cuenca, juanmanuel.sanchez@uclm.es

\section{Resumen}

Se presentan las medidas de transpiración media cada quince minutos, de la vid (Vitis vinifera cv. Tempranillo), en tres periodos fenológicos del cultivo: cerrado de racimo, envero y maduración. El estudio se realizó en dos plantas de 16 años de edad, a un marco de plantación de $3 \mathrm{~m} \times 1,5 \mathrm{~m}$, regadas mediante goteo y plantadas en un lisímetro de pesada continua monolítico de $9 \mathrm{~m}^{2}$ de superficie. Con la finalidad de poder medir la transpiración, la superficie del lisímetro fue cubierta con una lona impermeable, para evitar la pérdida de agua por evaporación, dejándose únicamente al aire libre el cultivo; de esta manera, las medidas registradas de pérdida de peso se debieron únicamente al efecto de la transpiración. Los resultados indicaron transpiración antes y después de la salida del sol, oscilando los valores de un $7 \%$ a un $16 \%$, con respecto a la transpiración total del día.

\section{1- Introducción y objetivos}

La transpiración ( $\mathrm{T}$ ) determina el estado hídrico de la planta. Este proceso comprende la evaporación del agua desde las células superficiales en el interior de los espacios intercelulares y su difusión fuera del tejido vegetal. Esta difusión la realizan principalmente a través de los estomas, los cuales se abren para captar $\mathrm{CO}_{2}$ y en ese proceso se produce la pérdida de vapor de agua, debido en parte a su menor peso molecular ( $18 \mathrm{~g} / \mathrm{mol}$ de la molécula de agua, frente a $44 \mathrm{~g} / \mathrm{mol}$ del anhídrido carbónico) y en gran medida al fuerte gradiente de diferencia de presión de vapor (DPV) entre el aire y la hoja. Por tanto, los estomas ejercen el mayor control a corto plazo en las relaciones hídricas de una planta (Squeo y Leon, 2007).

La conductancia estomática y la $\mathrm{T}$ se ven afectadas por los factores externos medioambientales que determinan la demanda evaporativa de la atmósfera, entre los que destacan la temperatura, radiación solar, velocidad de viento y humedad relativa del aire. Junto a estos factores, el contenido de humedad del suelo y su mayor o menor facilidad para ponerla a disposición de la planta son determinantes en el proceso de T. En tercer lugar, un complejo y gran número de variables biológicas intervendrán en el proceso de la $\mathrm{T}$ : respuestas hormonales a nivel radicular, señales de conductividad hidráulica del xilema (Sperry et al., 1998) y control estomático. Por último, todo lo referente a la arquitectura de la planta (altura del cultivo, cantidad y estructura foliar), determinará el proceso transpirativo.

Los mecanismos que subyacen en la apertura estomática y por tanto en la $\mathrm{T}$, no están totalmente aclarados, pues aunque usualmente la apertura de los estomas ocurre en presencia de luz, Sharkey y Raschke (1981) demostraron que a niveles bajos de radiación, 
la concentración de $\mathrm{CO}_{2}$ sería el principal factor regulador de la apertura estomática. Actualmente hay una controversia acerca de la apertura estomática nocturna y por tanto de la transpiración durante la noche en plantas C3 y C4.

El objetivo de este trabajo fue medir la transpiración diurna y nocturna en el cultivo de la vid, utilizando un lisímetro de pesada continua.

\section{2- Materiales y métodos}

El estudio se realizó en 2015, en la finca experimental "Las Tiesas" (Albacete, España), cuyas coordenadas geográficas son: $2^{\circ} 5^{\prime}$ longitud Oeste, $39^{\circ} 3^{\prime}$ latitud Norte, y $695 \mathrm{~m}$ sobre el nivel del mar. Las medidas se llevaron a cabo en vid (Vitis vinifera L., cv. Tempranillo), en dos cepas de 16 años de antigüedad plantadas en un lisímetro monolítico de pesada continua conducidas en espaldera, poda doble cordón y marco de plantación $3 \mathrm{x}$ $1,5 \mathrm{~m}$. El riego se aplicó por goteo, mediante una línea portagoteros con goteros autocompensantes de $4 \mathrm{l} / \mathrm{h}$ y 2 goteros por planta (López-Urrea et al., 2012) y de día. Las dimensiones del recipiente del lisímetro son de $3 \times 3 \mathrm{~m}$ de lado y $1,7 \mathrm{~m}$ de profundidad, conteniendo el cultivo en las mismas condiciones de desarrollo que el resto de la parcela de protección para que los datos sean representativos. El suelo del lisímetro se cubrió con una lona impermeable, con la finalidad de evitar el proceso evaporativo y poder medir directamente la $\mathrm{T}$ del cultivo cada 15 minutos. La T se calculó como la diferencia de las pérdidas de masa consecutivas registradas del lisímetro y repartidas entre toda la superficie del mismo $\left(9 \mathrm{~m}^{2}\right)$.

Con la finalidad de parametrizar el cultivo, se realizaron medidas a nivel de planta,

éstas fueron la conductancia estomática $\left(g_{s}\right)$ y el potencial hídrico de hoja $\left(\Psi_{1}\right)$. Estas medidas se hicieron sobre hojas adultas elegidas del tercio medio de los pámpanos y a las 12 horas solares, la primera de ellas en las plantas del lisímetro y la segunda en vides de la parcela de protección, con la finalidad de no alterar las plantas del lisímetro, al ser el método de medida destructivo. La $\mathrm{g}_{\mathrm{s}}$ se midió con un porómetro modelo SC-1 (Decagon Devices Inc., Pullman, WA, USA) y el $\Psi_{1}$, con una cámara Scholander (PMS Instrument Company, Albany, Oregon, USA).

El desarrollo vegetativo del cultivo nos lo determinó el porcentaje de fracción de cubierta vegetal verde $\left(f_{c}\right)$. Para ello se instaló una cámara de vídeo en una estructura metálica de 4 metros de alta, anclada en los laterales exteriores del lisímetro. Se tomaron fotogramas diarios y posteriormente se clasificaron utilizando la técnica del algoritmo de máxima probabilidad con ayuda del programa informático $E N V I \circledast$, obteniendo el porcentaje de cubierta vegetal verde y del suelo (Montoro, 2008).

El contenido de humedad del suelo fue medido de manera continua a 10, 40, 70 y $100 \mathrm{~cm}$ mediante sondas FDR (Frecuence Domain Reflectometry) (EnviroSCANTM, Sentek Pty Ltd., South Australia).

Las medidas atmosféricas se midieron en una estación meteorológica con medias de quince minutos, sincronizados estos con el reloj del lisímetro. Las medidas fueron de radiación solar (sensor piranómetro modelo CM14, Kipp \& Zonen Delft, Holland), velocidad del viento (anemómetro modelo A100R, Vector Instruments Ltd., UK), temperatura y humedad del aire (sensor PRT 100 Ohm e higrómetro C-80, respectivamente, ambas del modelo MP100, Campbell Scientific Instrument, Logan, UT, USA). La evapotranspiración de referencia $\left(\mathrm{ET}_{\mathrm{o}}\right.$ ) se calculó utilizando la ecuación de Penman-Monteith FAO56 (P-M FAO56) (Allen et al., 1998).

\section{3- Resultados y discusión}

La tabla 1 muestra los valores de evapotranspiración de referencia $\left(E T_{0}\right)$, riego aplicado y transpiración diurna y nocturna en los días que el lisímetro estuvo tapado con una lona impermeable, durante los estados fenológicos de cierre del racimo, envero y maduración, cuya fracción de cubierta vegetal verde era de 0.32 . En todos los días 
analizados se registró la T nocturna, oscilando ésta desde un $7 \%$ a un $16 \%$ del total diario, siendo en la mayoría de los días más elevada si ha venido seguida de horas de luz. Todo ello con independencia de la $\mathrm{ET}_{\text {o }}$ diaria registrada. Estos resultados están en la línea con los encontrados por otros autores recientemente (Caird et al., 2007 a, b; Novick et al., 2009; Escalona et al., 2013), viéndose comprometida la eficiencia del uso del agua en determinadas condiciones, en las que se favorecería una apertura estomática sin fotosíntesis asociada.

Tabla 1. Estado fenológico, fracción de cubierta vegetal verde, evapotranspiración de referencia $\left(E_{0}\right)$, riego aplicado y transpiración diurna y nocturna en los días que el lisímetro estuvo tapado con una lona impermeable.

\begin{tabular}{|c|c|c|c|c|c|c|c|c|c|}
\hline \multirow[t]{2}{*}{ Fecha } & \multirow{2}{*}{$\begin{array}{c}\text { Estado } \\
\text { fenológico }\end{array}$} & \multirow[t]{2}{*}{ fc } & \multirow{2}{*}{$\begin{array}{l}\text { ETo } \\
\text { (mm) }\end{array}$} & \multirow{2}{*}{$\begin{array}{l}\text { Riego } \\
(\mathrm{mm})\end{array}$} & \multirow{2}{*}{$\begin{array}{l}T \text { total } \\
(\mathrm{mm})\end{array}$} & \multicolumn{3}{|c|}{ T total al día (\%) } & \multirow{2}{*}{$\begin{array}{c}\text { T total } \\
\text { noche } \\
(\%)\end{array}$} \\
\hline & & & & & & noche & día & noche & \\
\hline 16-jul. & \multirow{2}{*}{$\begin{array}{c}\text { Cierre del } \\
\text { racimo }\end{array}$} & \multirow{2}{*}{0.32} & 8.72 & 4.68 & 2.34 & 2.6 & 92.7 & 4.7 & 7.3 \\
\hline 17-jul. & & & 8.78 & & 2.74 & 6.2 & 87.6 & 6.2 & 12.4 \\
\hline 30-jul. & \multirow{2}{*}{ Envero } & \multirow{2}{*}{0.32} & 7.35 & 5.16 & 1.83 & 1.1 & 84.1 & 14.8 & 15.9 \\
\hline 31-jul. & & & 9.14 & & 2.07 & 1.9 & 91.8 & 6.3 & 8.2 \\
\hline 13-ago. & \multirow{6}{*}{ Maduración } & \multirow{6}{*}{0.32} & 8.92 & 5.34 & 2.25 & 4.5 & 89.2 & 6.3 & 10.8 \\
\hline 14-ago. & & & 6.17 & & 2.11 & 6.2 & 87.2 & 6.6 & 12.8 \\
\hline 15-ago. & & & 5.79 & 5.74 & 1.94 & 2.1 & 88.1 & 9.8 & 11.9 \\
\hline 16-ago. & & & 4.81 & & 2.11 & 0.9 & 89.1 & 10.0 & 10.9 \\
\hline 17-ago. & & & 6.26 & 5.15 & 1.69 & 3.6 & 84.6 & 11.8 & 15.4 \\
\hline 18-ago. & & & 6.55 & & 2.97 & 1.7 & 89.2 & 9.1 & 10.8 \\
\hline
\end{tabular}

A modo de ejemplo se representa en la Figura 1 la evolución de los registros tomados cada 15 minutos del peso del lisímetro, así como la evolución de la transpiración calculada con dichos pesos, en uno de los días que estuvo tapado. Se observa el descenso continuo del peso, excepto de 8:15 a 8:45 (hora solar) en el que faltan 3 registros de datos por realizarse medidas en las plantas del lisímetro en ese intervalo. Las oscilaciones en la evolución de la transpiración cada quince minutos, corresponden a la mayor o menor pendiente que se produce entre dos medidas consecutivas de pesos.

Con el objeto de visualizar la transpiración nocturna, se muestra en la Figura 2 la transpiración junto con la radiación solar global cada cuarto de hora, destacando la existencia de transpiración de 0:00h a 4:45h y de 19:45h a 24:00h, horas en las que la radiación solar global no presenta valores positivos, por tanto, las medidas indican transpiración antes y después de la salida del sol en una noche de luna nueva, como se pone de manifiesto en la Figura 3, que representa la pérdida de peso nocturna en uno de los días, así como la transpiración calculada con la pérdida de peso. 


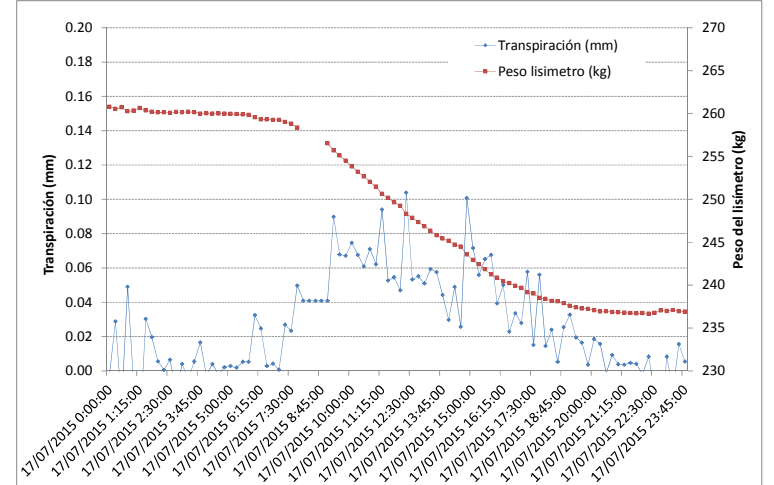

Figura 1. Evolución del peso del lisímetro y de la transpiración

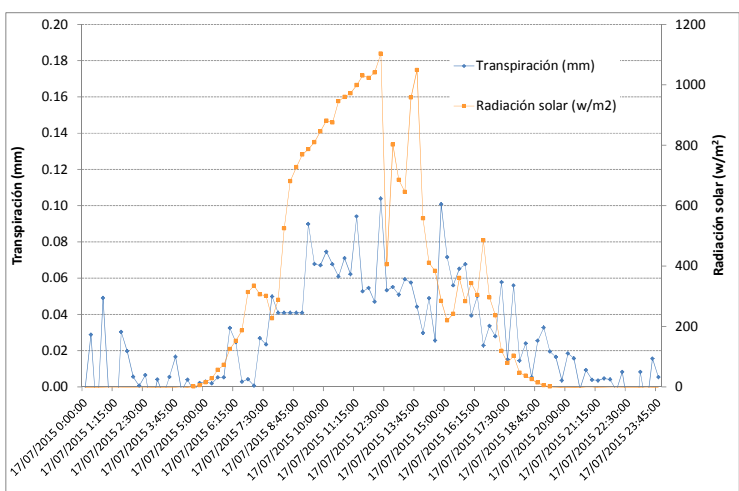

Figura 2. Evolución de la radiación solar frente a la transpiración medida en el lisímetro.

La relación encontrada en este trabajo entre transpiración y radiación solar presenta un $r^{2}$ de 0.40 (Figura 4), lo que parece indicar que aunque la radiación solar es uno de los parámetros externos que están más relacionados con la apertura estomática y por tanto con la transpiración, existen otros factores (tanto internos como externos) que determinan el proceso y serían los que están involucrados directamente en el proceso de transpiración nocturna.

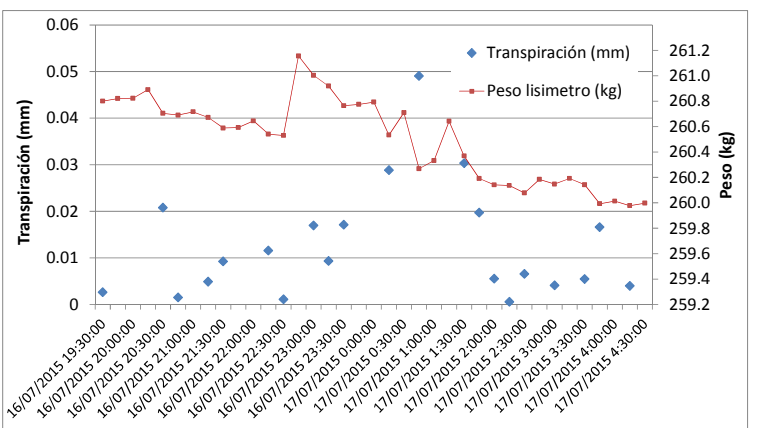

Figura 3. Evolución del peso del lisímetro y de la transpiración en la noche del 16 al 17 de julio.

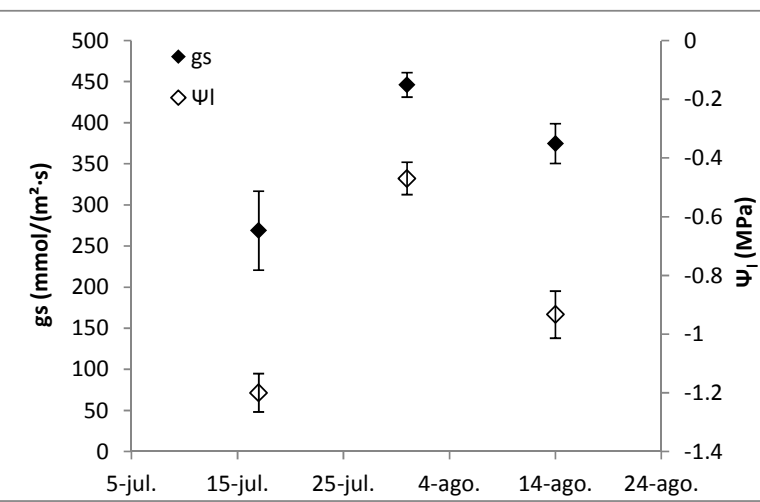

Figura 5. Potencial de hoja y conductancia estomática en cierre de racimo, envero y maduración.

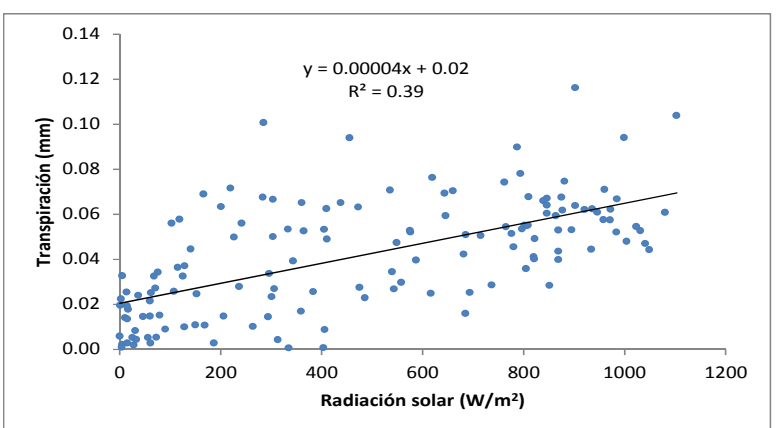

Figura 4. Relación entre radiación solar y transpiración.

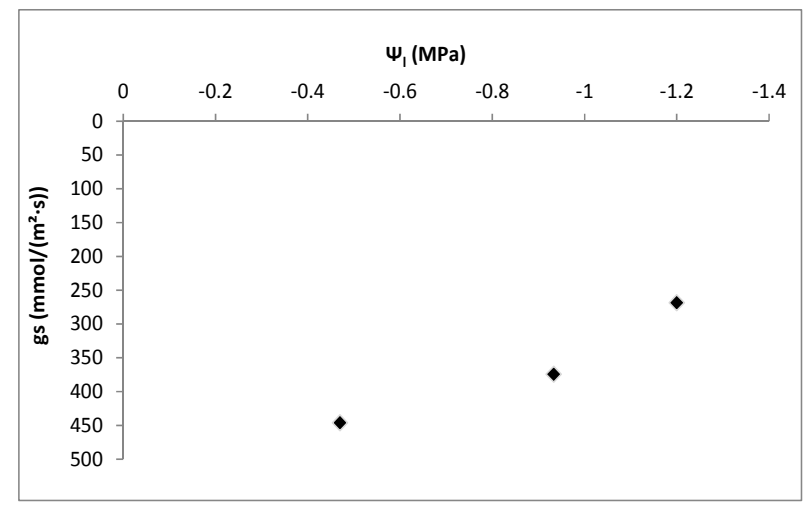

Figura 6. Relación entre potencial de hoja y conductancia estomática.

Por último, la Figura 5 representa el $\psi_{1} \mathrm{y} g_{s}$ en cierre del racimo, envero y maduración. Los valores de $\Psi_{1}$ indican que las plantas no presentaban estrés hídrico en envero, un estrés medio en maduración y el mayor estrés en el estado fenológico de cierre del racimo. Los valores de potencial para la valoración del estrés hídrico de las plantas se ha realizado teniendo en cuenta los resultados obtenidos en previos trabajos en el mismo área 
de estudio (Montoro et al., 2012) así como los obtenidos en otros estudios en diferentes áreas (Cifre et al., 2005; Sibille et al., 2007; Fuentes et al., 2014). La misma tendencia del potencial siguió la $\mathrm{g}_{\mathrm{s}}$. La Figura 6 muestra la relación entre ambos parámetros, siendo mayor $g_{s}$ cuanto mayor es $\Psi_{l}$, como era de esperar.

\section{4- Conclusiones y recomendaciones}

Los resultados indican la existencia de transpiración nocturna en plantas de Vitis vinifera $L$. en las condiciones ambientales y de régimen hídrico en el que se ha llevado el experimento.

\section{5.- Agradecimientos}

Agradecemos el apoyo económico obtenido del proyecto RTA2011-00100-C05-04 ya acabado y el actualmente vigente, el RTA 2014-00049-C05-03, así como el AGL201454201-C4-4-R, todos ellos financiados por el Ministerio de Economía y Competitividad, los dos primeros a través del Instituto Nacional de Investigación y Tecnología Agraria y Alimentaria y el último gracias al "Programa Estatal de Investigación, Desarrollo e Innovación Orientada a los Retos de la Sociedad"

\section{6- Bibliografía}

Allen, R.G., Pereira, L.S., Raes, D., Smith, M. (1998). Crop evapotranspiration. Guidelines for computing crop water requirements. FAO Irrigation and Drainage, paper $n^{\circ} .56$, FAO, Rome.

Caird, M.A., Richards, J.H., Donovan, L.A. (2007a). Nighttime Stomatal Conductance and Transpiration in C3 and C4 Plants. Plant Physiology 143:4-10.

Caird, M.A., Richards, J.H., Hsiao, T.C. (2007b). Significant transpiration and water loss occurs throughout the night in field-grown tomato. Functional Plant Biology 34, 172177.

Cifre, J., Bota, J., Escalona, J.M., Medrano, H., Flexas, J. (2005). Physiological tools for irrigations scheduling in grapevines (Vitis vinifera L.). An open gate improve water-use efficiency?. Agriculture, Ecosystems \& Environment 106, 159-170.

Escalona, J.M., Fuentes, S., Tomás, M., Martorell, S., Flexas, J., Medrano, H. (2013). Responses of leaf night transpiration to drought stress in Vitis vinifera L. Agricultural Water Management 118, 50-58.

Fuentes, S., de Bei, R., Collins, M.J., Escalona, J.M., Medrano, H., Tyerman, S. (2014). Night-time responses to water supply in grapevines (Vitis vinifera L.) under deficit irrigation and partial root-zone drying. Agricultural Water Management 138, 1-9.

López-Urrea, R., Montoro, A., Mañas, F., López-Fuster, P., Fereres, E. (2012). Evapotranspiration and crop coefficients from lysimeter measurements of mature "Tempranillo" wine grapes. Agricultural Water Management 112, 13-20.

Montoro, A. (2008). Avances en el Manejo del Agua en la Agricultura de Riego. Tesis Doctoral presentada en la ETSIA de la Universidad de Castilla-La Mancha.

Montoro, A., Fereres, E., López-Urrea, R., Mañas, F., López-Fuster, P. (2012). Sensitivity of trunk diameter fluctuations in Vitis vinifera L. Tempranillo and Cabernet Sauvignon Cultivars. American Journal of Enology and Viticulture 63 (1), 85-93.

Novick, K.A., Oren, R., Stoy, P.C., Siqueira, M.B.S., Katul, G.G. (2009). Nocturnal evapotranspiration in Eddy-covariance records from three co-located ecosystems in the Southeastern U.S.: Implications for anual fluxes. Agricultural and Forest Meteorlogy $149,1491-1504$. 
Sharkey, T.D. \& Raschke, K. (1981). Separation and measurement of direct and indirect effects of light on stomata. Plant Physiology 68: 33-40.

Sibille, I., Ojeda, H., Prieto, J., Maldonado, S., Lacapere, J.N., Carbonneau, A. (2007). Relation between the values of three pressure chamber modalities (midday leaf, midday stem and predawn water potential) of 4 grapevine cultivars in drought situation of the southern of France. Applications for the irrigation control. In: Proceedings of XVth Conference GESCO, Porec, Croatia, pp. 685-695.

Sperry J.S., Adler F.R., Campbell, G.S., Comstock, J.P. (1998). Limitation of plant water use by rhizosphere and xylem conductance: results from a model. Plant, Cell and Environment, 21: 347-359.

Squeo, F.A. y León, M. F. (2007). Capítulo III. Transpiración. En Fisiologia Vegetal. Squeo \& Cardemil, eds. Ediciones Universidad de La Serena, La Serena, Chile 3, 67-84. 


\title{
CARACTERIZACIÓN DEL CRECIMIENTO Y DESARROLLO DEL MAÍZ EN CONDICIONES DE NO LABOREO EN LA MANCHA ORIENTAL
}

\author{
Barroso Costa, F. R. ${ }^{1}$ Ortega Álvarez, J. F. ${ }^{2}$ Ballesteros González, R. ${ }^{3}$
}

1 Ingeniero Agrónomo, Estudiante de doctorado, Centro Regional de Estudios del Agua (CREA), Universidad de Castilla-La Mancha, Ctra. de Las Peñas km. 3.4, 02071 Albacete, fellyperodrigo.barrosocosta@alu.uclm.es.

${ }^{2}$ Profesor Titular, Centro Regional de Estudios del Agua (CREA), Universidad de Castilla-La Mancha, Ctra. de Las Peñas km. 3.4, 02071 Albacete, jose.ortega@uclm.es.

3 Personal Investigador, Centro Regional de Estudios del Agua (CREA), Universidad de Castilla-La Mancha, Ctra. de Las Peñas km. 3.4, 02071 Albacete, rocio.ballesteros@uclm.es.

\section{Resumen}

La biomasa es se define como la materia orgánica, viva o muerta, que se produce por un cultivo. Por medio de la metodología de los grados-día acumulados (GDA), se puede cuantificar la energía acumulada por el cultivo durante su ciclo. El objetivo de este trabajo es estudiar los principales parámetros que caracterizan el cultivo del maíz, en una parcela comercial y en condiciones de no laboreo, en una zona semiárida localizada en La Mancha Oriental. Se realizó un seguimiento fenológico durante todo el ciclo en una parcela comercial de maíz grano durante la campaña de riego del año 2015. Se recogieron muestras de plantas durante todo el ciclo del maíz. Se registraron los cambios fenológicos del cultivo siguiendo para ello la escala $\mathrm{BBCH}$. Con los datos obtenidos en campo y en el laboratorio, los resultados obtenidos de Índice de Área Foliar (IAF) frente a días después de emergencia (DDE), Materia Seca (MS) frente a GDA, entre otros, fueron sometidos a un análisis estadístico descriptivo. Los resultados estadísticos indican que la MS frente a DDE presentó mejor ajuste en el modelo logístico, con un coeficiente de determinación $\left(R^{2}\right)$ de 0,96 y raíz del error cuadrático medio $(\mathrm{RMSE})=248,55 \mathrm{~g} \mathrm{~m}^{-2}$. En relación al IAF, las dos metodologías (DDE y GDA) presentaron mejor ajuste en el modelo polinomial cuadrático, con $R^{2}=0,85$ y 0,88 , y RMSE $=0,88 \mathrm{~m}^{2}$ planta $\mathrm{m}^{-2}$ suelo y $0,78 \mathrm{~m}^{2}$ planta $\mathrm{m}^{-2}$ suelo, respectivamente. Se concluye que la MS y el IAF presentan comportamientos distintos en el cultivo del maíz. Con los valores de los GDA calculados, fue posible definir la duración de cada etapa del desarrollo fisiológico del maíz.

\section{1 - Introducción}

El maíz es un cultivo de gran importancia en la región de Castilla-La Mancha. El tipo más tradicional es el maíz grano, con variedades del ciclo 600 a 700, que en la región, tiene una producción correspondiente a un 9\% de la producción nacional. Estas variedades se caracterizan por una alta producción de biomasa seca, variando de 21 a $27 \mathrm{t} \mathrm{ha}^{-1}$ (Lloveras, Martínez, \& Santiveri, 2014).

La biomasa es, por definición, toda la materia orgánica, viva o muerta, producida por un cultivo, esté sobre el suelo o por debajo de él. La materia seca (MS) se refiere a lo que resta de un material tras extraer todo su contenido de agua posible, a través del secado hecho en laboratorio, en una estufa a unos $70^{\circ} \mathrm{C}$. 
Por medio de la metodología de los grados-día acumulados (GDA), es posible cuantificar la energía acumulada por la planta en cada etapa de su desarrollo. El grado-día consiste en la cantidad de energía calorífica que la planta consigue acumular diariamente (Ballesteros, 2014; İñiguez-Covarrubias, Ojeda-Bustamante, \& Sifuentes-lbarra, 2014). La aplicación de la metodología de los GDA permite estudiar y conocer en profundidad el desarrollo del cultivo, planificando así un adecuado calendario de riegos (Akmal, Asim, \& Gilbert, 2014).

Los cultivos anuales, como el caso del maíz, dividen su ciclo en cuatro etapas de desarrollo fenológico, con cada etapa teniendo duración distinta y variable. La etapa I es de establecimiento del cultivo, en la cual hay un crecimiento más lento del cultivo. La etapa II presenta rápido crecimiento, con mayor desarrollo de las hojas y del tallo. La etapa III empieza con el inicio de la floración. En esa etapa la planta dirige sus reservas en el desarrollo de la mazorca y llenado de los granos. También en esta etapa, el cultivo alcanza su máximo desarrollo y la máxima cubierta del suelo. La última etapa (IV) presenta una disminución de los valores de algunos parámetros fisiológicos, como la MS y del Índice de Área Foliar (IAF), ya que el cultivo inicia la senescencia (Allen, Pereira, Raes, \& Smith, 2006).

Una de las prácticas conservacionistas que más se utiliza hoy es el cultivo de no laboreo. En cual consiste en trabajar lo mínimo posible la tierra, haciendo la siembra directa del cultivo en el rastrojo de la campaña anterior. En esta práctica, el control de las malas hierbas se consigue con la aplicación de herbicidas. Además el rastrojo protege el suelo contra la erosión (Cid, Carmona, García, \& Mcpherson, 2014).

El objetivo de este trabajo es estudiar los principales parámetros que caracterizan el cultivo del maíz, en una parcela comercial y en condiciones de no laboreo, en una zona semiárida localizada en La Mancha Oriental. Además, se propone estudiar el ciclo del maíz mediante la metodología de los GDA y de los datos recogidos en campo.

\section{2 - Material e métodos}

Se realizó un seguimiento fenológico durante todo el ciclo en una parcela comercial de maíz grano, variedad P-1114, en una finca ubicada en Tarazona de La Mancha (Albacete) en la Unidad Hidrogeológica (U.H.) 08.29. (Mancha Oriental), durante la campaña de riego del año 2015. La región se caracteriza por ser de clima semiárido, con pluviometría media anual de $393,22 \mathrm{~mm}$.

Se registraron los cambios fenológicos del cultivo siguiendo para ello la escala $\mathrm{BBCH}$ (Weber \& Bleiholder, 1990) de forma semanal, lo que permitió una adecuada planificación de los muestreos en campo. Considerando los cambios más representativos en la fenología del cultivo se realizaron once de estos muestreos. La parcela se dividió en cuatro zonas distintas, considerando distintos tipos de suelo y topografía. Los puntos de muestreo fueron escogidos de forma aleatoria, muestreando una subparcela de cada una de las zonas anteriormente descritas en cada día de muestreo. El área de muestreo fue de $1 \times 0,7 \mathrm{~m}$. En cada muestreo, se recogieron 6 plantas por zona, siendo 24 plantas muestreadas cada día. También se midió la densidad de plantas de cada subparcela, además de otros parámetros como altura total de la planta y longitud de distintos órganos.

En laboratorio, fueron separados los distintos órganos de la planta. Después, se obtuvo el área foliar de cada planta utilizando el medidor de área foliar LICOR, modelo LI3100C. Posteriormente, se pesó cada uno de los órganos de las plantas por separado, y por último, éstos se introdujeron en una estufa a una temperatura constante de $70^{\circ} \mathrm{C}$ hasta alcanzar un peso constante, determinando así la biomasa seca.

Con los datos obtenidos en campo y en el laboratorio, se obtuvo el IAF, la MS de cada parte de la planta y la MS total. En paralelo con los resultados obtenidos en campo, se calcularon los GDA a través de la metodología del seno doble (Allen, 1976), durante todo el ciclo del maíz, posibilitando hacer una comparación con el desarrollo del cultivo en relación a los días después de emergencia (DDE). De esta forma, los resultados obtenidos de IAF frente a DDE, IAF frente a GDA, MS total frente a DDE, MS total frente a GDA, MS total 
frente a altura de plantas y altura de plantas frente a DDE, fueron sometidos a un análisis estadístico descriptivo. Las ecuaciones y gráficas que mejor se ajustaron a los modelos fueron estimadas utilizando el software MATLAB R2013b.

\section{3 - Resultados y discusión}

Los resultados estadísticos indican que la MS frente a DDE (Figura 1) presentó mejor ajuste en el modelo logístico, con un $R^{2}$ de 0,96 y $R M S E=248,6 \mathrm{~g} \mathrm{~m}^{-2}$. Eso indica que el cultivo del maíz tiene una producción de MS lenta en la etapa I (1 a $47 \mathrm{DDE}$ ), aumentando su crecimiento en la etapa II (48 a $75 \mathrm{DDE}$ ), hasta que alcanza su máxima producción de MS en la etapa III (76 a 154 DDE), alcanzando una producción máxima puntual de MS total de hasta $31.200 \mathrm{~kg} \mathrm{ha}^{-1}$ en una de las zonas de muestreo. A partir de entonces hay una pequeña reducción no relevante en la MS en la etapa IV (a partir de 155 DDE), debido al proceso de senescencia del cultivo.

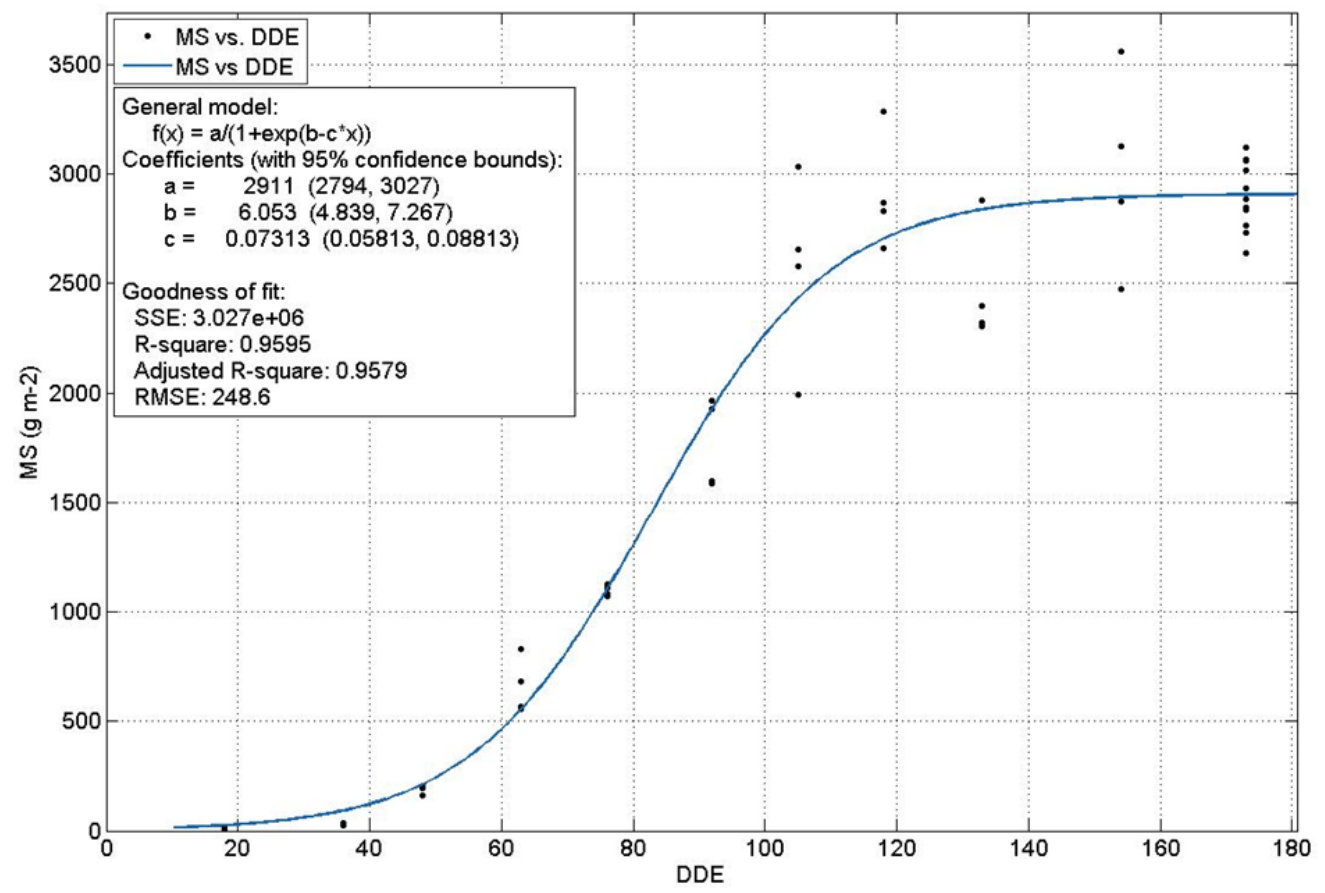

Figura 1. MS frente a DDE en maíz.

Resultado similar fue encontrado por Junior et al., (2014), que, estudiando el maíz en condiciones semiáridas en Alagoas, Brasil, describió cómo el maíz, en el inicio del ciclo, prioriza la acumulación de fotoasimilados para el crecimiento de sus hojas y tallo, y que, Ilegando a la etapa III, dirige su reserva para el desarrollo de la mazorca y posterior llenado de granos. Singer, Meek, Sauer, Prueger, \& Hatfield (2011), estudiando la producción de biomasa en maíz, encontraron valores de MS similares a los de este estudio, con el crecimiento inicial un poco más lento, una rápida producción de biomasa en la etapa de crecimiento y alcanzando su máxima MS media en la etapa productiva, con valores menores que los de este estudio ( $2.300 \mathrm{~g} \mathrm{~m}^{-2}$ frente a $3.000 \mathrm{~g} \mathrm{~m}^{-2}$ de este estudio).

La MS frente a GDA (Figura 2) presentó un mejor ajuste con el modelo logístico, con $R^{2}=0,96$ y RMSE $=247,6 \mathrm{~g} \mathrm{~m}^{-2}$. En esa gráfica se puede ver que la MS, cuando relacionada con los GDA, presenta un crecimiento más lento en la primera etapa (hasta 562,12 GDA), en la etapa II presenta crecimiento exponencial (562,13 a 1.015,84 GDA), luego estabiliza el crecimiento en la etapa III, alcanzando su mayor desarrollo (1.015,85 a 2.262,85 GDA) y empieza la senescencia y disminuye un poco su MS en la etapa IV (desde 2.262,86 GDA). 


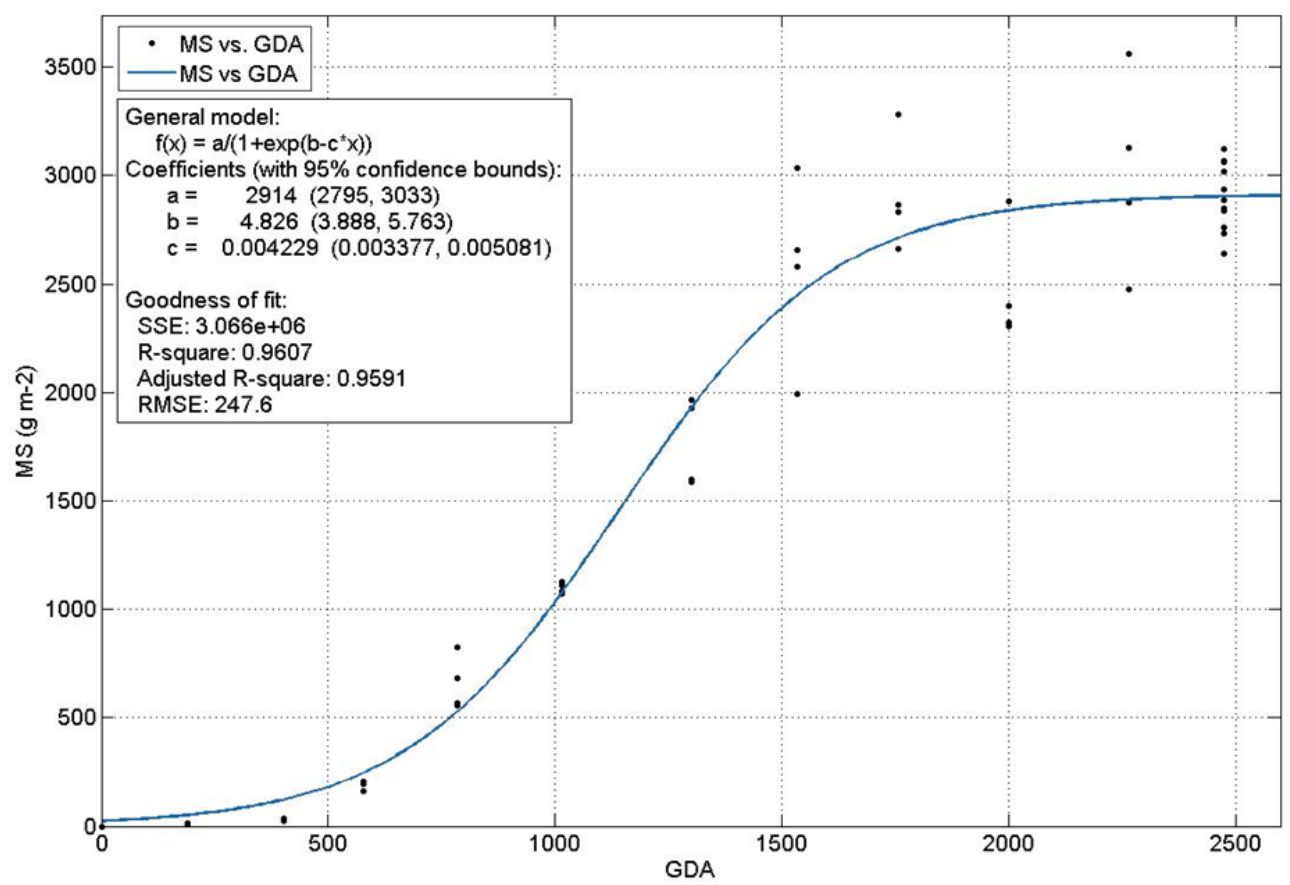

Figura 2. MS frente a GDA en maíz.

En relación al IAF, se nota el mismo comportamiento en las dos metodologías (DDE y GDA) (Figuras 3 y 4), ya que ambos presentaron mejor ajuste en el modelo polinomial cuadrático, con $R^{2}=0,85$ y 0,88 , y RMSE $=0,88 \mathrm{~m}^{2}$ planta $\mathrm{m}^{-2}$ suelo y $0,78 \mathrm{~m}^{2}$ planta $\mathrm{m}^{-2}$ suelo, respectivamente.

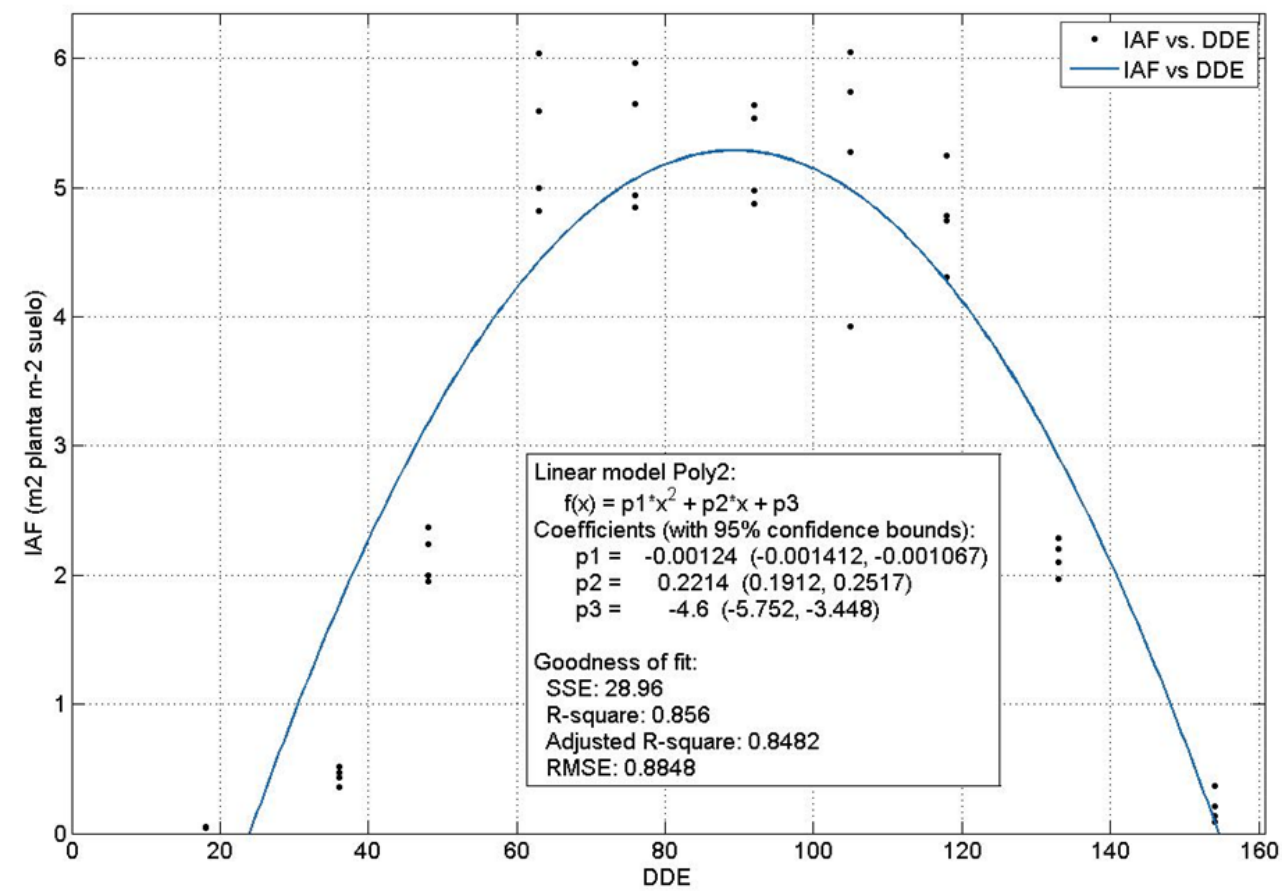

Figura 3. IAF frente a DDE en maíz.

Eso indica que el IAF aumenta de acuerdo con el desarrollo de la planta de maíz, alcanzando su máximo valor en el final de la etapa II, manteniendo los valores similares hasta el final de la etapa III, cuando empieza a decaer, debido a la senescencia del cultivo. 


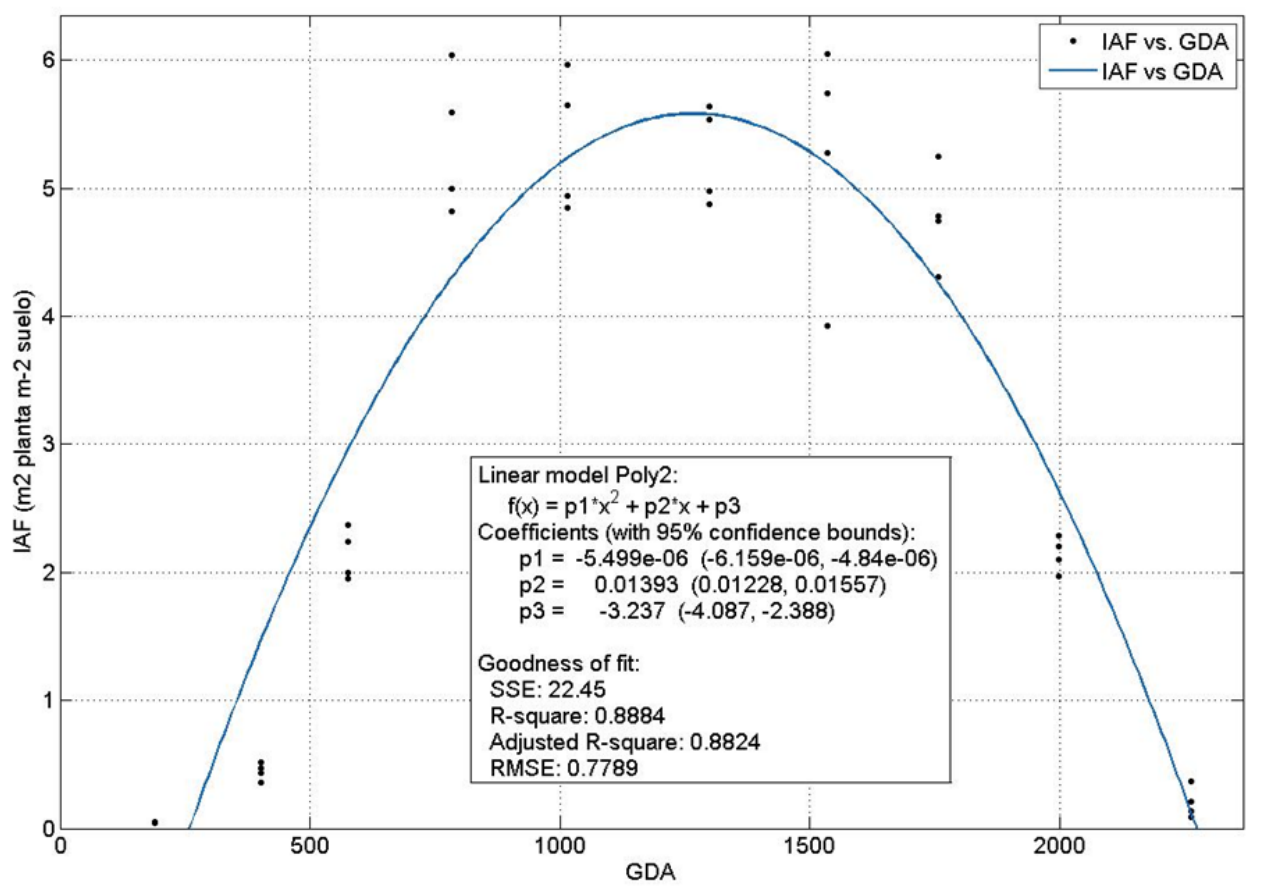

Figura 4. IAF frente a GDA en maíz.

Autores como Zegada-Lizarazu, Zatta, \& Monti (2012), encontraron valores de IAF en maíz semejantes a los encontrados en este estudio, ya que el valor de IAF estuvo cerca de $6 \mathrm{~m}^{2}$ planta $\mathrm{m}^{-2}$ suelo, en la etapa III del ciclo del maíz, reduciendo su valor al final de esta etapa, coincidiendo con el inicio de la senescencia del maíz. Lo mismo ocurrió en el trabajo de Quanqi, Yuhai, Xunbo, Songlie, \& Changcheng (2012), que obtuvo un comportamiento del IAF en el ciclo del maíz muy similar al de este estudio, obteniendo valores cercanos a los $6 \mathrm{~m}^{2}$ planta $\mathrm{m}^{-2}$ suelo en la etapa III, y luego disminuyendo los valores en la fase final del ciclo del maíz.

La MS frente a altura de plantas (Figura 5) presentó mejor ajuste en el modelo de Gompertz, con valores de $R^{2}=0,87$ y RMSE $=434 \mathrm{~g} \mathrm{~m}^{-2}$. A partir del modelo se nota que, en el cultivo del maíz, a medida en que aumenta la altura de las plantas, el cultivo aumenta su producción de MS. Normalmente, las plantas más altas producen más MS, debido a que sus tallos almacenan sus reservas. Otra razón es que plantas más altas interceptan más radiación solar, posibilitando así un mejor desarrollo de la mazorca. 


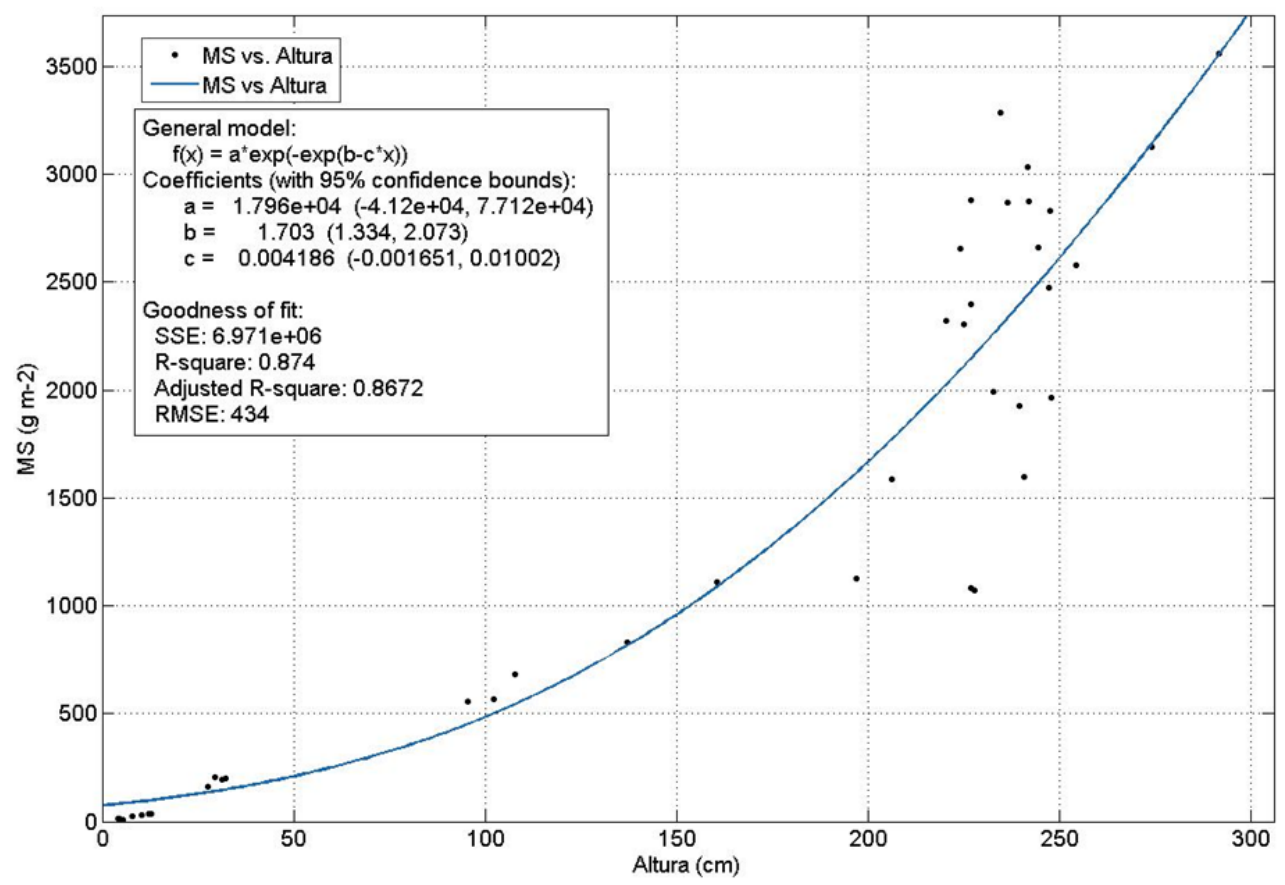

Figura 5. MS frente a Altura de plantas de maíz.

Schittenhelm \& Schroetter (2014), comparando la MS de plantas de maíz con su altura, encontraron que las plantas con altura media de $280 \mathrm{~cm}$ tenían una producción de MS de $1.910 \mathrm{~g} \mathrm{~m}^{-2}$, en cuanto que en este estudio, las plantas con altura media de $280 \mathrm{~cm}$ tuvieron una producción de MS de $3.279,37 \mathrm{~g} \mathrm{~m}^{-2}$.

En relación a la altura de plantas frente a DDE (Figura 6), se observa que la altura de las plantas tiene un aumento muy lento en la etapa I, aumenta exponencialmente en la etapa II, alcanza su máximo en la etapa III, y se mantiene constante hasta el fin del ciclo. El modelo que mejor se ajustó a ese parámetro fue el logístico, con $R^{2}=0,97$ y $R M S E=$ $17,01 \mathrm{~cm}$.

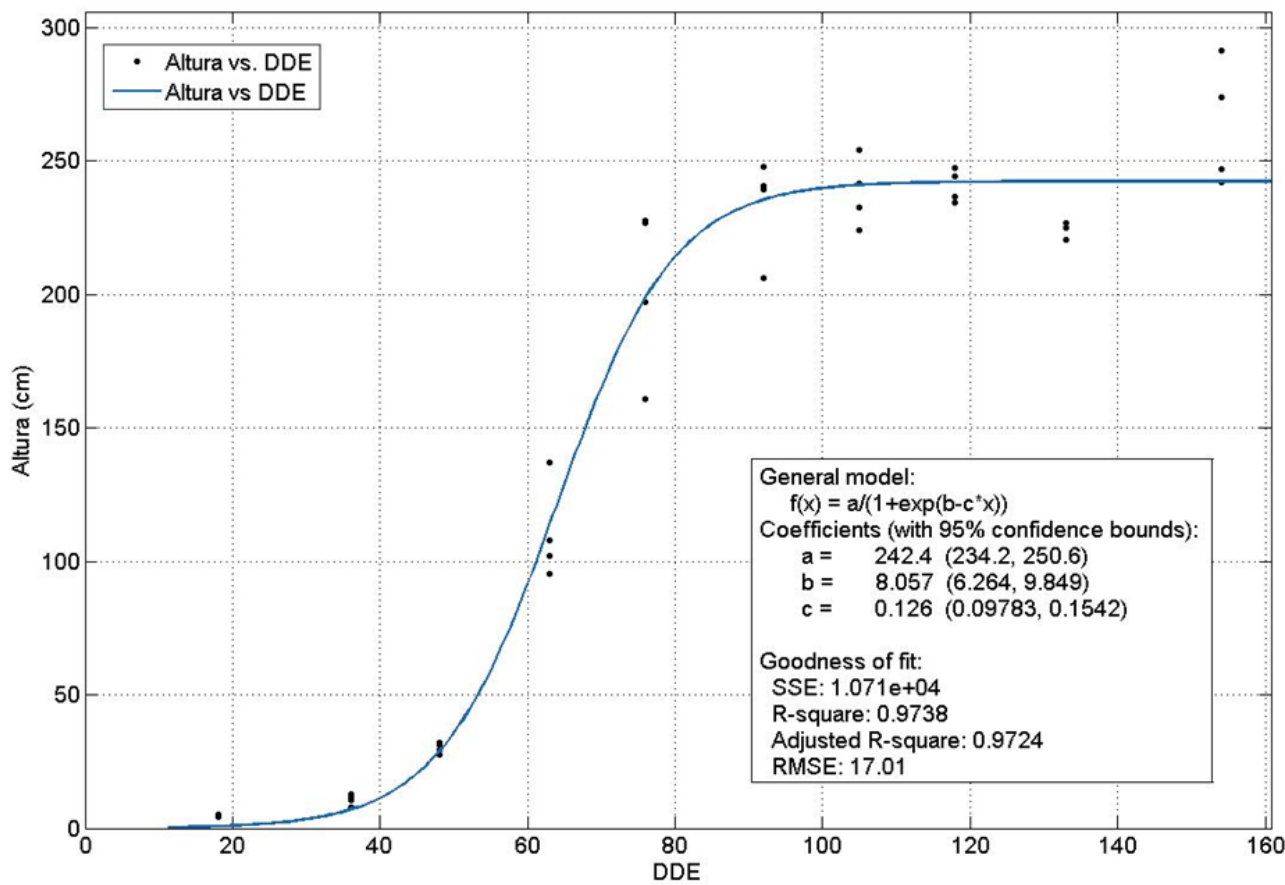

Figura 6. Altura de plantas frente a DDE en maíz. 
Autores como Liu, Chen, Liu, Wen, \& Liao (2016), obtuvieron valores de altura de planta muy similares a los de este estudio durante todo su ciclo, con alturas medias en la etapa III cerca de los $250 \mathrm{~cm}$.

\section{4 - Conclusiones y recomendaciones}

Con los valores de los GDA calculados, fue posible definir la duración de cada etapa del desarrollo fisiológico del maíz, lo que permite hacer una planificación del ciclo del cultivo, en lo que corresponde a la aplicación de agua, fertilizantes y operaciones culturales en el cultivo de maíz.

La MS y el IAF presentan comportamientos distintos en el cultivo del maíz, ya que el cultivo sólo alcanza su máxima MS al final de la etapa III, en cuanto el IAF máximo se da en el final de la etapa II y se mantiene hasta el fin de la etapa III. En relación al final del ciclo, la MS decrece muy poco en relación a su máximo valor alcanzado, en cuanto que el IAF se reduce mucho en la última etapa.

\section{5 - Agradecimientos}

Agradezco al Proyecto IBrasil - Erasmus Mundus por financiar mis estudios de doctorado en la Universidad de Castilla-La Mancha.

\section{6 - Referencias}

Akmal, M., Asim, M., \& Gilbert, M. (2014). Influence of seasonal variation on radiation use efficiency and crop growth of maize planted at various densities and nitrogen rates. Pakistan Journal of Agricultural Science, 51(4), 835-846.

Allen, J. C. (1976). A modified sine wave method for calculating degree days. Environmental Entomology, 5(3), 388-396.

Allen, R. G., Pereira, L. S., Raes, D., \& Smith, M. (2006). Evapotranspiración del cultivo Guías para la determinación de los requerimientos de agua de los cultivos. Manual FAO-56. Food and Agriculture Organization (FAO). Rome.

Ballesteros, R. (2014). Predicción de evapotranspiración de referencia y empleo de modelos de tiempo térmico junto a información geomática en la caracterización de cultivos para la gestión del regadío en la Mancha Oriental. Tesis Doctoral. Escuela Tecnica Superior de Ingenieros Agrónomos y de Montes. Universidad de Castilla-La Mancha, Albacete, España.

Cid, P., Carmona, I., García, R. C., \& Mcpherson, H. G. (2014). Claves para la viabilidad de la agricultura de conservación en la producción de maíz en regadío. Vida Rural, 382, 32-37.

Íñiguez-Covarrubias, M., Ojeda-Bustamante, W., \& Sifuentes-Ibarra, C. D. E. (2014). Análisis de cuatro variables del período de lluvias asociadas al cultivo maíz de temporal. Revista Mexicana de Ciencias Agrícolas, 5, 101-114.

Junior, R. A. F., Souza, J. L. De, Teodoro, I., Lyra, G. B., Souza, R. C. De, \& Neto, R. A. D. A. (2014). Eficiência do uso da radiação em cultivos de milho em Alagoas Radiation use efficiency in corn crop in Alagoas. Revista Brasileira de Engenharia Agrícola e Ambiental, 18(3), 322-328.

Liu, Q., Chen, Y., Liu, Y., Wen, X., \& Liao, Y. (2016). Coupling effects of plastic fi Im mulching and urea types on water use efficiency and grain yield of maize in the Loess Plateau, China. Soil and Tillage Research, 157, 1-10.

Lloveras, J., Martínez, E., \& Santiveri, F. (2014). Influencia de la fecha de siembra en el maíz en regadío del valle del Ebro. Vida Rural, 374, 36-40.

Quanqi, L., Yuhai, C., Xunbo, Z., Songlie, Y., \& Changcheng, G. (2012). Effect of irrigation to winter wheat on the radiation use efficiency and yield of summer maize in a double cropping system. The Scientific World Journal, 476272. 
Schittenhelm, S., \& Schroetter, S. (2014). Comparison of Drought Tolerance of Maize, Sweet Sorghum and Sorghum-Sudangrass Hybrids. Journal of Agronomy and Crop Science, 200(1), 46-53.

Singer, J. W., Meek, D. W., Sauer, T. J., Prueger, J. H., \& Hatfield, J. L. (2011). Variability of light interception and radiation use efficiency in maize and soybean. Field Crops Research, 121(1), 147-152.

Weber, E., Bleiholder, H. (1990). Erläuterungen zu den BBCH-Dezimal-Codes für die Entwicklungsstadien von Mais, Raps, Faba-Bohne, Sonnenblume und Erbse - mit Abbildungen. Gesunde Pflanzen, 42, 308-321.

Zegada-Lizarazu, W., Zatta, A., \& Monti, A. (2012). Water uptake efficiency and above and belowground biomass development of sweet sorghum and maize under different water regimes. Plant and Soil, 351(1-2), 47-60. 


\title{
COMPARACIÓN DE MODELOS MENSUALES Y ANUALES PARA ESTIMAR EL COEFICIENTE DE HARGREAVES EN LA COMUNIDAD VALENCIANA
}

\author{
Martí, $P^{1}(P)$, Zarzo, $M .^{2}$, Royuela, Á. ${ }^{3}$,Turégano, J.V. ${ }^{4}$ \\ 1 PDI, Universitat de les Illes Balears, Departament de Biologia, Àrea d'Enginyeria \\ Agroforestal (UIB). Ctra de Valldemossa km 7.5 07122 Palma, pau.marti@uib.cat \\ ${ }^{2}$ PDI, Departament d'Estadistica i Investigació Operativa, Universitat Politècnica de Valencia \\ (UPV). Camí de Vera s/n 46022 València, mazarcas@eio.upv.es \\ ${ }^{3}$ PDI, Universitat Politècnica de València (UPV), Centre Valencià d'Estudis sobre el Reg \\ (CVER). Camí de Vera s/n 46022 València, aroyuela@agf.upv.es \\ 4 PDI, Universitat Politècnica de València (UPV), Departament d'Enginyeria Rural i \\ Agroalimentària, Camí de Vera s/n 46022 València, jturegan@agf.upv.es
}

\section{Resumen}

El modelo de Hargreaves (HG) para estimar evapotranspiración de referencia $\left(E T_{0}\right)$ es una alternativa interesante a la ecuación de Penman Monteith (PM), propuesta como método estándar por la FAO, pero que no es aplicable en muchas situaciones porque requiere muchas variables climáticas que no suelen estar disponibles o cuyos valores medidos no son fiables. Para la aplicación de esta ecuación se recomienda una calibración local preliminar del llamado coeficiente de Hargreaves (AHC). Sin embargo, la obtención de valores concretos de $\mathrm{AHC}$ tiene un uso limitado, dado que se requieren valores locales de $\mathrm{PM}$, que se aplicará realmente para determinar la $\mathrm{ET}_{0}$ de la estación. Asimismo los valores de AHC no pueden extrapolarse. Por ello es preciso proponer y estudiar modelos para estimar el $\mathrm{AHC}$, dado que en las condiciones en las que la ecuación de HG pretende ser útil no habrá posibilidad de calibración previa mediante valores de PM.

Este estudio analiza si están justificadas las parametrizaciones mensuales o estacionales del AHC. Para ello se compararon tres escalas temporales en el desarrollo de los modelos de AHC: la anual, la mensual y la estacional. Los resultados sugieren que el desarrollo de modelos mensuales podría reducir el error relativo alrededor del $2 \%$ para $\mathrm{AHC}$ diarios y alrededor de $1 \%$ para AHC medios mensuales, es decir, un único modelo anual de AHC podría ser insuficiente para recoger toda la variabilidad anual de AHC. Por ello, la aplicación de modelos mensuales (o estacionales) podría estar justificado para una correcta estimación de los AHC. Asimismo, los resultados muestran que la estimación mensual del AHC fue más ajustada de mayo a septiembre que de octubre a abril, y, particularmente, que de noviembre a enero.

\section{1- Introducción}

La estimación precisa de la evapotranspiración (ET) puede contribuir a mejorar el diseño y gestión de instalaciones de riego. La ET es un parámetro crucial del ciclo hidrológico en agricultura, particularmente en sistemas de regadío. Jensen (1968) introdujo la metodología ampliamente extendida de estimar la ET como el producto de la evapotranspiración de referencia $\left(E T_{0}\right)$, i.e. la $E T$ de una superficie de referencia, y un coeficiente de cultivo, representativo de prácticas culturales, tipo de cultivo y desarrollo del mismo. 
La ecuación de Penman-Monteith (FAO56 PM), (Allen et al. 1998), es el método de referencia propuesto por la $\mathrm{FAO}$ para determinar la $\mathrm{ET}_{0} \mathrm{y}$ validar otras ecuaciones, pero en muchas situaciones no es aplicable porque requiere muchas variables climáticas (temperatura, humedad relativa, radiación solar y velocidad del viento) que no suelen estar disponibles o cuya medida puede no ser fiable. Este hecho ha dado lugar al desarrollo de ecuaciones más sencillas que requieren menos variables climáticas de entrada. La

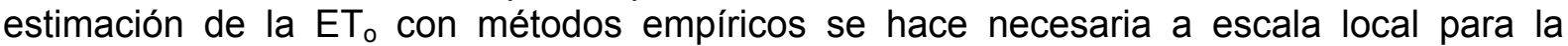
gestión de recursos hídricos y del riego en particular, debido a que no es posible obtener valores experimentales de $\mathrm{ET}_{\mathrm{o}} \mathrm{o}$ aplicar otros modelos más complejos.

Sin embargo, la validez de muchos de estos modelos empíricos depende de los rangos climáticos para los que fueron calibrados. Por otra parte, la aplicación de la ecuación FAO56 PM adoptando valores estimados de los inputs en lugar de valores medidos puede acarrear también errores. El estudio de modelos térmicos de $\mathrm{ET}_{0}$ está justificado por diversas razones. En primer lugar, la temperatura y la radiación solar explican al menos el $80 \%$ de la variabilidad de la $\mathrm{ET}_{\text {。 }}$ (Samani 2000). En segundo lugar, diversos estudios indican que el rango térmico diario puede relacionarse con la humedad relativa y la nubosidad (Di Stefano and Ferro 1997). En tercer lugar, la advección depende de la interacción entre temperatura, humedad relativa, presión de vapor y velocidad del viento, y estas variables pueden relacionarse con el rango térmico (Vanderlinden et al. 2004). Finalmente, la temperatura constituye la variable más ampliamente disponible en las estaciones climáticas de entre las que se necesitan para el cálculo de la ET。 (Mendicino and Senatore 2013).

La ecuación de Hargreaves, HG, (Hargreaves y Samani 1985) sólo requiere datos medidos de temperatura media del aire y rango térmico, al margen de valores calculados de radiación extraterrestre. Jensen et al. (1997) recomendó la ecuación de HG como una de las más simples y exactas de entre las ecuaciones empíricas para estimar $\mathrm{ET}_{\mathrm{o}}$. Según Allen et al. (1998), la ecuación de HG proporciona estimaciones razonables de $\mathrm{ET}_{0}$ con validez global. A pesar de que se han constatado aplicaciones de HG a escala diaria con bajos errores (Di Stefano and Ferro 1997), Hargreaves y Allen (2003) sugirieron que las estimaciones más precisas serían de esperar a partir de periodos de cinco días o superiores, debido a que las estimaciones diarias están sujetas a una mayor variabilidad, causada por el movimiento de frentes, la fluctuación de la velocidad del viento y la nubosidad. Sin embargo, numerosas aplicaciones agrícolas e hidrológicas requieren datos diarios de $\mathrm{ET}_{\mathrm{o}}$.

Según Maestre-Valero et al. (2013), la validez de la ecuación original de HG se ve fuertemente influenciada por las condiciones climáticas locales bajo las que se calibró. Según Samani (2000), la ecuación de HG no debería extrapolarse sin ser previamente calibrada a escala local. Esta calibración puede llevarse a cabo usando valores

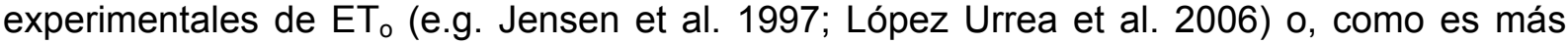
habitual en la práctica, mediante valores calculados de la ecuación FAO56 PM (e.g. Vanderlinden et al. 2004; Gavilán et al. 2006; Mendicino y Senatore 2013). El proceso de calibración da lugar a valores ajustados del coeficiente de Hargreaves (AHC).

Sin embargo, las ecuaciones calibradas de HG tienen sólo validez local y no pueden ser extrapoladas a otros lugares donde no existen valores de referencia de $\mathrm{ET}_{\text {}}$ para efectuar una calibración local. De hecho, en las estaciones donde se puede calibrar la ecuación de HG porque hay variables suficientes para calcular los valores de referencia requeridos de $\mathrm{ET}_{\text {。 }} \mathrm{FAO56} \mathrm{PM}$, se utilizaría directamente ésta última como método para calcular la $\mathrm{ET}_{0}$, dejando relegado el método de HG para casos de fallo del sistema de medida. Por ello, además de la calibración local de los AHCs, diferentes autores han sugerido la calibración paramétrica de AHC, es decir, la modelización de AHC a partir de diferentes inputs, como rango térmico (Samani 2000; Mendicino y Senatore 2013; Maestre-Valero et al. 2013), el cociente temperatura media-rango térmico $\left(\mathrm{T}_{\text {media }} / \Delta \mathrm{T}\right)$ (Vanderlinden et al. 2004; Lee 2010; 
Thepadia y Martínez 2012; Mendicino y Senatore 2013; Maestre-Valero et al. 2013; Martí et al. 2015), velocidad del viento (Jensen et al. 1997; Martínez-Cob y Tejero-Juste 2004), humedad relativa (Hargreaves y Allen 2003), precipitación (Droogers y Allen 2002), y altitud (Ravazzani et al. 2012). Shahidian et al. (2013) llevaron a cabo un análisis en profundidad de los siete parámetros más prometedores para efectuar la calibración de HG testando diferentes modelos bajo condiciones climáticas uniformes y no uniformes. Como conclusión, sugirieron que la velocidad del viento aparecía como el parámetro más importante para mejorar las estimaciones de HG. Sin embargo, los valores de velocidad del viento no suelen estar disponibles en los casos en los que la ecuación de HG puede ser útil.

Hasta hoy los estudios sobre modelización del AHC han propuesto fundamentalmente modelos que calculan un único valor de $\mathrm{AHC}$ por estación, excepto en algún caso donde se han propuesto modelos mensuales (e.g. Maestre-Valero et al. 2013). Sin embargo, no se han encontrado análisis comparativos entre ambos procedimientos. El trabajo actual pretende evaluar si la obtención de modelos mensuales de AHC podría estar justificada frente a la metodología de obtener un único AHC por estación. Para ello se compararán modelos mensuales y anuales de AHC en 30 estaciones de la Comunidad Valenciana.

\section{2- Métodos}

\subsection{Datos considerados}

En este estudio se han utilizado datos diarios de temperatura máxima ( $\left.T_{\max }\right)$, mínima $\left(T_{\min }\right)$ y media $\left(T_{\mathrm{m}}\right)$ del aire, humedad relativa $(\mathrm{HR})$, radiación solar $\left(R_{\mathrm{s}}\right)$ y velocidad del viento a $2 \mathrm{~m}$ de altura $\left(u_{2}\right)$ obtenidos en 30 estaciones de la Comunidad Valenciana durante el periodo 2000-2007. Los datos fueron suministrados por el Servicio de Tecnología del Riego del Instituto Valenciano de Investigaciones Agrarias (http://estaciones.ivia.es). Para obtener más información sobre las estaciones y las condiciones climáticas del área de estudio puede consultarse Martí y Zarzo (2012).

\subsection{Métodos para estimar $\mathrm{ET}_{\mathrm{o}}$}

\subsubsection{Ecuación FAO56 Penman Monteith}

Debido a la ausencia de lisímetro $u$ otros instrumentos para medir experimentalmente la ET, se aplicó la ecuación FAO56-PM para validar las estimaciones y para calibrar la ecuación de HG. Esta práctica es muy habitual en ausencia de datos experimentales y está

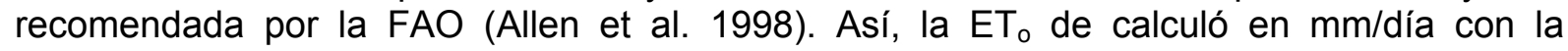
expresión

$$
E T_{o}^{P M}=\frac{0.408 \Delta\left(R_{n}-G\right)+\gamma \frac{900}{T+273} u_{2}\left(e_{s}-e_{a}\right)}{\Delta+\gamma\left(1+0.34 u_{2}\right)},
$$

donde $R_{\mathrm{n}}$ es la radiación neta en la superficie del cultivo $\left(\mathrm{MJ} / \mathrm{m}^{2} /\right.$ día); $G$ es la densidad de flujo de calor del suelo ( $\mathrm{MJ} / \mathrm{m}^{2} /$ día); $T$ es la temperatura diaria media del aire a $2 \mathrm{~m}$ de altura $\left({ }^{\circ} \mathrm{C}\right) ; \gamma$ es la constante psicrométrica $\left(\mathrm{kPa} /{ }^{\circ} \mathrm{C}\right) ; \Delta$ es la pendiente de la curva de presión de vapor $\left(\mathrm{kPa} /{ }^{\circ} \mathrm{C}\right)$; $e_{\mathrm{s}}$ es la presión de saturación de vapor $(\mathrm{kPa}) ; e_{\mathrm{a}}$ es la presión de vapor real $(\mathrm{kPa}) ; \mathrm{y} u_{2}$ es la velocidad del viento a $2 \mathrm{~m}$ de altura $(\mathrm{m} / \mathrm{s})$. Todos los parámetros se calcularon según las ecuaciones propuestas por Allen et al. (1998). G se supuso 0 para cálculos diarios, mientras que para cálculos mensuales se aplició la expresión

$$
G_{\text {mes } i}=0.07\left(T_{\text {mes } i+1}-T_{\text {mes } i-1}\right)
$$


donde $G_{\text {mes } i}$ es el flujo de calor del suelo en el mes $i, T_{\text {mes } i+1}$ es la temperatura media en el mes $i+1$, mientras que $T_{\text {mes } i-1}$ es la temperatura media en el mes $i-1$.

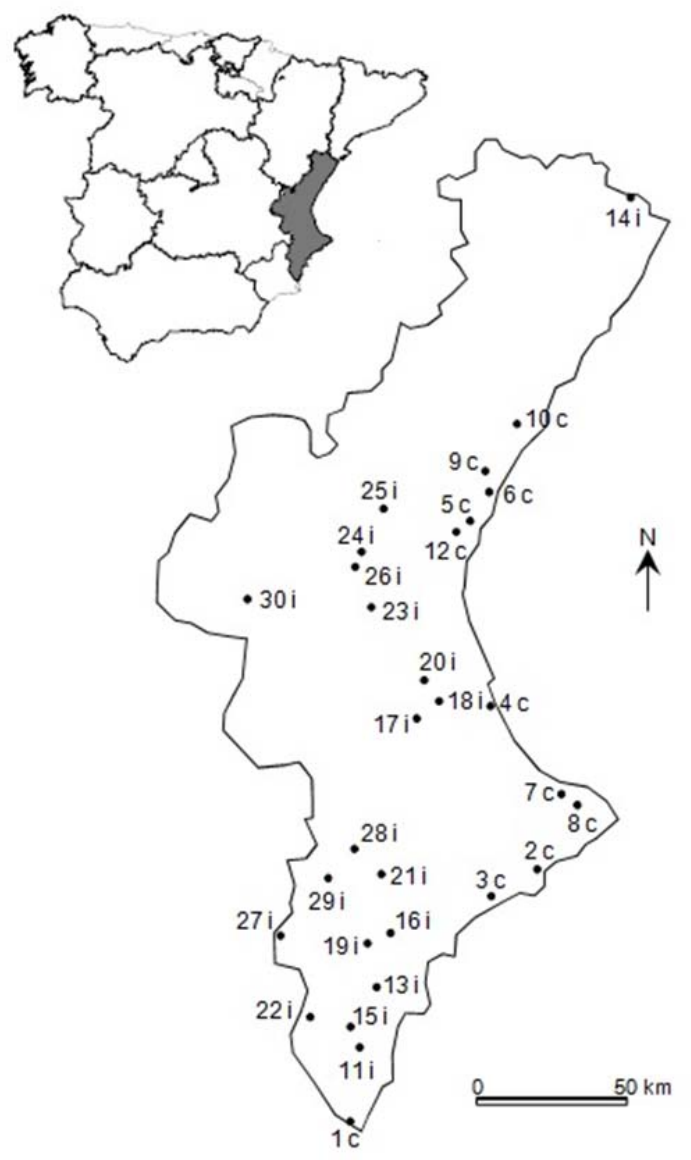

Figura 1. Localización de las estaciones estudiadas (Martí et al. 2015). 'c' indica estación costera, 'i' indica estación interior

\subsubsection{Ecuación de Hargreaves}

La ecuación de HG para estimar evapotranspiración de referencia $\left(E T_{0}{ }^{H G}, \mathrm{~mm} / \mathrm{día}\right)$ es según Hargreaves y Samani (1985)

$$
E T_{o}^{H G}=A H C R_{a}(T+17.8) \sqrt{\Delta T}
$$

donde $R_{\mathrm{a}}$ es el equivalente en $\mathrm{mm}$ de agua de la radiación extraterrestre ( $\mathrm{mm} /$ día); $\Delta T$ es el rango térmico diario $\left({ }^{\circ} \mathrm{C}\right) ; T$ es la temperatura media diaria $\left({ }^{\circ} \mathrm{C}\right), A H C$ es el coeficiente ajustado de Hargreaves, igual a 0.0023 en la ecuación original.

La evolución histórica de la ecuación de HG puede encontrarse en Hargreaves y Allen (2003), donde se detalla la evolución de los valores de AHC. Vanderlinden et al. (2004) sugiere que $A H C$ parece aumentar en áreas costeras, donde $\Delta T$ disminuye debido al efecto del mar, y parece disminuir en zonas montañosas, donde el movimiento de las masas de aire eleva el rango térmico. Vanderlinden et al. (2004) propusieron la siguiente expresión para estimar AHC basándose en el análisis de 16 estaciones en Andalucía durante un periodo de 38 años 


$$
A H C=k_{1} \frac{T_{m}}{\Delta T}+k_{2}
$$

donde $T_{\mathrm{m}}$ y $\Delta T$ corresponden a la temperatura media y al rango térmico medio por estación. Concretamente, propusieron los valores $k_{1}=0.0005$ y $k_{2}=0.00159$, con una bondad de ajuste de $R^{2}=0.90$. La misma expresión fue reajustada por Lee (2010) en la península de Corea con datos de 21 estaciones durante 10 años, y obtuvo $k_{1}=0.0004$ y $k_{2}=0.0013\left(R^{2}=0.84\right)$. La misma ecuación fue calibrada por Thepadia y Martínez (2012) usando datos de 22 estaciones en Florida durante 14 años, llegando a los valores $k_{1}=0.000411$ and $k_{2}=0.00132$ $\left(R^{2}=0.97\right)$. Mendicino y Senatore (2013) recalibraron la misma expresión en el sur de Italia con datos de 137 estaciones y obtuvieron $k_{1}=0.0006$ y $k_{2}=0.00121\left(R^{2}=0.46\right)$ considerando todas las estaciones, y $k_{1}=0.0006$ and $k_{2}=0.00097\left(R^{2}=0.83\right)$ considerando sólo estaciones costeras. Asimismo, adaptaron el modelo de Samani, basado en la estimación indirecta de $\mathrm{AHC}(A H C=0.0135 \cdot C)$ a partir de rango térmico:

$$
A H C=1.23057 \cdot 10^{-5} \Delta T^{2}-3.9237 \cdot 10^{-4} \Delta T+4.80226 \cdot 10^{-3}\left(\mathrm{R}^{2}=0.77\right)
$$

A partir de la expresión del coeficiente de Samani recalibrado

$$
C=0.0009115 \Delta T^{2}-0.02906 \Delta T+0.3557
$$

Finalmente, Martí et al. (2015) testaron los modelos de Vanderlinden et al. (2004) y Samani (2000), respectivamente, en la Comunidad Valenciana y constataron que no proporcionaban estimaciones suficientemente ajustadas del AHC, por lo que propusieron nuevos modelos incluyendo nuevas variables de entrada. La exactitud de las estimaciones de AHC se pudo incrementar, por una parte, incluyendo en los modelos datos geográficos de las estaciones (10), y, por otra, incluyendo información cualitativa sobre el rango de velocidad del viento (11).

$$
\begin{gathered}
\mathrm{AHC}=0.003704-0.000149 \cdot \Delta \mathrm{T}+0.000261 \cdot \tau+7.5212 \cdot 10^{-7} \cdot \mathrm{z} \\
\mathrm{AHC}=0.003456-0.000127 \cdot \Delta \mathrm{T}+0.000174 \cdot \tau+5.8737 \cdot 10^{-7} \cdot \mathrm{z}+0.000152 \cdot \mathrm{u}_{0-1}
\end{gathered}
$$

donde $\Delta T$ es el rango térmico, $\tau$ es la longitud, $z$ es la altitud y $u_{0-1}$ es la clase cualitativa de velocidad del viento.

\subsection{Desarrollo de los modelos}

En este estudio se van a comparar dos de las combinaciones de inputs sugeridas por Martí et al. (2015) con la particularidad de que se calibrarán a tres escalas temporales diferentes: la anual, la estacional y la mensual. En el primer caso se obtiene un único modelo de $\mathrm{AHC}$, en el segundo caso se obtienen 3 modelos, uno para verano, otro para invierno y otro para el resto del año, mientras que en el tercer caso se obtienen 12 modelos de $\mathrm{AHC}$, uno por mes.

Los valores diarios de $\mathrm{AHC}$ se obtuvieron multiplicando por 0.0023 el ratio de $\mathrm{ET}_{\mathrm{o}}{ }^{\mathrm{PM}}$ entre $\mathrm{ET}_{0}{ }^{\mathrm{HG}}$. Estos valores 'observados' de AHC sirvieron para obtener los modelos aplicando regresión lineal múltiple (RLM) a partir de inputs diarios (escala diaria). En el primer caso se consideró una única matriz global. En el segundo caso, los modelos se obtuvieron aplicando RLM a los datos de cada estación (3 estaciones). Finalmente, en el tercer caso, los modelos se obtuvieron individualmente por mes, también a escala diaria (e.g. el modelo para enero se obtuvo con todos los valores diarios de enero de todas las estaciones). Asimismo, la obtención de los modelos anteriores se repitió considerando esta 
vez valores medios mensuales de $A H C$ y del resto de variables climáticas involucradas (escala mensual), obtenidos del promedio de los datos diarios de cada mes en cada estación, y de la aplicación de la ecuación de $\mathrm{ET}_{\text {。 }}$ para el intervalo mensual según Allen et al. (1998).

Además, como se ha comentado, se consideraron dos combinaciones de inputs a partir de los resultados de Martí et al. (2015): a) modelo 1, que considera las variables de partida

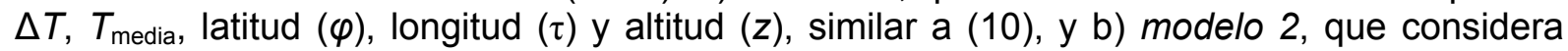
como inputs de partida los de a) y $u_{0-1}$ (velocidad cualitativa del viento considerando dos clases, muy ventoso/poco ventoso), similar a (11). Los inputs significativos para en cada caso podrían variar al aplicar RLM. Dichos modelos RLM se obtuvieron aplicando el software Statgraphics plus 5.1 (StatPoint Technologies Inc., Warrenton, VA, USA). EI resto de cálculos se implementaron con Matlab.

\subsection{Evaluación de los modelos}

La exactitud de las estimaciones se evaluó mediante la raíz cuadrada del error cuadrático medio en valor relativo (RRMSE),

$$
\text { RRMSE }=\frac{1}{\bar{x}} \cdot \sqrt{\frac{1}{n} \sum_{i=1}^{n}\left(x_{i}-\hat{x}_{i}\right)^{2}}
$$

y el error medio absoluto (MAE)

$$
M A E=\frac{1}{n} \cdot \sum_{i=1}^{n}\left|x_{i}-\hat{x}_{i}\right|
$$

donde $n$ y $\hat{x}_{i}$ son el número total de observaciones y los valores de $\mathrm{ET}_{0}$ calculados, respectivamente, $x_{i}$ son los valores de referencia, y $\bar{x}$ es el valor medio de los valores de referencia.

\section{3- Resultados y Discusión}

En la Tabla 1 se presentan los valores medios de AHC obtenidos por mes y estación, promediados a partir de los valores diarios calculados. Aunque el objetivo del estudio va más encaminado a evaluar los modelos de estimación de AHC, estos valores también tienen valor para ser aplicados en las estaciones estudiadas por mes o globalmente. Dicha tabla revela que las oscilaciones del valor de AHC pueden llegar a ser relevantes dentro del ciclo anual. Los rangos anuales medios de AHC oscilan entre 0.00014 (0.00206-0.00192, estación 25) y 0.00098 (0.00341-0.00243, estación 27).

La Tabla 2 muestra los indicadores medios de los modelos 1 y 2 en todas las estaciones usando AHC diarios y AHC medios mensuales. Estos resultados revelan que la consideración de un modelo de AHC para cada mes permite reducir el error relativo del modelo 1 (temperatura e información geográfica como inputs) alrededor de 0.02 (0.1092 vs. $0.1257)$ a escala diaria y alrededor de 0.01 (0.0519 vs. 0.0633) a escala media mensual. Los modelos estacionales sólo mejoran muy levemente el error medio de los modelos anuales ( 0.1225 vs. 0.1257 y 0.0504 vs. 0.0633 ). Las mismas pautas cualitativas se mantienen al comparar las escalas mensual, estacional y anual del modelo 2 (que incluye, además, velocidad cualitativa del viento).

Finalmente, como era de esperar atendiendo a los resultados ya presentados por Martí et al. (2015), los índices del modelo 2 mejoran respecto de los del modelo 1 , 
precisamente por incluir información cualitativa sobre el régimen de velocidad del viento local. La reducción de los rangos de los errores en los modelos que consideran AHC medios mensuales se explica por la reducción de la variabilidad introducida al promediar las variables. Sin embargo, cuando se calcule la $\mathrm{ET}_{0}$, los modelos de escala diaria considerarán un AHC estimado diferente para cada día, mientras que los modelos de la escala mensual asignarán el mismo AHC estimado para todos los días del mismo mes.

Tabla 1. Valores mensuales medios de AHC en las estaciones estudiadas.

\begin{tabular}{|c|c|c|c|c|c|c|c|c|c|c|c|c|}
\hline \multirow{2}{*}{ e } & \multicolumn{12}{|c|}{ mes } \\
\hline & 1 & 2 & 3 & 4 & 5 & 6 & 7 & 8 & 9 & 10 & 11 & 12 \\
\hline 1 & 0.00288 & 0.00262 & .00254 & 0.00250 & 0.00249 & 0.00257 & 0.00262 & 0.00261 & 0.00263 & 0.00264 & 0.00293 & 0.00304 \\
\hline 2 & 0.00237 & 0.00227 & 0.00230 & 0.00236 & 0.00233 & 0.00238 & 0.00250 & 0.00250 & 0.00250 & 0.00231 & 0.00252 & 0.00248 \\
\hline 3 & 00273 & 0.00245 & .00234 & 0.00238 & 0.00233 & 0.00236 & 0.00246 & 0.00251 & 0.00254 & 0.00257 & 0.00279 & 0.00279 \\
\hline 4 & 0.00257 & 0.00240 & 0.00234 & 0.00230 & 0.00229 & 0.00238 & 0.00251 & 0.00246 & 0.00239 & 0.00220 & 0.00276 & 0.00264 \\
\hline 5 & 0.00251 & 0.00238 & 0.00228 & 0.00231 & 0.00229 & 0.00232 & 0.00249 & 0.00245 & 0.00252 & 0.00240 & 0.00269 & 0.00271 \\
\hline 6 & 0.00194 & 0.00190 & 0.00190 & 0.00196 & 0.00195 & 0.00199 & 0.00210 & 0.00207 & 0.00209 & 0.00201 & 0.00212 & 0.00209 \\
\hline 7 & 0.00195 & 0.00192 & 0.00192 & 0.00197 & 0.00191 & 0.00198 & 0.00206 & 0.00203 & 0.00199 & 0.00195 & 0.00211 & 0.00205 \\
\hline 8 & 0.00177 & 0.00174 & 0.00179 & 0.00188 & 0.00186 & 0.00191 & 0.00199 & 0.00197 & 0.00193 & 0.00185 & 0.00190 & 0.00183 \\
\hline 9 & 0.00254 & 0.00235 & 0.00226 & 0.00229 & 0.00221 & 0.00225 & 0.00234 & 0.00231 & 0.00233 & 0.00238 & 0.00263 & 0.00272 \\
\hline 10 & 0.00207 & 0.00200 & 0.00197 & 0.00210 & 0.00204 & 0.00213 & 0.00225 & 0.00225 & 0.00223 & 0.00212 & 0.00225 & 0.00209 \\
\hline 11 & 00258 & 0.00244 & 0.00239 & 0.00236 & 0.00233 & 0.00237 & 0.00247 & 0.00246 & 0.00241 & 0.00241 & 0.00269 & 0.00272 \\
\hline 12 & 00200 & 0.00201 & 0.00192 & 0.00201 & 0.00195 & 0.00202 & 0.00213 & 0.00206 & 0.00203 & 0.00199 & 0.00202 & 0.00189 \\
\hline 13 & 0.00205 & 0.00200 & 0.00205 & 0.00211 & 0.00209 & 0.00218 & 0.00225 & 0.00225 & 0.00223 & 0.00210 & 0.00226 & 0.00213 \\
\hline 14 & 00278 & 0.00263 & .00241 & 0.00240 & 0.00232 & 0.00226 & 0.00242 & 0.00243 & 0.00245 & 0.00241 & 0.00284 & 0.00289 \\
\hline 15 & 0.00201 & 0.00199 & 0.00198 & 0.00197 & 0.00195 & 0.00200 & 0.00205 & 0.00200 & 0.00204 & 0.00201 & 0.00218 & 0.00212 \\
\hline 16 & 0.00293 & 0.00267 & 0.00259 & 0.00248 & 0.00237 & 0.00237 & 0.00242 & 0.00246 & 0.00246 & 0.00253 & 0.00279 & 0.00294 \\
\hline 17 & 0.00164 & 0.00171 & 0.00181 & 0.00181 & 0.00183 & 0.00187 & 0.00201 & 0.00199 & 0.00197 & 0.00186 & 0.00186 & 0.00174 \\
\hline 18 & 00159 & 0.00162 & 0.00171 & 0.00180 & 0.00176 & 0.00188 & 0.00197 & 0.00196 & 0.00189 & 0.00178 & 0.00173 & 0.00158 \\
\hline 19 & 0.00284 & 0.00251 & .00240 & 0.00230 & 0.00216 & 0.00216 & 0.00220 & 0.00217 & 0.00218 & 0.00227 & 0.00265 & 0.00288 \\
\hline 20 & 0.00220 & 0.00222 & 0.00216 & 0.00207 & 0.00194 & 0.00195 & 0.00206 & 0.00206 & 0.00202 & 0.00204 & 0.00224 & 0.00225 \\
\hline 21 & 0.00295 & 0.00288 & 0.00275 & 0.00259 & 0.00245 & 0.00254 & 0.00263 & 0.00259 & 0.00259 & 0.00262 & 0.00295 & 0.00300 \\
\hline 22 & 0.00235 & 0.00235 & 0.00234 & 0.00226 & 0.00220 & 0.00229 & 0.00235 & 0.00231 & 0.00230 & 0.00222 & 0.00232 & 0.00242 \\
\hline 23 & 0.00276 & 0.00253 & 0.00237 & 0.00223 & 0.00202 & 0.00193 & 0.00199 & 0.00202 & 0.00205 & 0.00222 & 0.00257 & 0.00275 \\
\hline 24 & 0.00272 & 0.00256 & 0.00239 & 0.00233 & 0.00212 & 0.00215 & 0.00222 & 0.00222 & 0.00225 & 0.00232 & 0.00274 & 0.00278 \\
\hline 25 & 0.00201 & 0.00197 & 0.00199 & 0.00200 & 0.00192 & 0.00197 & 0.00205 & 0.00205 & 0.00204 & 0.00196 & 0.00206 & 0.00194 \\
\hline 26 & 0.00228 & 0.00217 & 0.00209 & 0.00204 & 0.00185 & 0.00180 & 0.00183 & 0.00183 & 0.00190 & 0.00206 & 0.00234 & 0.00232 \\
\hline 27 & 0.00341 & 0.00303 & 0.00284 & 0.00264 & 0.00243 & 0.00245 & 0.00247 & 0.00250 & 0.00255 & 0.00273 & 0.00322 & 0.00341 \\
\hline 28 & 0.00251 & 0.00242 & 0.00242 & 0.00234 & 0.00223 & 0.00231 & 0.00238 & 0.00242 & 0.00247 & 0.00249 & 0.00258 & 0.00259 \\
\hline 29 & 0.00245 & 0.00243 & 0.00240 & 0.00228 & 0.00218 & 0.00221 & 0.00227 & 0.00225 & 0.00229 & 0.00225 & 0.00240 & 0.00248 \\
\hline 30 & 0.00239 & 0.00239 & 0.00236 & 0.00226 & 0.00211 & 0.00210 & 0.00216 & 0.00222 & 0.00225 & 0.00228 & 0.00243 & 0.00240 \\
\hline
\end{tabular}

La figura 2 presenta los valores desglosados del RRMSE para los modelos 1 y 2 considerando el intervalo mensual y la escala diaria de AHC. Se comprueba que la estimación de los AHC presenta errores relativos considerablemente menores de mayo a septiembre que en el resto de meses, especialmente en invierno (noviembre a febrero). Ello podría vincularse a una menor variabilidad de los parámetros climáticos durante ese periodo. 
El desglose del error anual en errores mensuales, i.e. utilizando modelos anuales, presenta un patrón similar (resultados no mostrados). Asimismo, las diferencias de RRMSE entre los modelos 1 y 2 parecen reducirse también entre mayo y septiembre, lo que podría indicar que los datos de temperatura tendrían un nivel de significación más alto que los de velocidad cualitativa del viento durante este periodo en la estimación de $\mathrm{AHC}_{\mathrm{H}} \mathrm{ET}_{\mathrm{o}}$.

Tabla 2. Indicadores de los modelos de AHC para las escalas temporales consideradas.

\begin{tabular}{|c|c|c|c|c|}
\hline \multirow{3}{*}{ intervalo } & \multirow{5}{*}{ modelo } & \multicolumn{3}{|c|}{$\begin{array}{c}\text { AHC } \\
(-)\end{array}$} \\
\cline { 3 - 5 } & \multicolumn{5}{|c|}{$\begin{array}{c}\text { RRMSE } \\
(-)\end{array}$} & $\begin{array}{c}\text { MAE } \\
(-)\end{array}$ \\
\hline \multirow{2}{*}{ mes } & 1 & 0.1092 & 0.570 & 0.000177 \\
\cline { 2 - 5 } & 2 & 0.0895 & 0.711 & 0.000145 \\
\hline \multirow{2}{*}{ estación } & 1 & 0.1225 & 0.459 & 0.000204 \\
\cline { 2 - 5 } & 2 & 0.0972 & 0.659 & 0.000156 \\
\hline \multirow{2}{*}{ año } & 1 & 0.1257 & 0.431 & 0.000207 \\
\cline { 2 - 5 } & 2 & 0.1063 & 0.592 & 0.000174 \\
\hline \multirow{2}{*}{ mes } & 1 & 0.0519 & 0.853 & 0.0000885 \\
\cline { 2 - 5 } & 2 & 0.0416 & 0.905 & 0.0000699 \\
\hline \multirow{2}{*}{ estación } & 1 & 0.0504 & 0.861 & 0.0000859 \\
\cline { 2 - 5 } & 2 & 0.0425 & 0.901 & 0.0000711 \\
\hline \multirow{2}{*}{ año } & 1 & 0.0633 & 0.782 & 0.000112 \\
\cline { 2 - 5 } & 2 & 0.0551 & 0.834 & 0.0000976 \\
\hline
\end{tabular}




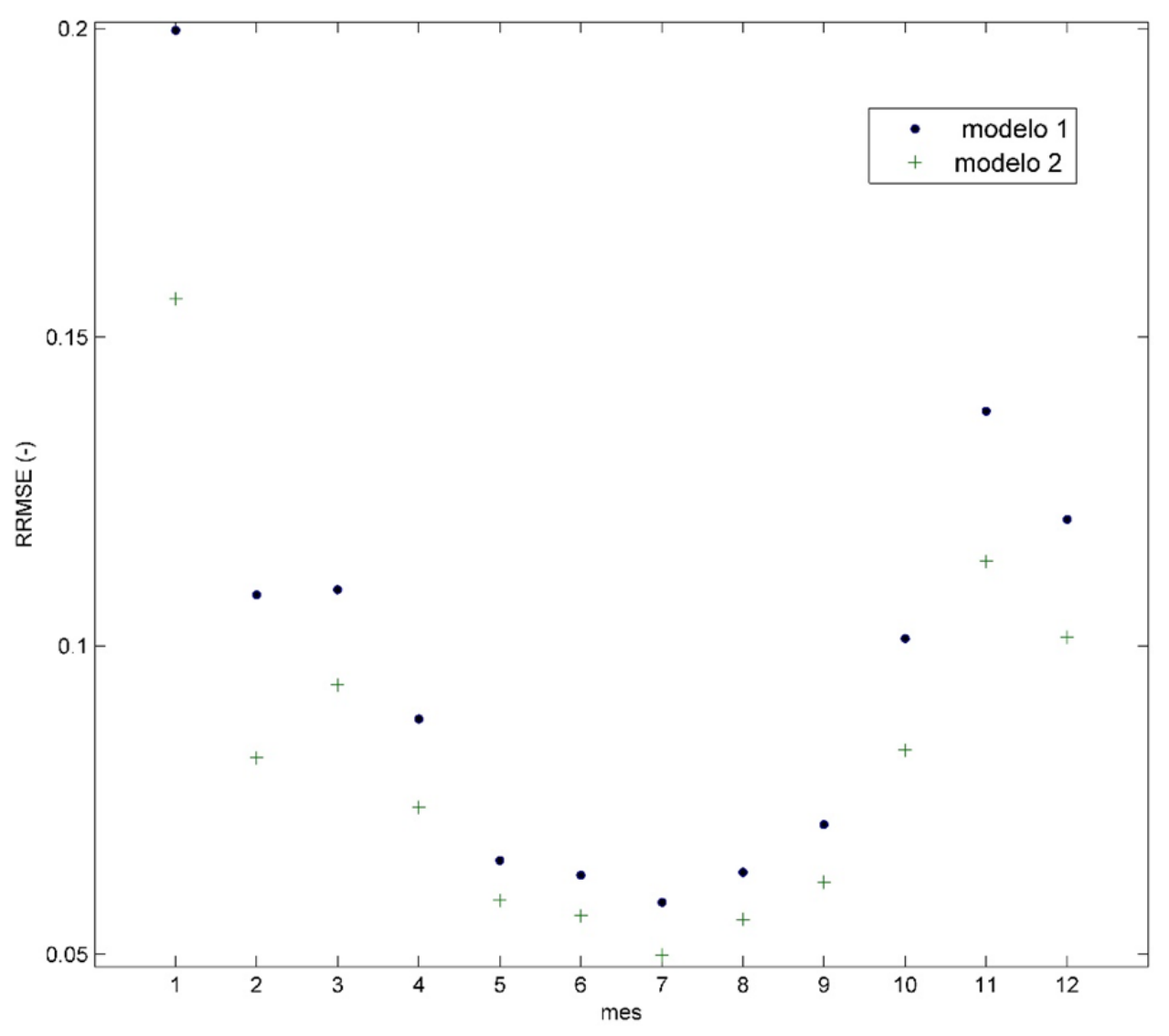

Figura 2. Valores del RRMSE medio por mes de los 12 modelos mensuales 1 y 2 en las 30 estaciones para el caso de escala diaria de AHC.

\section{4- Conclusiones}

Este trabajo presenta un análisis comparativo de modelos para estimar el coeficiente ajustado de Hargreaves considerando diferentes criterios temporales para definir los datos de calibración. Concretamente, se compararon tres escalas temporales en el desglose del set de datos para calibrar el modelo: la anual, la mensual y la estacional. Además, las tres escalas anteriores se aplicaron en modelos para estimar valores diarios de AHC y en modelos para estimar valores medios mensuales de AHC. $Y$ todo ello para dos combinaciones de inputs: una basada en datos geográficos y térmicos, y otra que incluía, además, velocidad cualitativa del viento (poco ventoso, muy ventoso).

Los resultados sugieren que el desarrollo de modelos mensuales podría reducir el error relativo alrededor de un $2 \%$ para valores diarios de $\mathrm{AHC}$ y alrededor de un $1 \%$ para valores medios mensuales de AHC, es decir, la aplicación de un solo modelo anual para estimar un único valor de AHC por estación podría ser insuficiente para recoger toda la variabilidad anual de AHC. Por ello, la aplicación de diferentes modelos mensuales (o estacionales) podría estar justificado para una correcta estimación de los AHC.

El desglose por mes de los indicadores de los AHC sugiere que la estimación de mayo a septiembre es más precisa que de octubre a abril, y particularmente, que de noviembre a enero. Esto se produce tanto para la estimación de los AHC a partir de modelos mensuales como para el desglose por mes de las estimaciones de los modelos anuales. Ello podría deberse a una menor variabilidad de los parámetros climáticos, incluyendo la $\mathrm{ET}_{\circ}$ y el $\mathrm{AHC}$, durante estos meses.

El estudio de modelos paramétricos de $\mathrm{AHC}$ es de especial relevancia para la aplicación de la ecuación de Hargreaves. Ello se debe, por una parte, a que se recomienda 
calibrar la ecuación original antes de ser aplicada localmente, y, por otra parte, a que dicha calibración no podrá efectuarse a partir de valores de referencia de la ecuación FAO56 PM, ya que sólo habría valores medidos de temperaturas disponibles y/o fiables. La única excepción sería una situación de fallo del sistema de medida. En este caso, además de valores de temperatura, también habría valores históricos locales de FAO56 PM, que permitirían calibrar la ecuación de Hargreaves con valores locales de AHC.

\section{5- Bibliografía}

Allen, R.G., Pereira, L.S., Raes, D., Smith, M. (1998). Crop evapotranspiration. Guidelines for computing water requirements. FAO Irrigation and Drainage, Paper 56. FAO, Rome.

Di Stefano, C., Ferro, V. (1997). Estimation of evapotranspiration by Hargreaves formula and remote sensed data in semi-arid Mediterranean areas. J. Agric. Eng. Res., 68, 189199.

Droogers, P. \& Allen, R.G. (2002). Estimating reference evapotranspiration under inaccurate data conditions. Irrig. Drain. Syst., 16(1), 33-45.

Gavilán, P., Lorite, I.J., Tornero, S., Berengena, J. (2006). Regional calibration of Hargreaves equation for estimating reference ET in a semi arid environment. Agric. Water Manage., 81, 257-281.

Hargreaves, G.H. \& Allen, R.G. (2003). History and evaluation of Hargreaves evapotranspiration equation. J. Irrig. Drain. Eng., 129(1), 53-63.

Hargreaves, G.H., Samani, Z.A. (1985). Reference crop evapotranspiration from ambient air temperature. Appl. Eng. Agric. 1 (2), 96-99.

Jensen, D.T., Hargreaves, G.H., Temesgen, B., Allen, R.G. (1997). Computation of ET。 under non ideal conditions. J. Irrig. Drain. Eng, 123(5), 394-400.

Lee, K.H. (2010). Relative comparison of the local recalibration of the temperature-based equation for the Korea Peninsula. J. Irrig. Drain. Eng., 136(9), 585-594.

López-Urrea, R., Martín de Santa Olalla, F., Fabeiro, C., Moratalla, A. (2006) Testing evapotranspiration equations using lysimeter observations in a semiarid climate. Agric. Water. Manage., 85(1-2), 15-26.

Maestre-Valero, J.F., Martínez-Álvarez, V., González-Real, M.M. (2013). Regionalization of the Hargreaves coefficient to estimate long-term reference evapotranspiration series in SE Spain. Span. J. Agric. Res., 11(4), 1137-1152.

Martí, P. \& Zarzo, M. (2012). Multivariate statistical monitoring of $E T_{0}$. A new approach for estimation in nearby locations using geographical inputs. Agr. Forest. Meteorol., 152(1), 125-134.

Martí, P., Zarzo, M., Vanderlinden, K., Girona, J. (2015). Parametric expressions for the adjusted Hargreaves coefficient in Eastern Spain. J. Hydrol., 529(10), 1713-1724.

Martínez-Cob, A., Tejero Juste, M. (2004). A wind-based qualitative calibration of the Hargreaves $\mathrm{ET}_{0}$ estimation equation in semiarid regions. Agric. Water Manage., 64(3), 251-264.

Mendicino, G., Senatore, A. (2013). Regionalization of the Hargreaves coefficient for the assessment of distributed reference evapotranspiration in Southern Italy. J. Irrig. Drain. Eng., 139(5), 349-362.

Ravazzani, G., Corbari, C., Morella, S., Gianoli, P., Mancini, M. (2012). Modified HargreavesSamani equation for the assessment of reference evapotranspiration in Alpine River Basins. J. Irrig. Drain. Eng., 138(7), 592-599.

Samani, Z. (2000). Estimating solar radiation and evapotranspiration using minimum climatological data. J. Irrig. Drain. Eng., 126(4), 265-267.

Shahidian, R., Serralheiro, P., Serrano, J., Teixeira, J.L. (2013). Parametric calibration of the Hargreaves-Samani equation for use at new locations. Hydrol. Process., 27(4), 605616. 
Thepadia, M. \& Martínez, C.J. (2012). Regional calibration of solar radiation and reference evapotranspiration estimates with minimal data in Florida. J. Irrig. Drain. Eng., 138(2), 111-119.

Vanderlinden, K., Giráldez, J. V., and Van Meirvenne, M. (2004). Assessing reference evapotranspiration by the Hargreaves method in Southern Spain. J. Irrig. Drain. Eng., 130(3), 184-191. 


\title{
GESTIÓN ECONÓMICAMENTE OPTIMIZADA DEL AGUA DE RIEGO EN UNA EXPLOTACIÓN AGRÍCOLA MEDIANTE EL MODELO "MOPECO"
}

\author{
Martínez, A.(1)(P), Martínez-Romero, A.(2), López-Mata, E.(2), Tarjuelo, J.M.(2), Pardo, J.J.
}

(1), Domínguez, A.(2)

1 Ingeniero Agrónomo, Doctorando, Universidad de Castilla-La Mancha. Antonio.Martinez26@alu.uclm.es

${ }^{2}$ Investigador, Centro Regional de Estudios del Agua (CREA), Universidad de Castilla-La Mancha, Ctra. de Las Peñas, km 3.2 ,02071 Albacete (Spain), Angel.MRomero@uclm.es; Eulogio.Lopez@uclm.es; Jose.Tarjuelo@uclm.es; JoseJesus.Pardo@uclm.es; Alfonso.Dominguez@uclm.es

\section{1- Introducción y Objetivos}

Es un hecho que los recursos hídricos para la agricultura en Castilla-La Mancha son escasos y el coste de utilización de éstos cada vez más elevado, por lo que los márgenes brutos obtenidos por los agricultores están llegando a los límites de la viabilidad económica.

Desde hace varios años se viene desarrollando en el CREA el modelo MOPECo (modelo de optimización económica del agua de riego) (Ortega et al., 2004), cuya finalidad es maximizar el margen bruto de beneficio de las explotaciones de regadío mediante una mayor eficiencia en el uso del agua de riego. Para una superficie regable y una cantidad de agua de riego disponible limitada, este modelo determina la superficie y la cantidad de agua de riego a aplicar a cada cultivo, estableciendo estrategias de riego deficitario optimizado por etapas (ORDI) (Domínguez et al., 2012) que maximizan la eficiencia en el uso del agua de riego en términos de kilogramo de cosecha por $\mathrm{mm}$ de agua aplicada.

En explotaciones que disponen de una cantidad limitada de agua de riego, parte de la explotación puede quedar sin cultivar (salvo con cultivos de secano) si se introducen en la rotación cultivos de altas necesidades, por lo que la aplicación de técnicas de riego deficitario permitiría incrementar el porcentaje de superficie regable cultivada de la explotación, pudiendo incrementar el margen bruto total obtenido.

El objetivo de este trabajo es aplicar MOPECO en una explotación de regadío real, y comparar los resultados económicos obtenidos con el manejo tradicional del riego de la misma, es decir, aplicando a los cultivos la cantidad de agua suficiente para cubrir sus necesidades, para una distribución de tres cultivos: cebada, cebolla y maíz.

\section{2- Materiales y métodos}

El trabajo de campo se ha realizado en una explotación de regadío ubicada en la provincia de Albacete. Los cultivos a introducir en la distribución que se pretende optimizar son: maíz C700, cebolla grano y cebada.

En todos los cultivos se han realizado dos tipos diferentes de estrategias de riego (No deficitario y ORDI) con cuatro repeticiones durante la campaña 2015. En el No deficitario se ha tratado de cubrir el $100 \%$ de las necesidades hídricas de los cultivos, 
calculadas según la metodología FAO (Allen et al., 1998) y en el segundo tratamiento el modelo MOPECO ha determinado el nivel de déficit global y por etapa a aplicar a cada cultivo, así como el calendario de riegos deficitarios, basado en la metodología ORDI, capaz de lograr los objetivos de déficit. La metodología ORDI (optimized regulated deficit irrigation) determina los niveles de déficit óptimos a aplicar (relación ETa/ETm) en cada etapa de desarrollo de los cultivos herbáceos en función del nivel de déficit global que se desee alcanzar. Para el control efectivo del contenido de humedad del suelo, se han utilizado sensores de tipo tensiómetro (Watermark) y volumétrico (Enviroscan), cuyas lecturas se han comparado con las estimadas por el modelo MOPECO. Los datos climáticos utilizados pertenecen a la estación "El Sanchón" (Casas de Fernando Alonso, Cuenca), situada próxima a la explotación y perteneciente a la red de estaciones SIAR.

Una vez obtenidos los valores de cosecha de los cultivos para ambos tratamientos, se han calculado y comparado los márgenes brutos reales obtenidos con las dos estrategias para un escenario económico (Tabla 1). Así, se ha considerado una explotación de 100 ha regables con una dotación de $5.000 \mathrm{~m}^{3} / \mathrm{ha}$. Con el fin de lograr una distribución de cultivos lo más realista posible en términos de cumplimiento de la normativa establecida por la PAC, así como los condicionantes agronómicos que recomiendan realizar una adecuada rotación de cultivos, se ha establecido que la superficie mínima que se debe dedicar a cada cultivo es de 20 ha.

Tabla 1. Precios de venta, costes de cultivo y coste del agua de riego.

Coste del agua $\left(€ / \mathrm{m}^{3}\right): 0,12 €$

\begin{tabular}{cccc}
\multicolumn{2}{c}{ Precio venta cosecha $(€ / \mathbf{K g})$} & Paja $(€ / \mathbf{K g})$ & Coste cultivo $(€ /$ ha \\
\hline Cebada & 0,16 & 0,04 & 580,20 \\
Cebolla & 0,11 & & $2.924,90$ \\
Maíz & 0,17 & 0,02 & $1.751,00$
\end{tabular}

\section{3- Resultados y discusión.}

Mopeco determinó como niveles globales de déficit: $70 \%$ de la ETm para cebada, y $90 \%$ de la ETm para cebolla y maíz. Los niveles de déficit (entendidos como relaciones $\mathrm{ETa} / \mathrm{ETm}$ ) a aplicar en cada una de las etapas de desarrollo de estos tres cultivos según ORDI aparecen recogidos en la Tabla 2. Bajo condiciones reales de cultivo, en ocasiones no es posible alcanzar las relaciones ETa/ETm objetivo como consecuencia de la distribución de las lluvias y los condicionantes que afectan al manejo de los sistemas de riego (Tabla 2).

Tabla 2. Relaciones ETa/ETm objetivo por etapas y reales alcanzadas.

TRATAMIENTOS SIN DÉFICIT

\begin{tabular}{|c|c|c|c|c|c|c|}
\hline & \multicolumn{2}{|c|}{ Cebada } & \multicolumn{2}{|c|}{ Cebolla } & \multicolumn{2}{|c|}{ Maíz } \\
\hline $\begin{array}{l}\text { Etapas } \\
\text { fenológicas }\end{array}$ & $\begin{array}{l}\text { ETa/ETm } \\
\text { real }\end{array}$ & $\begin{array}{l}\text { ETa/ETm } \\
\text { objetivo }\end{array}$ & $\begin{array}{l}\text { ETa/ETm } \\
\text { real }\end{array}$ & $\begin{array}{l}\text { ETa/ETm } \\
\text { objetivo }\end{array}$ & $\begin{array}{l}\text { ETa/ETm } \\
\text { real }\end{array}$ & $\begin{array}{c}\text { ETa/ETm } \\
\text { objetivo }\end{array}$ \\
\hline Establecimiento & 1,00 & 1,00 & 0,99 & 1,00 & 1,00 & 1,00 \\
\hline $\begin{array}{l}\text { Desarrollo } \\
\text { vegetativo }\end{array}$ & 1,00 & 1,00 & 0,95 & 1,00 & 1,00 & 1,00 \\
\hline Floración & 0,97 & 1,00 & --- & --- & 0,99 & 1,00 \\
\hline $\begin{array}{l}\text { Desarrollo del } \\
\text { grano } \\
\text { /bulbificación }\end{array}$ & 0,95 & 1,00 & 0,95 & 1,00 & 1,00 & 1,00 \\
\hline Maduración & 0,96 & 1,00 & 0,94 & 1,00 & 0,99 & 1,00 \\
\hline
\end{tabular}


TRATAMIENTOS ORDI

\begin{tabular}{lcccccc} 
& \multicolumn{2}{c}{ Cebada } & \multicolumn{2}{c}{ Cebolla } & \multicolumn{2}{c}{ Maíz } \\
\hline Etapas & $\begin{array}{c}\text { ETa/Etm } \\
\text { real }\end{array}$ & $\begin{array}{c}\text { ETa/Etm } \\
\text { objetivo }\end{array}$ & $\begin{array}{c}\text { ETa/Etm } \\
\text { real }\end{array}$ & $\begin{array}{c}\text { ETa/Etm } \\
\text { objetivo }\end{array}$ & $\begin{array}{c}\text { ETa/Etm } \\
\text { real }\end{array}$ & $\begin{array}{c}\text { ETa/Etm } \\
\text { objetivo }\end{array}$ \\
Establecimiento & 1,00 & 0,80 & 0,96 & 0,88 & 1,00 & 0,80 \\
Desarrollo & 0,75 & 0,55 & 0,89 & 0,92 & 0,67 & 0,70 \\
vegetativo & 0,74 & 0,80 & --- & --- & 0,98 & 1,00 \\
Floración & 0,54 & 0,79 & 0,95 & 1,00 & 1,00 & 0,99 \\
Desarrollo del & 0,55 & 0,54 & 0,68 & 0,65 & 0,85 & 0,94 \\
grano /bulbificación & $\mathbf{0 , 7 0}$ & $\mathbf{0 , 7 0}$ & $\mathbf{0 , 9 0}$ & $\mathbf{0 , 9 0}$ & $\mathbf{0 , 9 2}$ & $\mathbf{0 , 9 0}$ \\
Maduración & & & & & &
\end{tabular}

Las figuras 1 y 2 muestran, a modo de ejemplo para el maíz, la evolución del contenido de humedad del suelo teórico según el modelo y la distribución de los riegos. En el caso de los tratamientos no deficitarios (Fig. 1) el objetivo fue que el contenido de humedad del suelo (línea negra), se mantuviera por encima del nivel de agotamiento disponible (línea gris), con el fin de que el cultivo no entrara en estrés. La Figura 2, muestra como durante las etapas de desarrollo vegetativo y maduración, el contenido de humedad del suelo estuvo por debajo del nivel de agotamiento disponible hasta alcanzar la relación $\mathrm{ETa} / \mathrm{ETm}$ objetivo de estas etapas (línea negra rayada) (Tabla 2). Las líneas verticales indican el momento en el que se produce el cambio de etapa.

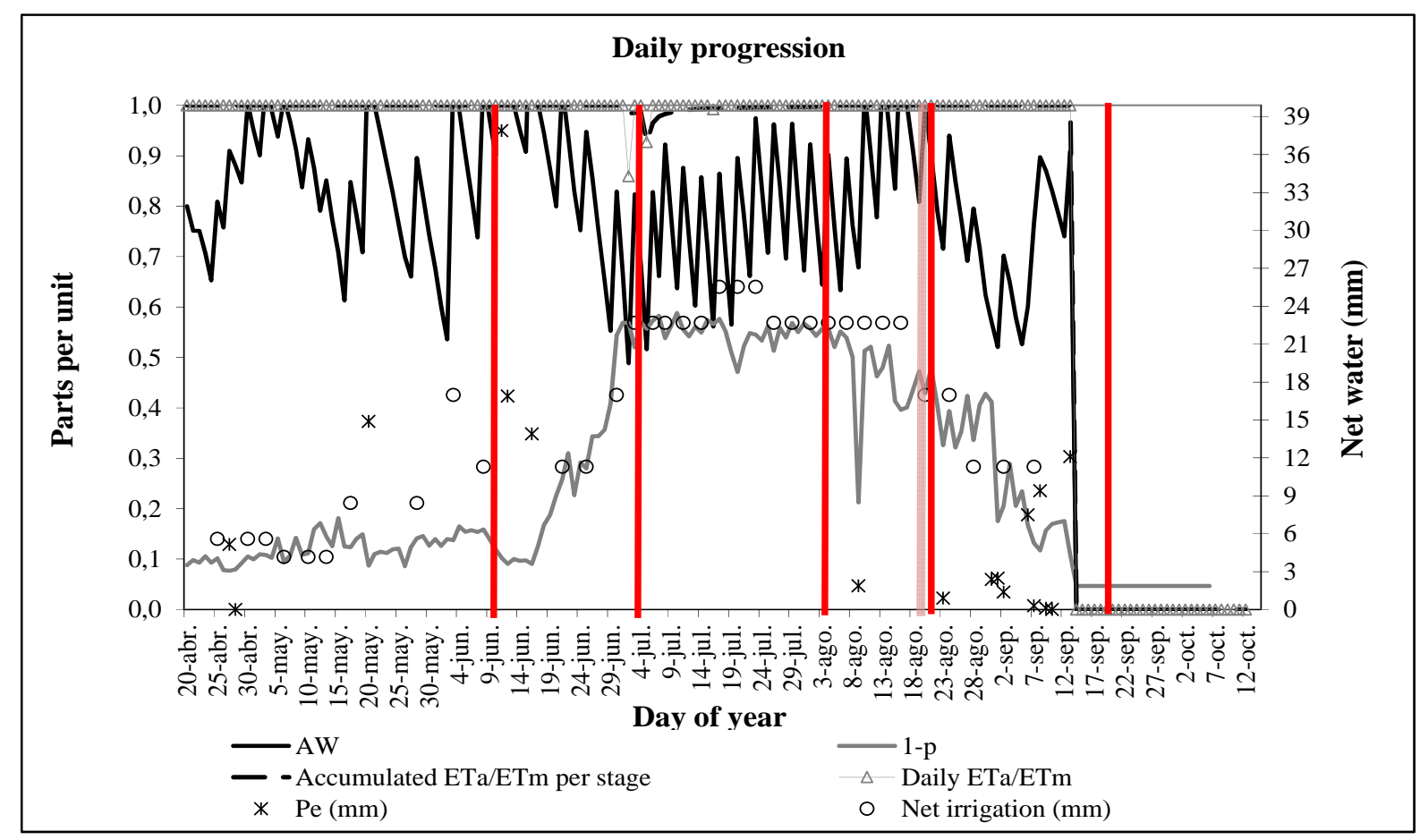

Figura 1. Evolución del agua en el suelo en Maíz Sin Déficit. 


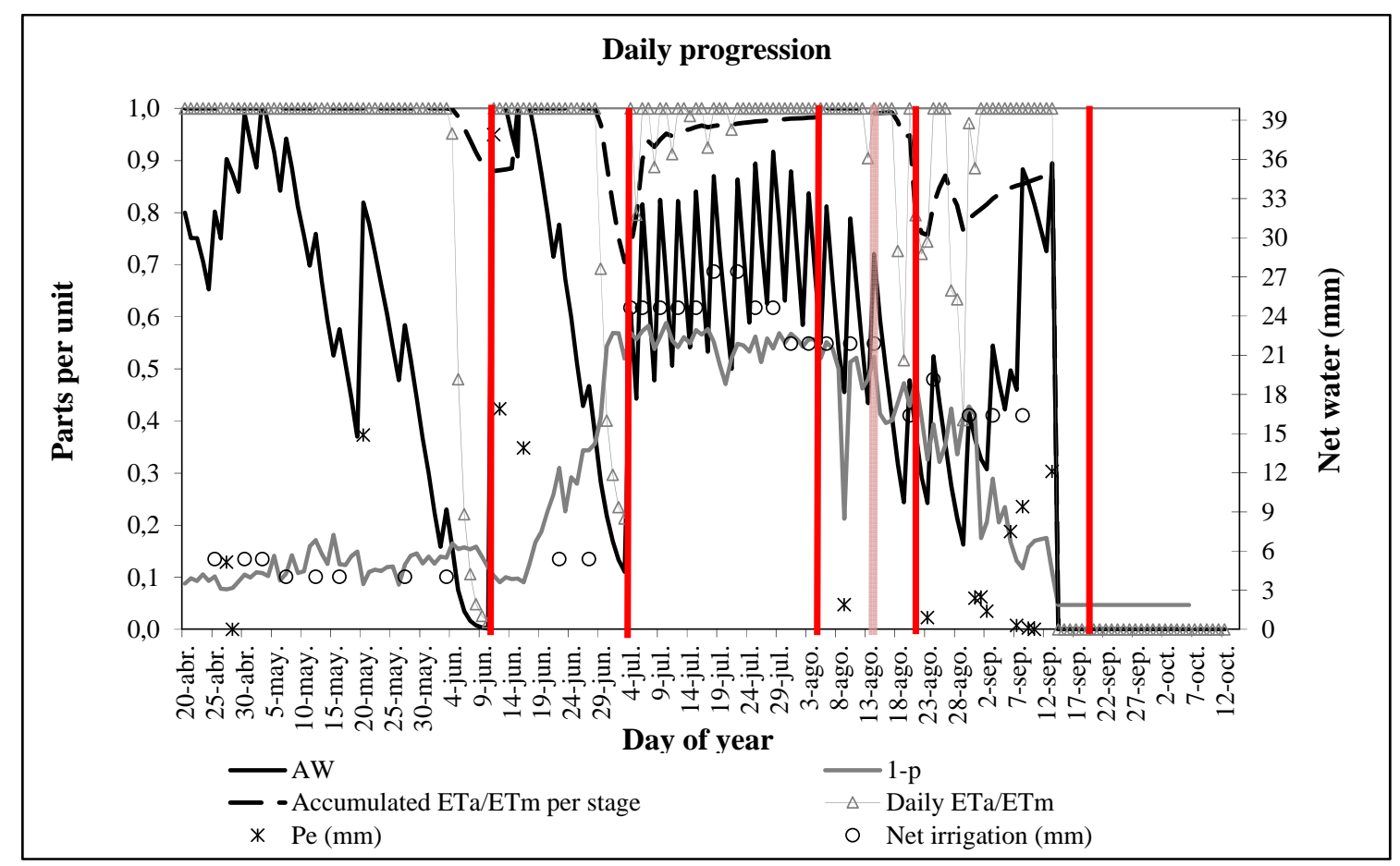

Figura 2. Evolución del agua en el suelo en Maíz ORDI.

Las figuras 3 y 4 muestran la evolución del contenido de humedad del suelo registrado por los sensores volumétricos a 3 profundidades para el caso del maíz.

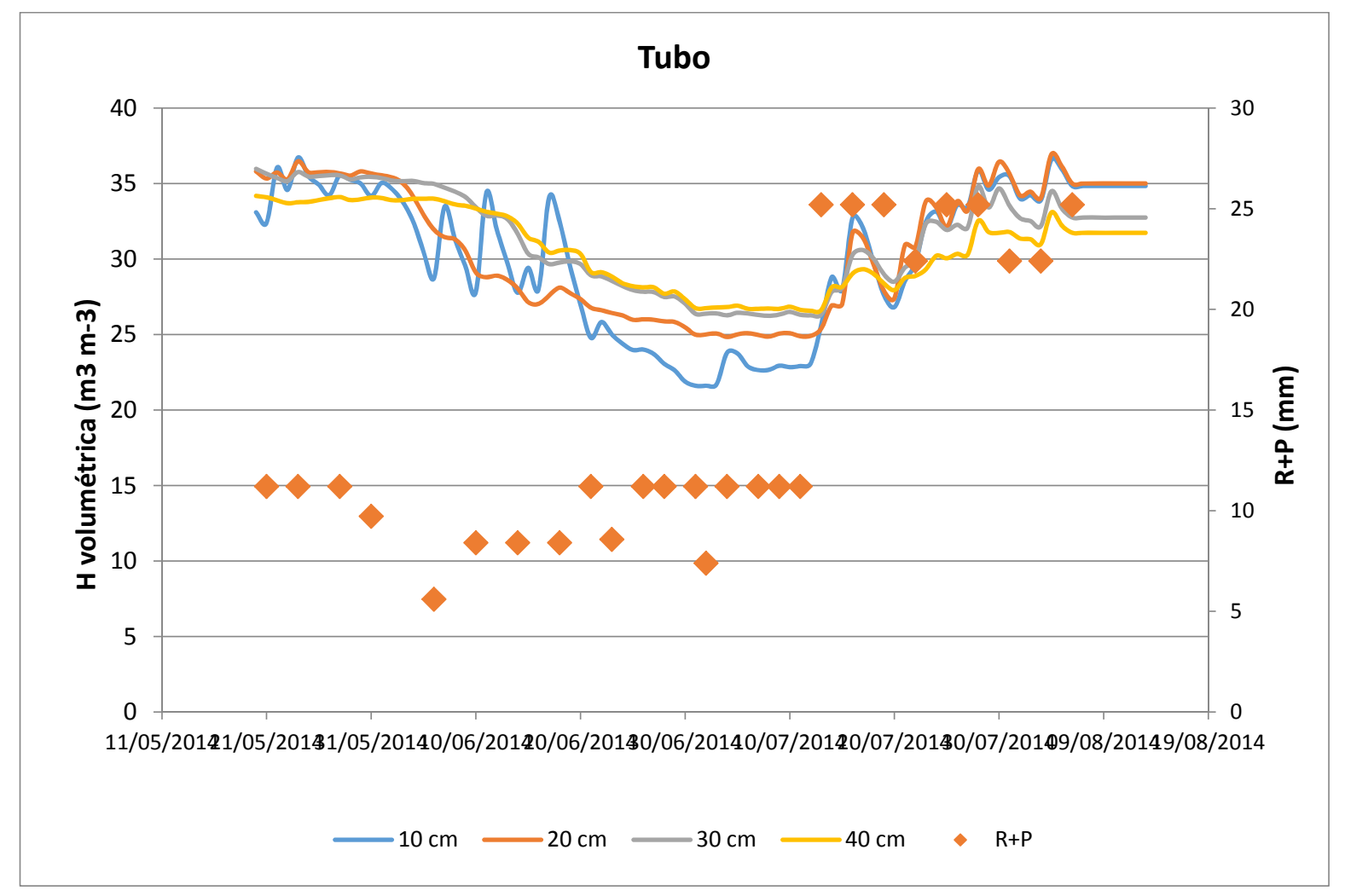

Figura 3. Lectura sonda Enviroscan en Maíz Sin Déficit. 


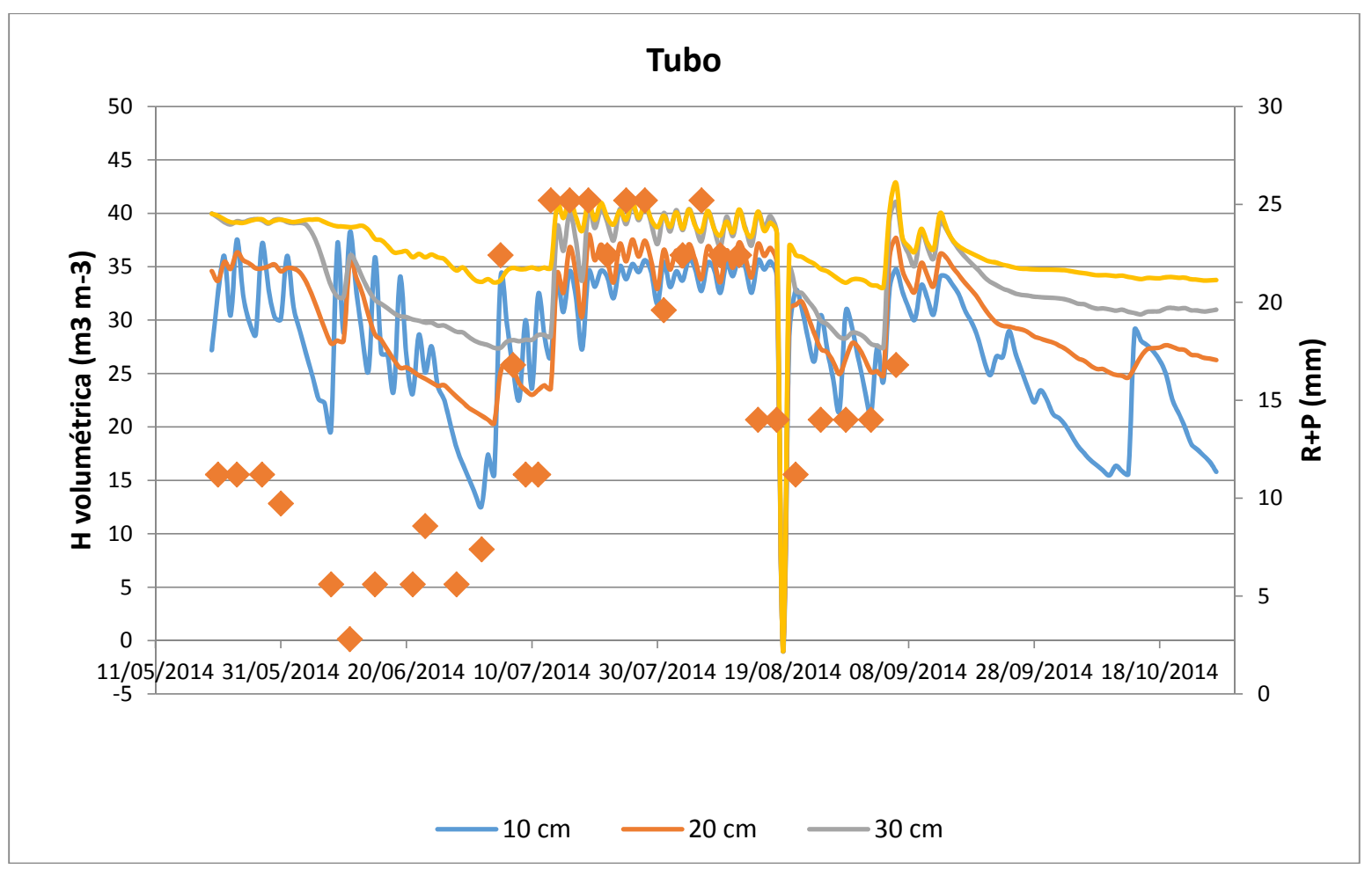

Figura 4. Lecturas sonda Enviroscan en Maíz ORDI.

El modelo MOPECO asignó menores restricciones de agua a los cultivos más rentables como el maíz o la cebolla, es decir, propuso un menor déficit (máximo 10\%). En consecuencia se encontraron menores diferencias de rendimiento neto entre los tratamientos sin restricciones (metodología FAO) y los tratamientos ORDI en estos cultivos (cebolla y maíz) que entre los dos tratamientos de la cebada (Tabla 3). La principal diferencia entre las estrategias es que los tratamientos deficitarios obtuvieron una mayor eficiencia en el uso del agua tanto en términos de rendimiento (EUAY) como en el de margen bruto obtenido (EUAMB) por unidad de volumen de agua de riego aplicada.

Tabla 3. Rendimientos y eficiencias en el uso del agua.

\begin{tabular}{|c|c|c|c|c|c|c|c|c|c|c|}
\hline \multirow[b]{2}{*}{ Cultivo } & \multicolumn{3}{|c|}{ Rendimiento (kg/ha) } & \multicolumn{3}{|c|}{ Agua de riego $\left(\mathrm{m}^{3} / \mathrm{ha}\right)$} & \multicolumn{2}{|c|}{$\operatorname{EUAY}\left(\mathbf{k g} / \mathrm{m}^{3}\right)$} & \multicolumn{2}{|c|}{ EUAMB $\left(€ / m^{3}\right)$} \\
\hline & ORDI & $\begin{array}{c}\text { No } \\
\text { déficit }\end{array}$ & $\begin{array}{c}\text { Diferencia } \\
\text { (\%) }\end{array}$ & ORDI & $\begin{array}{c}\text { No } \\
\text { déficit }\end{array}$ & $\begin{array}{l}\text { Diferencia } \\
\text { (\%) }\end{array}$ & ORDI & $\begin{array}{c}\text { No } \\
\text { déficit }\end{array}$ & ORDI & $\begin{array}{c}\text { No } \\
\text { déficit }\end{array}$ \\
\hline & 7479 & 9441 & 26,2 & 2184 & 3220 & 47,4 & 3,42 & 2,93 & 0,30 & 0,29 \\
\hline Cebolla & 91583 & 95646 & 4,4 & 7382 & 7981 & 8,1 & 12,41 & 11,98 & 0,85 & 0,83 \\
\hline Maíz & 14852 & 17360 & 16,9 & 4716 & 5572 & 18,2 & 3,15 & 3,12 & 0,17 & 0,16 \\
\hline
\end{tabular}

La mejora en la eficiencia en el uso del agua permite conseguir una distribución de cultivos que mejora la rentabilidad global de la explotación, en este caso hasta un $11,4 \%$ (Tabla 4). Como era de esperar, el optimizador dedica a los cultivos menos rentables la superficie mínima establecida como restricción. El agua ahorrada con el maíz y la cebada permiten incrementar la superficie de cebolla (también por aplicar a ésta una menor cantidad de agua de riego), pasando de 33,9 ha a 41,8 ha, siendo esta la principal causa de la mejora en la rentabilidad de la explotación. 
Tabla 4. Comparativa económica entre tratamiento sin déficit y ORDI.

Escenario A (Riego sin déficit)

Sup. Mínima por cultivo : 20 ha.

Sup. Total : 100 ha.

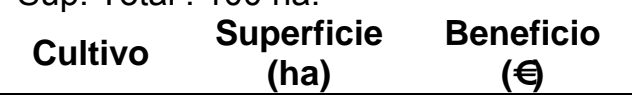

Cebada $20,0 \quad 18.432$

Cebolla $\quad 33,9 \quad 225.070$

Maíz $\quad 20,0 \quad 17.575$

Total

73,9

\section{Escenario B (Tratamiento ORDI)}

Sup. Mínima por cultivo : 20 ha. Sup. Total : 100 ha.

Cultivo Superficie(ha)

\begin{tabular}{lccc} 
& \multicolumn{1}{c}{$(\boldsymbol{\epsilon})$} & \\
Cebada & 20,0 & 13.070 & -5.362 \\
Cebolla & 41,8 & 261.692 & +36.622 \\
Maíz & 20,0 & 16.053 & -1.522 \\
Total & $\mathbf{8 1 , 8}$ & $\mathbf{2 9 0 . 8 1 5}$ & $\mathbf{+ 2 9 . 7 3 7}$
\end{tabular}

Comparativa Margen Bruto

Beneficio (€/\%)

\section{4- Conclusiones y recomendaciones.}

La combinación de técnicas de riego deficitario optimizado con una adecuada distribución de cultivos, permitiría incrementar el beneficio de las explotaciones para una misma dotación de riego y superficie regable.

Por lo tanto, para una cantidad anual limitada de agua de riego y de superficie cultivable, reducir la aplicación de agua en los cultivos con menor margen bruto para dotar de una mayor superficie y una mayor disponibilidad de agua a los cultivos con mayor margen bruto, hace posible incrementar la rentabilidad económica de las explotaciones de regadío y realizar un uso más eficiente y sostenible de los recursos disponibles, reduciendo adicionalmente la huella hídrica de los productos agrícolas.

\section{5- Bibliografía.}

Allen R.G., Pereira L.S., Raes D., Smith M., 1998. Crop Evapotranspiration: Guide- lines for Computing Crop Water Requirements. Irrigation and Drainage Paper No. 56. FAO, Italy.

Domínguez A., de Juan J.A., Tarjuelo J.M., Martínez R.S., Martínez-Romero A., 2012. Determination of optimal regulated deficit irrigation strategies for maize in a semi-arid environment. Agric. Water Manage., 110, 67-77.

Ortega J.F., de Juan J.A., Martínez-Romero A., Tarjuelo J.M., López-Mata E., 2004. MOPECO: an economic optimization model for irrigation water management. Irrigation Science 23(2), 61-75. 


\title{
DISTRIBUCIÓN OPTIMIZADA DE VOLÚMENES LIMITADOS DE AGUA DE RIEGO Y SU EFECTO SOBRE EL RENDIMIENTO Y LA CALIDAD DE LA CEBADA CERVECERA
}

\author{
Pardo, J.J. ${ }^{1}(\mathrm{P})$, Léllis, B.C. ${ }^{2}$, Martínez-Romero, A. ${ }^{3}$, Tarjuelo, J.M. ${ }^{4}$, Domínguez, A. $^{5}$
}

\author{
${ }^{1}$ Ingeniero Agrónomo, Investigador; Centro Regional de Estudios del Agua (CREA), UCLM, \\ Ctra. de Las Peñas km. 3.2, 02071 Albacete; josejesus.pardo@uclm.es \\ 2 Ingeniero Agrónomo, Investigador; Centro Regional de Estudios del Agua (CREA), UCLM, \\ Ctra. de Las Peñas km. 3.2, 02071 Albacete; brunolellismaria@yahoo.com.br \\ ${ }^{3}$ Dr. Ingeniero Agrónomo, Profesor Asociado; EIIAB, Departamento de Mecánica Aplicada e \\ Ingeniera de Proyectos, UCLM; angel.mromero@uclm.es \\ ${ }^{3}$ Dr. Ingeniero Agrónomo, Catedrático de Universidad; Departamento de Producción Vegetal \\ y Tecnología Agraria, UCLM; jose.tarjuelo@uclm.es \\ ${ }^{5}$ Dr. Ingeniero Agrónomo, Profesor Contratado Doctor; Departamento de Producción Vegetal \\ y Tecnología Agraria, UCLM; alfonso.dominguez@uclm.es
}

\section{Resumen}

En Castilla-La Mancha (C-LM), la cebada es un cultivo con bajas necesidades de agua de riego (lámina neta, $I n=2.500 \mathrm{~m}^{3} \mathrm{ha}^{-1}$ ) y con una gran diferencia de rendimiento entre secano y regadío. Sin embargo, por la escasez de recursos hídricos, las dotaciones limitadas de agua, y el alto coste de la energía, los agricultores se están planteando aplicar riego deficitario a este cultivo. El objetivo de este trabajo es determinar, para las condiciones de C-LM, las estrategias de riego deficitario controlado que, con volúmenes limitados de agua de riego, maximizan el rendimiento de la cebada cervecera sin que la calidad del producto se vea afectada. Se han desarrollado ensayos de campo considerado 5 volúmenes de agua disponible (llimitada, $1 \mathrm{ln}, 0.9 \mathrm{ln}, 0.8 \mathrm{ln}$, y $0.7 \mathrm{ln}$ ), optimizando los calendarios de riegos combinando las metodologías "año meteorológico típico" (Tipical Meteorological Year,TMY) y "riego deficitario optimizado por etapas" (Optimized Regulated Deficit Irrigation, ORDI) con el modelo MOPECO. Se ha conseguido una buena distribución del agua disponible a lo largo de la campaña, sin alcanzar un estrés severo global en ninguna de las etapas de desarrollo, logrando un alto rendimiento sin decremento de la calidad, pese a desconocer las condiciones climáticas en las que se iba a desarrollar el cultivo. Los rendimientos obtenidos fueron similares a los estimados al inicio de la campaña y los parámetros de calidad medidos, excelentes en todos los tratamientos.

\section{1- Introducción, objetivos}

Castilla-La Mancha (C-LM) es el segundo productor de cebada en España con una producción de 2.784.281 Tm (28\% nacional). En dicha comunidad se cultivan 857.267 ha, de las que 97.383 ha son en regadío (MAGRAMA, 2016). Pese a ser una región con escasez de recursos hídricos, la gran diferencia de rendimiento entre secano y regadío (hasta 3 veces mayor) junto con las bajas necesidades de agua riego de este cultivo (unos $2.500 \mathrm{~m}^{3} \mathrm{ha}^{-1}$ ), justifican la implantación de este cultivo en regadío. Sin embargo, el incremento de los costes de producción, especialmente de la energía eléctrica necesaria para el bombeo del agua subterránea y el funcionamiento de los sistemas de riego presurizados (Moreno et al., 2010), así como el tener dotaciones limitadas de agua por 
campaña de riego, está ocasionando que los agricultores se planteen la posibilidad de aplicar riego deficitario a este cultivo.

Si el grano de la cebada alcanza unos determinados índices de calidad, como ciertos calibres y especialmente determinado contenido en proteína, éste puede ser empleado en la fabricación de malta para cerveza. La empresa Intermalta España, situada en Albacete, que se dedica al malteado de cebada para la elaboración de cerveza, fija el contenido de proteína del grano en torno al 9-12.5\% siendo el óptimo 11.5-12\%.

El objetivo principal de este trabajo es determinar, para las condiciones de C-LM, las estrategias de riego deficitario controlado que, con volúmenes limitados de agua de riego, maximizan el rendimiento de la cebada cervecera sin que la calidad del producto se vea afectada. Para ello se han combinado las metodologías del "año meteorológico típico" (Tipical Meteorological Year, TMY) (Domínguez et al., 2013), que determina las características típicas ambientales de una zona, y del "riego deficitario optimizado por etapas" (Optimized Regulated Deficit Irrigation, ORDI) (Domínguez et al., 2012), que determina mediante optimizaciones sucesivas a lo largo de la campaña la distribución de una cantidad limitada de agua en cada una de las fases de desarrollo del cultivo en función de las condiciones ambientales previstas por el TMY y la disponibilidad de agua de riego. Ambas metodologías se han implementado en el modelo MOPECO y se han validado con ensayos de campo durante la campaña 2015.

\section{2- Materiales y métodos}

Durante la campaña 2015 se realizaron ensayos de campo en los que se analizó el efecto de 5 tratamientos de riego sobre el rendimiento y los parámetros de calidad de la cosecha. Los tratamientos planteados fueron: uno sin déficit, y los otros cuatro con distintos volúmenes máximos de agua de riego disponible, correspondientes al 100 (T100), 90 (T90), 80 (T80), y 70\% (T70) de las necesidades netas de riego en cebada para las condiciones climáticas de un año meteorológico típico (TMY) intermedio (fijadas en $2500 \mathrm{~m}^{3} / \mathrm{ha}=\mathrm{T} 100$ ). Este valor se obtuvo tras la calibración de los datos requeridos por el modelo MOPECO para la cebada en las condiciones de C-LM, aplicando la metodología TMY como se explicará más adelante.

Los ensayos tuvieron lugar en la finca experimental del Centro Integrado de Formación Profesional situado en Aguas Nuevas (Albacete), que consistieron en cuatro repeticiones de cada tratamiento en parcelas de $2.5 \times 18 \mathrm{~m}$. distribuidas al azar (Figura 1), salvo en los tratamientos sin déficit y T100, que tuvieron 3.

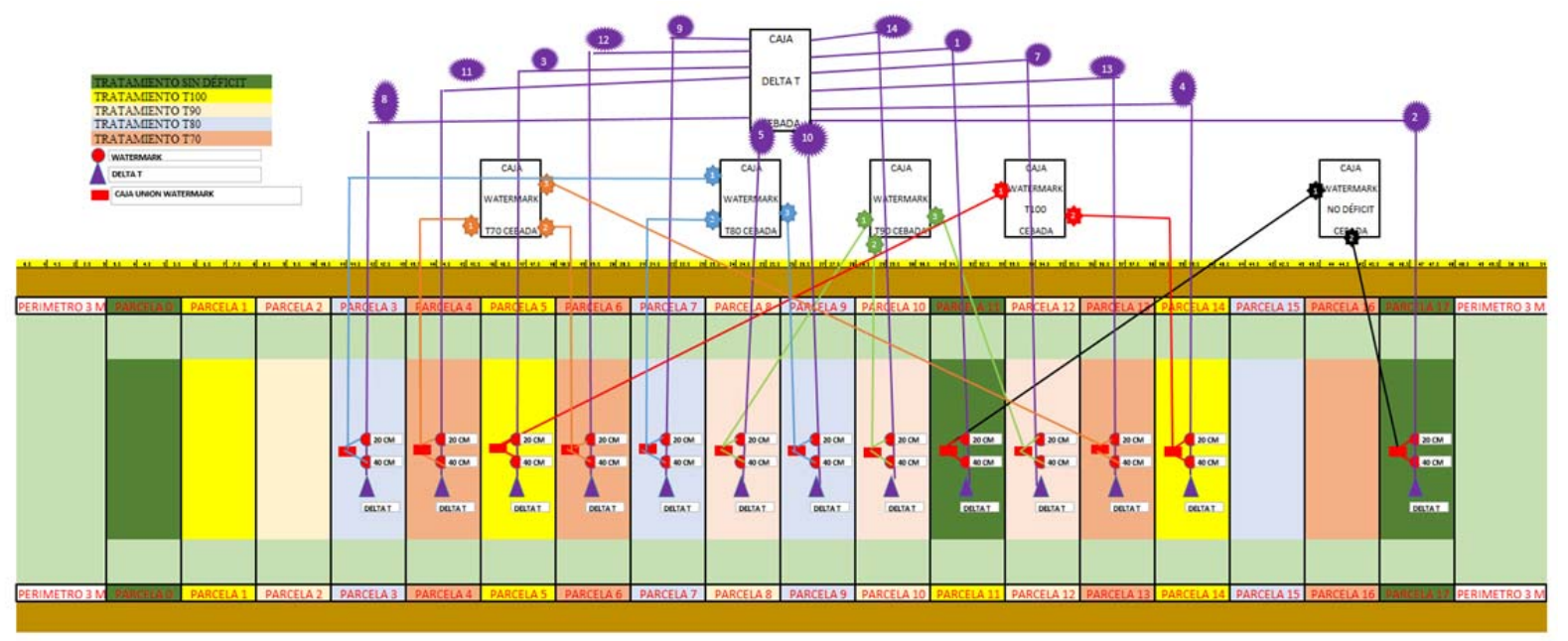

Figura 1. Esquema del ensayo

El agua se aplicó mediante un sistema de riego localizado por goteo de marco cuadrado (0.5 x $0.5 \mathrm{~m}$ de separación entre ramales y emisores) dotado de emisores autocompensantes 
con un caudal nominal de $3.8 \mathrm{~L} / \mathrm{h}$. En cada sector de riego, que corresponde con un tratamiento, se instaló un caudalímetro de pulsos de precisión para controlar el volumen de agua aplicada en cada riego. Además se realizaron evaluaciones de la uniformidad de aplicación de agua del sistema de riego antes de la siembra y periódicamente a lo largo del ciclo de cultivo.

\section{1- Calibración del modelo MOPECO. Establecimiento de las necesidades de riego netas.}

MOPECO utiliza la ecuación propuesta por Stewart et al. (1977) para estimar el rendimiento del cultivo que relaciona la evapotranspiración real y la máxima $\left(E T_{a} / E T_{m}\right)$ en las diferentes etapas de crecimiento. Doorenbos y Kassam (1979) consideran cuatro etapas de crecimiento de acuerdo a la distinta sensibilidad de los cultivos a déficit hídrico (desarrollo vegetativo, floración, formación de rendimiento y período de maduración). El factor de respuesta del rendimiento del cultivo, Ky, expresa lo sensible que es el cultivo al déficit hídrico en cada etapa de crecimiento. Cuando $\mathrm{ET}_{\mathrm{a}}<E T_{\mathrm{m}}$, la planta sufre estrés por déficit de agua, lo que puede causar una pérdida en el rendimiento [rendimiento real $\left(\mathrm{Y}_{\mathrm{a}}\right)<$ máximo rendimiento $\left.\left(\mathrm{Y}_{\mathrm{m}}\right)\right]$.

$$
\mathrm{Y}_{\mathrm{a}}=\mathrm{Y}_{\mathrm{m}} \prod_{\mathrm{k}=1}^{4}\left(1-\mathrm{K}_{\mathrm{y}_{\mathrm{k}}}\left(1-\frac{\mathrm{ET}_{\mathrm{a}_{\mathrm{k}}}}{\mathrm{ET}_{\mathrm{m}_{\mathrm{k}}}}\right)\right)
$$

donde $Y_{a}$ e $Y_{m}$, son el rendimiento real y máximo del cultivo $\left(\mathrm{kg} \mathrm{ha}^{-1}\right)$; $\mathrm{k}$, es etapa de crecimiento real; $\mathrm{K}_{\mathrm{yk}}$, es el factor de respuesta del rendimiento por etapa de crecimiento [desarrollo vegetativo (i), que incluye el establecimiento (Domínguez et al., 2012); (ii) la floración, (iii) formación de rendimiento; y (iv) periodo de maduración]; $E T_{a}$ y $E T_{m}$, indican las evapotranspiraciones acumuladas real y máxima en cada etapa de crecimiento $\mathrm{Ky}(\mathrm{mm})$.

La $\mathrm{ET}_{\mathrm{m}}$ diaria se calcula multiplicando el Kc diario por la evapotranspiración de referencia $\left(E_{0}\right.$ ) diaria (Allen et al., 1998). $\mathrm{ET}_{\mathrm{a}}$ diaria requiere un balance diario del contenido de agua en el suelo para su estimación, el balance de agua en el suelo diario se calcula como la diferencia entre las entradas (precipitaciones y riego) y salidas ( $E T_{a}$ y percolación profunda) (Domínguez et al., 2011).

Para la simulación de la cebada también se necesita la duración de las etapas de Kc y Ky en grados día acumulados (GDD). MOPECO utiliza el método de doble triangulación, que requiere dos parámetros para el cálculo GDD (Sevacherian et al., 1977): TL (temperatura umbral mínima para el desarrollo) y TU (temperatura umbral máxima a la que la tasa de desarrollo comienza a disminuir). Para establecer los valores de TL y TU en el área de estudio, se han analizado y comparado con los valores propuestos por otros autores en áreas similares (Canadá; Etiopia, Italia, Siria, EE.UU.). TL puede variar de 0 a $10^{\circ} \mathrm{C}$, y TU de 20 a $38^{\circ} \mathrm{C}$ (Kirby et al., 1982; López-Bellido, 1991; Juskiw et al., 2001; Araya et al., 2010; Abrha et al., 2012). Se seleccionó la combinación de valores con la menor desviación estándar (SD) y menor coeficiente de variación (CV) en función de los datos de campo.

Para determinar la duración de cada etapa Kc y Ky en términos de GDD, se utilizaron los resultados de los ensayos de campo realizados durante las campañas 2002, 2004, 2011, 2012 y 2013 en la finca experimental de Las Tiesas, perteneciente al Instituto Técnico Agronómico Provincial de Albacete (ITAP) complementados con 28 seguimientos fenológicos de cultivo de cebada llevados a cabo por el Servicio Integral de Asesoramiento al Regante (SIAR), perteneciente al CREA, durante los años 2002-2010 por toda C-LM. La escala fenológica utilizada en ambos casos fue Biologische Bundesanstalt, Bundessortenamt y la Industria Química (BBCH) (Bleiholder et al., 2001).

Una vez calibrado MOPECO y con la ayuda de la metodología TMY, se determinaron las necesidades de agua de riego típicas del cultivo (lámina neta, In). En base a estas necesidades, se plantearon los cuatro tratamientos de riego con volumen limitado de agua citados anteriormente $(100,90,80$, y $70 \%$ de In). A partir de los datos climáticos ambientales registrados por la estación agroclimática completa ubicada en el campo de ensayos, de los registros de los sensores de humedad en el suelo, y de la combinación de MOPECO con las 
metodologías ORDI y TMY, se estableció el nivel de déficit objetivo $\left(E T_{a} / E T_{m}\right)$ para cada etapa de crecimiento. Así, se determinó el calendario de riegos para cada uno de los tratamientos propuestos, sin que se superase en ningún caso el volumen de agua disponible prefijado.

\section{2- Seguimiento del consumo de agua por parte del cultivo}

En tres de cada cuatro repeticiones se instalaron sensores de humedad en el suelo del tipo Watermark ${ }^{\circledR}$ (tensiómetro) y PR2 ${ }^{\circledR}$ (humedad volumétrica) para determinar la evolución de la humedad del suelo a distintas profundidades (en los tratamientos sin déficit y T100, en dos de cada tres repeticiones).

Cada parcela dispuso de 2 Watermark $^{\circledR}$ a 20 y $40 \mathrm{~cm}$ de profundidad y una sonda PR2 ${ }^{\circledR}$ con sensores a 10, 20, 30 y $40 \mathrm{~cm}$ de profundidad.

\section{3- Seguimiento del desarrollo del cultivo.}

Durante el desarrollo fenológico del cultivo, se realizaron análisis fisiológicos (conductancia estomática y actividad fotosintética), se tomaron muestras periódicas para establecer el índice de área foliar y la evolución de la biomasa, así como fotografías RGB y térmicas. También se realizaron análisis de suelo para registrar la evolución de sus características físico-químicas.

Al acabar la campaña, se determinó el rendimiento final, se calculó la eficiencia en el uso de agua de riego, y se analizaron parámetros de calidad en colaboración con la empresa Intermalta España (ubicada en Albacete y perteneciente a la multinacional Malteurop, dedicada a la obtención de malta para la elaboración de cerveza) tales como: calibres, porcentaje de humedad, contenido en proteína del grano y capacidad de germinación.

\section{3- Resultados y discusión}

Se considera que un modelo está calibrado cuando la diferencia entre los rendimientos observados y simulados es igual o menor a un $10 \%$, y cuando el porcentaje de rendimientos simulados que cumplan el requisito anterior es igual o superior al 70\% (Farahani et al., 2009; Heng et al., 2009).

Para determinar los GDD acumulados de cada etapa de desarrollo, los valores de TL y TU que alcanzaron menor variabilidad en términos estadísticos fueron: 2 y $28^{\circ} \mathrm{C}$. Estos valores son idénticos a los propuestos por Abrha et al. (2012) y muy similares a los propuestos por otros autores como López-Bellido (1991), Juskiw et al. (2001), Qureshi et al. (2009), y Araya et al. (2010). En la Tabla 1 se recogen los valores de GDD acumulados en cada etapa de Kc y Ky para la cebada bajo las condiciones de C-LM.

La Tabla 2 muestra los valores de Kc y Ky así como el rendimiento potencial utilizados en MOPECO.

Tabla 1. GDD acumulados para las etapas de Kc y Ky.

\begin{tabular}{|c|c|c|c|c|c|c|c|c|}
\hline & \multicolumn{4}{|c|}{ Etapas de Kc } & \multicolumn{4}{|c|}{ Etapas de Ky } \\
\hline & Etapa 1 & Etapa 2 & Etapa 3 & Etapa 4 & Etapa 1 & Etapa 2 & Etapa 3 & Etapa 4 \\
\hline Media & 290.28 & 744.48 & 1087.18 & 1449.51 & 645.28 & 981.22 & 1186.09 & 1449.51 \\
\hline $\mathrm{SD}^{(1)}(\%)$ & 46.43 & 57.16 & 64.37 & 69.38 & 73.29 & 64.43 & 58.90 & 69.38 \\
\hline $\mathrm{CV}^{(2)}(\%)$ & 15.99 & 7.68 & 5.92 & 4.79 & 11.36 & 6.57 & 4.97 & 4.79 \\
\hline
\end{tabular}

(1) SD: Desviación estándar; ${ }^{(2)} \mathrm{CV}$ : Coeficiente de variación

Tabla 2. Valores de Kc, Ky, e $\mathrm{Y}_{\mathrm{m}}$ para la cebada bajo condiciones de C-LM.

Valores calibrados y validados para la cebada 


\begin{tabular}{|c|c|c|c|}
\hline Etapa & $\mathbf{K c}$ & $\mathbf{K y}$ & \multirow{2}{*}{$\mathbf{Y}_{\mathbf{m}}$ (kg/ha) } \\
\hline Etapa 1 & 0.3 & 0.2 & \\
\cline { 1 - 2 } Etapa 2 & $0.3-1.15$ & 0.55 & \multirow{2}{*}{9000} \\
\hline Etapa 3 & 1.15 & 0.30 & \\
\hline Etapa 4 & $1.15-0.45$ & 0.2 & \\
\hline
\end{tabular}

La Figura 2 muestra la evolución de los valores de Kc y Ky para el año 2015 en Albacete.

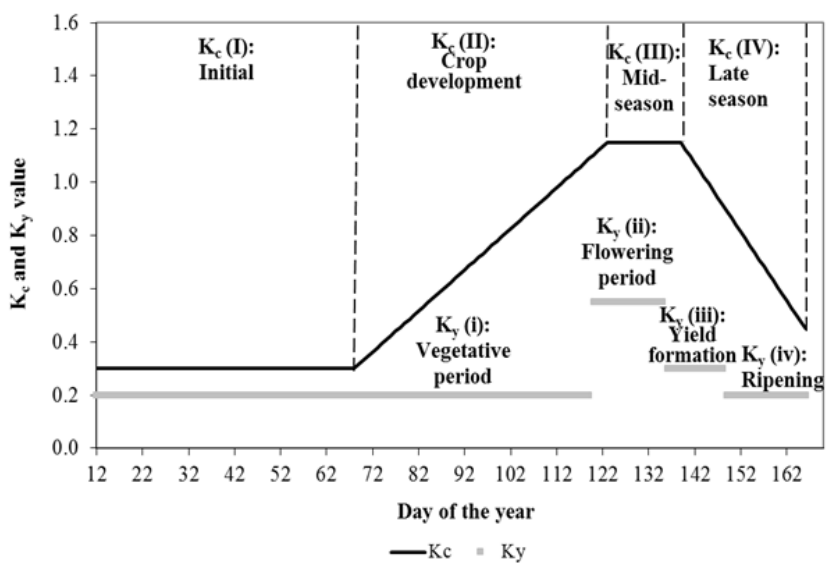

Figura 2. Evolución de los valores de Kc y Ky por etapas (año 2015).

En la Figura 3, en la gráfica superior, se puede apreciar la evolución del agua en el suelo simulada por MOPECO, y en la parte de abajo, los registros de los Watermark ${ }^{\circledR}$ para una parcela del T80. Se observa claramente que el modelo ha simulado muy bien las condiciones de agua en el suelo, ya que, aunque no se están representando las mismas unidades, las tendencias son similares. Por otra parte también se advierte que los objetivos de déficit planteados al principio de cada etapa no han coincidido con los conseguidos en algunas etapas, esto es debido principalmente a la distribución de las precipitaciones del año 2015, y en menor medida al resto de condiciones agroclimáticas (Tabla 4).

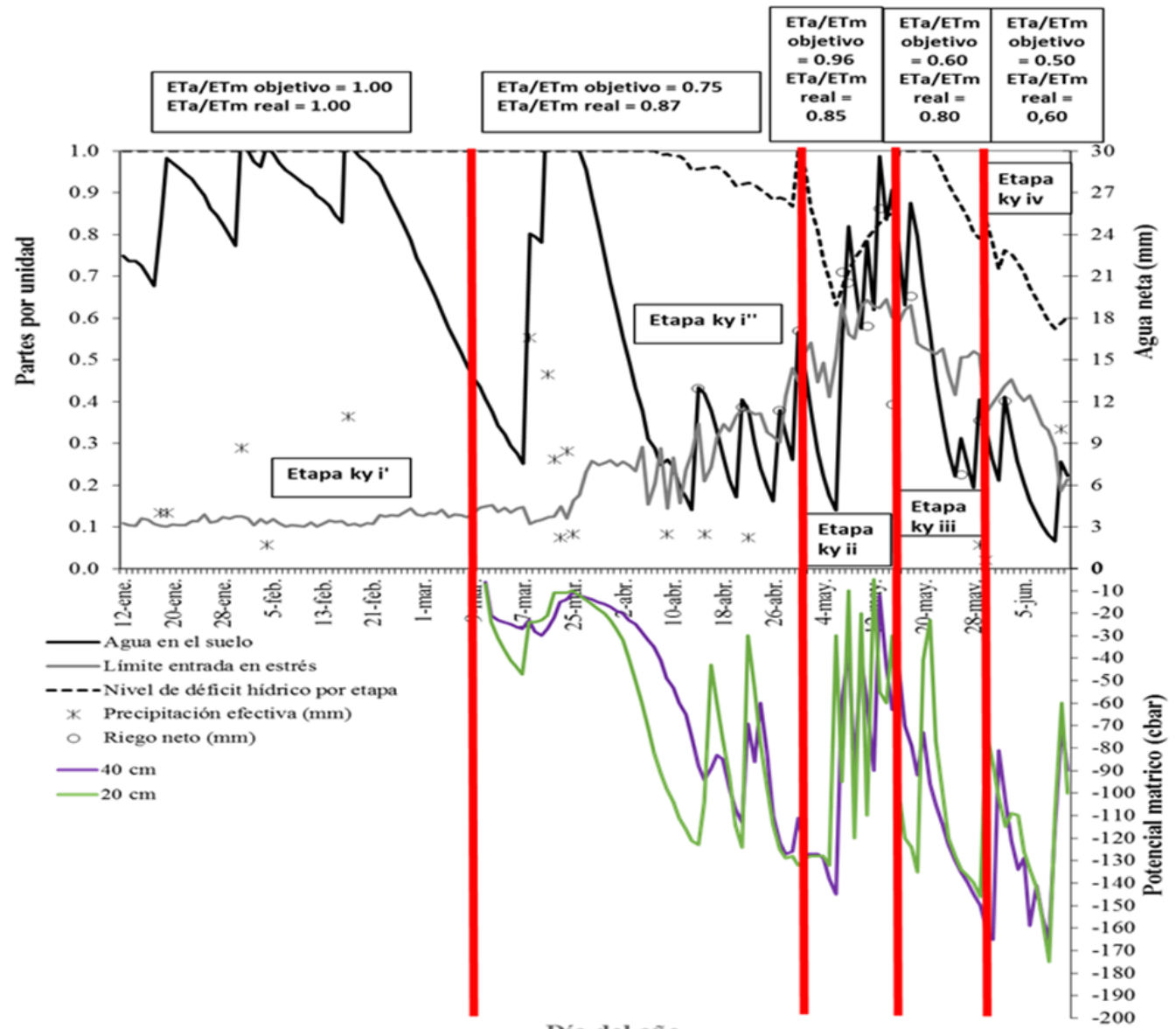


Figura 3. Evolución del agua en el suelo simulada por MOPECO para el tratamiento T80. Abajo, la evolución del agua en el suelo a 20 y $40 \mathrm{~cm}$ registrada por los Watermark ${ }^{\circledR}$.

Tabla 4. Riegos,ETa/ETm objetivos y reales por etapas Ky y tratamientos

\begin{tabular}{|c|c|c|c|c|c|c|c|c|c|c|c|c|c|c|c|}
\hline \multirow[b]{2}{*}{ Etapa } & \multicolumn{3}{|c|}{$\begin{array}{c}\text { Tratamiento Sin } \\
\text { déficit }\end{array}$} & \multicolumn{3}{|c|}{ Tratamiento T100 } & \multicolumn{3}{|c|}{ Tratamiento T90 } & \multicolumn{3}{|c|}{ Tratamiento T80 } & \multicolumn{3}{|c|}{ Tratamiento T70 } \\
\hline & $\begin{array}{l}\mathrm{ET}_{\mathrm{a}} / \\
\mathrm{ET}_{\mathrm{m}} \\
\text { obj. }\end{array}$ & $\begin{array}{l}\mathrm{ET}_{\mathrm{a}} / \\
\mathrm{ET}_{\mathrm{m}} \\
\text { real }\end{array}$ & $\begin{array}{l}\text { Riego } \\
\text { neto } \\
(\mathrm{mm})\end{array}$ & $\begin{array}{l}\mathrm{ET}_{\mathrm{a}} / \\
\mathrm{ET}_{\mathrm{m}} \\
\text { obj. }\end{array}$ & $\begin{array}{l}\mathrm{ET}_{\mathrm{a}} / \\
\mathrm{ET}_{\mathrm{m}} \\
\text { real }\end{array}$ & $\begin{array}{c}\text { Riego } \\
\text { neto } \\
(\mathrm{mm})\end{array}$ & $\begin{array}{l}\mathrm{ET}_{\mathrm{a}} / \\
\mathrm{ET}_{\mathrm{m}} \\
\mathrm{obj} .\end{array}$ & $\begin{array}{l}\mathrm{ET}_{\mathrm{a}} / \\
\mathrm{ET}_{\mathrm{m}} \\
\text { real }\end{array}$ & $\begin{array}{c}\text { Riego } \\
\text { neto } \\
(\mathrm{mm})\end{array}$ & $\begin{array}{l}\mathrm{ET}_{\mathrm{a}} / \\
\mathrm{ET}_{\mathrm{m}} \\
\text { obj. }\end{array}$ & $\begin{array}{l}\mathrm{ET}_{\mathrm{a}} / \\
\mathrm{ET}_{\mathrm{m}} \\
\text { real }\end{array}$ & $\begin{array}{c}\text { Riego } \\
\text { neto } \\
(\mathrm{mm})\end{array}$ & $\begin{array}{l}\mathrm{ET}_{\mathrm{a}} / \\
\mathrm{ET}_{\mathrm{m}} \\
\text { obj. }\end{array}$ & $\begin{array}{l}\mathrm{ET}_{\mathrm{a}} / \\
\mathrm{ET}_{\mathrm{m}} \\
\text { real }\end{array}$ & $\begin{array}{c}\text { Riego } \\
\text { neto } \\
(\mathrm{mm})\end{array}$ \\
\hline $1^{\prime}$ & 1.00 & 1.00 & 0.00 & 1.00 & 1.00 & 0.00 & 1.00 & 1.00 & 0.00 & 1.00 & 1.00 & 0.00 & 1.00 & 1.00 & 0.00 \\
\hline $1 "$ & 1.00 & 1.00 & 66.30 & 1.00 & 1.00 & & 0.75 & 0.87 & 00.00 & 0.75 & 0.87 & 36.20 & 0.75 & 0.86 & 33.20 \\
\hline 2 & 1.00 & 0.99 & 115.00 & 1.00 & 0.00 & 115.00 & 0.99 & 0.90 & & 0.96 & 0.85 & & 0.8 & 0.84 & 105.00 \\
\hline 3 & 1.00 & 0.99 & 69.30 & 1.00 & 099 & 69.30 & 0.76 & 0.81 & 26.10 & 0.60 & 0.81 & 26.50 & 0.54 & 0.65 & 23.90 \\
\hline 4 & 1.00 & 1.00 & 35.00 & 1.00 & 067 & 0.00 & 0.77 & 0.87 & 43.60 & 0.50 & 0.60 & 22.90 & 0.50 & 0.44 & 13.20 \\
\hline $\begin{array}{l}\text { Global/ } \\
\text { Total }\end{array}$ & 1.00 & 1.00 & 285.60 & 1.00 & 0.94 & 250.60 & 0.86 & 0.87 & 225.10 & 0.79 & 0.82 & 200.20 & 0.73 & 0.76 & 175.30 \\
\hline
\end{tabular}

En la primera etapa de Ky no hubo diferencias significativas en los calendarios de riego de los tratamientos T90, T80 y $\mathrm{T} 70$. Las $\mathrm{ET}_{\mathrm{a}} / \mathrm{ET}_{\mathrm{m}}$ objetivo hasta entonces fueron similares para estos tres tratamientos (el T100 siempre busca una $E T_{a} / E T_{m}$ objetivo de 1, es decir, no estrés). Es a partir de la etapa 2 de Ky cuando empezaron a distinguirse diferencias en las $\mathrm{ET}_{\mathrm{a}} / \mathrm{ET}_{\mathrm{m}}$ objetivo, acentuándose en las dos siguientes. No aparecieron diferencias en la evolución de la biomasa y del LAI hasta que el cultivo se encontraba en la etapa 2 de Ky (primera quincena de mayo) tal y como se aprecia en la Figura 4.
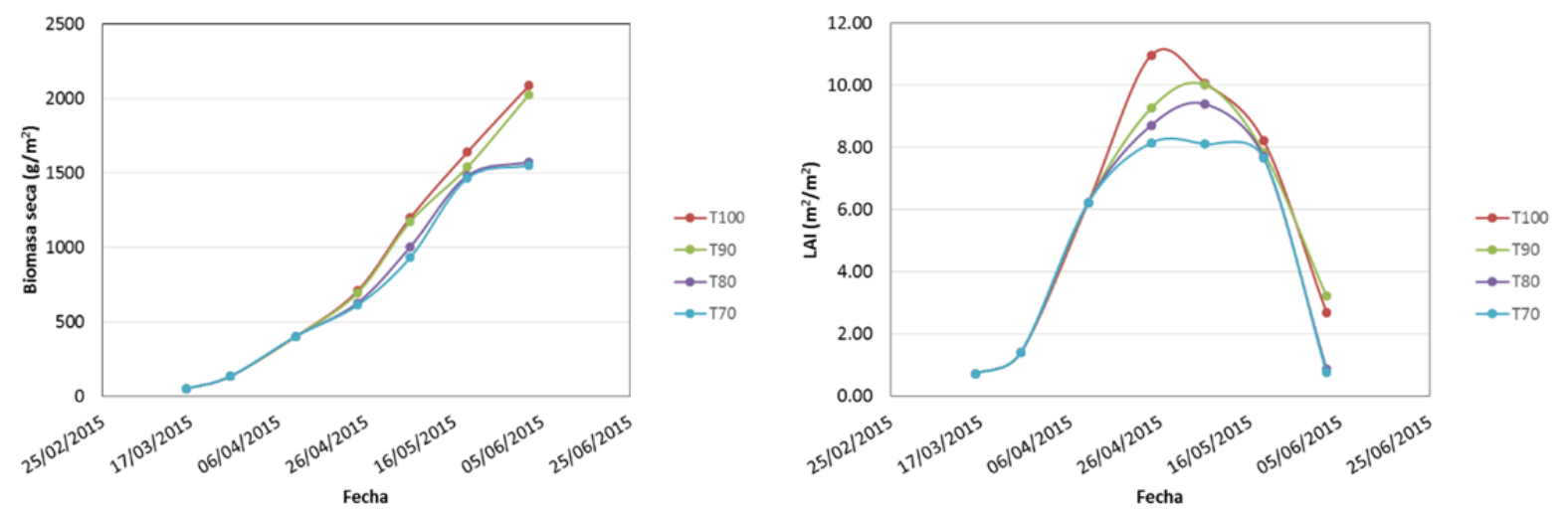

Figura 4. Evolución de la biomasa seca y del Índice de Área Foliar (LAI) en los tratamientos con volumen limitado de agua.

En cuanto a la resistencia estomática, sí que aparecieron diferencias entre tratamientos. En los tratamientos con mayores déficits la resistencia fue mayor, tal y como se aprecia en la Figura 5. El tratamiento T100 mantuvo una resistencia muy baja y prácticamente constante durante todo el periodo de medidas, el resto de tratamientos siguió la tendencia esperada. Cabe destacar que durante la etapa 2 de Ky, la más sensible al déficit, la resistencia ha sido similar en todos los tratamientos, eso es debido a que se buscaba la $\mathrm{ET}_{a} / \mathrm{ET}_{\mathrm{m}}$ mayor posible en todos ellos. Aunque al final de dicha etapa sí que aparecieron diferencias en la $E T_{a} / E T_{m}$ global, el que la resistencia haya sido igual se puede justificar porque en los días previos a 
la medida hubo muchos riegos, y la $\mathrm{ET}_{\mathrm{a}} / \mathrm{ET}_{\mathrm{m}}$ diaria para el momento de la medida era 1 en todos los casos.

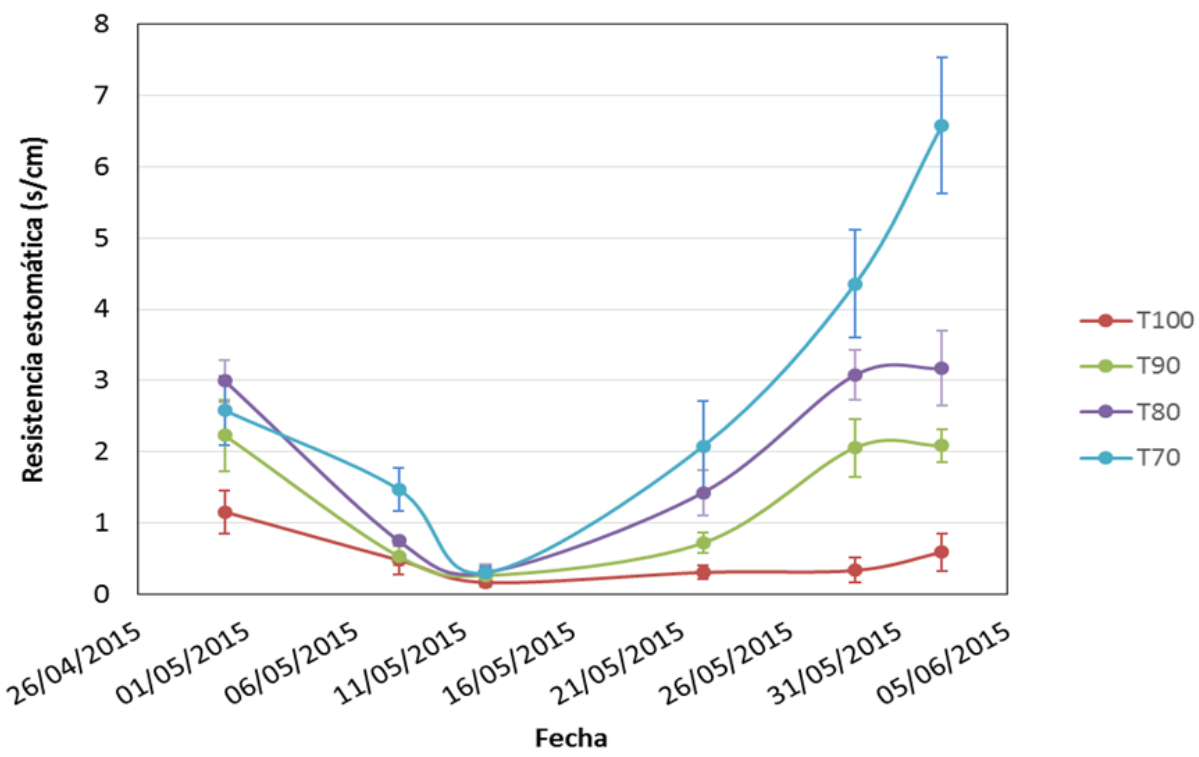

Figura 5. Evolución de la resistencia estomática $(\mathrm{s} / \mathrm{cm})$ de los cuatro tratamientos con volumen limitado de agua de riego.

La actividad fotosintética siempre fue mayor en los tratamientos con mayor volumen de agua disponible (Figura 6).

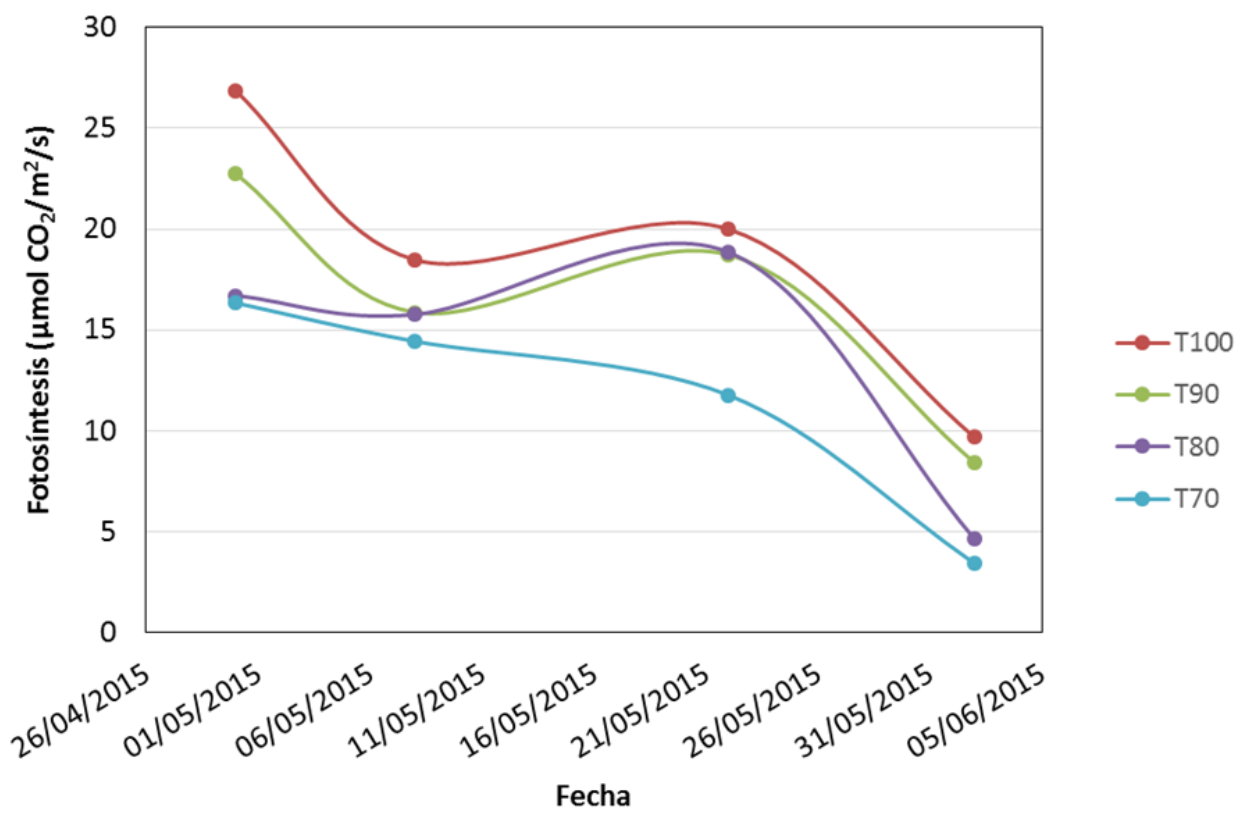

Figura 6. Evolución de la actividad fotosintética. 
Una vez que comienza la senescencia, la tasa fotosintética comienza a caer describiendo una curva. Según la Figura 6, esa curva no se aprecia en los tratamientos T100, T90 y T80. Esto se puede justificar porque la semana anterior a la medida del día 08/05, el sistema de bombeo se estropeó, las temperaturas fueron muy altas y las plantas estuvieron expuestas a un estrés mucho más severo del previsto. Por tanto, los registros de tasa fotosintética para ese día fueron más bajos de lo esperado.

En las fotos térmicas se observó que la temperatura de las hojas y espiga fue mayor en las parcelas con los tratamientos de menor agua de riego disponible (Figura 7).
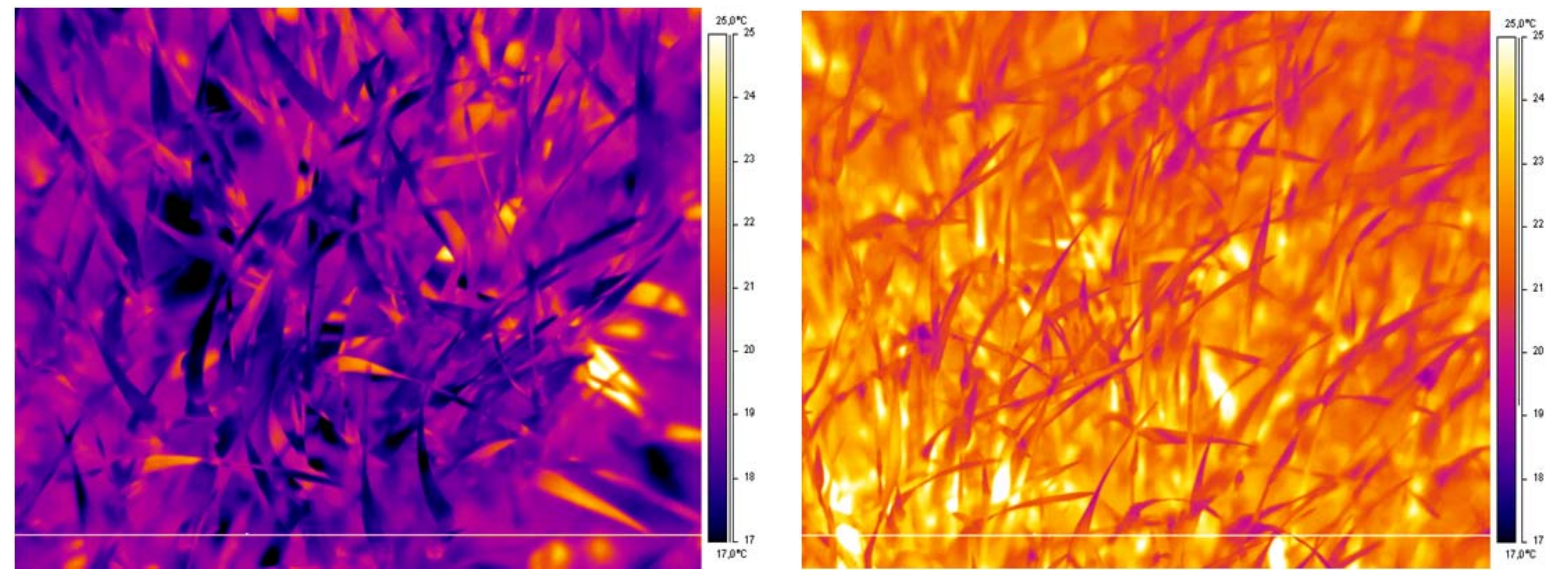

Figura 7. Fotografías térmicas del 30/04/2015. A la izquierda T100, a la derecha T70

Aparecieron diferencias significativas en el rendimiento final en todos los tratamientos salvo entre el T90 y T80. Como era de esperar, el mayor rendimiento se obtuvo en el tratamiento sin déficit. Entre el tratamiento T100 y el T70, la diferencia fue de $2210 \mathrm{~kg} / \mathrm{ha}$ con un ahorro de agua de $750 \mathrm{~m}^{3} / \mathrm{ha}$.

Tabla 5. Rendimientos simulados y reales de los tratamientos ensayados.

\begin{tabular}{|c|c|c|c|c|c|c|c|}
\hline \multirow{2}{*}{$\begin{array}{l}\text { TRATA - } \\
\text { MIENTO }\end{array}$} & \multirow{2}{*}{$\begin{array}{c}\text { Agua } \\
\text { neta de } \\
\text { riego } \\
\text { aplicada } \\
\left(\mathrm{m}^{3} / \mathrm{ha}\right)\end{array}$} & \multirow{2}{*}{$\begin{array}{l}\text { RENDIMIENTO } \\
\text { SIMULADO } \\
\text { MOPECO } \\
\text { (kg/ha) }\end{array}$} & \multicolumn{3}{|c|}{$\begin{array}{l}\text { RENDIMIENTO } \\
\text { REAL }\end{array}$} & \multirow{2}{*}{$\mathrm{Ys} / \mathrm{Yo}^{(3)}$} & \multirow{2}{*}{$\begin{array}{c}\text { EFICIENCIA } \\
\text { EN EL USO } \\
\text { DEL AGUA } \\
\text { DE RIEGO } \\
(\mathrm{kg} / \mathrm{mm})\end{array}$} \\
\hline & & & $\mathrm{kg} / \mathrm{ha}$ & $D V^{(1)}$ & $C V^{(2)}$ & & \\
\hline No Deficit & 2856 & 8936 & 9440 & 698 & 7.4 & 0.95 & 33.05 \\
\hline T100 & 2506 & 8349 & 8614 & 458 & 5.3 & 0.97 & 34.37 \\
\hline T90 & 2251 & 7615 & 7620 & 362 & 4.8 & 1.00 & 33.85 \\
\hline T80 & 2002 & 7022 & 7362 & 169 & 2.3 & 0.95 & 36.77 \\
\hline T70 & 1753 & 6369 & 6404 & 492 & 7.7 & 0.99 & 36.53 \\
\hline
\end{tabular}

(1) SD: Desviación estándar; ${ }^{(2)} \mathrm{CV}$ : Coeficiente de variación; ${ }^{(3)}$ Ys/Yo: Rendimiento simulado/Rendimiento observado

En la Figura 8 se distingue que hay solape entre el T80 y T90, de ahí las no diferencias significativas entre ambos tratamientos (sus $\mathrm{ET}_{\mathrm{a}} / \mathrm{ET}_{\mathrm{m}}$ globales fueron 0.87 y 0.82 respectivamente). También se advierte que los rendimientos esperados al principio de la campaña y los simulados al final de la campaña han sido muy similares a los reales, salvo en el caso del T100, ya que al final sufrió estrés.

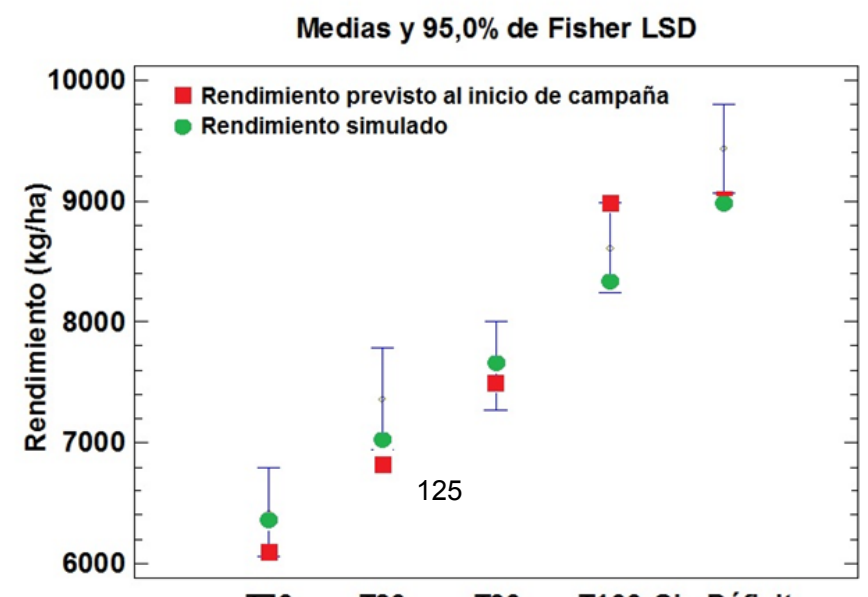


Figura 8. Rendimientos reales, simulados y previstos al inicio de la campaña.

Intermalta distingue 3 categorías en función del calibre del grano:

- Primeras: $>2.5 \mathrm{~mm}$

- Segundas: $2.2 \mathrm{~mm}$

- Terceras: $<2.2 \mathrm{~mm}$

Los granos catalogados como terceras directamente se derivan a pienso, no se utilizan para maltear, por tanto no interesan. Dentro de las "primeras" se distingue una subcategoría correspondiente a los granos que son mayores de $2.8 \mathrm{~mm}$. Ésta es la más relevante de todas.

Todos los tratamientos consiguieron un alto porcentaje de "primeras" (>95.5\%) habiendo diferencias significativas solo entre el T70 y el resto de tratamientos.

Dentro de la subcategoría $>2.8 \mathrm{~mm}$. aparecieron más diferencias significativas. Los mejores resultados los obtuvieron los tratamientos T90 y T80 con un 86 y $87 \%$ del total, seguidos del tratamiento sin déficit con un $83 \%$, el T100 con un $77 \%$ y el T70 con un $72 \%$. El mal resultado del T100 puede ser debido a que como siempre buscaba $E T_{a} / E T_{m}=1$, en la última etapa no quedaba agua y se castigó mucho el cultivo.

En "segundas", el orden ha sido el mismo, los mejores resultados los T90 y T80 (1.3\%) y el peor el T70 (2.5\%).

Todos los tratamientos tuvieron menos de un $1 \%$ de "terceras".

Todos los tratamientos consiguieron un contenido en proteína adecuado al marcado por la maltería. En concreto, todos los tratamientos salvo el sin déficit estuvieron dentro del rango óptimo (entre 11.5 y 12\%). Que el tratamiento sin déficit haya conseguido un porcentaje de proteína menor al $11.5 \%$ se justifica porque la producción real ha sido mayor a la esperada, y por tanto, el abonado se ha podido quedar un poco corto (el abonado fue distinto por cada tratamiento, se realizó en función al rendimiento esperado). No ha habido diferencias significativas entre los cuatro tratamientos deficitarios, sólo entre estos y el tratamiento sin déficit.

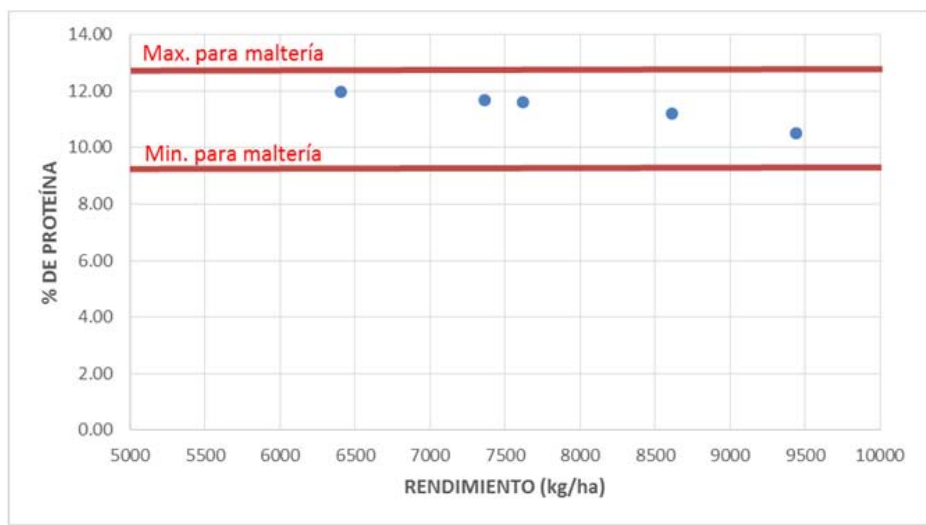

Figura 10. Porcentaje de proteína por rendimiento y tratamiento

\section{4- Conclusiones y recomendaciones}


La combinación de las metodologías ha permitido distribuir un volumen de agua limitado para cada tratamiento sin alcanzar un estrés severo global en ninguna de las etapas de desarrollo, logrando garantizar un alto rendimiento sin decremento de la calidad, pese a desconocer la evolución climática de la campaña de riegos.

Debido a la distribución de las lluvias y los parámetros climáticos reales, en algunas etapas, el déficit real ha sido distinto del objetivo previsto en un principio.

Los rendimientos reales han sido similares a los simulados por el modelo para cada tratamiento y a los esperados al inicio de la campaña. Se han encontrado diferencias significativas entre todos los tratamientos salvo entre el T90 y T80.

El porcentaje de proteína ha estado en el rango óptimo establecido por Intermalta.

\section{5- Bibliografía}

Abrha, B., Delbecques, N., Raes, D., Tsegay, A., Todorovic, M., Heng, L., Vanutrecht, E., Geerts, S., García-Vila, M., Deckers, S. (2012). Sowing strategies for barley (Hordeum vulgare L.) based on modelled yield response to water with AquaCrop. Expl. Agric., doi:10.1017/S0014479711001190.

Allen, R.G., Pereira, L.S., Raes, D., Smith, M. (1998). Crop Evapotranspiration: Guide- lines for Computing Crop Water Requirements. Irrigation and Drainage Paper No. 56. FAO, Italy.

Araya, A., Habtu, S., Hadgu, K.M., Kebede, A. Dejene, T. (2010). Test of AquaCrop model in simulating biomass and yield of water deficient and irrigated barley (Hordeum vulgare). Agricultural Water Management. 97 1838-1846.

Bleiholder, H., Weber, E., Lancashire, P.D., Feller, C., Buhr, L., Hess, M., Wicke, H., Hack, H., Meier, U., Klose, R., van den Boom, T., Stauss, R. (2001). Growth stages of mono-and dicotyledonous plants BBCH Monograph. 2nd edition. Ed. Meier, U. Federal Biological Research Centre for Agriculture and Forestry. Braunschweig, Germany.

Domínguez, A., Tarjuelo, J.M., de Juan, J.A., López-Mata, E., Breidy, J., Karam, F. (2011). Deficit irrigation under water stress and salinity conditions: The MOPECO-salt model. Agri Water Manage 98:1451-1461

Domínguez, A., de Juan, J.A., Tarjuelo, J.M., Martínez R.S., Martínez-Romero A. (2012). Determination of optimal regulated deficit irrigation strategies for maize in a semi-arid environment. Agric. Water Manage. 110, 67-77.

Domínguez, A., Martínez-Romero, A., Leite, K.N., Tarjuelo, J.M., de Juan, J.A., López-Urrea, R. (2013). Combination of typical meteorological year with regulated deficit irrigation to improve the profitability of garlic in central Spain. Agric.Water Manage. 130, 154-167.

Doorenbos, J., Kassam, A.H. (1979). Yield response to water. Irrigation and Drainage Paper No. 33. FAO, Italy.

Farahani, H.J., Izzi, G., Oweis, T.Y. (2009). Parameterization and evaluation of the AquaCrop model for full and deficit irrigated cotton. Agron. J. 101 (3), 469-476.

Heng L.K., Hsiao, T., Evett, S., Howell, T., Steduto, P. (2009). Validating the FAO AquaCrop model for irrigated and water deficient field maize. Agron. J., 101, 3, 488-498.

Juskiw, P.E., Jame, Y.W. \& Kryzanowski, L. (2001). Phenological development of spring barley in a short-season growing area. Agronomy Journal, 93, 370-379.

Kirby, E., Appleyard, M., \& Fellowes, M. (1982). Effect of sowing date on temperature response of leaf emergence and leaf size in barley, Plant Cell \& Environment, 5, 477-484.

López-Bellido L. (1991). Cultivos Herbáceos Extensivos. Cereales. Ediciones Mundi-Prensa. Madrid, España.

$\begin{array}{lllll}\text { MAGRAMA (2016). Anuario } & \text { de }\end{array}$ http://www.magrama.gob.es/estadistica/pags/anuario/2014/AE_2014_Completo.pdf

Ministerio de Agricultura, Alimentación y Medio Ambiente. Consulta 5 abril 2016 
Moreno, M.A., Ortega, J.F., Córcoles, J.I., Martínez, A., Tarjuelo, J.M. (2010). Energy analysis of irrigation delivery systems: monitoring and evaluation of proposed measures for improving energy efficiency. Irrig. Sci. 28, 445-460.

Qureshi, Z.A., Neibling, H. (2009). Response of two-row malting spring barley to water cutoff under sprinkler irrigation. Agricultural Water Management. 96 141-148.

Sevacherian, V., Stern, V.M., Mueller, A.J. (1977). Heat accumulation for timing Lygus control pressures in a safflower-cotton complex. J. Econ. Entomol. 70, 399-402.

Stewart, J.I., Hagan, R.M., Pruitt, W.O., Kanks, R.J., Riley, J.P., Danilson, R.E., Franklin, W.T., Jackson, E.B. (1977). Optimizing crop production through control of water and salinity levels. Utah Water Res. Lab. PWRG 151-1. Utah, USA. 


\title{
EFECTO DE LA FRECUENCIA DE RIEGO SOBRE LA CALIDAD DEL TOMATE EN LA REGIÓN COSTERA DEL NORDESTE BRASILEÑO
}

\author{
Morais, G.M. ${ }^{2}(P)$, Rebouças Neto, M. O. ${ }^{1}$, Brasil, S. O. S ${ }^{3}$, Palau, C.V. ${ }^{4}$, \\ Vasconcelos, D.V.
}

\author{
${ }^{1}$ Profesor, IFPI - Campus Corrente, Correntes - PI, agromario@gmail.com \\ ${ }^{2}$ Doctoranda en Ingeniería Agrícola, UFC, Fortaleza - CE, gislane_mendez@yahoo.com.br \\ ${ }^{3}$ Estudiante de grado en Ingeniería Agronómica, UFC, Fortaleza - CE, \\ suane_brasil@hotmail.com \\ ${ }^{4}$ PDI, Universitat Politècnica de València, Dpto. Ingeniería Rural, virpaes@agf.upv.es \\ ${ }^{5}$ Doctora en Ingeniería Agrícola, Dpto. de Ingeniería Agrícola, UFC, Fortaleza - Ceará, \\ denisevasconcelos@hotmail.com
}

\section{Resumen}

El objetivo de este estudio fue evaluar la calidad de la fruta de los tomates para diferentes frecuencias de riego en dos años de cultivo en la región costera del nordeste brasileño. El experimento fue conducido durante el período de agosto a diciembre de 2011 y 2012 en el área experimental de la Estación Meteorológica de la Universidad Federal del Ceará, situada en la ciudad Fortaleza, nordeste brasileño. El sistema de riego utilizado fue localizado con goteros integrados de caudal nominal $4 \mathrm{~L} \mathrm{~h}^{-1}$. El diseño experimental fue con bloques al azar factorial de 6x4. Los tratamientos adoptados fueron: F2 (dosis de riego cada dos días), F3 (dosis de riego cada tres días), F4 (dosis de riego cada cuatro días), F5 (dosis de riego cada cinco días), F6 (dosis de riego cada seis días) y F7 (dosis de riego a cada siete días). La dosis de riego diaria se estimó mediante un balance de agua entre evapotranspiración del cultivo y precipitaciones efectivas en la zona de estudio. Esta dosis aplicada será acumulativa en función de la frecuencia de riego de cada prueba experimental. Al final del experimento, las variables analizadas fueron: la firmeza de la fruta (FF), los sólidos solubles (SS), la acidez titulable (AT), el pH y la relación SS / AT. El manejo del riego aplicado al cultivo del tomate ha demostrado ser beneficioso por sus efectos positivos en la mejora de la calidad de los frutos para la industria de transformación. Los resultados que comparan diferentes frecuencias de riego dieron información útil sobre la posibilidad de mejorar su calidad nutricional. El intervalo de riego de 7 días proporcionó frutos de mejor calidad para el procesamiento industrial, y un intervalo de riego menor proporcionó frutos con características óptimas para su consumo en fresco.

\section{1- Introducción y objetivos}

Pocas son las hortalizas que a nivel mundial presentan una demanda tan alta como el tomate. Del grupo de las hortalizas, el tomate es la especie más importante, tanto desde una perspectiva social como desde un punto de vista económico, por el volumen de producción y de creación de empleos.

Según los datos de FAOSTAT (Food and Agriculture Organization of the United Nations), la producción mundial de tomates en 2013 fue de 163 millones de toneladas. Brasil es uno de los mayores productores, ocupando el octavo lugar seguido por España. La producción brasileña fue de cerca de 4 millones de toneladas en una superficie de 
60.000 hectáreas. Aproximadamente el $24 \%$ de la producción nacional se destina a la industria de transformación y el resto para consumo en fresco.

La frecuencia de riego requerida por un cultivo en un clima específico depende del agua que se puede almacenar en un determinado suelo después de un riego, de la profundidad efectiva del sistema radicular, del porcentaje de superficie cubierta y de la precipitación de la zona. En las regiones semiáridas, en general, las plantas requieren más agua por ciclo (Andrade y Borges Junior, 2008).

Dentro de las hortalizas, el tomate es uno de losmás exigentes en agua con un consumo superior a la media. En el fruto maduro del tomate, el contenido en agua es cercano al $93 \%$ e su constitución (Santana et al., 2011). Las necesidades totales de agua al año, después de trasplantar el cultivo de tomate son de 400-600 mm, dependiendo del clima (Silva et al., 2000). Según Oliveira et al. (2011) un exceso o deficit de agua es uno de los factores más limitantes para la obtención de altos rendimientos. La influencia de las prácticas de riego sobre la calidad de los frutos de tomate no ha sido suficientemente estudiada.

En particular, existen numerosos estudios sobre los efectos de la cantidad de riego en el cultivo del tomate que consideran la calidad de los frutos sólo en términos de sólidos solubles y de rendimiento (Hanson \& May, 2004; Hanson et al., 2006; Machado et al., 2005; Zegbe-Dominguez et al., 2003). Sin embargo, hay poca literatura sobre la influencia de la frecuencia de riego en el valor nutricional de tomate (Mahajan y Singh, 2006).

Siendo así, el objetivo de este trabajo fue identificar la frecuencia de riego que puede proporcionar una mayor productividad y una mejor calidad en los frutos de tomate para su procesamiento en la industria en las condiciones agroclimáticas de la región costera del nordeste brasileño.

\section{2- Materiales y métodos}

El experimento fue conducido durante el período de agosto a diciembre de 2011 y 2012, en el área experimental de la Estación Meteorológica de la Universidad Federal del Ceará, situada en la ciudad Fortaleza, nordeste brasileño, a $3^{\circ} 44^{\prime}$ de latitud sur, $38^{\circ} 33^{\prime}$ de longitud oeste y a $19,5 \mathrm{~m}$ de altitud. En esta región, el clima es tropical lluvioso, con precipitaciones importantes en el verano-otoño. Los datos mensuales de las variables climáticas recogidas durante los experimentos se muestran en la Tabla 1.

Tabla 1. Los datos mensuales de las variables climáticas durante la realización de experimentos, Fortaleza, Ceará, 2011 y 2012.

\begin{tabular}{lcccccc}
\hline \multirow{2}{*}{ Mes } & \multicolumn{2}{c}{ Temperatura del aire $\left({ }^{\circ} \mathrm{C}\right)$} & \multicolumn{2}{c}{ Precipitación $(\mathrm{mm})$} & \multicolumn{2}{c}{ Humedad Relativa (\%) } \\
\cline { 2 - 7 } & 2011 & 2012 & 2011 & 2012 & 2011 & 2012 \\
\hline Agosto & 26,6 & 28,7 & 51,0 & 0,0 & 71,0 & 73,3 \\
Septiembre & 27,0 & 28,8 & 0,0 & 0,0 & 67,0 & 73,2 \\
Octubre & 27,1 & 28,9 & 23,8 & 2,3 & 72 & 72,9 \\
Noviembre & 27,4 & 29,3 & 7,3 & 0,5 & 73 & 73,3 \\
Diciembre & 27,7 & 29,7 & 6,7 & 1,8 & 71 & 74,1 \\
\hline
\end{tabular}

Fuente: Estación agrometeorológica de la Universidad Federal de Ceará.

El sistema de riego utilizado fue localizado con goteros integrados de caudal nominal $4 \mathrm{~L} \mathrm{~h}^{-1}$. El diseño experimental fue de bloques al azar factorial de $6 \times 4$. Los tratamientos 
adoptados fueron: F2 (dosis de riego cada dos días), F3 (dosis de riego cada tres días), F4 (dosis de riego cada cuatro días), F5 (dosis de riego cada cinco días), F6 (dosis de riego cada seis días) y F7 (dosis de riego a cada siete días).

Para los experimentos, se utilizó el tomate caqui (Lycopersicon esculentum, Mill), híbrido F1 de la empresa Topseed, que tiene forma de crecimiento indeterminado.

La dosis de riego diaria se estimó mediante un balance de agua entre evapotranspiración del cultivo y precipitaciones efectivas en la zona de estudio. Esta dosis aplicada será acumulativa en función de la frecuencia de riego de cada prueba experimental. ecuación 1.

El tiempo de riego empleado en el experimento se determinó de acuerdo con la

$\mathrm{Ti}$ - tiempo de riego $(\mathrm{h})$;

$\mathrm{Di}$ - Dosis de riego $\left(\mathrm{mm} \mathrm{d}^{-1}\right)$;

$\mathrm{El}$ - espaciamiento entre las filas $(\mathrm{m})$;

Eg - espaciamiento entre goteros $(m)$;

Fc - factor de cobertura del suelo (sin dimensiones);

$\mathrm{Ei}$ - eficiencia de riego (sin dimensiones);

$\mathrm{q}_{\mathrm{g}}$ - caudal del gotero $\left(\mathrm{L} \mathrm{h}^{-1}\right)$.

La dosis del riego (Di) se estimó por ETo de Penman-Monteith, obtenida con los datos de una estación meteorológica automatizada equipados con sensores y accesorios necesarios para calcularla por el método de Penman-Monteith (Allen et al., 1998).

La siembra se realizó manualmente en bandejas de 128 celdas el de 15 julio 2011 y el 17 de julio de 2012, después de 26 días de la siembra se realizó el trasplante en campo con espacios de 1,0 y $0,5 \mathrm{~m}$ entre plantas de la misma fila. En el vigésimo día después del trasplante (DDT), cuando las plantas ya se habían aclimatado en el campo, se iniciaron los tratamientos.

En la fertilización de las plantas se utilizó urea y cloruro de potasio, correspondiente a $11,2 \mathrm{~g}$ por planta; lo que corresponde a las dosis de 300 y $400 \mathrm{~kg} \mathrm{ha}^{-1}$ de $\mathrm{N}$ y $\mathrm{K}_{2} \mathrm{O}_{2}$, respectivamente. El fósforo se aplicó todo de una vez con una dosis correspondiente a 200 $\mathrm{kg} \mathrm{ha}^{-1}$ de $\mathrm{P}_{2} \mathrm{O}_{5}$, los $2 / 3$ restantes de $\mathrm{N}$ y 11 aplicaciones parceladas de $\mathrm{K}_{2} \mathrm{O}$ a través de fertirrigación.

La cosecha se realizó del 70 al 90 DDT, donde se recogieron manualmente los frutos. Después de cosechar los frutos se colocaron en bolsas de plástico en cajas y fueron transportadas al Laboratorio de Fisiología y Tecnología de Postcosecha en EMBRAPA, las variables analizadas fueron: la firmeza de la fruta (FF), los sólidos solubles (SS), la acidez titulable (AT), el pH y la relación SS / AT.

Los resultados fueron sometidos a un análisis de regresión con un nivel de significación del $5 \%$ probando modelos: lineal, logarítmico, exponencial y polinómial cuadrático. 
La ecuación que mejor resultados proporcionó, se seleccionó como base en el análisis de los parámetros de regresión. Los análisis estadísticos se realizaron con la ayuda de las aplicaciones de Microsoft Office Excel (2007), y por medio de software ASSISTAT 7.6 .

\section{3- Resultados y discusión}

De acuerdo al análisis de varianza, presentado en la tabla 2, las diferentes frecuencias de riego aplicadas influyen significativamente en la firmeza de la fruta (FF), los sólidos solubles (SS), la acidez titulable (AT), y la relación SS / AT en los dos años de experimentos, el nivel de significación del 1 y $5 \%$ en la prueba $\mathrm{F}$. Sólo el pH no mostró diferencias significativas.

Tabla 2. Resumen del análisis de varianza para firmeza media del fruto (FMF), sólidos solubles (SS), pH, acidez titulable (AT) y relación SS/AT, en plantas de tomate con diferentes frecuencias de riego.

\begin{tabular}{|c|c|c|c|c|c|c|}
\hline \multirow{3}{*}{ Fuente de variación } & \multirow{3}{*}{ GL } & \multicolumn{5}{|c|}{ Promedio } \\
\hline & & \multicolumn{5}{|c|}{ Agosto-Diciembre, 2011} \\
\hline & & FMF & SS & $\mathrm{pH}$ & AT & SS/AT \\
\hline Tratamientos & 5 & $25.89^{*}$ & $0.074^{*}$ & $0.023^{\text {ns }}$ & $0.011^{* *}$ & $21.13^{* *}$ \\
\hline Bloques & 3 & $4.99^{\text {ns }}$ & $0.002^{\mathrm{ns}}$ & $0.046^{*}$ & $0.00043^{\text {ns }}$ & $3.41^{\mathrm{ns}}$ \\
\hline Residuo & 15 & 6.45 & 0.018 & 0.012 & 0.00108 & 2.74 \\
\hline \multirow[t]{3}{*}{$\mathrm{CV}(\%)$} & - & 17.26 & 3.26 & 2.26 & 9.09 & 13.36 \\
\hline & & \multicolumn{5}{|c|}{ Promedio } \\
\hline & & \multicolumn{5}{|c|}{ Agosto-Diciembre, 2012} \\
\hline Tratamientos & 5 & $21.77^{\star *}$ & $1.153^{* *}$ & $0.020^{\text {ns }}$ & $0.012^{* *}$ & $45.54^{\star *}$ \\
\hline Bloques & 3 & $0.562^{\mathrm{ns}}$ & $0.223^{\text {ns }}$ & $0.018^{\text {ns }}$ & $0.00106^{\text {ns }}$ & $1.65^{\text {ns }}$ \\
\hline Residuo & 15 & 0.86 & 0.109 & 0.048 & 0.00150 & 4.25 \\
\hline CV(\%) & - & 6.23 & 6.37 & 4.51 & 10.52 & 14.11 \\
\hline
\end{tabular}

$\mathrm{FV}=$ Fuente de variación, $\mathrm{GL}=$ grado de libertad, $\mathrm{CV}=$ coeficiente de variación; $\mathrm{T}=$ Testigo, ${ }^{* *}=$ Significativo a $1 \%,{ }^{*}$ Significativo a $5 \%$ y ${ }^{n s}=$ no significativo.

Para la variable firmeza de la fruta (Figura 1), el gráfico presenta una tendencia creciente lineal con el aumento de frecuencias de riego. La firmeza y la cantidad de agua son los principales atributos que determinan la calidad del almacenamiento de los frutos de tomate (Batu, 2004.; Dorais et al, 2001.; Viskelis et al., 2008). Cuanto mayor es la firmeza de la fruta mayor es suduración en el estante, debido a que la fruta es menos susceptible a los daños mecánicos durante el transporte. 


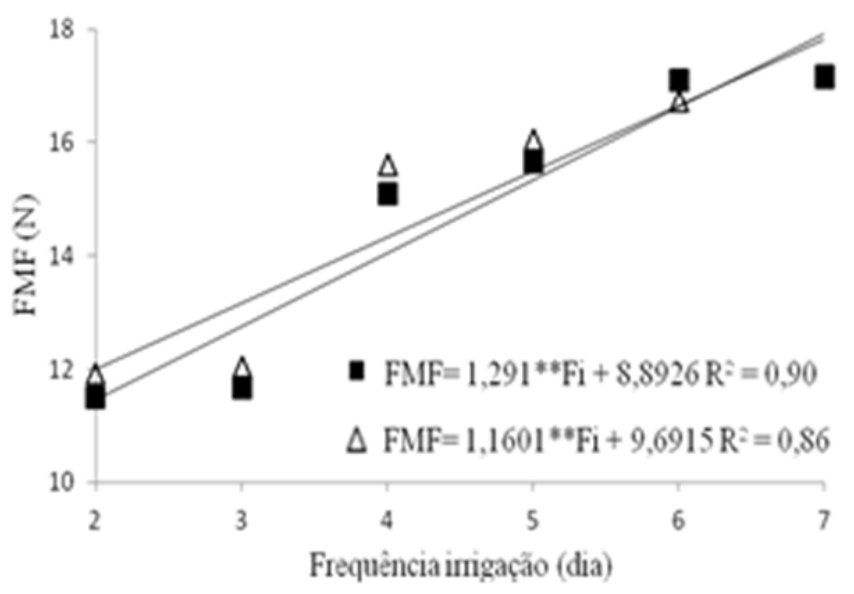

Figura 1. Firmeza media de los frutos de tomate en función de la frecuencia de riego, Fortaleza, Ceará, ( $) 2011$ y $(\Delta)$ 2012. ${ }^{* *}$ Significativo con un test t de Student, a $1 \%$ de probabilidad.

Las frecuencias de riego afectan significativamente a los sólidos solubles (SS) entre los años 2011 y 2012 (Figura 2). El valor medio de SS en los dos años fue de 4,0 y 4,5 Brix, respectivamente, en la prueba con menor frecuencia (F2) y de 4,8 y $6,1^{\circ}$ Brix para la frecuencia más amplia de aplicación de agua (F7). Estas diferencias entre los valores de sólidos solubles entre los años de estudiofue debida a lamayor precipitación durante 2011 en comparación con 2012, lo que puede haber causado menor cantidad de SS tanto para la frecuencia más baja como para la mayor, puesto que en el año de mayor precipitación las plantas sufrieron un estrés hídrico menor (Hanson \& Mai, 2004.; Hanson et al, 2006).

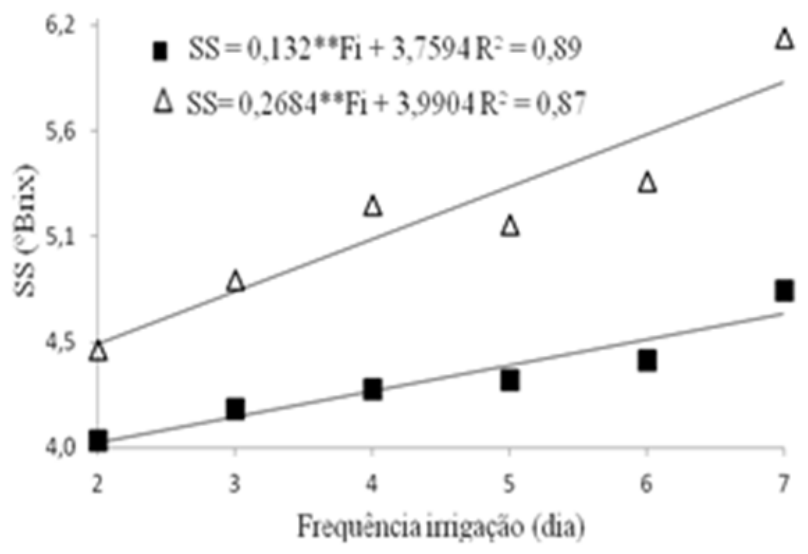

Figura 2. Sólidos solubles del fruto del tomate em función de la frecuencia de riego, Fortaleza, Ceará, $(\boldsymbol{\square}) 2011$ y $(\triangle)$ 2012. ${ }^{* *}$ Significativo con un test t de Student, a $1 \%$ de probabilidad.

Para la acidez titulable (Figura 3), los valores fueron de $0,451 \%$ y $0,456 \%$ para la mayor frecuencia de riego y de $0,320 \%$ y $0,319 \%$ para la menor frecuencia de riego, en los años 2011 y 2012, respectivamente. La acidez titulable de tomate para transformación industrial es por lo general cercana al 0,35\% (Garcia \& Barret, 2006).En nuestro estudio, los 
tomates con la frecuencia más baja de riego han producido frutos con un valor de acidez adecuado para la transformación industrial.

En particular, el aumento de intervalo de riego originó un incremento en la acidez titulable en ambos años. La verdad es que los valores de acidez titulable disminuyen y aumentan con la disponibilidad de agua. Algunos autores consideran que las concentraciones más altas de ácido en la fruta son resultado de un déficit de agua (Mitchell et al 1991; Tuzel et al., 1994).

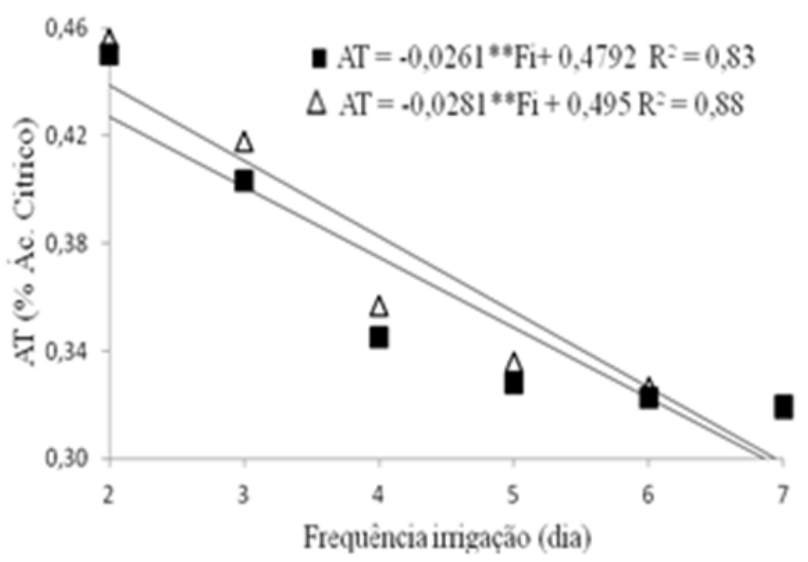

Figura 3. Acidez titulable de frutos de tomate en función de la frecuencia de riego, Fortaleza, Ceará, $(\boldsymbol{\square}) 2011$ e $(\Delta) 2012 .{ }^{* *}$ Significativo con un test t de Student, a $1 \%$ de probabilidad.

Para la relación sólidos solubles y acidez tilulable (Figura 4) se mostró un aumento lineal de esta relación con el aumento en el intervalo de riego, como se ha visto antes, esto se debe al aumento en sólidos solubles ocasionado por el estrés hídrico, mientras que la acidez titulable se reduce.

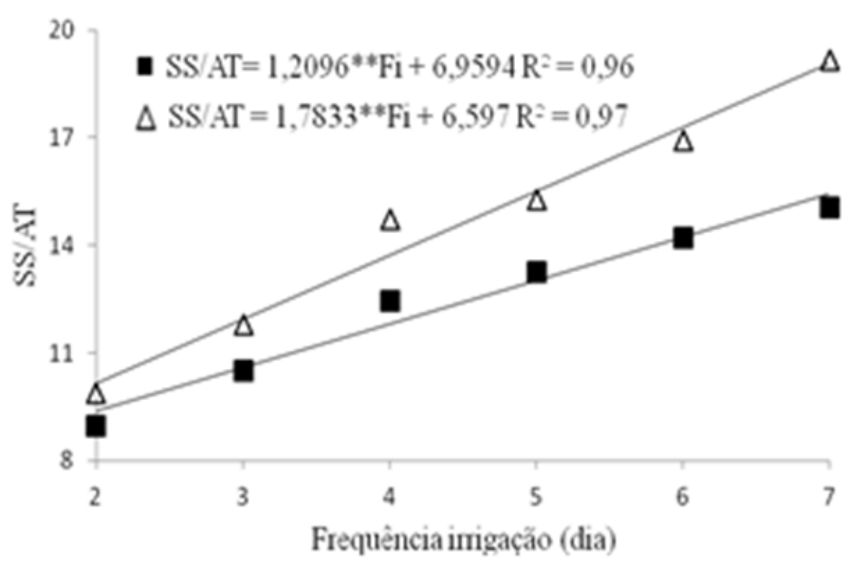

Figura 4. Relación entre sólidos solubles y acidez titulable en frutos de tomate en función de la frecuencia de riego, Fortaleza, Ceará, (⿴) 2011 e $(\triangle)$ 2012. **Significativo con un test $t$ de Student, a $1 \%$ de probabilidad. 
Los valores medios más altos fueron de 15 y 19,2, mientras que los mínimos fueron 9 y 9,9 obtenidos con el máximo y mínimo intervalo de riego en el año 2011 y 2012 . El valor alto en esta relación indica una excelente combinación de azúcar y ácido que se correlaciona con un sabor suave, mientras que los valores bajos dan un sabor ácido al fruto.

Se observa que los valores encontrados en el año 2011 son menores que en 2012 y esa diferencia puede atribuirse a la variable climática de precipitación como se ha comentado anteriormente.

\section{4- Conclusiones}

El manejo del riego aplicado al cultivo del tomate ha demostrado ser beneficioso por sus efectos positivos en la mejora de la calidad de los frutos para la industria de transformación.

Los resultados que comparan diferentes frecuencias de riego dieron información útil sobre la posibilidad de mejorar su calidad nutricional. El intervalo de riego de 7 días proporcionó frutos de mejor calidad para el procesamiento industrial, y un intervalo de riego menor proporcionó frutos con características óptimas para su consumo en fresco.

\section{5- Agradecimientos}

Agradezco al Universidad Federal de Ceará - Brasil, por permitir el desarrollo de la investigación y el CNPq por la financiación.

\section{6- Bibliografia}

Allen, R. G., Pereira, L. S., Raes, D., Smith, M. (1998). Crop evapotranspiration - Guidelines for computing crop water requirements. Rome: FAO, FAO Irrigation and Drainage. Paper 56. $319 p$.

Andrade, c. L. T.; Borges Júnior, j. C. F. (2008). Uso e manejo de irrigação. 1ed. Brasília: Ed. EMBRAPA, 528p.

Batu, A. (2004). Determination of acceptable firmness and colour values of tomatoes. Journal of Food Engineering, 61, 471-475.

Dorais, M.; Papadopoulos, A.; Gosselin, A. (2001). Greenhouse tomato fruit quality. Horticultural Reviews, 26, 239-319.

Garcia E., and D.M. Barrett. Feb. 2006. Evaluation of Processing Tomatoes from Two Consecutive Growing Seasons: Quality Attributes, Peelability and Yield. Journal of Food Processing and Preservation, 30(1), 20-36.

Hanson, B.R.; May, D. M. (2004). Effect of subsurface drip irrigation on processing tomato yield, water table depth, soil salinity, and profitability. Agric. Water Manage, 68, 1-6.

Hanson, B. R.; Hutmacher, R. B.; May, D. M. (2006). Drip irrigation of tomato and cotton under shallow saline ground water conditions. Irrig. Drain. Sys. 20, 155-175. 
Oliveira, E. C.; Carvalho, J. A.; Rezende, F. C.; Freitas, W. A. (2011). Viabilidade técnica e econômica da produção de ervilha (Pisum sativum L.) cultivada sob diferentes lâminas de irrigação. Engenharia Agrícola, 31 (2), 324-333.

Machado, R. M. A.; Rosário, M.; Oliveira, G. (2005). Tomato root distribution, yield and fruit quality under different subsurface drip irrigation regimes and depths. Irrig. Sci. 24, 15-24.

Mahajan, G.; Singh, K.G. (2006). Response of greenhouse tomato to irrigation and fertigation. Agric. Water Manage. 84, 202-206.

Mitchell, J.P., Shennan, C., Grattan, S.R. (1991). Developmental changes in tomato fruit composition in response to water deficit and salinity. Plant Physiol. 83, 177-185.

Santana, M. J; Pereira, U. C; Beirigo, J. D. C; Souza, S. S; Campos, T. M; Vieira, T. A. (2011). Coeficientes de cultura para o tomateiro irrigado. Revista irriga, Botucatu, 16 (1) 1120.

Silva, J. B. C.; Giordano, L. B. (2000). Tomate para processamento industrial. Brasília: Embrapa Comunicação para Transferência de Tecnologia - Embrapa Hortaliças, 168p.

Tuzel, I.H., UI, M.A., Tuzel, Y. (1994). Effects of different irrigation intervals and rates on spring season glasshouse tomato production. II. Fruit quality. Acta Hort. 366, 389-396.

Viskelis, P.; Jankauskiene, J.; Bobinaite, R. (2008). Content of carotenoids and physical properties of tomatoes harvested at different ripening stages. In: FOODBALT, 166-170. 
A-17

\title{
EL SISTEMA DE INFORMACIÓN AGROCLIMÁTICA PARA EL REGADÍO: LA APLICACIÓN MÓVIL COMO FORMA DE PROPORCIONAR LA INFORMACIÓN RELEVANTE PARA EL REGANTE
}

\author{
Bravo Rubio, $R$.
}

Responsable del SIAR. Subdirección General de Regadíos y Economía del Agua. Dirección General de Desarrollo Rural y Política Forestal. Ministerio de Agricultura, Alimentación y Medio Ambiente. Calle Gran Vía de San Francisco, n 4-6. 28003. Madrid

Correo electrónico: rbravo@magrama.es

\section{Resumen}

El Sistema de Información Agroclimática para el Regadío, SIAR, cuenta con 461 estaciones agrometeorológicas situadas en zonas regables representativas en el territorio de doce comunidades autónomas. Tiene como misión optimizar el uso del agua en el regadío, promoviendo su sostenibilidad económica, social y medioambiental, mediante el asesoramiento a los regantes, facilitándoles información agroclimática relevante y estimaciones de riego en la página web del SIAR, en el marco las actuaciones de impulso del desarrollo rural y del cumplimiento de requerimientos medioambientales que lleva a cabo el Ministerio de Agricultura, Alimentación y Medio Ambiente. Se explica en el presente trabajo el funcionamiento de la aplicación para dispositivos móviles Android e iOS del SIAR, que pretende incrementar la funcionalidad y versatilidad del SIAR, habiendo sido valorada positivamente por los regantes y técnicos en la fase de prueba llevada a cabo en colaboración con SEIASA en la campaña de riego del año 2015 en una superficie de 200.000 ha de riego.

\section{1- Introducción. Objetivos del trabajo}

Con el presente trabajo se pretende, por una parte, explicar cuáles son los elementos centrales del Sistema de Información Agroclimática para el Regadío, SIAR, que cuenta con 461 estaciones agrometeorológicas (361 propiedad del Ministerio de Agricultura, Alimentación y Medio Ambiente) situadas en zonas regables representativas en el territorio de doce comunidades autónomas, lo que representa el $91 \%$ de la superficie de regadío española.

El segundo objetivo consiste en presentar la aplicación desarrollada para ofrecer un modo adicional de consulta a través de dispositivos móviles (son sistema operativo Android e iOS) de los datos recogidos por dichas estaciones al existente hasta el momento, basado en la puesta a disposición del público en la página web del Ministerio de Agricultura, Alimentación y Medio Ambiente, así como en su envío por correo electrónico a los subscriptores. 


\section{2- El Sistema de Información Agroclimática para el Regadío, SIAR}

La misión del SIAR es optimizar el uso del agua en el regadío, promoviendo su sostenibilidad económica, social y medioambiental, mediante el asesoramiento a los regantes, facilitándoles información agroclimática relevante y estimaciones de riego en la página web del Sistema de Información Agroclimática para el Regadío, en el marco las actuaciones de impulso del desarrollo rural y del cumplimiento de requerimientos medioambientales que lleva a cabo el Ministerio de Agricultura, Alimentación y Medio Ambiente.

Resulta clave para el regadío el determinar con la mayor precisión posible las necesidades hídricas de los cultivos, con el objetivo de emplear el agua necesaria en el momento preciso, lo que llevará a un ahorro de agua y energía y, por otra parte, a la obtención de un rendimiento óptimo de los cultivos.

Para ello, en el año 1998, el entonces Ministerio de Agricultura, Pesca y Alimentación (MAPA) inició el proyecto, ejecución e instalación del Sistema de Información Agroclimática para el Regadío, SIAR, al amparo de la Iniciativa Comunitaria INTERREG II-C: Lucha contra la sequía, dentro de la medida 1 de mejora de la gestión y uso del agua de riego, correspondiente al subprograma 2 del FEOGA-Orientación, de competencia de la Administración General del Estado, en las comunidades autónomas de: Andalucía, Canarias, Castilla y León, Castilla-La Mancha, Comunidad Valenciana, Extremadura y Región de Murcia.

A continuación, en el marco del Plan Nacional de Regadíos, se procedió a su ampliación a las comunidades autónomas de Aragón, Islas Baleares, Galicia, Comunidad de Madrid y Comunidad Foral de Navarra, con superficies significativas en regadío, en las que fue posible su instalación.

En la actualidad, el SIAR es una red compuesta por un total de 461 estaciones agroclimáticas ubicadas en zonas de regadío, que cubre el $91 \%$ de la superficie de regadío española, siendo 361 de ellas propiedad del Ministerio de Agricultura, Alimentación y Medio Ambiente (MAGRAMA). Además, en la red se encuentran integradas un total de 100 estaciones de algunas de las comunidades autónomas que conforman el SIAR.

Las estaciones, que son automáticas, cuentan con una serie de sensores para medir las variables agroclimáticas de interés para el cálculo de las necesidades de agua de los cultivos: precipitación, humedad, temperatura, radiación, velocidad y dirección del viento.

La información de las variables que recogen las estaciones y la estimación de las necesidades hídricas de los cultivos se suministra gratuitamente en la página web del SIAR www.siar.es, la cual contó con un millón de páginas vistas en el año 2015. Además, también se pone directamente a disposición de los servicios regionales de asesoramiento al regante, que en sus propias páginas web ofrecen recomendaciones de riego en su territorio, basadas en dichos datos. 


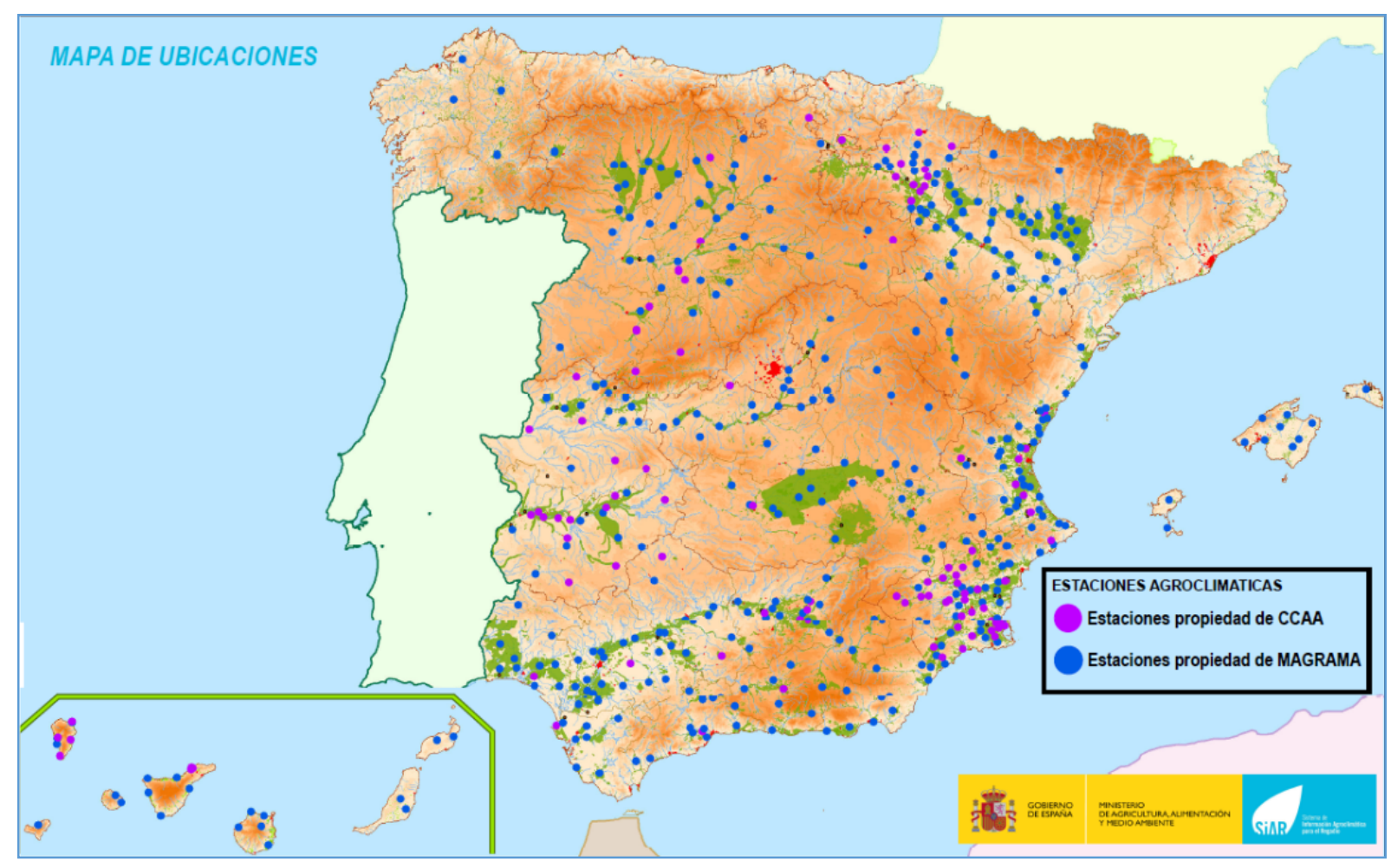

Figura 1. Mapa de ubicación de las estaciones que componen el SIAR

\section{3- Fundamentos de la aplicación para dispositivos móviles del SIAR}

La aplicación SIAR, diseñada para teléfonos móviles y tabletas con sistema operativo Android o iOS (Apple), permite la gestión de un programa de riegos mediante el cálculo de necesidades hídricas y dosis de riego necesarias de los cultivos, tomando como evapotranspiración de referencia la calculada a través de los datos suministrados por la red de estaciones del SIAR.

Se expondrán los elementos principales de la aplicación desarrollada para dispositivos móviles, abarcando desde los datos básicos que puede suministrar hasta su uso más avanzado y personalizado, siguiendo todos los pasos a dar desde la creación de un cultivo hasta la obtención de la estimación de las necesidades hídricas de los cultivos (herbáceos y leñosos):

- Selección de la ubicación de la parcela, del cultivo, del sistema de riego y de la tipología de suelo. Resumen de la configuración de dichos parámetros.

- Creación del cultivo personalizado.

- Selección del sistema de riego, la clase de suelo y las unidades.

- Gestión de mis cultivos.

- Necesidades hídricas diarias/semanales y estado del cultivo.

- Seguimiento del riego, aportaciones de riego efectuadas y consulta acumulada.

- Gráficos: de estado del suelo, aportaciones hídricas y balance hídrico

- Datos meteorológicos.

La primera vez que se accede a la aplicación SIAR es necesario darse de alta, mediante la opción registrarse, introduciendo un correo electrónico y una contraseña, lo que permite comenzar a crear los cultivos personalizados añadiendo nuevo cultivo (ver figura 2). 


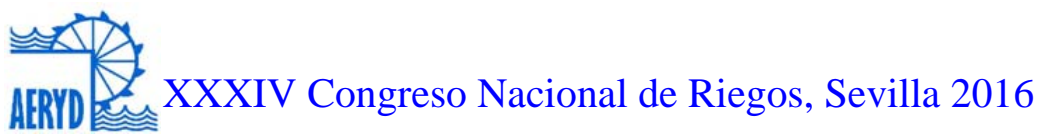

Es necesario tener en cuenta que, en el momento de creación del cultivo, se considera que el suelo está en tempero para efectuar los cálculos de las necesidades hídricas del mismo, por lo que se aconseja crear el cultivo después de una lluvia o riego. A continuación, se establecerá la ubicación de la parcela mediante georreferenciación, procediéndose a la asignación de la estación del SIAR más cercana (ver imagen de la derecha de la figura 2).

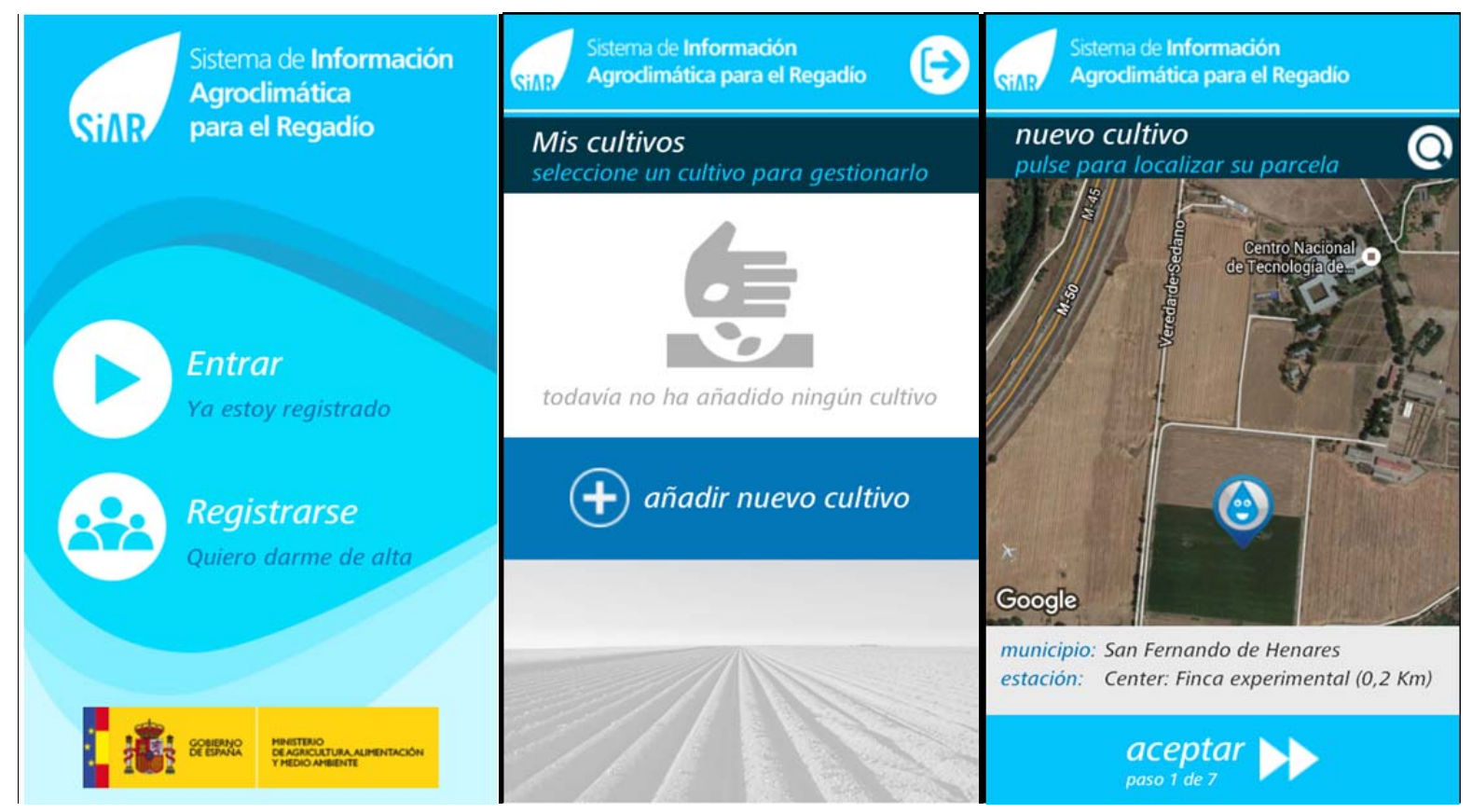

Figura 2. Primeros pasos para comenzar a usar la aplicación

Una vez completado este paso se puede proceder a la selección del cultivo de entre los más de cien disponibles en la aplicación SIAR, determinando la fecha de siembra para los cultivos herbáceos o, en el caso de los leñosos, la distancia entre filas, la distancia entre columnas y el diámetro de copa (ver figura 3).

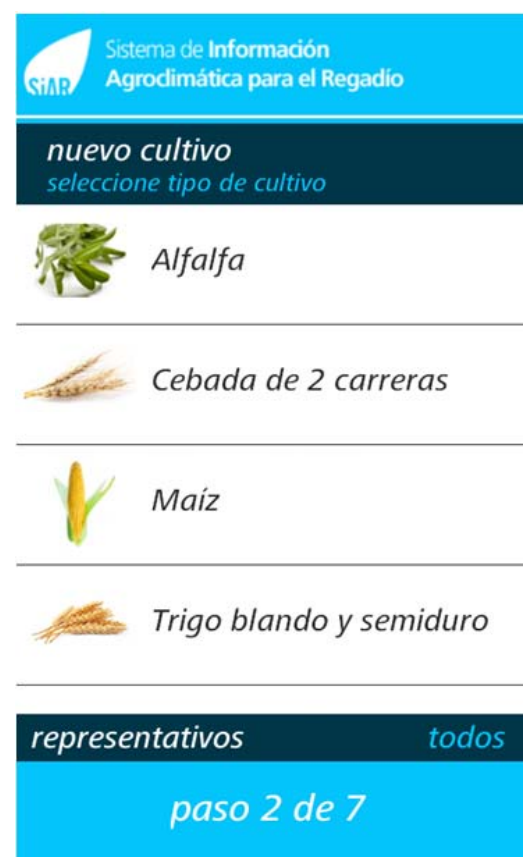

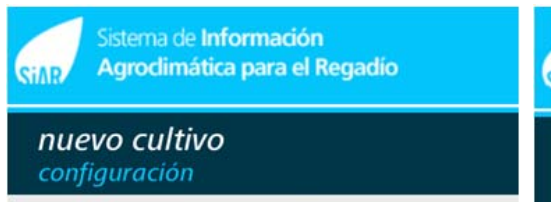

盟 fecha de siembra

$12-4-2016$

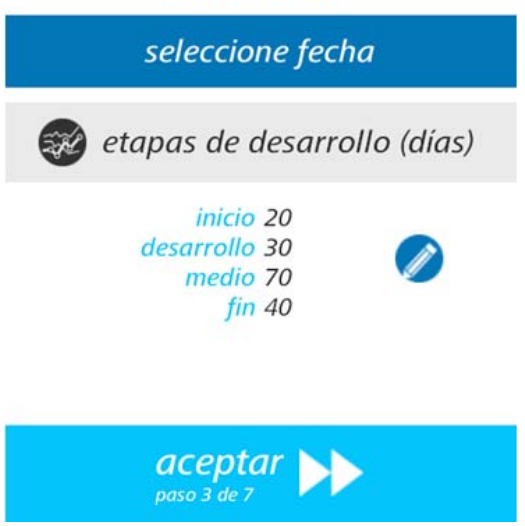

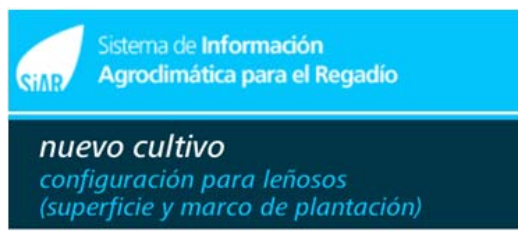

Superficie $\left(m^{2}\right)$ :

Distancia entre filas $(m)$ :

Distancia entre columnas $(m)$ :

Diametro de copa $(m)$ :

aceptar paso 3 de 7

Figura 3. Creación de un cultivo personalizado 
figura 4).

A continuación, se seleccionará el tipo de riego, la clase de suelo y las unidades (ver

\begin{tabular}{|c|c|c|}
\hline $\begin{array}{l}\text { Sistema de Informacóón } \\
\text { sinR Agrodimática para el Regadio }\end{array}$ & $\begin{array}{l}\text { Sistema de Información } \\
\text { SinR Agrodimática para el Regadio }\end{array}$ & $\begin{array}{ll}\text { Sistema de Información } \\
\text { sinR }\end{array}$ \\
\hline $\begin{array}{l}\text { nuevo cultivo } \\
\text { seleccione tipo de riego }\end{array}$ & $\begin{array}{l}\text { nuevo cultivo } \\
\text { seleccione tipo de suelo }\end{array}$ & $\begin{array}{l}\text { nuevo cultivo } \\
\text { seleccione unidades }\end{array}$ \\
\hline W/// aspersión & arenoso & \multirow{2}{*}{$\begin{array}{l}\text { volumen } \\
\text { I/m² } \\
m^{3} / h a \\
\text { I/árbol }\end{array}$} \\
\hline goteo & franco & \\
\hline \multirow{4}{*}{$\approx$ riego superficial } & \multirow{2}{*}{ limoso } & (1) superficie \\
\hline & & $\mathrm{O}^{m^{2}}$ \\
\hline & arcilloso & \multirow{2}{*}{$\begin{array}{l}\text { (1) caudal } \\
\text { 1/s } \\
1 / h\end{array}$} \\
\hline & & \\
\hline paso 4 de 7 & paso 5 de 7 & $\underset{\substack{\text { paso 6 de7 } 7 \\
\text { aceptar }}}{ }$ \\
\hline
\end{tabular}

Figura 4. Selección del sistema de riego, el suelo y las unidades

En la figura 5 se recogen las pantallas de la aplicación SIAR que nos muestran de forma esquemática los detalles de cada uno de los cultivos que hemos creado y las opciones de gestión para cada uno de ellos.

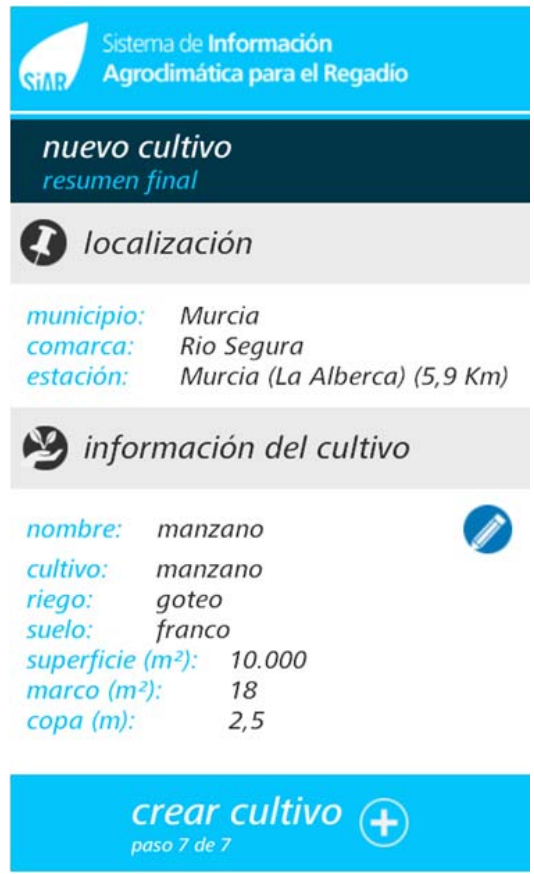
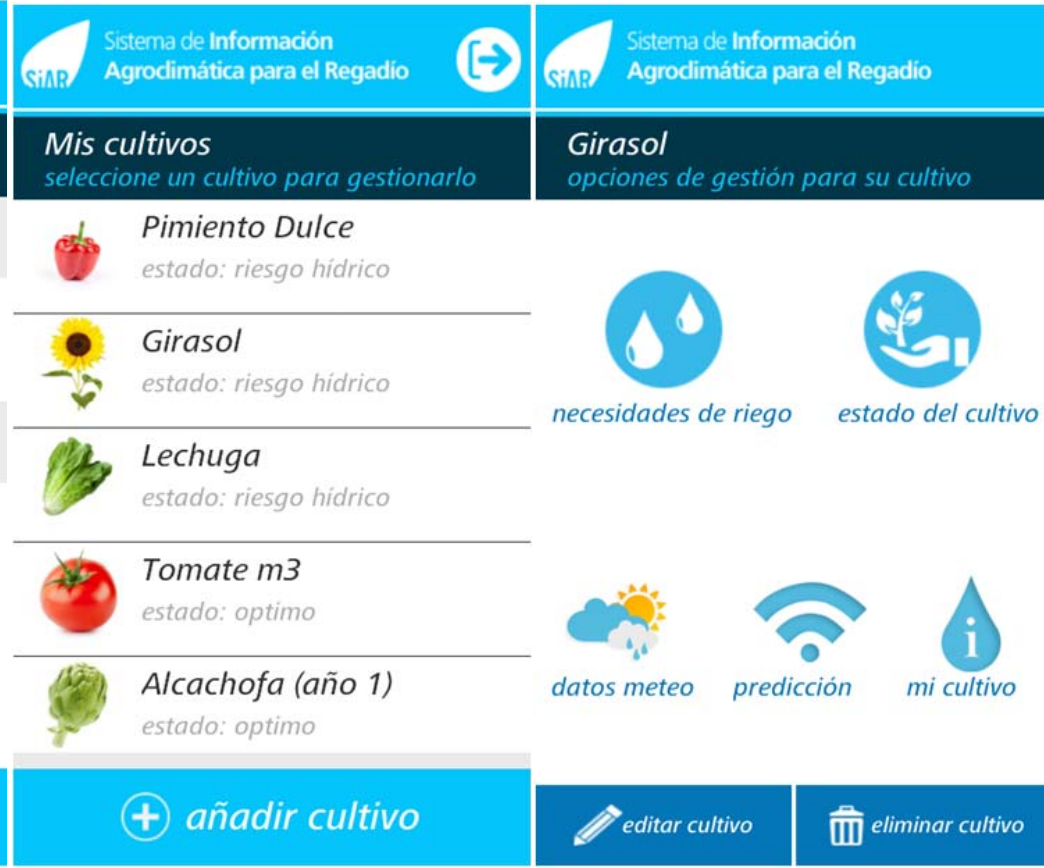

opciones de gestión para su cultivo

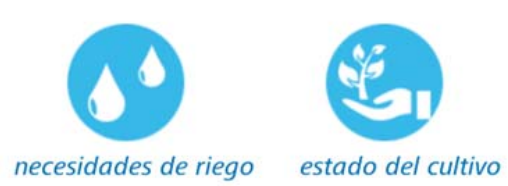

Figura 5. Gestión de mis cultivos 
En lo que se refiere a las necesidades de riego diarias y semanales, señalar que, por defecto, aparecen en la pantalla (ver primera imagen de la figura 6) las correspondientes al día actual pero que, mediante el calendario (imagen central), se pueden consultar las de cualquier otro día o semana desde que se creó el cultivo. Además, seleccionando el botón estado del cultivo, se accede a otra pantalla (última imagen de la figura 6), en la que se presenta un resumen del estado del cultivo y diversas funcionalidades para gestionar el riego.

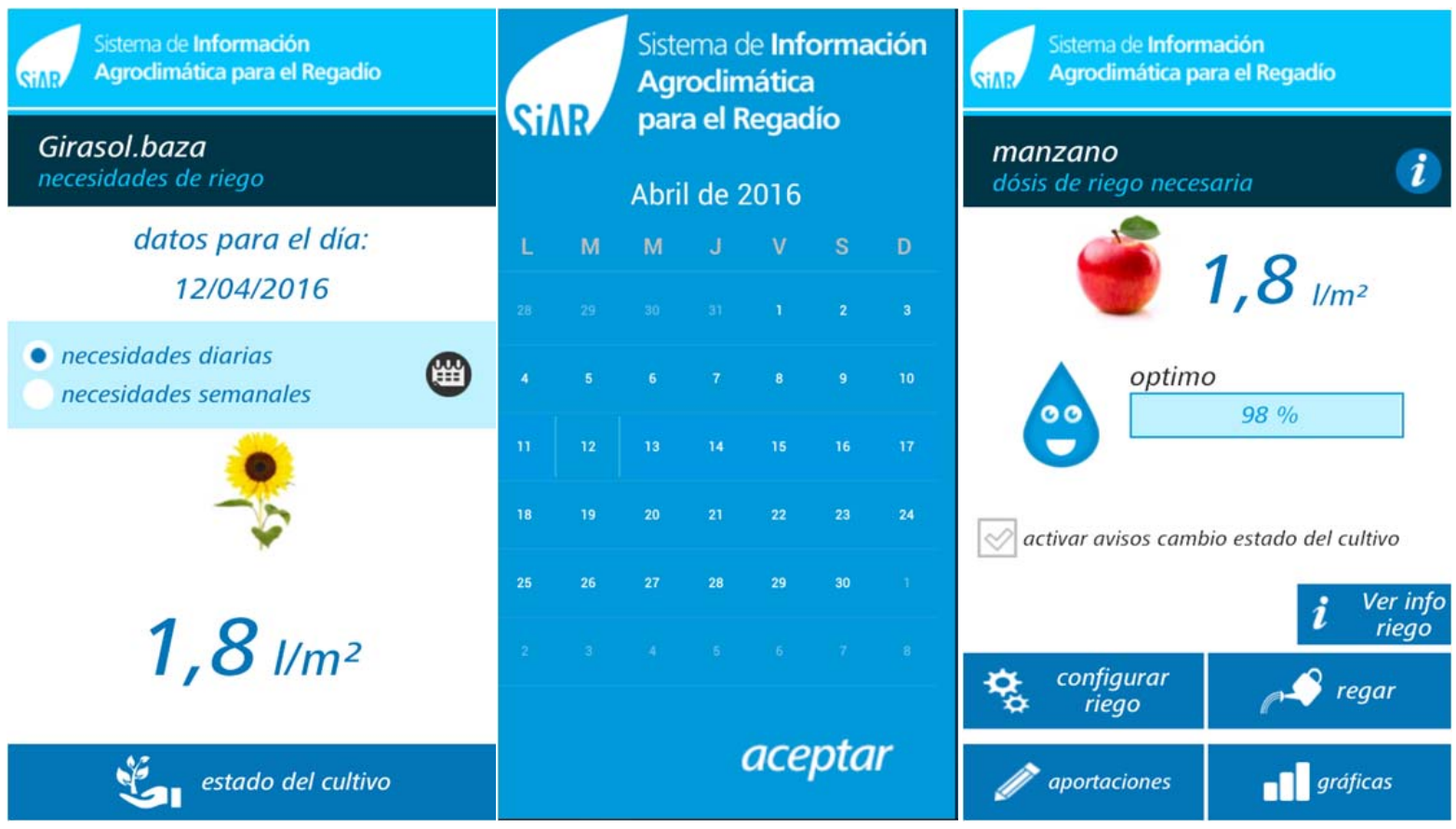

Figura 6. Necesidades de riego diarias/semanales y estado del cultivo

La situación hídrica del cultivo se presenta en forma de gota de agua de color variable, desde el azul que indica que el estado del cultivo es óptimo o adecuado, hasta el rojo que señala peligro de estrés hídrico (cuando la relación entre el agotamiento de humedad en la zona radicular del suelo y el agua disponible total es superior al $85 \%$ ), pasando por el color amarillo cuando esta relación se encuentra entre el 50 y el $85 \%$ (ver figura 7).

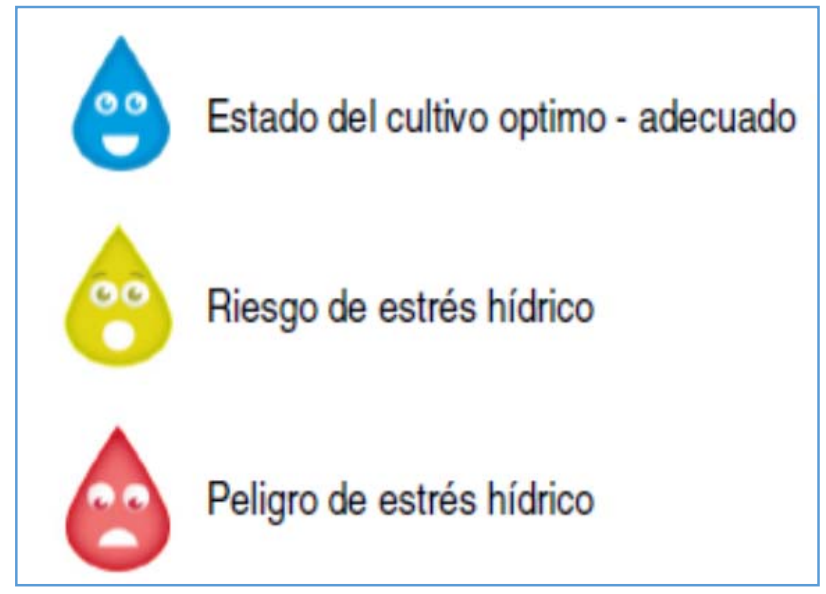

Figura 7. Estado del riesgo hídrico del cultivo 
Las aportaciones de riego efectuadas por el usuario, para que puedan ser tenidas en cuenta por el sistema en el cálculo de las necesidades hídricas del cultivo, que sigue las recomendaciones FAO-56 (Allen et al., 2006), se pueden introducir de tres maneras (ver imagen central de la figura 8): hasta cubrir necesidades (es decir, el riego se correspondería con las necesidades hídricas del cultivo calculadas por la aplicación SIAR), introduciendo el tiempo que efectivamente se ha regado o indicando el volumen aportado.

Para ello hay que haber configurado el riego previamente, de forma que sepamos, para leñosos, el caudal por gotero o microaspersor y el número de ellos, siendo necesario para herbáceos determinar el caudal y la superficie de riego.

En la última pantalla de la figura 8 se muestra el resumen de las aportaciones que ha recibido el cultivo, siendo posible eliminar riegos que han sido introducidos erróneamente o con el objetivo de realizar una simulación.

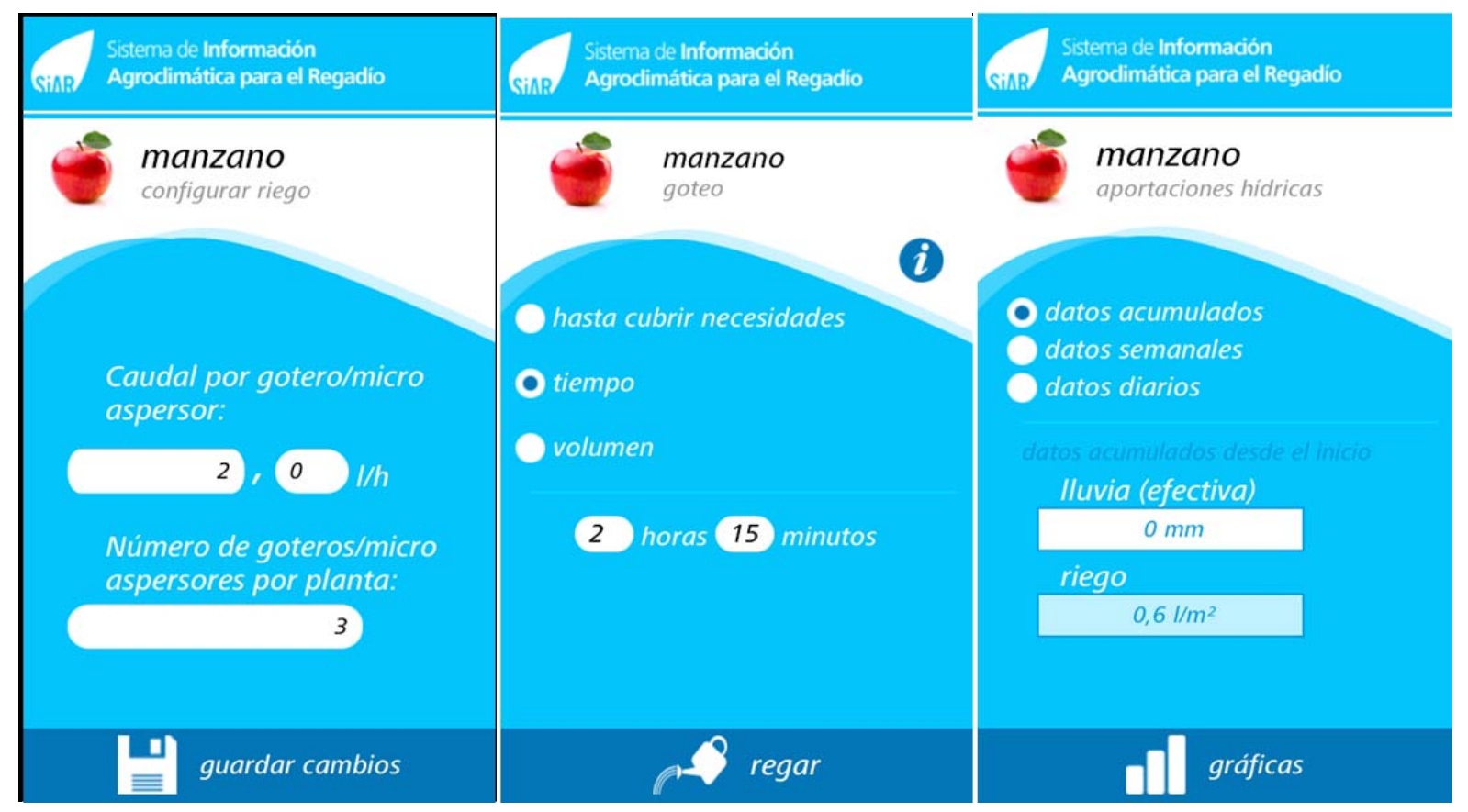

Figura 8. Configuración del riego, aportaciones de riego y consulta acumulada

En la figura 9, se muestran los tres tipos de gráficos que se generan para cada uno de los cultivos: el gráfico de estado del suelo, en el que se representa el contenido de humedad del suelo, el límite de estrés y el punto de marchitez del cultivo (primera imagen), el gráfico de aportaciones de agua, que muestra tanto la precipitación efectiva como el riego efectuado (imagen central) y el gráfico de balance hídrico, en el que observa la evolución del déficit de agua en el suelo junto con la precipitación efectiva y el riego aportado (imagen de la derecha). 

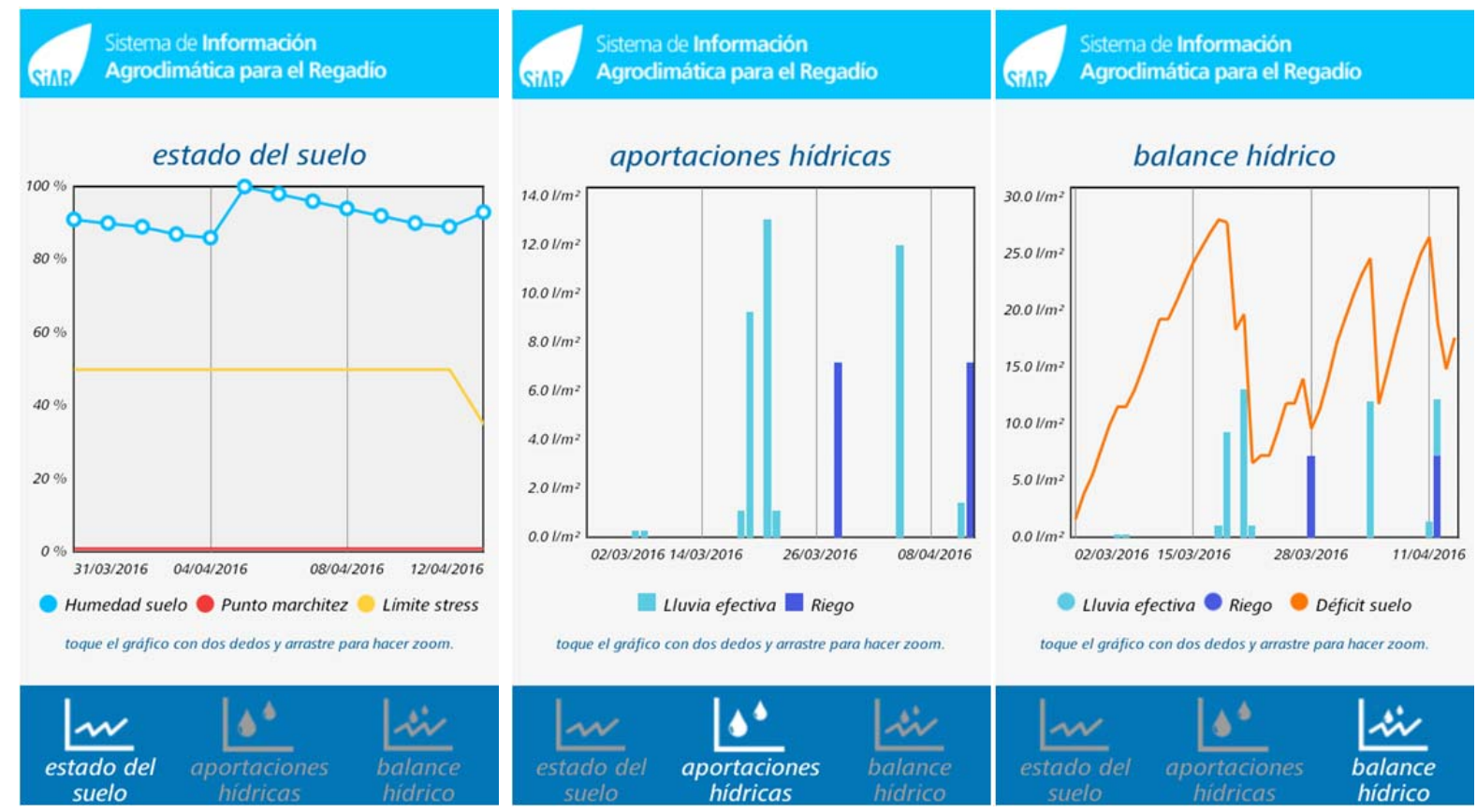

toque el gráfico con dos dedos y arrastre para hacer zoom
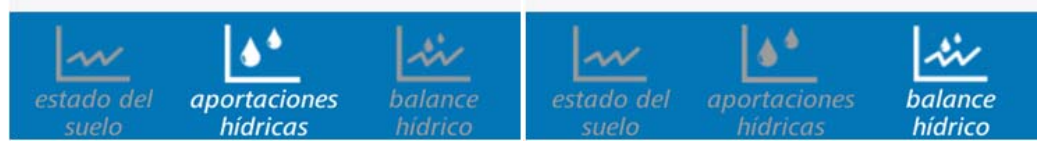

Figura 9. Gráficos de estado del suelo, aportaciones hídricas y balance hídrico

La aplicación SIAR dispone de un widget (ver figura 10), que se puede tener siempre visible en la pantalla del dispositivo móvil, para consultar de una manera rápida y sencilla el estado de los cultivos del usuario, pudiendo navegar mediante las fechas por los distintos cultivos dados de alta, mostrándose el estado de la parcela y el riesgo de estrés.

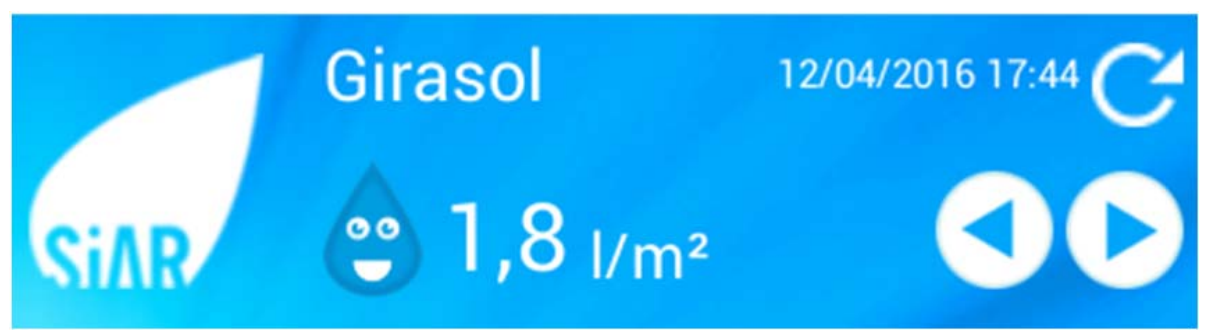

Figura 10. Widget de la aplicación SIAR

\section{5- Pruebas de la aplicación SIAR}

Antes de poner a disposición de la ciudadanía la aplicación (comienzo de la campaña de riego del año 2016), se ha efectuado un proceso de prueba de la versión preliminar durante la campaña de riego del año 2015, en colaboración con la Sociedad Estatal de Infraestructuras Agrarias, SEIASA, que ha implicado a 41 participantes, entre técnicos de SEIASA y usuarios, en las comunidades de regantes que se recogen en la tabla 1, las cuales representan una superficie de 200.000 ha de regadío repartida entre las comunidades autónomas de: Andalucía, Aragón, Castilla y León, Cataluña y Comunidad Valenciana. 
Tabla 1. Comunidades de regantes participantes en las pruebas de la aplicación SIAR

\begin{tabular}{|c|c|}
\hline Comunidad de Regantes (C.R.) & Comunidad autónoma \\
\hline C.R. de las Vegas Altas del Guadalquivir Sector II (Jaén) & \multirow{3}{*}{ Andalucía } \\
\hline C.R. de las Vegas Altas del Guadalquivir Sector IV (Jaén) & \\
\hline C.R. de las Vegas Altas del Guadalquivir Sector V (Jaén) & \\
\hline C.R. del Canal del Flumen Sector VII (Huesca) & \multirow{10}{*}{ Aragón } \\
\hline C.R. del Canal del Flumen Sector XI (Huesca) & \\
\hline C.R. Collarada $2^{a}$ sección-Montesusín (Huesca) & \\
\hline C.R. El Puntal (Huesca) & \\
\hline C.R. La Campaña (Huesca) & \\
\hline C.R. Lalueza (Huesca) & \\
\hline C.R. Molinar del Flumen (Huesca) & \\
\hline C.R. Montesnegros (Zaragoza) & \\
\hline C.R. de Poleñino (Huesca) & \\
\hline C.R. San Pedro de Castelflorite (Huesca) & \\
\hline C.R. Canal de Babilafuente (Salamanca) & \multirow{12}{*}{ Castilla y León } \\
\hline C.R. Canal de Guma (Burgos) & \\
\hline C.R. Canal del Duero (Valladolid) & \\
\hline C.R. Canal de la Maya (Salamanca) & \\
\hline C.R. Canal del Páramo (León) & \\
\hline C.R. Canal de Pisuerga (Burgos y Palencia) & \\
\hline C.R. Canal de Riaza (Burgos y Valladolid) & \\
\hline C.R. de Tordesillas (Valladolid) & \\
\hline C.R. Canal de Toro (Valladolid y Zamora) & \\
\hline C.R. Pantano de Águeda (Salamanca) & \\
\hline C.R. Simancas-Gería (Valladolid) & \\
\hline C.R. Villagonzalo (Salamanca) & \\
\hline C.G.R. Canal de Aragón y Cataluña-Soses (Lleida) & \multirow{6}{*}{ Cataluña } \\
\hline C.R. Canales de Urgel (Lleida) & \\
\hline C.R. Pantá de Ruidecanyes (Tarragona) & \\
\hline C.R. Presa de Colomers (Girona) & \\
\hline C.R. del Rec del Molí de Pals (Girona) & \\
\hline C.R. Valls (Tarragona) & \\
\hline C.R. Acequia Común de Carlet (Valencia) & \multirow{13}{*}{ Comunidad Valenciana } \\
\hline C.R. Alcudia (Valencia) & \\
\hline Comunidad General de Usuarios del Alto Vinalopó (Alicante) & \\
\hline C.R. Azuebar (Castellón) & \\
\hline C.R. Benimodo (Valencia) & \\
\hline C.R. del Canal Júcar Turia Sector 4 (Valencia) & \\
\hline C.R. del Canal Júcar Turia (Valencia) Sector X & \\
\hline C.R. del Canal Júcar Turia (Valencia) Sector XI & \\
\hline Real Acequia de Carcaixent (Valencia) & \\
\hline C.R. Río Alcoy (Valencia) & \\
\hline C.R. Tollos (Valencia) & \\
\hline Junta Central de Regantes de Turis (Valencia) & \\
\hline C.R. Villareal (Castellón) & \\
\hline
\end{tabular}


Las personas que han colaborado durante esta fase de prueba son los propios técnicos de SEIASA y, por parte de las comunidades de regantes, tanto técnicos como regantes, siendo en algunas ocasiones los propios presidentes de las mismas los que han contribuido con su experiencia y tiempo al buen desarrollo de la prueba de la aplicación. La valoración de la utilidad de la aplicación SIAR ha sido muy favorable.

\section{6- Conclusiones}

- El papel del SIAR es destacable en lo que se refiere a la optimización del uso del agua que realiza el regadío español.

- La aplicación SIAR desarrollada para dispositivos móviles (Android e iOS) ha sido valorada positivamente por los colaboradores de SEIASA y de las comunidades de regantes durante la fase de prueba en la campaña de riego del año 2015 en una superficie de riego representativa.

- Gracias a la versatilidad de la aplicación, se prevé que pueda ser utilizada por una amplia tipología de usuarios.

\section{7.- Agradecimientos}

En lo que se refiere al desarrollo de las pruebas de la aplicación para dispositivos móviles del SIAR, se agradece el tiempo y dedicación de los propios técnicos de SEIASA, de los técnicos y usuarios de las comunidades de regantes participantes así como de Javier Almorox Alonso, profesor titular del Departamento de Producción Agraria de la Escuela Técnica Superior de Ingenieros Agrónomos de la Universidad Politécnica de Madrid, quienes han participado desinteresadamente en las mismas.

En lo relativo al propio funcionamiento y gestión del SIAR, destacar la contribución del equipo de Tragsatec que presta el servicio de asistencia técnica a la Subdirección General de Regadíos y Economía del Agua del Ministerio de Agricultura Alimentación y Medio Ambiente, y de las comunidades autónomas participantes en el SIAR.

\section{9- Bibliografía}

Allen, R.G.; Pereira, L.S.; Raes, D.; Smith, M. (2006). Evapotranspiración del cultivo: Guías para la determinación de los requerimientos de agua de los cultivos. Estudio FAO Riego y Drenaje $\mathrm{n}^{\circ}$ 56. Roma: FAO.

Disponible en: http://www.fao.org/docrep/009/x0490s/x0490s00.htm 


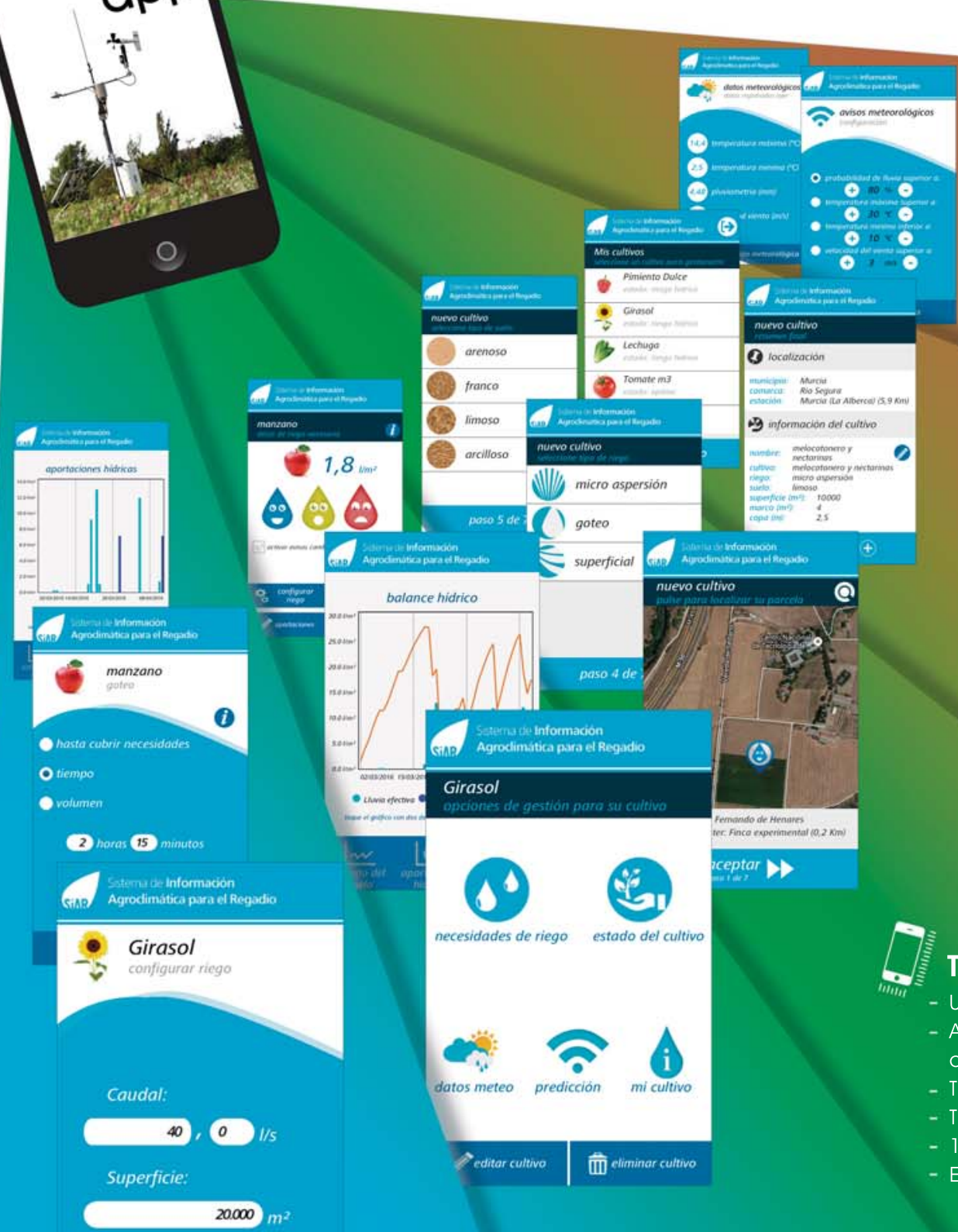

Avisos personalizados
- Cambio de estado del cultivo
- Predicción episodios meteorológicos

8

Consulta de datos

Consulta de datos meteorológicos, procedentes de la estación SiAR asignada

Metodología de cálculo - FAO56

- Kc cultivos leñosos ajustados por comarca agraria

- ETO calculada con datos de la estación SiAR asignada

Tu cultivo a medida

Ubicación de parcelas

Asignación estación SiAR más cercana de las 461 que componen la red

Tipo de suelo

Tipo de sistema de riego

104 Cultivos disponibles

Etapas de cultivo configurables

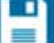
guardar cambios

(9)

Planificación de tu riego

Configuración personalizada del riego

- Registro de riegos

Información del riego por tiempo, o volumen en función del caudal y superficie

- Riegos y precipitaciones acumuladas por días y semanas

- Predicción meteorológica de los próximos cinco días
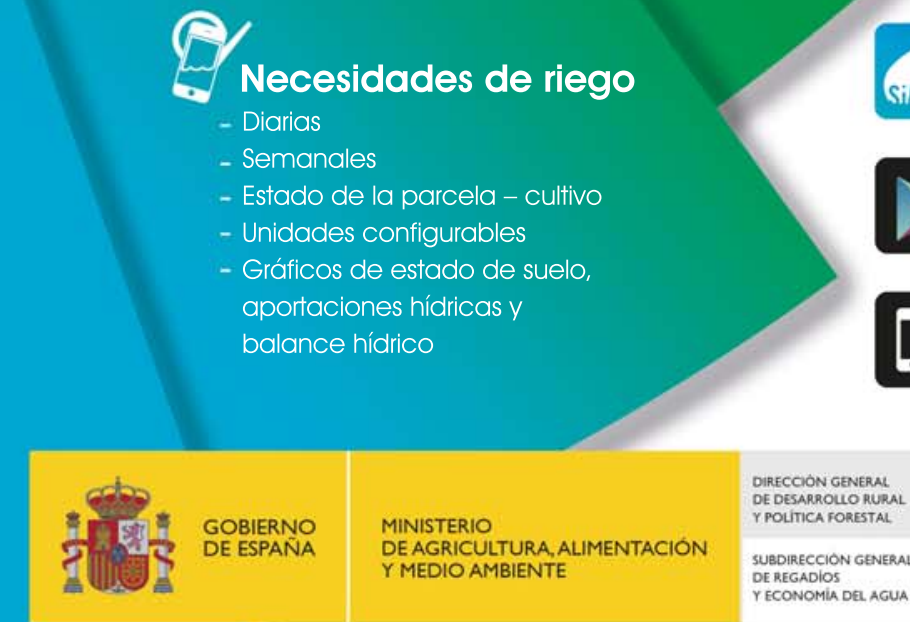

Disponible en la App Store 


\title{
COMPARACIÓN DE LA GESTIÓN DEL RIEGO AUTOMATIZADO CON TENSIOMETROS FRENTE A LA ESTIMACIÓN DE LA EVAPOTRANSPIRACIÓN EN CULTIVOS HORTICOLAS BAJO INVERNADERO
}

\author{
Alonso López, F., Contreras París, J.I., Baeza Cano, R.
}

Instituto de Investigación y Formación Agraria y Pesquera de Andalucía (IFAPA), Centro La Mojonera, Camino San Nicolás, n¹, 04745 La Mojonera, Almería.

rafaelj.baeza@juntadeandalucia.es

\section{Resumen}

La sostenibilidad del uso del agua en la agricultura se ha convertido en una prioridad y la adopción de estrategias de riego que permitan un uso eficiente de la misma manteniendo niveles de producción satisfactorios, en una necesidad. En particular, en áreas que presentan escasez de recursos hídricos, como la Mediterránea, resulta imprescindible maximizar la eficiencia en el uso del agua y la productividad de la misma. En este trabajo se compara la gestión del riego automatizado empleando tensiómetros electrónicos con la estimación de las necesidades hídricas en un cultivo de calabacín en invernadero. La comparación entre los consumos de agua de los tres tratamientos de riego ensayados y la $\mathrm{ET}_{\mathrm{c}}$ estimada a partir de datos reales de clima ( $\left.\mathrm{ET}_{\mathrm{c}-\mathrm{r}}\right)$ muestra que el tratamiento $\mathrm{T} 2$ con una consigna de potencial matricial de $-25 \mathrm{kPa}$ y una dotación de $2 \mathrm{~L} \mathrm{~m}^{-2}$ tuvo un consumo igual al calculado mediante la $\mathrm{ET}_{\mathrm{c}-\mathrm{r}}\left(315 \mathrm{Lm}^{-2}\right)$. Este tratamiento junto con el T3 $\left(-40 \mathrm{kPa}\right.$ y $\left.3 \mathrm{~L} \mathrm{~m}^{-2}\right)$ presentaron los mejores resultados en cuanto a eficiencia en el uso del agua. Sin embargo, el T3 redujo significativamente la cosecha en un 16\%. Por tanto, la activación automática del riego con la consigna del T2 fue la que mejores resultados arrojó aunando eficiencia y productividad.

\section{1- Introducción y objetivos}

El uso eficiente del agua se ha convertido en uno de los mayores desafíos mundiales y, la agricultura, en este contexto, constituye un factor clave en la mejora de la gestión del agua por ser el principal consumidor de este recurso ( $75 \%$ del consumo total). En particular, en áreas que presentan escasez de recursos hídricos, como la cuenca Mediterránea, resulta imprescindible maximizar la eficiencia en el uso del agua y la productividad de la misma. En este sentido, los cultivos hortícolas en invernadero son un modelo a seguir. La productividad del agua obtenida con este sistema productivo es considerablemente más elevada que la de los cultivos al aire libre (Gallardo et al. 2007). No obstante, todavía existe un margen de mejora que es necesario abordar para asegurar la sostenibilidad del sistema.

La programación del riego permite decidir cuándo regar y qué cantidad aplicar, pero está sujeta a la correcta definición de los parámetros que la definen: dotación y frecuencia. La dotación debe ir asociada al tipo de suelo, considerando textura y estructura, así como profundidad del mismo. La frecuencia irá asociada a las necesidades hídricas del cultivo, $\mathrm{ET}_{\mathrm{C}}$, a lo largo de su ciclo de desarrollo. Su determinación puede estar basada en medidas climáticas, de hidratación de los cultivos o de humedad de suelo. En base a medidas climáticas se ha determinado la $\mathrm{ET}_{\mathrm{c}}$ de la mayoría de los cultivos hortícolas bajo 
invernadero en el sureste peninsular (Fernández et al. 2001). Para optimizar la gestión del riego las investigaciones más recientes se centran en la medida del estado hídrico de la planta o en la medida directa de agua en el suelo (Buttaro et al. 2015, Létourneau et al. 2015). La medida del estado hídrico de la planta todavía presenta muchas dificultades teóricas y prácticas (Jones 2004). Sin embargo, la medida directa del agua en el suelo, ya sea el contenido de agua o el potencial matricial del suelo, es más factible por ser relativamente fácil de medir y automatizar (Van lersel et al. 2013). Los tensiómetros, que determinan el potencial matricial del suelo, se prefieren a menudo frente a otro tipo de sensores de humedad de suelo debido a la precisión y rapidez de la medición, su bajo coste y simplicidad de uso y a que las medidas no están influenciadas por la temperatura o el potencial osmótico del suelo. No menos importante es la posibilidad que ofrecen de adquirir electrónicamente datos a través de transductores de presión diferencial (Thalheimer 2003) permitiendo la automatización de la fertirrigación.

El éxito de la gestión del riego empleando tensiómetros electrónicos para la activación automática del riego depende del establecimiento del valor del potencial matricial de suelo adecuado para cada cultivo y condiciones de desarrollo que optimice la producción y la eficiencia en el uso del agua (EUA) y los nutrientes como demuestran Buttaro et al. (2015) y Létourneau et al. (2015).

El objetivo de este trabajo ha sido comparar la gestión del riego automatizado con tensiómetros, con diferentes consignas de activación, frente a la estimación de la evapotranspiración del cultivo.

\section{2- Materiales y métodos}

El ensayo se ha desarrollado en un invernadero tipo Almería de "raspa y amagado" situado en el Centro IFAPA La Mojonera (Almería), construido sobre un suelo enarenado artificial, característico de los cultivos hortícolas intensivos del sureste peninsular. El suelo presentaba los siguientes perfiles: capa superior de arena de granulometría $1-5 \mathrm{~mm}$ y 6-8 $\mathrm{cm}$ de espesor, capa de tierra de cañada aportada de textura franco-limosa y 20-30 cm de espesor y capa de suelo fértil original de textura franco arenosa, elevada pedregosidad y 20 $30 \mathrm{~cm}$ de espesor. El material vegetal implantado fue un cultivo de calabacín (Cucurbita pepo L.var. Casiopee). El trasplante se realizó el 13 de enero de 2015 a un marco de 1 planta $\mathrm{m}^{-2}$ y el ciclo finalizó el 1 de junio (Figura 1). El riego se aplicó mediante un sistema de riego localizado con emisores autocompensantes y antidrenantes de $3 \mathrm{~L} \mathrm{~h}^{-1}$ y un marco de riego de 2 emisores $\mathrm{m}^{-2}$. El invernadero cuenta con 12 lisímetros de drenaje de $1 \mathrm{~m}^{-2} \mathrm{de}$ superficie, instalados a $50 \mathrm{~cm}$ de profundidad (Figura 3). Se establecieron tres tratamientos de riego. Al tratamiento T1 se le asignó una consigna de potencial matricial de suelo de -10 kPa y dotación de 1,5 $\mathrm{L} \mathrm{m}^{-2}$, al T2 una consigna de $-25 \mathrm{kPa}$ y $2 \mathrm{~L} \mathrm{~m}^{-2}$ y al T3 una consigna de $-40 \mathrm{kPa}$ y $3 \mathrm{~L} \mathrm{~m}^{-2}$. La dotación de riego se estableció, considerado la curva de retención de humedad del suelo, al objeto de no alcanzar niveles de humedad en suelo que generasen drenaje. En cada tratamiento se instalaron cuatro tensiómetros electrónicos (Irrometer Co, inc. Riverside, CA, USA) instalados a $15 \mathrm{~cm}$ de profundidad por debajo de la capa de arena (zona radicular) y a $15 \mathrm{~cm}$ de la planta y del gotero. Todos los tensiómetros estaban acoplados a un transductor electrónico que transfería los datos a un equipo de control (Sistema Red Himarcan $囚$ ) (Figura 2). Cada tratamiento de riego era activado con un único tensiómetro electrónico, el resto se empleaban para registrar medidas del potencial matricial del suelo. 


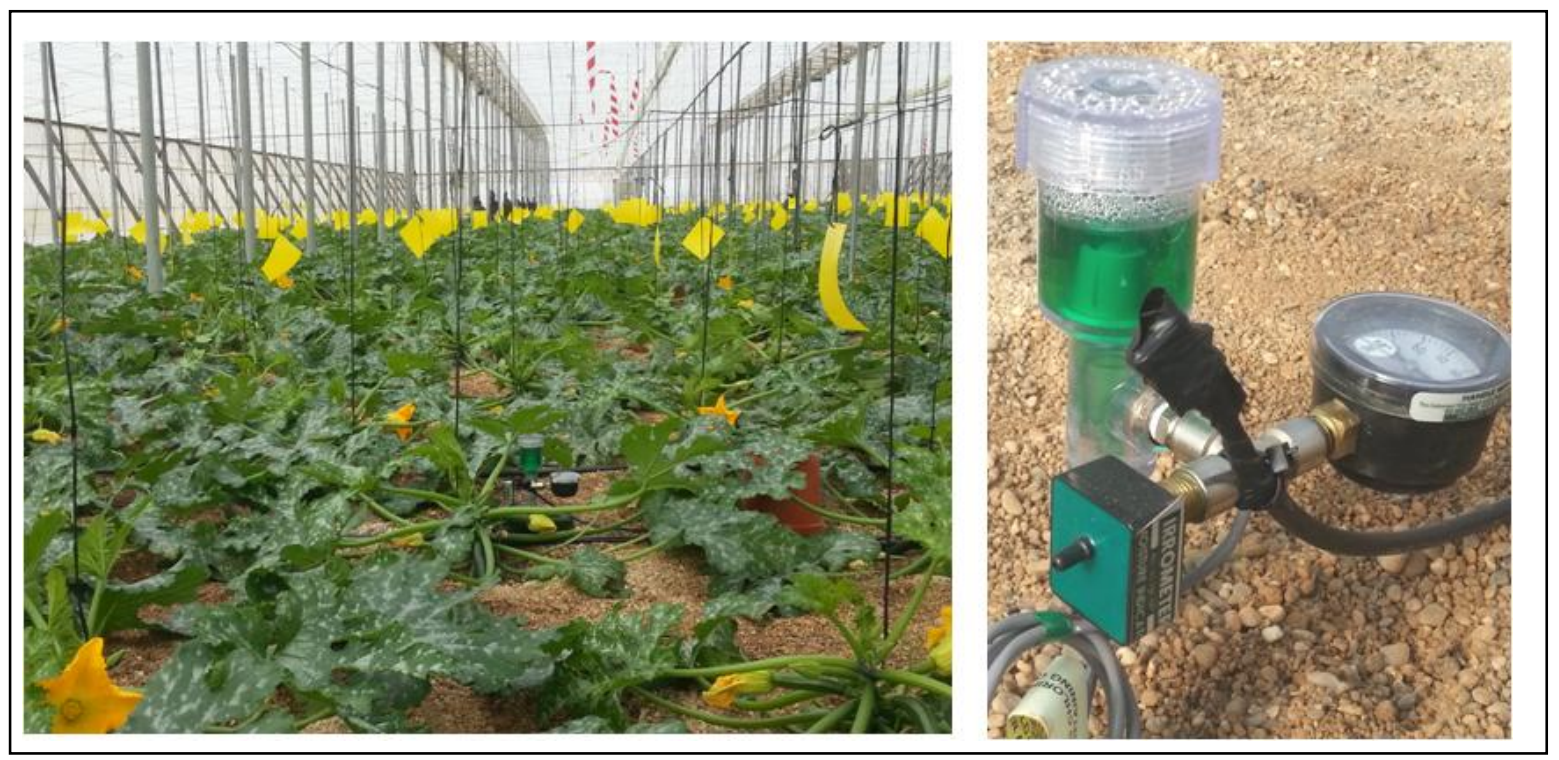

Figuras 1 y 2. Invernadero experimental de calabacín. Tensiómetro electrónico instalado.

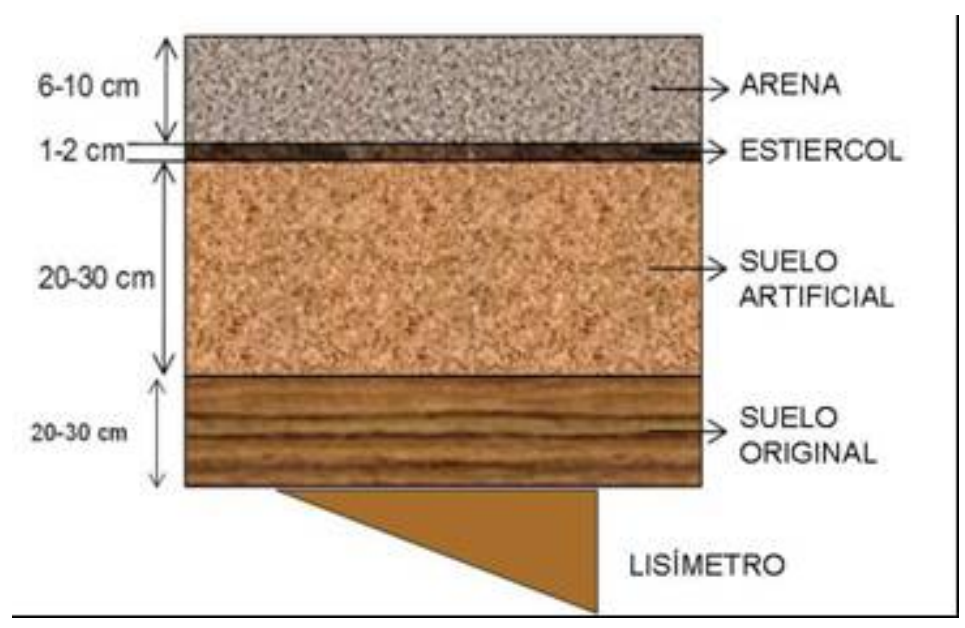

Figura 3. Perfil del suelo y lisímetro

Se realizaron determinaciones del volumen de agua aplicada y volumen de drenaje $\left(\mathrm{L} \mathrm{m}^{-2}\right)$, de la producción comercial $\left(\mathrm{kg} \mathrm{m}^{-2}\right)$, del área foliar $\left(\mathrm{cm}^{2}\right)$ y de la biomasa total, expresada en $\mathrm{g} \mathrm{m}^{-2}$ de materia seca. Además, se estimó la evapotranspiración del cultivo $\left(E T_{c}\right)$ usando el software de riegos PrHo v 2.0 @ 2008 (Fundación Cajamar) para cultivo de calabacín en invernadero. La $\mathrm{ET}_{\mathrm{c}}$ se estima con un modelo que está basado en el modelo propuesto por FAO y que ha sido adaptado para su uso en los cultivos hortícolas en invernadero, de manera que la $\mathrm{ET}_{\mathrm{c}}$ puede ser estimada con precisión a partir de valores medidos de radiación solar exterior y la temperatura dentro de invernadero (Fernández et al. 2001).

La estimación de la $E T_{c}$ se ha realizado a partir de datos reales $\left(E T_{c-r}\right)$ y también a partir de datos climáticos medios $\left(\mathrm{ET}_{\mathrm{c}-\mathrm{m}}\right)$. Para la obtención de datos medios, se utilizaron 
dos series de datos históricas, una para la temperatura interior del invernadero (perteneciente a la Estación Experimental Las Palmerillas, 15 años de registros) y otra para la radiación solar exterior (perteneciente a la estación de La Mojonera de la Red de Información Agroclimática de Andalucía, 10 años de registros).

\section{3- Resultados y discusión}

Los tratamientos han presentado consumos de agua muy diferentes entre sí. El T3 ha recibido la menor cantidad, $272 \mathrm{~L} \mathrm{~m}^{-2}$. En el otro extremo estaba el T1 que ha recibido un $46 \%$ más que el T3. Por su parte, el tratamiento T2 con la consigna intermedia ha generado un consumo de agua de $315 \mathrm{~L} \mathrm{~m}^{-2}$, un $16 \%$ más respecto al T3 (Figura 4 y Tabla 1). La evolución de los consumos de agua a lo largo del ciclo de cultivo muestra curvas paralelas para los tres tratamientos (Figura 4).

Por otro lado, la $\mathrm{ET}_{\mathrm{c}}$ estimada a partir de datos climáticos medios, $\mathrm{ET}_{\mathrm{c}-\mathrm{m}}$, ha arrojado un valor de $264 \mathrm{~L} \mathrm{~m}^{-2}$ que ha sido superado en un $16 \%$ cuando la estimación se ha realizado a partir de datos reales de campaña, $\mathrm{ET}_{\mathrm{c}-\mathrm{r}}=315 \mathrm{~L} \mathrm{~m}^{-2}$. La diferencia entre ambas $\mathrm{ET}_{\mathrm{c}}$ calculadas son el resultado de una campaña con una radiación y temperaturas diarias superiores a la media en buena parte del ciclo de cultivo. De estos resultados se desprende que la utilización de series climáticas medias para la estimación de la $\mathrm{ET}_{\mathrm{C}}$ es válida, siempre y cuando los valores de evapotranspiración estimados no se alejen de los reales (Bonachela et al. 2009).

La comparación de los consumos de agua de los tratamientos de riego ensayados con la $\mathrm{ET}_{\mathrm{c}-\mathrm{m}}$ y la $\mathrm{ET}_{\mathrm{c}-\mathrm{r}}$ muestra que el tratamiento $\mathrm{T} 3$ presentó un consumo similar al obtenido con la $\mathrm{ET}_{\mathrm{c}-\mathrm{m}}\left(272\right.$ vs. $\left.264 \mathrm{~L} \mathrm{~m}^{-2}\right)$ y el tratamiento 2 tuvo un consumo igual al calculado mediante la $\mathrm{ET}_{\text {c-r. }}$. Las curvas de evolución de los consumos de agua a lo largo del ciclo de cultivo muestran que estas similitudes entre tratamientos de riego aplicados y las necesidades hídricas calculadas a partir de la $\mathrm{ET}_{\mathrm{c}}$ se producen a lo largo de todo el ciclo de cultivo (Figura 4). La curva del T3 se superpone con la correspondiente a la de la $\mathrm{ET}_{\mathrm{c}-\mathrm{m}}$ y la del $\mathrm{T} 2$ se superpone a la de la $\mathrm{ET}_{\mathrm{c}-\mathrm{r}}$ (Figura 4).

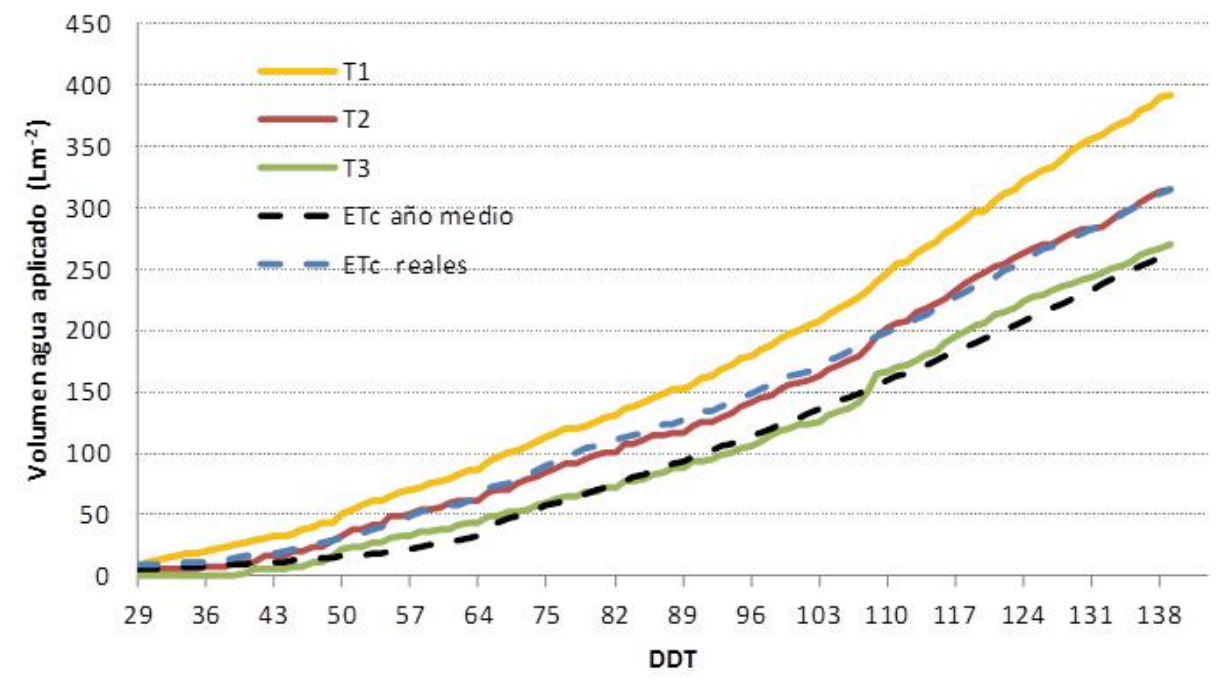

Figura 4. Volúmenes de agua aplicados por tratamiento de riego y volúmenes de agua estimados mediante la $\mathrm{ET}_{\mathrm{c}}$ con datos año medio y la $\mathrm{ET}_{\mathrm{c}}$ con datos reales de la campaña. DDT: días desde trasplante.

Cabe destacar, que durante la campaña de cultivo no se produjo drenaje en ninguno de los tratamientos. Previamente al trasplante y al finalizar el cultivo se realizaron dos riegos 
de hidratación hasta superar el punto de saturación del suelo recogiendo un volumen significativo de drenaje en todos los lisímetros.

Los tratamientos tuvieron un claro efecto sobre la producción. Los resultados muestran un efecto gradual en función del potencial matricial del suelo, de manera que cuanto menor fue la tensión matricial del suelo menor fue la producción (Tabla 1). El tratamiento que activaba el riego a $-40 \mathrm{kPa}$ (T3) redujo la producción en un $23 \%$ con respecto al que activaba el riego a $-10 \mathrm{kPa}(\mathrm{T} 1)$ y en un $14 \%$ con respecto al que activaba el riego a $-25 \mathrm{kPa}$ (T2). Las diferencias entre los tratamientos T1 y T2 fueron del 10\% (Tabla 1).

Tanto las diferencias en producción, como las de consumo de agua entre tratamientos están asociadas al desarrollo de las plantas. La activación del riego a mayor tensión matricial ha derivado en un menor desarrollo de las plantas. La biomasa total en el tratamiento T1 es un 33 \% superior a la obtenida en el tratamiento T3 (Tabla 2).

El tratamiento T3 junto al T2 fueron los que presentaron una mayor eficiencia en el uso del agua (Tabla 1). Teniendo en cuenta que el T2 en términos productivos tuvo una cosecha comercial significativamente superior a la del T3, en las condiciones de este ensayo y que además generó un consumo de agua igual al estimado con la $\mathrm{ET}_{\mathrm{c}}$ a partir de datos climáticos reales, se puede concluir que el T2 con una consigna de - $25 \mathrm{kPa}$ y y una dotación de $2 \mathrm{~L} \mathrm{~m}^{-2}$ fue el que arrojó los mejores resultados.

Tabla 1. Producción comercial, consumo de agua y eficiencia en el uso del agua (EUA) por tratamiento.

\begin{tabular}{cccc}
\hline Tratamiento & $\begin{array}{c}\text { Producción comercial } \\
\left(\mathbf{K g m}^{-2}\right)\end{array}$ & $\begin{array}{c}\text { Consumo agua } \\
\mathbf{( L m}^{-2} \mathbf{)}\end{array}$ & $\begin{array}{c}\text { EUA } \\
\left(\mathbf{K g m}^{-3} \mathbf{)}\right.\end{array}$ \\
\hline T1 & $16,6 \mathrm{a}$ & 390 & $42,6 \mathrm{~b}$ \\
T2 & $14,9 \mathrm{~b}$ & 315 & $47,3 \mathrm{a}$ \\
T3 & $12,8 \mathrm{c}$ & 272 & $47,1 \mathrm{a}$ \\
\hline
\end{tabular}

Letras diferentes en la misma columna indican diferencias significativas $(p \leq 0.05)$.

Tabla 2. Área foliar, biomasa total (expresada en $\mathrm{g} \mathrm{m}^{-2}$ de materia seca) y porcentaje de la biomasa destinada a fruto por tratamiento

\begin{tabular}{cccc}
\hline Tratamiento & Área foliar $\left(\mathbf{c m}^{2}\right)$ & Biomasa total $\left(\mathbf{g ~ m}^{-2}\right)$ & $\begin{array}{c}\text { Porcentaje de biomasa tota } \\
\text { destinada a fruto }\end{array}$ \\
\hline T1 & $59910 \mathrm{a}$ & $1402 \mathrm{a}$ & $66 \mathrm{a}$ \\
T2 & $46924 \mathrm{~b}$ & $1211 \mathrm{~b}$ & $65 \mathrm{a}$ \\
T3 & $32554 \mathrm{c}$ & $1054 \mathrm{c}$ & $67 \mathrm{a}$ \\
\hline
\end{tabular}

Letras diferentes en la misma columna indican diferencias significativas $(p \leq 0.05)$.

\section{4- Conclusiones y recomendaciones}

El riego automatizado con tensiómetros se presenta como una opción viable teniendo en cuenta su aproximación a las necesidades hídricas del cultivo calculadas mediante la estimación de la $\mathrm{ET}_{\mathrm{c}}$. 
Con diferentes consignas de activación se obtienen diferencias productivas y de eficiencia en el uso del agua. Es necesario por tanto establecer consignas adecuadas para cada cultivo.

Las diferencias productivas y de consumo de agua están asociadas al diferente desarrollo de las plantas cuando se trabaja a diferentes tensiones matriciales.

Del análisis conjunto de la producción comercial, la eficiencia en el uso del agua y la similitud del volumen de agua aplicado con las necesidades hídricas estimadas a partir de la $\mathrm{ET}_{\mathrm{c}}$, el T2 con consigna de activación del riego a $-25 \mathrm{KPa}$ presentó los mejores resultados.

\section{5- Bibliografía}

Bonachela, S., González, A.M. \& Fernández, M.D. (2006). Irrigation scheduling of plastic greenhouse vegetable crops based on historical weather data. Irrigation Sci., 25, 5362.

Buttaro, D., Santamaria, P., Signore, A., Cantore, V., Boari, F., Montesano, F.F. \& Parente, A. (2015). Irrigation management of greenhouse tomato and cucumber using tensiometer: Effects on yield, quality and water use. Agric. Sci. Procedia., 4,440-444.

Fernández, M.D., Orgaz, F., Fereres, E., López, J.C., Céspedes, A., Pérez, J., Bonachela, S. \& Gallardo, M. (2001). Programación del riego de cultivos hortícolas bajo abrigo en el sudeste español. Fundación Cajamar.

Gallardo, M., Fernández, M.D., Thompson, R.B., \& Magán, J.J. (2007). Productividad del agua en cultivos bajo invernadero en la costa mediterránea. Vida Rural, 259, 48- 51.

Jones, H.G. (2004). Irrigation scheduling: advantages and pitfalls of plant-based methods. J. Exp. Bot., 55, 2427-2436.

Létourneau, G., Caron, J., Anderson, L. \& Cormier, J. (2015). Matric potential-based irrigation management of field-grown strawberry: Effects on yield and water use efficiency. Agric. Water Manage., 161,102-113.

Thalheimer, M. (2003). Tensiometer modification for diminishing errors due to the fluctuating inner water column. Soil Sci. Soc. Am. J., 67, 737-739.

Van lersel, M.W., Chappell, M. \& Lea-Cox, J.D. (2013). Sensors for improved efficiency of irrigation in greenhouse and nursery production. HortTechnology, 23, 735-746. 


\title{
EMPLEO DE IMÁGENES TÉRMICAS OBTENIDAS MEDIANTE UAVs PARA LA DETERMINACIÓN DEL ESTRÉS HÍDRICO EN VITIS VINIFERA (CV. ALBARIÑO)
}

\author{
Cancela, J.J. (1)(P), Fandiño, M (2), Rey, B.J. (3), González, X.P. (4)
}

1 Profesor Contratado Doctor. Grupo de Investigación GI-1716 "Proyectos y Planificación". Dpto. Ingeniería Agroforestal. Universidad de Santiago de Compostela. Escuela Politécnica Superior, Campus Universitario s/n, 27002, Lugo.600940223, javierjose.cancela@usc.es

${ }^{2}$ Investigadora. Grupo de Investigación GI-1716 "Proyectos y Planificación”. Dpto. Ingeniería Agroforestal. Universidad de Santiago de Compostela. Escuela Politécnica Superior, Campus Universitario s/n, 27002, Lugo.98223605, maria.fandino@usc.es

3 Profesor Titular de Escuela Universitaria. Grupo de Investigación Gl-1716 "Proyectos y Planificación". Dpto. Ingeniería Agroforestal. Universidad de Santiago de Compostela. Escuela Politécnica Superior, Campus Universitario s/n, 27002, Lugo. 600940170, benjamín.rey@usc.es

${ }^{4}$ Profesor Interino. Grupo de Investigación Gl-1716 "Proyectos y Planificación". Dpto. Ingeniería Agroforestal. Universidad de Santiago de Compostela. Escuela Politécnica Superior, Campus Universitario s/n, 27002, Lugo.610968192, xesuspablo.gonzalez@usc.es

\section{Resumen}

El manejo del riego en viñedo es un aspecto crítico para obtener un producto de calidad, requiriéndose herramientas que permitan conocer el estrés hídrico en tiempo real, para gestionar la cantidad y el momento de riego adecuados. La termografía del dosel vegetal obtenida mediante vuelos no tripulados permite obtener la distribución espacial para el conjunto del viñedo en un momento determinado, por lo que su interrelación con los parámetros clásicos de manejo del riego: contenido de agua en el suelo y potencial hídrico foliar de tallo, se presenta como aspecto crítico para facilitar su implementación como herramienta. En el presente estudio se exponen los resultados de la termografía del dosel de Vitis vinífera cv. Albariño durante el envero del año 2015, en una espaldera con diferentes tratamientos de fertirriego. Se muestra una buena correlación entre el contenido de agua en suelo y la temperatura mínima del dosel vegetal $\left(r^{2}=0,57\right)$, lo que permite gestionar el estado hídrico del viñedo, siendo preciso emplear las relaciones existentes entre el contenido de agua en el suelo y el potencial hídrico foliar, obtenidas previamente para la variedad y la zona de estudio por Martínez et al., (2016).

\begin{abstract}
Vineyard irrigation management is critical for obtain a quality product, requiring tools to determine water stress in real-time, to manage the irrigation depth and appropriate irrigation time. Plant canopy thermography obtained by unmanned aerial vehicles (UAV) allows to obtain the spatial distribution for the whole vineyard at a certain period, so their interrelationship with the classical parameters of irrigation management: soil water content and stem-leaf water potential, it is presented as critical aspect to facilitate its implementation as a tool. Thermography canopy results are showed in the present study for Vitis vinifera cv Albariño, during veraison 2015, on a trellis system with different fertigation treatments. Good correlations were achieved, between the soil water content and minimum temperature of canopy $\left(r^{2}=0.57\right)$, allowing vineyard water status management, however it is necessary to
\end{abstract}


use the relationship between the soil water content stem-leaf water potential, previously obtained for the variety and the area of study by Martinez et al., (2016).

\section{1- Introducción, Objetivos}

Los avances en el manejo de imágenes multiespectrales y térmicas han supuesto un nuevo campo de trabajo para manejar los sistemas de riego en diferentes cultivos. El desarrollo de UAVs de bajo coste con mayor autonomía de vuelo, y la mejora en los equipos de captación de imágenes, permite realizar un mayor número de vuelos por campaña, obteniendo la dinámica del cultivo en cuanto a índices de vegetación y estrés térmico. Por el contrario, los indicadores clásicos empleados para el seguimiento del estrés hídrico en el viñedo, como el potencial hídrico foliar, conllevan un gran esfuerzo en mano de obra y cualificación técnica, además de ser medidas destructivas. Por todo lo expuesto, el objetivo del estudio es valorar los efectos de diferentes tratamientos de fertirrigación sobre el estado hídrico del viñedo en el año 2015, empleando imágenes térmicas obtenidas mediante aeronaves no tripuladas en envero, en una parcela comercial en la DO Rías Baixas, determinando: a) la evolución del potencial hídrico foliar de tallo y el contenido de agua en el suelo; b) temperatura del dosel vegetal y c) relaciones entre ambos parámetros, para el cv. Albariño.

\section{2- Materiales y métodos}

El estudio se ha llevado a cabo en los viñedos de la bodega Lagar de Cervera, S.A. (DO Rías Baixas), sobre la variedad Albariño conducida en espaldera. La parcela se

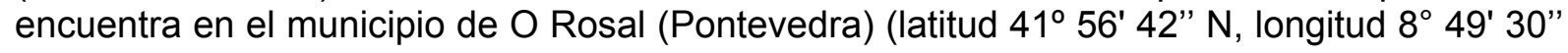
O, 37 m.s.n.m., con una pendiente del 19,5\%). La plantación se ha realizado en el año 1996 sobre 110-R, con un marco de plantación de 3,0 x 2,0 m, con orientación E-O. Se han implementado tres tratamientos de fertirriego (F100, F80 y F60) (Cancela et al., 2016b), cubriéndose el 100, 80 y $60 \%$, de las necesidades nutricionales del cultivo, respectivamente; y un control en secano (S). Los emisores de riego son autocompensantes con un caudal de $2,1 \mathrm{~L} \mathrm{~h}^{-1}$ separados $0,75 \mathrm{~m}$. En total se aplicaron 104 riegos, con una dosis total de $64,9 \mathrm{~mm}$, repartida entre finales de abril y finales de agosto. Durante el año 2015, en la DO Rías Baixas se acumularon $389 \mathrm{~mm}$ de precipitación, desde marzo hasta vendimia (14 septiembre), con una evapotranspiración de referencia de $609 \mathrm{~mm}$. Se seleccionaron puntos característicos de cada tratamiento (Figura 2), con un total de 9 puntos de medición para cada tratamiento. Al mediodía se cuantificó el potencial hídrico de tallo $\left(\psi_{\text {stem }}\right)$ (Williams y Araujo, 2002), empleando una cámara de presión (Scholander et al., 1965) modelo PMS 600 (Albany, OR, USA). Además se determinó el contenido de agua en el suelo (SWC) a $60 \mathrm{~cm}$, mediante TDR, para las mismas plantas (Fandiño et al., 2012).

Para el análisis termográfico se empleó una aeronave no tripulada (UAV) de ala fija, controlada desde tierra y dotada con un sistema de autopiloto. En dicha aeronave se acopló un sensor térmico con longitud de onda entre 8.000 y $12.000 \mathrm{~nm}$ y sensibilidad (sin lente) menor o igual de $50 \mathrm{mk}\left(0,05^{\circ} \mathrm{C}\right)$. Se planificó una ruta de vuelo a $150 \mathrm{~m}$ de altitud, con solapes del $70 \%$ entre fotogramas y $50 \%$ entre pasadas, del que se obtuvo un mosaico de $26 \mathrm{~cm} /$ pixel de resolución. El vuelo se realizó el 10 de agosto de 2015, coincidiendo esta fecha con el envero, y la toma de datos ecofisiológicos y de contenido de agua en suelo en el campo experimental. Una vez capturadas las imágenes térmicas, se realiza la corrección radiométrica de la misma, aplicando un cálculo de regresión a partir de los datos medidos en campo con las lonas testigo (blanco y negro) en la ortofoto térmica (Tabla 1), y sus respectivas temperaturas medidas in situ mediante pistola térmica. 
Tabla 1. Temperaturas corrección radiométrica.

\begin{tabular}{|c|c|}
\hline & Temperatura medida \\
\hline Lona fría (blanco) & $30,3^{\circ} \mathrm{C}$ \\
\hline Lona caliente (negro) & $53,6^{\circ} \mathrm{C}$ \\
\hline
\end{tabular}

Para la representación cartográfica de los resultados se han considerado rangos de $4^{\circ} \mathrm{C}$ para el rango central de temperaturas entre 20 y $32^{\circ} \mathrm{C}$.

El análisis de varianza (ANOVA) fue realizado separadamente para cada variable, empleando el procedimiento UNIANOVA del programa SPSS (SPSS Version 20.0.0). La separación de medias fue realizado con el test HSD de Tukey $(P<0,05)$. Además se determinaron las correlaciones entre las variables ligadas a la temperatura del dosel, y los parámetros medidos directamente en el campo experimental.

\section{3- Resultados y discusión}

La dinámica del potencial de tallo, ha mostrado valores ligeramente más negativos para el tratamiento secano a partir de finales de Julio (Figura 1), lo que muestra el escaso estrés hídrico en la zona de estudio para el cv. Albariño en el año 2015, en correspondencia con los datos mostrados en campañas previas por Cancela et al. (2016a).

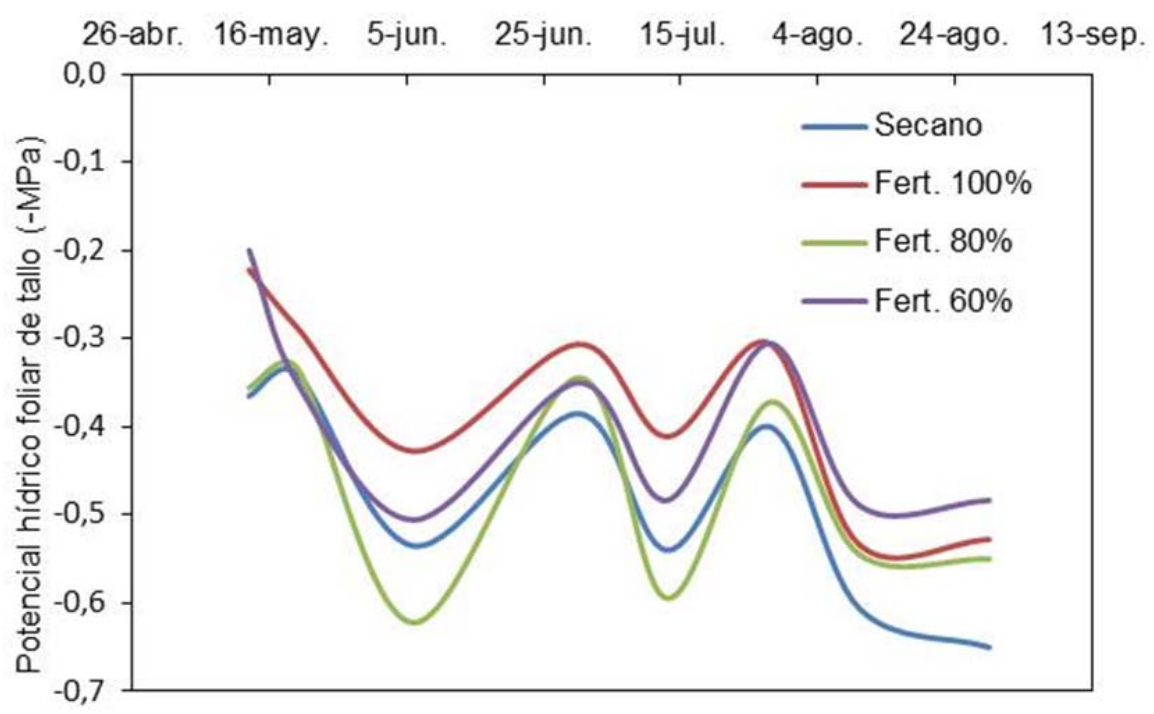

Figura 1. Dinámica del potencial hídrico foliar de tallo - 2015.

Por el contrario se ha observado una mayor variabilidad entre los diferentes tratamientos, en relación con la temperatura del dosel vegetal (Figura 2). El contenido de agua en el suelo mostró diferencias significativas entre el tratamiento secano y los tratamientos 60 y $100 \%$, siguiendo un patrón similar al obtenido con la temperatura mínima y media del dosel vegetal en el mismo punto (Tablas 2 y 3 ).

La correlación lineal entre la temperatura del dosel vegetal (Tmin, Tmax y Tmed) y los parámetros de suelo, han mostrado un coeficiente de determinación mayor a 0,35 , siendo el valor mayor con la temperatura mínima del dosel (Figura $3-r^{2}=0,57$ ). Por el contrario no se han encontrado relaciones con el $\psi_{\text {stem }}$, ni con las temperaturas del dosel, ni 
con el SWC, como las obtenidas por Cancela et al. (2015) para la variedad Godello, en este último caso.

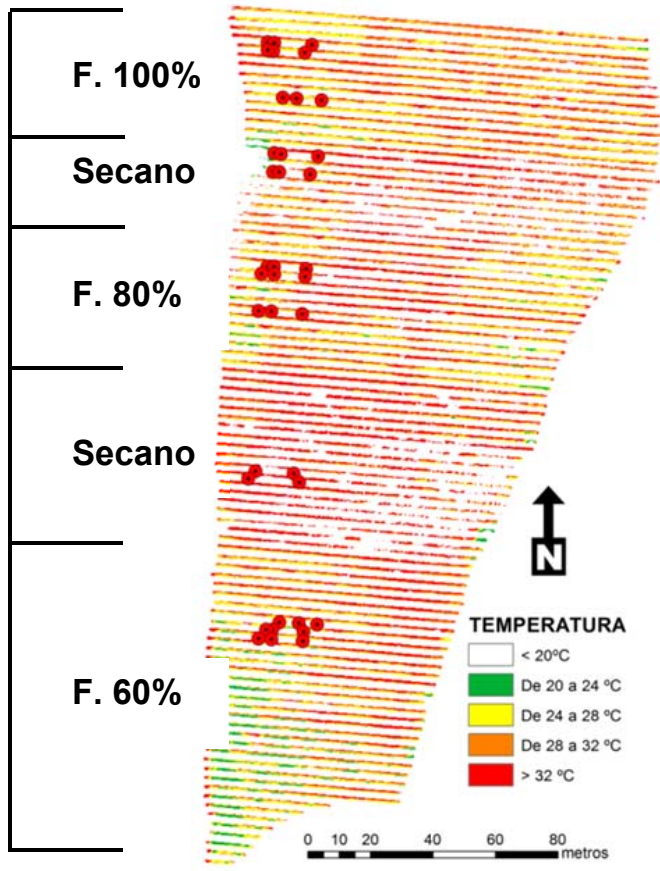

Figura 2. Clasificación Térmica de la parcela de ensayo. Localización puntos muestreo y tratamientos.

Tabla 2. Análisis de varianza para el contenido de agua en el suelo y potencial hídrico foliar de tallo.

\begin{tabular}{|c|c|c|}
\hline Tratamiento & SWC & $\boldsymbol{\Psi}_{\text {STEM }}$ \\
\hline Secano & $0,115 \mathrm{a}$ & 0,606 \\
\hline Fertirriego $60 \%$ & $0,141 \mathrm{~b}$ & 0,489 \\
\hline Fertirriego $80 \%$ & $0,121 \mathrm{ab}$ & 0,544 \\
\hline Fertirriego 100\% & $0,141 \mathrm{~b}$ & 0,533 \\
\hline$p$-valor & 0,002 & 0,312 \\
\hline
\end{tabular}

Diferentes letras en columna indican diferencias significativas según HSD de Tukey

$$
(p<0,05)
$$

Tabla 3. Análisis de varianza para la temperatura del dosel vegetal (mínima, máxima y media) adquirida con cámara térmica.

\begin{tabular}{|c|c|c|c|}
\hline Tratamiento & Tmin & Tmax & Tmed \\
\hline Secano & 28,05 & 39,22 & 33,64 \\
\hline Fertirriego 60\% & 25,88 & 35,50 & 30,69 \\
\hline Fertirriego $80 \%$ & 27,45 & 35,36 & 31,41 \\
\hline Fertirriego 100\% & 26,62 & 35,30 & 30,96 \\
\hline$p$-valor & 0,847 & 0,753 & 0,802 \\
\hline
\end{tabular}

En la Figura 2, se observa que las temperaturas inferiores se encuentran en los bloques Fertirrigados al 60 y $100 \%$, a pesar de existir una alta heterogeneidad en la 
distribución de temperaturas. Los resultados obtenidos concuerdan con los datos medidos en los puntos de muestreo (Tabla 3), en los que no se observan diferencias significativas entre tratamientos. Grant et al. (2016) exponen la alta variabilidad de la temperatura del dosel vegetal, refiriéndose a hojas laterales y superiores, lo que se corresponde con la variabilidad obtenida con la adquisición de imágenes aéreas, en el presente trabajo.

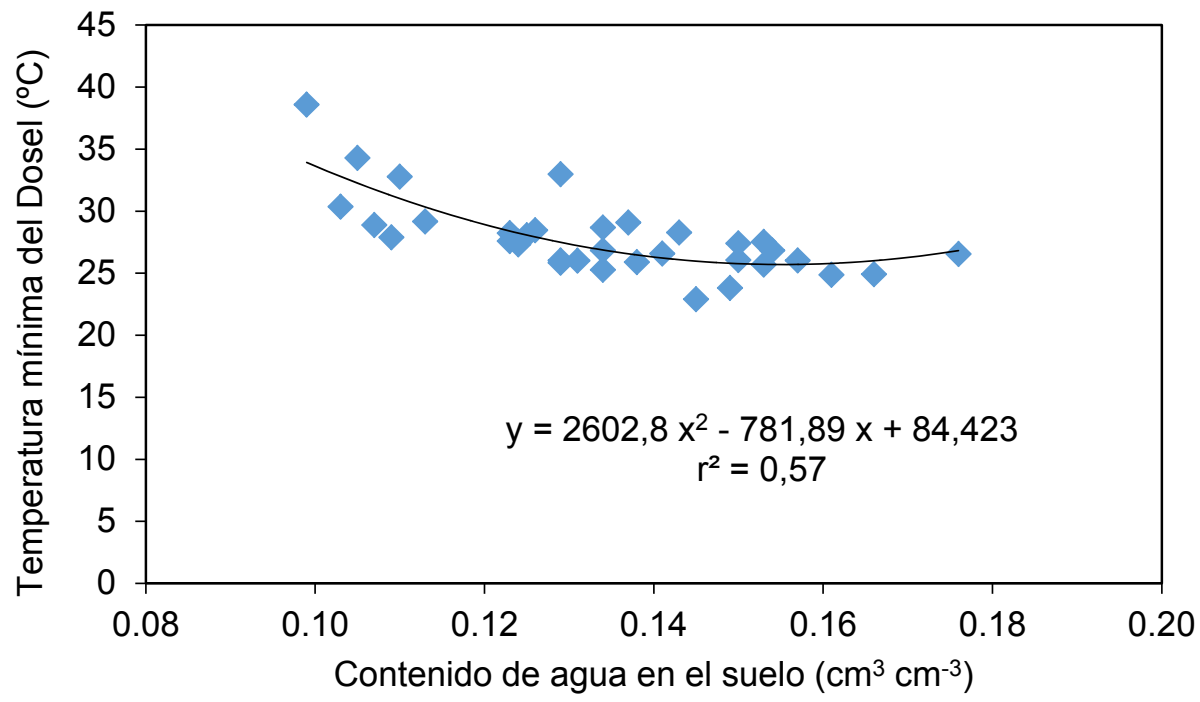

Figura 3. Contenido de agua en el suelo \& Temperatura mínima del dosel vegetal determinado en envero (50\%) para Vitis vinífera cv. Albariño.

\section{4- Conclusiones y recomendaciones}

El empleo de imágenes térmicas permite definir zonas con mayor estrés hídrico ligado a una mayor temperatura y un potencial hídrico foliar más negativo. Además permite definir puntos de muestreo de cara a una mejora del manejo del riego. Los efectos del riego y la fertirrigación han mostrado una buena correlación con las temperaturas obtenidas con las imágenes, frente a los valores del contenido de agua en el suelo, si bien no con los parámetros medidos en planta. Estos resultados sugieren determinar el crop water stress index (CWSI) para tener presente las condiciones climáticas y sus efectos sobre el viñedo, así como determinar relaciones útiles entre el estado hídrico de la planta y las temperaturas de las hojas superiores, como ha sido propuesto por Grant et al. (2016).

\section{5- Agradecimientos} Rioja Alta".

Al proyecto "VINISOST - CIEN 2014 (CDTI) Lagar de Cervera / Comercializadora

\section{6- Bibliografía}

Cancela, J.J., Fandiño, M., Rey, B.J., Martínez, E.M. (2015). Automatic irrigation system based on dual crop coefficient, soil and plant water status for Vitis vinifera (cv Godello and cv Mencía). Agricultural Water Management, 151, 52-63. 
Cancela, J.J., et al., Effects of climate variability on irrigation scheduling in white varieties of Vitis vinifera (L.) of NW Spain. Agricultural Water Management (2016a), http://dx.doi.org/10.1016/j.agwat.2016.01.004

Cancela, J.J., González, X.P., Rey, B.J., Fandiño, M. (2016b). Uso de imágenes multiespectrales para el manejo de la fertirrigación en Vitis vinifera cv. Albariño (Galicia). Actas de Horticultura $n^{\circ} 72$. II Simposio Nacional de Ingeniería Hortícola. "Automatización y TICs en Agricultura”, (pp. 95-98). Sociedad Española de Ciencias Hortícolas: Almería.

Fandiño M., Cancela J.J., Rey B.J., Martínez E.M., Rosa R.G., Pereira L.S. (2012). Using the dual-Kc approach to model evapotranspiration of Albariño vineyards (Vitis vinifera L. cv. Albariño) with consideration of active ground cover. Agricultural Water Management, 112: 75-87.

Grant, O.M., Ochagavía, H., Baluja, J., Diago, M. P., Tardáguila, J. (2016). Thermal imaging to detect spatial and temporal variation in the water status of grapevine (Vitis vinifera L.). The Journal of Horticultural Science and Biotechnology, 91(1), 43-54.

Martínez, E.M., Rey, B.J., Fandiño, M., Cancela, J.J. (2016). Impact of water stress and nutrition on Vitis vinifera cv.'Albariño': Soil-plant water relationships, cumulative effects and productivity. Spanish Journal of Agricultural Research, 14(1), 1202.

Scholander, P.F., Hammel, H.J., Bradstreet, A., Hwemmingsen, E.A. (1965). Sap pressure in vascular plants. Science, 148 339-346

Williams L.E., Araujo F.J., 2002. Correlations among predawn leaf, midday leaf, and midday stem water potential and their correlations with other measures of soil and plant water status in Vitis vinifera. Journal of America Society of Horticultural Science, 127(3): 448454. 


\author{
Ruiz Gómez, J.C., Temnani Rajjaf, A., Blaya Ros, P.J., Fernández Bastida, I, Cañavate sastre, \\ M.D., López Guerrero, M.C., Pérez Abellán, M.A., Morales Navarro, A., Navarrete \\ Martínez, S., de la Rosa Sánchez, J.M., Conesa Saura, M.R., Pérez-Pastor, A*
Universidad Politécnica de Cartagena (UPCT). Dpto. Producción Vegetal. Paseo Alfonso XIII, 48. 30203. Cartagena (Murcia). alex.perez-pastor@upct.es

\title{
1- Introducción
}

En zonas áridas como la región de Murcia los agricultores se ven obligados a regar por debajo de las necesidades hídricas del cultivo. Dentro de las estrategias de riego deficitario, el Riego Deficitario Controlado (RDC) permite reducir los aportes hídricos en periodos fenológicos del cultivo (no críticos) donde el déficit hídrico no afecta negativamente a la calidad y cantidad de la cosecha, cubriendo plenamente las necesidades durante el resto del ciclo. Los periodos no críticos del melocotonero son las fases I y II de crecimiento del fruto y la poscosecha. El objetivo de este trabajo fue evaluar el efecto del riego deficitario durante las fases I y II de crecimiento del fruto del melocotonero en: i) los indicadores del estado hídrico de la planta; ii) el crecimiento vegetativo; iii) la producción y iv) la calidad de la cosecha.

\section{2- Material y métodos}

El estudio se realizó entre febrero y agosto de 2015 en la finca comercial situada en Molina de Segura, Murcia (38ㅇ 9’ N; 1 14오. S). Los melocotoneros (Prunus persica (L.) Batsch) variedad Catherine tenían 7 años de edad al inicio del experimento y estaban colocados a un marco de plantación de $5 \times 3.5 \mathrm{~m}$. Se establecieron dos tratamientos de riego: i) Control ( $\left.T_{\text {CTL }}\right)$ regado al $100 \%$ de la evapotranspiración de cultivo (ETc) durante todo el periodo; ii) Riego Deficitario Controlado $\left(T_{R D C}\right)$ regado como $T_{C T L}$ excepto en la fases I y II de crecimiento del fruto en las que se regó la mitad. Se determinó el estado hídrico de la planta a partir de medidas de: i) potencial hídrico de tallo al mediodía $\left(\Psi_{T}\right)$; Fluctuaciones de diámetro de tronco, a partir de las cuales se calculó la máxima contracción diaria $(\mathrm{MCD})$ y la tasa de crecimiento diaria de tronco (TCD). Además se evaluó el crecimiento vegetativo y los parámetros productivos y de calidad de la cosecha.

\section{3.- Resultados}

El riego aplicado durante el periodo estudiado fue 3666 y $2878 \mathrm{~m}^{3} \cdot \mathrm{ha}^{-1}$ para $\mathrm{T}_{\mathrm{CTL}}$ y $\mathrm{T}_{\mathrm{RDC}}$, respectivamente, lo que supuso una disminución del aporte hídrico en $T_{R D C}$ de un $21.5 \%$ (Tabla 1). Los indicadores de estado hídrico de planta, MCD, TCD y $\Psi_{T}$, apenas presentaron diferencias entre tratamientos durante el periodo de déficit hídrico (Fig. 1) lo que puede ser debido a la hora de inicio del riego (impuesta por el agricultor) el cual empezaba a las 10 de la mañana y duraba entre 3 y 5 horas. El crecimiento acumulado del tronco (MXDT) presentaba valores significativamente inferiores en $T_{\text {RDC }}$ durante el periodo de déficit hídrico para recuperarse tras la reanudación del riego en plenitud (Fig. 1) . $\mathrm{T}_{\mathrm{RDC}}$ presentó diámetros ecuatoriales de fruto significativamente inferiores a los de $T_{C T L}$ al final del periodo de déficit pero después del déficit hídrico los frutos de $T_{R D C}$ experimentaron un crecimiento compensatorio que permitió que los dos tratamientos se igualaran. No se han encontrado diferencias significativas ni en producción, ni en ninguno de los parámetros de calidad estudiados.

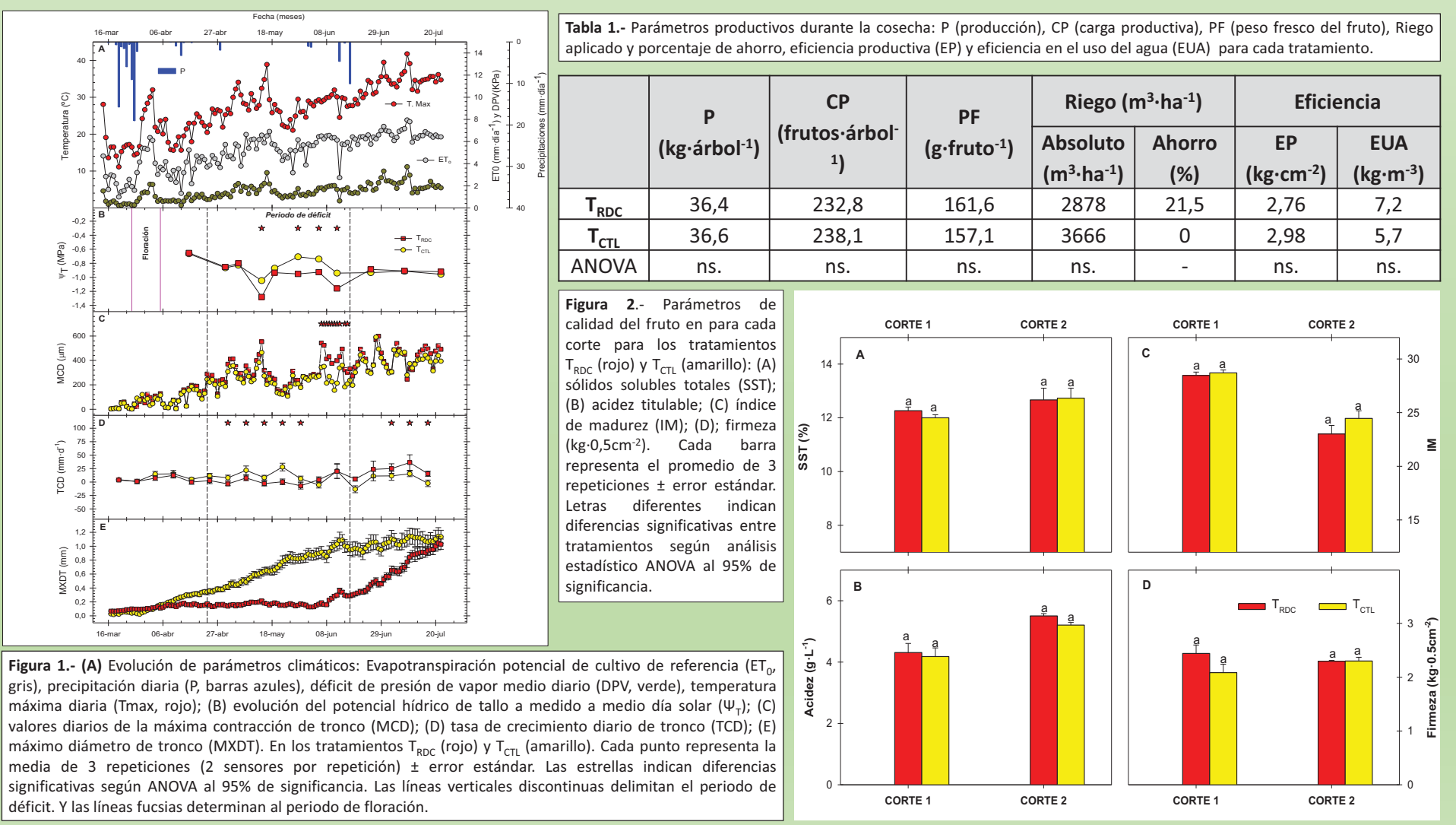

\section{4.- Conclusiones}

La estrategia de riego deficitario controlado estudiada ha permitido disminuir el aporte hídrico en $800 \mathrm{~m}^{3} \cdot \mathrm{ha}^{-1}$ sin generar mermas en la cantidad y calidad de la cosecha e incrementando la eficiencia en el uso del agua de riego. 
A-21

\title{
EFECTO DE DIFERENTES CONCENTRACIONES DE NUTRIENTES EN EL FERTIRRIEGO DE UN CULTIVO DE FRESA EN LA PROVINCIA DE HUELVA. EFICIENCIA EN EL USO DEL ABONADO
}

\author{
Molina, F. ${ }^{1}$, Gavilán, P. ${ }^{2}$, Ruiz, ${ }^{2}{ }^{3}$ \\ ${ }^{1}$ Director Departamento Agronómico. Gat Fertiliquidos, Niebla (Huelva). \\ pacomolina@gatfertiliquidos.com \\ ${ }^{2}$ Investigador Titular. IFAPA Centro Alameda del Obispo, Apdo. 3092, 14080 Córdoba, \\ pedrod.gavilan@juntadeandalucia.es \\ ${ }^{3}$ Técnica Especialista Contratada. IFAPA Centro Alameda del Obispo. Apdo. 3092, 14080 \\ Córdoba, natividad.ruiz.baena@juntadeandalucia.es
}

\section{Resumen}

En este trabajo se presentan los resultados de un ensayo de fertirrigación en un cultivo de fresa en la provincia de Huelva. Los objetivos fueron determinar el déficit de fertilizante que se produce al aportar cantidades de riego menores a las normalmente usadas por los agricultores y si se puede compensar con un mayor aporte de fertilizante en la solución de riego, y relacionar la eficiencia en el uso del abonado con la eficiencia en el uso del agua de riego. Para ello se realizó un seguimiento analítico durante toda la campaña y se compararon la solución fertilizante real aportada al cultivo por el sistema de riego con la solución del suelo, extraída con sondas de succión y con muestras de suelo analizadas por el método de extracto saturado. También se realizó un seguimiento y comparación de análisis foliares. No se observaron diferencias importantes ni se produjeron acumulaciones de sales en la zona radicular en tratamientos con distintas concentraciones de abonado en el fertirriego. Las pequeñas diferencias aparecieron en favor de la CE de entrada intermedia, tratamiento T2, que presentó mayores eficiencias y aprovechamiento en el uso de los fertilizantes. Sin embargo, no se apreció esta ventaja en los análisis de hoja ni en la producción.

\section{1- Introducción y Objetivos}

La fresa en gran parte de la provincia de Huelva se cultiva en suelos arenosos, con escaso poder de retención de agua y nutrientes, y se riega con agua que tampoco aporta nutrientes. Se riega con alta frecuencia y, en cierto modo, se puede considerar un cultivo hidropónico en suelo. Por todo ello, la tendencia en la zona es abonar por concentración de nutrientes equilibrados en el agua de riego, es decir utilizan el sistema de manejo proporcional, en el que la cantidad de fertilizantes va ligada a la cantidad de agua.

En el cultivo protegido de la fresa está muy extendido el control de los parámetros climáticos y de humedad del suelo para manejar el riego (Gavilán y col., 2014). Sin embargo, los sistemas de control de la nutrición han tenido menor grado de desarrollo. Se conocen la concentración y equilibrios de sales necesarios para la fertirrigación con volúmenes de agua de riego superiores a los necesarios para cubrir las necesidades de agua del cultivo, pero no tanto para volúmenes de riego más ajustados a las necesidades del cultivo.

Gat Fertiliquidos, empresa fabricante de fertilizantes líquidos, en colaboración con el IFAPA, estudia la fertirrigación de la fresa en la provincia de Huelva, para poder ayudar a los agricultores a fertirrigar de forma más eficiente. 
Al comenzar los ensayos sobre riego, se planteaba la duda de si se produciría un déficit de fertilizante al bajar el volumen de agua de riego, manteniendo las concentraciones de fertilizantes que actualmente se aplican al cultivo con el fertirriego. Es decir, si al recibir menos volumen de riego $\mathrm{y}$, por tanto, menos fertilizante sería necesario compensarlo con un aumento de la concentración del mismo en el agua de riego.

Los objetivos de este trabajo fueron: 1) Determinar si cantidades de riego menores a las normalmente usadas se podrían compensar con un mayor aporte de fertilizante, para mejorar su absorción. 2) Relacionar la eficiencia en el uso del abonado con la eficiencia en el uso del agua de riego.

\section{2- Materiales y Métodos}

Los trabajos se realizaron en una parcela comercial del T.M. de Almonte, en un suelo arenoso, sobre un cultivo de fresa (Fragaria $x$ ananassa) de la variedad Fortuna durante la campaña 2014/15. Se realizó un ensayo con cuatro tratamientos. Los tres primeros tratamientos recibieron volúmenes similares de riego, con el objetivo de cubrir las necesidades de agua del cultivo de forma que T1, T2 y T3 recibieron 4402, 4417, y 4532 $\mathrm{m}^{3} / \mathrm{ha}$, respectivamente. La diferencia entre ellos estuvo en la concentración de fertilizantes aplicada con la fertirrigación. T1 aplicó una solución con una conductividad eléctrica (CE) superior en un $50 \%$ a la de la finca, mientras que T2 y T3 aplicaron conductividades eléctricas un $25 \%$ superior e igual a la de la finca, respectivamente. T4 recibió el volumen de riego tradicional de la finca y la misma CE que T3.

Se trató, por tanto, de compensar los tratamientos con menos agua y fertilizante con un aumento de la CE, y comparar la nutrición mineral de la planta en cada uno de ellos.

Se realizó un seguimiento analítico mensual, desde noviembre hasta mayo, en el que se analizaron parámetros como $\mathrm{CE}, \mathrm{pH}$, bicarbonatos y macronutrientes, expresados en $\mathrm{mS} / \mathrm{cm}$ y $\mathrm{mmol} / \mathrm{l}$, respectivamente. Para determinar el contenido de fertilizante aportado se analizó la solución fertilizante real (SFR) que aportaba el sistema de riego. Para determinar lo que la planta tenía a su disposición se analizó la solución del suelo $\left(\mathrm{SS}_{\text {sonda }}\right.$ ) a $15 \mathrm{~cm}$ de profundidad, usando sondas de succión, y se tomaron muestras de suelo analizadas por el método de extracto saturado $\left(S_{\text {Extr. Sat. }}\right)$ a $20 \mathrm{~cm}$ de profundidad.

Para comparar la concentración de nutrientes que la planta tenía a su disposición en el suelo (SS) con la concentración que le entraba con el sistema de fertirrigación en cada momento (SFR), se usaron las relaciones "SS sonda $_{\text {SSF" y "SS }}$ Extr. Sat. $/ S F R$ " de cada ion.

Para la eficiencia en el uso del abonado se convirtieron los nutrientes analizados de unidades de concentración (mmol/litros) a Unidades Fertilizantes (kg/100 litros) realmente aplicadas en cada tratamiento por cada 100 litros de agua de riego y se restó las unidades fertilizantes de salida por su volumen de agua de drenaje para calcular su aprovechamiento por la planta. Se expresó en \% de cada volumen de solución, es decir por cada 100 litros de agua de riego que entraba cuantas unidades fertilizantes aportaban, y su correspondiente volumen de drenaje cuantas aportaba. Luego se calculó la relación entre esta eficiencia en el uso del abonado con la del agua de riego.

Por último, se recogieron muestras vegetales tomando hojas adultas representativas de cada tratamiento. Se analizaron todos los macro y microelementos.

\section{3- Resultados}

\subsection{Evolución de los fertilizantes aplicados en cada tratamiento (SFR)}

Los valores de CE de las muestras analizadas durante la campaña de la SFR o entrada al cultivo, fue la indicada en la Tabla 1.

En la finca (tratamiento T4) comenzaron la campaña con valores de 0,55 y llegaron hasta $1 \mathrm{mS} / \mathrm{cm}$ al final del cultivo. 
Tabla 1: Evolución de la CE de la SFR de entrada al cultivo en cada tratamiento $(\mathrm{mS} / \mathrm{cm})$ :

\begin{tabular}{|c|c|c|c|c|c|c|c|}
\hline Gotero & Nov & Dic & Ene & Feb & Mar & Abr & May \\
\hline T1 & 0,78 & 1,15 & 1,45 & 1,36 & 1,48 & 1,44 & 1,48 \\
\hline T2 & 0,66 & 1,00 & 1,15 & 1,19 & 1,20 & 1,12 & 1,24 \\
\hline T3 & 0,58 & 0,80 & 1,02 & 0,92 & 0,96 & 0,98 & 0,89 \\
\hline T4 & 0,55 & 0,80 & 0,81 & 0,92 & 0,96 & 0,98 & 0,89 \\
\hline
\end{tabular}

\subsection{Evolución de los nutrientes en la solución de suelo (SS) en cada tratamiento}

Los valores de CE de las muestras analizadas durante la campaña en la solución de suelo, fue la indicada en la tabla 2 y 3.

La solución de suelo se analizó con dos métodos, utilizando sondas de succión

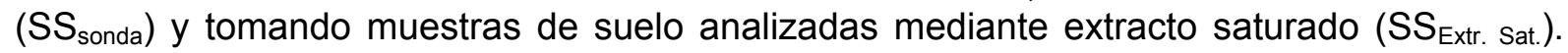
En la solución del suelo los valores fueron superiores en $\mathrm{T} 1$, el tratamiento que recibió menos volumen de agua y mayor CE, mientras que fueron menores en T4, el tratamiento que recibió más volumen de agua y la CE más baja.

Tabla 2: Evolución de la CE de la Solución de suelo de Sonda $\left(\mathrm{SS}_{\text {sonda }}\right)$ en cada tratamiento (mS/cm):

\begin{tabular}{|c|c|c|c|c|c|c|c|c|}
\hline Sonda & $21 / 11 / 14$ & $23 / 12 / 14$ & $25 / 01 / 15$ & $25 / 02 / 15$ & $25 / 03 / 15$ & $28 / 04 / 15$ & $28 / 05 / 15$ & Promedio \\
\hline T1 & 0,67 & 0,36 & 0,84 & 1,25 & 1,74 & 1,70 & 3,53 & 1,44 \\
\hline T2 & 0,62 & 1,13 & 0,77 & 1,06 & 1,16 & 1,07 & 1,68 & 1,07 \\
\hline T3 & 0,68 & 1,40 & 0,49 & 0,68 & 0,98 & 1,56 & 1,49 & 1,04 \\
\hline T4 & 0,79 & 0,67 & 0,43 & 0,77 & 0,85 & 0,75 & 1,27 & 0,79 \\
\hline
\end{tabular}

Tabla 3: Evolución de la CE de la Solución de suelo de Sonda $\left(\mathrm{SS}_{\text {Extr. Sat. }}\right.$ ) en cada tratamiento $(\mathrm{mS} / \mathrm{cm})$ :

\begin{tabular}{|c|c|c|c|c|c|c|c|c|}
\hline Suelo & $21 / 11 / 14$ & $23 / 12 / 14$ & $25 / 01 / 15$ & $25 / 02 / 15$ & $25 / 03 / 15$ & $28 / 04 / 15$ & $28 / 05 / 15$ & Promedio \\
\hline T1 & 1,26 & 0,52 & 0,81 & 0,54 & 0,83 & 0,71 & 0,85 & 0,79 \\
\hline T2 & 0,49 & 0,42 & 0,78 & 0,60 & 0,73 & 0,66 & 0,83 & 0,64 \\
\hline T3 & 0,40 & 0,30 & 0,83 & 0,36 & 0,79 & 0,66 & 0,64 & 0,57 \\
\hline T4 & 0,70 & 0,45 & 0,70 & 0,47 & 0,51 & 0,55 & 0,59 & 0,57 \\
\hline
\end{tabular}

\subsection{Comparación de las relaciones solución de nutrientes del Suelo/Entrada al cultivo en cada tratamiento (SS/SFR)}

En cada tratamiento se compararon los valores promedios, de los análisis de toda la campaña, de la solución que quedaba en el suelo con la solución nutritiva que entraba al sistema suelo-planta (Tabla 4 y 5 ).

Presentó menor concentración de nutrientes en la solución del suelo (SS) respecto a la SFR el tratamiento T2, que recibió menor volumen de agua de riego y CE intermedia. $Y$ presentó mayor concentración de nutrientes y mayor valor de esta relación de CE el tratamiento T4, que recibió mayor volumen de riego y una CE similar al T1. Sin embargo estas diferencias fueron pequeñas.

Tabla 4. Comparación de valores promedios de las relaciones $\mathrm{SS}_{\text {Sonda }} / \mathrm{SFR}$. (CE $\mathrm{mS} / \mathrm{cm}$, iones $\mathrm{mmol} \mathrm{I}^{-1}$ )

\begin{tabular}{|c|c|c|c|c|c|c|c|c|c|}
\hline $\begin{array}{c}\text { Sonda } \\
\text { SS/SFR }\end{array}$ & $\mathrm{CE}$ & $\mathrm{NO}_{3}^{-}$ & $\mathrm{PO}_{4} \mathrm{H}_{2}^{-}$ & $\mathrm{SO}_{4}{ }^{-}$ & $\mathrm{Cl}^{-}$ & $\mathrm{Na}^{+}$ & $\mathrm{K}^{+}$ & $\mathrm{Ca}^{++}$ & $\mathrm{Mg}^{++}$ \\
\hline $\mathrm{T} 1$ & 1,06 & 1,06 & 0,67 & 1,84 & 1,57 & 1,76 & 0,38 & 1,40 & 1,73 \\
\hline $\mathrm{T} 2$ & 0,99 & 0,78 & 0,25 & 5,89 & 6,98 & 1,30 & 0,37 & 1,96 & 6,42 \\
\hline
\end{tabular}




\begin{tabular}{|l|l|l|l|l|l|l|l|l|l|}
\hline T3 & 1,20 & 1,02 & 0,72 & 7,00 & 1,87 & 1,61 & 0,40 & 1,72 & 2,11 \\
\hline T4 & 0,96 & 0,94 & 0,47 & 1,56 & 1,32 & 1,36 & 0,44 & 1,12 & 1,64 \\
\hline
\end{tabular}

Tabla 5. Comparación de valores promedios de las relaciones $\mathrm{SS}_{\text {Extr. Sat. }} / \mathrm{SFR}$. (CE mS/cm, iones $\mathrm{mmol} \mathrm{I}^{-1}$ )

\begin{tabular}{|c|c|c|c|c|c|c|c|c|c|}
\hline $\begin{array}{c}\text { Suelo } \\
\text { SS/SFR }\end{array}$ & $\mathrm{CE}$ & $\mathrm{NO}_{3}^{-}$ & $\mathrm{PO}_{4} \mathrm{H}_{2}^{-}$ & $\mathrm{SO}_{4}{ }^{-}$ & $\mathrm{Cl}^{-}$ & $\mathrm{Na}^{+}$ & $\mathrm{K}^{+}$ & $\mathrm{Ca}^{++}$ & $\mathrm{Mg}^{++}$ \\
\hline $\mathrm{T} 1$ & 0,67 & 0,45 & 0,39 & 17,76 & 0,87 & 1,08 & 0,31 & 1,42 & 1,06 \\
\hline $\mathrm{T} 2$ & 0,60 & 0,49 & 0,39 & 8,81 & 0,82 & 1,13 & 0,25 & 0,95 & 0,92 \\
\hline $\mathrm{T} 3$ & 0,64 & 0,46 & 0,41 & 8,22 & 0,74 & 1,11 & 0,22 & 0,96 & 0,84 \\
\hline $\mathrm{T} 4$ & 0,71 & 0,59 & 0,49 & 3,63 & 0,78 & 1,06 & 0,33 & 1,07 & 1,13 \\
\hline
\end{tabular}

\subsection{Comparación de la acumulación de sales}

Para el cálculo de la acumulación de sales en la zona de absorción radicular del cultivo se utilizó la siguiente formula: ((CE $\left.\left.E_{S S}-C E_{S F R}\right) / C E_{S S}\right) \times 100$.

La CE que tenía la solución de suelo (SS) fue menor a la de entrada, en todos los tratamientos y en gran parte de la campaña. Por eso estos valores presentaron valores negativos o muy pequeños, es decir no se produjo acumulación de sales ni $\mathrm{Cl}^{-}$ni de $\mathrm{Na}^{+}$en ningún tratamiento.

Tabla 6. Valores promedios \% drenaje de la CE (CE $\mathrm{mS} / \mathrm{cm})$.

\begin{tabular}{|c|c|c|c|c|c|c|c|c|}
\hline Sonda & $21 / 11 / 14$ & $23 / 12 / 14$ & $25 / 01 / 15$ & $25 / 02 / 15$ & $25 / 03 / 15$ & $28 / 04 / 15$ & $28 / 05 / 15$ & Promedio \\
\hline T1 & $-16,42$ & $-219,44$ & $-72,62$ & $-8,80$ & 14,94 & 15,29 & 58,07 & $-32,71$ \\
\hline T2 & $-6,45$ & 11,50 & $-49,35$ & $-12,26$ & $-3,45$ & $-4,67$ & 26,19 & $-5,50$ \\
\hline T3 & 14,71 & 42,86 & $-108,16$ & $-35,29$ & 2,04 & 37,18 & 40,27 & $-0,92$ \\
\hline T4 & 30,38 & $-19,40$ & $-88,37$ & $-19,48$ & $-12,94$ & $-30,67$ & 29,92 & $-15,79$ \\
\hline Ext.Sat. & $21 / 11 / 14$ & $23 / 12 / 14$ & $25 / 01 / 15$ & $25 / 02 / 15$ & $25 / 03 / 15$ & $28 / 04 / 15$ & $28 / 05 / 15$ & Promedio \\
\hline T1 & 38,29 & $-119,89$ & $-78,57$ & $-151,85$ & $-78,96$ & $-102,25$ & $-74,12$ & $-81,05$ \\
\hline T2 & $-35,52$ & $-139,81$ & $-47,44$ & $-100,00$ & $-63,93$ & $-69,44$ & $-50,30$ & $-72,35$ \\
\hline T3 & $-45,00$ & $-166,67$ & $-22,89$ & $-156,98$ & $-21,21$ & $-48,48$ & $-38,41$ & $-71,38$ \\
\hline T4 & 21,20 & $-77,78$ & $-15,06$ & $-96,58$ & $-88,24$ & $-78,18$ & $-51,62$ & $-55,18$ \\
\hline
\end{tabular}

\subsection{Comparación de la eficiencia del abono/eficiencia riego}

Respecto a la eficiencia del abono ofrecieron valores mayores de eficiencia en solución de suelo el T1 (Tabla 7). En cuanto a la relación eficiencia abono/eficacia riego ofrecieron valores mayores de eficiencia en solución de suelo sonda $_{\text {el }} \mathrm{T} 1$ y de solución

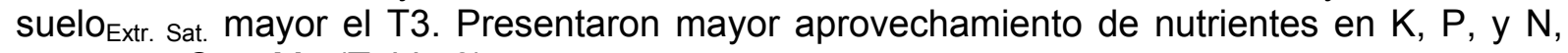
menor en Ca y Mg (Tabla 8).

Tabla 7. Valores promedios Eficiencia de abono y de agua (\%).

\begin{tabular}{|c|c|c|c|}
\hline $\begin{array}{c}\text { Resumen } \\
\text { Consumo }\end{array}$ & $\begin{array}{c}\text { Eficiencia } \\
\text { Abonado }\end{array}$ & $\begin{array}{c}\text { Eficiencia } \\
\text { Agua }\end{array}$ & $\begin{array}{c}\text { Eficiencia Abonado/ } \\
\text { Eficiencia Agua }\end{array}$ \\
\hline Sonda T1 & 58,11 & 63,20 & 0,92 \\
\hline Sonda T2 & 41,91 & 62,70 & 0,67 \\
\hline Sonda T3 & 53,17 & 60,30 & 0,88 \\
\hline Ext. Sat. T1 & 78,38 & 63,20 & 1,24 \\
\hline Ext. Sat. T2 & 77,92 & 62,70 & 1,24 \\
\hline Ext. Sat. T3 & 77,09 & 60,30 & 1,28 \\
\hline
\end{tabular}


Tabla 8. Valores promedios Eficiencia de nutrientes (\%).

\begin{tabular}{|c|c|c|c|c|c|}
\hline Consumo & $\mathrm{N}$ & $\mathrm{P}_{2} \mathrm{O}_{5}$ & $\mathrm{~K}_{2} \mathrm{O}$ & $\mathrm{CaO}$ & $\mathrm{MgO}$ \\
\hline Sonda T1 & 55,12 & 73,90 & 81,49 & 42,08 & 37,96 \\
\hline Sonda T2 & 69,22 & 88,04 & 83,24 & 45,68 & $-76,63$ \\
\hline Sonda T3 & 59,47 & 70,93 & 80,36 & 36,43 & 18,67 \\
\hline Promedio & 61,27 & 77,62 & 81,70 & 41,40 & $-6,67$ \\
\hline Ext. Sat. 1 & 85,24 & 83,25 & 88,72 & 65,98 & 68,71 \\
\hline Ext. Sat. 2 & 82,18 & 81,82 & 89,37 & 69,69 & 66,55 \\
\hline Ext. Sat. 3 & 82,85 & 81,20 & 91,33 & 64,59 & 65,48 \\
\hline Promedio & 83,42 & 82,09 & 89,80 & 66,75 & 66,91 \\
\hline
\end{tabular}

\subsection{Comparación de los análisis foliares y producción}

En cuanto a los análisis foliares, no existieron diferencias de valor en concentración de nutrientes en hoja entre tratamientos (Figura 1). Tampoco existieron diferencias en producción entre los tres tratamientos con el mismo volumen de agua de riego y CE diferentes. Los valores fueron iguales a 923,3, 936,2, 934,8 gr/planta para los tratamientos $\mathrm{T} 1, \mathrm{~T} 2, \mathrm{y} \mathrm{T} 3$, respectivamente

Figura 1. Análisis foliares (\%).
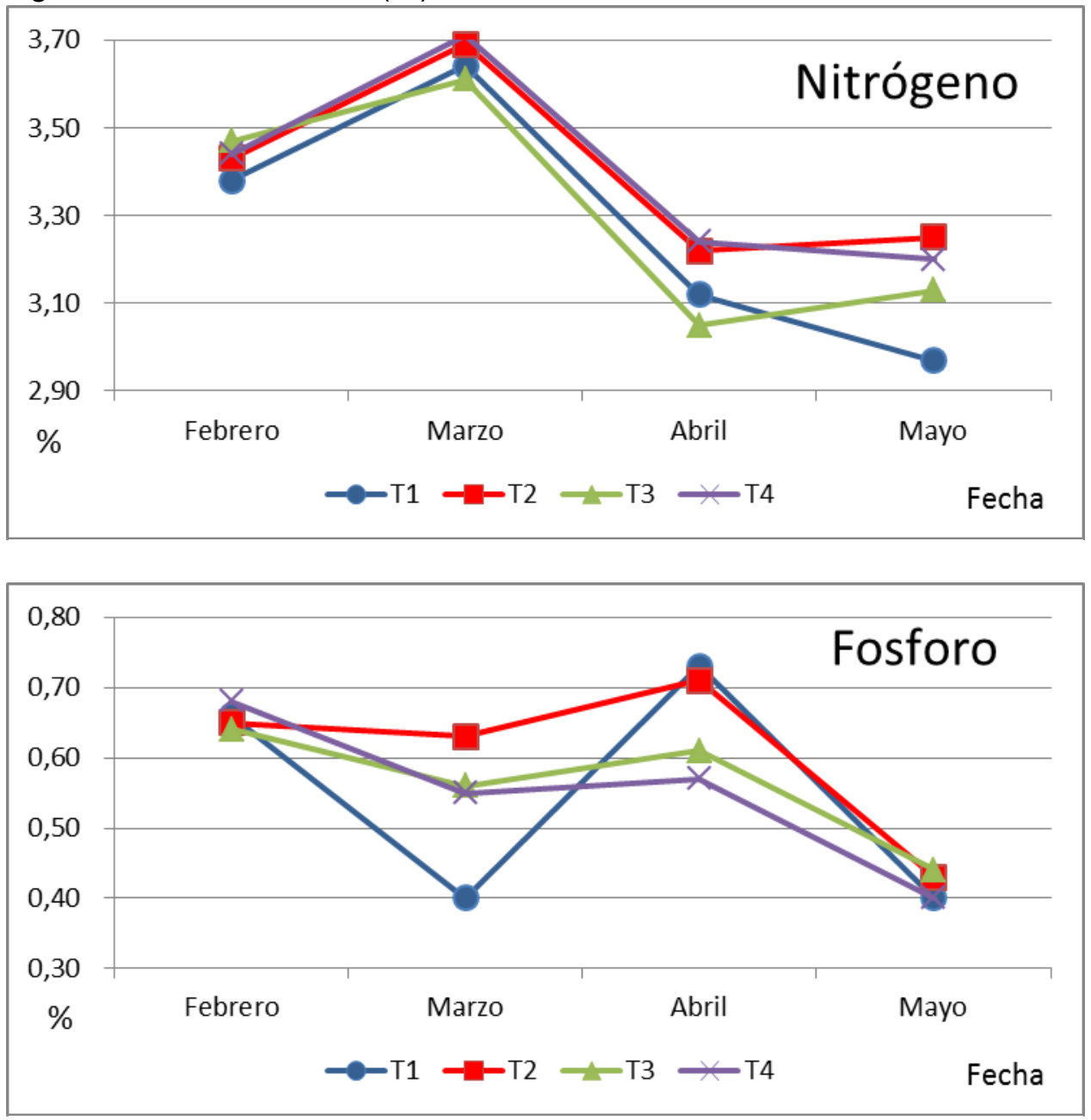

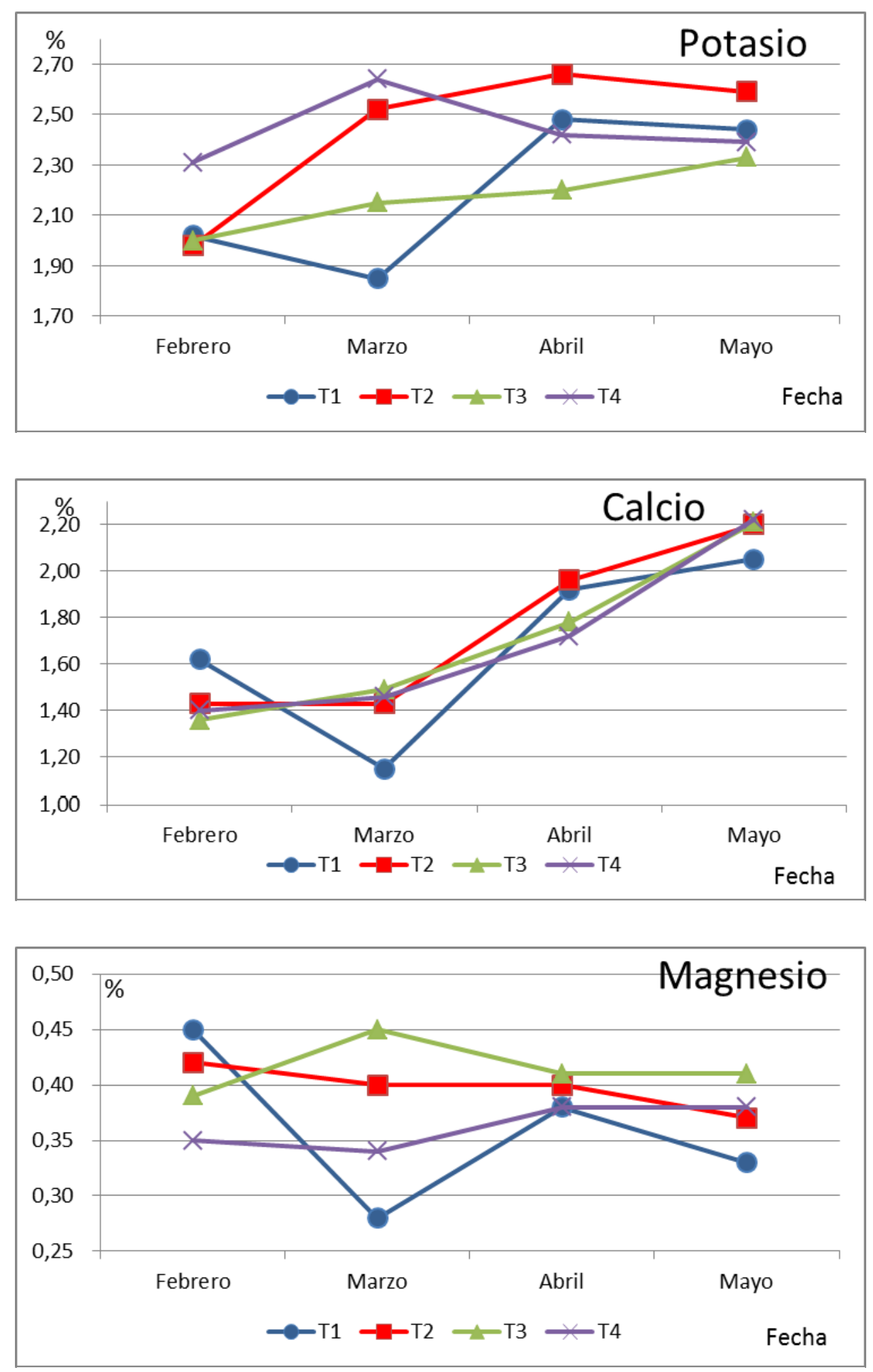

\section{4- Conclusiones y Recomendaciones}

No se observaron grandes diferencias y no se produjeron acumulaciones de sales en zonas radiculares en tratamientos con distintas CE del fertirriego. Las pequeñas diferencias aparecieron en favor de la CE de entrada intermedia, T2, que presentó mayores eficiencias 
y aprovechamiento en el uso de los fertilizantes. Sin embargo, no se aprecia esta ventaja en los análisis de hoja ni en la producción.

Es recomendable aumentar CE en los primeros meses, noviembre a marzo, con volúmenes de riego menores, en los que todos los tratamientos se han quedado bajos de concentración de nutrientes. $Y$ en los siguientes bajarlos, con volúmenes de riego mayores. Así mismo aumentar en los primeros meses la concentración de $\mathrm{N}, \mathrm{P}, \mathrm{y} \mathrm{Ca}$ y luego aumentar $\mathrm{K}$ y $\mathrm{Mg}$. Sería interesante conocer la respuesta del cultivo a estos cambios también en calidad.

\section{Agradecimientos}

Este trabajo no habría podido ser realizado sin el patrocinio de las empresas FRUTAS BORJA y GAT FERTILIQUIDOS.

\section{5- Referencias}

Duchein, M.C., Baile, M., Balle, A., (1994)."Water use efficiency and nutrient consumption of greenhouse rose grown in rockwool". Acta Horticulturae.

Gavilán, P., Lozano, D., Ruiz, N., Molina, F., 2014. El riego de la fresa en el entorno de Doñana. Evapotranspiración, coeficientes de cultivo y eficiencia del riego. XXXII Congreso Nacional de Riegos. Asociación Española de Riegos y Drenajes. Madrid, 1012 junio de 2014.

Cadahía, C. (1988). Fertilización en riego por goteo de cultivos hortícolas, Edit. ERT Fertilizantes, Unión Explosivos Rio Tinto, Madrid. 


\section{RECORTE HÍDRICO MODERADO}

E. Martínez-Ferrii ${ }^{1 *}$, M.T. Ariza ${ }^{1}$, M. Carrera ${ }^{1}$, C. Soria ${ }^{1}$, L. Miranda ${ }^{2}$, A.B. Prieto-Rueda ${ }^{1}$, P. Domínguez ${ }^{2}$,

J.J. Medina ${ }^{3}$, J.L. Muriel Fernández².

${ }^{1}$ IFAPA Centro de Churriana, Cortijo de la Cruz s/n, 29140 Churriana, Málaga, España. *Autor para correspondencia:

elsa.martinez@iuntadeandalucia.es

${ }^{2}$ IFAPA Centro Las Torres-Tomejil. Ctra. Sevilla-Cazalla, Km. 12,2, 41200 Alcalá del Río, Sevilla, España.

${ }^{3}$ IFAPA. Centro de Huelva. C/ Julio Caro Baroja s/n. 21002 Huelva. Spain.

\section{INTRODUCCIÓN}

El cultivo de fresa es de gran importancia siendo España es quinto productor a nivel mundial (FAOSTAT, 2014) y la provincia de Huelva, la primera región productora de la Unión Europea. En los últimos años, la superficie de cultivo de fresa en Huelva ha incrementado notablemente (un 8,2\% entre 2010-14; Martínez-Ferri et al. 2015) lo que conlleva una mayor demanda hídrica para la zona, que ya de por sí está sujeta a una escasez de agua. Esta situación provoca un claro desequilibrio entre las posibilidades reales de suministro y la demanda de agua para el cultivo (cultivo intensivo sobre suelos arenosos bajo macrotúnel), siendo necesario optimizar y ahorrar agua. Desde la caída de la variedad 'Camarosa' (en 2001-02 representaba el 97\%), cada año se cultiva en la región un amplio abanico de variedades (obtenidas en distintos programas de mejora) que presentan diferencias en sus características agronómicas y fisiológicas que se pueden traducir en distintas necesidades hídricas y/o en distinta eficiencia con la que el agua consumida es transformada en frutos bajo condiciones de invernadero (Martínez-Ferri et al. 2016). En este sentido, la elección de aquéllas más eficientes en el uso del agua (baja demanda hídrica e igual productividad) o con mayor tolerancia frente a dotaciones reducidas de agua y/o al estrés hídrico puede constituir un ahorro sustancial de agua y podría permitir la aplicación de riegos deficitarios (RD; un recorte de agua respecto a las necesidades del cultivo sin que se afecte negativamente la producción ni la calidad de la fruta), representando una estrategia para mantener la sostenibilidad del cultivo de la fresa en la zona. El objetivo de este trabajo fue evaluar las necesidades hídricas de tres variedades de fresa más cultivadas en Huelva, y su respuesta frente a un tratamiento de riego deficitario moderado.

\section{MATERIAL Y MÉTODOS

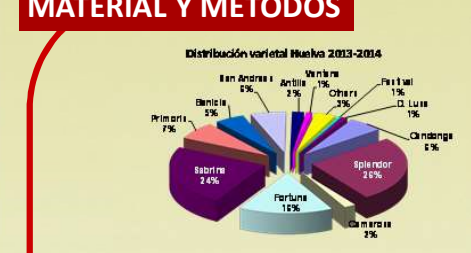 \\ DISEÑO EXPERIMENTAL

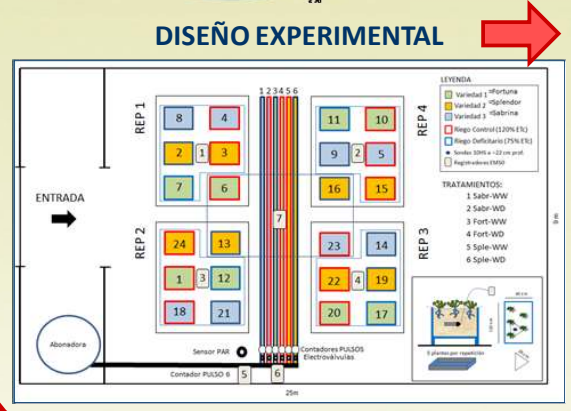 \\ SIMULACION DEL CULTIVO EN CONDICIONES DE INVERNADERO \\ Contenedores de dimensiones similares a los lomos de Huelva (LXAXH, 80x45×40) \\ s con 5 plantas por varieda - Marco de plantación estándar $(25 \times 30 \mathrm{~cm})$
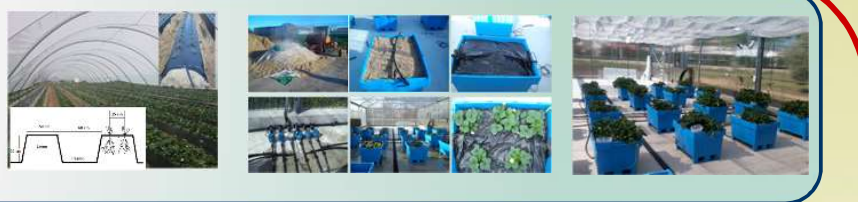 \\ 3 VARIEDADES MÁS \\ 'Fortuna' (FOR) \\ 'Sabrina' (SAB) \\ 2 TRATAMIENTOS \\ DE RIEGO: \\ WW: $120 \% \mathrm{ETC}$ \\ WD: $75 \%$ ETC \\ BALANCE HÍDRICO SUELO

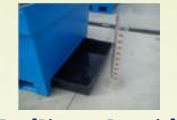 \\ CRECIMIENTO Y BIOMASA
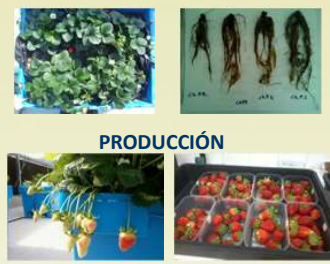 \\ CONTENIDO HÍDRICO FOLIAR (LWC)
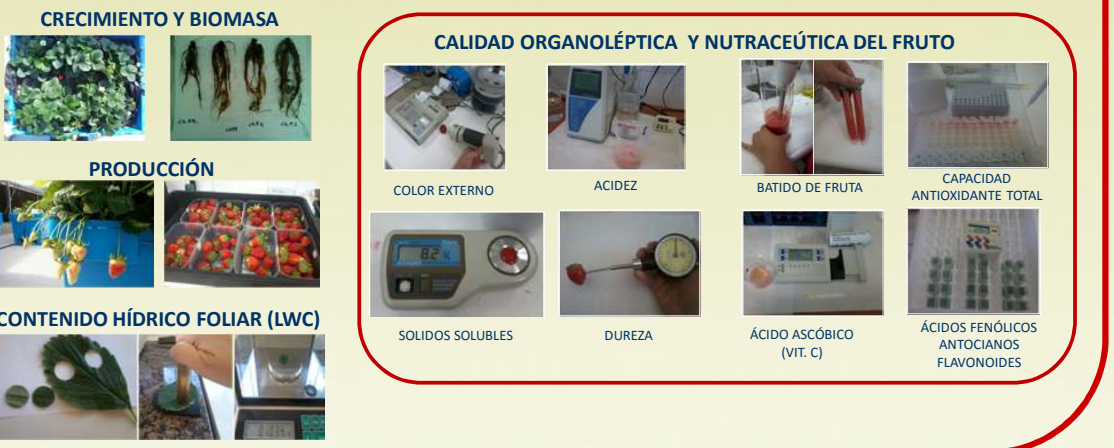

\section{RESULTADOS}

Tabla 1. Riego aplicado en los tratamientos de riego (WW: $120 \%$ ETc y WD: 75 \% ETC ) desde mediados de Enero hasta finales de Mayo de 2014 (136 d) evapotranspiración (ETc) en el mismo periodo, producción total de frutos $>10 \mathrm{~g}$ por planta, biomasa, eficiencia en el uso del agua de riego para la producción de frutos $>10 \mathrm{~g}$ (WUEi) y eficiencia productiva tratamientos hídricos $(P<0.05$, ANOVA 2 vías).

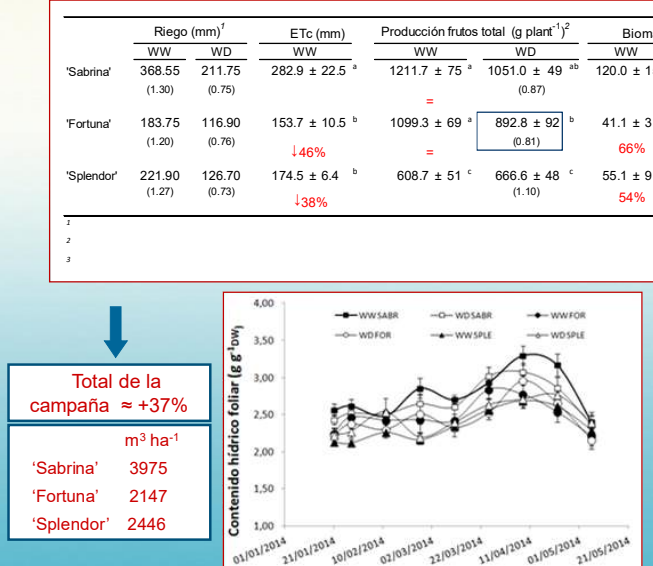

Figura 1. Evolución del contenido hídrico de la hoja en las tres variedades y los dos tratamientos hídricos a lo largo

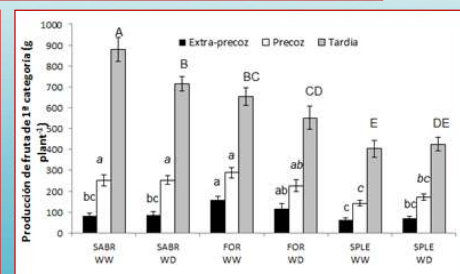

Tabla 2. Comparación de la calidad organoléptica y nutraceútica de los frutos de 3 variedades de fresa (SPLE, 'Splendor'; SAB, 'Sabrina'; FOR, 'Fortuna') producidos bajo dos tratamientos hídricos ( $120 \%$ y $\sim 75 \%$ ETc). Dentro de cada variable, las distintas letras indican diferencias significativas $(P<0.05)$.

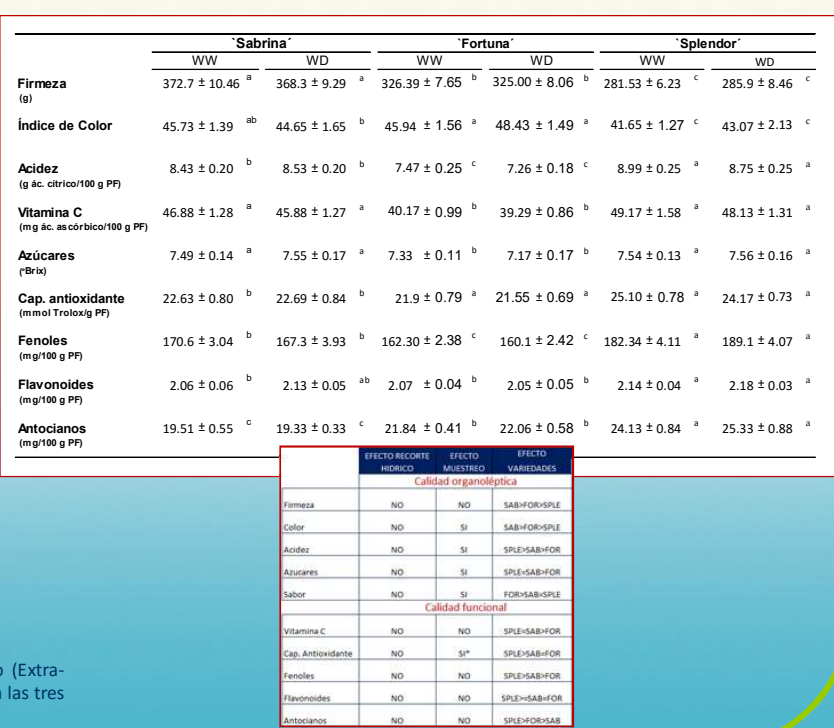

\section{CONCLUSIONES}

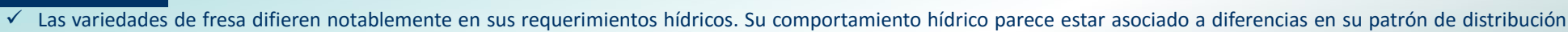
de biomasa entre la parte vegetativa y la parte reproductiva (YE).

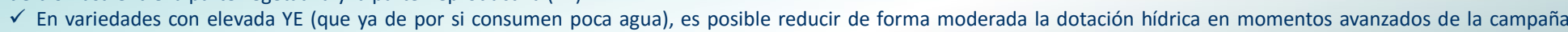
(desde Febrero) hasta la época del cultivo en que se dan valores elevados de demanda evaporativa (Mayo), sin que se afecte notablemente la producción.

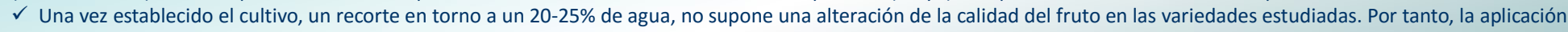
de riegos deficitarios podría representar un ahorro sustancial de agua en el cultivo de la fresa si bien se han de realizar más ensayos en campo.

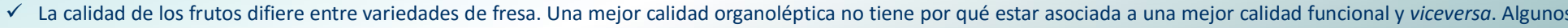
parámetros de calidad de los frutos pueden variar a los largo de la campaña por lo que su uso para comparaciones entre variedades ha de integrar varios muestreos. 


\title{
A-23 \\ COMPORTAMIENTO DE ASTRAGALUS NITIDIFLORUS BAJO DÉFICIT HÍDRICO
}

\author{
Martínez-Sánchez, J.J. Vicente, M.J., Conesa, E., Franco, J.A., Bañón, S.
}

Dpto. de Producción Vegetal. Universidad Politécnica de Cartagena. 30203 Cartagena, España. juan.martinez@upct.es. Proyecto LIFE11 BIO/ES/727 - Conservation of Astragalus nitidiflorus in its potential habitat in the Murcia region

\section{1- Introducción y Objetivos}

Astragalus nitidiflorus («Garbancillo de Tallante») es una leguminosa vivaz endémica del oeste del municipio de Cartagena y que actualmente se encuentra catalogada como "en peligro de extinción». La introducción de ejemplares en el campo es una de las técnicas más empleadas para la conservación de especies en extinción. Se hace por tanto necesario conocer el comportamiento viverístico de $A$. nitidiflorus. Con este trabajo pretendemos conocer la respuesta de la planta al déficit hídrico en términos de crecimiento, desarrollo, estado hídrico e intercambio gaseoso.

\section{2- Materiales y Métodos}

Plántulas de tres meses fueron trasplantadas en abril de 2014 a macetas de PVC de $1,5 \mathrm{~L}(15 \mathrm{~cm} \varnothing)$, que contenían una mezcla de turba rubia y tierra del hábitat (6:1 volumen, respectivamente). Las macetas se dispusieron en un invernadero sobre mesas metálicas, y cada una de ellas tuvo 2 emisores de riego ( 2 I $\mathrm{h}^{-1}$ ).

Cuatros niveles de contenido volumétrico de agua $(\theta)\left(0,40,0,35,0,30\right.$ y $\left.0,25 \mathrm{~cm}^{3} \mathrm{~cm}^{-3}\right)$ fueron mantenidos en el sustrato usando un equipo automático de riego formado por sensores dieléctricos (EC5-Decagon) y un programador-registrador de datos CR1000. Los sensores fueron insertados en el sustrato con su cara más estrecha formando un ángulo de $45^{\circ}$ con la superficie del sustrato, entre los dos emisores y en la cara sur de la maceta. El CR1000 fue programado para regar cuando el $\theta$ del sustrato bajaba del umbral fijado en cada tratamiento, siendo el volumen de un riego el mismo para todos los tratamientos (valor medio aproximado de 290 ml maceta-1 $^{-1}$ mientras que el número de riego lo determinaba el cabezal de riego.

Las temperaturas en el invernadero fueron $15,8 \pm 4,6^{\circ} \mathrm{C}$ (mínima), $34,6 \pm 3,3^{\circ} \mathrm{C}$ (máxima). La humedad relativa $38,83 \pm 12,65 \%$ (mínima) y $78,98 \pm 9,3 \%$ (máxima). La luz diaria integral $12,7 \pm 5,1 \mathrm{~mol} \mathrm{~m}^{-2} \mathrm{~s}^{-1}$

Se midieron el porcentaje de drenaje y la conductividad eléctrica (CE) del drenaje tras cada riego. Al final del experimento se realizaron medidas de crecimiento y desarrollo, se determinó la clorofila SPAD en las hojas, la eficiencia en el uso del agua, el potencial hídrico foliar, la conductancia estomática y la tasa de fotosíntesis (Fig. 1).

Cada tratamiento dispuso sobre una mesas en dos filas de 7 macetas (Fig. 2). Los análisis de regresión fueron realizados con el programa SigmaPlot 10.0 (Systat Software Inc., San Jose, CA).

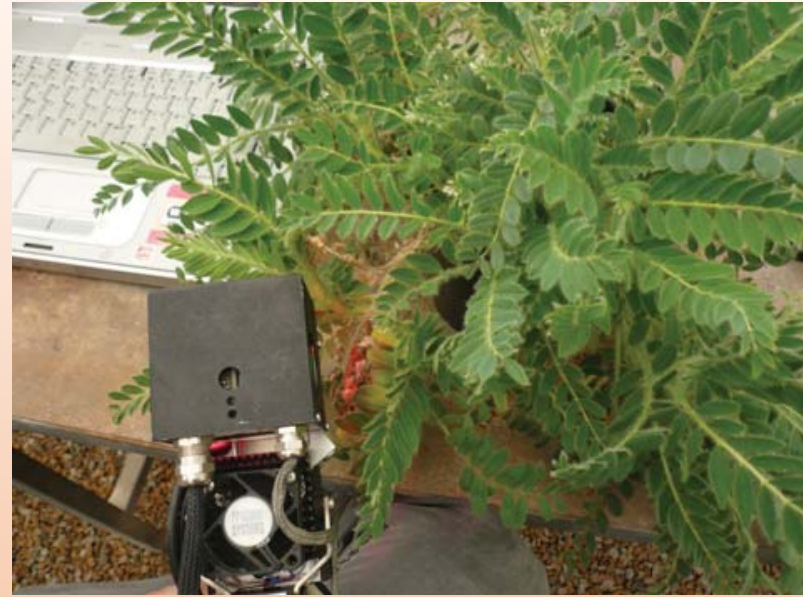

Fig. 1 - Aspecto de A. nitidiflorus

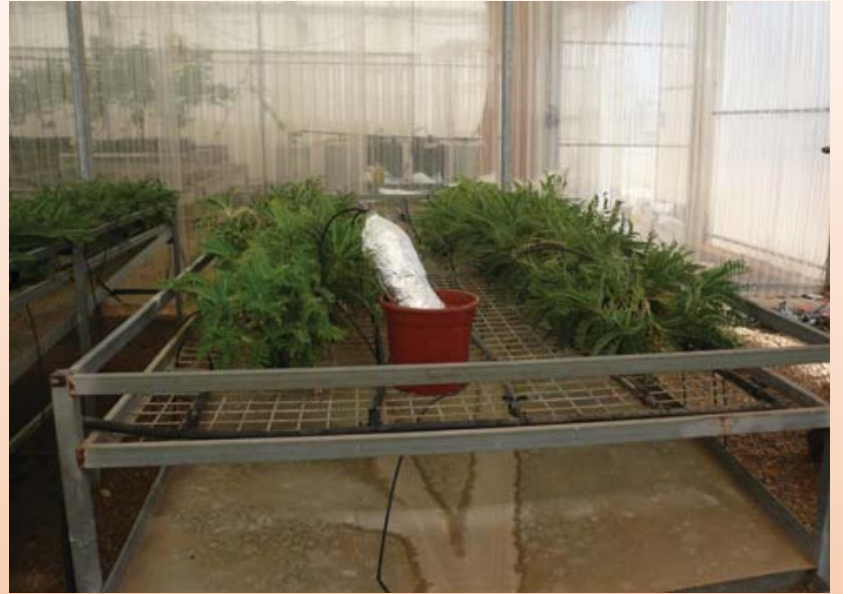

Fig. 2 - Mesa de cultivo

\section{3- Resultados}

Como era de esperar, cuanto más bajo fue el umbral de $\theta$ del sustrato menor fue el número de riegos (Tabla 1$)$. Esto fue muy evidente entre $0,40,0,35$ y $0,30 \mathrm{~cm}^{3}$ $\mathrm{cm}^{-3}$, mientras que entre los tratamientos de 0,30 y 0,25 sólo hubo una diferencia de tres riegos. Como el volumen de riego fue el mismo para todos los tratamientos, el agua aplicada por maceta siguió un comportamiento similar al número de riegos. Así, las macetas bajo el umbral de $0,40 \mathrm{~cm}^{3} \mathrm{~cm}^{-3}$ recibieron aproximadamente el doble de agua $\left(31,2\right.$ I maceta $\left.^{-1}\right)$ que las plantas bajo los tratamientos de 0,30 y 0,25 , y estos dos últimos tratamientos recibieron una cantidad de agua similar. Conforme se reducía el umbral de $\theta$ que decidía el riego el drenaje tendía a aumentar, mientras que la CE del drenaje tuvo una respuesta contraria.

Se obtuvieron relaciones lineales significativas entre el $\theta$ del sustrato y la altura de planta, anchura de planta, peso seco aéreo, área foliar, área del limbo y número de hojas (Figs. 3A, B, C, D y E). La altura fue menos sensible a la disminución del $\theta$ que la anchura (Fig. 3A). El peso seco aéreo y el área foliar estuvieron fuertemente relacionado con el $\theta$, descendiendo con la bajada del $\theta$ en el sustrato. La disminución del $\theta$ redujo la eficiencia en el uso del agua consumida expresada como la relación entre el peso seco y el consumo de agua (Fig. 3F).

El contenido relativo de clorofila foliar (SPAD) disminuyó conforme el $\theta$ descendía (Fig. 4A), pero este descenso fue pequeño. La fotosíntesis, conductancia estomática y potencial hídrico foliar medidos al mediodía al final del experimento no fueron afectados por los tratamientos (Figs. 4B, C y D).

\section{4- Discusión}

La disminución de la humedad en el sustrato redujo fuertemente al crecimiento foliar de $A$. nitidiflorus, lo que fue evidente por debajo de un $\theta$ en el sustrato de 0,35 $\mathrm{cm}^{3} \mathrm{~cm}^{-3}$. Esto explica el aumento de la EUA de esta planta conforme aumenta la humedad en el sustrato. Sin embargo, bajos niveles de humedad en el sustrato más bajos no produjeron daños foliares en forma de necrosis. E incluso no hubo clorosis foliares, a pesar de la caída de la clorofila SPAD en las hojas con la reducción del $\theta$ del sustrato, porque visualmente no se observaron diferencias en el verdor de las hojas.

La respuesta contraria del porcentaje y la CE del drenaje a la humedad del sustrato puede estar relacionada con la capacidad de retención de agua del sustrato, puesto que un sustrato que se mantiene bien humedecido a lo largo del cultivo (uniformemente y constantemente humedecido), como ocurrió aquí con los dos valores de $\theta$ mayores, tiene mejor aptitud para retener agua que un sustrato mal humedecido porque evita problemas de rehidratación y canalización del agua (Valdés et al., 2014). Problemas de rehidratación y de canalización pudieron contribuir a que el lavado de sales en las macetas bajo 0,25 y $0,30 \mathrm{~cm}^{3} \mathrm{~cm}^{-3}$ fuera poco eficaz, según los datos de la CE de los drenajes. 

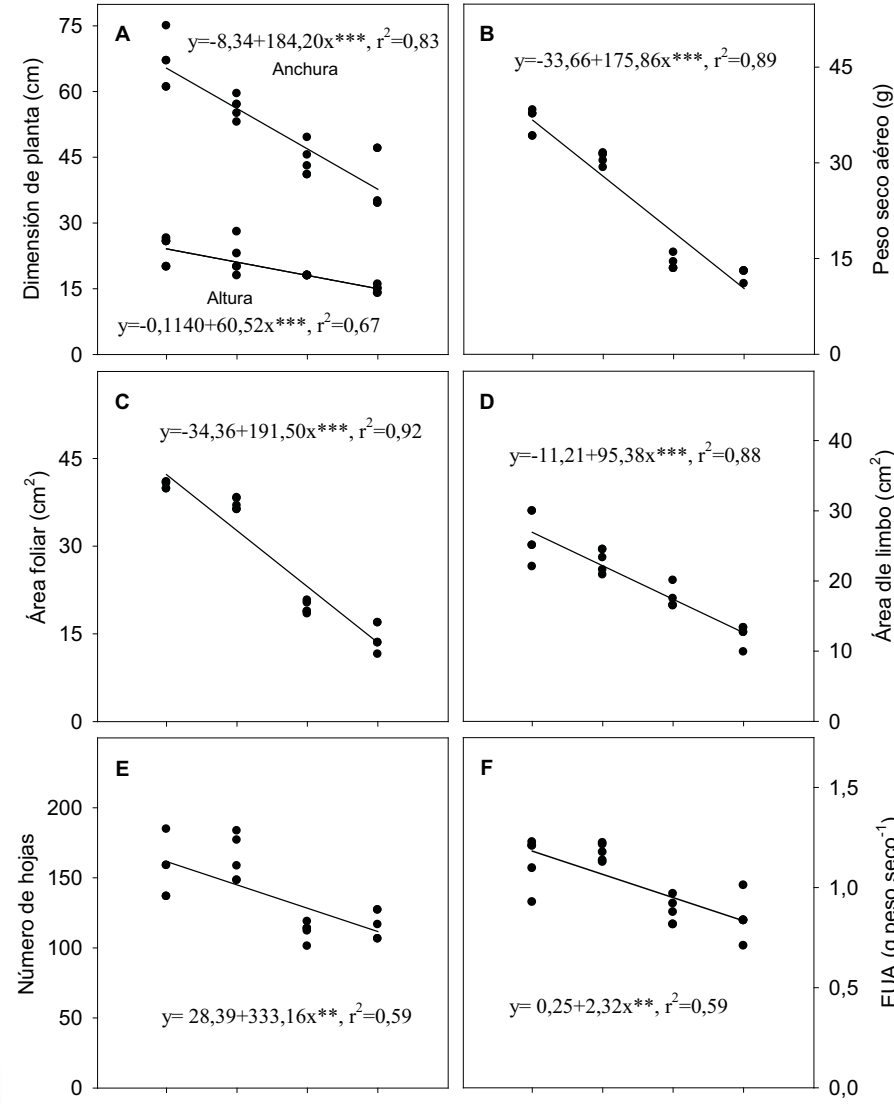

$0,40 \quad 0,35 \quad 0,30 \quad 0,25$
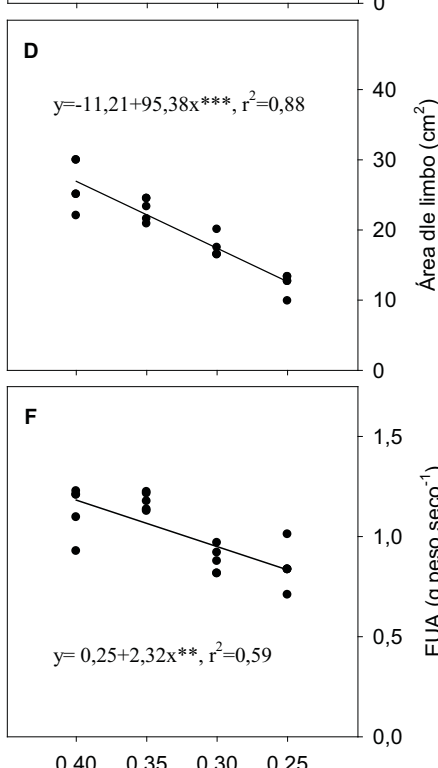

Contenido volumétrico de agua en el sustrato $\left(\mathrm{cm}^{3} \mathrm{~cm}^{-3}\right)$

Fig. 3 - Parámetros de crecimiento y desarrollo. **,*** indican significación estadística con $P<0,05$ y $P<0,001$, respectivamente.

\begin{tabular}{lcccc} 
Tabla 1 - Parámetros de riego & \multicolumn{5}{l}{} \\
\hline \multirow{2}{*}{ Parámetros } & \multicolumn{4}{c}{ Contenido volumétrico de agua $\left(\mathrm{cm}^{3} \mathrm{~cm}^{-3}\right)$} \\
\cline { 2 - 5 } & 0,40 & 0,35 & 0,30 & 0,25 \\
\hline Número de riegos & 104 & 86 & 55 & 52 \\
Agua aplicada (litros maceta $\left.{ }^{-1}\right)$ & 31,2 & 25,8 & 16,5 & 15,6 \\
Porcentaje de drenaje & 7,78 & 9,85 & 17,54 & 16,87 \\
CE del drenaje $\left(\mathrm{dS} \mathrm{m}^{-1}\right)$ & 2,61 & 2,05 & 1,71 & 1,59 \\
\hline
\end{tabular}
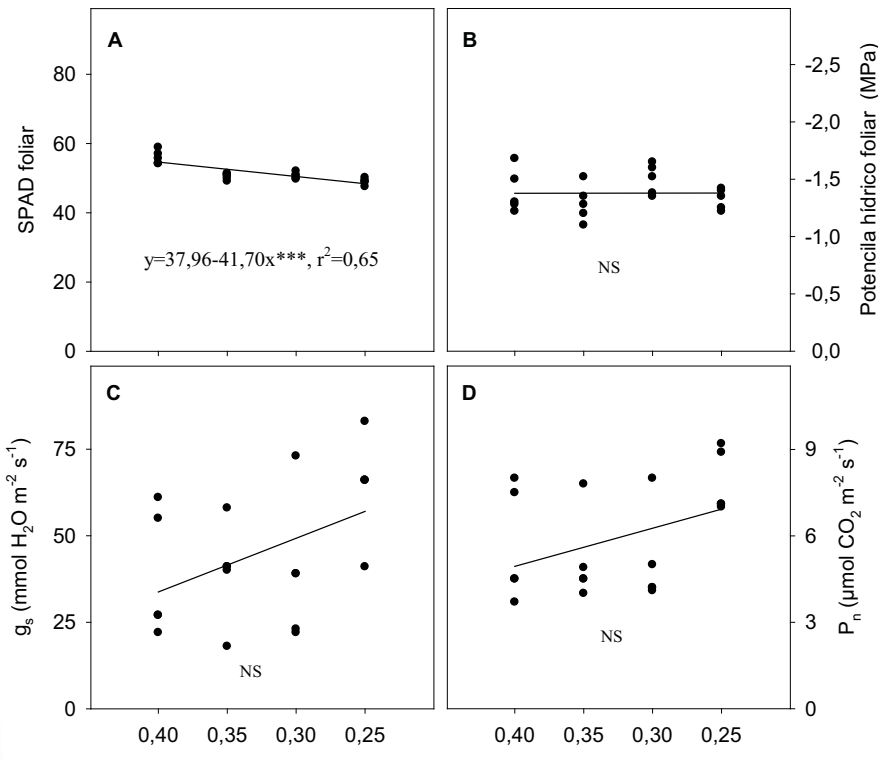

Contenido volumétrico de agua en el sustrato $\left(\mathrm{cm}^{3} \mathrm{~cm}^{-3}\right)$

Fig. 4 - Parámetros de intercambio gaseoso y SPAD. NS, ${ }^{* * *}$ indican ausencia de significación estadística o significación estadística con $P<0,001$ respectivamente.

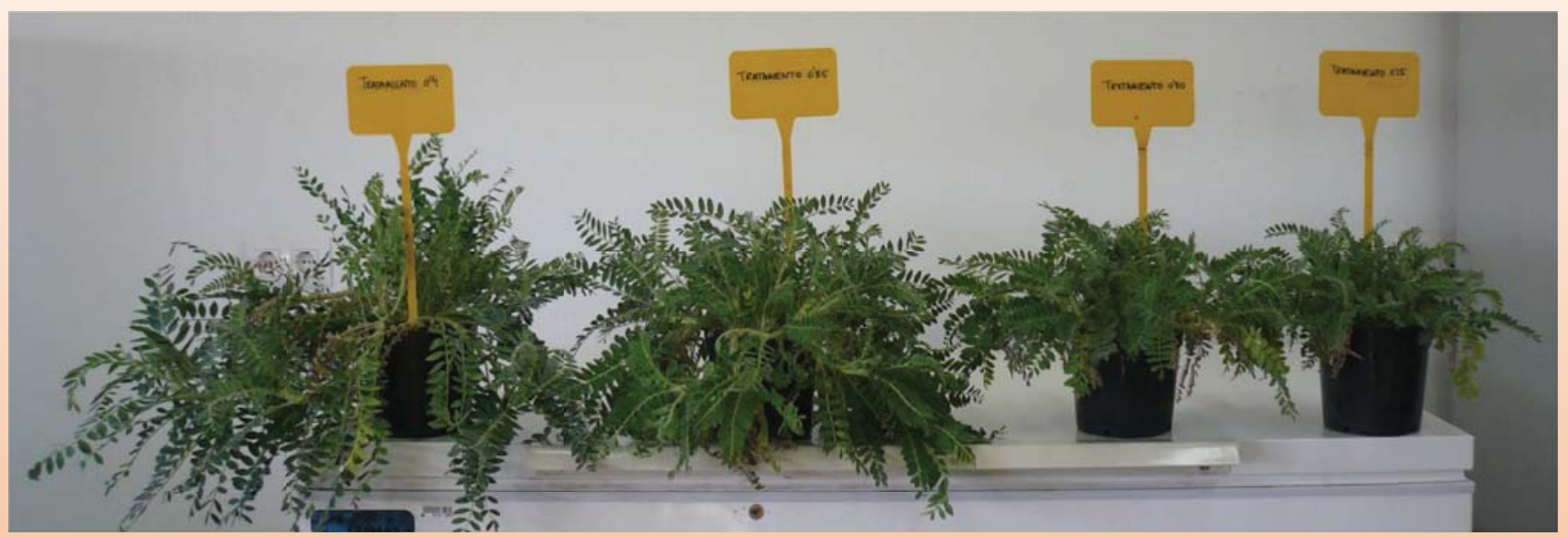

Fig. 5 - Aspecto de las plantas al final del experimento según tratamientos

Es bien conocido que las plantas pueden adaptarse a condiciones de sequía mediante cambios morfológicos y fisiológicos. En este experimento fueron evidentes los primeros (reducción del crecimiento aéreo por déficit hídrico, Fig. 5), lo que sugiere que $A$. nitidiflorus reduce su superficie foliar y/o de su biomasa seca como mecanismos de evitación frente a la sequía. Una disminución del crecimiento foliar suele conducir a la reducción de fotoasimilados, y por tanto a la caída de la producción de biomasa seca de la planta, como aquí sucedió. El crecimiento de $A$. nitidiflorus fue más sensible al déficit hídrico que el intercambio gaseoso, lo que justificaría la caída de la EUA con la bajada del $\theta$ en el sustrato. Sin embargo, $A$. nitidiflorus no mostró cambios adaptativos por déficit hídrico promovidos a través de mecanismos fisiológicos relacionados con la $P_{\mathrm{n}}$ y $g_{\mathrm{s}}$. Quizás, un seguimiento a lo largo del ensayo del intercambio gaseoso hubiera mostrado diferencias de $P_{\mathrm{n}}$ y $g_{\mathrm{s}}$ entre tratamientos, e incluso en un estudio evolutivo a lo largo del día,

\section{5- Conclusiones y recomendaciones}

- Astragalus nitidiflorus responde al déficit hídrico reduciendo su tamaño y biomasa seca aérea, especialmente reduciendo el crecimiento foliar

- Esta especie exhibió una buena regulación estomática bajo condiciones de luz y calor

- A. nitidiflorus se adapta bien al déficit hídrico sin presentar daños foliares ni clorosis foliares

- La reducción de la humedad en el sustrato disminuye la eficiencia en el uso del agua en $A$. nitidiflorus

- Recomendamos regar esta planta manteniendo bajos niveles de humedad en el sustrato, porque mejora su compacidad sin sufrir fisiológicamente, y además se reduce el consumo de agua

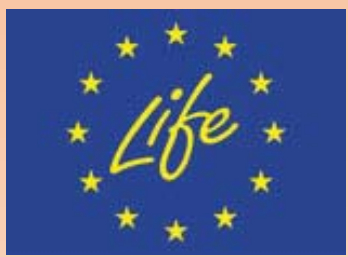




\section{GRUPO TEMAS B: Salinidad, Drenaje, Efectos Ambientales y}

Agua de riego

Adecuación de las características del suelo al método de riego. Efecto del clima y de su posible cambio en las prácticas e infraestructuras de riego. Impacto del regadío y drenaje en el entorno natural. Las prácticas de riego y sus efectos sobre la mejora de la capacidad de reserva de agua en el suelo. Lixiviación de sales y otros elementos. Recuperación de suelos salinos. Calidad del agua de riego (sales, contaminantes). Escasez de agua de buena calidad. Aprovechamiento de aguas subterráneas para riego. Utilización para el riego de aguas depuradas, regeneradas o desalinizadas. Efecto de estas aguas sobre el suelo, cultivos y acuíferos. Riesgos de la utilización de aguas residuales regeneradas en los seres vivos. 


\title{
B-01
}

\section{DSS-SALTIRSOIL: UN SISTEMA DE AYUDA A LA DECISIÓN EN INTERNET PARA LA OBTENCIÓN DE RECOMENDACIONES DE GESTIÓN DEL RIEGO Y EL CULTIVO EN TIERRAS AMENAZADAS POR SALINIZACIÓN}

\author{
Visconti Reluy, F. (1) (P), de Paz Bécares, J.M. (2)
}

1 Titulado Superior, Instituto Valenciano de Investigaciones Agrarias, Centro para el Desarrollo de la Agricultura Sostenible, fernando.visconti@uv.es

${ }^{2}$ Colaborador Científico Adjunto, Instituto Valenciano de Investigaciones Agrarias, Centro para el Desarrollo de la Agricultura Sostenible, depaz jos@gva.es

\section{Resumen}

En el presente trabajo se presenta un ejemplo de utilización del sistema de ayuda a la decisión DSS-SALTIRSOIL para la recomendación del riego en una plantación de caqui "Rojo Brillante" en la zona de riegos del Magro de la Ribera del Xúquer (Valencia). De acuerdo con la simulación realizada con datos de la zona representativos de su meteorología (año 2010), suelo (franco arcilloso), calidad de agua (2.3 dS/m) y manejo del riego (goteo) y el cultivo, se esperaría una pérdida del $15 \%$ de producción como consecuencia de la salinización. Un incremento de la dotación anual de riego de $140 \mathrm{~mm}$, o una disminución de la salinidad hasta $2.0 \mathrm{dS} / \mathrm{m}$ reducirían dicha pérdidas a tan solo un $10 \%$ en dicho año de meteorología media. No obstante, la simulación del periodo 2000-2015 indica que una disminución de $100 \mathrm{~mm}$ en la precipitación anual media supone una amenaza de pérdida de producción de más del $20 \%$ en promedio. En consecuencia una solución satisfactoria a los problemas de salinidad en el cultivo del caqui en la zona pasa necesariamente por usar aguas de riego de salinidad más baja $(<2.0 \mathrm{dS} / \mathrm{m})$, o bien por un cambio del patrón del caqui a uno más tolerante a la salinidad como es el $D$. virginiana.

\begin{abstract}
In this article an example of utilization of the decision support system DSSSALTIRSOIL is shown for the recommendation of irrigation in a persimmon "Rojo Brillante" plantation in the Magro irrigation district in the Ribera del Xúquer (Valencia). According to the simulation carried out with data from the area, which is representative of the meteorology (2010), soil (clay loam), water quality ( $2.3 \mathrm{dS} / \mathrm{m}$ ) and irrigation (drip) and crop management, $15 \%$ yield losses would be expected as a result of salinization. An increase in the annual irrigation dose of $140 \mathrm{~mm}$, or a decrease in salinity down to $2.0 \mathrm{dS} / \mathrm{m}$ would reduce such losses to only $10 \%$ in such a year of average meteorology. However, the simulation of the span 2000-2015 indicates that an average decrease of $100 \mathrm{~mm}$ in the annual rainfall poses a threat of yield losses over $20 \%$ on average. Consequently a satisfactory solution for the salinity problems in persimmon cropping in the area necessarily involves using irrigation water of lower salinity $(<2.0 \mathrm{dS} / \mathrm{m})$, or replacing the persimmon rootstock by a more salttolerant one such as the $D$. virginiana.
\end{abstract}

\section{1- Introducción}


La amenaza de la salinización siempre está presente sobre el regadío, máxime cuando este se desarrolla en tierras con una o varias de las siguientes características: topografía deprimida, nivel freático elevado, agua de riego de calidad insuficiente, suelo de textura arcillosa y/o limosa, clima de árido a subhúmedo seco, y cultivo sensible a la salinidad. En España se estiman entre 0.6 y 1 Mha las tierras afectadas por salinidad principalmente bajo riego (FAO, 1997; Wicke et al., 2011). En la Comunidad Valenciana el $42 \%$ de los suelos de regadío presentan algún problema de salinidad con efectos limitantes sobre la producción (de Paz et al., 2004). En el escenario actual de creciente competencia por agua de calidad para usos urbanos, industriales y agrícolas, disponibilidad de aguas no convencionales, incremento de la aridez por el cambio climático, y expansión de cultivos muy sensibles como por ejemplo el caqui "Rojo Brillante", la salinización de suelos se perfila como un problema cuya importancia va a seguir aumentando en los próximos años.

Dejando a un lado la bioingeniería, los métodos con que tradicionalmente han contado los agricultores para superar los problemas de salinidad pueden clasificarse en tres tipos de mayor a menor efecto. En primer lugar para luchar contra la salinización se debe favorecer la infiltración, redistribución y drenaje del agua de riego y lluvia y en consecuencia, la lixiviación de las sales del suelo. Esto se consigue actuando sobre las propiedades hidrofísicas del suelo y el subsuelo mediante la instalación de sistemas de drenaje enterrado, cultivando en mesetas y favoreciendo la estructuración del suelo. Así se consigue aumentar la permeabilidad de los suelos y/o bajar el nivel freático. En segundo lugar, una vez aseguradas estas dos cosas, el agricultor cuenta con varias alternativas para luchar contra la salinización como son: i) aumentar la dosis de riego con una fracción de lavado que ayude a lixiviar las sales, ii) cambiar a aguas de mayor calidad, es decir, menos salinas, y/o menos cloruradas, y iii) cambiar a cultivos menos sensibles a la salinidad y/o el cloruro, o injertar en patrones más tolerantes. En tercer lugar y de manera complementaria el agricultor puede optimizar la fertilización, y/o estimular la tolerancia de los cultivos a la salinidad y/o el cloruro. Algunas de estas acciones es posible llevarlas a cabo y otras no, y a costes que se deben valorar para hallar la solución más sostenible.

La sencillez con que se puede actuar sobre la salinidad del suelo mediante el uso de una fracción de lavado ha hecho de este, un método muy popular de lucha contra la salinización. Así, desde mediados del siglo pasado se han propuesto métodos cada vez más sofisticados para calcular la fracción de lavado necesaria para bajar la salinidad del suelo hasta un nivel no perjudicial para el cultivo, esto es el cálculo del requerimiento de lavado (Visconti et al., 2012a). Por otro lado el regadío moderno no puede entenderse sin la programación de riegos que parte del cálculo de las necesidades hídricas de los cultivos, teniendo en cuenta además la eficiencia de los sistemas de riego y el aporte de las lluvias. Con la creación del sistema de ayuda a la decisión accesible en Internet DSS-SALTIRSOIL se ha logrado un sistema automatizado que programa los riegos mensualmente y recomienda otras prácticas de gestión agrícola considerando tanto las necesidades hídricas de las plantas como el requerimiento de lavado, y otras limitaciones y posibilidades de gestión del cultivo.

El objetivo de este trabajo es mostrar el funcionamiento del DSS-SALTIRSOIL mediante un ejemplo de gestión del riego, el suelo y el cultivo de caqui "Rojo Brillante" en el término municipal de Carlet (Valencia).

\section{2- Aplicación del sistema de recomendación DSS-SALTIRSOIL}

\subsection{Descripción del DSS-SALTIRSOIL}

El sistema de ayuda a la decisión DSS-SALTIRSOIL se encuentra alojado en el portal de Internet AGROSAL (http://agrosal.ivia.es/). Se trata de una web pensada para la 
difusión hacia el sector de contenidos relacionados con la salinidad de los suelos agrícolas en regadío (de Paz et al., 2015). El núcleo del DSS-SALTIRSOIL es el modelo SALTIRSOIL, diseñado para la predicción mensual de la salinidad en suelos de regadío con drenaje libre (Visconti et al., 2011; Visconti et al., 2014). Se trata de un modelo unidimensional de estado transitorio (transient-state), el cual simula el movimiento del agua en el suelo mediante un algoritmo capacitivo, y el movimiento de las sales mediante una aproximación de flujo pistón con dispersión hidrodinámica. El modelo SALTIRSOIL dispone, además, de un módulo llamado SALSOLCHEM que ajusta las concentraciones de las sales en la solución del suelo en virtud de su solubilidad, el contenido de agua, el contenido de carbonato de calcio y de yeso, así como el de $\mathrm{CO}_{2}$. Como resultado final de las simulaciones el modelo presenta al usuario la conductividad eléctrica a $25^{\circ} \mathrm{C}$ del extracto de saturación del suelo (CEe), así como su relación de adsorción de sodio (RASe), y su contenido de cloruro (Cle), y todo ello mes a mes durante el desarrollo del cultivo. El modelo SALTIRSOIL ha sido validado en varias parcelas ensayo en diferentes zonas de la Comunidad Valenciana y con diferentes cultivos (Visconti et al., 2010a; Visconti et al., 2012b; Visconti et al., 2014).

Los datos de entrada del modelo y en consecuencia del DSS-SALTIRSOIL se clasifican en cinco categorías. Por orden de importancia en la simulación de CEe estos son (Visconti et al., 2010b): meteorológicos (lluvia, evapotranspiración de referencia), calidad de agua de riego (contenidos de iones), cultivo (coeficientes de cultivo, marco de plantación, profundidad de enraizamiento), suelo (propiedades hidrofísicas, carbonato de calcio, yeso, $\mathrm{CO}_{2}$ ) y manejo del riego (dosis, frecuencia de riego y superficie humedecida). EI DSSSALTIRSOIL se encuentra vinculado en el portal AGROSAL a una base de datos meteorológicos, de calidad de agua, cultivos y suelos georreferenciados y representativos de la Comunidad Valenciana. De este modo los agricultores y técnicos agrícolas que se enfrenten a problemas de salinidad, simplemente conociendo la ubicación de sus parcelas pueden realizar sus simulaciones, y obtener sus recomendaciones de gestión.

\subsection{El cultivo de caqui "Rojo Brillante"}

El caqui "Rojo Brillante" (Diospyros kaki L. cv "Rojo Brillante") es un cultivo arbóreo que presenta características agronómicas y comerciales muy interesantes como alternativa a cítricos y frutales de hueso en áreas de clima mediterráneo. En consecuencia su cultivo se encuentra en plena expansión, sobre todo en la Comunidad Valenciana, de donde con más de 220.000 t se obtiene más del $80 \%$ de la producción nacional de esta fruta (Arnandis, 2015). El caqui es, no obstante, un cultivo sensible a la salinidad, acusando una notable fitotoxicidad al cloruro sobre todo cuando se injerta sobre $D$. lotus, lo cual supone una de las limitaciones más importantes a que se enfrentan los agricultores (de Paz et al., 2016). La sensibilidad al cloruro es tal, que incluso en condiciones de ligera salinidad manifiesta síntomas adversos que incluyen menor calibre de los frutos cosechados, maduración acelerada y menor eficacia de los tratamientos poscosecha (Besada et al., 2016). Así pues, a continuación se mostrará cómo el DSS-SALTIRSOIL se puede aplicar para recomendar el manejo más idóneo de una plantación adulta de caqui "Rojo Brillante" en el término municipal de Carlet (Valencia). Carlet y su comarca, la Ribera Alta del Xúquer, constituye el centro de difusión pionero del caqui "Rojo Brillante" (Llácer et al., 2008), y donde a principios de la presente década se describió por primera vez en España la sintomatología que posteriormente se ha diagnosticado como fitotoxicidad al cloruro (de Paz et al., 2016).

\subsection{Simulación de la salinidad del suelo con DSS-SALTIRSOIL}

Desde la página web AGROSAL (http://agrosal.ivia.es/) (Fig. 1) pinchando sobre el botón DSS-SALTIRSOIL en el encabezado o bien pinchando en el logo abajo a la derecha accedemos al sistema. En esta primera página se presenta una descripción del DSSSALTIRSOIL, y mediante los botones de la columna a la izquierda podemos navegar hacia 
una guía de manejo, un vídeo demostración y el propio sistema, bien pinchando en "Recomendación de Riego" bien en su logo. Así accedemos a una página donde nos identificamos con nuestras credenciales de usuario. En caso de ser nuevos en el sistema, antes de poder utilizarlo nos registraremos.

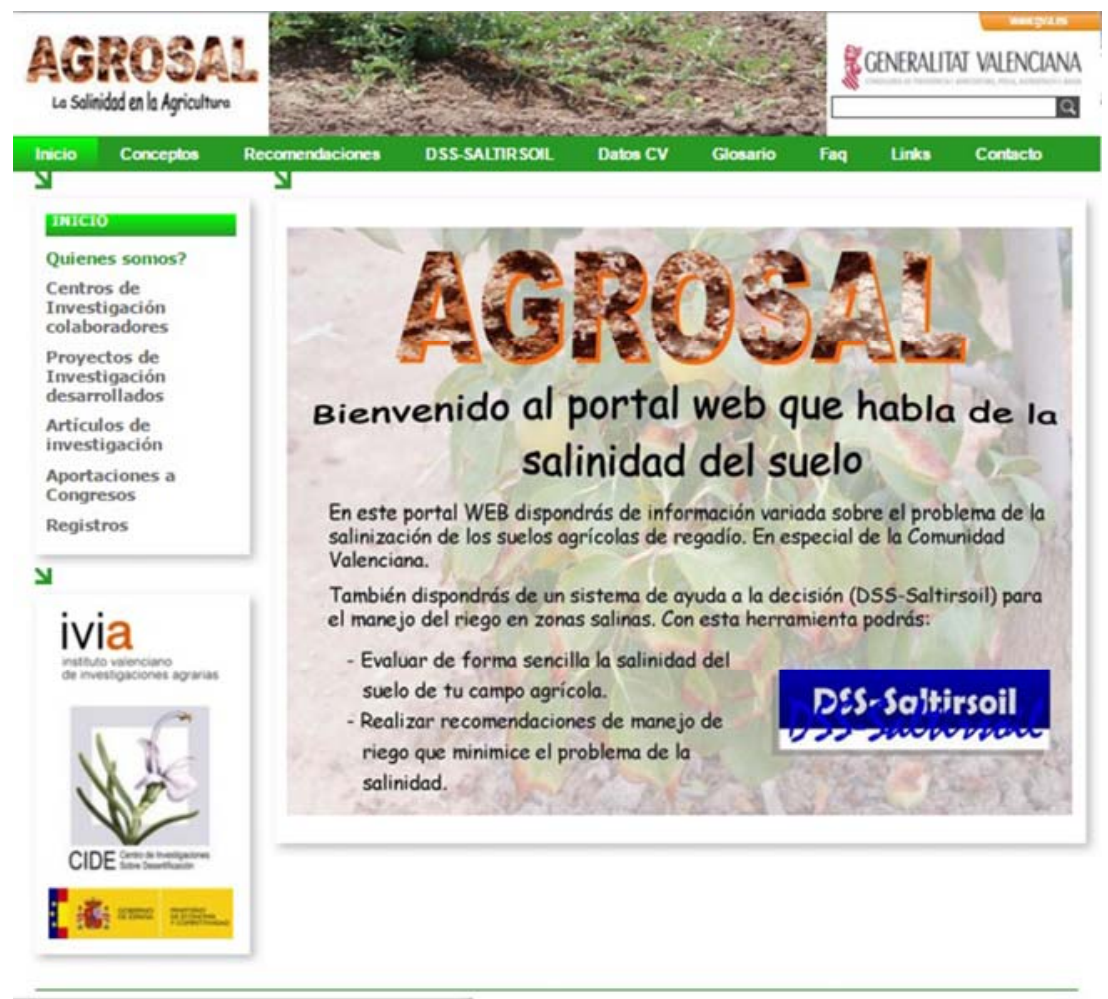

Figura 1. Entrada al portal AGROSAL.

Una vez dentro del sistema se nos presenta una página con diferentes pestañas mediante las cuales accederemos a los menús que nos permitirán seleccionar e introducir los datos necesarios para trabajar. En primer lugar en la pestaña «General» se nos pide un nombre para la simulación que queremos realizar. En nuestro caso escribimos por ejemplo "Caqui-Carlet», como provincia seleccionamos "Valencia», como término municipal «Carlet» y finalmente como profundidad para la simulación elegimos $60 \mathrm{~cm}$. Esta es una profundidad de enraizamiento razonable para un caqui adulto injertado sobre $D$. lotus, pie que se caracteriza por presentar una raíz muy fibrosa y en consecuencia, de desarrollo superficial. Para hacer efectivos estos datos en nuestra simulación pinchamos en el botón «Guardar», lo cual nos lleva a la siguiente pestaña.

En la pestaña «Clima» se presenta un cuadro de lista desplegable con los nombres de todas las estaciones meteorológicas que el «Sistema de Información Agroclimática para el Regadío» (http://eportal.magrama.gob.es/websiar/lnicio.aspx) tiene distribuidas en la Comunidad Valenciana. De entre estas estaciones, gestionadas por el Servicio de Tecnología del Riego (STR) del IVIA (http://riegos.ivia.es/), seleccionamos la estación de "Carlet CE Coop». Como año de simulación seleccionamos 2010, y a continuación se nos muestran los datos mensuales y el anual total de precipitación, número de días de lluvia, evapotranspiración de referencia y temperatura para dicha estación y año. El año 2010 ejemplifica con $518 \mathrm{~mm}$ de precipitación total, lo que es un año normal en una zona que se caracteriza por una precipitación media anual de $490 \pm 70 \mathrm{~mm}$ (IC95\%). Los datos que se presentan en este cuadro son editables pinchando en cada celda, cambiando el dato y haciendo clic en «intro». Así que en el caso de que el usuario disponga de datos propios, puede introducirlos y adaptar las simulaciones a la meteorología concreta de su parcela. 
Hacemos efectivos los cambios pinchando en el botón «Guardar», con lo cual pasamos a la siguiente pestaña.

En la pestaña «Cultivo» se presenta un cuadro de lista desplegable con los cultivos cuyos datos de coeficientes de desarrollo, tolerancia a la salinidad, etc., están incluidos en la base de datos del sistema. Seleccionamos "Kaki_Lotus», y dado que se trata de un cultivo multianual, como duración del cultivo seleccionamos 365 días, y como «Inicio cultivo» seleccionamos la fecha de 1 de enero de 2010. En caso de tratarse de un cultivo anual, p.ej., hortalizas, cereales, etc., seleccionaríamos la fecha de siembra o trasplante como "Inicio cultivo», y la fecha de cosecha como "Fin cultivo». A continuación en el cuadro «Riego» a la derecha, en el primer cuadro de lista desplegable seleccionamos de entre los tipos de riego «manta», "surcos» y "goteo», éste último. Con esta acción se habilitan varios cuadros que nos van a permitir introducir la información que caracteriza el riego por goteo de nuestra parcela como «Dosis mín. de cada riego» donde escribiremos $5 \mathrm{~mm}$, «No máx. riegos/mes» donde pondremos 20, "Diámetro de copa» donde introduciremos $3.8 \mathrm{~m}, \mathrm{y}$ finalmente «Distancia entre plantas», y «Distancia entre líneas» que serán $3.5 \mathrm{~m}$ y $4 \mathrm{~m}$ respectivamente. Estos datos arrojan un área sombreada de $11 \mathrm{~m}^{2}$ por árbol, lo cual supone un $79 \%$ de la superficie de la parcela. Finalmente introducimos los datos de «Porcentaje de suelo mojado» por el sistema de riego, que dejamos como $15 \%$, y « $\mathrm{N}^{\circ}$ goteros por árbol» y «Caudal del gotero» que serán en este ejemplo 4 y $4 \mathrm{~L} / \mathrm{h}$ respectivamente. Finalmente pinchamos en "Calcular Riego» y se nos muestra un cuadro con la programación mensual del riego adecuada para atender las necesidades hídricas de un cultivo de caqui con las características consideradas previamente. Vemos que en total se recomendarían $276 \mathrm{~mm}$, iniciándose los riegos en mayo con $43 \mathrm{~mm}$, y finalizándose en agosto con $83 \mathrm{~mm}$, y con un máximo de $87 \mathrm{~mm}$ en julio. Es importante destacar que estos datos también son editables, de tal modo que el usuario del sistema puede introducir los datos de las cantidades reales de agua que se utilizaron para regar su plantación. Una vez tenemos todos los datos introducidos de manera adecuada los hacemos efectivos pinchando en "Guardar» y pasamos así a la pestaña siguiente.

En la pestaña "Suelo» se presenta un cuadro de lista desplegable con suelos presentes en el término municipal donde tenemos la plantación, en este caso Carlet. Los suelos se encuentran clasificados en virtud de su textura y acompañando ésta, una estimación de la permeabilidad de los mismos. Elegimos un suelo franco arcilloso de permeabilidad media, cuyas propiedades se nos muestran por profundidades. Estos datos de suelo no son editables para asegurar su consistencia edafológica. Pinchamos en «Guardar» y pasamos a la siguiente pestaña.

En la pestaña «Agua Riego» se presentan varios cuadros de lista desplegable donde en orden de arriba abajo seleccionamos el término municipal, la unidad de demanda agraria y el origen del agua dentro de la misma. En nuestro caso seleccionamos respectivamente, «Carlet», «Riegos del Magro» y «Subterránea». En último lugar seleccionamos la salinidad del agua de riego, en este caso un valor de $2.3 \mathrm{dS} / \mathrm{m}$, es representativo del riego con agua subterránea, ya sea de pozo o manantial, en la zona de riegos del río Magro. En un cuadro al lado se nos muestran los datos de concentración de iones y otros parámetros de calidad del agua. Dada su salinidad, cloruro de $6.7 \mathrm{meq} / \mathrm{L}$, RAS de $2.1(\mathrm{mmol} / \mathrm{L})^{1 / 2}$ y carbonato de sodio residual (CSR) de $-13 \mathrm{meq} / \mathrm{L}$ el agua que hemos elegido se clasificaría como ligeramente salina, moderadamente clorurada, no sódica, y no alcalina (Fig. 2). Los datos del agua de riego no son editables para asegurar, del mismo modo que con los datos de suelo, su coherencia interna. Una vez seleccionados los datos de calidad de agua ya se puede realizar la simulación de la salinidad pinchando en el botón «Evaluar y Recomendar», lo cual nos lleva a la siguiente pestaña. 


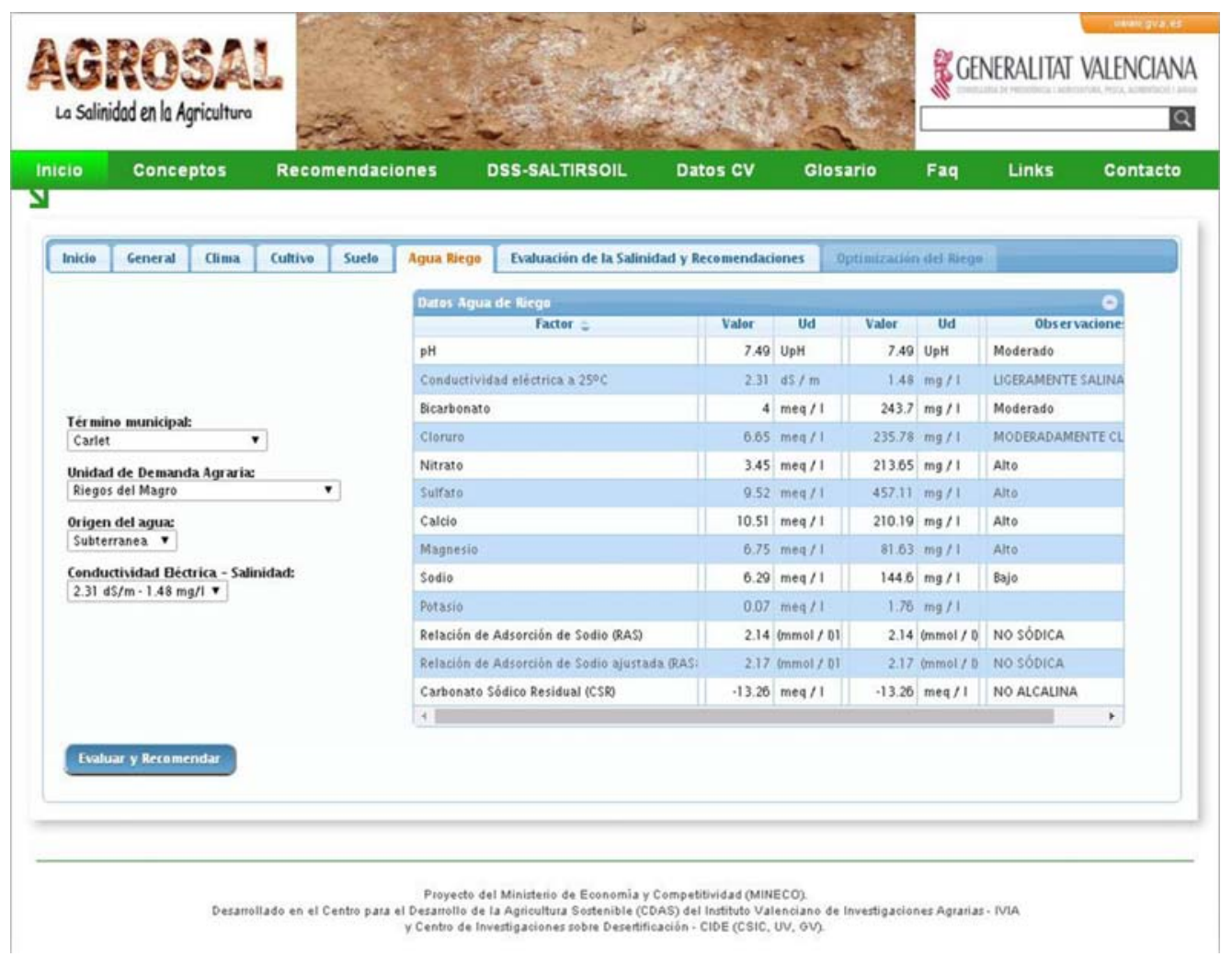

Figura 2. Pestaña «Agua Riego» con el agua seleccionada para la simulación.

En la pestaña «Evaluación de la Salinidad y Recomendaciones» se presentan los resultados de la simulación en forma gráfica, numérica y con mensajes en pantalla. En primer lugar llama nuestra atención la evaluación de ligera salinidad de la parcela, la cual ocasiona un descenso de la producción del $15 \%$. En las gráficas se presenta la evolución de CEe, RASe y Cle a lo largo del año (Fig. 3). Vemos así que la CEe varía entre 1.6 y 2.5 $\mathrm{dS} / \mathrm{m}$ a lo largo de la temporada de riegos (abril-noviembre), lo cual explica el problema de salinidad; que la RASe varía entre 0.9 y $2.8(\mathrm{mmol} / \mathrm{L})^{1 / 2}$, lo cual no ocasiona ningún problema de sodicidad; y que Cle varía entre 4.6 y $9.4 \mathrm{meq} / \mathrm{L}$, dando así lugar a una evaluación de ligera toxicidad al cloruro. Realizando la simulación para todos los años desde 2000 hasta 2015 se observa que la salinidad ha presentado una tendencia ascendente durante estos primeros años del siglo XXI (Fig. 4). Este hecho contribuye a explicar que el problema de fitotoxicidad al cloruro no se manifestase con claridad hasta comienzos de la presente década. Los mensajes de recomendación en pantalla nos indican las alternativas principales de que disponemos para mejorar el manejo del cultivo y evitar así los problemas de salinidad: "Optimizar el riego para lavar sales del suelo», "Cambiar a un agua de riego de salinidad más baja», y "Cambiar a otro cultivo o patrón más tolerante a la salinidad», y también para evitar los problemas de toxicidad al cloruro mediante mensajes similares. En el caso de la sodicidad se presenta un escueto «El manejo del riego es adecuado para evitar problemas de sodicidad». Todos los datos seleccionados para la simulación así como los resultados pueden descargarse como documento "pdf» pinchando para ello en el botón «Informe PDF». Dados los problemas descubiertos mediante la simulación, a continuación calculamos la programación de riegos que permitiría atender las necesidades hídricas del cultivo a la vez que se lavan sales para evitar el problema de salinidad que ocasiona la pérdida de producción del 15\%. Así pinchamos en el botón «Optimizar Riego» lo cual nos lleva a la siguiente pestaña. 


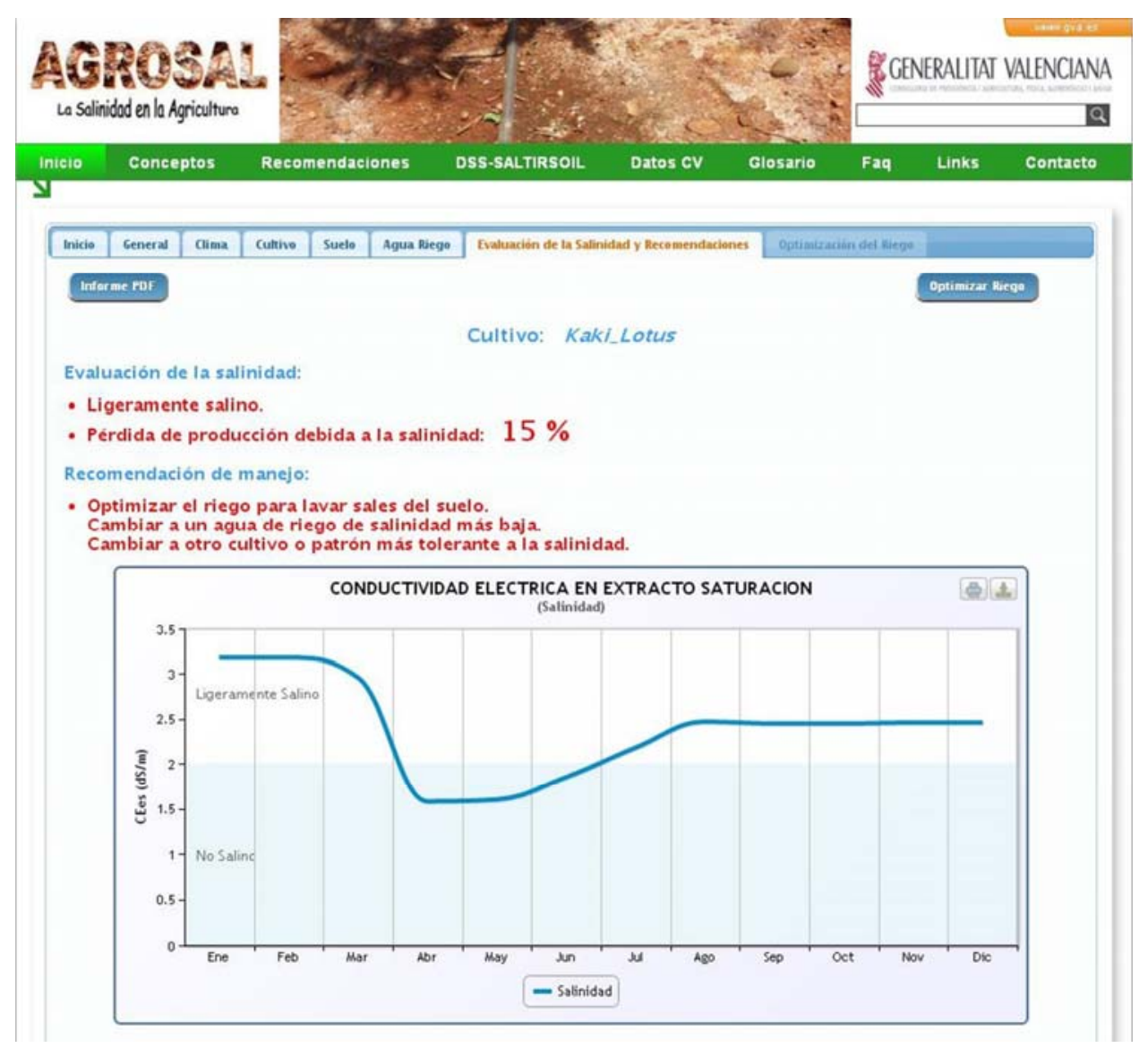

Figura 3. Pestaña «Evaluación de la Salinidad y Recomendaciones».

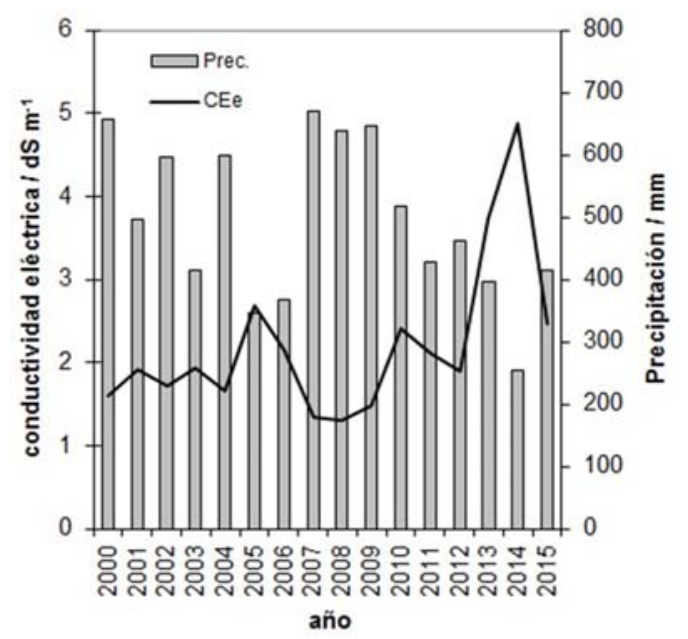

Figura 4. Evolución de la salinidad y precipitación promedio desde 2000 hasta 2015.

\subsection{Optimización de la gestión del riego, el suelo y el cultivo}

En la pestaña «Optimización del Riego» el sistema muestra los resultados de los cálculos de optimización. Estos son en primer lugar una programación mensual de riegos capaz de disminuir la pérdida de producción a tan solo un $10 \%$. El riego optimizado de este modo asciende ahora a $417 \mathrm{~mm}$ anuales, $140 \mathrm{~mm}$ más que el calculado teniendo únicamente en cuenta las necesidades hídricas del cultivo. En segundo lugar se presentan 
también en pantalla las gráficas con la evolución temporal tanto de la CEe, como de la RASe y el Cle. En este caso la CEe presenta valores entre 1.1 y $2.2 \mathrm{dS} / \mathrm{m}$ durante toda la temporada de riegos, mientras que el Cle se mantiene entre 3.3 y $8.1 \mathrm{meq} / \mathrm{L}$, estos son valores inferiores en más de $1 \mathrm{meq} / \mathrm{L}$ a los anteriores. Igual que antes todos estos resultados pueden descargarse como «pdf» pinchando en «Informe PDF».

Una mayor reducción de la salinidad, esto es, buscar una salinidad conducente a un $0 \%$ de pérdida de producción no se contempla en el sistema. Esto es debido a que no suele resultar una práctica sostenible buscar tales reducciones, dado que no existe una relación lineal entre la salinidad del suelo y la fracción de lavado (Ayers y Westcot, 1985; Visconti et al., 2012a) y en consecuencia tampoco la dosis de riego. En consecuencia, a medida que disminuye la salinidad, para obtener un mismo porcentaje de reducción de la misma, se necesitan incrementos cada vez mayores de la dosis de riego. Otras limitaciones son la cantidad de agua de riego, p.ej. el sistema nunca recomendará, en general, dosis de más de $1200 \mathrm{~mm}$ anuales, ni en particular para los cítricos de más de $800 \mathrm{~mm}$ anuales. En caso de que el único camino para alcanzar rendimientos del $90 \%$ fuese regar por encima de dichas cantidades anuales, se recomienda que el usuario opte por alguna de las otras recomendaciones relacionadas con la calidad del agua de riego o con el cultivo, esto es el cambio a un agua de mayor calidad, o bien a un cultivo o patrón más tolerante a la salinidad.

Ambas alternativas de manejo pueden también explorarse mediante el sistema DSSSALTIRSOIL. En primer lugar, manteniendo la programación de riegos tal y como estaba originalmente, tan solo se necesitaría cambiar a un agua de riego de $2.0 \mathrm{dS} / \mathrm{m}$ en lugar de $2.3 \mathrm{dS} / \mathrm{m}$, para hacer que la pérdida de producción fuese tan solo de un $10 \%$ en lugar del $15 \%$. En segundo lugar, el usuario puede obtener información acerca de qué otros cultivos arbóreos darían una producción de al menos el $90 \%$ en condiciones similares de manejo y en consecuencia, de salinidad. Estos serían el limonero, la higuera, el olivo, la palmera datilera, la vid para vinificación y para uva de mesa, el granado y el caqui injertado en $D$. virginiana.

EI D. virginana es otro caqui que también se utiliza como pie de "Rojo Brillante" en la Comunidad Valenciana, aunque de manera mucho menos extendida que $D$. lotus. Debe tenerse en cuenta en todo caso que esta estimación de los cultivos alternativos es un dato menos fiable que los anteriores proporcionados por el sistema y que deberemos realizar la simulación para confirmar que de verdad se trata de una alternativa. También es importante tener en cuenta que la estimación del rendimiento se lleva a cabo en términos relativos al potencial propio de cada especie y cultivar. Esto significa que, aunque el rendimiento en términos relativos del caqui "Rojo Brillante" sobre pie $D$. virginiana en las anteriores condiciones de salinidad sea superior que sobre $D$. lotus, en términos absolutos ocurre al revés dado el gran vigor que confiere el pie $D$. lotus a la variedad en comparación con $D$. virginiana.

\subsection{Incertidumbre en las simulaciones y optimizaciones a lo largo del tiempo}

Para una plantación dada, de todos los factores que influyen sobre la salinidad, sodicidad y toxicidad al cloruro y en consecuencia sobre las recomendaciones de manejo, el más variable es la meteorología, y en concreto la lluvia. Como se ha presentado mediante la Fig. 4, durante el periodo 2000-2015 la salinidad simulada por el sistema para la zona de Carlet ha aumentado siguiendo las fluctuaciones en la precipitación. Así que los años 2007, 2008 y 2009 que fueron, con 650 mm de precipitación media, muy húmedos para el clima de la zona, dieron como resultado una salinidad y cloruro en el suelo de $1.1 \mathrm{dS} / \mathrm{m}$ y $3.3 \mathrm{meq} / \mathrm{L}$ en promedio durante la temporada de riegos. Por el contrario los años 2013, 2014 y 2015 que se han caracterizado por ser, con tan solo $355 \mathrm{~mm}$ de precipitación media, entre secos y muy secos para el clima de la zona, dieron como resultado una salinidad y cloruro en el suelo de $3.5 \mathrm{dS} / \mathrm{m}$ y $14 \mathrm{meq} / \mathrm{L}$. En consecuencia para años muy húmedos como el trienio 
2007-2009, no se recomendaría ningún incremento de los riegos para lavar sales y cloruro. Por el contrario para aquellos años de secos a muy secos como el trienio 2013-2015 se recomendarían riegos que oscilarían entre 510 y $930 \mathrm{~mm}$ anuales. En las condiciones de la zona tales dotaciones pueden ser muy difíciles de satisfacer, sobre todo si superan los 800 $\mathrm{mm}$ como en 2014. En general, para un manejo medio del riego un descenso de la precipitación de $100 \mathrm{~mm}$ ocasionaría una pérdida de producción de más del $20 \%$. En consecuencia, para tratar de superar el problema de salinidad definitivamente sería más adecuado otro tipo de solución como buscar un agua de riego de menos salinidad y cloruro, específicamente de menos de $2 \mathrm{dS} / \mathrm{m}$, o la utilización del patrón $D$. virginiana.

\section{3- Conclusiones}

Como se ha mostrado mediante el ejemplo desarrollado en este trabajo, disponer de un sistema de ayuda a la decisión como es el DSS-SALTIRSOIL, resulta útil debido a que permite evaluar las diferentes posibilidades con que cuenta el agricultor para lograr rendimientos de cultivo aceptables en situaciones de riesgo de salinización del suelo. El sistema DSS-SALTIRSOIL presenta una notable flexibilidad de uso debido a su vinculación a bases de datos meteorológicos, de cultivo, suelo, calidad de agua, etc. y a las posibilidades que ofrece a sus usuarios de editar toda esta información para adaptarla en la medida de lo posible a las condiciones concretas de sus plantaciones.

\section{4- Recomendaciones}

En el ejemplo desarrollado en este trabajo se ha mostrado la utilidad del DSSSALTIRSOIL para estudiar las alternativas de manejo de riego y cultivo de una plantación de caqui "Rojo Brillante" en la zona de riegos del río Magro en la Ribera del Xúquer (Valencia). En esta zona y dadas sus condiciones climatológicas se deberían utilizar, en general, siempre aguas de menos de $2 \mathrm{dS} / \mathrm{m}$, y dotaciones de riego de entre 400 y $450 \mathrm{~mm}$ anuales para asegurarnos una producción no límitada por la salinidad. Únicamente si alguna de estas dos condiciones no puede cumplirse, se recomendaría el cambio de $D$. lotus a $D$. virginiana como patrón de la variedad "Rojo Brillante".

\section{5- Agradecimientos}

El portal AGROSAL fue desarrollado en el marco de los proyectos-14592-C02-01 y CGL2009-14592-C02-02 financiados por el Ministerio de Ciencia e Innovación. Fernando Visconti agradece así mismo las ayudas disfrutadas dentro del programa Val i+d financiado por la Generalitat Valenciana, y el programa "Juan de la Cierva" financiado por el Ministerio de Economía y Competitividad, para el desarrollo del DSS-SALTIRSOIL.

\section{6- Bibliografía}

Arnandis, C. (2015). Prólogo. En M. L. Badenes, D. S. Intrigliolo, A. Salvador \& A. Vicent (Eds.), El cultivo del caqui (pp. 11-13). Valencia: Generalitat Valenciana.

Ayers, R. S., \& Westcot, D. W. (1985). Water quality for agriculture. Irrig Drain Paper 29, Rev. 1. Rome: Food and Agriculture Organization of the United Nations.

Besada, C., Gil, R., Bonet, L., Quiñones, A., Intrigliolo, D., \& Salvador, A. (2016). Chloride stress triggers maturation and negatively affects the postharvest quality of 
persimmon fruit. involvement of calyx ethylene production. Plant Physiology and Biochemistry, 100, 105-112.

de Paz, J. M., Visconti, F., Tudela, L., Quiñones, A., Intrigliolo, D. S., Jordà, M. \& Bonet, L. (2016). La fitotoxicidad por cloruro en el cultivo del caqui: Descripción del problema. Agrícola Vergel: Fruticultura, Horticultura, Floricultura (en prensa).

de Paz, J. M., Visconti, F., Moreno, G., Molina, M. J., Ingelmo, F., Martínez, D. \& Sánchez, J. (2015). AGROSAL: Presentación de un nuevo portal web que trata sobre la salinidad de los suelos agrícolas de regadío. parte I. Agrícola Vergel: Fruticultura, Horticultura, Floricultura, 380, 37-42.

de Paz, J. M., Visconti, F., Zapata, R. \& Sánchez, J. (2004). Integration of two simple models in a geographical information system to evaluate salinization risk in irrigated land of the valencian community, spain. Soil Use and Management, 20, 333-342.

FAO. (1997). FAO/UNESCO Soil Map of the World, Revised Legend, with Corrections and Updates. World Soil Resources Report 60 (Reprinted with updates as Technical Paper 20 ed.). Wageningen: ISRIC.

Llácer, G., Martínez-Calvo, J., Naval, M. \& Badenes, M. L. (2008). From germplasm to fruit export: The case of 'rojo brillante' persimmon. Advances in Horticultural Science, 22, 281-285

Visconti, F., de Paz, J. M., Molina, M. J., Ingelmo, F., Sánchez, J. \& Rubio, J. L. (2010a). Progress towards DSS-SALTIRSOIL: Monthly calculation of soil salinity, sodicity and alkalinity in irrigated well-drained lands. Proceedings of the Global Forum on Salinization and Climate Change, Burjassot (Valencia, España). pp. 37.

Visconti, F., de Paz, J. M., Martínez, D. \& Molina, M. J. (2014). Irrigation recommendation in a semi-arid drip-irrigated artichoke orchard using a one-dimensional monthly transient-state model. Agricultural Water Management, 138, 26-36.

Visconti, F., de Paz, J. M., Molina, M. J. \& Sánchez, J. (2012b). Advances in validating SALTIRSOIL at plot scale: First results. Journal of Environmental Management, 95, S31-S36.

Visconti, F., De Paz, J. M., Rubio, J. L., \& Sánchez, J. (2010b). Preliminary results for the global sensitivity analysis of SALTIRSOIL model outputs. Procedia - Social and Behavioral Sciences, 2, 7763-7764.

Visconti, F., de Paz, J. M., Rubio, J. L. \& Sánchez, J. (2011). SALTIRSOIL: A simulation model for the mid to long-term prediction of soil salinity in irrigated agriculture. Soil Use and Management, 27, 523-537.

Visconti, F., de Paz, J. M., Rubio, J. L. \& Sánchez, J. (2012a). Comparison of four steady-state models of increasing complexity for assessing the leaching requirement in agricultural salt-threatened soils. Spanish Journal of Agricultural Research, 10, 222-237.

Wicke, B., Smeets, E., Dornburg, V., Vashev, B., Gaiser, T., Turkenburg, W. \& Faaij, A. (2011). The global technical and economic potential of bioenergy from salt-affected soils. Energy and Environmental Science, 4, 2669-2681. 


\title{
B-02
}

\section{EVALUACIÓN CUANTITATIVA Y CUALITATIVA DEL CULTIVO DE AJO MORADO BAJO APLICACIÓN OPTIMIZADA DE VOLÚMENES LIMITADOS DE AGUA DE RIEGO}

\author{
Léllis, B.C. ${ }^{1}$, Pardo, J.J.2 , Tarjuelo J.M. ${ }^{3}$, Martínez-Romero A. ${ }^{4}$ \\ Domínguez $A^{5}$
}

1 Ingeniero Agrónomo, Investigador, Centro Regional de Estudios del Agua (CREA) UCLM,Ctra. De Las Peñas km. 3,2, 02071 Albacete, brunolellismaria@yahoo.com.br

2 Ingeniero Agrónomo, Investigador, Centro Regional de Estudios del Agua (CREA) UCLM,Ctra. De Las Peñas km. 3,2, 02071 Albacete, josejesus.pardo@uclm.es

${ }^{3}$ Dr. Ingeniero Agrónomo, Catedrático de Universidad; Departamento de Producción Vegetal y Tecnología Agraria, UCLM; jose.tarjuelo@uclm.es

${ }^{4}$ Dr. Ingeniero Agrónomo, Profesor Asociado; EIIAB, Departamento de Mecánica Aplicada e Ingeniería de Proyectos, UCLM; angel.mromero@uclm.es

5 Dr. Ingeniero Agrónomo, Profesor Contratado Doctor; Departamento de Producción Vegetal y Tecnología Agraria, UCLM; Alfonso.dominguez@uclm.es

\section{Resumen}

Castilla-La Mancha (C-LM) es una región de clima semiárido con escasez de recursos hídricos para el regadío. De las variedades de ajo utilizadas en la región, el Ajo Morado de las Pedroñeras presenta valores añadidos, tanto en aspectos económicos, como culturales y de calidad nutricional. Todo ello, unido al elevado coste de la energía asociada a los sistemas de riego presurizados, hace que muchos productores demanden estrategias para mejorar la eficiencia en el uso del agua y hacer más rentable el cultivo. El objetivo principal de este trabajo, es definir y validar estrategias de manejo del riego deficitario controlado, basadas en las metodologías año meteorológico típico (TMY) y del riego deficitario optimizado por etapas (ORDI) que distribuyan de manera óptima un volumen de agua de riego limitado durante las distintas etapas de desarrollo fenológico del Ajo Morado de Las Pedroñeras. Para ello, se ensayaron 5 tratamientos, uno sin déficit y cuatro con distintos volúmenes máximos de agua de riego disponible, correspondientes al 100 (T100), 90 (T90), 80 (T80) y 70\% (T70) de las necesidades netas de riego del cultivo para las condiciones climáticas de un año meteorológico típico (TMY) intermedio en C-LM (fijadas en 3400 $\mathrm{m}^{3} / \mathrm{ha}$ ). Como consecuencia de las condiciones climáticas del año del ensayo, los tratamientos no alcanzaron los niveles de déficit hídrico deseados. No se observaron diferencias significativas en cuanto a rendimiento y calidad para los tratamientos T90, T80 y T70.

\section{1- Introducción}

El ajo (Allium sativum L.) es uno de los cultivos más difundidos en el mundo, con cerca de 1,5 millones de hectáreas plantadas, generando un movimiento de alrededor de 500 millones de dólares por año (FAO, 2016). En Europa existen aproximadamente 108.000 ha del cultivo, de las cuales 21.000 ha pertenecen a España. En la comunidad autónoma de Castilla-La Mancha se localiza la principal zona productora de ajo española, con el $58 \%$ del total nacional (MAGRAMA, 2016). 
De las variedades utilizadas en la zona, el Ajo Morado de las Pedroñeras presenta valores añadidos, tanto en aspectos económicos, como culturales y de calidad nutricional. Sin embargo, la introducción en los últimos años de variedades de ajo blanco, con mayores rendimientos y con menores costes de producción, dificulta la competencia del Ajo Morado en el mercado.

Más del 95\% del área cultivada de ajo en C-LM es bajo regadío (MAGRAMA, 2016) y debido a la escasez de recursos hídricos en la región, los regantes tienen limitada en amplias zonas la disponibilidad de agua para riego. Este hecho, unido al elevado coste de la energía asociada a los sistemas de riego presurizados, hace que muchos productores demanden estrategias para mejorar la eficiencia en el uso del agua y hacer más rentable el cultivo del Ajo Morado (LOPEZ-MATA et al., 2010, LÓPEZ-URREA et al., 2003, FABEIRO CORTÉS et al., 2003, LÓPEZ-URREA et al., 2002). En este sentido Domínguez et al. (2013) desarrollaron una técnica para incrementar la eficiencia en el uso del agua mediante la combinación de las metodologías del año meteorológico típico (TMY) y del riego deficitario optimizado por etapas (ORDI), que permite distribuir de forma óptima una cantidad limitada de agua de riego, inferior a las necesidades del cultivo, maximizando el rendimiento final.

El objetivo principal de este trabajo es definir y validar estrategias de manejo del riego deficitario controlado, basadas en las metodologías TMY y ORDI (DOMíNGUEZ et al., 2012) que distribuyan de manera óptima un volumen de agua de riego limitado, durante las distintas etapas de desarrollo fenológico del Ajo Morado de Las Pedroñeras. De este modo se plantea limitar el efecto del estrés hídrico en el cultivo, maximizando el rendimiento y garantizando la calidad final del producto, para las condiciones de clima semiárido de Castilla-La Mancha.

\section{2- Materiales y métodos}

Durante la campaña 2015 se realizaron los ensayos de campo en los que se analizó el efecto de 5 tratamientos de riego sobre el rendimiento y los parámetros de calidad de la cosecha. Los tratamientos planteados fueron: uno sin déficit, y los otros cuatro con distintos volúmenes máximos de agua de riego disponible, correspondientes al 100 (T100), 90 (T90), 80 (T80) y $70 \%$ (T70) de las necesidades netas de riego en ajo morado para las condiciones climáticas de un año meteorológico típico (TMY) intermedio (fijadas en $3400 \mathrm{~m}^{3} / \mathrm{ha}=\mathrm{T} 100$ ). Este valor se obtuvo tras la calibración de los datos requeridos por el modelo MOPECO para el ajo en las condiciones de C-LM, aplicando la metodología TMY (Domínguez et al., 2013).

El uso del Modelo de OPtimización ECOnomica - MOPECO (ORTEGA et al., 2005) con las metodologías ORDI y TMY ha permitido establecer para un volumen de agua disponible, el nivel de déficit de cada fase de desarrollo, así como el calendario de riegos para cada uno de los tratamientos planteados que maximiza el rendimiento. Los objetivos de déficit y los calendarios de riegos se han ido actualizando en función de la evolución de los parámetros climáticos del año actual, haciendo nuevas optimizaciones en cada cambio de fase, permitiendo redistribuir el agua de la manera más óptima posible, respetando el volumen de agua de riego fijado para cada tratamiento (Sin déficit: sin limitación de agua, T100: $3400 \mathrm{~m}^{3} / \mathrm{ha}$, T90: $3060 \mathrm{~m}^{3} / \mathrm{ha}$, T80: $2720 \mathrm{~m}^{3} / \mathrm{ha}$ y T70: $2380 \mathrm{~m}^{3} / \mathrm{ha}$ ).

La plantación del ajo se realizó manualmente, con un marco de 0,08 metros entre plantas y 0,5 metros entre líneas de cultivo, para un área de ensayo total de $918 \mathrm{~m}^{2}$. Se realizaron cuatro repeticiones de cada tratamiento en parcelas de $2,5 \mathrm{~m} \times 18,0 \mathrm{~m}$ distribuidas al azar, salvo en los tratamientos sin déficit y el T100, donde fueron tres. El agua se aplicó mediante un sistema de riego localizado por goteo de marco cuadrado $(0,5 \times 0,5 \mathrm{~m}$ de separación entre ramales y emisores) dotado de emisores autocompensantes con un caudal nominal de 3,8 I/h. En cada sector de riego, que corresponde con un tratamiento, se instaló un caudalímetro de pulsos para controlar los volúmenes de agua aplicados. Además 
se realizaron evaluaciones de la uniformidad de aplicación de agua del sistema de riego antes de la siembra y periódicamente a lo largo del ciclo de cultivo.

En cada parcela se instalaron tensiómetros (a 20 y $40 \mathrm{~cm}$ de profundidad) y sensores de humedad volumétrica (a 10, 20,30 y $40 \mathrm{~cm}$ ) para controlar la evolución del agua en el suelo (Figura 1). A partir de los datos ambientales registrados por la estación agroclimática completa ubicada en el campo de ensayos, de los registros de los sensores de humedad en el suelo, y de la combinación de MOPECO con las metodologías ORDI y TMY, se estableció una programación de riegos con un nivel de déficit objetivo (ETa/ETm) para cada etapa de crecimiento. Así, se fijó el calendario de riegos para cada uno de los tratamientos propuestos, sin superar en ningún caso el volumen de agua disponible prefijado.

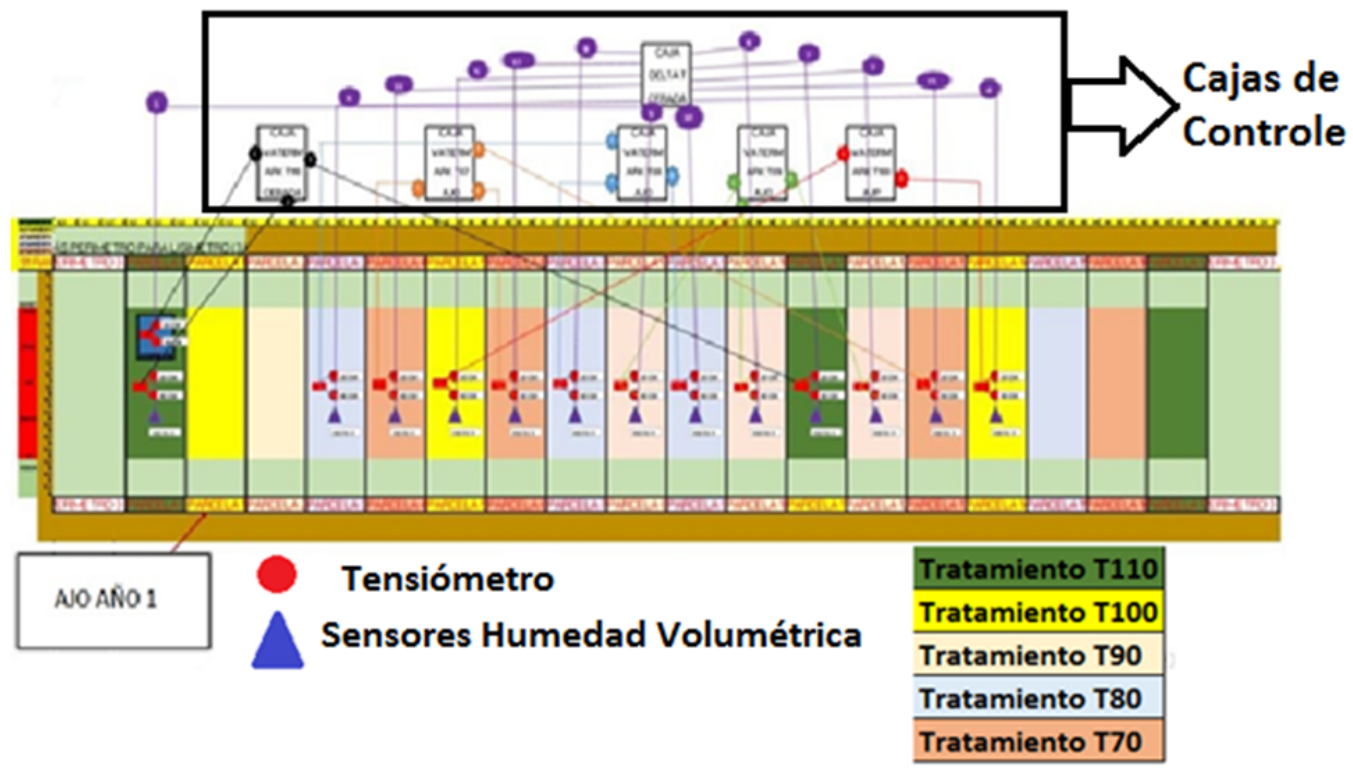

Figura 1. Esquema de la distribución de las parcelas y sensores de humedad de suelo.

Periódicamente se recogieron muestras del cultivo para analizar la evolución de parámetros fisiológicos, tales como el índice de área foliar y la biomasa. Para la determinación del índice de cobertura se tomaron fotografías RGB, mientras que para el seguimiento del nivel de estrés alcanzado por el cultivo se tomaron fotografías térmicas. Con el fin de estudiar la respuesta de la planta a los distintos déficits hídricos en fechas próximas al cambio de etapa de desarrollo fenológico, se midieron parámetros tales como la capacidad fotosintética utilizando un analizador de gases por infrarrojo, o la conductancia estomática, utilizando un porómetro.

Tras la cosecha, además del rendimiento total y su distribución por calibres, se evaluaron varios parámetros de calidad y la eficiencia del uso del agua, relacionando todo ello con los distintos tratamientos de riego aplicados y los niveles de estrés hídrico. Los parámetros analizados fueron: el color típico del Ajo Morado por medio de técnicas de colorimetría, los sólidos solubles y la textura. En condiciones de almacenamiento, se está registrando la evolución de la masa para cada uno de los tratamientos diferenciados.

\section{3- Resultados y discusión}

En el año de 2015, las optimizaciones para las tres primeras etapas de desarrollo fenológico se hicieron a partir de los datos de un TMY intermedio, y dada a la evolución climática durante el ciclo, para la última etapa se utilizaron datos de un TMY seco. Los 
valores de agua de riego neto, las relaciones entre evapotranspiración actual o real (ETa) y evapotranspiración máxima $(E T m)$ y las obtenidas por el optimizador se presentan en la Tabla 1.

Tabla 1. Relaciones ETa/ETm optimizadas y reales para las etapas de desarrollo fenológico.

\begin{tabular}{|c|c|c|c|c|c|c|c|c|}
\hline \multirow[b]{2}{*}{2015} & \multicolumn{2}{|c|}{ Tratamiento $100 \%$} & \multicolumn{2}{|c|}{ Tratamiento $90 \%$} & \multicolumn{2}{|c|}{ Tratamiento $\mathbf{8 0 \%}$} & \multicolumn{2}{|c|}{ Tratamiento $70 \%$} \\
\hline & \begin{tabular}{|c|} 
ETa/ETm \\
(Opt.)
\end{tabular} & \begin{tabular}{|c|} 
ETa/ETm \\
(Real)
\end{tabular} & $\begin{array}{c}\text { ETa/ETm } \\
\text { (Opt.) }\end{array}$ & $\begin{array}{c}\text { ETa/ETm } \\
\text { (Real) }\end{array}$ & $\begin{array}{c}\text { ETa/ETm } \\
\text { (Opt.) }\end{array}$ & $\begin{array}{c}\begin{array}{c}\text { ETa/Etm } \\
\text { (Real) }\end{array} \\
\end{array}$ & $\begin{array}{c}\text { ETa/ETm } \\
\text { (Opt.) }\end{array}$ & \begin{tabular}{|c|c|}
$\begin{array}{c}\text { ETa/ETm } \\
\text { (Real) }\end{array}$ \\
\end{tabular} \\
\hline Etapa 1' & 1,00 & 1,00 & 1,00 & 1,00 & 1,00 & 1,00 & 1,00 & 1,00 \\
\hline Etapa 1" & 1,00 & 1,00 & 0,76 & 0,75 & 0,70 & 0,73 & 0,70 & 0,74 \\
\hline Etapa 2 & 1,00 & 0,91 & 1,00 & 0,91 & 1,00 & 0,91 & 0,84 & 0,80 \\
\hline Etapa 3 & 1,00 & 0,98 & 0,81 & 0,74 & 0,54 & 0,66 & 0,50 & 0,66 \\
\hline Global/Total & 1,00 & 0,95 & 0,90 & 0,84 & 0,80 & 0,81 & 0,70 & 0,76 \\
\hline $\begin{array}{c}\text { Riego } \\
\text { Neto(mm) }\end{array}$ & \multicolumn{2}{|c|}{253,69} & \multicolumn{2}{|c|}{188,1} & \multicolumn{2}{|c|}{179,6} & \multicolumn{2}{|c|}{159,4} \\
\hline
\end{tabular}

*Opt: Optimizado.

Al tratamiento sin déficit se le aplicó la misma cantidad de agua que al T100, por lo que no se analizaron conjuntamente. Para las programaciones de riegos establecidas, según la información proporcionada por los sensores de humedad instalados en el suelo, parece que en ningún tratamiento se alcanzaron niveles de estrés tanto en las etapas de establecimiento como al inicio del desarrollo vegetativo (Figura 2).

Daily progression

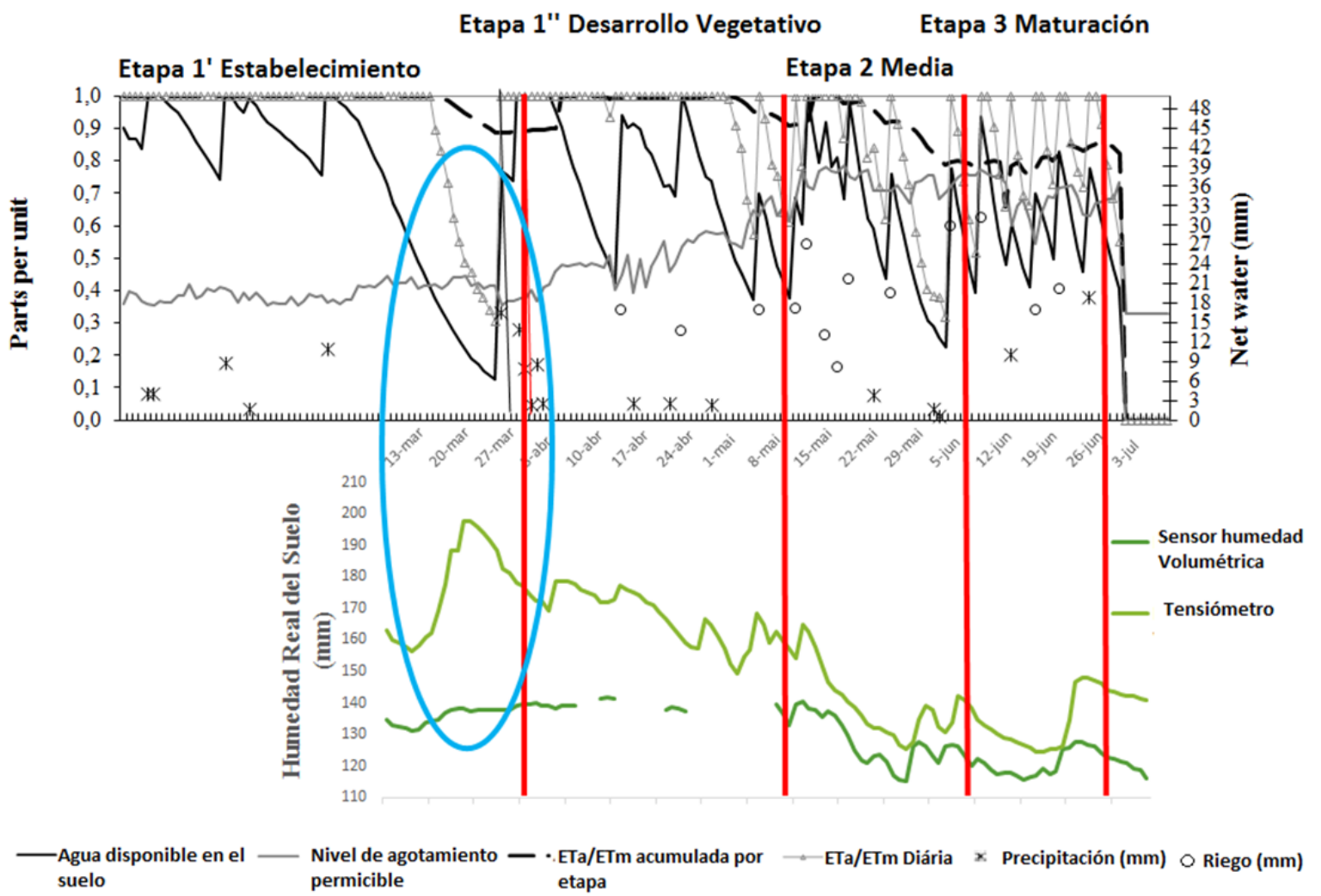

Figura 2. Comparación entre la curva de humedad del MOPECO y la curva de humedad de los sensores de suelo. 
En la parte superior de la Figura 2 se representa la evolución del agua en el suelo simulada por el modelo y en la inferior, la registrada por los sensores. En el periodo de días remarcados por el óvalo azul se presenta una diferencia significativa entre las tendencias de ambos métodos. Mientras la simulación indicaba que en las primeras etapas podría haber estrés, los sensores indicaban una elevada humedad del suelo. Esto puede ser debido a las condiciones climáticas (aparición de rocío) que podría estar aportando un agua que no ha sido considerada por el modelo para el cálculo del balance, y/o a que los valores de $\mathrm{Kc}$ utilizados, procedentes de la bibliografía, podrían estar sobrestimados para esta variedad.

Así, la lámina de riego necesaria para satisfacer las necesidades máximas del cultivo estimada en base a las condiciones medias, se redujo de $3400 \mathrm{~m}^{3} / \mathrm{ha}$ a $2550 \mathrm{~m}^{3} / \mathrm{ha}$. Por otro lado, la aplicación de un menor nivel de déficit hídrico al previsto durante las dos primeras etapas, debido a una menor necesidad de riego, redujo la diferencia de rendimiento entre los tratamientos (Tabla 2). En este caso, no aparecieron diferencias significativas entre tratamientos cercanos (T80 y T70), pero sí entre los más alejados (T100 y T70).

Tabla 2. Rendimientos simulados y reales para el cultivo del ajo en el año 2015.

\begin{tabular}{|c|c|c|c|c|c|c|}
\hline \multirow{2}{*}{$\begin{array}{c}\text { Agua } \\
\text { neta } \\
\left.\text { ( } \mathrm{m}^{3} / \mathrm{ha}\right)\end{array}$} & \multirow[b]{2}{*}{ TRATAMIENTO } & \multicolumn{4}{|c|}{ Rendimiento } & \multirow{2}{*}{$\begin{array}{c}\text { Diferencia } \\
\text { Rendimiento } \\
\text { Real-Simulado } \\
\text { (kg/ha) }\end{array}$} \\
\hline & & $\begin{array}{c}\text { SIMULADO } \\
(\mathrm{kg} / \mathrm{ha})\end{array}$ & $\begin{array}{l}\text { REAL } \\
(\mathrm{kg} / \mathrm{ha})\end{array}$ & DV & CV & \\
\hline 3787 & T100 & 10366,2 & 10000 & 314,8 & 3,3 & $-366,2$ \\
\hline 3131 & T90 & 8724,1 & 8900 & 580,0 & 6,5 & 175,9 \\
\hline 3046 & T80 & 8410,3 & 8500 & 691,3 & 7,9 & 89,7 \\
\hline 2844 & T70 & 7892,2 & 8480 & 439,8 & 4,9 & 587,8 \\
\hline
\end{tabular}

El rendimiento en todos los tratamientos se aproxima a los valores medios de producción de la zona, que es de $8500 \mathrm{~kg} / \mathrm{ha}$ (MAGRAMA, 2016), superándolo en todos los casos excepto para el más restrictivo. La Figura 3 muestra los datos de la eficiencia del uso del agua de riego, donde se observa cómo los tratamientos más deficitarios, generan una mayor eficiencia en el uso del agua ( $\mathrm{kg}$ producidos por unidad de volumen de agua aplicada). Esto indica que el riego deficitario en el ajo puede ser apropiado para situaciones de baja disponibilidad hídrica, permitiendo aprovechar el agua que se ahorre para aplicarla a otros cultivos, o ampliar el área cultivada de ajo, creando la posibilidad de incrementar la rentabilidad total de la finca. 


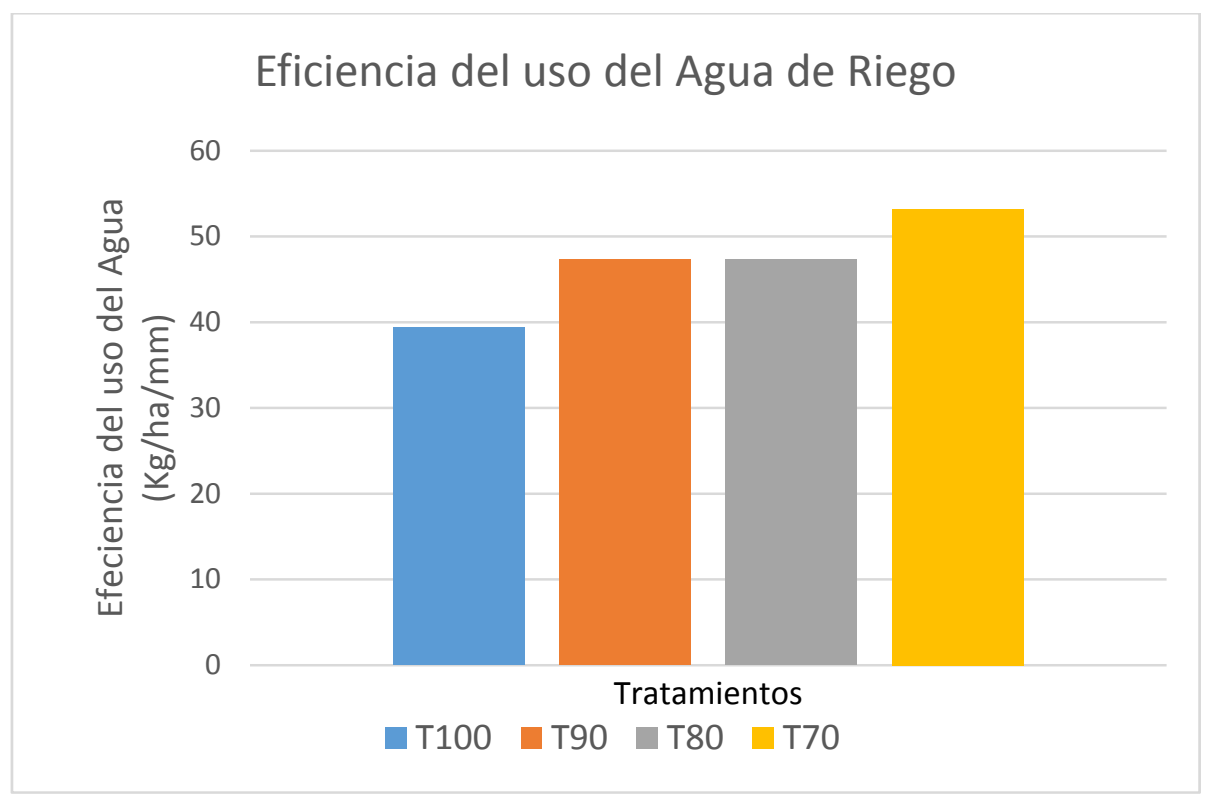

Figura 3. Eficiencia del uso del agua del riego en el cultivo de ajo e el año de 2015.

En el Ajo Morado, los parámetros cualitativos influyen directamente en el precio de venta. El color y el diámetro, son dos de los principales condicionantes de precio final. Para el año de 2015 los calibres de los ajos se encuentran en su gran mayoría en las categorías Flor (diámetro de $45-50 \mathrm{~mm}$ ) y Súper (diámetro de $50-55 \mathrm{~mm}$ ), que son las más demandadas comercialmente (Figura 4).

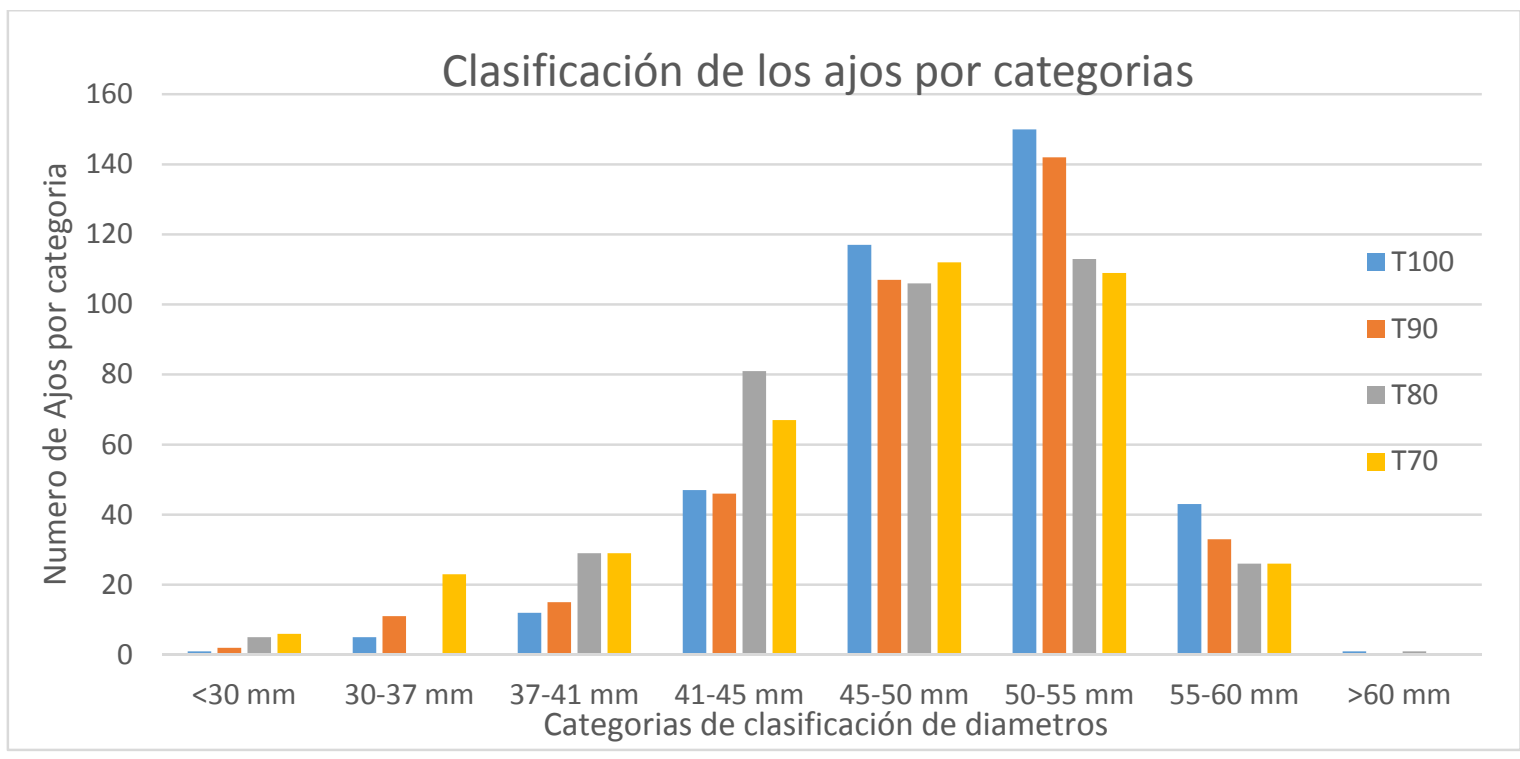

Figura 4. Clasificación de las cabezas de Ajo Morado según la categoría.

En la Tabla 3 se presenta el valor medio de los paramentos físicos (coordenadas cromáticas $\left(L^{*}, a^{*}, b^{*}\right)$, atributos cromáticos $\left(C^{*}, h^{*}\right)$ ) relacionados con el color. Para el análisis de colorimetría se compararon los distintos tratamientos y una muestra de un patrón de color considerado óptimo para la comercialización. No se detectaron diferencias significativas entre tratamientos, ni entre éstos y la muestra tomada como patrón. Todo ello indica que para los niveles de estrés hídrico generados, no hay una disminución de la calidad referida al color.

Tabla 3. Valores medios de los parámetros físicos de colorimetría para el Ajo Morado. 


\begin{tabular}{|c|c|c|c|c|c|}
\hline TRATAMIENTO & $\mathbf{L}^{*}$ & $\mathbf{a}^{*}$ & $\mathbf{b}^{*}$ & $\mathbf{C}^{*}$ & $\mathbf{h}^{*}$ \\
\hline T100 & $66,83^{\mathrm{a}}$ & $12,04^{\mathrm{a}}$ & $11,84^{\mathrm{a}}$ & $17,40^{\mathrm{a}}$ & $45,64^{\mathrm{a}}$ \\
\hline T90 & $63,11^{\mathrm{a}}$ & $13,74^{\mathrm{a}}$ & $11,43^{\mathrm{a}}$ & $18,30^{\mathrm{a}}$ & $40,32^{\mathrm{b}}$ \\
\hline T80 & $63,75^{\mathrm{a}}$ & $13,36^{\mathrm{a}}$ & $12,19^{\mathrm{a}}$ & $18,56^{\mathrm{a}}$ & $44,05^{\mathrm{a}}$ \\
\hline T70 & $64,46^{\mathrm{a}}$ & $13,38^{\mathrm{a}}$ & $12,88^{\mathrm{a}}$ & $18,96^{\mathrm{a}}$ & $44,72^{\mathrm{a}}$ \\
\hline Referencia & $63,11^{\mathrm{a}}$ & $13,74^{\mathrm{a}}$ & 11,43 & $18,30^{\mathrm{a}}$ & $40,32^{\mathrm{b}}$ \\
\hline
\end{tabular}
(Test de Duncan).

En cuanto a la textura, el tratamiento T100 presentó la media de resistencia a penetración más elevada, aunque no se encontraron diferencias significativas en relación a los demás tratamientos y la muestra de referencia facilitada por la empresa colaboradora. El valor medio para los sólidos solubles en todos los tratamientos fue de $39^{\circ} \mathrm{BRIX}$, superior al presentado como referencia por otros autores (PARDO et al., 2003) para otras variedades de ajo morado, con aproximadamente $28^{\circ} \mathrm{BRIX}$. El análisis de la variación de la masa durante el almacenaje se ha realizado durante un año a partir de la fecha de almacenamiento (21 de septiembre de 2015), por lo que todavía no hay datos concluyentes respecto a la influencia de los tratamientos.

Con los valores obtenidos en los muestreos, realizados periódicamente durante todo el ciclo de desarrollo del ajo, se calcularon los índices de área foliar (LAI) y biomasa. La evolución de los valores de LAl para las distintas fechas, fue similar en todos los tratamientos (Figura 5); con respecto a biomasa, el T100 presentó una ligera diferencia al final del ciclo (Figura 5).
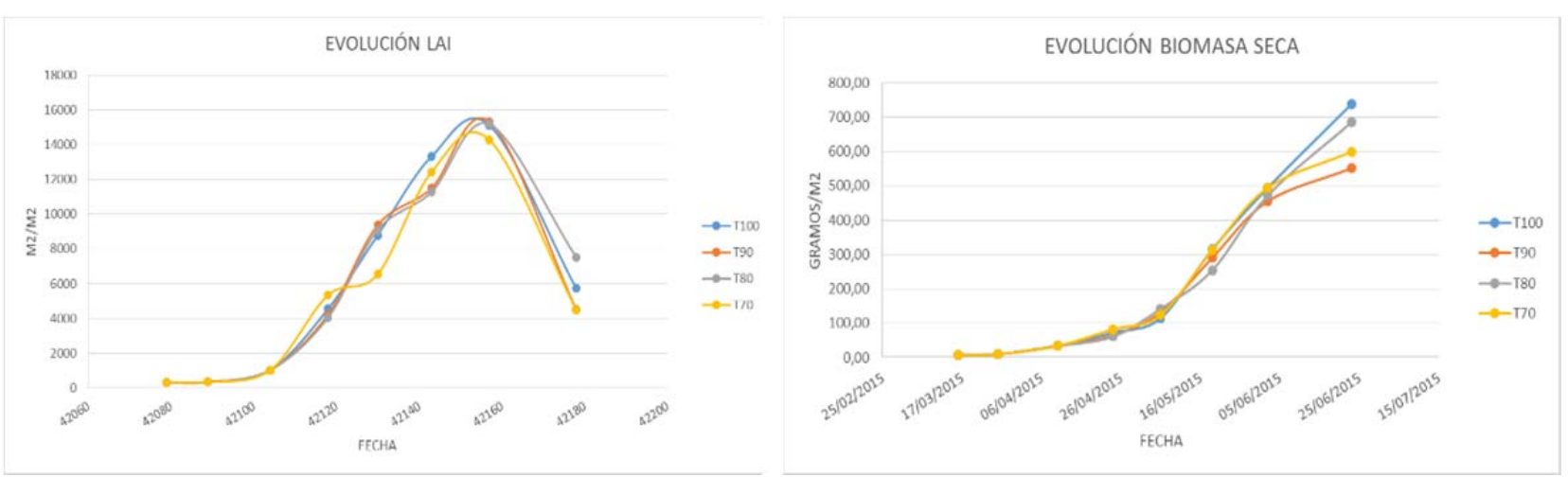

Figura 5. Evolución del área foliar (LAI) y de la biomasa seca del ajo para los diferentes niveles de agua de riego en el año 2015.

Al final de la segunda etapa de desarrollo, para disminuir el nivel de humedad del suelo, se redujo el volumen de riego, forzando la planta a consumir la reserva de agua disponible. Esto, generó en el cultivo los primeros síntomas de estrés, que fueron registrados por las lecturas del porómetro. Los valores más altos de resistencia estomática se dieron en todos los tratamientos el día 8 de mayo (Figura 6). 


\section{EVOLUCIÓN RESISTENCIA ESTOMÁTICA AJO 2015}

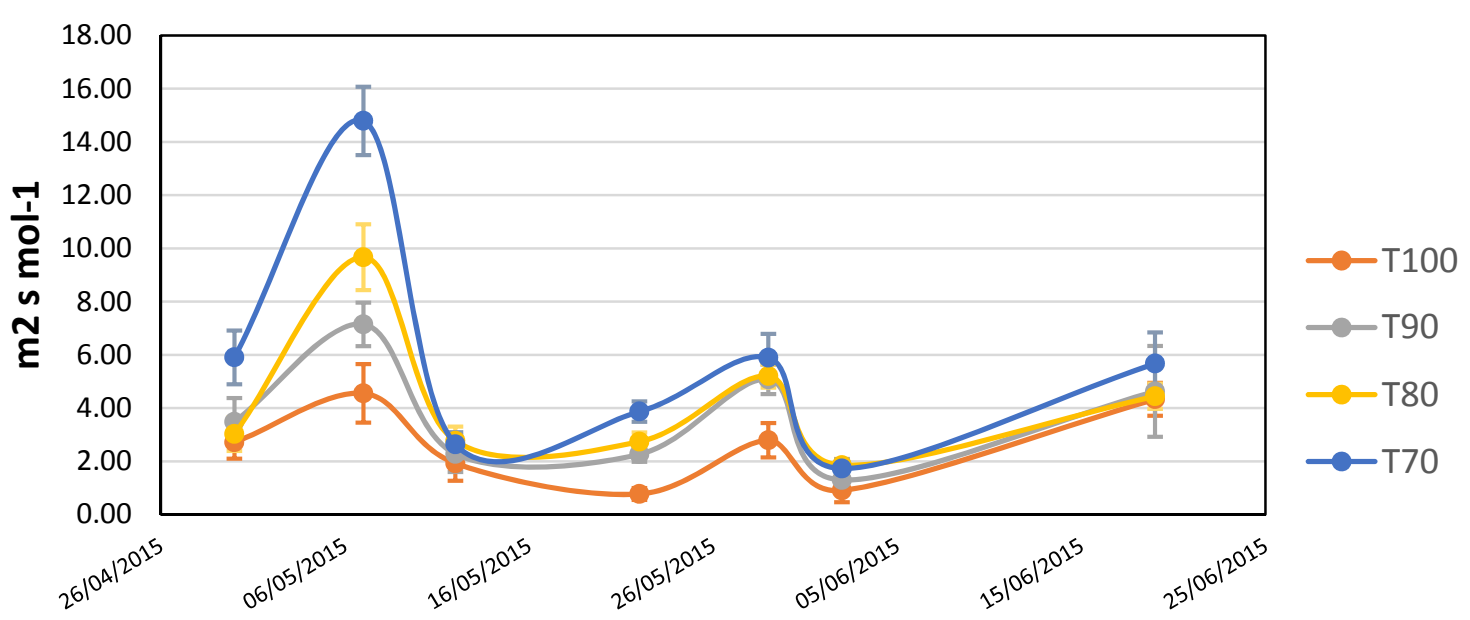

Fecha

Figura 6. Evolución de la resistencia estomática en el cultivo del ajo en el año de 2015.

El T70 fue el tratamiento que presentó el valor de resistencia estomática más elevado durante todo el ciclo, aunque la dificultad que ello conlleva para realizar los intercambios gaseosos y consecuentemente la fotosíntesis, no derivó en pérdidas significativas en la asimilación de carbono y el crecimiento vegetativo, tal como fue descrito anteriormente.

\section{4- Conclusiones y recomendaciones}

La metodología empleada logró un nivel adecuado, tanto en lo referido a los rendimientos como a la calidad de la cosecha en todos los tratamientos. Esto fue debido en parte a que las necesidades del ajo en la zona son inferiores a las inicialmente previstas, especialmente durante la fase de establecimiento e inicio del desarrollo vegetativo. Es interesante realizar un seguimiento de la evolución en los valores de rocío en la zona, que permitan ajustar los kc para la variedad de Ajo Morado de la Pedroñeras.

\section{5- Bibliografía}

Domínguez, A., de Juan, J.A., Tarjuelo, J.M., Martínez, R.S., Martínez-Romero, A., 2012.Determination of optimal regulated deficit irrigation strategies for maize in a semi-arid environment. Agric.Water Manage. 110, 67-77

Domínguez, A., Martínez-Romero, A., Leite, K.N., Tarjuelo, J.M., de Juan, J.A., López-Urrea, R., 2013. Combination of typical meteorological year with regulated deficit irrigation to improve the profitability of garlic in central Spain. Agric.Water Manage. 130, 154-167.

Fabeiro Cortés, C.,Martín de Santa Olalla, F., López Urrea, R., 2003. Production of garlic (Allium sativum L.) under controlled deficit irrigation in a semi-arid climate. Agric.Water Manage. 59, 155-167. 
FAO, 2016. Food and Agricultural Commodities Production. Food and Agriculture Organization of the United Nations, www.fao.org (Consulta 31.03.16)

López-Mata, E., Tarjuelo,J.M., de Juan, J.A., Ballesteros, R.,Domínguez, A., 2010. Effect of irrigation uniformity on the profitability of crops. Agric. Water Manage. 98, 190-198.

López-Urrea, R., López, H., López, P., Fabeiro, C., Martín de Santa Olalla, F.J., 2002. Ensayo de riego deficitario controlado en ajo morado. In: Anuario Técnico ITAP 2001. Instituto Técnico Agronómico Provincial,www.itap.es/ITAPPublicaciones/4Publicaciones/Publicaciones.asp (Consulta 31 de Marzo 2016).

López-Urrea, R., López, H., López, P., Fabeiro, C., Martín de Santa Olalla, F.J., 2003. Ensayo de riego deficitario controlado en ajo morado. In: Anuario Técnico ITAP 2002. Instituto Técnico Agronómico Provincial, www.itap.es/ITAPPublicaciones/4Publicaciones/Publicaciones.asp (Consulta 31 de Marzo 2016).

MAGRAMA, 2016. Anuario de estadística $2014 . \quad$ Avance: http://www.magrama.gob.es/estadistica/pags/anuario/2014-avance/AE 2014 13.pdf; Ministerio de Agricultura, Alimentación y Medio Ambiente, Consulta 31 de marzo 2016.

Ortega, J.F., de Juan, J.A., Tarjuelo, J.M., 2005. Improving water management: the Irrigation Advisory Service of Castilla-La Mancha (Spain). Agric.Water Manage. 77 (1), 37-58.

Pardo, J.E., González, M.E., Escribano, J., Granell, J.D., Alvarruiz, A. 2003. Evaluación de la calidad de variedades seleccionadas de ajo I.Parámetros físico-químicos. Alimentaria. Diciembre 03, 121-125. 


\title{
B-03
}

\section{EFECTOS DE LOS REGADÍOS DEL DELTA DEL EBRO SOBRE LA CALIDAD DE SUS MASAS DE AGUA ASOCIADAS}

\author{
Martínez Beltrán, J.
}

Centro de Estudios Hidrográficos del CEDEX, Paseo Bajo de la Virgen del Puerto 3, 28005 Madrid, julian.martinezbeltran@cedex.es

\section{Resumen}

El delta, situado al final del valle inferior del Ebro, tiene un área de aproximadamente 32.533 ha. El agua derivada en el azud de Xerta a los canales de la derecha e izquierda del Ebro riega 22.123 ha en el delta, de las que unas 21.400 ha son arrozales.

El clima es de tipo mediterráneo con carácter marítimo-fluvial, con una precipitación y una evapotranspiración anual media respectivamente de $526 \mathrm{~mm}$ y $1.016 \mathrm{~mm}$. El delta es la llanura de inundación del Ebro sobre un medio marino. Los suelos son arenosos en las planicies litorales y aluviales de profundidad y textura variables en el resto. Tiene asociadas varias masas de agua superficial y un acuífero superficial y otro profundo, ambos salinos.

Además de los dos canales, la red de riego consta de acequias primarias, secundarias y terciarias que conducen por gravedad el agua hasta las tomas de las fincas. Una red abierta de desagües, primarios y secundarios y de circunvalación de las lagunas, conduce los retornos de riego y el exceso de agua de lluvia a estaciones de bombeo y compuertas basculantes que los evacuan al mar, a las dos bahías y al propio Ebro y su brazo de Migjorn.

El balance de sales, estimado a partir del de agua, está equilibrado en el conjunto de la campaña de riego. La salinidad de las tierras regadas está controlada mediante el riego y drenaje de los arrozales. La cuña de agua salina de la desembocadura del Ebro apenas aporta sales a las tierras adyacentes del Ebro.

La dotación media anual de un arrozal (unos $23.300 \mathrm{~m}^{3} / \mathrm{ha}$ ) es necesaria para el consumo del arroz y para controlar la salinidad del agua de los arrozales. Aproximadamente la mitad del agua de riego aplicada se convierte en agua de drenaje superficial.

El aporte de agua de drenaje con sales y nitratos al Ebro a las lagunas interiores y al acuífero superficial no es relevante. La masa de sales procedente de las tierras regadas va a las dos bahías y al mar abierto. El arroz consume una porción muy significativa de los nitratos aplicados con el agua de riego. Sin arroz la masa de nitratos que llegaría al mar sería mayor que la aportada actualmente.

\section{Introducción}

La agricultura de regadío tiene un efecto socioeconómico importante e incluso impactos ambientales favorables, pero detrae agua de una masa superficial o subterránea y evacua agua de drenaje a otras masas. EI CEDEX ha estudiado los efectos del regadío en la detracción de agua y sobre la calidad del agua de las masas asociadas a una zona regable. En los últimos 5 años, por encomienda de la Dirección General del Agua (DGA), del Ministerio de Agricultura, Alimentación y Medio Ambiente, mediante un estudio metodológico aplicado a tres zonas regables de España, una de ellas la zona regada en el delta por el Canal de la Derecha del Ebro. Posteriormente, por encargo de la Confederación Hidrográfica del Ebro ( $\mathrm{CHE}$ ), ha estudiado en todo el delta la salinidad de suelos y aguas porque allí es un problema permanente.

Esos estudios han caracterizado los regadíos del delta para posteriormente analizar los efectos del riego y drenaje sobre las masas de agua asociadas, en lo que concierne a 
salinidad y nitratos, y han propuesto opciones para asegurar la sostenibilidad actual de su agricultura de regadío. A partir de balances de agua, los estudios estimaron la masa de sales evacuada por 4 cuencas de drenaje del delta a las bahías, durante los años hidrológicos del 2011-2012 al 2013-2014 y parte del 2014-2015. También la masa de nitratos evacuada en el hemidelta derecho en los años hidrológicos 2011-2012 y 2012-2013. Distinguen los balances tres períodos del año hidrológico: las campañas de riego (abriloctubre) y de medidas ambientales (octubre-enero); y febrero-abril sin aportes de agua de canal. Esas cuencas son las que tienen datos de caudal de drenaje $(Q)$, nitratos $\left(\mathrm{NO}_{3}\right)$ y conductividad eléctrica $(C E)$ de la Red de Indicadores Ambientales del Delta del Ebro (RIADE) de la CHE. Este artículo sintetiza los resultados de esos dos estudios.

\section{Características climáticas y edáficas del delta del Ebro}

El delta está situado al final del valle inferior del Ebro, en la provincia de Tarragona. Tiene una superficie de aproximadamente 32.533 ha: 20.165 ha en el hemidelta derecho y 12.368 ha en el izquierdo.

El clima es de tipo mediterráneo condicionado por su carácter marítimo-fluvial y por la orientación del valle inferior del Ebro. Las zonas costeras del delta tienen unas temperaturas mínimas algo más altas que en la parte alta junto al río y unas máximas algo menores. También la humedad relativa es más alta en la costa que en el interior. En Amposta, la precipitación media anual durante el período 1992-2013 fue $526 \mathrm{~mm}$, con cierta variabilidad interanual (322 mm en 2009 y $691 \mathrm{~mm}$ en 1995). Junio y julio, y en menor medida agosto, son los meses menos lluviosos. Las precipitaciones más intensas se dan en otoño, con 125 $\mathrm{mm}$ en un día para un periodo de retorno de 10 años (IRYDA, 1982). Los vientos de componente NW y $\mathrm{N}$ alcanzan una velocidad en la cabecera del delta mayor que en sus zonas costeras. Los de levante ocasionan temporales que elevan el nivel del mar hasta $1 \mathrm{~m}$. La evapotranspiración de referencia $\left(E T_{0}\right)$ anual, media de tres estaciones, fue $1.016 \mathrm{~mm}$ durante el período 2012-2104.

Las tierras del delta están situadas en la llanura de inundación del Ebro formada sobre un medio marino. Las llanuras deltaicas comienzan en ambos bancos del río y terminan en depresiones en torno a lagunas interiores. Están diseccionadas por dos antiguos cauces que partían del Ebro, uno por la derecha y otro por la izquierda. Próximas a las líneas de costa hay planicies litorales, claramente diferenciadas de la formación fluvial. Tramos bajos de varios abanicos aluviales y estrechas franjas de origen coluvial forman el límite con las tierras altas adyacentes. El espesor de los depósitos fluviales decrece paulatinamente en dirección al mar, a medida que las arenas de origen marino van siendo más superficiales. La arena marina tienen un espesor de hasta unos $10 \mathrm{~m}$ junto a las costas. La cota sobre el nivel del mar varía entre 3 y $2 \mathrm{~m}$ en los bancos del río, de 2 a $1 \mathrm{~m}$ en las llanuras y menos de $1 \mathrm{~m}$ en las depresiones y planicies litorales.

Los suelos de los bancos del Ebro son aluviales, profundos y estratificados, de textura franca pero sus subsuelos son poco permeables y la arena no aparece a menos de $2 \mathrm{~m}$ de profundidad. Los de los de los antiguos cauces son profundos y de textura fina. Los de las llanuras deltaicas son de textura fina con subsuelos de arena y arenas francas a profundidad variable, desde más de $1 \mathrm{~m}$ en las partes más altas hasta menos de $0,5 \mathrm{~m}$ en las más bajas. Los de las depresiones son de textura fina superficialmente con arena marina a aproximadamente $1 \mathrm{~m}$ y los de las planicies litorales son uniformemente arenosos. Hay suelos con horizontes de turba debidos al hidromorfismo asociado a manantiales de agua subterránea (ullales).

\section{Masas de agua superficial}

El Ebro y su brazo de Migjorn, lagunas interiores (La Encañizada y La Tancada en el hemidelta derecho, La Estrella en el izquierdo y Los Calaixos en la isla de Buda son las mayores), las bahías (El Fangar y Los Alfaques) y el mar abierto son masas de agua superficial asociadas al delta y receptoras de agua de drenaje (Figura 1). 


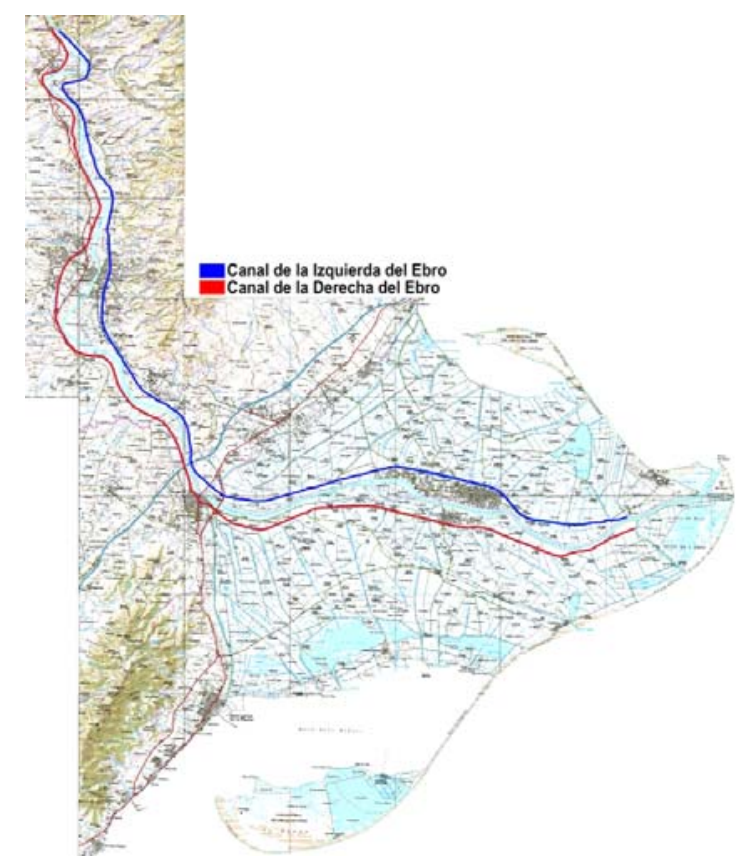

Figura 1. Canales de la derecha y de la izquierda del Ebro y sus zonas dominadas respectivas. Masas de agua superficial asociadas al delta (DGA/CEDEX, 2013)

El Ebro a su vez aporta el agua de riego, que tiene una concentración media de solidos disueltos totales (SDT) de $0,68 \mathrm{~g} / \mathrm{L}$ y un $\mathrm{pH}$ de 8 . Los aniones predominantes son sulfatos, bicarbonatos y cloruros; los cationes calcio y sodio y en menor medida magnesio. La CE media mensual varía desde $0,76 \mathrm{dS} / \mathrm{m}$ en mayo a $1,26 \mathrm{dS} / \mathrm{m}$ en octubre y progresivamente disminuye en otoño-invierno. La media en los últimos 12 años fue 0,98 dS/m. En el tramo final del Ebro la CHE (2010) determinó en 2009 y 2010 cambios de la CE del agua desde $3 \mathrm{dS} / \mathrm{m}$ a menos de $2-2,5 \mathrm{~m}$ a $57 \mathrm{dS} / \mathrm{m}$ a mayor profundidad, con una oscilación anual de $\pm 1,5 \mathrm{~m}$ en función del caudal y de la elevación del nivel del mar.

La salinidad del agua de las bahías varía a lo largo del año hidrológico. La CE del agua del estrato superior de la bahía Los Alfaques fue disminuyendo en julio de 2013 de 27 a $17 \mathrm{dS} / \mathrm{m}$, manteniéndose en agosto-septiembre entre 10 y $20 \mathrm{dS} / \mathrm{m}$, con la del estrato inferior en el intervalo de 35-45 dS/m. Al comienzo del año 2013-2014 la CE del agua del estrato superior era $53 \mathrm{dS} / \mathrm{m}$ y la del inferior $57 \mathrm{dS} / \mathrm{m}$, manteniéndose así durante el período sin riego de 2014, excepto en episodios con lluvias, durante los cuales bajó hasta 35-40 $\mathrm{dS} / \mathrm{m}$ y a $45-50 \mathrm{dS} / \mathrm{m}$ respectivamente. En la bahía de El Fangar también es ligeramente más salina la del estrato inferior que en el superior. Durante la campaña de riego de 2014 descendió ligeramente en mayo hasta $40-45 \mathrm{dS} / \mathrm{m}$ en el estrato superior y $45-50 \mathrm{dS} / \mathrm{m}$ en el inferior, para subir en ambos a 45-50 dS/m en julio. También aumentó en otoño, en el estrato inferior especialmente, con valores comprendidos entre 55 y $65 \mathrm{dS} / \mathrm{m}$.

En las campañas de riego de 2012 a 2014, la CE del agua de La Encañizada varió entre 30 y $35 \mathrm{dS} / \mathrm{m}$, pero en dos años (2012 y 2013) bajó en agosto hasta unos $15 \mathrm{dS} / \mathrm{m}$ de media. En septiembre y en ausencia de lluvias (2013 y 2014) subió a 50-55 dS/m, similar al del agua de Los Alfaques en esa época. Precipitaciones de otoño ocasionan descensos significativos, como ocurrió en noviembre y diciembre de 2014 (5-10 dS/m). Durante períodos sin lluvias de 2013 y 2014 la CE del agua se mantuvo entre 45 y $50 \mathrm{dS} / \mathrm{m}$, pero durante cortos episodios de lluvias bajó hasta 30-35 dS/m.

\section{Masas de agua subterránea}

Hay dos acuíferos, uno superficial y otro profundo. El primero es detrítico y se extiende desde los bancos del Ebro hasta las líneas de costa. Está constituido por 
sedimentos aluviales sobre arena marina. En el hemidelta derecho limita con el acuífero carbonatado adyacente y en el izquierdo con los acuíferos superficiales de los abanicos aluviales. Tiene un espesor variable entre unos $10 \mathrm{~m}$ en los bancos y en las líneas de costa, y unos $5 \mathrm{~m}$ en las depresiones. Es libre excepto en los bancos y en las depresiones donde está semiconfinado por sedimentos de textura fina de menor permeabilidad que los de textura gruesa subyacentes. El límite inferior de este acuífero es un acuitardo, de espesor creciente desde el borde oeste del delta al mar, constituido por arcillas y limos saturados de agua salina en un medio reductor muy poco permeable.

El nivel freático está en la superficie del terreno por el riego de los arrozales y por la inundación de los campos con fines ambientales. Sin lluvias significativas de febrero a abril, desciende hasta casi $1 \mathrm{~m}$. Mientras se riega, el agua más superficial del acuífero es poco salina $(C E<5 \mathrm{dS} / \mathrm{m})$ y flota por su menor densidad sobre un agua salobre de entre 5 y 20 $\mathrm{dS} / \mathrm{m}$. Por debajo, tiene una de CE de 50-60 dS/m similar a la de mar. En las depresiones las aguas más profundas son salmueras de más de $80 \mathrm{dS} / \mathrm{m}$. Sin aportaciones a los campos queda el agua salobre en la parte superior del acuífero (DGA/CEDEX, 2013).

El plano de isohipsas (INC/Hydrotechnic, 1966) muestra flujo de los bancos a las depresiones de ambos hemideltas a través de las llanuras deltaicas, con un gradiente hidráulico del 0,2 al 1 por mil y también de los bancos al Ebro. Puede haber ocasionalmente gradiente del río a las tierras adyacentes durante crecidas, pero este flujo no es significativo debido a la baja permeabilidad del acuífero en los bancos, con valores de transmisividad hidráulica de 0,12 a 2,7 $\mathrm{m}^{2} / \mathrm{d}$ (CHE/IGME, 2014). Sin bancos, hay flujo del río al acuífero con un gradiente de 0,5 a 0,7 por mil. En las llanuras litorales hay flujo directo al mar o a las dos bahías con un gradiente de 0,2-0,5 por mil.

Por debajo del acuitardo existe un acuífero profundo confinado de espesor variable no conectado hidráulicamente con el superior. En el borde occidental del hemidelta derecho sí existe conexión con el acuífero carbonatado de la sierra de Montsiá, originando ullales cuya agua tiene una CE entre 1,6 y 2,2 dS/m (DGA/CEDEX, 2013).

\section{Redes de riego y de drenaje}

El agua del Ebro derivada en el azud de Xerta al canal de la derecha riega 12.715 ha en el delta y la derivada al canal de la izquierda 9.408 ha. Ambos canales riegan antes el valle inferior. En el delta discurren por la parte más alta de ambos bancos del río dominando las tierras cultivadas por lo que el riego es por gravedad. La Figura 1 muestra el trazado de los dos canales y de las acequias principales que de ellos derivan. Los dos canales son operados y mantenidos respectivamente por la Comunidad General de Regantes del Canal de la Derecha del Ebro (CGRCDE) desde 1970 y por la Comunidad de Regantes-Sindicato Agrícola del Ebro (CR-SAE) desde 1967. Ambas tienen concesiones anuales de agua de la $\mathrm{CHE}$, con caudales máximos de riego de unos $23 \mathrm{~m}^{3} / \mathrm{s}$ y $20 \mathrm{~m}^{3} / \mathrm{s}$ respectivamente.

El sistema de riego consta de una red de acequias primarias, derivadas de los dos canales, secundarias y terciarias que distribuyen el agua con un caudal continuo nominal $\left(q_{i}\right)$ de $1,84 \mathrm{ss}^{-1} \mathrm{ha}^{-1}$ en el hemidelta derecho y de $1,9 \mathrm{Is}^{-1} \mathrm{ha}^{-1}$ en el izquierdo. Las comunidades llenan los canales a mitad de abril y reducen progresivamente el caudal hasta alcanzar entre el 75 y el 80 por ciento del nominal al terminar la campaña de riego. Los regantes aplican el agua a los arrozales a partir de tomas de las acequias de finca. Solamente, de mayo a julio, interrumpen el riego para tratamientos y fertilización del arroz durante dos o tres episodios con un total de unos diez días. La dotación media anual para el riego de las variedades más cultivadas de arroz de ciclo largo es de unos $23.300 \mathrm{~m}^{3} / \mathrm{ha}$ (DGA/CEDEX, 2013).

La red de desagües, primarios y secundarios, es de zanjas abiertas con talud protegido por vegetación natural. Los primarios van a favor de la pendiente natural desde las tierras más altas hasta las estructuras de evacuación del agua de drenaje. Tienen capacidad para almacenar y conducir el exceso de agua de lluvia en 4 días durante las labores de recolección en septiembre-octubre, con una escorrentía de $31,2 \mathrm{~mm} / \mathrm{d}$ equivalente a un caudal de drenaje $\left(q_{d r}\right)$ máximo $3,61 \mathrm{Is}^{-1} \mathrm{ha}^{-1}$. Los desagües de circunvalación de las lagunas 
están dotados de compuertas que generalmente están cerradas, pero se abren cuando el nivel de agua en esas lagunas está por debajo del de los desagües.

Con objeto de evacuar el exceso de agua de lluvia y de riego de los arrozales, los regantes refinan los bancales, nivelados a cero, para eliminar cualquier depresión y evacuan el agua superficial al desagüe de último orden a través de una arqueta y una tubería de forma que no se erosione su talud. Sistemas de drenaje subterráneo, con drenes laterales y colectores de tubería, solamente hay en dos grandes fincas del hemidelta derecho. El caudal de drenaje subterráneo es elevado desde cubetas de bombeo a un emisario que desagua por gravedad.

El exceso de agua de lluvia se evacúa mediante 9 estaciones de bombeo con tornillos de Arquímedes y de 7 casetas con bombas de aspiración vertical, todas ellas situadas a lo largo de las líneas de costa con excepción de una estación del hemidelta izquierdo que está situada junto al Ebro. También durante la campaña de riego para rebajar el nivel del agua en la red de desagües, con objeto de facilitar el drenaje superficial en momentos críticos, como son los de tratamientos, fertilización y preparación del terreno para la recolección del arroz. Los retornos de riego, que originan menores caudales, se evacuan principalmente por gravedad a través de compuertas basculantes. Las tierras situadas entre los dos canales principales y el Ebro drenan por gravedad al río a través de bocanas. El agua del final de los primarios llega a las estaciones de evacuación mediante canales de aproximación.

En el hemidelta derecho hay 4 bombas de realimentación que pueden elevar el agua de drenaje y verterla en la red de riego. Estas bombas entran en operación si la CE del agua de drenaje es menor de $2 \mathrm{dS} / \mathrm{m}$, de forma que la del agua resultante tenga de 1,5 a 1,6 $\mathrm{dS} / \mathrm{m}$ de $C E$.

\section{Agricultura de regadío}

El arroz es el cultivo principal del delta por ser la única opción en la mayor parte de sus tierras, que carecen de drenaje natural y solamente disponen de sistemas de drenaje superficial. Durante 2014 los agricultores cultivaron arroz en aproximadamente 12.600 ha en el hemidelta derecho y 8.800 ha en el izquierdo, unas 21.400 ha en total (97 por ciento del área total cultivada). Cultivan variedades de arroz de ciclo largo (180 días) y menos de ciclo corto (140 días). La Tabla 1 describe la duración de las fases de cultivo de las de ciclo largo.

\begin{tabular}{|l|l|c|}
\hline Fases & Fecha & $\begin{array}{c}\text { Número } \\
\text { de días }\end{array}$ \\
\hline Siembra, germinación y fase de plántula & 15 abril a 17 mayo & 32 \\
\hline Crecimiento y ahijado & 18 mayo a 24 julio & 68 \\
\hline Espigado y formación del grano & 25 julio a 25 agosto & 32 \\
\hline Maduración hasta la recolección & 26 agosto a 12 octubre & 48 \\
\hline
\end{tabular}

Tabla 1.Duración de las fases de cultivo de variedades de arroz de ciclo largo (CGRCDE)

Las máximas necesidades de agua las tiene el arroz al final de la fase de crecimiento y comienzo de la de espigado, con un consumo potencial de 5,7 a $6,1 \mathrm{~mm} / \mathrm{d}$ según zonas. Entonces los regantes mantienen una altura de lámina de agua de 15 a $18 \mathrm{~cm}$. Durante la maduración disminuye el consumo (DGA/CEDEX, 2013).

Cultivan también hortalizas y frutales en las tierras más altas de los dos bancos del Ebro y en los bordes occidentales del delta que tienen drenaje natural. En las dos fincas que disponen de sistemas de drenaje subterráneo además del arroz han cultivado hortalizas y actualmente césped para campos deportivos.

\section{Balances de agua}

En la campaña de riego consideran las entradas de agua de lluvia y de riego y las salidas por consumo de agua del arroz y por drenaje superficial de los arrozales. En la de medidas ambientales también la evaporación de la lámina de agua. No contemplan 
filtraciones del Ebro, por estar protegidas las tierras regadas de esas cuencas por las de los dos bancos del río. Tampoco filtraciones de las lagunas interiores, captadas por los desagües de circunvalación y conducidas a las estaciones de evacuación, ni aportes de los ullales. Sin aportes de agua de canal durante episodios sin lluvias significativas que den lugar a percolación puede haber elevación capilar de agua. La diferencia entre las entradas y salidas es el cambio del contenido de agua de cada cuenca $(\Delta W)$, que incluye las variaciones en el nivel de agua en los desagües y las de la lámina de agua en los arrozales. Al estar saturados de agua los campos no hay variación del contenido de humedad en la zona radicular del arroz.

Los balances de los arrozales, expresados en altura de lámina de agua en $\mathrm{mm}$, parten de los caudales $q_{i}$ y de los coeficientes $q_{d r}$, determinados con los caudales $Q$ aforados en las estaciones de salida del agua. Consideran la superficie efectivamente cultivada y regada de arroz en cada cuenca y no su superficie total, porque el drenaje en estas campañas procede mayoritariamente de los retornos de agua de riego, con excepción de algunos cortos períodos con lluvias suficientes para producir escorrentía superficial en los arrozales. También períodos de las series de datos RIADE en los que las diferencias entre los valores máximos y mínimos de $Q$ son más pequeñas. La Tabla 2 resume los resultados de los balances de agua en las campañas de riego de los años 2012-2015.

\begin{tabular}{|c|c|c|c|c|c|}
\hline Fase & $\begin{array}{l}\text { Campaña } \\
\text { de riego }\end{array}$ & $\begin{array}{l}\text { Cuenca } \\
\text { estación }\end{array}$ & $\begin{array}{c}q_{d r} \\
I s^{-1} h^{-1}\end{array}$ & $\begin{array}{c}\Delta W \\
\mathrm{~mm} / \mathrm{d}\end{array}$ & Observaciones \\
\hline \multirow{2}{*}{$\begin{array}{l}\text { Germinación y } \\
\text { emergencia }\end{array}$} & \multirow[t]{2}{*}{2015} & \multirow[t]{2}{*}{ EB7 } & 1,133 & 2,4 & Episodio de 3 días a final de abril \\
\hline & & & 1,642 & $-2,1$ & Episodio de 12 días de mayo \\
\hline \multirow{10}{*}{$\begin{array}{l}\text { Ahijado y } \\
\text { crecimiento }\end{array}$} & \multirow[t]{4}{*}{2013} & EB1 & 0,995 & $<2$ & Episodios varios de 25 días en total \\
\hline & & EB2 & 1,088 & $<2,3$ & $\begin{array}{l}\text { Episodios de } 17 \text { días en total durante las } \\
\text { campañas 2013-2014 }\end{array}$ \\
\hline & & \multirow[t]{2}{*}{ EB8 } & 1,406 & 0,91 & Períodos en las campañas 2013 y 2014 \\
\hline & & & 1,472 & & Episodios con precipitación \\
\hline & \multirow[t]{4}{*}{2014} & EB1 & 0,855 & 3,7 & Episodio de 13 días \\
\hline & & EB2 & $1,7-2,2$ & & Episodios cortos \\
\hline & & EB7 & 1,099 & 1,1 & Episodio de 9 días \\
\hline & & & 1,472 & $-0,1$ & 2 episodios de 28 días con precipitación \\
\hline & \multirow[t]{2}{*}{2015} & \multirow[t]{2}{*}{ EB7 } & 0,655 & 5,8 & Período de 16 días \\
\hline & & & 1,267 & 0,2 & Período de 17 días \\
\hline \multirow{6}{*}{$\begin{array}{l}\text { Espigado y } \\
\text { formación del } \\
\text { grano }\end{array}$} & \multirow[t]{3}{*}{2013} & EB1 & 0,783 & $<4$ & $\begin{array}{l}\text { Varios episodios de } 28 \text { días durante las } \\
\text { campañas } 2012-2014\end{array}$ \\
\hline & & EB2 & 1,127 & $<1$ & Periodo de 9 días \\
\hline & & EB8 & 1,951 & & Período de 24 días \\
\hline & \multirow[t]{3}{*}{2014} & \multirow[t]{2}{*}{ EB7 } & 0,804 & 4,4 & 2 episodios de 16 días \\
\hline & & & 2,272 & $-5,3$ & 9 días con lluvias \\
\hline & & EB8 & 0,733 & & Período de 28 días \\
\hline \multirow[t]{11}{*}{$\begin{array}{l}\text { Maduración } \\
\text { del grano }\end{array}$} & \multirow[t]{2}{*}{2012} & \multirow[t]{2}{*}{ EB1 } & 1,579 & & $\begin{array}{l}\text { Período de } 29 \text { días en septiembre durante las } \\
\text { campañas } 2012-2013\end{array}$ \\
\hline & & & 0,865 & & Episodio de 6 días en octubre \\
\hline & \multirow[t]{3}{*}{2013} & \multirow[t]{3}{*}{ EB8 } & 1,914 & -4 & 11 días en agosto-septiembre \\
\hline & & & 1,407 & & 15 días en la $2^{\mathrm{a}}$ decena de septiembre \\
\hline & & & 0,819 & & 16 días en septiembre-octubre \\
\hline & \multirow[t]{6}{*}{2014} & \multirow[t]{2}{*}{ EB2 } & 2,800 & & Período de 12 días en agosto-septiembre \\
\hline & & & 2,400 & $-11,1$ & Período de la $2^{\mathrm{a}}$ decena de septiembre \\
\hline & & \multirow[t]{3}{*}{ EB7 } & 2,155 & $-7,5$ & Episodios de 23 días en agosto-septiembre \\
\hline & & & 1,325 & & 3 días en la $4^{\text {a }}$ semana de septiembre \\
\hline & & & 1,199 & & 6 días en la $1^{\text {a }}$ semana de octubre \\
\hline & & EB8 & 0,865 & & En agosto-septiembre \\
\hline
\end{tabular}

Tabla 2. Resultados de los balances de agua durante campañas de riego (CHE-CEDEX, 2016) 
La lámina de agua en los arrozales aumenta al comienzo de la campaña y disminuye al final. También hay variaciones durante períodos cortos de unos 5 días por aplicación de tratamientos. Durante períodos más estables de los niveles de agua en desagües y arrozales, las diferencias determinadas podrían deberse a que el consumo real del arroz es mayor que la $E T_{c}$ calculada, a que $q_{i}$ es menor que el nominal supuesto y a errores propios de las estimaciones de las cantidades de drenaje a partir de los aforos RIADE y de las superficies cultivadas de arroz. Los resultados indican que durante las dos fases del cultivo en las que la lámina de agua es más constante, la cantidad de agua consumida por el arroz es similar a la evacuada por drenaje para el control de la temperatura y de la salinidad de la lámina de agua de los arrozales.

En las campañas de medidas ambientales los balances consideran los caudales de agua de canal y las precipitaciones diarias. A falta de datos sobre la evaporación del agua $(E)$ de la lámina de los campos inundados toman la $E T_{0}$. La superficie de los campos inundados coincide con la de los arrozales en los años estudiados. Los caudales $q_{d r}$ durante las medidas ambientales varían en función de las precipitaciones, más probables en otoño que durante la campaña de riego. Esos caudales han sido menores en octubre mientras los campos vuelven a llenarse de agua tras la recolección del arroz. La Tabla 3 incluye los resultados durante los años 2012-2015 en las 4 cuencas estudiadas.

\begin{tabular}{|c|c|c|c|c|c|}
\hline Mes & $\begin{array}{c}\text { Campaña } \\
\text { de } \\
\text { medidas }\end{array}$ & $\begin{array}{l}\text { Cuenca } \\
\text { estación }\end{array}$ & $\begin{array}{l}\text { Q }_{d r} \\
\text { Is }^{-1} \mathbf{h}^{-1}\end{array}$ & $\begin{array}{c}\Delta W \\
\mathrm{~mm} / \mathrm{d}\end{array}$ & Observaciones \\
\hline \multirow[t]{4}{*}{ Octubre } & \multirow[t]{2}{*}{2013} & EB1 & 1,188 & $-0,8$ & Periodo de 9 días \\
\hline & & EB8 & 1,005 & 2,1 & Periodo de 15 días \\
\hline & \multirow[t]{2}{*}{2014} & EB7 & 1,760 & $-4,3$ & Periodo de 22 días con lluvias \\
\hline & & EB8 & 0,655 & 5,4 & $\begin{array}{l}2 \text { periodos de } 27 \text { días en total; el segundo hasta el } 4 \\
\text { de noviembre }\end{array}$ \\
\hline \multirow[t]{3}{*}{ Noviembre } & \multirow[t]{3}{*}{2014} & EB2 & 2,046 & $-7,0$ & 3 episodios de 8 días en total con lluvias previas \\
\hline & & EB7 & 1,988 & $-5,8$ & Periodo de 9 días con lluvia \\
\hline & & EB8 & 0,653 & 5,8 & 3 períodos de 19 días en total \\
\hline \multirow[t]{5}{*}{ Diciembre } & 2012 & EB1 & 0,986 & 2,0 & Episodio de 3 días durante la $1^{a}$ semana \\
\hline & \multirow[t]{4}{*}{2014} & \multirow[t]{3}{*}{ EB2 } & 3,979 & $-16,3$ & Episodios con lluvias previas en noviembre-diciembre \\
\hline & & & 1,453 & $-2,2$ & Episodio de 6 días en la $2^{\mathrm{a}}$ semana \\
\hline & & & 2,297 & $-6,8$ & Episodio de 6 días en la $3^{\text {a }}$ semana con lluvias previas \\
\hline & & EB8 & 0,070 & 11,0 & Período de 17 días hasta el 3 de enero de 2015 \\
\hline \multirow[t]{3}{*}{ Enero } & 2013 & EB1 & 1,633 & $-4,2$ & $2^{a}$ quincena de diciembre de 2012 y enero de 2013 \\
\hline & 2014 & EB2 & 1,352 & $-3,0$ & A final de mes \\
\hline & 2015 & EB8 & 0,095 & 10,7 & Período de 11 días \\
\hline
\end{tabular}

Tabla 3. Resultados de los balances de agua durante campañas de medidas ambientales (CHE-CEDEX, 2016)

Sin lluvias de octubre a diciembre, aproximadamente el 80 por ciento del agua del canal aportada a los campos anegados es evacuada por los sistemas de drenaje superficial. Episodios de lluvias en otoño aumentan significativamente el caudal $q_{d r}$ que supera al $q_{i}$. En enero aún sin lluvia, el caudal $q_{d r}$ es mayor que $q_{i}$ debido al desagüe progresivo de los campos al final de la campaña de medidas ambientales.

La Tabla 4 muestra los resultados en el período sin riego, entre primeros de febrero y mediados de abril, durante los años 2013-2015. Al inicio de este período, los caudales $q_{d r}$ se debieron al desagüe progresivo de los campos inundados hasta final de enero. Después de la segunda decena de febrero, esos caudales dependieron fundamentalmente de la escorrentía superficial del exceso de agua de lluvia. Pudo haber también una pequeña contribución del drenaje subterráneo hacia la red de desagües y de los retornos del riego de las huertas de los bancos que se riegan con agua del Ebro, así como de las situadas en las periferias occidentales de ambos hemideltas.

Pequeñas precipitaciones originan inmediatamente aumentos de los caudales de drenaje. Este hecho indica que el contenido de humedad de los campos tras las medidas ambientales es alto, próximo a capacidad de campo. Los suelos solamente pierden humedad por efecto de la $E$ de su superficie que en esa época (final del invierno y comienzo 
de la primavera) está libre de vegetación. El aumento del caudal $q_{d r}$ es inmediato al período con lluvias.

\begin{tabular}{|c|c|c|c|c|c|}
\hline Mes & $\begin{array}{c}\text { Campaña } \\
\text { de } \\
\text { medidas }\end{array}$ & $\begin{array}{l}\text { Cuenca } \\
\text { estación }\end{array}$ & $\mathrm{Is}^{-{ }^{-1} \mathrm{ha}^{-1}}$ & $\underset{\mathrm{mm} / \mathrm{d}}{\Delta W}$ & Observaciones \\
\hline \multirow[t]{8}{*}{ Febrero } & \multirow[t]{2}{*}{2013} & \multirow[t]{2}{*}{ EB1 } & 0,119 & $-2,5$ & $1^{\mathrm{a}}$ y $2^{\mathrm{a}}$ decena de febrero \\
\hline & & & 0,223 & $-2,8$ & $4^{\text {a }}$ semana de febrero con lluvia \\
\hline & \multirow[t]{4}{*}{2014} & EB7 & 0,007 & $-1,2$ & Período de 25 días \\
\hline & & EB8 & 0,129 & $-2,7$ & $1^{\mathrm{a}}$ quincena de febrero \\
\hline & & \multirow[t]{2}{*}{ EB2 } & 0,443 & $-4,4$ & $1^{\mathrm{a}}$ decena de febrero \\
\hline & & & 0,167 & $-2,4$ & $2^{a}$ decena de febrero \\
\hline & \multirow[t]{2}{*}{2015} & EB7 & 0,051 & $-2,4$ & $2^{\mathrm{a}}$ quincena de febrero \\
\hline & & EB8 & 0,016 & $-2,4$ & $2^{\mathrm{a}}$ quincena de febrero y $1^{\mathrm{a}}$ quincena de marzo \\
\hline \multirow[t]{5}{*}{ Marzo } & 2013 & EB1 & 0,372 & $-5,4$ & $2^{\mathrm{a}}$ semana de marzo con precipitación previa \\
\hline & \multirow[t]{3}{*}{2014} & EB7 & 0,040 & $-4,0$ & Período de 17 días \\
\hline & & EB8 & 0,050 & $-2,8$ & Período de 25 días \\
\hline & & EB1 & 0,278 & $-4,7$ & Período de 18 días \\
\hline & 2015 & EB8 & 0,031 & 8,7 & Episodio de 12 días con precipitación \\
\hline \multirow[t]{4}{*}{ Abril } & 2013 & EB1 & 0,505 & $-6,5$ & Final de marzo y comienzo de abril \\
\hline & & EB1 & 0,275 & $-3,8$ & Final de marzo y comienzo de abril \\
\hline & \multirow[t]{2}{*}{2015} & EB7 & 0,010 & $-3,4$ & Período de 16 días \\
\hline & & EB8 & 0,012 & $-3,5$ & $1^{\mathrm{a}}$ quincena de abril \\
\hline
\end{tabular}

Tabla 4. Resultados de los balances de agua durante períodos sin riego (CHE-CEDEX, 2016)

\section{Balances de sales}

Estos balances parten de los de agua teniendo en cuenta las concentraciones de sales respectivas de las entradas y salidas de agua en cada cuenca. Estas concentraciones han sido estimadas a partir de los datos de CE de las aguas, del Ebro en Xerta y de drenaje en las estructuras de su evacuación. Para transformar los datos de CE de RIADE en valores de $S D T$, se han utilizado los coeficientes SDT/CE deducidos de la correlación entre estos parámetros determinada con los resultados de los análisis completos disponibles.

Las entradas de sales en los arrozales de esas cuencas son las que aporta el agua de canal durante las campañas de riego del arroz y de medidas ambientales. También, desde febrero hasta la segunda quincena de abril, las que pudiera aportar el acuífero superficial por elevación capilar de agua durante episodios sin lluvia. No se han considerado aportaciones de sales desde el río Ebro por las razones expuestas anteriormente ni las que aporta la precipitación, porque la concentración de sales en el agua de lluvia es irrelevante comparada con la del agua de riego. Tampoco las aportadas con los fertilizantes por una razón similar. Las salidas de sales de los balances de las cuencas estudiadas incluyen solamente las evacuadas con el agua de drenaje sin tener en cuenta absorción alguna de sales por parte del arroz.

La Figura 2 muestra la variación de los $S D T$ en el agua de un arrozal durante la campaña de riego en las 4 cuencas de drenaje. Como indica algunas diferencias no es posible elaborar un balance medio de sales de las 4 cuencas. Sin embargo, la disminución del contendido de sales de los arrozales determinado en la última fase de cultivo (de 3 a 4 t/ha) es igual o superior a la cantidad de sales aportadas con el agua de riego durante la inundación de los campos y la fase de espigado y formación del grano del arroz, incluso si hay cierto aumento durante la fase de ahijado y crecimiento del arroz. Todo sin contar que durante la campaña de riego puede haber mayor evacuación de sales durante episodios de lluvias que ocasionan mayor cantidad de agua de drenaje superficial. Además, el balance de sales de la cuenca que desagua por la estación EB2 muestra que la cantidad de sales evacuadas es mayor que la de las aportadas con el agua de riego. Esto es un indicio de que en algunas cuencas podría haber eliminación de sales del acuífero superficial. Con el actual riego y drenaje de los arrozales el balance de sales es favorable y no existe riesgo de 
aumento de la salinidad a medio plazo, pero hay que estudiar si el incremento de la salinidad en el espigado y formación del grano del arroz influye en el rendimiento del cultivo.

a)

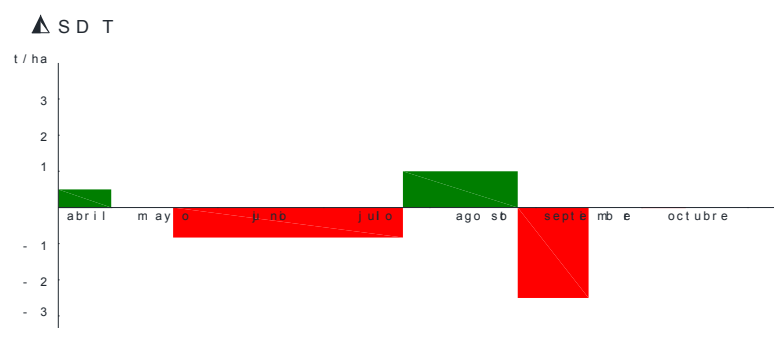

b)
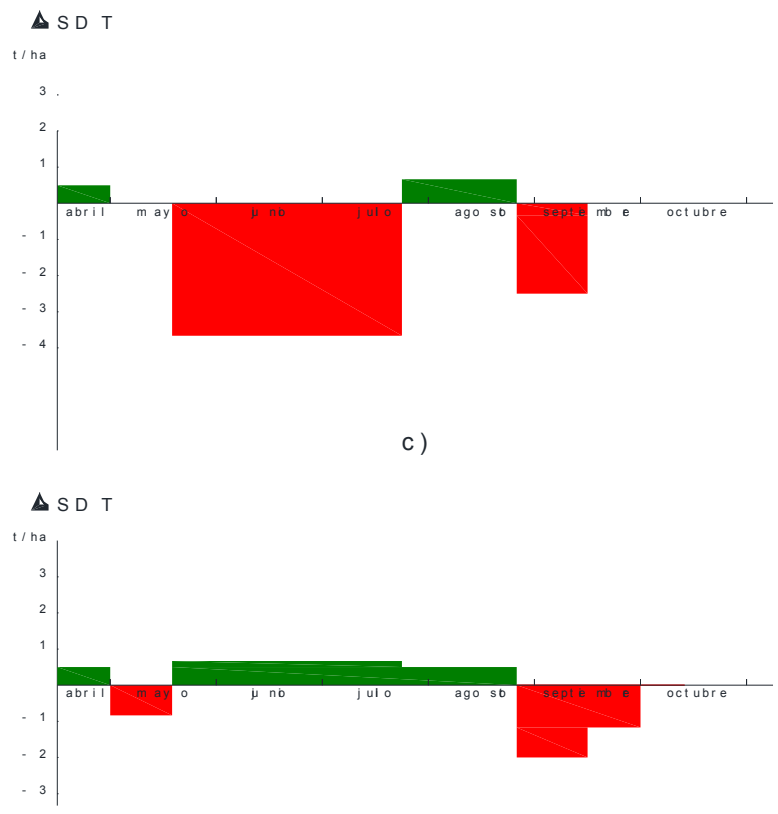

d)

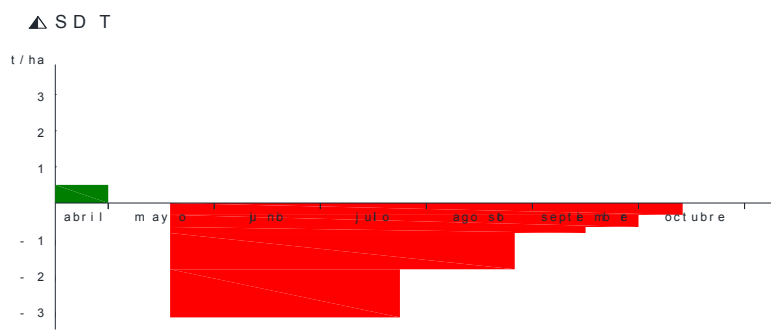

a)

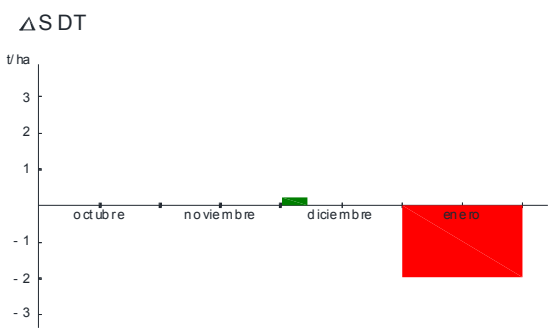

b)

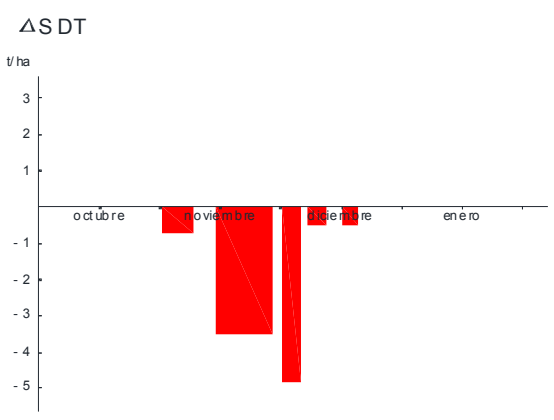

c)

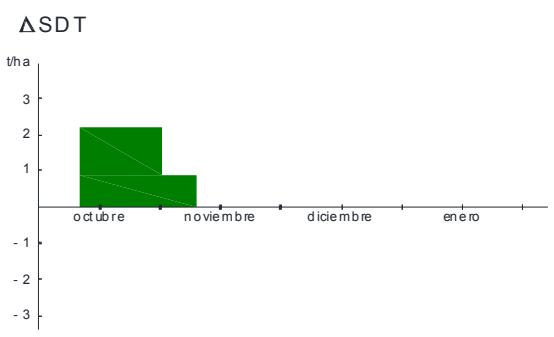

d)

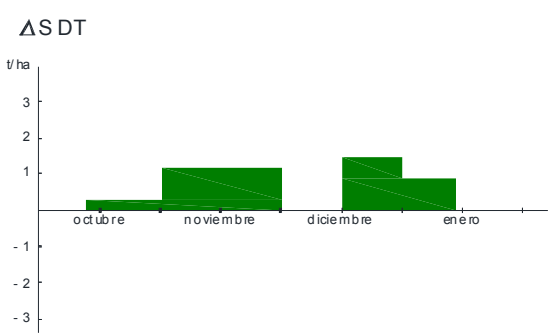

Figura 2. Esquema de la variación de los SDT en el agua de un campo en las cuencas de drenaje durante las campañas de riego y de medidas ambientales (CHE-CEDEX, 2016)

a) EB1; b) EB2; c) EB7; d) EB8

También la Figura 2 muestra la variación de los SDT en el agua de los campos inundados durante las campañas de medidas ambientales. Si se combinan los esquemas de las cuencas de las estaciones EB1, EB2 y EB7 puede obtenerse una idea del balance global durante esta parte del año hidrológico. Los balances están equilibrados porque las entradas y las salidas de sales son muy similares. En ausencia de lluvias aumenta la salinidad en octubre-noviembre al reponerse la lámina de agua de los campos y en 
diciembre-enero disminuye al irse rebajando esa lámina. En el conjunto del período octubreenero, las sales aportadas con el agua del canal son evacuadas a las bahías y al mar.

Son pocos los períodos estudiados de febrero a mitad de abril debido a la escasa coincidencia de datos disponibles de $Q$ y $C E$ del agua de drenaje, pero son suficientes para destacar tres procesos relevantes en lo que se refiere al control de la salinidad: la eliminación de sales con el agua remanente de la inundación de los campos en la campaña de medidas ambientales; la aportación de sales al suelo por elevación capilar de agua freática en períodos sin lluvia; y la eliminación de esas sales con el exceso de agua de lluvia drenada en períodos con precipitación.

\section{Balances de nitratos}

Los balances se basan en los de agua y en la concentración de $\mathrm{NO}_{3}$ del agua de riego y de drenaje. La primera es más constante que la segunda, aunque progresivamente decrece en la campaña de riego para aumentar también paulatinamente durante las medidas ambientales. La segunda disminuye gradualmente a lo largo de la campaña de riego alcanzando valores mínimos en agosto, siendo en ocasiones menor que la del agua de riego. Como un ejemplo, la Tabla 5 muestra los de una hectárea de arrozal en una de las cuencas de drenaje del hemidelta derecho durante dos campañas de riego.

\begin{tabular}{|c|c|c|c|c|c|c|c|c|c|}
\hline \multirow[b]{2}{*}{ Período } & \multirow{2}{*}{$\begin{array}{l}T \\
\mathrm{~d}\end{array}$} & \multicolumn{3}{|c|}{$\begin{array}{c}\text { Nitratos } \\
\text { aportados con el } \\
\text { agua de riego }\end{array}$} & \multicolumn{3}{|c|}{$\begin{array}{l}\text { Nitratos evacuados } \\
\text { con el agua de drenaje }\end{array}$} & \multirow{2}{*}{$\begin{array}{c}\Delta N \\
\mathrm{~kg} / \mathrm{ha}\end{array}$} & \multirow[t]{2}{*}{ Observaciones } \\
\hline & & $\begin{array}{l}\mathrm{NO}_{3 i} \\
\mathrm{mg} / \mathrm{l}\end{array}$ & $\begin{array}{c}\text { I } \\
\mathrm{m}^{3} / \mathrm{ha}\end{array}$ & \begin{tabular}{|c|} 
Nitrato \\
$\mathbf{s}$ \\
$\mathrm{kg} / \mathrm{ha}$
\end{tabular} & $\begin{array}{c}\mathrm{NO}_{3 d r} \\
\mathrm{mg} / \mathrm{l}\end{array}$ & $\begin{array}{c}D r \\
\mathrm{~m}^{3} / \mathrm{ha}\end{array}$ & $\begin{array}{c}\text { Nitratos } \\
\mathrm{kg} / \mathrm{ha}\end{array}$ & & \\
\hline 1 al 15 de mayo & 15 & 11,06 & 2.151 & 23,79 & 7,00 & 618 & 4,33 & 19,46 & $\begin{array}{l}\text { Llenado de arrozales con agua y } \\
\text { fase de plántula del arroz }\end{array}$ \\
\hline 26 al 31 de julio & 6 & 6,67 & 861 & 5,74 & 3,19 & 474 & 1,51 & 4,23 & Crecimiento y ahijado del arroz \\
\hline $\begin{array}{l}11 \text { al } 25 \text { de } \\
\text { septiembre }\end{array}$ & 15 & 5,90 & 1.788 & 10,55 & 8,29 & 2.215 & 18,36 & $-7,81$ & $\begin{array}{l}\text { Reducción de la lámina de agua } \\
\text { y maduración del arroz }\end{array}$ \\
\hline Totales 2012 & 36 & & 4.800 & 40,08 & & 3.307 & 24,20 & 15,88 & \\
\hline 8 al 15 de mayo & 8 & 8,59 & 1.251 & 10,75 & 8,25 & 885 & 7,30 & 3,44 & $\begin{array}{l}\text { Llenado de arrozales con agua y } \\
\text { fase de plántula del arroz }\end{array}$ \\
\hline 22 mayo-1de junio & 11 & 8,57 & 1.720 & 14,74 & 6,20 & 805 & 4,99 & 9,75 & Crecimiento y ahijado del arroz \\
\hline 20 al 30 de junio & 11 & 7,40 & 1.720 & 12,73 & 6,32 & 873 & 5,52 & 7,21 & Crecimiento y ahijado del arroz \\
\hline 1 al 14 de julio & 14 & 7,99 & 2.189 & 17,49 & 4,40 & 1.192 & 5,24 & 12,25 & Crecimiento y ahijado del arroz \\
\hline 16 al 28 de julio & 13 & 8,50 & 2.033 & 17,28 & 3,19 & 714 & 2,28 & 15,00 & Comienzo del espigado \\
\hline 11 al 22 de agosto & 12 & 7,93 & 1.877 & 14,88 & 2,23 & 680 & 1,52 & 13,37 & Espigado y formación de grano \\
\hline Totales 2013 & 69 & & 10.790 & 87,87 & & 5.149 & 26,85 & 61,02 & Totales \\
\hline \begin{tabular}{|l}
5 al 15 de \\
septiembre, 2013
\end{tabular} & 11 & 8,84 & 1.549 & 13,69 & - & 1.741 & - & - & $\begin{array}{l}\text { Vaciado de agua y maduración } \\
\text { del arroz }\end{array}$ \\
\hline
\end{tabular}

Tabla 5. Balances de nitratos en una hectárea de arrozal de la cuenca de drenaje EB1 durante las campañas de riego de 2012 y 2013 (DGA/CEDEX, 2013)

El contenido de $\mathrm{NO}_{3}$ de la lámina del arrozal aumenta al llenarlos de agua. A lo largo de la campaña de riego buena parte de los $\mathrm{NO}_{3}$ aportados con el agua de riego es consumida por el arroz, progresivamente del 50 al 85 por ciento durante el crecimiento y ahijado y hasta el 90 por ciento en el espigado y formación de grano. Durante el desagüe de los arrozales para la recolección, parte de los $\mathrm{NO}_{3}$ acumulados son evacuados con el agua de drenaje, pero en menor cuantía que los aportados al inicio de la campaña.

Durante la campaña de medidas ambientales del año hidrológico 2012/2013, la concentración del agua del canal fue mayor que durante la de riego. La Tabla 6 muestra los balances de $\mathrm{NO}_{3}$ en una hectárea de campo inundado en la cuenca de drenaje EB1. 


\begin{tabular}{|c|c|c|c|c|c|c|c|c|}
\hline \multirow[b]{2}{*}{ Período } & \multirow[b]{2}{*}{$\begin{array}{l}T \\
\mathrm{~d}\end{array}$} & \multicolumn{3}{|c|}{$\begin{array}{l}\text { Nitratos aportados } \\
\text { con el agua de riego }\end{array}$} & \multicolumn{3}{|c|}{$\begin{array}{l}\text { Nitratos evacuados con } \\
\text { el agua de drenaje }\end{array}$} & \multirow[b]{2}{*}{$\begin{array}{c}\Delta N \\
\mathrm{~kg} / \mathrm{ha}\end{array}$} \\
\hline & & $\begin{array}{l}\mathrm{NO}_{3 i} \\
\mathrm{mg} / \mathrm{l}\end{array}$ & \begin{tabular}{|c|}
$I$ \\
$\mathrm{~m}^{3} / \mathrm{ha}$
\end{tabular} & $\begin{array}{l}\text { Nitratos } \\
\mathrm{kg} / \mathrm{ha}\end{array}$ & $\begin{array}{c}\mathrm{NO}_{3 d r} \\
\mathrm{mg} / \mathrm{l}\end{array}$ & $\begin{array}{c}D r \\
\mathrm{~m}^{3} / \mathrm{ha}\end{array}$ & $\begin{array}{l}\text { Nitratos } \\
\mathrm{kg} / \mathrm{ha}\end{array}$ & \\
\hline $\begin{array}{l}25 \text { de noviembre a } 7 \\
\text { de diciembre, } 2012 \\
\end{array}$ & 13 & 13,95 & 1.651 & 23,03 & 29,63 & 411 & 12,18 & 10,85 \\
\hline $\begin{array}{l}8 \text { al } 13 \text { de diciembre, } \\
2012\end{array}$ & 6 & 14,06 & 762 & 10,71 & 25,18 & 447 & 11,26 & $-0,54$ \\
\hline $\begin{array}{l}14 \text { al } 31 \text { de diciembre, } \\
2012\end{array}$ & 18 & 13,39 & 2.286 & 30,61 & 19,55 & 2.460 & 48,09 & $-17,48$ \\
\hline 1 al 18 de enero, 2013 & 18 & 12,53 & 2.286 & 28,64 & 8,37 & 2.102 & 17,59 & 11,05 \\
\hline Totales & 55 & & 6.985 & 93,00 & & 5.420 & 89,12 & 3,88 \\
\hline
\end{tabular}

Tabla 6. Balances de nitratos en un campo inundado de la cuenca de drenaje EB1 durante las medidas ambientales del año 2012/2013 (DGA/CEDEX, 2013)

Las cifras de entradas y salidas de $\mathrm{NO}_{3}$ son similares. El campo no retiene $\mathrm{NO}_{3}$ porque no hay cultivo que los consuma.

\section{Efectos del riego de los arrozales sobre la calidad del agua}

La masa de sales y $\mathrm{NO}_{3}$ evacuadas al Ebro y a su brazo de Migjorn es mucho menor que la aportada al mar y a las bahías, porque el área que drena a esas masas de agua también lo es. La entrada de agua de drenaje con sales y $\mathrm{NO}_{3}$ a las lagunas es puntual y limitada a excesos de agua de lluvia con concentraciones bajas.

La masa aportada a las bahías y al mar no se puede cuantificar con precisión en su totalidad, por carecer de datos de $Q, S T D$ y $\mathrm{NO}_{3}$ en el agua de drenaje de todas las cuencas que vierten a esas masas. Sin embargo, adoptando valores medios de los $q_{d r}$ determinados en los balances de agua durante la campaña de riego puede estimarse que durante el crecimiento, ahijado y espigado hasta el inicio de la maduración del arroz, las cuencas con datos evacuaron a la bahía de Los Alfaques aproximadamente el 99,4 por ciento de las sales aportadas con el agua de riego. Quedan disueltas en la lámina de agua una pequeña cantidad de sales que todavía tienen los arrozales cuando el arroz ha formado ya su grano (Tabla 7). Asimismo, se vertieron a la bahía durante esas fases del cultivo del arroz el 27,8 por ciento de los $\mathrm{NO}_{3}$ aportados con el agua de riego. Durante la maduración del arroz, en la cuenca EB1 la masa de sales y $\mathrm{NO}_{3}$ evacuada superó a la importada con el agua de riego. Al reducirse la lámina de agua se reduce la masa de sales y $\mathrm{NO}_{3}$ disuelta en el volumen de agua de los arrozales.

Durante la campaña de medidas ambientales en la cuenca EB1 aproximadamente el 83 por ciento de las sales aportadas con el agua del canal fueron evacuadas y un 14 por ciento más de $\mathrm{NO}_{3}$ que los aportados con el agua de riego. El volumen de agua aportado a la bahía durante la campaña de riego, con una salinidad muy inferior a la del agua del mar, explica que la salinidad del agua del estrato superior de la bahía vaya disminuyendo progresivamente a lo largo de la campaña hasta alcanzar en septiembre valores muy inferiores a los de la $C E$ del agua del mar. El efecto sobre el estrato inferior es menor, aunque también hay cierto descenso de la CE del agua al final de la campaña.

Durante las medidas ambientales también las dos cuencas de drenaje aportan a la bahía agua de menor salinidad que el agua de mar, pero las tierras inundadas no retienen los $\mathrm{NO}_{3}$ disueltos en el agua de riego que reciben y son aportados a la bahía.

El riego de los arrozales y la inundación de los campos con agua del canal elevan el nivel freático hasta la superficie del terreno. El acuífero superficial no recibe sales del agua de canal, porque son evacuadas a las masas de agua superficial. Sin embargo, el riego sí produce cierta pérdida de sales del agua de este acuífero elevadas por capilaridad cuando la superficie del suelo se seca en períodos sin riego y en ausencia de lluvias significativas las sales son lavadas por el agua de riego y evacuadas al mar disueltas en el agua de 
drenaje. Tampoco hay aporte de $\mathrm{NO}_{3}$ a ese acuífero porque el arroz absorbe la mayor parte de los aplicados con el agua de riego además de los del abonado.

\begin{tabular}{|c|c|c|c|c|c|c|c|c|c|c|c|c|c|}
\hline \multirow[t]{2}{*}{ Período } & \multirow{2}{*}{$\begin{array}{l}\text { Fase del } \\
\text { arroz }\end{array}$} & \multicolumn{2}{|c|}{ Riego } & \multicolumn{2}{|c|}{$\begin{array}{c}\text { Sales } \\
\text { aportadas }\end{array}$} & \multicolumn{2}{|c|}{$\begin{array}{c}\text { Nitratos } \\
\text { aportados }\end{array}$} & \multicolumn{2}{|c|}{ Drenaje } & \multicolumn{2}{|c|}{$\begin{array}{c}\text { Sales } \\
\text { evacuadas }\end{array}$} & \multicolumn{2}{|c|}{$\begin{array}{c}\text { Nitratos } \\
\text { evacuados }\end{array}$} \\
\hline & & $\mathrm{m}^{3} / \mathrm{ha}$ & $\mathrm{hm}^{3}$ & t/ha & $10^{3} t$ & kg/ha & $t$ & $\mathrm{~m}^{3} / \mathrm{ha}$ & $\mathrm{hm}^{3}$ & t/ha & $10^{3} \mathrm{t}$ & kg/ha & $\mathbf{t}$ \\
\hline \multirow{3}{*}{$\begin{array}{l}1 \text { al } 17 \text { de } \\
\text { mayo } \\
17 \mathrm{~d}\end{array}$} & \multirow{3}{*}{ Plántula } & \multirow{3}{*}{2.556} & 6,43 & \multirow{3}{*}{1,81} & 4,57 & \multirow{3}{*}{26,07} & 65,59 & \multirow{3}{*}{1.087} & 2,73 & 1,46 & 3,66 & 8,08 & 20,32 \\
\hline & & & 7,27 & & 5,16 & & 74,11 & & 3,09 & - & - & - & - \\
\hline & & & 3,95 & & 2,80 & & 40,25 & & 1,68 & - & - & - & - \\
\hline \multirow{3}{*}{$\begin{array}{l}18 \text { mayo al } \\
24 \text { de julio } \\
68 \mathrm{~d}\end{array}$} & \multirow{3}{*}{$\begin{array}{l}\text { Crecimiento } \\
\text { y ahijado }\end{array}$} & \multirow{3}{*}{10.223} & 25,72 & \multirow{3}{*}{5,83} & 14,66 & \multirow{3}{*}{81,37} & 204,74 & 6.345 & 15,96 & 6,28 & 15,80 & 35,15 & 88,44 \\
\hline & & & 29,06 & & 16,57 & & 231,35 & 4.876 & 13,86 & 7,27 & 20,66 & 18,63 & 52,96 \\
\hline & & & 15,78 & & 9,00 & & 125,64 & 4.994 & 7,71 & - & - & - & - \\
\hline \multirow{3}{*}{$\begin{array}{l}25 \text { de julio } \\
\text { al } 25 \text { de } \\
\text { agosto } \\
32 \text { d }\end{array}$} & \multirow{3}{*}{ Espigado } & \multirow{3}{*}{4.811} & 12,10 & \multirow{3}{*}{2,98} & 7,50 & \multirow{3}{*}{38,15} & 95,98 & 1.769 & 4,45 & 1,88 & 4,72 & 5,59 & 14,07 \\
\hline & & & 13,68 & & 8,48 & & 108,46 & 2.488 & 7,07 & 2,02 & 5,73 & 7,86 & 22,35 \\
\hline & & & 7,43 & & 4,61 & & 58,90 & 2.129 & 3,29 & - & - & - & - \\
\hline \multirow{3}{*}{$\begin{array}{l}26 \text { de } \\
\text { agosto al } \\
15 \text { de } \\
\text { septiembre } \\
21 \mathrm{~d}\end{array}$} & \multirow{3}{*}{$\begin{array}{l}\text { Maduración } \\
\text { y desagüe } \\
\text { arrozales }\end{array}$} & \multirow{3}{*}{2.830} & 7,12 & \multirow{3}{*}{1,61} & 4,06 & \multirow{3}{*}{20,21} & 50,85 & \multirow{3}{*}{3.248} & 8,17 & - & - & - & - \\
\hline & & & 8,05 & & 4,59 & & 57,46 & & 9,23 & - & - & - & - \\
\hline & & & 4,37 & & 2,49 & & 31,20 & & 5,01 & - & - & - & - \\
\hline \multirow{3}{*}{$\begin{array}{l}16 \text { al } 30 \text { de } \\
\text { septiembre } \\
15 \mathrm{~d}\end{array}$} & \multirow{3}{*}{$\begin{array}{l}\text { Maduración } \\
\text { y desagüe } \\
\text { arrozales }\end{array}$} & & 3,39 & & 2,78 & & 25,16 & & 5,45 & 4,55 & 11,44 & 17,94 & 45,14 \\
\hline & & 1.348 & 3,83 & 1,11 & 3,14 & 10,00 & 28,43 & 2.164 & 6,15 & - & - & - & - \\
\hline & & & 2,08 & & 1,71 & & 15,44 & & 3,34 & - & - & - & - \\
\hline $\begin{array}{l}153 \text { d de } \\
\text { la } \\
\text { campaña } \\
\text { de riego }\end{array}$ & $\begin{array}{l}153 \mathrm{~d} \text { del } \\
\text { ciclo }(180 \mathrm{~d})\end{array}$ & 21.768 & 150,3 & 13,34 & 92,11 & 175,80 & $1.213,56$ & 14.083 & 97,21 & - & - & - & - \\
\hline $21 \mathrm{de}$ & & & 28,56 & & 27,14 & & 351,91 & & 21,33 & 8,98 & 22,60 & 159,35 & 400,91 \\
\hline $18 \mathrm{de}$ & $\begin{array}{l}\text { Medidas } \\
\text { ambientales }\end{array}$ & 11.353 & 32,28 & 10,79 & 30,66 & 139,87 & 397,65 & 8.476 & 24,10 & - & - & - & - \\
\hline $90 \mathrm{~d}$ & & & 17,53 & & 16,65 & & 215,96 & & 13,09 & - & - & - & - \\
\hline
\end{tabular}

Tabla 7. Volúmenes de agua y masas de sales y nitratos importados con el agua del canal y evacuados a la bahía de Los Alfaques durante las campañas de riego 2012 y 2013 y el período de medidas ambientales 2012/2013 (DGA/CEDEX, 2013)

\section{Conclusiones y recomendaciones}

La salinidad es un problema latente en el delta por ser inherente a su propia condición de llanura de inundación sobre un medio marino. Sin embargo, el riego y drenaje de los arrozales evita la salinización de los suelos y que la mayor parte del delta sea una marisma salobre. Para ello, es necesaria una dotación media anual de agua de unos $23.300 \mathrm{~m}^{3} / \mathrm{ha}$ para satisfacer, casi en partes iguales, el consumo de agua del arroz y controlar la salinidad y temperatura del agua de los arrozales.

Aproximadamente el 80 por ciento del agua de canal aportada a los campos para medidas ambientales en 4 cuencas de drenaje estudiadas es evacuada a las dos bahías, con las sales aportadas con el agua del Ebro e incluso eliminando más sales de los suelos. Períodos sin precipitación ni riego de febrero a abril son más críticos porque entonces el acuífero superficial aporta cierta cantidad de agua por capilaridad y sales a los suelos, pero durante episodios lluviosos pueden evacuarse parte de las sales acumuladas en el suelo en episodios previos sin precipitación.

El aporte de sales del río Ebro a las tierras adyacentes no es relevante, bien por no haber flujo de agua del río al acuífero superficial o por ser la salinidad del río baja en el caso de crecidas, porque entonces la cuña salina se desplaza hacia su desembocadura. 
El arroz consume buena parte de los nitratos proporcionados por el agua de riego, del 50 al 85 por ciento progresivamente en las primeras fases del ciclo del cultivo y hasta el 90 por ciento durante el espigado y maduración del grano. Sin arroz la masa de nitratos aportada al mar por el Ebro sería mayor que la actual.

No es relevante el aporte de agua de drenaje con sales y nitratos disueltos a las lagunas interiores del delta, porque están hidráulicamente aisladas de las tierras regadas por desagües de circunvalación. Solamente entra en esas lagunas agua de exceso de lluvia con baja concentración y agua de canal a petición de los pescadores. Tampoco lo es el aporte al acuífero superficial, más bien el riego y el drenaje eliminan progresivamente sales de este acuífero.

El agua aportada a las dos bahías durante la campaña de riego tiene una salinidad muy inferior a la del agua del mar. Por ello, la salinidad del agua del estrato superior de las bahías disminuye progresivamente a lo largo de la campaña.

Es imprescindible mantener agua dulce sobre el agua salina del acuífero superficial mediante la red de riego, el drenaje superficial de los arrozales, la red de desagües y las compuertas y estaciones de bombeo que evacuan el agua de drenaje, todos ellos actualmente operativos. También el riego de las tierras adyacentes al Ebro para evitar filtraciones de agua del río.

El control de la salinidad de la mayor parte de las tierras del delta obliga actualmente al cultivo permanente del arroz, con una dotación anual de agua más alta que en otros regadíos españoles donde la salinidad no es tan limitante como en el delta. El drenaje subterráneo de las tierras regadas facilita la diversificación de cultivos y un mejor control de la salinidad de los suelos con menos agua y la introducción de otros cultivos de regadío, manteniendo el arroz en la rotación. Esto contribuiría a disminuir las necesidades de agua de riego del delta y facilitaría el control integral de plagas.

\section{Agradecimientos}

A la DGA, a la CHE y al CEDEX por la oportunidad de llevar a cabo los dos estudios de referencia (2013 y 2016) y a las dos comunidades de regantes del delta del Ebro, que con la información proporcionada los hicieron factibles. A la CGRCDE por su invitación a exponer los resultados de estos estudios en sus jornadas técnicas anuales en Amposta.

\section{Referencias bibliográficas}

CHE. 2010. Estudio de la incidencia de la lengua salina de la desembocadura del río Ebro en el acuífero superficial del Delta. Confederación Hidrográfica del Ebro. Zaragoza.

CHE/IGME. 2014. Determinación de parámetros hidrogeológicos en el delta del Ebro. Confederación Hidrográfica del Ebro e Instituto Geológico y Minero de España. Informe técnico provisional. Zaragoza.

CHE/CEDEX. 2016. Estudio de la salinidad de suelos y aguas en las zonas regables del delta del Ebro mediante balances de agua y sales y propuestas de mejora. Confederación Hidrográfica del Ebro. Centro de Estudios y Experimentación de Obras Públicas, Madrid. DGA/CEDEX, 2013. Gestión sostenible del agua de riego en zonas de presiones significativas (detracción/contaminación) sobre masas de agua. Estudio de 3 zonas piloto (85.000 ha). Asistencia técnica, investigación y desarrollo tecnológico en materias de competencia de la Dirección General del Agua. Centro de Estudios y Experimentación de Obras Públicas, Madrid.

INC/Hydrotechnic. 1966. Proyecto de saneamiento y riegos del delta del Ebro. Informe tipo de reconocimiento de la viabilidad técnica y económica del drenaje del delta del Ebro y sustitución del cultivo del arroz por otros cultivos de regadío. Hydrotechnic Corporation S.A. Instituto Nacional de Colonización, Madrid.

IRYDA. 1982. Proyecto de estaciones de bombeo para la mejora del desagüe superficial del delta derecho del Ebro, Tarragona. Instituto Nacional de Reforma y Desarrollo Agrario, Ministerio de Agricultura, Pesca y Alimentación, Madrid. 


\title{
B-04
}

\section{SEGUIMIENTO DE LA EVOLUCIÓN DE LOS NIVELES DE SALINIDAD Y NITRATOS EN EL ACUÍFERO SUPERFICIAL DE ZAFARRAYA Y EN FINCAS DE HORTICOLAS AL AIRE LIBRE}

\author{
Alonso López, F., Contreras París, J.I., Cánovas Fernández, G., González Vizcaino, A.
}

Instituto de Investigación y Formación Agraria y Pesquera de Andalucía (IFAPA), Centro La Mojonera, Camino San Nicolás, n¹, 04745 La Mojonera, Almería.

f.alonso@juntadeandalucia.es

\section{Resumen}

La horticultura al aire libre del Llano de Zafarraya es el motor económico de la comarca. El riego de este sector se sustenta en el sistema acuífero del Polje de Zafarraya y Sierra Gorda. En estos acuíferos, como consecuencia de la explotación agrícola de la zona, se viene produciendo desde hace décadas sobreexplotación del recurso, con la consiguiente salinización y nitrificación. Los objetivos de este trabajo han sido estudiar los niveles de salinidad y nitratos de las aguas del acuífero de Zafarraya y hacer un seguimiento de la solución del suelo en explotaciones hortícolas de la zona, para poder realizar recomendaciones que permitan mejorar la gestión de la fertilización y evitar el aumento de la contaminación por nitratos. Los niveles de salinidad obtenidos a lo largo del periodo de estudio han sido estables y no representan problemas para los principales cultivos hortícolas de la zona. En lo que respecta a la concentración de nitratos, los resultados muestran niveles excesivos por encima de $300 \mathrm{mg} \mathrm{L}^{-1}$. Estos resultados son consecuencia de la práctica habitual de aplicaciones excesivas de fertilizantes nitrogenados. La recomendación inicial sería mantener una concentración de nitratos estable a lo largo del ciclo de cultivo para evitar acumulaciones en el suelo sobre todo al final del mismo.

\section{Introducción y objetivos}

El Llano de Zafarraya, está situado al suroeste de la provincia de Granada en el límite con la de Málaga. Su especial microclima y la fertilidad de su suelo, la convierten en una zona de intensa actividad agrícola. La superficie de cultivo de unas 2000 hectáreas, está dedicada mayoritariamente al cultivo de hortícolas al aire libre (tomate, alcachofa, lechuga, coliflor, judía, etc.). El riego de este sector se sustenta en el acuífero detrítico del Polje y en el acuífero carbonatado subyacente de Sierra Gorda (Cherif et al. 1995).

Como consecuencia de la explotación agrícola de esta zona, se viene provocando una fuerte contaminación por nitratos del sistema de acuíferos. Ya en el año 1995, Morell y colaboradores cifraban niveles máximos de nitratos de $400 \mathrm{mg} \mathrm{L}^{-1}$ en los pozos del acuífero del Polje y, a día de hoy, en determinadas épocas son superiores a esta cantidad.

A pesar de la sobreexplotación del acuífero y el empeoramiento de la calidad del agua, la aplicación del riego y los fertilizantes realizados en la zona se basan fundamentalmente en la experiencia del agricultor. Esto supone, en muchos casos, la aplicación de dosis de agua y nutrientes excesivos.

La Unión Europea publicó la directiva 96/6767CEE relativa a la protección de las aguas contra la contaminación causada por nitratos procedentes de fuentes agrarias, con el 
fin de proteger la salud humana, los recursos vivos y los ecosistemas acuáticos. Para tal fin, se estableció un límite máximo de $50 \mathrm{mg}$ de nitratos por litro. Con arreglo a este valor en aguas superficiales o subterráneas, se han establecido 24 zonas vulnerables a la contaminación por nitratos en Andalucía (decreto 36/2008, de 5 de febrero, de la Junta de Andalucía y órdenes posteriores). Sierra Gorda-Zafarraya constituyen la zona vulnerable número 20. Para estas zonas se establece un código de buenas prácticas agrícolas y un programa de actuación de obligado cumplimiento (Orden 18 noviembre de 2008, Junta de Andalucía).

En este contexto, los objetivos de este trabajo han sido estudiar la evolución de los niveles de salinidad y nitratos de las aguas del acuífero superficial de Zafarraya y hacer un seguimiento de la solución del suelo en explotaciones hortícolas de la zona, con el fin de realizar recomendaciones que permitan mejorar la gestión de la fertilización y evitar el aumento de la contaminación por nitratos.

\section{Materiales y métodos}

El Polje de Zafarraya es una depresión interna endorréica que ocupa una extensión aproximada de $28 \mathrm{Km}^{2}$ y una altura media de $900 \mathrm{~m}$ sobre el nivel del mar. Presenta un clima mediterráneo semicontinental de media montaña (Gómez-Zotano et al. 2015) y la precipitación media anual es de 950 mm (ITGE-JUNTA, 1998). El acuífero detrítico del Polje, es un acuífero libre que tiene unas dimensiones aproximadas de $22 \mathrm{Km}^{2}$ y un espesor máximo de $60 \mathrm{~m}$ (ITGE-JUNTA, 1998). Está constituido por materiales de relleno: conglomerados, arenas, limos y arcillas (Morell et al. 1995) y su principal recarga se produce por infiltración de la lluvia útil y en menor medida por infiltración de aguas de escorrentía externas al acuífero ("arroyo de la Madre").

Este acuífero está conectado al acuífero subyacente de Sierra Gorda que ocupa una extensión de $293 \mathrm{Km}^{2}$. Se considera como esencialmente libre, aunque confinado en los bordes norte y este, y bajo el Polje de Zafarraya. El drenaje natural del acuífero del Polje hacia este acuífero de Sierra Gorda se altera sensiblemente por los bombeos realizados en unos 400 pozos de gran radio y escasa penetración que captan el acuífero detrítico en su sector central (ITGE-JUNTA, 1998).

Para evaluar el nivel de salinidad y nitratos del acuífero del Polje se muestrearon un total de diez pozos superficiales y diez parcelas comerciales en las que estaban ubicados dichos pozos (Figura 1). Tres de las parcelas tenían cultivado tomate, otras tres alcachofa y las restantes lechuga. El estudio se llevó a cabo desde mayo de 2015, momento en el que comenzaba la campaña de estos cultivos, hasta marzo de 2016, incluyendo así en el periodo de seguimiento la época de baldío. La selección de las parcelas se hizo en función de su ubicación geográfica y del cultivo plantado. De esta manera se consiguió una distribución representativa por toda la zona de influencia del acuífero y tener repetidas distintas parcelas con un mismo cultivo (Figura 2). 


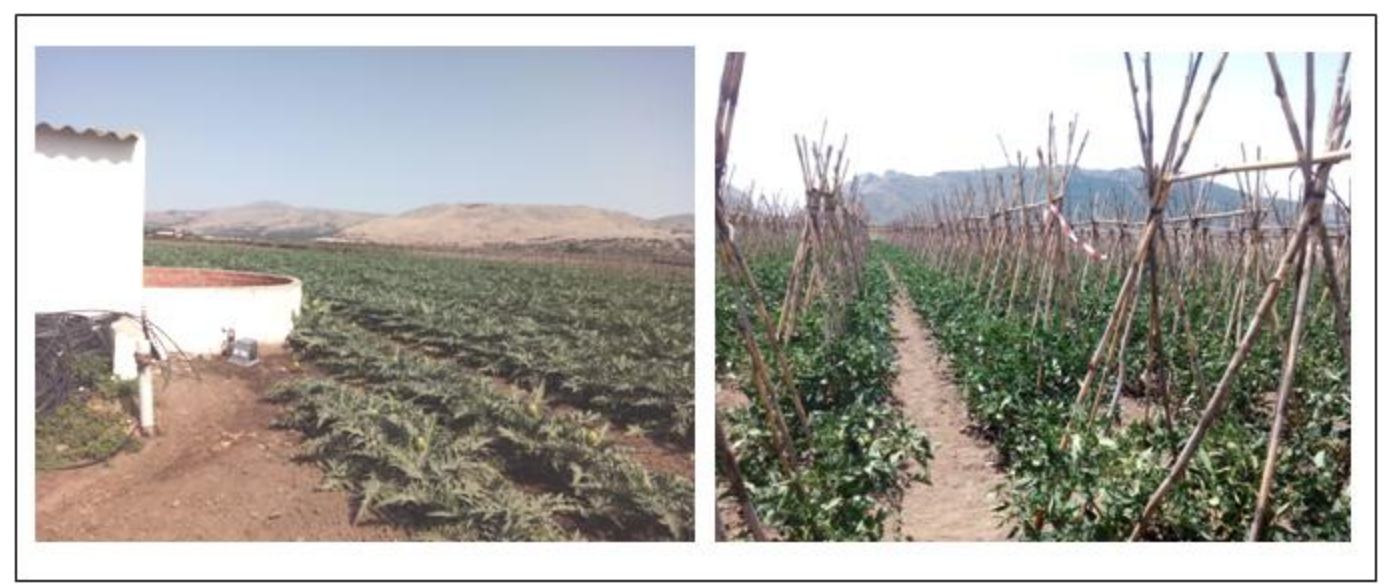

Figura 1. Vista de parcela experimental de alcachofa con pozo superficial (izq.). Detalle de parcela experimental de tomate (dcha.).

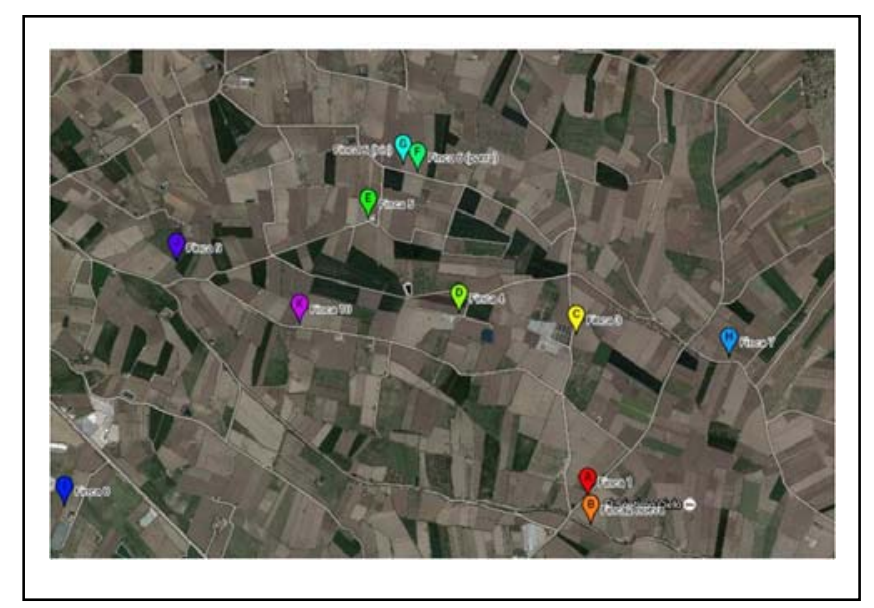

Figura 2. Distribución de las parcelas experimentales en el Llano de Zafarraya.

En cada parcela experimental se realizó un seguimiento de:

- La concentración de nitratos, [NO3-] $\left(\mathrm{mg} \mathrm{L}^{-1}\right)$, y la conductividad eléctrica (CE) $\left(\mathrm{dS} \mathrm{m}^{-1}\right.$ ) del agua del pozo superficial. Para la obtención de muestras se empleó una botella de recogida de agua en profundidad. Estas muestras se recogían a 5 $\mathrm{m}$ respecto a la lámina de agua (Figura 3 ).

- La concentración de nitratos, [NO3-] $\left(\mathrm{mmol} \mathrm{L}^{-1}\right)$, y la conductividad eléctrica en la solución del suelo $\left(C E_{S S}\right)\left(\mathrm{dS} \mathrm{m}^{-1}\right)$. Para la obtención de la solución del suelo se instalaron dos sondas de succión (Rhizon sampler SMS, Rhizosphere Research Products, NL-6700 AN Wageningen) en la zona radicular (Figura 3). 


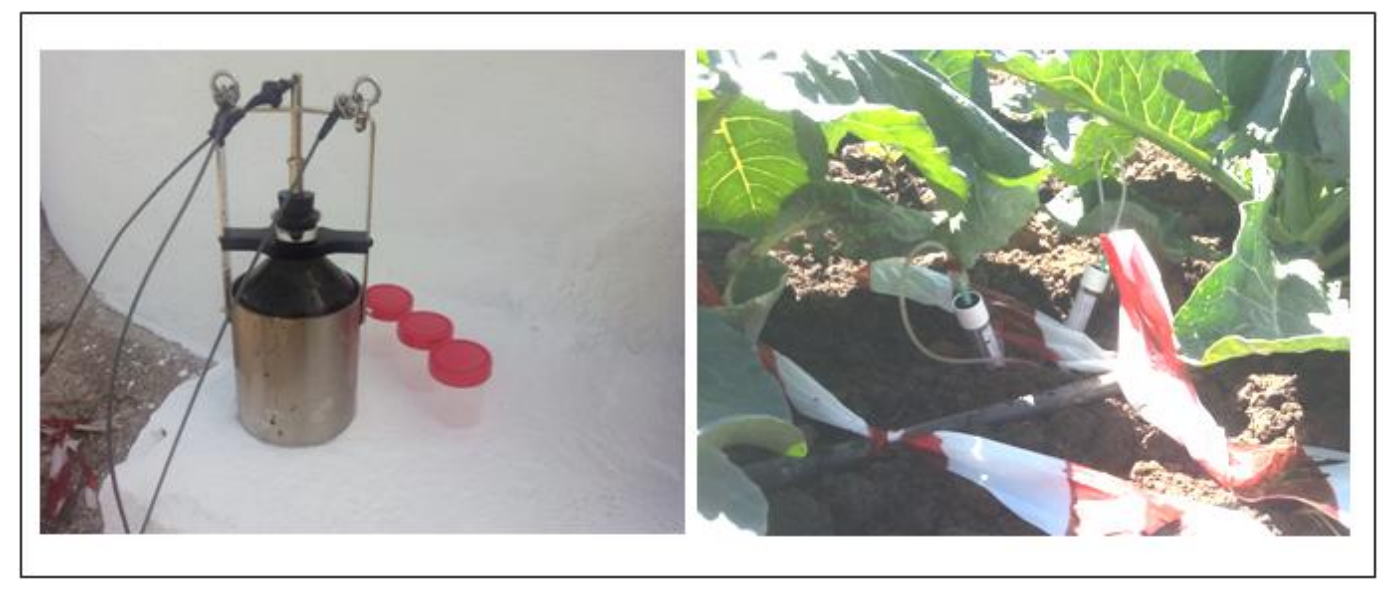

Figura 3. Botella para recogida de muestras de agua en profundidad (izq.).Sondas de succión tipo Rhizon instaladas en parcela experimental (drcha.).

Los análisis de [NO3-], se realizaron con el medidor de iones B-743 LAQUAtwin Compact Nitrate Meter (Horiba Co. Ltd., Japón). La CE con un conductímetro EC-Meter Basic 30+ (Crison Instruments). La periodicidad de los muestreos de las sondas de succión dependió del tipo de cultivo implantado y de la programación de los riegos de cada parcela experimental (semanal, quincenal, mensual). En el caso de los pozos el muestreo se realizó cada dos meses.

Destacar que el sistema de riego empleado en las parcelas de estudio es el riego localizado por goteo, comúnmente empleado en la zona. De manera generalizada la fertilización comienza con una aplicación previa en fondo de materia orgánica (estiércol) a razón de $0,5-0,7 \mathrm{~kg} \mathrm{~m}^{-2}$ o fertilizante organomineral peletizado (6-12-10) a una dosis de 0,3$0,4 \mathrm{~kg} \mathrm{~kg} \mathrm{~m}^{-2}$. Durante el ciclo de cultivo se realiza fertirrigación con fertilizantes sólidos solubles aplicados con tanques de fertilizante (abonadoras). Los equilibrios aplicados se deciden en función de la experiencia del agricultor o la recomendación del técnico asesor. Varían entre cultivos y ciclo y no se realiza un seguimiento en el suelo o el cultivo con el fin de corregir las recetas.

Los datos de pluviometría se obtuvieron de la estación meteorológica de Zafarraya (Latitud: 3659' 25” N, longitud: 040 09' 13" W, altitud: $903 \mathrm{~m}$ ).

\section{Resultados y discusión}

La conductividad eléctrica del agua de los pozos permaneció estable a lo largo de todo el periodo de muestreo (Figura 4). Los valores medios oscilaron entre 1,0 y $1,5 \mathrm{dS} \mathrm{m}^{-1}$. A pesar de la escasa variación se observa un descenso progresivo de la salinidad de manera que los niveles más elevados se obtuvieron entre mayo y julio y, a partir de este momento se observó un ligero y progresivo descenso de la CE hasta el mes de enero (Figura 4). Estos valores de CE no representan problemas para los principales cultivos hortícolas que se plantan en la zona.

En lo que respecta a la concentración de nitratos, los resultados muestran niveles excesivos que oscilan entre 300 y $375 \mathrm{~g} \mathrm{~L}^{-1}$ (Figura 4). Estos valores están un $86 \%$ por encima del umbral de $50 \mathrm{mg} \mathrm{L}^{-1}$ marcados por la directiva 96/6767CEE. La [NO3] no ha variado sustancialmente respecto a los observados por Morell et al. en 1995. Dichos autores obtienen valores máximos de $400 \mathrm{mg} \mathrm{L}^{-1}$. Aunque la situación de la [NO3] no parece haberse agravado, estos datos ponen en evidencia la ausencia de planes de actuación para realizar una mejor gestión del riego y la fertilización en la zona, a pesar de la existencia de 
tecnologías para conseguirlo (máquinas de fertirriego, tensiómetros, sondas de succión, etc.).

Cabe destacar que la evolución de la [NO3-] a lo largo del periodo de estudio muestra un considerable aumento de los niveles de nitratos a partir del mes de julio, que está directamente relacionado con la fertilización de los cultivos (Figura 4). El descenso que se observa a partir de septiembre coincide con la presencia de lluvias (Figuras 4 y 5 ). Por tanto, aquí se observa un efecto de dilución de los nitratos en el agua de los pozos. Este fenómeno de dilución hace que los valores de nitratos obtenidos en el último mes de muestreo, marzo, sean similares a los de partida del mes de mayo, momento en el que empieza la campaña de cultivos (Figura 4). Morell et al. (1995) observan igualmente este considerable aumento a partir del mes de julio, aunque en su caso no lo relacionan con la fertilización de los meses previos sino que lo asocian al intenso proceso de lavado consecuente al periodo de lluvias. A la vista de los datos de precipitaciones obtenidos para este periodo de estudio esta no parece ser la causa (Figura 5).
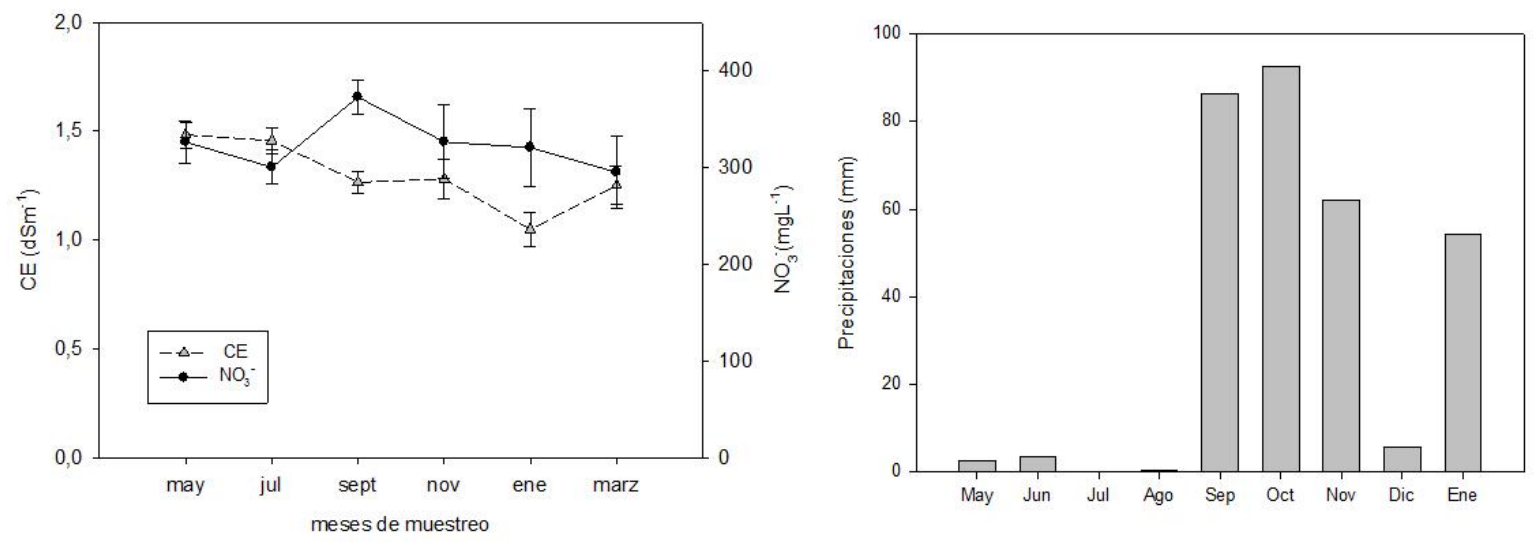

Figuras 4 y 5. Evolución de la concentración de nitratos [NO3-] y la conductividad eléctrica (CE) en los pozos del acuífero superficial detrítico (las barras verticales indican el error estándar). Precipitaciones correspondientes al periodo de estudio (mayo 2015-marzo 2016).

Los resultados de la conductividad eléctrica en la solución del suelo (CEss) en el cultivo de tomate muestran variabilidad entre parcelas y dentro de la misma parcela a lo largo del ciclo de cultivo. El rango de valores medios está entre 1,45 y $5 \mathrm{dS} \mathrm{m}^{-1}$ (Figura 6). A pesar de esta variabilidad, se observa que a comienzos del mes de agosto se produce un aumento de la CEss que se prolonga hasta la primera mitad del mes de septiembre, momento en el que empieza a descender (Figura 6). Estos valores parecen mostrar un sobreabonado de los cultivos en ese periodo, coincidiendo con el cuaje y engorde de los frutos.

La concentración de nitratos en la solución de suelo presenta una menor variabilidad y se aprecia una tendencia más clara a nivel de parcela y considerando el conjunto de parcelas. De esta manera, se observa que al comienzo del ciclo los valores medios de [NO3-] se encontraban dentro de un rango de $10-15 \mathrm{mmol} \mathrm{L}^{-1}$ y a partir de finales de junio se produce un aumento hasta alcanzar valores máximos en agosto de $27,5 \mathrm{mmol} \mathrm{L}^{-1}$ (Figura 7). Estos niveles están por encima de los niveles recomendables para este cultivo, 7-10 mmol $\mathrm{L}^{-1}$ (Fernández et al. 2012) y, por tanto, claramente por encima de las extracciones del cultivo. Su acumulación en el suelo a finales de campaña, coincidiendo con el periodo de lluvias, supone su lixiviación y la contaminación del acuífero del Polje. Estos resultados 
ponen de manifiesto la práctica habitual de aplicaciones excesivas de fertilizantes nitrogenados.
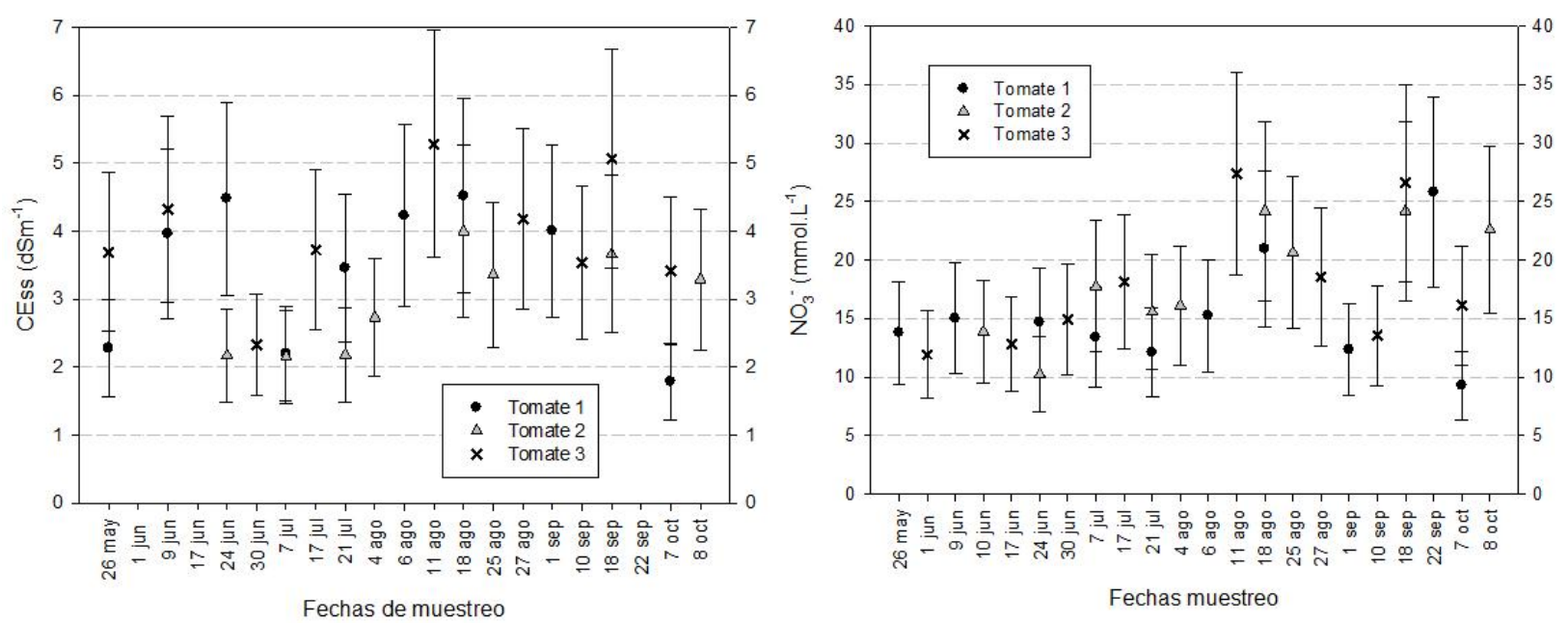

Figuras 6 y 7. Evolución de la conductividad eléctrica de la solución de suelo (CEss) y de la concentración de nitratos [NO3-] en parcelas experimentales de tomate

(las barras verticales indican el error estándar).

En las parcelas cultivadas de alcachofa la conductividad eléctrica en la solución del suelo (CEss) osciló entre 1 y $4 \mathrm{dS} \mathrm{m}^{-1}$ (Figura 8). Al comienzo del ciclo de cultivo la CEss presentaba valores en torno a 1-2 $\mathrm{dS} \mathrm{m}^{-1}$ que se mantuvieron estables hasta finales de julio, momento a partir del cual se produjo un aumento alcanzando valores máximos en agosto. $A$ finales de agosto se produce un descenso progresivo en los niveles de CEss situándose en valores similares a los observados al inicio del ciclo de cultivo (Figura 8). La [NO3] de la solución del suelo es similar en todas las parcelas de alcachofa en el periodo de mayo-julio. Los valores para este periodo estuvieron entre 3,5 y $11 \mathrm{mmol} \mathrm{L}^{-1}$ (Figura 9). A partir de julio una de las parcelas mostró un aumento significativo alcanzando niveles superiores a 20

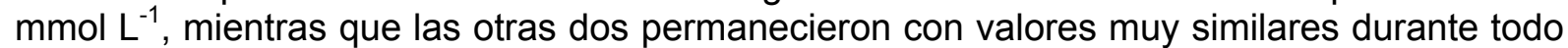
el ciclo de cultivo (Figura 9).
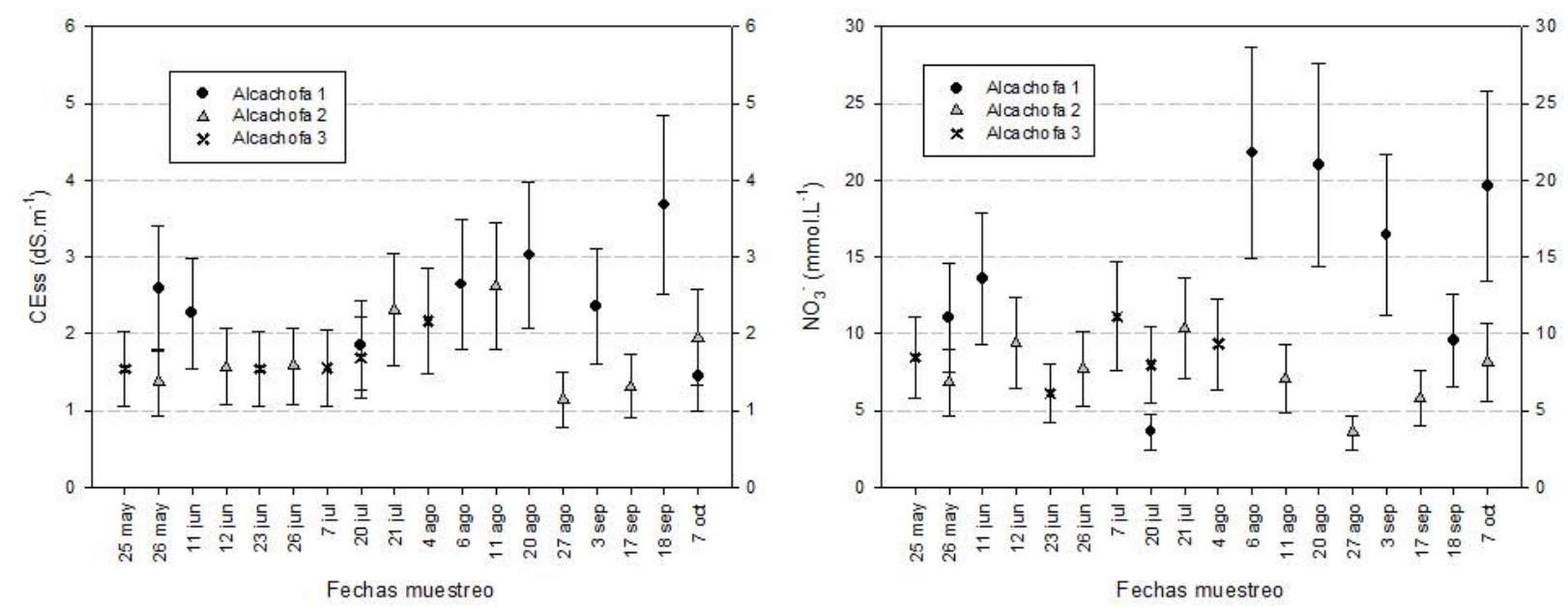

Figuras 8 y 9. Evolución de la conductividad eléctrica de la solución de suelo (CEss) y de la concentración de nitratos [NO3-] en parcelas experimentales de alcachofa (las barras verticales indican el error estándar). 
Los resultados obtenidos en las parcelas cultivadas con lechuga no se muestran en este trabajo por la variabilidad los datos obtenidos.

\section{Conclusiones y recomendaciones}

Los niveles de salinidad obtenidos en el agua de los pozos a lo largo del periodo de estudio oscilaron entre 1,0 y $1,5 \mathrm{dS} \mathrm{m}^{-1}$. Estos valores no representan problemas para los principales cultivos hortícolas que se plantan en la zona. Sin embargo, en lo que respecta a la concentración de nitratos, los resultados muestran niveles excesivos que superan en un $86 \%$ el umbral de $50 \mathrm{mg} \mathrm{L}^{-1}$ marcado por la directiva 96/6767CEE.

Los niveles de nitratos en la solución del suelo a partir del mes de junio están claramente por encima de las extracciones del cultivo, sobre todo en el cultivo de tomate. Su acumulación en el suelo a finales de campaña, coincidiendo con el periodo de lluvias, suponen su lixiviación y la contaminación del acuífero del Polje. Estos resultados ponen de manifiesto la práctica habitual de aplicaciones excesivas de fertilizantes nitrogenados.

La recomendación inicial sería mantener una concentración de nitratos estable a lo largo del ciclo de cultivo para evitar acumulaciones en el suelo y sobre todo al final del mismo (Fernández et al. 2011). En tomate, cultivo donde se han obtenido los resultados más negativos de nitratos en solución de suelo, se recomienda mantener los niveles entre 7 y 10

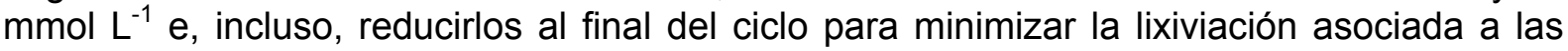
lluvias otoñales (Fernández et al. 2012). Este control y ajuste es posible empleando sondas de succión y análisis rápido de nitratos a lo largo de todo el ciclo de cultivo.

\section{Bibliografía}

Cherif, L., Pulido-Bosch, A., López Chicano, M., Morell, I. \& Gámez, J.A. (1995). Las actividades agrícolas en el Polje de Zafarraya y la evolución del contenido en nitratos en dos manantiales del acuífero de Sierra Gorda (Granada y Málaga). Geogaceta, 18, 146-149.

Decreto 36/2008, 5 de febrero. BOJA núm. 36 de 20 de febrero 2008 en el que se designan las zonas vulnerables y se designan medidas contra la contaminación por nitratos de origen agrario.

Fernández, M., Baeza, R., Cánovas, G. \& Martín, E. (2011). Protocolo de actuación para disminuir la contaminación por nitratos en cultivos de pimiento y tomate bajo abrigo.17pp.

Fernández, M., Martín, E., Cánovas, G. \& Baeza, R. (2012). Manejo controlado de la aplicación de nitratos en cultivos de tomate y pimiento en invernadero. Vida Rural, 343, 38-44.

Gómez-Zotano, J., Alcántara-Manzanares, J., Olmedo-Cobo, J.A. \& Martínez-lbarra, E. (2015). La sistematización del clima mediterráneo: identificación, clasificación y caracterización climática de Andalucía (España). Revista de Geografía Norte Grande, 61, 161-180.

ITGE-JUNTA, D.A. (1998). Atlas hidrogeológico de Andalucía. Consejería de Obras Públicas y Transportes, Consejería de Trabajo e Industria de la Junta de Andalucía, Instituto Tecnológico Geominero de España, 216 pp. Madrid. 
Morell, I., López-Chicano, M., Pulido-Bosch, A., Gámez, J.A. \& Cherif, L. (1995). Procesos de lixiviado de nitratos en el acuífero detrítico del polje de Zafarraya (Granada). Avances en la investigación en zona no saturada, 63-69.

Orden del 18 de noviembre de 2008, BOJA n ${ }^{\circ} 4$ del 8 de enero de 2009, por la que se aprueba el programa de actuación aplicable en las zonas vulnerables a la contaminación por nitratos en Andalucía. 


\title{
B-05
}

\section{ESTUDIO DE MEJORA DE LA CALIDAD DEL AGUA PARA EL OLIVAR DE RIEGO DE LA PROVINCIA DE JAÉN MEDIANTE LA APLICACIÓN DE HERRAMIENTAS SIG}

\author{
Pérez-Latorre, F.J. (1), Peragón, J.M. (2) (P), Delgado, A.(3)
}

\begin{abstract}
${ }^{1}$ Dr. Ingeniero Agrónomo. Área Mecánica de Fluidos. EPS. Campus Científico Tecnológico Universidad de Jaén, fjperez@ujaen.es. Cinturón Sur s/n 23700 Linares (Jaén).

2 Ingeniero Geomática y Topografía, jpjuarez@ujaen.es. EPS. Campus Científico

Tecnológico Universidad de Jaén. Cinturón Sur s/n 23700 Linares (Jaén).

${ }^{3}$ Dr. Ingeniero Agrónomo. Departamento de Ciencias Agroforestales, EUITA, Universidad de Sevilla, adelgado@us.es. Ctra. Utrera km 1, 41013 Sevilla.
\end{abstract}

\section{Resumen}

El objetivo de este trabajo es el estudio, por medio de SIG, de la viabilidad de la utilización conjunta para el riego de olivar de aguas superficiales y subterráneas, para disminuir la salinización de acuíferos y los riesgos de contaminación por retornos de agua en la provincia de Jaén (sur de España). Se procede a evaluar las proporciones óptimas de los dos tipos de agua en función al umbral de salinidad a partil del cual puede afectar a la producción de la cosecha de olivar, y realizar mapas temáticos con el fin de evitar una acumulación excesiva de sal en el suelo. Se consideraron diferentes variables de la evaluación de riesgos, y un mapa temático para cada variable desarrollado por medio de análisis geoestadístico de los datos, utilizando el software de código abierto gvSIG.

La herramienta basada en GIS fue una estrategia capaz de realizar mapas de mezcla de agua superficial y subterránea para disminuir los riesgos de salinización. Con este trabajo se expone la posibilidad de solucionar la afección de las superficies regadas en sus cuencas vertiente, desde las que la escorrentía superficial puede arrastrar sustancias contaminantes hacia áreas permeables a las que recarga, mediante la mezcla de agua de distinta procedencia, minimizando el riesgo de afección y vulnerabilidad de las escorrentías superficiales y aguas subterráneas frente a la contaminación.

\section{1) Introducción, objetivos}

La calidad del agua de riego, y en particular su concentración de sal, pueden determinar dependiendo de la estrategia de riego, la posible degradación del suelo regado y un mayor consumo de agua. Efectos de la salinidad en el suelo se manifiestan en la pérdida de soporte, la reducción del crecimiento de la planta, reducción de los rendimientos, y en casos graves, pérdida de cosechas. Los problemas derivados de la salinidad, afectan a la productividad de algunos regadíos, siendo un problema incipiente en la provincia de Jaén.

El consumo continuado de agua para el riego en estos últimos años ha generado una disminución de las reservas. De esta manera el riego de la mayoría de las nuevas plantaciones de olivos, principalmente en zonas semiáridas (como en el presente trabajo), se surten de fuentes de baja calidad de agua con una relativa alta salinidad.

En el caso particular del olivo su respuesta frente a la salinidad ha sido estudiada por diversos autores (Aragues et al, 2005; Bernstein, 1964; Gucci y Tattini, 1997; Maas y 
Hoffman, 1977; Munns, 1993; Wiesman et al., 2004; Fipps, 1996). Para disminuir el contenido de sales y cuando se tiene mala calidad de agua, la principal estrategia es la de evitar la acumulación de sales, provocando drenaje mediante la aplicación de una Fracción de Lavado (FL), que se estima en función de las características del agua y de la sensibilidad del cultivo. Si a la escasez de recursos se une la mala calidad del agua, queda muy limitada la posibilidad de aplicar FL de forma continua.

Los sistemas de información geográfica (SIG) pueden ser herramientas útiles para evaluar la calidad del agua de riego a escala regional y tomar decisiones para su manejo en el riego, como la estima de las proporciones de mezcla idóneas para un manejo más sostenible del agua de riego (Peragón et al., 2015).

El objetivo del presente trabajo es, mediante el empleo de los sistemas de información geográfica, optimizar la mezcla de aguas en el cultivo del olivo, previniendo el exceso de acumulación de sales solubles desde el punto de vista del ahorro de agua.

\section{2) Materiales y Métodos}

\section{- Área de estudio}

El estudio se lleva a cabo en la provincia de Jaén (sudeste de España), que cuenta con una extensión total de 1.348.900 has. Respecto a las masas de aguas subterráneas, se distribuyen en unidades hidrogeológicas con una superficie total en la provincia de unas 803.000 has (IGME, 2010).

La disponibilidad de agua de riego en la provincia de Jaén es limitada, siendo el factor limitante de la cosecha. La dotación de riego propuesta por el organismo regulador de la cuenca en el olivar es de $1500 \mathrm{~m}^{3} \mathrm{ha}^{-1}$ (Pastor et al., 2002), aunque las dosis de riego son frecuentemente inferiores.

\section{- Conjunto de datos}

Los datos de conductividad eléctrica del agua de riego (CEa) se obtuvieron tanto para las aguas superficiales como para las aguas subterráneas, así las primeras fueron proporcionadas por la autoridad del agua de la cuenca del Guadalquivir (Confederación Hidrográfica del Guadalquivir, entre los años 1994-2013. Esta información se obtuvo de 66 estaciones. Con respecto a las subterráneas se recogieron de las 136 estaciones que corresponden a 26 unidades hidrogeológicas, facilitadas por el Instituto Nacional de Geología y Minería de España (IGME, 2010).

http://www.chguadalquivir.es/opencms/portalchg/laDemarcacion/guadalquivir/calidadAguas/)

\section{- Modelo}

Se ha utilizado un modelo SIG elaborado en estudios previos en Peragón et al., (2015), al que se le podrán incorporar, mediante algoritmos matemáticos, los diferentes datos de conductividad del agua de riego inicial, tanto en aguas superficiales como en subterráneas, asociados a los distintos territorios, siendo posible que este modelo establezca las zonas en las que sería necesaria y posible la mezcla de aguas superficiales y subterráneas para conseguir una conductividad eléctrica menor. Mediante algoritmos matemáticos de rasterización ("rasterizar capa vectorial" y "cortar capar raster con capa de polígonos"), y posterior vectorización ("vectorizar capa raster"), del módulo Sextante del SIG se reduce el mapa temático de CE en aguas superficiales a la región que ocupan las masas de aguas subterráneas, aplicando la mezcla de aguas, con el empleo del algoritmo "calculadora de mapas" del SIG (Figura 1). 


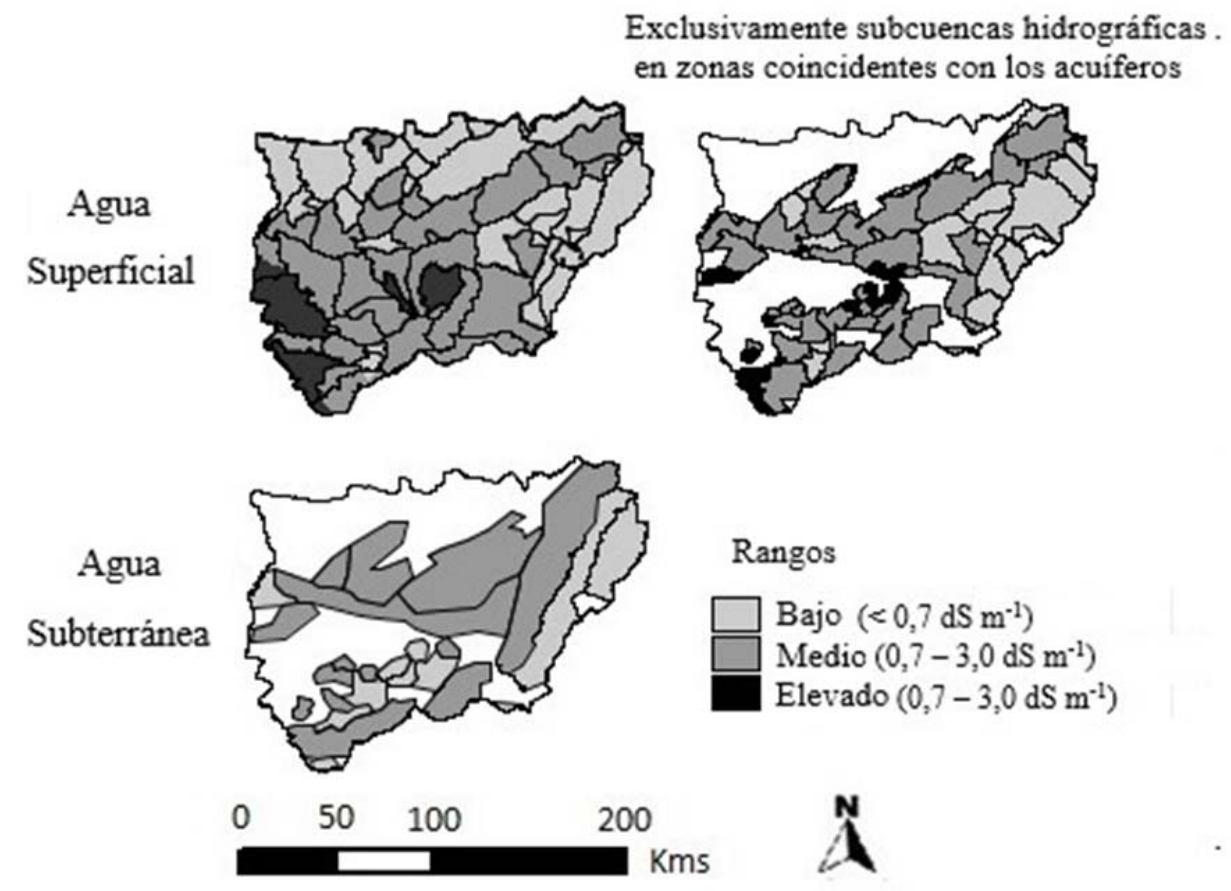

Figura 1. Mapas temáticos de salinidad (conductividad eléctrica del agua de riego)

La concentración de sales totales en la mezcla final, expresada en valores de Conductividad Eléctrica, CE, puede estimarse como la media ponderada entre las concentraciones de las aguas mezcladas:

$\mathrm{Cf}=[\mathrm{Ca}(\mathrm{Qa} / \mathrm{Qt})]+[\mathrm{Cb}(\mathrm{Qb} / \mathrm{Qt})](1)$,

donde $\mathrm{Cf}$ es la conductividad eléctrica final en la mezcla, $\mathrm{Ca}$ y $\mathrm{Cb}$ son respectivamente, las conductividades eléctricas del agua superficial "a" y del agua subterránea, "b" en dS $\mathrm{m}^{-1}$, Qa y Qb, serán las cantidades relativas de agua utilizada en tanto por uno, y Qt la cantidad total de agua $(\mathrm{Q} a+\mathrm{Qb})$ en tanto por uno.

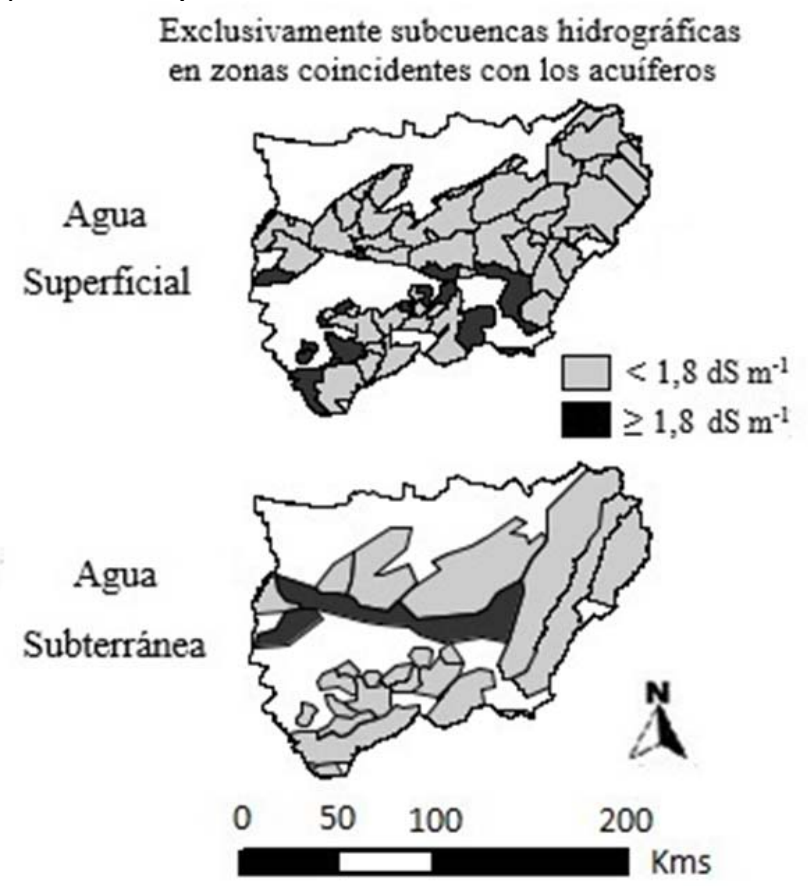

Figura 2. Mapas temáticos de umbral de salinidad (salinidad de $1,8 \mathrm{dS} \mathrm{m}^{-1}$ ) 
Para el presente estudio se establece una Conductividad Eléctrica umbral de $1.8 \mathrm{dS} \mathrm{m}^{-1}$, (Maas y Hoffman, 1977; Fipps, 1996). El modelo SIG permitirá definir la superficie de olivar de riego de Jaén en la cual será posible aplicar la mezcla de aguas, con el requisito que la conductividad final sea igual o inferior al límite establecido (Figura 2). Este límite representa el umbral de la CE del agua de riego a partir del cual podrían verse afectado el olivo en su producción. En la misma se observa una zona donde no es posible aplicar esta metodología al no existir coincidencia geográfica entre la cuenca del acuífero y las subcuencas de aguas superficiales (Figura 3).

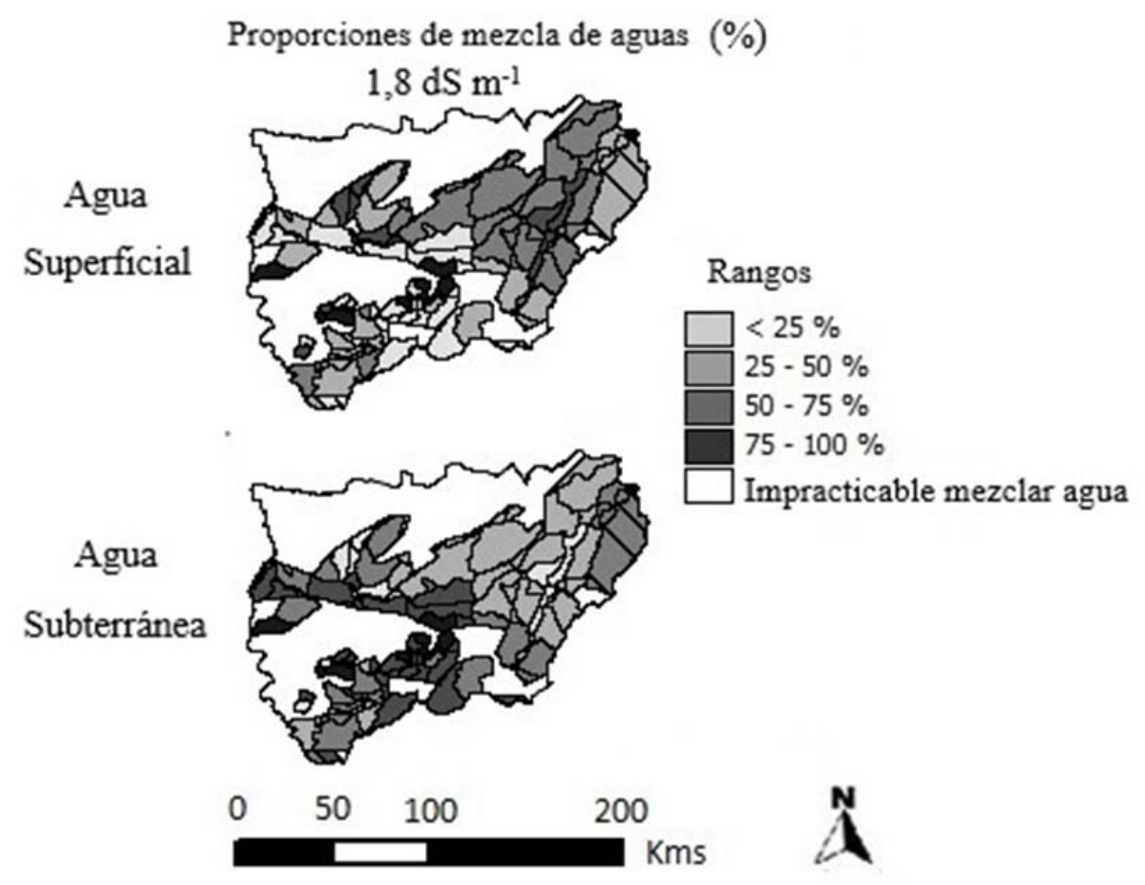

Figura 3. Mapas temáticos de proporciones de mezcla de aguas (salinidad de 1,8 dS m $\mathrm{m}^{-1}$ )

\section{3) Resultados y Discusión}

\section{- Hidroquímicos}

Respecto a la conductividad eléctrica, en agua superficial, aproximadamente el $8 \%$ de la superficie provincial tiene un elevado riesgo de salinización. Con riesgo intermedio (riesgo potencial de salinización) se encuentra un $57,2 \%$, que en aguas subterráneas es superior al $80 \%$ (Tabla 1, Figura 1).

Tabla 1. Conductividad eléctrica de las aguas superficiales y subterráneas, superficie y porcentaje afectado en la provincia de Jaén.

\begin{tabular}{|c|c|c|c|c|c|}
\hline \multirow{2}{*}{ Variable } & \multirow{2}{*}{ Rangos } & \multicolumn{2}{|c|}{ Agua superficial } & \multicolumn{2}{c|}{ Agua Subterránea } \\
\cline { 3 - 6 } & $\begin{array}{c}\text { Superficie } \\
\text { Provincial } \\
\left(\mathbf{k m}^{2}\right)\end{array}$ & $\begin{array}{c}\text { \% } \\
\text { Superficie } \\
\text { Provincial }\end{array}$ & $\begin{array}{c}\text { Superficie } \\
\text { Provincial } \\
\left(\mathbf{k m}^{2}\right)\end{array}$ & $\begin{array}{c}\% \\
\text { Superficie } \\
\text { Provincial }\end{array}$ \\
\hline \multirow{3}{*}{ CEa $\left(\mathrm{dS} \mathrm{m}^{-1}\right)$} & $>3.0$ & 1064 & 7.9 & - & - \\
\cline { 2 - 6 } & $0.7-3.0$ & 7716 & 57.2 & 6473 & 80.6 \\
\cline { 2 - 6 } & $<0.7$ & 4709 & 34.9 & 1557 & 19.4 \\
\hline
\end{tabular}

CEa, Conductividad eléctrica del agua de riego conforme a Ayers y Westcot (1985); 


\section{- Mezcla de aguas}

En la zona estudiada, $(8030 \mathrm{~km} 2)$ las calidades del agua de riego son similares entre ambas fuentes de agua. Así en las masas de agua subterráneas un $85 \%$ tiene niveles de CEa inferiores a $1,8 \mathrm{dS} \mathrm{m}^{-1}$, mientras que en las aguas superficiales un $86 \%$ tiene niveles inferiores a dicho umbral. Se tiene pues valores próximos al $15 \%$ de zonas de riego, en la que se están aplicando actualmente riegos con aguas de CEa superiores al límite considerado (Tabla 2, Figura 2).

Tabla 2. Niveles de salinidad en función al umbral a aplicar en el agua de riego $\left(1,8 \mathrm{dS} \mathrm{m}^{-1}\right)$

\begin{tabular}{|c|c|c|c|c|}
\cline { 2 - 5 } \multicolumn{1}{c|}{} & \multicolumn{2}{c|}{ Agua Superficial } & \multicolumn{2}{c|}{ Agua Subterránea } \\
\hline CEa & $\begin{array}{c}\text { Superficie } \\
\text { Provincial } \\
\left.\mathbf{( k m}^{2}\right)\end{array}$ & $\begin{array}{c}\text { \% Superficie } \\
\text { Provincial }\end{array}$ & $\begin{array}{c}\text { Superficie } \\
\text { Provincial } \\
\left.\text { (km }^{2}\right)\end{array}$ & $\begin{array}{c}\text { \% Superficie } \\
\text { Provincial }\end{array}$ \\
\hline$\geq 1,8 \mathrm{dS} / \mathrm{m}$ & 1129,1 & 14,1 & 1175,8 & 14,6 \\
\hline$<1,8 \mathrm{dS} / \mathrm{m}$ & 6900,9 & 85,9 & 6854,2 & 85,4 \\
\hline
\end{tabular}

Una vez aplicado el modelo SIG, los resultados reflejan mapas de zonas en las que se puede realizar la mezcla de aguas, así como los porcentajes de cada uno de los tipos de agua a utilizar. En los mismos se observa que es posible disminuir la superficie regada con aguas de mala calidad hasta un $4 \%$, de este modo, si se aplicaran diferentes porcentajes de mezcla de aguas superficiales y subterráneas (dependiendo de la zona) se podría conseguir que el $96 \%$ de la zona estudiada se regara con calidades de agua cuya CE estuviera por debajo del límite establecido (Tabla 3, Figura 3).

Tabla 3. Superficie de la provincia de Jaén donde es posible realizar la mezcla de aguas (salinidad de $1,8 \mathrm{dS} \mathrm{m}^{-1}$ )

\begin{tabular}{|c|c|c|}
\cline { 2 - 3 } \multicolumn{1}{c|}{} & \multicolumn{2}{c|}{ CEa: $\mathbf{1 , 8} \mathbf{~ d S / m}$} \\
\cline { 2 - 3 } \multicolumn{1}{c|}{} & $\begin{array}{c}\text { Superficie } \\
\text { Provincial } \\
\left(\mathbf{k m}^{2}\right)\end{array}$ & $\begin{array}{c}\text { \% Superficie } \\
\text { Provincial }\end{array}$ \\
\hline $\begin{array}{c}\text { Mezcla de } \\
\text { Aguas }\end{array}$ & 7697,3 & 95,9 \\
\hline
\end{tabular}

Los porcentajes de mezcla varían lógicamente en las más de 180 subcuencas analizadas. A modo de ejemplo, si tomamos como referencia la relación agua superficial agua subterránea, el $21 \%$ de la superficie tendría mezclas en las que el agua subterránea estaría en el intervalo (75\%-99\%), el $31 \%$ en el intervalo (50\%-75\%), el $38 \%$ en el intervalo $(25 \%-50 \%)$ y el $8 \%$ en el intervalo (1\%-25\%). Los porcentajes hasta completar la mezcla se aplicarían con agua superficial (Tabla 4, Figura 3).

Tabla 4. Porcentajes de mezcla de aguas: superficial y subterránea, en el área de estudio.

\begin{tabular}{|c|c|c|c|c|}
\cline { 2 - 5 } \multicolumn{1}{c|}{} & \multicolumn{2}{c|}{ Aguas Superficiales } & \multicolumn{2}{c|}{ Aguas Subterráneas } \\
\hline $\begin{array}{c}\text { Mezcla de } \\
\text { aguas }\end{array}$ & $\begin{array}{c}\text { Superficie } \\
\text { Provincial } \\
\left(\mathbf{k m}^{2}\right)\end{array}$ & $\begin{array}{c}\% \\
\text { Superficie } \\
\text { Provincial }\end{array}$ & $\begin{array}{c}\text { Superficie } \\
\text { Provincial } \\
\left.\mathbf{( k m}^{2}\right)\end{array}$ & $\begin{array}{c}\% \\
\text { Superficie } \\
\text { Provincial }\end{array}$ \\
\hline$<25 \%$ & 1627,8 & 20,3 & 610,7 & 7,6 \\
\hline $25-50 \%$ & 2448 & 30,5 & 3010,8 & 37,5 \\
\hline $50-75 \%$ & 3010,8 & 37,5 & 2448 & 30,5 \\
\hline $75-100 \%$ & 610,7 & 7,6 & 1627,8 & 20,3 \\
\hline
\end{tabular}




\section{4) Conclusiones}

La herramienta que se propone puede facilitar el análisis y tratamiento de datos, permitiendo visualizar la información geográfica y ofreciendo todas las funcionalidades de manipulación de los datos geográficos, representando espacialmente multitud de datos, que serán utilizados en los procesos de planificación y toma de decisiones. El modelo de gestión de la información propuesto para riego sostenible a escala regional es útil para generar mapas para el cumplimiento de las mejores prácticas de riego en las diversas comarcas de la región estudiada. El sistema de información geográfica puede ser un sistema útil para el manejo de la información climática e hidroquímica destinado a crear mapas de cantidades de agua a aportar utilizando un sistema mixto mediante la mezcla de aguas. El empleo de la mezcla de agua reduce progresivamente la aportación de sales, de tal manera que se contribuye a una gestión más sostenible del riego deficitario en la cuenca del Guadalquivir.

\section{5) Bibliografía}

Aragues R., Puy J., Royo A., Espada J.L., (2005). Three-year field response of young olive trees (Olea europea L., cv. Arbequina) to soil salinity: Trunk growth and leaf ion accumulation. Plant Soil 271:265-273.

Ayers R.S., Westcot D.W., (1985). La calidad del agua en la agricultura. FAO Riego y Drenaje No. 29. Food and Agriculture Organization of the United Nations. Roma.174p.

Benlloch M., Marín L., Fernández-Escobar R., 1994 Salt tolerante of various olive verieties. Acta Horticulturae, 356: 215-217.

Bernstein L., (1964). Effects of salinity on mineral composition and growth of plants. In: Proc. Fourth Int. Coll. Plant Analysis and Fertilizer Problems 4:25-45.

Fipps, G., (1996). Irrigation Water Quality Standards and Salinity Management Strategies, Texas Agricultural Extension Service, Texas A\&M University System.

Gucci R., Tattini M., (1997). Salinity tolerance in olive. Hort. Rev. (Amer. Soc. Hort. Sci.) $21: 177-214$.

IGME (National Institute of Geology and Minery of Spain), (2010). Updatind the atlas of hydrogeological Jaen. (http://www.igme.es/INTERNET/SIDIMAGENES/153000/874/153874 0000001.PDF)(in Spanish).

Mass E.V., Hoffman G.J., (1977). Crop salt tolerance-Current assessment J. Irring and Drainage Div., ASCE 103(IR2):115-134.

Munns R., (1993). Physiological processes limiting plant growth in saline soil: Some dogmas and hypotheses. Plant Cell Environ. 16:15-24.

Pastor M., Hidalgo J., Orgaz F., Moriana A., Fereres E., (2002). Riego del olivar: estudio de la respuesta a riegos por goteo deficitarios y obtención de la función de producción. Actas de las I Jornadas Técnicas del Aceite de Oliva. Ed. Ministerio de Ciencia y Tecnología. Madrid. 53-61.

Peragón J.M., Pérez-Latorre F.J., Delgado A., (2015). A GIS-based quality assessment model for olive tree irrigation water in southern Spain. Agricultural Water Management 148:232-240.

Wiesman Z., David Y., Ben-Dom N., (2004). Optimization of saline water level for sustainable Barnea olive and oil production in desert conditions. Sci. Hort. 100:257-266. 


\title{
B-06
}

\section{INFLUENCIA DE LA FERTIRRIGACIÓN CON AGUA REGENERADA Y LAS LABORES DE MANTENIMIENTO EN LA UNIFORMIDAD DE RIEGO}

Contreras París, J.I.(1), López Segura, J.G. (1), Trujillo Delgado, J. (2), Alonso López, F.(1) , Baeza Cano, R. (1)

\author{
${ }^{1}$ Instituto de Investigación y Formación Agraria y Pesquera de Andalucía (IFAPA), Centro La \\ Mojonera, Camino San Nicolás, n¹, 04745 La Mojonera, Almería. \\ juanai.contreras@juntadeandalucia.es \\ ${ }^{2}$ Universidad de Almería, Ctra. De Sacramento s/n, 04120 Almería.
}

\section{Resumen}

El objetivo del trabajo ha sido estudiar el efecto de la fertirrigación y las labores de mantenimiento en la uniformidad de distribución de caudal utilizando agua urbana regenerada. El ensayo se desarrolló en un invernadero experimental en el Centro IFAPA La Mojonera en La Cañada (Almería). Se estableció un diseño experimental factorial con dos factores, manejo del riego y tipo de emisor. En lo que respecta al factor manejo de riego se dispusieron tres tratamientos, AR-Riego con agua residual urbana regenerada; ARFRFertirriego con agua residual urbana regenerada+equilibrio fertilizante estándar y ARFRMFertirriego con agua residual urbana regenerada+equilibrio fertilizante estándar +mantenimiento. En el factor tipo de emisor, se evaluaron 20 modelos comerciales de goteros seleccionados en estudios previos de diferentes tipologías. Se determinó el coeficiente de uniformidad de caudal y el porcentaje de obturación a las 0, 40, 60, 80 y $100 \mathrm{~h}$ de funcionamiento. De los resultados obtenidos se puede concluir que el tratamiento de riego afectó al porcentaje de obturación, siendo mayor en los tratamientos fertirrigados. Las labores de mantenimiento predefinidas mejoraron la uniformidad pero no resultaron eficaces para evitar la obturación, por lo que sería necesario redefinir las labores de mantenimiento más adecuadas a este tipo de agua.

\section{1- Introducción y Objetivos}

La horticultura intensiva desarrollada en el Sureste de España ha sufrido, durante sus más de 50 años de trayectoria, una serie de adaptaciones y cambios propiciados por la incorporación de nuevas tecnologías y como respuesta a los problemas que han ido surgiendo. En lo que respecta a los recursos hídricos, se ha producido un descenso, en términos de calidad y cantidad, de las reservas de agua subterránea (CMAOT, 2012), fuente principal de abastecimiento del sistema productivo. Por este motivo, se ha hecho necesario la incorporación de nuevas fuentes de agua como las Residuales Urbanas Regeneradas (ARUR). Este tipo de agua, en general se caracterizan por presentar una buena calidad química, sin embargo una peor calidad física y biológica, en comparación con las tradicionales aguas subterráneas. Como consecuencia del empleo de estas aguas, en las instalaciones de riego localizado, se han detectado problemas relacionados con el mantenimiento y mayores niveles de obturación de los emisores de riego (Baeza et al. 2010).

Los principales agentes causantes de obturación no son exclusivamente los sólidos en suspensión, sino la aglomeración de estos (partículas finas minerales u orgánicas) con 
subproductos microbianos y biomasa desarrollada en el interior de las tuberías y ramales. Este problema se agrava por la incorporación de nutrientes en el agua de riego, fertirrigación, ya que estos nutrientes sirven de alimento a los microorganismos presentes en el agua, incrementando la biomasa presente.

Estudios previos, realizados por el IFAPA, demuestran que las instalaciones de riego en las fincas que utilizan estas aguas presentan habitualmente problemas de funcionamiento y uniformidad relacionados con frecuencia a obturaciones en los emisores (Baeza et al., 2010). Además, estudios complementarios concluyen que estos problemas pueden ser de mayor o menor magnitud dependiendo del tipo de emisor instalado (Baeza et al., 2012; Contreras et al., 2013).

El objetivo del trabajo fue estudiar el efecto de la fertirrigación y las labores de mantenimiento en la uniformidad de distribución de caudal utilizando agua urbana regenerada.

\section{2- Materiales y Métodos}

El ensayo se desarrolló en un invernadero experimental multitúnel de $1200 \mathrm{~m}^{2}$, situado en el Centro IFAPA La Mojonera en La Cañada (Almería) (Fotografía 1) y equipado con control automático de riego. Este invernadero disponía de un banco de pruebas de emisores, preparado para evaluar 240 líneas de riego. Se estableció un diseño experimental factorial con dos factores, manejo del riego y tipo de emisor, en bloques al azar con tres repeticiones. La unidad experimental básica fue un lateral de riego.

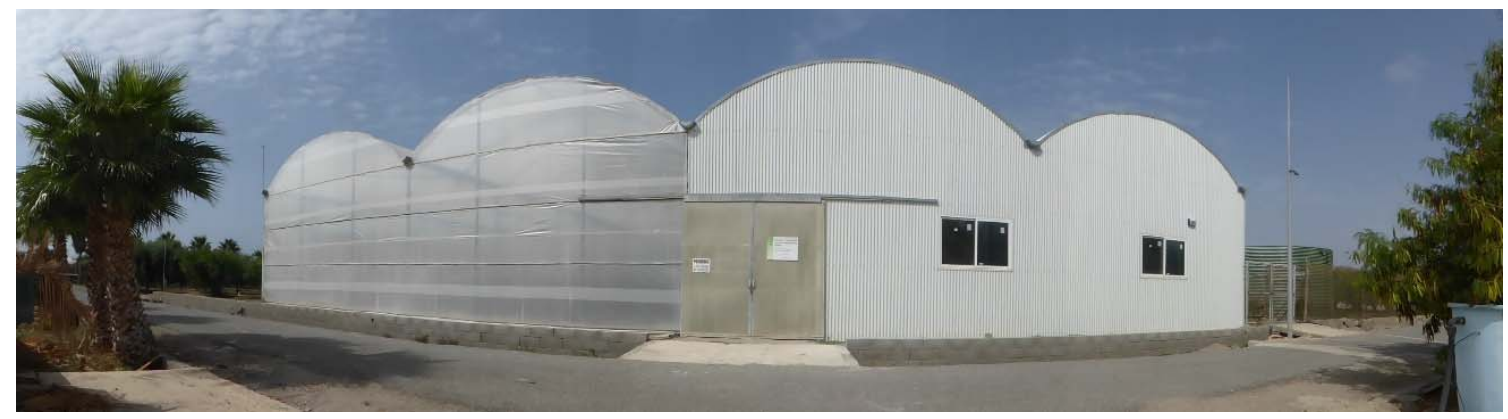

Fotografía 1. Frontal del invernadero multitúnel usado en la realización del ensayo.

En lo que respecta al factor manejo de riego se dispusieron tres tratamientos:

1. AR - Riego con agua residual urbana regenerada. estándar.

2. ARFR - Fertirriego con agua residual urbana regenerada+equilibrio fertilizante

3. ARFRM - Fertirriego con agua residual urbana regenerada+equilibrio fertilizante estándar+mantenimiento.

A los tratamientos AR y ARFR no se les realizó labor alguna de mantenimiento, en cambio en el ARFRM se realizó:

-Apertura durante varios segundos de los tapones finales de los ramales de riego para la limpieza de los sedimentos. Esta labor se realizaba con una periodicidad mensual.

-Mantenimiento del $\mathrm{pH}$ de la solución de riego en valores constantes de $\mathrm{pH} 6$ para evitar la formación de precipitados. 
En el factor tipo de emisor, se evaluaron 20 modelos comerciales de goteros seleccionados en estudios previos de diferentes tipologías, y que se recogen en la Tabla 1.

Tabla 1. Emisores analizados.

\begin{tabular}{|c|l|l|l|c|}
\hline & Modelo & Fabricante & $\begin{array}{l}\text { Tipo de } \\
\text { Inserción }\end{array}$ & $\begin{array}{l}\text { Compensación } \\
\text { de Caudal }\end{array}$ \\
\hline $\mathbf{1}$ & $\begin{array}{l}\text { T D Advanced } \\
\text { OL }\end{array}$ & Mondragon & Pinchado & NO \\
\hline $\mathbf{2}$ & ADO & Caudal & Pinchado & SI \\
\hline $\mathbf{3}$ & Interlínea 12 & Hidroten & Interlínea & NO \\
\hline $\mathbf{4}$ & NYA & Primaram & Interlínea & NO \\
\hline $\mathbf{5}$ & PCJ & Netafim & Pinchado & SI \\
\hline $\mathbf{6}$ & $\begin{array}{l}\text { Cónico } \\
\text { desmontable }\end{array}$ & Hidroten & Pinchado & $\mathrm{NO}$ \\
\hline $\mathbf{7}$ & PC-CNL & Netafim & Pinchado & $\mathrm{SI}$ \\
\hline $\mathbf{8}$ & TD Advanced M & Mondragon & Pinchado & $\mathrm{NO}$ \\
\hline $\mathbf{9}$ & Hydrogol & John DeereWater & Integrado & $\mathrm{NO}$ \\
\hline $\mathbf{1 0}$ & AGR & Azud & Interlínea & $\mathrm{NO}$ \\
\hline $\mathbf{1 1}$ & AmnonDrip & NaanDanJainlbérica & Integrado & $\mathrm{SI}$ \\
\hline $\mathbf{1 2}$ & Interlínea 16 & Hidroten & Interlínea & $\mathrm{NO}$ \\
\hline $\mathbf{1 3}$ & Interlínea 16 & Amacom & Interlínea & $\mathrm{NO}$ \\
\hline $\mathbf{1 4}$ & PRO & Azud & Integrado & $\mathrm{NO}$ \\
\hline $\mathbf{1 5}$ & Megadrip & Mondragon & Integrado & $\mathrm{SI}$ \\
\hline $\mathbf{1 6}$ & Topdrip & NaanDanJainlbérica & Integrado & $\mathrm{NO}$ \\
\hline $\mathbf{1 7}$ & Hydro PC & John DeereWater & Integrado & $\mathrm{SI}$ \\
\hline $\mathbf{1 8}$ & UniRam & Netafim & Integrado & $\mathrm{SI}$ \\
\hline $\mathbf{1 9}$ & LIN & Extruline Caudal & Integrado & $\mathrm{NO}$ \\
\hline $\mathbf{2 0}$ & ARIES & Netafim & Integrado & $\mathrm{NO}$ \\
\hline & & & & \\
\hline
\end{tabular}

Se realizaron pulsos continuos de riego de 30 minutos, en 5 aplicaciones semanales durante un periodo de 37 semanas, equivalente a una campaña de riego en un ciclo medio de cultivos hortícolas en invernadero. El agua utilizada fue agua residual urbana procedente de la ciudad de Almería y regenerada mediante tratamiento terciario de filtración, ozonización y/o cloración. Los parámetros del agua utilizada se muestran en la Tabla 2. 
Tabla 2. Parámetros medios presentes en el agua de riego e intervalo de variación. $\mathbf{N}$ (número de muestras)=13.

\begin{tabular}{|c|c|c|c|}
\hline Parámetros & Media & Mínimo & Máximo \\
\hline Sólidos en suspensión $(\mathrm{mg} / \mathrm{l})$ & 16,93 & $<2$ & 156 \\
\hline E.coli $($ u.f.c./100ml) & 0 & 0 & 0 \\
\hline $\mathrm{pH}$ & 7,47 & 7,2 & 7,8 \\
\hline Turbidez U.N.T. & 8,4 & 1,3 & 64 \\
\hline Cloro libre residual mg Cl $/ / \mathrm{l}$ & 1,62 & 0,12 & 4,72 \\
\hline Salmonella spp (en un litro) & \multicolumn{3}{|c|}{ Ausencia } \\
\hline Huevos de nematodos intestinales & 4,07 & 0 & 53 \\
\hline $\mathrm{DBO}_{5}\left(\mathrm{mgO}_{2} / \mathrm{l}\right)$ & 5 & $<5$ & 34 \\
\hline $\mathrm{DQO}_{\left(\mathrm{mgO}_{2} / \mathrm{l}\right)}$ & 52,53 & 24 & 246 \\
\hline
\end{tabular}

Se determinó el coeficiente de uniformidad de caudal y el porcentaje de obturación a las $0,40,60,80$ y $100 \mathrm{~h}$ de funcionamiento.

La uniformidad se determinó por el método clásico del cuarto inferior propuesto por Merriam y Keller (1978), y cuya fórmula se recoge en la Ecuación 1.

$$
\text { CUC }=\frac{9_{\text {Mar }}}{9_{m}} \cdot 100 \quad(\text { Ecuación } 1)
$$

Siendo:

CUC el Coeficiente de Uniformidad de Caudal, en tanto por 100.

$\mathbf{q}_{25 \%}$ el promedio de los caudales del $25 \%$ de los emisores, cuyo caudal sea de menor valor.

$\mathbf{q}_{\mathbf{m}}$ el promedio del caudal del total de los emisores.

Según el Coeficiente de Uniformidad de Caudal (CUC) obtenido, la calificación de la instalación se realizará según se muestra en la Tabla 3.

Tabla 3. Calificación de la instalación de riego, en función del Coeficiente de Uniformidad de Caudal (CUC) (Merriam y Keller, 1978).

\begin{tabular}{|c|c|}
\hline CUC & Calificación \\
\hline$>95 \%$ & Excelente \\
\hline $85 \%-95 \%$ & Buena \\
\hline $80 \%-85 \%$ & Aceptable \\
\hline $70 \%-80 \%$ & Pobre \\
\hline$<70 \%$ & Inaceptable \\
\hline
\end{tabular}


El porcentaje de obturación medio se ha determinado como la reducción de caudal presentada por los emisores, según la Ecuación 2.

$$
\Psi_{0 \text { obturactôn }}=\frac{Q_{\mathrm{Q}}-\varphi_{n}}{Q_{\mathrm{E}}} \cdot 100 \quad \text { (Ecuación 2) }
$$

Siendo:

$Q_{0}$ el Caudal obtenido en el $1^{\mathrm{er}}$ muestreo.

$\mathbf{Q}_{\mathbf{n}}$ el Caudal obtenido en el muestreo $\mathrm{n}$.

Los resultados fueron analizados estadísticamente con el software STATGRAPHICS Plus (versión 5.1). Se realizó un análisis multifactorial ANOVA para identificar la significación de los factores estudiados. Cuando el análisis estadístico reveló diferencias significativas entre tratamientos se aplicó un test de comparación de media (LSD; mínima diferencia significativa) con $\mathrm{p} \leq 0.05$.

\section{3- Resultados y conclusiones}

El efecto de los factores estudiados y la interacción entre ambos en la uniformidad de caudal se muestra en la Tabla 3 . El tratamiento de riego solo tuvo efecto al final del ensayo, a las $100 \mathrm{~h}$ de trabajo, por lo que es un efecto que se produce a largo plazo. Sin embargo, el modelo de emisor presentó influencia desde el inicio del ensayo hasta el final $(0,40,60,80$ y 100 horas de trabajo). No existió interacción entre el modelo de emisor y los distintos tratamientos.

Tabla 3. Análisis factorial de la varianza, nivel de significación e interacción de los factores

CUC (\%)

\begin{tabular}{cccccc}
\hline Factor & $\mathbf{0}$ horas & $\mathbf{4 0}$ horas & $\mathbf{6 0}$ horas & $\mathbf{8 0}$ horas & $\mathbf{1 0 0}$ horas \\
\hline A: Tratamiento riego & $\mathrm{ns}$ & $\mathrm{ns}$ & $\mathrm{ns}$ & $\mathrm{ns}$ & $*$ \\
B: Modelo de emisor & $* *$ & $* *$ & $*$ & $*$ & $*$ \\
Interacción AxB & $\mathrm{ns}$ & $\mathrm{ns}$ & $\mathrm{ns}$ & $\mathrm{ns}$ & $\mathrm{ns}$ \\
\hline
\end{tabular}

ns, no significativo. * *Significativo para $p<0.05 . \quad$ **Significativo para $p<0.01$

En la Figura 1 se muestran los valores medios del CUC (\%) a las 100 horas de trabajo, para los diferentes tratamientos de riego. El tratamiento fertirrigado con labores de mantenimiento (ARFRM), con independencia del modelo de emisor, presentó al finalizar en ensayo, un coeficiente de uniformidad de caudal significativamente mayor que el tratamiento sin labores de mantenimiento (ARFR). El tratamiento ARFR mostró un CUC de 92,7\% que se diferenció estadísticamente de los tratamientos AR (95,0\%) y ARFRM (94,8\%).

La mejora de la uniformidad en el tratamiento de fertirrigación más mantenimiento frente al tratamiento de fertirrigación sin mantenimiento pudo deberse a que las labores realizadas de mantenimiento hayan evitado precipitados y acumulación de los mismos en los tramos finales de las tuberías. 
Media e intervalo LSD al 95\%

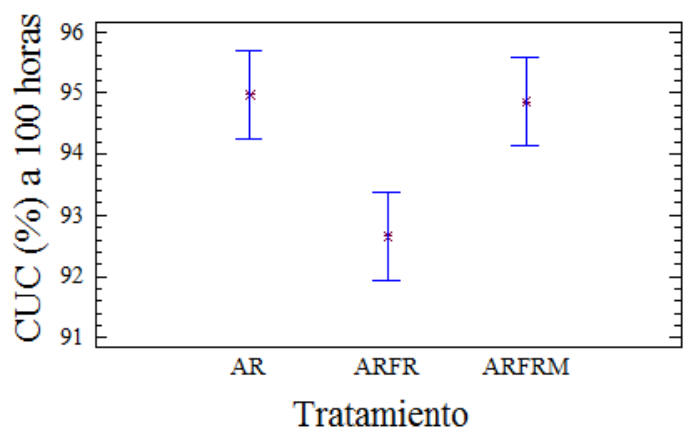

Figura 1. Valores medios e intervalo de confianza $(p<0,05)$ del coeficiente de Uniformidad de Caudal (\%) a las 100 horas de trabajo (CUC), para los diferentes tratamientos de riego.

La Figura 2 muestra los valores medios del CUC (\%) a las 0, 40, 6080 y 100 horas de riego, del total de 20 modelos de emisores de riego analizados. Todos los modelos de emisores analizados al comienzo de su ciclo de trabajo (0 horas) presentaron una alta uniformidad independientemente del tratamiento, sin embargo, al final del ciclo de trabajo (100 horas) la mayor parte de modelos de emisores redujeron ligeramente el CUC.

Los CUC obtenidos por los modelos de emisores evaluados fueron elevados, clasificándose como excelentes o buenos en todas las mediciones. A las 0 horas de riego el $85 \%$ de los modelos de emisores se clasificaron como excelente, conservándose esta distribución tras 40 horas de riego. A las 60 horas de riego el $80 \%$ de los emisores se clasificaban como excelente descendiendo al $50 \%$ a las 80 horas. Al finalizar el ensayo (100 horas de riego) solo el $40 \%$ los modelos de emisores que se clasificaron como excelente.

En cuanto a la reducción de caudal tras las 100 horas de riego, tanto el tratamiento como el modelo de emisor mostraron efecto, sin presentar interacción entre ellos (Tabla 4). 
Media e intervalo LSD al 95\%

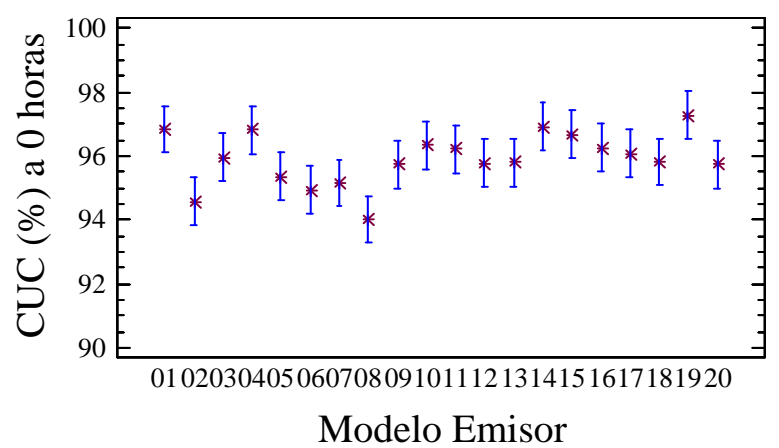

Media e intervalo LSD al 95\%

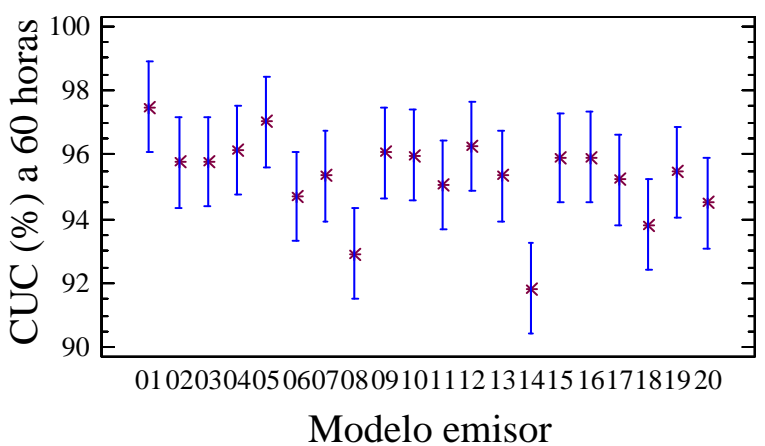

Modelo emisor
Media e intervalo LSD al 95\%

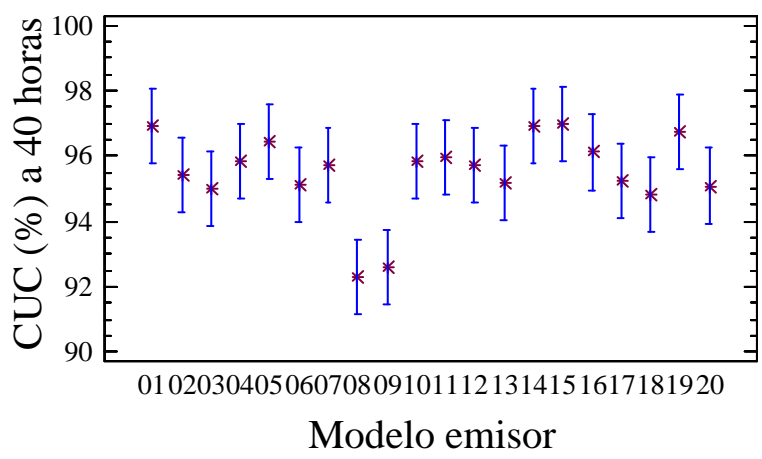

Media e intervalo LSD al 95\%

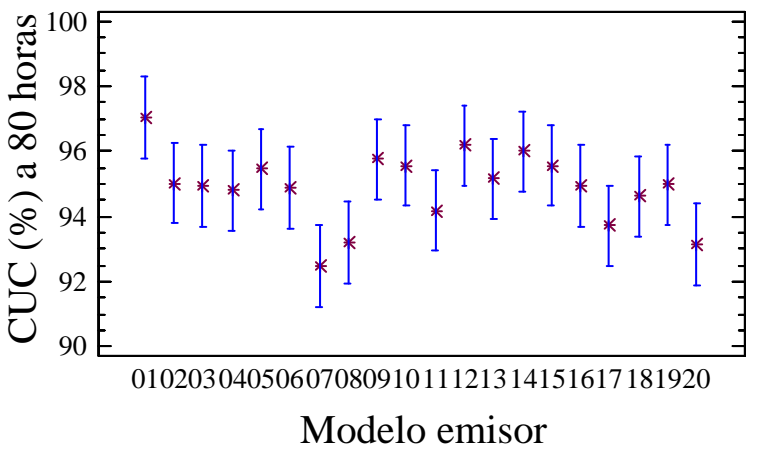

Media e intervalo LSD al 95\%

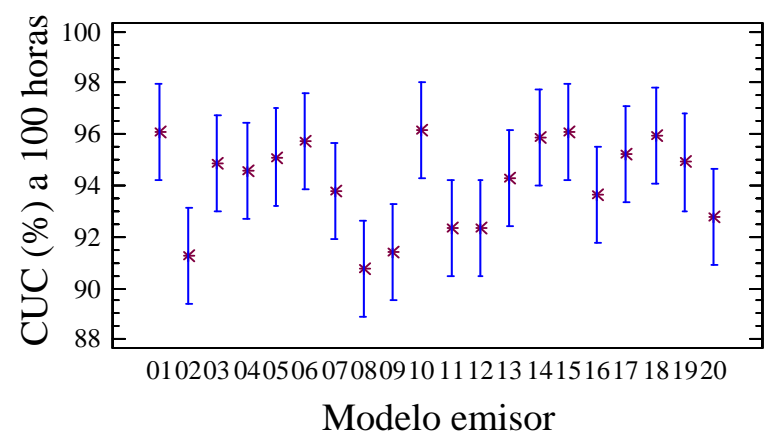

Figura 2. Valores medios e intervalo de confianza $(p<0,05)$ del coeficiente de Uniformidad de Caudal (\%) a las 0, 40, 6080 y 100 horas de trabajo (CUC), de los 20 modelos analizados.

Tabla 4.Nivel de significación e interacción de los factores en cuanto a la reducción del caudal.

Reducción de caudal (\%)

\begin{tabular}{cc}
\hline Factor & Nivel de significación \\
\hline A: Tratamiento & $*$ \\
B: Modelo de emisor & $* *$ \\
Interacción AxB & ns \\
\hline
\end{tabular}

ns, no significativo. $\quad$ *Significativo para $p<0,05 . \quad$ **Significativo para $p<0,01$ 
Independientemente del modelo del emisor, tras 100 horas de riego, los tratamientos con fertirrigación mostraron una reducción de caudal significativamente mayor que el tratamiento sin fertirrigación (Figura 3). La reducción de caudal se cifró en un 4,0 y 4,6\% para los tratamientos ARFR y ARFRM, respectivamente, sin embargo el tratamiento AR solo mostró una reducción del 1,3\%, mostrando la influencia que tiene la fertirrigación sobre la obturación de los emisores.

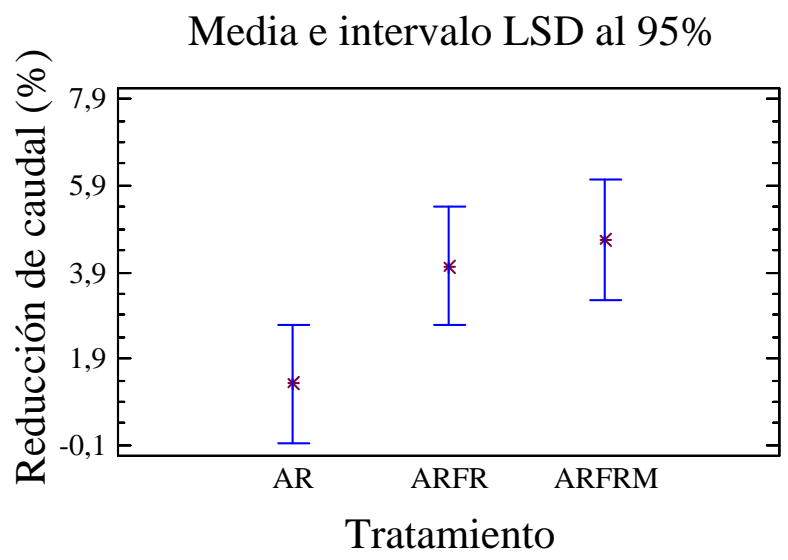

Figura 3. Reducción de caudal (\%) tras 100 horas de trabajo de los tratamientos estudiados, con la representación del intervalo de Mínima Diferencia Significativa (LSD) al 95\%.

En lo que respecta al modelo de emisor, en la mayoría se produjo una reducción del caudal (Figura 4), cabe destacar el modelo 6 con una reducción del 16\%. Se pudo observar que en algunos modelos de emisores, no se produjo una reducción del caudal, sino que se produjo un incremento, esto pudo ser debido a que estos emisores eran compensantes y el aumento de caudal pudo estar asociado a una afección al mecanismo de membrana.

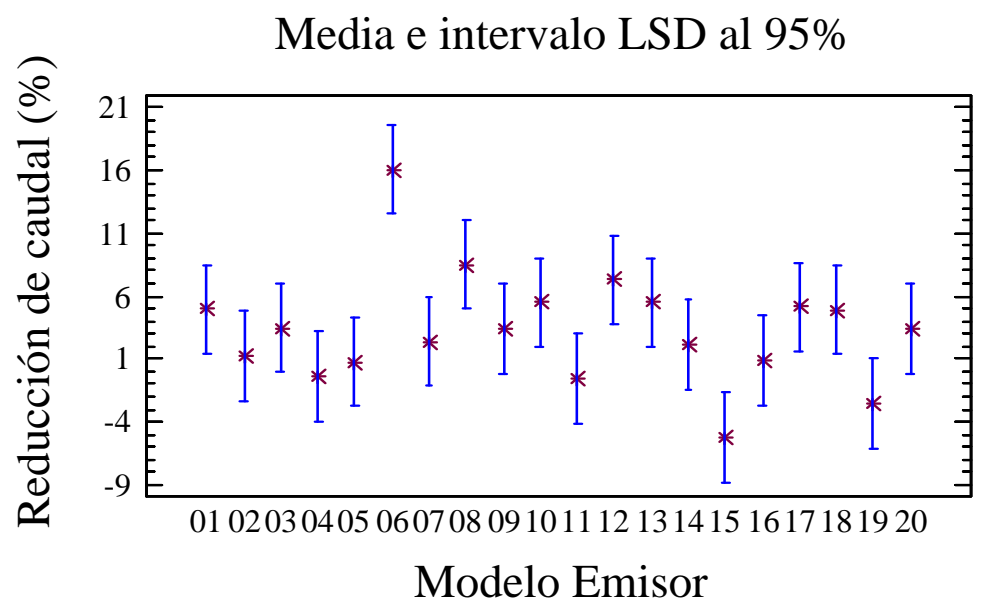

Figura 4. Reducción de caudal (\%) tras 100 horas de trabajo de los 20 modelos analizados, con la representación del intervalo de Mínima Diferencia Significativa (LSD) al 95\%.

De los resultados obtenidos se puede concluir que el tratamiento de riego afecta al porcentaje de obturación, siendo mayor en los tratamientos fertirrigados. Las labores de mantenimiento predefinidas mejoraron la uniformidad pero no resultaron eficaces para evitar la obturación, por lo que sería necesario redefinir las labores de mantenimiento más adecuadas a este tipo de agua. 


\section{4- Bibliografía}

Baeza Cano, R., Contreras París, J.I., Martín Usero, F., Zapata Sierra, A. \& López Segura J.G. (2012). Estudio prospectivo de los emisores de riego localizado instalados en la zona regable del Bajo Andarax con aguas residuales urbanas regeneradas. XXX Congreso Nacional de Riegos. Albacete, 12-14 de junio de 2012.

Baeza Cano, R., Gavilán Zafra, P., Del Castillo Lupiáñez, N., Berenguel, P. \& López Segura, J.G. (2010). Programa de evaluación y asesoramiento en instalaciones de riego en invernadero con uso de dos fuentes distintas de agua: subterránea y regenerada. XXXVIII Congreso Nacional de Riegos. León 15-17 Junio de 2010.

Consejería de Medio Ambiente y Ordenación del Territorio (CMAOT). (2012). Demarcación Hidrográfica de las Cuencas Mediterráneas Andaluzas. Documentos plan hidrológico de la demarcación hidrográfica de las cuencas mediterráneas andaluzas. Consejería de Medio Ambiente y Ordenación del Territorio. Junta de Andalucía.

Contreras París, J.I., Baeza Cano, R, López Segura J.G. \& Gavilán Zafra, P. (2013). Comportamiento de emisores de riego localizado de bajo caudal con aguas residuales urbanas regeneradas. Estudio prospectivo de los emisores de riego localizado instalados en la zona regable del Bajo Andarax con aguas residuales urbanas regeneradas. XXXI Congreso Nacional de Riegos. Orihuela, Alicante, 18-20 de junio de 2013.

Merrian, J.L \& Keller, J. (1978). Farm irrigation system evaluation: a guide for management. Utah State University. 


\author{
S. Álvarez ${ }^{1}$, M.C. Ruiz-Sánchez ${ }^{1}$, F. Broetto ${ }^{2}$, M.F. Ortuño-Gallud ${ }^{1}$, M.J. Sánchez-Blanco ${ }^{1}$ \\ ${ }^{1}$ Centro de Edafología y Biología Aplicada del Segura (CEBAS-CSIC). P.O.Box 164. 30100. Murcia, España \\ salvarez@cebas.csic.es \\ 2 Instituto de Biociências UNESP, Departamento de Quimica e Bioquimica, Botucatu, Brasil,
}

\title{
INTRODUCCIÓN
}

Pistacia lentiscus es una especie silvestre mediterránea que se emplea como planta ornamental en proyectos de jardinería y paisajismo. Sin embargo a pesar de su adaptabilidad a determinadas condiciones adversas, puede sufrir estrés osmótico por falta de agua y/o por el uso de agua de baja calidad y poco se conoce sobre las respuestas en plantas arbustivas ornamentales (Álvarez y Sánchez-Blanco 2016). Por ello, el objetivo de este trabajo ha sido profundizar en el conocimiento de aspectos fisiológicos y morfológicos relacionados con el estado hídrico, intercambio gaseoso, acumulación de iones y crecimiento de plantas de Pistacia lentiscus bajo condiciones de salinidad y distintos niveles de riego deficitario.

\section{RESULTADOS Y DISCUSIÓN}

Al finalizar el ensayo, la altura de la planta se redujo con el riego deficitario y la salinidad, especialmente en las plantas del riego deficitario severo, mientras que la acumulación de biomasa solo se redujo en las plantas regadas deficitariamente (Tabla 1 ).

\begin{tabular}{|c|c|c|c|c|}
\hline \multirow{2}{*}{ Parámetros } & \multicolumn{4}{|c|}{ Tratamientos } \\
\hline & Control & Sal & RDM & RDS \\
\hline Altura (cm) & $63,8 \pm 3,0 \quad \mathrm{c}$ & $53,2 \pm 2,2$ & $48,7 \pm 2,6 \quad b$ & $37,3 \pm 1,2 \quad a$ \\
\hline Peso seco $\left(\mathrm{g} \mathrm{pl}^{-1}\right)$ & $61,8 \pm 2,9 \quad b$ & $62,3 \pm 7,1$ & $53,5 \pm 2,7 \quad \mathrm{ab}$ & $41,2 \pm 1,5$ \\
\hline
\end{tabular}

La salinidad aumentó la concentración de $\mathrm{Na}$ y $\mathrm{Cl}$ en la planta, aunque la entrada de cloro por las raíces fue más limitada que la de sodio (Figura 1). En cuanto a la distribución de los iones en los distintos tejidos, las plantas regadas con sal acumularon el $\mathrm{Cl}^{+}$principalmente en la raíz, limitando su paso a las hojas. Estas plantas, sin embargo no fueron capaces de retener el ion $\mathrm{Na}$ en las partes leñosas, alcanzando un valor de concentración de $\mathrm{Na}^{+}$en hoja 30 veces mayor que en las plantas control, lo que posiblemente contribuyó al descenso de crecimiento observado en estas plantas al final del ensayo (Cassaniti et al. 2009).

Los parámetros de intercambio gaseoso (conductancia estomática y fotosíntesis) disminuyeron más acusadamente en las plantas que recibían menos agua (RDS), las cuales presentaron los más bajos valores de contenido relativo de agua, provocando una importante disminución de los valores de potencial hídrico foliar (Figura 2). El efecto de las sales en el estado hídrico (CRA) apenas fue significativo, si comparamos ambos tratamientos control y salino.

\section{Conclusión}

Nuestros resultados indican que aunque ambos, estrés hídrico y salino reducen el crecimiento en $P$. lentiscus, las respuestas fisiológicas y morfológicas son diferentes y dependen de la naturaleza y de la intensidad del estrés. Las plantas de lentisco fueron mas afectadas por el riego deficitario que por la salinidad.

La aplicación de riego deficitario moderado y el uso de agua con un nivel determinado de salinidad $\left(4 \mathrm{dS} \mathrm{m}^{-1}\right)$ podrían usarse de forma satisfactoria en la producción de plantas de $P$. lentiscus, ya que estas mantienen una buena calidad. Sin embargo el riego deficitario severo no es recomendado, ya que reduce considerable la fotosíntesis y el crecimiento y podría retrasar la recuperación de la planta y causar daños permanentes.

\section{MATERIAL Y MÉTODOS}

Se emplearon 160 plantas de Pistacia lentiscus, de 1 año de edad, que fueron trasplantadas a macetas de $4 \mathrm{~L}$. El sustrato fue una mezcla de fibra de coco, turba y perlita (8:7:1) (Foto 1). Estas macetas fueron trasladadas a un invernadero, donde crecieron durante 3 semanas regándose hasta completar sus necesidades hídricas y a partir de ahí sometidas durante 11 meses a cuatro tratamientos de riego: un control regado diariamente a capacidad de campo (CE; $\left.1 \mathrm{dS} \mathrm{m}^{-1}\right)$, dos tratamientos deficitarios, (RDM y RDS), que corresponden al 60 y $40 \%$ de la cantidad aportada al control, y un tratamiento regado como el control pero con agua salina (CE; 4 dS $\left.m^{-1}\right)$.

\section{MEDIDAS}

- Peso seco de la planta

- Altura de la planta

- Contenido relativo de agua foliar (CRA)

-Concentración de $\mathrm{Na}$ y $\mathrm{Cl}$

-Potencial hídrico foliar al mediodía

$\left(\Psi_{h}\right)$, usando una cámara de presión

(Model 3000; Soil Moisture Equipment)

- Conductancia estomática $\left(\mathrm{g}_{\mathrm{s}}\right)$ y la tasa de fotosíntesis neta $\left(P_{n}\right)$ aparato portátil LI-COR 6400 (LI-COR Inc., Lincoln, NE, USA).

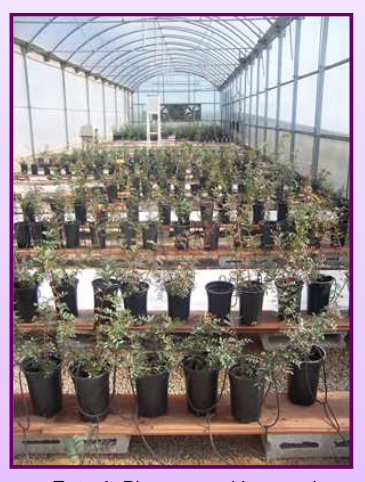

Foto 1. Plantas en el invernadero durante el ensayo.

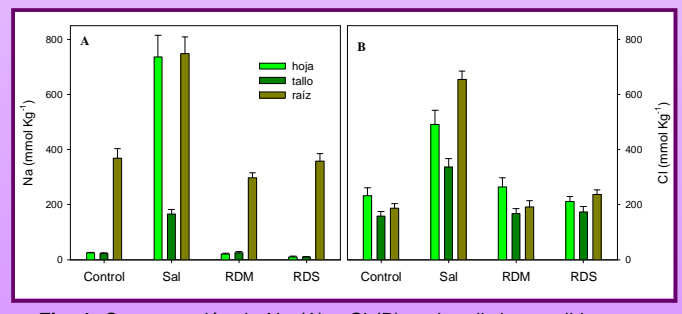

Fig. 1. Concentración de $\mathrm{Na}(\mathrm{A})$ y $\mathrm{Cl}(\mathrm{B})$ en los distintos tejidos en plantas de lentisco al final del ensayo.

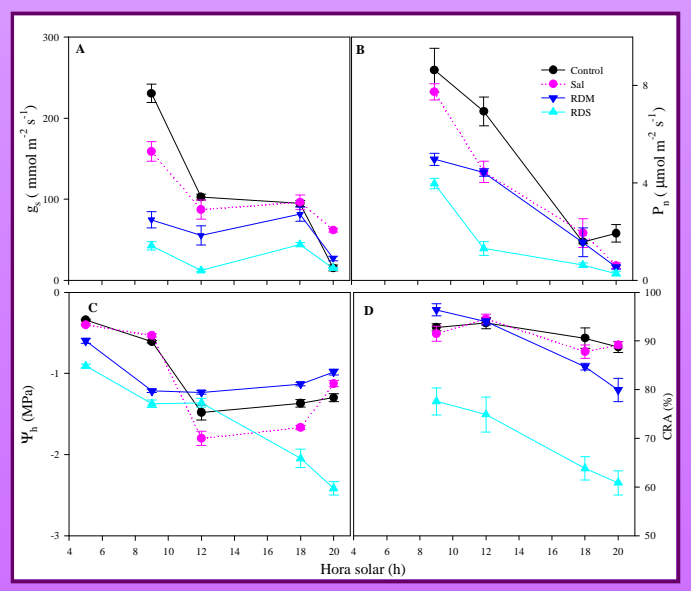

Fig. 2. Evolución diaria de la conductancia estomática $\left(\mathrm{g}_{\mathrm{s}} ; \mathrm{A}\right)$, tasa de fotosíntesis neta $\left(P_{n} ; B\right)$, potencial hídrico foliar $\left(\Psi_{h} ; C\right)$ y contenido relativo de agua (CRA; D) BIBLIOGRAFíA

Álvarez, S., Sánchez-Blanco, M.J. 2015. J. Plant Physiol . 185, 65-74. Cassaniti, C., Leonardi, C., Flowers, T. 2009. Sci. Hort. 122, 586-593. 


\section{GRUPO TEMAS C: Ingeniería y Modernización del Riego}

Equipos, materiales, instrumentación, etc. Métodos de riego y respuesta de los cultivos. Explotación, mantenimiento, modernización y rehabilitación de los sistemas de riego y drenaje. Ahorro de agua, energía y otros insumos. Reducción de costes de explotación. Programación de la red de riego. Modelos matemáticos. Utilización de fuentes alternativas de energía en riegos a presión. Proyectos de ingeniería de riego, experiencias y enseñanzas adquiridas de su ejecución. Aplicación práctica de técnicas experimentadas. 


\title{
C-01
}

\section{ANÁLISIS DEL FUNCIONAMIENTO DE UNA RED COLECTIVA ANTE DISTINTAS ESTRATEGIAS DE RIEGO EN PARCELA}

\author{
Lima, F.A. ${ }^{1}$, Córcoles, J.I ${ }^{2}$, Moreno, M.A ${ }^{4}$,Tarjuelo, J.M $M^{5}$ Martínez-Romero, A.M ${ }^{3}$
}

${ }^{1}$ Doctorando, Universidad Castilla-La Mancha (UCLM), Centro Regional de Estudios del Agua, aldiel_metal@hotmail.com

2 Dr. Ingeniero Agrónomo, Profesor Contratado Doctor Temporal EIIAB, Departamento de Mecánica Aplicada e Ingeniera de Proyectos, UCLM, juanignacio.corcoles@uclm.es

${ }^{3}$ Dr. Ingeniero Agrónomo, Profesor Asociado; EIIAB, Departamento de Mecánica Aplicada e Ingeniera de Proyectos, UCLM, angel.mromero@uclm.es

4 Dr. Ingeniero Agrónomo. Contratado Doctor; Departamento de Producción Vegetal y Tecnología Agraria, UCLM- ETSIAM; MiguelAngel.Moreno@uclm.es

${ }^{5}$ Dr. Ingeniero Agrónomo. Catedrático de UCLM. Centro Regional de Estudios del Agua. Albacete. jose.tarjuelo@uclm.es

\section{Resumen}

En zonas colectivas de riego, la tarifa a pagar por los agricultores está muy condicionada con el gasto energético de los equipos de bombeo, relacionada a su vez con la cantidad de agua aplicada a los cultivos. Así pues, es necesario el desarrollo de herramientas de ayuda a la toma de decisiones que busquen mejorar la eficiencia en el uso del agua y la energía, sin comprometer el rendimiento y productividad de los cultivos. El objetivo del trabajo es analizar el consumo energético en una estación de bombeo de una red colectiva de riego a la demanda ante distintos escenarios de riego en parcela y de presiones en la cabecera. La metodología propuesta ha sido aplicada a la zona regable de Tarazona de La Mancha (Albacete, España). Se han establecidos dos manejos de riego en parcela (con y sin déficit) para los principales cultivos de la zona y diferentes estrategias de presiones en la cabecera (variable y fija), para analizar el efecto sobre la eficiencia y consumo energético del bombeo. Para ello, se ha utilizado una herramienta de simulación desarrollada en MATLAB®, en combinación con el motor de cálculo EPANET $®$, y se ha aplicado como ejemplo a un día de elevada demanda de agua en la red. Los resultados indican que la utilización de presión en cabecera variable y manejo deficitario, genera ahorros energéticos de $12,43 \%$ en relación al mismo manejo con presión fija.

\section{1) Introducción. Objetivo del trabajo.}

En regiones semiáridas como Castilla-La Mancha (C-LM), el regadío en la agricultura permite diversificar los cultivos, garantizar un mayor nivel de producción y, en muchos casos, mantener la viabilidad económica de las explotaciones. En estas zonas, donde el principal factor limitante es la escasez de los recursos hídricos, junto con el hecho de tratarse en su mayoría de aguas subterráneas, hace que el coste ligado a la extracción y aplicación del agua con el riego sea uno de los factores más relevantes dentro de los costes de producción, debido al elevado coste de la energía.

El conocimiento preciso del posible ahorro de agua aplicada en parcela (mejorando la programación de riegos, utilizando riego deficitario, etc.) y de energía que se puede conseguir con una adecuada gestión de la red, resulta de gran interés por su correspondiente repercusión económica y medioambiental. Este aspecto tiene mayor 
importancia en grandes redes colectivas de riego, donde el uso colectivo de los recursos debe optimizarse para garantizar la sostenibilidad del regadío.

En la gestión de estas redes se plantean alternativas de manejo a turnos o a la demanda, si bien en ambos casos cada agricultor realiza su programación del riego en parcela, utilizando criterios no siempre optimizados para cada uno de sus cultivos.

Por lo tanto, para mejorar la gestión de una red colectiva de riego se hace necesario profundizar en el manejo del riego en parcela, buscando estrategias que permitan gestionar el agua de riego de modo óptimo para cada cultivo. En condiciones de escasez de recursos hídricos, con regadíos infradotados, o en las que los costes energéticos de extracción de aguas subterráneas son muy altos, la aplicación de técnicas tales como el Riego Deficitario Controlado (RDC) (English, 1990) permiten reducir costes productivos, e incrementar la eficiencia en el uso del agua por parte de los cultivos (López-Urrea et al., 2009), consiguiendo un mayor rendimiento por unidad de volumen de agua aplicada al cultivo a costa de reducir el rendimiento por unidad de superficie. Esta técnica consiste en reducir el aporte de agua durante las etapas menos sensibles al estrés hídrico para evitar o limitar el déficit en las más sensibles.

El objetivo del trabajo es analizar el consumo energético en una estación de bombeo de una red colectiva de riego a la demanda, considerando dos manejos de la presión en cabecera, fija o variable, y dos manejos del riego en parcela, con riego deficitario controlado y sin él.

\section{2) Material y métodos}

\subsection{Caso de estudio}

La metodología propuesta ha sido aplicada en una Comunidad de Regantes (CCRR) en Tarazona de La Mancha (Albacete, España). La zona regable de 1044 ha, está compuesta por dos redes colectivas de riego a la demanda independientes (Sector I y Sector II).

En el sector de estudio (sector I), el agua se distribuye mediante un grupo de rebombeo compuesto por 10 bombas iguales (140 CV por bomba) conectadas en paralelo, dos de ellas con variador de velocidad (Tabla 1). La estación de bombeo funciona con regulación manométrica en cabecera, con presión fija de $52 \mathrm{~m}$.

Tabla 1. Características hidráulicas de los dos sectores de SORETA.

\begin{tabular}{|c|c|}
\hline Características & Sector I \\
\hline Superficie regable (ha) & 550,2 \\
\hline Numero de hidrantes & 389 \\
\hline Volumen del embalse $\left(\mathrm{m}^{3}\right)$ & 23000 \\
\hline Número de sondeos & 4 \\
\hline Numero de bombas para el rebombeo & 10 \\
\hline Potencia de las bombas para el rebombeo $(\mathrm{CV})$ & 140 \\
\hline Longitud total de tuberías $(\mathrm{m})$ & 30504 \\
\hline
\end{tabular}

Este sector tiene una superficie regable de 550,2 ha, dedicadas principalmente a cultivos herbáceos (cereales de invierno y verano, cebolla y ajo), y con predominio de sistema de riego mediante cobertura total enterrada. La presencia de cultivos leñosos es menor (aproximadamente del 20\%), aunque ha aumentado en los últimos años, con la transformación de los sistemas de riego en parcela por aspersión a sistemas de riego localizado.

\subsection{Metodología propuesta}


En la Figura 1, se muestra el diagrama de flujo de los escenarios de manejo (con y sin déficit) y de presión en cabecera (variable y fija), que se pretenden comparar en una red colectiva de riego ya calibrada en trabajo previos (Moreno et al, 2007a). La comparación de resultados se realizará evaluando el consumo energético de la red para un día de elevada demanda hídrica, utilizando para ello una herramienta programada en MATLAB® en combinación con el motor de cálculo EPANET® (Rossman, 2001).

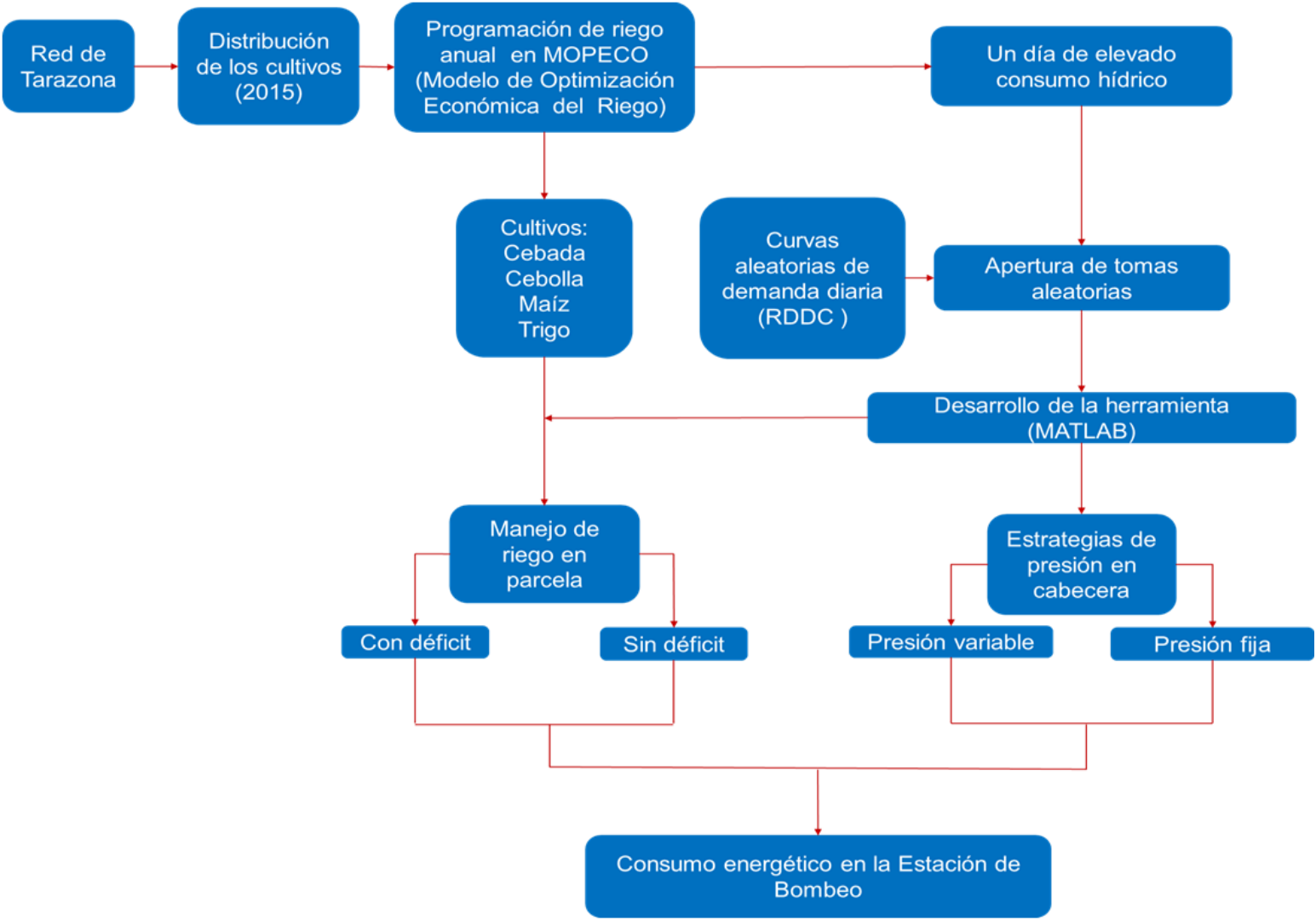

Figura 1. Diagrama de flujo de la metodología aplicada.

Como punto de partida, se ha utilizado la distribución de los cultivos para el sector de estudio en el año de 2015, donde aproximadamente la mitad de la superficie está ocupada por los cultivos de cebada (30\%), trigo (9\%), maíz (6\%) y cebolla (4\%) (Fig. 2), representando un consumo de agua anual del $56 \%$ del que se presenta en la red.

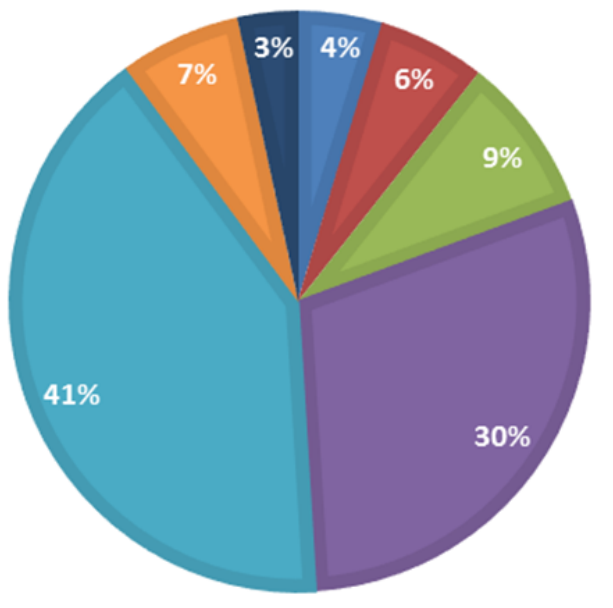

- CEBOLLA

- MAIZ

- TRIGO

- CEBADA

- OTROS CULTIVOS

- OTROS CONSUMOS

- BARBECHOS

Figura 2. Distribución de los cultivos (\%) para el año 2015. 
Para estos cultivos, se han planificado las programaciones de riego optimizadas para el año 2015, con dos manejos de riego en parcela, uno con riego deficitario, con el objetivo de conseguir los niveles de déficit recogidos en la Tabla 3 durante el ciclo de cultivo, y otro sin riego deficitario. La programación de ambos tipos de riegos se han realizado utilizando el método de balance simplificado diario de agua en el suelo usando el módulo destinado para este fin en el programa MOPECO (Modelo de Optimización Económica del Riego) (Domínguez, et al., 2012ab) que aplica la metodología FAO (Allen et al., 1998), y que ha sido previamente calibrado para los cultivos seleccionados.

En la Tabla 2, se muestra la duración en días y los valores de los coeficientes de cultivo (kc), para cada etapa de desarrollo de los mismos, utilizados para establecer las programaciones de riego.

Tabla 2. Duración de las etapas y valores de coeficiente de los cultivos (kc).

\begin{tabular}{|l|c|c|c|c|c|c|c|c|}
\hline & \multicolumn{2}{|c|}{ Cebada } & \multicolumn{2}{c|}{ Cebolla } & \multicolumn{2}{c|}{ Maíz } & \multicolumn{2}{c|}{ Trigo } \\
\hline $\begin{array}{l}\text { Etapa } \\
\text { fenológica }\end{array}$ & Días* & $\mathrm{kc}^{* *}$ & Días* & $\mathrm{kc}^{* *}$ & Días*$^{*}$ & $\mathrm{kc}^{* *}$ & Días $^{*}$ & $\mathrm{kc}^{* *}$ \\
\hline Establecimiento & 102 & $0,30-0,30$ & 60 & $0,65-0,65$ & 41 & $0,30-0,30$ & 98 & $0,30-0,30$ \\
\hline $\begin{array}{l}\text { Desarrollo } \\
\text { vegetativo }\end{array}$ & 45 & $0,30-1,15$ & 31 & $0,65-1,20$ & 39 & $0,30-1,10$ & 40 & $0,30-1,15$ \\
\hline Etapa media & 16 & $1,15-1,15$ & 47 & $1,20-1,20$ & 38 & $1,10-1,10$ & 36 & $1,15-1,15$ \\
\hline Maduración & 20 & $1,15-0,45$ & 19 & $1,20-0,75$ & 27 & $1,10-0,55$ & 21 & $1,15-0,45$ \\
\hline
\end{tabular}

*Días: Duración en días de cada etapa fenológica; ${ }^{* \star} \mathrm{kc}$ : Coeficiente del cultivo.

Para el manejo del Riego Deficitario Controlado (RDC) se ha determinado el nivel de déficit que debe aplicarse en cada etapa del cultivo para lograr el máximo rendimiento posible bajo un cierto nivel de déficit global objetivo. El nivel de déficit global para los cultivos se ha establecido en base al manejo común en la zona (Tabla 3), con reducciones de entre el $20 \%$ y el $30 \%$ sobre los consumos máximos. La distribución del déficit hídrico por etapas en los cultivos se realizó siguiendo las recomendaciones de Domínguez et al (2012ab) (Tabla 3), aplicando la técnica de Riego Deficitario Optimizado por Etapas (ORDI- Optimized Regulated Deficit Irrigation), que determina los niveles de déficit óptimos a aplicar (relación $\mathrm{ET}_{\mathrm{a}} / \mathrm{ET}_{\mathrm{m}}$ ) en cada etapa de desarrollo de los cultivos herbáceos en función del nivel de déficit global que se desee alcanzar.

Para los distintos escenarios de manejo, se han seleccionado dos parcelas de seguimiento de cada cultivo, en las que previamente se han evaluado los sistemas de riego para definir las condiciones de funcionamiento (presión de funcionamiento, caudales descargados y uniformidad de distribución del agua). Además se ha instalado un transductor de presión en el aspersor que presentaba aproximadamente la presión media en cada parcela de seguimiento, lo que ha permitido registrar cada dos minutos la presión de funcionamiento, determinando factores como los momentos de inicio y finalización de los riegos, presiones medias de trabajo y el agua aplicada al cultivo en cada riego.

Para definir las simulaciones de funcionamiento de la red, se ha escogido una semana (entre el 11 y el 17 de mayo) donde se dan las condiciones de mayor demanda de agua en la red (Fig. 3), dado que en este período se encuentran implantados cultivos de invierno (cereales) y de verano (cebolla y maíz), siendo los primeros los que demandan una mayor proporción del agua de riego en el conjunto de la red. 


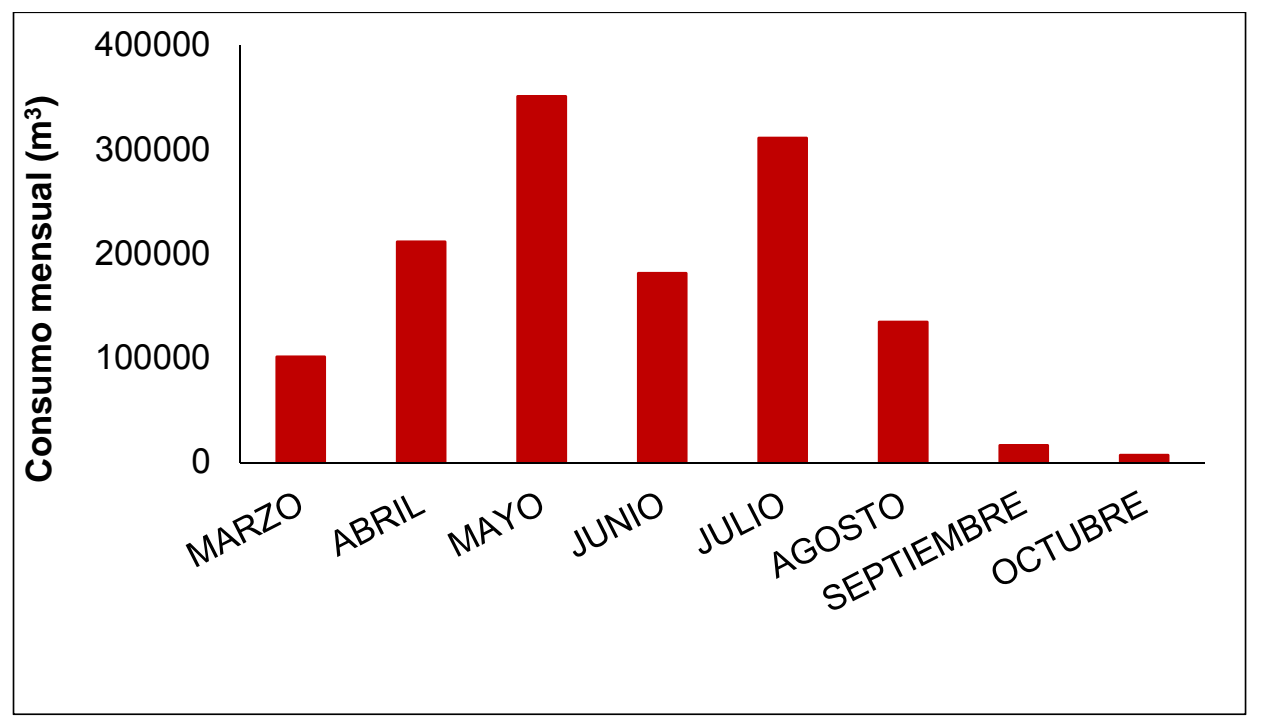

Figura 3. Consumo mensual de agua en la CCRR de Tarazona para el año de 2015.

Para realizar las simulaciones, se ha desarrollado una herramienta en MATLAB $®$ en combinación con el motor de cálculo EPANET $®$ (Rossman, 2001). Con esta herramienta se determinarán los caudales circulantes por las líneas de la red así como las presiones, permitiendo así obtener la eficiencia energética de la estación de bombeo y su consumo energético para los escenarios planteados.

Para el desarrollo de las simulaciones, se parte de una distribución de apertura de tomas al azar, basada en apertura aleatoria utilizando metodología de Curvas Aleatorias de Demanda Diaria (RDDC) (Moreno et al. 2007a), que tiene en cuenta la probabilidad de apertura de tomas para un día; el tiempo de riego ( $\mathrm{Tr}$, en horas); el número de sectores; la Jornada Efectiva de Riego (horas); y el Intervalo de riegos (días). Además, el tiempo de inicio de apertura también se ha generado de forma aleatoria.

En las simulaciones realizadas, el número de tomas abiertas durante un día son las mismas para los dos manejos (con y sin déficit), variando únicamente el $\mathrm{Tr}$ en cada caso (Tabla 3).

Tabla 3. Determinación de tiempo de riego para una semana.

\begin{tabular}{|c|c|c|c|c|c|c|c|c|}
\hline \multirow{2}{*}{ Cultivo } & \multirow{2}{*}{$\begin{array}{c}\text { Etapa } \\
\text { fenológica }\end{array}$} & \multirow{2}{*}{$\begin{array}{c}\mathrm{ETm}^{*} \\
(\mathrm{~mm} \\
\text { semana }\end{array}$} & \multirow{2}{*}{$\begin{array}{c}\text { Intervalo } \\
\text { de riego } \\
\text { (días) }\end{array}$} & \multirow{2}{*}{$\begin{array}{l}\text { Riegos } \\
\text { por } \\
\text { semana }\end{array}$} & \multicolumn{2}{|c|}{ Déficit } & \multicolumn{2}{|c|}{$\begin{array}{l}\text { Tiempo de } \\
\text { riego }(\mathrm{h})\end{array}$} \\
\hline & & & & & Global & Etapa & $\begin{array}{l}\text { Sin } \\
\text { déficit }\end{array}$ & $\begin{array}{l}\text { Con } \\
\text { déficit }\end{array}$ \\
\hline Cebada & Etapa media & 53,02 & 3,5 & 2 & 0,70 & 0,75 & 4,5 & 3,5 \\
\hline Cebolla & $\begin{array}{l}\text { Desarrollo } \\
\text { vegetativo }\end{array}$ & 34,15 & 3,5 & 2 & 0,80 & 0,63 & 3,0 & 2,0 \\
\hline Maíz & Establecimiento & 13,83 & 7,0 & 1 & 0,80 & 0,80 & 2,5 & 2,0 \\
\hline Trigo & Etapa media & 53,02 & 3,5 & 2 & 0,75 & 0,85 & 4,5 & 4,0 \\
\hline
\end{tabular}

*Etm: Evapotranspiración máxima semanal de cultivo $(E t m=$ Evapotranspiración $x$ Coeficiente de cultivo $(\mathrm{kc})$.

La jornada efectiva de riego (JER) ha sido de 24 horas, referente a un día de fin de semana, correspondiendo al período de tarifa más barata contratada por la CCRR.

Con las tomas seleccionadas y los tiempos de riego en cada parcela para cada tipo manejo de riego (deficitario y no deficitario), se han determinado los caudales circulantes en las tuberías así como las presiones en cada toma de la red, tanto para el caso de la presión variable necesaria en cabecera capaz de garantizar una presión mínima de 35 m.c.a en el hidrante abierto más desfavorable, como para el caso de considerar el valor de presión fija en cabecera empleado en la regulación actual de la CCRR (52 m.c.a). 
Para analizar el consumo de energía $\left(\mathrm{kW} \mathrm{h}^{-1}\right)$ de la estación de bombeo en las distintas condiciones de presión y caudal, se ha determinado la eficiencia de la estación de bombeo para distintos rangos de caudal y presión en cabecera empleando el Modelo de Análisis de Eficiencia Energética en Estaciones de Bombeo (MAEEB) (Moreno et al. 2007b).

Para determinar la eficiencia actual de la estación de bombeo, ha sido necesario adquisición de datos en la campaña 2015, relativos a parámetros hidráulicos y eléctricos en la estación de bombeo. Los parámetros eléctricos se han determinado con un analizador de redes QNA (Circutor, Barcelona, España) mediante un registro continuo de los parámetros eléctricos (intensidad, voltaje, potencia, etc). Es un equipo especialmente diseñado para el análisis de la calidad de suministro eléctrico, que permite detectar cualquier evento que se produzca en la red (huecos, interrupciones, armónicos, potencia, frecuencia, etc.) (Moreno, 2005; QNA, 2006, Córcoles 2009). EI QNA se instaló entre el transformador de media a baja tensión y a la entrada a la estación de bombeo, con registro de medidas cada diez minutos, desde el inicio de la campaña de riegos.

El registro de presión se ha realizado de forma continua mediante un transductor de presión (Druck, Leicester, UK) con un registrador de datos (Dickson, modelo ES-120). Este dispositivo, con un rango de medida de 0 a 6 bar, se instaló en el colector de impulsión de la estación de bombeo, siendo alimentado por una batería de $12 \mathrm{~V}$.

Además, se realizó una evaluación de las bombas de la EB (mediciones de caudal, presión y potencia absorbida) determinando el caudal descargado por cada una de las bombas, utilizando un caudalimetro de ultrasonidos (PT-868, de Panametric) así como su consumo eléctrico mediante un analizador de redes tipo AR5 (Circutor, Barcelona, España).

\section{3) Resultados y discusiones}

Se han realizado numerosas simulaciones para comprobar el funcionamiento de la herramienta, mostrando una de ellas para describir los resultados. En la Figura 4 se muestra la similitud de distribución de los caudales simulados por la herramienta, frente a los datos reales de caudal medidos en la campaña 2015.

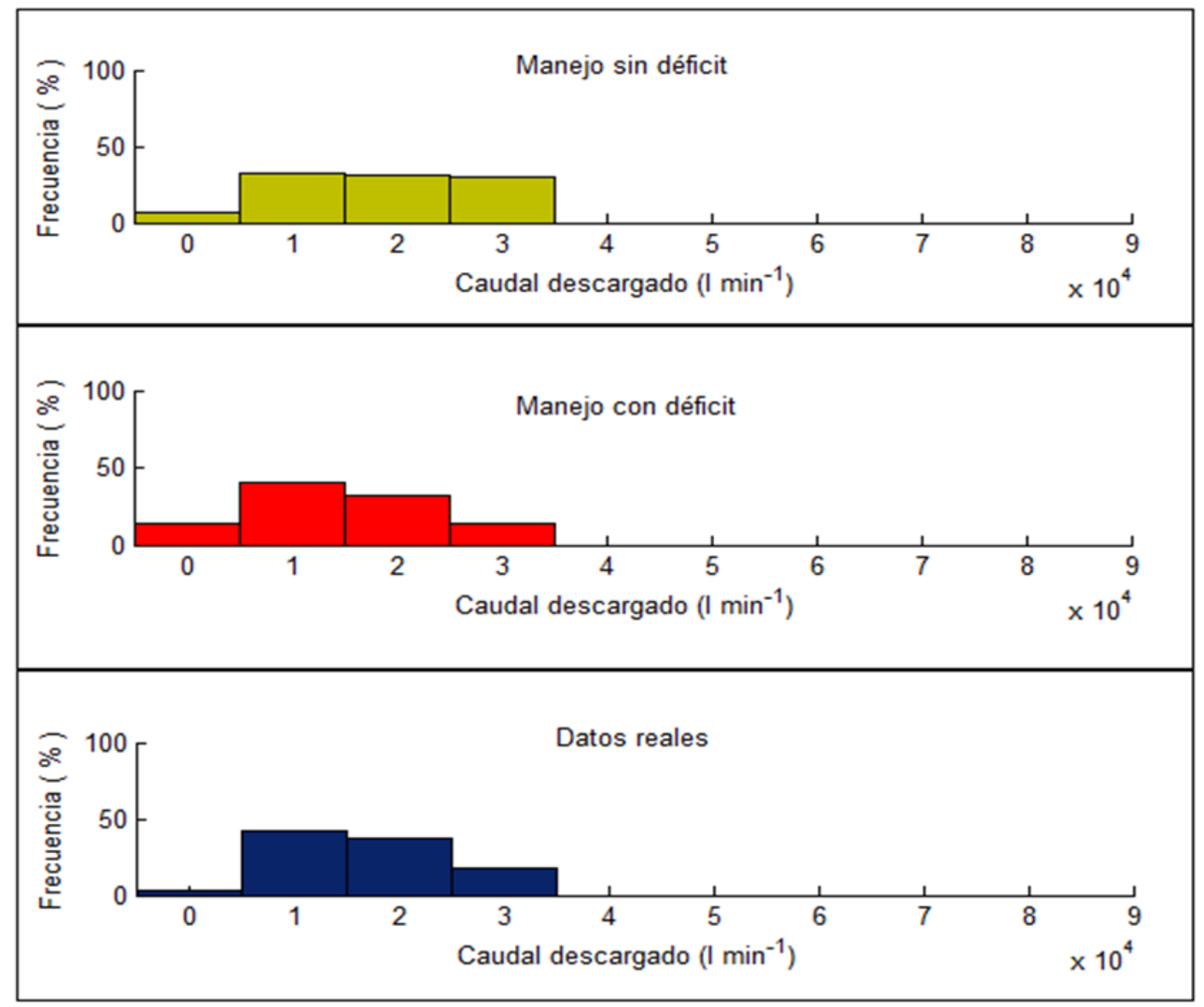

Figura 4. Frecuencia de caudales simulados y real. 
En el caso del manejo sin déficit, la Figura 4 muestra que el $93 \%$ de los caudales demandados se concentran en un rango que varían de 5000 a $35000 \mathrm{I} \mathrm{min}^{-1}$. La frecuencia de caudales en el manejo con déficit es semejante a la distribución de frecuencias de caudal de los datos reales. Para este manejo, los caudales más bajos (entre 0 y $15000 \mathrm{I} \mathrm{min}^{-1}$ ), representan más de la mitad $(54,17 \%)$ de los caudales demandados.

Para esta simulación, la probabilidad de tomas abiertas, generada por medio de las curvas aleatoria de demanda (hecha en Matlab®), ha establecido al azar un total de 36 tomas abiertas, utilizada para los dos manejos de riego. En el caso de los datos reales, no se dispone de información relativa al número de tomas abiertas en un determinado momento ni tampoco el número total de parcelas que han regado en un día. En relación con esto, en base a un día de elevada demanda en la red, con los datos medidos en la estación de bombeo ha sido posible determinar la distribución de los caudales demandados en la red, de utilidad para poder validar las simulaciones realizadas con la herramienta. De este modo, la apertura aleatoria de tomas intenta representar un escenario de riego habitual en la zona, representando así una petición real de puesta en riego por parte de los agricultores.

En la Figura 5 se muestra la distribución de los caudales para los escenarios planteados (riego sin déficit y con déficit) a partir de la aleatoriedad de aperturas de tomas.

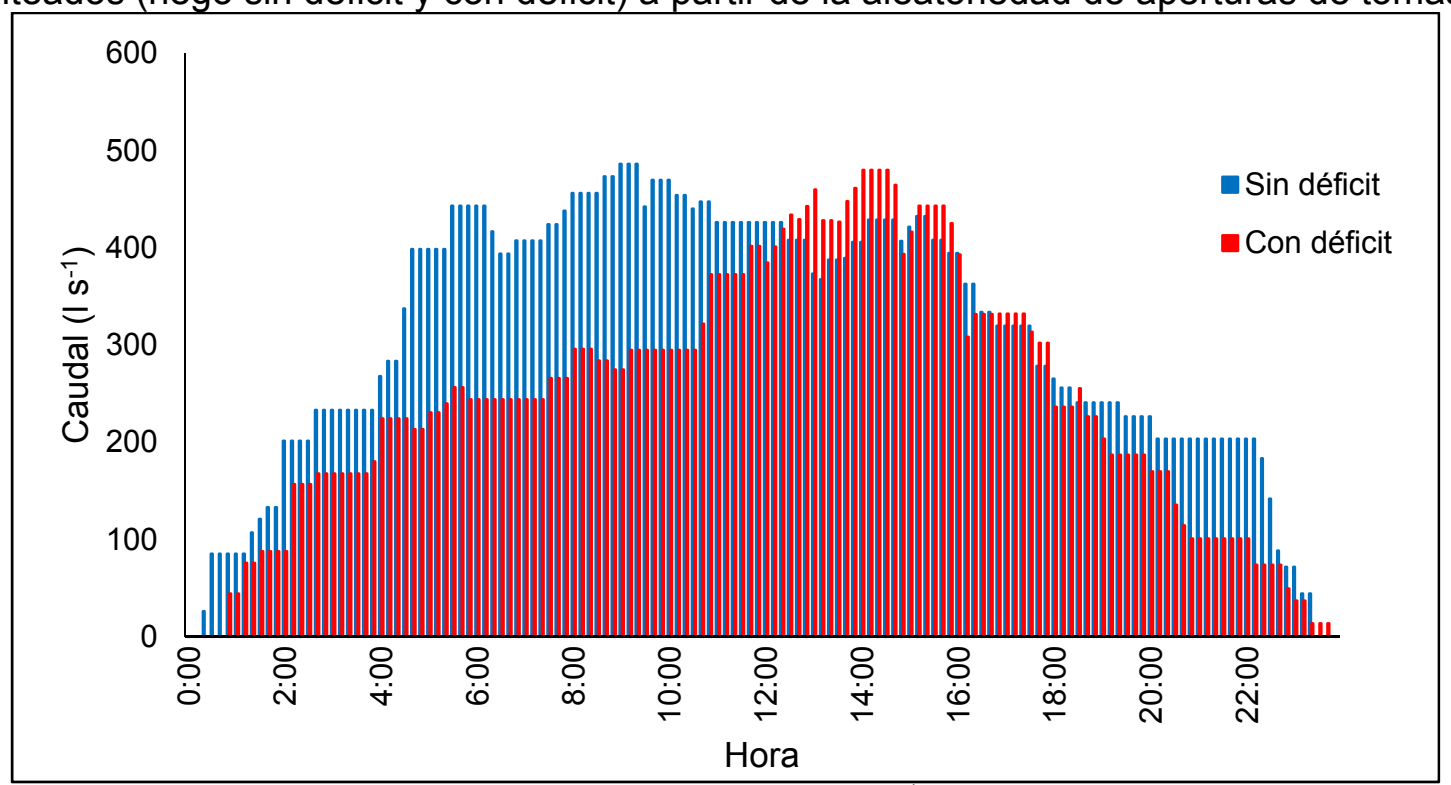

Figura 5. Distribución de los caudales $\left(\mathrm{I} \mathrm{s}^{-1}\right)$ para la simulación.

Para los dos manejos (sin y con déficit), la distribución de caudales muestra una distribución homogénea, con mayores demandas a lo largo del día para el manejo sin déficit. Las mayores demandas de caudales para el manejo sin déficit, se debe al mayor tiempo necesario de riego para los cultivos, además, la distribución de los dos manejos son distintos, no presentando la misma forma a lo largo del día, porque, a pesar de utilizar las mismas tomas, el momento de inicio de su apertura es distinto.

Teniendo en cuenta el volumen de agua total aportado para el periodo considerado, cabe destacar que, en el caso de riego con déficit, el volumen ha sido inferior (alrededor de $21 \%$ ), en comparación con el manejo sin déficit.

Utilizando la herramienta desarrollada, la presión en cabecera para los dos manejos, alcanza valores medios (alrededor de $40 \mathrm{~m}$ ) inferiores al sistema de regulación actual de la estación de bombeo (52 m) (Tabla 4).

Tabla 4. Presiones en cabecera simulados para los dos manejos de riego.

\begin{tabular}{|c|c|c|c|c|}
\hline Escenario & Media & Mínimo & Máximo & Desviación estándar \\
\hline Sin déficit & 41,50 & 38,10 & 45,17 & 2,69 \\
\hline Con déficit & 40,62 & 38,10 & 43,86 & 2,09 \\
\hline
\end{tabular}


En relación a los rendimientos de la estación de bombeo, aunque las diferencias son pequeñas, los valores obtenidos fueron mayores para la presión fija en cabecera que para la variable, siendo algo mayor cuando se ha simulado para un manejo sin déficit en ambos casos (Tabla 5).

Tabla 5. Rendimiento medio de la EB para presión variable y fija.

\begin{tabular}{|l|c|c|c|c|}
\hline \multirow{2}{*}{} & \multicolumn{2}{|c|}{ Presión variable } & \multicolumn{2}{c|}{ Presión fija } \\
\cline { 2 - 5 } & Sin déficit & Con déficit & Sin déficit & Con déficit \\
\hline Rendimiento (\%) & 54,53 & 53,54 & 59,46 & 59,00 \\
\hline
\end{tabular}

El consumo de energía por la estación de bombeo (Fig. 6A y B) mostró una evolución similar a la obtenida con la distribución de caudales (Fig. 5). El consumo energético a lo largo del día, es mayor cuando se ha utilizado la presión fija, independiente del tipo de manejo de riego adoptado.

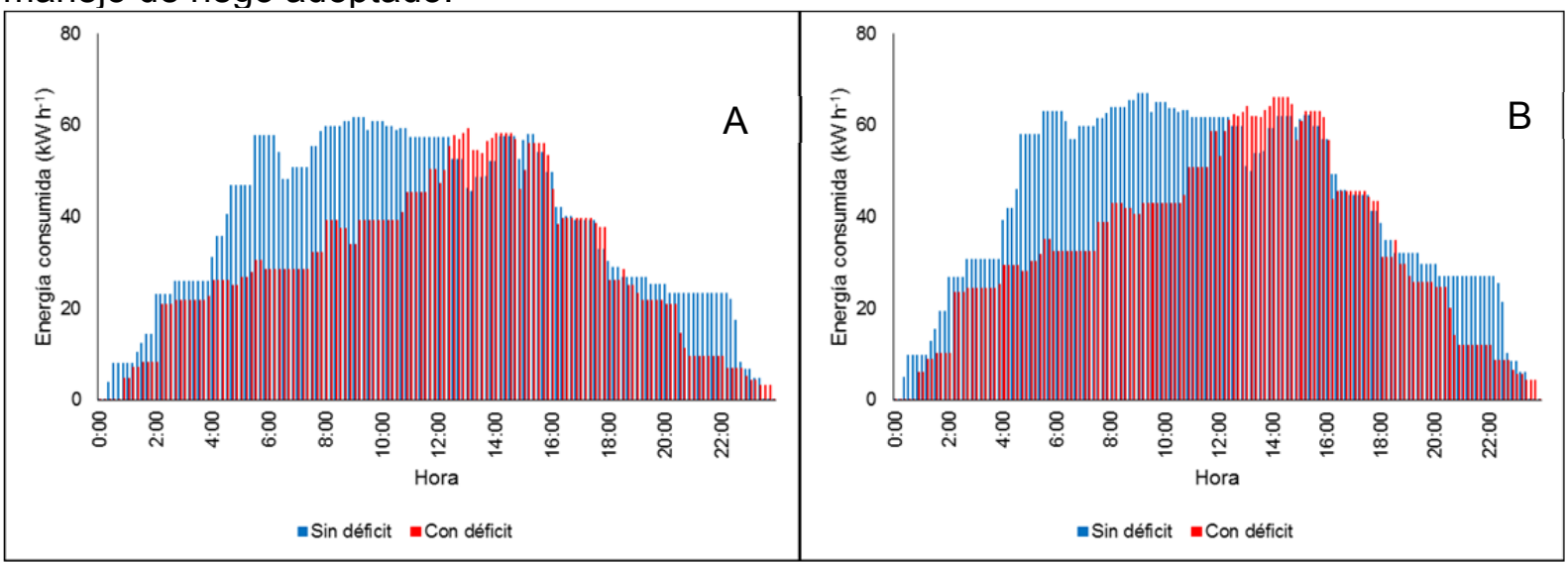

Figura 6. Consumo energético para la EB para la presión variable $(A)$ y fija $(B)$ para un día de simulación.

En la Tabla 6 se muestran los valores de consumo energético total para un día simulado. Es posible observar que en todos los casos analizados, el consumo fue menor que el consumo real obtenido por la red, excepto cuando se ha utilizado una presión fija con manejo sin déficit, que presentan un consumo energético superior $(3,33 \%)$ al medido en la EB.

Tabla 6. Consumo energético total para un día simulado.

\begin{tabular}{|l|c|c|c|c|c|}
\hline & \multicolumn{2}{|c|}{ Presión variable } & \multicolumn{2}{c|}{ Presión fija } & \multirow{2}{*}{ Datos Reales } \\
\cline { 2 - 5 } & Sin déficit & Con déficit & Sin déficit & Con déficit & \\
\hline Energía consumida $\left(\mathrm{kW} \mathrm{h}^{-1}\right)$ & 5509,59 & 4274,49 & 6213,43 & 4881,22 & 6012,93 \\
\hline
\end{tabular}

Entre los escenarios planteados, la presión variable y el manejo de riego deficitario en parcela, ha conseguido el mayor ahorro energético (Tabla 7). En comparación con los datos reales, con ese escenario se consigue un ahorro de $28,91 \%$ y cuando se compara con el mismo manejo pero adoptando la estrategia de mantener una presión fija, se ha conseguido un ahorro de $12,43 \%$.

\section{4) Conclusiones}

El presente trabajo muestra la utilidad de una herramienta generada para analizar la influencia que tiene las programaciones de riego en parcela sobre el consumo energético y el manejo de las estaciones de bombeo. De este modo se puede analizar el comportamiento de la estación de bombeo y de la red en estas zonas a través del conocimiento de los escenarios de demanda derivados de las programaciones del riego en parcela. Por todo ello, 
es un aspecto esencial integrar la programación de riego en parcela como una actividad complementaria dentro de las actividades realizadas por los gestores de las redes de riego.

El uso de manejos de riego en parcela y estrategia de presión en cabecera conllevan un ahorro en el consumo energético y, consecuentemente, económicos, cuando se utiliza manejo de riego deficitario en parcela y presiones variables en la cabecera.

Se pretende que la herramienta generada pueda servir para la optimización de recursos hídricos y energéticos en redes colectivas, a partir de programaciones de riego en parcela. De esta forma, se continuará con el desarrollo de la herramienta para profundizar el comportamiento utilizando diferentes días de la semana, así como etapa de mínima y máxima demanda de la red.

\section{5) Bibliografía}

Allen, R.G. Pereira, L.S. Raes, D. Smith,M. 1998. Crop evapotranspiration: guidelines for computing crop water requirements. FAO. Irrigation and Drainage Paper, 56, 297.

Córcoles, J.I. 2009. La gestión del agua y la energía en el regadío mediante técnicas de "Benchmarking". Tesis Doctoral, escuela Técnica Superior de Ingenieros Agrónomos, Universidad Castilla la Mancha, Albacete, España.

Domínguez, A, Juan, J,A, Tarjuelo, J,M, Martínez, R,S, Martínez-Romero, A, (2012a), Determination of optimal regulated deficit irrigation strategies for maize in a semi-arid environment, Agricultural Water Management, 110, 67-77.

Domínguez, A, Jiménez, M, Tarjuelo, J,M, Juana, J,A, Martínez-Romero A, Leite, K,N, (2012b), Simulation of onion crop behavior under optimized regulated deficit irrigation using MOPECO model in a semi-arid environment, Agricultural Water Management, 113, 64-75.

English, M.J, (1990), Deficit irrigation. I: Analytical framework. Journal of Irrigation and Drainage Engineering, 116, 399-412.

López-Urrea, R, Montoro, A, González-Piqueras, J, López-Fuster, P, Fereres, E. (2009). Water use of spring wheat to raise water productivity. Agric. Water Manage., $96,1305-1310$.

Moreno, M. A., Planells, P., Ortega, J. F., Tarjuelo, J. (2007a). New methodology to evaluate flow rates in on-demand irrigation networks. Journal of Irrigation and Drainage Engineering, 133(4), 298-306.

Moreno, M. A., Carrión, P. A., Planells, P., Ortega, J. F., Tarjuelo, J. M. (2007b). Measurement and improvement of the energy efficiency at pumping stations. Biosystems Engineering, 98(4), 479-486.

Rossman, L, A, (2001), EPANET 2, Users Manual, Water supply and Water Resources Division National Risk Management Research Laboratory, Cincinati, USA: U,S, Enviromental Protection Agency. 


\title{
AHORRO ENERGÉTICO EN RIEGO POR ASPERSIÓN. PRUEBAS DE NUEVOS ASPERSORES EN BANCO AUTOMÁTICO CON VIENTO
}

\author{
Salvatierra Bellido, B. (1) (P), Morillo Velarde, R. (2), Pérez Urrestarazu, L. (3), Andrades \\ Gonzalez, J.A(4), Bermejo Corrales, J.L. (4)

\footnotetext{
${ }^{1}$ Tecnólogo titular, IFAPA Centro Chipiona, (Cádiz), benito.salvatierra@juntadeandalucia.es

${ }^{2}$ Investigador y Director de AIMCRA, Valladolid, r.morillo@aimcra.es

${ }^{3}$ Investigador y Profesor Titular de la Universidad de Sevilla. Iperez@us.es

${ }^{3}$ Técnico de AIMCRA, IFAPA Centro Chipiona, (Cádiz), lord noru@hotmail.com

${ }^{4}$ Director técnico de la Zona Sur de AIMCRA, Sevilla,j.I.bermejo@aimcra.es
}

\section{Resumen}

El consumo energético en regadío es directamente proporcional a los valores objetivos de presión de una red colectiva de riego presurizada. El sistema de riego en parcela que más condiciona esta presión objetivo es el riego por aspersión. En este trabajo se ha analizado el comportamiento de los aspersores más utilizados en España en condiciones normales de funcionamiento frente a condiciones de presiones más bajas. Para ello se utilizó un banco de ensayo automático con viento y otro en condiciones confinadas sin viento. Se analizaron los aspersores en múltiples condiciones de trabajo, priorizando en el estudio la variable presión. Para ello se contempló un rango de presiones de 1,5 bar a 3.5 bar y con dos regímenes de viento: sin viento y con viento moderado. Como resultados del estudio se ofrece un análisis global de los datos obtenidos, que justifican la posibilidad de reducir la presión en riego por aspersión Además, se profundiza en resultados concretos para la reducción de la presión en el marco de riego de doce por quince metros.

\section{1-Introducción y objetivos}

En el año 2015 el Instituto de Investigación Agraria y Pesquera de Andalucía (IFAPA) y la Asociación de Investigación para la Mejora del Cultivo de la Remolacha Azucarera (AIMCRA) hicieron un convenio de colaboración para ensayar nuevas combinaciones de aspersores y boquillas en el banco de aspersores con viento del IFAPA Centro de Chipiona. El objetivo ha sido analizar distintas combinaciones de aspersores y boquillas que pudieran conseguir buenas uniformidades de riego a presiones más bajas, lo que supondría un gran ahorro energético para instalaciones individuales y en un futuro cercano para instalaciones de redes colectivas de riego. Esta línea de trabajo se abordó con el banco automático de ensayo de aspersores con viento existente en el centro IFAPA de Chipiona. El cultivo de la remolacha azucarera en España y en otros países mediterráneos va íntimamente unido al riego por aspersión, por lo que bajar los requerimientos de presión supondría bajar los costes energéticos del riego y por tanto, los costes de cultivo. Este esquema de innovación generaría resultados para los demás cultivos que utilizaran el riego por aspersión.

Para el estudio se han ensayado todos aquellos aspersores convencionales utilizados habitualmente en el cultivo de la remolacha azucarera. Estos aspersores son los más usados en España, debido a que este cultivo está implantado en las zonas más representativas de cultivos herbáceos extensivos. Se trata de un amplio trabajodonde se tienen en cuenta las condiciones reales de funcionamiento con viento. Se han incluido la mayoría de los fabricantes y contemplado todas las situaciones de riego posibles para analizar las respuestas en condiciones de bajas presiones. En fases posteriores y para 
ofrecer resultados concretos, se contará con la participación de empresas del sector interesadas en conocer el comportamiento de sus productos en condiciones dónde se optimice el consumo energético.

El objetivo final de esta línea es conseguir un ahorro de los costes de riego(energía y agua) manteniendo o mejorando la uniformidad del riego. Para ello se buscaron combinaciones de diseño de aspersores concretos ya conocidos, en condiciones de presión de trabajo reducida, dónde se asegurara una óptima Uniformidad de Distribución (UD) del agua de riego.

\section{2- Materiales y métodos}

Para la realización del trabajo se han utilizado dos bancos de ensayos de aspersores (Salvatierra et al, 2015): uno automático con viento, con datos de distribución de agua a través del modelo matricial; y otro sin viento, a través del modelo de curva radial. El objetivo de este segundo banco fue obtener datos básicos del comportamiento de un grupo de aspersores sin viento y ver cómo influía esta variable sobre el funcionamiento en condiciones reales.Los datos obtenidos de los ensayos con viento son resultados muy precisos al tratarse de un banco automático de recogida de datos continuos(Salvatierra, 2014) y con el cumplimento de la norma ISO 7749-2 que regula el método de ensayo en banco de aspersores rotativos.

Para la ejecución de los ensayos se fijaron tres valores de presión en los ensayos con viento. Las presiones utilizadas fueron: 3.5, 2.5, y 2 bares. Para el banco manual de aspersores sin viento: $3.5,2.5,2$, y 1.5 bares.

Para el banco de ensayos automático de aspersores con viento se obtuvieron 29.160 resultados de UD y para el banco manual de aspersores sin viento21.384 resultados de UD. En total suponen $\mathbf{5 0 . 5 4 4}$ resultados de UD del material ensayado. Este número de resultados viene en relación a las variables contempladas en tabla 1.

Tabla 1. Número de variables contempladas para los resultados obtenidos.

\begin{tabular}{|c|c|c|c|c|c|c|}
\hline & 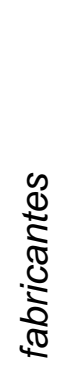 & 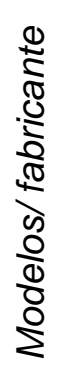 & 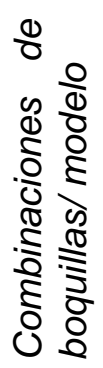 & 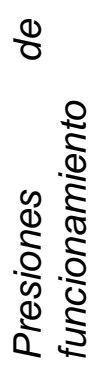 & 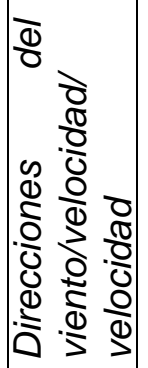 & 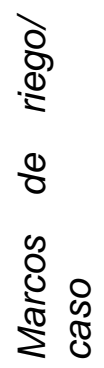 \\
\hline Banco automático de aspersores con viento & 5 & 2 & 3 & 3 & 3 & 81 \\
\hline Banco manual de aspersores sin viento & 1 & 2 & 5 & 4 & 0 & 81 \\
\hline
\end{tabular}

Los resultados que se obtiene incluyen información de variables directas medidas y otras de variables indirectas obtenidas por fórmulas empíricas y simulación. Las variables directas medidas fueron

- Fabricante aspersor.

- Modelo de aspersor.

- Boquilla principal.

- Boquilla secundaria.

- Accesorio en la boquilla.

- Caudal. 
- Presión.

- Velocidad del viento.

Y las variables indirectas fueron:

- Distancias entre aspersores.

- Distancia entre ramales.

- Disposición del marco.

- Dirección del viento.

- Índice de grosor de gota.

- Pérdidas por evaporación y arrastre.

Todos los resultados han sido clasificados para disponer de una herramienta potente de análisis y por tanto, generar resultados como los que a continuación se exponen.

\section{3- Resultados y discusión}

Un primer análisis de los resultados se focalizó sobre una muestra referida a todos los aspersores ensayados con viento en el marco de riego $12 \times 12$ (distancia entre aspersores $X$ distancia entre ramales de riego), esta muestra supone el $1,54 \%$ del total de resultados obtenidos de aspersores con viento.

En ella se obtienen los resultados siguientespara presionesmenores a 3,5 bares (que corresponde al $61 \%$ de la muestra de aspersores con viento ensayados a baja presión):

- El $48 \%$ son uniformidades aceptables y están por encima de una UD del $75 \%$

- El $33 \%$ son buenas y por encima del $80 \%$

- El $16 \%$ son excelentes y por encima del $85 \%$

Por otro lado, los ensayos a la presión nominal habitual (3,5 bares) muestran los valores siguientes: $57 \%, 36 \%$ y $12 \%$ respectivamente y según la clasificación anterior. Los valores a baja presión no son muy diferentes, y por tanto es interesante un estudio pormenorizado de los resultados generados.

A continuación se detallan los porcentajes de ensayos por cada valor de presión y marco, en relación a dos valores de uniformidad de distribución de agua críticos: UD aceptable $(>75 \%)$ y buena $(>80 \%)$. El siguiente gráfico detalla los resultados obtenidos para

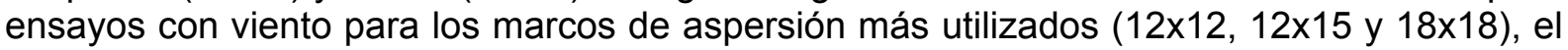
porcentaje de ensayos para cada valor de presión (3,5, 2,5 y 2 bares). 


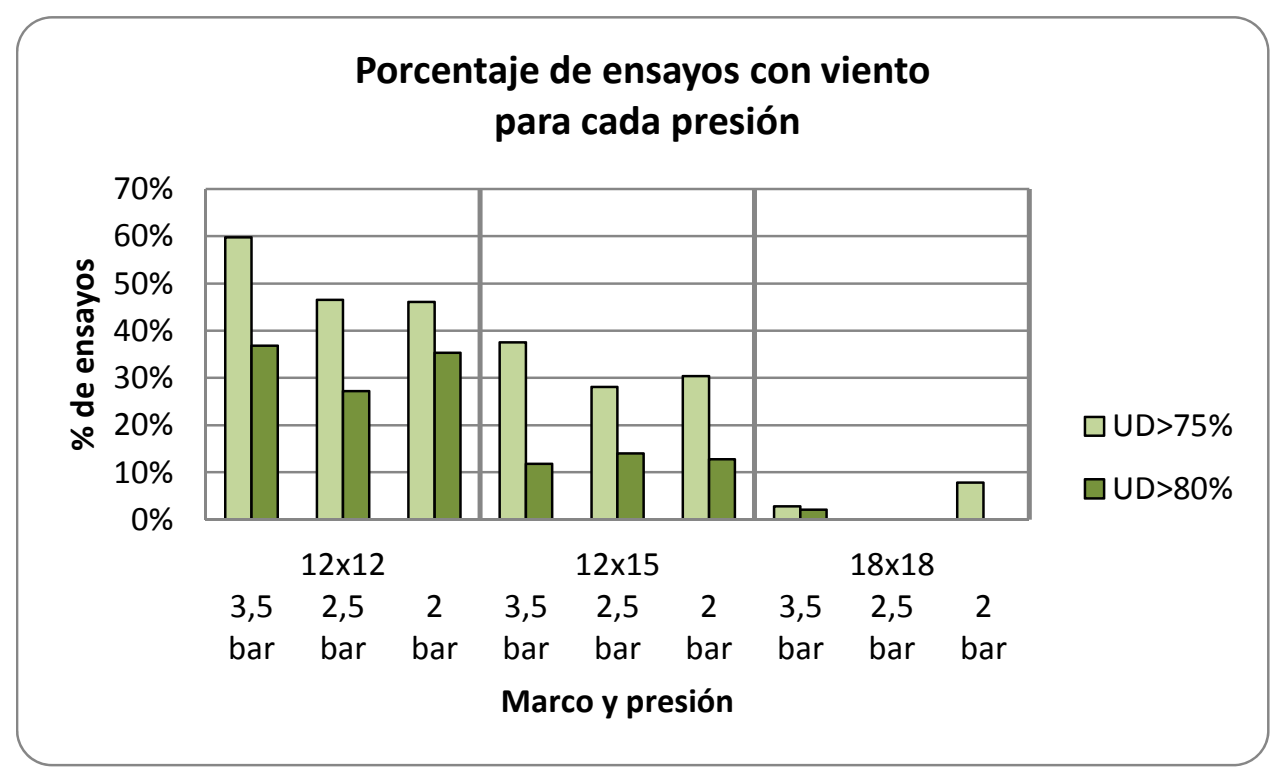

Figura 1. Porcentaje de aspersores ensayadosque tienen Uniformidad de Distribución aceptable y buena, para cada una de las presiones ensayadas y según los márcos más utilizados en riego por aspersión.

De este modo, sería posible trabajar a presiones más bajas siempre que el emisor que se utilice se haya ensayado previamente y funcione en las mismas condiciones en el ensayo.

En las gráficas siguientes, se comparará para un tipo de aspersor específico de impacto, las diferencias de funcionamiento con viento y sin viento. Éstas se refieren a los mismos criterios que la gráfica 1 , pero diferenciando el porcentaje de ensayos con Uniformidad de Distribución aceptable cuando no hace viento y cuando funcionan en condiciones de viento.

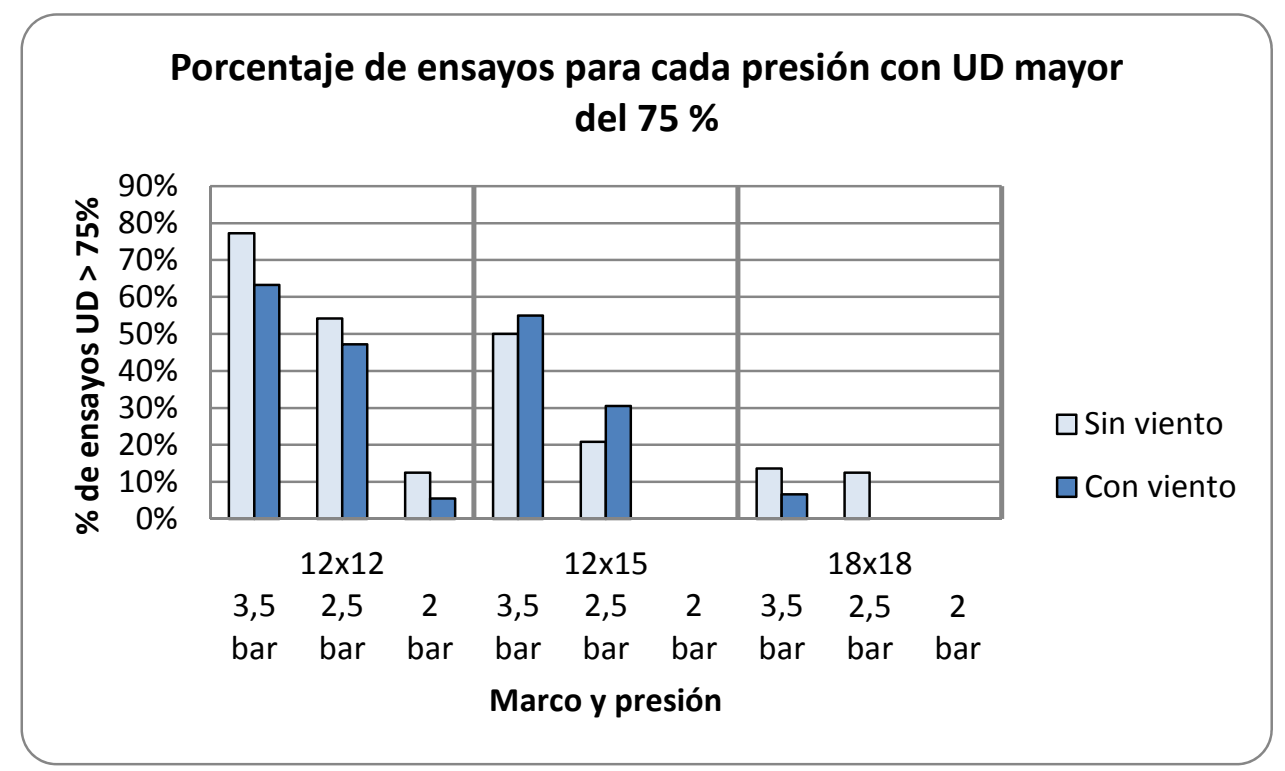

Figura 2. Ensayos realizados de un modelo convencional de aspersor de impacto para aquellos que tienen Uniformidad de Distribución aceptable, para cada una de las presiones ensayadas y según los márcos más utilizados en riego por aspersión. 
Igualmente en la siguiente gráfica se analiza el mismo tipo de aspersor pero con el criterio de obtener el porcentaje de ensayos con una Uniformidad de Distribución mayor al $80 \%$.

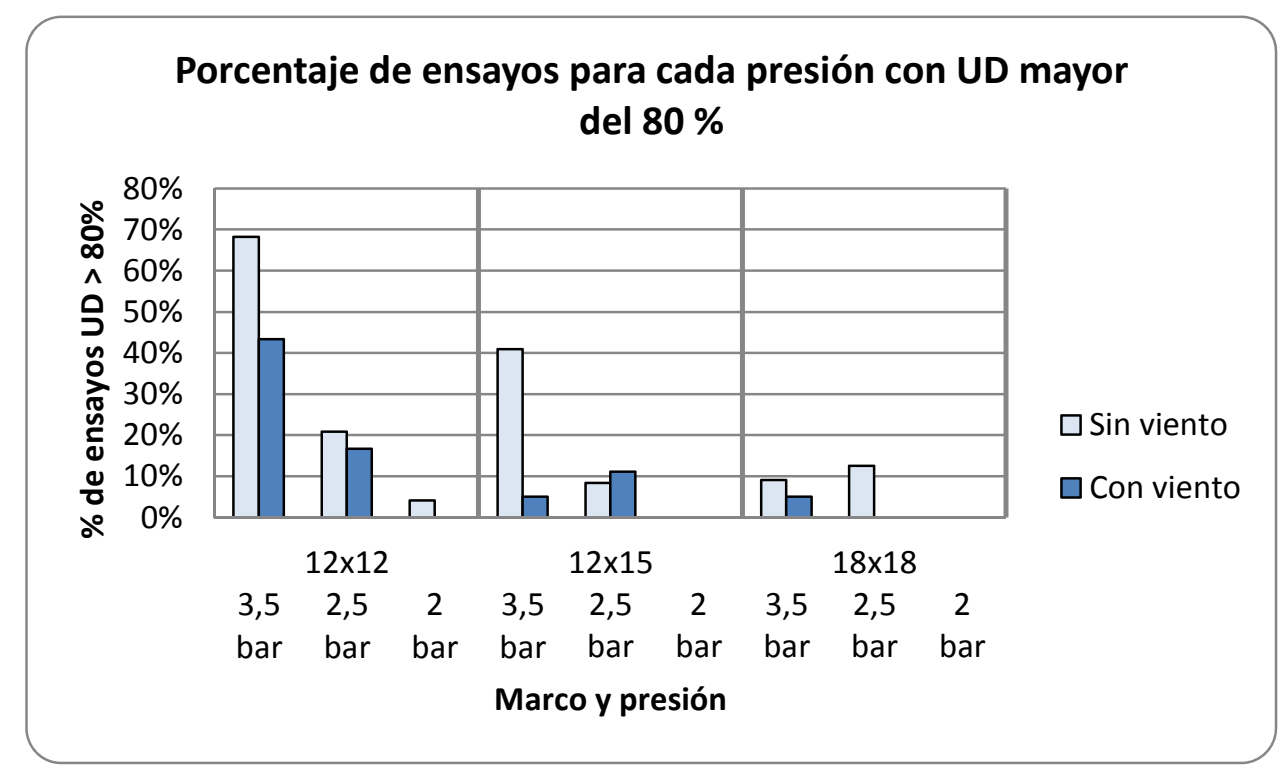

Figura 3. Ensayos realizados de un modelo convencional de aspersor de impacto para aquellos que tienen Uniformidad de Distribución buena, para cada una de las presiones ensayadas y según los márcosmás utilizados en riego por aspersión.

Según se indica en la gráfica 1 , dónde se analizan todos los ensayos con viento, se aprecian unos resultados para el marco $12 \times 15$ no tan buenos como en el marco de $12 \times$ 12pero mejores que para el marco de $18 \times 18$. Por ello, se podría bajar la presión, ya que existe en torno a $13 \%$ de los ensayos que tienen buena uniformidad tanto a 3,5 como en 2,5 y 2 bares de presión. Esta circunstancia es única para el marco $12 \times 15$ y para riego con viento moderado, entre 0,9 y $2,9 \mathrm{~m} / \mathrm{s}$.

En las siguientes tablas se muestran los aspersores y las variable con las que se han obtenido los valores de Uniformidad de Distribución. La primera tabla hace referencia a los obtenidos para una presión de funcionamiento de 3,5 bares, la segunda para 2,5 y la tercera para 2 bares.

Los ensayos señalados en verde oscuro, corresponden aaquellos aspersores,ycondiciones de funcionamientoquepresentanbuena uniformidad en las tres presiones ensayadas. Los señalados con color verde claro son aquellos que tienen buena uniformidad sólo a 3,5 y a 2,5 bares. Para no identificar la marcar comercial del aspersor, se ha decido codificarla como se puede apreciar en la columna de fabricante y modelo. 
Tabla 2. Ensayos de aspersores con buena uniformidad en marco de $12 \times 15$, a 3,5 bares con viento.

\begin{tabular}{|c|c|c|c|c|c|c|c|c|c|c|c|}
\hline 5 & 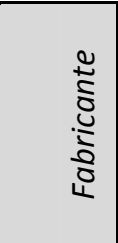 & $\begin{array}{l}\frac{0}{8} \\
\frac{1}{2}\end{array}$ & 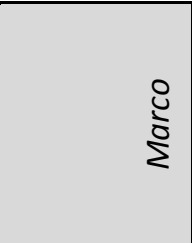 & 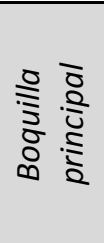 & 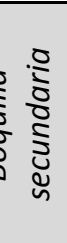 & t) & 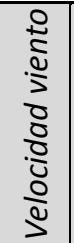 & 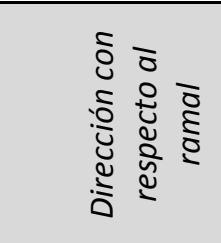 & $\begin{array}{l}\frac{1}{5} \\
\overline{0} \\
\frac{0}{0} \\
0 \\
0\end{array}$ & 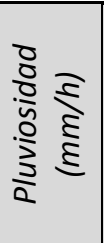 & 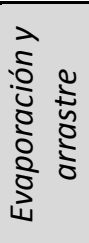 \\
\hline $81 \%$ & vvvvvv & gggg & Rectangular & $11 / 64$ & & & 1,9 & Perpendicular & 1361 & 7,56 & $18 \%$ \\
\hline $83 \%$ & $x x x x x x$ & bbbb & Rectangular & $5 / 32$ & si & si & 2,9 & Paralelo & 527 & 8,48 & $28 \%$ \\
\hline $84 \%$ & $x x x x x x$ & bbbb & Rectangular & $5 / 32$ & si & si & 2,9 & Perpendicular & 1527 & 8,48 & $28 \%$ \\
\hline $82 \%$ & $x x x x x x$ & bbbb & Rectangular & 9/64 & si & si & 2,6 & Perpendicu & 1350 & 7,50 & $26 \%$ \\
\hline $82 \%$ & $x x x x x x$ & bbbb & Triangular & $5 / 32$ & si & si & 2,9 & Paralelo & 1527 & 8,48 & $28 \%$ \\
\hline $82 \%$ & $x x x x x x$ & bbbb & Triangular & $5 / 32$ & si & si & 2,9 & Perpendicular & 1527 & 8,48 & $28 \%$ \\
\hline $82 \%$ & $x x x x x x$ & bbbb & Triangular & $9 / 64$ & si & si & 2,6 & Perpendicular & 1350 & 7,50 & $26 \%$ \\
\hline $83 \%$ & $x x x x x x$ & $\operatorname{cccc}$ & Triangular & $5 / 32$ & si & si & 2,7 & Perpendicular & 1408 & 7,82 & $26 \%$ \\
\hline $81 \%$ & yyyyyy & aaaa & Rectangular & $9 / 64$ & & si & 1,5 & Paralelo & 909 & 5,05 & $17 \%$ \\
\hline $84 \%$ & yyyyy & hhhh & Rectangular & $3 / 16$ & si & si & 2,0 & Perpendicular & 1927 & 10,71 & $17 \%$ \\
\hline $86 \%$ & yyyyyy & hhhh & Triangular & $3 / 16$ & si & si & 2,0 & Perpendicular & 1927 & 10,71 & $17 \%$ \\
\hline $86 \%$ & zzzzzz & ffff & Rectangular & $5 / 32$ & si & si & 1,6 & Oblicuo & 1520 & 8,45 & $18 \%$ \\
\hline $84 \%$ & zzzzzz & $\mathrm{ffff}$ & Rectangular & $5 / 32$ & si & si & 1,6 & Paralelo & 1520 & 8,45 & $18 \%$ \\
\hline $90 \%$ & zzzzzz & ffff & Rectangular & $5 / 32$ & si & si & 1,6 & Perpendicular & 1520 & 8,45 & $18 \%$ \\
\hline $86 \%$ & zzzzzz & $\mathrm{ffff}$ & & $5 / 32$ & si & si & 1,6 & Oblicuo & 1520 & 8,45 & $18 \%$ \\
\hline $82 \%$ & zzzzzz & $\mathrm{ffff}$ & & $5 / 32$ & si & si & 1,6 & Paralelo & 1520 & 8,45 & $18 \%$ \\
\hline $91 \%$ & zzzzzz & ffff & Triangular & $5 / 32$ & si & si & 1,6 & Perpendicular & 1520 & 8,45 & $18 \%$ \\
\hline
\end{tabular}

Tabla 3. Ensayos de aspersores con buena uniformidad en marco de $12 \times 15$, a 2,5 bares con viento.

\begin{tabular}{|c|c|c|c|c|c|c|c|c|c|c|c|}
\hline$\Im$ & 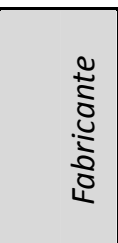 & $\begin{array}{l}\frac{0}{8} \\
\frac{0}{0} \\
\sum\end{array}$ & $\begin{array}{l}\text { Oे } \\
\text { के }\end{array}$ & 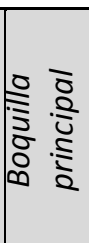 & 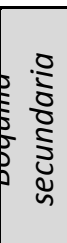 & ) & 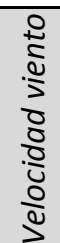 & 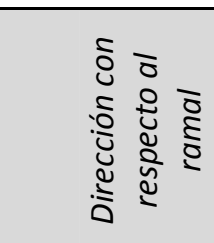 & 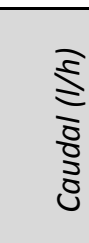 & 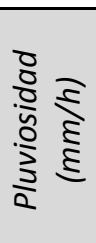 & 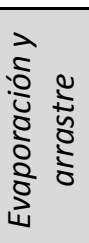 \\
\hline $84 \%$ & xxxxxx & $\mathrm{bbbb}$ & \begin{tabular}{|l|} 
Rectangular \\
\end{tabular} & $5 / 32$ & si & si & 2,1 & Paralela & 1.293 & 7,18 & $13 \%$ \\
\hline $86 \%$ & $x x x x x x$ & bbbb & Rectangular & $5 / 32$ & si & si & 2,1 & Perpendicular & 1.293 & 7,18 & $13 \%$ \\
\hline $84 \%$ & $x x x x x x$ & bbbb & Rectangular & $9 / 64$ & si & si & 1,5 & Oblicuo & 1.221 & 6,78 & $12 \%$ \\
\hline $87 \%$ & $x x x x x x$ & bbbb & Rectangular & $9 / 64$ & si & si & 1,5 & Paralela & 1.221 & 6,78 & $12 \%$ \\
\hline $87 \%$ & $x x x x x x$ & bbbb & Rectangular & $9 / 64$ & si & si & 1,5 & Perpendicular & 1.221 & 6,78 & $12 \%$ \\
\hline $82 \%$ & $x x x x x x$ & bbbb & Triangular & $5 / 32$ & si & si & 2,1 & Paralela & 1.293 & 7,18 & $13 \%$ \\
\hline $85 \%$ & $x x x x x x$ & bbbb & Triangular & $5 / 32$ & si & si & 2,1 & Perpendicular & 1.293 & 7,18 & $13 \%$ \\
\hline $84 \%$ & $x x x x x x$ & bbbb & Triangular & $9 / 64$ & si & si & 1,5 & Oblicuo & 1.221 & 6,78 & $12 \%$ \\
\hline $84 \%$ & $x x x x x x$ & bbbb & Triangular & $9 / 64$ & si & si & 1,5 & Paralela & 1.221 & 6,78 & $12 \%$ \\
\hline $89 \%$ & xxxxxx & bbbb & Triangular & $9 / 64$ & si & si & 1,5 & Perpendicular & 1.221 & 6,78 & $12 \%$ \\
\hline $82 \%$ & yyyyyy & aaaa & Rectangular & $5 / 32$ & si & si & 1,0 & Oblicuo & 1.325 & 7,36 & $8 \%$ \\
\hline $84 \%$ & yyyyy & aaaa & Triangular & $5 / 32$ & si & si & 1,0 & Oblicuo & 1.325 & 7,36 & $8 \%$ \\
\hline $83 \%$ & yyyyy & aaaa & Triangular & $5 / 32$ & si & si & 1,0 & Paralela & 1.325 & 7,36 & $8 \%$ \\
\hline $82 \%$ & yyyyy & aaaa & Triangular & $5 / 32$ & si & si & 1,0 & Perpendicular & 1.325 & 7,36 & $8 \%$ \\
\hline $82 \%$ & zzzzzz & $\mathrm{ffff}$ & Rectangular & $5 / 32$ & si & si & 2,1 & Perpendicular & 1.277 & 7,09 & $14 \%$ \\
\hline $82 \%$ & zzzzzz & ffff & Triangular & $5 / 32$ & si & si & 2,1 & Perpendicular & 1.277 & 7,09 & $14 \%$ \\
\hline
\end{tabular}


Tabla 4. Ensayos de aspersores con buena uniformidad en marco de $12 \times 15$, a 2 bares con viento.

\begin{tabular}{|c|c|c|c|c|c|c|c|c|c|c|c|}
\hline$\stackrel{ి}{9}$ & $\begin{array}{l}0 \\
0 \\
0 \\
0 \\
0 \\
0 \\
0 \\
4\end{array}$ & $\begin{array}{l}\frac{0}{2} \\
\frac{0}{2} \\
\frac{0}{2}\end{array}$ & $\begin{array}{l}0 \\
\frac{0}{2} \\
\sum\end{array}$ & 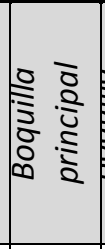 & 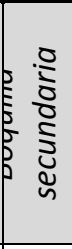 & : & $\begin{array}{l}0 \\
\stackrel{0}{0} \\
\frac{0}{2} \\
0 \\
0 \\
\frac{0}{0} \\
\frac{0}{2} \\
\frac{0}{2} \\
د\end{array}$ & 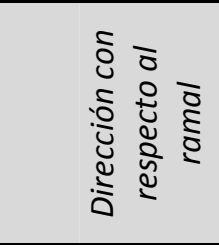 & $\begin{array}{l}\frac{2}{\vdots} \\
\frac{5}{0} \\
0 \\
0 \\
0\end{array}$ & $\begin{array}{l}0 \\
\frac{0}{0} \\
\frac{0}{n} \\
\frac{2}{2} \\
\frac{1}{2} \\
\frac{1}{2}\end{array}$ & 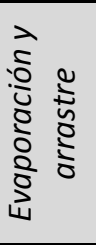 \\
\hline $84 \%$ & $\mathrm{XXXXXX}$ & $\mathrm{bbbb}$ & Rectangular & $9 / 64$ & si & si & 0,9 & Oblicuo & 967 & 5,37 & $6 \%$ \\
\hline $86 \%$ & XXXXXX & bbbb & Rectangular & $9 / 64$ & si & si & 0,9 & Paralela & 967 & 5,37 & $6 \%$ \\
\hline $86 \%$ & $x x x x x x$ & $\mathrm{bbbb}$ & Rectangular & $9 / 64$ & si & si & 0,9 & Perpendicular & 967 & 5,37 & $6 \%$ \\
\hline $88 \%$ & $\mathrm{XXXXXX}$ & $\mathrm{bbbb}$ & Triangular & $5 / 32$ & si & si & 0,8 & Oblicuo & 1.141 & 6,34 & $5 \%$ \\
\hline $88 \%$ & $x x x x x x$ & $\mathrm{bbbb}$ & Triangular & $5 / 32$ & si & si & 0,8 & Paralela & 1.141 & 6,34 & $5 \%$ \\
\hline $90 \%$ & XXXXXX & $\mathrm{bbbb}$ & Triangular & $5 / 32$ & si & si & 0,8 & Perpendicular & 1.141 & 6,34 & $5 \%$ \\
\hline $89 \%$ & Xxxxxx & $\mathrm{bbbb}$ & Triangular & $9 / 64$ & si & si & 0,9 & Oblicuo & 967 & 5,37 & $6 \%$ \\
\hline $88 \%$ & $x x x x x x$ & $\mathrm{bbbb}$ & Triangular & $9 / 64$ & si & si & 0,9 & Paralela & 967 & 5,37 & $6 \%$ \\
\hline $86 \%$ & $x x x x x x$ & bbbb & Triangular & $9 / 64$ & si & si & 0,9 & Perpendicular & 967 & 5,37 & $6 \%$ \\
\hline $82 \%$ & ZzZZZZ & ffff & Rectangular & $5 / 32$ & si & si & 1,6 & Oblicuo & 1.125 & 6,25 & $8 \%$ \\
\hline $88 \%$ & ZzZzZZ & ffff & Rectangular & $5 / 32$ & si & si & 1,6 & Perpendicular & 1.125 & 6,25 & $8 \%$ \\
\hline $81 \%$ & zzzzzz & ffff & Triangular & $5 / 32$ & si & si & 1,6 & Oblicuo & 1.125 & 6,25 & $8 \%$ \\
\hline $87 \%$ & zzzzzz & ffff & Triangular & $5 / 32$ & si & si & 1,6 & Perpendicular & 1.125 & 6,25 & $8 \%$ \\
\hline
\end{tabular}

Una vez comprobado en los resultados anteriores la viabilidad de bajar los niveles de presión en determinados emisores y en situaciones concretas, se muestra un análisis global comparativo del comportamiento de los aspersores ensayados en distintas presiones y para los distintos valores de viento.

El objetivo de dicho análisis es poder conocer cómo influyen las presiones en los distintos rangos de valores de velocidad de viento. Igual que en los resultados expuestos en la figura 1, se van a diferenciar los tres marcos más utilizados en el riego por aspersión. En las figuras 4,5 y 6 , se muestran las correspondencias entre los valores deUD frente a la variable viento y para cada una las presiones ensayadas.ese han ajustado curvaspolinómicas de quinto grado. La finalidad de esta gráfica es una visión global de la tendencia de la Uniformidad de Distribución para las distintas presiones. 


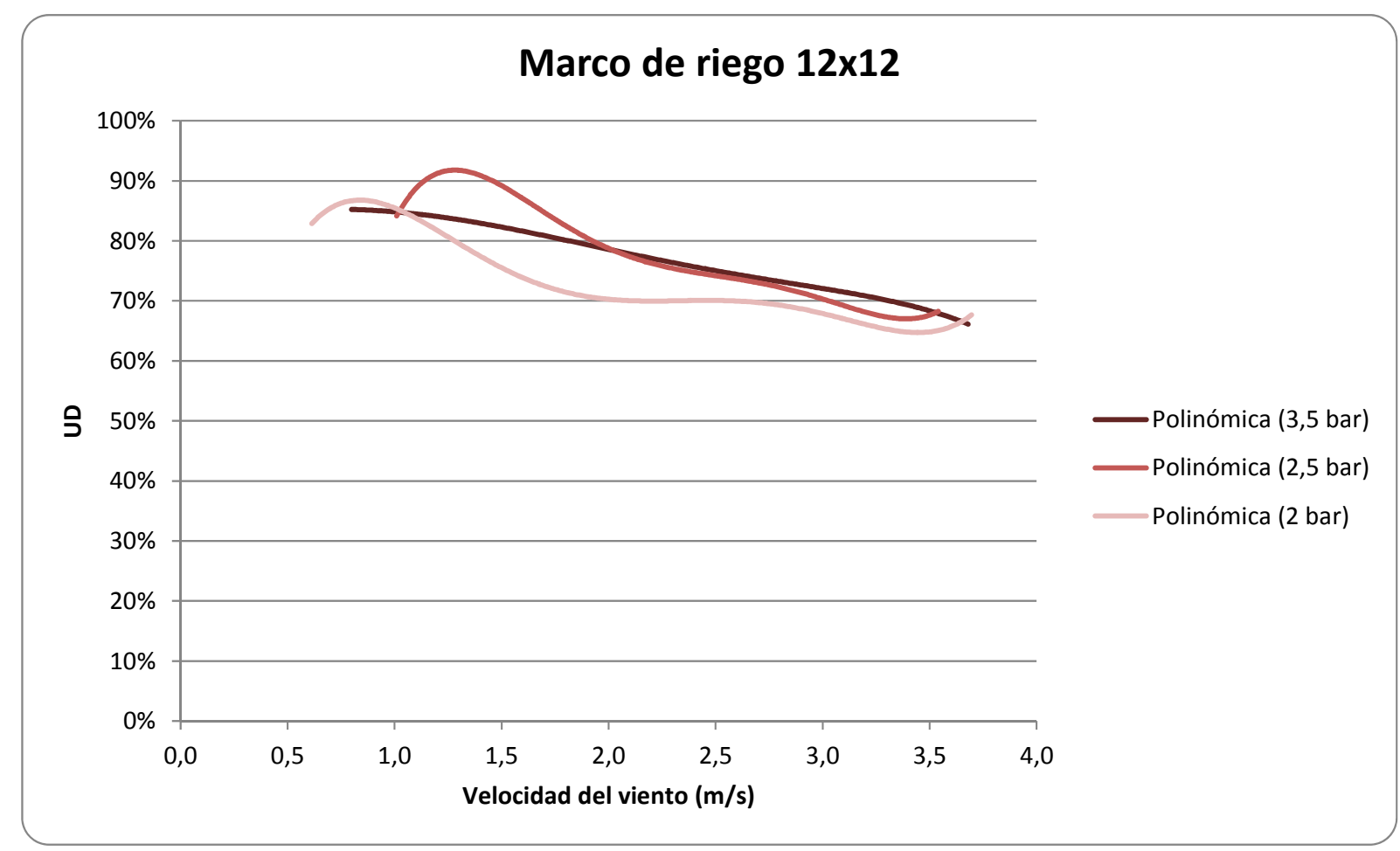

Figura 4. Gráficas de las líneas de tendencia polinómica de grado 5 resultante de los datos de UD en relación a la velocidad del viento y para los tres valores de presiones ensayadas para el marco de riego de 12×12.

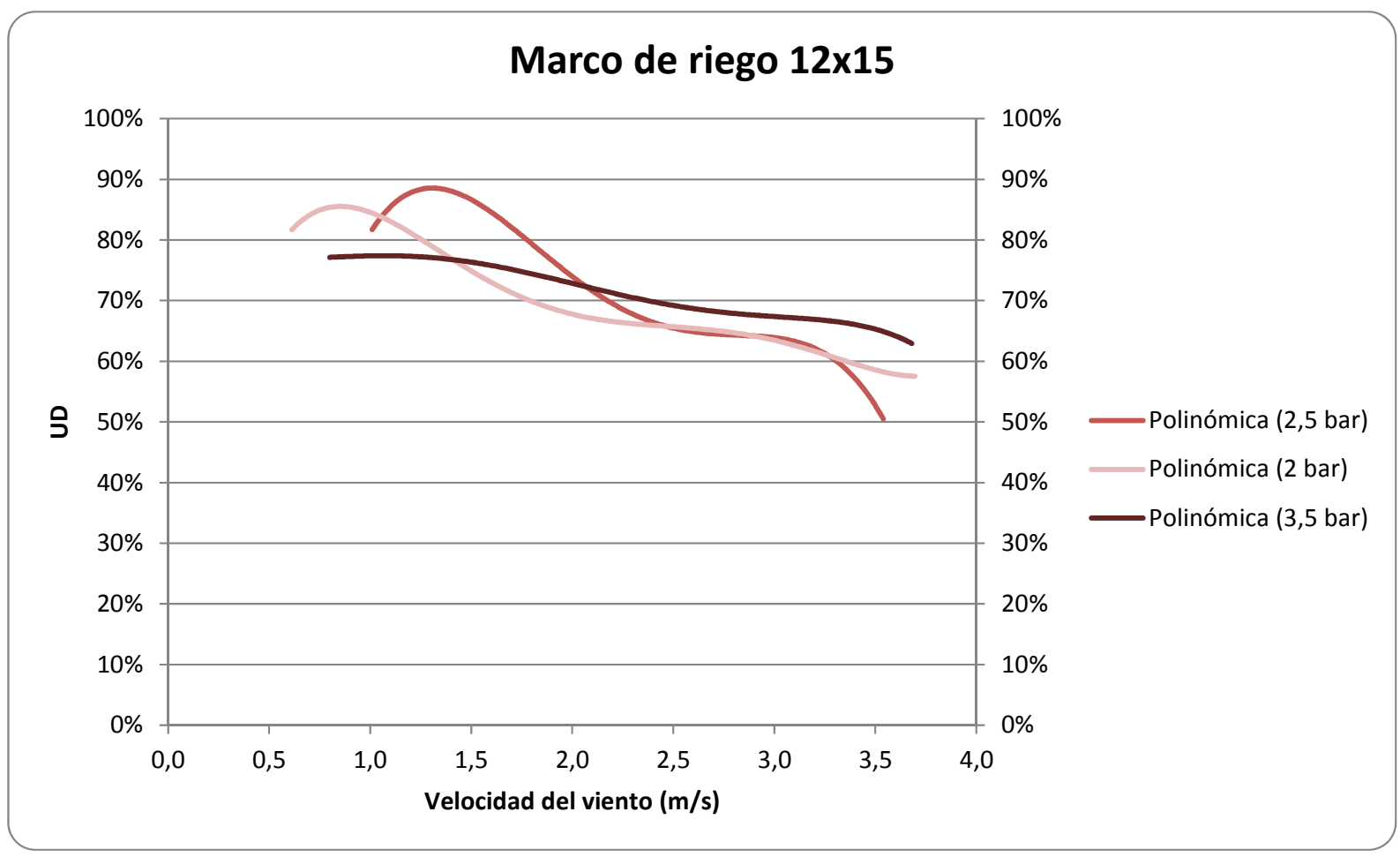

Figura 5. Gráficas de las líneas de tendencia de los datos de UD en relación a la velocidad del viento y para los tres valores de presiones ensayadas para el marco de riego de $12 \times 15$. 


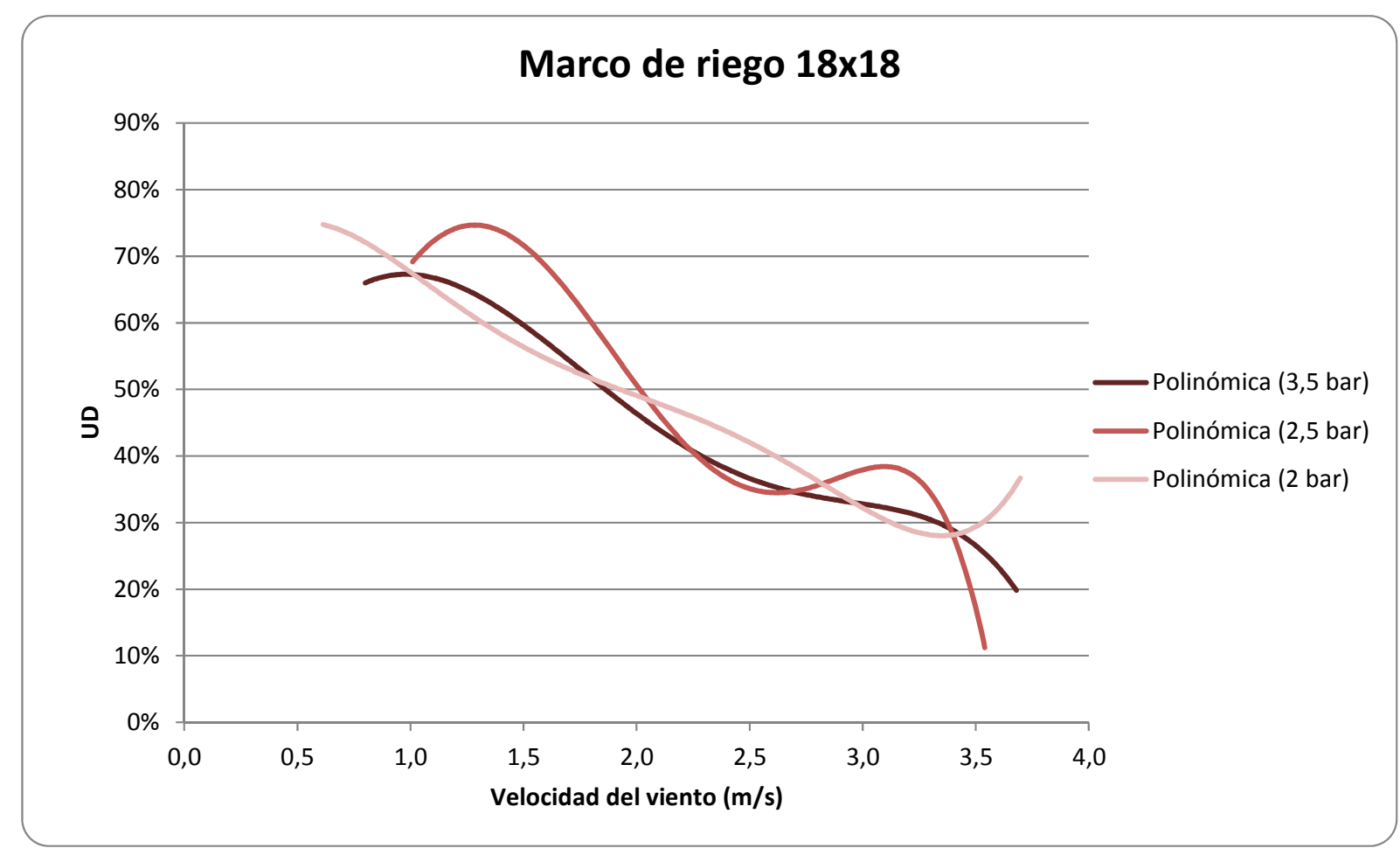

Figura 6. Gráficas de las líneas de tendencia de los datos de UD en relación a la velocidad del viento y para los tres valores de presiones ensayadas para el marco de riego de $18 \times 18$.

La gran cantidad de datos obtenidos representa una herramienta muy útil para realizar consultas concretas sobre situaciones particulares. Según los resultados presentados, para marcos más pequeños $(12 \times 12$ y $12 \times 15)$ es posible bajar las presiones hasta 2,5 bares, siempre que la velocidad de viento estuviera por debajo de $2 \mathrm{~m} / \mathrm{s}$. En los marcos mayorestambién sería posible, pero con valores de velocidad de viento más restrictivos. Esta aproximación generalista jamás debe considerarse como una recomendación para todos los casos de modo que habrá que recurrir a ensayos similares a los descritos que se correspondan con las condiciones a evaluar.

\section{4- Conclusiones y recomendaciones}

La gran cantidad de información generada representa una gran ayuda para realizarun asesoramientoal regante específico de cada caso, mejorando la uniformidad del riego y posibilitando un ahorro energético.

Vistos los resultados, existela posibilidadde bajar la presión de funcionamiento para los sistemas de riego por aspersión, siempre que se haya ensayado previamente el sistema con los condicionantes existentes en la realidad.

Para la obtención de valores aceptables o incluso buenos de Uniformidad de Distribución, intervienen en mayor o menor medida todas las variables tenidas en cuenta. Como se ha podido comprobar, en muchos casos, incluso depende del fabricante y del modelo del aspersor. 
Los datos podrían ser más numerosos para cubrir toda la casuística del mercado, por tanto, se ofrece la posibilidad a los fabricantes de realizar más ensayos y utilizarel conjunto de resultados generados para crear una aplicación que sirva para ayudar a optimizarel diseño de los riegos por aspersión.

\section{6- Bibliografía}

De Juan, J. Tarjuelo, J. Valiente, M. Garcia, P. (1994): Non-uniformity and management of sprinkler irrigation systems. Proceedings of the third congress of the European Society for Agronomy, Padova University, Abano-Padova, Italy, 18-22 September 1994.; 1994. 102-103.

ISO 7749-1:1986, Equipos de riego-Aspersores rotativos-Parte 1: Diseño y exigencias de funcionamiento.

ISO 7749-2:1990, Equipo de riego - Aspersores Rotativos - Parte 2: Uniformidad de distribución y métodos de prueba.

Merrian, J.L. Y Keller, J. (1978): Farm irrigation system evaluation: a guide for management. UTAH StateUniversity. Logan. Utah. USA.

Salvatierra, B. (2010). Uniformidad de riego en las instalaciones de riego. Boletín trimestral SAR. NN 14. Enero, marzo 2010.

Salvatierra, B. (2014).Banco automático de ensayo de aspersorescon viento. XXXII Congreso Nacional de Riegos. Madrid.

Salvatierra, B. Andrades, J.A, Gómez, E. Viqueira,S. (2015). Resultados de ensayos del banco automático de aspersores.XXXIII Congreso Nacional de Riegos. Valencia.

Salvatierra, B. Andrades, J.A. (2015). Mejoras en el riego por aspersión. Revista AIMCRA, 122: $18-22$.

Sánchez, I. Faci, J. M. Zapata, N. (2011). The effects of pressure, nozzle diameter and meteorological conditions on the performance of agricultural impact sprinklers.Agricultural Water Management; 2011. 102: 1, 13-24.

Seginer, I. Nir, D. And Bernuth, R. (1991).Simulation of wind-distorded sprinkler patterns.J. Irrig. DrainEng., 117(2), 285-306.

Tarjuelo Martín Benito, J. M. (1992). El riego por aspersión: diseño y funcionamiento. Albacete: Caja de Albacete; [Toledo]. Ediciones de la Universidad de Castilla-La Mancha, D.L.

Tarjuelo Martín Benito, J. M. (2005). El riego por aspersión y su tecnología. Ediciones MundiPrensa. $581 \mathrm{pp}$.

Tarjuelo, J. M. Carrion, P. Valiente, M. (1994).Simulation of irrigation distribution by sprinkler under windy conditions.Investigacion Agraria, Produccion y Proteccion Vegetales; 9: 2, 255272.

Zapata, N. Playan, E. Martinez-Cob, A. Sanchez, I. Faci, J. M. Lecina, S. (2008).From onfarm solid-set sprinkler irrigation design to collective irrigation network design in windy areas.AgriculturalWater Management; 2007. 87: 2, 187-199. 


\title{
C-03
}

\section{MODELO HIDRÁULICO PARA LA OPTIMIZACIÓN DE SUBUNIDADES IRREGULARES DE RIEGO POR GOTEO}

\author{
Cervera Gascó, $\mathrm{J}^{1}$, Del Castillo Sánchez-Cañamares, $A^{2}$, Montero Martinez, $\mathrm{J}^{3}$, Tarjuelo \\ Martín-Benito, J.M. ${ }^{4}$, Moreno Hidalgo, M. $A^{5}$
}

1 Ingeniero Agrónomo, Contratado predoctoral; Centro Regional de Estudios del Agua (CREA), UCLM, Ctra de Las Peñas km. 3.2, 02071 Albacete, Jorge.Cervera@uclm.es

2 Ingeniero Técnico Agrícola, Investigador; Centro Regional de Estudios del Agua (CREA), UCLM, Ctra. de Las Peñas km. 3.2, 02071 Albacete; Amaro.Castillo@uclm.es

${ }^{3}$ Dr. Ingeniero Agrónomo, Titular de universidad; Centro Regional de Estudios del Agua (CREA), UCLM, Ctra de Las Peñas km. 3.2, 02071 Albacete; Jesus.Montero@uclm.es

${ }^{4}$ Dr. Ingeniero Agrónomo, Catedrático de Universidad; Centro Regional de Estudios del Agua (CREA), UCLM, Ctra de Las Peñas km. 3.2, 02071 Albacete; jose.tarjuelo@uclm.es

5 Dr. Ingeniero Agrónomo, Profesor Contratado Doctor; Centro Regional de Estudios del Agua (CREA), UCLM, Ctra de Las Peñas km. 3.2, 02071 Albacete; MiguelAngel.Moreno@uclm.es

\section{Resumen}

La escasez de los recursos hídricos actuales, especialmente en las zonas con clima árido o semiárido, provocan la necesidad de desarrollar herramientas de ayuda en la toma de decisiones para el diseño y manejo del riego, y más cuando se pretende utilizar energía fotovoltaica. El objetivo del trabajo ha sido desarrollar un modelo hidráulico que pueda acoplarse al modelo fotovoltaico, para el caso más general de subunidades de riego de forma y topografía irregular, constituyendo una herramienta de ayuda en la toma de decisiones para el diseño y manejo del riego con energía fotovoltaica, analizando la calidad del riego en las distintas subunidades con forma y topografía irregular. Para la calibración y validación del modelo, se ha aplicado a una parcela de 90 ha, de un cultivo de almendro regado por goteo, situada en una zona con topografía y forma muy irregular. Los resultados permiten identificar las zonas con problemas en la uniformidad de emisión en función de la presión disponible en la entrada de la subunidad de riego.

\section{Abstract}

Nowadays, water resources are limited especially in places with arid and semi-arid conditions. For that reason, it is essential the development of decision support system models (DSS) aiming the design and management of irrigation systems, especially when they are fed with photovoltaic energy. The main objective of this study was the development of a hydraulic model linked with a photovoltaic model, considering the most general case of irrigation subunits with irregular shape and topography. Thus, a decision support system tool (DSS) for the design and management irrigation with photovoltaic power is developed.

Analyzing the irrigation quality in different subunit with irregular shape and topography is a main issue in precision irrigation. For model calibration and validation has been applied in an almond field with 90 ha with drip irrigation located in a shape and topography land. The results enabled us to identify the areas with uniformity problems depending on the pressure in the subnit head. 


\section{1- Introducción y Objetivos}

Tal y como indica Daccache et al (2014) la agricultura sostenible debería ser respaldada por políticas compensatorias entre el ahorro de agua, las emisiones de CO2 y la producción de alimentos, particularmente en las regiones con escasez de agua como ocurre en la cuenca mediterránea, donde debido a la intensificación de la agricultura, las necesidades de bombeo son aún mayores al tener que utilizar en gran medida aguas subterráneas

No obstante, el óptimo de funcionamiento de un sistema de riego, desde un punto de vista ecológico, solamente se podrá conseguir considerando simultáneamente criterios medioambientales y económicos (Carrillo-Cobo et al., 2014).

En el diseño de las diferentes subunidades de riego hay que tener en cuenta, la diferente cota de los emisores, provocada por la irregularidad del terreno, las pérdidas de carga en la tubería y las características propias del emisor en cuanto a su coeficiente de variación de fabricación, exponente de descarga, sección de paso, sistema de filtrado, etc., lo que condiciona la uniformidad de emisión y la eficiencia de riego, siendo estos indicadores fundamentales para caracterizar la calidad del riego.

El desarrollo de herramientas y modelos, de ayuda en la toma de decisiones para el diseño y el manejo de las instalaciones de riego contribuye al ahorro de agua y energía, tanto en instalaciones nuevas como en las que están en funcionamiento Así, Carrion et al. (2013 y 2014) desarrollaron la herramienta PRESUD para el diseño óptimo de subunidades regulares de riego a presión, tanto localizado como aspersión, buscando el coste total mínimo (operación más inversión) por unidad de superficie regada, teniendo en cuenta la uniformidad de emisión y la eficiencia de aplicación en las subunidades de riego A su vez, Moreno et al. (2016) han desarrollado la herramienta PRESUD-irregular, que permite el diseño de mínimo coste total de subunidades de riego a presión en parcela con forma y topografía irregulares.

Carrion et al (2016) desarrollaron una herramienta llamada DOPIR (Dimensioning Of Pressurized IRrigation) para la optimización del proceso de extracción y aplicación del agua con el sistema de riego, buscando el coste total mínimo (inversión más operación), contemplando el proceso en su conjunto, desde la fuente de agua hasta el emisor.

El objetivo del trabajo es desarrollar un modelo hidráulico que pueda acoplarse a un modelo fotovoltaico, previamente desarrollado, para analizar la calidad del riego en las distintas subunidades de forma y topografía irregular en que se haya dividido la parcela a regar, que se alimentan directamente de un depósito elevado o de una bomba alimentada con energía fotovoltaica. Para la calibración y validación del modelo, se aplica a una parcela de 90 ha, de un cultivo de almendro regado por goteo, situada en una zona con topografía y forma muy irregular.

\section{2- Materiales y métodos}

Para la realización de este trabajo se ha utilizado una parcela de 90 ha de almendros, con marco de $7 \times 7 \mathrm{~m}^{2}$ regada por goteo La finca está situada en el término municipal de Hellín, al sureste de la provincia de Albacete, y está dividida en 18 subunidades, que están ubicadas en una topografía muy irregular, con grandes diferencias de pendiente incluso dentro de la misma subunidad.

Los goteros utilizados son autocompensantes, con un caudal de diseño de $2 \mathrm{l} / \mathrm{h}$, habiéndolos ensayado en laboratorio para obtener su curva de descarga y el coeficiente de 
variación de fabricación. El agua suministrada a la plantación procede de un sondeo con nivel dinámico situado a $200 \mathrm{~m}$, utilizando una bomba sumergida de $26 \mathrm{~kW}$ alimentada con energía fotovoltaica. Además, la finca cuenta con un embalse de $12.500 \mathrm{~m}^{3}$ aproximadamente.

En la figura 1 se muestra el plano con las subunidades, la red de distribución, ubicación de las placas solares, pozo y embalse.

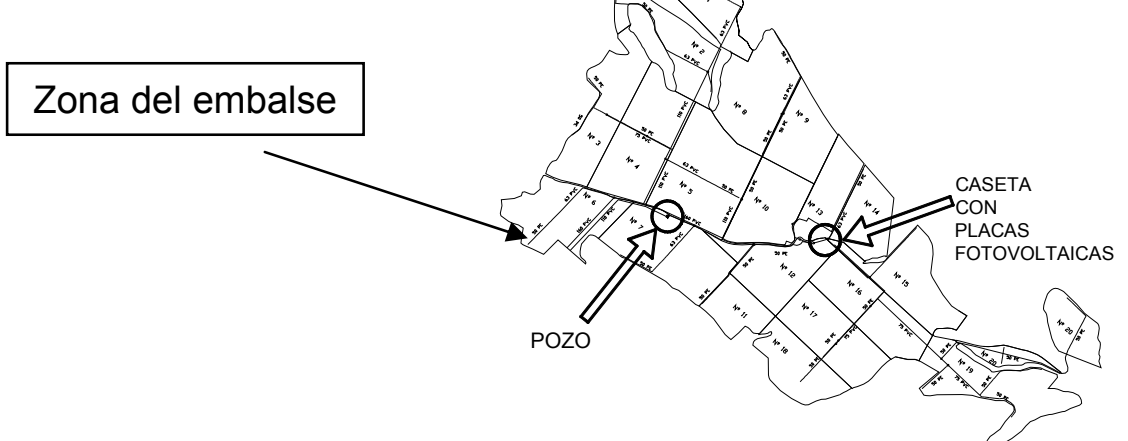

Figura 1. Plano de la finca con las subunidades, la red de distribución, ubicación de las placas solares, pozo y embalse.

En la cubierta de la caseta, que se encuentra en la parte central de la finca, están instaladas 136 placas solares, que aportan una potencia máxima de $30 \mathrm{~kW}$, con la que se alimenta la bomba través de un variador de velocidad.

Con el fin de tener una precisa caracterización de la finca, se ha realizado un levantamiento topográfico con GPS-RTK, y precisión centimétrica en altimetría, identificando además el inicio y fin de cada ramal, y la localización de cada una de las válvulas de apertura de las subunidades, consiguiendo así una muy buena caracterización del sistema de riego instalado. En la figura 2 se muestra una ortofoto con todos los puntos obtenidos con GPS-RTK.

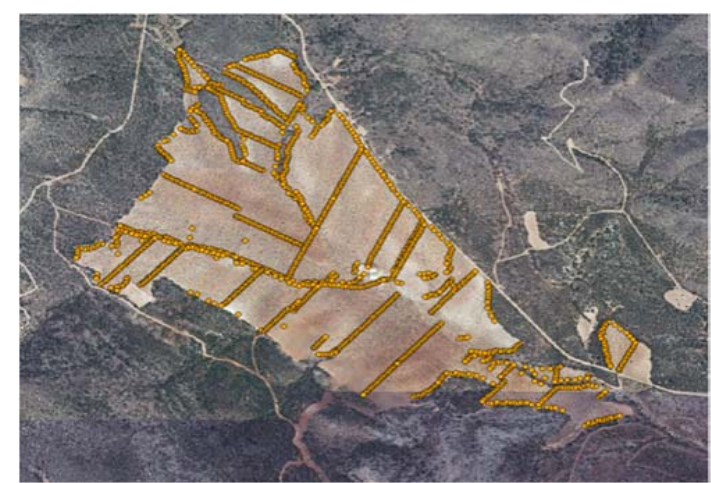

Figura 2. Medición de puntos de inicio y final de ramal así como de las válvulas de apertura de cada subunidad mediante GPS-RTK.

Además, se han realizado diferentes vuelos mediante vehículos aéreos no tripulados (drones) utilizando un drone de tipo cuadracóptero md-400 con el fin de obtener el modelo digital del terreno (MDT), lo que ha permitido determinar la cota de cada uno de los goteros con precisión centimétrica.

La información obtenida ha permitido reproducir el diseño hidráulico de la red de distribución y de las distintas subunidades de riego. Para la obtención del modelo hidráulico 
de la instalación se ha utilizado el motor de cálculo EPANET (Rossman, 2000), implementado en un software propio desarrollado en Matlab®.

La descarga de los goteros se ha estimado con la ecuación (Karmeli y Keller, 1975), obtenida en laboratorio:

$$
\mathrm{q}_{\mathrm{h}}=\mathrm{K} \cdot \mathrm{h}_{\mathrm{e}}^{\mathrm{x}}
$$

Siendo $\mathrm{q}_{\mathrm{h}}$ el caudal del emisor, $\mathrm{K}$ el coeficiente del emisor, $\mathrm{x}$ el exponente del emisor $\mathrm{y} \mathrm{h}_{\mathrm{e}}$ la presión en cabecera del emisor.

Con ayuda de la herramienta PRESUD-irregular se ha deducido la ecuación de descarga de cada subunidad, que determina el caudal descargado por el conjunto de goteros en función de la presión a la entrada de la subunidad, así como la presión y caudal descargado por cada uno de los goteros. Esto permite calcular los correspondientes coeficientes de uniformidad de emisión, y los coeficientes de variación de caudal y presión en cada una de las subunidades, teniendo una muy buena caracterización de la calidad del riego.

La simulación hidráulica de la red de distribución figura 3 permite establecer la presión en cada uno de los nudos o hidrantes a partir de la presión y caudal en cabecera, para cualquier combinación de subunidades de riego abiertas.

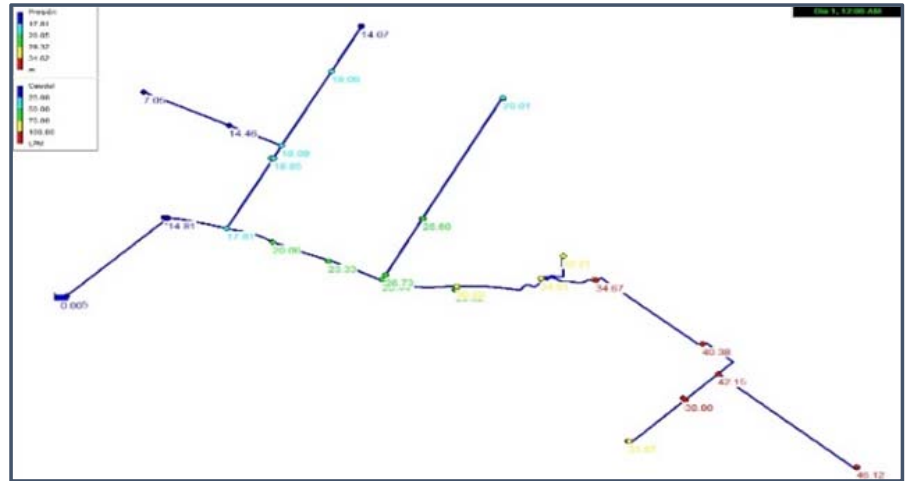

Figura 3. Simulación de la red de distribución con presión en cada uno de los nudos.

El modelo hidráulico de la red y de las subunidades de riego permite identificar las subunidades que podían ser regadas adecuadamente desde el embalse, situado en la parte más alta de la finca, así como establecer el valor de presión adicional que sería necesario tener en el origen de la red para obtener un mínimo valor de uniformidad de emisión en cada subunidad de riego.

\section{3- Resultados y discusión}

La herramienta generada que se ha desarrollado en Matlab $®$ permite obtener los siguientes resultados. A modo de ejemplo, en la figura 4 se muestra la distribución de caudales de los goteros de una subunidad determinada asociada a una presión en cabecera de 45, 32, 19, y 7 m.c.a. En la figura 5 se muestra la distribución de caudales de los goteros de otra subunidad con forma muy distinta a la anterior para una presión en cabecera de 45 , 39, 33, 27 m.c.a. 
El rango de valores de presión en cabecera disponible es más grande pero en este caso se han seleccionado 4 valores de presión en cabecera representativos de cada subunidad.

a)

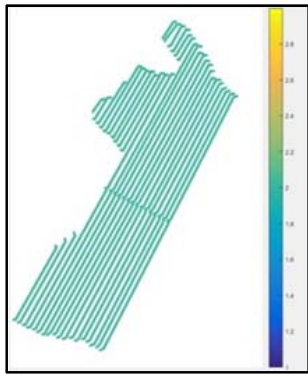

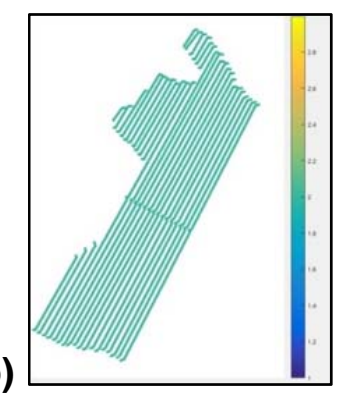

c)

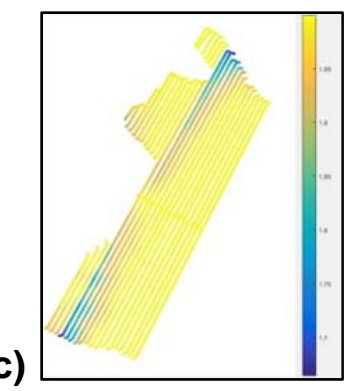

d)

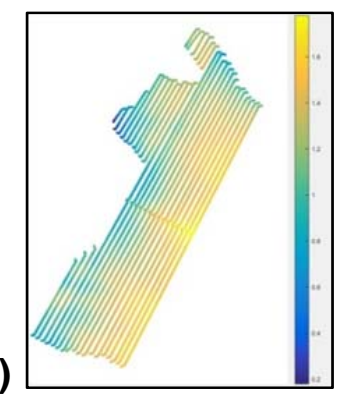

Figura 4. Distribución de caudales de los goteros de una subunidad determinada asociada a una presión de 45 (a), 32 (b), 19 (c) y 7 m.c.a. de presión en cabecera dada.

En las figuras 4 a) y 4 b), se puede ver que la simulación indica que para una presión en cabecera de 45 m.c.a y 32 m.c.a todos los goteros esta autocompensando, es decir todos los goteros están suministrando el caudal de diseño que es de $2 \mathrm{l} / \mathrm{h}$. y por tanto la uniformidad de emisión es del $100 \%$.

En la figura $4 \mathrm{c}$ ), se puede ver que la simulación indica que para una presión en cabecera de 19 m.c.a el caudal máximo producido es de $2 \mathrm{l} / \mathrm{h}$ mientras que hay emisores que presentan un caudal mínimo de $1.66 \mathrm{l} / \mathrm{h}$. La diferencia de caudales es de un $17 \%$ y la uniformidad de emisión es del $98 \%$.

En la figura $4 \mathrm{~d}$ ), se puede ver que la simulación indica que para una presión en cabecera de 7 m.c.a el caudal máximo producido es de $1.78 \mathrm{l} / \mathrm{h}$ mientras que hay emisores que presentan un caudal mínimo de $0.17 \mathrm{l} / \mathrm{h}$. La diferencia de caudales es de un $127 \%$ y la uniformidad de emisión es del $84 \%$.

a)

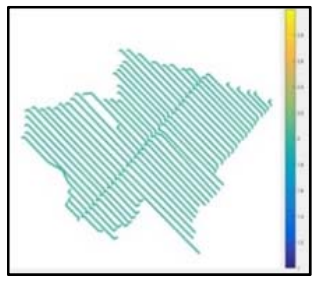

b)

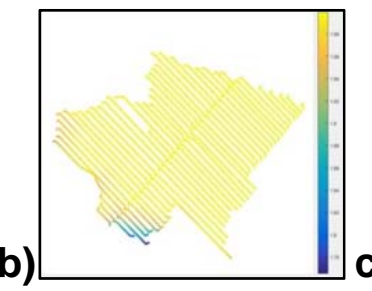

c)

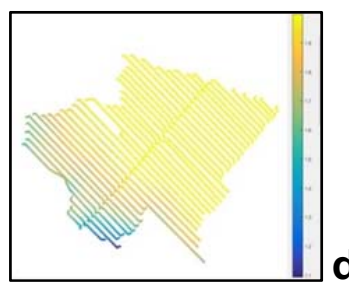

d)

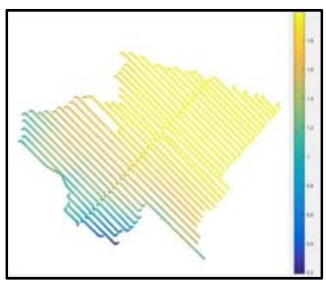

Figura 5. Distribución de caudales de los goteros de una subunidad determinada asociada a una presión de 45 (a), 39 (b), 33 (c) y 27 m.c.a. de presión en cabecera dada.

En la figura $5 \mathrm{a}$ ), podemos ver que la simulación indica que para una presión en cabecera de 45 m.c.a todos los goteros esta autocompensando, es decir todos los goteros están suministrando el caudal de diseño que es de $2 \mathrm{l} / \mathrm{h}$ y por tanto la uniformidad de emisión es del $100 \%$.

En la figura $5 \mathrm{~b}$ ), podemos ver que la simulación indica que para una presión en cabecera de 39 m.c.a el caudal máximo producido es de $2 \mathrm{l} / \mathrm{h}$ mientras que hay emisores que presentan un caudal mínimo de 1,76 l/h. La diferencia de caudales es de un $11,77 \%$ y la uniformidad de emisión es del $99 \%$.

En la figura $5 \mathrm{c}$ ), podemos ver que la simulación indica que para una presión en cabecera de 33 m.c.a el caudal máximo producido es de $2 \mathrm{l} / \mathrm{h}$ mientras que hay emisores 
que presentan un caudal mínimo de $1,09 \mathrm{l} / \mathrm{h}$. La diferencia de caudales es de un $47.52 \%$ y la uniformidad de emisión es del $94 \%$.

En la figura $5 \mathrm{~d}$ ), podemos ver que la simulación indica que para una presión en cabecera de 27 m.c.a. el caudal máximo producido es de $2 \mathrm{l} / \mathrm{h}$ mientras que hay emisores que presentan un caudal mínimo de 0,19l/h. La diferencia de caudales es de un $106 \%$ y la uniformidad de emisión es del $82 \%$.

Como se puede ver, con los datos presentados, según la presión en cabecera de la subunidad, existen zonas cuyos emisores están aportando caudales muy bajos mientras que en otras zonas existen emisores que están trabajando con valores similares o iguales al caudal de diseño.

\section{4- Conclusiones y recomendaciones}

La irregularidad de las subunidades así como las grandes pendientes del terreno tienen una clara influencia sobre la presión en el origen de la subunidad y en consecuencia sobre el caudal y la uniformidad de emisión de la misma.

Los resultados obtenidos permiten conocer las curvas caudal-presión de cada subunidad, además de la uniformidad de emisión y el coeficiente de variación de presiones y caudales, entre otros, lo que permite cuantificar la calidad del riego, además de ayudar a establecer la secuencia optima de apertura de subunidades de acuerdo a la presión disponible en cabecera de la red de distribución. Esto, también permite identificar las zonas de la subunidad de riego con mayores problemas de falta de presión y caudal, lo que resulta fundamental para intentar buscar soluciones con distintos diámetros de tuberías, tipos de goteros, etc.

Queda clara pues la utilidad de la herramienta generada, y que el conocimiento de las necesidades de presión, caudal y uniformidad de emisión son fundamentales para decidir el momento óptimo del día para el riego según la energía generada por el sistema fotovoltaico, constituyendo una herramienta de gran ayuda para el diseño y dimensionamiento de las instalaciones con bombeo solar, dependiendo de la radiación solar disponible.

\section{5- Bibliografía}

Daccache, A., Ciurana, J.S., Rodriguez Diaz, J.A., Knox, J.W. (2014). Water and energy footprint of irrigated agriculture in the Mediterranean region. Environ. Res. Lett., 9, $124014(12 \mathrm{pp})$.

Carrillo-Cobo, M.T., Camacho Poyato, E., Montesinos, P., Rodríguez Díaz, J.A. (2014). Assessing the potential of solar energy in pressurized irrigation networks. The case of Bembézar MI irrigation district (Spain). Span. J. Agric. Res. 12 (3), 838-849.

Carrión, F., Montero, J., Tarjuelo, J.M., Moreno, M.A. (2014). Design of sprinkler irrigation subunit of minimum cost with proper operation. Application at corn crop in Spain. Water Resour. Manag., 28, 5073-5089.

Carrión, F., Sanchez-Vizcaino, J., Corcoles, J.I., Tarjuelo, J.M., Moreno, M.A. (2016). Optimization of groundwater abstraction system and distribution pipe in pressurized irrigation systems for minimum cost. Irrig Sci., 34, 145-159. 
Carrión, F., Tarjuelo, J.M., Hernández, D., Moreno, M.A. (2013). Design of microirrigation subunit of minimum cost with proper operation. Irrig. Sci., 31(5), 1199-1211.

Karmeli, D., Keller, J. (1975). Trickle irrigation design. Rain Bird Sprinkler Manufacturing Corp. Glendora, 133p.

Moreno, M.A., Planells, P., Córcoles, J.I., Tarjuelo, J.M., Carrión, P.A. (2009). Development of a new methodology to obtain the characteristic pump curves that minimize the total cost at pumping stations. Biosyst. Eng., 102 (1), 95-105.

Moreno M.A., del Castillo A., Montero J., Tarjuelo J.M., Ballesteros R. (2016). Design optimization of irregular pressurized irrigation subunits. Biosyst. Eng. (en revision)

Moreno, M.A., Medina, D., Ortega, J.F., Tarjuelo, J.M. (2012). Optimal design of centre pivot systems with water supplied from wells. Agricultural Water Management, 107, 112-121.

Rossman, L.A. (2000). EPANET 2, users' manual, Water supply and Water Resources Division, National Risk Management Research Laboratory, U.S. Enviromental Protection Agency, Cincinnati. 


\title{
C-04
}

\section{DISEÑO DE UNA NUEVA CREPINA PARA REDUCIR LA CAÍDA DE PRESIÓN EN FILTROS DE ARENA}

\author{
Bové, J. (1)(P); Puig-Bargués, J. (2); Arbat, G. (3); Duran-Ros, M. (4); Pujol, T. (5); Pujol, J.
} (6); Ramírez de Cartagena, F. (7)

${ }^{1}$ Investigador en formación, Universidad de Girona, Departamento de Ingeniería Química, Agraria y Tecnología Agroalimentaria, josep.bove@udg.edu

2 Profesor Titular de Universidad, Universidad de Girona, Departamento de Ingeniería Química, Agraria y Tecnología Agroalimentaria, jaume.puig@udg.edu

${ }^{3}$ Profesor Agregado Interino, Universidad de Girona, Departamento de Ingeniería Química, Agraria y Tecnología Agroalimentaria, gerard.arbat@udg.edu

${ }^{4}$ Profesor Agregado Interino, Universidad de Girona, Departamento de Ingeniería Química, Agraria y Tecnología Agroalimentaria, miquel.duranros@udg.edu

${ }^{5}$ Profesor Agregado, Universidad de Girona, Departamento de Ingeniería Mecánica y de la Construcción Industrial, toni.pujol@udg.edu

${ }^{6}$ Profesor Agregado, Universidad de Girona, Departamento de Ingeniería Química, Agraria y Tecnología Agroalimentaria, joan.pujol@udg.edu

7 Profesor Titular de Universidad, Universidad de Girona, Departamento de Ingeniería Química, Agraria y Tecnología Agroalimentaria, francisco.ramirez@udg.edu

\section{Resumen}

La filtración es necesaria para evitar la obturación de los emisores, que es el principal problema del riego por goteo. Sin embargo, los filtros necesitan presiones elevadas que están relacionadas con un mayor consumo energético. Estudios anteriores han mostrado que la caída de presión en los filtros de arena, considerados como los estándares en riego por goteo, se localiza principalmente en el drenaje. El principal objetivo del trabajo fue diseñar un nuevo modelo de crepina que redujera la caída de presión en el filtro. Esta nueva crepina tiene mayores pasajes a la salida del drenaje, está rodeada con un medio granular de mayor conductividad hidráulica y modifica la curvatura del flujo por encima de la crepina. La nueva crepina fue construida y ensayada en condiciones de filtrado y contralavado, con y sin medio filtrante, en un filtro de laboratorio escalado a partir de un filtro comercial. Esta nueva crepina redujo considerablemente la caída de presión con respecto el diseño comercial. Se desarrolló también un modelo CFD para analizar con detalle las zonas donde se consigue la reducción observada.

\section{Abstract}

Filtration is mandatory for preventing emitter clogging, which is the main drawback of microirrigation. However, microirrigation filters have high pressure requirements, which in turn are related to higher energy consumption. Previous studies have shown that pressure loss in sand media filters, which are usually considered the standard for microirrigation, are mainly located in the filter underdrain. The main objective was to design a new underdrain that could reduce sand media filter pressure drop. The new underdrain has wider passages to the underdrain outlet, is surrounded with a granular medium with higher hydraulic conductivity and it modifies the flow curvature above the underdrain. The new underdrain was built and tested under filtration and backwashing conditions and with and without filter bed using a laboratory filter which was scaled from a commercial filter. The new underdrain considerably reduced pressure loss compared with a commercial filter. A CFD model was 
developed for further study those filter areas where the underdrain achieved a higher reduction of pressure drop.

\section{Introducción. Objetivo del trabajo}

El riego por goteo es el sistema de riego más extendido en España, puesto que se utiliza en el $49 \%$ de la superficie agrícola de regadío (Ministerio de Agricultura, Alimentación y Medio Ambiente, 2015). La adopción de sistemas de riego presurizados como el riego por goteo y por aspersión que se ha producido en los últimos años dentro del programa de modernización de regadíos españoles, ha permitido reducir el uso de agua por hectárea en un $15 \%$ entre 1990 y 2007 pero, en cambio, ha incrementado el consumo de energía por $\mathrm{m}^{3}$ en un $69 \%$ en el mismo periodo (Corominas, 2010).

La filtración es necesaria para evitar la obturación de los emisores en las instalaciones de riego por goteo y garantizar así un correcto funcionamiento de las mismas (Ayars et al, 2007). Los filtros de arena son uno de los filtros más utilizados en riego puesto que son los más indicados cuando se utilizan aguas de peor calidad puesto que suelen conseguir mayores reducciones de los sólidos potencialmente obturadores de los goteros (Duran-Ros et al., 2009). Sin embargo, estos filtros presentan unos requisitos de presión que son muy superiores a los de los emisores (Burt, 2010), por lo que inciden muy directamente en el consumo energético de las instalaciones de riego por goteo. Por lo tanto, si se quiere reducir el consumo energético en estos sistemas de riego, disminuyendo a la vez el coste eléctrico para el agricultor, uno de los principales puntos de actuación sería desarrollar filtros que necesitasen menor presión. Diversos autores (Burt, 2010; Arbat et al., 2013; Bové et al., 2015c) han analizado la caída de presión en los distintos elementos de los filtros de arena, comprobando que es en los drenajes o crepinas del fondo de los mismos donde se produce una mayor reducción de la presión, por lo que es el primer punto dónde incidir. La caída de presión en el drenaje de salida se incrementa con la velocidad superficial de filtración, como señalaron diversos autores (Bové et al., 2015c; Burt, 2010; Mesquita et al., 2012) que estudiaron diferentes diseños de drenaje.

Mediante el uso de la técnica de dinámica de fluidos computacional (CFD), Arbat et al. (2011) hallaron que la caída de presión en el drenaje del filtro se debía a la aceleración del fluido al atravesar el drenaje y a la curvatura del flujo hidráulico dentro del medio de filtración al aproximarse al drenaje. Bové et al. (2015c), utilizando esta misma técnica, señalaron diversos puntos en los que se podía intervenir para reducir la caída de presión en el drenaje.

El objetivo del presente trabajo ha sido el de diseñar, construir y verificar experimentalmente un nuevo modelo de crepina para filtros de arena que permita reducir la caída de presión.

\section{Material y métodos}

Se diseñó y construyó un nuevo modelo de crepina (Figura 1) para un filtro de laboratorio escalado a partir de uno comercial (Arbat et al., 2013) considerando las sugerencias de Bové et al. (2015c). En concreto, se incrementó la sección de salida del drenaje, se recubrió el drenaje con vidrio reciclado triturado previamente tamizado a un tamaño de partícula entre 0,85 y $1,50 \mathrm{~mm}$ para que tuviese mayor conductividad hidráulica que el resto del medio filtrante formado por arena silícea, tamizada entre 0,63 y 0,75 mm, y se modificó la disposición de las aperturas en el drenaje para no afectar tanto las líneas de flujo hidráulico. Las características físicas e hidráulicas de ambos medios y granulometrías 
se determinaron en un trabajo anterior (Bové et al., 2015b). Para retener el vidrio triturado dentro de la crepina las aperturas de esta se recubrieron con malla de acero inoxidable de $1,25 \times 1,25 \mathrm{~mm}$ de luz.

Para poder determinar la caída de presión a lo largo del filtro experimental, se dispusieron manómetros digitales (Figura 1) con una precisión de $\pm 0,01 \mathrm{kPa}$ en 5 posiciones distintas: en la tubería de entrada, en 3 alturas del medio filtrante y en la tubería de salida. El filtro operó con agua de red procedente de un depósito a partir del cual se bombeó con una bomba centrífuga (Figura 2), a la salida de la cual se ubicó un caudalímetro electromagnético de $\pm 0,05 \mathrm{~m}^{3} / \mathrm{h}$ de precisión para determinar el caudal circulante y poder calcular la velocidad superficial de filtración. Aguas abajo, se dispuso una válvula de compuerta para ajustar el caudal y 2 válvulas de bola, ubicadas a la entrada y salida del filtro, respectivamente, para regular la presión.
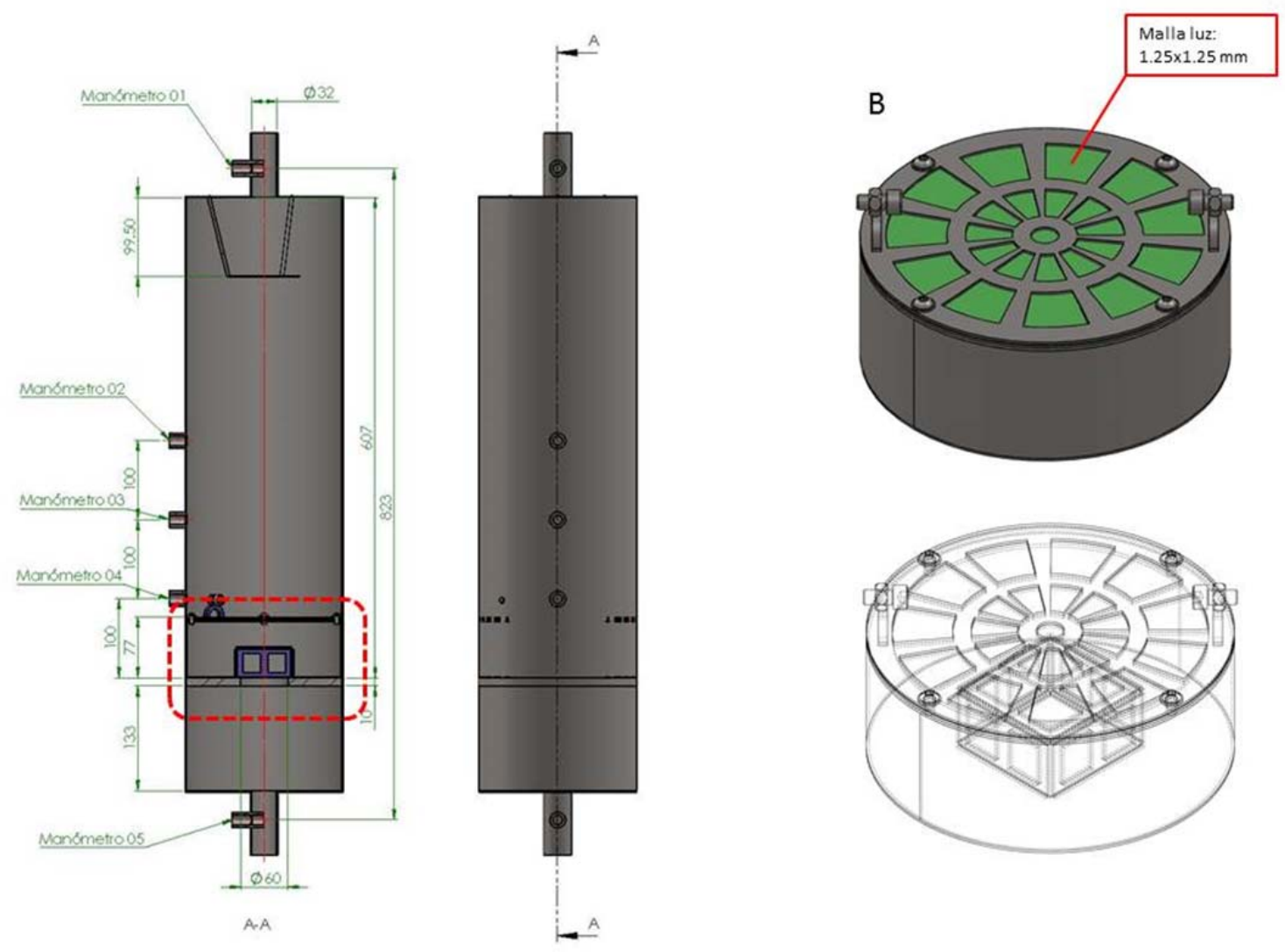

Figura 1. Filtro de laboratorio escalado con el nuevo diseño de crepina y su vista isométrica (B). Dimensiones en $\mathrm{mm}$.

En la instalación experimental (Figura 2) se realizaron pruebas en régimen de filtración y de contralavado, sin medio filtrante y con medio filtrante de $300 \mathrm{~mm}$ de altura. Cada experimento se repitió 3 veces. En cada repetición, se evaluó el funcionamiento del filtro trabajando a 12 velocidades de filtración distintas entre los 0,003 y los 0,030 m/s.

Con la intención de mejorar la comprensión del funcionamiento de la nueva crepina, se desarrolló un modelo tridimensional mediante CFD. Este modelo se comparó con otro 
desarrollado con anterioridad (Bové et al., 2015c) para la crepina comercial del filtro que se utilizó para escalar el filtro de laboratorio.

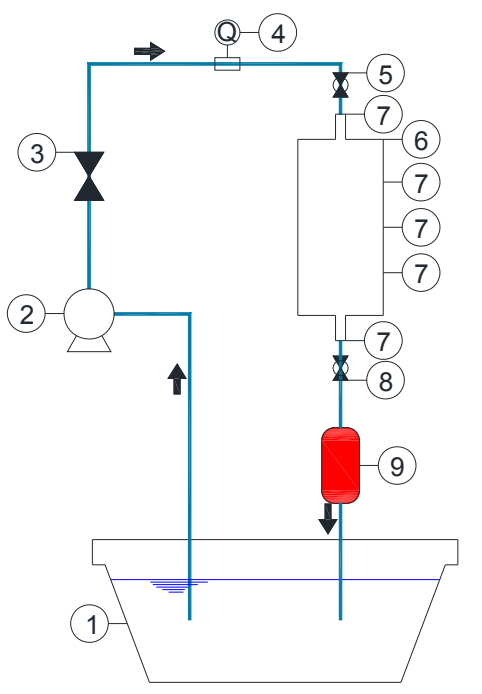

\section{DEPÓSITO}

2. BOMBA CENTRÍFUGA

3. VÁLVULA DE COMPUERTA

4. CAUDALÍMETRO

5. VÁLVULA DE BOLA

6. FILTRO A ESCALA

7. MANÓMETRO

8. VÁLVULA DE BOLA

9. FILTRO DE MALLA

Figura 2. Esquema de la instalación experimental.

Se utilizaron los códigos ANSYS ICEMCFD para dibujar y mallar el modelo y ANSYS Fluent para resolverlo. El modelo desarrollado constaba de una malla tridimensional que representaba un cuarto del filtro con un plano de simetría $X Y$ y otro en el plano $Y Z$ (Figura 3 ), lo que permitió disminuir el número total de elementos del modelo y reducir así el tiempo de cálculo. La malla estaba formada por 1.391 .082 elementos y, como tenía los 2 planos de simetría, la geometría del filtro se discretizó en 5.564 .328 elementos. Para una correcta caracterización del nuevo diseño, las aperturas internas de la nueva crepina se discretizaron en celdas de una longitud máxima de $0,50 \mathrm{~mm}$. El resto del dominio del drenaje se discretizó con celdas de, como máximo, $1 \mathrm{~mm}$ de longitud. En cambio, para el área más ancha del cuerpo del filtro, fue suficiente utilizar celdas de una longitud máxima de $5 \mathrm{~mm}$. Para verificar la idoneidad de la malla definida, el modelo fue ejecutado con otras 2 mallas con un grosor que se incrementó con un factor de 2,2 con respecto la malla definida anteriormente para analizar la robustez del modelo. Para un valor determinado de velocidad, las caídas de presión obtenidas con las 3 mallas se diferenciaron en menos del $1 \%$, por lo que se consideró que la malla descrita cumplía satisfactoriamente.

Se simularon dos condiciones operacionales del filtro para comparar el funcionamiento hidráulico del nuevo diseño de crepina con el diseño comercial de referencia. En la primera, se consideró un régimen de filtración sin medio filtrante, mientras que la segunda consistió en un régimen de filtración con un medio filtrante de $300 \mathrm{~mm}$ de altura (posición del manómetro 2 de la Figura 1) formado por arena silícea de un tamaño de partícula entre 0,63 y $0,75 \mathrm{~mm}$. La operación de contralavado sólo se simuló en condiciones de ausencia de medio filtrante, porque la expansión del lecho filtrante no se consiguió modelar con precisión en el modelo desarrollado.

El modelo desarrollado se ejecutó con el código ANSYS-Fluent, el cual dispone de distintos modelos para representar la turbulencia. En este caso, se utilizó el modelo k- $\varepsilon$ con valores de la constante $\mathrm{C} \varepsilon_{2}=1,9$, un número efectivo de Prandtl para el transporte de la energía cinética turbulenta TKE-Prandtl $=1,0$, un número efectivo de Prandtl para el transporte del nivel de disipación de la turbulencia TDR-Prandtl $=1,2$, una intensidad de turbulencia $=5 \%$ y un valor del cociente entre la viscosidad turbulenta y la viscosidad molecular igual a 10 en la entrada del filtro. 


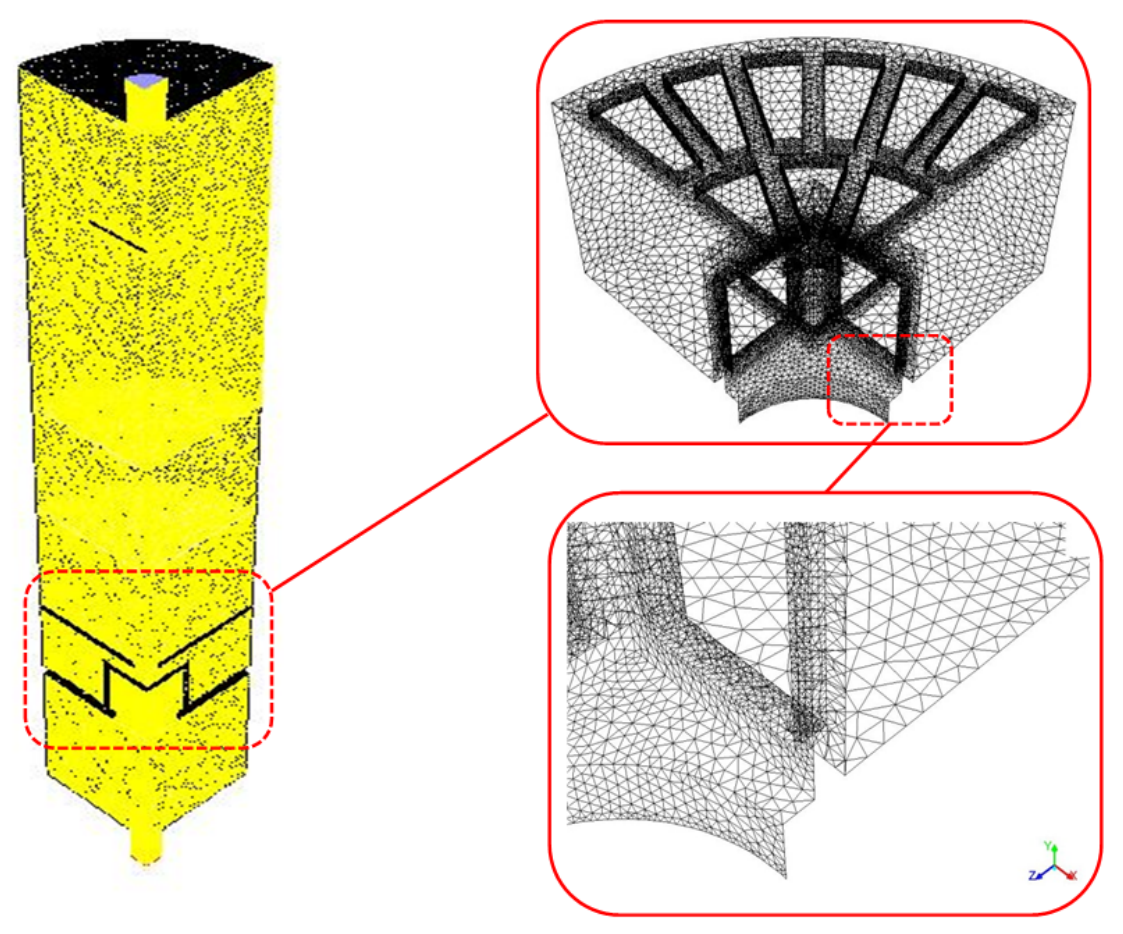

Figura 3. Dominio de flujo simulado (un cuarto de la sección del filtro; izquierda) y malla del elemento de drenaje (derecha superior, con detalle en la derecha inferior).

Los factores de viscosidad y de inercia de cada medio granular se definieron de acuerdo con la Guía del Usuario de ANSYS-Fluent (ANSYS, 2009). La ecuación (1) es la que utiliza ANSYS Fluent para calcular la caída de presión en un medio poroso. La ecuación (1) es equivalente a la ecuación de Ergun, que ha mostrado un buen nivel de predicción de la caída de presión en distintos tipos de medios filtrantes (Bové et al., 2015a).

Siendo $\Delta \mathrm{p} / \Delta \mathrm{L}$ la caída de presión por unidad de longitud del medio filtrante $(\mathrm{Pa} / \mathrm{m}) ; 1 / \mathrm{a}$ es el factor viscoso del medio filtrante $\left(1 / \mathrm{m}^{2}\right) ; \mu$ es la viscosidad del fluido (Pa.s); $v$ es la velocidad de filtración superficial $(\mathrm{m} / \mathrm{s}) ; C_{2}$ es el factor inercial del medio $(1 / \mathrm{m})$; y $\rho$ es la densidad del fluido $\left(\mathrm{kg} / \mathrm{m}^{3}\right)$. Los valores utilizados en la modelización se indican en la Tabla 1 , los valores para el vidrio reciclado incorporan la malla para retener el medio filtrante.

Tabla 1. Valores de los parámetros utilizados en la modelización de cada medio.

\begin{tabular}{|c|c|c|}
\hline \multirow{2}{*}{ Parámetro } & \multicolumn{2}{|c|}{ Medio } \\
\cline { 2 - 3 } & Arena silícea & Vidrio reciclado \\
\hline Porosidad $(\%)$ & 42,2 & 42,7 \\
\hline $\mathrm{C}_{2}(1 / \mathrm{m})$ & 67.809 & 49.944 \\
\hline $1 / \alpha\left(1 / \mathrm{m}^{2}\right)$ & 1.426 .866 .416 & 794.666 .385 \\
\hline
\end{tabular}

Las condiciones de contorno para la modelación fueron un caudal de $0,5 \mathrm{l} / \mathrm{s}$ (que se corresponde con una velocidad superficial de filtración de $0,016 \mathrm{~m} / \mathrm{s}$ ) y una presión a la salida del filtro de $50 \mathrm{kPa}$. De esta forma, se aseguraba que no se generaban zonas con una presión excesivamente baja en los puntos donde el agua alcanzaba mayor velocidad. 
Además, se realizaron 12 simulaciones para cada diseño de crepina (comercial y nueva) con el mismo rango de velocidad superficial de filtración $(0,003-0,030 \mathrm{~m} / \mathrm{s})$ en el que se realizaron los experimentos de laboratorio descritos anteriormente. Al proceder de esta forma, se pudieron comparar los resultados modelados con los simulados utilizando el coeficiente de eficiencia de Nash y Sutcliffe (1970):

Siendo NSE el coeficiente de eficiencia de Nash-Sutcliffe (adimensional); Oi el valor experimental de la caída de presión $(\mathrm{Pa})$; $\mathrm{Pi}$ el valor predicho de la caída de presión $(\mathrm{Pa}) ; \mathrm{O}$ la caída de presión experimental media $(\mathrm{Pa})$; y $\mathrm{N}$ el número de observaciones.

\section{Resultados y discusión}

La caída de presión con respecto la velocidad de filtración superficial del nuevo diseño de crepina en comparación con el diseño comercial en las condiciones de filtrado y contralavado sin medio filtrante, se muestra en la Figura 4. La caída de presión que se produjo con el nuevo diseño de la crepina se redujo, con respecto al filtro con el diseño comercial de crepina, en un $50 \%$ para las menores velocidades superficiales de filtración $(<0,01 \mathrm{~m} / \mathrm{s})$ y en más del $80 \%$ para las mayores velocidades superficiales de filtración $(>0,02$ $\mathrm{m} / \mathrm{s}$ ). Las mismas magnitudes de reducción de la caída de presión se observaron en condiciones de contralavado sin medio filtrante.

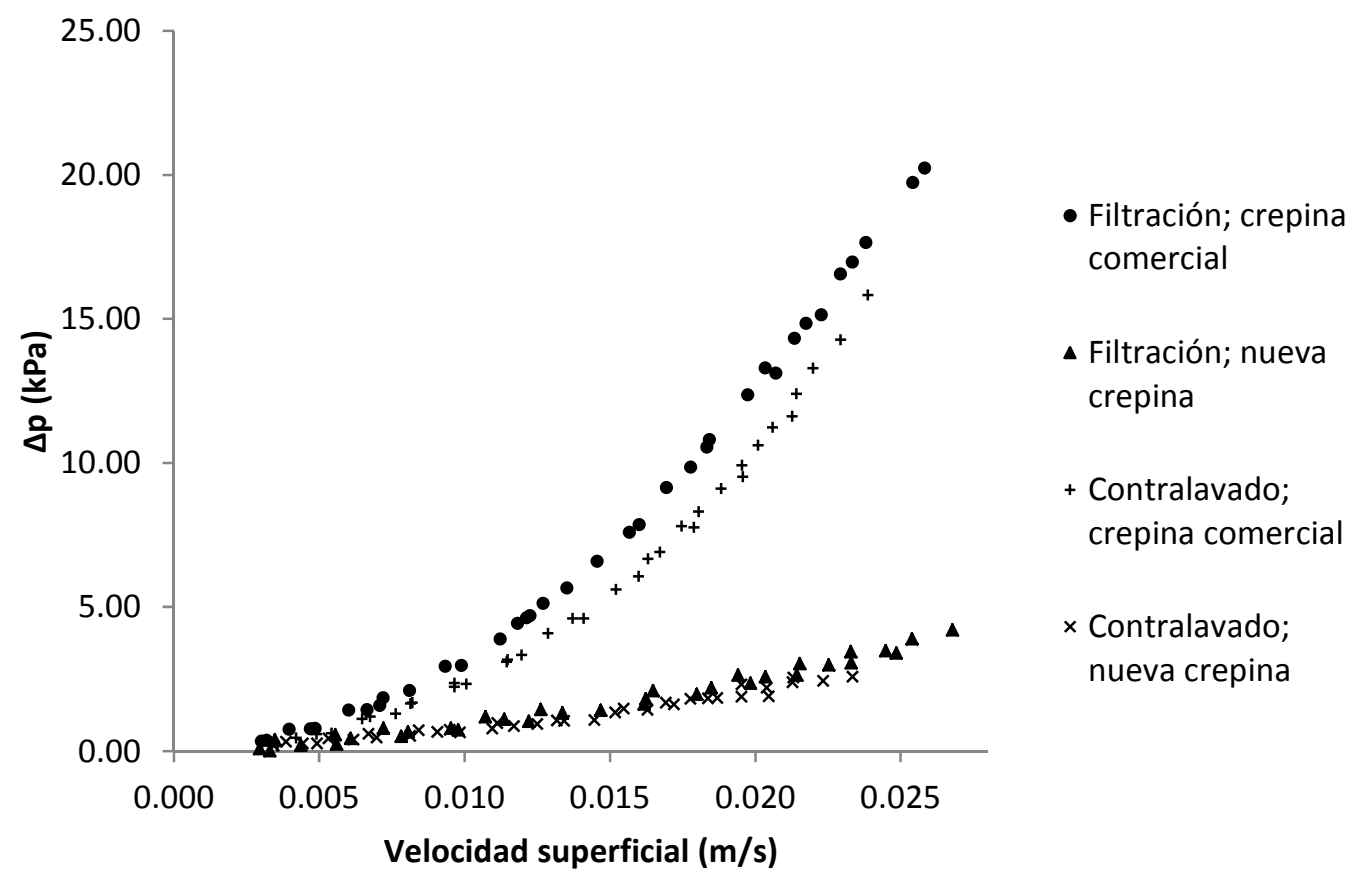

Figura 4. Caída de presión en el conjunto del filtro con la crepina comercial y el nuevo diseño de crepina en condiciones de filtración convencional y contralavado sin medio filtrante. 
Cuando se introdujo un medio filtrante de arena silícea de tamaño de partícula entre 0,63 y $0,75 \mathrm{~mm}$ y $300 \mathrm{~mm}$ de altura, la caída de presión producida con el nuevo diseño de crepina fue también inferior a la observada con el drenaje comercial (Figura 5). En este caso, las reducciones de caída de presión fueron del $20 \%$ para velocidades superficiales de filtración inferiores a $0,01 \mathrm{~m} / \mathrm{s}$ y del $45 \%$ para las que superaron los $0,02 \mathrm{~m} / \mathrm{s}$. Estas disminuciones de caída de presión fueron inferiores a las observadas cuando no se dispuso medio filtrante. En condiciones de contralavado, la caída de presión en el filtro fue prácticamente la misma que sin medio filtrante: $50 \%$ y $80 \%$ para las velocidades superficiales de filtración más pequeñas y mayores, respectivamente. Si se comparan las caídas de presión producidas con el nuevo diseño con datos disponibles en la bibliografía de distintos filtros de arena (Burt, 2010; Mesquita et al., 2012), éstas también son menores con el nuevo diseño.

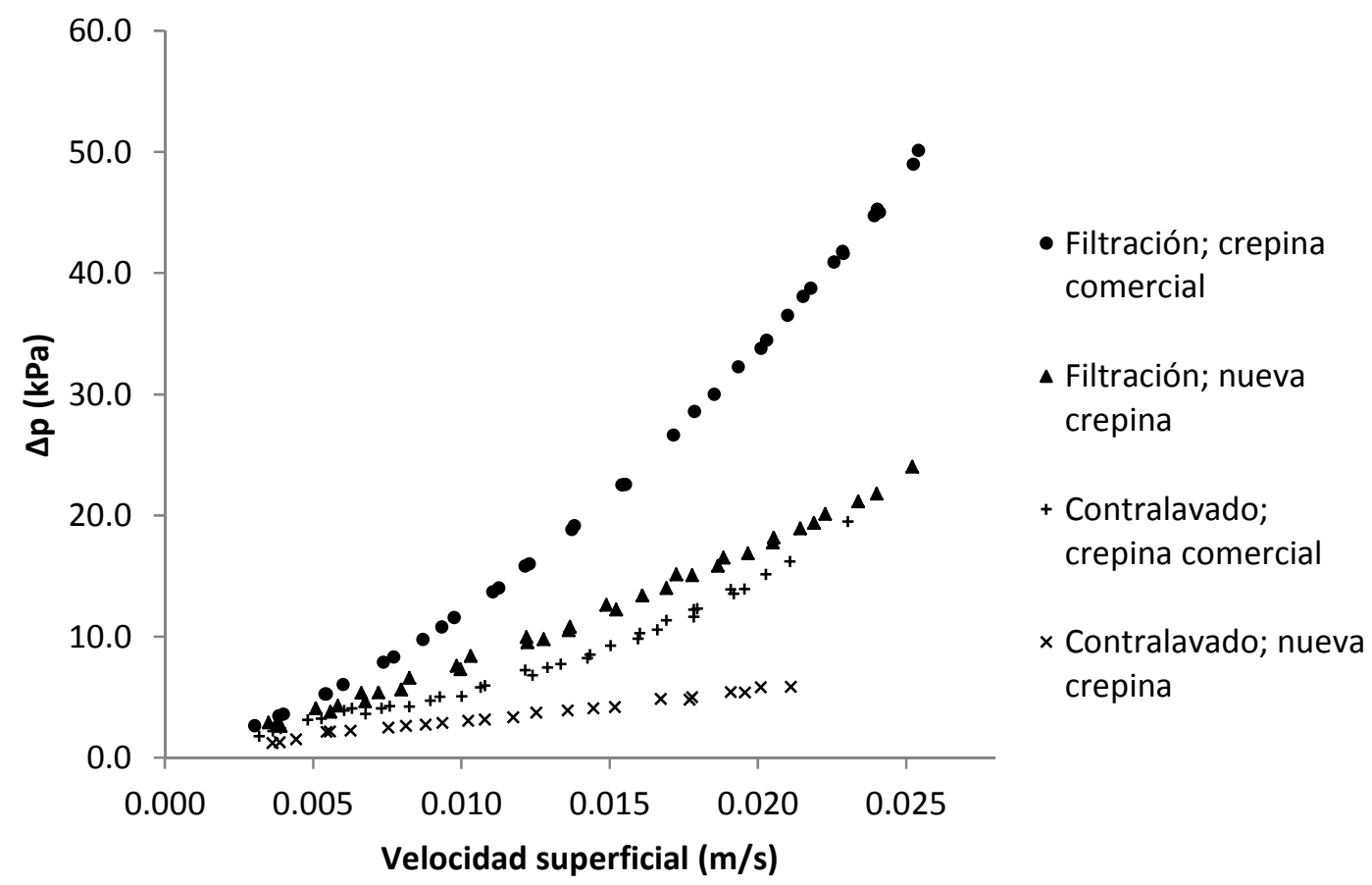

Figura 5. Caída de presión en el conjunto del filtro con la crepina comercial y el nuevo diseño de crepina en condiciones de filtración convencional y contralavado con una columna de $300 \mathrm{~mm}$ de medio filtrante.

En la Tabla 2 se muestran los valores del coeficiente de eficiencia de Nash-Sutcliffe (NSE) obtenidos usando la ecuación (2) con los datos experimentales y con los resultados del modelo CFD para la crepina comercial y el nuevo modelo de crepina. Como el NSE fue mayor de 0,9 , la capacitad predictiva del modelo fue muy buena, de acuerdo con Ritter y Muñoz-Carpena (2013). Por lo tanto, el modelo desarrollado describe con precisión la caída de presión producida en el filtro. 
Tabla 2. Coeficientes de eficiencia de Nash-Suttclife para los datos experimentales y modelados con CFD para los distintos escenarios considerados.

\begin{tabular}{|l|c|c|}
\hline \multicolumn{1}{|c|}{ Escenario } & Drenaje comercial & Nuevo drenaje \\
\hline Filtración sin medio filtrante & 0,993 & 0,963 \\
\hline $\begin{array}{l}\text { Filtración con medio filtrante de } 300 \mathrm{~mm} \text { de } \\
\text { altura con arena silícea de tamaño de } \\
\text { partícula entre } 0,63 \text { y } 0,75 \mathrm{~mm} .\end{array}$ & 0,998 & 0,997 \\
\hline
\end{tabular}

Una vez validada la capacidad predictiva del modelo desarrollado, éste se utilizó para analizar el perfil de caída de presión a lo largo del filtro. En la Figura 6 se compara la caída de presión a lo largo del filtro en régimen de filtración con un lecho filtrante de $300 \mathrm{~mm}$ de altura y un caudal de $0,50 \mathrm{l} / \mathrm{s}$ (es decir, con una velocidad superficial de filtración de 0,016 $\mathrm{m} / \mathrm{s}$ ). Se puede observar que la principal caída de presión se produce en la zona del drenaje. El nuevo diseño redujo un $42 \%$ la caída de presión con respecto a la crepina comercial. Esta disminución llegó hasta el $80 \%$ cuando no se dispuso medio filtrante. La menor caída de presión obtenida con el nuevo diseño se debe a la reducción de la velocidad de paso entre el medio filtrante y la cámara de salida del filtro. En la Figura 7 se muestra la diferencia entre los contornos de velocidad y presión de los dos diseños de crepina comparados.

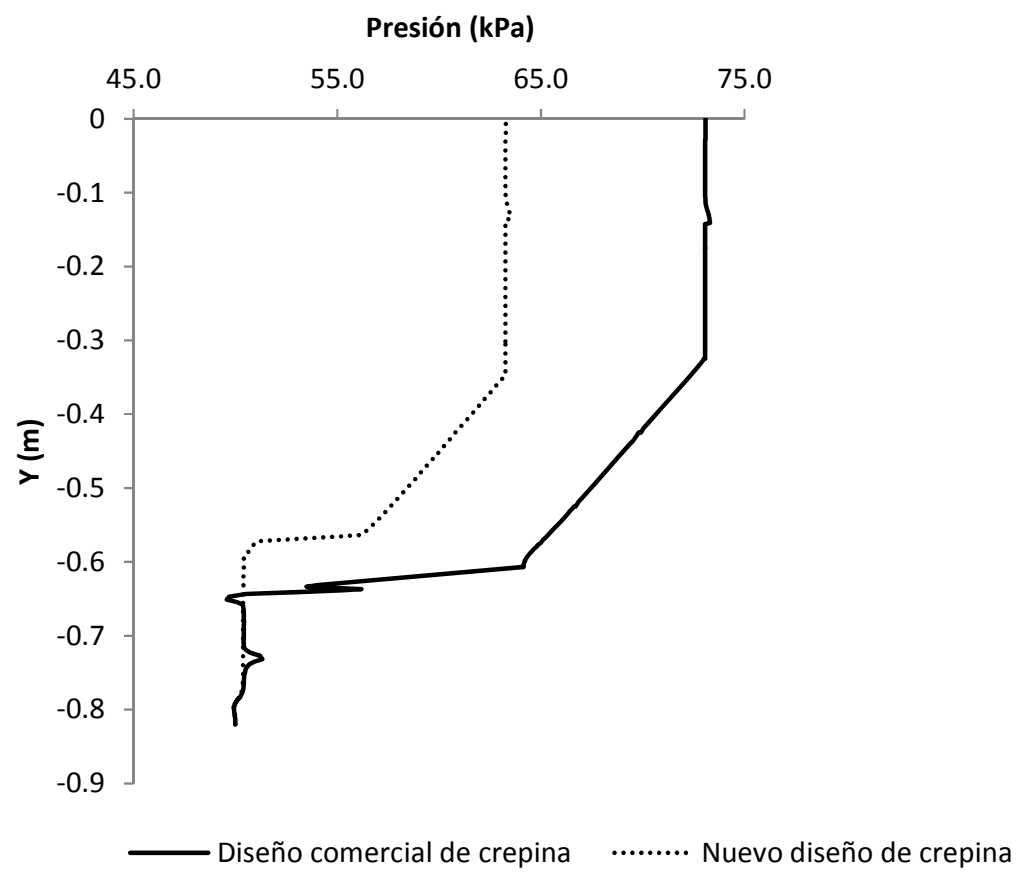

Figura 6. Comparación entre la caída de presión a lo largo del filtro de arena con una crepina comercial y el nuevo diseño de crepina en régimen de filtración con medio filtrante. 

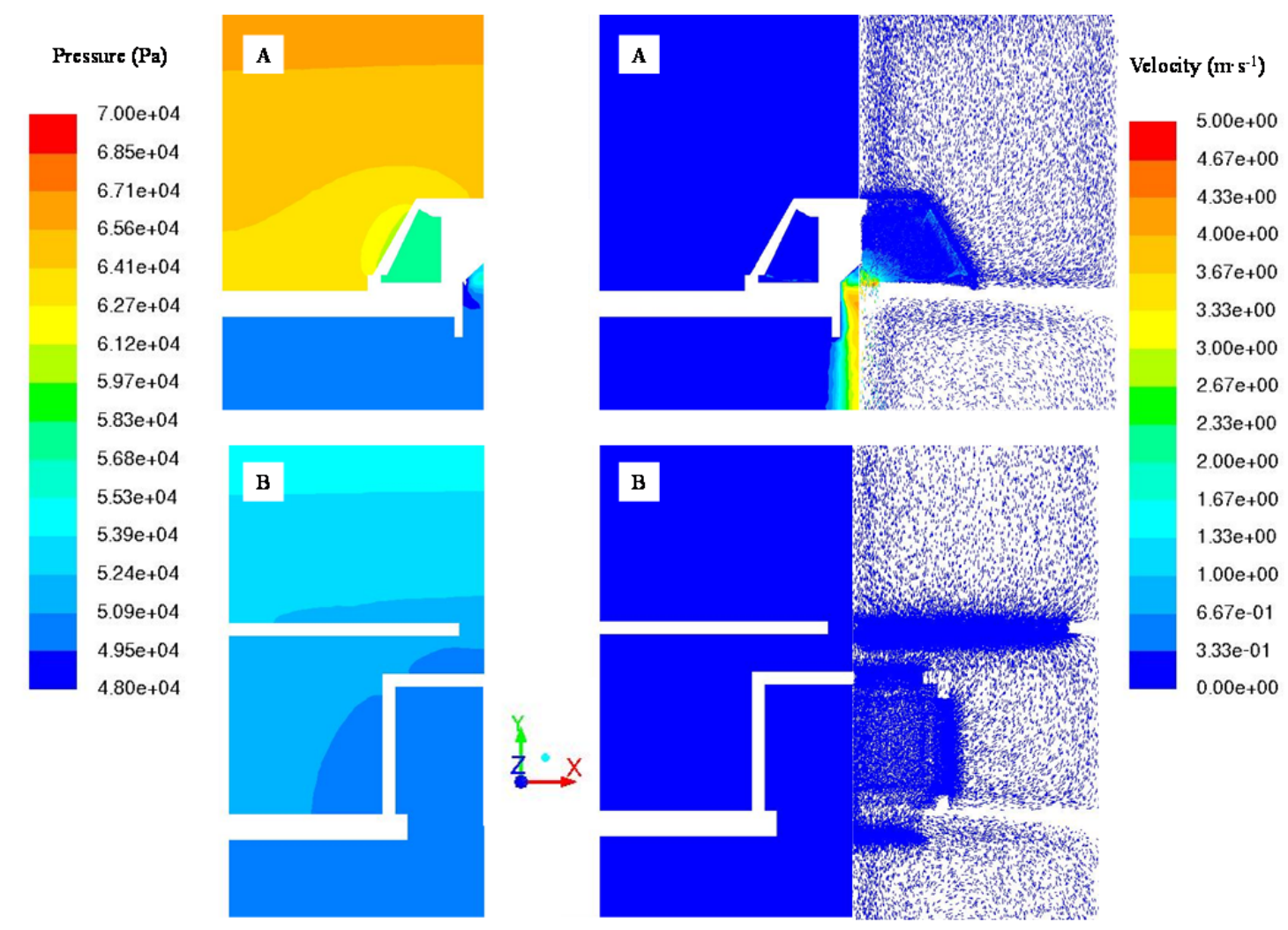

Figura 7. Contornos de velocidad y presión en la crepina comercial $(A)$ y en el nuevo diseño de crepina (B) operando en filtración con una columna de arena silícea de 0,63 a 0,75 mm de granulometría con una velocidad superficial de $0,016 \mathrm{~m} / \mathrm{s}$ y una presión a la salida de 50

$\mathrm{kPa}$.

\section{Conclusiones}

Se ha diseñado y construido un nuevo modelo de crepina para reducir la caída de presión en los filtros arena y, de esta forma, disminuir los requisitos de presión y el consumo energético asociado a estos filtros ampliamente utilizados en riego por goteo. Las pruebas de laboratorio han confirmado que el nuevo diseño reduce claramente la caída de presión con respecto a un diseño comercial de referencia.

Un modelo utilizando la dinámica de fluidos computacional fue desarrollado y validado con los datos experimentales para identificar las zonas donde el nuevo diseño ejerce su mejora. En concreto, el nuevo diseño redujo la velocidad de paso a la salida del drenaje y redujo también la curvatura del flujo en la zona de aproximación a la crepina. En esta misma zona, al disponer de un medio de mayor conductividad hidráulica, se redujo también la caída de presión por roce en el medio.

Este nuevo diseño de crepina ha sido registrado como el modelo de utilidad U201530629 (Bové et al., 2015b). Con este nuevo drenaje se podría mejorar el funcionamiento de los filtros de arena utilizados en instalaciones de riego por goteo, consiguiendo por tanto una mayor eficiencia en el uso del agua y de la energía. 


\section{Agradecimientos}

Los autores quieren agradecer al Ministerio de Economía y Competitividad la concesión de la ayuda para la realización del proyecto de investigación referencia CGL201231180 .

\section{Bibliografía}

ANSYS (2009). ANSYS Fluent User's Guide. Canonsburg, PA: ANSYS.

Arbat, G., Pujol, T., Puig-Bargués, J., Duran-Ros, M., Barragán, J., Montoro, L., Ramírez De Cartagena, F. (2011). Using computational fluid dynamics to predict head losses in the auxiliary elements of a microirrigation sand filter. Transactions of the ASABE 54, 13671376.

Arbat, G., Pujol, T., Puig-Bargués, J., Duran-Ros, M., Montoro, L., Barragán, J., Ramírez de Cartagena, F. (2013). An experimental and analytical study to analyze hydraulic behavior of nozzle-type underdrains in porous media filters. Agricultural Water Management, 126, 64-74.

Ayars, J.E., Bucks, D.A., Lamm, F.R., Nakayama, F.S. (2007). Introduction. En: Lamm, F.R., Ayars, J.E., Nakayama, F.S. (Eds.), Microirrigation for Crop Production. Amsterdam: Elsevier. 1-26.

Bové, J., Arbat, G., Duran-Ros, M., Pujol, T., Velayos, J., Ramírez de Cartagena, F., PuigBargués, J. (2015a). Pressure drop across sand and recycled glass media used in micro irrigation filters. Biosystems Engineering, 137, 55-63.

Bové, J., Arbat, G., Puig-Bargués, J., Pujol, T., Duran-Ros, M., Ramírez de Cartagena, F., Pujol, J. (2015b). Filtro de matriz granular. Modelo de utilidad U201530629. Madrid: Oficina Española de Patentes y Marcas.

Bové, J., Arbat, G., Pujol, T., Duran-Ros, M., Ramírez de Cartagena, F., Velayos, J., PuigBargués, J. (2015c). Reducing energy requirements for sand filtration in microirrigation: Improving the underdrain and packing. Biosystems Engineering, 140, 67-78.

Burt, C.M. (2010). Hydraulics of commercial sand media filter tanks used for agricultural drip irrigation. San Luis Obispo, CA: Irrigation Training \& Research Center, California Polytechnic State University.

Corominas, J. (2010). Agua y energía en el riego, en la época de la sostenibilidad. Ingeniería del Agua 17, 219-233.

Duran-Ros, M., Puig-Bargués, J., Arbat, G., Barragán, J., Ramírez de Cartagena, F. (2009). Effect of filter, emitter and location on clogging when using effluents. Agricultural Water Management, 96, 67.

Mesquita, M., Testezlaf, R., Ramirez, J.C.S. (2012). The effect of media bed characteristics and internal auxiliary elements on sand filter head loss. Agricultural Water Management, 115, 178-185.

Ministerio de Agricultura, Alimentación y Medio Ambiente (2015). Encuesta sobre superficies y rendimientos de cultivos. Informe sobre regadíos en España. Madrid: Ministerio de Agricultura, Alimentación y Medio Ambiente.

Nash, J.E., Sutcliffe, J.V. (1970). River flow forecasting through conceptual models part I A discussion of principles. Journal of Hydrology. 10, 282-290.

Ritter, A., Muñoz-Carpena, R. (2013). Performance evaluation of hydrological models: Statistical significance for reducing subjectivity in goodness-of-fit assessments. Journal of Hydrology, 480, 33-45. 


\title{
WRESUITLADOSDEE ENSAMO MAANEDO-DIEL

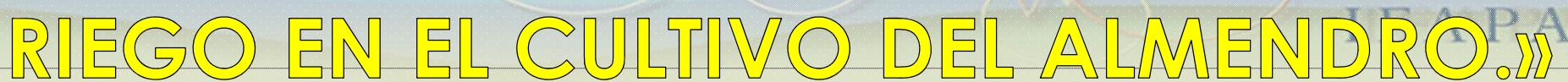

Salvatierra Bellido, B. ${ }^{1}$, Gómez Durán, E. ${ }^{2}$, Viqueira Pina, S.(p). ${ }^{3}$

\begin{abstract}
${ }^{1}$ Tecnólogo titular, IFAPA Centro Chipiona, (Cádiz),
2 Técnico Colaborador, IFAPA Centro Chipiona, (Cádiz).

${ }^{3}$ Técnico I+D+F, IFAPA Centro Chipiona, (Cádiz),
\end{abstract}

Desde hace ya unos años, el cultivo del almendro se está introduciendo con fuerza en la zona del bajo Guadalquivir, la comodidad de manejo de un cultivo leñoso, los buenos precios de la almendra y la magnífica respuesta al riego del almendro, hacen que cada vez más agricultores afronten las inversiones necesarias para implantar el cultivo.

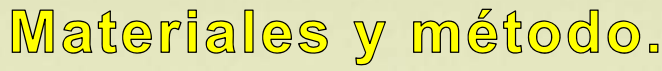

Una parcela de almendros adultos, en suelo franco arcilloso, marco $7 \times 5 \mathrm{~m}$, de Almendro GUARA, regados con riego localizado .

$\mathrm{T} 1 \rightarrow$ Riego de referencia.

T2 y T3 $\rightarrow$ Riego Deficitario Controlado (RDC).

T4, T5 y T6 $\rightarrow$ Riego Deficitario Sostenido (RDS).

T5 y $\mathrm{T} 6 \rightarrow$ Uno o dos ramales de goteo.

Tabla1. Resumen de tratamientos.

\begin{tabular}{|c|c|c|c|c|}
\hline \multicolumn{2}{|c|}{ Tratamiento } & $\begin{array}{l}\text { Fase: I-II-II } \\
\text { vegetativo, } \\
\text { floración y } \\
\text { cuajado. }\end{array}$ & $\begin{array}{c}\text { Fase IV: } \\
\text { Llenado a } \\
\text { recolección, } \\
\text { Junio a Agosto. }\end{array}$ & $\begin{array}{c}\text { Fase V: De } \\
\text { recolección a } \\
\text { caida de hojas, } \\
\text { reservas. }\end{array}$ \\
\hline T1 & Doble ramal & $100 \%$ NBR. & $100 \%$ NBR & $100 \%$ NBR \\
\hline T2 & Doble ramal & $100 \%$ NBR. & $80 \%$ NBR. & $100 \%$ NBR \\
\hline T3 & Doble ramal & $50 \%$ NBR. & $15 \%$ NBR. & $50 \%$ NBR \\
\hline T4 & Doble ramal & $60 \%$ NBR. & $60 \%$ NBR. & $60 \%$ NBR \\
\hline T5 & Doble ramal & $37 \%$ NBR. & $37 \%$ NBR. & $37 \%$ NBR \\
\hline T6 & Ramal simple & $37 \%$ NBR. & $37 \%$ NBR. & $37 \%$ NBR \\
\hline
\end{tabular}

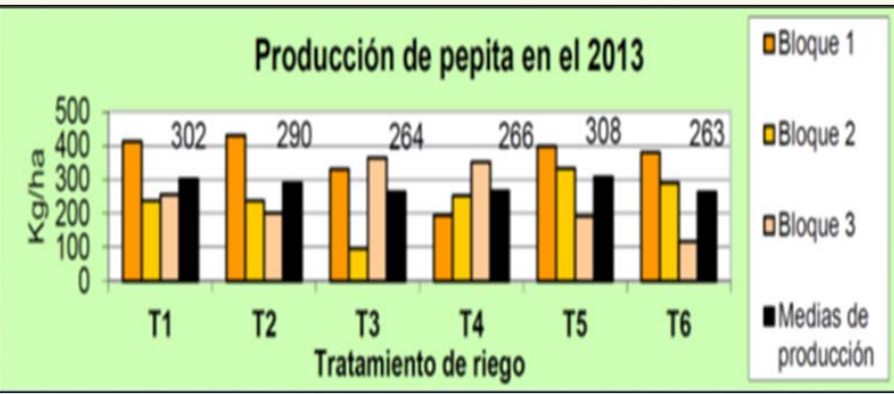

Figura 3. Producción de pepita campaña de transición 2013.

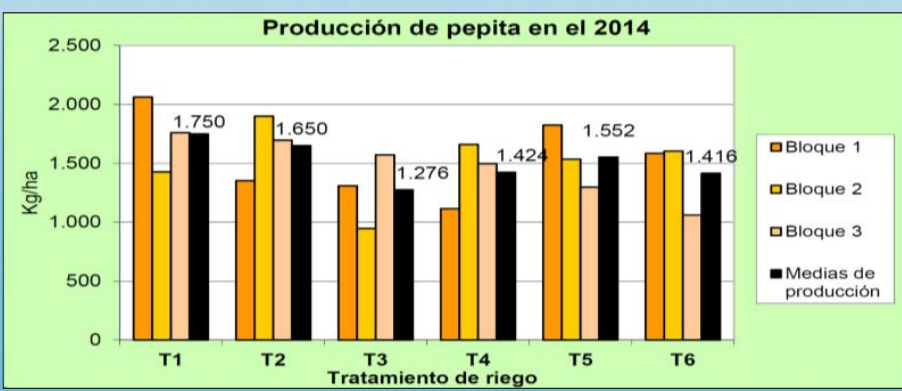

Figura 6. Producción de pepita de campaña ensayo 2014
En el presente panel se muestran los resultados obtenidos en el ensayo experimental de manejo de riegos en el cultivo de almendro llevado a cabo en las campañas 2013 y 2014 en una parcela experimental situada en la provincia de Sevilla.

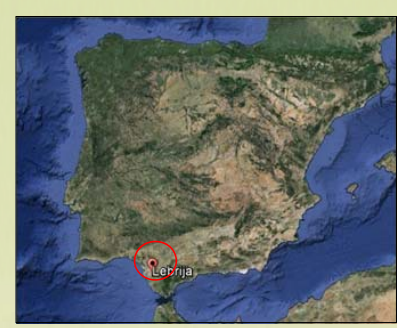

Figura 1: Localización de Lebrija, en la campiña del bajo Guadalquivir.

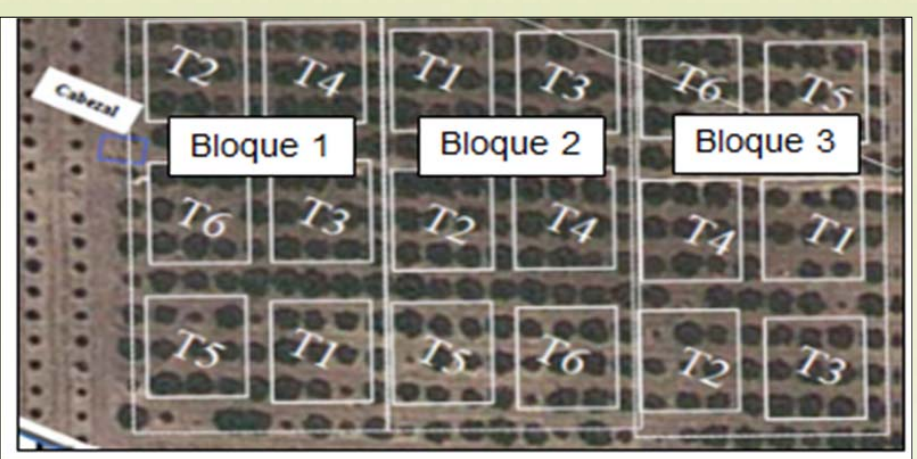

Figura 2. Tratamientos de riego del ensayo.

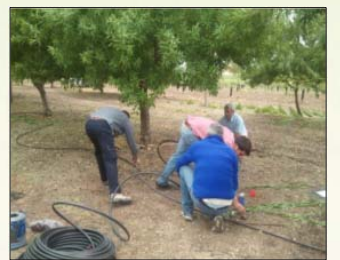

Figura 4. Instalación del sistema de riego.

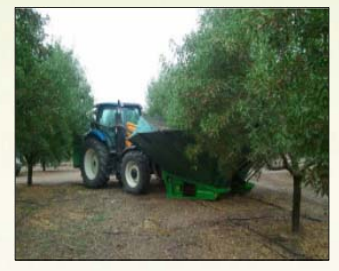

Figura 5. Recogida de almendra.

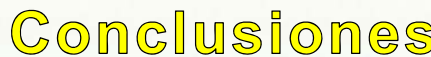

- Existe una mayor producción en los tratamientos de riego de menor déficit de agua.

- Siempre que la dotación de agua sea un factor limitante, es conveniente un riego deficitario controlado (RDC) con el menor déficit posible, frente al riego deficitario sostenido (RDS).

- En plantación adulta y suelos franco arcillosos no existe significación estadística entre las producciones de T5 y T6, uno o dos ramales.

- En RDS, un menor número de puntos de emisión,T4 (cuatro, $60 \%$ NBR) presenta menor aprovechamiento del agua frente a un número mayor, T5 y T6 (diez emisores, 37\%). 


\title{
C-05
}

\section{RESULTADOS DE ENSAYO MANEJO DEL RIEGO EN EL CULTIVO DEL ALMENDRO}

\author{
Salvatierra Bellido, B. ${ }^{1}$, Gómez Durán, E. ${ }^{2}$, Viqueira Pina, S.(p). ${ }^{3}$
}

\author{
${ }^{1}$ Tecnólogo titular, IFAPA Centro Chipiona, (Cádiz), benito.salvatierra@juntadeandalucia.es \\ ${ }^{2}$ Técnico Colaborador, IFAPA Centro Chipiona, (Cádiz). \\ ${ }^{3}$ Técnico I+D+F, IFAPA Centro Chipiona, (Cádiz), salvador.viqueira@juntadeandalucia.es
}

\section{Resumen}

Desde hace ya unos años, el cultivo del almendro se está introduciendo con fuerza en la zona del bajo Guadalquivir, la comodidad de manejo de un cultivo leñoso, los buenos precios de la almendra y la magnífica respuesta al riego del almendro, hacen que cada vez más agricultores afronten las inversiones necesarias para implantar el cultivo.

En el presente artículo se reflejan los resultados obtenidos en el ensayo experimental de manejo de riego en el cultivo de almendro. El ensayo se desarrolla durante las campañas 2013 y 2014 en una parcela experimental situada en el término municipal de Lebrija, Sevilla, en terreno de campiña, donde existía una plantación adulta y sana de almendros, con una producción estabilizada en riego deficitario sostenido con un $37 \%$ de las necesidades máximas cubiertas.

Se han ensayado 5 estrategias de riego, con el fin de documentar el comportamiento del cultivo frente a distintos manejos y diseños de sistemas para así poder extraer conclusiones que trasladar al sector, esta primera serie de ensayos se encuadran en un conjunto de actividades experimentales que el Servicio de Asesoramiento al Regante de Andalucía (S.A.R. Andalucía) comenzó en 2013 sobre manejo de riego en almendro y que continuarán en el próximo marco 2016-2020, con nuevos ensayos.

\section{1-Introducción y objetivo.}

Andalucía, en 2007, contaba con 151.374 ha de almendros, de las que aproximadamente 7.000 ha son de riego, con una producción total de 45.945 toneladas, que generaron un valor estimado de 64.840 miles de $€$ (Consejería de Agricultura, Pesca y medio Ambiente), siendo Granada y Almería las provincias más representativas seguidas de Málaga y Sevilla. Estos datos incluyen plantaciones de todo tipo dando una producción media entorno a $300 \mathrm{~kg} / \mathrm{ha}$ al existir gran superficie en terrenos marginales.

La superficie en la fecha perteneciente a la provincia de Sevilla era 1.728 ha, estando en continuo crecimiento, la mayoría de las nuevas plantaciones son en regadío o como alternativa al cereal de secano. Se ha observado con una producción media de $1.362 \mathrm{Kg} / \mathrm{ha}$ de almendra cáscara para regadíos, estando producción media tan baja relacionada con plantaciones jóvenes y con un manejo no tan intensivo del riego. Por tanto, era perentorio generar una línea de experimentación para la optimización del uso del agua en el cultivo del almendro y unificar criterios de actuación para mejorar la rentabilidad.

Desde el Centro IFAPA de Chipiona, el equipo del Sistema de Asistencia al Regante (SAR) del IFAPA, ha diseñado una serie de actividades de transferencia 
sobre el manejo de riego en el cultivo del almendro para el Bajo Guadalquivir. Con el objetivo de conocer, analizar y documentar, las diferentes estrategias de riego en almendro y sus consecuencias productivas, se desarrolló el ensayo sobre manejo de riego del cultivo del almendro y se presenta el presente trabajo.

\section{2- Materiales y métodos}

Para cubrir la demanda anteriormente expuesta se puso en marcha el ensayo de distintas estrategias de riego sobre una finca en plena producción. Para ello se contó con lo siguiente:

- Una parcela de almendros adultos regados con riego localizado de un agricultor colaborador y localizada en el término municipal de Lebrija. Las características son las siguientes:

o Fecha de plantación: 2007.

o Marco 7x5.

o Variedad: Guara.

o Suelo franco arcilloso de $0-25 \mathrm{~cm} \mathrm{y}$ arcilloso de $25-50 \mathrm{~cm}$.

- Un nuevo sistema de riego localizado diseñado para aplicar distintas necesidades de agua para el mismo tiempo de riego y distribuido según el diseño experimental propuesto (Ver figuras 1 ).

- Un sistema de seguimiento de la programación del riego. Este sistema incluía: sondas de humedad con tecnología FDR

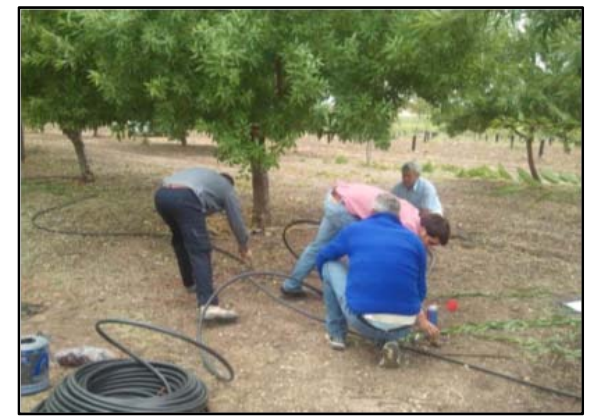

Figura 1. Instalación de sistema de riego localizado. (FrequencyDomainReflectometry) y transmisión de datos a tiempo real. Las profundidades de seguimientofueron a 20, 40, 60 y $80 \mathrm{~cm}$. (Ver figura 2).

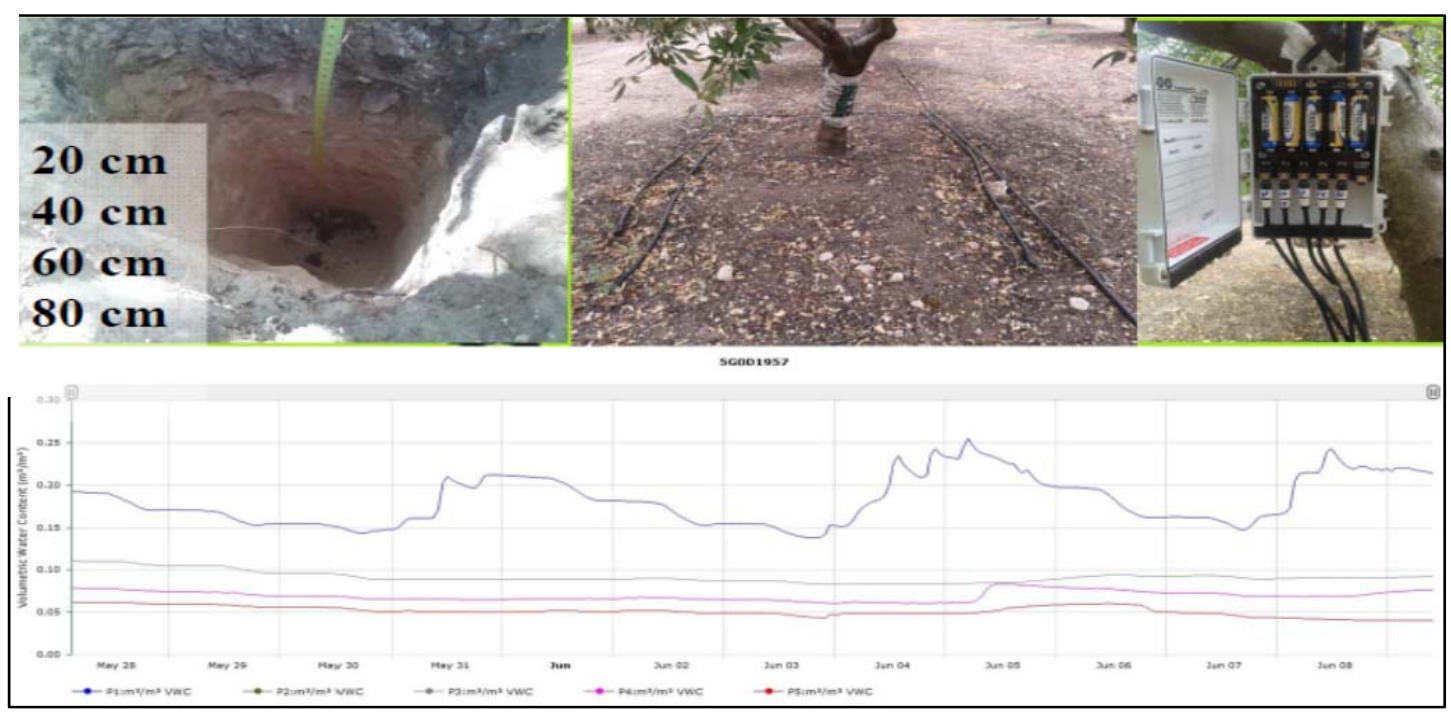

Figura 2. Imágenes del funcionamiento del sistema de seguimiento de humedad en los distintos perfiles del suelo. Arriba a la izquierda, detalle de la instalación de los sensores en el suelo. Arriba en el centro y a la derecha, detalle de la instalación del data-logger sobre el tronco y el sistema de transmisión de datos. Y abajo el resultado, en gráficas de la evolución de la humedad en las distintas profundidades. 
La metodología del ensayo consistió en llevar a cabo seis manejos de riegos distintos. Ensayándose, las variable dosis, con distintas estrategias de riego deficitario, la variable distribución temporal de riego y la variable distribución espacial, con distintas configuraciones de goteros.

Para ello se escogieron parcelas experimentales de nueve árboles y aisladas entre ellas por filas guardas, según se indica en la figura 3.

El diseño experimental del ensayo es en bloques al azar con 6 tratamientos y tres repeticiones, en una parcela de almendros adultos en plena producción (5 años).

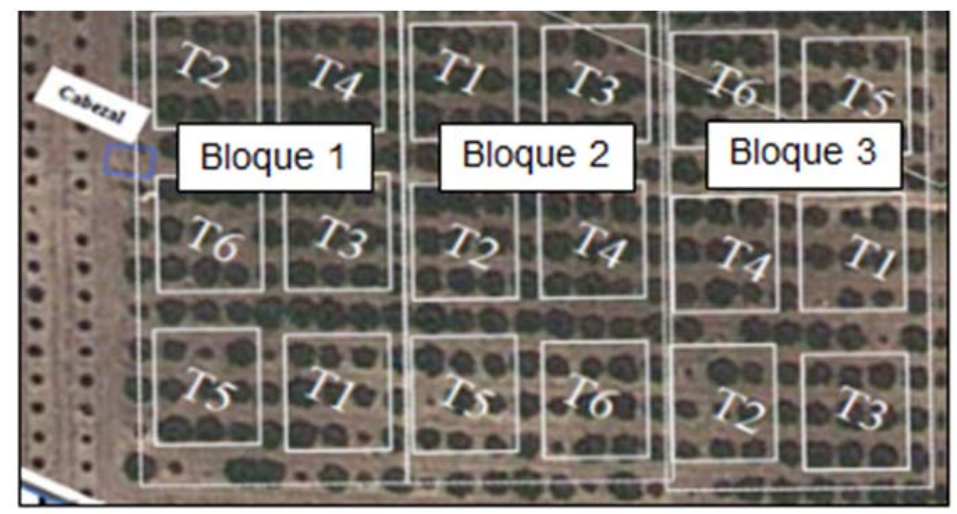

Figura 3. Tratamientos de riego del ensayo.

Sobre un tratamiento testigo (T1), se aplica una programación de riego según las necesidades máximas del cultivo, mediante el método de balance de agua en el suelo. Para ello se contó con:

- Datos climáticos en tiempo real de la estación de Red de Estaciones Agroclimáticas del IFAPA de Lebrija.

- Coeficiente de cultivo del almendro actualizado (Girona, 2008).

A partir de este tratamiento, se modifica la instalación de riego de cada parcela experimental según los requerimientos del tratamiento perseguido.

La definición de los criterios para los distintos tratamientos de riego, tiene varios objetivos específicos, entre los que están:

1. Determinar el potencial productivo de un almendro con manejo de riego.

2. Determinar las producciones según qué de déficit de se aplica.

3. Analizar la producción entre un tratamiento de riego deficitario controlado frente a un riego deficitario proporcional.

4. Ver la importancia en el diseño agronómico del riego el número de ramales de riego por árbol.

En la tabla 1 se resumen los distintos tratamientos y los criterios adoptados.

- El tratamiento T1, es el tratamiento control, en el aplicamos el $100 \%$ de la lámina requerida calculada según balance de agua.

- Los tratamientos T2 y T3 son riego deficitario controlado (RDC) con dos dosificaciones diferentes.

- Los tratamientos T4, T5 y T6 son riego deficitario sostenido (RDS), con diferentes niveles de déficit. En la tabla 1 se recogen los distintos tratamientos. 
Tabla1. Resumen de tratamientos.

\begin{tabular}{|c|l|r|r|r|}
\hline \multicolumn{2}{|l|}{ Tratamiento } & $\begin{array}{c}\text { Fase: I-II-II } \\
\text { vegetativo, } \\
\text { floración y } \\
\text { cuajado. }\end{array}$ & $\begin{array}{c}\text { Fase IV: } \\
\text { Llenado a } \\
\text { recolección, } \\
\text { Junio a Agosto. }\end{array}$ & $\begin{array}{c}\text { Fase V: De } \\
\text { recolección a } \\
\text { caída de hojas, } \\
\text { reservas. }\end{array}$ \\
\hline T1 & Doble ramal & $100 \%$ NBR. & $100 \%$ NBR. & $100 \%$ NBR. \\
\hline T2 & Doble ramal & $100 \%$ NBR. & $80 \%$ NBR. & $100 \%$ NBR. \\
\hline T3 & Doble ramal & $50 \%$ NBR. & $15 \%$ NBR. & $50 \%$ NBR. \\
\hline T4 & Doble ramal & $60 \%$ NBR. & $60 \%$ NBR. & $60 \%$ NBR. \\
\hline T5 & Doble ramal & $37 \%$ NBR. & $37 \%$ NBR. & $37 \%$ NBR. \\
\hline T6 & Ramal simple & $37 \%$ NBR. & $37 \%$ NBR. & $37 \%$ NBR. \\
\hline
\end{tabular}

El ensayo se mantiene durante las campañas de producción 2013,2014 y 2015 con los criterios anteriormente señalados de manera regular. Salvo que, en el tercer año se practica una poda mecánica que afecta a la tendencia productiva de los ensayos. Se valoran los resultados del año 2014 como datos finales del ensayo

Para la valoración de la cosecha se recolectó selectivamente cada parcela experimental sobre los árboles que tenían una estructura normal, excluyendo aquellos que hayan sido replantados. La recolección era mecanizada como refleja la figura 4.

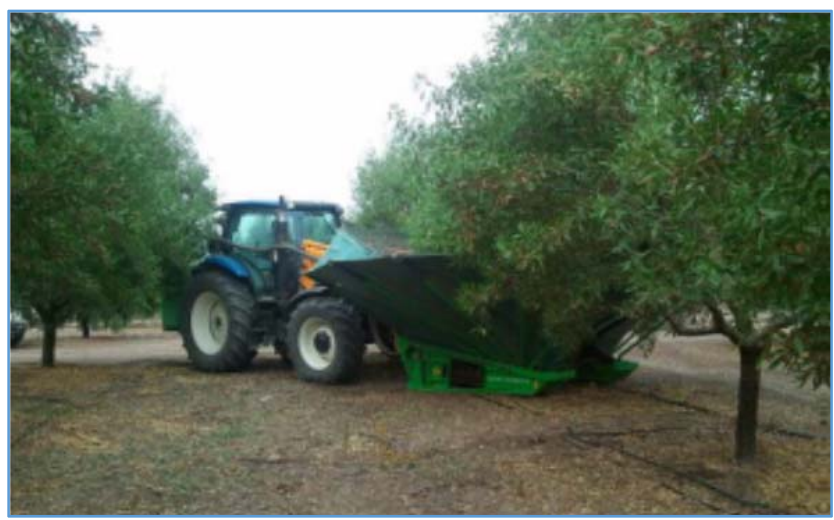

Figura 4. Recolección mecanizada del almendro.

Semanalmente se facilitaba al regante las dosis de riego calculada a partir de los datos climáticos recogidos de las estaciones agroclimáticas de la Junta de Andalucía a través del método Penman-Monteith (Allen, R.G et al,1998) y utilizando el método de balance de agua en el suelo.

Para la ejecución de los tratamientos de RDC en los periodos de menor dosis de riego, se modificada el diseño de riego de los tratamientos T2 y T3, de manera que se eliminaban goteros a ambos lados de los ramales de riego, como se puede apreciar en la figura 5.

3-

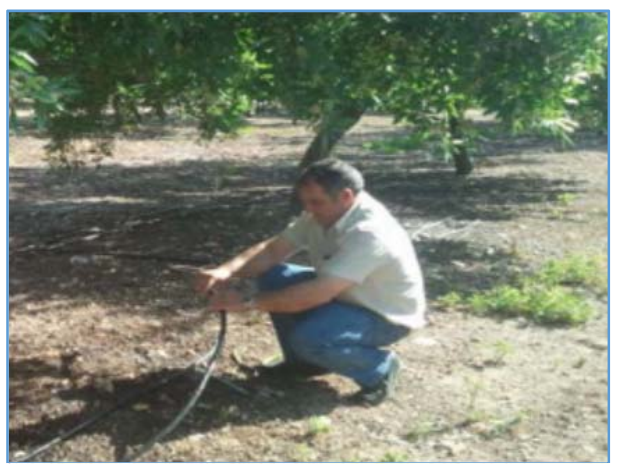

Figura 5. Reducción de dosis. 


\section{Resultado y Discusión.}

Los resultados obtenidos han sido sobre las campañas 2013 y 2014. El primer año de riego diferenciado fue el año 2013. Fue un año bien regado pero precedido de un año regado en precario, y que consideramos como transición, pero aporta una serie de datos interesantes. En esta campaña además hay que considerar las situaciones siguientes:

- Fue una campaña agrícola con una pluviometría por encima de la media, con precipitaciones hasta la primavera. Por tanto las necesidades de riego comenzaron después de la floración y formación del fruto.

- Se dio un porcentaje alto de abortos florales por las condiciones meteorológicas adversas de viento, y coincidió con un año vecero desfavorable.

De la recolección de la campaña 2013, se obtuvieron los datos de la figura 6:

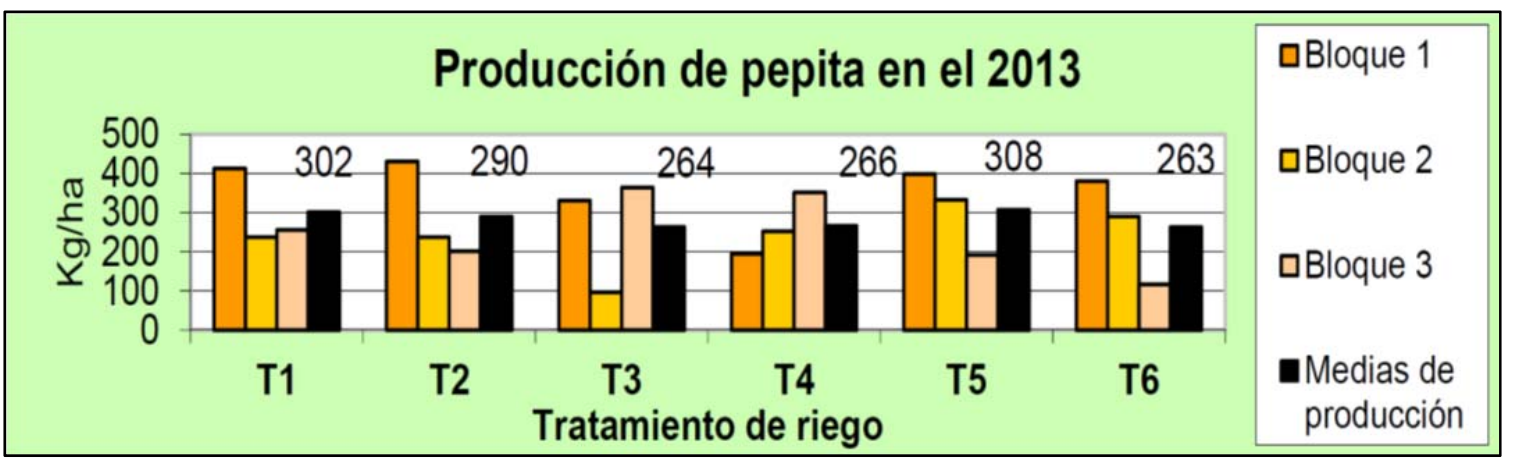

Figura 6. Recolección de la campaña 2013.

De los resultados de 2013 se extrae la siguiente información:

- El tratamiento T2 (RDC; $100 \%-80 \%-100 \%$ ) es, a pesar de ser un riego deficitario controlado, estadísticamente no tiene diferencia significativa en la producción respecto al T1, pero si con respecto al T3. Por tanto, y según las circunstancias del primer año de ensayo, es una estrategia poco arriesgada regar con un ligero déficit en verano.

- Igualmente entre los tratamientos T5 y T6, dónde la diferencia es tener dos o un ramal de goteo por filas de árboles, no ofrece significación estadística en la producción, debido a la variabilidad entre repeticiones, pero si una diferencia en la producción media que se confirmará en la campaña siguiente.

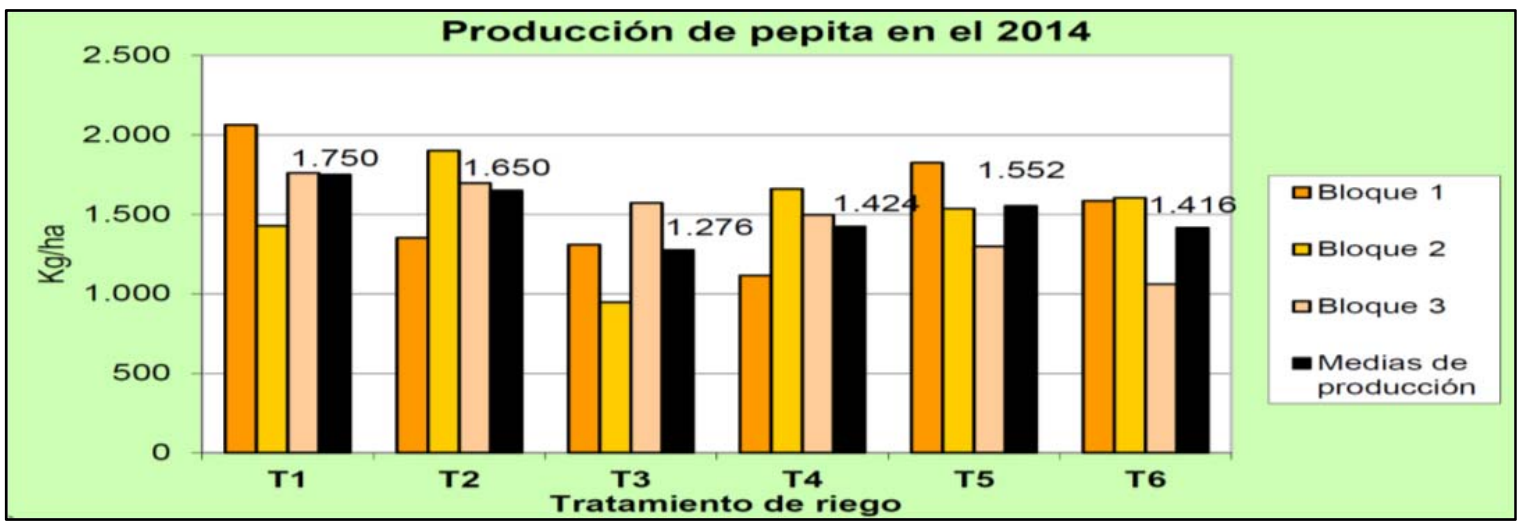

Figura 7. Producción de pepita campaña 2014. 
En el gráfico de la figura 7 se reflejan los datos de producción de la campaña 2014.Como se puede apreciar los resultados de producción quintuplican los del 2013, pero la tendencia en los valores medios es similar.

Los datos de significación estadística entre medias son menores, una de las posibles causas es la influencia de la exposición solar de los árboles de la periferia en los bordes inferior e izquierdo de la parcela al estar orientadas las filas en la dirección Este-Oeste

Por tanto, la orientación de las filas en marco rectangular afectan a la producción y es decisivo en el diseño de la plantación es que debería de estar orientadas en la dirección Norte-Sur.

Si atendemos al rendimiento peso con cascara y pepita, mostrado en la figura 8, existe una variación sustancial entre los resultados de una campaña y los de la siguiente al igual que en producción. La figura siguiente recoge los valores obtenidos para cada tratamiento.

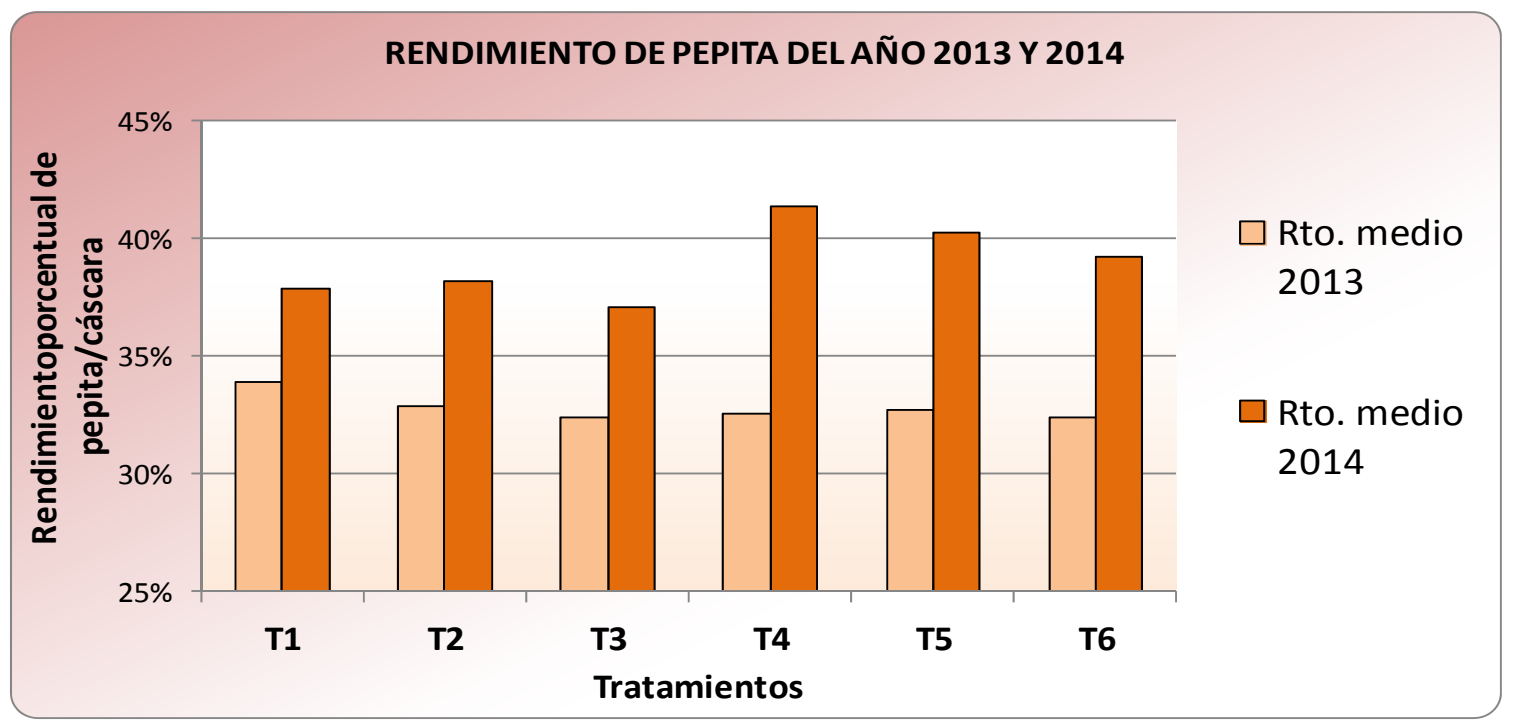

Figura 8. Rendimientos de las diferentes estrategias de riego.

\section{4- Conclusiones.}

- En general existe una mayor producción en los tratamientos de riego de menor déficit de agua. Los datos son corroborados por las medias de producción y por existir diferencias significativas entre los tratamientos T1 y T2 frente al T3.

- Siempre que la dotación de agua sea un factor limitante, es conveniente un riego deficitario controlado (RDC) con el menor déficit posible, frente al riego deficitario sostenido (RDS). La poca diferencia entre producción media y la ausencia de significación estadística entre los tratamientos T3 y T6, confirma la conveniencia del RDC. En el RDC asegura la mejor formación de los fruto, al atender las necesidades en el momento de floración y cuajado del fruto, minimizando la caída de flores y abortos, mientras que en el riego deficitario sostenido aplica más agua en el engorde del fruto final de primavera y verano. Todo ello con mayor consumo de agua en el RDS frente al RDC en cualquier año pluviométrico. 
- Frente a un diseño de riego de un ramal por fila de árboles a dos (Tratamiento T6 frente al T5), en una plantación adulta y suelos franco arcilloso la distribución horizontal del agua es adecuada, sólo parece haber un ligerísimo aumento de la producción media para el segundo caso y para un suelo franco arcilloso, pero no es corroborado estadísticamente.

- A pesar de lo anterior, incluso en suelo franco arcilloso, como es el caso ensayado, la superficie mojada y los puntos de emisión deben ser suficientes. Los tratamientos T4, T5 y T6 son RDS, el tratamiento T4 es un RDS con un $60 \%$ de déficit sobre las necesidades máximas con 4 puntos de goteo por árbol, mientras que T5 y T6 tienen $37 \%$ de déficit y con 10 puntos de goteo. Todos ellos tienen valores medios de producción similares y sin ninguna significación estadística en las producciones, lo que denota que el incremento de agua no se ha visto reflejado por un incremento de producción.

- Un sistema de seguimiento de la humedad del suelo en tiempo real y a distintas profundidades, como el empleado en este ensayo, es muy útil para adecuar las dosis calculadas, además de, ser una herramienta importante para el caso de gestionar un RDC.

- En un marco rectangular de una plantación de almendros es muy importante que las filas estén orientadas en la dirección Norte-Sur para obtener la mayor producción, permitiendo una insolación más homogénea de la plantación. En caso de ser un marco cuadrado ha de ser lo suficientemente amplio para buena iluminación y aireación.

\section{5- Bibliografía.}

- Girona, J. 2006. La respuesta del cultivo del almendro al riego. Revista Vida rural, № 234, págs. 12-16.

- Maña, F., López, R., López, P., Girona, J. 2008. Respuesta del almendro a diferentes programas de riego deficitario controlado. XXVI Congreso Nacional de Riegos. Huesca, 24-26 de junio de 2008, págs. 37-38.

- Fernández, J.L., Oliva, A., Gallego, J.C., Navarro, C., Navarro, A., Arquero, O. 2002. El cultivo del almendro en Andalucía. Revista Fruticultura Profesional 126: 5-14.

- Lorite, I., Arquero, O. 2008. El almendro y el riego deficitario como alternativa a los cultivos tradicionales de regadío en Andalucía. IFAPA. Boletín Trimestral de Asesoramiento al Regante $n^{\circ} 8$, Julio-Septiembre: 9-10..

- Salvatierra, B. 2014. Resultados de experimentación de riego en almendros. IFAPA. Boletín Trimestral de Asesoramiento al Regante $n^{\circ} 25$. Enero-Marzo: 19-26. 


\title{
C-06
}

\section{LA PRÁCTICA DE RIEGOS ANCESTRALES ANDINOS: EL RIEGO POR KANIS}

\author{
Moreno-Pérez, M. $F^{(1)}$, Roldán-Cañas, J. ${ }^{(2)}(P)$, Chipana Rivera, $R^{(3)}$ \\ ${ }^{1}$ Profesora Contratada Doctora, Universidad de Córdoba, Dpto. Agronomía (Área Ingeniería \\ Hidráulica), Edif. Leonardo Da Vinci (Campus Rabanales), 14071 Córdoba, mfatima@uco.es \\ ${ }^{2}$ Catedrático, Universidad de Córdoba, Dpto. Agronomía (Área Ingeniería Hidráulica), Edif. \\ Leonardo Da Vinci (Campus Rabanales), 14071 Córdoba, jroldan@uco.es \\ ${ }^{3}$ Profesor, Universidad Mayor de San Andrés, Facultad de Agronomía, Héroes del Acre, \\ 1850, La Paz, Bolivia, renechipana@yahoo.com
}

\section{Resumen}

El riego es una técnica agrícola ancestral desarrollada por las culturas tradicionales andinas, en armonía con las características ambientales y productivas de la zona. La práctica de riego tuvo que ser adaptada a las grandes pendientes dando lugar a técnicas muy particulares que aún hoy día se practican. Los valles interandinos del Departamento de La Paz, Bolivia, es un lugar privilegiado para el estudio de sistemas de riego tradicionales. El trabajo experimental se llevó a cabo en la comunidad de Jatichulaya, localizada en el pueblo de Charazani, Bolivia, a una altitud de $3250 \mathrm{msnm}$ con una precipitación anual media de 450 $\mathrm{mm}$. El sistema de riego tradicional en ella practicado es el llamado riego por kanis. La palabra kanis es un vocablo quechua que hace alusión a la apertura de surcos para la conducción del agua. El sistema de riego no causa erosión del suelo ya que el manejo del agua se hace siguiendo las curvas de nivel. Sin embargo, las necesidades de mano de obra son muy elevadas. La persona a cargo de la distribución del agua y de su entrega a los regantes es el llamado Agente de Aguas.

\begin{abstract}
Irrigation is an ancient agricultural technique developed by the Andean traditional cultures in harmony with environmental and productive characteristics of the area. Irrigation practice had to be adapted to the steep slopes leading to very specific techniques that are practiced even today In Bolivia, the interandean valleys of La Paz's Department are privileged places for the study of traditional irrigation systems. The experimental work was carried out in the peasant community of Jatichulaya, located in Charazani, at an altitude of 3,250 meters above sea level, with an average annual rainfall of about $450 \mathrm{~mm}$. The traditional irrigation system practiced there is called the kanis's method. The word kanis is a quechua word that refers to furrow irrigation opening for water conveyance. This irrigation system avoids soil erosion because it follows contour lines. Thereby, soil is protected but manpower required in the irrigation practice was excessive. The person in charge of water distribution and delivery to irrigators is called Agente de Aguas (Water's officer).
\end{abstract}

\section{1- Introducción y Objetivos}

En Bolivia la superficie total bajo riego es de unas 303000 ha, el $65 \%$ de las cuales se localiza en el Altiplano y en los valles interandinos, entre los 1500 y los 4200 msnm (Ministerio de Medio Ambiente y Agua, 2013). En estas zonas la pluviosidad anual se sitúa entre los 350 y los $600 \mathrm{~mm}$ que cae, principalmente, entre los meses de diciembre y marzo. 
A pesar de las grandes pendientes y del accidentado terreno, el riego mayoritario es por superficie, y el $70 \%$ de los regantes poseen menos de 1 ha.

En los valles mesotermales existentes en las cordilleras andinas se desarrollaron culturas prehispánicas muy florecientes, como la cultura Mollo (Ponce Sanginés, 1957, Arellano López, 1978) que transformaron la abrupta geografía para poder cultivarla. Los mollos desarrollaron técnicas para construir terrazas, tanques de almacenamiento de agua en rocas, canales para conducir agua de formas trapezoidales y triangulares y estructuras de captación de agua (Chipana et al., 2011). El riego es una técnica agrícola ancestral desarrollada por las culturas tradicionales andinas, en armonía con las características ambientales y productivas de la zona. La práctica de riego tuvo que ser adaptada a las grandes pendientes dando lugar a técnicas muy particulares, como el riego por kanis o los surcos corrugados en zigzag (Roldán-Cañas et al., 2014), que aún hoy día se efectúan en zonas próximas a la ciudad de La Paz, Bolivia. Los campesinos lograron, durante siglos, aprovechar las aguas de los ríos, lagunas y manantiales para complementar o suplir el régimen de precipitaciones pluviales, caracterizado por su irregular distribución en una corta estación de lluvias.

La palabra kanis es un vocablo quechua que hace alusión a la apertura de surcos para la conducción del agua.El riego por kanisconsta de unos canales principales de distribución llamados mama kanis, cuya longitud y número dependen del tamaño de la parcela a regar. A continuación, se encuentran los canales secundarios o juchuy kanis que van en dirección opuesta a los mama kanis. De los juchuy kanis parten los surcos de riego de corta longitud. El riego se empieza en el extremo más alejado y se va desplazando hacia atrás. La particularidad de este riego radica en la forma en que se practica pues los canales y surcos se abren conforme el agua va entrando en la parcela. Ello supone, por un lado, un tamaño de parcelas relativamente pequeño y, por otro lado, un alto requerimiento de mano de obra. Por el contrario, cabe esperar una uniformidad muy alta, dada la pequeña longitud de los surcos de riego, y un mayor control en la distribución del agua evitando pérdidas (Chipana Rivera et al., 2015). Es curioso comprobar que este sistema presenta grandes similitudes con los sistemas de riego árabes en forma de peine tal y como son descritos por del Pino et al. (2011).

El objetivo principal de este trabajo es analizar el funcionamiento, eficiencia y sostenibilidad del riego por kanis.

\section{2- El valle de Charazani y la comunidad de Jatichulaya}

Charazani -o Villa Juan José Pérez-, capital del valle al que da nombre, se encuentra situado a una altitud de $3250 \mathrm{msnm}$, en la Provincia Bautista de Saavedra, Departamento de La Paz, Bolivia (ver figura 1). Abarca una superficie de $2524 \mathrm{~km}^{2}$ y está constituida por dos secciones municipales, Charazani y Curva, y 14 cantones. Conforma el espacio sociogeográfico más significativo para el estudio del riego tradicional ya que el agua en la zona es un recurso escaso del que dependen las actividades agrícolas que realiza el campesinado. En efecto, la precipitación media anual oscila alrededor de los $450 \mathrm{~mm}$ distribuidos principalmente entre los meses de diciembre a marzo.

Aquí vive, entre otras, la comunidad campesina de Jatichulaya, situada entre los paralelos de $15^{\circ} 8^{\prime}$ y $15^{\circ} 12^{\prime}$ de Latitud Sur, y los meridianos de $68^{\circ} 57^{\prime}$ y $68^{\circ} 59^{\prime}$ de Longitud Oeste, y una altitud entre los 2900 a 3250 m.s.n.m (ver figura 2). En la actualidad, posee una superficie aproximada de 202 ha, de las que 45.5, 22.5\%, cuentan con riego siendo el resto tierras de secano. La zona presenta una topografía accidentada, con laderas de pendientes empinadas y terrazas angostas. Los suelos son de tipo coluvial, variando la textura entre franco arcilloso y franco arenoso. 


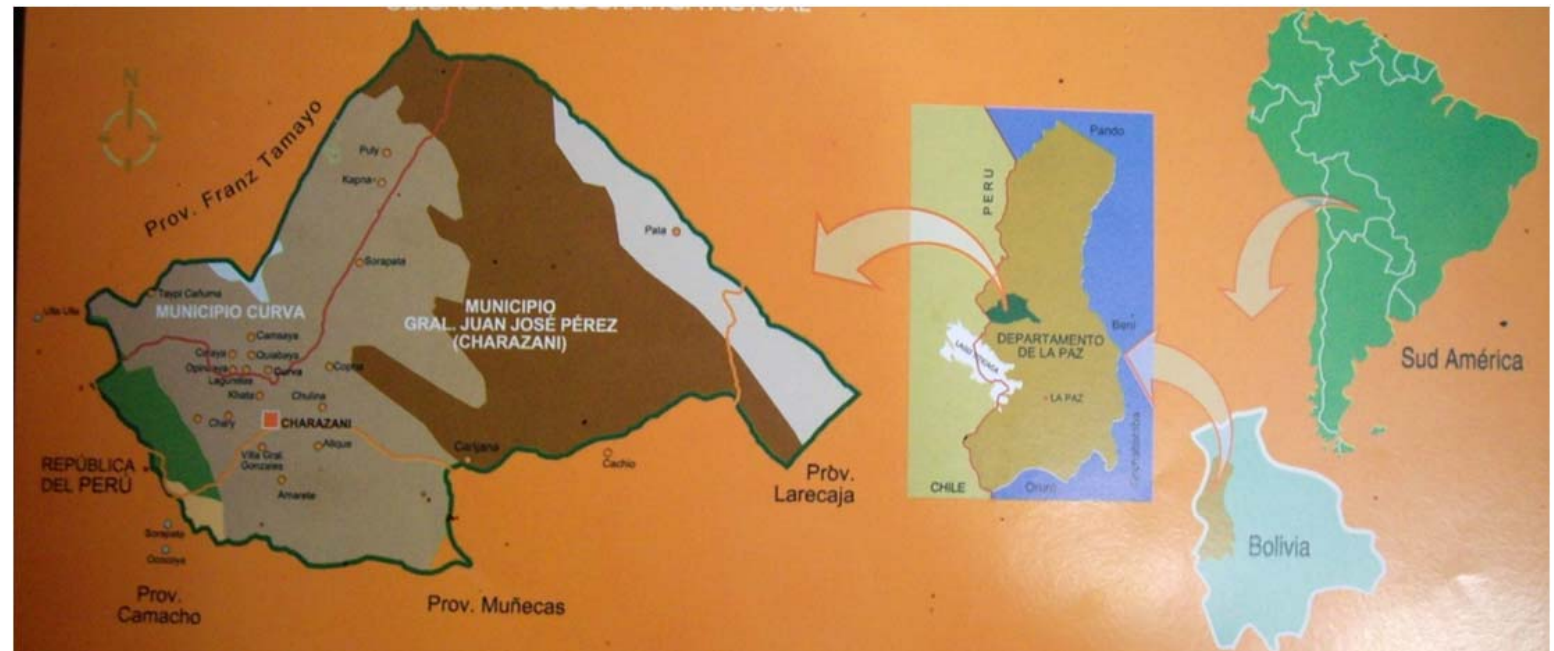

Figura 1. Ubicación del municipio de Charazani dentro del Departamento de La Paz.

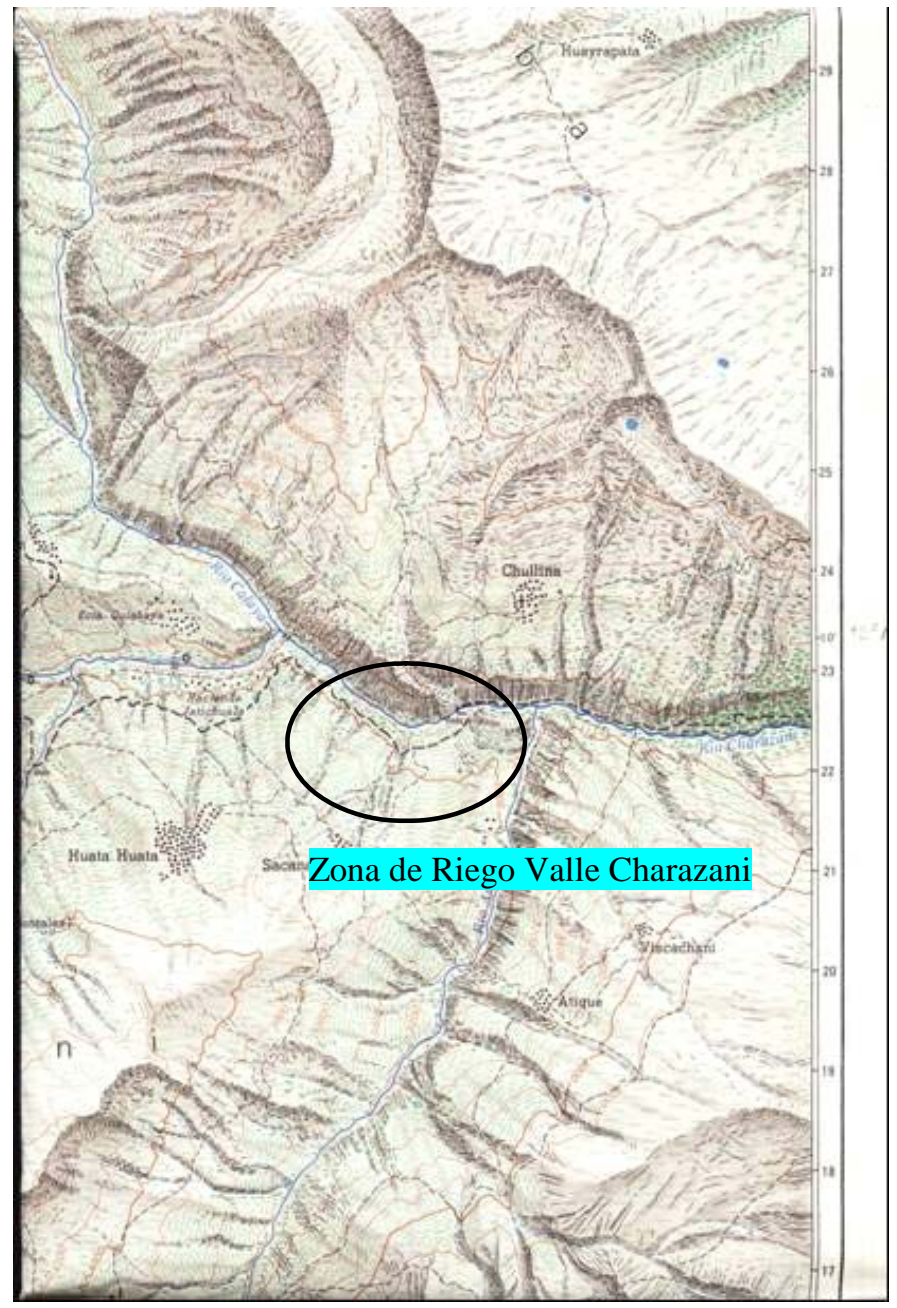

Figura 2. Ubicación de la comunidad de Jatichulaya.

Las fuentes de agua son las precipitaciones pluviales y las aguas superficiales, producto del deshielo de la cordillera de Apolobamba, que dan origen al Río Calaya y a parte del Río Charazani. El Río Charazani es una de las fuentes de agua de importancia para la zona de estudio y tiene su origen en las pequeñas vertientes y en los llamados ojos 
de agua (aguas subterráneas). También existen pequeñas vertientes situadas al sureste de la comunidad de Charazani, que forman el Río Wasawayqho, con caudales reducidos en épocas de estiaje, de mayo a julio, que aumentan en la época de lluvias. Existe otro ojo de agua en la parte baja de la comunidad de Inca Roca, situado al Sur de la comunidad de Jatichulaya (Quebrada del Inca), originando de esta manera la tercera fuente de agua para la comunidad.

\section{3- Organización del riego}

El manejo del agua está de acuerdo a los ciclos agrícolas que se practican en el valle de Charazani. La distribución del agua de riego varía a lo largo del año. Desde agosto hasta enero o febrero, se hace bajo un control estricto del llamado Agente de Aguas y el establecimiento de un turno específico cuya trasgresión es sancionada por el mismo. El Agente de Aguas es elegido anualmente y dentro de sus funciones, que hace mediante visitas periódicas, están, además, el mantenimiento y cuidado de todas las obras hidráulicas que posee el sistema, es decir, las obras de toma, canales de conducción y de distribución (Céspedes, 1995). El sistema de distribución consiste en programar el uso del agua de riego de acuerdo a los pedidos que hagan los usuarios en un período dado. El agua se entrega de acuerdo al turno programado por el Agente de Aguas y el usuario tiene que ajustarse a dicho turno. La adopción de la distribución por turnos comienza en el mes de agosto con la siembra de papa-milli (papa temprana), cultivo que requiere de riego. El Agente de Aguas lo hace en forma equitativa sin dar preferencia a nadie.

Por el contrario, en la época donde no existe mucha demanda de agua de riego ya que los cultivos satisfacen, en gran manera, su requerimiento hídrico con las precipitaciones pluviales, esto es, desde febrero hasta julio, el uso del agua no es por turnos sino a la demanda y las personas que deseen regar piden permiso, o bien dan aviso al Agente de Aguas, y van ellos mismos hasta la toma conveniente a soltar el agua.

Los campesinos organizan las asambleas, presididas por el Agente de Aguas, donde planifican y se establecen las fechas fijas para los trabajos comunales de reparación y limpieza de canales. Los trabajos de limpieza incluyen también la reparación de los caminos de herradura usados para el manejo del agua. Estos caminos van paralelos al recorrido de los canales. Las fechas de los trabajos de limpieza generalmente son antes del inicio de la siembra grande, normalmente en el mes de agosto.

\section{4- La práctica del riego}

El riego comienza con la construcción de un canal de reparto de agua dentro de la parcela. Los principales indicadores para la construcción de dicho canal son, por un lado, la entrada del agua desde el canal de distribución a la parcela y, por otro lado, la pendiente de la misma. Una vez que se tienen los dos parámetros, se traza una línea imaginaria hasta el otro extremo superior de la parcela de modo que tenga una pendiente descendente del 2 al $3 \%$. Una vez trazada dicha línea imaginaria se procede a la apertura del canal con la ayuda de una Laukana (ver figura 3), de abajo hacia arriba hasta llegar al extremo inicial o parte superior del canal. El canal tiene la forma de un surco amplio y es de tierra.

La longitud y el número de canales principales o mama kanis es variado y está en función del tamaño de la parcela a regar lo que constituye el tercer parámetro para la construcción de los canales. Generalmente, como mínimo, se construyen 2 o 3 canales. La separación entre los canales construidos es de 8 a $10 \mathrm{~m}$. Cuando el terreno es accidentado, o con una topografía irregular, el campesino consigue trazar los canales principales sin dificultad empleando todo el conocimiento ancestral heredado de sus padres y abuelos. La construcción de los mama kanis dentro de la parcela es similar sea cual fuere el cultivo. 


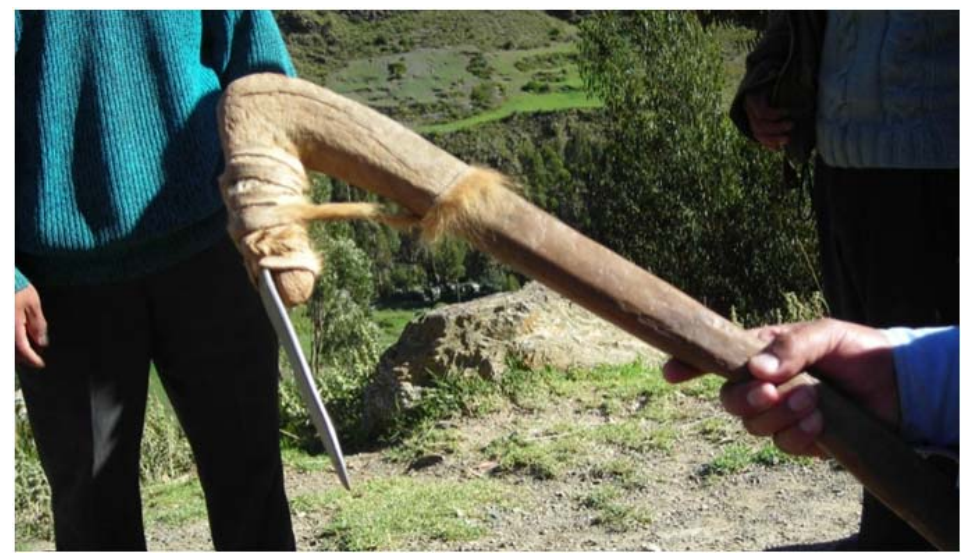

Figura 3. Laukana o instrumento utilizado para abrir o cerrar los surcos de riego.

La orientación de las parcelas es importante, ya que las que se encuentran orientadas al sur no tienen muro de contención, y además se riegan, mientras que las orientadas al norte tienen muro de contención y no hay que regarlas. Se observa como las parcelas orientadas al norte son más verdes que las orientadas al sur que son más secas.

Para evaluar la práctica actual de riego, se realizó un ensayo en una parcela previamente preparada y desbrozada, situada a $3065 \mathrm{msnm}$, en la que la comunidad de Jatichulaya hizo una demostración de las prácticas de riego habituales en la zona. Esta parcela tiene una extensión aproximada de $150 \mathrm{~m}^{2}$ y una pendiente que oscila entre $15 \mathrm{y}$ el $45 \%$. Según estimaciones de la propia Comunidad, el canal de abastecimiento de agua o kani suele llevar entre 4 y $5 \mathrm{l} / \mathrm{s}$, y el tiempo que se invierte en regarla es de unos $15 \mathrm{~min}$. En la parcela trabajada por los campesinos, el mama kani divide el terreno en dos. En este caso, se procede al riego de la mitad inferior.

El campesino inicia la apertura de un mama kanis para que el agua procedente de un kanis entre a la parcela y la inunde (ver figuras 4a y b). Para la construcción de los canales secundarios o juchuy kanis dentro de la parcela se toma al canal principal, como referencia. Los juchuy kanis generalmente van en dirección opuesta a los mama kanis, son paralelos entre si y tienen también inclinaciones que están entre el 2 y el $3 \%$. La longitud de los juchuy kanis es menor con relación a la de los mama kanis y tienen, como promedio, de 6 a $8 \mathrm{~m}$. En cambio, el número de los juchuy kanis es mayor, superior a 6 canales habitualmente. La separación entre juchuy kanis es de 4 a $4.5 \mathrm{~m}$. como promedio y son también surcos aunque más angostos que los canales principales. Una de las funciones de los juchuy kanis es la de unir los mama kanis, cuando el usuario está conduciendo el agua hacia la parte baja de la parcela.
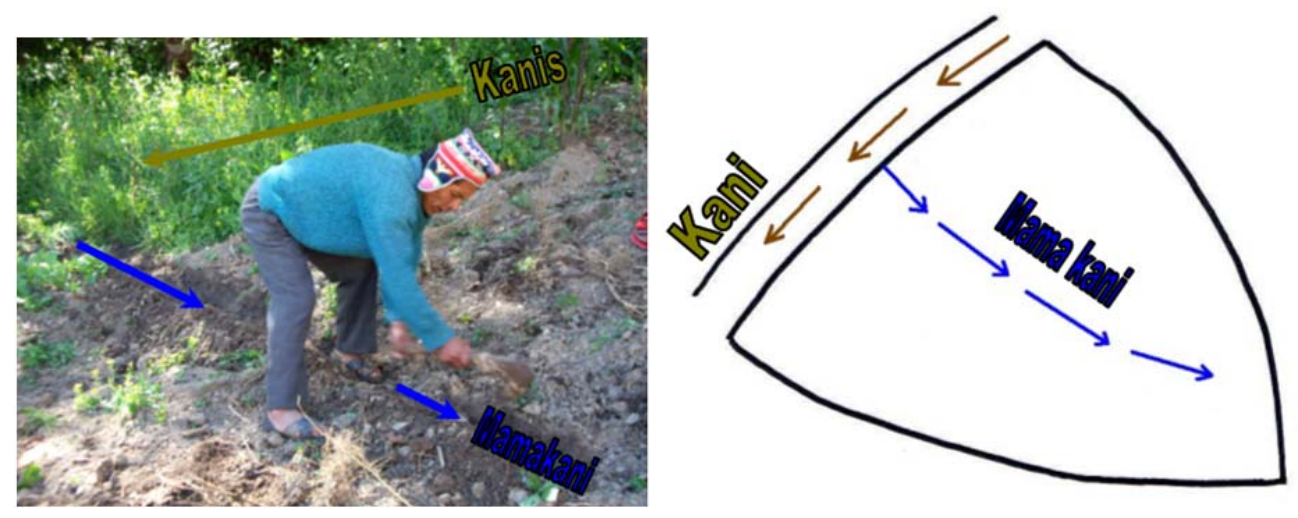

Figura 4. a) Campesino iniciando la apertura de un mama kanis. b) Esquematización de 4a. 
Cuando el agua llega al final del mama kani, se van abriendo juchuy kanis desde el final del mama kani hacia atrás, para que el agua humedezca la margen derecha del mama kani (ver figura 5). Mientras el agua va empapando el suelo de la parte final de la parcela, con cuidado de que no rebose y caiga a la parcela que hay por debajo, se abre un nuevo surco que parte desde el mama kani por su parte central, y que será otro mama kani, para que cuando los juchuy kanis lleguen a éste, se derive todo el agua hacia el nuevo mama kani. El sistema funciona apropiadamente, acomodándose a las condiciones topográficas de la zona y eliminando la erosión hídrica debido a que el manejo del agua, dentro y fuera de la parcela, está dado por un conocimiento ancestral de los campesinos de acuerdo a las curvas a nivel, lo que permite la protección del suelo sin provocar erosión.

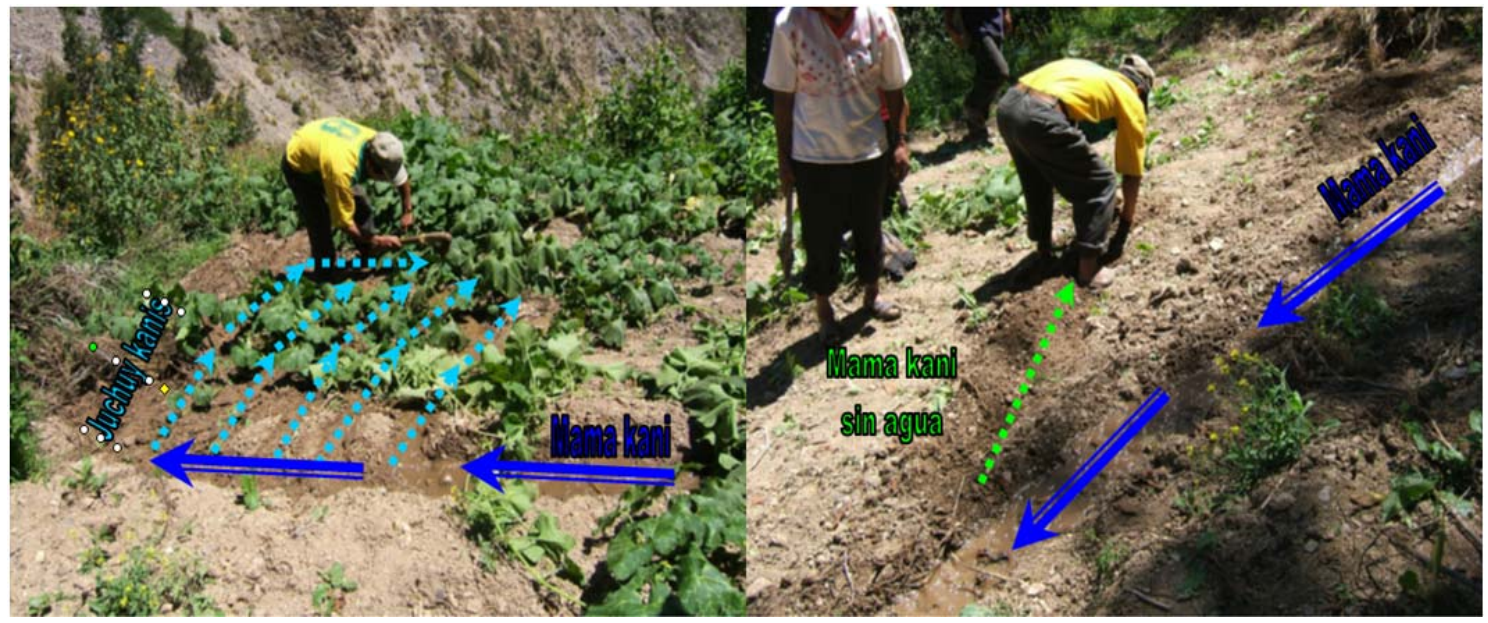

Figura 5. Apertura de juchuy kanis desde el final del mama kani.

Cuando los juchuy kanis han llegado hasta el segundo mama kani $(\longrightarrow$ ), que parte desde el primer mama kani ( $($ ), se abre el paso de agua hacia este quedándose sin agua el trozo del primer mama kani situado aguas abajo ( $\Longrightarrow$ ) (ver figuras $6 a$ y b).
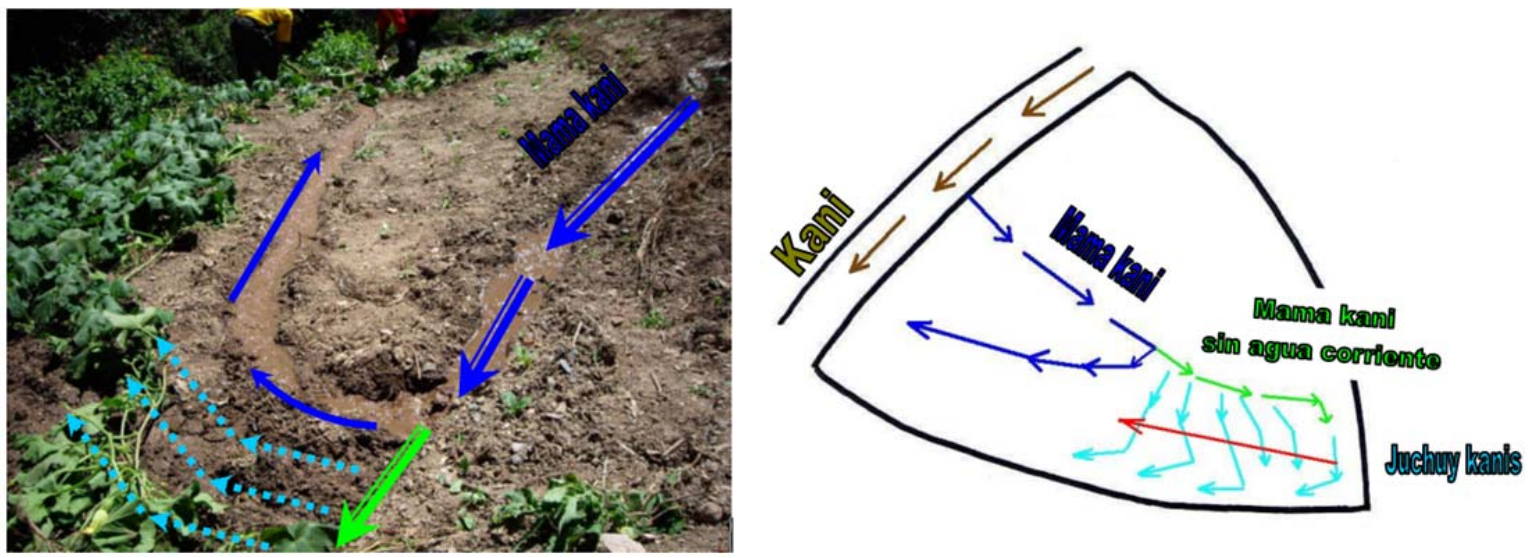

Figura 6. a) Al abrir un nuevo mama kani, los juchuy kanis aguas arriba se quedan sin agua.

b) Esquematización de la figura $6 a$.

Cuando el agua ha llegado al final del segundo mama kani se empiezan a abrir juchuy kanis desde el final y con pendiente descendente (ver figuras7a y $7 \mathrm{~b}$ ). 

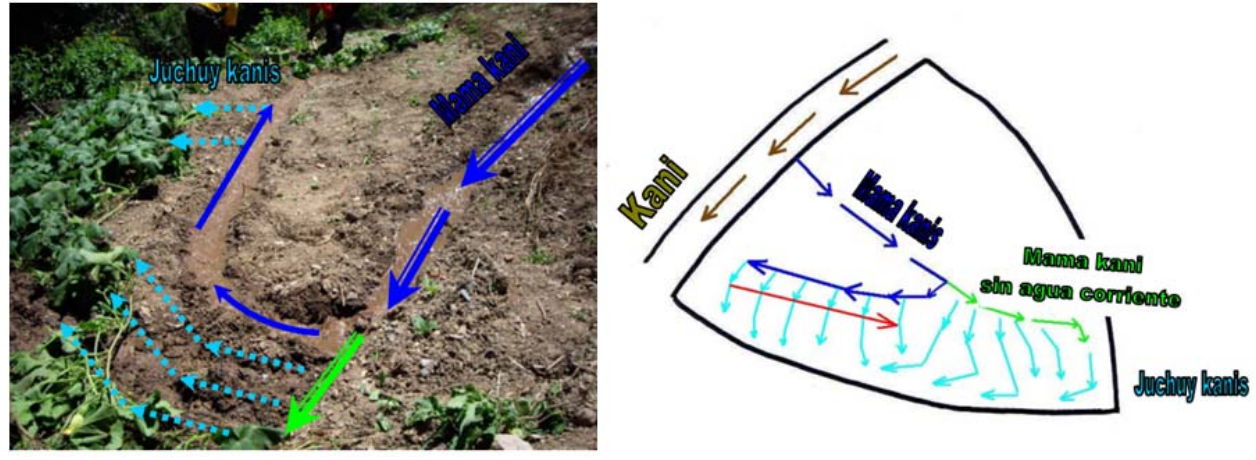

Figura 7. a) Apertura de los juchuy kanisdesde el final del segundo mama kani y con pendiente descendente. b) Esquematización de la figura $7 a$.

Finalmente, la mitad de la parcela quedó regada (ver figuras $8 a$ y b). El tiempo invertido fue de unos 40 minutos, muy superior al manifestado previamente por la Comunidad.
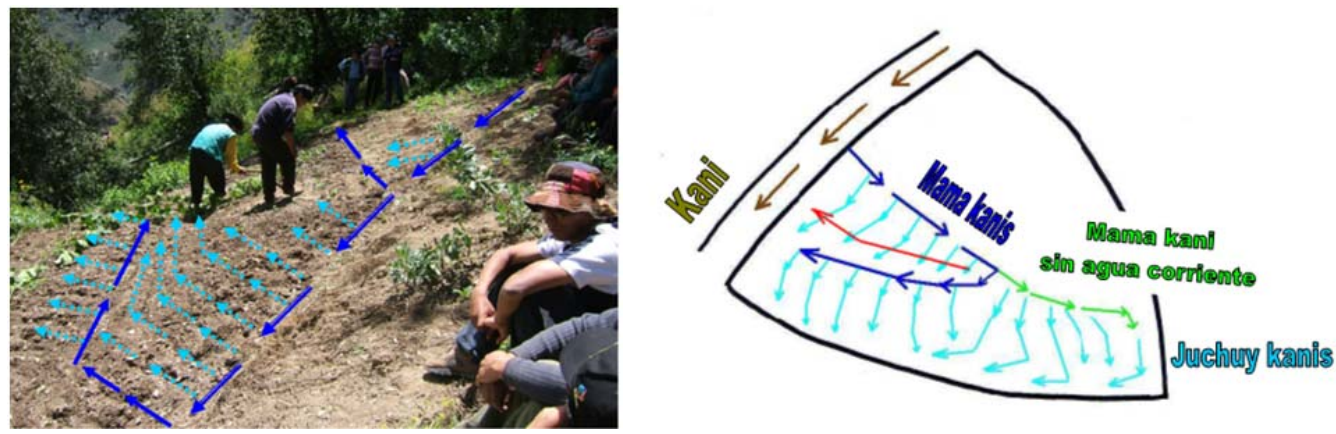

Figura 8. a) Fase final del riego. b) Esquematización de la figura 8a.

Una vez que se terminó el riego de la parcela, se midió el caudal que lleva el canal de riego, utilizando el método del flotador con una hoja seca. La medida se realizó repetidas veces tomándose la media de los valores obtenidos: $L=2.5 \mathrm{~m} ; \mathrm{t}=7 \mathrm{~s}$.

Teniendo en cuenta la geometría de la sección transversal del canal rectangular( $\mathrm{B}=$ $0.25 \mathrm{~m} ; \mathrm{y}=0.036 \mathrm{~m})$ ) el caudal circulante resulta ser de:

$$
Q=v \cdot \omega=\frac{2.5 \mathrm{~m}}{7 \mathrm{seg}} \cdot 0.25 \mathrm{~m} \cdot 0.036 \mathrm{~m}=3.2 \mathrm{l} / \mathrm{seg}
$$

valor parecido al que los campesinos comentaron previamente. No se ha aplicado un coeficiente reductor en el cálculo del caudal dado el escaso calado de la corriente.

Conocido el tiempo invertido (40 minutos) y la superficie regada $\left(75 \mathrm{~m}^{2}\right)$, se pueden calcular las características agronómicas del riego:

Volumen aplicado: $3.2 \mathrm{l} / \mathrm{s} \times 40 \times 60 \mathrm{~s}=7680$ litros

Dosis por riego $=7680$ litros $/ 75 \mathrm{~m}^{2}=102.4 \mathrm{l} / \mathrm{m}^{2} \approx 1000 \mathrm{~m}^{3} / \mathrm{ha}$

Dado que en una campaña normal de riegos se aplican 4 riegos, el volumen total aplicado es de $4000 \mathrm{~m}^{3} / \mathrm{ha}$, bien ajustado a las características de la zona. No obstante, la mano de obra requerida se aleja del óptimo, ya que se necesitó del concurso de 3 personas. Posiblemente, nuestra presencia y la necesidad de explicar a la misma vez el procedimiento de riego aumentaron tanto el tiempo de riego como la mano de obra utilizada. 


\section{5- Conclusiones}

En Bolivia, los valles interandinos de La Paz constituyen lugares privilegiados para el estudio de sistemas de riego tradicionales, por el importante legado de los campesinos andinos, que durante siglos, lograron aprovechar las aguas de los ríos, lagunas y manantiales para satisfacer sus necesidades, dentro de la cosmovisión holística del mundo que construyeron, en la que el agua tenía un papel fundamental.

En este estudio se ha tratado de describir y comprender los sistemas tradicionales de riego, mediante la descripción de infraestructuras y la caracterización de la organización en la distribución de las aguas. El trabajo de campo se desarrolló en la Provincia Bautista Saavedra del Departamento de La Paz donde se analizó el sistema de riego tradicional practicado por comunidades campesinas pertenecientes a la municipalidad de Charazani en áreas de dominio de las comunidades de Jatichulaya, donde el riego está condicionado al método de kanis.

Este método consiste en un riego superficial, ampliamente desarrollado por las culturas tradicionales andinas del país, completamente adecuado y en equilibrio con las características ecológicas y productivas de la zona. No obstante, se pudo evidenciar un elevado uso de mano de obra en la práctica del riego quizás derivado de nuestra presencia y de la necesidad de explicarnos a la vez el procedimiento de trabajo.

\section{6- Agradecimientos}

Este trabajo se desarrolló en el marco de proyectos desarrollados entre 2008 y 2009 y financiados por la Agencia Española de Cooperación Internacional para el Desarrollo (AECID), a quién se agradece su colaboración, y en el que participaron profesores de las Universidades de Córdoba, Córdoba, España, y Mayor de San Andrés, La Paz, Bolivia.

\section{7- Bibliografía}

Arellano López, J. (1978). La cultura Mollo: ensayo de síntesis arqueológico. INAR, La Paz, $81 \mathrm{p}$.

Céspedes, R., (1995). Descripción y Análisis del Sistema de riego Tradicional en la Comunidad de Jatichulaya de la provincia Bautista Saavedra.Tesis de Grado Universidad Mayor de San Andrés - La Paz, 140 p.

Chipana, R., Bosque, H., Del Pino, J.L., Roldán-Cañas, J. \& Moreno-Pérez, M.F.(2011).Sistemas de riego prehispánicos en Bolivia. En: Roldán-Cañas, J. \& Chipana, R. (coords.), 2011. Sistemas ancestrales de riego a ambos lados del Atlántico. Universidad de Córdoba, España, pp. 1-61.

Chipana Rivera, R., Moreno-Pérez, M.F., Choque Velasco, R.\& Roldán-Cañas, J. (2015). Performance of pre-hispanic irrigation systems in the Andean región of Bolivia. Agricultural Water Management,Published online 27/11/2015,DOI: http://dx.doi.org/10.1016/j.agwat.2015.11.010.

Del Pino, J.L., Roldán-Cañas, J. \& Moreno-Pérez, M.F.(2011). El agua y el riego en laPenínsula Ibérica. En: Roldán-Cañas, J. \& Chipana, R. (coords.), 2011. Sistemasancestrales de riego a ambos lados del Atlántico. Universidad de Córdoba, España, pp. 63-232. 
Ministerio de Medio Ambiente y Agua. (2013). Inventario Nacional de Sistemas de Riego. Bolivia, $29 \mathrm{p}$.

Ponce Sanginés, C. (1957). La cerámica Mollo. Biblioteca Paceña, La Paz.

Roldán-Cañas, J., Chipana, R., Moreno-Pérez, M. F. \& Chipana, G. (2015). Description and Evaluation of Zigzag Furrow Irrigation in the Inter-Andean Valleys of Bolivia. Journal of Irrigation and Drainage Engineering, 141(11): 04015019, DOI: 10.1061/(ASCE)IR.1943-4774.0000902. 


\title{
OPTIMIZACIÓN DE LA PRODUCTIVIDAD DEL AGUA EN ZONAS REGABLES MEDIANTE UNA HERRAMIENTA DE SIMULACIÓN DEL SISTEMA HIDRÁULICO, AGRARIO Y ECONÓMICO
}

\author{
Elmalki, E. ${ }^{1}$ Playán, E. ${ }^{2}$, Gallinat, J. ${ }^{3}$ y Zapata, N. $^{4}$
}

\begin{abstract}
${ }^{1}$ Personal Investigador en Formación. Depto. Suelo y Agua, Estación Experimental Aula Dei (EEADCSIC). Avda. Montañana 1005, 50059, Zaragoza. E-mail: hmalki@eead.csic.es

${ }^{2}$ Profesor de Investigación Depto. Suelo y Agua, Estación Experimental Aula Dei (EEAD-CSIC). Avda. Montañana 1005, 50059, Zaragoza. E-mail: enrique.playan@csic.es

${ }^{3}$ Ingeniero en la empresa CINGRAL S.L., C/Santa Cruz, 8, bajo. 50003, Zaragoza. Email: jgallinat@cingral.es.

${ }^{4}$ Científico Titular, Depto. Suelo y Agua, Estación Experimental Aula Dei (EEAD-CSIC). Avda. Montañana 1005, 50059, Zaragoza. E-mail: v.zapata@csic.es
\end{abstract}

\section{Resumen}

Este trabajo presenta una aplicación de la herramienta de simulación CINTEGRAL que permite adaptar el diseño de la red de riego a la realidad agraria local de las zonas regables (meteorología, suelos, cultivos y productividad global). Se estudian las condiciones locales (meteorología, suelos y cultivos) de una zona regable del Valle Medio del Ebro cuya red se ha diseñado de forma estándar. Se analiza el efecto de la variabilidad meteorológica y de diferentes alternativas de gestión del riego sobre la productividad global de la zona. Se discuten las diferencias en producción y productividad global de la zona bajo tres alternativas de gestión del riego: 1) gestión a la demanda, 2) gestión en turnos de riego coincidentes con pisos de presión, y 3) gestión en dos redes independientes. Los resultados obtenidos muestran un efecto claro de la variabilidad meteorológica sobre los ingresos brutos, ingresos netos y la factura eléctrica. La gestión del riego en turnos ajustados en función de la presión requerida permite ahorrar el $22 \%$ en la factura eléctrica respecto de la gestión del riego a la demanda. Sin embargo, las producciones se ven afectadas de forma muy notable, reduciendo notablemente la productividad de la zona. Para mantener la productividad con un riego a turnos es necesario realizar modificaciones en el diseño original de la red. Por lo tanto, en esta zona la gestión en turnos coincidentes con pisos de presión no mejora los ingresos netos. La división de la red global en dos sub redes independientes de riego reduce la factura eléctrica en un $20 \%$ y además mantiene los niveles de producción, por lo que los ingresos netos se incrementan en un $9 \%$.

\section{Introducción}

El diseño de los sistemas colectivos de riego por aspersión en cobertura total está basado en varios supuestos: 1) Una hipótesis de necesidades hídricas de la alternativa de cultivos prevista; 2) Una hipótesis sobre el tiempo disponible para el riego, expresado en porcentaje; 3) Una hipótesis de presión mínima necesaria a la salida de hidrante; 4) Una hipótesis sobre el modelo de reparto de agua; y 5) Una hipótesis de simultaneidad de la operación de la red.

Esta metodología ha llevado al diseño de las redes de riego que permitieran un funcionamiento compatible con las condiciones supuestas aguas abajo. Este funcionamiento resulta en la práctica en un nivel de garantía muy alto, que optimiza la red de forma hidráulica y que permite minimizar el coste de inversión de la red o el coste energético. Sin embargo, esta metodología arrastra carencias importantes derivadas de un proceso de diseño de arriba (el punto de captación) a abajo (el sistema de riego en parcela). Ignorar en el diseño las condiciones aguas abajo del hidrante ha llevado a que las redes las diseñen los 
estudios de ingeniería, mientras que en los sistemas de riego en parcela los instaladores instalen soluciones estándar, no adaptadas a las situaciones particulares de los cultivos, del medio o del suministro de agua. El desacople entre la red y el sistema de riego en parcela con frecuencia ha llevado a sistemas sobredimensionados en capacidad de conducción y en necesidades de presión.

En los últimos años se ha producido un cambio sustancial en las condiciones de los proyectos de modernización de regadíos y de nuevos regadíos. Así pues, en la actualidad: 1) Es preciso minimizar el coste de las nuevas instalaciones, tanto en inversión como en explotación (coste de energía); y 2) En redes con bombeos es preciso contar con sistemas de demanda negociada que permitan optimizar no sólo el consumo de energía sino su coste.

Estas circunstancias se combinan con progresos relevantes en investigación sobre sistemas de riego por aspersión. Uno de estos desarrollos en investigación es CINTEGRAL (Zapata et al. 2015) una herramienta de diseño de zonas regables que acopla desarrollos ya publicados en todos los procesos que participan en el riego por aspersión de una zona colectiva: hidráulica de redes presurizadas (basadas en EPANET, Rossman et al. 1994), distribución de agua desde el emisor hasta el cultivo basada en la teoría balística (Fukui et al. 1980) y aprovechamiento del agua por el cultivo, basado en modelos de cultivos como CropWat (Smith 1992).

El objetivo de este trabajo es evaluar sobre una zona regable del Valle Medio del Ebro cuya red se ha diseñado de forma estándar, el efecto que tendrá sobre la productividad de la zona la variabilidad meteorológica local así como diferentes alternativas de gestión del riego. Así se estudiarán tres formas alternativas de gestión del riego: 1) Gestión a la demanda (GRD); 2) Gestión del riego a turnos coincidentes con pisos de presión manteniendo el diseño original (GRT $T_{D O}$ ) o con pequeñas modificaciones ( $G R T_{D M}$ ); y 3) Gestión del riego en dos redes de riego independientes gestionadas a la demanda y coincidentes con las dos zonas de diferentes necesidades de presión (GR2R).

\section{Material y métodos}

\subsection{Herramienta CINTEGRAL}

La herramienta CINTEGRAL ha sido creada de forma cooperativa por investigadores de la EEAD-CSIC y por la empresa CINGRAL S.L. La herramienta permite realizar el diseño de una zona regable adaptándose a los suelos, la meteorología y la agronomía, así como a los precios de las cosechas y de los insumos de producción (entre ellos el agua y la energía), es decir, considerando la realidad agraria local de forma global.

CINTEGRAL engloba un conjunto de modelos y programas ya desarrollados en trabajos anteriores, los más importantes son los siguientes:

1. El modelo de red parcelaria y de la red general colectiva, para ello se utilizó el programa ADOR-Red desarrollado y presentado en Zapata et al. (2009), al que se le incorporó el módulo de simulación hidráulica desarrollado a partir de EPANET (Rossman et al. 1994).

2. El modelo de reparto de agua desde el emisor hasta la planta en riego por aspersión ADOR-Aspersión desarrollado y presentado en Playán et al. (2006) para cobertura total de aspersión.

3. El modelo ADOR-Cultivo desarrollado y presentado en Dechmi et al. (2004a). Se adaptó a los cultivos más importantes de la zona. Se revisaron y ajustaron las ecuaciones de cálculo de las necesidades hídricas de los cultivos y de su respuesta al estrés hídrico.

4. Un módulo de optimización que analiza el funcionamiento de la zona en términos de productividad global y que permite optimizar la contratación de potencia.

\subsubsection{Input del programa}

Para su funcionamiento el programa requiere numerosos datos de entrada que sintetizan las condiciones locales de la zona de estudio. A continuación se resumen los datos de entrada necesarios:

1. El diseño hidráulico de la red general y algunos datos sobre la red parcelaria. Las redes parcelarias no son necesarias ya que no se realiza una simulación hidráulica de cada una de 
estas redes, sino que se simplifican. Para ello se requieren datos básicos sobre la parcela, tales como la disposición y distanciamiento entre aspersores, o el número y tamaño de las boquillas de los aspersores. Con el caudal del hidrante disponible en la red general, la superficie de la parcela y el caudal del aspersor se calcula el número probable de sectores o posturas de riego de la parcela.

2. El cultivo y el/los suelos de las parcelas. Esta asignación puede ser manual si se dispone de un mapa de suelos y cultivos de la zona, o se puede hacer una asignación automática proporcionándole a la herramienta el porcentaje en superficie de cada cultivo o tipo de suelo. La asignación automática de cultivo y suelo a cada parcela se realiza así de forma aleatoria.

3. Los datos eléctricos: Potencia contratada en cada periodo tarifario, así como el precio de la potencia y el de la energía de cada periodo. La herramienta permite realizar una optimización de la potencia a contratar en cada periodo tarifario a partir de la alternativa de cultivos de la zona y de una serie meteorológica local.

4. Los datos de gestión del riego: si queremos limitar los riegos por motivos de calidad mínima (uniformidad de riego mínima, eficiencia mínima) o de duración.

5. Los datos meteorológicos locales. Para ello la herramienta proporciona una base de datos de las estaciones agrometeorológicas de la red SIAR de Aragón que disponen de todos los datos necesarios para realizar la simulación. De esta forma el usuario sólo tiene que seleccionar la estación más cercana de la zona de estudio, así como el año de datos en el que quiere realizar el análisis. La base de datos de estaciones meteorológicas puede ampliarse con estaciones de otras zonas de España con disponibilidad de datos diarios y semihorarios.

6. Módulo económico. Por un lado se incorporan los datos globales de inversión, el de la red colectiva y el de las parcelarias (se totaliza el coste de las redes parcelarias), así como las condiciones de financiación para poder obtener la amortización anual. Además, para calcular los ingresos netos por cosecha necesitamos incorporar para cada cultivo: los costes de producción (sin incluir el coste del riego que se calculará en el proceso), la producción máxima zonal (el programa calcula la producción como un porcentaje respecto al máximo) y los ingresos por venta de cosecha.

\subsubsection{Output del programa}

Los resultados que proporciona la herramienta responden a diferentes escalas espaciales, desde el sector o postura de riego de una parcela, pasando por la parcela, el hidrante hasta la zona regable. Para cada elemento de la escala espacial el programa proporciona resultados de la evapotranspiración potencial y la real, el volumen de riego bruto y el neto, la uniformidad y eficiencia de riego estacional, la producción, el coste energético, los ingresos brutos y los ingresos netos. Para visualizar estos resultados, CINTEGRAL proporciona dos opciones:

1. Visualización espacial. Para ello es necesario incorporar una cobertura GIS de los lotes regados por cada hidrante. En la tabla asociada a dicha cobertura GIS debe de aparecer una columna llamada "contenido" con los nombres de los hidrantes tal y como aparecen en el archivo de la red hidráulica. Con la cobertura GIS como fondo pueden graficarse los resultados obtenidos a escala de hidrante, como por ejemplo, el margen neto, la producción media, fallos de red (fallos por insuficiencia de presión), fallos debidos a la falta de energía, la dosis de riego, etc.

2. Visualización en forma de tablas y gráficos. Los resultados se presentan para diferentes escalas espaciales (toda la red, por hidrante, por parcela, por cultivo por sector). Se pueden comparar gráficamente diferentes simulaciones en términos de producción media, eficiencia y uniformidad de riego estacional, fallos de la red y de energía, volumen de riego en cada periodo, coste de agua, margen neto, etc.

\subsection{Zona de estudio}

Para el estudio se ha seleccionado una comunidad de regantes (CR) del Valle Medio del Ebro. Dicha comunidad tiene una superficie regable de 3644 ha, repartida en 273 hidrantes. 
Se utilizó la red SIAR (Sistema de Información Agroclimática para el Regadío) para la obtención de los datos. Dicha red proporciona datos semihorarios y diarios en todas sus estaciones. La estación más representativa de la zona de estudio es la de Grañén. En dicha estación se dispone de datos desde el año 2004 hasta 2014.

La red general de la CR se diseñó con un programa de diseño de redes presurizadas. Las redes parcelarias todavía no están diseñadas, por lo que se realizó un pre-diseño a partir del parcelario de la zona en formato GIS y de los datos de los hidrantes (caudal y presión) resultantes del diseño de la red general. Con el programa GVGIS, se delimitaron la superficie y el número de parcelas regadas por cada hidrante. Se supuso un diseño homogéneo de las parcelas con una disposición de los aspersores en tresbolillo a $18 \mathrm{~m}$ entre filas y $18 \mathrm{~m}$ entre aspersores (T18x18), muy común en zonas de riego de cultivos extensivos, y con aspersores de impacto de doble boquilla $(4,4 \mathrm{~mm}$ y $2,4 \mathrm{~mm})$. El diseño original de la red general se realizó para asegurar una presión en boquilla de $350 \mathrm{kPa}$. Sin embargo dicha presión resulta elevada para los costes energéticos actuales. Se realizó un segundo pre-diseño de las parcelas asegurando una presión en boquilla de $300 \mathrm{kPa}$.

A partir del mapa de suelos de los municipios Barbués y Torres de Barbués publicado por Nogués (2002) y utilizando la herramienta de análisis espacial GVSIG, se asignaron las características del suelo de las 3155 ha regadas. Solamente 1880 ha de la zona regable están incluidas en el mapa de suelos presentado por Nogués (2002). Para la superficie de la que no se disponía de mapa de suelos, se realizó una asignación aleatoria de los suelos, conservando los porcentajes del mapa original. Los parámetros del suelo que nos interesa establecer son aquellos más directamente relacionados con el riego: la profundidad efectiva y la capacidad de retención de agua (CRA).

En el mapa de Nogués (2002) la profundidad del suelo se clasifica en 4 clases, desde poco profundo $(30 \mathrm{~cm})$ a muy profundo $(140 \mathrm{~cm})$. En cuanto a la CRA se clasifica en cinco niveles, de muy baja (inferior a $64 \mathrm{~mm}$ en 1,5 m) a muy alta (superior a $250 \mathrm{~mm}$ en 1,5 m). Los datos de CRA se transformaron a $\mathrm{mm} / \mathrm{m}$ (unidades que utiliza la herramienta CINTEGRAL) y se atribuyó a cada parcela el tipo de suelo que le correspondía.

El diseño de la red general de riego se realizó para la alternativa de cultivos extensivos (\% de superficie cultivada de cada uno) que se presenta en la Tabla 1. En la misma también se presentan los datos económicos requeridos por el programa, como son: 1) los gastos de producción, incluyendo los costes de la semilla, la siembra, los fertilizantes, tratamientos fitosanitarios y sus aplicaciones, así como los de otras labores del cultivo incluida la cosecha (no se incluyen los costes del agua y la energía asociada, pues estos se calculan con la herramienta); 2) el rendimiento máximo de la zona, 3) el precio de venta de la cosecha.

Tabla 1. Alternativa de cultivos para la que se realizó el diseño de la zona regable. Se incluyen los gastos de producción, el rendimiento máximo esperable en la zona y el precio de venta.

\begin{tabular}{lcccc}
\hline Cultivo & $\begin{array}{c}\text { Porcentaje } \\
(\%)\end{array}$ & Gastos $€ /$ ha & $\begin{array}{c}\text { Rendimient } \\
\text { o Kg/ha }\end{array}$ & $\begin{array}{c}\text { Precios } \\
€ / \text { Tonelada }\end{array}$ \\
\hline Alfalfa & 40 & 1500 & 18000 & 130 \\
Maíz & 40 & 1500 & 14000 & 170 \\
Cebada & 10 & 450 & 4500 & 175 \\
Trigo & 10 & 500 & 4500 & 200 \\
\hline
\end{tabular}

\subsection{Análisis de alternativas de gestión y diseño de la zona regable \\ 2.3.1 Gestión a la demanda}

Se plantea el análisis del funcionamiento de la red bajo las condiciones de diseño original. Dicho diseño se realizó para gestionar el riego a la demanda, GRD. La fiabilidad del diseño se analiza ante diferentes condiciones meteorológicas (serie meteorológica 2004-2014), en términos de productividad global de la zona. En principio se analizan los ingresos netos que resultan de descontar a los ingresos brutos los costes de producción y de aplicación del 
agua de riego (factura eléctrica). También se analiza la producción de los cultivos y los parámetros de la calidad de riego (uniformidad y eficiencia de riego), así como el consumo de agua.

\subsubsection{Gestión en turnos de riego}

Trabajos recientes indican que mejoras en la gestión de riego - como el riego por turnos en pisos de presión - pueden reducir los consumos energéticos hasta un 20\% (Carrillo-Cobo et al. 2011; Fernández-García et al. 2014a). En este trabajo se propone el análisis de la gestión del riego a turnos sobre el diseño original de la red (GRT $\mathrm{DO}_{\mathrm{DO}}$ ). El sistema a turnos se ha basado en asignar a cada turno parcelas con necesidades homogéneas de presión (pisos de presión). El análisis de las cotas y las necesidades de presión de cada hidrante permitió identificar dos zonas diferenciadas en cuanto a necesidades de presión. Así se identificaron: un turno o zona alta en el que se permitirá regar solo en las horas de energía barata (P6), y un turno o zona baja en el que se podrá regar en cualquier momento del día. Los dos turnos tienen aproximadamente la misma superficie.

La estación de bombeo se programa para que en los periodos de tarifa barata (P6) en los que solo riega el turno de necesidades altas de presión, la altura de bombeo sea igual a la de la red original, $63 \mathrm{~m}$, mientras que en el resto de periodos tarifarios, de P5 a P1, la altura de bombeo se regulará a $43 \mathrm{~m}$. Esta diferencia en la altura de bombeo afecta de igual forma a la potencia específica, pasando de $0,27 \mathrm{kWh} \cdot \mathrm{m}^{-3}$ cuando se bombea en P6 a 0,18 kWh.m $\mathrm{m}^{-3}$ cuando bombeamos en cualquier otro periodo tarifario. Se analizó el funcionamiento de la red para los dos turnos establecidos manteniendo el diseño original de la red y surgieron problemas. El diseño original se realizó para gestionar el riego a la demanda, es decir, de forma que existiera libre disponibilidad de apertura de los hidrantes en las condiciones de caudal y presión preestablecidas. Regar en turnos organizados en la forma establecida significa que una serie de hidrantes (los situados en la zona alta o turno alto) solo pueden regar en periodos de energía barata, lo que reduce su tiempo disponible para riego respecto para el que fueron diseñados. Este hecho puede acarrear una serie de carencias como que el hidrante no sea capaz de aplicar el riego necesario en el momento adecuado y la producción se resienta. Para evitar estas deficiencias se realizaron pequeños cambios en el diseño de la red de riego original, incrementando el caudal de algunos de estos hidrantes situados en la zona alta así como los diámetros de las tuberías que los alimentan. Esta nueva alternativa de gestión de riego a turnos con diseño modificado ( $G R T_{\mathrm{DM}}$ ) se comparó con la GRT $\mathrm{DO}_{\mathrm{DO}}$ y con la GRD. Las comparaciones se realizaron en términos de producción de los cultivos, de costes eléctricos y de ingresos netos.

\subsubsection{Gestión en dos redes independientes}

La CR es muy grande y heterogénea, con un desnivel máximo muy importante (52 m entre la parcela de mayor elevación respecto a la de menor). Estas diferencias tan notables parecen indicar la conveniencia de analizar el funcionamiento de la zona regable dividiendo la zona en dos subzonas con dos redes independientes (GR2R: Gestión de Riego en dos Redes). Los nuevos diseños se realizaron mediante las herramientas GVSIG y GESTAR. La distribución de los porcentajes de superficie de cultivos en ambas redes fue la misma que la alternativa original (Tabla 1). La distribución en dos subzonas fue la misma que la realizada para dividir la zona en dos turnos de riego: zona alta (mayores requerimientos de presión) y zona baja (menores requerimientos de presión). Las comparaciones GRD, GRT $T_{D O}$, $\mathrm{GRT}_{\mathrm{DM}}$ y GR2R se realizaron en términos de coste eléctrico, ingresos brutos (producciones), ingresos netos y productividad global de la zona.

\section{Resultados y discusión}

\subsection{Herramienta CINTEGRAL}

La Figura 1 muestra un ejemplo de los datos de entrada y de salida de la herramienta CINTEGRAL. En la Figura 1a se presentan como ejemplo de datos de entrada la pantalla de datos de hidrantes y de usos. De forma automática y a partir del diseño de la red general se 
completan una serie de datos generales (como superficie y caudal del hidrante) y se les asigna una parcela y un uso. Estos datos asignados de forma automática pueden editarse y modificarse manualmente. En la Figura $1 \mathrm{~b}$ se muestra un ejemplo de la visualización espacial de los resultados obtenidos en cuanto a producción media por hidrante. Si se hace un clic sobre una parcela salen los datos y resultados numéricos de dicha parcela.

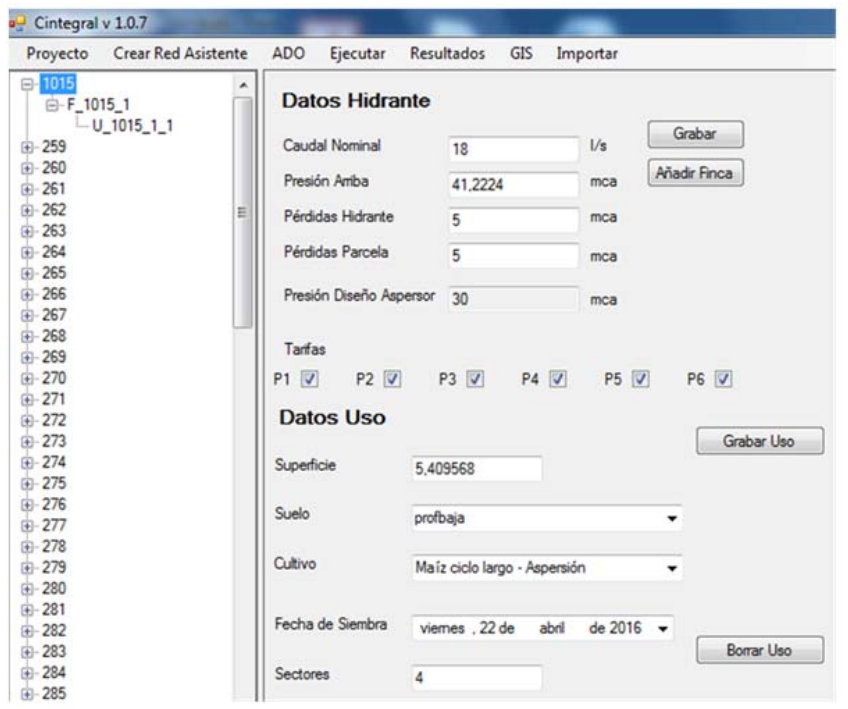

(a)

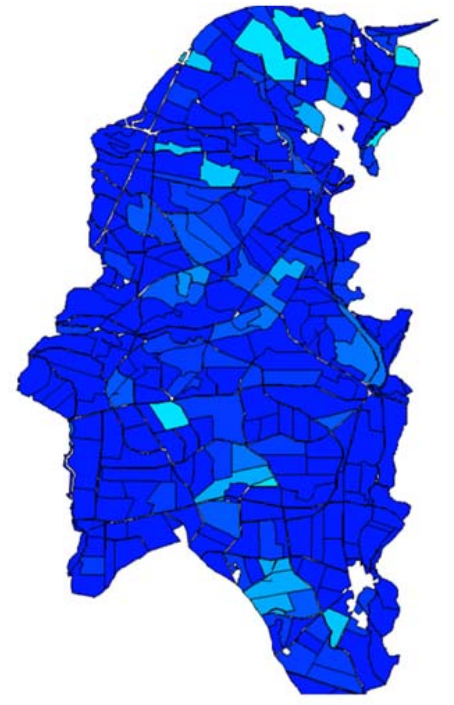

(b)

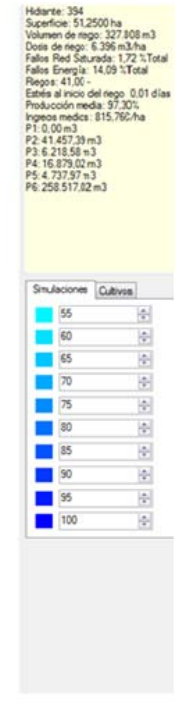

Figura 1. Ejemplo de datos de entrada (a) y de salida (b) de la herramienta CINTEGRAL.

\subsection{La zona de estudio}

La evapotranspiración de referencia $\left(\mathrm{ET}_{0}\right)$ presentó una media anual de $1205 \mathrm{~mm}$ año-1 con un CV de 3,8\%, un máximo de $1286 \mathrm{~mm}_{\text {año }}{ }^{-1}$, registrado en el año 2012, y un mínimo de $1119 \mathrm{~mm}$ año ${ }^{-1}$, en el año 2008. La ET 0 mensual máxima fue de $198 \mathrm{~mm}$, que se produce todos los años en el mes de julio. La $\mathrm{ET}_{0}$ más baja fue de $25 \mathrm{~mm}$, que se produce en todos los años en el mes de diciembre.

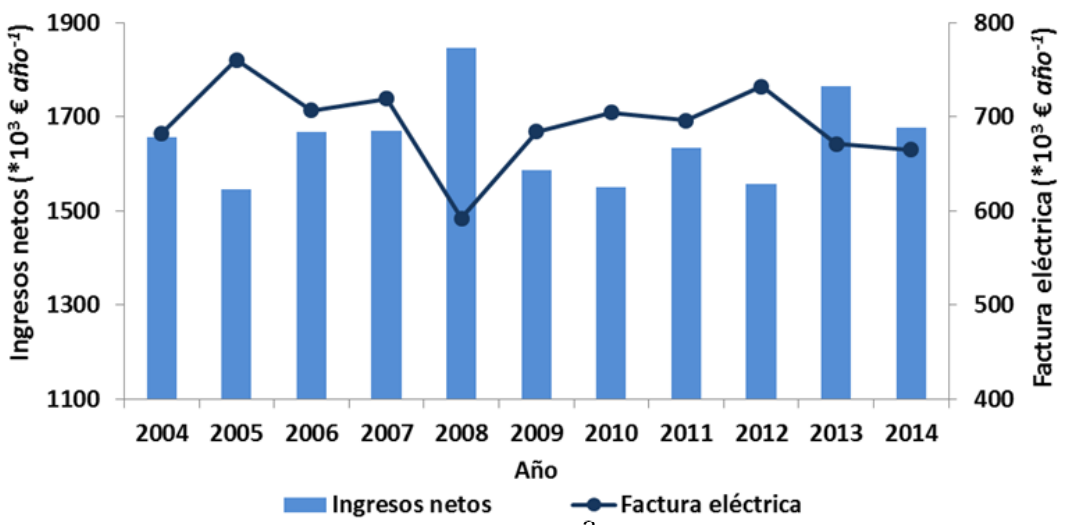

Figura 2. Ingresos netos y factura eléctrica en ${ }^{\star} 10^{3} €$ por año, GRD.

Se analizó el efecto de la variabilidad interanual de la meteorología sobre el funcionamiento de la red de riego a la demanda asegurando una presión de $300 \mathrm{kPa}$ en boquilla. La alternativa de cultivos presentada en la Tabla 1 y la serie meteorológica disponible se utilizaron para optimizar la potencia a contratar en cada uno de los tramos tarifarios y años meteorológicos. Para ello se utilizó el módulo de optimización descrito en la herramienta CINTEGRAL. Los resultados de ingresos netos y factura eléctrica para la serie meteorológica analizada se presentan en la Figura 2. La media interanual de los ingresos netos fue de 2,342 M€, con un CV de 2,6\%. El coste de la factura eléctrica medio fue de 
0,692 M€, con un CV de 6,2\%. El año de menor coste fue $2008(0,592 \mathrm{M} €)$ y el de mayor coste $(0,760 \mathrm{M} €)$ fue 2005 . En el año 2008 se obtuvieron los mayores ingresos netos de la serie analizada $(1,850 \mathrm{M} €)$, mientras que en el 2005 se obtuvieron los menores ingresos netos $(1,545 \mathrm{M} €)$. Parte de la diferencia se debe a los costes de la factura eléctrica, que en 2008 fueron los más bajos y en 2005 los más elevados de la serie estudiada. La meteorología tiene mucho que decir sobre estos resultados, ya que 2008 fue un año de precipitaciones por encima de la media (especialmente en los meses de verano), y además la $\mathrm{ET}_{0}$ fue de las más bajas de la serie. Por otro lado, 2005 fue un año poco lluvioso en los meses de mayores necesidades de riego. La variabilidad meteorológica y sobre todo las necesidades de riego de los meses de verano determinan los costes eléctricos que afectan a la productividad global de la zona.

En la Figura 3 se muestran para toda la zona y a escala de parcela: la distribución espacial de los suelos (Figura 3a), la distribución de cultivos utilizada para el análisis (Figura 3b), la producción media en porcentaje sobre el máximo rendimiento (Figura 3c) y dos parámetros de calidad del riego, eficiencia (Figura 3d) y uniformidad de reparto (Figura 3e). Los resultados de producción y calidad del riego corresponden a la campaña 2014.

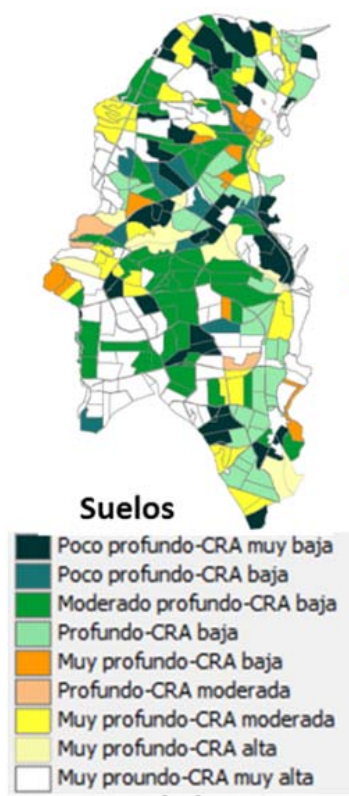

(a)

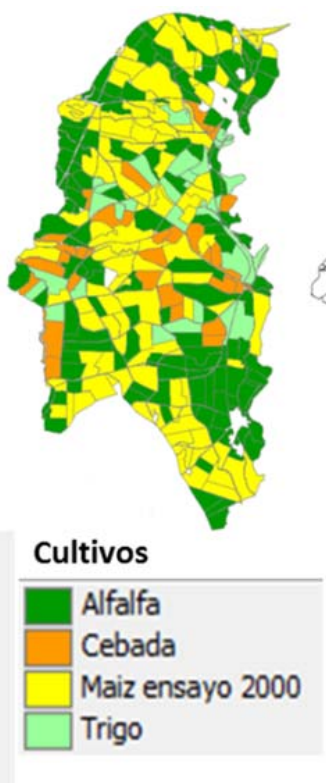

(b)

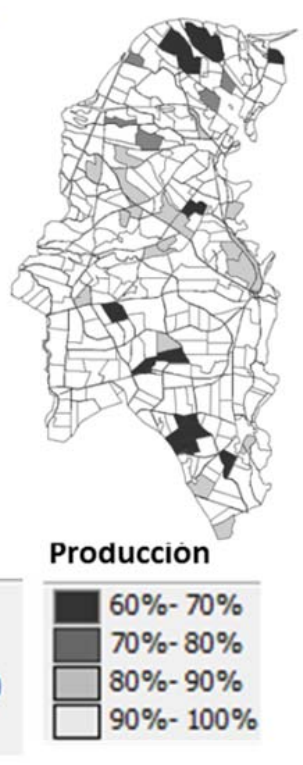

(c)

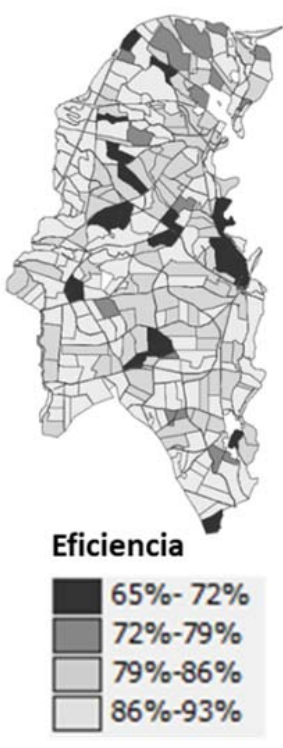

(d)

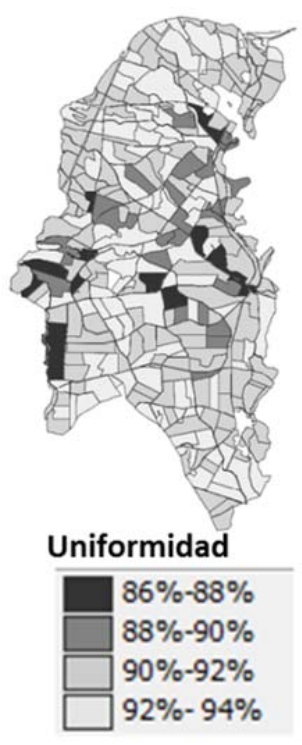

(e)

Figura 3. Suelos (a), alternativa de cultivo (b) en la zona de estudio, producción media \% (c) Eficiencia \% (d) y uniformidad \% (e), año 2014.

Se identificaron 9 tipos de suelos según su profundidad y CRA (Figura 3a). Los más abundantes, el $33 \%$ de superficie de la zona, son suelos muy profundos con una CRA muy alta, los suelos pobres desde el punto de vista hidráulico (poco profundos y CRA muy baja) aparecen en un $15 \%$ de la superficie total de la CR. La distribución de los cultivos se realizó de forma aleatoria y se conservó esta misma distribución en todos los análisis realizados en este estudio.

En la Figura 4 se presenta la media por cultivo del consumo de agua (Figura 4a), la producción (Figura 4b), la eficiencia estacional del riego (Figura 4c) y la uniformidad estacional (Figura 4d) para el año 2014.

En cuanto al consumo de agua de riego, el consumo medio de la alfalfa fue de $8333 \mathrm{~m}^{3} \mathrm{ha}^{-1}$, con un CV entre parcelas del 5\%. El consumo del maíz fue de $6478 \mathrm{~m}^{3} \mathrm{ha}^{-1}$ con un CV del $5 \%$, el de la cebada $4069 \mathrm{~m}^{3} \mathrm{ha}^{-1}$, con un CV del $11 \%$ y el del trigo, $4509 \mathrm{~m}^{3}$ ha $^{-1}$ y un CV del $9 \%$.

En 2014 la producción media de alfalfa fue del $98 \%$ con un CV de 2,6\%, la del maíz del $91 \%$ con mayor variabilidad entre parcelas, CV de $10,5 \%$, la de la cebada de $97 \%$ con un CV de $3,4 \%$ y la del trigo del $95 \%$ con un CV de $4,6 \%$. Los valores de producción media 
tanto de alfalfa como de cebada fueron elevados, indicando que los cultivos se regaron adecuadamente y también que, si en algún momento se retrasó la aplicación del riego a estos cultivos, la producción no se vio afectada. Sin embargo, la producción media del maíz fue menor y su variabilidad entre parcelas más elevada. Esto se debe a que los problemas que originaron retrasos en la aplicación del riego en maíz sí que afectaron al desarrollo y producción del mismo, pues se trata de un cultivo muy sensible al estrés hídrico. La distribución espacial de las producciones (Figura 3c) está muy relacionada con la distribución de suelos (Figura 3a) y con la de cultivos (Figura 3b). Las parcelas que presentan producciones más bajas, se corresponden con el cultivo de maíz y se localizan en suelos con baja calidad para el riego (suelos poco profundos y con una CRA muy baja). El riego de suelos de baja calidad hidráulica exige un manejo muy cuidadoso, como aplicar riegos ligeros con mayor frecuencia. Este manejo a veces no es posible en momentos de máxima demanda hídrica, ya que la disponibilidad de la red no permite aplicar el riego con la frecuencia que estos suelos requieren. Cuando estos suelos se combinan con cultivos de alta sensibilidad al estrés hídrico como el maíz, la producción de dichas parcelas se resiente (parcelas de colores más oscuros en la Figura 3c).
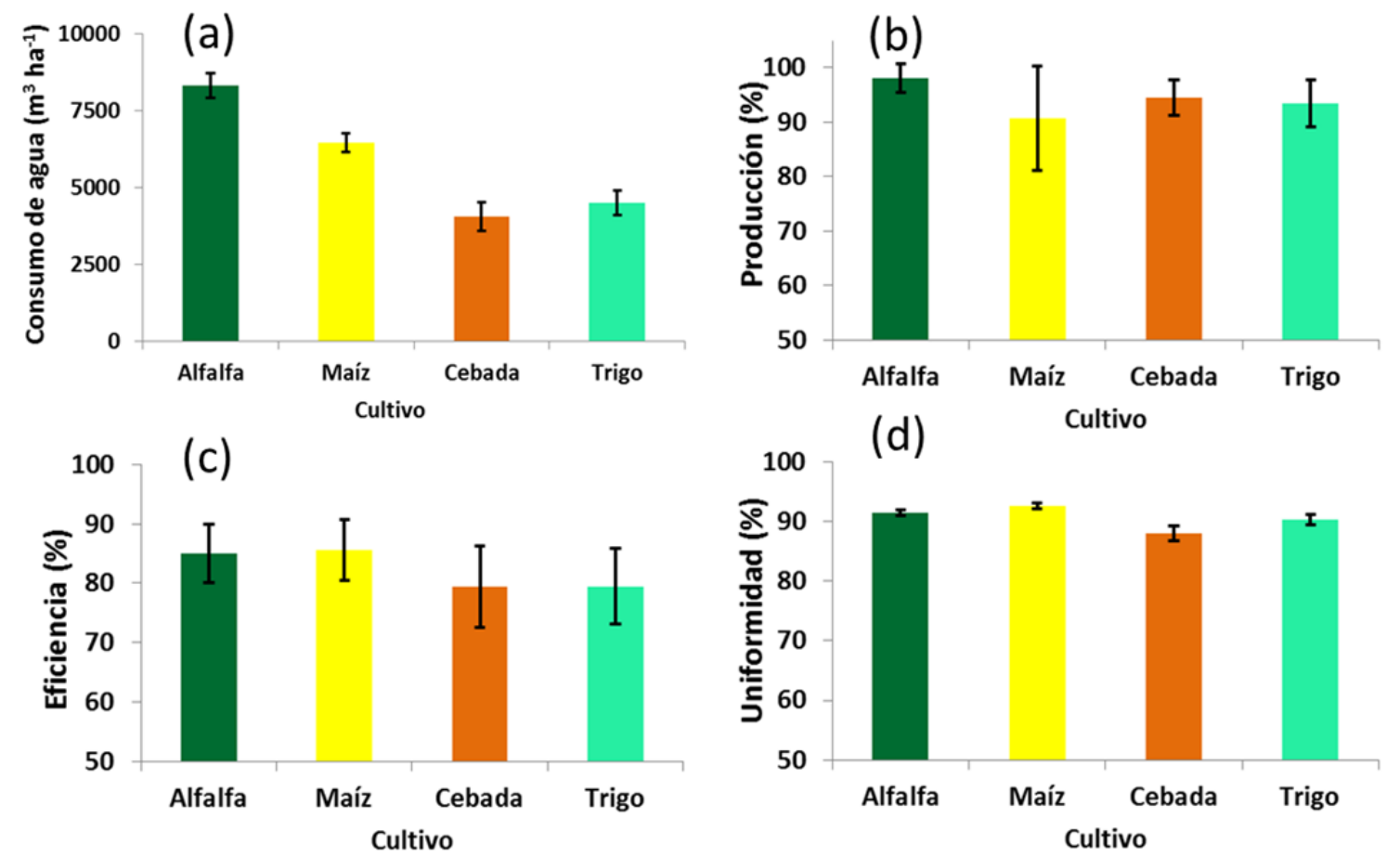

Figura 4. Consumo de agua (a) en $\mathrm{m}^{3} \mathrm{ha}^{-1}$, producción media \% (b), eficiencia \% (c) y uniformidad \% (d) por cultivo, resultados del 2014. Las barras indican la variabilidad entre las parcelas del mismo cultivo.

La eficiencia del riego media global durante la campaña 2014 fue del 84\%. La distribución espacial de dicha eficiencia (Figura 3d) indica que las parcelas que presentan menores eficiencias de riego se corresponden con las de los suelos más pobres desde el punto de vista hidráulico (poco profundos y CRA muy baja o baja). En estos suelos las pérdidas por percolación profunda fueron más importantes. El CU medio global en la campaña 2014 fue del $91 \%$. El análisis espacial de la uniformidad (Figura 3e) muestra parcelas con uniformidades inferiores al $90 \%$ que en la mayoría de los casos están cultivadas de cebada y de trigo. La baja uniformidad se justifica por el periodo de riego de estos cultivos que coinciden con los meses más ventosos del año, abril y mayo. La uniformidad del riego por aspersión se ve gravemente afectada por la velocidad del viento. 


\subsection{Análisis de alternativas de gestión y diseño de la zona regable}

En la Figura 5 se presenta la comparación entre las 4 alternativas de gestión y diseño analizadas en la zona: GRD, GRT $T_{\mathrm{DO}}, \mathrm{GRT}_{\mathrm{DM}}$ y GR2R en términos de consumo de agua (Figura 5a), ingresos brutos (Figura $5 b$ ), factura eléctrica (Figura $5 c$ ) e ingresos netos (Figura $5 \mathrm{~d}$ ). El consumo medio de agua en la gestión en turnos de presión (GRT $\mathrm{DO}_{\mathrm{DO}} \mathrm{GRT}_{\mathrm{DM}}$ ) fue inferior (entre un 3 y un 3,5\%) al consumo en una gestión a la demanda tanto en una red (GRD) o en dos redes (GR2R). Pero este menor consumo afectó de forma importante a la producción media de los cultivos y a sus ingresos brutos (Figura $5 \mathrm{~b}$ ). Las modificaciones en el diseño de la red para adaptarla a una gestión por turnos mejoraron los ingresos brutos respecto a los resultados de aplicar esta gestión en la red original, sin embargo, no se alcanzaron los ingresos brutos de la GRD. En cuanto a la GR2R, los ingresos brutos resultaron en valores medios muy similares a los de la GRD, y con menos variabilidad interanual ya que el CV no supera el $1,5 \%$.
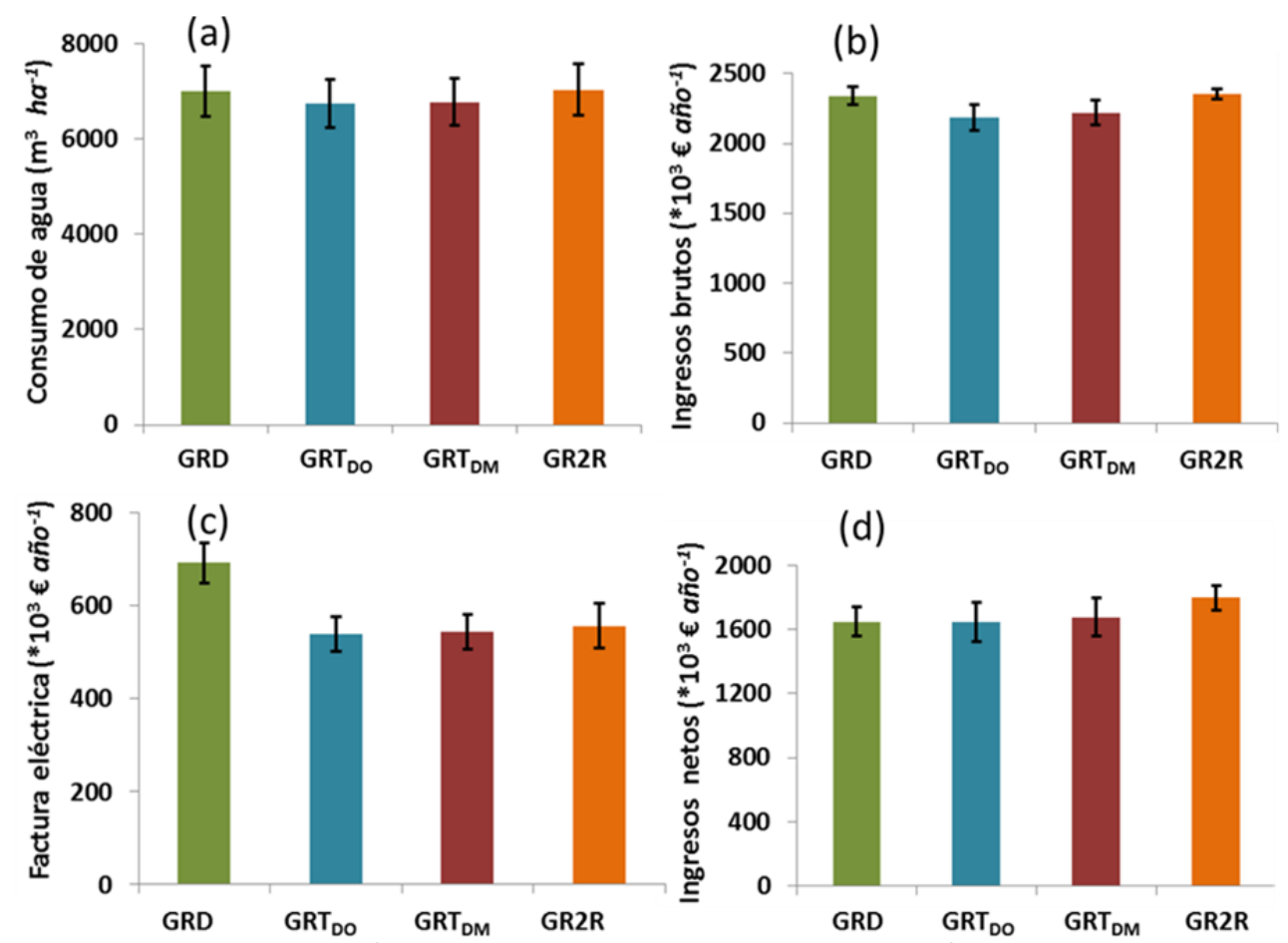

Figura 5. Ingresos brutos $\left({ }^{\star} 10^{3} €\right.$ por año), factura eléctrica $\left({ }^{\star} 10^{3} €\right.$ por año), ingresos netos $\left({ }^{\star} 10^{3} €\right.$ por año) y consumo de agua $\left(\mathrm{m}^{3} \mathrm{ha}^{-1}\right)$ para las 4 alternativas: $G R D, G R T_{D O}, G R T_{D M} y$ GR2R. Las barras representan la variabilidad entre los años de estudio.

Como era de esperar (ya que el volumen de riego aplicado en notablemente inferior), la factura eléctrica del riego a turnos en sus dos modalidades ( $G R T_{D O}$ y $G R T_{D M}$ ) fue inferior (aproximadamente un 22\%) a la del riego a la demanda, especialmente el de toda la red GRD. Sin embargo, los valores medios de los ingresos netos (Figura 5d) en la gestión a turnos, $\mathrm{GRT}_{\mathrm{DO}}\left(1,649 \mathrm{M} €\right.$ por año) y $\mathrm{GRT}_{\mathrm{DM}}(1,677 \mathrm{M} €$ por año), son muy similares a los obtenidos en la GRD (1,650 M€ por año), lo que indica que lo que se ahorra en electricidad y se pierde en producción. La conclusión es que en esta red de riego el cambio de la gestión de riego a la demanda a riego organizado en turnos necesita un cambio importante de la red y que las mejoras en productividad global no son muy relevantes. La división de la zona en dos redes de riego a la demanda independientes (GR2R) mantiene los ingresos brutos respecto a la GRD y permite un ahorro en la factura eléctrica $(20 \%)$, lo que se traduce en una mejora de los ingresos netos del 9\% (1,797 ${ }^{*} \mathrm{M} €$ por año) comparando a la GRD. Esta división de la red permite, también, una amortiguación del efecto de la variabilidad meteorológica interanual sobre les ingresos netos ya que el CV es de $4,2 \%$ en la GR2R frente a $5,6 \%$ en la GRD, $7,4 \%$ en la GRT Do y $7,2 \%$ en la GRT $\mathrm{DM}_{\text {. }}$ 
Para analizar la disminución de los ingresos brutos de la GRT frente a la GRD se analizaron los resultados de las producciones medias por parcela (Figura 6) para el año 2014. En la Figura 6a se presentan los suelos, en la Figura $6 \mathrm{~b}$ los cultivos, en la Figura $6 \mathrm{c}$ la producción en \% de la GRD, en la Figura 6 d la producción en \% de la GRTDM y en la Figura $6 d$ la producción en \% de la GR2R. En general las parcelas con menores producciones (colores más oscuros) en la gestión a la demanda también resultan en producciones menores en la gestión a turnos. Sin embargo en la gestión a turnos el número de parcelas con problemas de producción es mayor, y los valores de producción son en general inferiores. En la mayoría de los casos se trata de parcelas que o bien tienen un suelo pobre (poco profundo y CRA baja o muy baja, colores verde oscuros en la Figura 6a), o/y presentan un número elevado de sectores/posturas de riego, o/y pertenecen a la subzona (turno) alta o/y están cultivadas de maíz, un cultivo sensible al estrés hídrico

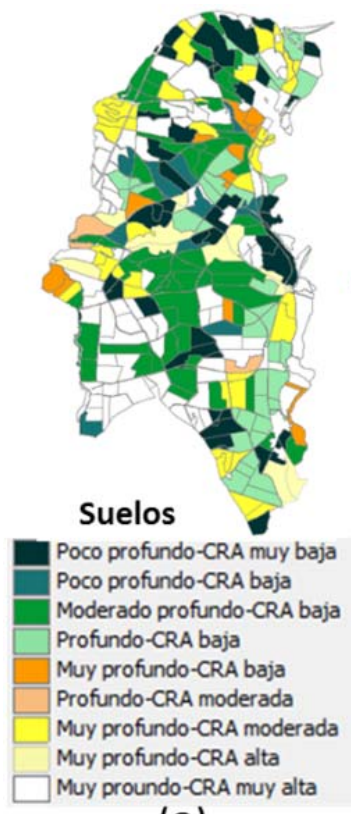

(a)
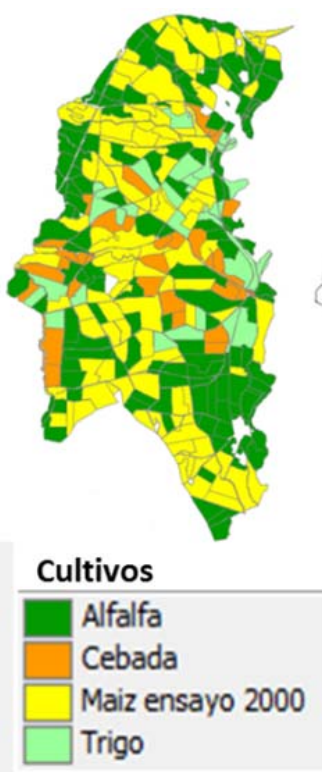

(b)

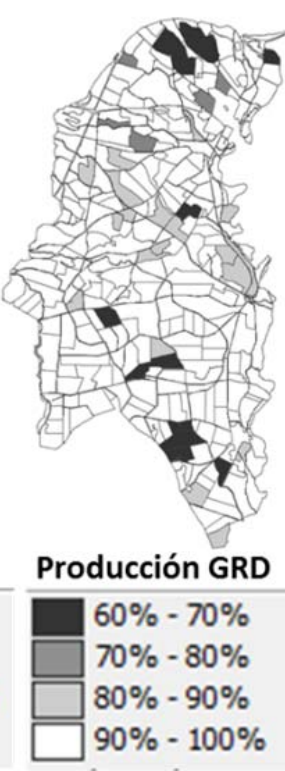

(c)

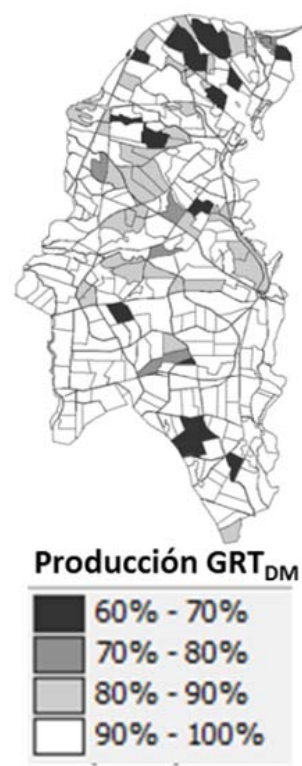

(d)

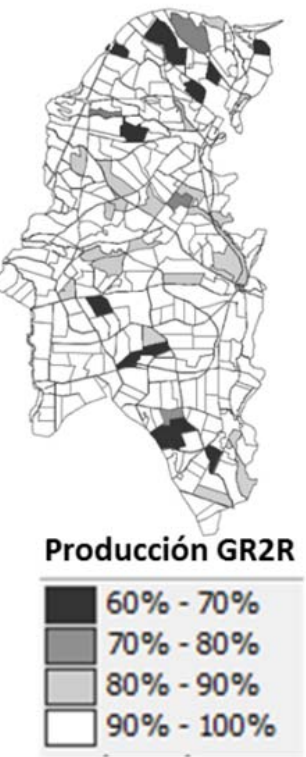

(e)

Figura 6. Producción media (\%) de los hidrantes para las alternativas: $G R D, G R T_{D M}$ y GR2R, año 2014.

\section{Conclusiones}

Este estudio presenta una aplicación de la herramienta de simulación CINTEGRAL que permite analizar el diseño y la gestión de una zona regable adaptándose a las redes (colectivas y parcelarias), los suelos, la meteorología, la agronomía, así como a los precios de cosecha y de los insumos de producción (entre ellos el agua y la energía). Este enfoque permite realizar un análisis global que incorpora la realidad agraria local de la zona regable.

Los resultados obtenidos en una gestión a la demanda muestran el efecto de la variabilidad meteorológica interanual sobre los ingresos brutos, ingresos netos y la factura eléctrica. Las producciones mínimas se registran en suelos más pobres desde el punto de vista hidráulico (poco profundos y CRA muy baja o baja) y para cultivos más sensibles al estrés hídrico (maíz).

La comparación de las 4 alternativas, gestión a la demanda de la zona global, gestión en 2 turnos de riego adaptados a zonas de presión homogénea (sin y con cambios en el diseño) y gestión en 2 redes independientes, muestra que la división de la zona en dos redes permite reducir la factura eléctrica en $20 \%$ sin afectar a la producción, lo que arroja un incremento del $9 \%$ de los ingresos netos. Sin embargo, la gestión a turnos reduce la factura eléctrica pero también produce notables mermas de producción que reducen los ingresos brutos, resultando en un incremento de los ingresos netos en un escaso $2 \%$ respecto a la gestión a la demanda. 


\section{Referencias}

Alexandratos, N. and Bruinsma, J., (2012), World Agriculture: Toward 2030/2050, The 2012 Revision. Publicación FAO: 12-03.

Carrillo Cobo, M.T., Rodríguez Díaz, J.A., Montesinos, P., López Luque, R., Camacho Poyato, E., (2011). Low energy consumption seasonal calendar for sectoring operation in pressurized irrigation networks. Irrig Sci 29:157-169.

Dechmi, F., Playán, E., Cavero, J., Martinez-Cob, A., Faci, J.M., (2004a). Coupled crop and solid-set sprinkler simulation model. I: Model development. J Irrig Drain Eng ASCE 130(6):499-510.

Fernández García, I., Moreno, M.A., Rodríguez Díaz, J.A., (2014). Optimum pumpingstation management for irrigation networks sectoring: case of Bembezar Ml (Spain). Agric. Water Manage. 144, 150-158.

Fukui, Y., Nakanishi, K., Okamura, S., (1980). Computer evaluation of sprinkler irrigation uniformity. Irrig. Sci. 2, 23-32.

Martínez-Cob, A., Zapata, N., Sánchez, I., (2010). Viento y riego: la variabilidad del viento en Aragón y su influencia en el riego por aspersión, Fernando el Católico.

Nogüés, J., (2002). Mapa de suelos (E 1/25000) de Barbués y Torres de Barbués. Aplicación para modernización de regadíos, Consejo de Protección de la Naturaleza de Aragón.

Playán, E., Zapata, N., Faci, J. M., Tolosa, D., Pelegrín, J., Salvador, R., Lafita, A., Sánchez, I. (2006). Assessing sprinkler irrigation uniformity using a ballistic simulation model. Agric. Wat. Manage., 84 (1-2):89-100.

Rossman, L.A., Clark, R.M., Grayman, W.M., (1994). Modeling chlorine residuals in drinkingwater distribution-systems

Smith, M., (1992). CropWat: a computer program for irrigation planning and management. FAO Irrig and Drain paper 46, Rome, Italy.

Zapata, N., Latorre, B., Citoler, F.J., Gallinat, J., Bescós, M., Castillo, R., Mantero, N., Burguete, J. and Playán, E. Collective irrigation network design and management for energy optimization: the "cintegral" tool. ICID 26th Euro Mediterranean Regional Conference and ICID 56th International Executive Council. Innovate to Improve Irrigation Performance. Montpellier, France. 11-16 october 2015.

Zapata, N., Playán, E., Skhiri, A., Burguete, J., (2009). A collective solid-set sprinkler irrigation controller for optimum water productivity. J Irrig Drain Eng ASCE 135(1):13-24. 


\title{
C-08
}

\section{BAJA PRESIÓN EN ASPERSORES DE IMPACTO EN COBERTURAS DE RIEGO: ANÁLISIS TÉCNICO Y AGRONÓMICO}

\author{
Robles, O. $^{1}$ y Zapata, $N^{2}$ \\ ${ }^{1}$ Personal Investigador en Formación. Depto. Suelo y Agua, Estación Experimental Aula Dei \\ (EEAD-CSIC). Avda. Montañana 1005, 50059, Zaragoza, España, E-mail: \\ coctaviorobles@eead.csic.es \\ ${ }^{2}$ Científico Titular, Depto. Suelo y Agua, Estación Experimental Aula Dei (EEAD-CSIC). \\ Avda. Montañana 1005, 50059, Zaragoza, España, E-mail: v.zapata@csic.es
}

\section{Resumen}

La eficiencia energética en riego presurizado se ha abordado desde la gestión hidráulica de las infraestructuras de red y la eficiencia en los bombeos, sin embargo, es necesario analizar los ahorros que pueden realizarse a escala de parcela. Resultados preliminares indican que la reducción de la presión de funcionamiento de un aspersor de impacto de $300 \mathrm{kPa}$ a $200 \mathrm{kPa}$ ligeramente reduce la uniformidad del riego. En este trabajo se evalúa en campo la calidad del riego y los resultados agronómicos de tres configuraciones aspersor+presión: 1) un aspersor de impacto convencional trabajando a 300 $\mathrm{kPa}(\mathrm{AC} 300)$, 2) un aspersor convencional trabajando a $200 \mathrm{kPa}$ (AC 200) y 3) un aspersor modificado con una pequeña placa deflectora sobre el brazo de impacto trabajando a 200 kPa (APD 200). En una parcela experimental de cobertura total formada por 12 subparcelas, se realizó un ensayo en bloques al azar sobre un cultivo de maíz durante la campaña 2015. Se caracterizaron las condiciones meteorológicas (velocidad y dirección del viento) de los riegos aplicados al maíz. Para cada tratamiento se realizaron ensayos de uniformidad, evaluaciones agronómicas, cosecha manual de biomasa aérea y cosecha de grano. Los resultados indican que la uniformidad media evaluada no fue significativamente diferente entre tratamientos. La biomasa y producción de grano del tratamiento de $300 \mathrm{kPa}$ resultaron menores que las de los tratamientos a $200 \mathrm{kPa}$ (AC 200 y APD 200), no resultando significativas las diferencias entre ambos tratamientos de $200 \mathrm{kPa}$. Se detectó un problema en el crecimiento de cultivo que afectó principalmente a las subparcelas de $300 \mathrm{kPa}$, por lo que los resultados deben de considerarse con cuidado y realizar el ensayo en una o dos temporadas más.

\section{1- Introducción}

La expansión de los sistemas de riego presurizados ha tenido gran importancia en los últimos años debido a los Planes de Modernización de regadíos impulsados por el Ministerio de Agricultura. El uso de sistemas de riego por aspersión genera incrementos en la productividad del agua al modernizar una zona de riego, pero los costes energéticos implican un incremento muy importante en los costes de producción. Debido al importante aumento del consumo energético en el regadío, al coste de la amortización de las infraestructuras modernizadas y al elevado coste de la energía eléctrica, los beneficios de los agricultores se han visto reducidos de forma drástica, peligrando la viabilidad de las explotaciones recién modernizadas.

Conscientes de lo anterior, diversos trabajos se han realizado entorno a la eficiencia del uso del agua mediante la reducción de las pérdidas (Playán et al, 2005; Cavero et al, 2008).También se ha abordado en la literatura la mejora de la eficiencia energética desde 
diferentes perspectivas como la gestión de infraestructuras de red general de riego (CarrilloCobo et al, 2010) y las condiciones óptimas de operación de las estaciones de bombeo (Moreno et al, 2010; Lamaddalena y Khila, 2012). Sin embargo, en necesario seguir avanzando en la optimización energética de todo el sistema, prestando atención también al riego en parcela.

Las zonas de riego por aspersión para cultivos extensivos se han diseñado para proporcionar una presión en la boquilla del aspersor de impacto de entre $300 \mathrm{kPa}$ a $350 \mathrm{kPa}$. Según varios autores (Keller y Bliesner, 1990; Tarjuelo, 2005) la calidad de riego (uniformidad y eficiencia) depende de diversos factores, tales como: las características del aspersor, el tamaño y forma de las boquillas, la presión de trabajo y su variabilidad, la altura de aspersor, el espaciamiento entre ellos y las condiciones meteorológicas durante el riego. Sin embargo, en un trabajo reciente Playán et al, (2006) presentaron ensayos de uniformidad de riego de dos modelos de aspersor de impacto trabajando a diferentes presiones $(200,300$ y $400 \mathrm{kPa}$ ) sus resultados apuntan a que las diferencias en uniformidad entre 200 y $300 \mathrm{kPa}$ no son muy relevantes. La reducción de la presión en boquilla a 200 $\mathrm{kPa}$ puede suponer un ahorro considerable de energía, sin embargo tenemos que asegurarnos que la calidad del riego cumple unos mínimos y que la producción del cultivo no se ve afectada.

Un riego a baja presión tiene otros efectos como la disminución del área efectiva de riego y la generación de gotas grandes que poseen mayor resistencia al ser arrastradas. También hay que citar el posible efecto que la distribución de tamaños de gotas tiene sobre los procesos erosión-sellado del suelo (Seginer, 1965; Kohl et al, 1985) y, por ende, los de infiltración (Mohammed y Kohl, 1987). Las técnicas de no laboreo o de laboreo de conservación pueden mitigar este efecto negativo sobre el suelo.

El objetivo de este trabajo es caracterizar experimentalmente mediante un ensayo de campo las diferencias en calidad del riego y producción de un cultivo entre un riego por aspersión a $300 \mathrm{kPa}$ y a $200 \mathrm{kPa}$. Para ello se analizarán tres configuraciones aspersor+presión que comprenden: 1) un aspersor de impacto convencional trabajando a $300 \mathrm{kPa}$ (AC 300), 2) un aspersor convencional trabajando a $200 \mathrm{kPa}$ (AC 200) y 3) un aspersor modificado con una pequeña placa deflectora sobre el brazo de impacto trabajando a $200 \mathrm{kPa}$ (APD 200).

\section{2- Materiales y métodos}

El ensayo se realizó en una finca experimental de la Estación Experimental Aula Dei (EEAD-CSIC) en Montañana Zaragoza. El clima de la zona es mediterráneo semiárido con precipitación y evapotranspiración media anual de $322 \mathrm{~mm}$ y $1100 \mathrm{~mm}$, respectivamente, las temperaturas promedio máximas y mínimas oscilan entre $20,9^{\circ} \mathrm{C}$ y $8,5^{\circ} \mathrm{C}$. El suelo de la zona se clasifica como xerofluvente típico.

La parcela experimental tiene una superficie de 1,8 ha, dividida en 12 subparcelas elementales de $324 \mathrm{~m}^{2}$. Se ensayan tres configuraciones aspersor+presión: 1) un aspersor de impacto convencional trabajando a $300 \mathrm{kPa}$ (AC 300), 2) un aspersor convencional trabajando a $200 \mathrm{kPa}(\mathrm{AC} 200)$ y 3) un aspersor modificado con una pequeña placa deflectora sobre el brazo de impacto trabajando a $200 \mathrm{kPa}$ (APD 200). Los tratamientos se distribuyeron en bloques al azar con cuatro repeticiones. La configuración de cada una de las 12 subparcelas fue cuadrada de $18 \mathrm{~m} \times 18 \mathrm{~m}$ y los cuatro aspersores que la componen están regulados por una válvula de sector (Figura 1). Los aspersores que operaban a una presión de $200 \mathrm{kPa}$ se equiparon con boquillas de $5,2 \mathrm{~mm}+2,4 \mathrm{~mm}$, mientras que los aspersores que operaban a $300 \mathrm{kPa}$ estaban equipados con boquillas de $4,4 \mathrm{~mm}+2,4 \mathrm{~mm}$. Estas diferencias en tamaños de boquilla compensan las diferencias en presión, de forma que la pluviometría media es la misma. La presión en cada una de las 12 subparcelas se mantuvo constante de acuerdo a su tratamiento correspondiente (200 kPa o $300 \mathrm{kPa})$ con válvulas reguladoras de presión instaladas en cada una de las válvulas de sector. La presión de funcionamiento se media en continuo (frecuencia de 5 minutos) en cada una de las subparcelas mediante un transductor de presión instalado en uno de los aspersores de cada 
subparcela (Figura 1). Los bordes de la parcela (V1 y V14) fueron regadas independientemente de las 12 subparcelas que componen el ensayo.

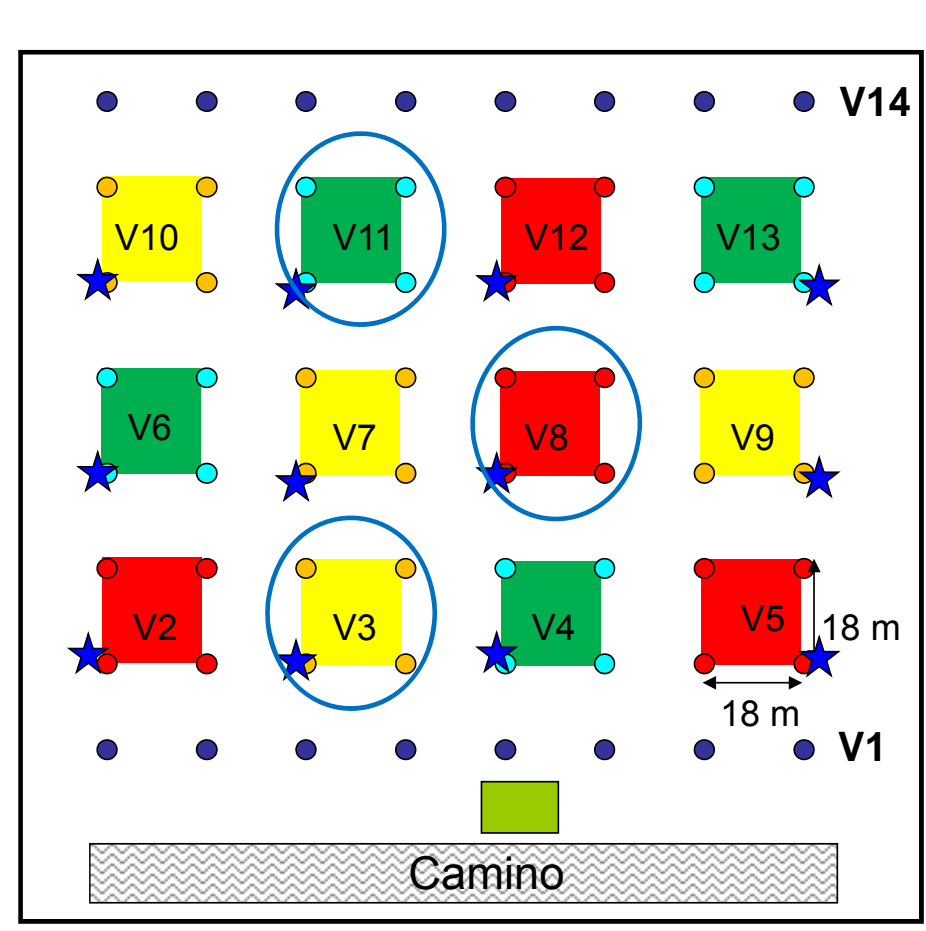

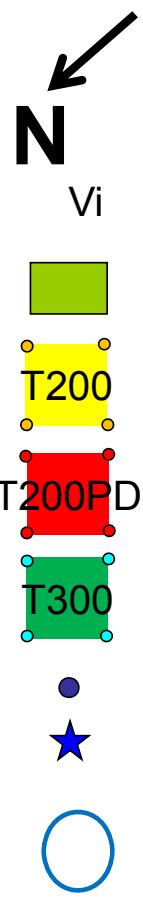

Electroválvulas

Caseta de riego

AC $200 \mathrm{kPa}, 5,2+2,4$

APD 200 kPa, 5,2 + 2,5

AC $300 \mathrm{kPa}, 4,4+2,4$

Aspersores bordadura

Transductores de presión /manómetros

Pluviómetros

Figura 1. Diseño experimental del sistema de riego de cobertura total. Cada experimento analizado se muestra con un color diferente.

En la parcela se sembró maíz (Pioneer P1758) con densidad de 89500 semillas ha ${ }^{-1}$ en abril de 2015, la separación entre filas fue de $0,75 \mathrm{~m}$ y entre plantas de aproximadamente $0,15 \mathrm{~m}$. Se aplicó una fertilización antes de la siembra de $\mathrm{N}\left(64 \mathrm{~kg} \mathrm{ha}^{-1}\right), \mathrm{P}_{2} \mathrm{O}_{5}\left(120 \mathrm{~kg} \mathrm{ha}^{-1}\right)$ y $\mathrm{K}_{2} \mathrm{O}\left(120 \mathrm{~kg} \mathrm{ha}^{-1}\right)$. Además, se aplicó $100 \mathrm{~kg} \mathrm{ha}^{-1}$ de solución $\mathrm{N}-32$ con agua de riego después de la nascencia del maíz. Las hierbas y plagas fueron controladas de acuerdo a las prácticas de la zona (solución CAMIX 3,75 I ha $^{-1}$ como preemergente y solución Clorpirifós en 2 I ha ${ }^{-1}$ como insecticida).

Tras la nascencia del cultivo se instalaron mallas de 25 pluviómetros en tres subparcelas, una en cada tratamiento (V3, V8 y V11, Figura 1). Se evaluaron 6 de los riegos aplicados al maíz para determinar las uniformidades de riego (Christiansen, 1942) ante diversas condiciones meteorológicas. La duración aproximada del riego en cada ensayo fue de 2 horas como mínimo. Se utilizaron los registros agrometeorológicos de la estación SIAR de Montañana localizada a $1200 \mathrm{~m}$ del ensayo. Se realizó un análisis de la frecuencia de las diferentes intensidades y direcciones del viento durante los eventos de riego. Para ello se clasificó la intensidad del viento de los eventos de riego en tres categorías: viento bajo, medio y alto. El cálculo de las necesidades hídricas netas del cultivo se realizó a partir de la evapotranspiración diaria del cultivo de referencia (Método Penman-Monteith, Allen et al, 1998) facilitado por la estación SIAR antes mencionada y de los coeficientes de cultivo basados en la integral térmica propuesta para el cultivo del maíz en la zona por Martínez-Cob (2008), considerando la precipitación efectiva (75\% de la precipitación real).

Se realizaron dos medidas agronómicas después de la floración del maíz: a) la altura de planta, y b) la radiación fotosintéticamente activa interceptada por el cultivo (IPAR). La altura de planta se midió en 20 puntos internos de cada una de las subparcelas, utilizando una regla de madera con precisión en centímetros. La IPAR se midió en 12 puntos de cada sector, utilizando un ceptómetro (Sunscan Delta-T, Cambridge, UK) para medir la radiación interceptada al nivel del suelo y un sensor de fracción de haz (BF3 Delta-T, Cambridge, UK) 
para medir la radiación solar interceptada fuera de la parcela. IPAR se calculó como la diferencia entre las lecturas del ceptómetro y del sensor de fracción.

Se realizó cosecha manual de un $1,4 \%$ de la superficie de la subparcela para estimar la biomasa aérea. Las plantas se cortaron por encima de la superficie del suelo separando la mazorca del resto de la planta. A su vez, se separó de la mazorca el grano y el zuro. Toda la biomasa aérea (grano, planta y mazorca) fue pesada por separado y posteriormente secada a $60^{\circ} \mathrm{C}$ durante 72 horas, obteniendo el peso de la biomasa seca. Se determinó el índice de cosecha (IC) de cada subparcela como la relación entre el peso del grano al $14 \%$ y la biomasa aérea seca.

La cosecha final se llevó a cabo en septiembre de 2015, una cosechadora comercial recolectó el grano de cada subparcela por separado que se pesó in-situ con ayuda de un remolque pesador (precisión de $1 \mathrm{~kg}$ ). En cada una de las 12 cosechas se aisló una muestra de $1 \mathrm{~kg}$ para verificar la humedad del grano. La producción de grano por subparcela se estimó convirtiendo el peso del grano al $14 \%$ de humedad.

Las variables analizadas en este trabajo: presión de trabajo en aspersor, altura de planta, IPAR, biomasa aérea, IC y producción de grano fueron tratadas estadísticamente con ANOVA al $95 \%$ de confiabilidad $(p=0,05)$, resaltando las diferencias significativas entre tratamientos.

\section{3- Resultados y discusión}

El caudal medio de cada aspersor fue de $1607 \mathrm{I} \mathrm{h}^{-1}$ (APD 200), $1584 \mathrm{I} \mathrm{h}^{-1}$ (AC 200) y $1597 \mathrm{I} \mathrm{h}^{-1}$ (AC 300), las diferencias entre éstas fueron inferiores a 1,3\%. La pluviometría media de los tres tratamientos fue de $4,9 \mathrm{~mm} \mathrm{~h}^{-1}$. La dosis estacional de riego aplicada al maíz para la campaña de riego 2015 fue de $635 \mathrm{~mm}$ distribuido en 35 riegos. Salvo los riegos de nascencia, la duración de los mismos era de entre 3 y 4 horas (generalmente de las 07:00 a 11:00 hora civil) con una frecuencia de entre uno a tres eventos por semana, en función de las necesidades del cultivo.

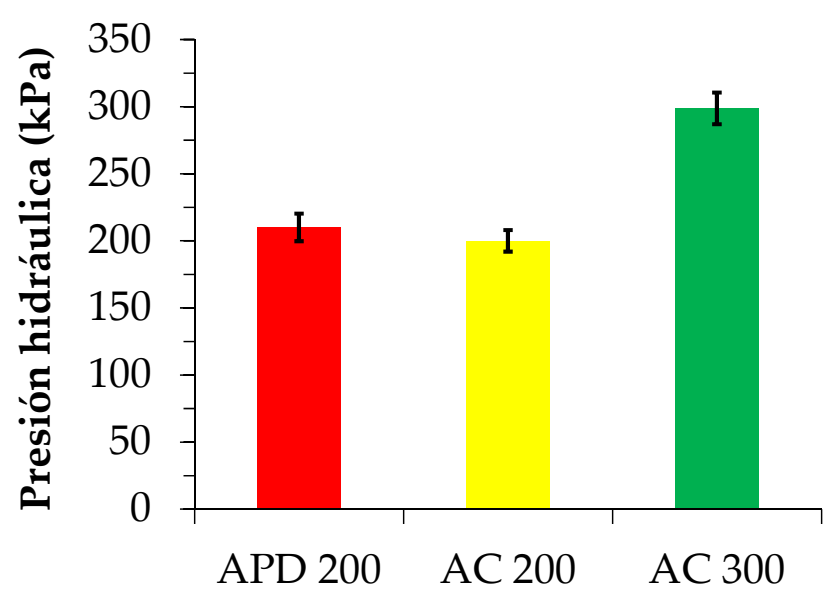

Figura 2. Presiones registradas por los transductores en los aspersores de impacto de cada tratamiento.

El promedio por tratamiento de las presiones registradas por los transductores se muestra en la Figura 2. Los valores fueron de $210 \mathrm{kPa}, 200 \mathrm{kPa}$ y $300 \mathrm{kPa}$ para los tratamientos APD 200, AC 200 y AC 300, respectivamente. En general, para todo el experimento la desviación estándar promedio fue de $10 \mathrm{kPa}$.

El viento promedio durante los 35 eventos de riego aplicados al maíz en la campaña 2015 fue de 2,1 $\mathrm{m} \mathrm{s}^{-1}$. La dirección del viento predominante fue OSO en $22 \%$ (8 riegos) de los casos (Figura 3a), ESE en el 15\% (5 riegos) y en el resto de los eventos la dirección fue cambiante. En alrededor de $14 \%$ de los casos (5 riegos) se presentó un viento superior a los 
$4 \mathrm{~m} \mathrm{~s}^{-1}$ ocurriendo en los meses de junio, julio y agosto (Figura 3b). En toda la campaña se presentaron vientos menores a $2 \mathrm{~m} \mathrm{~s}^{-1}$ en 18 eventos de riego (51\% de los casos).
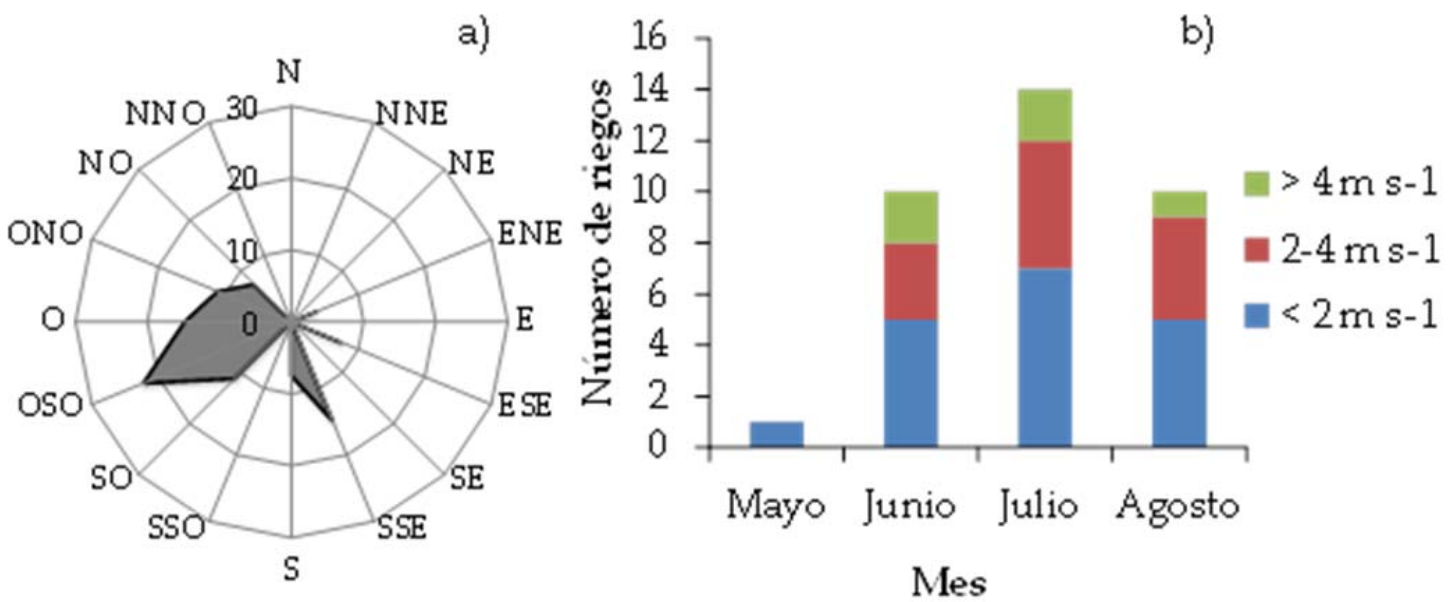

Figura 3. Comportamiento del viento en los eventos de riego de la campaña del maíz. a) frecuencia de dirección de viento durante los riego de maíz y b) frecuencia de velocidades baja, media y alta $\left(<2 \mathrm{~m} \mathrm{~s}^{-1}, 2-4 \mathrm{~m} \mathrm{~s}^{-1} y>4 \mathrm{~m} \mathrm{~s}^{-1}\right)$ durante los meses en los que ocurrió el riego.

El CU promedio de los seis riegos evaluados fue de $84 \%, 84 \%$ y $86 \%$, para los tratamientos APD 200, AC 200 y AC 300, respectivamente. Cuatro de los riegos evaluados se efectuaron en condiciones de viento en calma $\left(<2 \mathrm{~m} \mathrm{~s}^{-1}\right)$, uno con viento medio ( $>=$ $\left.2 \mathrm{~m} \mathrm{~s}^{-1} \mathrm{y}<4 \mathrm{~m} \mathrm{~s}^{-1}\right)$ y otro con viento alto $\left(>4 \mathrm{~m} \mathrm{~s}^{-1}\right)$. La Figura 4 muestra dos de los riegos evaluados en dos casos de viento muy diferente, viento bajo $\left(1 \mathrm{~m} \mathrm{~s}^{-1}\right)$ y viento alto $\left(4,5 \mathrm{~m} \mathrm{~s}^{-1}\right)$. En ambos caso el tiempo de riego fue de 2 horas. En el riego efectuado en condiciones de viento en calma, el CU fue mayor para el tratamiento AC $300(91 \%)$, seguido del tratamiento APD 200 (89\%), siendo el tratamiento de menor CU (88\%) el tratamiento AC 200. Las diferencias son pequeñas y las uniformidades medias de todos los tratamientos están por encima del mínimo CU recomendado. En cuanto al riego efectuado en condiciones de viento alto, la mayor uniformidad se obtuvo en el tratamiento AC 200 (77\%), siendo el menor valor el del tratamiento APD 200 (66\%). En este caso todos los valores están por debajo del CU recomendado. Los valores medios del CU de los seis riegos evaluados no indican una relación clara entre tratamientos, pues las diferencias no son estadísticamente significativas entre ninguno de ellos. 


\section{APD 200 kPa}

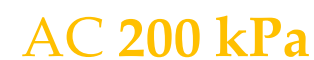

$\mathrm{AC} 300 \mathrm{kPa}$
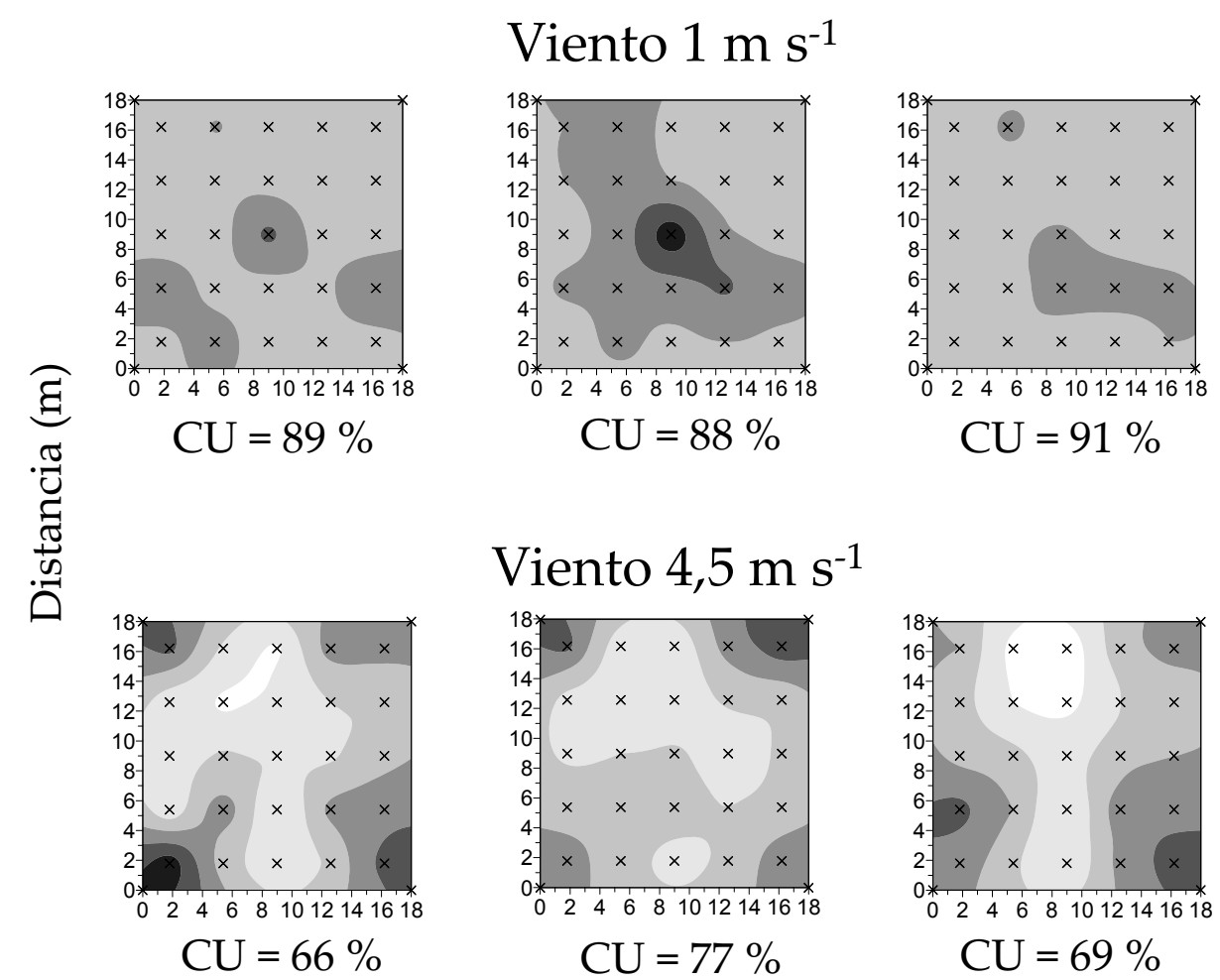

Viento $4,5 \mathrm{~m} \mathrm{~s}^{-1}$
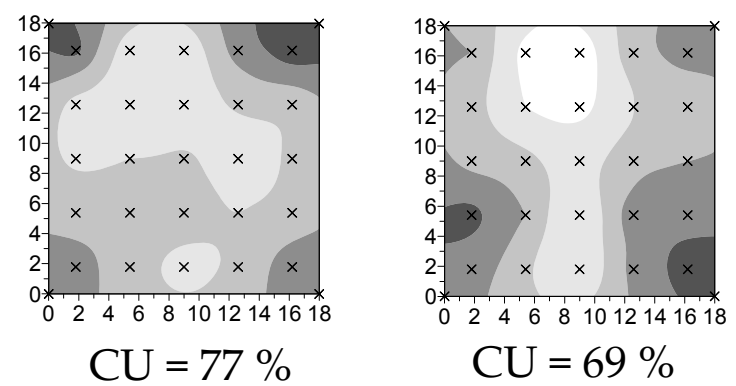

Distancia (m)

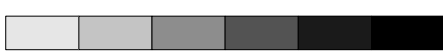

\section{$2,5 \quad 4 \quad 5,5 \quad 7 \quad 8,5 \quad 10(\mathrm{~mm})$}

Figura 4. Coeficientes de uniformidad (CU) y mapas de distribución de agua en una de las subparcelas de cada tratamiento en dos eventos de la campaña de riego, uno de viento bajo y otro de viento alto. La escala de pluviometría se muestra en grises con intervalos de 1,5 $\mathrm{mm}$.

Los valores medios por tratamiento de la altura de planta se presentan en la Figura 5a. El análisis de los datos nos indica que la altura de planta en los tratamientos de $200 \mathrm{kPa}$, APD 200 y AC 200, no presenta diferencias estadísticamente significativas. Tampoco es significativa la diferencia en altura de planta entre los tratamientos AC 200 y AC 300. Sin embargo, la diferencia es significativa entre los tratamientos APD 200 y AC 300. Hay que comentar que en el tratamiento $A C 300$, en dos de sus repeticiones, las localizadas en la parte final de la parcela (válvulas 11 y 13 de la Figura 1), la altura de planta resultó claramente por debajo de la media global. En esta parte se observó visualmente retraso en la fase de nascencia en relación con el resto de subparcelas.

Las medidas de IPAR (Figura $5 \mathrm{~b}$ ) no presentaron diferencias significativas entre tratamientos. En general no se aprecia una relación clara entre la radiación interceptada por el cultivo y la altura del mismo. 


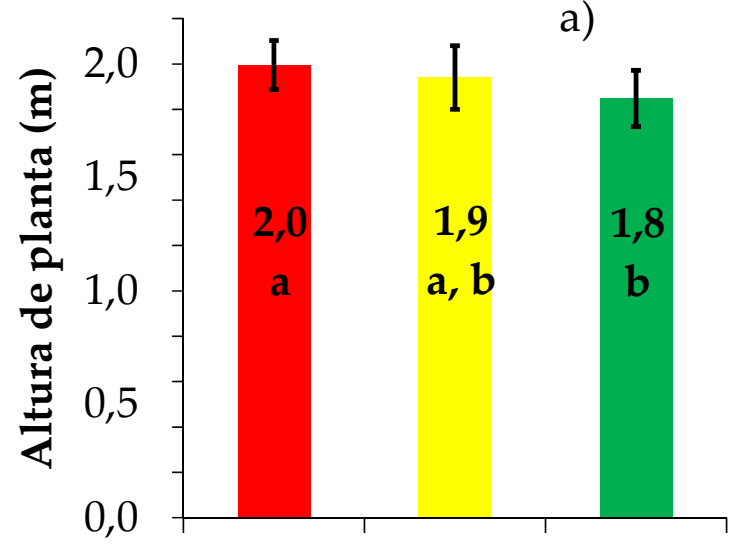

APD 200 AC 200 AC 300

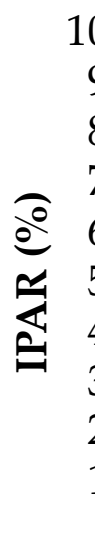

100
90
80
70
60
50
40
30
20
10
0 b)
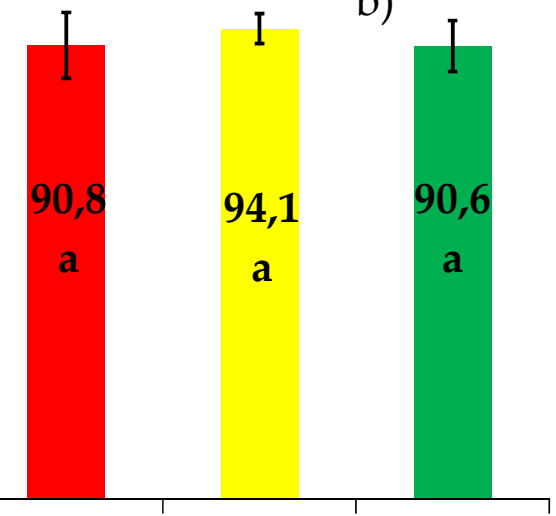

APD 200 AC $200 \quad$ AC300

Figura 5. Evaluaciones agronómicas sobre el maíz. a) altura de planta promedio ( $m$ ) y b) radiación solar interceptada por el cultivo (\%). Los valores de ambas imágenes se expresan para cada tratamiento analizado (APD 200, AC 200 y AC 300). Los números seguidos de letras distintas presentan diferencias significativas al $95 \%$ de confiabilidad $(p=0,05)$ para cada variable.

La Tabla 1 muestra la biomasa aérea, la producción en grano, la eficiencia en el uso del agua y el índice de cosecha de cada una de las subparcelas del ensayo. La menor biomasa y menor producción de grano se dio en la válvula 13 (V13, tratamiento AC 300) con 22,1 Ton ha ${ }^{-1}$ y 13,2 Ton ha ${ }^{-1}$, respectivamente. Además, la V13, obtuvo la menor cantidad de grano por metro cúbico de agua (menor eficiencia en el uso del agua). Sin embargo, fue la que obtuvo mayor producción de grano por biomasa recolectada (mayor IC). También fue la V13 la que menor altura de planta presentó. Los dos valores mayores de producción en grano se dieron en las válvulas V5 y V2, ambas del mismo tratamiento, APD 200. En estas mismas válvulas también se dieron los valores máximos de eficiencia en el uso del agua de todo el ensayo. La V7 (AC 200) fue la que presentó el mayor valor de biomasa aérea.

La producción media del ensayo fue de $14885 \mathrm{~kg} \mathrm{ha}^{-1}$. En promedio se necesitaron $2,34 \mathrm{~m}^{3}$ de agua para producir un kilogramo de grano de maíz. El índice de cosecha medio indica que la producción del grano representa el $52 \%$ de la biomasa recolectada.

Tabla 1. Resultados de la cosecha del maíz. La biomasa aérea, producción del grano al $14 \%$ de humedad y el uso eficiente del agua se muestran para cada subparcela del experimento.

\begin{tabular}{|c|c|c|c|c|c|}
\hline Válvula Tratamiento & $\begin{array}{c}\text { Biomasa aérea } \\
\left(\mathrm{kg} \mathrm{ha}^{-1}\right)\end{array}$ & $\begin{array}{c}\text { Producción de } \\
\text { grano al 14\% } \\
\left(\mathrm{kg} \mathrm{ha}^{-1}\right)\end{array}$ & $\begin{array}{c}\text { Eficiente del uso } \\
\text { del agua }\left(\mathrm{kg} \mathrm{m}^{-3}\right)\end{array}$ & $\begin{array}{c}\text { IC } \\
(-)\end{array}$ \\
\hline 2 & APD 200 & 28941 & 16151 & 2,54 & 0,48 \\
\hline 3 & AC 200 & 28845 & 15234 & 2.40 & 0,48 \\
\hline 4 & AC 300 & 29821 & 15115 & 2,38 & 0,47 \\
\hline 5 & APD 200 & 28224 & 16286 & 2,56 & 0,52 \\
\hline 6 & AC 300 & 24335 & 14093 & 2,22 & 0,54 \\
\hline 7 & AC 200 & 30200 & 15029 & 2,37 & 0,53 \\
\hline 8 & APD 200 & 29547 & 15485 & 2,44 & 0,50 \\
\hline 9 & AC 200 & 25782 & 15242 & 2,40 & 0,54 \\
\hline 10 & AC 200 & 27582 & 14665 & 2,31 & 0,53 \\
\hline
\end{tabular}




\begin{tabular}{|c|c|c|c|c|c|}
\hline 11 & AC 300 & 22248 & 13468 & 2,12 & 0,54 \\
\hline 12 & APD200 & 23285 & 14702 & 2,32 & 0,53 \\
\hline 13 & AC 300 & 22097 & 13148 & 2,07 & 0,55 \\
\hline
\end{tabular}

Las medias por tratamiento de biomasa aérea y producción de grano al $14 \%$ de humedad se muestran en la Figura 6. La biomasa aérea no fue significativamente diferente entre los tres tratamientos analizados. En cuanto a la producción en grano, los análisis estadísticos indican que entre los dos tratamientos de baja presión (AC 200 y APD 200) no hubo diferencias significativas. Sin embargo, sí que hubo diferencias entre los tratamientos de $300 \mathrm{kPa}$ y los de $200 \mathrm{kPa}$, resultando el tratamiento de presión estándar (300 kPa) el que menor producción presentó. Estos resultados son llamativos, pues se esperaba que el tratamiento de presión estándar (AC 300) resultase en mayor o igual producción que los tratamientos de baja presión (AC 200 y APD 200).

Se hizo un análisis pormenorizado de las mediciones del ensayo y se constató que durante la fase de nascencia las subparcelas de las válvulas $\mathrm{V} 10, \mathrm{~V} 11$ y V13, sufrieron un retraso comparadas con el resto. Este retraso afectó al desarrollo de la planta como lo indican las medidas de altura de planta y las de producción en grano. Se intentó aislar este problema realizando de nuevo el análisis estadístico ANOVA descartando las repeticiones en las que se observaron problemas. Los resultados del nuevo análisis indicaron que no había diferencias estadísticamente significativas entre los tratamientos AC 200 y APD 200 (igual que en el análisis anterior); tampoco entre los tratamientos AC 200 y AC 300, pero sí que las había entre los tratamientos AC 300 y APD 200, con menor producción en grano para el tratamiento AC 300 . A pesar de que las diferencias se suavizaban, la producción en grano del tratamiento estándar seguía siendo menor. También se realizaron una serie de comprobaciones sobre el suelo de los diferentes tratamientos, así se comparó el contenido de agua en los primeros $60 \mathrm{~cm}$ del suelo antes de realizar el ensayo agronómico. También se determinaron las diferencias en humedad del suelo por tratamiento tras el ensayo agronómico y en ninguna de las determinaciones se identificaron diferencias significativas. Tampoco se observaron diferencias entre tratamientos en el contenido de nitrógeno en el suelo analizado tras la cosecha. Sin embargo, la revisión del historial de la parcela nos indicó que precisamente en las válvulas donde se localizaban las cuatro repeticiones del tratamiento AC 300, se localizaron los dos tratamientos de menor dosis de riego de un ensayo anterior sobre diferentes dosis de riego en alfalfa. Este hecho nos ha llevado a reorganizar la localización de las repeticiones de los tratamientos y el próximo año de ensayo los tratamientos se volverán a sortear entre las parcelas experimentales. Hemos de decir en nuestra defensa que las producciones medias en grano obtenidas en los tratamientos de baja presión (ADP 200 y AC 200) son comparables con el rendimiento de obtenido en una parcela aledaña en la que se ensaya la misma variedad de maíz regado a $300 \mathrm{kPa}$ (J. Cavero comunicación personal). 


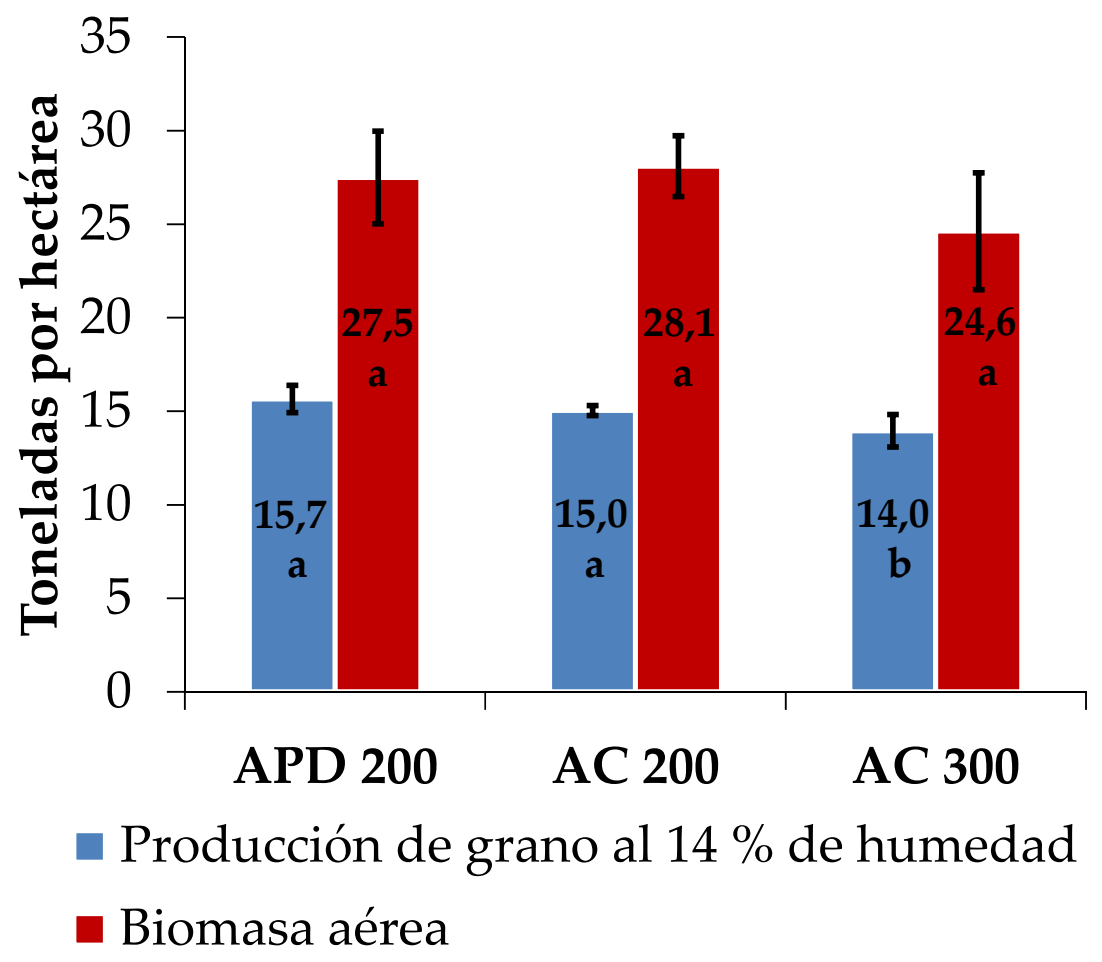

Figura 6. Resultados globales de la cosecha. Se presenta en color distinto la producción de grano al $14 \%$ de humedad y la biomasa aérea obtenida para cada tratamiento del ensayo. Los números seguidos de letras distintas presentan diferencias significativas al $95 \%$ de confiabilidad $(p=0,05)$ para cada variable.

\section{4- Conclusiones y recomendaciones}

Los resultados de los ensayos nos indican que la calidad del riego de las evaluaciones de los riegos realizadas no fue diferente entre los diferentes tratamientos ensayados, APD 200, AC 200 y AC 300. En algunos riegos la uniformidad fue superior para los tratamientos de baja presión y en otros lo contrario. Sin embargo, es necesario analizar la campaña completa de riegos para sacar conclusiones sobre el CU entre tratamientos. En cuanto a la cosecha, los resultados indican una mayor producción de maíz en los tratamientos de $200 \mathrm{kPa}$ respecto a los de presión convencional de $300 \mathrm{kPa}$. En las subparcelas experimentales de la parte final de la parcela (válvulas 10, 11, 12 y 13) se registraron problemas de nascencia que tuvieron su repercusión en la altura de planta, en la biomasa aérea y en la producción de grano. Dado que en esta zona se localizan dos de las repeticiones del tratamiento $A C 300$, es necesario tomar estos datos con precaución y repetir el ensayo una o dos campañas de cultivos más.

\section{5- Agradecimientos}

La ejecución de esta investigación se respalda por una beca del MICINN del Gobierno de España (AGL2013-48728-C2-1-R). En este trabajo fue posible gracias al apoyo del personal del EEAD-CSIC y CITA-DGA: José Cavero, Eva Medina, Pilar Paniagua, Miguel Izquierdo, Miguel Á. Millán, Vicente Villarroya, César Romano, Pablo García y Laura Pérez.

\section{6- Referencias}

Allen, R.G., Pereira, L.S., Raes, D., Smith, M. (1998). Crop evapotranspiration: Guidelines for computing crop water requirements. Irrigation and Drainage Paper 56. FAO, Rome. 
Carrillo-Cobo, M.T., Rodríguez-Díaz, J.A, Camacho-Poyato (2010). The role of energy audits in irrigated areas. The case of 'Fuente Palmera' irrigation district (Spain). Spain. J. Agric. Res, 8 (S2), 152-161.

Cavero, J., Jiménez, L., Puig, M., Faci, J.M., Martínez-Cob, A. (2008). Maize growth and yield under daytime and nighttime solid-set sprinkler irrigation. Agron. J., 100 (6), 5731579.

Christiansen, J.E. (1942). Irrigation by sprinkling. Agric. Exp. Stn. Bull. 670. Univ. of California, Berkeley.

Keller, J. y Bliesner, R.D. (1990). Sprinkle and trickle irrigation. Van Nostrand Reinhold, New York, NY, 86-89.

Kohl, R.A., DeBoer, D.W., Evenson, P.D. (1985). Kinetic Energy of low pressure spray sprinklers. Trans ASAE, 28 (5), 1526-1529.

Lamaddalena, N. y Khila, S. (2012). Energy saving with variable speed pumps in on-demand irrigation systems. Irrig. Sci., 30, 157-166.

Martínez-Cob, A. (2008). Use of thermal units to estimate corn crop coefficients under semiarid climatic conditions. Irrig. Sci., 26(4), 335-345.

Mohammed, D. y Kohl, R.A. (1987). Infiltration response to kinetic energy. Trans. ASAE, 30(1), 108-111.

Moreno, M.A., Córcoles, J.I., Tarjuelo, J.M., Ortega, J.F. (2010). Energy efficiency of pressurised irrigation networks managed on-demand and under a rotation schedule. Biosyst. Eng., 107 (4), 349-363.

Playán, E., Salvador, R., Faci, J.M., Zapata, N., Martínez-Cob, A., Sánchez, I. (2005). Day and night wind drift and evaporation losses in sprinkler solid-sets and moving laterals. Agr. Water Manage., 76 (3), 139-159.

Playán, E., Zapata, N., Faci, J. M., Tolosa, D., Lacueva, J. L., Pelegrín, J., Salvador, R., Sánchez, I., Lafita, A. (2006). Assessing sprinkler irrigation uniformity using a ballistic simulation model. Agr. Water Manage., 84, 89-100.

Seginer, I. (1965). Tangential velocity of sprinkler drop. Trans. ASAE, 90-93.

Tarjuelo, J.M. (2005). El riego por aspersión y su tecnología. S.A. Mundi-Prensa Libros, España. 


\title{
C-09
}

\section{NORMATIVA DE TELECONTROL EN ZONAS REGABLES}

\author{
Madurga del Cura, Cristina $(P)^{1}$, Cervantes Díaz-Toledo, Alfonso ${ }^{2}$, Sánchez de Ribera \\ González, Alejandro ${ }^{3}$, Zazo Salinero, Teresa $^{4}$
}

\author{
${ }^{1}$ Ing. Sup. Agrónomo, CENTER, Camino de la Vega, s/n, 28830 San Fernando de Henares, \\ Madrid, cmadurga@tragsa.es \\ ${ }^{2}$ Ing. Tco. en Informática de Gestión, CENTER, Camino de la Vega, s/n, 28830 San \\ Fernando de Henares, Madrid, acervant@tragsa.es \\ ${ }^{3}$ Ing. Sup. Agrónomo, CENTER, Camino de la Vega, s/n, 28830 San Fernando de Henares, \\ Madrid, asanche4@tragsa.es \\ ${ }^{4}$ Ing. Sup. Agrónomo, CENTER, Camino de la Vega, s/n, 28830 San Fernando de Henares, \\ Madrid, tzazo@tragsa.es
}

\section{Resumen}

Para definir los requisitos mínimos de calidad y funcionalidad que deben tener todos los equipos de telecontrol que se instalan en campo es imprescindible que se genere una normativa en el ámbito de telecontrol. Por este motivo, desde el organismo de normalización AEN/CNT68/SC2 "Riegos" cuya Secretaría ostenta el MAGRAMA - CENTER, se está dando forma, junto con todos los implicados en el sector, a una norma que no excluya a nadie, pero que a su vez sirva para hacer una caracterización inequívoca de estos equipos, facilitando la elección del sistema más adecuado en función de las necesidades de cada regadío y asegurando su correcto funcionamiento. Actualmente se está trabajando tanto a nivel internacional (ISO) como a nivel nacional en la elaboración de dicha norma que contará con cuatro partes: Definiciones, Ensayos de funcionalidad y robustez, Interoperabilidad y Especificaciones.

\section{Abstract}

To define the minimum quality and functional requirements for all field remote control equipment to be installed in an irrigation system it's indispensable to have a Standard for Remote Monitoring and Control Systems. For this reason, the Normalization Organization AEN/CNT68/SC2 "Irrigation", the Secretariat of which is hold by MAGRAMA - CENTER, is preparing, in collaboration with all stakeholders in the business, a Standard which whilst not selective, it is also useful for a unique characterization of the equipment, making easier the selection of the most suitable system taking into account the needs of every irrigation system and guaranteeing its correct performance. Work is currently in progress at both an International level (ISO) and a National level to elaborate the Standard which will have four sections: Definitions, Functionality and Robustness Tests, Interoperability and Specifications.

\section{1- Introducción}

Uno de los objetivos fundamentales de la modernización de los regadíos, además de reducir el consumo de agua y mejorar la eficiencia en su aplicación, ha sido el mejorar la calidad de vida de los agricultores.

Ello ha supuesto la instalación de diferentes sistemas de telecontrol que permiten regar de forma automática y a cualquier hora del día, sin necesidad de actuar de forma 
manual sobre los equipos de riego y facilitando los trabajos de gestión y mantenimiento de los regadíos.

Sin embargo, la ausencia de normativa nacional/internacional que regule este tipo de sistemas, ha hecho que, en ocasiones, no haya sido fácil su puesta en marcha y que incluso, en algunos casos, se haya abandonado su uso.

Por este motivo, desde la Secretaría del Organismo de normalización AEN/CTN68/SC2 "Riegos", que desempeña el MAGRAMA - CENTER, se ha promovido la redacción de una norma nacional-europea-internacional, que establezca los requisitos mínimos que deben cumplir estos equipos en cuanto a funcionalidad e interoperabilidad.

Tanto a nivel nacional como internacional, se está trabajando en la redacción de la norma, que está previsto que tenga 4 partes.

En noviembre de 2007 se publicó la norma UNE-EN 15099-1 "Técnicas de riego. Telecontrol de zonas regables. Parte 1: "Consideraciones generales", vigente en Europa y España.

Actualmente se están elaborando las partes 2 y 3 de la norma, relativas a ensayos e interoperabilidad, y que son las que se describirán en esta ponencia.

La parte 2 de ensayos tiene como objetivo la evaluación de las unidades remotas, de modo que se pueda conocer su funcionalidad y operatividad con todo detalle, facilitando la elección de la más adecuada en función de las necesidades que tenga cada usuario y asegurando, de ese modo, unos requisitos mínimos de calidad.

En cuanto a la parte 3, este documento proporciona las directrices para implementar el modelo estandarizado aplicado al regadío, bajo cualquier plataforma tecnológica. De ese modo, se facilitará la comunicación entre los sistemas de control y gestión, independientemente del fabricante, aumentando las posibilidades de modificación, mejora o ampliación de las instalaciones, tanto existentes como futuras.

La última parte de la norma, relativa a especificaciones técnicas, se desarrollará en función del avance de las partes anteriormente citadas.

\section{2- Materiales y Métodos}

EI CENTER lleva a cabo una importante labor en materia de normalización de materiales y equipos de riego. Tal y como se ha dicho anteriormente, a nivel nacional, desempeña la Secretaría del AEN/CTN68/SC2 y, a nivel internacional, coordina diversos grupos de trabajo, entre los que cabe destacar el grupo de trabajo de telecontrol.

Esto ha permitido transmitir la necesidad de redactar una norma específica de telecontrol, norma en la que se está trabajando activamente en el CENTER, apoyándose de manera importante en el Laboratorio.

En los siguientes apartados se va a describir qué trabajos se han llevado a cabo para desarrollar la parte 2 y la parte 3 de este proyecto de norma.

\section{1- Parte 2: Funcionalidad y robustez} CENTER.

En el desarrollo de esta parte ha jugado un papel fundamental el Laboratorio del 
El Laboratorio Central para Ensayo de Materiales y Equipos de Riego, ubicado en el Centro Nacional de Tecnología de Regadíos (CENTER), órgano dependiente del Ministerio de Agricultura, Alimentación y Medio Ambiente (MAGRAMA), dispone de un laboratorio específico para sistemas de telecontrol, así como un banco de ensayo de electroválvulas que sirven de apoyo al desarrollo de estas normas.

Para la realización de los ensayos se dispone de un conjunto de equipos calibrados que permiten asegurar la exactitud y fiabilidad en los resultados.

De esta manera algunos de los equipos más representativos para la realización de las pruebas son:

- Osciloscopio: equipo para poder medir y representar gráficamente diferentes magnitudes escalares como puede ser la tensión. De esta manera, facilita algunas de las pruebas que se realizan como puede ser lectura de pulsos y carga del condensador en el accionamiento de una electroválvula, entre otras.

- Generador de pulsos: se emplea como verificación de las entradas digitales de los equipos. Permite generar pulsos con diferentes anchos, de manera síncrona y asíncronamente.

- Fuente de alimentación: se alimentan los equipos a diferentes tensiones para verificar hasta qué valores sigue operativa.

- Simuladores de 100 metros de cable: equipo que simula la impedancia de 100 metros de cable para asegurarse que el equipo de telecontrol es capaz de accionar electroválvulas y leer contadores a grandes distancias.

- Calibrador de lazo: Genera señales de 4 a $20 \mathrm{~mA}$ para que conectado a las entradas analógicas del terminal se garantice su correcta medida.

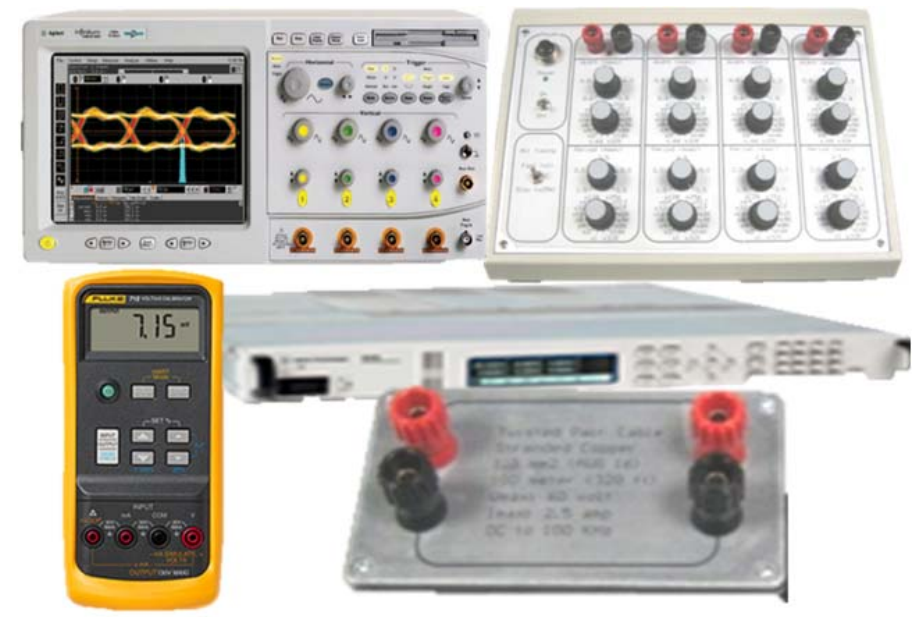

Figura 1: Osciloscopio, calibrador de lazo, generador de pulsos, fuente de alimentación y simulador de 100 metros de cable.

- Cámara climática: habitáculo donde se introducen los equipos remotos y someten a diferentes condiciones de temperatura y humedad. Así se verifica la correcta estanqueidad y funcionamiento de las unidades remotas con condiciones ambientales adversas.

- Banco de electroválvulas: circuito cerrado de agua con diferentes tipos de solenoides, de dos y tres hilos, y con diferentes voltajes de disparo. Cada 
electroválvula tiene un contador digital asociado. Con el equipo remoto conectado, se realizan aperturas y cierres verificando que el terminal remoto comande las órdenes y realice el conteo de los pulsos generados correctamente.

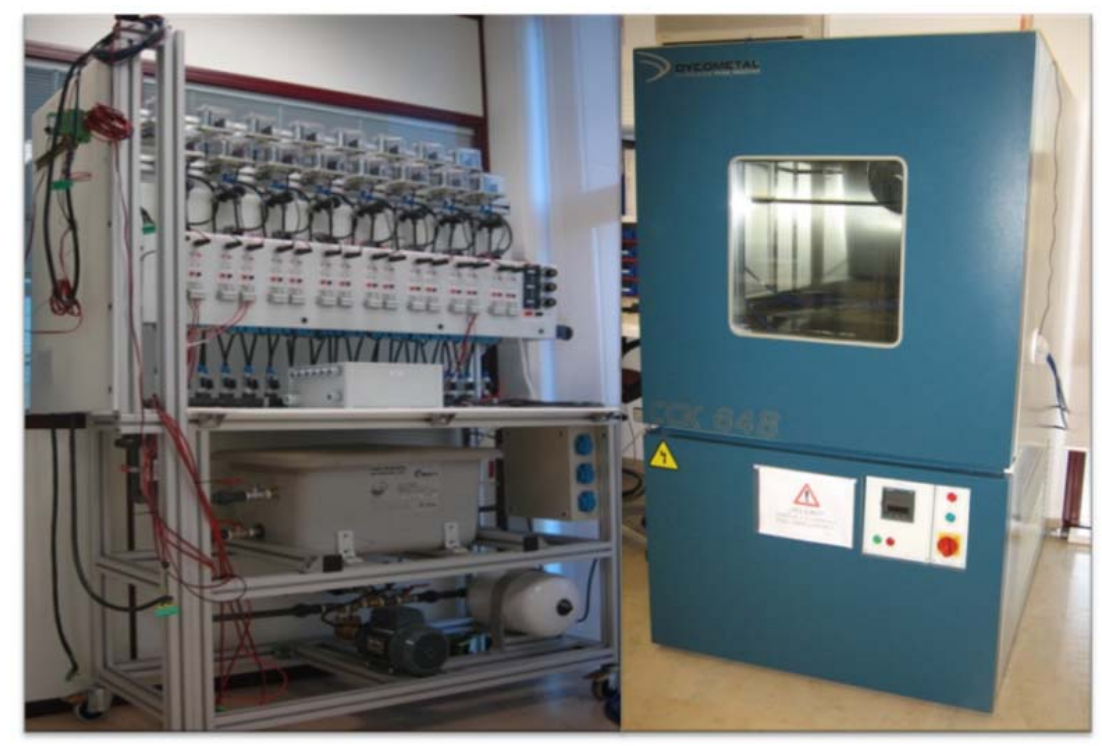

Figura 2: Banco de electroválvulas y cámara climática

\section{2- Parte 3: Interoperabilidad}

El desarrollo de esta parte de la norma se ha hecho, fundamentalmente, englobado dentro de un proyecto de I+D+i de la empresa TRAGSA, contando con la colaboración del personal del CENTER.

Aunque en este documento no se va a entrar en mucho detalle, puesto que se describe en la ponencia "Resultados prácticos de la aplicación de estándares industriales a la interoperabilidad en el regadío: Proyecto MEGA", sí que se van a definir los principales trabajos llevados a cabo hasta definir el primer borrador presentado en ISO en la pasada reunión celebrada en junio de 2015 en Madrid.

El objetivo fundamental, en este caso, es conseguir no depender de un único sistema de telecontrol sino que se permita la interoperabilidad entre diferentes sistemas, estandarizando el lenguaje y la arquitectura de los mismos.

Para alcanzar la interoperabilidad entre sistemas de control y de explotación de infraestructuras hidráulicas se definen los niveles y componentes identificados en la Figura 3. 


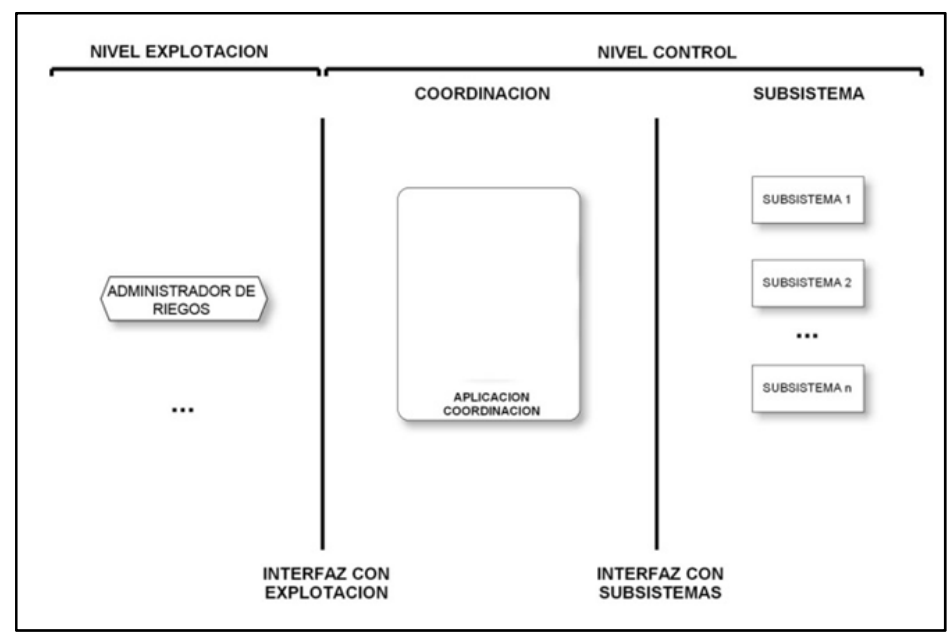

Figura 3: Niveles y componentes de una arquitectura interoperable sistemas.

Esto va a facilitar tanto el mantenimiento como el desarrollo continuo de estos

La nueva arquitectura pretende alcanzar una diferenciación clara dos partes de los sistemas muy diferentes, pero dependientes entre sí:

- Nivel de gestión/explotación, orientado a la toma de decisiones.

- Nivel de control, que incluye la transmisión y adquisición de datos, así como la ejecución de procesos.

Inicialmente se ha hecho un importante trabajo en la definición de las pruebas desde el punto de vista teórico y preparando todos los equipos necesarios para luego ejecutarlas en un banco de ensayo. El trabajo de programación es esencial en estas pruebas y ha llevado la mayor parte del tiempo, al igual que la adaptación de los equipos al sistema interoperable.

Las instalaciones de ensayo deben disponer de dos partes claramente diferenciadas pero ambas necesarias:

- Infraestructura informática para la verificación de interfaces. Las instalaciones deben disponer de testers para todos los interfaces definidos en el estándar. Esos testers emplearán los protocolos de comunicación definidos en los anexos descriptivos de los interfaces.

- Infraestructura hidráulica y sensórica para verificación de funcionalidades. Las instalaciones de ensayo deben disponer de todas las entidades hidráulicas modeladas en la norma. 


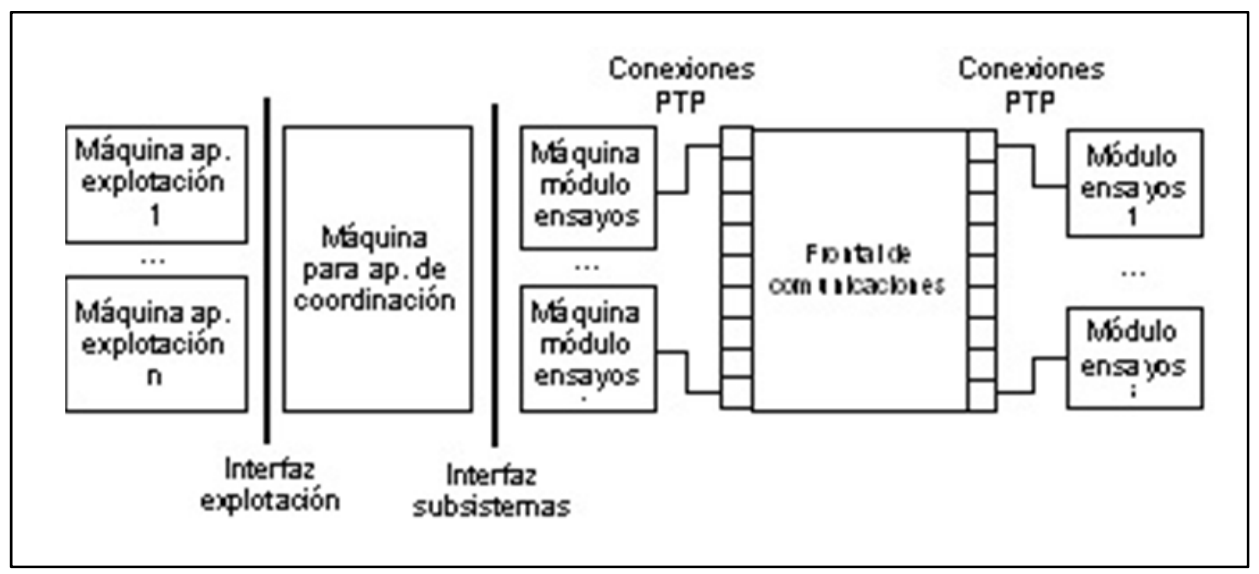

Figura 4: Componentes de la infraestructura de comunicaciones

En cuanto a la infraestructura hidráulica y sensórica, a día de hoy, sólo se ha implementado la unidad que se conoce como hidrante simple (HYS)

El módulo de pruebas del hidrante simple dispondrá de los siguientes dispositivos para verificar sus funcionalidades básicas:

- Totalizador de volumen;

- Elemento de corte.

Además, integrará otros dispositivos con dos finalidades diferenciadas:

- Dispositivos para comprobación de funcionalidades extendidas: transmisores de presión y otros sensores de parámetros climáticos (humedad relativa, temperatura, radiación solar, viento y pluviometría). El transmisor de presión convertirá la presión preferiblemente a una señal normalizada $4 \ldots 20 \mathrm{~mA}$. Los sensores climáticos que puedan ser compatibles con un subsistema que controle una entidad tipo HYS, serán también de señal normalizada $4 \ldots 20 \mathrm{~mA}$. Estos elementos se conectarán a las entradas analógicas disponibles en el elemento de control.

- Dispositivos para la ratificación del correcto funcionamiento de la entidad hidráulica: detector de paso de agua (confirmación de seccionamiento abierto/cerrado) y detector de posición del elemento de corte (confirmación de seccionamiento abierto/cerrado). Ambos elementos serán llevados a una entrada digital del elemento de control.

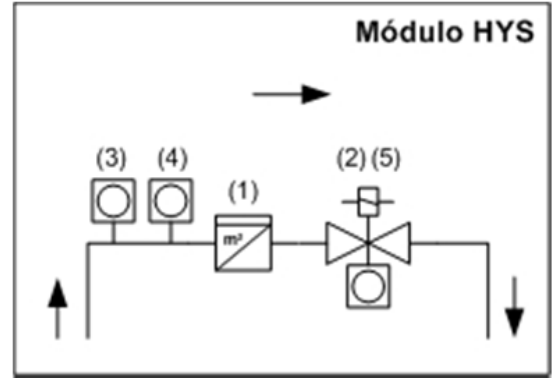

Figura 5: Diagrama de componentes del módulo HYS

Los componentes del módulo identificados en la Figura 5 son:

- (1) Totalizador de volumen 
- (2) Elemento de corte controlado por subsistema

- (3) Medidor de presión

- (4) Detector de paso de agua

- (5) Detector de posición de elemento de corte

La infraestructura hidráulica se ha implementado en Aula Dei, desarrollando un banco de ensayo que replica un sistema completo, desde la acometida hasta el hidrante, con el fin de poder extender la interoperabilidad a cualquier infraestructura típica del regadío.

En este año 2016 se han iniciado los ensayos en campo en el banco de pruebas de Aula Dei estando todavía en una primera fase de obtención de resultados.

En la figura 6 puede verse dicha instalación.

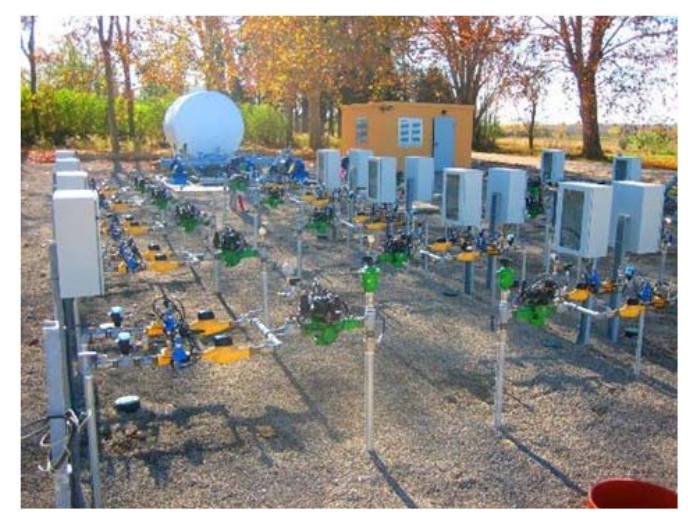

Figura 6: Banco de ensayo de Aula Dei

\section{3- Resultados y discusión}

Todo el trabajo y el esfuerzo dedicado en estas pruebas tenían como fin último la preparación de unos borradores que sirvieran como base a la norma de telecontrol.

Esta ardua labor no se ha concluido con la presentación en ISO de estos primeros documentos, sino que se sigue trabajando teniendo en cuenta los comentarios recibidos por parte de los expertos nacionales e internacionales, con el objetivo de publicar una norma útil para todo el sector.

A continuación se van a describir los ensayos que se reflejan en dichos documentos.

\section{1- Parte 2: Funcionalidad y robustez}

A lo largo de los últimos 10 años se han llevado a cabo numerosas pruebas a decenas de unidades remotas que han permitido ir definiendo los protocolos de ensayo para comprobar su funcionamiento, así como establecer los requisitos mínimos de calidad que deben exigirse.

Los ensayos se han dividido en funcionalidad, donde se verifica el correcto funcionamiento de los equipos, y robustez, donde se somete al terminal remoto a pruebas extremas para verificar los valores límite de las remotas. 
A modo de resumen, todos los ensayos se pueden dividir en seis grandes bloques:

1. Pruebas de alimentación:

Dentro de los ensayos de alimentación destacan tres:

- Alimentación a diferentes tensiones: Con estas pruebas se comprueba qué sucede con las remotas cuando están sometidas a diferentes tensiones de alimentación.

- Pérdidas de alimentación: La pérdida brusca de alimentación de la remota no debe suponer una pérdida de valores críticos, como son los programas de riego y los valores de contadores. Restableciendo la alimentación la remota debe seguir funcionando con normalidad, continuando la ejecución de los programas de riego que tuviera.

Se programa un riego y se procede a interrumpir la alimentación en los instantes reflejados en la Figura 7, comprobando posteriormente la respuesta de la remota.

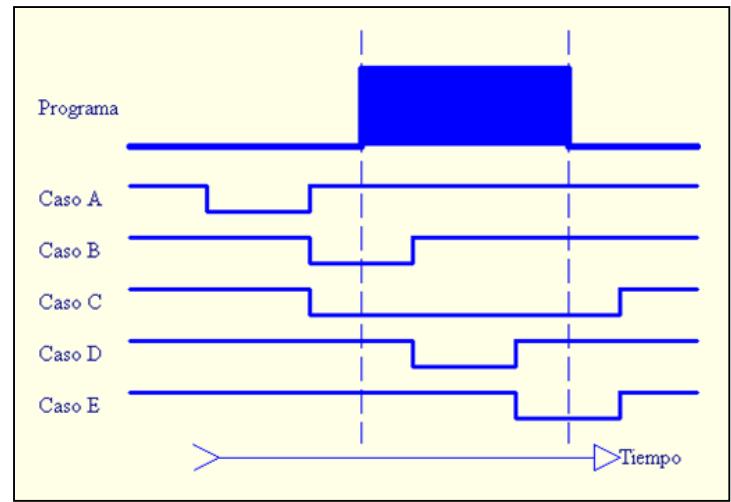

Figura 7: Diferentes casos de pérdida de alimentación para el ensayo de programaciones

2. Inversión de polaridad:

Si la remota soporta una inversión accidental de la polaridad, se invierte la polaridad en los cables que conectan la fuente de energía con la remota. Se mantiene durante 1 minuto y se comprueba que, al restablecerse la alimentación nominal, la remota sigue operativa.

3. Consumos.

Las pruebas de consumos suponen un punto importante en telecontrol. La razón fundamental es que, al ser equipos instalados en campo y no disponer de abastecimiento eléctrico, se requiere el uso de baterías recargables o de pilas. Para que la duración en tiempo de vida de los equipos sea el máximo posible, es necesario que los terminales remotos tengan unos consumos adecuados para poder alargar la vida útil de las baterías. Por este motivo es importante verificar los consumos que se producen cuando se realizan actuaciones y cierres de electroválvulas, lecturas de contador, lecturas de entradas analógicas y más importante si cabe, cuando se producen las comunicaciones.

4. Estudio de las condiciones de trabajo. 
La remota debe estar preparada para trabajar a la intemperie, en una arqueta en el campo, en condiciones extremas de humedad y temperatura. Esto exige que tenga, al menos, un grado de protección IP65 una vez conectados cables de entradas y salidas en las conexiones de la remota. Además, debe ser capaz de llevar a cabo todas sus funciones, en todo el rango de temperaturas especificado por el fabricante.

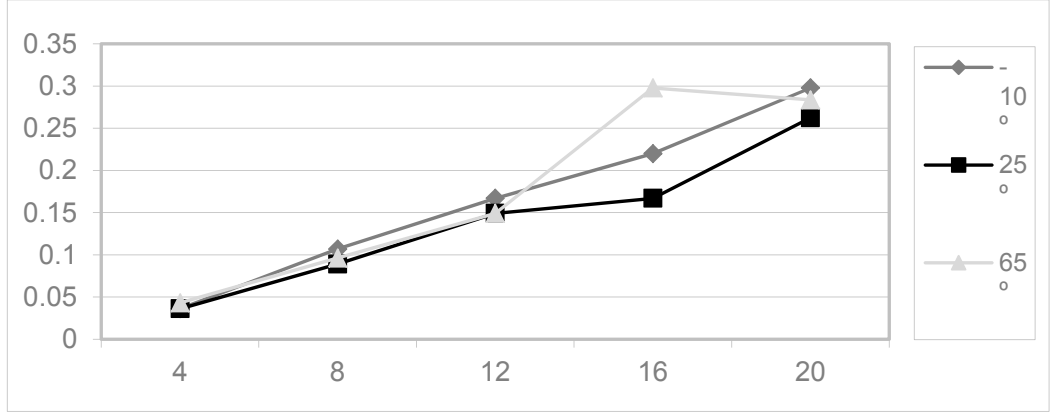

Figura 8: Desviación de la entrada analógica con respecto a la temperatura

Se verificará la capacidad de la remota de accionar electroválvulas, y la fiabilidad en la lectura de contadores y la estabilidad en las medidas de las entradas analógicas.

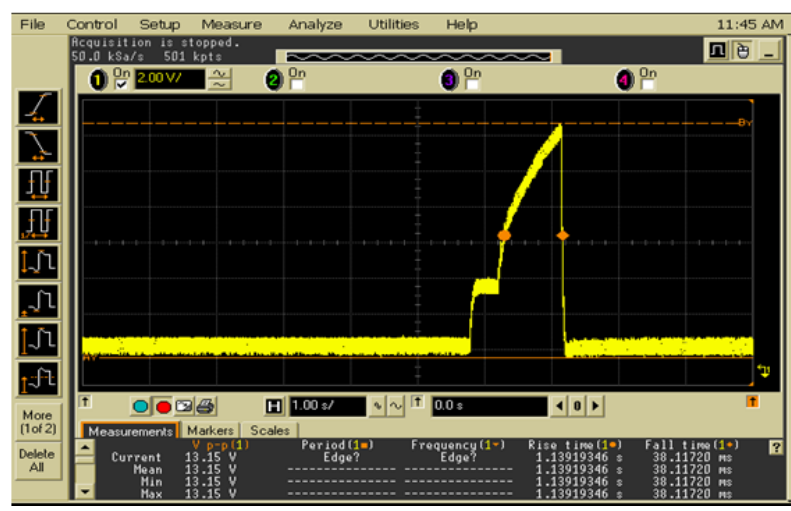

Figura 9: Gráfica del proceso de disparo de una salida digital de la unidad remota

5. Protección ante situaciones anómalas.

Supone un punto importante conocer al detalle el funcionamiento de los equipos remotos. Hay que tener en cuenta qué sucede si se producen, por ejemplo en el momento de la instalación de los equipos, errores accidentales de cableado, como el intercambio de los cables entre las entradas y salidas.

Es importante, además, conocer qué sucede si se cortocircuitan las salidas digitales o las entradas analógicas.

Para que el resultado de la prueba sea positivo es necesario que la remota, una vez realizados los cortocircuitos en las entradas/salidas, siga funcionando correctamente sin verse afectada.

El módem/radio supone otro factor de riesgo en los terminales remotos. Es importante que los equipos no se vean afectados si se produce un cortocircuito o si se queda en circuito abierto.

6. Comportamiento a largo plazo 
Con esta prueba se pretende probar la fiabilidad de la remota tras un uso intensivo y en los límites máximos admisibles especificados por el fabricante.

Las pruebas de fiabilidad se realizan a temperatura ambiente con una remota, alimentada desde una fuente de alimentación regulable y utilizando el banco de pruebas de electroválvulas/solenoides. La prueba realiza 18.250 ciclos de aperturas y cierres de solenoides, pensando en un tiempo de vida del equipo de 50 años, realizando 2 actuaciones diarias.

Posteriormente, se procede a leer el valor del contador almacenado por la remota y se verifica que son los mismos que aparecen en el contador digital del banco de electroválvulas. Se espera que se produzcan todos los disparos comandados a los solenoides y la lectura de pulsos de contador, con un error inferior al 0,05\%, para comprobar la fiabilidad del sistema.

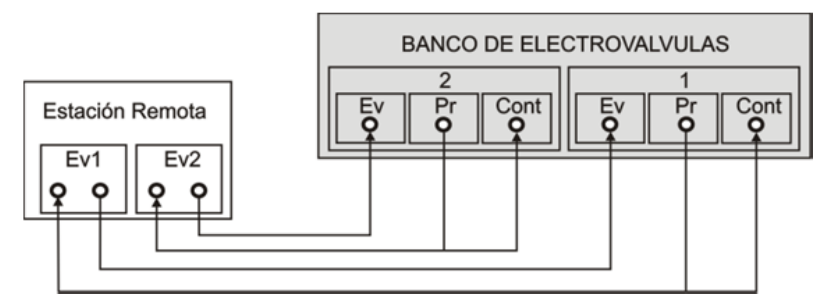

Figura 10: Conexionado de Estación Remota a Banco de EV para Prueba de comportamiento a largo plazo.

\section{2- Parte 3: Interoperabilidad}

Los ensayos comprenden un conjunto de pruebas informáticas e hidráulicas a las que se someten los subsistemas, las aplicaciones de coordinación y las aplicaciones de explotación. Dichos ensayos se dividen en dos fases:

- Fase 1. Pruebas informáticas de verificación de interfaz. Se verificará que los mensajes (tanto peticiones como respuestas) que intercambia el elemento objeto de los ensayos con el resto de componentes de la arquitectura respetan el estándar.

- Fase 2. Ensayos de campo para verificación de funcionalidades. Una vez superada la fase anterior, se verificará que el elemento objeto de los ensayos ejecuta correctamente aquellas funcionalidades asociadas a la entidad hidráulica que éste puede explotar o controlar.

Se entenderá como adaptado al estándar aquel producto que supere ambas fases, verificándose que es capaz de realizar todas las funciones exigibles para el control o explotación de la/s entidad/es hidráulica/s definidas en el estándar.

El primer borrador de los ensayos se presentará en la reunión del ISO TC23/SC18 que se celebrará a mediados de mayo en Montpellier.

\section{4- Conclusiones}

Las normas tienen como uno de sus objetivos fundamentales garantizar la calidad de los productos y sistemas. Por ello las normas deben definir una serie de criterios técnicos que van a servir para caracterizar un producto y establecer sus requisitos mínimos de 
calidad. De esa manera, se facilita también la comercialización y la certificación, si fuese necesario.

Eso es lo que se ha pretendido a la hora de redactar la norma de telecontrol, que los equipos que forman parte de estos sistemas, estén regulados de alguna forma y, así, poder asegurar un correcto funcionamiento en las redes de riego.

Hay que destacar, además, el gran interés que ha despertado este tema a nivel internacional, ya que países tan importantes en el regadío como Israel, USA o India que siempre han ido un paso por detrás de España en materia de telecontrol, están trabajando muy intensamente en el desarrollo de estos sistemas con el objetivo de aplicar las más avanzadas tecnologías al regadío.

Como se ha comentado, este es un trabajo que está muy vivo y es importante contar con la participación de todos los implicados en el sector, de forma que se consiga una norma útil para todos. 


\title{
C-10
}

\section{COMPORTAMIENTO DE 13 MODELOS DE CINTA DE RIEGO EN CONDICIONES DE INVERNADERO CON AGUA REGENERADA}

\author{
Baeza Cano, R. (1), Zapata Sierra, A.J. (2), Alonso López, F. (1), Fernández Guerrero, A.J.
}

(2), Contreras París, J.I. (1)

\author{
${ }^{1}$ Instituto de Investigación y Formación Agraria y Pesquera de Andalucía (IFAPA), Centro La \\ Mojonera, Camino San Nicolás, n¹, 04745 La Mojonera, Almería. \\ rafaelj.baeza@juntadeandalucia.es \\ ${ }^{2}$ Universidad de Almería, Ctra. De Sacramento s/n, 04120 Almería. \\ ajzapata@ual.es
}

\section{Resumen}

El objetivo de este trabajo ha sido seleccionar modelos de cinta de riego con una mejor adaptación a las condiciones de invernadero y riego con aguas regeneradas. Se ha evaluado el comportamiento de 13 modelos comerciales de cintas de riego seleccionados de entre los más utilizados en los cultivos hortícolas al aire libre, y aquellos que, las empresas instaladoras y fabricantes consideren que, por sus características, pueden tener un buen comportamiento con este tipo de aguas.

En la evaluación de campo todos los emisores han presentado valores de uniformidad elevados al comienzo de la campaña de riego. Cinco de las cintas se clasifican como excelentes y el resto como buenas. Al finalizar las 114 horas de trabajo decae sustancialmente la uniformidad. El comportamiento tras la finalización de la primera campaña de riego se puede considerar equiparable al obtenido en un estudio previo con una selección de 20 emisores en ramal convencional y este tipo de aguas.

Se puede concluir que las cintas de riego localizado pueden ser una alternativa a los ramales de riego convencionales cuando se riega con aguas residuales urbanas regeneradas, siempre que se elija un material de una mínima calidad y el ratio de sustitución garantice una uniformidad alta.

\section{1- Introducción y Objetivos}

La situación de déficit hídrico en Andalucía es especialmente crítica en las zonas costeras, especialmente en las Mediterráneas. En la provincia de Almería, donde existe la mayor concentración de cultivos hortícolas bajo invernadero, el déficit estructural es superior a los $100 \mathrm{Hm}^{3}$ (Junta de Andalucía, 2014). La situación de déficit ha obligado a la búsqueda y empleo de nuevas fuentes de agua, principalmente desaladas y residuales urbanas regeneradas (Agencia Andaluza del Agua, 2009; Baeza et al. 2015). El empleo de estas últimas no está exento de problemas, en concreto suelen ser frecuentes los fenómenos de obturación de emisores de riego localizado como consecuencia, principalmente, de la elevada carga microbiológica presente en estas aguas. EI IFAPA ha acometido diversos trabajos previos en los que se ha podido corroborar la problemática en emisores de goteo en ramal de riego convencional, en las que se producen rápidos descensos en la uniformidad de distribución de riego (Baeza et al. 2010, 2012, 2015). Como alternativa se plantea el empleo de cintas de riego de bajo coste que se puedan sustituir antes de perder la uniformidad. El objetivo de este trabajo ha sido seleccionar modelos de cinta de riego con una mejor adaptación a las condiciones de invernadero y riego con aguas regeneradas. Se ha evaluado el comportamiento de 13 modelos comerciales de cintas de riego seleccionados 
de entre los más utilizados en los cultivos hortícolas al aire libre, y aquellos que, las empresas instaladoras y fabricantes consideren que, por sus características, pueden tener un buen comportamiento con este tipo de aguas.

\section{2- Material y Métodos}

En la tabla 1 se muestran las características técnicas de los 13 modelos evaluados. Se han elegido los modelos de cinta de riego, seleccionando los mas empleados en los cultivos de fresa de Huelva y en los cultivos hortícolas de hoja de Andalucía Oriental (en ambas zonas es común el empleo de cintas de riego). Se ha completado la colección para el ensayo consultando a 5 empresas fabricantes que han recomendado varios modelos que consideran, que por sus características, pueden tener un buen comportamiento con este tipo de aguas.

Tabla 1. Modelos de cinta evaluados

\begin{tabular}{|c|c|c|c|c|c|}
\hline $\mathbf{N}^{\circ}$ & Modelo & Fabricante & $\begin{array}{l}\text { Caudal*/Separación } \\
\text { emisores }\left(\mathrm{I} \mathrm{h}^{-1} / \mathrm{cm}\right)\end{array}$ & $\begin{array}{l}\text { Tipología } \\
\text { emisor }\end{array}$ & $\begin{array}{l}\text { Compensación } \\
\text { Caudal }\end{array}$ \\
\hline 1 & $\begin{array}{l}\text { URA-T } \\
\text { Pathfinder }\end{array}$ & CHAMSA & $1,24 / 20$ & Doble pared & NO \\
\hline 2 & $\begin{array}{l}\text { Streamline } \\
16060\end{array}$ & NETAFIN & $0,78 / 20$ & Integrado pastilla & NO \\
\hline 3 & T-Tape & RIVULIS & $1,42 / 20$ & Doble pared & NO \\
\hline 4 & Azudline & AZUD & $1,45 / 30$ & Integrado pastilla & NO \\
\hline 5 & Azudline & AZUD & $2,20 / 20$ & Integrado pastilla & NO \\
\hline 6 & Tal-Drip & $\begin{array}{l}\text { NAAN DAN } \\
\text { JAIN }\end{array}$ & $1,60 / 30$ & Integrado pastilla & NO \\
\hline 7 & Top-Drip & $\begin{array}{l}\text { NAAN DAN } \\
\text { JAIN }\end{array}$ & $1,74 / 40$ & Integrado pastilla & SI \\
\hline 8 & $\begin{array}{l}\text { Streamline } \\
16080\end{array}$ & NETAFIN & $0,69 / 20$ & Integrado pastilla & NO \\
\hline 9 & Rodrip & RIVULIS & $1,67 / 20$ & Doble pared & NO \\
\hline 10 & $\begin{array}{l}\text { URA-T } \\
\text { Pathfinder }\end{array}$ & CHAMSA & $1,25 / 20$ & Doble pared & NO \\
\hline 11 & $\begin{array}{l}\text { Streamline } \\
16080\end{array}$ & NETAFIN & $1,05 / 30$ & Integrado pastilla & NO \\
\hline 12 & Lin One & CAUDAL & $1 / 20$ & Integrado pastilla & NO \\
\hline 13 & P1/Ultra & IRRITEC & $1,1 / 30$ & Integrado pastilla & NO \\
\hline
\end{tabular}

En un banco de ensayo homologado de emisores de riego se ha determinado el coeficiente de variación (ecuación 1) y el rendimiento hidráulico del emisor de cada una de las cintas mediante la función empírica que relaciona el caudal emitido por el emisor en función de la presión de funcionamiento (curva de gasto del emisor) (Keller y Karmeli, 1974) (ecuación 2):

$$
\mathrm{CV}=\mathrm{S} / \mathrm{qm}
$$

(Ecuación 1) 
Donde:

S es la desviación típica respecto a la media de los caudales muestreados. qm es el valor medio de los caudales muestreados.

$\mathbf{Q}=\mathbf{k} \mathbf{P}^{\mathbf{x}}$ (Ecuación 2)

Donde:

Q es el caudal de descarga del emisor $\left(\mathrm{L} \mathrm{h}^{-1}\right)$

$\mathbf{k}$ es la constante del emisor

$\mathbf{P}$ presión de trabajo (bar)

$\mathbf{x}$ es el exponente de descarga

El banco de ensayo utilizado se diseñó según la norma UNE 68-075-86 (figura 1), evaluando veinticinco emisores por modelo.

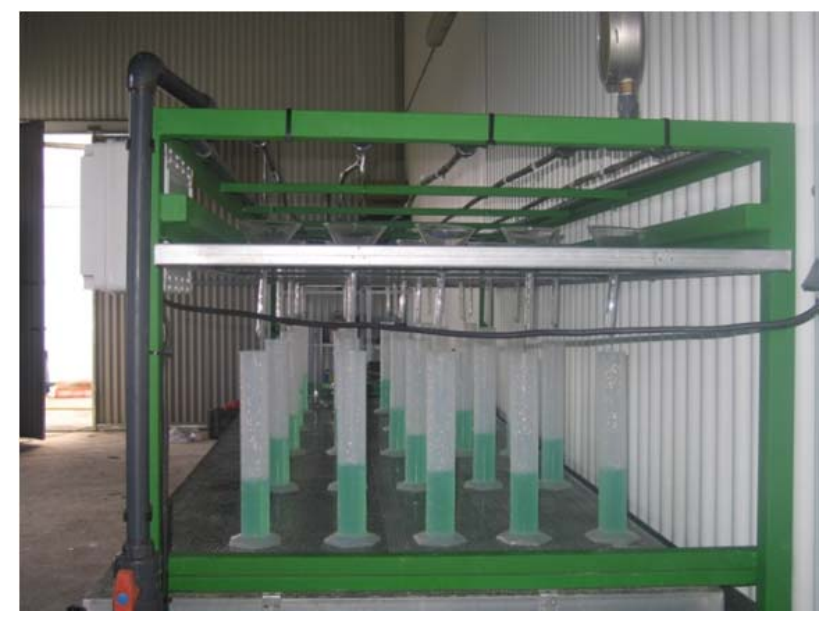

Figura 1. Banco de ensayo diseñado según norma UNE 68-075-86

A continuación en un invernadero experimental multitúnel de $1.200 \mathrm{~m}^{2}$ situado en las instalaciones que posee el Centro IFAPA La Mojonera en La Cañada (Almería) y equipado con control automático de clima y autómata de riego se ha instalado el banco de pruebas en campo de cintas de riego. Haciendo uso del controlador automático de clima se han mantenido unos parámetros climáticos equivalentes a los medidos en un invernadero convencional cultivado con tomate.

Se ha establecido un dispositivo experimental de bloques completos al azar, con tres repeticiones, donde la unidad experimental básica ha sido el lateral de riego (figura 2). Las cintas han sido sometidas a 228 pulsos de riego de 30 minutos de duración y $0,1 \mathrm{MPa}$ de presión. Para cintas con un caudal de $5 \mathrm{I} \mathrm{m}^{-1}$, instaladas a un marco de $1 \mathrm{~m}$, el volumen aplicado equivaldría a $570 \mathrm{I} \mathrm{m}^{-2}$, que corresponde de manera aproximada al consumo de un ciclo largo de tomate (Fernández et al. 2001). 


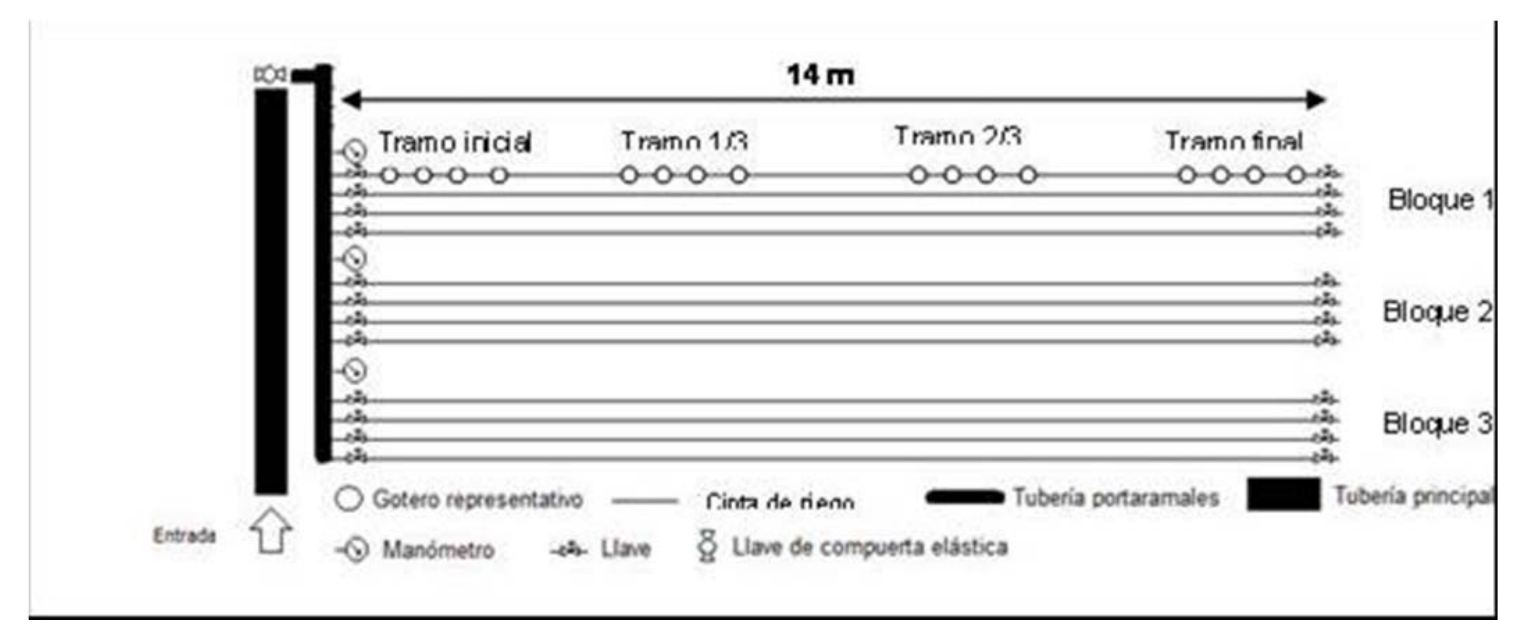

Figura 2. Diseño experimental del ensayo

Se ha empleado agua regenerada procedente de la Comunidad de Regantes Las Cuatro Vegas, concesionaria de las aguas residuales depuradas de la ciudad de Almería.

Se han realizado una serie de evaluaciones periódicas de cada unidad de riego, cuantificando el volumen de agua desalojado por cada emisor, y posteriormente se ha calculado el coeficiente de uniformidad del caudal (CUC) siguiendo el método clásico propuesto por Merrian y Keller (1978) (ecuación 3).

$$
\operatorname{CUC}=\left(\mathrm{q}_{25 \%} / \mathrm{q}_{\mathrm{m}}\right) \times 100
$$

(Ecuación 3)

Donde:

$\mathbf{q}_{25 \%}=$ caudal medio del $25 \%$ de emisores con menor descarga $\left(L h^{-1}\right)$.

$\mathbf{q}_{\mathrm{m}}=$ caudal medio de todos los emisores evaluados $\left(\mathrm{L} \mathrm{h}^{-1}\right)$.

Los valores de CUC fueron clasificados según by Merriam y Keller (1978) (Tabla 2).

Tabla 2. Clasificación del coeficiente de uniformidad de caudal (CUC) por Merriam y Keller (1978).

\begin{tabular}{|c|c|}
\hline CUC & Clasificación \\
\hline$>95 \%$ & Excelente \\
\hline $85 \%-95 \%$ & Bueno \\
\hline $80 \%-85 \%$ & Aceptable \\
\hline $70 \%-80 \%$ & Pobre \\
\hline$<70 \%$ & Inaceptable \\
\hline
\end{tabular}

\section{3- Resultados y Conclusiones}

Por lo que respecta al coeficiente de variación de fabricación, en diez de los modelos el material recibido es de categoría $A(C V<5)$. Dos modelos se clasifican como categoría $B$ $(5<\mathrm{CV}<10)$ y solo un modelo tiene un coeficiente de variación fuera de categoría (tabla 3$)$. El exponente de descarga de la fórmula de gasto oscila en los emisores turbulentos de laberinto entre 0,46 y 0,53 , en un rango similar a los emisores instalados en ramal convencional (tabla 3). 
Tabla 3. Resultados obtenidos en banco de ensayo

\begin{tabular}{|c|c|c|c|}
\hline Modelo & Fórmula de gasto * & CV & Categoría \\
\hline 1 & $\mathrm{Q}=1,24^{*} \mathrm{H}^{0,49}$ & 4,07 & $\mathrm{~A}$ \\
\hline 2 & $\mathrm{Q}=0,78^{*} \mathrm{H}^{0,47}$ & 2,85 & $\mathrm{~A}$ \\
\hline 3 & $\mathrm{Q}=1,42^{*} \mathrm{H}^{0,51}$ & 1,96 & $\mathrm{~A}$ \\
\hline 4 & $\mathrm{Q}=1,45^{*} \mathrm{H}^{0,51}$ & 2,01 & $\mathrm{~A}$ \\
\hline 5 & $\mathrm{Q}=2,20^{*} \mathrm{H}^{0,53}$ & 1,70 & $\mathrm{~A}$ \\
\hline 6 & $\mathrm{Q}=1,60^{*} \mathrm{H}^{0,46}$ & 1,71 & $\mathrm{~A}$ \\
\hline 7 & $\mathrm{Q}=1,74^{*} \mathrm{H}^{-0,06}$ & 2,02 & $\mathrm{~A}$ \\
\hline 8 & $\mathrm{Q}=0,69^{*} \mathrm{H}^{0,48}$ & 2,56 & $\mathrm{~A}$ \\
\hline 9 & $\mathrm{Q}=1,67^{*} \mathrm{H}^{0,92}$ & 10,59 & $\mathrm{f} . \mathrm{C}$. \\
\hline 10 & $\mathrm{Q}=1,27^{*} \mathrm{H}^{0,51}$ & 5,16 & $\mathrm{~B}$ \\
\hline 10 & $\mathrm{Q}=0,96^{*} \mathrm{H}^{0,48}$ & 5,21 & $\mathrm{~A}$ \\
\hline 11 & $\mathrm{Q}=0,85^{*} \mathrm{H}^{0,48}$ & 2,04 & $\mathrm{~A}$ \\
\hline 12 & $\mathrm{Q}=1,15^{*} \mathrm{H}^{0,46}$ & 2,04 & \\
\hline
\end{tabular}

En la evaluación de campo todos los emisores han presentado valores de uniformidad elevados al comienzo de la campaña de riego. Cinco de las cintas se clasifican como excelentes y el resto como buenas. Al finalizar las 114 horas de trabajo decae sustancialmente la uniformidad. Sólo una de las cintas presenta una calificación de excelente y 9 calificación de bueno. El resto quedan en el rango de aceptable ( 2 modelos) y pobre ( 1 modelo) (tabla 4, figuras 3 y 4). La calificación de aceptable $(85>C U C>80)$ no se puede considerar apropiada cuando se riegan cultivos hortícolas de alto valor, por lo que sería recomendable la sustitución de las cintas cuando se alcancen dichos valores de uniformidad.

Tabla 4. Cálculo de los la media de las 3 repeticiones, de los coeficientes de uniformidad de caudal (CUC) inicial y tras $114 \mathrm{~h}$ de trabajo

\begin{tabular}{|l|c|c|c|c|}
\hline MODELO & $\begin{array}{c}\text { CUC } \\
\text { INICIAL }\end{array}$ & Calificación & $\begin{array}{c}\text { CUC } \\
\mathbf{1 1 4} \text { Horas }\end{array}$ & Calificación \\
\hline MODELO 1 & 92,68 & Bueno & 83,6 & Aceptable \\
\hline MODELO 2 & 90,68 & Bueno & 89,7 & Bueno \\
\hline MODELO 3 & 95,57 & Excelente & 91,4 & Bueno \\
\hline MODELO 4 & 96,33 & Excelente & 84,6 & Aceptable \\
\hline MODELO 5 & 96,72 & Excelente & 93,2 & Bueno \\
\hline MODELO 6 & 96,15 & Excelente & 95,8 & Excelente \\
\hline MODELO 7 & 96,39 & Excelente & 94,7 & Bueno \\
\hline MODELO 8 & 94,59 & Bueno & 87,5 & Bueno \\
\hline MODELO 9 & 94,12 & Bueno & 72,3 & Pobre \\
\hline MODELO 10 & 93,31 & Bueno & 87,8 & Bueno \\
\hline MODELO 11 & 91,23 & Bueno & 87,3 & Bueno \\
\hline MODELO 12 & 90,01 & Bueno & 94,5 & Bueno \\
\hline MODELO 13 & 94,96 & Bueno & 93,4 & Bueno \\
\hline
\end{tabular}

El comportamiento tras la finalización de la primera campaña de riego se puede considerar equiparable al obtenido en un estudio previo con una selección de 20 emisores en ramal convencional y este tipo de aguas. En este caso de un $85 \%$ de emisores con la calificación de excelente al inicio, sólo el $30 \%$ la mantenía al finalizar la campaña de riego (Baeza et al. 2015). 


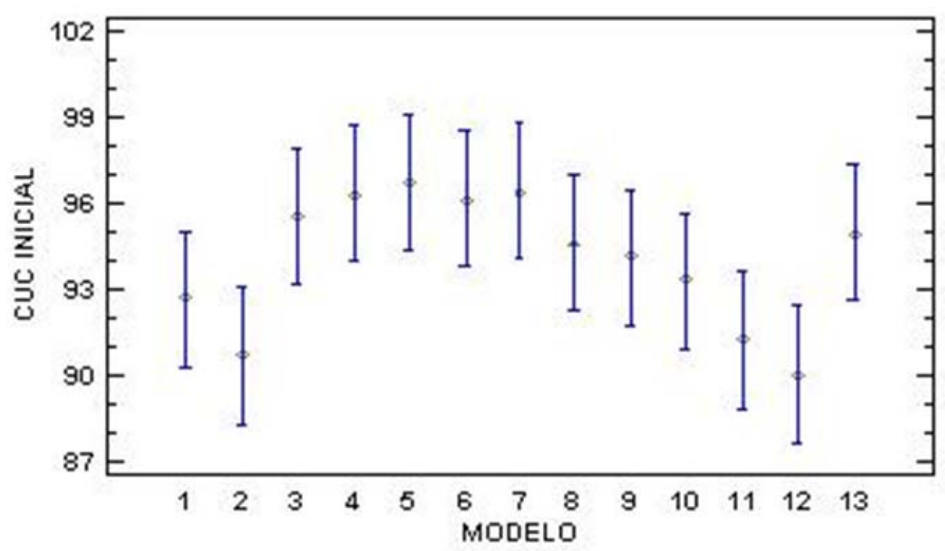

Figura 3. Coeficiente de Uniformidad de Caudal (CUC) inicial, expresado en tanto por ciento, de los 13 modelos analizados, con la representación del intervalo de Mínima Diferencia Significativa (LSD) al 95\%.

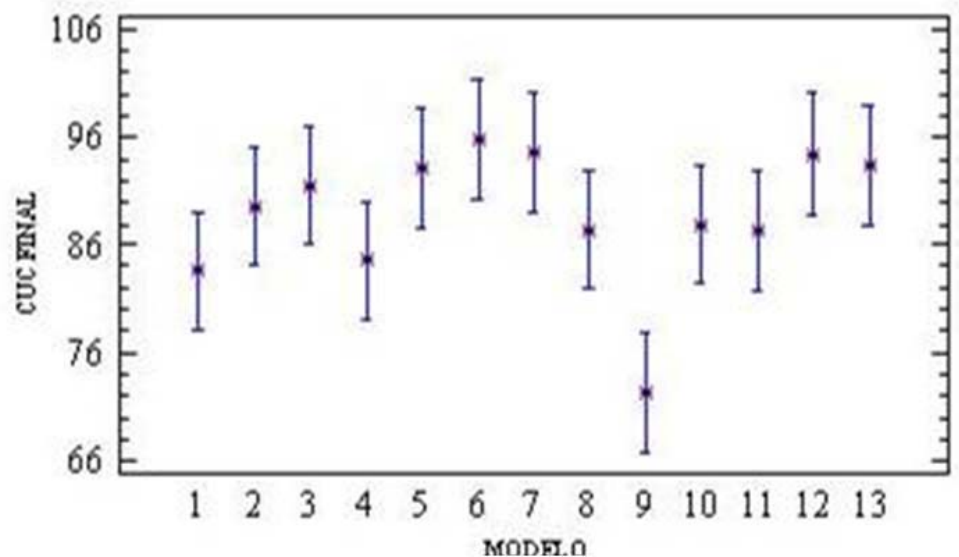

Figura 4. Coeficiente de Uniformidad de Caudal (CUC) final, expresado en tanto por ciento, de los 13 modelos analizados, con la representación del intervalo de Mínima Diferencia Significativa (LSD) al 95\%.

Tras analizar los resultados de laboratorio y campo, se puede concluir que las cintas de riego localizado pueden ser una alternativa a los ramales de riego convencionales cuando se riega con aguas residuales urbanas regeneradas, siempre que se elija un material de una mínima calidad y el ratio de sustitución garantice una uniformidad alta. Este estudio se va a ampliar con una segunda campaña de riego con el fin de analizar el comportamiento de las cintas a más largo plazo.

El coste de las cintas y goteros en tubería convencional es muy variable. Como referencia se puede considerar que el coste de la cinta de doble pared es un $50 \%$ del de la cinta con emisores integrados de pastilla, que a su vez suele corresponder con el $50 \%$ del ramal de riego en tubería convencional con emisores similares. La decisión de elegir uno u otro material requiere de un estudio económico previo. En cualquier caso la decisión tomada debe garantizar una uniformidad de riego alta y permanente.

\section{Bibliografía}

Agencia Andaluza del Agua. 2009. Posibilidad de reutilizar las aguas residuales regeneradas. Documento estratégico. 
Baeza, R., Contreras, J.I., Martín, F., Zapata, A. \& López, J.G. 2012. Estudio prospectivo de los emisores de riego localizado instalados en la zona regable del Bajo Andarax con aguas residuales urbanas regeneradas. XXX Congreso Nacional de Riegos. Albacete 12 al 14 de junio.

Baeza, R., Contreras, J.I., Trujillo, J. \& Alonso, F. 2015. Comportamiento de una selección de emisores para fertirriego de cultivos hortícolas en invernadero con aguas regeneradas. XXXIII Congreso Nacional de Riegos. Valencia 16 al 18 de junio.

Baeza, R., López, J.G., Domínguez, P., De Miguel, J. \& Cánovas, G. 2015. Jornada Técnica. Los recursos hídricos en el Campo de Dalías. Junta de Andalucía. Instituto de Investigación y Formación Agraria y Pesquera.

Baeza, R., Gavilán, P., Del Castillo, N., Berenguel, P. \& López, J.G. 2010. Programa de evaluación y asesoramiento en instalaciones de riego en invernadero con uso de dos fuentes distintas de agua: subterránea y regenerada. XXVIII Congreso Nacional de Riegos. León 15 al 17 de junio.

Fernández, M.D., Orgaz, F., Fereres, E., López, J.C., Céspedes, A., Pérez, J., Bonachela, S. \& Gallardo, M. 2001. Programación del riego de cultivos hortícolas bajo invernadero en el sudeste español. Estación Experimental Las Palmerillas. Cajamar

Junta de Andalucía. Consejería de Agricultura, Pesca y Medio Ambiente. 2014. Plan hidrológico de la Demarcación Hidrográfica de las Cuencas mediterráneas Andaluzas

Keller,J. \& Karmeli, D. 1974. Trickle irrigation design parameters. Transactions of de ASAE, 17(4): 678-684. 
METODOLOGIAA DE ENSAYO Y CARACTERÍSTICAS DEL BANCO DE CONTADORES DEL LABORATORIO DE HIDRÁULICAY RIEGOS

Balbastre, I. (1), Palau, C. V. (2), Arviza J. (3), Morais, G. M. (4), Sanchis, L (5)

(1) Responsable, Laboratorio Ingeniería Hidráulica y Riegos (LHIR), Dpto. DIRA Universidad Politécnica de Valencia, Camino de Vera s/n, 46022 Valencia, (ibbalpe@agf.upv.es)

(2) Docente e Investigador. Centro Valenciano de Estudios del Riego (CVER). Universidad Politécnica de Valencia, Camino de Vera s/n, 46022 Valencia (virpaes@agf.upv.es)

(3) Docente e Investigador, UD Hidráulica, Dpto. IRA (DIRA).Universidad Politécnica de Valencia, Camino de Vera s/n, 46022 Valencia (jarviza@agf.upv.es)

(4) Doctoranda en Ingeniería Agrícola, UFC,Fortaleza - CE (gislane_mendez@yahoo.com.br )

(5) Técnico de Laboratorio, Laboratorio, Laboratorio Ingeniería Hidráulica y Riegos (LHIR),Dpto. DIRA Universidad Politécnica de Valencia, Camino de Vera s/n, 46022 Valencia, (luisanal@upvnet.upv.es)

$$
\begin{aligned}
& \text { UNIVERSITAT } \\
& \text { POLITĖCNICA } \\
& \text { DE VALENCIA }
\end{aligned}
$$

OBJETIVOS

Presentar la metodología de ensayo metrológico a contador lanzado del LHIR

\section{METODOLOGÍA}

Método de ensayo por gravimetría, aforando el agua durante un tiempo a unos depósitos que disponen de células de carga calibradas para realizar la pesada.

El volumen de agua acumulado en el depósito se contrasta con la diferencia de lecturas del contador, estimando de esta forma el error a diferentes caudales de ensayo.

$$
\operatorname{Error}(\%)=\left(\frac{Q_{\text {contador }}-Q_{\text {pesada }}}{Q_{\text {pesada }}}\right) \cdot 100
$$

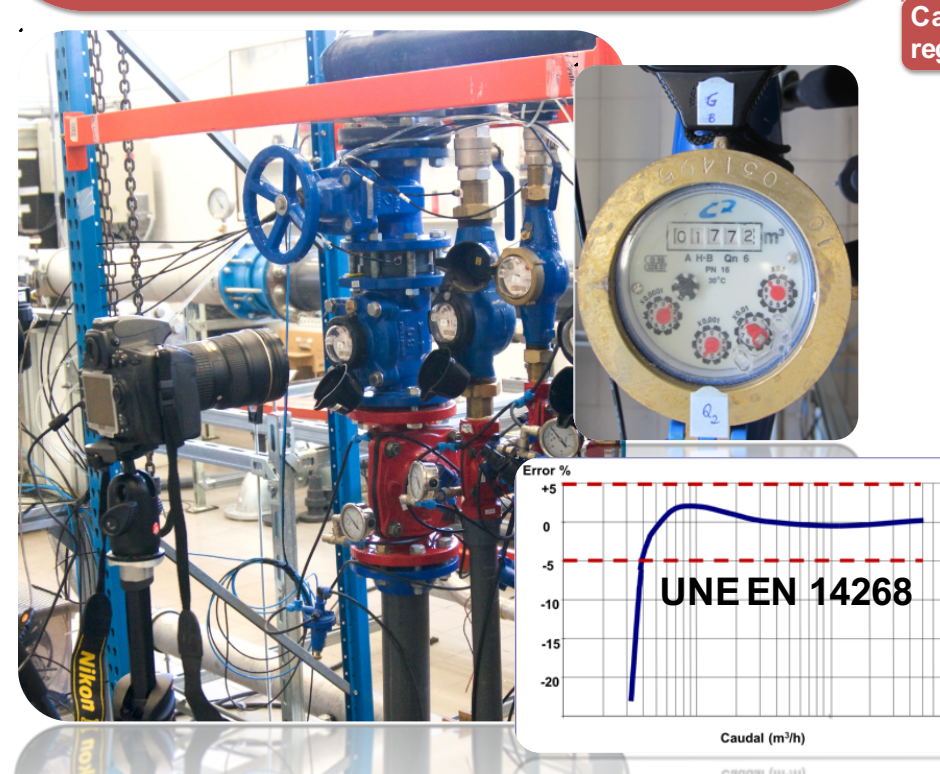

Ensayos metrológicos precisos a contador lanzado con la toma instantánea de lectura mediante fotografía para determinar volumen trasegado y el tiempo.

Pruebas a diferentes caudales dentro del rango de medición, Q1 a Q4, para trazar la curva de error del instrumento.
Especificar las características y elementos que componen el banco

\section{CARACTERISTICASY ELEMENTOS DEL BANCO}

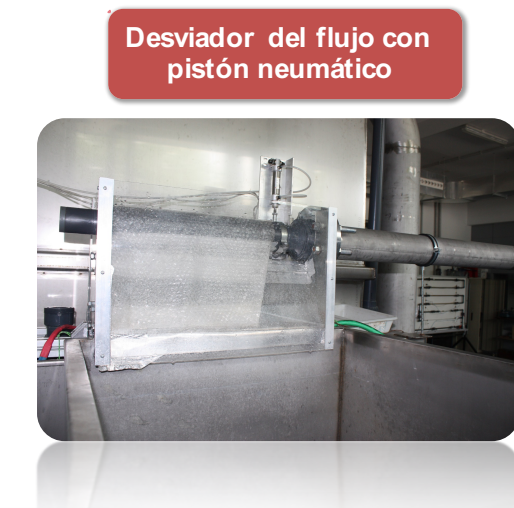

Caudalímetros electromagnéticos para regular el caudal DN25 y DN50, $\varepsilon<0,2 \%$
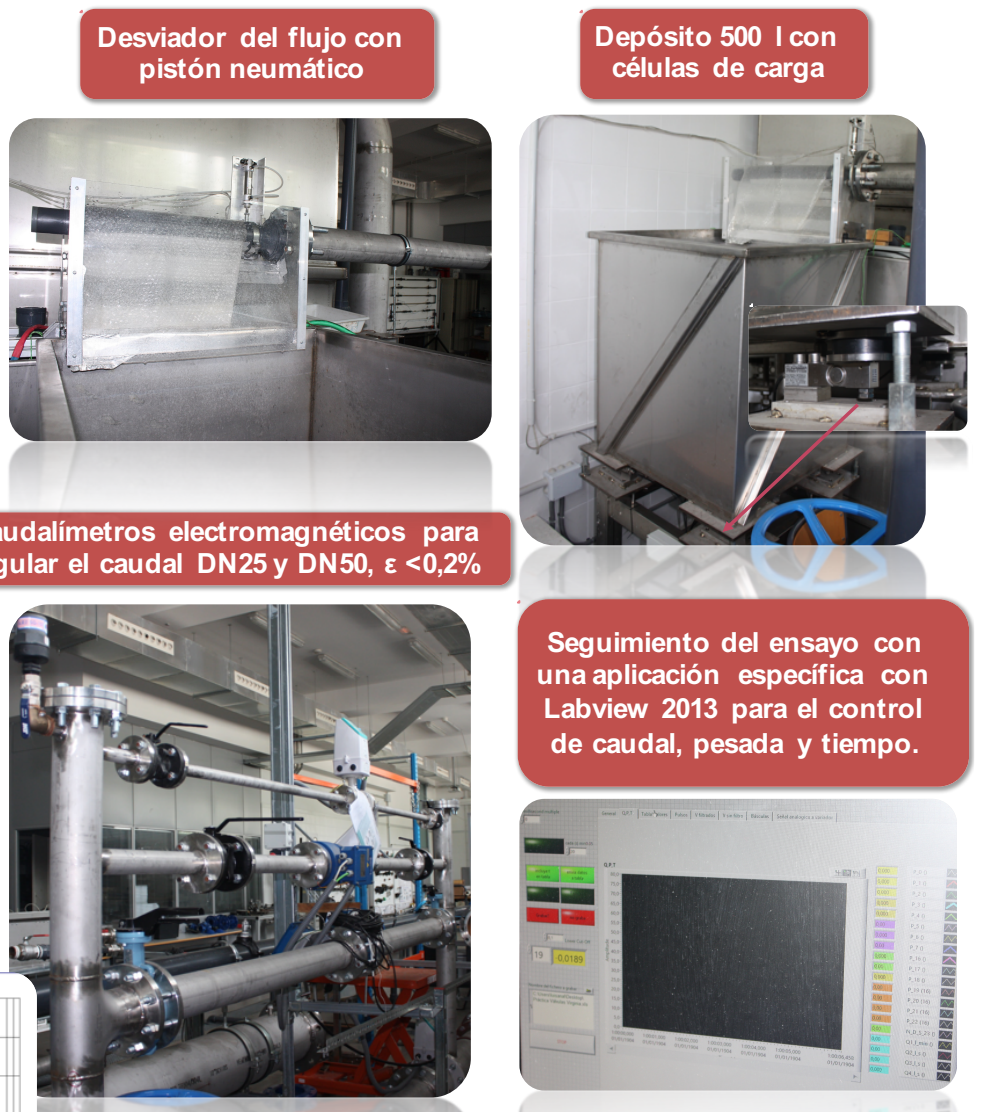

Seguimiento del ensayo con una aplicación especifica con Labview 2013 para el control de caudal, pesada y tiempo.

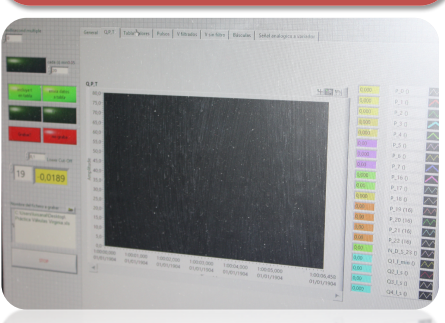

\section{CONCLUSIONES}

LHIR permite el ensayo de contadores de riego según la norma UNE EN 14268 hasta un Qmax $=235 \mathrm{~m}^{3} / \mathrm{h}$.

El método de ensayo a contador lanzado con toma instantánea de lectura con fotografía evita fluctuaciones de caudal y permite la calibración más precisa.

Puesta a punto y control automático del ensayo metrológico en el LHIR (Universitat Politècnica de València). 


\title{
C-12
}

\section{REDES SOSTENIBLES EN PVC ORIENTADO (PVC-O) HUELLA AMBIENTAL}

\author{
Martínez del Amo, Y (1) (P), Romero Montoya, M (2)
}

${ }^{1}$ Director Marketing y Certificación, Molecor, yolanda.martinez@molecor.com

${ }^{2}$ Técnico Infraestructuras Hidráulicas, Molecor, manel.romero@molecor.com

\section{1- Impacto ambiental de las Tuberías de PVC Orientado.}

El impacto ambiental de un sistema de tuberías depende de su composición y la aplicación de las mismas. Los factores que determinan la eficiencia durante todo el ciclo de vida de una tubería son principalmente: el tipo de materia prima utilizada, el proceso de producción, el acabado del producto, y su vida útil.

Las Tuberías de PVC-O se presentan como la solución más ecológica debido a su mejor contribución al correcto desarrollo sostenible del planeta, tal como demuestran diferentes estudios a nivel mundial. EI PVC-O presenta ventajas medioambientales en todas las fases de su ciclo de vida (figura 1):

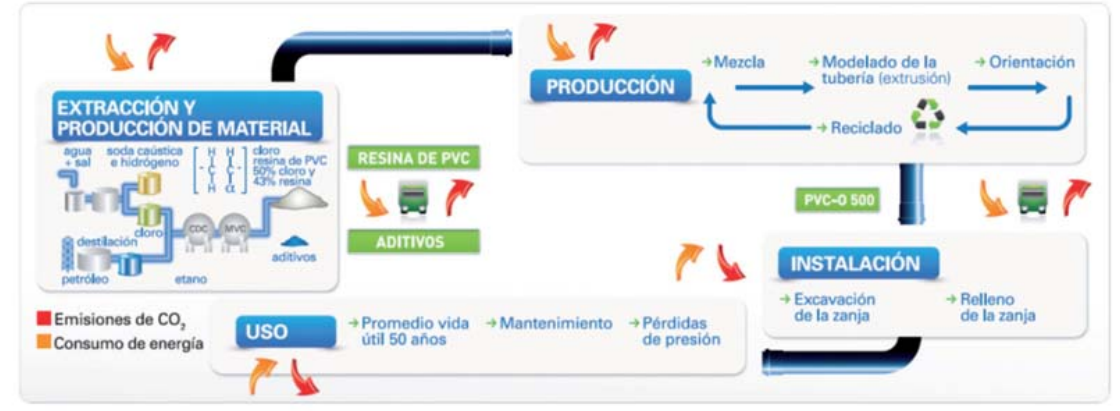

Figura 1. Ciclo de vida de las tuberías de PVC-O

\section{Eficiencia en Recursos Naturales}

- Petroleo. Sólo el 43\% de la composición del PVC depende del petróleo.

- Materias primas. Gracias a la mejora de propiedades que se consigue durante la orientación molecular, se puede utilizar menor cantidad de materia prima.

- Energía. Menor consumo en: extracción de la materia prima, fabricación de la tubería y en el uso.

\section{Eficiencia en la Gestión de Residuos}

EI PVC es un material $100 \%$ reciclable que puede ser reutilizado en la fabricación de otras aplicaciones plásticas.

\section{Mejor Contribución a la Sostenibilidad}

- Menor huella de carbono. Por las menores emisiones de $\mathrm{CO}_{2}$ a la atmósfera según muestran diversos estudios internacionales.

- Menor huella ambiental. Según la declaración ambiental de producto (EPD), las tuberías de PVC-O presentan un menor impacto ambiental, no sólo en el calentamiento global, sino en otros 5 parámetros medioambientales.

- $\underline{\text { Otros }}$ 
- Optimización del transporte. Por su menor menos se puede transportar más cantidad de material, por tanto realizaremos ahorro de combustible

- Eficiencia en costes de instalación. Es más ligera y manejable que los tubos fabricados con otros materiales, con lo que se reduce la utilización de maquinaria.

\section{2- Directrices europeas sobre la Huella Ambiental.}

Desde la Unión Europea se está fomentando la correcta preservación del medioambiente. Por ejemplo, el Reglamento de Productos de Construcción como requisitos básicos en obras de construcción, requiere considerar: ahorro de energía, uso sostenible de los recursos naturales, durabilidad de las obras y respeto al medioambiente de los materiales utilizados.

En Europa se han desarrollado diversas metodologías de estudio del impacto ambiental, y desde la Comisión Europea, recopilando toda esta información, se ha lanzado la Recomendación 179/2013/CE relativa al cálculo de Huella Ambiental de Producto (HAPPEF). Está basada en el análisis del ciclo de vida del producto (ACV-LCA) y la evaluación de su impacto ambiental en diferentes parámetros ambientales.

Según ésta, se ha realizado el estudio de Huella Ambiental de la Tubería PVC Orientado clase 500. Este método está basado en el análisis del ciclo de vida (ACV) del producto a lo largo de todas las fases de cuna a tumba.

El cálculo se ha realizado con el software profesional Air.e LCA integrado con las bases de datos de Ecoinvent y ELCD, teniendo en cuenta además, la normativa aplicable sobre ciclo de vida y declaraciones ambientales del producto (EPD), y las metodologías IPCC 2007 e ILCD.

Así, se estiman 14 impactos ambientales que se agrupan en función de la afección a los distintos medios:

- Aire y atmósfera: Cambio climático, Acidificación, Agotamiento de la capa de ozono y Formación de ozono fotoquímico

- Agua: Agotamiento de recursos (agua), Ecotoxicidad del agua dulce y Eutrofización del agua

- Suelo: Agotamiento de recursos (minerales), Eutrofización terrestre y Uso del terreno

- Salud humana: Elementos respiratorios inorgánicos, Radiación ionizante, Efectos en la salud humana (cancerígenos) y Efectos en la salud humana (no cancerígenos)

La Huella de Carbono se obtiene del impacto Cambio Climático,

\section{3- Resultados estudio huella ambiental}

Los resultados obtenidos se muestran en la figura 2 


\begin{tabular}{|c|c|c|c|}
\hline & Absolutos & & Normalizados \\
\hline Cambio climático: & $8.5 E+01$ & $\mathrm{~kg}$ de COze & $9.5 \mathrm{E}-03$ \\
\hline Agotamiento de ozono & $4.8 E-06$ & $\mathrm{kgCFC-11e}$ & $2.2 E-04$ \\
\hline Ecotoxicidad agua dulce & $1.8 E+02$ & CTue & $2.1 \mathrm{E}-02$ \\
\hline $\begin{array}{l}\text { Efectos en la salud humana } \\
\text { (cancerigenos) }\end{array}$ & 4.8E-06 & crue & 1.3E-01 \\
\hline $\begin{array}{l}\text { Efectos en la salud humana (no } \\
\text { cancerígenos) }\end{array}$ & $8.5 E-06$ & cTun & $1.6 E-02$ \\
\hline Elementos respiratorios inorgánicos & $1.2 E-02$ & $\mathrm{~kg}$ PM2.5e & 2.7E-03 \\
\hline Radiación ionizante (humana) & $4.2 E+00$ & $\mathrm{~kg} \mathrm{U235e}$ & 3.7E-03 \\
\hline Formación ozono fotoquímico & 2.0E-01 & $\mathrm{kg} \mathrm{NMVOC}$ & $6.3 E-03$ \\
\hline Acidificación & $2.4 E-01$ & molHte & $5.3 \mathrm{E}-03$ \\
\hline Eutrofización terrestre & $8.4 E-02$ & $\mathrm{molNe}$ & $4.8 E-04$ \\
\hline Eutrofización agua dulce & $1.2 E-03$ & $\mathrm{kgPe}$ & 8.3E-04 \\
\hline Eutrofización agua marina & 4.6E-02 & $\mathrm{kg} \mathrm{Ne}$ & 2.7E-03 \\
\hline Agotamiento de recursos (agua) & $9.9 E-01$ & $m^{3} s w U$ & $1.2 E-02$ \\
\hline Agotamiento de recursos (minerales) & 5.7E-03 & $\mathrm{kg}$ Sbe & $5.6 \mathrm{E}-02$ \\
\hline Uso del terreno & $2.7 E+02$ & $\mathrm{~kg}$ Cdef & $4.0 E-04$ \\
\hline
\end{tabular}

Figura 2. Resultados huella ambiental tuberías PVC-O clase 500

\section{4- Conclusiones.}

La orientación molecular otorga a las tuberías de PVC-O significativas ventajas en la calidad del producto, su instalación y uso. Ofrecen un mejor comportamiento de respeto al medioambiente, presentando una huella ambiental inferior a otros materiales (figura 3), mejorando la contribución al correcto desarrollo sostenible del planeta, y optimizando el consumo de recursos naturales.

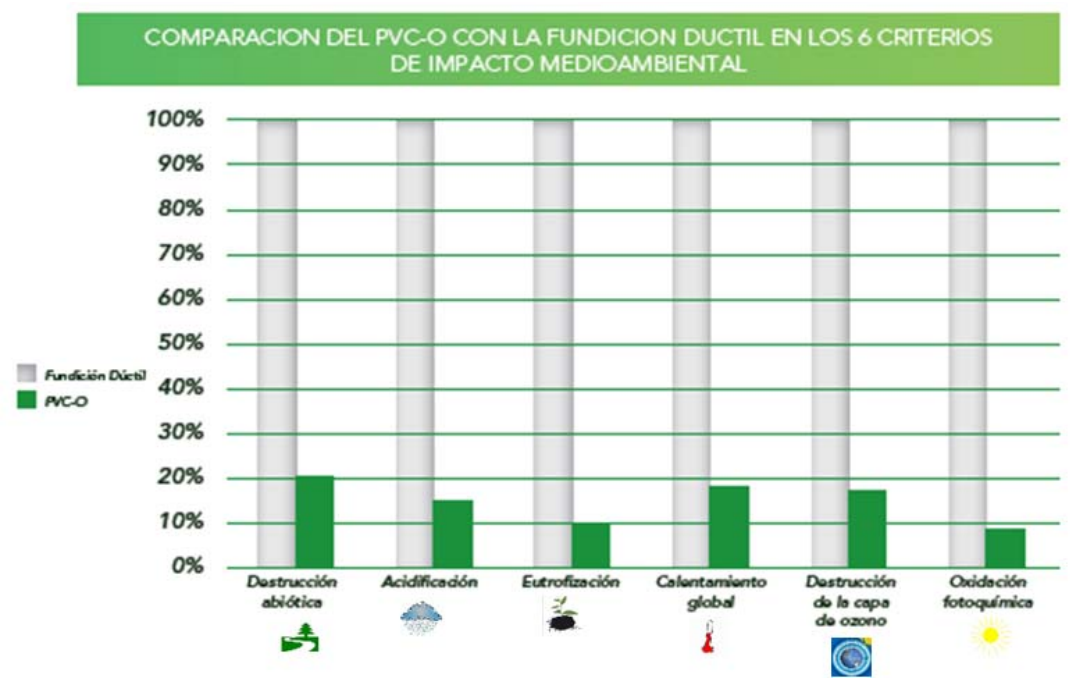

Figura 3. Comparación impacto ambiental PVC-O vs Fundición dúctil 


\title{
ANÁLISIS DE LA UNIFORMIDAD DE RIEGO EN SISTEMAS DE ASPERSIÓN SEMIPORTÁTIL CON ASPERSORES DE GRAN TAMAÑO
}

\author{
Laserna Arcas, S. ${ }^{1}$, Montero Martínez, J. ${ }^{2}$, Sheikhesmaeili, O. ${ }^{3}$, Alcázar Bascuñana, E. ${ }^{4}$
}

${ }^{1}$ Dr. Ingeniero Agrónomo, Investigador; Centro Regional de Estudios del Agua (CREA), UCLM; Albacete; Santiago.Laserna@uclm.es

${ }^{2}$ Dr. Ingeniero Agrónomo, Titular de Universidad; Centro Regional de Estudios del Agua (CREA), UCLM; Albacete; Jesus.Montero@uclm.es

${ }^{3}$ Ingeniero en Riegos y Drenajes, Investigador; Faculty of Water Sciences Engineering, Shahid Chamran University of Ahvaz, Ahvaz, Iran; omid.sheikh@hotmail.com

${ }^{4}$ Ingeniera Agrónomo, Investigadora; Escuela Técnica Superior de Ingenieros Agrónomos y de Montes, UCLM; Albacete; elena.alcazar@outlook.com

\section{Resumen}

La sostenibilidad en la agricultura de regadío depende en gran medida de conseguir una alta eficiencia de aplicación en el riego. Es muy importante conocer los factores que afectan a la uniformidad de riego, especialmente en aspersores semi-portátiles de gran tamaño, que son un sistema muy común en áreas áridas y semiáridas, como Irán. Hasta el momento, la uniformidad de distribución del agua aplicada no ha sido considerada cuantitativamente en la mayoría de las combinaciones de variables hidráulicas y meteorológicas con aspersores portátiles de gran tamaño. En este trabajo, se ha caracterizado el coeficiente de uniformidad (CU) analizando la influencia de los principales factores que le afectan, como la velocidad del viento $(W)$, la presión de trabajo $(P)$ y el marco de riego. Los ensayos de campo se realizaron con un solo aspersor al aire libre. Se aprecia un efecto significativo del viento, como parámetro meteorológico, sobre el CU bajo diferentes condiciones climáticas, en relación a la presión y la separación entre aspersores. Este comportamiento es muy similar al obtenido con aspersores de tamaño medio. Los criterios técnicos propuestos en los resultados se pueden utilizar para optimizar la gestión del riego por aspersión de acuerdo con factores de diseño adecuados para una amplia gama de condiciones climáticas y presión (es decir 450 y $500 \mathrm{kPa}$ ). Así, la relación entre la separación entre aspersores y el radio mojado no debe superar los 0,45 con el fin de alcanzar el coeficiente de diseño de uniformidad aceptable ( $80 \%)$ bajo condiciones de viento $\left(>2 \mathrm{~m} \mathrm{~s}^{-1}\right)$ en el sistema de riego.

\section{1.- Introducción. Objetivos}

La sostenibilidad en la agricultura de regadío bajo sistemas de riego a presión aplicado a áreas con mucho viento y semiáridas depende en gran medida de lograr una alta eficiencia de riego mediante un adecuado diseño y manejo del sistema. Muchos trabajos se han llevado a cabo para analizar el papel de los parámetros que influyen en la eficiencia y uniformidad de distribución del agua en sistemas de riego por aspersión, pero sobre todo, con aspersores de tamaño medio. Sin embargo, la bibliografía disponible no aborda los problemas de mejorar el coeficiente de uniformidad (CU) influenciado por la combinación de variables hidráulicas y meteorológicas con aspersores semi-portátiles de gran tamaño. No 
hay estudios realizados con aspersores de gran tamaño que trabajen con altos caudales (mayor de $3 / \mathrm{s} \mathrm{s}^{-1}$ ) y gran separación entre aspersores (superior a $24 \mathrm{~m}$ ).

La aspersión semi-portátil con aspersores de gran tamaño es un sistema de riego muy popular y extendido en zonas de regadío con condiciones climáticas áridas y semiáridas. En Irán, el $48 \%$ de la superficie total de riego a presión o el $85 \%$ de la superficie de riego por aspersión está cubierta por este sistema (660.000 ha) (Report, 2014).

La uniformidad en la distribución del agua es un indicador de las variaciones espaciales aplicadas sobre la superficie de regadío. Este factor de diseño afecta a aspectos importantes de la agricultura como, la eficiencia del uso del agua, la lixiviación de fertilizantes y el rendimiento del cultivo (Seginer et al., 1991a). Está demostrado que un aumento de la uniformidad en la aplicación del agua en el campo puede favorecer la eficiencia del riego mediante la reducción de la percolación profunda y la escorrentía superficial causada por un exceso de riego. Por lo tanto, las evaluaciones de campo son un excelente procedimiento para investigar los factores que afectan a la uniformidad del riego real bajo múltiples combinaciones de condiciones climáticas e hidráulicas en los sistemas de riego por aspersión. Por otra parte, una distribución no uniforme no sólo podría dejar algunas parte de la cosecha en una situación deficitaria de agua, sino que también podría exceder el riego de otras partes causando acumulaciones de agua, daños a las plantas, la salinización del suelo, y la lixiviación de fertilizantes químicos en las aguas subterráneas (Solomon, 1983).

Las variables meteorológicas, como la velocidad y dirección del viento $(\mathrm{W})$ son los principales parámetros que tienen mayor impacto en el modelo de distribución de agua de riego por aspersión, jugando un papel importante en el arrastre del viento y las perdidas por evaporación (Dechmi et al., 2003; Tarjuelo et al., 2000; Keller y Bliesner, 1990). Estas referencias han dado lugar a dos importantes conclusiones: en primer lugar, el modelo de distribución de agua de un aspersor aislado se distorsiona y reduce bajo condiciones de viento; en segundo lugar, el agua aplicada podría perderse parcialmente por evaporación, especialmente por el arrastre fuera de la superficie de riego. La consecuencia de estos problemas podrían ser el riego excesivo o insuficiente riego de partes del campo.

Muchos autores indican que, aunque la velocidad del viento es el parámetro meteorológico más importante que afecta a los indicadores del uso del agua en el campo de los sistemas de riego por aspersión (Tarjuelo et al., 1999a y b; Sánchez et al., 2010), su influencia depende enormemente de los parámetros del diseño del sistema, tales como la presión de los aspersores y su separación, el tamaño de la boquilla o el tipo de aspersor (Keller y Bliesner, 1990).

Burt et al. (1997) indicaron que los factores más influyentes en la heterogeneidad de la distribución del agua son las variaciones de presión, el diseño del aspersor, el marco de riego, y sobre todo las condiciones climáticas, tales como la velocidad del viento.

Según Keller y Bliesner (1990), la mayoría de los sistemas de riego por aspersión requieren un valor mínimo de Coeficiente de Uniformidad de Christiansen (CU) $\geq 80 \%$. Bralts et al (1994) indicaron que un aumento del $5-12 \%$ en el CU podría supones el $3-17 \%$ más de rendimiento en el grano de trigo. Los bajos valores de CU indican generalmente una combinación defectuosa del número y tamaño de boquillas, presión y separación entre aspersores (Tarjuelo et al., 1999a).

Otro de los factores decisivos del sistema para mejorar la uniformidad de distribución de agua es el grado de solapamiento de los aspersores. Los sistemas de riego por aspersión requieren un solapamiento adecuado entre aspersores para obtener una buena uniformidad de distribución (Keller y Bliesner, 1990). Phocaides (2007) recomienda que, con el fin de obtener una buena uniformidad por solapamiento de aspersores, esta no debería exceder el $65 \%$ del diámetro mojado en condiciones de viento bajas a moderadas, para marcos cuadrados y rectangulares. También afirmó que, en condiciones de viento fuertes, la separación entre aspersores debería ser del 50\% del diámetro mojado con la dirección lateral perpendicular a la dirección del viento. 
Los objetivos de este documento son: (1) caracterizar el CU bajo diferentes escenarios de funcionamiento de presión para una amplia gama de condiciones climáticas en sistema de riego con aspersores semi-portátiles de gran formato; (2) analizar la uniformidad de riego en respuesta a los diversos escenarios evaluados de la combinación de los parámetros climáticos influyentes como la velocidad del viento y las características del diseño del sistema de aspersión incluyendo la presión, la separación y el marco de riego, y (3) dar algunas recomendaciones para ayudar en el diseño de proyectos y la gestión práctica en sistemas de riego por aspersión con aspersores de gran tamaño semi-portátiles en zonas semiáridas.

\section{2.- Material y métodos}

\section{1.- Localización de los ensayos}

Los ensayos al aire libre se realizaron en la zona sur-oeste de Irán (Región

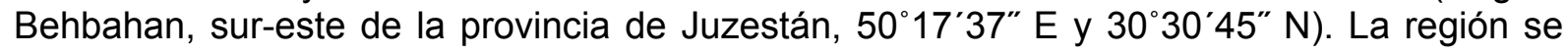
caracteriza por un clima semiárido, con inviernos suaves y veranos calurosos. La evotranspiración anual y la precipitación media son de 1717 y $350 \mathrm{~mm}$, respectivamente. El sistema de riego por aspersión típico en este área son los aspersores semi-portátiles de gran tamaño (Sheikhesmaeili, 2003). Actualmente, este sistema de riego es la configuración principal en ciertas regiones iraníes, como la provincia de Juzestán, donde está cubierto por el 73,1\% (22.634 ha) de la superficie total de riego a presión o $99 \%$ de la superficie de riego por aspersión (Report, 2014). En este sistema de aspersores de gran tamaño portátil, toda la red de tuberías está enterrada y sólo los aspersores se mueven manualmente sobre el lateral, que se puede extender hasta $300 \mathrm{~m}$.

\section{2.- Ensayos de un aspersor al aire libre}

Para analizar la uniformidad en sistemas de riego con aspersores de gran tamaño, se realizaron cuarenta ensayos de un aspersor aislado al aire libre, siguiendo las normas ISO 15886-3 (2012) y ASAE S398.1 (2001). El tipo de aspersor de impacto de gran tamaño utilizado en estas pruebas fue el A-D-5 (Abyaran Dasht Inc., Tehran, Iran). Este aspersor tiene tres boquillas $(11+6,2+3,2 \mathrm{~mm})$ y es similar al aspersor VYR 155 (VIRSA Inc., Burgos, España) (figura 1). Los dos escenarios de presiones $(P)$ de trabajo utilizados fueron las recomendadas por el fabricante (450 y $500 \mathrm{kPa}$ ), con un caudal descargado de 3,25 y 3,46 $\mathrm{I} \cdot \mathrm{s}^{-1}$, respectivamente. Las pruebas se realizaron en los meses de abril a noviembre durante diferentes horas del día para cubrir todas las condiciones climáticas. En estas pruebas se utilizó una red de pluviómetros de 22 × 22 filas y columnas de pluviómetros (figura 2). Las boquillas de los aspersores se colocaron $1,35 \mathrm{~m}$ por encima de la abertura del pluviómetro. Los pluviómetros, con un diámetro de abertura de $0,1 \mathrm{~m}$ y $0,15 \mathrm{~m}$ de altura, se colocan en una cuadrícula de $3 \times 3 \mathrm{~m}^{2}$. El agua procede de un sondeo; una válvula regula la presión del agua, y se utilizó un caudalímetro en línea calibrado (con un rango de error $<2 \%$ ) para medir la cantidad total de agua bombeada. La presión de trabajo en el aspersor se midió utilizando un medidor de presión de tubo Pitot en el centro del chorro del aspersor, aproximadamente a $1,5 \mathrm{~mm}$ de la boquilla. Las condiciones climáticas (la temperatura del aire, la humedad relativa y la velocidad y dirección del viento a 2 metros de altura) se midieron en una estación meteorológica automática situada a $50 \mathrm{~m}$ del lugar de ensayo a intervalos de 5 minutos durante la duración de la prueba. La tabla 1 resume los valores medios, así como los máximos y mínimos, de los parámetros ambientales (temperatura, humedad y velocidad del viento) durante los ensayos.

La duración de las pruebas fue de una hora. Una vez finalizado el ensayo, el volumen de agua recogida en los pluviómetros se midió con una probeta calibrada, con la particularidad de seguir siempre el mismo orden de lectura. En cada pluviómetro, el volumen 
de agua recogido se corrigió para cuantificar las pérdidas por evaporación durante el tiempo de riego (una hora).

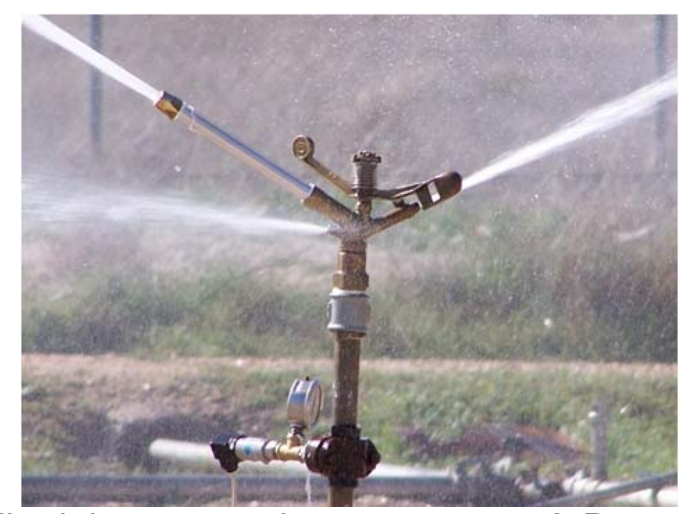

Figura 1. Detalle del aspersor de gran tamaño A-D-5 con tres boquillas
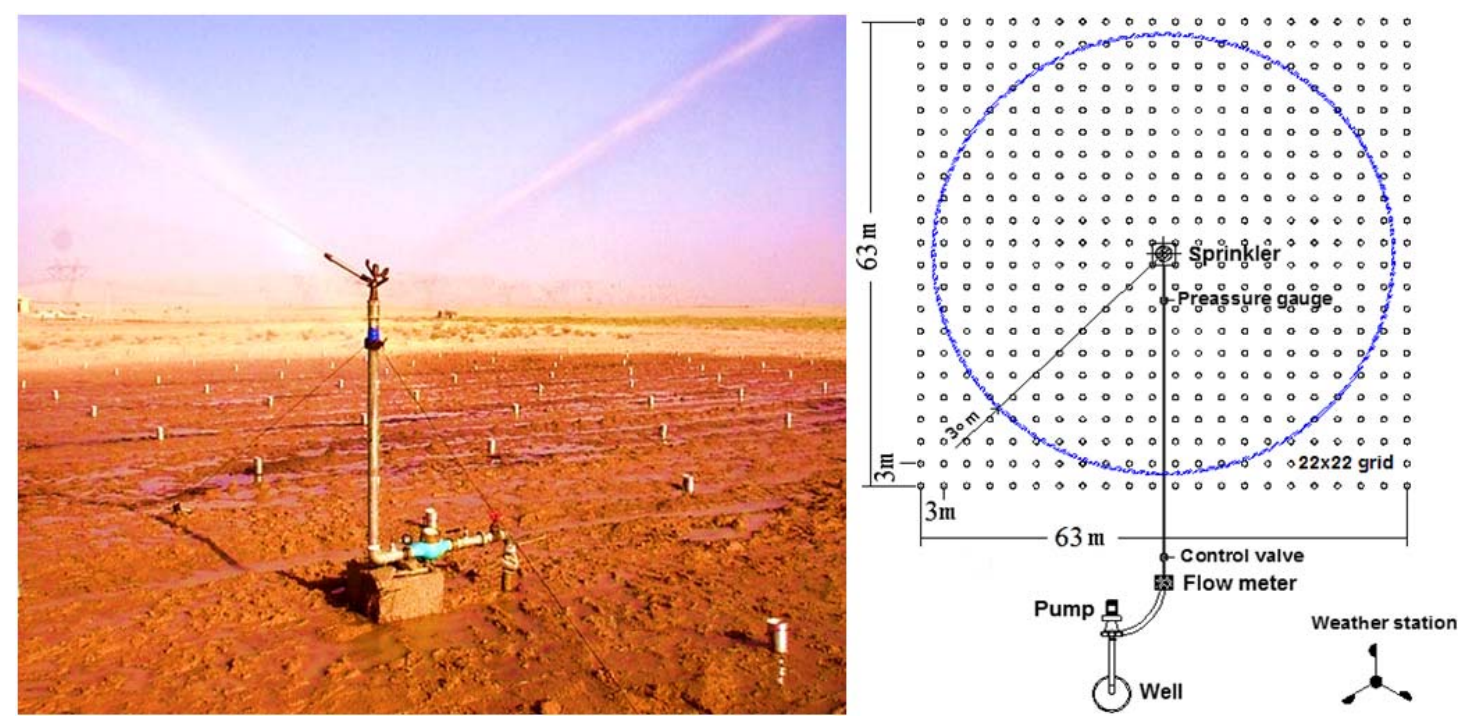

Figura 2. Esquema del ensayo del aspersor aislado al aire libre

Tabla 1. Media de los valores medidos de los parámetros meteorológicos (y valores mínimo y máximo) para los 40 ensayos experimentales

\begin{tabular}{ccc}
\hline $\mathbf{W}(\mathbf{m} / \mathbf{s})$ & $\mathbf{T}\left({ }^{\circ} \mathbf{C}\right)$ & $\mathbf{H ~ ( \% )}$ \\
\hline $1.62(0-6.8)$ & $31.9(21.4-44.9)$ & $41.8(11.8-80.0)$ \\
\hline
\end{tabular}

\section{3.- Caracterización del patrón de distribución de agua por aspersión sin viento}

Con el fin de caracterizar el patrón de distribución de agua del aspersor A-D-5 se realizaron varios ensayos, de conformidad con la norma ISO 15886-3 (2012), bajo condiciones sin viento en las instalaciones del Centro Regional de Estudios del Agua (CREA) de la Universidad de Castilla-La Mancha (Albacete, España). Los ensayos se realizaron con el aspersor con tres boquillas $(11+6,2+3,2 \mathrm{~mm})$, a dos presión de trabajo, 450 y $500 \mathrm{kPa}$. El aspersor se dispuso a 1,5 metros sobre el suelo. Se colocaron dos líneas de 
pluviómetros de 0,16 $\mathrm{m}$ de diámetro formando un ángulo de $90^{\circ}$ con una separación de $1 \mathrm{~m}$ entre ellos. Se hicieron dos repeticiones de cada presión de trabajo. El volumen de agua de cada uno de los pluviómetros se determinó como el promedio de las dos filas de pluviómetros y para ambas repeticiones.

\section{4.- Medida del tamaño de gota de los aspersores}

Con el fin de establecer la relación entre el CU y el tamaño de gota del aspersor, se utilizó un disdrómetro óptico modelo ODM 470, fabricado por Eigenbrodt (Königsmoor Inc., Alemania), a las presiones de trabajo de 450 y $500 \mathrm{kPa}$. Se puede encontrar una descripción detallada del equipo en Montero et al. (2006). El dispositivo se basa en la atenuación de un haz de luz infrarroja cuando las gotas cruzan a través de una ventana óptica. La forma del detector del haz es circular con un diámetro de $20 \mathrm{~mm}$. El disdrómetro realiza mediciones continuas de las gotas emitidas por el aspersor. Cada gota produce una atenuación en el haz luminoso. El análisis de la señal permite estimar el diámetro de la gota y el tiempo que tarda en atravesar el haz de luz (tiempo de paso).

La medida del tamaño de gota se realizó al mismo tiempo que las pruebas radiales. Las distancias al aspersor fueron de 4, 8, 12, 16, 20, y $24 \mathrm{~m}$. Para cada distancia, se calculó el Diámetro Mediano de Volumen (VMD), que es el diámetro de gota al que le corresponde el $50 \%$ del volumen de agua acumulada (Montero et al., 2003). La medida de la distribución de las gotas engloba las gotas arrojadas por el conjunto de las tres boquillas. La trayectoria de los ángulos para cada boquilla es $28^{\circ}-28^{\circ}-13^{\circ}$.

\section{5.- Análisis del Coeficiente de Uniformidad de Christiansen (CU)}

La distribución de agua medida para un aspersor aislado bajo diferentes condiciones de viento, se solapó para determinar la uniformidad de riego en dos tipos de marcos de aspersores (cuadrado y rectangular), con tres separaciones entre aspersores $(21,24$ y 30 $\mathrm{m})$

La disposición de los marcos, Se (separación entre aspersores dentro de cada línea, en $\mathrm{m}$ ) $\mathrm{x}$ SI (separación entre líneas, en $\mathrm{m}$ ), fue la siguiente: $21 \times 21,24 \times 24$ y $30 \times 30$ para marcos cuadrados, y $21 \times 24,21 \times 30$ y $24 \times 30$ para marcos rectangulares.

El parámetro calculado para determinar la uniformidad de riego fue el Coeficiente de Uniformidad de Christiansen (Christiansen, 1942).

Se realizó un análisis de varianza (ANOVA) y la prueba Tukey HSD, para determinar los efectos significativos de las variables analizadas ( $\mathrm{P}, \mathrm{W}, \mathrm{SI}$ y $\mathrm{Se}$ ) sobre el $\mathrm{CU}$, utilizando los software SPSS v.18 (SPSS Inc.) y EXCEL 2010 (MicroSoft Inc.).

\section{3.- Resultados y discusión}

\section{1.- Curvas radiales y distribución de los tamaños de gota}

Una representación gráfica de las curvas pluviométricas del aspersor obtenidas en los ensayos radiales se muestra en la figura 3a. En ella, se puede observar unas curvas con forma triangular. También se observa que el volumen de aplicación es más alto cerca del aspersor $(8-10 \mathrm{~cm})$, y luego disminuye hasta el final. Esto es indicativo del buen comportamiento previsible del aspersor en condiciones de poco viento, pero no tan bueno cuando haga fuertes vientos (Tarjuelo et al, 1999a). Respecto a las medidas de los tamaños de gota para el aspersor, se calculó la VMD para cada distancia, representándolos gráficamente en la figura $3 \mathrm{~b}$.

No se observaron diferencias significativas en la distribución del tamaño de las gotas entre las dos presiones (450 y $500 \mathrm{kPa}$ ). En relación con las distancias al aspersor, cuando 
mayor es la distancia, mayores son los tamaños de gota, siguiendo una tendencia exponencial. Para estos aspersores, con diámetros de boquilla grande y altas presiones (450-500 kPa), se forman un rango de tamaño de gota similares (hasta 3,5-4 mm) a los aspersores de tamaño medio, con boquillas pequeñas y presiones medias (250-350 kPa) (Li et al., 1994; Montero et al., 2003 y 2006).

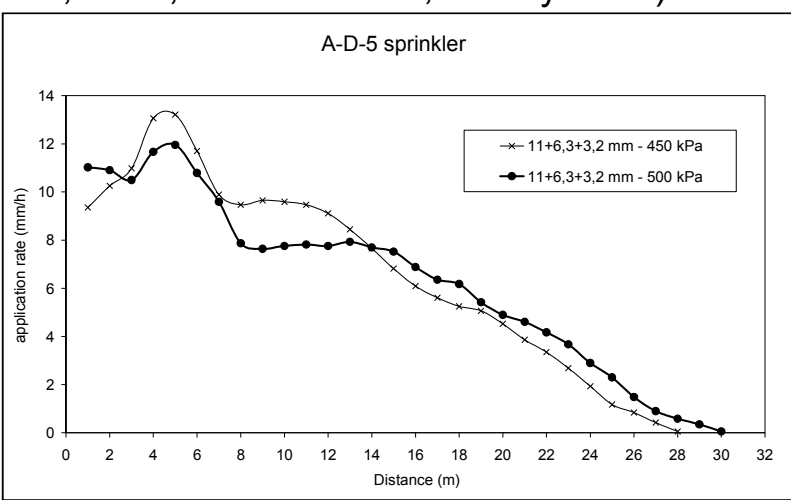

(a)

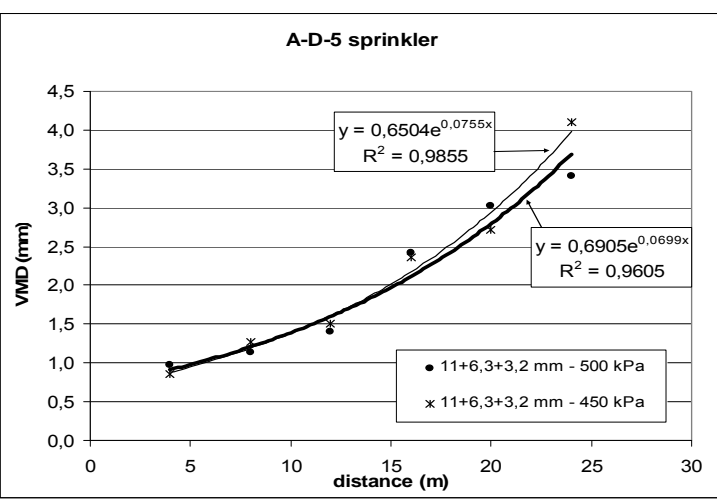

(b)

Figura 3. Distribución radial (a) y distribución de los tamaños de gota (b), para las presiones de 450 y $500 \mathrm{kPa}$

\section{2.- Análisis del Coeficiente de Uniformidad al aire libre}

Los patrones de distribución del agua obtenidos bajo diversas condiciones de viento y presiones de trabajo, se solaparon para calcular los valores de CU para los diferentes marcos de riego definidos. La tabla 2 resume los valores resultantes de $\mathrm{CU}$ de todos los escenarios simulados. Los datos se clasifican en tres intervalos de viento diferentes (bajo: $\mathrm{W}<2 \mathrm{~m} \mathrm{~s}^{-1}$, moderado: $2-4 \mathrm{~m} \mathrm{~s}^{-1} \mathrm{y}$ alto: $\mathrm{W}>4 \mathrm{~m} \mathrm{~s}^{-1}$ ).

Tabla 2 Valores de CU obtenidos en los diferentes ensayos

\begin{tabular}{|c|c|c|c|c|c|c|c|c|c|}
\hline \multirow{3}{*}{$\begin{array}{c}W \\
\left(\mathrm{~m} \mathrm{~s}^{-1}\right)\end{array}$} & \multirow{3}{*}{$\begin{array}{l}\text { Presión } \\
\text { (kPa) }\end{array}$} & \multicolumn{6}{|c|}{ Marco de riego (mxm) } & \multirow{2}{*}{\multicolumn{2}{|c|}{ Valores Medios }} \\
\hline & & \multicolumn{3}{|c|}{ Cuadrado } & \multicolumn{3}{|c|}{ Rectangular } & & \\
\hline & & $21 \times 21$ & $24 \times 24$ & $30 \times 30$ & $21 \times 24$ & $21 \times 30$ & $24 \times 30$ & $\begin{array}{l}\text { Por } \\
\text { presión }\end{array}$ & Global \\
\hline \multirow{2}{*}{$<0$} & 450 & 90,5 & 83,3 & 79,7 & 87,0 & 86,9 & 83,7 & 85,2 & \multirow{2}{*}{86,1} \\
\hline & 500 & 91,7 & 86,1 & 83,2 & 87,5 & 87,6 & 86,1 & 87,0 & \\
\hline \multirow{2}{*}{$2-4$} & 450 & 76,0 & 74,7 & 66,4 & 74,0 & 67,0 & 68,4 & 71,1 & \multirow{2}{*}{74,8} \\
\hline & 500 & 79,0 & 77,5 & 76,2 & 79,2 & 80,5 & 78,9 & 78,6 & \\
\hline \multirow{2}{*}{$>4$} & 450 & 78,2 & 78,3 & 61,5 & 76,9 & 66,6 & 68,4 & 71,6 & \multirow{2}{*}{68,4} \\
\hline & 500 & 72,4 & 70,0 & 59,0 & 69,9 & 59,6 & 60,3 & 65,2 & \\
\hline \multirow{3}{*}{ Media } & 450 & 85,1 & 80,6 & 73,1 & 82,3 & 78,7 & 77,5 & 79,6 & \multirow{2}{*}{80,2} \\
\hline & 500 & 85,9 & 81,6 & 77,5 & 82,8 & 81,2 & 80,1 & 81,5 & \\
\hline & Global & $\begin{array}{c}85,3 \\
(\mathrm{~A})\end{array}$ & $\begin{array}{c}81,0 \\
(\mathrm{~B})\end{array}$ & $\begin{array}{c}74,6 \\
(\mathrm{C})\end{array}$ & $\begin{array}{l}82,5 \\
(A B)\end{array}$ & $\begin{array}{c}79,5 \\
\text { (B) }\end{array}$ & $\begin{array}{l}78,3 \\
\text { (BC) }\end{array}$ & & \\
\hline
\end{tabular}

$\left.{ }^{*}\right)$ Los paréntesis muestras grupos homogéneos obtenidos después de realizar el análisis de varianza (grupo de filas)

Efectos de la presión de trabajo sobre el Coeficiente de Uniformidad:

Como el tamaño de gota está controlado por la presión de funcionamiento y las boquillas del aspersor, es muy importante que el aspersor funcione en el rango adecuado de 
presiones (es decir, 450 a $500 \mathrm{kPa}$ ) recomendado por el fabricante. Se realizó la prueba estadística ANOVA para comprobar el efecto de la presión en el CU cuando se cambia de $450 \mathrm{kPa}$ a $500 \mathrm{kPa}$. Los resultados estadísticos muestran que no hay diferencia significativa entre los valores de CU sin diferenciación de la velocidad del viento, debido a la similitud de los modelos de distribución radial en las dos presiones $(p=0,13,>0,05)$. Así, y de acuerdo con Keller y Bliesner (1990), se recomienda evitar trabajar con presiones superiores a 450 $\mathrm{kPa}$, ya que una mayor presión implica un mayor coste económico energético para obtener el mismo valor de CU.

Sin embargo, cuando la influencia de la presión se analiza con la diferenciación en clases de velocidad de viento, se observa como la presión produce diferencias significativas en CU. De acuerdo con la tabla 2, los valores de CU para baja y media W son altos en 500 $\mathrm{kPa}(87,7 \%-78,6 \%)$ en comparación con los $450 \mathrm{kPa}(85,9 \%-71,1 \%)$, pero cuando se incrementa W por encima de $4 \mathrm{~m} \cdot \mathrm{s}^{-1}$, influye negativamente este efecto sobre el CU para $\mathrm{P}=500 \mathrm{kPa}(\mathrm{CU}=65,9 \%)$ en comparación con $450 \mathrm{kPa}(\mathrm{CU}=73,0 \%)$.

Estos resultados concuerdan con las conclusiones de Li (1997), que demostró que la formación de los tamaños de gota estaba influenciado principalmente por la presión, y es una razón importante para explicar que las gotas pequeñas resultantes de una alta presión pueden perturbar gravemente el modelo de aplicación del agua y ser también el motivo de las pérdidas por el viento y la evaporación.

\section{Efectos de la velocidad del viento en el coeficiente de uniformidad}

De acuerdo con los análisis de varianza mencionados realizados, se encontraron diferencias significativas en la variación de la uniformidad debidas a la velocidad del viento $\left(p=3,0 \cdot 10^{-9},<0,05\right)$, de modo que el CU disminuye con el aumento de $W$, aunque no linealmente. La figura 4 muestra la variación de los valores de CU frente a W para los diferentes marcos de riego y a la presión de trabajo de $450 \mathrm{kPa}$.

De acuerdo con Tarjuelo et al. (1999a) el mejor coeficiente de determinación $\left(R^{2}\right)$ se consiguió gracias a las ecuaciones polinómicas de tercer grado, debido a que $\mathrm{W}$ tuvo un efecto negativo en los valores del CU por encima de una velocidad mínima del viento $(\approx 2$ $\left.\mathrm{m} \cdot \mathrm{s}^{-1}\right)$, mientras que con vientos fuertes $\left(\mathrm{W}>4 \mathrm{~m} \cdot \mathrm{s}^{-1}\right)$ los valores de CU se mantuvieron casi constantes.
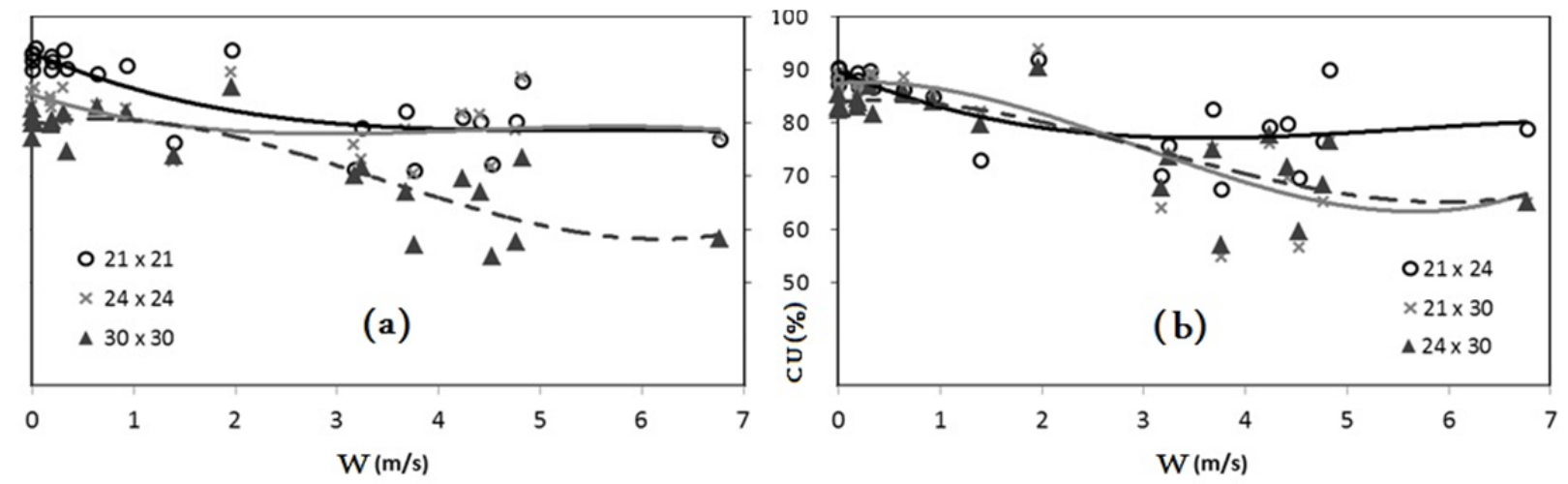

Figura 4. Coeficiente de uniformidad vs velocidad del viento para diferentes marcos de riego, en cuadrado (a) y en rectángulo (b), a $450 \mathrm{kPa}$

Los resultados indican que los valores de $\mathrm{CU}$ aumentan ligeramente en condiciones de baja velocidad del viento $\left(\mathrm{W}<2 \mathrm{~m} \cdot \mathrm{s}^{-1}\right)$ conforme se pasa de 450 a $500 \mathrm{kPa}$, según la tabla 2. Se confirman los resultados de De Lima y Torfs (1994), quienes explicaron que el mayor efecto del $\mathrm{W}$ afecta al tener gotas más pequeñas, debido principalmente a una mayor fricción y menor velocidad de caída, estando más sometidas a la acción del viento. Por otro lado, el CU cae por debajo del $75 \%$ cuando $W$ es superior a $3,5-4 \mathrm{~m} \cdot \mathrm{s}^{-1}$, que según Phocaides (2007), es la velocidad crítica que recomienda para la aplicación de riego por aspersión. De acuerdo con Yacoubi et al. (2012), se puede afirmar que la velocidad del 
viento superior a $4 \mathrm{~m} \cdot \mathrm{s}^{-1}$ afecta significativamente al CU (76,3\%), independientemente de las separaciones entre aspersores y la presión.

La tabla 2 confirma las conclusiones de Seginer et al. (1991b) que indica que la distribución del agua se distorsiona en gran medida para una velocidad del viento mayor a 4 $\mathrm{m} \cdot \mathrm{s}^{-1}$, especialmente cuando la presión aumenta a $500 \mathrm{kPa}$, ya que el efecto anteriormente mencionado de la distorsión del modelo de gotas, no es tan evidente a $450 \mathrm{kPa}$ de presión.

\section{Efectos de la separación entre aspersores y el marco en el coeficiente de uniformidad}

El resultado del test ANOVA mostró que no existen diferencias significativas entre los valores del CU en los marcos cuadrados y rectangulares analizados $(p=0,7911,>0,05)$. Por lo tanto, no es posible concluir qué tipo de marco es más adecuado, cuadrado o rectangular, para el sistema de aspersión analizado y para esta configuración de boquillas. Como se demuestra a continuación, dependerá de la separación entre aspersores seleccionada.

Los resultados muestran claramente como la separación entre aspersores (Se y SI) sí tienen influencias significativas sobre el CU $\left(p=5,75 \cdot 10^{-5},<0,05\right)$. Se puede confirmar la conclusión de Montero et al. (2004), quienes afirmaron que el parámetro de diseño más importante es la separación entre aspersores, después de analizar la influencia de parámetros de diseño y rendimiento, tales como la disposición de la subunidad, la separación entre laterales, la presión, la pluviometría del sistema y la eficiencia de aplicación en el coste de la aplicación del agua, en un sistema de riego por aspersión fijo.

El test de Tukey HSD se ha aplicado con el objetivo de revelar las diferencias significativas del Se y SI en el CU. La tabla 3 muestra los grupos homogéneos para cada marco de riego, diferenciando en las pruebas globales, la presión de trabajo, o las velocidades del viento. De acuerdo con los resultados mostrados en la tabla 3 , los valores medios de CU disminuyen mientras Se y SI aumentan, obteniendo tres grupos homogéneos y destacando que los marcos $21 \times 24,24 \times 24,21 \times 30$ y $24 \times 30$ se incluyen en el mismo grupo, por lo que no hay diferencias significativas entre los valores del CU obtenidos para estos marcos, incluso diferenciando la presión de trabajo.

Tabla 3. Grupos homogéneos de CU para los diferentes marcos de riego, diferenciando por presiones de trabajo y velocidad del viento.

\begin{tabular}{|c|c|c|c|c|c|c|c|c|c|c|c|}
\hline \multirow{3}{*}{$\begin{array}{c}\text { MARCO } \\
\text { Tipo } \\
30 \times 30\end{array}$} & \multirow{2}{*}{\multicolumn{2}{|c|}{$\begin{array}{l}\text { Global } \\
\text { Todas P y W } \\
\text { Media }\end{array}$}} & \multicolumn{4}{|c|}{ Por presión (P) } & \multicolumn{5}{|c|}{ Por velocidad del viento (W) } \\
\hline & & & \multicolumn{2}{|c|}{$\begin{array}{l}450 \mathrm{kPa} \\
\text { Media }\end{array}$} & \multicolumn{2}{|c|}{$\begin{array}{l}500 \mathrm{kPa} \\
\text { Media }\end{array}$} & \multicolumn{2}{|c|}{$\begin{array}{c}<2 \mathrm{~m} \mathrm{~s}^{-1} \\
\text { Media }\end{array}$} & $\begin{array}{r}2-4 \mathrm{~m} \mathrm{~s}^{-1} \\
\text { Media }\end{array}$ & \multicolumn{2}{|c|}{$\begin{array}{r}>4 \mathrm{~m} \mathrm{~s}^{-1} \\
\text { Media }\end{array}$} \\
\hline & 74,6 & $\mathrm{C}$ & 73,1 & $\mathrm{C}$ & 77,5 & $\mathrm{~B}$ & 80,9 & $\mathrm{D}$ & $69,7 \quad A$ & 60,8 & $\mathrm{~B}$ \\
\hline $24 \times 30$ & 78,3 & $\mathrm{BC}$ & 77,5 & $\mathrm{BC}$ & 80,1 & B & 84,5 & C & 71,9 A & 66,1 & $B$ \\
\hline $21 \times 30$ & 79,5 & $B$ & 78,7 & $B$ & 81,2 & $\mathrm{BC}$ & 87,2 & $B$ & $71,5 \mathrm{~A}$ & 64,6 & $B$ \\
\hline $24 \times 24$ & 81,0 & B & 80,6 & $A B$ & 81,6 & $\mathrm{BC}$ & 84,3 & C & 75,1 A & 75,9 & A \\
\hline $21 \times 24$ & 82,5 & $A B$ & 82,3 & $A B$ & 82,8 & $\mathrm{BC}$ & 87,2 & B & 75,8 A & 74,9 & $A$ \\
\hline $21 \times 21$ & 85,3 & $A$ & 85,1 & $A$ & 85,9 & $\mathrm{C}$ & 90,9 & A & $77,0 \quad A$ & 76,5 & A \\
\hline
\end{tabular}

Centrándonos en el análisis de $\mathrm{CU}$ por intervalos de $\mathrm{W}$, para bajo viento los resultados muestran (tabla 3 ) que un aumento de $24 \mathrm{~m}$ hasta $30 \mathrm{~m}$ en la separación entre líneas (SI) no tiene diferencias significativas en el valor de CU cuando "Se" se encuentra a $21 \mathrm{~m}$ (grupo B) o $24 \mathrm{~m}$ (grupo C). Por lo tanto, es importante tenerlo en cuenta en el diseño del sistema de riego puesto que un aumento en la separación entre líneas SI supone soluciones más económicas, incluso, en este sistema semi-portátil en particular, pues implica reducir el tiempo requerido para mover todos los aspersores y, en consecuencia, disminuyen los tiempos muertos entre riegos. 
Sin embargo, seleccionar una separación máxima de aspersores de hasta $30 \mathrm{~m}$ podría originar una disminución importante en el valor de CU cuando aumenta la velocidad del viento por encima de $4 \mathrm{~m} \cdot \mathrm{s}^{-1}$, obteniendo valores del CU $10-15 \%$ más bajos que con separaciones entre aspersores de $21 \mathrm{~m}$ y $24 \mathrm{~m}$. De esta manera, un análisis minucioso de las tablas 2 y 3 revela que todos los marcos cumplen el CU aceptable (80\%) bajo condiciones de poco viento, pero cuando el viento supera este valor, disminuye el CU por debajo del $80 \%$, obteniendo $\mathrm{CU} \approx 75 \%$ para Se $<30 \mathrm{~m}$.

Por lo tanto, se llega a la conclusión de que una buena solución técnico-económica sería un marco de riego cuadrado de $24 \times 24$ o rectangular de 21 × 24 a $450 \mathrm{kPa}$, dependiendo del viento predominante para la superficie de riego. Hoy en día, la separación entre aspersores "Se" que se utiliza con mayor frecuencia en el sistema de riego por aspersión semi-portátil en Irán es de $25 \times 30$ (Sheikhesmaeili, 2003), para las condiciones recomendadas en este estudio (presiones hasta $450 \mathrm{kPa}$ y $\mathrm{W}<4 \mathrm{~m} \cdot \mathrm{s}^{-1}$. Para facilitar la ejecución y el mantenimiento es recomendable seleccionar "Se" múltiplo de $5 \mathrm{~m}$, como $25 \times 30$ en lugar de $24 \times 30$. Por otro lado, una buena recomendación del Se=21 m (o $20 \mathrm{~m}$ ) es que puede ser aplicado en vientos por encima de $4 \mathrm{~m} \cdot \mathrm{s}^{-1}$ con un CU aceptable $(79,4 \%$, según la tabla 2).

Por último, y como resumen de los resultados, la tabla 4 se podría utilizar para seleccionar la mejor separación entre aspersores en el sistema de riego semiportátil con aspersores de gran formato.

Tabla 4. Recomendación de la separación entre aspersores (Se $x$ SI) bajo diferentes velocidades de viento, presión de trabajo y condiciones de solapamiento.

\begin{tabular}{cccccc}
\hline $\begin{array}{c}\text { Viento } \\
\left(\mathbf{m ~ s}^{-1}\right)\end{array}$ & $\begin{array}{c}\text { Se } \times \mathbf{S I} \\
(\mathbf{m} \times \mathbf{m})\end{array}$ & $\begin{array}{c}\mathbf{P} \\
(\mathbf{k P a})\end{array}$ & $\begin{array}{c}\text { Diámetro } \\
\mathbf{m o j a d o} \\
\text { Dw }(\mathbf{m})\end{array}$ & Se/Dw & SI/Dw \\
\hline \hline 2 & $30 \times 30$ & 500 & 60 & 0,50 & 0,50 \\
& $25 \times 30$ & 450 & 56 & 0,45 & 0,54 \\
$2-4$ & $25 \times 25$ & 450 & 56 & 0,45 & 0,45 \\
$>4$ & $25 \times 25$ & 450 & 56 & 0,45 & 0,45 \\
\hline
\end{tabular}

\section{4.- Conclusiones}

La distribución de agua en sistemas de riego por aspersión con aspersores de gran tamaño es muy similar a la producida con aspersores de tamaño medio. Los resultados de este estudio sugieren que es mejor trabajar con una presión de trabajo de $450 \mathrm{kPa}$ frente a $500 \mathrm{kPa}$, a pesar de utilizar boquillas con un gran diámetro. La influencia del viento es significativa sobre el patrón de distribución de agua, sobre todo para velocidades mayores de $2 \mathrm{~m} / \mathrm{s}$. Coeficientes de uniformidad aceptables se pueden conseguir incluso con marcos de riego de $24 \times 30 \mathrm{~m}^{2}$ y $30 \times 30 \mathrm{~m}^{2}$ en situaciones de riegos nocturnos con bajo viento, a la presión de $450 \mathrm{kPa}$. Como consecuencia de este estudio, unos criterios técnicos pueden ser usados para optimizar el manejo del riego con aspersores de gran tamaño, para diferentes escenarios de trabajo que incluyen el marco de riego, la presión de trabajo y el efecto del viento.

\section{5.- Bibliografía}

ASAE. (2001). Standard S398.1: Procedure for Sprinkler Testing and Performance Reporting. ASAE Standards. ASABE, St. Joseph, MI. USA.

Bralts, VF, Pandey, SR \& Miller, A. (1994). Energy saving and irrigation performance of a modified center pivot irrigation systems. App Eng Agric 10(1): 27-36. 
Burt, CM, Clemmens, AJ, Strelkoff, TS, Solomon, KH, Bliesner, RD, Hardy, LA, Howell, TA \& Eisenhauer, DE. (1997). Irrigation Performance Measures: Efficiency and Uniformity. J Irrig Drain Eng 123(6): 423-442.

Christiansen, JE. (1942). Irrigation by sprinkling. California Agricultural Experimental Station Bulletin 670. Univ. California, USA.

De Lima, JL \& Torfs, PJ. (1994). Effects of wind on simulated rainfall and overland flow under single fullcone nozzle sprays. In: Trakiris, G., Santos, M.A. (Eds.). Proceedings of the Second European Conference on Advances in Water Resources Technology and Management. Balkema, Lisbon, Portugal. pp: 443-450.

Dechmi, F, Playán, E, Cavero, J, Faci, JM \& Martínez-Cob, A. (2003). Wind Effects on SolidSet Sprinkler Irrigation Depth and Yield of Maize (Zea mays). Irrig Sci 22(2): 67-77.

ISO Standard 15886-3. (2012). Agricultural Irrigation Equipment. Sprinklers. Part 3. Characterization of distribution and test methods. Geneva, Switzerland.

Keller, J \& Bliesner, RD. (1990). Sprinkle and Trickle Irrigation. AVI Book. Van Nostrand Reinhold. New York. USA.

$\mathrm{Li}, \mathrm{J}$ (1997). Effect of pressure and nozzle shape on the characteristics of sprinkler droplet spectra. J Agric Eng Res 66: 15-21.

Li, J, Kawano, H \& Yu, K. (1994). Droplet size distributions from different shaped sprinkler nozzles. T ASAE 37(6):1871-1878.

Montero, J, Carrión, P, Tarjuelo, JM \& Nin, R. (2006). Calibración de un Disdrómetro óptico para la medida de los tamaños de gota producidas por los aspersores. XXIV Congreso Nacional de Riego, Lugo, Spain. pp: 148-149.

Montero, J, Martínez, RS \& Tarjuelo, JM. (2004). Analysis of water application cost with permanent set sprinkler irrigation systems. Irrig Sci 23(3): 103-110.

Montero, J, Tarjuelo, JM \& Carrión, P. (2003). Sprinkler droplet size distribution measured with an optical spectropluviometer. Irrig Sci 22: 47-56.

Phocaides, A. (2007). Handbook on pressurized irrigation techniques. Food and Agriculture Organization of the United Nations (FAO). 2nd Edition. Rome, Italy.

Report (2014). Pressurized irrigation systems implemented in IRAN. Department of Development of New Irrigation Systems. Ministry of Agriculture Jihad. Iran.

Sánchez, I, Zapata, N \& Faci, JM. (2010). Combined effect of technical, meteorological and agronomical factors on solid-set sprinkler irrigation. II. Modifications of the wind velocity and of the water interception plane by the crop canopy. Agric Water Manage 97(10): 1591-1601.

Seginer, I, Nir, D \& Von Bernuth, RD. (1991a). Simulation of wind-distorted sprinkler patterns. J Irrig Drain Eng 117(2): 285- 306.

Seginer, I, Kantz, D \& Nir, D. (1991b). The distortion by wind of the distribution patterns single sprinklers. Agric Water Manage 19: 341-359.

Sheikhesmaeili, O. (2003). Analysis of the Uniformity, Evaporation and Drift Losses in SemiPortable Sprinkling Irrigation System. MSc Thesis. Univ. Shahid Chamran of Ahvaz. Iran.

Solomon, KH. (1983). Irrigation uniformity and yield theory. Doctoral Thesis. Univ. Utah State. USA.

Tarjuelo, JM, Montero, J, Carrión, PA, Honrubia, FT \& Calvo, MA. (1999a). Irrigation uniformity with medium size sprinklers Part II: influence of wind and other factors on water distribution. T ASAE 42(3): 677-689.

Tarjuelo, JM, Montero, J, Honrubia, FT, Ortiz, J \& Ortega, JF. (1999b). Analysis of uniformity of sprinkler irrigation in semi-arid area. Agric Water Manage 40(2): 315-331.

Tarjuelo, JM, Ortega, JF, Montero, J \& de Juan, JA. (2000). Modelling evaporation and drift losses in irrigation with medium size impact sprinklers under semi-arid conditions. Agric Water Manage 43: 263-284.

Yacoubi, S, Zayani, K, Slatni, A \& Playán, E. (2012). Assessing sprinkler irrigation performance using field evaluations at the Medjerda lower valley of Tunisia. Engineering 4 (10), 682-691. 


\title{
"DimSUb" APLICACIÓN PARA EL DISEÑO Y DIMENSIONADO DE SUBUNIDADES DE RIEGO LOCALIZADO
}

\author{
Arviza Valverde, Jaime (1). Balbastre Peralta, Ibán (2), Palau Estevan, Carmen \\ Virginia (3)
}

${ }^{1}$ Universitat Politècnica de València. Dpto. Ingeniería Rural. jarviza@agf.upv.es
${ }^{2}$ Universitat Politècnica de València. Dpto. Ingeniería Rural. ibbalpe@agf.upv.es
${ }^{3}$ Universitat Politècnica de València. Dpto. Ingeniería Rural. virpaes@agf.upv.es

\section{Resumen}

DimSub es una aplicación informática desarrollada con Visual Basic for Application (VBA) en el entorno Excel cuyo objetivo es el diseño y dimensionado de subunidades de riego localizado admitiendo múltiples opciones: Emisores auto compesantes y no compensantes; alimentación del lateral y terciaria tanto por extremo, punto medio y punto intermedio; doble lateral por fila de plantas en terciarias y posibilidad de terciarias telescópicas. Además, admite varios materiales para la terciaria y el usuario puede modificar todas estas variables. También, permite la gestión de ficheros de datos, calcula el estado de mediciones y los resultados pueden exportarse a RGW2015 para su posterior dimensionado de la red de transporte.

Se ha utilizado un único formulario para facilitar el manejo de la aplicación y que todas las opciones de dimensionado y cálculo se seleccionen en la misma, y que los resultados se visualicen de forma conjunta para una correcta interpretación. soluciones.

Para cada caso estudiado cuantifica las mediciones y los costes de las distintas

\section{Abstract}

DimSub is a software application developed with Visual Basic for Application (VBA) in the Excel whose objective is the design and sizing of drip irrigation subunits admitting multiple options: auto regulated drippers and non regulated ones. Feeding lateral and maninfold by extreme, midpoint or an intermediate point. Lateral double row of plants in manifolds and double diameter manifold possibility. It supports various materials for manifold and the user can modify all these variables. Allows management of data files, enables to calculate measurements and results can be exported to RGW2015 for subsequent sizing the pressure distribution network.

A unique userform has been used to run all options in order to improve the use of the application. Each alternative can be studied in terms of costs and measures. 


\section{Introducción y objetivos.}

El uso generalizado de tecnologías de riego a presión no ha llevado asociado el desarrollo de herramientas de diseño y dimensionado acordes a las necesidades de técnicos e ingenieros, y que garanticen que las soluciones propuestas den respuesta a las necesidades planteadas en estas obras de infraestructura.

En el caso en particular de los sistemas de riego localizado, debido en gran medida a las dimensiones discretas de las parcelas, y por otra parte debido a determinadas políticas comerciales de fabricantes y distribuidores a que no se le preste al diseño y dimensionado el rigor que requiere.

En riego localizado la subunidad de riego o conjunto de laterales conectadas a una terciaria y controlados por un elemento de regulación de presión ya sea manual o automático es la parte fundamental del diseño de los sistemas de riego localizado, en tanto en cuanto, el objetivo principal de cualquier sistema de riego es alcanzar la máxima eficiencia de aplicación, y ello pasa por garantizar una alta uniformidad de distribución en subunidad.

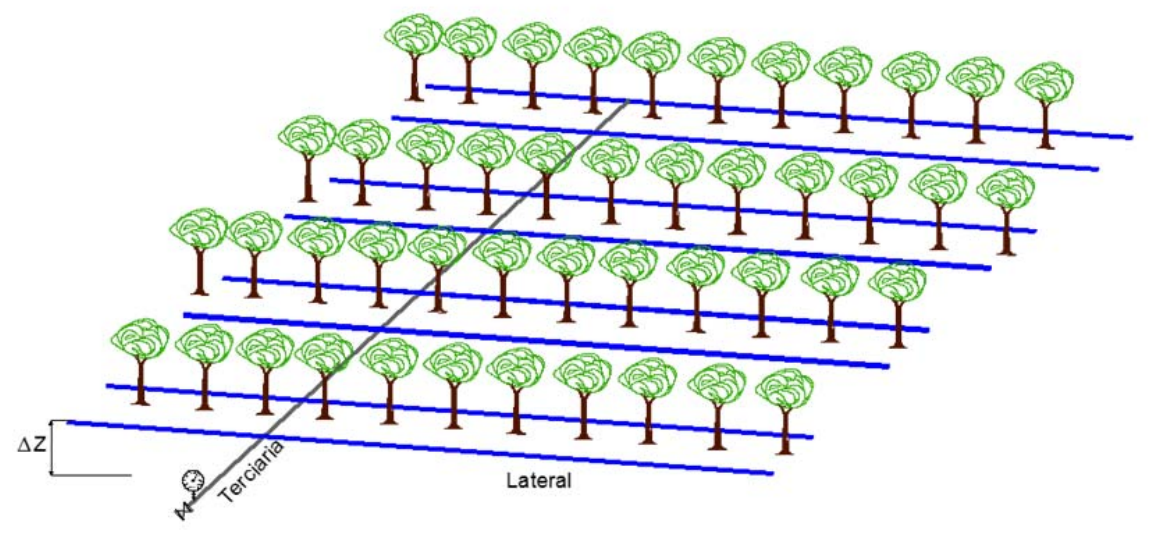

Figura 1: Subunidad de riego

El objetivo que se ha planteado es desarrollar una aplicación informática de distribución libre que permite abordar el diseño y dimensionado de subunidades de riego con el mayor rigor posible, considerando la alta casuística que se presenta en lo que se refiere a tipos de emisores, alimentación de lateral y terciaria, y disposición de emisores en lateral y laterales en la terciaria.

\section{Materiales y métodos}

Dado que la aplicación iba a ser de libre distribución se planteó utilizar el entono de Excel de Microsoft, software comercial universalmente difundido, desarrollando una serie de formularios mediante Visual Basic for Application (VBA) 
La metodología de cálculo de subunidades, ya sea para emisores no compensantes como para emisores auto compensantes se ilustran en las siguientes figuras.

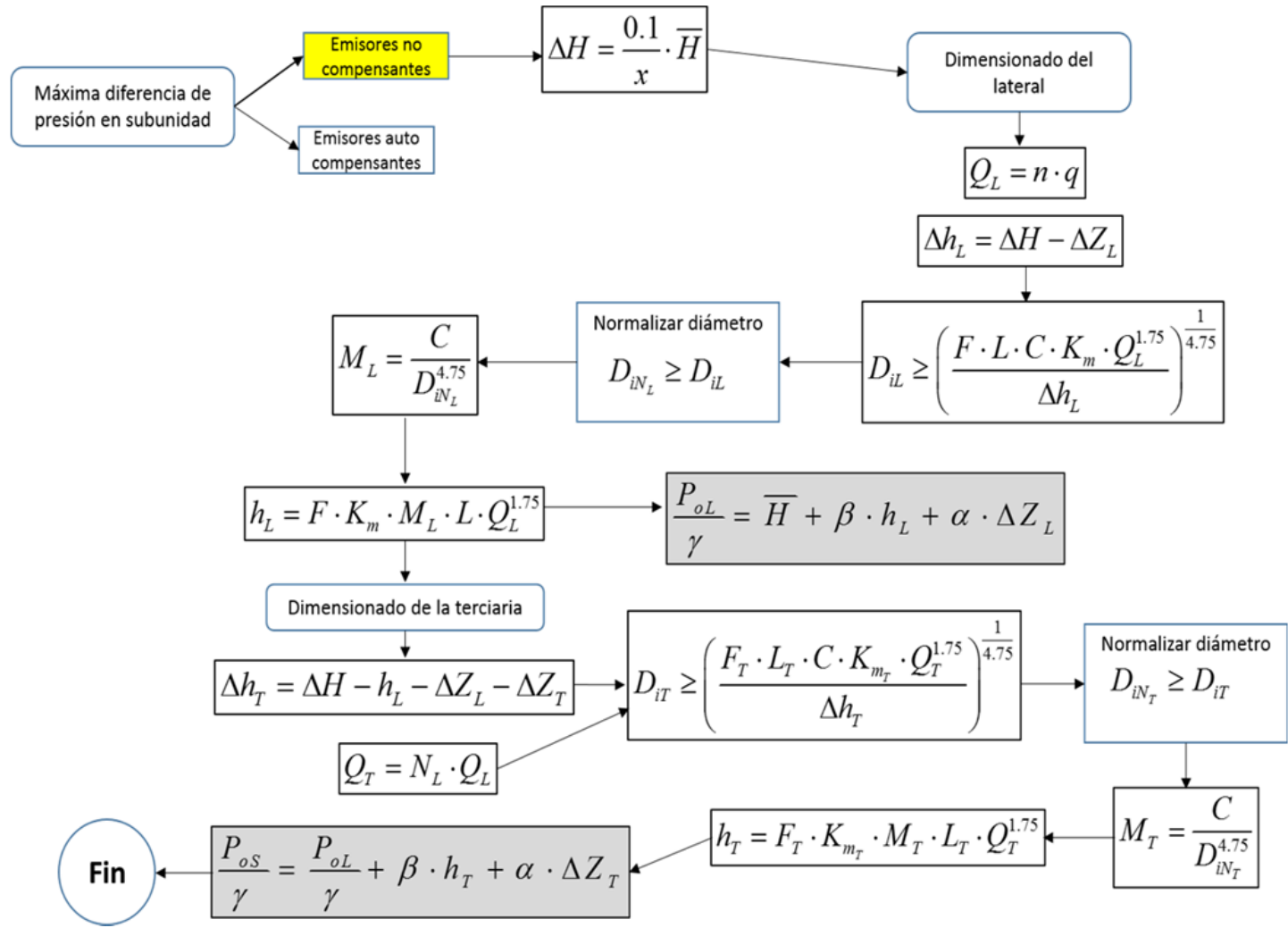

Figura 2: Diagrama para el dimensionado de una subunidad con emisores no compesantes.

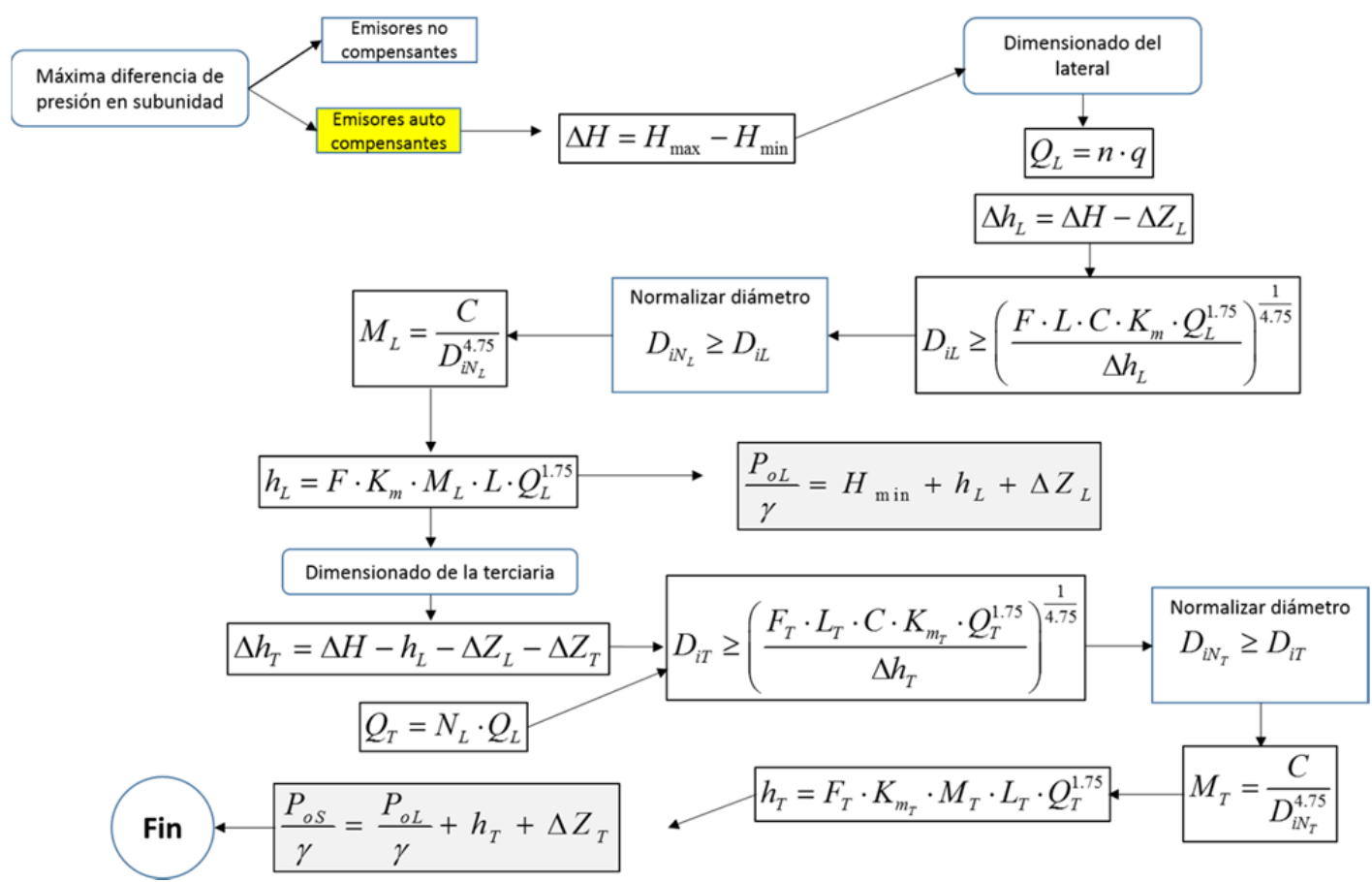

Figura 3: Diagrama de dimensionado para una subunidad con emisores auto compensantes

Cuando tanto lateral o terciaria tiene desnivel descendente, la presión mínima no se verifica al final del lateral, por lo que ha sido necesario desarrollar los correspondientes algoritmos para la determinación del punto de presión mínima en 
lateral y terciaria, y poder proceder a posteriori a el correcto cálculo de la variación máxima de presión en ambas tuberías.

En el caso de laterales y terciarias de dimensiones importantes y con desniveles significativos se ha contemplado la posibilidad de alimentación por un punto intermedio.

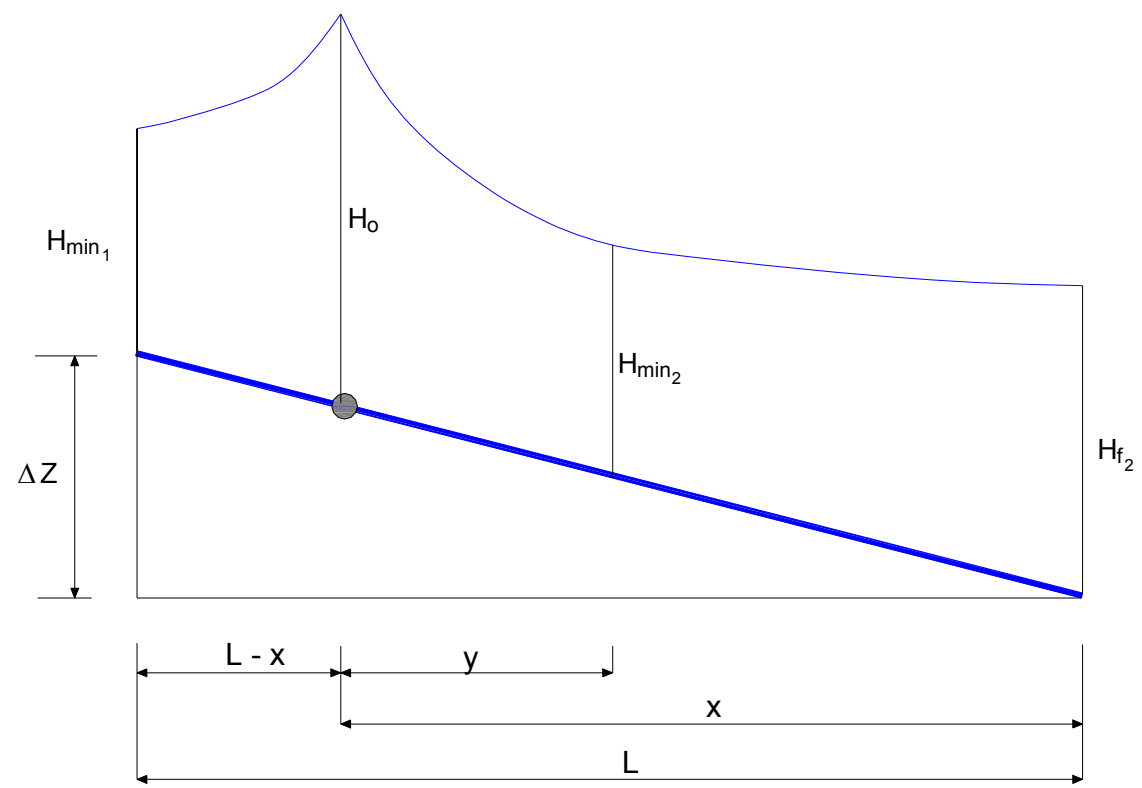

Figura 4: Localización del punto de alimentación intermedio en lateral o terciaria con desnivel.

La localización del punto de alimentación debe ser tal que la presión mínima en el tramo ascendente se iguale a la presión mínima en el tramo descendente.

Para la determinación del punto de alimentación se ha seguido el proceso que se indica en la siguiente figura. 


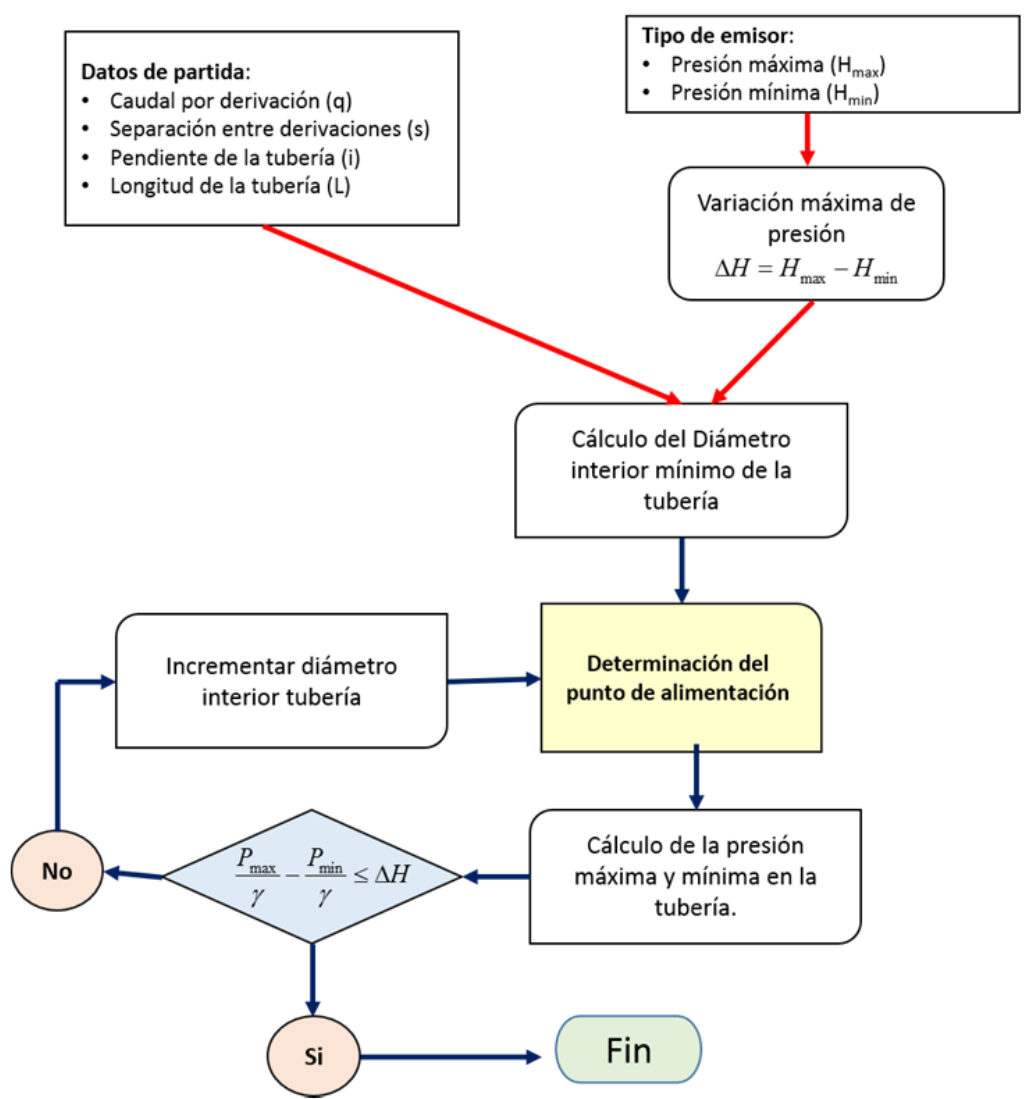

Figura 5:Esquema del proceso de determinación del punto de alimentación y dimensionado.

Se ha contemplado que las tuberías terciarias puedan ser telescópicas. En la figura se ilustra el diagrama de cálculo para este tipo de tuberías.

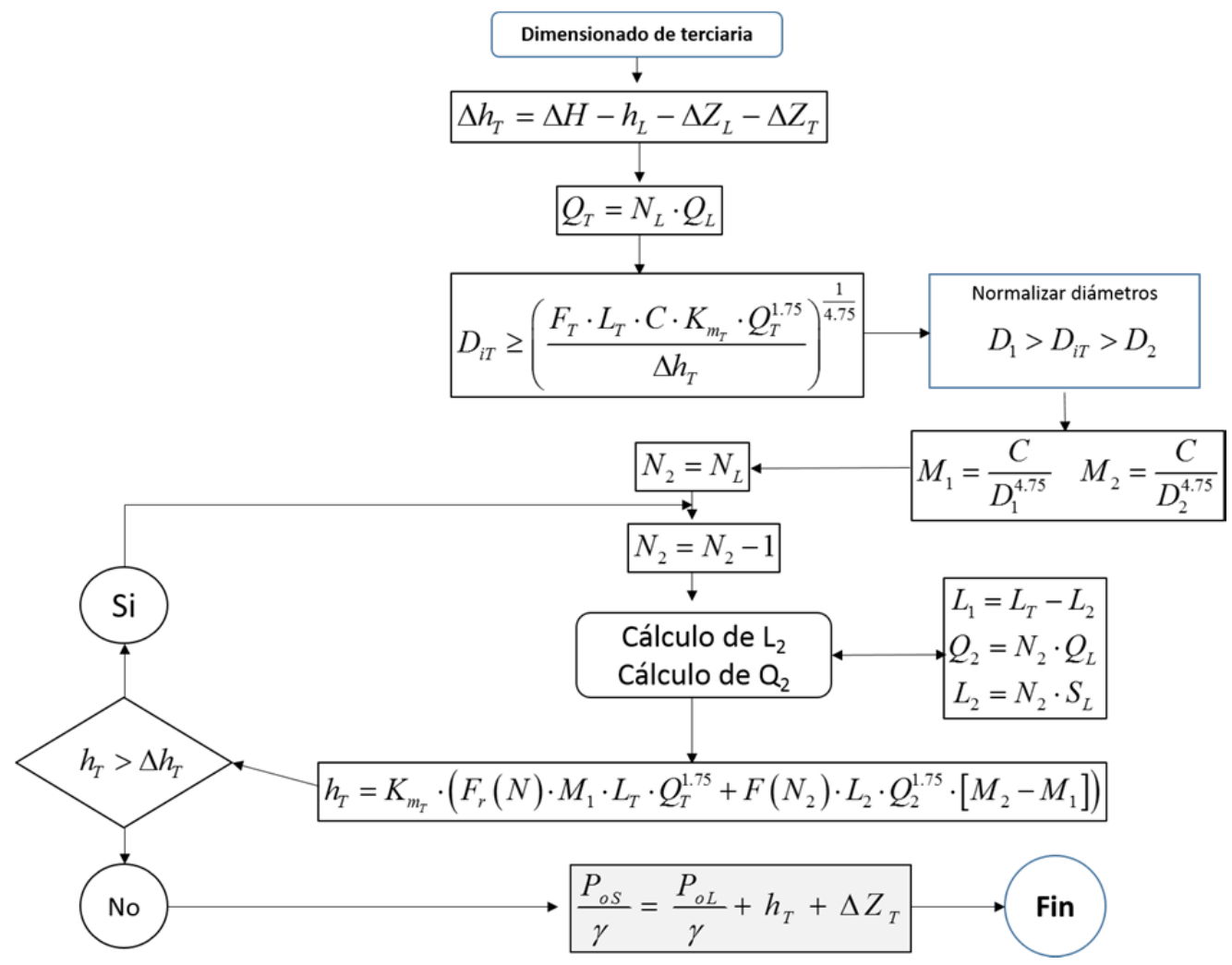

Figura 6: Proceso de cálculo de terciarias telescópicas. 


\section{Resultados}

El resultado final de la aplicación se presenta como un libro Excel habilitado para macros, aunque puede ser incorporado como complemento "Add-Ins" en el menú principal de Excel.

Al abrir el libro aparece una ventana de presentación.

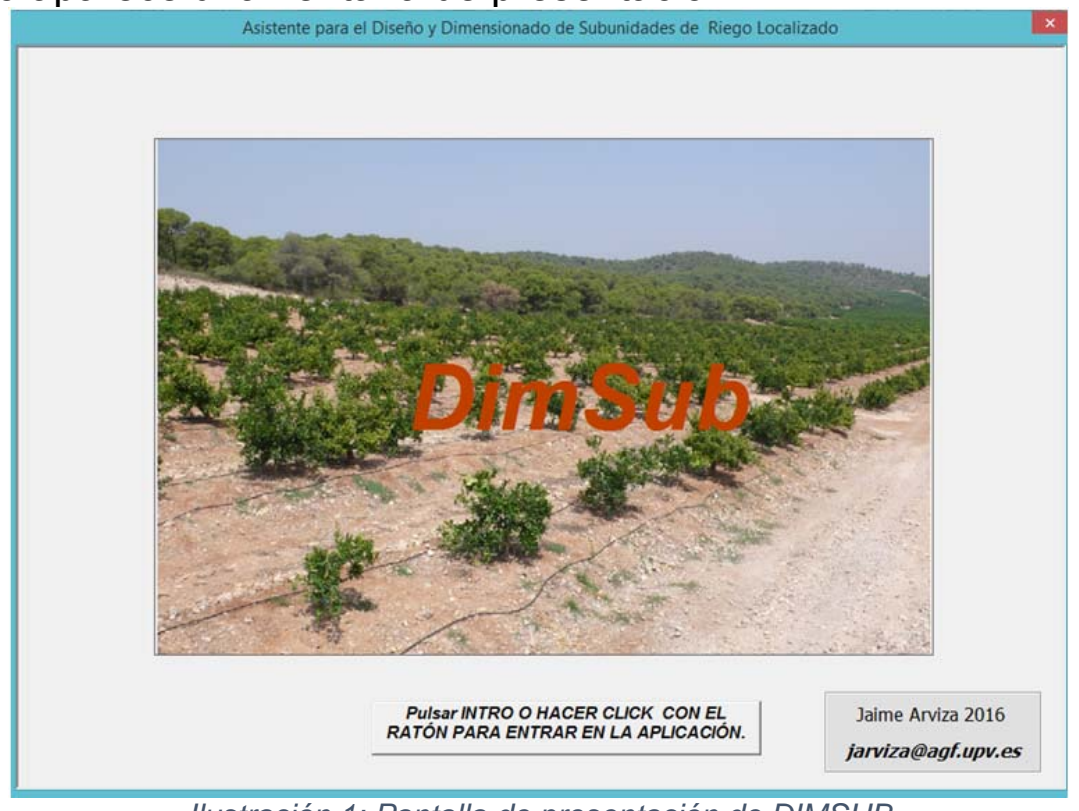

Ilustración 1: Pantalla de presentación de DIMSUB

Clicando en el botón de comando correspondiente se accede a la hoja activa desde la que se activan los formularios.

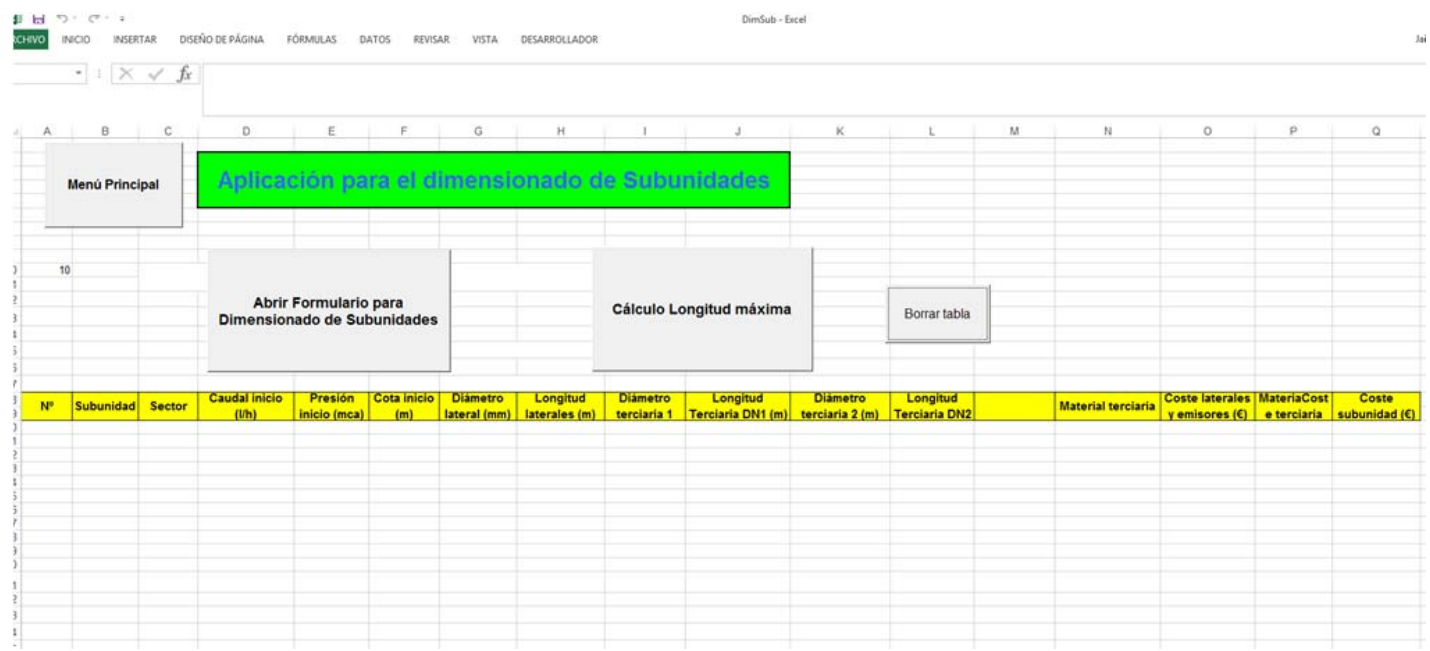

Ilustración 2: Hoja activa con los botones de comando con los formularios disponibles.

Si clicamos en "Abrir Formulario para dimensionado de Subunidades" aparece el mismo en pantalla. 


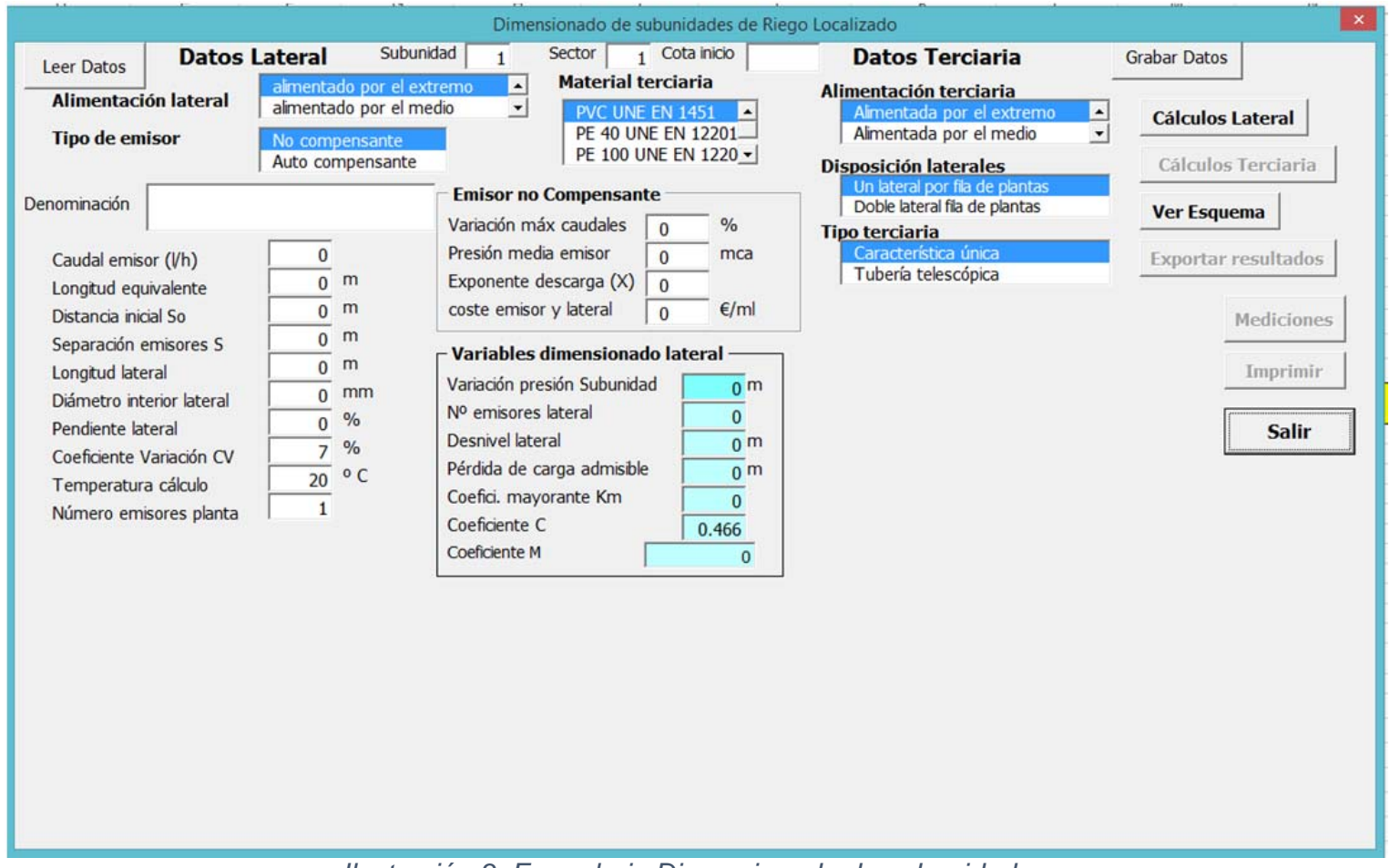

Ilustración 3: Formulario Dimensionado de subunidades.

Para ilustrar sus prestaciones y opciones de cálculo lo aplicaremos a un ejemplo concreto.

\section{Ejemplo}

Se trata del diseño y dimensionado de una subunidad de riego con emisores autocompesantes en una parcela con desniveles y cultivo de cítricos. El caudal del emisor es de $3.5 \mathrm{l} / \mathrm{h}$ con un rango de auto compensación de 10 a 40 mca. El emisor está integrado en una tubería lateral cuyo diámetro interior es de $146 \mathrm{~m}$. Los emisores están dispuestos a un metro en el lateral.

La superficie regable es de 11,67 has. El marco de plantación es de $6 \mathrm{~m} \times 4 \mathrm{~m}$ con doble lateral por fila de plantas. La separación entre laterales que alimentan a la misma fila es de $1 \mathrm{~m}$ y entre laterales que alimentan a filas adyacentes es de $5 \mathrm{~m}$. Las pendientes calculadas en las direcciones de lateral y terciarias son del $2 \%$ y 4 $\%$ respectivamente. 


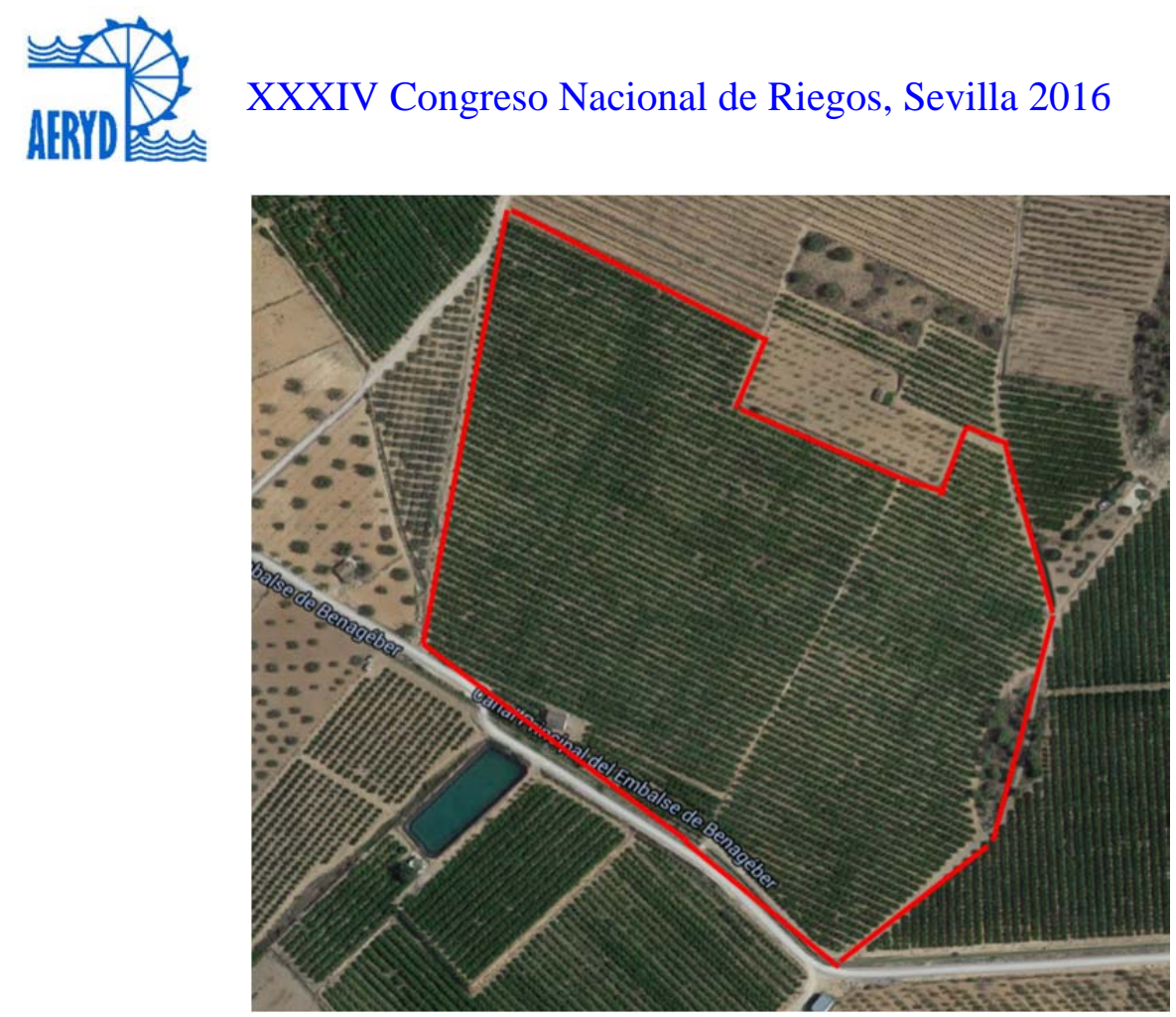

Ilustración 4: Plano y perímetro de la superficie regable
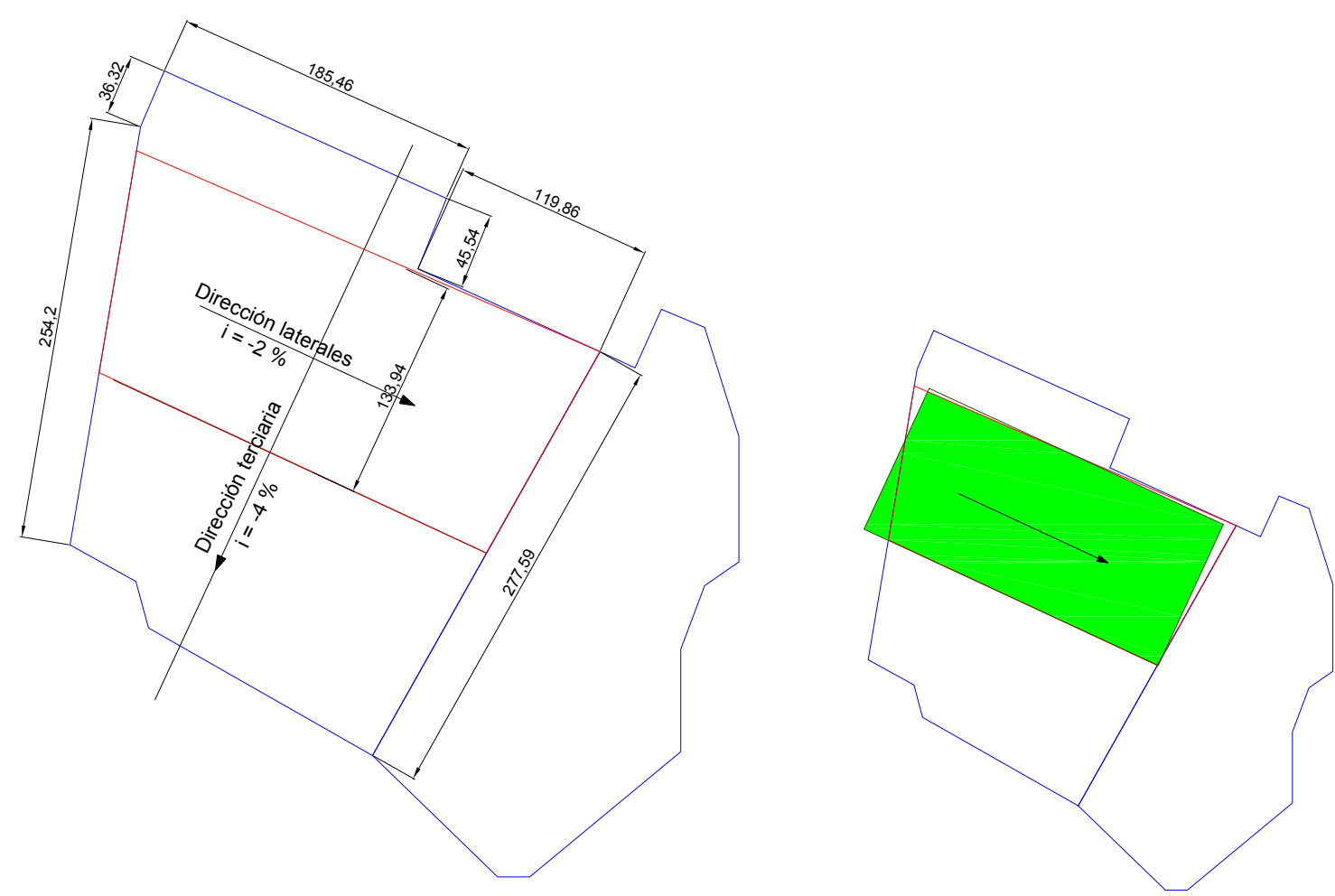

Ilustración 5: Cotas y dimensiones y subunidad a dimensionar

Una vez abierto el formulario se procede a la introducción de datos. Se acepta en primera instancia que los laterales se alimentarán por el extremo. Cuando procedo a calcular aparece la siguiente ventana de aviso. 


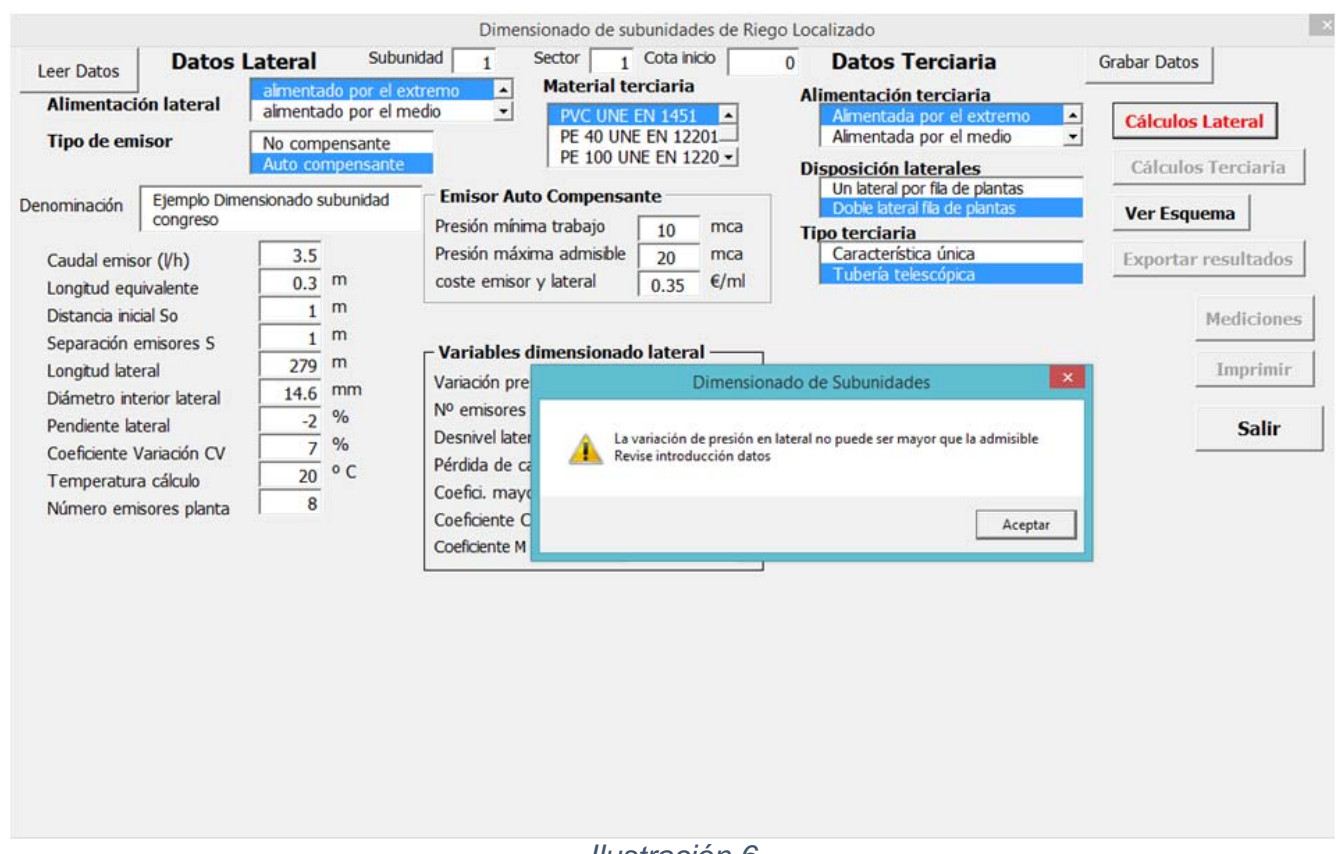

Ilustración 6

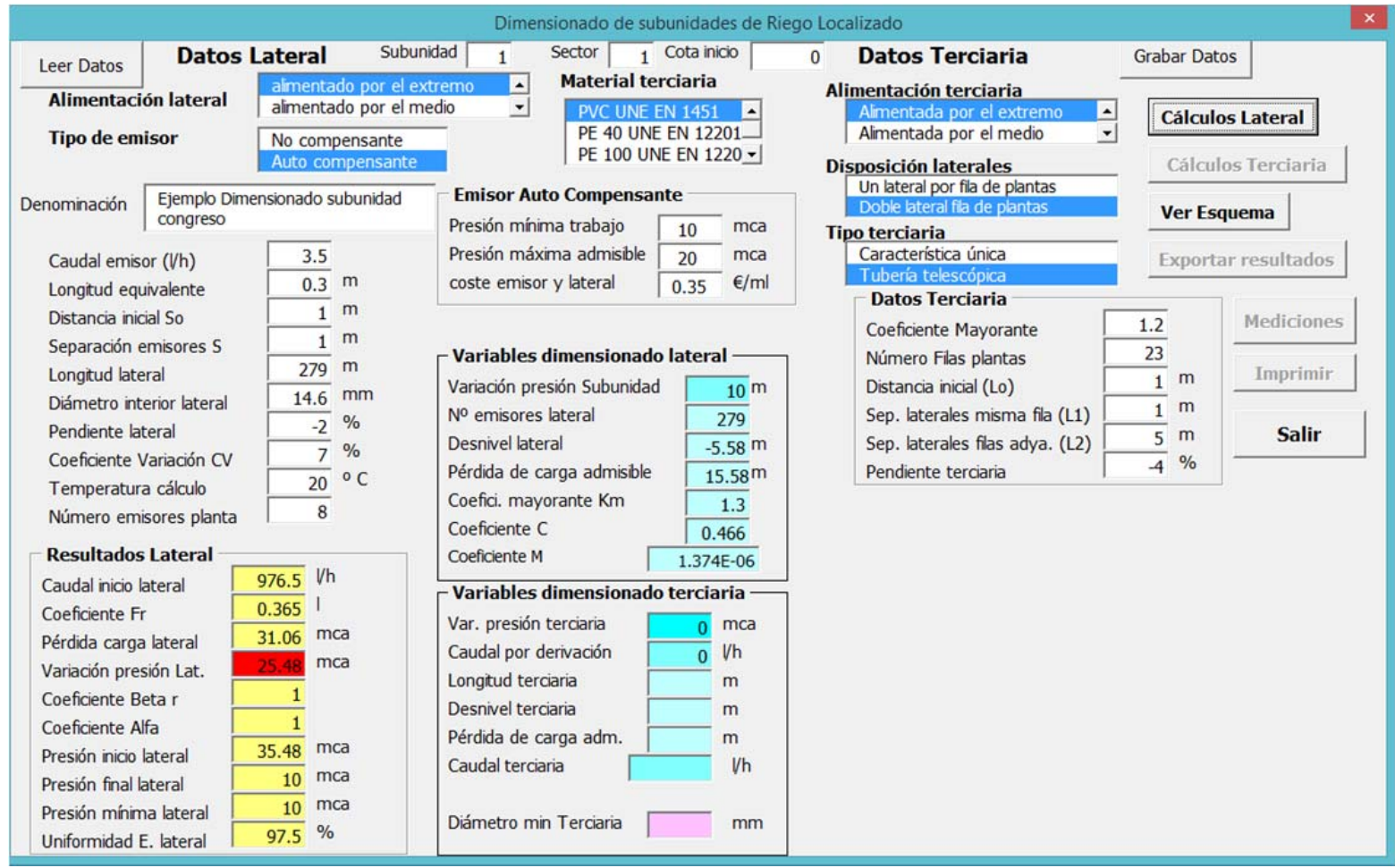

Ilustración 7: Dimensionado de lateral con exceso de variación de presión.

La aplicación me permite continuar los cálculos para ver el exceso de variación de presión en lateral y a qué es debido. La longitud es excesiva. Como la pendiente es significativa se opta por alimentar el lateral por un punto intermedio.

En este caso la variación de presión es admisible, tendré un tramo ascendente de longitud menor y otro descendente de mayor longitud cumpliendo que las presiones mínimas en ambos tramos son iguales, e iguales o mayores que la presión mínima admisible.

Podré proceder al dimensionado de la terciaria: 


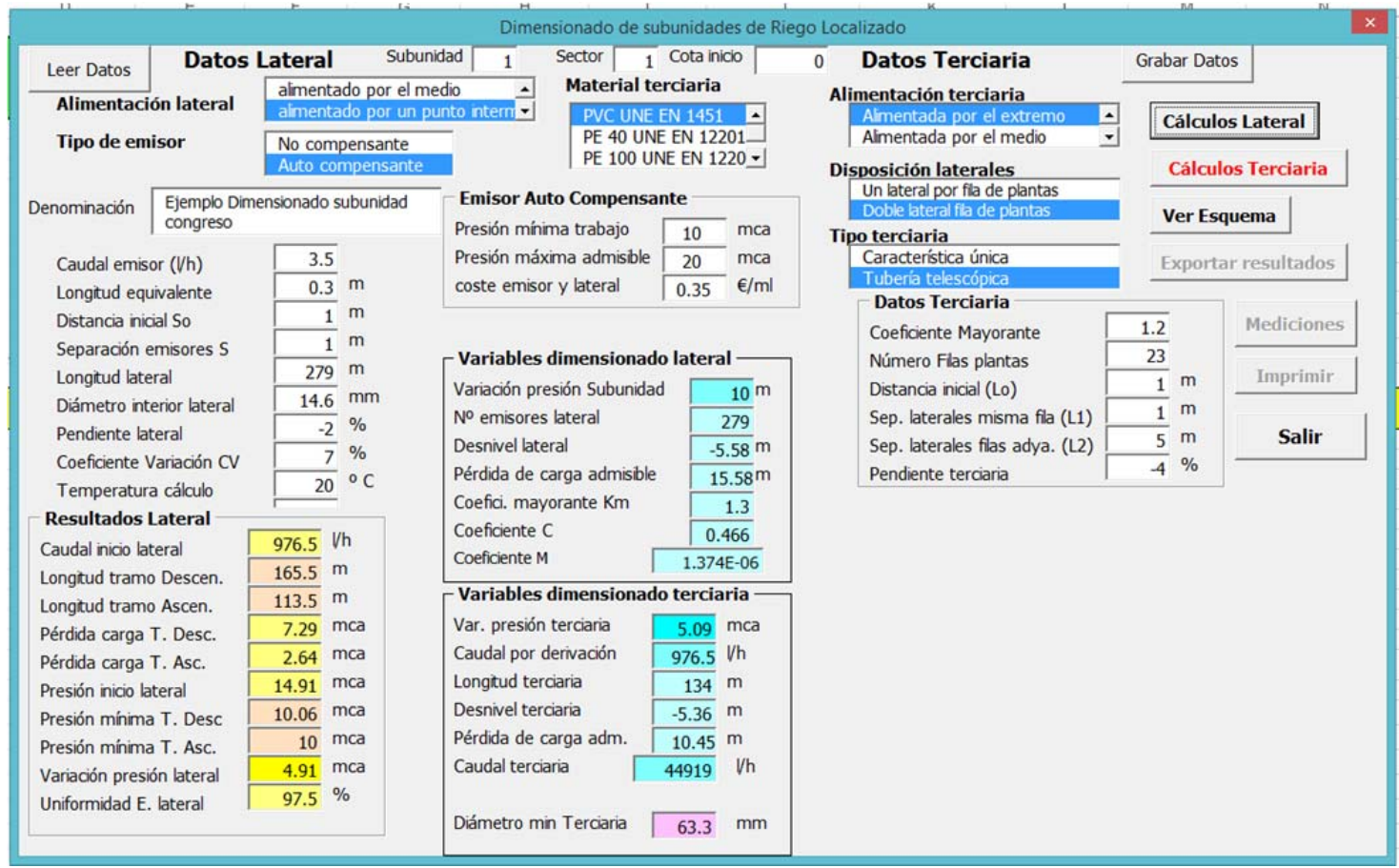

Ilustración 8: Resultados de la alimentación del lateral por el punto intermedio

En el dimensionado de la terciaria se ha optado por la solución de tubería telescópica.

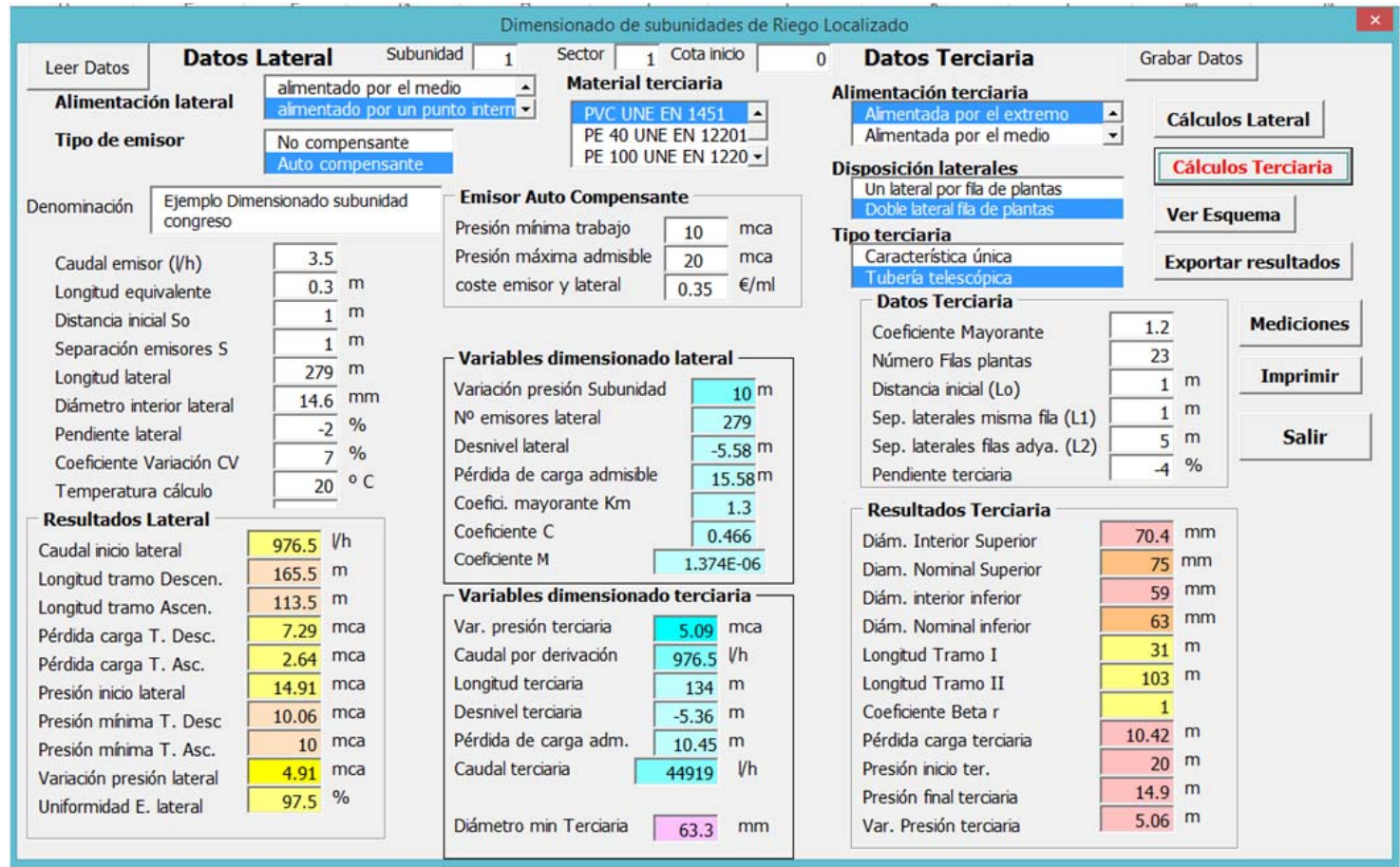

Ilustración 9: Resultados del dimensionado de la terciaria.

La aplicación permite la gestión de ficheros de datos desde el propio formulario, así como visualizar el esquema de cualquier tipo de alimentación de lateral y terciaria (llustración 10). Puede crearse una hoja de impresión para cada subunidad 
dimensionada y exportar resultados para su posterior tratamiento en el dimensionado de la red de transporte.

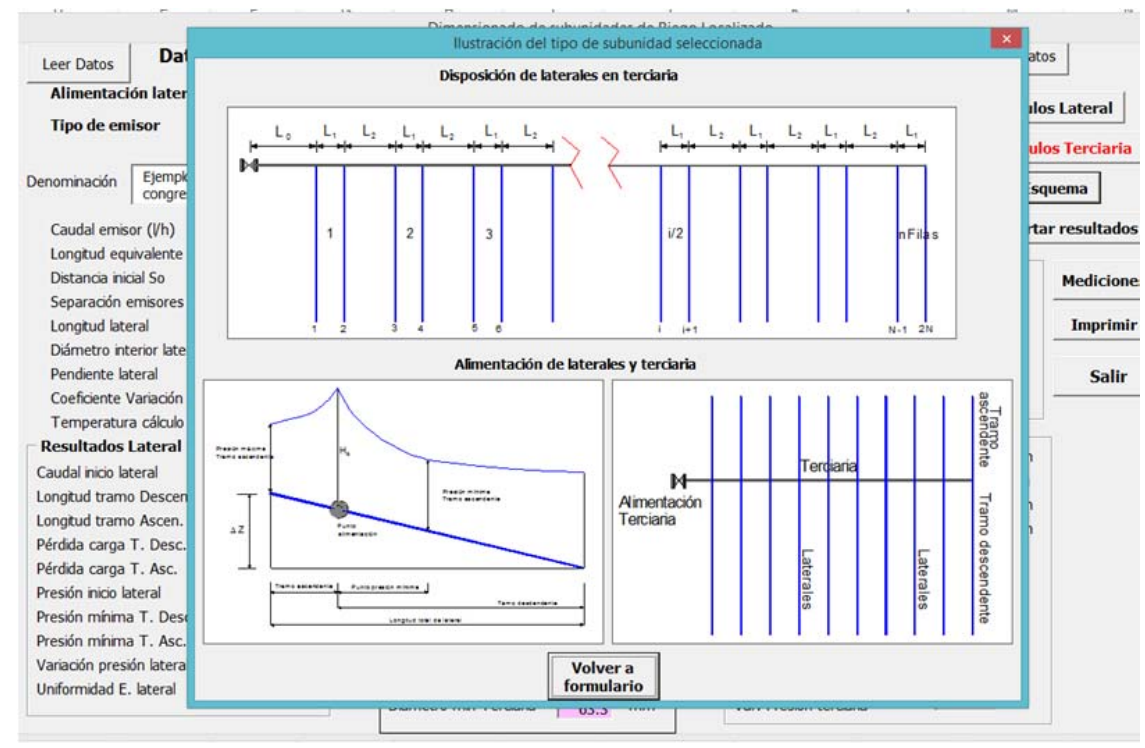

Ilustración 10

Finalmente, permite realizar para cada subunidad las mediciones de laterales, emisores y terciarias así como la correspondiente valoración económica.

\section{Conclusiones}

DimSub es una herramienta de gran utilidad para el diseño de subunidades en proyectos de sistemas de riego localizado a presión.

Consideramos que la aplicación resulta de gran interés tanto en el ámbito técnico como académico, habiendo sido utilizada en el desarrollo de metodologías activas en la actividad docente con muy buenos resultados.

Como siguiente evolución de la aplicación, ésta debe ser integrada en RGW2015 y se está desarrollando un entorno gráfico propio para ampliar las prestaciones de la aplicación.

Al ser un software de distribución libre los autores están abiertos a cualquier tipo de sugerencias, mejoras y comentarios.

\section{Bibliografía}

Arviza, J. "Riego Localizado". Servicio Publicaciones Universitat Politècnica de València. 1996

Arviza, J et Al. "RG WIN 2015, Aplicación para el Diseño y Dimensionado de Redesde Riego a Presión en entorno Excel integrando parámetros agronómicos, energéticos e hidráulicos". XXXIII Congreso Nacional de Riegos. Universitat Politècnica de València. 2015 


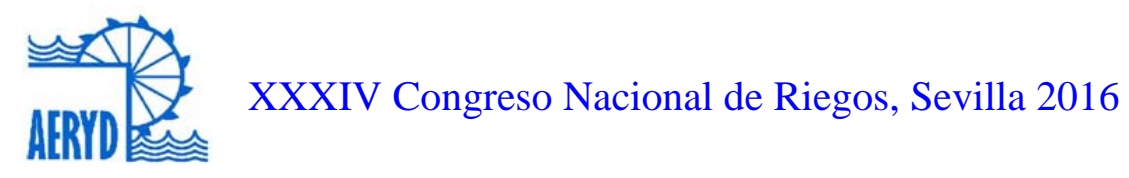

Kreyszig, Erwin. "Matemáticas avanzadas para ingenieros". Volumen 2. Ed. Limusa Willey. 2000

Montalvo López, T. "Riego Localizado. Diseño de instalaciones". Ediciones VJ. Valencia. 2005

Walkenbach,j "Excel 2010. Programación con VBA" Editorial Anaya. Madrid. 2010 


\title{
C-15
}

\section{METODOLOGÍA PARA LA OPTIMIZACIÓN CONJUNTA DE LA PROGRAMACIÓN DEL RIEGO Y ESTACIONES DE BOMBEO EN BOMBEOS DIRECTOS}

\author{
Faci, $E^{1}$, Seral, $P^{2}$, Zorrilla $F^{2}$, Garcia, $A^{2}$, Aliod $R^{2}$, García Asín, $S^{2}$ \\ ${ }^{1}$ Ing. Químico, estudiante doctorado Ingeniería Mecánica. Escuela de Ingeniería y \\ Arquitectura. Zaragoza efaci@unizar.es \\ ${ }^{2}$ Área de Mecánica de Fluidos. Grupo I+D+I GESTAR Escuela Politécnica Superior \\ Huesca.,raliod@unizar.es,susana.garcia@unizar.es
}

\section{Resumen}

Se describe una nueva metodología para reducción de los costes energéticos de operación del riego en redes de riego con bombeo directo, contemplando la optimización conjunta de la organización de los riegos y la modulación de las presiones de la estación de bombeo a lo largo de diferentes periodos tarifarios. Se describe el funcionamiento del método de optimización investigado, que es una extensión y mejora del algoritmo inicial existente desarrollado en (Faci E., 2014) destacando las diferencias y mejoras. Por último, se muestran los resultados en el caso de la red de la CR Callén (Huesca), y se comparan con los obtenidos en un estudio para la optimización energética utilizando el algoritmo inicial.

\begin{abstract}
A new methodology to reduce energy cost in irrigation networks is developed in this paper. Its goal is to optimize simultaneously both pumping station and hydrant operation by setting different discharge pressure on the pumping station and distributing adequately hydrant irrigation during different tariff periods. This methodology is an extension an existing one described in Faci E., (2014) which is only capable of optimize hydrant operation. Advantages and differences between them are described and they are compared in the case study of CR Callén network (Huesca) which shows the new methodology is capable to save an additional $10 \%$ of the annual electricity costs.
\end{abstract}

\section{1.- Introducción, Objetivos}

El objeto de la presente comunicación es describir una nueva metodología para reducción de los costes energéticos de operación del riego en redes de riego con bombeo directo, contemplando la optimización conjunta de la organización de los riegos y la modulación de las presiones de la estación de bombeo a lo largo de diferentes periodos tarifarios.

Se describe el funcionamiento del método de optimización investigado, que es una extensión y mejora del algoritmo inicial existente desarrollado en (Faci, 2014) y con ejemplos de explotación en (Aliod et al. 2015) y (García et al., 2015) en que se optimizaban las peticiones de riego, pero la modulación de presiones de la estación de bombeo era un dato impuesto, destacando las diferencias y mejoras. 
Por último, se muestran los resultados en el caso de la red de la CR Callén (Huesca), y se comparan con los obtenidos en un estudio para la optimización energética utilizando el algoritmo inicial.

\section{2.- Materiales y Métodos}

Se ha construido una extensión del sistema de optimización de programaciones de riego en redes con bombeo directo desarrollado (Faci, 2014)

En el algoritmo original permite optimizar únicamente el momento de apertura y cierre de hidrantes, de modo que la curva de consigna de la estación de bombeo tiene que ser conocida a priori.

Se observó que en algunos estudios era necesario calcular la altura de bombeo de las estaciones de bombeo. Esto requería un proceso iterativo manual en el que se asignan diferentes consignas y elegir aquella que diera mejor resultado.

Por ello, se ha desarrollado una extensión al algoritmo, que es capaz de suplir esta carencia, incorporando como variable de decisión los parámetros de la curva de consigna de las bombas además de los momentos de apertura y cierre que ya incluía el original.

El modelo que representa la bondad de una programación de riego se compone de una suma de funciones validadoras que ponderan distintos aspectos hidráulicos y energéticos del sistema tales como: presión en los hidrantes, velocidad en las tuberías, coste energético, entre otros.

La jornada de riego se discretiza en intervalos de tiempo iguales. En cada uno de ellos, se calcula el estado hidráulico del sistema y se evalúan las funciones validadoras, de modo que la bondad o función objetivo de una jornada de riego se define según la Eq 1.

$$
\text { función objetivo }=\Delta t \cdot \sum_{\mathrm{i}=0}^{\mathrm{N} n \mathrm{n}} \sum_{\mathrm{j}=0}^{\mathrm{NVal}} \mathrm{f}_{\mathrm{j}}\left(\mathrm{t}_{\mathrm{i}}\right)
$$

$\Delta \mathrm{t}$ : duración del intervalo de discretizacion de la jornada de riego

NInt : numero total de intervalos en los que se ha discretizado la jornada de riego

$\mathrm{NVal}$ : número de funciones validadoras.

$\mathrm{f}_{\mathrm{j}}\left(\mathrm{t}_{\mathrm{i}}\right)$ : valor de la función validadora $\mathrm{i}$ - esima en el intervalo $\mathrm{j}$ - esimo

Eq 1. Definición de la función objetivo

Para cada intervalo temporal i-ésimo se evalúan cada una de las funciones validadoras j-ésimas en el instante $t_{i}$. Este valor es el que se pretende minimizar. Las variables independientes del problema son:

- La hora de apertura de cada hidrante

- El valor de los coeficientes: $\operatorname{coef}_{1}, \ldots, \operatorname{coef}_{n}$ que definen la curva de consigna $H=f\left(Q, \operatorname{coef}_{1}, \ldots, \operatorname{coef}_{n}\right)$ de la estación de bombeo. El algoritmo soporta cualquier tipo de curva cuya definición sea explícita. 
El algoritmo para la optimización es de tipo metaheurístico basado en el Ant Colony descrito por (Dorigo, 1992). con optimización local mediante Hill-Climbing. Se ha implementado en C\# (.NET 4.6) y permite el uso de diferentes librerías de cálculo hidráulico como Epanet (Rossman L.) y Netcal (Estrada et al., 2009) desarrollada en el grupo GESTAR.

\section{3.- Caso de estudio}

Se realizó un estudio, año 2014, efectuado para el rediseño de la red de la CRR Callén (Huesca), que consta de 57 hidrantes que riegan una superficie de 698 ha, utilizando el algoritmo original. En tal estudio, las presiones de la estación de bombeo, variables en el tiempo, eran impuestas como condiciones forzadas de explotación, previamente ajustadas mediante tanteos.

El objetivo del estudio era proponer dos niveles de presión en la estación de bombeo, dependiendo del periodo tarifario de modo que se consiguiera un ahorro energético, teniendo en cuenta también el término de potencia, manteniendo una buena calidad de servicio (presión en hidrante suficiente).

En este nuevo estudio, se considera la siguiente curva de consigna constante para cada nivel de presión, de modo que durante P6 la altura de bombeo será $\operatorname{coef}_{1}, \mathrm{y}$ durante P5 hasta P2 será coef $_{2}$ tal y como muestran Eq. 2 y Fig 1:

$$
\mathrm{H}(\mathrm{t})=\left\{\begin{array}{ccc}
\text { coef }_{1} & \text { si } & \mathrm{t} \subset \mathrm{P} 6 \\
0 & \text { si } & \mathrm{t} \subset \mathrm{P} 1 \\
\text { coef }_{2} & \text { si } & \mathrm{t} \subset \mathrm{P} 2-\mathrm{P} 5
\end{array}\right.
$$

Eq. 2 Curva de consigna de la EB

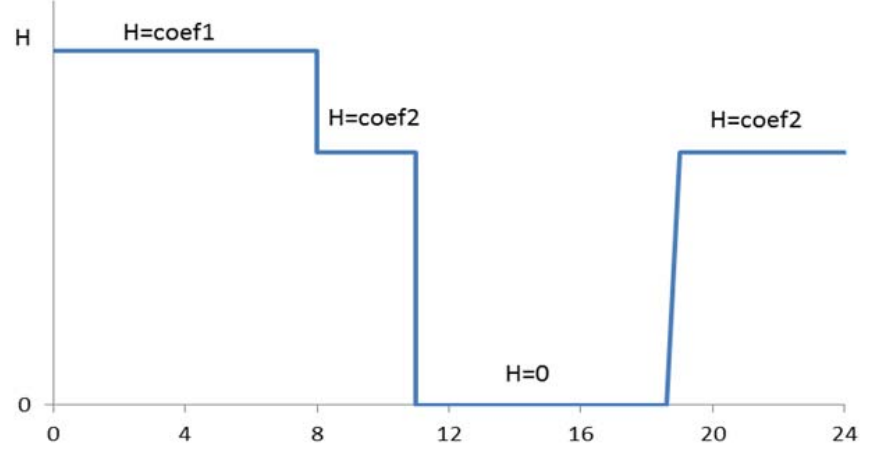

Figura 1. Curva de consigna tipo de la EB en el mes de Julio.

Se optimizará de manera conjunta un día tipo de los meses que tienen relevancia en el riego: mayo, primera quincena de junio, segunda quincena de junio, julio, agosto y septiembre. Se ponderan teniendo en cuenta el número de días de cada mes, de modo que se obtiene el coste anual equivalente.

El caso de estudio pretende optimizar simultáneamente:

1. Apertura y cierre anual de los hidrantes

2. Punto de funcionamiento de la estación de bombeo en alta presión (P3-P6) y el de baja presión (P2).

3. Potencia contratada.

Por ello, se construye la función objetivo de la Eq. 3. 


$$
\mathrm{f} \text { obj. }=\mathrm{f}_{\text {energia }}+\mathrm{f}_{\text {servicio }}+\mathrm{f}_{\text {potencia }}
$$

\section{Eq 3. Función objetivo.}

La función validadora de coste energético evalúa la energía consumida y evalúa su coste dependiendo del periodo tarifario en el que sea consumida tal y como se muestra en la Eq.4:

$$
\begin{aligned}
& \mathrm{f}_{\text {energia }}=\Delta \mathrm{t} \cdot \sum_{\mathrm{i}=0}^{\mathrm{N} n \mathrm{t} t}\left(\sum_{\mathrm{j}=0}^{\mathrm{NBom}} \frac{\mathrm{Y} \cdot \mathrm{Q}_{\mathrm{ij}} \cdot \mathrm{H}_{\mathrm{ij}}}{\eta_{\mathrm{ij}}}\right) \cdot \mathrm{CE}_{\mathrm{i}} \\
& \mathrm{Y}: \text { peso especifico del agua } \\
& \mathrm{Q}_{\mathrm{ij}} \text { : caudal trasegado en el intervalo } \mathrm{i} \text { - esimo en la estacion de bombeo } \mathrm{j} \text { - esima } \\
& \mathrm{H}_{\mathrm{ij}} \text { : altura de impulsión en el intervalo } \mathrm{i} \text { - esimo de la estacion de bombeo } \mathrm{j} \text { - esima } \\
& \eta_{\mathrm{ij}} \text { : rendimiento en el intervalo } \mathrm{i} \text { - esimo de la estacion de bombeo } \mathrm{j} \text { - esima } \\
& \mathrm{C} \mathrm{E}_{\mathrm{i}} \text { : coste de la energía consumida en el intervalo } \mathrm{i} \text { - esimo } \\
& \Delta \mathrm{t} \text { : duración de cada intervalo temporal }
\end{aligned}
$$

Eq 4. Función validadora del coste energético

El coste de potencia contratada se compone de dos términos. El primero evalúa la potencia requerida en P6 y el segundo en los periodos desde P5 hasta P2. Se considera que no se contrata potencia en periodo P1. Se realiza esta distinción, porque es lógico pensar que se requerirá de diferente potencia puesto que el punto de funcionamiento de la EB será diferente.

$$
\begin{aligned}
& \mathrm{f}_{\text {potencia }}=\underset{\mathrm{t} \subset \mathrm{P} 6}{\operatorname{Max}}\left(\sum \mathrm{Pot}_{\mathrm{i}}\right) \cdot \mathrm{CPot}_{\mathrm{P} 6}+\operatorname{Max}_{\mathrm{t} \not \mathrm{P} 6}\left(\sum \mathrm{Pot}_{\mathrm{i}}\right) \cdot \mathrm{CPot}_{\mathrm{P} 2} \\
& \mathrm{Pot}_{\mathrm{i}} \text { : potencia instantáne a consumida por la bomba i - esima } \\
& \mathrm{CPot}_{\mathrm{P} 6} \text { : coste anual unitario de contratacion en } \mathrm{P} 6 \\
& \mathrm{CPot}_{\mathrm{P} 2} \text { : coste anual unitario de contrataci on en P2 (incluyend o P5 - P2) }
\end{aligned}
$$

Eq. 5 Función validadora del coste de potencia

La calidad del servicio, depende únicamente del margen de presión, que se define como MP=P- $P_{\text {Requerida. }}$ Se aplica una penalización lineal por tramos de modo que se aplica un mayor coeficiente si el margen de presión sobrepasa el umbral de MP Leve como se muestra en Eq. 6

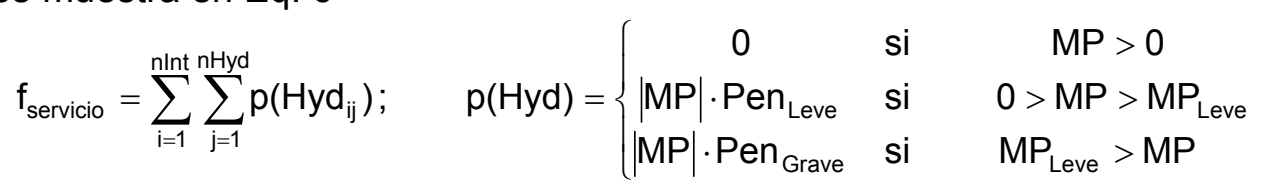

Eq. 6 Función validadora de la calidad del servicio

La altura de bombeo en la metodología original se fijó en 44,5m y $25 \mathrm{~m}$ respectivamente obtenidos de un análisis preliminar mediante el modelo GESTAR de la red. Sin embargo, durante el mes de julio fue preciso regar a altura constante de $44,5 \mathrm{~m}$ para satisfacer los caudales y presiones requeridas por los hidrantes. 
Por el contrario se observa como es preferible mantener una altura de bombeo similar $(39,5 \mathrm{~m}$ y $38,3 \mathrm{~m})$ produciéndose un coste energético ligeramente superior pero consiguiendo disminuir el coste en potencia contratada además de satisfacer casi en su totalidad los requisitos de presión.

Únicamente en durante el mes de julio, se observa que hay un hidrante que incurre en un déficit de presión de 1 mca durante 2 horas, lo cual es perfectamente asumible.

En las figuras Fig 2. y Fig 3. se muestran de forma consecutiva los resultados obtenidos para cada uno de los días tipo que representan los principales meses de la campaña, desde mayo hasta septiembre. En ellos se muestra la distribución de caudales y el margen de presión del hidrante más desfavorable así como el funcionamiento de la EB que se ha optimizado.

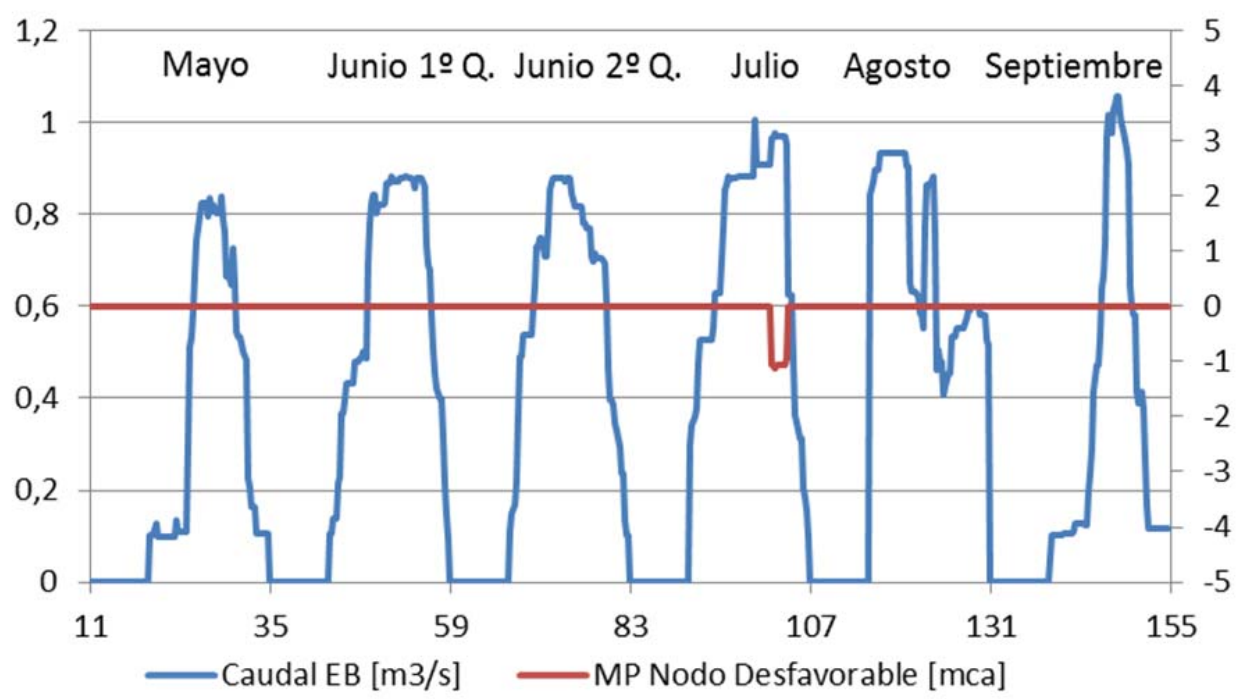

Fig 2. Caudal de la estación de bombeo y margen de presión del Nodo más desfavorable durante cada día tipo de cada mes de la campaña de riego optimizada. 


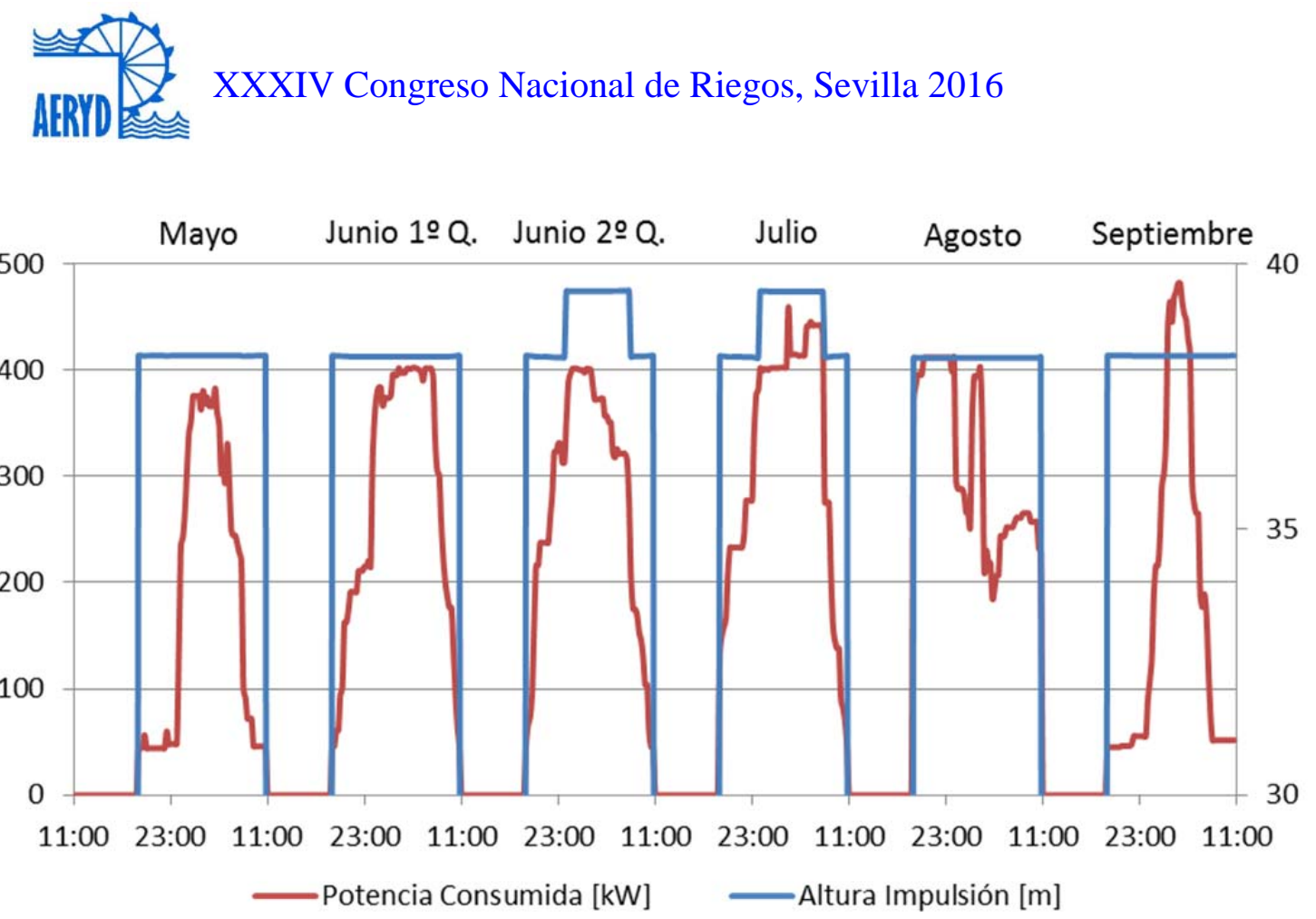

Fig 3. Funcionamiento de la estación de bombeo durante cada día tipo de cada mes de la campaña de riego optimizada.

El tiempo de cálculo, depende en gran medida del tamaño de la red y del número de intervalos en que se haya discretizado. En este caso, la red es pequeña (apenas 50 hidrantes), pero el número de discretizaciones elevadas (casi 600).

El tiempo de cálculo en un ordenador portátil con procesador Intel i7-4710HQ y $16 \mathrm{~Gb}$ de RAM ha sido de apenas 20 minutos. En otros casos, con redes de gran tamaño (en torno a 300 hidrantes) ha supuesto cerca de 2 horas. Por la naturaleza del algoritmo y por cómo se ha implementado, permite su paralelización, por lo que hace uso de todos los cores de la CPU lo que permitiría su utilización en redes de gran tamaño y gran número de discretizaciones.

Por último en la Tabla 1 se muestra una tabla con el resumen de los principales resultados de cada metodología.

Tabla 1. Comparativa de la programación de riego obtenida con ambas metodología.

\begin{tabular}{|l|l|l|}
\hline & Algoritmo original & Algoritmo extendido \\
\hline $\begin{array}{l}\text { Estrategia de } \\
\text { bombeo }\end{array}$ & $44,5 \mathrm{~m} \quad$ P6 +Julio (Impuesta) & $39,5 \mathrm{~m}$ en P6 \\
\hline Potencia contratada & $25 \mathrm{~m} \quad$ Resto P2-P5 (Impuesta) & $38,3 \mathrm{~m}$ en P2-P5 \\
& $\mathrm{P} 2-\mathrm{P} 6 \quad 5 \times 110 \mathrm{~kW}$ (Impuesto) & $\begin{array}{l}\text { P2-P5 4x110kW } \\
\text { P6 5x110kW }\end{array}$ \\
\hline Coste potencia & $38016 €$ & $31132 €(-18 \%)$ \\
\hline Coste energético & $27039 €$ & $27544 €(+2 \%)$ \\
\hline Coste global & $65055 €$ & $58676 €(-10 \%)$ \\
\hline
\end{tabular}

\section{3.- Resultados y Discusión}

El nuevo algoritmo es capaz de optimizar de manera satisfactoria tanto la apertura y cierre como la curva de consigna de la estación conjuntamente. Además de automatizar el proceso, eliminando pasos manuales como la fijación de la potencia 
contratada y de las curvas de consigna que el algoritmo original requería y en un periodo de tiempo aceptable.

\section{4.- Bibliografía}

Aliod R., García S., Faci E., Paño J., Seral P., García A. (2015) "Algorithms and tools for optimum scheduling of on-demand irrigation for an effective energy cost reduction" ICID2015 Conference, Montpellier

Dorigo M. (1992) "Optimization, Learning and Natural Algorithms". Tesis Doctoral, Politecnico di Milano

Estrada, C.; González, C.; Aliod, R.; Paño, J. (2009) “Improved pressurized pipe network for applications in irrigation Systems". Journal of Irrigation and Drainage. ASCE., Vol. 135, No. 4, August 1, 2009..

Faci E. (2014) "Algoritmos evolutivos para la optimización de la gestión hidráulica y energética de redes de riego a presión". Proyecto fin de máster, Universidad de Zaragoza.

García Asin S., Faci E., Aliod R., Paño J., Seral P. (2015) "Algoritmos y herramientas para la aplicación de estrategias de reducción de costes energéticos en sistemas de riego a presión". IV Jornadas de Ingeniería del Agua. Córdoba.

Rossman L. "EPANET 2 USERS MANUAL", Water Supply and Water Resources Division, United States Environment Policy Agency. 


\title{
C-16
}

\section{RESULTADOS PRÁCTICOS DE LA APLICACIÓN DE ESTANDARES INDUSTRIALES A LA INTEROPERABILIDAD EN EL REGADÍO: PROYECTO MEGA}

\author{
González, $D .{ }^{1}$, Calero, $R^{2}{ }^{2}$, Navarro, $M .{ }^{3}$, Iglesias, $S^{4}{ }^{4}$, Martín, $D .{ }^{5}$, Alcarria $R .^{6}$, Robles, \\ $T^{7}{ }^{3}$ López $M^{8}{ }^{8}$
}

${ }^{1}$ Ing. Agrónomo, Empresa de Transformación Agraria S.A. (TRAGSA), C/ Conde de Peñalver, 84, 28006 Madrid, dgonzal5@tragsa.es

2 Ing. Agrónomo, Empresa de Transformación Agraria S.A. (TRAGSA), C/ Conde de Peñalver, 84, 28006 Madrid, rcalero@tragsa.es

3 Ing. Telecomunicaciones, Empresa de Transformación Agraria S.A. (TRAGSA), C/ Conde de Peñalver, 84, 28006 Madrid, mnc@tragsa.es

${ }^{4}$ Ing. Agrónomo, Empresa de Transformación Agraria S.A. (TRAGSA), C/ Conde de Peñalver, 84, 28006 Madrid, siglesia@tragsa.es

${ }^{5}$ Doctor Ciencias de la Computación, Dpto. Ingeniería de Sistemas Telemáticos de ETSI Telecomunicaciones, Av. Complutense 30, 28040 Madrid, diego.martin.de.andres@upm.es

${ }^{6}$ Doctor Ing. Telecomunicación, Dpto. de Ingeniería Topográfica y Cartografía de la ETSI en Topografía, Geodesia y Cartografía, Carretera de Valencia, km 7, 28031 Madrid, ramon.alcarria@upm.es

${ }^{7}$ Doctor Ing. Telecomunicaciones, Dpto. de Ingeniería de Sistemas Telemáticos de la ETSI Telecomunicaciones, Av. Complutense 30, 28040 Madrid, tomas.robles@upm.es

8 Doctor Ing. Agrónomo, Empresa de Transformación Agraria S.A. (TRAGSA), C/ Conde de Peñalver, 84, 28006 Madrid, mlopez@tragsa.es

\section{Resumen}

La falta de estandarización en los sistemas de telecontrol de regadío dificulta enormemente la gestión y el mantenimiento de los mismos, pero no menos importante es reconocer que dificulta la explotación de las propias infraestructuras modernizadas. El proyecto MEGA define los criterios para establecer interoperabilidad entre los diferentes sistemas de control y gestión que se emplean en el regadío. Dicha interoperabilidad se basa en el establecimiento de una nueva arquitectura de control a través de la cual se comuniquen los diferentes sistemas mediante un lenguaje de modelización desarrollado exprofeso. El desarrollo teórico de la modelización y el diseño de la nueva arquitectura tienen un largo recorrido y son conocidos por todo el sector. Se pretende presentar a continuación cómo se ha procedido a la validación empírica de esas bases teóricas estableciéndose una interoperabilidad real entre diferentes sistemas, participando en las pruebas diferentes agentes del sector del regadío. 


\begin{abstract}
The lack of standardization of telecontrol systems for irrigation complicates their management and maintenance as well as the exploitation of modernized infrastructures. The MEGA project defines the criteria for establishing interoperability between different control and management systems used in irrigation. Such interoperability is based on the establishment of a new control architecture enabling the communication of various systems by a modeling language developed for this purpose. The theoretical development of modeling and design of the new architecture have a long way and are known throughout the sector. In this work we present the procedure to empirical validation of these theoretical bases, establishing a real interoperability between different systems, participating different operators from the irrigation sector in the testing.
\end{abstract}

\title{
1. Introducción y objetivos
}

Los sistemas de telecontrol son la cara más visible del regadío modernizado. Gran parte de sus potencialidades teóricas no han podido ser explotadas por dos grandes carencias en su concepción:

- Son soluciones cerradas e integrales. Incluyen hardware y software, ambos desarrollados atendiendo a las capacidades del fabricante del sistema y no a las necesidades de los usuarios finales. Por otro lado, pretenden abarcar ámbitos ligados pero que responden a necesidades diferentes: el control y la gestión.

- No están sometidos a normalización, al no existir estándares que definan especificaciones funcionales mínimas ni mecanismos de integración entre componentes de diferente fabricante.

Estas dos situaciones plantean limitantes críticos que producen ineficiencias en la explotación de infraestructuras modernizadas ya que:

- Dificultan el mantenimiento. No permiten una renovación y sustitución progresiva de equipamientos averiados y/u obsoletos si no es por los mismos elementos.

- Establecen barreras de acceso. Se establece una relación de dependencia entre los explotadores de las infraestructuras modernizadas y los instaladores del sistema de telecontrol elegido. La introducción de mejoras y actualizaciones de funcionalidades queda fuertemente restringida.

- Inhiben la aparición de aplicaciones de gestión especializadas. El foco de la modernización ha estado, hasta la fecha en los sistemas de control, dejando en un segundo plano la necesidad de gestionar las infraestructuras en base a criterios de eficiencia energética e hidráulica. Es en este punto donde reside actualmente el interés fundamental de los gestores y explotadores. La gestión coordinada entre agua y energía, o la generación de índices operacionales, no es asumible en la actualidad. Multitud de datos recogidos por los sistemas de 
telecontrol tienen una gran relevancia para la toma de decisión, pero no existen mecanismos para explotar esta potencialidad.

- Como no existe una caracterización unívoca de formatos, contenidos y dimensiones de los datos recogidos por los sistemas, los gestores se encuentran con informaciones de origen, formato y constitución diferentes. Esta ausencia de normalización en los datos acentúa la ineficiencia en la gestión.

Para contribuir a la problemática descrita surge el proyecto MEGA (Modelo Estandarizado de Gestión del Agua), con el objetivo de definir y desarrollar los criterios para establecer interoperabilidad entre los diferentes sistemas de control y gestión que se emplean en el regadío. El proyecto se centra en facilitar a los usuarios de instalaciones modernizadas las herramientas adaptadas a sus necesidades, buscando el máximo consenso con el resto de agentes involucrados: empresas del sector, administraciones y otros organismos del sector de la agricultura y la gestión de agua.

\section{Materiales y métodos}

El proyecto MEGA ha permitido elaborar un documento técnico sobre interoperabilidad entre sistemas de telecontrol. Este documento además, ha sido presentado y aprobado en la reunión ISO/TC 23/SC 18 - Remote monitoring and control systems del comité de normalización de ISO para que sea la base para la normalización de estos sistemas en términos de interoperabilidad. La estrategia que se ha seguido para resolver los problemas detectados se fundamenta en la normalización de tres ejes: modelización de regadío, definición de una nueva arquitectura interoperable y desarrollo de las herramientas informáticas necesarias para la aplicación de los dos primeros ejes.

Modelización de los elementos propios del regadío: informaciones básicas y operacionales.

La modelización se ha abordado empleando experiencias de otros sectores productivos a nivel internacional. Esta línea permite avanzar en la definición de soluciones sin fijar especificaciones tecnológicas que restrinjan el presente y el futuro del telecontrol y la gestión de regadíos. Define con fines de control y gestión, la estandarización de las infraestructuras hidráulicas del regadío. Se basa en el estándar internacional EN61512 - Control de los procesos de fabricación por lotes, conocido en el sector industrial como S-88. La metodología empleada aporta además herramientas para mejorar el control y la gestión, destacando:

- clasificación para los sistemas de control según con sus especificaciones constructivas, facilitando la correcta especificación de acuerdo con las necesidades de los usuarios. Esta clasificación permitirá reducir la dispersión en cuanto a calidad y funcionalidades entre sistemas.

- generación de indicadores de gestión de consumo de agua y eficiencia energética, entre otros. Con esos indicadores, el gestor podrá evaluar los resultados del manejo y mantenimiento de las instalaciones, ayudando a su mejora y corrección. 


\section{Nueva arquitectura software de los sistemas actuales, estableciendo los cauces para el lenguaje fruto de la modelización.}

Para alcanzar el objetivo de la interoperabilidad entre diferentes sistemas que operan en el regadío, no sólo debe estandarizarse el lenguaje común que emplearán, sino la arquitectura a la que todos estos sistemas deben responder. La nueva arquitectura definida por MEGA incluye dos interfaces normalizados a través de los cuales se empleará el lenguaje fruto de la modelización.

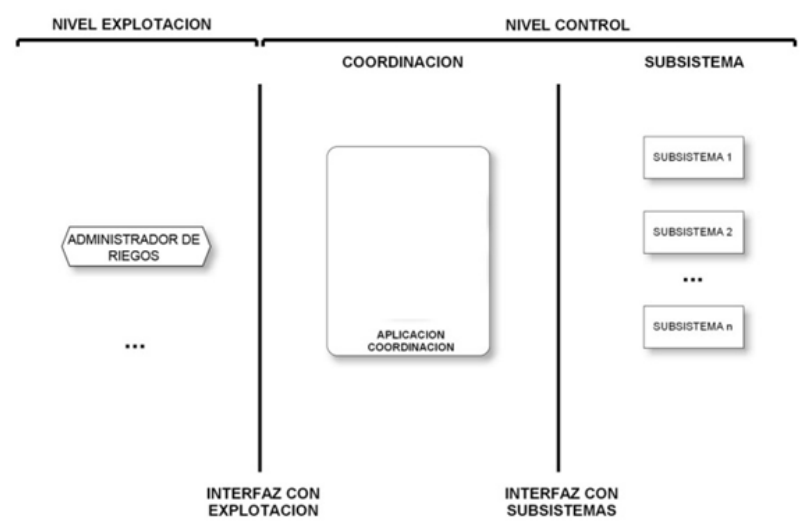

Figura 1: Arquitectura interoperable en las TICs del regadío

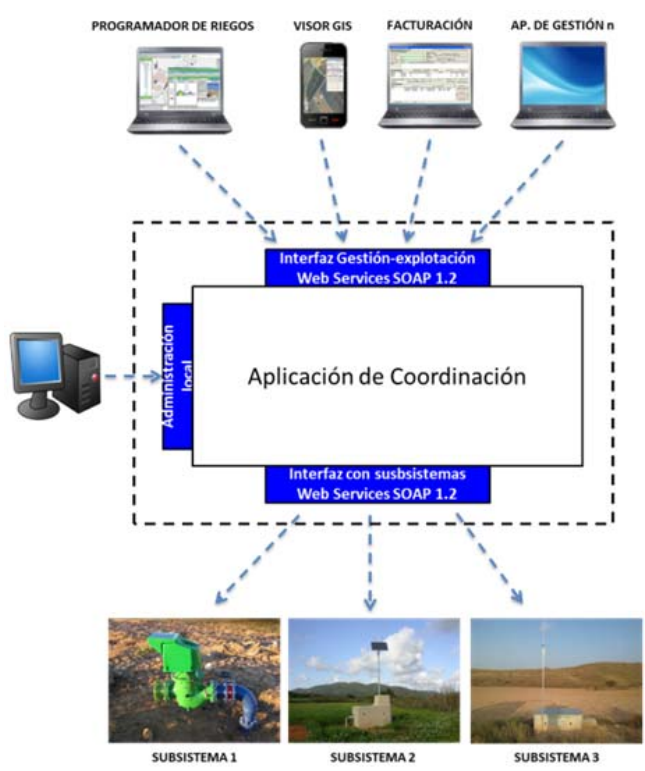

Figura 2: Aplicación de la arquitectura interoperable a las TICs del regadío

La nueva arquitectura pretende alcanzar una diferenciación clara entre dos mundos dependientes pero distintos:

- Nivel de gestión/explotación, orientado a la toma de decisiones.

- Nivel de control, dividido a su vez en dos subniveles, se orienta a la transmisión y adquisición de datos, así como a la ejecución de los procesos que se realizan en una entidad hidráulica. 
Esta nueva arquitectura será tendente a la especialización de los elementos que la componen.

Desarrollo de las herramientas necesarias para habilitar la nueva arquitectura que usa el lenguaje de modelización: la aplicación de coordinación.

La Universidad Politécnica de Madrid y Tragsa han colaborado en el desarrollo de la primera aplicación de coordinación con el fin de validar el lenguaje y la arquitectura definidos en el estándar, así como proporcionar los elementos comunes para el acoplamiento e interconexión de los sistemas de control y gestión del mercado. La aplicación de coordinación sustenta la interoperabilidad mediante la implementación de las siguientes funciones:

- Función 1. Mapeado/carga de entidades hidráulicas.

- Función 2. Monitorización de entidades hidráulicas.

- Función 3. Gestión de recetas de operación (programas de riego).

- Función 4. Envío de peticiones y recogida de respuestas.

- Función 5. Comunicación con los sistemas de telecontrol (subsistemas).

- Función 6. Comunicación con las aplicaciones de gestión.

- Función 7. Repositorio de datos.

Implementa dos interfaces de comunicación usando la tecnología de Servicios Web (o Web Services) para comunicarse con sistemas de telecontrol (interfaz con subsistemas) y con aplicaciones de gestión (interfaz con explotación). Recibe peticiones a través del protocolo SOAP (Simple Object Access Protocol) de la capa de gestión y realiza peticiones SOAP a la capa de subsistemas.

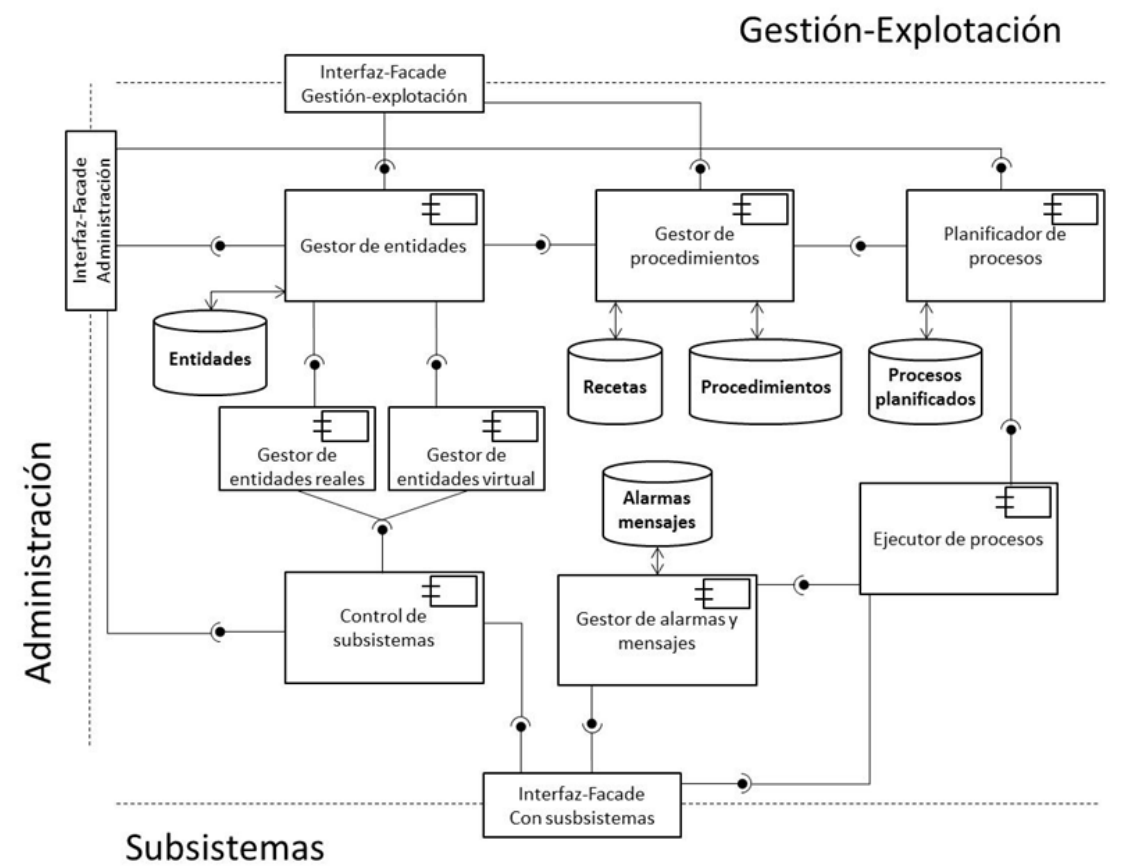

Figura 3: Diagrama de módulos que conforman una aplicación de coordinación 


\section{Resultados y discusión}

La adaptación de los sistemas de gestión y telecontrol al estándar de interoperabilidad definido, se ha verificado mediante la aplicación de una batería de ensayos sobre un conjunto de sistemas que han participado como pioneros. Las pruebas realizadas en el banco de ensayos de Aula Dei, centro de investigación que forma parte del CSIC, se basan en la especificación de un protocolo de ensayos que será presentado en ISO para avanzar en el estándar de interoperabilidad a nivel internacional.

Las pruebas se han iniciado en 2016 y continúan actualmente en desarrollo, continuando los participantes los desarrollos necesarios para adaptarse completamente a la especificación de MEGA. Actualmente la adaptación es parcial pero ilustrativa de los objetivos y metas esperables a corto plazo. Los participantes en esta fase de pruebas inicial son un núcleo de empresas con un claro interés estratégico en liderar la adaptación de los sistemas tradicionales de control y gestión del regadío:

- Tragsa, Universidad Politécnica de Madrid y EEAD-CSIC como organizadores e impulsores del proyecto MEGA y supervisores en las pruebas de validación.

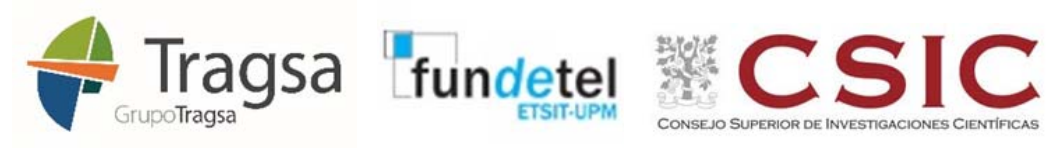

- ICR, Regaber e Isastur como empresas fabricantes de sistemas de telecontrol.
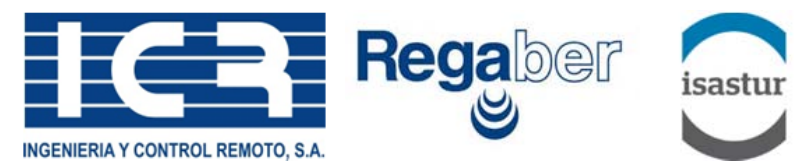

- Batchline Control y Serina como empresas desarrolladoras de aplicaciones de gestión (módulos de facturación y programación de riegos).
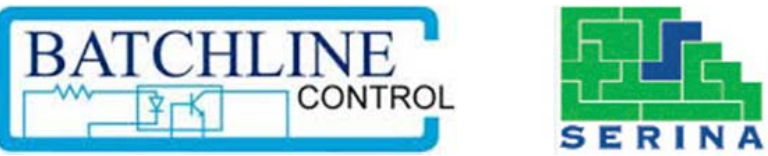

Figura 4: Participantes en las pruebas de validación del prototipo de interoperabilidad

\section{Entorno de pruebas}

Las pruebas necesarias para verificar la interoperabilidad se han realizado en un banco de ensayos diseñado para tal fin y ubicado en, estación experimental de Aula Dei, adscrita al Centro de Investigaciones Científicas (CSIC). El banco de ensayos replica un sistema completo, desde la acometida hasta el hidrante, con el fin de poder extender la interoperabilidad a cualquier infraestructura típica del regadío. 


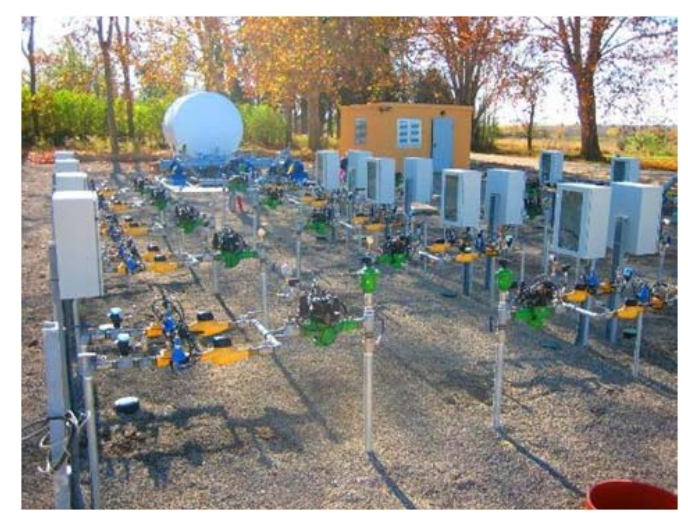

Figura 5: Banco de ensayos de interoperabilidad (Aula Dei)

La instalación dispone, entre otros elementos, de 40 hidrantes denominados hidrantes (HYS) simples en la modelización, con un hidrómetro de cabecera. El esquema hidráulico característico de un hidrante simple (replicado en el banco de ensayos) es el siguiente:
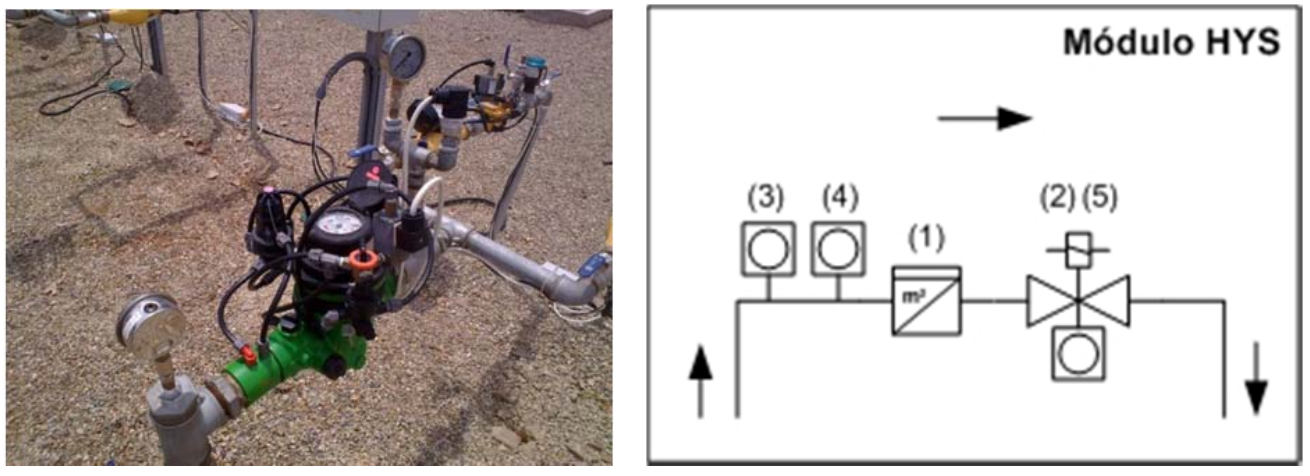

Figuras 6 y 7 - Fotografía de un módulo de pruebas de hidrante y diagrama de componentes de un hidrante simple (HYS)

Los componentes del módulo identificados en el diagrama son:

(1) Totalizador de volumen

(2) Elemento de corte controlado por subsistema

(3) Medidor de presión

(4) Detector de paso de agua

(5) Detector de posición de elemento de corte

A su vez, el banco dispone de la infraestructura informática necesaria para comprobar y validar la arquitectura propuesta para los sistemas de control y gestión. El control de los diferentes elementos incluidos en el banco se basa en la instalación del software necesario en máquinas virtuales. Cada subsistema, aplicación de gestión y/o 
aplicación de coordinación se instala en una máquina virtual independiente a la que sólo tienen acceso los organizadores de los ensayos y los propietarios de la misma. Todos los elementos hidráulicos que componen el banco de ensayos disponen de conexión directa con la red informática, disponiendo a su vez de suministro energético para los sistemas de control que se desee testar.

Se establece la siguiente metodología para la ejecución de los ensayos sobre el sistema o aplicación en pruebas, de acuerdo con las exigencias fijadas por el estándar para la explotación y el control de cada tipo de entidad hidráulica. El fabricante 0 desarrollador deberá informar de cuáles son las entidades susceptibles de control o explotación por su producto.

Todo sistema o aplicación susceptible de ser compatible con el presente estándar se somete al procedimiento de ensayo, divido en la siguiente secuencia de fases:

- Fase 1. Pruebas informáticas de verificación de interfaz. Se verifica que los mensajes (tanto peticiones como respuestas) que intercambian los componentes de la arquitectura que se están probando (aplicaciones de gestión, sistemas de telecontrol y aplicación de coordinación) son acordes con el estándar de comunicaciones definido para esos componentes.

- Fase 2. Ensayos de campo para verificación de funcionalidades. Una vez superada la fase anterior, se verifica que los sistemas interoperables, actuando de forma conjunta, ejecutan correctamente las funcionalidades que se les asocian.

Las pruebas realizadas están orientadas a las funciones básicas que deben resolver los sistemas de gestión y de telecontrol de regadíos, siendo que el estándar de interoperabilidad incluye otras funcionalidades que serán testadas en el futuro. Las pruebas realizadas se han orientado a dos funciones básicas que se atribuyen a estos sistemas:

- La facturación;

- y la programación de riegos.

Para validar el correcto desarrollo de estas funcionalidades de acuerdo con los criterios establecidos por el estándar de MEGA se ha realizado la siguiente batería de pruebas básicas:

- Prueba 1. Facturación sin discriminación horaria. Obtener la facturación correspondiente a dos o más hidrantes, controlados por diferentes subsistemas, obteniendo los datos necesarios para que un único software los incorpore con el fin de realizar la facturación.

- Prueba 2. Ejecución de riego programado finalizado por tiempo. Programar uno o más riegos con finalización por tiempo, al menos en tres hidrantes controlados por diferentes subsistemas, lanzando la petición a los mismos desde un único software de programación de riegos. Condición de fin: tiempo máximo.

- Prueba 3. Ejecución de riego programado finalizado por volumen. Programar uno o más riegos con finalización por volumen, al menos en tres hidrantes 
controlados por diferentes subsistemas, lanzando una petición a los mismos desde un único software de programación de riegos. Condiciones de fin: tiempo máximo y volumen máximo.

- Prueba 4. Ejecución de riego programado finalizado por petición directa. Programar uno o más riegos con finalización por tiempo, al menos en tres hidrantes controlados por diferentes subsistemas, lanzando la petición de paro desde un único software de programación de riegos. Una vez se haya iniciado el riego, se enviará la orden de paro.

Estas pruebas se han realizado de forma pautada, atendiendo al protocolo de ensayos de MEGA que, junto con los anexos de implementación, es otro de los documentos presentados en los comités de normalización.

\section{Conclusiones y recomendaciones}

Con la batería de pruebas definidas, se consigue cerrar una primera fase en la interoperabilidad, en la que se ha tratado de validar la línea de trabajo mantenida a lo largo del desarrollo teórico. Se demuestra empíricamente que sistemas de telecontrol de diferentes fabricantes pueden explotarse desde aplicaciones pensadas para la gestión de las infraestructuras modernizadas, también diseñadas y desarrolladas por terceros.

Las potencialidades de MEGA se verán traducidas, en los próximos tiempos en:

- Valorización de las herramientas de gestión, ahora infrautilizadas y con un amplio margen de implantación para la mejora de la explotación y el mantenimiento en las áreas regables. En línea con lo anterior, se abre el abanico al desarrollo de nuevas herramientas de gestión que cubran aspectos que actualmente son deficitarios al tratarse de condicionantes nuevos que no existían en el momento en el que se diseñaron las soluciones actuales (gestión coordinada y eficiente de agua y energía).

- Desligamiento entre usuarios y fabricantes de sistemas de telecontrol, permitiendo la elección de la mejor solución en cada momento, fomentándose la competitividad y mejora de los productos ofertados por el sector. El desligamiento permite abrir un mercado de prestación de servicios de explotación y mantenimiento, que también contribuirá a reducir el abandono de los sistemas y la potenciación de las informaciones que de ellos se pueden obtener.

Entre 2000 y 2014 , se ha modernizado casi el $40 \%$ de la superficie de regadío en España, alcanzando los 1,5 millones de hectáreas modernizadas sobre los 3,6 millones de hectáreas totales en $2014^{1}$, repartidas entre 7200 Comunidades de Regantes. De acuerdo con datos de la Junta de Castilla y León, el coste de explotación se ubica entorno a los 700 euros por hectárea ${ }^{2}$. No debe obviarse que la

\footnotetext{
1 Aumenta la superficie regada en España pero se mantiene una tendencia a la baja en el volumen de agua de riego utilizado en el sector agrario. Nota de prensa MAGRAMA. 18 de marzo de 2015

2 Coste del riego según tipo de infraestructura. Portal www.inforiego.org. Instituto Tecnológico Agrário de Castilla y Leon (ITACyL), Datos campaña agrícola 2012-2013.
} 
tendencia de ese valor es a incrementarse (coste de energía, coste de uso del recurso agua por aplicación de la DM del Agua).

A nivel Comunidad de Regantes, y desde el punto de vista técnico, la implementación de elementos estandarizados e interoperables, facilitará las tareas de explotación y mantenimiento consiguiendo mayores eficiencias en el nexo agua-energía. Al ahorro conseguido por la mejora de la eficiencia hidro-energética, hay que sumar los que se conseguirán al tener mejores precios en la reposición de elementos de control al dejar de ser las zonas regables "esclavas" de una marca determinada y poder seleccionar las compras dentro de un marco de competencia comercial. Es por ello que la interoperabilidad contribuye de forma significativa al incremento de los márgenes económicos y a la viabilidad económica de las modernizaciones realizadas en los últimos 15 años.

\section{Bibliografía}

- $\quad$ EN 61512: Batch control - Part 2: Data structures and guidelines for languages. EN 61512-2:2002.

- EN 62264: Enterprise-control system integration - Part 1: Models and terminology. EN 62264-1:2013.

- $\quad$ EU Water Framework Directive (Directive 2000/60/EC), 23 October 2000.

- $\quad$ ISO 9646 Conformance Testing Methodology and Framework. 


\title{
C-17
}

\section{OPTIMIZACIÓN DEL COSTE ENERGÉTICO EN REDES DE RIEGO A PRESIÓN MEDIANTE SU REHABILITACIÓN}

\author{
Fernández García, $I^{1}{ }^{1}$, Rodríguez Díaz, J.A ${ }^{1}$. Montesinos, $P .{ }^{1}$, Camacho Poyato, E. ${ }^{1}$
}

\begin{abstract}
${ }^{1}$ Departamento de Agronomía. Universidad de Córdoba. Campus Rabanales, Edif. Da Vinci, 14071. Córdoba. E-mail: g52fegai@uco.es, jarodriguez@uco.es, pmontesinos@uco.es, ecamacho@uco.es
\end{abstract}

\section{Resumen}

La gestión óptima de los recursos agua y energía en todos los sectores económicos, incluida la agricultura, tiene cada vez más importancia. El sector del riego, que ha experimentado una profunda transformación hacia sistemas de riego a presión, más eficientes en el uso del agua, pero con mayor demanda energética, también requiere medidas encaminadas al aumento de la eficiencia en la gestión de estos recursos.

Este trabajo presenta una metodología fundamentada en la rehabilitación de redes de riego, mediante su rediseño, que determina el funcionamiento óptimo de la estación de bombeo que conlleva un coste de operación mínimo. La estrategia planteada se ha desarrollado en varios módulos. El primero de ellos consiste en la aplicación del algoritmo multiobjetivo NSGA-II, enlazado al simulador hidráulico EPANET, que minimiza el coste de rediseño de la red y de operación considerando un $100 \%$ de simultaneidad de hidrantes. El segundo módulo contempla un análisis de la operación a la demanda de la red, generando múltiples patrones aleatorios de hidrantes abiertos/ cerrados. El tercer módulo analiza la operación a la demanda de la red en cada uno de los rediseños propuestos en el primer módulo y determina el funcionamiento de la estación de bombeo que minimiza el coste energético, teniendo en cuenta la tarifa eléctrica.

La metodología propuesta se ha analizado en la CR EI Villar (Sevilla) proporcionando un frente de Pareto que ofrece soluciones quasi óptimas con distinto grado de satisfacción de los objetivos propuestos. Mediante el posterior análisis financiero se ha determinado que la solución más viable a largo plazo, considerando una vida útil para la red de riego de 40 años y un interés del $5 \%$, conlleva un coste de inversión asociado al reemplazo de tuberías de $205.627 €$, un coste de operación anual de $300.532 €$ y un coste total (inversión en el diseño, costes asociados a la renovación de las bombas y coste de operación) a lo largo de la vida útil de $6.019 .447 €$, lo que supondría un importante ahorro económico para la comunidad aplicando mayores volúmenes de agua para satisfacer las necesidades de los cultivos, en comparación con la situación actual en la que se aplica un riego deficitario debido a los elevados costes energéticos.

\section{1-Introducción}

El aumento de la eficiencia en la gestión de los recursos ha suscitado gran interés teniendo en cuenta el significativo incremento de población que se ha producido en los últimos años y la tendencia creciente esperada para las próximas décadas.

Por ello, los objetivos planteados para el año 2020 en la Estrategia Energética establecida por la Unión Europea consideran un aumento del $20 \%$ de la eficiencia energética, una reducción del $20 \%$ de las emisiones de gases de efecto invernadero y un aumento en el mismo porcentaje del uso de energías procedentes de fuentes renovables (European Commission 2010). Estos objetivos se deben considerar en todos los sectores 
económicos y el sector de la agricultura de regadío no está exento de ello. Las infraestructuras para el riego han experimentado una profunda transformación hacia sistemas a presión, más eficientes en el uso del agua pero con mayores necesidades energéticas (Corominas 2010). Este hecho, junto con el aumento de la tarifa eléctrica para el riego, han supuesto una importante reducción de los beneficios del agricultor, lo que justifica la necesidad de desarrollar estrategias que mejoren la eficiencia en el uso de la energía, uno de los retos perseguidos por la Unión Europea, y reduzcan los costes del agricultor (Rocamora et al. 2013).

Entre las medidas propuestas para minimizar el consumo de energía en las redes de riego destacan la sectorización de la red, estableciendo turnos de riego (Carrillo Cobo et al. 2011) y el control de puntos críticos, que son hidrantes con elevadas necesidades energéticas (Rodriguez Díaz et al. 2012). El análisis de estas estrategias en varias redes de riego a presión mostró ahorros energéticos que oscilaron entre el $9 \%$ y el $27 \%$ cuando se adoptó la estrategia de sectorización y entre el $5 \%$ y el $12 \%$ cuando el control de puntos críticos fue la medida analizada.

Sin embargo, las metodologías fundamentadas en el control de puntos críticos no contemplan la detección y el control de estos hidrantes de forma automática, por lo que la decisión final sobre las medidas a adoptar para mejorar el funcionamiento de los puntos críticos es del evaluador. De esta forma, una estrategia en la que ambos aspectos, detección y control de hidrantes críticos, se integren, puede contribuir a mejorar la toma de decisiones.

Para la resolución de problemas de optimización como el señalado anteriormente, se han aplicado diversos algoritmos que han permitido resolver problemas de optimización en redes de distribución de agua relativos al diseño (Farmani et al. 2007) o a la operación de la red (Fernández García et al. 2016), entre otros. Sin embargo, no se han desarrollado estrategias que combinen la optimización del diseño de la red y múltiples condiciones de funcionamiento vinculadas a la tarifa energética.

Teniendo en cuenta que una gran mayoría de las de redes de riego a presión en funcionamiento se diseñaron para operar en la condición más desfavorable y, además, muy diferentes a las actuales, en este trabajo se propone una metodología que considera, de forma conjunta, el rediseño de la red mediante la sustitución de algunas tuberías y la optimización simultánea del coste de operación bajo múltiples condiciones de carga considerando la estructura de la tarifa eléctrica.

\section{2- Metodología}

\subsection{Planteamiento del problema}

La metodología propuesta contempla la búsqueda simultánea del óptimo de dos objetivos. El primero de ellos considera la minimización del coste de rehabilitación de la red de riego mediante la determinación de los tramos de tubería que se deben reemplazar por tuberías con diámetro distinto para satisfacer las necesidades de riego, OF1. A la vez, el rediseño propuesto debe implicar que la potencia absorbida sea mínima, lo que se engloba dentro del segundo objetivo, OF2 (Fernández García et al. 2015).

Donde $j$ e $i$ son los índices relativos a la tubería y a la bomba, respectivamente, $n j$ el número de tuberías, $n_{\text {pumps }}$ el número de bombas que conforman la estación de bombeo, $U C_{j}$ el coste unitario de la tubería en función del diámetro $D_{j}\left(€ \mathrm{~m}^{-1}\right), L_{j}(\mathrm{~m})$ la longitud de la tubería $j, \gamma$ el peso específico del agua $\left(\mathrm{N} \mathrm{m}^{-3}\right), H$ la altura manométrica proporcionada por la 
estación de bombeo $(\mathrm{m}), F_{i}$ el caudal suministrado por la bomba $i\left(\mathrm{~m}^{3} \mathrm{~s}^{-1}\right)$ y $\eta_{i}$ el rendimiento de la bomba $i$.

Ambas funciones objetivo, que se determinan considerando que todos los hidrantes están abiertos, están sujetas al cumplimiento de que la presión en el hidrante más desfavorable, Pcrit, debe ser mayor o igual a la presión de servicio, Pser. Además, la resolución de OF1 y OF2, está condicionada al cumplimiento de las ecuaciones de continuidad y de conservación de la energía en redes hidráulicas.

\subsection{Rehabilitación de la red para una simultaneidad de la demanda del $100 \%$}

Para la resolución de las ecuaciones planteadas anteriormente se ha empleado como método de optimización el algoritmo multiobjetivo NSGA-II, Non-Sorted Genetic Algorithm (Deb et al. 2002), ya que se ha usado ampliamente en diversos tipos de problemas de optimización de redes de distribución de agua (e.g. Siew and Tanyimboh 2012; Carrillo Cobo et al. 2014).

El algoritmo NSGA-II comienza con la generación aleatoria de la población inicial, formada por individuos que contienen las variables del problema de optimización planteado. En este caso, cada individuo está definido por tres grupos de variables: el primer grupo se corresponde con la relación de velocidades para cada bomba de velocidad variable presente en la estación, $R R S$; el segundo grupo está asociado a las bombas fijas y cada variable de este grupo indica si una determinada bomba fija está funcionando o no, FP. El último grupo de variables se corresponde con los posibles diámetros para cada una de las tuberías de la red. En este caso, se optó por sustituir aquellas tuberías infradimensionadas por lo que si en el proceso de generación aleatoria de diámetros se obtenían diámetros iguales o inferiores a los actuales, se mantenían los actuales. Con la información contenida en cada individuo de la población inicial y la demanda base de los hidrantes se procedió a la evaluación de las funciones objetivo en EPANET (Rossman 2000), proporcionando el caudal suministrado por cada bomba y la presión en todos los hidrantes. A partir de la curva de rendimiento de cada bomba, se determinó éste para cada una de ellas y, por tanto, se calculó OF2. A continuación se llevaron a cabo los procesos de selección, cruzamiento y mutación para generar las sucesivas poblaciones de tal forma que los mejores individuos se mantuvieron y los peores se eliminaron. Estas últimas etapas se repitieron hasta alcanzar el número de generaciones a evaluar fijado al comienzo del proceso de optimización (Figura 1).

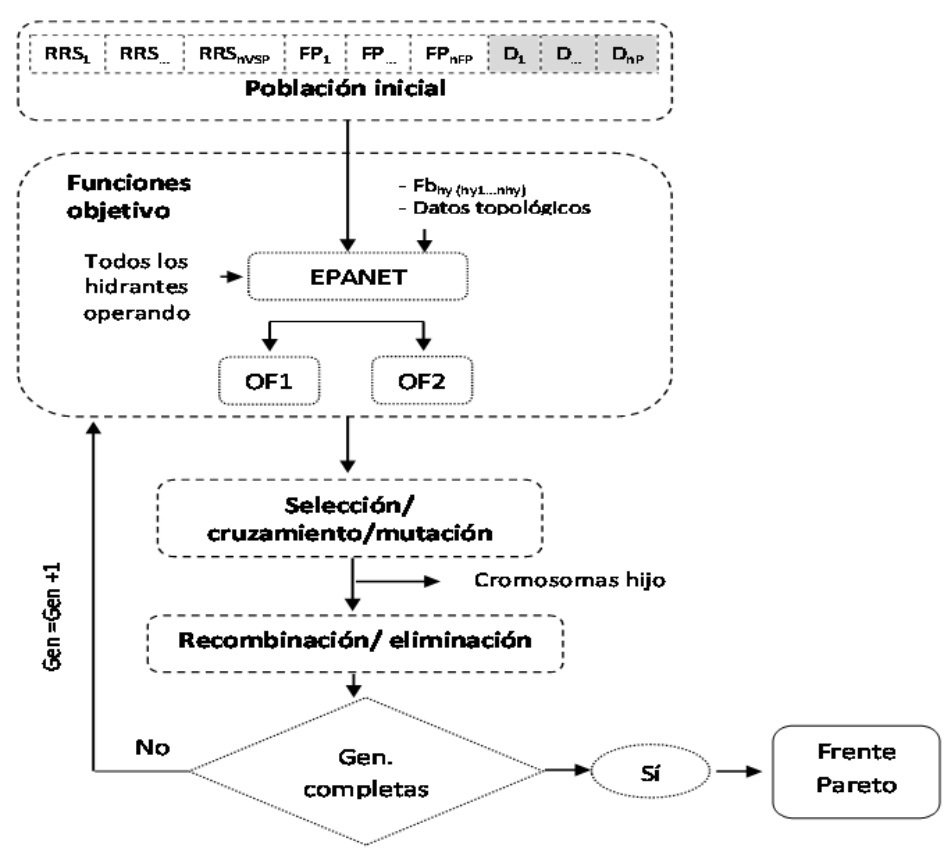

Figura 1. Esquema del proceso de optimización (epígrafe 2.2) 
El proceso de optimización se ha llevado a cabo en MATLAB (Deb et al. 2002).

\subsection{Determinación del coste de operación de los rediseños propuestos} considerando la operación a la demanda

Como resultado de la aplicación del algoritmo NSGA-II se obtiene un frente de Pareto con el conjunto de soluciones quasi-óptimas al problema planteado. Sin embargo, estas soluciones son válidas para un $100 \%$ de simultaneidad de hidrantes, lo cual no es habitual en las redes de riego. Por ello, se ha propuesto un algoritmo, compuesto por dos módulos (desarrollados en MATLAB), en el que se analiza el coste de operación, considerando la gestión a la demanda de la red, en varias soluciones seleccionadas del frente de Pareto de acuerdo al porcentaje de reducción de la potencia absorbida en relación a la inversión necesaria en la instalación (Fernández García et al. 2015). A continuación se describe el algoritmo (Figura 2).

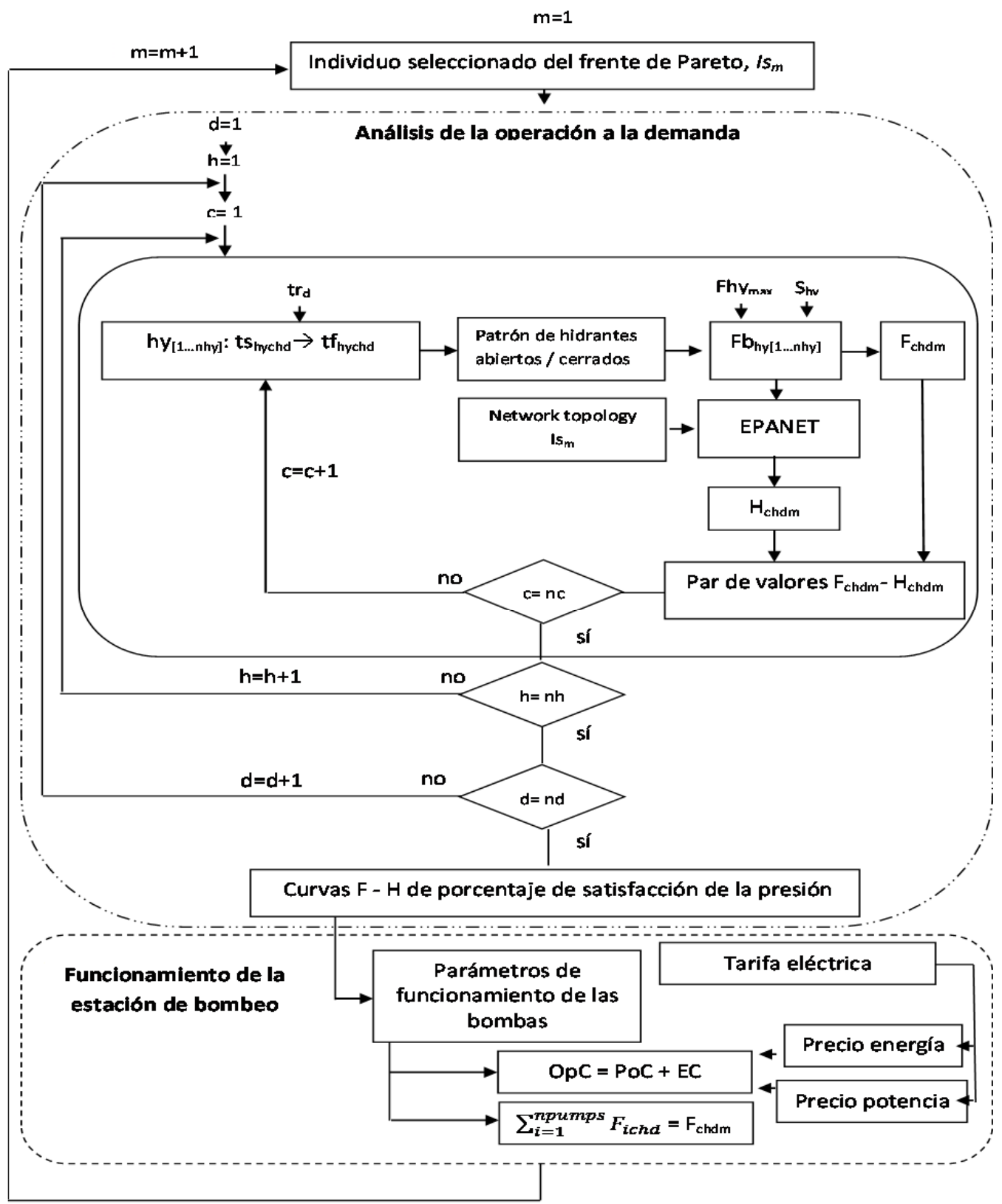

Figura 2. Esquema del análisis a la demanda de la red y la determinación del coste de operación (epígrafe 2.3) 


\subsubsection{Análisis de la operación a la demanda de la red}

En este módulo se lleva a cabo un análisis de la operación a la demanda de la red, generando múltiples patrones aleatorios de hidrantes abiertos/ cerrados. Para cada día $d$ analizado se genera un número aleatorio por hidrante hy que marca el inicio del riego, $t s_{\text {hychd. }}$. Ese número aleatorio estará incluido dentro del tiempo disponible para el riego por día. Para determinar la finalización del riego para cada hidrante, $t f_{\text {hychd, }}$ se suma el tiempo necesario de riego, $t r_{d}$, determinado a partir de las necesidades teóricas de riego del cultivo (Allen et al. 1998), al tiempo de comienzo del riego. De esta forma, para cada día se generan $c$ configuraciones en las que para cada hora $h$ se determina aleatoriamente el número de hidrantes abiertos.

En el número de horas disponibles para el riego por día influye si se establecen turnos de riego y/o si se quieren evitar las horas en las que la tarifa eléctrica es crítica en cuanto al precio. Así, cuando estos criterios se tienen en cuenta, las horas disponibles para el riego se reducen.

Una vez generados los patrones aleatorios, se lleva a cabo la evaluación de cada uno de ellos en EPANET. Cada patrón contiene información sobre los hidrantes abiertos y cerrados. Por tanto, la demanda base de cada hidrante, $F b_{h y}$, de acuerdo a cada patrón se obtiene multiplicando la superficie asociada a cada hidrante abierto, $S_{h y}$, por el caudal de

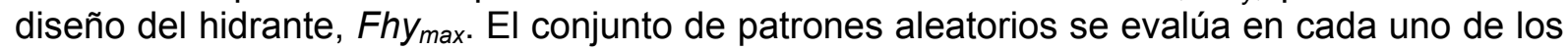
rediseños seleccionados en la etapa anterior, proporcionando el caudal y la altura manométrica que debe suministrar la estación de bombeo para garantizar la presión de servicio en todos los hidrantes, lo cual genera una nube de puntos $\mathrm{F}-\mathrm{H}$. A partir de esta nube de puntos, se pueden trazar curvas que definen, en función del caudal, el porcentaje de hidrantes que reciben la presión de servicio (Lamaddalena and Sagardoy 2000).

\subsubsection{Funcionamiento de la estación de bombeo vinculado a la tarifa eléctrica}

En el módulo anterior se obtienen las curvas del porcentaje de satisfacción de la presión en los hidrantes en función del caudal. Además, cada par de valores F-H está asociado a una hora. Para determinar el coste de operación es necesario tener en cuenta la tarifa eléctrica. La tarifa eléctrica se estructura en dos términos, un término fijo relativo a la potencia y otro variable que tiene en cuenta el consumo de energía. A su vez, las comunidades de regantes tienen que acogerse a una tarifa específica en función de la potencia contratada y de la tensión de suministro. Las comunidades de regantes suelen contratar una tarifa de alta tensión, ya sea de tres o seis periodos, en las que el precio de la potencia y la energía varían en función de cada periodo. Por tanto, el coste de operación mínimo se determinará mediante la siguiente expresión:

Donde $P o C$ es el coste asociado a la potencia, obtenido mediante la ecuación 4 y EC el coste energético, determinado mediante la ecuación 5.

$p$ es el índice para el periodo, $n p$ es el número de periodos de la tarifa eléctrica, $P_{o_{\operatorname{maxp}}}$ es la potencia contratada en función de la potencia absorbida máxima en el periodo $p$ (W) y Ppower $_{p}$ el precio del término de potencia en el periodo $p\left(€ \mathrm{~kW}^{-1}\right)$. 
Donde $n d$ es el número de días con tarifa eléctrica diferente, $n h$ el número de horas de operación de la red de riego durante el día $d$ ( 24 horas si no hay turnos de riego y/o si no se evita el riego en las horas críticas), $n c$ el número de configuraciones generadas para cada hora $h$ and Penergy Pd $_{\text {el }}$ precio de la energía en función de la hora $h$ y día $d\left(€ \mathrm{kWh}^{-1}\right)$.

El algoritmo propuesto en este módulo determina el comportamiento de la estación de bombeo (relación de velocidades para las bombas de velocidad variable y el funcionamiento o no de las bombas fijas) que proporciona el par de valores F-H en función de la curva de satisfacción de la presión en los hidrantes. Para ello, se fijó el valor de $\mathrm{H}$ y se identificó la configuración de funcionamiento de la estación de bombeo que, garantizando como mínimo el valor de $F$, minimizaba las ecuaciones 4 y 5 .

\subsection{Análisis financiero}

En este apartado se lleva a cabo un análisis financiero para seleccionar la solución más rentable a largo plazo, determinando para ello el coste total, OvC $(€)$, que tiene en cuenta el coste de rediseño, el coste asociado al reemplazo de las bombas y el coste de operación a lo largo de la vida útil de la red:

Donde $y$ es un índice relativo al año y $k$ un índice relativo al reemplazo de las bombas. $T$ es la vida útil de la red, $s$ la vida útil de las bombas, $K$ el número de reemplazos de las bombas determinado por $T / s$ y $r$ la tasa de amortización. $R C$ y PumpC son los costes de rehabilitación y de sustitución de las bombas, respectivamente, en $€$.

\section{$\underline{2.5 \text { Caso de estudio }}$}

La metodología propuesta se ha analizado en la CR EI Villar (Sevilla), que cuenta con una superficie de $3017 \mathrm{~h}$ dedicadas a algodón, trigo, girasol y olivar. La red de riego está diseñada para aplicar un caudal máximo de $1.2 \mathrm{Ls}^{-1}$ ha-1 a una presión de servicio de 30 $\mathrm{m}$, garantizados por una estación de bombeo compuesta por 8 bombas: dos bombas de velocidad variable, con potencias de $132 \mathrm{~kW}$ y $355 \mathrm{~kW}$ y 6 fijas, de $400 \mathrm{~kW}$.

\section{3- Resultados y discusión}

\subsection{Determinación de la rehabilitación óptima de la red}

La metodología propuesta se ha aplicado a la red de riego descrita anteriormente considerando para las variables asociadas a la relación de velocidades valores comprendidos entre 0.3 y 2 , valores binarios para las bombas fijas ( 0 si la bomba está parada o 1 si la bomba está en funcionamiento) y los diámetros en función del catálogo seleccionado para las variables asociadas a las tuberías, los cuales variaron entre 160 y $1000 \mathrm{~mm}$, con precios unitarios comprendidos entre 11.28 y $432.57 €$.

En total, cada individuo contenía 67 variables, 2 variables para las bombas de velocidad variable, 6 variables correspondientes a las bombas fijas y 59 variables asociadas al número de tuberías que conforman la red. Para el número de individuos y para el número de generaciones se ha considerado un valor de 200 en ambos casos.

Como resultado de la aplicación del algoritmo multiobjetivo se ha obtenido un frente de Pareto que ofrece soluciones quasi óptimas con distinto grado de satisfacción de los objetivos propuestos (Figura 3 ). El coste de rehabilitación varió entre $44828 €$ con un valor de potencia asociada de $1973 \mathrm{~kW}$ y 3,664,885 € con una potencia asociada de $1566 \mathrm{~kW}$. Como se puede observar en la figura, el frente de Pareto desciende de forma más acusada al principio (parte izquierda de la figura), lo que indica que cuando se efectúan poco cambios en la red se obtiene una importante reducción en la potencia. Esto es debido a la presencia 
de puntos críticos que son responsables de un elevado consumo de energía (Rodriguez Díaz et al. 2012).

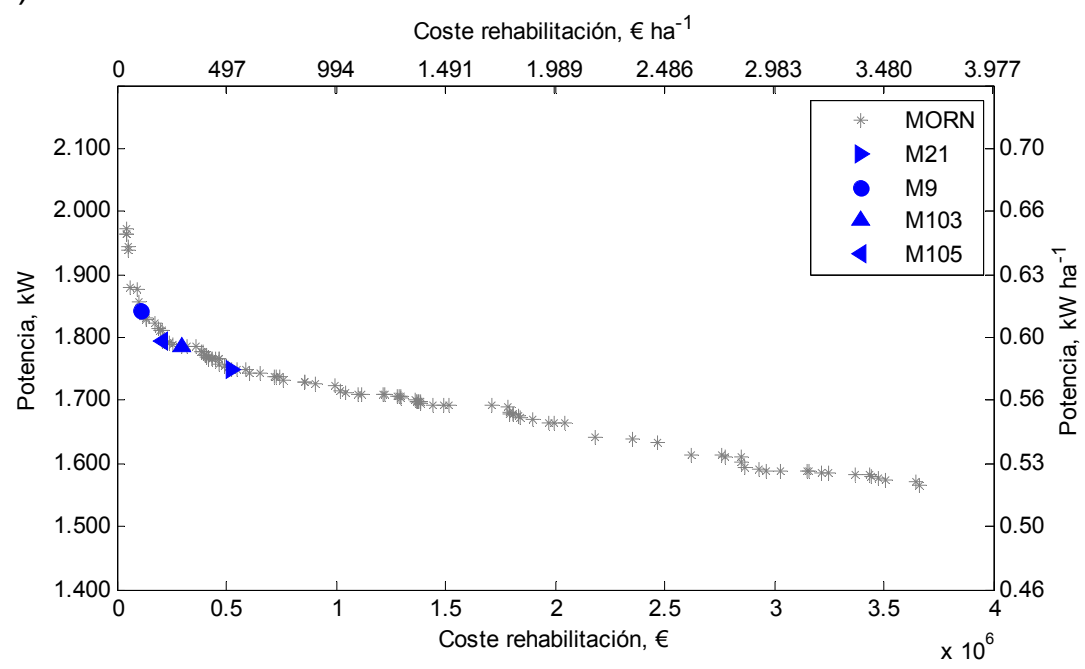

Figura 3. Frente de Pareto y soluciones seleccionadas

3.2 Coste de operación considerando la gestión a la demanda y los nuevos rediseños propuestos

En la etapa anterior se han obtenido rediseños quasi-óptimos de la red cuando ésta se gestiona para un $100 \%$ de simultaneidad de hidrantes. Teniendo en cuenta que el descenso más acusado en el frente de Pareto se produce en el primer cuartil (Fernández García et al. 2015), para el análisis a la demanda de la red se han seleccionado cuatro soluciones contenidas en dicho cuartil.

Diversos autores han analizado el efecto que la tarifa eléctrica tiene sobre el coste energético, determinando que concentrando el riego en las horas más baratas y, por tanto, evitando las horas críticas, se consigue una importante reducción del coste energético (Córcoles et al. 2015; Fernández García et al. 2016). Por ello, para la generación de los patrones aleatorios se evitó el riego durante las horas críticas, teniendo en cuenta para ello la estructura de la tarifa eléctrica. La tarifa eléctrica a la que se acoge esta comunidad se estructura en 6 periodos, en los que el precio varía en función de la hora del día y del día del año. La estructura y el precio de la parte regulada por el Gobierno se define en BOE 2014, mientras que la parte no regulada se ha determinado a partir del análisis del precio de la energía en el mercado libre (OMIE 2014). Por tanto, teniendo en cuenta la estructura de la tarifa eléctrica, se decidió evitar el riego entre las 10:00 y las 19:00 durante la segunda mitad de junio y durante el mes de julio (en los días laborables).

Se analizaron 30 patrones de demanda aleatorios $(n c=30)$ por hora y día diferente (nd=13) en función de la tarifa. Tras la evaluación hidráulica en EPANET, cada patrón tuvo asociado un valor de caudal y su correspondiente altura manométrica (Figura 4). En la figura 4 se observa cómo se produce una importante reducción de la altura manométrica para todo el rango de caudal en las soluciones analizadas con respecto al diseño original de la red. 
a)

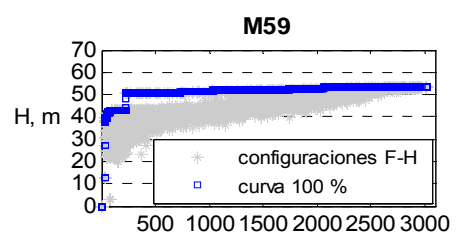

M103

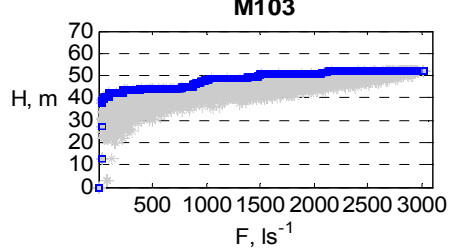

b)

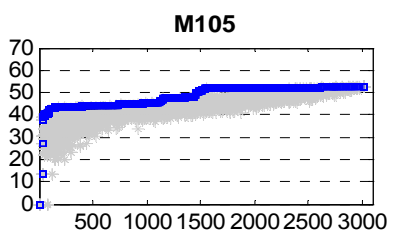

M21

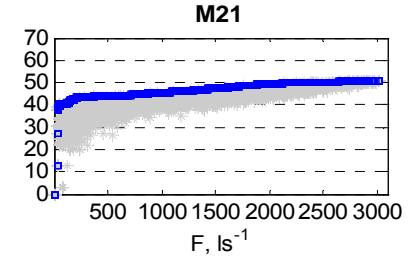

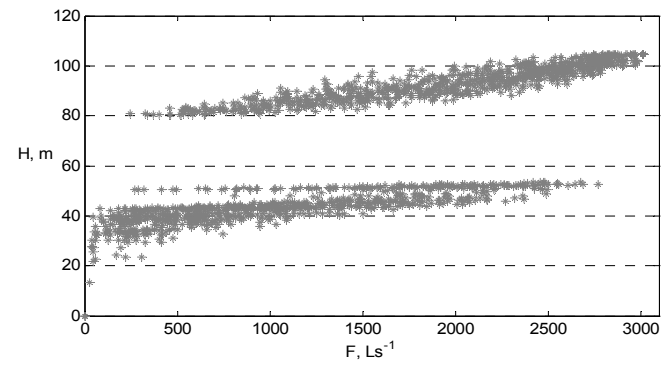

Figura 4. Pares de valores F-H en las soluciones seleccionadas (a) y en la red original (b) para cada patrón de demanda (configuración de hidrantes operativos)

Tabla 1. Número de bombas que entran en funcionamiento y costes asociados a las soluciones seleccionadas

\begin{tabular}{|c|c|c|c|c|c|c|c|c|}
\hline \multirow[t]{3}{*}{ Solución } & \multicolumn{3}{|c|}{$\begin{array}{l}\mathrm{N}^{\circ} \text { bombas en } \\
\text { funcionamiento }\end{array}$} & \multicolumn{3}{|c|}{$\begin{array}{l}\text { Coste sustitución } \\
\text { bomba, } € \text { (año } 0)\end{array}$} & \multirow[t]{2}{*}{$\begin{array}{c}\text { Coste } \\
\text { rehabilitación, } €\end{array}$} & \multirow[t]{3}{*}{$\begin{array}{c}\text { Coste } \\
\text { operación, } € \\
(\text { año 0) }\end{array}$} \\
\hline & & & & VSP1 & VSP2 & FP & & \\
\hline & VSP1 & VSP2 & FP & 60,264 & 109,152 & 21,152 & & \\
\hline M59 & $X^{*}$ & $x$ & 5 & & 275,176 & & 112,268 & 306,508 \\
\hline M105 & $x$ & $x$ & 5 & & 275,176 & & 205,627 & 300,532 \\
\hline M103 & $x$ & $x$ & 5 & & 275,176 & & 297,852 & 299,962 \\
\hline M21 & $\mathrm{X}$ & $\mathrm{X}$ & 4 & & 254,024 & & 525,484 & 295,489 \\
\hline
\end{tabular}

A partir de los rediseños seleccionados y el análisis a la demanda de la red se determinó el funcionamiento de la estación de bombeo para todo el rango de caudales. En este caso, se optó por una solución conservadora y se seleccionó la curva F-H que garantizaba la presión en todos los hidrantes (Figura 4a). En la tabla 1 se observa el número de bombas que entran en funcionamiento en la situación más desfavorable (segunda mitad de junio y julio) en cada una de las soluciones elegidas. Excepto en la solución M21, en la que en la situación más desfavorable actúan las 2 bombas de velocidad variable y 4 fijas, en las otras 3 soluciones trabajan, además de las 2 bombas de velocidad variable, 5 bombas fijas. Es importante conocer el número de bombas en funcionamiento ya que éste determina el coste total de renovación de la estación de bombeo. En este caso se ha considerado que en el año 0 se lleva a cabo la renovación de todas las bombas, lo cual implica un coste de renovación de 275,176 € para las soluciones M59, M105 y M103 y de 254,484 € para la solución M21. En cuanto al coste de rehabilitación, éste varió desde 112,268 € con un coste de operación asociado de 306,508 € hasta un coste de rehabilitación de 525,484 € con un coste de operación de 295,489 €.

\subsection{Análisis financiero}

Para el análisis financiero se ha considerado una vida útil de 40 años y un interés del $5 \%$. Teniendo en cuenta estos valores, el coste total (inversión en el diseño, costes asociados a la renovación de las bombas y coste de operación) de cada solución ha sido $6,034,617 €, 6,019,447 €, 6 ., 101,322 €$ y $6,220,335 €$ en las soluciones M59, M105, M103 y 
M21, respectivamente. Por tanto, de acuerdo a estos valores la solución más conveniente es M105, que implica el reemplazo de 10 tuberías por otras de mayor diámetro (Figura 5).

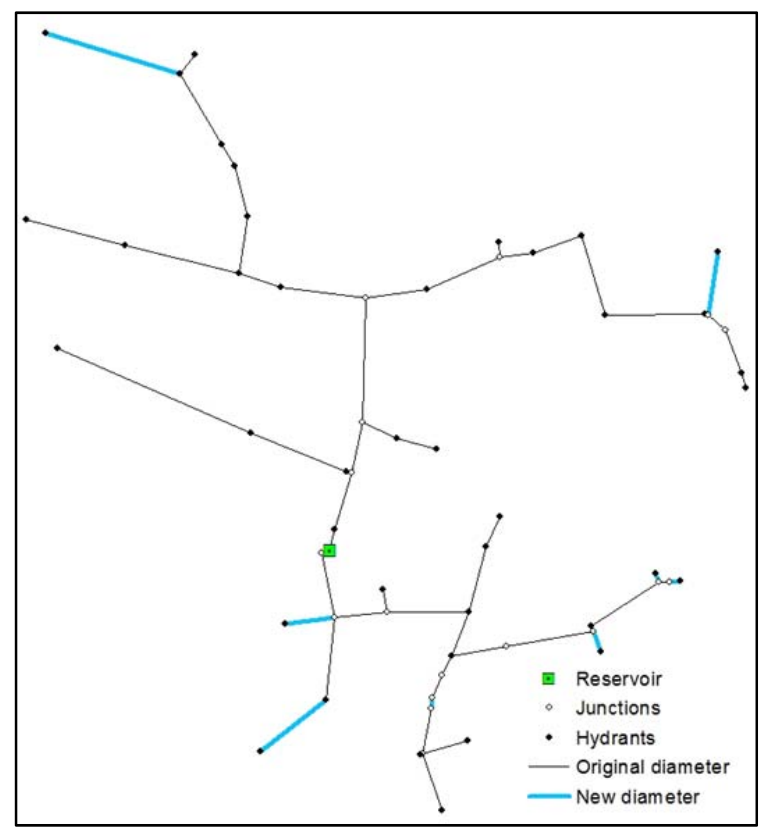

Figura 5. Esquema de la red de riego de El Villar y cambios propuestos de acuerdo a la solución M105

\section{5- Conclusiones}

La necesidad de mejorar la gestión de los recursos agua y energía repercute en todos los sectores económicos, incluida la agricultura y, más concretamente, la agricultura de regadío.

En este trabajo se ha propuesto una metodología para determinar el rediseño de la red y el funcionamiento de su estación de bombeo minimizando el coste de total (inversión y operación) teniendo en cuenta la gestión a la demanda de la red y a la estructura de la tarifa eléctrica

La metodología propuesta se ha evaluado en la CR de El Villar y tras el análisis financiero, la opción más viable, considerando una vida útil para la red de riego de 40 años y un interés del $5 \%$, conlleva un coste de inversión asociado al reemplazo de tuberías de $205.627 €$, un coste de operación anual de $300.532 €$, que supone un coste total (inversión en el diseño, costes asociados a la renovación de las bombas y coste de operación) a lo largo de la vida útil de 6.019.447 €. Aplicando el volumen total de agua requerido para satisfacer las necesidades de los cultivos tras la adopción de los cambios propuestos en la red y en el funcionamiento de la estación de bombeo, se obtendría un ahorro económico anual respecto al coste actual de operación de la red de $514.653 €(63 \%)$.

La metodología propuesta representa una estrategia fácil de implantar y adaptable en función de la gestión llevada a cabo en cada red que puede suponer un importante ahorro en el coste de operación.

\section{6- Agradecimientos}

Este trabajo se ha desarrollado en el marco del proyecto TEMAER (AGL2014-59747C2-2-R), financiado por el Ministerio de Economía y Competitividad. 


\section{7- Bibliografía}

Allen RG, Pereira L, Raes D, Smith M (1998) Crop evapotranspiration: Guidelines for computing crop water requirements. In: FAO Irrigation and Drainage Paper No. 56. Rome. Italy,

BOE (2014) Circular 3/2014, de 2 de julio, de la Comisión Nacional de los Mercados y la Competencia, por la que se establece la metodología para el cálculo de los peajes de transporte y distribución de electricidad. Boletín Of Estado 175:57158-57184.

Carrillo Cobo MT, Camacho Poyato E, Montesinos P, Rodríguez-Díaz JA (2014) New model for sustainable management of pressurized irrigation networks. Application to Bembézar MD irrigation district (Spain). Sci Total Environ 473-474:1-8. doi: 10.1016/j.scitotenv.2013.11.093

Carrillo Cobo MT, Rodríguez Díaz JA, Montesinos P, et al (2011) Low energy consumption seasonal calendar for sectoring operation in pressurized irrigation networks. Irrig Sci 29:157-169. doi: 10.1007/s00271-010-0228-2

Córcoles JI, Tarjuelo JM, Carrión PA, Moreno MÁ (2015) Methodology to Minimize Energy Costs in an On-Demand Irrigation Network Based on Arranged Opening of Hydrants. Water Resour Manag 29:3697-3710. doi: 10.1007/s11269-015-1024-9

Corominas J (2010) Agua y Energía en el riego en la época de la sostenibilidad.

Deb K, Pratap A, Agarwal S, Meyarivan T (2002) A fast and elitist multiobjective genetic algorithm: NSGA-II. IEEE Trans Evol Comput 6:182-197. doi: 10.1109/4235.996017

European Commission (2010) Energy 2020 A strategy for competitive, sustainable and secure energy. Communication from the Commission to the European Parliament, the Council, the European Economic and Social Committee and the Committee of the Regions.

Farmani R, Abadia R, Savic D (2007) Optimum Design and Management of Pressurized Branched Irrigation Networks. J Irrig Drain Eng 133:528-537. doi: 10.1061/(ASCE)0733-9437(2007)133:6(528)

Fernández García I, Creaco E, Rodríguez Díaz JA, et al (2015) Rehabilitating pressurized irrigation networks for an increased energy efficiency. Agric Water Manag. doi: 10.1016/j.agwat.2015.10.032

Fernández García I, Montesinos P, Camacho Poyato E, Rodríguez Díaz JA (2016) Energy cost optimization in pressurized irrigation networks. Irrig Sci 34:1-13. doi: 10.1007/s00271-015-0475-3

Lamaddalena N, Sagardoy JA (2000) Performance analysis of on-demand pressurized irrigation systems. In: FAO Rome. Irrigation and Drainage Paper No. 59.

OMIE (2014) OMI-Polo Español S.A. http://www.omie.es/files/flash/ResultadosMercado.swf. Accessed 1 Jan 2014

Rocamora C, Vera J, Abadía R (2013) Strategy for Efficient Energy Management to solve energy problems in modernized irrigation: Analysis of the Spanish case. Irrig Sci 31:1139-1158. doi: 10.1007/s00271-012-0394-5

Rodriguez Díaz JA, Montesinos P, Camacho Poyato E (2012) Detecting Critical Points in OnDemand Irrigation Pressurized Networks - A New Methodology. Water Resour Manag 26:1693-1713. doi: 10.1007/s11269-012-9981-8

Rossman L (2000) EPANET 2. Users manual. US Environmental Protection Agency (EPA), USA,

Siew C, Tanyimboh TT (2012) Penalty-Free Feasibility Boundary Convergent Multi-Objective Evolutionary Algorithm for the Optimization of Water Distribution Systems. Water Resour Manag 26:4485-4507. doi: 10.1007/s11269-012-0158-2 


\title{
OPTIMIZACIÓN DE LA PREDICCIÓN DE DEMANDA DE AGUA MEDIANTE ALGORITMOS NEURO-GENÉTICOS PARA UN CONJUNTO DE DATOS REDUCIDO
}

\author{
González Perea, $R^{1}{ }^{1}$, Camacho Poyato, E. ${ }^{2}$, Montesinos, $P .{ }^{3}$, Rodríguez Díaz, J.A. ${ }^{4}$
}

\author{
${ }^{1}$ Doctorando FPU. Departamento de Agronomía. Universidad de Córdoba. Campus \\ Rabanales, Edif. Da Vinci, 14071. Córdoba.g72goper@uco.es \\ ${ }^{2}$ Catedrático. Departamento de Agronomía. Universidad de Córdoba. Campus Rabanales, \\ Edif. Da Vinci, 14071. Córdoba. ecamacho@uco.es \\ ${ }^{3}$ Profesora Titular. Departamento de Agronomía. Universidad de Córdoba. Campus \\ Rabanales, Edif. Da Vinci, 14071. Córdoba.pmontesinos@uco.es \\ ${ }^{4}$ Contratado Doctor. Departamento de Agronomía. Universidad de Córdoba. Campus \\ Rabanales, Edif. Da Vinci, 14071. Córdoba. jarodriguez@uco.es
}

\section{Resumen}

La predicción de la demanda de agua es uno de los factores principales en el diseño y gestión de sistemas de abastecimiento y distribución de agua. Recientemente, avanzadas técnicas en inteligencia computacional como las Redes Neuronales Artificiales (RNAs) han sido aplicadas para la predicción de series temporales con importantes resultados. En este trabajo se ha desarrollado una metodología híbrida que combina RNAs y Algoritmos Genéticos multiobjetivo para la predicción a corto plazo de la demanda de agua en una Comunidad de Regantes cuando la disponibilidad de datos es escasa. El modelo fue desarrollado utilizando datos de series temporales del Sector VII de la Zona Regable Bembézar M.D. Tras el proceso de optimización con un algoritmo genético multiobjetivo se obtuvo una RNA de tipo perceptrón multicapa entrenada mediante el algoritmo Regularización Bayesiana con 24 neuronas en la primera capa oculta y 21 en la segunda. El modelo desarrollado fue capaz de explicar el $95 \%$ de la varianza total de los datos observados con un Error Estándar de Predicción del 9.38 \% (periodo de test).

\section{1.- Introducción}

El aumento de la población mundial unido a la creciente demanda de alimentos hace que sea necesario incrementar la producción agrícola. Para asegurar este aumento de la producción agrícola, la agricultura de regadío desempeña un papel fundamental.

La agricultura de regadío es el mayor usuario de agua en todo el mundo, presentando el $70 \%$ del total de agua dulce. En países como España, el uso del agua en la agricultura representa el $80 \%$ de la demanda total de agua, correspondiendo la mayor parte a la agricultura de regadío. Así, con el objetivo de aumentar la eficiencia en el uso del agua, muchas zonas de regadío han sido sometidas a procesos de modernización. En consecuencia, la mayoría de los nuevos sistemas de riego (goteo y aspersión) operan bajo demanda respetando el tiempo, la duración y la frecuencia de riego que lo agricultores deciden. Debido a este aumento de la flexibilidad en la gestión del riego de cada agricultor, se produce una gran variabilidad temporal de la demanda de agua en toda la red de riego. Por esta razón, la predicción de la demanda de agua se ha convertido en uno de los principales problemas en el diseño, gestión y modernización de los sistemas de abastecimiento y distribución de agua.

En los últimos años, ha sido posible una importante evolución en el campo de la predicción gracias a los avances en los modelos de sistemas no lineales conocidos como 
Redes Neuronales Artificiales (RNAs). Las características de las RNAs están inspiradas en el sistema nervioso biológico que les da una serie de ventajas como la capacidad de aprendizaje adaptativo, son auto-organizadas, pueden funcionar en paralelo en tiempo real y proporcionan tolerancia a errores por codificación de la información redundante.

Por otra parte, cuando se consideran varios objetivos simultáneamente en la gestión de redes de agua, el proceso de toma de decisiones se mejora de manera significativa con una amplia gama de alternativas por lo general debido a que se identifica y se consigue un modelo más realista del problema. Sin embargo, en este tipo de problemas es difícil encontrar una solución utilizando técnicas de optimización tradicionales. Por esta razón, los enfoques heurísticos son adecuados para resolver este tipo de problemas (Baños et al. 2010). Estas herramientas se basan por lo general en los algoritmos genéticos multiobjetivo (Savic 2002; Farmani et al. 2005), que implican más de una función objetivo a optimizar simultáneamente obteniendo la mejor combinación de los valores de las variables de decisión.

Las RNAs y los algoritmos genéticos son tecnologías de "soft-computing" que pueden ser muy eficaces cuando son usados de forma individual. Sin embargo, cuando se combinan juntos, las fortalezas individuales de cada enfoque pueden ser explotadas de manera sinérgica para la construcción de sistemas de gran alcance, híbridos e inteligentes (See y Openshaw 2000).

Uno de los principales problemas al desarrollar un modelo predictivo es la escasez de información con la que se cuenta que hace que el modelo desarrollado sea poco robusto y/o representativo. Así, el objetivo de este trabajo fue desarrollar un modelo predictivo mediante algoritmos neuro-genéticos multiobjetivo cuando la información que se posee es reducida. El modelo desarrollado se aplicó en el Sector VII de la Zona Regable Bembézar M.D.

\section{2.- Materiales y métodos}

\subsection{Zona de estudio y fuente de datos}

La Comunidad de Regantes Bembézar Margen Derecha (BMD) se extiende por 4 municipios que son: Hornachuelos, Palma del Río, Peñaflor y Lora del Río. Los cultivos principales son: Maíz, Algodón, cítricos y frutales. El sector VII, objeto de este trabajo, está situado en el Término municipal de Lora del Río. Después de la modernización, BMD posee un sistema de distribución de agua a presión que suministra a 11 sectores de riego independientes, organizados a la demanda. Dentro de la red, el Sector VII suministra agua de riego a 935 ha aproximadamente.

El Sector VII cuenta con un sistema de telemedida que almacena datos de caudal y altura de presión en la estación de bombeo cada minuto. Los datos de demanda de agua utilizados para la calibración y validación del modelo desarrollado fueron obtenidos a partir del promedio de los valores registrados por el sistema durante las campañas de riego 2010, 2012 y 2013.

\subsection{Redes Neuronales Artificiales}

Una Red Neuronal Artificial (RNA) es un modelo heurístico utilizado para determinar la relación no linear entre input y output. El modelo de RNA más ampliamente utilizado es el Perceptrón Multicapa (Multilayer Perceptron, MLP) (Rumelhart et al. 1986). Una estructura típica de un MLP está formada por cuatro capas (capa de entrada, primera y segunda capa oculta y capa de salida). Cada capa está formada por un número de neuronas. Así, la anotación típica de un MLP es $(\mathrm{g}, \mathrm{n}, \mathrm{m}, \mathrm{s})$ siendo $\mathrm{g}, \mathrm{n}, \mathrm{m}$ y $\mathrm{s}$ los nodos o neuronas en la capa de entrada, la primera y segunda capa oculta y la capa de salida, respectivamente. Las neuronas de cada capa están conectadas a las neuronas de la siguiente capa mediante los pesos sinápticos (w). Todas las conexiones se alimentan hacia delante, es decir, que sólo permiten la transferencia de información desde una capa anterior a una posterior. El número 
de neuronas de las capas de entrada y salida son las mismas que el número de variables de entrada y salida, respectivamente. El número de neuronas de la primera y segunda capa oculta fueron dos variables de decisión del algoritmo genético utilizado para el proceso de optimización del modelo predictivo desarrollado.

Las neuronas de cada capa son activadas según una función de activación. Esta función representa simultáneamente la salida de la neurona y su estado de activación. En este trabajo, la función de activación asociada a las neuronas de cada capa fueron tres variables de decisión (capa de entrada, capas oculta y capa de salida). En la tabla 1 se muestran las distintas funciones de activación utilizadas.

Tabla 1. Variables de decisión de cada cromosoma.

\begin{tabular}{|c|c|c|}
\hline Número & $\begin{array}{c}\text { Nombre de la variable } \\
\text { de decisión }\end{array}$ & Rango de valores de cada variable de decisión \\
\hline 1 & Neuronas $1^{\mathrm{a}}$ capa oculta & Número entero entre 1 y 50. \\
\hline 2 & Neuronas $2^{\mathrm{a}}$ capa oculta & Número entero entre 0 y 50. \\
\hline 3 & $\begin{array}{c}\text { Función de } \\
\text { Transferencia de la capa } \\
\text { de entrada }\end{array}$ & $\begin{array}{l}\text { Número entero entre } 1 \text { y 3: } \\
\text { (1) Función de Transferencia Log-Sigmoid (LogST); } \\
\text { (2) Función de Transferencia Tan-Sigmoid; (3) } \\
\text { Función de Transferencia Linear (LinT). }\end{array}$ \\
\hline 4 & $\begin{array}{l}\text { Función de } \\
\text { Transferencia de las } \\
\text { capas ocultas }\end{array}$ & $\begin{array}{l}\text { Número entero entre } 1 \text { y 3: } \\
\text { (1) Función de Transferencia Log-Sigmoid (LogST); } \\
\text { (2) Función de Transferencia Tan-Sigmoid; (3) } \\
\text { Función de Transferencia Linear (LinT). }\end{array}$ \\
\hline 5 & $\begin{array}{c}\text { Función de } \\
\text { Transferencia de la capa } \\
\text { de salida }\end{array}$ & $\begin{array}{l}\text { Número entero entre } 1 \text { y 3: } \\
\text { (1) Función de Transferencia Log-Sigmoid (LogST); } \\
\text { (2) Función de Transferencia Tan-Sigmoid; (3) } \\
\text { Función de Transferencia Linear (LinT). }\end{array}$ \\
\hline
\end{tabular}

\subsubsection{Entrenamiento y generalización de una RNA.}

Para determinar el valor del conjunto de pesos $(w)$ que constituyen la red neuronal, se lleva a cabo un proceso repetitivo-correctivo que es conocido como entrenamiento o aprendizaje. El objetivo de la fase de entrenamiento es definir las interconexiones entre neuronas ajustando los pesos sinápticos a través de patrones de entrenamiento (conjunto de relaciones de entradas y salidas conocidas). Estos patrones de entrenamiento son presentados a la RNA de forma ordenada, ajustando los pesos sinápticos hasta que se alcanzan las salidas deseadas. Para determinar la actualización de los pesos sinápticos en cada una de las iteraciones se utilizan diferentes algoritmos denominados "algoritmos de aprendizaje por corrección de errores". Los algoritmos de este tipo ajustan los pesos en proporción a la diferencia existente entre la salida actual de la red y la salida deseada, con el objetivo de minimizar el error actual de la red.

Durante la fase de entrenamiento de una red neuronal, el error de predicción del conjunto de datos en esta fase puede llegar a ser muy pequeño pero cuando una serie de nuevos datos son presentados a la red neuronal, este error crece considerablemente. Este fenómeno es conocido como sobreajuste. La red no ha aprendido a generalizar para nuevas situaciones sino que ha memorizado los datos en la fase de entrenamiento. Para mejorar la generalización de la red se suele utilizar un método conocido como "parada temprana" que consiste en dividir todos los datos disponibles en tres subconjuntos: conjunto de entrenamiento, conjunto de validación y conjunto de test. El primer conjunto es utilizado para calcular el gradiente de la función de error y actualizar los pesos sinápticos de la red. El conjunto de validación se utiliza para evitar el sobreajuste y el conjunto de test es utilizado para comprobar la robustez y representatividad del modelo predictivo así como para comparar entre diferentes modelos.

Cuando el conjunto de datos disponibles para entrenar la RNA es reducido, los 
conjuntos de entrenamiento, validación y test son muy reducidos y el modelo predictivo obtenido resulta poco representativo y/o con un error de predicción alto. Por otro lado, existe un algoritmo de entrenamiento conocido como Regularización Bayesiana (RB) (Mackay 1992) el cual asume que los pesos sinápticos de la RNA son variables aleatorias con distribuciones normales. Cuando el conjunto de datos dispones es reducido, RB da mejores rendimientos de generalización que la "parada temprana" debido a que este algoritmo no requiere dividir el conjunto de datos en sus correspondientes conjuntos de entrenamiento y validación. Por tanto, en este trabajo se ha utilizado BR como función de entrenamiento de la RNA.

La función de rendimiento típica utilizada en redes neuronales alimentadas hacia delante (feedforward) es el error cuadrático medio (mean square error, mse) (Ecuación 1).

donde $\mathrm{OB}$ es el número total de datos utilizados para el entrenamiento de la red neuronal; $Q_{\mathrm{t}}$ es la demanda de agua observada en el dato número $t\left(\mathrm{~L} \mathrm{~s}^{-1}\right)$ y $\quad$ es la demanda de agua estimada para el mismo dato $t\left(\mathrm{~L} \mathrm{~s}^{-1}\right)$.

El modelo de predicción desarrollado se implementó en Matlab utilizando la herramienta para Redes Neuronales Artificiales (Artificial Neural Network toolbox).

\subsection{Optimización del modelo RNA mediante un algoritmo genético}

\subsubsection{Planteamiento del problema}

El objetivo de este trabajo fue desarrollar un modelo de predicción diaria de demanda de agua en una red de riego cuando el conjunto de datos que se disponen es reducido. El problema fue formulado como un problema de optimización multiobjetivo con dos funciones objetivo.

La finalidad de la primera función objetivo (F1) fue maximizar la suma de los coeficientes de determinación $\left(R^{2}\right)$ del conjunto de test (Ecuación 2). Este coeficiente describe la proporción de varianza total de los datos observados que puede ser explicado por el modelo.

La finalidad de la segunda función objetivo (F2) fue minimizar el RMSE (Average Root Mean Square Error) (Ecuación 3).

donde $\mathrm{OB}_{\text {test }}$ es el número total de observaciones utilizadas durante el periodo de test de la red neuronal artificial. (F1 y F2).

F2 fue normalizada, con la finalidad de poder comparar las dos funciones objetivo

Con el objetivo de poder comparar el rendimiento de los diferentes modelos de predicción desarrollados se utilizó el error estándar de predicción (Standard Error of Prediction (SEP)) (Ventura et al. 1995). El SEP es definido según la ecuación 4. 
donde es la demanda de agua media observada del conjunto de test $\left(L s^{-1}\right)$.

\subsubsection{Método de optimización. NSGA-II.}

El algoritmo de optimización NSGA (Deb et al. 2002) fue implementado en MATLAB (Deb 2010) para obtener un modelo óptimo de predicción de demanda de agua en una red de riego. Se utilizó el algoritmo de optimización NSGA-II el cual fue adaptado a este problema (Figura 1). Las etapas iniciales, la población inicial y las funciones objetivo de este algoritmo fueron ligeramente modificadas para adaptarlo al caso particular de este trabajo. El resto de etapas: "cruzamiento", "mutación" y "selección" no fueron modificadas con respecto al algoritmo original.

En la primera etapa, la población inicial de $\mathrm{N}$ cromosomas (diferentes configuraciones de RNAs) fue generado aleatoriamente. Cada cromosoma representa un modelo de RNA. El número de variables de decisión $(C)$ en el cromosoma representa un parámetro a optimizar de la RNA. A continuación, F1 y F2 fueron calculadas para cada cromosoma. Con el objetivo de poder comparar las dos funciones objetivo, F2 fue normalizada previamente utilizando una función de distribución uniforme continua en el intervalo [0, 1]. Así, los valores de ambas funciones objetivo estaban comprendidos en ese intervalo. En las etapas restantes, cada valor de las variables de decisión de los cromosomas fueron modificados (cruzamiento y mutación) y los $\mathrm{N}$ cromosomas con mejores valores de las funciones objetivo fueron seleccionados. El proceso fue repetido durante varias generaciones (GEN). Finalmente, el conjunto de $\mathrm{N}$ cromosomas óptimas de la última generación es conocida como el Frente de Pareto. 


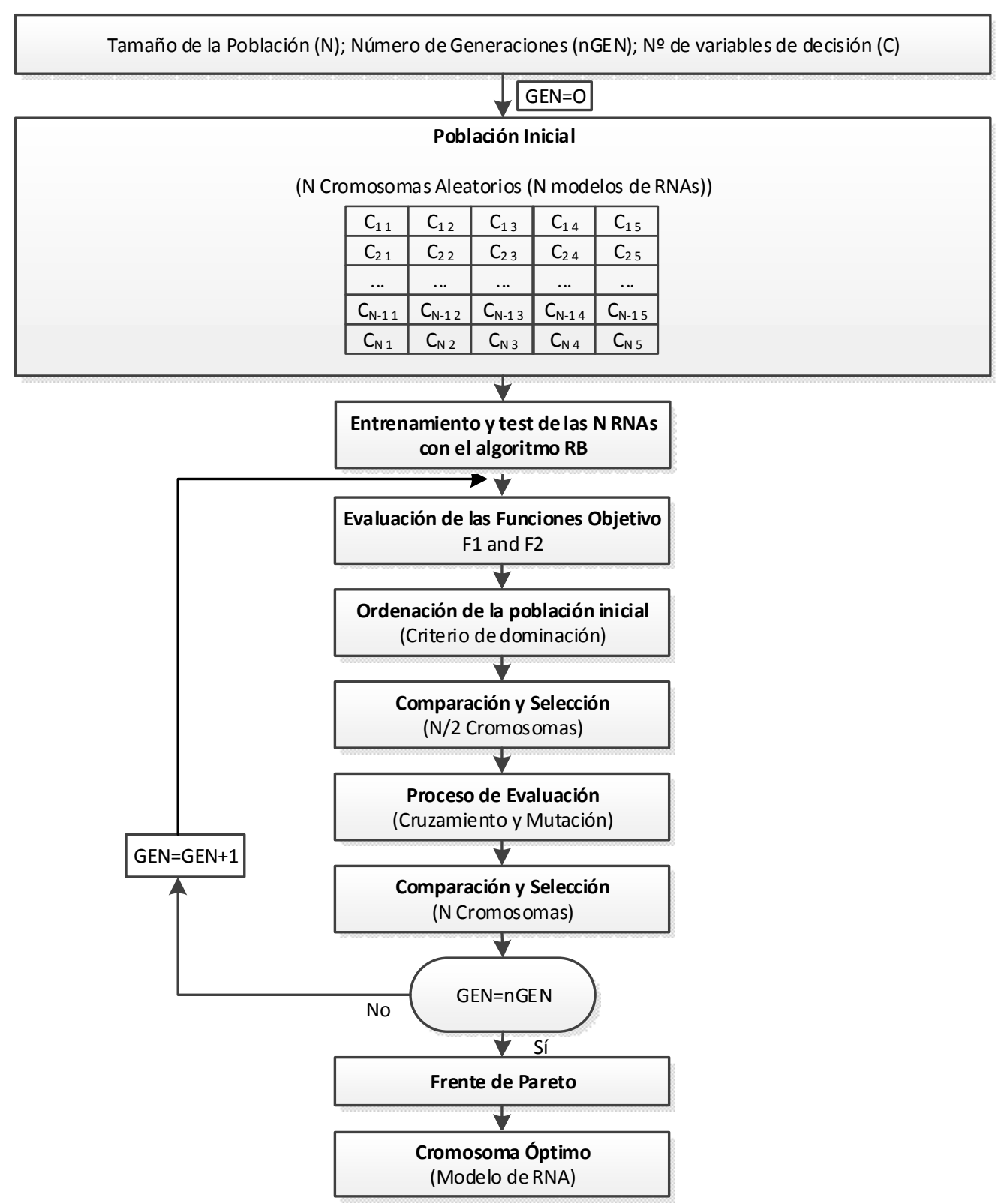

Figura 1. Proceso de optimización utilizando NSGA-II.

\section{3.- Resultados y discusión}

En este trabajo se consideraron 5 variables de decisión. Los valores que pueden tomar cada una de estas variables de decisión se muestran en la Tabla 1. Los conjuntos de entrenamiento y test fueron elegidos aleatoriamente del total de los datos disponibles en una proporción de $85 \%$ para el conjunto de entrenamiento y un $15 \%$ para el conjunto de test.

Con el objetivo de implementar los modelos desarrollados en una Comunidad de Regantes y predecir la demanda de agua en tiempo real, la velocidad de entrenamiento de la red neuronal constituye un factor clave. Así, durante la implementación de las funciones objetivo se programó una restricción de tiempo del entrenamiento de las diferentes RNAs (60 segundos), seleccionando el algoritmo genético de manera indirecta aquellas configuraciones de RNAs más rápidas.

Después de realizar un análisis de correlación de 21 variables potenciales de entrada al modelo de predicción, se seleccionaron las 7 siguientes: demanda de agua del día anterior $\left(\mathrm{L} \mathrm{s}^{-1}\right)$, demanda de agua de dos días anteriores $\left(\mathrm{L} \mathrm{s}^{-1}\right)$, temperatura media del día a predecir $\left({ }^{\circ} \mathrm{C}\right)$, radiación solar del día a predecir $\left(\mathrm{MJ} \mathrm{m}^{-2}\right)$, radiación solar del día anterior $(\mathrm{MJ}$ 
$\left.\mathrm{m}^{-2}\right)$, evapotranspiración de referencia del día a predecir $\left(\mathrm{mm}\right.$ día $\left.{ }^{-1}\right)$ y evapotranspiración de referencia del día anterior $\left(\mathrm{mm} \mathrm{día}^{-1}\right)$.

\subsection{Evolución de las funciones objetivo en el proceso de optimización}

El modelo basado en el algoritmo NSGA-Il y descrito en la figura 1 fue aplicado al Sector VII de la Zona Regable Bembézar M.D. y tanto F1 como F2 fueron optimizadas. La población inicial aleatoria fue de 70 cromosomas. Cada cromosoma está compuesto por 5 genes. Cada gen representa una característica diferente de una RNA. La población inicial se desarrolló para 130 generaciones y las probabilidades de cruce y mutación fueron $90 \%$ y 10 $\%$, respectivamente.

En la figura 2 se muestra el Frente de Pareto que se obtuvo tras el proceso de optimización (generación 130). Esta figura muestra claramente aquellos RNAs con una única capa oculta (línea inferior de puntos) y con dos capas ocultas (línea superior de puntos). Debido a la restricción de tiempo anteriormente especificada, aquellas redes neuronales con una capa oculta, tendrán menor número de neuronas y por tanto la fase de entrenamiento es más rápida, es decir, para el mismo tiempo de entrenamiento obtienen valores de F2 más pequeños. Por el contrario, si la RNA tiene dos capas ocultas, ésta es más densa y necesita más tiempo de entrenamiento. Así, para el mismo tiempo de entrenamiento, el error cometido en la predicción (F2) es mayor con respecto a redes con una capa oculta, aunque la variabilidad explicada (F1) es mayor debido a ese aumento de neuronas en la segunda capa oculta.

Los mejores individuos para RNAs con una y dos capas ocultas están representados por los colores rojo y verde, respectivamente.

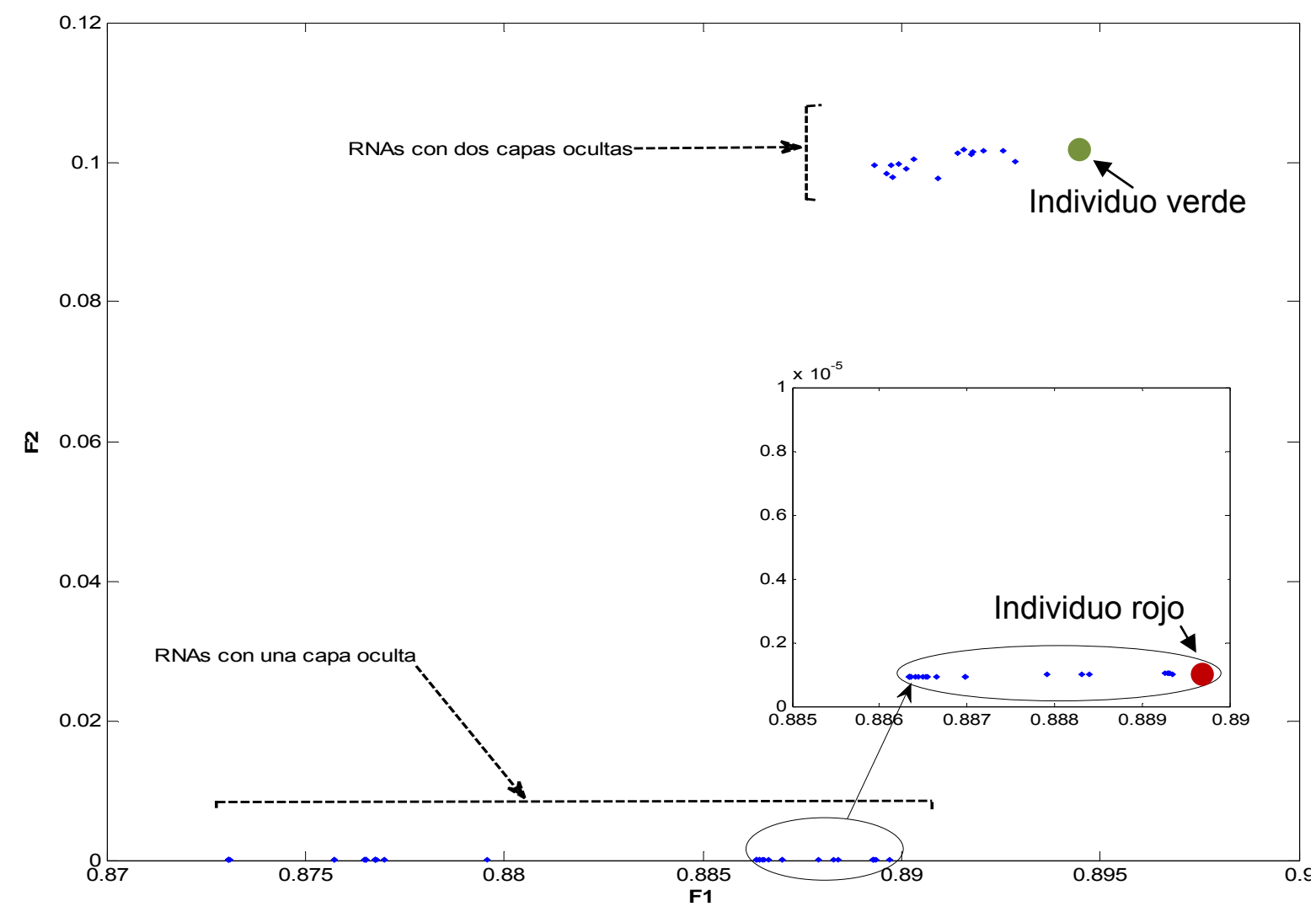

Figura 2. Frente de Pareto para la Generación 130. 


\subsection{Modelos de RNAs óptimos}

Cuando el algoritmo RB es utilizado para entrenar RNAs es importante dejar que éste se ejecute hasta que sus parámetros hayan convergido. Así, los dos individuos seleccionados anteriormente fueron entrenados de nuevo con 100 repeticiones para favorecer la convergencia dichos parámetros y disminuir el efecto de la aleatoriedad inicial de los valores de los pesos sinápticos.

El mejor individuo para las RNAs con una sola capa oculta (individuo rojo) y con dos capas ocultas (individuo verde) se muestran en la Tabla 2 . Los valores de $R^{2}$ y RMSE durante el periodo de test fueron 0.88 y $0.95 ; 68.06 \mathrm{~L} \mathrm{~s}^{-1}$ y $42.44 \mathrm{~L} \mathrm{~s}^{-1}$, para los individuos rojo y verde, respectivamente. La configuración de la red neuronal para los dos individuos fueron $\operatorname{RNA}_{\text {rojo }}(7,30,1)$ y $\operatorname{RNA}_{\text {verde }}(7,24,21)$.

En la figura 2, el valor de F2 del individuo rojo fue de varios órdenes de magnitud mayor con respecto al individuo verde mientras que $\mathrm{F} 1$ no varió considerablemente entre ambos individuos, siendo estos valores de 0.889 y 0.895 , respectivamente. Sin embargo, después de que estos dos individuos se volvieran a entrenar sin restricción de tiempo, claramente, el individuo verde que cuenta con dos capas ocultas obtiene mejores resultados que el individuo rojo. Con restricción de tiempo, aquellas redes con menor número de neuronas (una única capa oculta) obtienen mejores resultados ya que la convergencia del algoritmo de entrenamiento (RB) es más rápida cuando la red neural es más simple. Pero, cuando el algoritmo de entrenamiento RB tiene tiempo suficiente para converger bien, las redes neuronales más complejas son más precisas y representan mejor la variabilidad observada. Así, el error estándar de predicción (SEP) para el individuo verde es del $9.38 \%$ mientras que para el individuo rojo es del $15.05 \%$, siendo además considerablemente mejor la representatividad de la variabilidad observada del individuo verde con respecto al individuo rojo.

Tabla 2. Mejores modelos de RNA obtenidos tras el proceso de optimización.

\begin{tabular}{|c|c|c|c|}
\hline & Individuo Rojo & Individuo Verde \\
\hline \multicolumn{2}{|c|}{$N^{\circ}$ Neuronas de la $1^{a}$ capa oculta } & 30 & 24 \\
\hline \multicolumn{2}{|c|}{$N^{\circ}$ Neuronas de la $2^{a}$ capa oculta } & 0 & 21 \\
\hline \multicolumn{2}{|c|}{ Función de Transferencia de la capa de entrada } & TanST & LinT \\
\hline \multicolumn{2}{|c|}{ Función de Transferencia de las capas ocultas } & TanST & LogST \\
\hline \multicolumn{2}{|c|}{ Función de Transferencia de la capa de salida } & LogST & TanST \\
\hline \multicolumn{2}{|c|}{ Algoritmo de entrenamiento } & RB & RB \\
\hline \multirow{3}{*}{ Periodo de test } & $\mathbf{R}^{2}$ & 0.88 & 0.95 \\
\hline & $\begin{array}{l}\text { RMSE } \\
\left(\mathrm{L} \mathrm{s}^{-1}\right)\end{array}$ & 68.06 & 42.44 \\
\hline & SEP (\%) & 15.05 & 9.38 \\
\hline
\end{tabular}

En la figura 3 se muestra la predicción de los valores del conjunto de test así como el diagrama de dispersión para la $\mathrm{RNA}_{\text {rojo }}$ y $\mathrm{RNA}_{\text {verde. }}$.

Esta figura muestra como la demanda de agua predicha con el modelo verde $\left[\operatorname{RNA}_{\text {verde }}(7,24,21,1)\right]$ se ajusta mejor a la demanda de agua observada para todo el rango de caudales. Tanto en el modelo predictivo representado por el individuo rojo como en el representado por el individuo verde de la figura 3 se puede observar algunos picos de demanda de agua que el modelo no predice correctamente. Este hecho muestra que durante el periodo de entrenamiento no se ha producido un sobreajuste, ya que esos valores máximos pueden ser valores atípicos (outliers) o el ruido propio del sistema. 


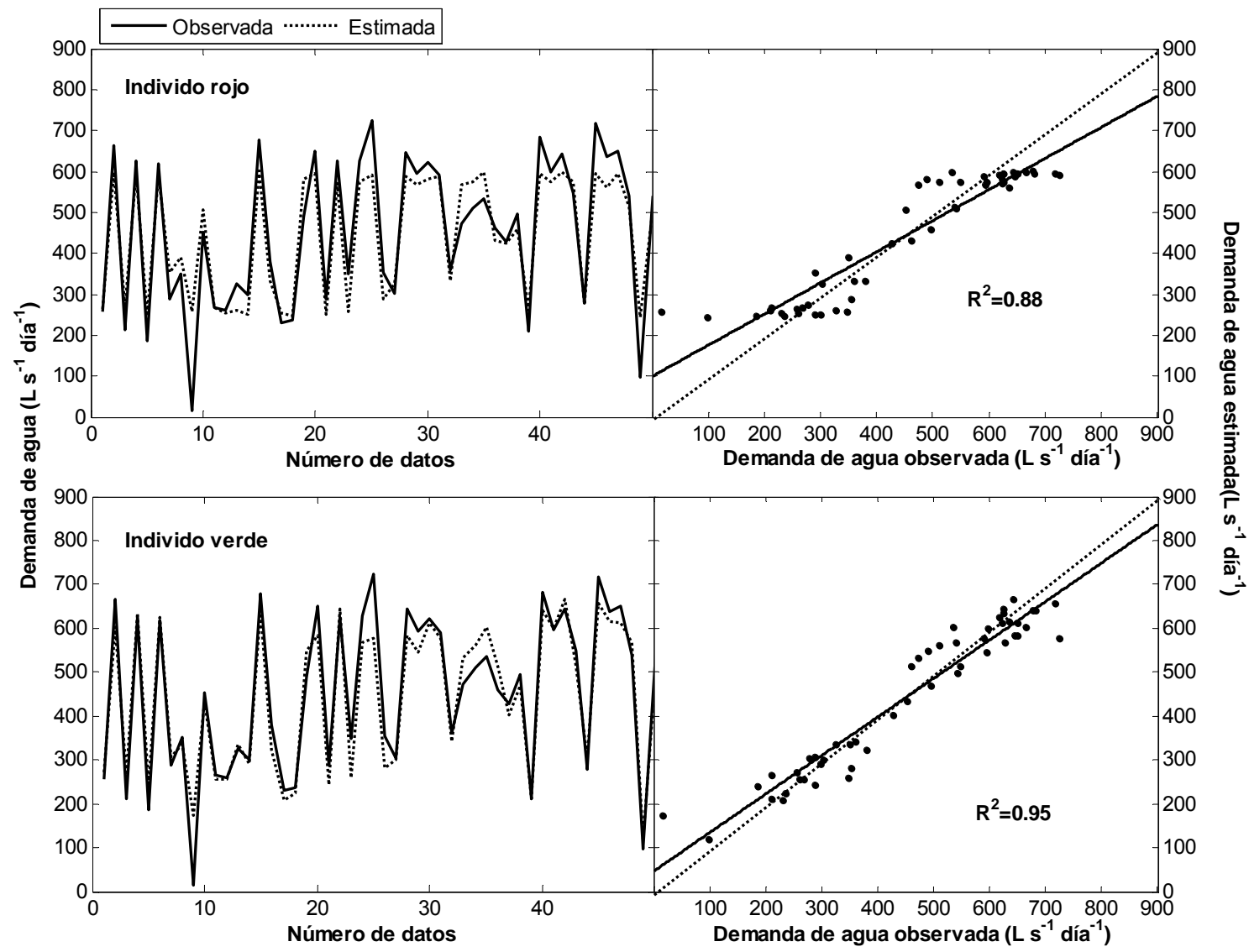

Figura 3. Predicción de demanda de agua para los valores de test y diagrama de dispersión entre la demanda de agua observada y estimada.

Según los valores de $\mathrm{R}^{2}$ y SEP, la RNA más adecuada para predecir la demanda de agua diaria fue la $R N A_{\text {verde. }}$ Los valores $\left(R^{2}=0.95\right.$ y $\left.S E P=9.38 \%\right)$ fueron superiores a los obtenidos por Pulido-Calvo (2009) y Gonzalez et al. (2015) que obtuvieron valores de $R^{2}$ y SEP en sus modelos predictivos de 0.89 y $20.27 \%$; 0.93 y $12.63 \%$, respectivamente.

\section{4.- Conclusiones}

El objetivo de este trabajo fue predecir la demanda diaria de agua de una zona de riego utilizando la información que nos facilitaba la estación de bombeo y una metodología híbrida que combina RNAs y algoritmos genéticos cuando el número de datos de los que se disponen es reducido. En este modelo, se utilizó un algoritmo genético multiobjetivo para encontrar la configuración óptima de una RNA que explique la máxima varianza de demanda de agua observada con el mínimo error de estimación. La función de entrenamiento utilizada fue RB la cual asume que los pesos sinápticos de la RNA son variables aleatorias con distribuciones normales, no siendo necesario la división de los datos en los subconjuntos de entrenamiento y validación. Así, cuando el número de datos es reducido, esta función de entrenamiento presenta mejor generalización que la "parada temprana".

El modelo desarrollado para predecir la demanda de agua diaria se aplicó al Sector VII de la Zona Regable Bembézar M. D., Sur de España. Los resultados indicaron el modelo desarrollado en este trabajo tuvo mejores estadísticos y medidas de error que los modelos desarrollados por otros autores.

Este modelo ha demostrado ser una herramienta útil que, con necesidades no muy grandes de datos y de tiempo, puede ofrecer importantes ventajas para el desarrollo de políticas y la gestión del agua de riego. Además, dicha información puede ser de utilidad para la programación del funcionamiento de la estación de bombeo y la contratación de la 
tarifa eléctrica que reduzca al mínimo los términos de potencia.

\section{5.- Agradecimientos}

Este trabajo es parte del proyecto TEMAER (AGL2014-59747-C2-2-R), financiado por el Ministerio de Economía y Competitividad de España.

Este trabajo fue apoyado por el contrato predoctoral FPU (Formación del Profesorado Universitario) del Ministerio de Educacion, Cultura y Deporte de España cuyo beneficiario es Rafael González Perea.

\section{6.- Bibliografia}

Baños R, Gil C, Reca J, Montoya F.G., 2010. A memetic algorithm applied to the design of water distribution networks. Appl Soft Comput 10:261-266

Deb K, Pratap A, Agarwal S, Meyarivan T, 2002. A fast and Elitist Multiobjective Genetic Algorithm: NSGA-II. IEEE Transactions on Evolutionary Computation, 2002; Vol. 6, № 2

Farmani R, Savic D.A., and Walters G.A., 2005. Evolutionary multi-objective optimization in water distribution network design. Eng. Optimiz 37 (2), 167-183

González Perea R, Camacho Poyato E, Montesinos P, Rodríguez Díaz J.A., 2015. Irrigation Demand Forecasting Using Artificial Neuro-Genetic Networks. Water Resources Management 29, 5551-5567

Mackay D, 1992. Bayesian Interpolation. Neural Computation 4(3), 415-447

Pulido-Calvo I, Gutiérrez-Estrada J.C., 2009. Improved irrigation water demand forecasting using a soft-computing hybrid model. Biosystems Engineering 102(1), 202-218

Rumelhart D.E., Hinton G.E., Williams R.J., 1986. Learning representations by backpropagation errors. Nature 323(9), 533-536

Savic D, 2002. Single-objective vs. multiobjetive optimization for integrated decision support. Proc., First Biennial Meeting of the Int. Environmental Modeling and Software Society (IEMSs), Lugano, Switzerland, 7-12

See L, Openshaw S, 2000. A hybrid multi-model approach to river level forecasting. Hydrological Sciences Journal 45(4), 523-536

Ventura S, Silva M, Pérez-Bendito D, Hervás C, 1995. Artificial neural networks for estimation of kinetic analytical parameters. Analytical Chemistry 67(9), 1521-1525 


\title{
C-19
}

\section{POTENCIAL DEL CABLE DE FIBRA ÓPTICA Y DE LA TÉCNICA DTS EN EL RIEGO DE JARDINES}

\author{
Horcajo Diestro, Daniel (1); Rodríguez Sinobas, Leonor (2); Zubelzu Mínguez, Sergio (3); \\ Sánchez Calvo, Raúl (4)
}

1 Alumno, Universidad Politécnica de Madrid, Escuela Técnica Superior de Ingenieros Agrónomos, daniel.horcajo.diestro@gmail.com

2 Profesor, Universidad Politécnica de Madrid, Grupo de Investigación Hidráulica del Riego, Escuela técnica Superior de Ingenieros Agrónomos, leonor.rodriguez.sinobas@upm.es

3 Profesor, Universidad Politécnica de Madrid, Grupo de Investigación Hidráulica del Riego, Escuela técnica Superior de Ingenieros Agrónomos, sergio.zubelzu@upm.es

${ }^{4}$ Profesor, Universidad Politécnica de Madrid, Grupo de Investigación Hidráulica del Riego, Escuela técnica Superior de Ingenieros Agrónomos, raul.sanchez@upm.es

\section{RESUMEN}

El cable de fibra óptica y la técnica Distributed Temperature Sensing puede ser una opción en la programación del riego de jardines para mejorar, no sólo la eficiencia en el uso del agua, sino también, por ende, el de fertilizantes y ahorrar energía. Esta metodología permite estimar en continuo la temperatura hasta $12,5 \mathrm{~cm}$ y temporal de $1 \mathrm{~s}$. Posteriormente, se relaciona la temperatura con el contenido de agua en el suelo obteniéndose errores de hasta $\pm 2 \%$. En este trabajo se aplicó esta técnica al riego por aspersión de un área ajardinada de la ETSI de Agrónomos de Madrid. Los resultados son prometedores dado que permiten conocer la variabilidad espacial de la distribución del agua en el suelo y relacionarla con la distribución del agua por la unidad de riego para elaborar criterios de riego que mejoren la eficiencia de todos los recursos.

\begin{abstract}
The fiber optic cable and the technique Distribute Temperature Sensing show potential to be used for the irrigation programming in green areas, not only to improve the water use efficiency but, the use of fertilizers and saving energy as well. This methodology can measure temperature along the cable, every $12.5 \mathrm{~cm}$, and every second. Then, temperature is correlated with soil water content with up to $\pm 2 \%$ accuracy. This study was performed in a green area located at the ETSI de Agrónomos de Madrid that was irrigated by sprinkler irrigation. The results are promising since the water spatial variability within the soil is known and it can be correlated with the water distribution in the irrigation unit to elaborate better irrigation strategies in the garden.
\end{abstract}

\section{1- Introducción y objetivos}

Los sensores de temperatura distribuida (Distributed Temperature Sensing, DTS) cuentan con un amplio campo de aplicación que incluye, entre otros los campos ambiental 
(Selker et al., 2006a; Selker et al., 2006b; Lowry et al., 2007; Vercauteren et al., 2011; Briggs et al., 2012; 2014; Benitez-Buelga et al., 2014; Benitez-Buelga et al., 2016). Una de sus ventajas es la precisión en la medida de la temperatura de forma continua tanto en el espacio como en el tiempo que se han correlacionado con otras variables como por ejemplo la humedad del suelo $\theta$ (Sayde et al., 2010; Sayde et al. 2014).

EI DTS consta de un láser que emite un pulso luminoso, a una determinada frecuencia, a lo largo del cable de fibra óptica y de filtros y espectrofotómetros. La luz se dispersa en función del índice de refracción de la fibra. La mayor parte de dicha dispersión se produce en la misma longitud de onda que el pulso original, mientras que una porción denominada dispersión de Raman se dispersa a longitudes de onda distintas de las del láser inicial: una parte, denominada Stoke, lo hace a una longitud de onda inferior, mientras que otra porción, llamada anti-Stoke, se dispersa con una longitud de onda superior. La intensidad de la dispersión anti-Stoke es sensible a la temperatura de la fibra, al contrario que la dispersión Stoke. A partir del ratio de la intensidad de las ondas Stokes/Anti-Stokes y del tiempo que tarda la luz reflejada en llegar al punto de emisión, se determina la temperatura en cada a lo largo del cable.

En la estimación de $\theta$, se usa la técnica Active Fiber Optic Temperature System (AFTS) que aplica una potencia calorífica durante un tiempo determinado al encamisado metálico de protección del cable de fibra óptica (Sayde, 2010; Sayde, 2014, Benitez-Buelga et al. 2014).

La mejora en la precisión de la medida depende del cable de FO y del DTS. Como en el resto de sensores para mejorarla, debe existir buen contacto entre el cable y suelo circundante $\mathrm{y}$, además, la instalación debe de calibrarse de forma correcta. Actualmente algunas unidades DTS estiman $\theta$ con una resolución espacial de $12,5 \mathrm{~cm}$ y temporal de $1 \mathrm{~s}$ (Gil et al, 2012; Benitez-Buelga et al., 2016) y con un error de medida pequeño.

El objetivo de este trabajo es estudiar el potencial del cable de fibra óptica y de la técnica DTS para estimar el contenido de agua en el suelo, y su variabilidad, en el riego de áreas verdes.

\section{2- Materiales y métodos}

Para la ejecución de los experimentos se dispusieron de dos instalaciones: por un lado se contó con un recipiente de metacrilato $(2,5 \times 0,5 \times 0,25 \mathrm{~m})$ en el laboratorio del grupo de investigación y en segundo lugar, del área ajardinada "Pico de la Glorieta" de los jardines centrales de la Escuela Técnica Superior de Ingenieros Agrónomos de la Universidad Politécnica de Madrid (ETSIA).

Se tomó muestras de suelo del jardín y se rellenó el recipiente de metacrilato manteniendo la densidad aparente de jardín. Posteriormente, se colocó el cable de fibra óptica tal y como se observa en la figura 1. 


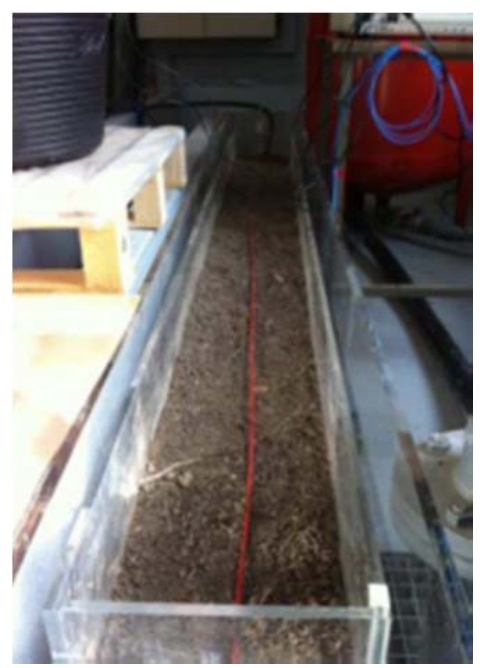

Figura 1. Detalle del contenedor de suelo del jardín con el cable de fibra óptica.

Por su parte, en el jardín se instaló $147 \mathrm{~m}$ cable de fibra óptica enterrados a una profundidad de $0,25 \mathrm{~m}$. La figura 2 muestra un esquema del trazado de la instalación y de la colocación del cable en la zanja.
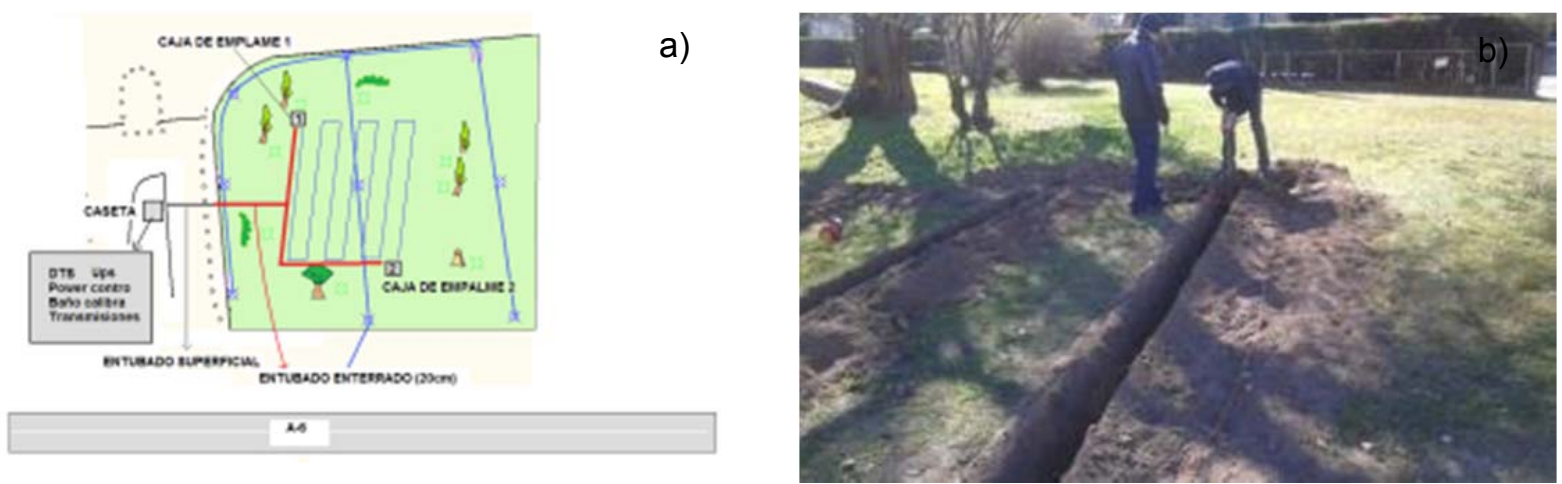

Figura 2. Esquema de la instalación de los jardines de la ETSIA (a) y tendido de la fibra en la zanja (b).

Para la caracterización de la humedad en el suelo $\theta$ se utilizó el concepto de integral térmica $T_{\text {cum }}$ y $\theta$ desarrollado por Sayde et al. (2010):

La medida de la $T_{\text {cum }}$ requiere del uso de la técnica de calentamiento activo de la fibra (Actively Heated Fiber Optics - AHFO -) que consiste en aplicar una diferencia de potencial a la camisa metálica del cable de fibra óptica lo cual requiere de un cable especial que incluya dicha camisa. Para los experimentos se empleó el cable modelo Brusteel de la casa BRUG, la diferencia de potencial al cable se proporcionó mediante un autotransformador modelo Microfusión de marca Control Concepts. Como sensor de temperatura se empleó un DTS modelo Última 004 de la casa comercial Silixa capaz de proporcionar medidas de temperatura cada $0,125 \mathrm{~m}$ y con una frecuencia temporal máxima de $1 \mathrm{~s}$.

Con estas características se calentó la fibra mediante la aplicación de pulsos caloríficos de $7 \mathrm{~W} / \mathrm{m}$ durante $2 \frac{1}{2}$ min con el objeto de obtener una curva de calibración $T_{\text {cum }}{ }^{-}$ $\theta$. Para ello se procedió a saturar el suelo del contenedor y realizar diferentes medidas con diferentes niveles de $\theta$. Para acelerar la perdida de humedad en el suelo se sembró semillas 
de pradera de crecimiento rápido y se aplicó corrientes de aire caliente en el extremo inferior que está perforado. Aparte, $\theta$ se midió con sensores TDR (SM300 Delta-T devices Ltd).

El procedimiento fue el mismo en el laboratorio que en el jardín, realizándose: 5 minutos iniciales, 2,5 minutos de calentamiento y 12,5 minutos finales de enfriamiento. Se programó para registrar una medida de temperatura cada $0,125 \mathrm{~m}$ de cable y cada $5 \mathrm{~s}$ con el procedimiento interno de calibración del DTS y se llevaron a cabo medidas tipo "single ended".

La medida de $\theta$ en el jardín se realizó en dos instantes diferentes: uno para medir el contenido de humedad inicial del suelo y otro, tras aplicar un riego durante $30 \mathrm{~min}$. También se calculó la uniformidad de distribución del agua de riego.

\section{3- Resultados y discusión}

La Figura 3 muestra la curva de calibración $T_{\text {cum }}-\theta$.

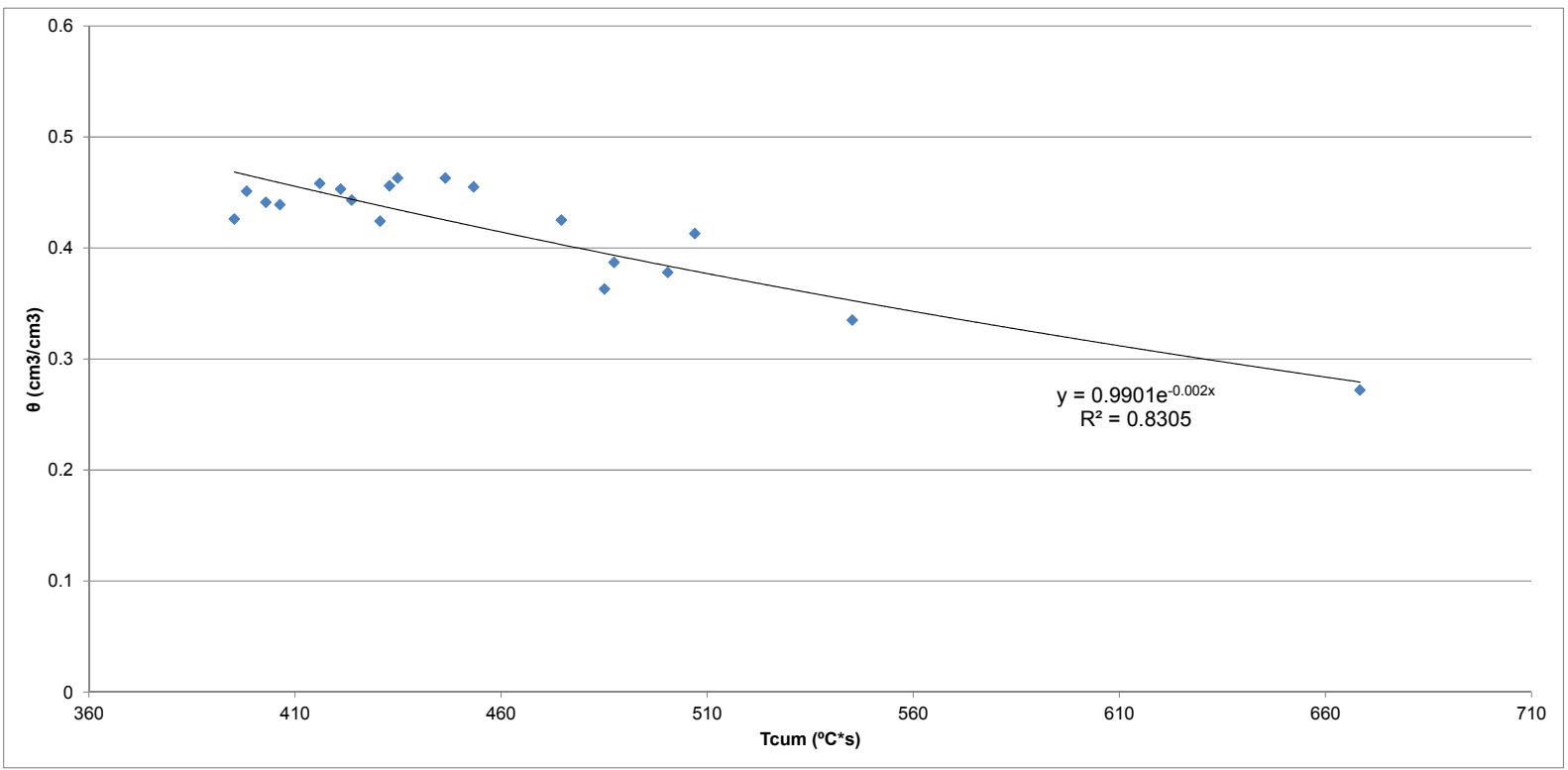

Figura 3. Curva de calibración $T_{\text {cum }}-\theta$.

El mejor ajuste se obtuvo con una curva exponencial con resultados aceptables en cuanto a capacidad explicativa, medida por el coeficiente de determinación $\left(R^{2}\right)$ aunque inferiores a los obtenidos en otros trabajos similares como por ejemplo en Gil-Rodríguez et al. (2011). Este hecho puede deberse a la naturaleza del terreno, formado por rellenos antrópicos recientes que le confieren gran irregularidad al perfil y que dificultad la obtención de y una medida constante de humedad a lo largo del cable de fibra óptica.

Esta curva de calibración se utilizó para estimar $\theta$ en el jardín cuyos resultados se muestran en la figura 4. 


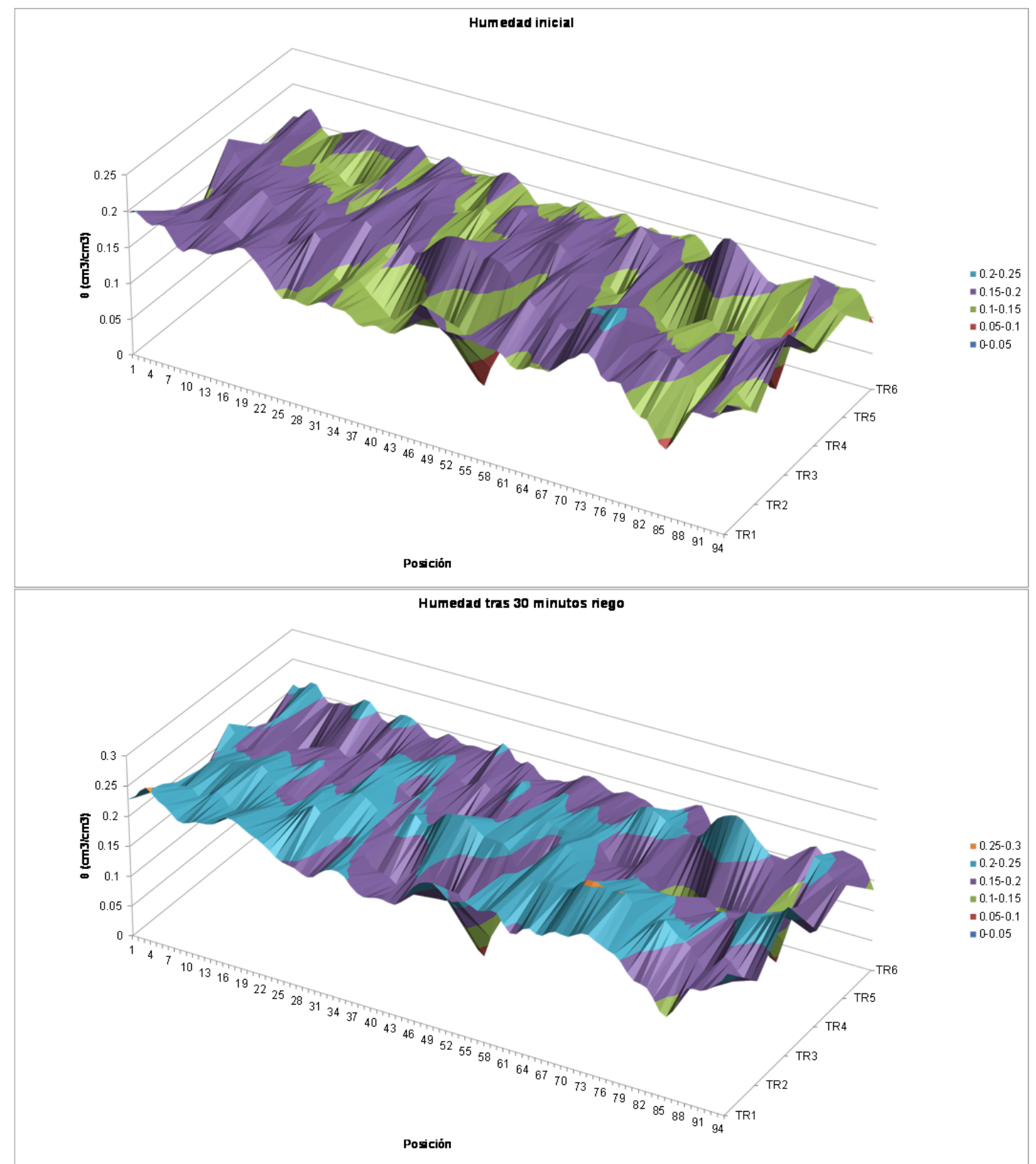

Figura 4. Contenido de agua en el suelo. (a): Antes del riego y (b): tras $30 \mathrm{~min}$ de riego

Los resultados muestran una distribución desigual del agua en el suelo, fruto de un riego con una baja uniformidad $(\mathrm{CV}=0.61)$. Sin embargo, la redistribución del agua mejora parcialmente los resultados de la uniformidad del riego al obtenerse resultados para el coeficiente de variación de $\theta$ de 0,17 y 0,15 correspondientes a las situaciones previa y posterior al riego, respectivamente.

En cualquier caso, la fibra proporciona una herramienta óptima para el control del riego y de la distribución del agua del riego en el suelo, permitiendo un control continuo tanto en el espacio como en el tiempo.

\section{4- Conclusiones y recomendaciones}

El cable de fibra óptica y la técnica del DTS de este trabajo han servido para estimar la variabilidad espacial del agua en el suelo en el riego de jardines. La resolución de medida por parte del aparato es muy alta, permitiendo medir la temperatura cada $12,5 \mathrm{~cm}$, siendo un 
avance en la metrología ya que pueden localizarse zonas que estén con una mayor demanda de agua o que sufran algún cambio (sombreado, raíces, alteración del suelo...).

La sensibilidad y precisión temporal que proporciona el DTS también permiten un avance en el control del riego pudiendo programar de forma precisa los riegos y la lámina de agua aportada al terreno en función de las necesidades.

Hay que tener en cuenta que el cálculo de la humedad del suelo ha sido calculada a partir de la calibración del DTS con un TDR, dando una $R^{2}=0.830$, actualmente se está trabajando para calibrar de mejor manera el aparato pero la problemática aparece en controlar la resolución tan alta que tiene el DTS.

\section{5- Referencias}

Benítez-Buelga, J.; Sayde, C.; Rodríguez-Sinobas, .L., Selker, J., (2014). Heated fiber optic distributed temperature sensing for measuring soil volumetric heat capacity and water content: A dual probe heat-pulse approach. Vadose Zone Journal, 13(11): 13-20.

Benitez-Buelga, J., Rodríguez-Sinobas, L., García-Calvo, R., Gil-Rodríguez, M., Sayde, C., Selker, J., (2016). Calibration of soil moisture sensing with subsurface heated fiber optics using numerical simulation. Water resources research. DOI: 10.1002/2015WR017897.

Briggs, M. A., Lautz, L. K., Mckenzie, J. M., Gordn, R. P., \& Hare, D. K., (2012). Using high resolution distributed temperature sensing to quantify spatial and temporal variability in vertical hyporheic flux. Water resources research, 48.

Gil Rodríguez, M.; Rodríguez Sinobas, L.; Benitez Buelga, J. y Sánchez-Calvo, R.(2013). Application of active heat pulse method with fiber optic temperature sensing for estimation of wetting bulbs and water distribution in drip emitters.. "Agricultural Water Management", v. 120 ; pp. 72-78.

Lowry, C. S., Walker, J. F., Hunt, R. J., \& Anderson, M. P., 2007. Identifying spatial variability of groundwater discharge in wetland stream using a distributed temperature sensor. Water resources research, 43.

Sayde, C., Gregory, C., Rodríguez, M., Tufillaro, N., Tyler, S., Van de Giesen, N., English, M., Cuenca, R., \& Selker, J. S. (2010). Feasibility of soil moisture monitoring with heated fiber optics. Water Resources Research, 46.

Sayde C., Benitez, J. B., Rodríguez, L., Loraine, E. K., English, M., Van de Giesen, N., \& Selker, J. S. (2014). Mapping variability of soil water content and flux across $1-1000 \mathrm{~m}$ scales using the actively heated fiber optic method. Water Resources Research, 50.

Selker, J. S., Van de Giesen, N., Westhoff, M., Luxemburg, W., \& Parlange, M.B..2006a. Fiber optics open window on stream dynamics. Geophysical Research Letters, 33.

Selker, J. S., Thévenaz, L., Huwald, H., Mallet, A., Luxemburg, W., Van de Giesen, N., Stejskal, M:, Zeman, J., Westhoff, M., \& Parlange, M.B., 2006b. Distributed fiber optic temperature sensing for hydrologic systems. Water Resources Research, 42 
AERYDXIV Congreso Nacional de Riegos, Sevilla 2016

Vercauteren, N., Huwald, H., Bou-Zeid, E., Selker, J. S., Lemmin, U., Parlange, M. B., Lunati, I., 2011. Evolution of superficial lake water temperature profile under diurnal radiative forcing. Water resources research, 47. 


\title{
SISTEMA DE PROGRAMACIÓN Y CONTROL AUTOMÁTICO DE UN RIEGO POR GOTEO SUBTERRÁNEO EN UN CULTIVO DE OLIVAR
}

\author{
Autores: Reca Cardeña, J. (1),Martínez López, J. (1), Sánchez Molina, J.A. (2), Rivas Ruiz, \\ J.L. (2), Ferre Giménez, J.A. (2) \\ ${ }^{1}$ Profesor Titular de Universidad. Universidad de Almería. Departamento de Ingeniería, Crta. \\ Sacramento S.N. La Cañada de S. Urbano. 04120. Almería. jreca@ual.es \\ ${ }^{2}$.Grupo de Investigación en Automática, Electrónica y Robótica. Universidad de Almería. \\ Crta. Sacramento S.N. La Cañada de S. Urbano. 04120. Almería. jorgesanchez@ual.es
}

\section{Resumen}

En esta comunicación se presenta un nuevo sistema de programación y control automático del riego por goteo subterráneo para un cultivo de olivar ecológico de una finca situada en el T.M. de Tabernas en Almería (España) y propiedad de la empresa Rafael Alonso Aguilera S.L. La finca se riega mediante un novedoso sistema de riego subterráneo patentado por esta empresa. El sistema de control propuesto está basado en el establecimiento de un balance hídrico diario en el en el sistema suelo-planta a partir de la estimación de las necesidades de riego del cultivo en tiempo real a partir de los datos climáticos medidos en tiempo real a partir de una estación agroclimática. Se presentan también los resultados de la evaluación del funcionamiento del sistema a lo largo de un periodo de 5 años y se analiza el ahorro de agua proporcionado por la combinación del sistema de control del riego y del método de riego subterráneo.

\section{1- Introducción. Objetivo del trabajo}

Un manejo eficiente del agua de riego es fundamental, especialmente en zonas áridas, como es el caso de Almería, en las que el agua constituye un factor de producción escaso y vulnerable. Las condiciones favorables de radicación y temperatura en esta zona han permitido el desarrollo de cultivos de gran calidad y rentabilidad económica, como es el caso de las recientes plantaciones de olivar en regadío en la zona de Tabernas. No obstante, el manejo inadecuado del riego puede provocar serios impactos ambiéntales como el agravamiento del déficit hídrico, la erosión del suelo y la contaminación de los acuíferos por lixiviación de nutrientes o fitosanitarios.

La utilización de sistemas de riego por goteo subterráneos (Ayars y col., 1999) permite mejorar la eficiencia del riego ya que aplican el agua en el interior del suelo y evitan las pérdidas de agua por evaporación directa. Además, localizan mejor el agua y los nutrientes en la zona donde la absorción radical es más activa, favoreciendo su correcta absorción. Sin embargo, presenta algunos inconvenientes que dificultan su manejo como la rotura de tuberías debido a la acción de las raíces, la obturación de los emisores y la dificultad de localización y reposición de emisores obturados y fugas de agua. Para evitar estos inconvenientes, un nuevo método de riego subterráneo, patentado por Rafael Alonso Aguilera S.L. (en adelante sistema RA), se está utilizando con éxito en la zona. Este sistema, consiste en instalar la red de distribución de agua y los goteros en superficie e introducir la descarga de los goteros en profundidad, a través de unas tuberías perforadas de plástico colocadas verticalmente en el suelo (ver figura 1). Este sistema es sencillo de instalar, económico y potencialmente eficiente, por presentar todas las ventajas del riego subterráneo. 


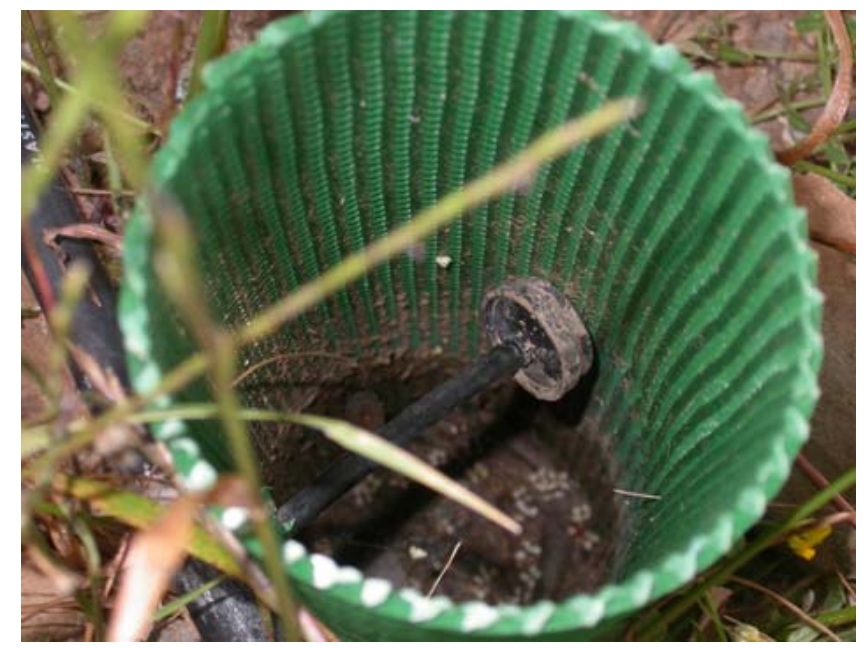

Figura 1. Sistema de riego subterráneo RA

En el año 2005, nuestro grupo inicia un proyecto de investigación financiado por la mencionada empresa, cuyo objetivo fundamental fue evaluar agronómicamente el nuevo sistema de riego por goteo subterráneo en un cultivo de olivar ecológico de la zona de Tabernas. Para ello se planteó un ensayo de campo, en el que se evaluó la respuesta del nuevo sistema de riego RA, en comparación con un sistema de riego por goteo superficial, bajo tres dosis de agua diferentes $(100 \%, 80 \%$ y $60 \%$ de las necesidades de riego respectivamente). Este ensayo de campo se prolongó durante 3 campañas (2005, 2006 y 2007) en una primera fase y 2 campañas más (2009 y 2010) en una segunda fase del proyecto. Los resultados de este estudio experimental demostraron que el sistema de riego RA resultó ser más eficiente ya que permitió mejorar la eficiencia del uso del agua hasta en un $20 \%$ (Martínez y Reca, 2014). No obstante, poder hacer efectivo dicho ahorro, es necesario realizar una programación y un manejo del riego en tiempo real, con criterios racionales que tengan en cuenta las necesidades de riego del cultivo con este nuevo sistema

Como consecuencia, en el año 2009 se inicia un nuevo proyecto, cuyo objetivo fundamental fue desarrollar un sistema automático de programación y control del riego para un cultivo de olivar ecológico regado con el nuevo sistema RA. El objetivo es implementar en el mencionado sistema de control los resultados obtenidos en los ensayos de campo, junto con una metodología racional de cálculo de necesidades hídricas. Esta herramienta permitirá conseguir la máxima eficiencia en el uso del agua de riego con el sistema de riego subterráneo RA, sin que el agricultor tenga que preocuparse de realizar la programación del riego. En este trabajo, se presenta el desarrollo de este nuevo sistema de programación y control automático del riego de un cultivo de olivar ecológico regado con el sistema RA y los resultados del seguimiento de su funcionamiento durante un total de 5 campañas agrícolas.

\section{2- Materiales y métodos.}

Para evaluar el funcionamiento del nuevo sistema de control automático del riego, se desarrolló un prototipo del mismo que se instaló en una finca de olivar ecológico propiedad de Rafael Alonso Aguilera S.L., situada en la comarca del desierto de Tabernas de la provincia de Almería (España).

\subsection{Caracterización de la finca experimental}

La primera actividad que fue necesario realizar para el desarrollo del sistema de control fue la caracterización de la finca de olivar y de su instalación de riego. Dicha 
explotación, tiene una superficie total de cultivo de aproximadamente 56,28 ha, fundamentalmente de olivar ecológico (ver figura 2).

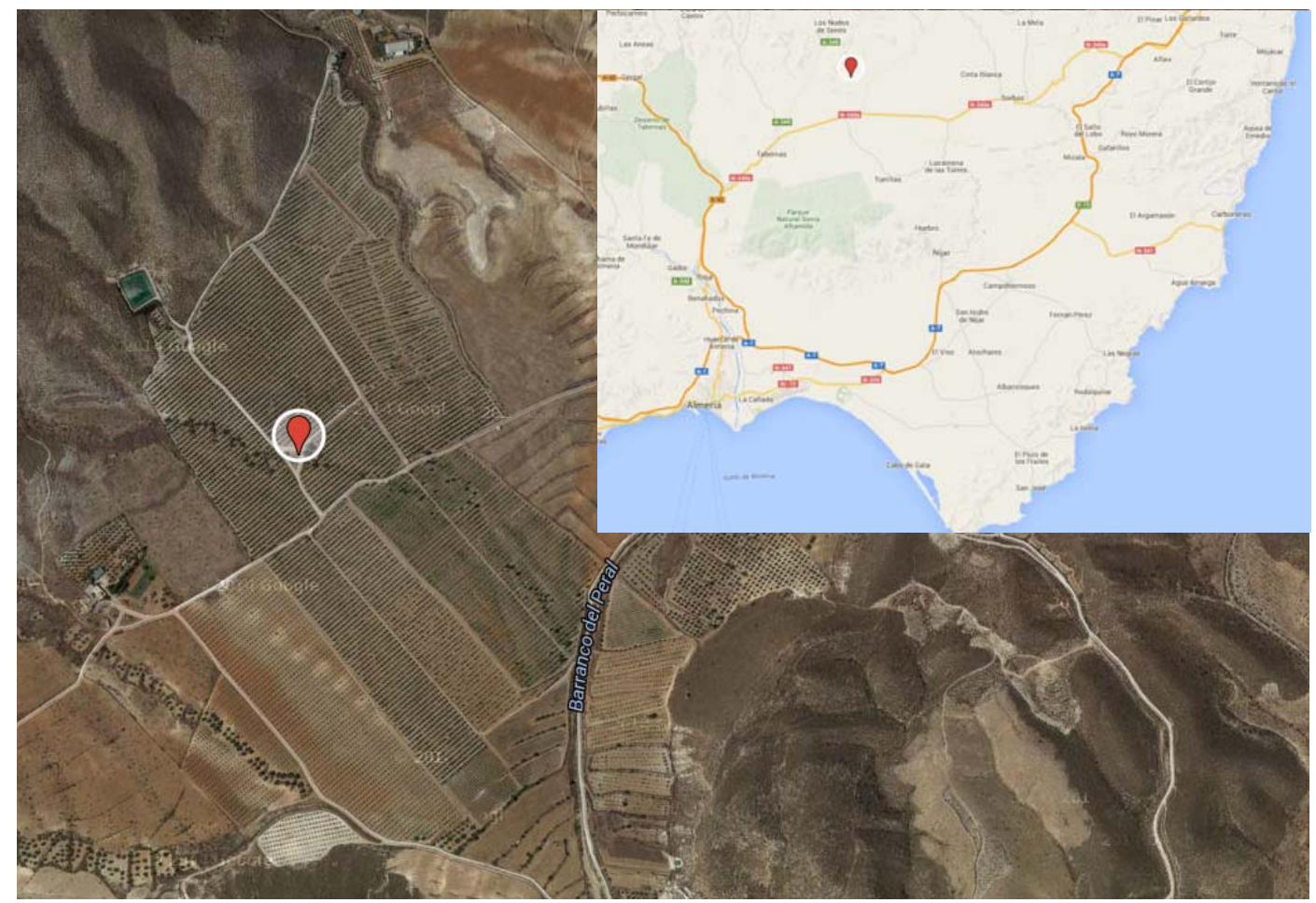

Figura 2. Situación y emplazamiento de la finca experimental

Actualmente dispone de un sistema de riego por goteo subterráneo RA. El agua de riego, procedente del acuífero de la zona, la extrae mediante 4 sondeos, con sus respectivas bombas, que la inyectan directamente a la red de distribución de agua. Esta red presenta dos depósitos de regulación desde los que riega por gravedad. Debido a que los depósitos se encuentran a distinta cota y para evitar que se vacíe el de mayor altura, la red sólo se puede alimentar alternativamente de uno de ellos. Cuando los requerimientos de presión del sistema son altos, se alimenta del depósito situado a mayor cota, mientras que en el resto de ocasiones se alimenta del localizado a menor cota. Esta operación se realiza mediante dos electroválvulas motorizadas que alternativamente abren y cierran los depósitos que correspondan. El método de riego es por goteo subterráneo RA en toda la finca y se utilizan goteros de tipo autocompensante. El número de goteros por árbol y el caudal de cada uno varían entre sectores de riego, dependiendo de la edad y marco de plantación del cultivo. El equipo de filtración está formado por 5 filtros de anillas de 125 micras autolimpiantes. La operación de limpieza se realiza por tiempo y por variación de presión entre la entrada y la salida del filtro para lo que se dispone de un manómetro diferencial tarado para activar el sistema de limpieza cuando dicha presión diferencial sea mayor que un valor prefijado. El equipo de fertirriego está formado por 3 bombas dosificadoras, cuatro depósitos de fertilizante y dos agitadores neumáticos.

Para el diseño del sistema de control se han establecido ocho sectores independientes de riego con diferentes variedades, edades, marcos de plantación y número y caudal de goteros.

\subsection{Balance hídrico en el sistema suelo-planta.}

El sistema de programación automática implementado se basa en el establecimiento de un balance hídrico diario. En un sistema suelo-planta, bien delimitado y considerando las 
entradas y salidas a dicho sistema, puede plantearse la siguiente ecuación de balance hídrico o conservación de masa (ecuación 1):

$$
A_{t}=A_{t-1}+H_{n}+P e-E T_{c}
$$

Donde: $A_{t}$ y $A_{t-1}$ son el agotamiento para un día $t$ y $t-1$, respectivamente, $H_{n}$ es la lámina neta de riego, $P_{e}$ la precipitación efectiva o fracción de la precipitación total que es utilizada por el cultivo, $E T_{c}$ es la evapotranspiración del cultivo o agua que se pierde por evaporación desde el sistema suelo-planta.

La lámina neta de riego se calcula a partir de la lámina bruta $\left(H_{b}\right)$ y del rendimiento de aplicación $\left(R_{a}\right)$ del riego que tiene en cuenta las pérdidas de agua en la aplicación.

$$
H_{n}=\frac{H_{b}}{R_{a}}
$$

La lámina bruta $\left(H_{b}\right.$ en $\left.\mathrm{mm}\right)$ aportada en cada riego se estima en función del tiempo de aplicación del riego $\left(t_{a r}\right.$, en $\left.\mathrm{h}\right)$, del número de goteros por árbol $\left(n_{e}\right)$, del caudal del emisor ( $q$ en $\mathrm{l} / \mathrm{h}$ ) y del marco de plantación en $\mathrm{m}^{2}\left(s_{a} s_{f}\right)$.

$$
H_{b}=\frac{n_{e} \cdot q \cdot t_{a r}}{s_{a} \cdot s_{f}}
$$

La precipitación efectiva calcula a partir de la precipitación medida mediante un pluviómetro y con la aplicación de un coeficiente reductor (Dastane, 1978).

La evapotranspiración del cultivo se puede estimar a partir de la medida de variables climáticas siguiendo la metodología propuesta por la FAO (Allen et al., 1998). Según esta metodología, la $E T_{c}$ se calcula como el producto de 3 términos:

$$
E T_{c}=E T_{o} \cdot K_{c} \cdot K_{r}
$$

Donde: $E T_{o}$ es la evapotranspiración de referencia, $K_{c}$ es el coeficiente de cultivo y $K_{r}$ es un coeficiente reductor por localización.

La evapotranspiración de referencia $\left(E T_{0}\right)$ se ha calculado mediante la ecuación de Penman-Monteith (Allen y col. 1998). En este trabajo se han utilizado los coeficientes de cultivo mensuales propuestos por Orgaz y Fereres (1999). Para el coeficiente reductor por localización $\left(K_{r}\right)$ se ha utilizado la fórmula propuesta por Fereres et al. (1981). Debido a que el sistema de riego era un nuevo sistema de riego subterráneo, se ha introducido también un factor reductor para tener en cuenta la reducción de evaporación desde el bulbo húmedo. El valor recomendado para este factor reductor oscila entre fue estudiado experimentalmente por el equipo investigador en un estudio previo realizado (Martínez y Reca, 2014) y se recomiendan valores que oscilan entre 0.8 y 0.9 .

\subsection{Criterios de programación del riego.}

La programación del riego está basada en la aplicación de dosis de riego fijas y en intervalos de riego variables dependiendo de las necesidades de riego del cultivo.

El cálculo de las dosis de riego se ha realizado tomando el valor de la $E T_{c}$ en la época de máximo consumo para un olivar con un grado de cobertura superficial completa. Los tiempos de riego de cada sector se han calculado aplicando la ecuación 4, redondeándolos posteriormente a múltiplos de $1 \mathrm{~h}$. Con estos criterios se han obtenido los tiempos de riego y las dosis que se muestran en la tabla 1 para cada uno de los sectores de riego. 
Estos cálculos se realizan de forma automática por el sistema de control en función de los parámetros que caracterizan al cultivo y al sistema de riego de cada sector (variedad, marco de plantación, caudal por árbol y diámetro de copa).

Tabla 1. Características de los sectores de riego, tiempos de riego y dosis por árbol.

\begin{tabular}{|c|c|c|c|c|c|c|c|c|}
\hline Sector & Variedad & Plant. & $\begin{array}{c}\text { Marco } \\
\left(\mathrm{m}^{2}\right) \\
\end{array}$ & Sup. (ha) & $\begin{array}{c}\text { Q árbol } \\
\text { (I/h) }\end{array}$ & $\begin{array}{l}\text { D. Copa } \\
\text { (m) }\end{array}$ & $\begin{array}{l}T_{\text {ar }} \\
\text { (h) }\end{array}$ & $\begin{array}{c}\text { Dosis } \\
\text { (l/árbol) }\end{array}$ \\
\hline 1 & Picual & 2009 & $7 \times 5$ & 7.77 & 4.00 & 1.02 & 1 & 4.00 \\
\hline 2 & Arbequina & 2002 & $7 \times 5$ & 6.11 & 15.67 & 3.08 & 3 & 47.01 \\
\hline 3 & Arbequina & 2002 & $7 \times 5$ & 7.57 & 15.67 & 3.08 & 3 & 47.01 \\
\hline 4 & Picual & 2005 & $7 \times 5$ & 6.54 & 15.67 & 2.78 & 3 & 47.01 \\
\hline 5 & Picual & 2005 & $7 \times 5$ & 3.22 & 15.67 & 2.78 & 3 & 47.01 \\
\hline 6 & Hojiblanca & 2000 & $7 \times 7$ & 4.70 & 25.00 & 3.96 & 3 & 14.10 \\
\hline 7 & Arbequina & 2007 & $7 \times 1.2$ & 7.32 & 4.60 & 1.32 & 2 & 9.20 \\
\hline 8 & Picual & 2007 & $7 \times 5$ & 11.06 & 6.30 & 1.56 & 2 & 12.60 \\
\hline
\end{tabular}

\subsection{Descripción del sistema de control}

Los elementos físicos que componen el sistema de control son los siguientes:

1. Estación agroclimática: es la encargada de medir las variables climáticas necesarias para el cálculo de la evapotranspiración del cultivo y de la precipitación efectiva (ver figura 3). La estación está dotada de los siguientes sensores (Campbell Scientific):

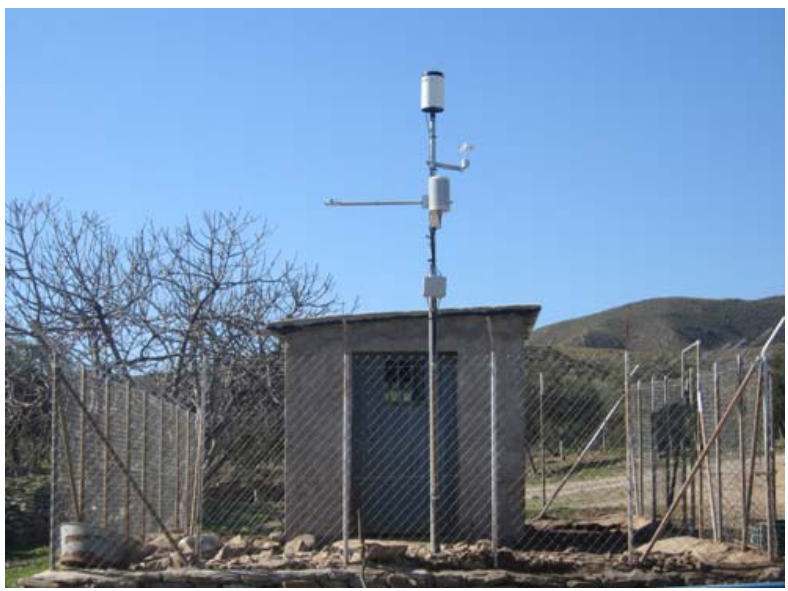

Figura 3. Estación agroclimática instalada en la finca experimental.

- Sensor de temperatura y humedad relativa modelo HMP45C. La temperatura se mide con un sensor Pt1000, que se basa en la variación de la resistencia del platino. La humedad se mide con un dispositivo capacitivo de estado sólido. Ambos sensores se alojan en el interior de una garita modelo 41003-5.

- Anemómetro modelo A100L2. Es un sensor de tres cazoletas preciso y de bajo consumo. El anemómetro está fabricado con una aleación de aluminio anodizado, acero inoxidable y plásticos resistentes al clima.

- Piranómetro de silicio modelo CS300, fabricado por Apogee Instruments, usa un detector fotovoltaico de silicio. 
- Pluviómetro RMYoung 52202. Es un sensor de balancín con sendas cazoletas situadas en sus extremos. Cuando se llena la cazoleta superior, el balancín bascula y emite un pulso. Cada vuelco del brazo equivale a $0.1 \mathrm{~mm}$.

2. Autómata programable, modelo Compact FieldPoint, comercializado por la empresa National Instruments ( $\mathrm{NI}$ ), encargado de controlar todos los elementos del sistema de riego (sensores y actuadores) y dar robustez al sistema. Se trata de una nueva familia de controladores, que se denominan Controladores de Automatización Programables (PACs), que supera en prestaciones a los tradicionales Controladores Lógicos Programables (PLCs). Los PACs de National Instruments están basados en la tecnología LabVIEW de NI. Con LabVIEW, se pueden crear sistemas de medición y control a la medida. El sistema permite integrar subrutinas programadas en Mathlab. Este automáta programable está dotado también de módulos de entradas y salidas de datos tanto analógicos como digitales.

3. Ordenador industrial, modelo IPPC-6152A, comercializado por Advantech. Es el encargado de registrar las variables climáticas, realizar el cálculo de las necesidades hídricas en tiempo real, establecer la programación de riegos más racional e introducirla en el autómata programable. Este equipo posee una pantalla táctil que permite una comunicación más versátil e interactiva entre el usuario y el sistema de control el encargado de servir de interfaz de usuario, también permite su conexión a través de Internet con otro equipo remoto. Las características técnicas de este equipo son las siguientes: procesador Socket 478 Celeron M $1.5 \mathrm{GHz}$, memoria 1 GB DDR2 240pin SDRAM 400/533 MHz, disco duro HDD 80GB SATA-300 2.5" SEAGATE y pantalla táctil XGA TFT LC 15

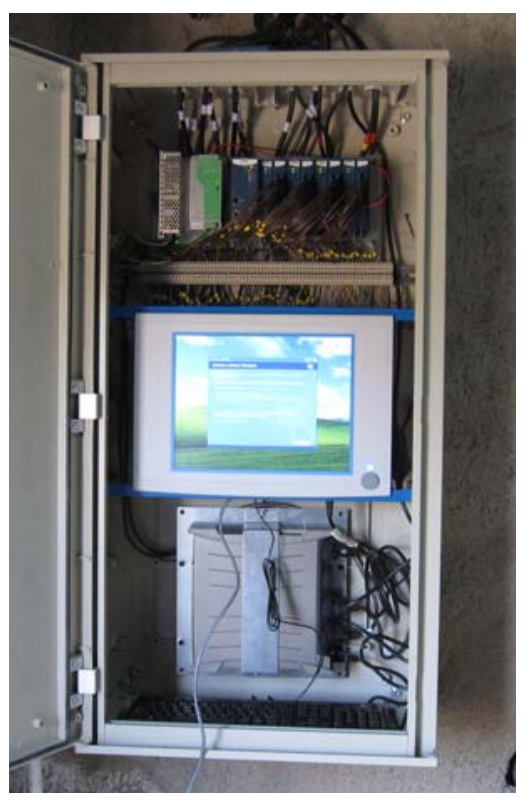

Figura 4. Armario de control con el autómata programable, ordenador industrial y sistema de alimentación ininterrumpida (SAI).

El ordenador industrial y el autómata programable se han instalado en el interior de un armario de protección situado dentro de la caseta que alberga la cabeza del sistema de riego. En dicho armario se encuentra el Sistema de Alimentación Ininterrumpida (SAI), que alimenta a ambos equipos y los protege de sobretensiones. Además, el armario contiene dos fuentes de alimentación, una de 24 VDC y $5 \mathrm{~A}$, que alimenta al controlador, y al modulo de entradas analógico (sensores climáticos y transductores de presión), y otra de 12 VDC y $5 \mathrm{~A}$, que alimenta los módulos de salidas digitales (relés de actuación) (ver figura 4).

\section{3- Resultados y conclusiones.}


Se ha desarrollado una aplicación informática original denominada SISRIERA que permite controlar los distintos elementos que componen el sistema de riego (sistemas de bombeo, depósitos, sectores de riego y sistemas de abonado y filtrado), ejecutar los algoritmos de cálculo de necesidades y de balance hídrico, adoptar las decisiones de riego más adecuadas y ejecutar dichas ordenes, organizando y priorizando el riego de los distintos sectores de la explotación y todo ello, a través de una interfaz plenamente amigable e interactiva. Para permitir su adaptación a otros tipos de explotaciones y su extensión a otros cultivos, el sistema se ha diseñado con elementos y protocolos de comunicación abiertos, con objeto de que sea perfectamente configurable y escalable. La conexión del ordenador personal a Internet, con ayuda del escritorio remoto, permite disponer de todos los datos y actuar sobre el sistema de forma remota desde cualquier otro ordenador personal con conexión a Internet.

La pantalla principal de la aplicación de control se muestra en la figura 5 . A esta pantalla se puede acceder localmente desde el ordenador industrial instalado en la caseta de riego o por vía remota. En este segundo caso, es necesario especificar un nombre de usuario o una clave para acceder al sistema.

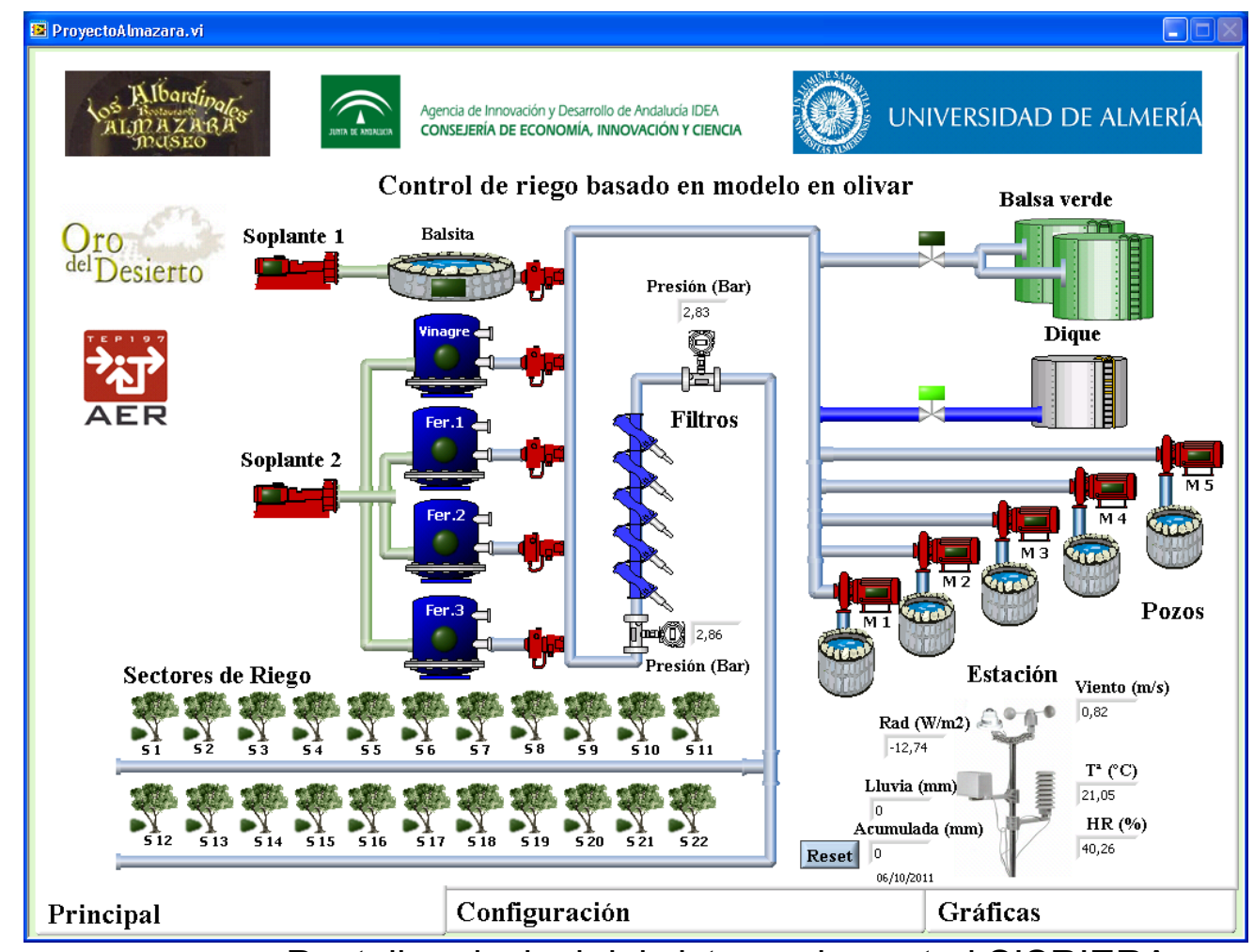

Figura 5. Pantalla principal del sistema de control SISRIERA

La pantalla "Principal" muestra de forma visual el estado de todos los elementos que se pueden controlar en el sistema, además de las variables climáticas a las que se tiene acceso desde la estación meteorológica instalada en la finca.

En la parte inferior derecha de la pantalla se muestra un esquema de la estación climática y la información en tiempo real medida por los sensores: Humedad Relativa (HR, $\%)$, Temperatura $\left(\mathrm{T}^{\mathrm{a}},{ }^{\circ} \mathrm{C}\right)$, Viento $(\mathrm{m} / \mathrm{s})$, Radiación Solar $(\operatorname{Rad}, \mathrm{W} / \mathrm{m} 2)$, Precipitación diaria (Lluvia, mm) y Precipitación Acumulada (Acumulada, mm). La lluvia acumulada puede inicializarse mediante el botón "Reset" que está situado a su izquierda y el texto inferior indica la fecha del última reinicio 
Por encima de la estación meteorológica se muestran los iconos de 5 motores que representan a los grupos motobomba que inyectan el agua en la red de distribución. En la esquina superior derecha de la pantalla se muestran los dos depósitos elevados que alimentan al sistema de riego. La balsa verde, que se encuentra situada a mayor cota, se utiliza para regar los sectores con mayores requerimientos de presión, mientras que el dique se utiliza en el resto de los casos. El sistema debe evitar la apertura simultánea de ambos depósitos. En la parte superior izquierda se muestra el sistema de abonado. Éste consta de 5 bombas inyectoras con sus correspondientes depósitos de fertilizante. Para la agitación de las soluciones nutritivas el sistema dispone de 2 bombas soplantes. A continuación se encuentra el sistema de filtrado de agua que consta de un grupo de 5 filtros de anillas autolimpiantes dispuestos en paralelo. Finalmente, se muestran las unidades de riego (sectores), representados cada una de ellas mediante un olivo. Todos los actuadores (electroválvulas, bombas, etc.) disponen de un indicador (led) que se ilumina en caso de que dicho elemento esté en funcionamiento.

La pestaña "Configuración" permite acceder y editar todos los parámetros configurables del sistema. Entre ellos se pueden destacar los siguientes:

- Modo de funcionamiento: el sistema admite un modo de funcionamiento completamente automático en el que el se adoptan y ejecutan las decisiones de riego sin intervención alguna del usuario y un modo semiautomático en el que el usuario tiene que definir los programas de riego deseados manualmente. Este segundo modo de funcionamiento es equivalente a los sistemas de automatización del riego más habituales.

- $\quad$ Sensores: permite configurar la recta de calibración de los sensores y ver el estado de las salidas digitales que actúan sobre los relés.

- $\quad$ Planificación de riegos: se visualizan los riegos previstos para la semana en el modo semiautomático: hora de inicio, hora final, abonado, etc.

Riego manual: esta opción permite configurar los riegos semanales de forma manual. Se pueden definir las horas de comienzo y finalización del riego, el plan de abonado, el orden de riego de los sectores, etc.

- Riego automático: en esta opción se configura el modo de funcionamiento automático. En este caso no es necesario definir la planificación de riego ya que éstos se calculan de forma automática por el algoritmo de balance de agua. Sólo es necesario configurar las opciones de abonado.

- Motores: esta opción permite configurar los programas de puesta en marcha y parada de los diferentes sondeos así como la apertura y cierra de las llaves de paso de los embalses de acumulación.

- Soplantes: Permite la configuración de los soplantes o agitadores neumáticos asociados a cada depósito de abonado.

- $\quad$ Limpieza filtros: Permite configurar las opciones disponibles para realizar la limpieza de los filtros, tanto por diferencia de presión como periódicamente.

- Algoritmo: Contiene los parámetros asociados al algoritmo que calcula la planificación de riegos automáticos. En este apartado se configuran los datos de los sectores de riego, características de la plantación, y parámetros de cálculo de las necesidades y del balance hídrico.

Uno de los aspectos originales del sistema diseñado, además de programar automáticamente el riego de los sectores de forma individual, es la organización de la aplicación de los riegos, dando prioridad a los sectores con mayor déficit hídrico y dejando para el final a los que tienen menores necesidades. De esta forma, los riegos se ordenan dentro de la jornada atendiendo a sus necesidades y, posponiendo el riego de los sectores menos necesitados para otro día, en caso de que el tiempo de riego disponible en la jornada sea insuficiente para regar todos los sectores necesitados.

El diseño e instalación del prototipo experimental situado en la finca propiedad de Rafael Alonso Aguilera S.L se concluyó en el año 2011, estando el sistema operativo desde 
el día 19 de mayo de 2011 hasta la actualidad. Se dispone, por tanto de un periodo de evaluación del sistema de unos 5 años de funcionamiento continuado. Durante este tiempo y tras un periodo inicial de puesta a punto del sistema, éste ha funcionado de forma continua sin apenas interrupciones, salvo algunas debidas a cortes del suministro eléctrico o alguna labor de mantenimiento. Esto hecho confirma que el sistema diseñado ha demostrado su robustez y fiabilidad.

Con objeto de contrastar las condiciones climáticas en la zona de estudio, se han comparado los datos climáticos registrados por la estación climática del sistema de control, con los datos climáticos de la estación climática de Tabernas, perteneciente a la red Agroclimática de la Junta de Andalucía, situada cerca de la finca experimental. Las variables climáticas medidas han correlacionado bastante bien con los datos de la estación de Tabernas. Los coeficientes de correlación han sido del $98 \%$ para la temperatura media, del $94 \%$ para la humedad relativa, del $98 \%$ para la radiación y del $75 \%$ para la velocidad media de viento. En el caso de la velocidad del viento, se midieron valores inferiores en el anemómetro instalado en la finca con respecto al de la estación de Tabernas. Esto es debido a que la finca se encuentra en una zona protegida, rodeada de montañas en la que la incidencia del viento es localmente menor que en la estación de Tabernas que se encuentra más expuesta. Como consecuencia de ello, la $E T_{o}$ calculada por el sistema de control ha resultado menor a la $E T_{o}$ proporcionada por la estación de Tabernas (un $78 \%$ de esta), debido a la influencia menor del viento (ver Figura 6). La medida local de las condiciones climáticas ha permitido calcular mejor las necesidades del cultivo de forma local ahorrando aproximadamente un $22 \%$ respecto a las que se calcularía utilizando los datos de Tabernas.

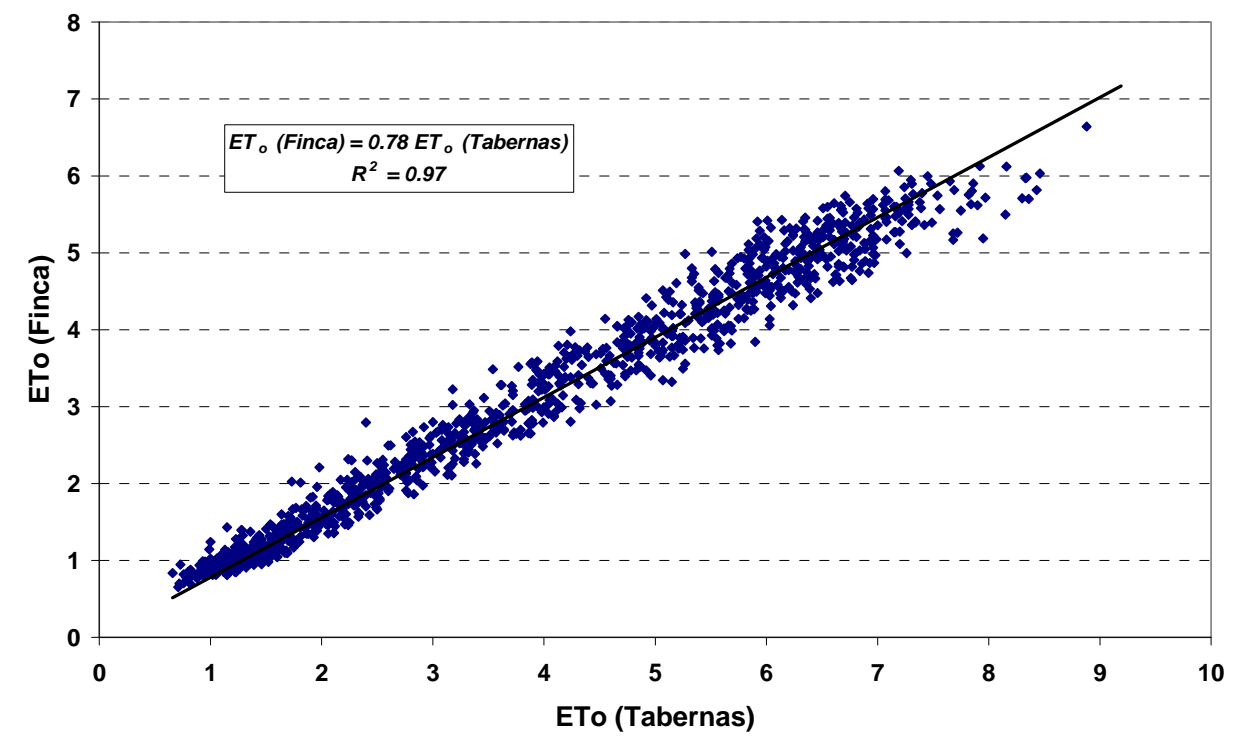

Figura 6. Comparación $E T_{o}$ medida en la finca y en la estación agroclimática de Tabernas (2012-2015)

Durante este periodo se ha comprobado el uso eficiente y racional del agua de riego que este sistema automático ha permitido realizar. Una de sus principales ventajas ha sido la posibilidad de establecer una programación de riego individualizada para cada uno de los 8 sectores de riego homogéneos en los que se ha organizado la explotación. Esto ha permitido ajustar las dosis de riego a las necesidades específicas de cada uno de ellos en función de las variedades, edad del cultivo o marco de plantación. La tabla 1 recoge los riegos totales registrados por el sistema durante un periodo de funcionamiento de 4 años (desde el 1 de enero de 2012 hasta 31 de diciembre de 2015). Durante los tres primeros años del 2012 a 2014, los días fuera de servicio fueron mínimos, sin embargo, durante el 2015 el sistema dejó de funcionar debido a una avería en un sensor y no fue posible su reparación hasta trascurrido un tiempo. En dicha tabla, se recogen además, el número de horas de funcionamiento total del sistema en modo automático y las dosis de riego 
aportados por sector. Se puede comprobar como las dosis de riego anuales han sido variables entre sectores debido a sus diferentes características. Las dosis de riego anuales han oscilado desde una decena de $\mathrm{mm}$ para una plantación joven con un marco amplio hasta valores superiores a los $200 \mathrm{~mm}$ para los sectores con un olivar adulto y con mayor superficie de cubierta vegetal. La dosis media para toda la finca durante el periodo de estudio ha sido de unos $116 \mathrm{~mm}$.

Tabla 1. Riegos totales registrados por el sistema automático durante 4 años de funcionamiento.

\begin{tabular}{|c|c|c|c|c|c|c|c|c|c|c|c|}
\hline \multirow[b]{2}{*}{ Año } & \multirow[b]{2}{*}{ Días } & \multirow{2}{*}{$\begin{array}{c}\text { Riego } \\
\text { (Horas) }\end{array}$} & \multicolumn{9}{|c|}{ Dosis riego (mm/año) } \\
\hline & & & Sec. 1 & Sec. 2 & Sec. 3 & Sec. 4 & Sec. 5 & Sec. 6 & Sec. 7 & Sec. 8 & Media \\
\hline 2012 & 343 & 1781 & 16.8 & 143.7 & 3.7 & & & & 112.2 & 37.4 & 103.6 \\
\hline 2013 & 355 & 2437 & 23.2 & 199.4 & 199.4 & 138.0 & 138.0 & 233.0 & 151.8 & 51.5 & 141.8 \\
\hline 2014 & 363 & & 22.5 & 4.4 & 19 & 134.0 & 13 & 6 & 148.5 & 49.7 & 137.8 \\
\hline 2015 & 296 & 1435 & 17.3 & 110.8 & 110.8 & 78.4 & 78.4 & 132.7 & 86.3 & 28.8 & 80.4 \\
\hline Media & 339 & 2005 & 20.0 & 162.1 & 162.1 & 113.4 & 113.4 & 189.7 & 124.7 & 41.9 & 115.9 \\
\hline
\end{tabular}

Como conclusión, cabe destacar que el sistema ha gestionado el riego de una finca de olivar ecológico en producción durante un periodo de tiempo de unos 5 años, de forma eficiente, fiable y autónoma. El sistema de control ha conseguido un ahorro de agua significativa respecto a la gestión del riego anterior ( $20 \%$ menos de agua aproximadamente), habiendo permitido mantener e incluso incrementar los niveles productivos de la finca, consiguiendo una mejor eficiencia del uso del agua. Como consecuencia de ello, es previsible que este uso más racional del agua si se extiende a otras fincas de la zona, pueda contribuir a garantizar la sostenibilidad de la actividad agrícola en la zona del desierto de Tabernas tan vulnerable a la falta de recursos hídricos.

\section{4.- Agradecimientos}

Los autores agradecen a la empresa Rafael Alonso Aguilera S.L. (Oro del desierto) el apoyo financiero para desarrollar el trabajo de investigación y su iniciativa y entusiasmo.

\section{5- Bibliografía}

Allen, R.G., L.S. Pereira, D. Raes and M. Smith. (1998). Crop evapotranspiration. Guidelines for computing crop water requirements. FAO Irrigation and Drainage Paper 56. FAO. Roma Ayars, J.E., C.J. Phene, R.B. Hutmacher, K.R. Davis, R.A. Schoneman, S.S. Vail and R.M. Mead. (1999). Subsurface drip irrigation of row crops: a review of 15 years of research at the Water Management Research Laboratory. Agricultural Water Management. 42:1-27. Elsevier.

Dastane, N.G. (1978). Efective Rainfall in Irrigated Agriculture. FAO Irrigation and Drainage Paper $N^{\circ}$ 25. FAO. Roma

Fereres, E., W.O. Pruitt, J.A. Beutel, D.W. Henderson, E. Holzapfel, H. Shulbach and K. Uriu. (1981). ET an drip irrigation scheduling, In drip irrigation management, of Fereres Ed. University of California. Div. of Agric. Sci. № 21259. pp. 8-13

Martínez, J. and Reca, J. (2014). "Water Use Efficiency of Surface Drip Irrigation versus an Alternative Subsurface Drip Irrigation Method." J. Irrig. Drain Eng., 10.1061/(ASCE)IR.19434774.0000745, 04014030 
AEXXYDIV Congreso Nacional de Riegos, Sevilla 2016

Orgaz, F. y E. Fereres. (1999). Riego, en el cultivo del olivo, de Barranco, Fernández y Rallo Eds. Mundi-Prensa. Madrid 
Rocamora Osorio, C., Abadía Sánchez, R., Melián Navarro, A., Puerto Molina, H. Hernández García, F.

Escuela Politécnica Superior de Orihuela. Universidad Miguel Hernández.

Ctra. de Beniel, km. 3,2 - 03312 Orihuela (Alicante). e-mail: rocamora@umh.es

\section{INTRODUCCIÓN Y OBJETIVOS}

El regadío tradicional de la Vega Baja del Segura es de origen romano, aunque apenas se conservan vestigios de obras de fábrica de esta época (Gil Olcina y Morales Gil, 1992). Tras la ocupación árabe se consolidó y organizó tal y como se conoce hoy, tanto en la infraestructura como en el sistema de reparto (Pérez, 1995). La superficie bruta de riego asciende a 22.872 ha

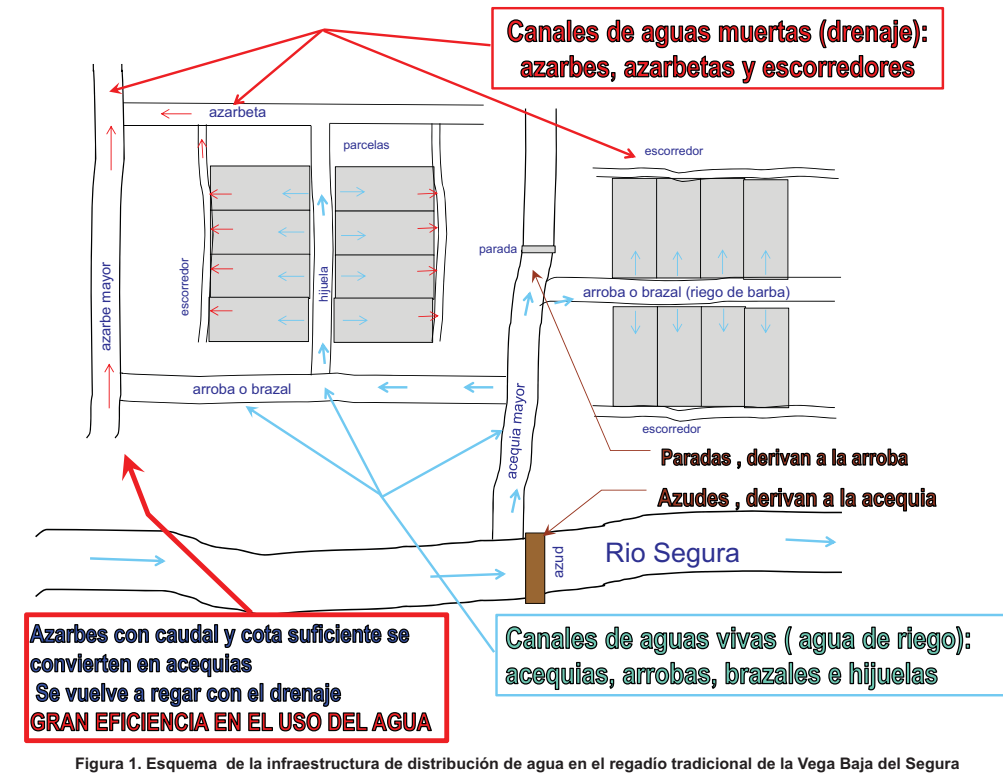

El reparto de agua se hace en base a la tanda de la acequia.

La tanda es el tiempo en que tarda en producirse el riego en toda la longitud de la acequia y está dividida en turnos fijos asignados a cada parada.

En el turno se establece un número determinado de horas de riego, pudiendo regar sólo durante las horas que tiene asignadas en el entande de la acequia.

La duración del turno no guarda una relación directa con la superficie que abastece la parada: en ocasiones proviene de antiguos privilegios, dando lugar a tierras con diferentes dotaciones.

El agua de riego está adscrita a la tierra, quedando reflejados los derechos de agua en las escrituras de propiedad de la tierra, lo que ocasiona diferencias muy importantes entre parcelas, según los derechos de agua que la parcela posea.

El sistema de aplicación de agua de riego en parcela es por inundación, en donde el exceso de agua aportado es drenado a través de la red de canales de aguas muertas. Este sistema de reparto de agua hace que en muchos casos no se haya podido desarrollar una agricultura competitiva, debido a la falta de seguridad que tienen algunas tierras para recibir la dotación completa de agua de riego. Esta situación se ve agravada por la infradotación habitual de agua de riego en toda la cuenca del río Segura,

La modernización del regadío tradicional en la Vega Baja del Segura Desde principios de los años 90 se ha tratado de poner en marcha diversos planes de modernización que no han terminado de cristalizar.

La transformación a sistemas de riego por goteo únicamente se ha producido en algunas zonas, ejecutando pequeñas redes a presión, que conviven con el sistema de reparto tradicional, o bien transformando el sistema de riego en parcela. Esta dificultad de implementación del riego a presión se debe, entre otras, a las siguientes causas:

Necesidad de construir balsas de almacenamiento perdiendo superficie de cultivo

Dependencia de energía eléctrica para presurizar la red de distribución.

Pérdida de calidad de la producción percibida por los agricultores en determinados cultivos, como la alcachofa.

En el regadío tradicional no se paga por el agua, sino por el mantenimiento de la infraestructura, lo que no ocurre en el riego a presión.

Pérdida de valor ambiental del ecosistema agrícola que se produciría al detraer el agua del rio para transportarla por las redes a presión.

A pesar estas dificultades, el mantenimiento de la actividad agraria en la comarca es fundamental porque:

supone mantener un paisaje funcional como es la huerta

permite absorber a parte de la población desempleada y asegura la independencia alimentaria del territorio y su abastecimiento (Cases y Marroquí, 2011).

La modernización del regadío en torno a su eje principal, el río Segura, es una actuación necesaria que debe ser acometida de forma conjunta en toda la comarca y debe plantearse como una oportunidad que permita no solo consolidar la actividad agrícola como seña de identidad de la comarca, sino la puesta en valor de su rico patrimonio material e inmaterial, como el patrimonio hidráulico, la arquitectura popular, el paisaje cultural, el ecosistema agrícola, los conocimientos agrícolas, las tradiciones etc. que deben potenciarse para asegurar el sostenimiento de la población y el progreso de la comarca. El proceso debe plantearse de forma integradora entre todos los usos que han de beneficiarse de la modernización y que, en muchos casos, tienen intereses contrapuestos, por lo que se debe valorar el proceso desde un punto de vista pluridisciplinar

En este trabajo se analizan cuatro alternativas de modernización del regadío tradiciona de la Vega Baja del Segura desde el punto de vista de los regantes.
MATERIAL Y MÉTODOS

El regadío tradicional de la Vega Baja del Segura está gestionado por 17 Comunidades de Regantes (Figura 2).

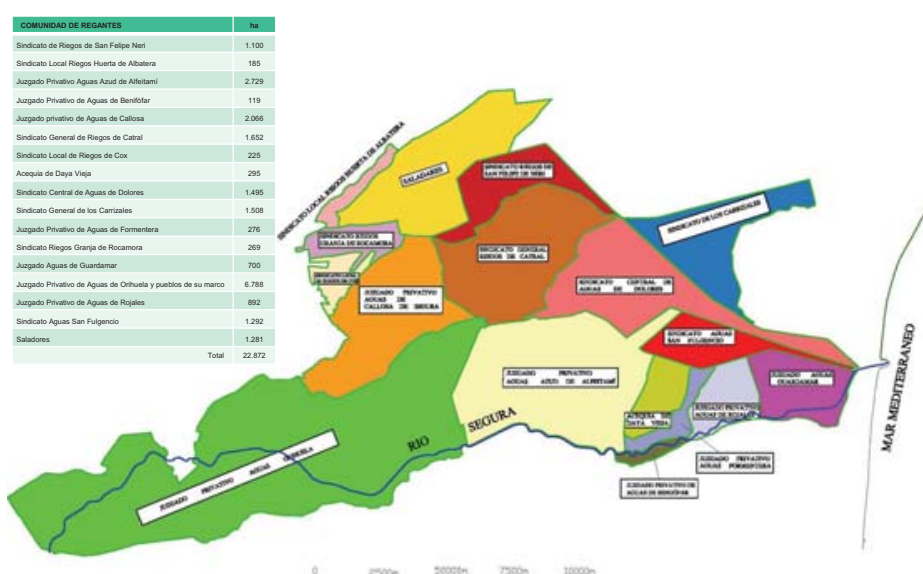

Figura 2. Plano de las Comunidades de Regantes del regadío tradicional de la Vega Baja del Segura

Mediante una encuesta a usuarios del regadío tradicional se analiza la percepción que tienen los agricultores de la modernización y de la repercusión que dichas actuaciones tendrían en su explotación. De las encuestas se deducen cuáles son las mejoras en el regadío que demandan los usuarios. Se plantearon las siguientes 4 alternativas:

\begin{tabular}{|c|c|c|}
\hline $\mathrm{A} 1$ & A3 & A4 \\
\hline $\begin{array}{l}\text { - Rehabilitar la red actual } \\
\text { de acequias } \\
\text { - Sin modificar las tandas } \\
\text { ni los turnos de riego } \\
\text { - Mantener la dotación de } \\
\text { agua a todas las } \\
\text { parcelas } \\
\text { - Mínima actuación. } \\
\text { A2 }\end{array}$ & $\begin{array}{l}\text { - Sustituir acequias por } \\
\text { tuberías a presión } \\
\text { abastecidas del río } \\
\text { Segura } \\
\text { - Conectar el riego por } \\
\text { goteo directamente a } \\
\text { la nueva red de } \\
\text { tuberías a presión. } \\
\text { - Mantener activo el rio } \\
\text { Segura y parte de la } \\
\text { red de acequias } \\
\text { - Mantener la gestión } \\
\text { independiente de los } \\
\text { Juzgados de Agua. } \\
\text { - Costes de bombeo } \\
\text { asociados al riego. }\end{array}$ & $\begin{array}{l}\text { - Sustituir las acequias por tuberías } \\
\text { a presión abastecidas del Post- } \\
\text { trasvase Tajo-Segura } \\
\text { - Conectar el riego por goteo } \\
\text { directamente a la red de tuberías } \\
\text { a presión, sin consumo energético } \\
\text { asociado al riego. } \\
\text { - El Rio Segura solo llevaria el } \\
\text { caudal ambiental; las acequias } \\
\text { dejarían de transportar agua de } \\
\text { riego. } \\
\text { - Modificar la gestión de Juzgados } \\
\text { de Agua, agrupando éstos en } \\
\text { varios sectores hidráulicos } \\
\text { - Los Juzgados de Aguas y } \\
\text { Sindicatos de Riegos compartirían } \\
\text { la infraestructura y la gestión del } \\
\text { riego. }\end{array}$ \\
\hline
\end{tabular}

\section{RESULTADOS}

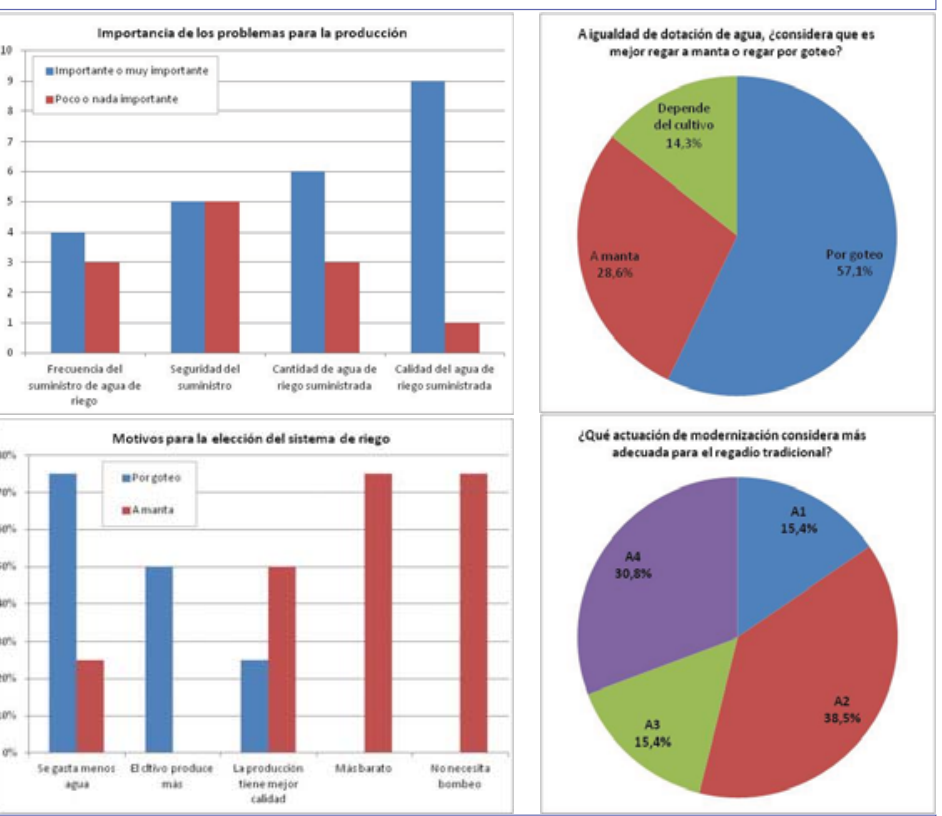

CONCLUSIONES

- A pesar de que se estima que el riego por goteo tiene ventajas y es preferible a la hora - A pesar di se mantiene la dotación de riego, el mantener el regadí tradicional, con o sin mejoras en los turnos de riego, ha sido la opción mayoritaria con casi el 54\% de las respuestas. 
GRUPO TEMAS D: Gestión, Legislación, Economía del Riego y Otros

Formación del regante. Asesoría del riego. Aspectos sociales e institucionales, economía del regadío, legislación del agua y derechos de uso. Mercados del agua. Huella hídrica y agua virtual. Comunidades de usuarios y gestión integral de los recursos. Métodos de cálculo y repercusión sostenible del coste de los servicios de agua de riego, tarifas. Influencia del regadío en el ciclo del agua y la panificación hidrológica. Conservación de los recursos superficiales y subterráneos. Agricultura de regadío sostenible. Competitividad y mercados agrarios. 


\title{
D-01
}

\section{ESTRATEGIAS PARA REDUCIR EL COSTE ENERGÉTICO EN COMUNIDADES DE REGANTES}

\author{
Yusta Loyo, J. M. (1) \\ ${ }^{1}$ Dr. Ingeniero Industrial, Profesor Titular, Universidad de Zaragoza, C/María de Luna 3 \\ 50018 Zaragoza, jmyusta@unizar.es
}

\section{Resumen}

Los costes de suministro eléctrico de las comunidades de regantes se han duplicado en los últimos años desde la desaparición de la tarifa especial de riego agrícola en 2008. Aunque el mercado eléctrico liberalizado ofrece oportunidades para elegir al suministrador de energía y negociar los precios, las comunidades se han visto gravemente penalizadas por el incremento del término fijo de potencia contratada, a pesar del esfuerzo por concentrar al máximo el consumo de energía en los periodos más baratos. La Comunidad General de Riegos del Alto Aragón ha desarrollado distintas iniciativas desde 2010 para reducir el coste energético de las comunidades de regantes, entre otras el diseño de una plataforma online para el seguimiento de consumos y facturas eléctricas, el desarrollo de herramientas para la programación horaria del bombeo, el ajuste óptimo de las potencias contratadas, la negociación colectiva de los contratos de suministro o el estudio permanente de alternativas para la reducción del coste mediante fuentes de energías alternativas.

\section{1- Introducción}

El sistema de Riegos del Alto Aragón (RAA) comprende 52 comunidades de regantes con una superficie en regadío superior a 135.000 hectáreas, que utilizan anualmente 50 millones de kilovatios-hora de energía eléctrica en 42 estaciones de bombeo de agua.

En el sistema de RAA y en gran parte de los regadíos españoles, las inversiones para su modernización se realizaron teniendo en cuenta en los estudios previos de rentabilidad económica un coste del suministro eléctrico para el bombeo de agua que a día de hoy se ha duplicado. Hasta 2008, las tarifas especiales de riego agrícola garantizaban unos precios regulados por parte del gobierno para el suministro de energía a las instalaciones de bombeo de las comunidades de regantes, pero desde esta fecha las comunidades tienen que contratar la electricidad en el mercado liberalizado a precios muy superiores, lo que pone en serio riesgo de supervivencia muchas de las instalaciones modernizadas, al tener que hacer frente a precios de la electricidad caros y además volátiles e inciertos a lo largo de los meses del año. Frente a un precio medio de 7,7 céntimos de euro por kWh en 2007, las comunidades de regantes del sistema de RAA han tenido que hacer frente a precios superiores a 15 céntimos de euro por kWh en 2014, IVA incluido.

En el aumento del coste del suministro eléctrico ha influido especialmente el incremento de peajes de acceso a la red, la parte del precio de la electricidad que pagan los consumidores en el mercado libre y que utiliza el gobierno para recaudar los costes regulados, que no ha dejado de crecer exponencialmente en los últimos años. Sólo el incremento del término de potencia de estos peajes en un $115 \%$ en virtud de la orden ministerial IET/1491/2013 supuso un incremento medio desde el 3 de agosto de 2013 del $20 \%$ del coste final de la electricidad en las comunidades de regantes del sistema de Riegos 
del Alto Aragón, que han visto además como este término fijo que depende de la potencia contratada supone más del $40 \%$ del precio final de la electricidad. Este porcentaje es mucho más elevado en los bombeos de las comunidades de regantes que en otros perfiles de consumidores por motivo de la singular estacionalidad del consumo de electricidad en los meses de campaña de riego, concentrada entre los meses de mayo a septiembre en el caso de Riegos del Alto Aragón.

A pesar del esfuerzo por concentrar al máximo el consumo de energía en los periodos más baratos (especialmente el periodo P6 que comprende las noches, los fines de semana y todo el mes de agosto) y consecuentemente reducir la potencia contratada en los periodos más caros renunciando en algunos casos a su utilización, la obligación de contratar la potencia durante los doce meses del año grava injustamente la factura eléctrica de los regantes. Las comunidades de regantes de RAA concentran en promedio el $80 \%$ de su consumo en el periodo P6, periodo valle del sistema eléctrico, coadyuvando a la mejora del factor de carga del sistema eléctrico y a la utilización más eficiente de las infraestructuras eléctricas de generación, transporte y distribución, y sin embargo son penalizadas en el coste del suministro eléctrico.

El único alivio para el sector procede de la aprobación de la reducción parcial del $85 \%$ del impuesto sobre la electricidad para riegos agrícolas desde el 1 de enero de 2015. Ha supuesto una reducción del coste mensual del suministro eléctrico del $4,35 \%$. A esto se suma la aprobación mediante el Real Decreto-Ley 9/2015 y la Orden IET/2735/2015 de la reducción de los pagos de capacidad, que sin embargo apenas tiene impacto en las comunidades de regantes, ya que no se aplica este concepto de coste en el periodo P6, periodo horario en el que se realiza el $80 \%$ del consumo eléctrico en el regadío.

\section{2 - Iniciativas para la reducción de costes energéticos}

Para contrarrestar la situación descrita en el apartado anterior, la Comunidad General de Riegos del Alto Aragón viene desarrollando distintas iniciativas desde 2010 para reducir el coste energético de las comunidades de regantes en el mercado eléctrico liberalizado, que se presentan brevemente a continuación.

\subsection{Sistema online de seguimiento de facturas y consumos eléctricos}

Desde 2010 se mantiene un sistema de seguimiento anual de consumos eléctricos y revisión de las facturas, para garantizar el correcto pago del servicio eléctrico, revisar las posibles desviaciones de coste de cada comunidad de regantes y recoger centralizadamente toda la información del consumo de las comunidades. Esto permite desarrollar posteriormente estudios y análisis para optimizar los parámetros de la contratación y reducir el coste del suministro.

\subsection{Programación del bombeo en horas más baratas}

Las comunidades de regantes planifican habitualmente el funcionamiento de las bombas para maximizar su uso en las horas con electricidad más barata, en función del calendario anual de periodos tarifarios de cada tarifa de acceso. Para contribuir a esta tarea se han desarrollado modelos matemáticos de previsión de consumos diarios de energía en función de las peticiones de agua y se han propuesto herramientas informáticas para la programación horaria del bombeo con objeto de minimizar el coste del suministro eléctrico.

\subsection{Ajuste óptimo de potencias contratadas}


Dado el elevado coste del término fijo de potencia, al comienzo de cada campaña de riego se propone la revisión de las potencias contratadas. Estas acciones han permitido reducir el coste un promedio del $10 \%$ en los últimos años.

Para ajustar las potencias contratadas en cada estación de bombeo, se procede mediante el siguiente procedimiento:

- Análisis de las necesidades de demanda de potencia de bombeo en función de la planificación de cultivos y reservas hídricas disponibles para la campaña.

- Cálculo de potencias óptimas en cada periodo tarifario incluso incurriendo en excesos de potencia en los meses de verano.

- Elección de potencia a contratar: en suministros en alta tensión han de ser crecientes en los distintos periodos ( $P 1 \leq P 2 \leq P 3 \leq P 4 \leq P 5 \leq P 6)$, estando limitada la modificación de la potencia en el periodo 6 por valores de potencia máxima y mínima en función de los transformadores de medida del centro de transformación.

- Comunicación por escrito a la empresa comercializadora de las potencias a contratar.

En la Figura 1 se muestra un ejemplo real de optimización de potencias contratadas donde se observa que aun incurriendo en excesos de potencia se obtiene un notable ahorro por la disminución del coste fijo anual de potencia en los periodos P1 a P5. No se modifica la potencia del periodo P6 para no perder derechos de acometida y no tener que realizar cambios en los equipos de medida.

En este ajuste es preciso observar tres precauciones:

- Según el artículo 5 del Real Decreto 1164/2001 no se pueden realizar modificaciones de potencia hasta transcurridos doce meses de la anterior (algunas distribuidoras sí permiten aumentos sucesivos de potencia en un plazo inferior a un año pero no reducción).

- Los aumentos de potencia pueden suponer costes por derechos de acometida, las reducciones sólo derechos de actuación en el equipo de medida.

- La nueva regulación de los derechos de acometida del Real Decreto 1048/2013 permite conservar los derechos de extensión (en alta tensión durante 5 años) pero no los derechos de acceso. Si se reduce la potencia contratada en el periodo 6 y de nuevo se amplía en un plazo no superior a 5 años, se abonarán de nuevo derechos de acceso. Si ha transcurrido un plazo superior a 5 años, se abonarán derechos de acceso y derechos de extensión.

La figura legal del contrato de temporada no se aplica en ninguna comunidad de regantes de este sistema. Aunque de escasa utilización previa, el contrato de temporada de cinco meses regulado mediante el Real Decreto 1578/2008 estaba siendo firmemente valorado como una alternativa para reducir el coste del suministro en conjunto con otras fuentes de energía eléctrica autónomas en los 7 meses restantes, ya que permitía el pago del término de potencia con pequeñas penalizaciones del $35 \%$ en los meses de junio y julio y del $15 \%$ en el resto de meses de la temporada de riego comprendidos en los cinco meses del contrato, pero evitaba el pago del término fijo de potencia el resto del año. Dado que el Real Decreto 1578/2008 ha sido derogado, queda únicamente vigente la figura del contrato de temporada regulada por el real decreto 1164/2001, claramente inviable porque penaliza el término de potencia en un $100 \%$ en los meses de junio y julio y en un $50 \%$ en el resto. 


\begin{tabular}{|c|c|c|c|c|c|c|}
\hline $\begin{array}{c}\text { POTENCIAS } \\
\text { CONTRATADAS }\end{array}$ & Periodo 1 & Periodo 2 & Periodo 3 & Periodo 4 & Periodo 5 & Periodo 6 \\
\hline Iniciales & 12 & kW & kW & kW & kW & kW \\
\hline Modificadas & 1382 & 1382 & 1382 & 1382 & 1882 \\
\hline
\end{tabular}

\begin{tabular}{|c|c|c|}
\hline Resumen costes AÑO 2015 & $\begin{array}{l}\text { Con nuevas } \\
\text { potencias }\end{array}$ & $\begin{array}{c}\text { Con } \\
\text { potencias } \\
\text { anteriores }\end{array}$ \\
\hline COSTE POTENCIA (euros) & 85.717 & 99.277 \\
\hline COSTE EXCESOS POTENCIA (euros) & 2.648 & 339 \\
\hline COSTE ENERGIA ACTIVA (euros) & 122.242 & 122.242 \\
\hline COSTE ENERGIA REACTIVA (euros) & 9 & 9 \\
\hline Impuesto eléctrico & 1.615 & 1.702 \\
\hline ALQUILER equipo de medida & 780 & 780 \\
\hline IVA & 44.732 & 47.113 \\
\hline TOTAL (euros) & 257.743 & 271.461 \\
\hline
\end{tabular}

Figura 1. Ejemplo real de optimización de potencias contratadas en una comunidad de regantes

\subsection{Negociación conjunta de contratos de suministro eléctrico}

Existen distintas fórmulas de agrupación de los consumidores para obtener las mejores condiciones posibles en el mercado eléctrico liberalizado: licitaciones, centrales de compras, etc. La Comunidad General de Riegos del Alto Aragón ha optado por ofrecer a sus comunidades de regantes una propuesta más flexible, donde se negocia conjuntamente desde 2010 con todas las comercializadoras de electricidad pero no existe adhesión obligatoria al resultado del proceso. Esta acción conjunta de todos los puntos de suministro ha permitido una reducción del 10\% del coste de la energía en 2015.

En la petición de ofertas se examinan modalidades no sólo con precio fijo por periodos, sino también indexadas a la evolución del mercado eléctrico mayorista.

Contrariamente a lo que sucede en otros tipos de consumidores, un contrato indexado hora a hora al mercado eléctrico mayorista de OMIE o de futuros de OMIP puede no representar oportunidad de mejora respecto a un contrato a precio fijo, dado que el periodo estival de máximo consumo eléctrico de las comunidades suele coincidir con periodos de mayor inestabilidad de precios en el mercado eléctrico. Esto se observa claramente en la Figura 2, donde se muestra un ejemplo real de una comunidad de regantes que ha optado por este tipo de contratación indexada en 2015. El coste de la energía ha resultado un $14 \%$ superior al que hubiera pagado al precio fijo resultante de la negociación conjunta de Riegos del Alto Aragón. 


\begin{tabular}{|l|r|r|r|}
\cline { 2 - 4 } & \multicolumn{3}{|c|}{ Contrado Indexado Pass-through 2015} \\
\cline { 2 - 4 } & \multicolumn{1}{c|}{$\begin{array}{c}\text { Energía } \\
\text { euros }\end{array}$} & $\begin{array}{r}\text { Tarifa de acceso } \\
\text { euros }\end{array}$ & \multicolumn{1}{c|}{ TOTAL } \\
\hline MAYO & 4.208 & 186 & 4.394 \\
\hline JUNIO & 5.036 & 575 & $\mathbf{5 . 6 1 1}$ \\
\hline JULIO & 9.915 & 1.603 & $\mathbf{1 1 . 5 1 8}$ \\
\hline AGOSTO & 7.596 & 236 & $\mathbf{7 . 8 3 2}$ \\
\hline SEPTIEMBRE & 4.686 & 202 & $\mathbf{4 . 8 8 8}$ \\
\hline
\end{tabular}

34.243

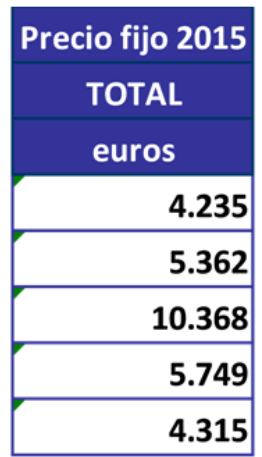

Diferencia

TOTAL

$\%$

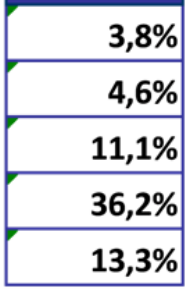

30.028

$14,0 \%$

Figura 2. Contrato indexado horario versus contrato a precio fijo en la campaña de riego de 2015

\subsection{Alternativas de suministro mediante otras fuentes de energía}

Se han realizado estudios de alternativas para analizar el ahorro que se obtendría mediante aplicación de distintas estrategias en comunidades de regantes que precisan el uso de todos los periodos tarifarios para el bombeo de agua, entre otras:

a) Reducir la potencia contratada a un valor mínimo en el periodo P1, suministrando la energía del periodo P1 con un grupo electrógeno.

b) Reducir la potencia contratada a un valor mínimo en los periodos P1 y P2, suministrando la energía de los periodos P1 y P2 con un grupo electrógeno.

c) Contratación en todos los periodos P1 a P5 de menor potencia de la demandada, aun incurriendo en excesos de potencia, manteniendo en el P6 la potencia suficiente para la instalación.

d) Contratación de suministro eléctrico durante los meses de mayor demanda y los restantes suplir la energía con grupo electrógeno (contrato de temporada)

Evaluadas en distintos escenarios y en cinco comunidades de regantes diferentes, las dos alternativas que en la mayoría de los casos resultarían más económicas son la primera y la tercera, si bien la primera precisa de inversiones mientras que la tercera necesita un seguimiento diario de los excesos de potencia registrados.

También se han realizado estudios de aplicación del nuevo Real Decreto 900/2015 de autoconsumo eléctrico, para analizar la viabilidad de disponer de instalaciones fotovoltaicas de producción de electricidad en apoyo a las estaciones de bombeo. Los resultados obtenidos no son muy satisfactorios por cuanto el plazo de amortización de las inversiones es superior a 15 años, motivado por el elevado coste de las instalaciones y la penalización al autoconsumo que introduce el citado decreto. Es preciso tener en cuenta que la rentabilidad de este tipo de instalaciones es mayor cuanto más elevado sea el porcentaje de energía producida que sea consumida, pero en las comunidades de regantes sólo se aprovecharía la producción fotovoltaica de manera más intensa en los meses de campaña de riego. Aunque en el autoconsumo tipo 2 se permite la venta de los excedentes a la red eléctrica, el precio obtenido no compensa la elevada inversión.

\subsection{Energía de reserva}

Una de las esperanzas de las comunidades de regantes de Riegos del Alto Aragón para reducir el coste del suministro eléctrico es la posible aportación de energía mediante convenios de cesión de parte de la energía reservada al Estado a la Confederación 
Hidrográfica del Ebro procedente de los saltos hidroeléctricos de Mediano y El Grado I y II, a un precio acordado de 29,72 euros/MWh.

Los estudios realizados muestran que se podría reducir un $15 \%$ el coste del suministro eléctrico a las comunidades de regantes si se aplicaran dichos convenios, cubriendo una parte de las necesidades de energía para el bombeo de agua. El ahorro está limitado por la obligación de consumir la energía en el mismo periodo horario en que se está produciendo en las centrales eléctricas, y la imposibilidad de revender la energía cedida en los periodos en que no es consumida por las comunidades.

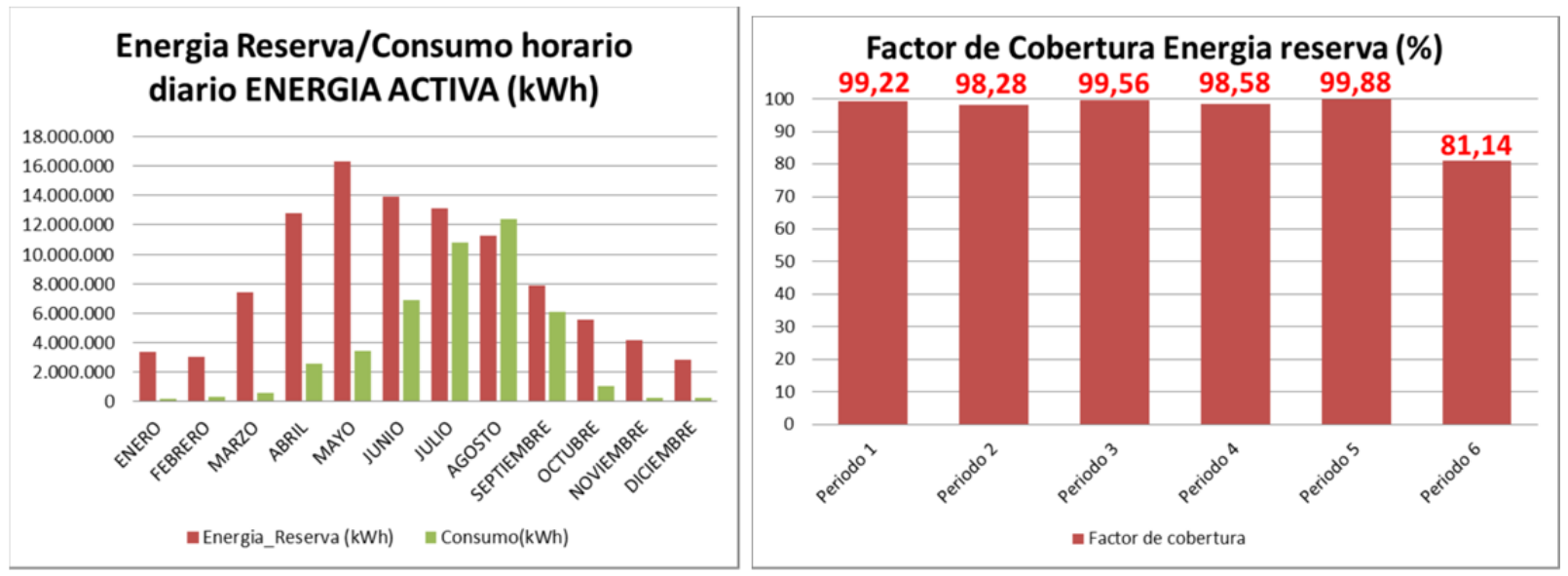

Figura 3. Cobertura que ofrecería la energía de reserva al consumo eléctrico de las comunidades de regantes

\section{Conclusiones}

Las medidas adoptadas en la gestión del suministro eléctrico de las comunidades de Riegos del Alto Aragón han supuesto un ahorro del 10\% del coste energético, lo que compensa sólo parcialmente el aumento del precio de la electricidad en los últimos años. Sin embargo hay otras fuentes de posible reducción del coste que las decisiones políticas no están favoreciendo, como el uso de energía solar de apoyo al bombeo o la cesión de la energía reservada al Estado en centrales hidroeléctricas, cuyo ahorro potencial también se ha cuantificado para prever su posible impacto en el coste energético del regadío.

\section{Agradecimientos}

A la Comunidad General de Riegos del Alto Aragón, y al Ministerio de Economía y Competitividad por su apoyo mediante el proyecto ENE2013-48517-C2-1-R.

\section{Bibliografía}

Yusta Loyo, J.M. (2013). Contratación del suministro eléctrico: oportunidades y estrategias para reducir el coste de las facturas eléctricas. Ed. Paraninfo, Madrid. 


\title{
RETOS Y OPORTUNIDADES DE LA IMPLANTACIÓN DE LOS BANCOS DE AGUA EN ESPAÑA
}

\author{
Montilla-López, N.M. (1) (P), Gómez-Limón, J.A. (2), Gutiérrez-Martín, C. (3)
}

1 Investigador en formación, Universidad de Córdoba, Departamento de Economía, Sociología y Política Agrarias, Campus Universitario Rabanales, Ctra. N-IV Km 396, 14014 Córdoba, g02molon@uco.es

2 Catedrático de Universidad, Universidad de Córdoba, Departamento de Economía, Sociología y Política Agrarias, jglimon@uco.es

3 Profesor Ayudante Doctor, Universidad de Córdoba, Departamento de Economía, Sociología y Política Agrarias, es1gumac@uco.es

\section{Resumen}

Con el fin de conseguir una buena gobernanza del agua, que trate de alcanzar un equilibrio entre los objetivos de eficiencia económica y sostenibilidad ambiental, durante las últimas décadas se ha potenciado el uso de instrumentos económicos para una mejor gestión de la demanda de los recursos hídricos, dada la dificultad de seguir aumentando la oferta de los mismos. En este contexto, este trabajo se centra en los bancos de agua como mecanismo de mercado que aporta la necesaria flexibilidad institucional en la asignación de los recursos hídricos entre los diferentes usuarios. La investigación realizada en este sentido ha permitido desarrollar una tipología de los bancos de agua que actualmente operan a nivel mundial en base a sus características operativas. Esta caracterización ha permitido igualmente realizar un análisis crítico de las experiencias de bancos de agua implementadas hasta la fecha, con el fin poder valorar el desempeño de este instrumento económico para la mejora de la gestión pública del agua. La investigación llevada a cabo revela que los bancos de agua son un instrumento útil para la gestión de los recursos hídricos, aportando sugerencias para la mejora de su implementación operativa en España mediante la correspondiente reforma de la Ley de Aguas.

\section{1- Introducción y objetivos}

La escasez e incertidumbre de los recursos hídricos se han convertido en uno de los principales problemas al que debe enfrentarse la agricultura mundial en la actualidad. El aumento de la población y la consecuente demanda de alimentos ha provocado que a lo largo del siglo XX la superficie de regadío se incremente considerablemente a nivel global, convirtiéndose en la actividad humana con mayores extracciones y consumo de agua a nivel mundial (FAO 2012). Esta presión sobre los recursos hídricos es especialmente intensa en zonas semiáridas como California, Australia o España, donde la agricultura de regadío resulta especialmente competitiva, en las cuales los usos agrícolas representan hasta el $80 \%$ de los usos del agua. Esta situación de intensa demanda de recursos se ha denominado como "fase de madurez de la economía del agua" (Randall 1981), que puede llegar a provocar el "cierre" de las cuencas hidrográficas (imposibilidad de atender nuevas demandas sino es a costa de reducir la demanda de otros usuarios (Berbel et al. 2013). En 
este contexto resulta evidente la necesidad de promover una gestión eficiente del recurso, permitiendo su asignación preferente hacia los usos que generan mayor valor social, proceso en el que la agricultura de riego tendrá un papel central como mayor usuario del recurso en la actualidad.

En este sentido, la implementación de instrumentos políticos de demanda de agua, como la tarifación, la modernización de regadíos o los mercados de agua, se consideran prioritarios para la mejora del bienestar asociado al uso del recurso, dotando a las administraciones responsables de su gestión mecanismos para flexibilizar los sistemas de asignación de agua entre los usuarios. Dentro de este contexto, este trabajo se centra en el análisis de los bancos de agua, como un tipo específico de mercado de agua, que ya ha sido implementado con éxito en varios países al objeto de mejorar la gestión pública del recurso. Este instrumento se caracteriza por facilitar los cambios de uso del agua entre los diferentes usuarios, a través de un mecanismo controlado por la Administración pública competente en materia de agua (o de algún otro organismo), que actúa como gestora necesaria en todas las transacciones.

El presente trabajo se centra en estudiar la potencialidad de los bancos de agua (denominados centros de intercambio en la legislación española), como instrumento económico de gestión de la demanda enfocada hacia la satisfacción de las necesidades de agua en un contexto de cuencas cerradas (imposibilidad de aumento de la oferta de agua) y fuerte incertidumbre en cuanto la disponibilidad del recurso (impacto creciente de las sequias como consecuencia del cambio climático). Con este propósito se realiza un análisis crítico de la implementación real de los bancos de agua a nivel nacional e internacional, al objeto de poder analizar las ventajas e inconvenientes de este instrumento económico para la gestión de la escasez e incertidumbre de agua dentro de la política hidráulica. De esta manera se pretende concluir aportando una serie de sugerencias para la mejora del diseño de este instrumento económico dentro de la política del agua públicas en España, orientadas a la implementación operativa de los bancos de agua en nuestro país.

\section{2- Bancos de agua: concepto y tipologías}

La Teoría Económica demuestra que los mercados suponen un mecanismo eficiente de asignación de los recursos escasos (Coase 1960), siempre y cuando estos reúnan una serie de condiciones (mercados competitivos, que no produzcan externalidades y en ausencia de costes de transacción). Por este motivo los mercados de agua han sido señalados como un instrumento económico que puede mejorar la gestión del agua en contexto de escasez e incertidumbre sobre la disponibilidad del recurso.

Al hablar de mercados de agua, se hace en realidad referencia a todo un conjunto de instituciones que posibilitan intercambios de agua entre los usuarios. No obstante, de forma resumida los mercados de agua pueden dividirse en dos grandes categorías (Hadjigeorgalis 2009):

- Mercados descentralizados, en los que las transacciones se negocian bilateralmente entre los potenciales compradores y vendedores, bien para intercambiar cantidades de agua (cesión temporal de derechos de uso en mercados temporales o spot), o la propia titularidad del derecho de uso del recurso de manera definitiva (mercados permanentes o de derechos).

- Mercados centralizados o Bancos de agua, cuando la Administración (u otro agente) actúa como intermediaria necesaria en todas las operaciones de compraventa (Delacámara et al. 2015; MacDonnell 1995).

Los bancos de agua son pues un tipo de mercado de agua, que pueden implementarse tanto como único instrumento de mercado, como complemento a otros instrumentos económicos que promueven la gestión de la demanda de agua (McCrea \& Niemi 2007). 
Este trabajo se centra en el estudio de los bancos de agua ("water banks" en inglés), conocidos en España igualmente como centros de intercambio. Sin embargo, no conviene confundir este tipo de mercado de agua con el instrumento del "water banking", denominación anglosajona para describir una estrategia de gestión del recurso basada en el almacenamiento del recurso (Dellapenna 2000). Efectivamente, el water banking implica depositar derechos de agua, sea en papel o en volumen efectivo, en un "banco" (entendido éste como las reservas de agua en un embalse, acuífero, etc.), depósito que permite a su titular una amplia variedad de operaciones, entre las que se incluye el uso diferido del recurso y su transferencia a otros depositarios (Clifford et al. 2004).

Bajo el concepto general descrito anteriormente de "bancos de agua", en la práctica se engloban instituciones muy variadas. En este sentido, a continuación se analiza la heterogeneidad de este tipo de mercados de agua sobre la base de las experiencias que se han llevado a cabo hasta la fecha, analizando las principales características que los definen. Este análisis de las variables características de los bancos de agua ha permitido establecer distintas tipologías, tal y como se expone seguidamente.

En primer lugar debe señalarse que los bancos de agua se diferencian en función del tipo de iniciativa que hace posible su creación. En este sentido cabe considerar:

- Bancos de agua públicos, que son organizados y gestionados por una administración pública, normalmente aquella competente en materia de agua.

- Bancos de agua privados, que son organizados y gestionados por la iniciativa privada, principalmente mediante la actuación de organizaciones sin ánimo de lucro, tal y como las ONG dedicadas a la conservación del medioambiente.

Una segunda variable definitoria de los bancos de agua es el bien o derecho objeto de intercambio. Así pueden diferenciarse entre:

- Bancos de agua permanentes. Los vendedores transfieren al banco de agua la titularidad del derecho de uso o propiedad del recurso de manera definitiva. Los derechos así adquiridos por el banco pueden posteriormente asignarse, en su totalidad o parcialmente, a nuevos usuarios, bien mediante adquisición, bien mediante un sistema de concesión pública gratuita. Estos bancos están orientados a resolver problemas asociados a la escasez estructural del agua, tanto los de carácter económico como los ambientales (Bjornlund 2003; Wheeler et al. 2012), tal y como se comenta más adelante.

- Bancos de agua temporales o spot. Estos bancos se comportan de la misma manera que los bancos de agua permanentes pero, a diferencia de los anteriores, el objeto de las transferencias son cesiones temporales de los derechos de uso del agua (normalmente por una campaña de riego) o cantidades de agua concretas (spot). En ambos casos, su actividad se concentra en períodos de sequía, orientándose a mitigar los efectos de la escasez coyuntural del recurso.

- Bancos de contratos de opción. El banco de agua intercambia contratos que permiten a sus compradores tener la opción (pero no la obligación) de comprar agua al vendedor del contrato (titular de los derechos de uso del recurso), a cambio de un precio determinado o "prima" (Cui \& Schreider 2009; Israel \& Lund 1995; Jercich 1997). Si finalmente se ejecuta la mencionada opción de compra, el comprador pagará una compensación adicional al vendedor, denominado "precio de ejecución" o strike. Estos contratos permiten al comprador protegerse del riesgo de no disponer de agua suficiente para su actividad, permitiendo al mismo tiempo que el vendedor no pierda el derecho de propiedad o uso del agua.

Los bancos de agua pueden clasificarse igualmente según su finalidad. En este sentido cabe distinguir entre:

- Bancos de agua para la reasignación del recurso para usos productivos. Los intercambios de derechos que permiten los bancos de agua posibilitan la 
reasignación del recurso (temporal o permanentemente) en función de la oferta y la demanda de los usuarios (actuales y potenciales), favoreciendo la transferencia de agua desde usos de menor valor a otros de mayor valor. Estas trasferencias, en ausencia de externalidades negativas, permite la mejora de la eficiencia económica (mejora del valor de la producción) asociadas al uso de agua (Booker et al. 2005; Grafton et al. 2012; Wheeler et al. 2014).

- Bancos de agua para la consecución de fines ambientales. La operatividad de estos bancos se basa en la compra de derechos sin posterior reasignación de los mismos (Burke et al. 2004; Wheeler et al. 2013). De esta manera, este tipo de bancos permite solucionar problemas ambientales que puedan derivarse de la escasez de agua, tanto estructural (por la sobreasignación de recursos en la cuenca, mediante la compra de derechos permanentes) como coyuntural (caudales de estiaje insuficientes, mediante la compra de derechos temporales).

- Bancos de agua para gestión del riesgo de disponibilidad de agua. La incertidumbre climática e hidrológica intrínseca a la gestión de agua motiva la variabilidad interanual de la dotación del recurso, situación que les genera una importante exposición al riesgo a los usuarios, que justifica que estos tomen decisiones no eficientes desde una perspectiva económica (Alcón et al. 2014). Al objeto de minimizar decisiones subóptimas y mejorar la eficiencia en el uso del agua, este tipo de bancos se implementan mediante la negociación de contratos de opción sobre el agua. Con ello, este tipo de bancos de agua permite mejorar la garantía de suministro de los compradores de los contratos de opción (a base de empeorar la garantía de los vendedores de tales contratos), posibilitando de esta manera la transferencia efectiva del riesgo entre usuarios con distinto nivel de aversión al mismo (Howitt 1998; Ranjan 2010; Rey et al. 2016).

entre:

Finalmente, en función de la estrategia de gestión del mercado, cabe diferenciar

- Bancos de agua activos, aquellos donde los gestores del banco adoptan una estrategia proactiva como "creadores de mercado" (market-maker), comprando derechos de agua con su propio presupuesto, para posteriormente venderlos entre los usuarios potencialmente interesados. En este sentido, la entidad gestora del banco de agua persigue alcanzar una situación próxima al equilibrio de mercado que ocurrirá en un mercado descentralizado, tratando que el conjunto de operaciones de compra y venta no le suponga un coste neto (importe de la cifra de compras equivalente al importe de la cifra de ventas), o que tal coste no supere un presupuesto máximo dispuesto para tal fin. Debe señalarse que en estos casos el administrador del banco es el que establece las condiciones para la compra y venta de derechos (u opciones), de manera que estos bancos adquieren una característica de mercado monopolista, con un sistema de contratación de sentido único (Loomis et al. 2003). Así, en primer lugar, el banco actúa como único comprador de derechos u opciones de agua (monopsonio mediante ofertas públicas de compra), para posteriormente ser el único vendedor de tales derechos u opciones (monopolio mediante ofertas públicas de venta).

El sistema de compra puede variar en función de las características de la oferta pública: i) estableciendo el importe máximo de las compras (presupuesto), ya sea mediante un precio fijado o mediante un procedimiento de subasta (incrementos sucesivos del precio de adquisición hasta agotar el presupuesto asignado); ii) estableciendo el volumen máximo de agua que se desea adquirir, también mediante procedimientos de precio fijado o subasta; y iii) estableciendo un precio de mercado fijo de adquisición, sin limitaciones presupuestarias o de volúmenes de agua a adquirir. Las ofertas públicas también pueden diferenciarse por su carácter abierto o restringido; mientras en las primeras pueden acudir de manera voluntaria todos los titulares de derechos del ámbito territorial afectado por el banco (p. ej., una 
demarcación hidrográfica o usuarios de una acuífero), en las segundas sólo pueden hacerlo los usuarios autorizados para ello (p. ej., determinados tipos de usuarios). De manera análoga, las ofertas públicas de venta pueden diferenciarse en función tanto de las condiciones de precio y cantidad a contratar, como del carácter abierto/restringido de las mismas.

Este tipo de bancos de agua resultan útiles para incrementar la actividad de mercado (mejora de eficiencia económica) y ejercer un control más efectivo sobre las operaciones de mercado (minimización de externalidades y evitar la especulación).

- Bancos de agua pasivos, aquellos que no intervienen de forma activa en el mercado, limitando sus funciones a facilitar el contacto entre compradores y vendedores para la realización de operaciones en función de la demanda y la oferta existente en cada momento. En estos casos el papel del gestor del banco es únicamente como intermediario necesario de las compraventas (broker) y cámara de compensación (clearinghouse). En este contexto, las ofertas de compra y venta de derechos están basadas en un sistema de contratación de doble sentido, donde el banco ofrece la información de forma transparente (posiciones u ofertas de compra y de venta) para realizar las transacciones de forma similar como se hace en los mercados bursátiles. Así pues, mediante el cruce de las ofertas de compra y venta existentes, se establece un precio de mercado, al cual se intercambian todos los derechos de todos los agentes interesados en aceptar/pagar el precio de equilibrio alcanzado en cada momento (Bjornlund 2003).

Tras analizar las alternativas de diseño de los bancos de agua, y establecida la tipología sobre la heterogeneidad de características existentes, debe señalarse que no todas las combinaciones de variables definitorias de estos mercados se dan en la realidad. Efectivamente, de las experiencias implementadas hasta la fecha se evidencia que existe una fuerte correlación entre las variables arriba analizadas. Así por ejemplo, se puede comprobar como aquellos bancos creados para la resolución de problemas ambientales derivados de la sobreasignación de derechos son normalmente de iniciativa pública, donde se intercambian derechos de forma permanente y con una forma de gestión activa. Alternativamente, cuando se trata de minimizar las consecuencias económicas derivada de la de escasez coyuntural motivada por la sequía, los bancos de agua implementados son igualmente públicos, pero intercambiando derechos de agua temporales, bien a través de estrategias de gestión activa o pasiva.

\section{3- Los bancos de agua como instrumento para la gestión de la escasez}

Los períodos de sequías están siendo cada vez más comunes en todo el planeta como consecuencia del cambio climático. Hasta la fecha las estrategias de gestión de la escasez coyuntural han pasado por soluciones eminentemente estructurales, basadas medidas de oferta como el incremento de la capacidad de embalse, la explotación de aguas subterráneas y la reutilización de aguas residuales tratadas (Calatrava et al. 2011; Hanak et al. 2011). No obstante, evidencias recientes (Bjornlund 2003; Brewer et al. 2008; Harou et al. 2010; Martínez-Granados \& Calatrava 2014) demuestran que tales alternativas de gestión resultan mucho más costosas que las basadas en la gestión de la demanda, como son los mercados de agua. En este sentido cabe señalar los ejemplos ofrecidos por las experiencias internacionales basadas en bancos de agua, especialmente las de California y Australia, donde se ha puesto de manifiesto en éxito de este instrumento económico para la mejora de la gestión de sequías. De manera similar, también debe señalarse la interesante experiencia española en la implementación de bancos de agua, aunque en este caso la actividad ha sido muy escasa y los resultados controvertidos. Por este motivo el análisis crítico de la experiencia internacional resulta de especial interés para España, dadas las características climáticas (climas mediterráneos con alta variabilidad en la disponibilidad del recurso), hidrológicas (alta demanda de agua y cierre de cuencas) y productivas (usos agrarios 
altamente rentables en competencias con usos urbanos e industriales) comunes, con el propósito de mejorar la implementación de este tipo de mercados en nuestro país.

El estudio de las experiencias de los bancos de agua a nivel internacional y nacional permite evidenciar cómo su operatividad plantea una serie de ventajas e inconvenientes, que deben tenerse en cuenta a la hora de diseñar adecuadamente este instrumento económico al objeto de mejorar la gestión de la escasez. En este sentido se ha realizado una extensa revisión de la literatura existente al respecto, con el propósito de catalogar convenientemente las principales ventajas e inconvenientes asociadas a los bancos de agua, tal y como se sintetiza a continuación.

\section{Ventajas}

Los bancos de agua, al tratarse de un tipo de mercado de agua, comparten las mismas ventajas que estos, principalmente las relacionadas con la mejora de eficiencia en el uso del recurso (Bauer 1997; Easter \& Huang 2014; Easter et al. 1998, 1999; Garrick et al. 2009; Grafton et al. 2011; Howe et al. 1986; Michelsen \& Young 1993; Rosegrant \& Binswanger 1994):

$\checkmark$ Producen un aumento de las rentas a todos los usuarios del agua. La participación de los usuarios en el mercado es siempre voluntaria, circunstancia que justifica que todas las operaciones resulten beneficiosas (mejora de renta) para ambas partes.

$\checkmark$ Mejoran la eficiencia asignativa del recurso, favoreciendo transferencias de agua desde actividades de menor productividad marginal del agua hacia aquellas actividades con mayor productividad marginal, maximizando con ello el valor de la producción total derivada del uso del recurso disponible, lo que se traduce normalmente en una mejora del bienestar social.

$\checkmark$ Revelan el verdadero coste de oportunidad o coste de escasez del recurso, haciendo visible el valor económico para la sociedad, favoreciendo con ello un uso más racional del mismo.

$\checkmark$ Permiten aumentar la garantía de suministro a los usuarios más adversos al riesgo, ya que gracias a la posibilidad de intercambio reducen los efectos de la incertidumbre hidrológica.

$\checkmark$ Racionalizan la construcción de nuevas obras de infraestructuras hidráulica para el aumento de la oferta de agua, pues los mercados constituyen una alternativa a la construcción de costosas obras hidráulicas (precio de mercado inferior al coste marginal de los nuevos recursos).

Además de las ventajas comunes al resto de mercados de agua, los bancos de agua presentan una serie de ventajas específicas (Bauer 2010; Calatrava et al. 2011; Clifford et al. 2004; Gómez-Ramos 2013; O'Donnell \& Colby 2010):

$\checkmark$ Reducen los costes de transacción en las operaciones de intercambio, ya que al centralizar las compras y ventas de derechos (u opciones), reducen los costes derivados de la búsqueda de agentes interesados en participar, así como los administrativos relacionados con formalización de las operaciones y la verificación del cumplimiento de lo acordado. Esta reducción de los costes de transacción favorece los intercambios, haciendo de los bancos un instrumento más adecuado para la mejora de eficiencia en el uso del agua.

$\checkmark$ Los bancos de agua destacan en la reasignación de los derechos de agua con fines ambientales. Esta no es una función exclusiva de los gobiernos, ya que en muchos estados norteamericanos existen organizaciones sin ánimo de lucro que ejercen control sobre las externalidades ambientales y sociales como el incremento de los flujos de agua de los ríos a través de compras de derechos de agua en masas de agua sobreexplotadas para la recuperación de los caudales.

$\checkmark$ Mayor transparencia, ya que se consigue que los precios de compra y/o venta sean públicos y accesibles a todos los usuarios. 
$\checkmark$ Los bancos de agua de iniciativa pública, al estar gestionados por la Administración, aportan mayor seguridad y garantía de disponibilidad de recursos hídricos que los mercados de agua.

$\checkmark$ La implementación temprana de los bancos de agua en los primeros estadios de la sequía concienciaría de manera más efectiva al conjunto de usuarios sobre la necesidad de realizar esfuerzos para disminuir la demanda con el fin de mitigar los efectos negativos de un eventual agravamiento de la sequía.

Tras las ventajas descritas, podemos concluir que los bancos de agua proporcionan la flexibilidad necesaria para la gestión de los recursos hídricos, favoreciendo la reasignación del agua en zonas donde los recursos disponibles ya están asignados y siguen surgiendo nuevos usuarios que reclaman agua, incluido el medio ambiente (WWF España 2005).

\section{Inconvenientes}

Los mercados de agua presentan una serie de inconvenientes, que por ende son comunes a los bancos de agua. A continuación se hace una relación de los principales inconvenientes que muestran estos instrumentos económicos (Bjornlund \& McKay 2002; BOE 2001; Delacámara et al. 2015; Dinar et al. 1997; Hearne \& Easter 1997; Johansson 2000; Qureshi et al. 2009; Rosegrant \& Binswanger 1994; Thobani 1997; Tsur 2000):

$\checkmark$ Activación de "derechos durmientes" o "derechos de papel". Con este nombre se conocen aquellos derechos de agua asignados a usuarios que realmente no los utilizan. Así, si el destino fuera la reasignación de derechos, se incrementaría el uso de agua total en el sistema, mientras que si el destino fuera el incremento de los caudales de las masas de agua, su compra no tendría efecto.

$\checkmark$ Compraventa del total de la concesión en lugar el agua realmente utilizada. Vender el volumen correspondiente al derecho del agua (concesión) resultaría en una situación similar a la anterior en la que se pondrían en circulación derechos de agua no utilizados.

$\checkmark$ Externalidades ambientales negativas al realizar la compraventa de la dotación (agua realmente utilizada) en vez del agua consumida, que derivaría en la pérdida de retornos de agua en la zona cedente, degradando el medio ambiente al afectar al mantenimiento de los caudales en las zonas de origen.

$\checkmark$ Disminución global de los retornos. Realizar transferencias desde zonas de baja eficiencia en el uso del agua a zonas de mayor eficiencia puede disminuir los retornos de agua al medio de forma global.

$\checkmark$ Otra externalidad negativa es el impacto a terceros por el empeoramiento socioeconómico en la zona de origen, debido a la pérdida de empleo por el abandono de la actividad y despoblamiento como consecuencia de la pérdida de renta asociada al empleo.

$\checkmark$ Elevados costes de transacción asociados al intercambio de derechos del agua, que provocan rigidez en el mercado y pérdida de capacidad de respuesta ante situaciones inciertas. Estos costes de transacción incluyen: i) costes derivados de poner en contacto a compradores y vendedores, ii) costes administrativos asociados al contrato que ha de realizarse, y iii) coste de las infraestructuras para realizar las transferencias físicas de agua. Aunque, como ya se ha mencionado, los bancos de agua disminuirían parte de estos costes de transacción.

$\checkmark \quad$ Imperfecciones en el mercado. El flujo unidireccional del agua de los ríos implica que en principio solo puedan realizarse las transferencias de recursos dentro de una misma cuenca, y de los usuarios situados en las partes más elevadas hacia otros situados en zonas más bajas. No obstante, si hay suficientes recursos en la cabecera de la cuenca, también se pueden transferir derechos aguas arriba. Para solventar estos obstáculos sería necesario realizar costosas infraestructuras (que incrementarían aún más los costes de transacción). 
$\checkmark$ Fraudes en el uso del agua tras la venta del recurso. Si no existe un control adecuado, podría resultar que el cedente siga utilizando agua tras la venta de los derechos.

Además de los inconvenientes descritos, hay que tener en cuenta las barreras culturales (el agua no es considerada un bien objeto de comercio), físicas (inexistencia de las infraestructuras adecuadas para realizar las transacciones) y legales, que producen que los mercados de agua movilicen un volumen escaso de agua, considerándose por tanto "mercados estrechos". Así pues, si la actividad es escasa, se genera falta de competencia y dispersión en los precios, que dejan de ser un buen indicador de la escasez del recurso (Tisdell 2011).

Cabe destacar que los bancos de agua poseen unas características específicas que hacen que, además de tener los inconvenientes descritos para los mercados de agua, sea compleja su creación. Así, la creación de un banco de agua requiere de una gestión administrativa compleja, que sea capaz de gestionar los contratos entre compradores y vendedores, así como asegurar que todos los agentes implicados pueden participar en el mercado con los volúmenes de agua realmente utilizados, minimizando las externalidades negativas.

\section{Experiencia internacional}

Entre los países con mayor volumen de agua intercambiado se encuentran Australia y Chile, que puede llegar a superar el $10 \%$ del total de los recursos consumidos (Hadjigeorgalis \& Lillywhite 2004), siendo muy superior a los volúmenes que se movilizan en España. En este sentido, en los estados del oeste de los Estados Unidos, las transferencias de agua son similares a las de las cuencas del sureste español y no llegan a superar el $5 \%$ del consumo total en los períodos más secos (Briscoe 1997; Hanak \& Stryjewski 2012).

Las experiencias en bancos de agua tanto en Australia como en Estados Unidos se pueden encuadrar según la tipología que se ha establecido. En la Tabla 1 se recogen de forma sintética la clasificación según la tipología y los estados en los que se han desarrollado los bancos de agua.

Tabla 1. Bancos de agua en el Oeste de los Estados Unidos.

\begin{tabular}{|c|c|c|c|c|c|c|c|c|c|c|c|c|c|c|c|c|}
\hline & & 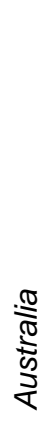 & 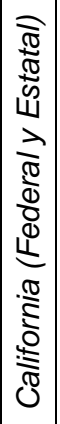 & 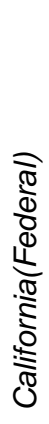 & 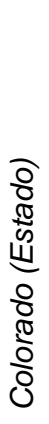 & 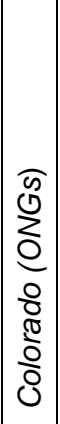 & 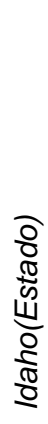 & 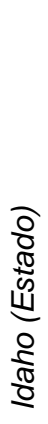 & 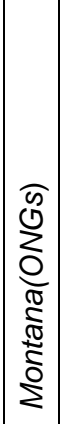 & 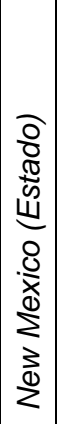 & 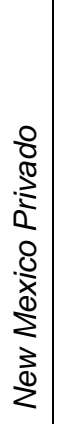 & 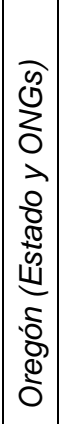 & 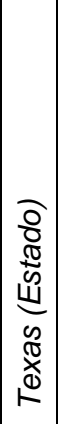 & 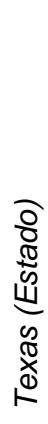 & 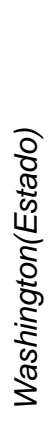 & 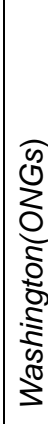 \\
\hline \multirow{3}{*}{$\begin{array}{l}\text { En función del bien } \\
\text { intercambiado }\end{array}$} & Permanentes & $x$ & $x$ & $x$ & & & & $x$ & & $x$ & & & $\mathrm{X}$ & $x$ & & $x$ \\
\hline & Temporales o spot & $\mathrm{X}$ & $\mathrm{X}$ & $\mathrm{X}$ & $\mathrm{X}$ & $\mathrm{X}$ & $\mathrm{X}$ & & $\mathrm{X}$ & $\mathrm{X}$ & $\mathrm{X}$ & $\mathrm{X}$ & $\mathrm{X}$ & & $\mathrm{X}$ & $\mathrm{X}$ \\
\hline & Opciones o futuros & & $\mathrm{X}$ & & & & & & & & & & & & $\mathrm{X}$ & \\
\hline \multirow{3}{*}{ Según la finalidad } & Reasignación del recurso & $\mathrm{X}$ & $\mathrm{X}$ & & $\mathrm{X}$ & & $\mathrm{X}$ & & & $\mathrm{X}$ & $\mathrm{X}$ & & $\mathrm{X}$ & & $\mathrm{X}$ & \\
\hline & Fin medioambiental & $\mathrm{X}$ & & $\mathrm{X}$ & & $\mathrm{X}$ & & $\mathrm{X}$ & $\mathrm{X}$ & $\mathrm{X}$ & & $\mathrm{X}$ & & $\mathrm{X}$ & & $\mathrm{X}$ \\
\hline & \begin{tabular}{|l|} 
Gestión del riesgo de \\
disponibilidad de agua
\end{tabular} & & $\mathrm{X}$ & & & & & & & & & & & & $X$ & \\
\hline \multirow{2}{*}{ Operatividad del banco } & Activo & & $\mathrm{X}$ & $\mathrm{X}$ & & $\mathrm{X}$ & $\mathrm{X}$ & $\mathrm{X}$ & $\mathrm{X}$ & & & $\mathrm{X}$ & $\mathrm{X}$ & $\mathrm{X}$ & $\mathrm{X}$ & $\mathrm{X}$ \\
\hline & Pasivo & $\mathrm{X}$ & & & $\mathrm{X}$ & & & & & $\mathrm{X}$ & $\mathrm{X}$ & & & & & \\
\hline
\end{tabular}

Fuente: Elaboración propia. 


\section{4- Los bancos de agua en España}

La rigidez del sistema concesional español hace que sea necesario introducir flexibilidad, con el objetivo de permitir un uso más eficiente del agua que proporcione mayor satisfacción al conjunto de la sociedad. En este sentido, la Ley de Aguas 46/1999, de Reforma de la Ley de Aguas de 1985, rompe el principio de "la vinculación del agua a la tierra" y permite nuevas formas de reasignación de recursos hídricos mediante la regulación de mercados formales de agua ${ }^{1}$ a través de dos figuras diferentes: i) contratos de cesión de derechos de uso de agua (art. 67), que se corresponden con un diseño de mercado de derechos temporales o spot entre particulares y ii) los centros de intercambio (art. 71), que se ajustan a los bancos de agua objeto de este trabajo, donde pueden transferirse tanto derechos temporales como permanentes.

El Real Decreto-ley 15/2005, aprobó la constitución de los centros de intercambio de derechos de uso del agua como tipo de mercado de agua en situaciones excepcionales y urgentes para paliar los efectos de la sequía en determinadas cuencas (Segura, Júcar, Guadiana y Guadalquivir). Esta situación de excepcionalidad se fue prorrogando a través de sucesivos reales decreto-ley hasta noviembre 2008, cuando se consideró terminado el episodio de sequía. En el sistema original del TRLA no cabe reservar derechos para usos ambientales y es desde el Real Decreto Ley 9/2006, de 15 de septiembre, cuando los centros de intercambio ganan operatividad y se adoptan medidas urgentes para paliar los efectos producidos por la sequía en las poblaciones y en las explotaciones agrarias de regadío en determinadas cuencas hidrográficas. La última reforma de la Ley de Aguas española de mayo de 2012 se centra en los recursos de agua subterránea y pone de relieve la necesidad de simplificar y acelerar los procedimientos administrativos para añadir más flexibilidad y eficiencia al sistema de gestión del agua, incluyendo el fomento de la transformación de los derechos de aguas privadas en concesiones de agua pública (Rey et al. 2014).

En España se han desarrollado tres casos donde se han creado centros de intercambio en las cuencas de los ríos Guadiana, Júcar y Segura. Según la tipología establecida, se podrían clasificar estas tres experiencias como bancos de agua activos de iniciativa pública mediante ofertas públicas de adquisición de derechos (OPAD), cuya finalidad principal fue la mejora del medio ambiente. No obstante, hay algunas diferencias fundamentales que hacen que estos bancos hayan tenido características diferenciadas. La principal divergencia reside en que, a diferencia de los centros de intercambio del Júcar y Segura, donde se trataba de paliar un problema coyuntural de caudal en los ríos debido a la sequía, en el caso del Guadiana se trataba de un problema estructural de escasez por sobreexplotación del acuífero de la Mancha Occidental. Así, en el caso del Guadiana se estableció un centro de intercambio para la compra permanente de derechos de agua, cuya finalidad fue doble: la recuperación del acuífero y la reasignación de recursos, dotando de agua a algunos cultivos sociales. Por el contrario, en los casos del Júcar y Segura, al tratarse de un problema coyuntural, se realizaron adquisiciones temporales de derechos de agua. Además, cabe destacar que las adquisiciones de derechos en el Guadiana y Segura se realizaron mediante subastas, mientras que en el Júcar se realizaron a precio fijado en función de la distancia a la masa de agua afectada.

No obstante, se detectaron algunos inconvenientes en las OPAD del Guadiana, donde se compraron derechos que realmente no se utilizaban y además se detectó que, en algunos casos, el agua se continuó utilizando tras su venta. Sin embargo, en el caso del Júcar, se evitaron estos problemas gracias un mejor control de la elegibilidad de los cedentes y un mayor control sobre el uso posterior del agua.

\footnotetext{
${ }^{1}$ Los mercados formales son aquellos en los que la Administración pública interviene en su regulación (PalomoHierro et al. 2015).
} 
Además de la ley nacional, existe legislación específica que regula los bancos de agua en Andalucía en los distritos hídricos que dependen enteramente de la administración regional. En este contexto, la Ley 9/2010 de Aguas de Andalucía permite obviar la prelación de usos del agua, igualando en un mismo nivel de prioridad a los usos agrarios, industriales y de turismo, así como la obligatoriedad de ser concesionario para poder actuar como comprador, evitándose así asimetrías en el mercado. Además, permite adquirir agua de propiedad privada, transformándola en agua de propiedad pública.

A pesar de la posibilidad de creación de bancos de agua en España, la rigidez para su constitución ha impedido que se hayan desarrollado más experiencias, ya que es necesario que se den circunstancias de excepcionalidad para que el Ministro de Medio Ambiente proponga la creación de un banco de agua activo al Consejo de Ministros y haya un acuerdo formal para que sea constituido, además de la necesaria dotación presupuestaria.

\section{5- Lecciones aprendidas: directrices para la mejora de la normativa española}

A través del trabajo se han expuesto las ventajas y los inconvenientes de los bancos de agua según las experiencias tanto a nivel nacional como internacional. Antes de finalizar, en este apartado cabe comentar opciones de mejora en base a los inconvenientes encontrados en el funcionamiento de los bancos de agua:

1) Facilitar las gestiones para la constitución de un banco de agua.

2) Posibilitar que los organismos no gubernamentales puedan gestionar bancos de agua, tanto para fines medioambientales como para la reasignación del recurso.

3) Establecer de forma continua los bancos de agua, no solo en ocasiones excepcionales, con el objeto de atraer a los usuarios del agua a participar en el mercado con mayor regularidad y así poder evaluar si este instrumento resultaría realmente útil para la gestión del recurso en España.

4) Establecer un método ágil, apoyado en un sistema de información geográfica, para verificar con rapidez la información requerida para aprobar una adquisición de derechos por parte de un banco de agua (derechos de uso de agua, localización de las explotaciones agrarias, uso efectivo del derecho, infraestructura existente, etc.), evitando entre otros problemas la compraventa de derechos de agua no utilizados.

5) Eliminar barreras físicas, estableciendo la infraestructura necesaria y capacidad hidráulica para que las transferencias del recurso sean eficientes.

6) Transferir solo la fracción de agua consumida, y no la concesión o la dotación completa, evitando por una parte que se transfieran derechos no utilizados (al limitarlo a la dotación) y evitando que desde la zona de origen se transfiera la fracción de agua correspondiente a los flujos de retorno al medio (al limitarlo al agua realmente consumida), de manera que se minimicen o anulen los efectos ambientales en la zona de origen. En este sentido, la Ley de Aguas establece que solo se podrá ceder el derecho de uso correspondiente al agua utilizada en un periodo de referencia, pero habría que ir más allá y solo permitir la cesión de los volúmenes consumidos.

7) Establecer un método de control para evitar fraudes tras la venta del derecho de uso.

8) Incrementar la transparencia para disminuir los costes de transacción derivados de poner en contacto a compradores y vendedores. En este sentido, sería necesario definir claramente las zonas donde se puede comprar y/o vender derechos de agua a través del banco de agua con la infraestructura existente.

Para finalizar con la relación sobre las lecciones aprendidas, cabe destacar que resultaría necesaria una reforma de la Ley de Aguas que recoja todos los puntos anteriores, estableciendo leyes robustas para la mejora de la gobernanza que consiga la conexión entre instituciones, la eficiencia económica y la sostenibilidad ambiental. 


\section{6- Conclusiones}

El trabajo se ha centrado en los bancos de agua como mecanismo de mercado implementado ya en varios países al objeto de facilitar la reasignación del recurso entre los distintos usuarios. Así pues, la primera conclusión que se deriva del documento es que los bancos de agua han sido una herramienta útil a nivel internacional para resolver problemas de escasez de recursos hídricos, tanto coyuntural como estructural.

La introducción de este tipo de instrumentos mejora de la eficiencia asignativa del uso del agua, ya que permite que emerjan los costes de oportunidad del recurso, permitiendo su reasignación desde actividades de menor valor hacia usos de mayor valor donde el agua es pagada a precios más altos y su rendimiento es mayor. También permiten reducir conflictos sociales, poniendo en contacto a compradores y vendedores, evitando así la especulación de precios y cantidades que se intercambian, ya que es la Administración (u otro organismo) la que adquiere un papel central proporcionando agilidad y una rápida respuesta frente a situaciones excepcionales tales como la sequía.

En este contexto, aportan más flexibilidad a la gestión del agua, reduciendo la variabilidad en el beneficio, mejorando el bienestar social asociado al uso del agua y siendo además mejores que los mercados de derechos de agua a la hora de estabilizar la disponibilidad de agua de un usuario, ya que disminuyen los costes de transacción asociados a la puesta en contacto entre usuarios y los costes administrativos, aportando mayor transparencia.

La investigación llevada a cabo revela que al mercado español aún le queda un largo recorrido para conseguir alcanzar el buen funcionamiento de los bancos de agua, tal y como se ha alcanzado en otras zonas como California y Australia. El número de operaciones llevadas a cabo en España han sido escasas, y no es posible analizar y evaluar con exactitud si esta herramienta sería mejor que otras medidas. Sin embargo, creemos que un diseño adecuado de los bancos de agua, una adecuada regulación y una actuación activa por parte de la Administración (u otro organismo), pueden conseguir la eficiencia económica y la sostenibilidad ambiental, objetivos básicos de la gestión pública de los recursos hídricos.

Para ello, puede resultar interesante establecer, bajo un protocolo adecuado, un banco de agua de manera continua que promueva la participación activa de todas las partes implicadas. Así, podrían obtenerse de forma regular evaluaciones anuales y analizar con mayor detalle las ventajas e inconvenientes que se derivan de su uso, de las que se podrían extraer aportaciones que mejoren el diseño de este instrumento económico dentro de la política del agua.

\section{7- Agradecimientos}

Esta investigación ha sido financiada por el Ministerio de Economía y Competitividad (MINECO) y el Fondo Europeo de Desarrollo Regional (FEDER), a través del Proyecto de Investigación AGL2013-48080-C2-1-R y de la Ayuda Predoctoral FPI asociada al mismo.

\section{8- Bibliografía}

Alcón, F., Tapsuwan, S., Brouwer, R. \& de Miguel, M.D. (2014). Adoption of irrigation water policies to guarantee water supply: A choice experiment. Environmental Science and Policy, 44, 226-236.

Bauer, C.J. (1997). Bringing water markets down to earth: The political economy of water rights in Chile, 1976-1995. World Development, 25(5), 639-656.

Bauer, C.J. (2010). El abanico de bancos de aguas en las Américas. Estudios de economía aplicada, 28(2), 227-236.

Berbel, J., Pedraza, V. \& Giannoccaro, G. (2013). The trajectory towards basin closure of a European river: Guadalquivir. International Journal of River Basin Management, 11(1), 111-119. 
Bjornlund, H. (2003). Efficient water market mechanisms to cope with water scarcity. International Journal of Water Resources Development, 19(4), 553-567.

Bjornlund, H. \& McKay, J. (2002). Aspects of water markets for developing countries: Experiences from Australia, Chile, and the US. Environment and Development Economics, 7(4), 769-795.

BOE. (2001). Real Decreto Legislativo 1/2001, de 20 de julio, por el que se aprueba el texto refundido de la Ley de Aguas.: Boletín Oficial del Estado no 176, de 24/07/2001.

Booker, J.F., Michelsen, A.M. \& Ward, F.A. (2005). Economic impact of alternative policy responses to prolonged and severe drought in the Rio Grande Basin. Water Resources Research, 41(2), W02026.

Brewer, J., Glennon, R., Ker, A. \& Libecap, G.D. (2008). 2006 Presidential address. Water markets in the West: Prices, trading, and contractual forms. Economic Inquiry, 46(2), 91-112.

Briscoe, J. (1997). Managing water as an economic good: Rules for reformers. Water Supply, 15(4), 153-172.

Burke, S.M., Adams, R.M. \& Wallender, W.W. (2004). Water banks and environmental water demands: Case of the Klamath project. Water Resources Research, 40(9), W09S02.

Calatrava, J., Guillem, A. \& Martínez-Granados, D. (2011). Análisis de alternativas para la eliminación de la sobreexplotación de acuíferos en el Valle de Guadalentín. Economía Agraria y Recursos Naturales, 11(2), 33-62.

Clifford, P., Landry, C.J. \& Larsen-Hayden, A. (2004). Analysis of water banks in the western states. Olympia, USA: Washington State University, Department of Ecology.

Coase, R.H. (1960). The problem of social cost. Journal of Law and Economics, 3(1), 1-28.

Cui, J. \& Schreider, S. (2009). Modelling of pricing and market impacts for water options. Journal of Hydrology, 371(1-4), 31-41.

Delacámara, G., Gómez, C.M. \& Maestu, J. (2015). Water trading opportunities and challenges in Europe. In K. Burnett, R.E. Howitt, J.A. Roumasset, \& C.A. Wada (Eds.), Routledge handbook of water economics and institutions (pp. 281-295). Oxon, UK: Routledge.

Dellapenna, J.W. (2000). The importance of getting names right: The myth of markets for water. William \& Mary Environmental Law and Policy Review, 25(2), 317-377.

Dinar, A., Rosegrant, M.W. \& Meinzen-Dick, R. (1997). Water allocation mechanisms: Principles and examples. Washington D.C.: The World Bank.

Easter, K.W. \& Huang, Q. (2014). Water markets for the 21st century: What have we learned? New York: Springer.

Easter, K.W., Rosegrant, M.W. \& Dinar, A. (1998). Markets for water: Potential and performance. Boston: Kluwer Academic Publishers.

Easter, K.W., Rosegrant, M.W. \& Dinar, A. (1999). Formal and informal markets for water: Institutions, performance, and constraints. The World Bank Research Observer, 14(1), 99-116.

FAO. (2012). Irrigation water requirement and water withdrawal by country. Rome: FAO.

Garrick, D., Siebentritt, M.A., Aylward, B., Bauer, C.J. \& Purkey, A. (2009). Water markets and freshwater ecosystem services: Policy reform and implementation in the Columbia and Murray-Darling Basins. Ecological Economics, 69(2), 366-379.

Gómez-Ramos, A. (2013). Drought management uncertainty and option contracts. In J. Maestu (Ed.), Water trading and global water scarcity: International experiences (pp. 286-297). Oxon, UK: RFF Press.

Grafton, R.Q., Libecap, G.D., Edwards, E.C., O'Brien, R.J. \& Landry, C.J. (2012). Comparative assessment of water markets: Insights from the Murray-Darling Basin of Australia and the Western USA. Water Policy, 14(2), 175-193.

Grafton, R.Q., Libecap, G.D., McGlennon, S., Landry, C.J. \& O'Brien, R.J. (2011). An integrated assessment of water markets: A cross-country comparison. Review of Environmental Economics and Policy, 5(2), 219-239.

Hadjigeorgalis, E. (2009). A place for water markets: Performance and challenges. Review of Agricultural Economics, 31(1), 50-67. 
Hadjigeorgalis, E. \& Lillywhite, J. (2004). The impact of institutional constraints on the Limarí River Valley water market. Water Resources Research, 40(5), W05501.

Hanak, E., Lund, J.R., Thompson, B., Cutter, W.B., Gray, B., Houston, D., Howitt, R.E., Jessoe, K., Libecap, G.D., Medellín-Azuara, J., Olmstead, S.M., Sumner, D., Sunding, D., Thomas, B. \& Wilkinson, R. (2011). Managing California's water: From conflict to reconciliation. San Francisco, USA: Public Policy Instititute of California.

Hanak, E. \& Stryjewski, E. (2012). California's water market, by the numbers: Update 2012. San Francisco, USA: Public Policy Institute of California.

Harou, J.J., Medellín-Azuara, J., Zhu, T., Tanaka, S.K., Lund, J.R., Stine, S., Olivares, M.A. \& Jenkins, M.W. (2010). Economic consequences of optimized water management for a prolonged, severe drought in California. Water Resources Research, 46(5), W05522.

Hearne, R.R. \& Easter, K.W. (1997). The economic and financial gains from water markets in Chile. Agricultural Economics, 15(3), 187-199.

Howe, C.W., Schurmeier, D.R. \& Shaw, W.D. (1986). Innovate approaches to water allocation: The potenctial for water markets. Water Resources Research, 22(4), 439445.

Howitt, R.E. (1998). Spot prices, option prices, and water markets: an analysis of emerging markets in California. In K.W. Easter, M.W. Rosegrant, \& A. Dinar (Eds.), Markets for water-potential and performance (pp. 119-140). New York: Springer.

Israel, M. \& Lund, J.R. (1995). Private water leasing: Working within the prior appropriation system to restore stream flows. Natural Resources Journal, 35, 1-32.

Jercich, S.A. (1997). California's 1995 water bank program: Purchasing water supply options. Journal of Water Resources Planning and Management, 123(1), 59-65.

Johansson, R.C. (2000). Pricing irrigation water. A literature survey. Washington: The World Bank.

Loomis, J.B., Quattlebaum, K., Brown, T.C. \& Alexander, S.J. (2003). Expanding institutional arrangements for acquiring water for environmental purposes: Transactions evidence for the Western United States. International Journal of Water Resources Development, 19(1), 21-28.

MacDonnell, L.J. (1995). Water banks: Untangling the Gordian knot of Western water. In R.M.M.L. Foundation (Ed.), Proceedings of the Forty-First Annual Rocky Mountain Mineral Law Institute (pp. 1-63). Denver, Colorado: Mineral Law Institute.

Martínez-Granados, D. \& Calatrava, J. (2014). The role of desalinisation to address aquifer overdraft in SE Spain. Journal of Environmental Management, 144, 247-257.

McCrea, M.E. \& Niemi, E. (2007). Technical report on market-based reallocation of water resources alternative. A component of the Yakima River Basin storage feasibility study. Olympia, USA: Washington State University Department of Ecology.

Michelsen, A.M. \& Young, R.A. (1993). Optioning agricultural water rights for urban water supplies during drought. American Journal of Agricultural Economics, 75(4), 10101020.

O'Donnell, M. \& Colby, B. (2010). Water banks: A tool for enhancing water supply reliability. Tucson: University of Arizona, Department of Agricultural and Resource Economics.

Palomo-Hierro, S., Gómez-Limón, J.A. \& Riesgo, L. (2015). Water markets in Spain: Performance and challenges. Water, 7(2), 652-678.

Qureshi, M.E., Shi, T., Qureshi, S.E. \& Proctor, W. (2009). Removing barriers to facilitate efficient water markets in the Murray-Darling Basin of Australia. Agricultural Water Management, 96(11), 1641-1651.

Randall, A. (1981). Property entitlements and pricing policies for a maturing water economy. Australian Journal of Agricultural Economics, 25(3), 195-220.

Ranjan, R. (2010). Factors affecting participation in spot and options markets for water. Journal of Water Resources Planning and Management, 136(4), 454-462.

Rey, D., Calatrava, J. \& Garrido, A. (2016). Optimisation of water procurement decisions in an irrigation district: The role of option contracts. Australian Journal of Agricultural and Resource Economics, 59, 1-25. 
Rey, D., Garrido, A. \& Calatrava, J. (2014). The water markets in Spain: Moving towards 21st century mechanisms and approaches with 20th century regulations. In K.W. Easter \& H. Qiuqiong (Eds.), Water markets for the 21st century: What have we learned? (pp. 127-147). New York: Springer.

Rosegrant, M.W. \& Binswanger, H.P. (1994). Markets in tradable water rights: Potential for efficiency gains in developing country water resource allocation. World Development, 22(11), 1613-1625.

Thobani, M. (1997). Formal water markets: Why, when, and how to introduce tradable water rights. The World Bank Research Observer, 12(2), 161-179.

Tisdell, J.G. (2011). Water markets in Australia: An experimental analysis of alternative market mechanisms. Australian Journal of Agricultural and Resource Economics, 55(4), 500-517.

Tsur, Y. (2000). Water regulation via pricing: The role of implementation costs and asymmetric information. In A. Dinar (Ed.), The Political Economy of Water Pricing Reforms (pp. 105-120). New York: Oxford University Press.

Wheeler, S.A., Garrick, D., Loch, A. \& Bjornlund, H. (2013). Evaluating water market products to acquire water for the environment in Australia. Land Use Policy, 30(1), 427436.

Wheeler, S.A., Loch, A., Zuo, A. \& Bjornlund, H. (2014). Reviewing the adoption and impact of water markets in the Murray-Darling Basin, Australia. Journal of Hydrology, 518, 2841.

Wheeler, S.A., Zuo, A., Bjornlund, H. \& Lane Miller, C. (2012). Selling the farm silver? Understanding water sales to the Australian Government. Environmental and Resource Economics, 52(1), 133-154.

WWF España. (2005). Los mercados de aguas y la conservación del medio ambiente: Oportunidades y retos para su implantación en España. Madrid: WWF España. 


\title{
D-03
}

\section{TRANSFERENCIA DE RESULTADOS DE INVESTIGACIÓN PARA EL AHORRO DE AGUA Y DE LA ENERGIA EN COMUNIDADES DE REGANTES A TRAVÉS DEL ENTORNO DE GESTIÓN INTEGRADA CORENET-COREGEST}

\author{
Ortiz Ruiz del Castillo, José (P), Aliod Sebastián, R.,Mora Gómez, M., Abadía Sánchez, R, \\ Intrigliolo, D.S.
}

${ }^{1}$ Director, Serina, Servicios de Ingeniería y Arquitectura, S.L, San Marcos, 29, Madrid, jortiz@serina.es. ${ }^{2}$ Profesor Titular, Universidad de Zaragoza, Área Mecánica de Fluidos, raliod@unizar.es ${ }^{3}$ Dr. Ingeniero Agrónomo, Moval Agroingeniería S.L.mmora@moval.es

${ }^{4}$ Director Escuela Ingeniería, Universidad Miguel Hernández, abadia@umh.es ${ }^{5}$ Científico titular, CEBAS-CSIC. dintri@cebas.csic.es

\section{Resumen}

En la actualidad se está produciendo un incremento en la demanda para realizar una gestión optimizada del agua y de la energía empleadas en el regadío. Esto ha dado lugar a una importante actividad de I+D con diferentes sistemas, productos y servicios, que comparten el objetivo de mejorar la aplicación del agua y/o de la energía. Sin embargo, el conocimiento generado choca con dificultades a la hora de transferir los resultados hacia los usuarios finales. Esto es debido, al menos en parte, a la necesidad de que las Comunidades de Regantes cambien su modelo de gestión y sean capaces de integrar los resultados de este conocimiento con los procesos normales de gestión que se emplean en las mismas.

SERINA ha desarrollado la metodología y el Enterprsise Resource Planning (ERP) de gestión CORENET-COREGEST, que permite modernizar los procesos de gestión de las Comunidades de Regantes e integrar herramientas/sistemas/servicios externos generados por los centros de I+D con el objetivo de mejorar la gestión, fundamentalmente, del agua y de la energía.

En este trabajo se muestran algunos casos que ilustran lo anterior y se explican las ventajas para las Comunidades de Regantes usuarias así como por los centros de I+D que han integrado sus productos en CORENET-COREGEST.

\section{Introducción}

En el contexto actual existe una importante presión para que el regadío sea cada vez más eficaz en su uso de agua. Por otro lado, la situación tarifaria de la energía eléctrica obliga a una minimización en el uso de este recurso. También se exige la minimización del impacto medioambiental debido a la aplicación en campo de productos agroquímicos y a otros factores.

Por otro lado, las actividades de modernización de infraestructuras están convirtiendo a las Comunidades de Regantes en entidades cuya gestión tiene que ser más profesionalizada que antaño debido a la introducción de costosas infraestructuras y tecnologías sofisticadas. Todo esto obliga a que las Comunidades de Regantes comiencen a preocuparse por mejorar sus procedimientos de gestión para adaptarse a estos nuevos desafíos. 
Una Comunidad de Regantes tiene que atender, coordinadamente, bajo el punto de vista de gestión los siguientes aspectos: Personas (Regantes, Administraciones, trabajadores), Agua, Energía, Territorio, Tecnología, Infraestructura, Grandes Presupuestos, Documentación.

Tradicionalmente, estos aspectos se han gestionado de forma estanca e individual, sin tener en cuenta que las decisiones que se toman en relación a cada uno de ellos repercute en los otros de forma directa (por ejemplo: el vínculo entre consumo de agua y energía o las posibilidades de disminución en el consumo de agua que se producen cuando se aplica una dosificación optimizada a los cultivos para lo que es necesario conocer la estructura de cultivos). Este enfoque de gestión individual no aprovecha la sinergia combinada que se produce cuando se aborda la gestión de una Comunidad de Regantes de forma global o integral gracias a la cual los gestores pueden tener una visión general del funcionamiento de la Comunidad y optimizar su rendimiento adaptándolo a la nueva situación en la cual se desenvuelven.

Por tanto, es necesario cambiar el estilo de gestión hacia una gestión integral de todos los aspectos que hay que administrar en la Comunidad de Regantes. Esto se traduce en una disminución de los costes anuales para el regante, en un mejor servicio al mismo, en una utilización más controlada de los recursos agua y energía y en una reducción del impacto ambiental del regadío.

La implantación de una filosofía de gestión integral en una Comunidad de Regantes requiere:

- El diseño e implantación de procesos de gestión capaces de responder a las necesidades de la Comunidad de una forma integrada

- La implantación de herramientas de gestión integrada basadas en tecnologías de la información y comunicación tipo ERP que den soporte, formalicen los procesos de gestión y permitan una explotación de los datos correspondientes a distintos procesos de gestión para obtener información sofisticada mediante la combinación de los mismos, capaz de apoyar la toma de decisiones. Estas herramientas deben ser capaces de comunicarse e integrar información de otras herramientas y sistemas externos con el objetivo de facilitar y optimizar los resultados de gestión.

Las herramientas CORENET-COREGEST constituyen un sistema abierto, que cumple todos los requisitos anteriores y que es capaz de comunicarse con herramientas externas e integrar los resultados de I+D que provengan de Centros de Investigación y Universidades que puedan suponer una mejora en la gestión de cualquiera de los procesos de negocio de una Comunidad de Regantes.

CORENET-COREGEST está ya implantado en un elevado número de Comunidades de Regantes y éste número sigue creciendo a buen ritmo por lo que constituye una eficaz manera de transmitir estos resultados de I+D a los usuarios finales de los mismos.

A continuación se describen algunos ejemplos en los que el conocimiento, herramientas y servicios de centros de I+D y universidades ha sido incorporado a CORENET-COREGEST para su uso por Comunidades de Regantes y Regantes. 


\section{Caso 1: Módulo de cálculo de indicadores para gestión de agua y energía. Colaboración CORENET-COREGEST y Universidad Miguel Hernández}

CORENET-COREGEST dispone de herramientas software que permiten la generación de indicadores para la gestión eficiente del agua y de la energía en las que se emplea el conocimiento desarrollado por el Departamento de Ingeniería de la Universidad Miguel Hernández (Escuela Politécnica Superior de Orihuela). Este módulo es utilizable por cualquier Comunidad usuaria de CORENET-COREGEST siendo tanto más indicado su uso cuanto más elevado sea el consumo energético de la Comunidad.

Mediante este módulo los gestores de una Comunidad de Regantes pueden disponer de información tanto de la campaña corriente como información histórica que les permita:

- Realizar un seguimiento de los costes de sus contratos eléctricos

- Disponer de información sobre el funcionamiento de los bombeos para proceder a su reparación preventiva en caso de consumo excesivo.

- Evaluar la eficiencia general de la red de riego en cuanto a distribución de agua, detectando pérdidas.

- Disponer de información sobre el agua teórica que necesitarían los cultivos y compararla con el agua real suministrada.

Este módulo genera indicadores de los siguientes tipos para poder cumplir su objetivo:

- Indicadores de rendimiento de uso del agua:

- De la eficiencia de distribución del agua

- Del consumo de agua de los cultivos

- De adecuación del suministro de agua a las necesidades de los cultivos

- Indicadores energéticos:

- De tipo individual por cada contrato eléctrico (mensuales y anuales)

- De tipo individual por cada estación de bombeo (de seguimiento mensual y de sus parámetros de funcionamiento instantáneo)

o De tipo general para toda la Comunidad de Regantes.

La figura siguiente muestra una pantalla de CORENET-COREGEST correspondiente al módulo de cálculo de indicadores de agua y energía.
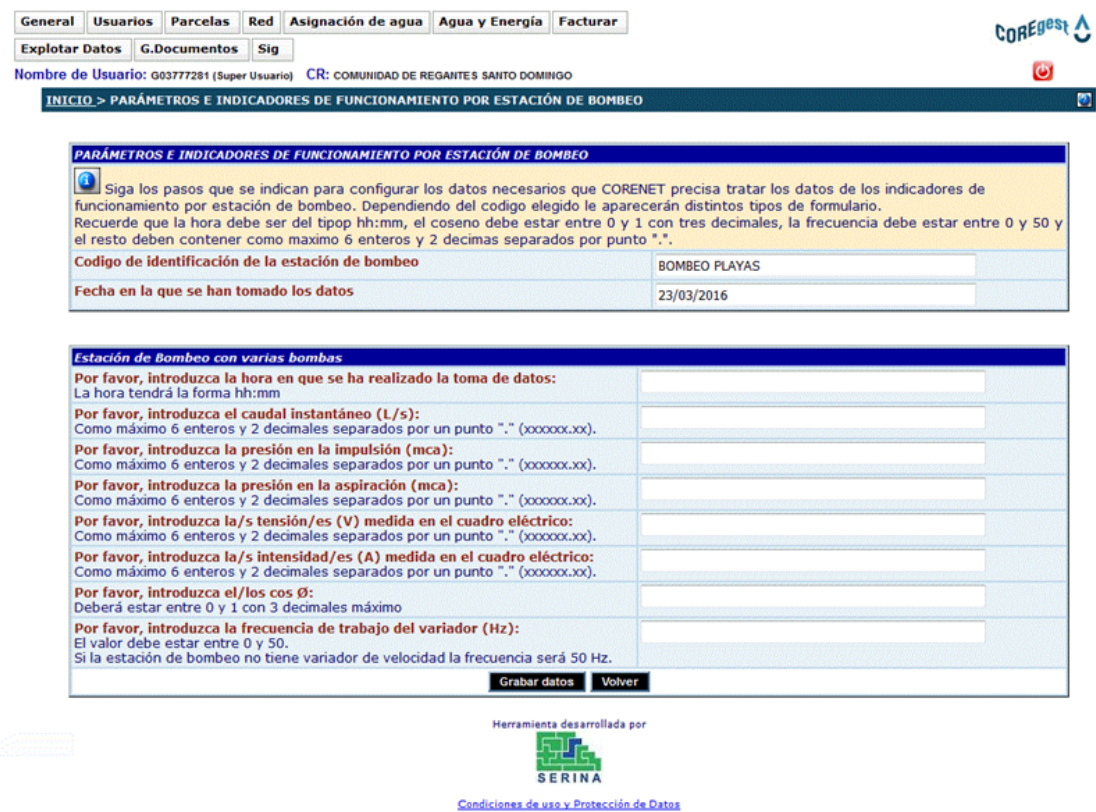
El funcionamiento del módulo requiere datos de entrada que se utilizan de modo exclusivo para el funcionamiento del mismo, siendo necesario establecer en la Comunidad procedimientos de gestión que los recojan. Algunos de estos datos son:

- Extensión temporal de la Campaña de Riego

- Datos sobre los contratos eléctricos existentes en la Comunidad

- Información sobre las estaciones de bombeo

- Coeficientes de cultivo (Kc) para los cultivos que se han recogido previamente en la declaración de cultivos de la Comunidad

- Información de facturas eléctricas

- Volumen de agua acumulado en las balsas

- Volumen de agua acumulado por tomas

- Datos agroclimáticos, evapotranspiración de referencia (ETo) y precipitación media durante la campaña

- Diversos parámetros de seguimiento de los bombeos

En el caso en que exista un SCADA en la Comunidad que recoja todos o algunos de estos datos, resulta posible que el módulo de agua-energía tome la información directamente desde el mismo, simplificando el proceso de recopilación e introducción manual de la información necesaria. Es conveniente considerar este aspecto de manera previa a la instalación del SCADA.

Adicionalmente el módulo necesita información no exclusiva y que se genera en otros procesos de gestión habituales y básicos de la Comunidad tales como la asignación de cupos de riego, declaración de cultivos, gestión de diferentes tipos de agua, etc. CORENETCOREGEST se encarga de transferir al módulo ésta información. Algunos ejemplos de la misma son los siguientes:

- Modelo de la red de riego para trazabilidad de agua.

- Parcelario actualizado con cultivos y superficies ocupadas por los mismos.

- Agua suministrada a cada cultivo por la Comunidad.

Por tanto, a la vista de lo anterior, hay que resaltar que el módulo de agua-energía se ha desarrollado en base a los resultados de investigación que lo han generado, habiéndose implementado dentro de un entorno de gestión CORENET-COREGEST, lo que permite normalizar su utilización dentro de los procesos habituales de gestión de la Comunidad de Regantes, evitando la introducción duplicada de datos para su funcionamiento.

\section{Caso 2: Predicción de necesidades de riego en la Comunidad de Regantes del Canal de Orellana. Colaboración CORENET-COREGEST y CEBAS-CSICIIVIA}

La Comunidad de Regantes del Canal de Orellana es una Comunidad muy extensa (42.000 ha) que se riega a partir del Canal de Orellana mediante una red de acequias recientemente modernizada por la SEIASA.

Como parte de las obras de modernización se ha realizado un inventario de la red de Riego así como la determinación del parcelario empleando referencias catastrales de la Comunidad. Este trabajo ha sido realizado por TRAGSA, y sus resultados han sido cargados en un SIG así como en CORENET-COREGEST. 
Para la gestión integral de la Comunidad se ha implantado CORENET-COREGEST para cubrir las siguientes áreas:

- Gestión Económica Administrativa

- Gestión y control de personal

- Gestión y control del agua

- Gestión de costes de mantenimiento.

Para posibilitar el control y la gestión del agua se han llevado a cabo las actuaciones siguientes:

- Implantación de elementos de medida consistentes en compuertas monitorizadas y caudalímetros en puntos críticos de la red que vuelcan sus datos de medida en un servidor situado en la Comunidad. Estos datos se incorporan también a CORENETCOREGEST a partir de un módulo software específicamente desarrollado al efecto. De esta manera, a través de la modelización de la red de riego existente en CORENTE-COREGEST es posible disponer de informes de uso del agua suministrada por las distintas acequias.

- Implantación de una metodología de determinación empírica de las necesidades de riego, basada en resultados de I+D del IVIA (Instituto Valenciano de Investigaciones Agrarias) y del CEBAS-CSIC en colaboración con el Centro de Investigaciones Científicas y Tecnológicas de Extremadura (CICyTEX). Esta metodología ha sido integrada en CORENET-COREGEST y para su funcionamiento utiliza datos que se recogen anualmente durante el proceso de declaración de cultivos y carga en CORENET-COREGEST el modelo de la red de riego para una trazabilidad del agua integrada en CORENET-COREGEST. Esta metodología empírica permite:

- Predecir las necesidades de riego en cada parcela y para cada cultivo en función de parámetros tales como la variedad del cultivo, el tipo de suelo, tipo de riego empleado, precipitación efectiva, etc.

- Predecir para cada acequia las necesidades de suministro de agua en función de los cultivos que se riegan y sus características.

Gracias a esta información es posible:

- Comparar el consumo de agua por acequias con el consumo teórico comprobando así si se está realizando una gestión adecuada del agua de riego.

- Sensibilizar al regante a través de la oficina electrónica del regante de CORENETCOREGEST para un uso del agua más racional.

- Permitir la programación de riegos en parcela basándose en criterios agronómicos de necesidades de los cultivos.

- Predecir las necesidades de riego de la Comunidad para apoyar las solicitudes de agua al Canal de Orellana, evitando las posibles peticiones excesivas.

La metodología empleada para el cálculo de las necesidades de riego ha sido la propuesta por la Organización de las Naciones Unidas para la Alimentación y la Agricultura (FAO), recogida en la publicación de la serie Riego y Drenaje 56; Evapotranspiración del cultivo: Guías para la determinación de los requerimientos de agua de los cultivos. (Allen et al. 1998), estimando las necesidades hídricas mediante un procedimiento que tiene en cuenta dos factores: 
1) Variables climáticas (temperatura y humedad del aire, radiación solar y velocidad del viento) que influyen en la demanda evaporativa o evapotranspiración de referencia (ETo)

2) Un factor ligado al cultivo, denominado coeficiente del cultivo (Kc).

Bajo este modelo, las necesidades hídricas o evapotranspiración del cultivo (ETc) se calculan como $\mathrm{ETc}=\mathrm{ETO}{ }^{*} \mathrm{Kc}$.

Los coeficientes de cultivo empleados para obtener las necesidades hídricas de los cultivos se resumen en los puntos siguientes:

- Coeficientes de cultivo (leñosos y hortícolas) expresados en función de los meses de año. Propuestos por Villalobos et al. en el "Estudio Sobre Necesidades de Agua de Riego de los Cultivos en la Zona del Transvase Tajo - Segura".

- Coeficientes de cultivo (leñosos, hortícolas y otros) divididos en tres etapas $\left(K_{\mathrm{c}}\right.$ inicial, $K_{c}$ medio y $K_{c}$ final), propuestos por Allen et al. (1998). Crop evapotranspiration. Guidelines for computing crop water requirements. Irrigation and Drainage Paper 48. FAO, Roma, Italia. En esta hoja también se presenta la altura y profundidad máxima de los cultivos, la fracción de agotamiento de agua permisible en el suelo, el umbral de salinidad máxima a partir del cual la producción se ve negativamente afectada y las necesidades de lavado.

- Coeficientes de cultivo (leñosos y hortícolas) expresados en función del periodo fenológico del cultivo. Obtenidos del Servicio de Información Agraria de la Región de Murcia (SIAM). La dirección web de acceso es http://siam.imida.es/apex/f?p=101:39:8087656247004068.

- Coeficientes de cultivo (leñosos, hortícolas y otros) expresados en función de los meses de año. Obtenidos del sistema de información agroclimática para el regadío (SIAR). La dirección web de acceso es http://www.magrama.gob.es/es/agua/temas/observatorio-del-regadioespanol/sistema-de-informacion-agroclimatica-para-el-regadio/.

- Coeficientes de cultivo leñosos expresados en función de los meses de año. Propuestos por el Instituto Valenciano de Investigaciones Agrarias (IVIA). La dirección web de acceso es http://riegos.ivia.es

- Coeficientes de cultivo hortícolas expresados en función de las semanas de cultivo. Propuestos por el Instituto Valenciano de Investigaciones Agrarias (IVIA). La dirección web de acceso es http://riegos.ivia.es

Hay que resaltar que para el cálculo de las dosificaciones óptimas, ha sido necesaria la utilización de los resultados de investigación del CEBAS/IVIA, integrándolos dentro del entorno CORENET-COREGEST. Para ello ha sido necesario modificar el procedimiento de declaración de cultivos para recopilar la información necesaria para el cálculo. Esta modificación sólo le supone un pequeño trabajo adicional a la Comunidad que se ve compensado por la información relativa al uso del agua que se genera.

\section{Caso 3: Optimización de turnos de riego bajo el punto de vista energético en la Comunidad de Regantes del Pantano Estrecho de Peñarroya. Colaboración CORENET-COREGEST y Universidad de Zaragoza.}

La Comunidad de Regantes del Pantano Estrecho de Peñarroya se extiende sobre $7.000 \mathrm{Ha}$ y riega mediante redes a presión con un gran consumo energético. Toma el agua del 
Pantano Estrecho de Peñarroya. Los usuarios riegan por turnos que se venían organizando por el propio personal de la Comunidad en función de la capacidad de la red.La Comunidad dispone de cinco sectores con riego automatizado de forma independiente en cada sector empleando sistemas de Motorola.

La Comunidad emplea CORENET-COREGEST para su gestión integral, habiéndose empleado un proceso de control de asignación del agua a los usuarios mediante la herramienta de gestión de cupos de agua de CORENET-COREGEST que limita el agua que puede suministrarse a cada usuario en función de la superficie de sus parcelas y otros parámetros.

Debido al elevado gasto económico que supone el consumo de energía, se tomó la decisión de establecer un mecanismo de concesión de los turnos de riego que no solamente tuviese en cuenta la capacidad de suministro de la red sino también la minimización del coste de la energía.

Para esto, se ha contado con la herramienta TELEGESTAR, desarrollada por la Universidad de Zaragoza (Aliod et al. 2015) cuyo objetivo consiste en realizar, a partir de las peticiones de riego registradas, una reordenación de las mismas que garantice un coste económico minimizado compatible con la capacidad de la red de riego.

La implantación de TELEGESTAR y los procedimientos de gestión asociados se han realizado con la colaboración de la empresa MOVAL Agroingeniería, especializada en la implantación de CORENET-COREGEST.

La implantación de TELEGESTAR ha requerido que la funcionalidad de esta herramienta se compatibilizase con CORENET-COREGEST de la forma siguiente:

- En CORENET-COREGEST se recogen las peticiones de riego realizadas por los regantes. Para poder tramitar una petición de riego, CORENET-COREGEST comprueba que el regante disponga de cupo de agua y no esté en situación de morosidad.

- Semanalmente se envía un archivo a los servidores de TELEGESTAR que contiene la información de peticiones de riego así como otra información adicional requerida por TELEGESTAR, tal como características de los contratos eléctricos, etc.

- TELEGESTAR procesa esta información y devuelve las peticiones de riego reordenados a COREGEST. Estas programaciones se incorporan a una herramienta que permite su edición manual por parte del personal de gestión de la Comunidad.

- Una vez se aprueba la reordenación, ésta se incorpora ya a COREGEST, detrayendo las peticiones de los cupos de agua y se envía a los SCADA para la apertura de las válvulas correspondientes.

\section{Conclusiones}

La integración de metodologías y herramientas desarrolladas por centros de I+D en los procesos de gestión de Comunidades de Regantes usuarias de CORENET-COREGEST, constituye una forma viable y práctica de transferir los resultados de investigación al usuario final (Comunidad de Regantes), así como lograr una mayor sostenibilidad del regadío a través de una disminución de costes asociados al uso del agua y la energía. Igualmente, permite la evaluación de estos resultados de investigación a través de la experiencia que se obtiene con su utilización en casos reales. 


\section{Bibliografía}

Aliod R., García S., Faci E., Paño J., Seral P., García A. (2015) "Algorithms and tools for optimum scheduling of on-demand irrigation for an effective energy cost reduction" ICID2015 Conference, Montpellier

Allen, R.G., Pereira, L.S., Raes, D., Smith, M., 1998. Crop evapotranspiration. Guidelines for computing crop water requirements. Irrigation and Drainage Paper 56, FAO, Rome, pp. 300.Shuttleworth, W.J. and Wallace, J.S., 2009. Calculating the water requirements of irrigated crops in Australia using the Matt-Shuttleworth approach. Transactions of the American Society of Agricultural and Biological Engineers 52 (6), 1895-1906.

Allen et al. (1998). Crop evapotranspiration. Guidelines for computing crop water requirements. Irrigation and Drainage Paper 48. FAO, Roma, Italia..

Francisco J. Villalobos, Francisco Orgaz y Elías Fereres. "Estudio Sobre Necesidades de Agua de Riego de los Cultivos en la Zona del Transvase Tajo - Segura"

Coeficientes de cultivo (leñosos y hortícolas) expresados en función del periodo fenológico del cultivo. Obtenidos del Servicio de Información Agraria de la Región de Murcia (SIAM). La dirección web de acceso es http://siam.imida.es/apex/f?p=101:39:8087656247004068.

Coeficientes de cultivo (leñosos, hortícolas y otros) expresados en función de los meses de año. Obtenidos del sistema de información agroclimática para el regadío (SIAR). La dirección web de acceso es http://www.magrama.gob.es/es/agua/temas/observatorio-delregadio-espanol/sistema-de-informacion-agroclimatica-para-el-regadio/.

Coeficientes de cultivo leñosos expresados en función de los meses de año. Propuestos por el Instituto Valenciano de Investigaciones Agrarias (IVIA). La dirección web de acceso es http://riegos.ivia.es

Coeficientes de cultivo hortícolas expresados en función de las semanas de cultivo. Propuestos por el Instituto Valenciano de Investigaciones Agrarias (IVIA). La dirección web de acceso es http://riegos.ivia.es 


\title{
D-04
}

\section{EL DRENAJE FRANCÉS PREFABRICADO, ITINERARIO PARA LA OBTENCIÓN DEL MARCADO CE}

\author{
Madurell Fernández, Josep. (1) (P), Navarro Granados, Jordi (2) (P)
}

${ }^{1}$ Ingeniero Técnico de Obras Públicas. Especialidad Construcciones Civiles col. n 9636 Responsable Técnico y Comercial del drenotube ${ }^{\circledR}$ en FUMOSO INDUSTRIAL S.A., areatecnica@drenotube.com.

2 Ingeniero Escuela Superior de Ingeniería Industrial y Aeronáutica de Terrassa ETSEIAT. Jefe de proyecto, Departamento de Apoyo a la Innovación. ITeC-Instituto de Tecnología de la Construcción de Cataluña, inavarro@itec.cat.

\section{Resumen}

El drenaje tipo francés o también llamado subsuperficial contribuye en numerosos aspectos en la mejora de las condiciones para la producción agrícola. El más común de sus usos es captar y conducir el exceso de agua del terreno. A este uso van asociadas mas aportaciones como acortar tiempos tanto de siembra como de recolección, mejorar la aireación en la zona radicular contribuyendo a minimizar enfermedades y también para remediación de suelos con exceso de agroquímicos o sales naturales. En este trabajo se describe el proceso seguido para dar el respaldo técnico al nuevo sistema de drenaje francés prefabricado (DFP en adelante) que en vez de grava de cantera utiliza un granulado de EPS. Demostrando su idoneidad en el ámbito de la Unión Europea con la certificación CE según ETA 15/0201. El DFP tiene aplicación en drenaje agrícola y también en obras lineales como ferrocarril, carreteras, autovías y autopistas, obras de urbanización, edificación residencial e industrial, paisajismo, instalaciones deportivas de césped natural, artificial etc. (con ejemplos en todos estos casos). Los DFP con árido de EPS se inventaron en USA y tienen más de 25 años de experiencia, también se utiliza en Canadá por proximidad al mercado americano, en Japón como drenaje agrícola y más recientemente en Turquía, Rusia e Italia para construcción. En España la instalación agrícola más antigua tiene 6 años.

\section{1) Introducción}

El sector del drenaje a día de hoy no dispone de un marco normativo homogéneo en la UE; cada territorio tiene su forma de hacer y en cierta medida protege dicha tradición.

Existe la posibilidad de realizar de forma voluntaria, según se establece en el Reglamento de Productos de la Construcción (RPC 305/2011), el ETA (European Technical Assessment), que es la vía para conseguir el marcado CE para aquellos productos innovadores que carecen de norma armonizada o se desvían de una norma armonizada. El ETA recoge las prestaciones del producto en relación a los requisitos que el RPC 305/2011 considera para las obras de construcción. La conformidad del producto con estas prestaciones permite la obtención del marcado CE.

Así se realizó el ETA 15/0201 y el marcado CE de este DFP en el que se basa este trabajo. 
El DFP se presenta habitualmente en unidades de 3 o 6 metros en formato barra, que tiene un tubo de polietileno corrugado y ranurado en el centro y una capa de granulado de EPS rodeando al tubo. Está protegido por un geotextil filtrante y se cierra el conjunto con una malla de polietileno. Las barras se conectan mediante acopladores de plástico o manguitos.

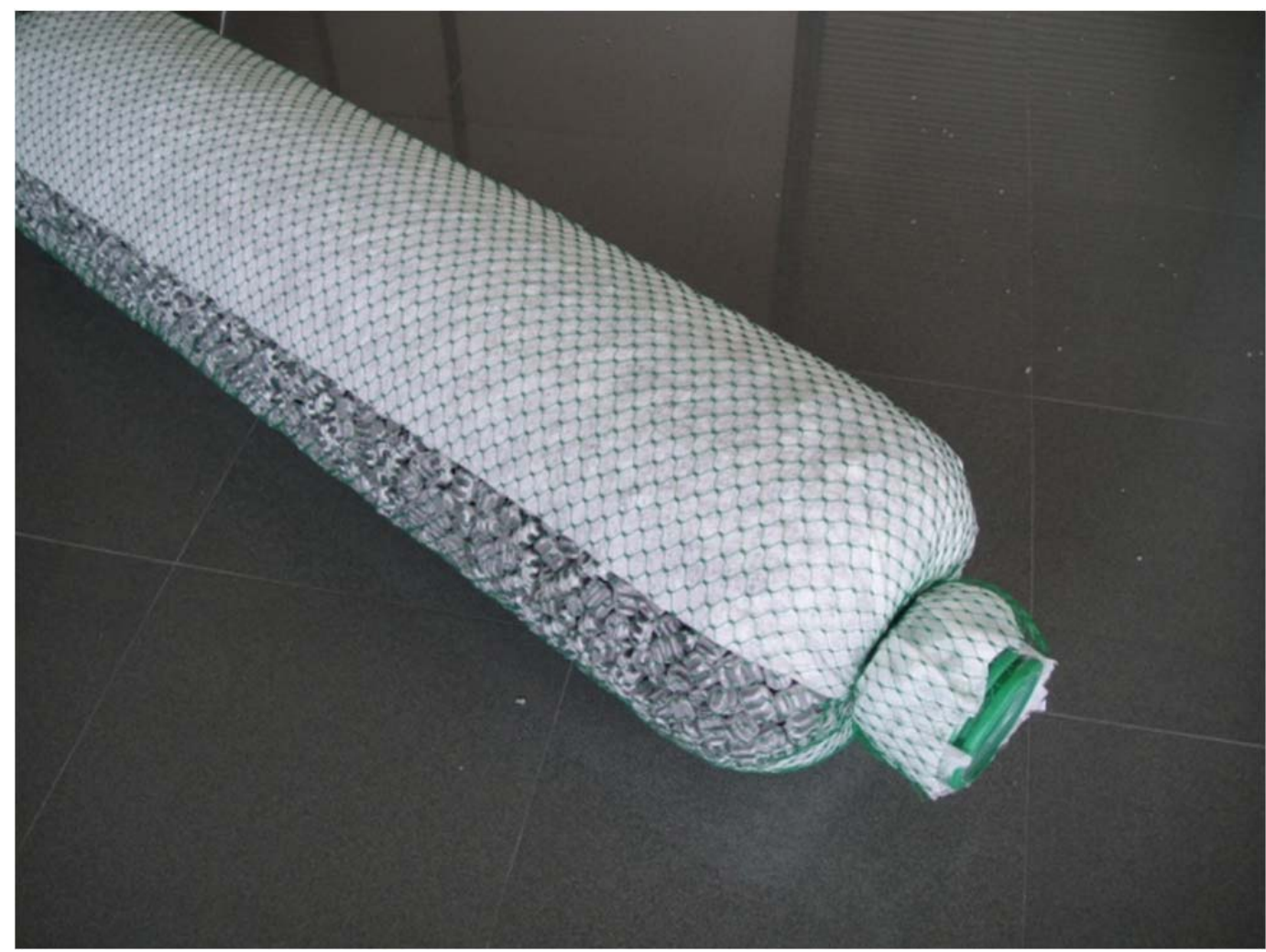

Imagen 1. Ejemplo de DFP

Las principales innovaciones del DFP, respecto a un drenaje tradicional son:

\section{En cuanto al dispositivo}

-geometría del dispositivo optimizada para mejorar el comportamiento hidráulico.

-el granulado de EPS de geometría específica que sustituye a la grava del drenaje francés convencional aporta:

-ligereza para fabricar un DFP para ser movido manualmente ( $>100$ veces más ligero que la grava), sin comprometer su componente resistente necesario para un amplio rango de usos para los que se ha ensayado ampliamente su comportamiento bajo presión.

- forma de granulado es más eficiente que la grava se estima en $30 \%$, por su forma y también porque el índice de huecos es del $50 \%$, superando ampliamente a cualquier material granular empleado en drenaje.

En las imágenes a continuación se detalla la forma más efectiva y principalmente utilizada, es el estándar americano y la que se ha certificado en Europa. Además se incluye el cuadro resumen con los resultados del estudio que aporta el fabricante americano en su documentación técnica, firmado por Mr. Donald Oderkirk, P.Eng, of BPI,pllc MEMPHIS, TENNESSEE de fecha 17/7/2001, en que analiza la capacidad drenante de varios materiales empleados en drenajes, de forma aislada y en conjunto. Tanto el planteamiento como los resultados son valorados por su facilidad de comprensión y el haber podido contrastar esos resultados con los ensayos realizados para este caso en la U.E. 


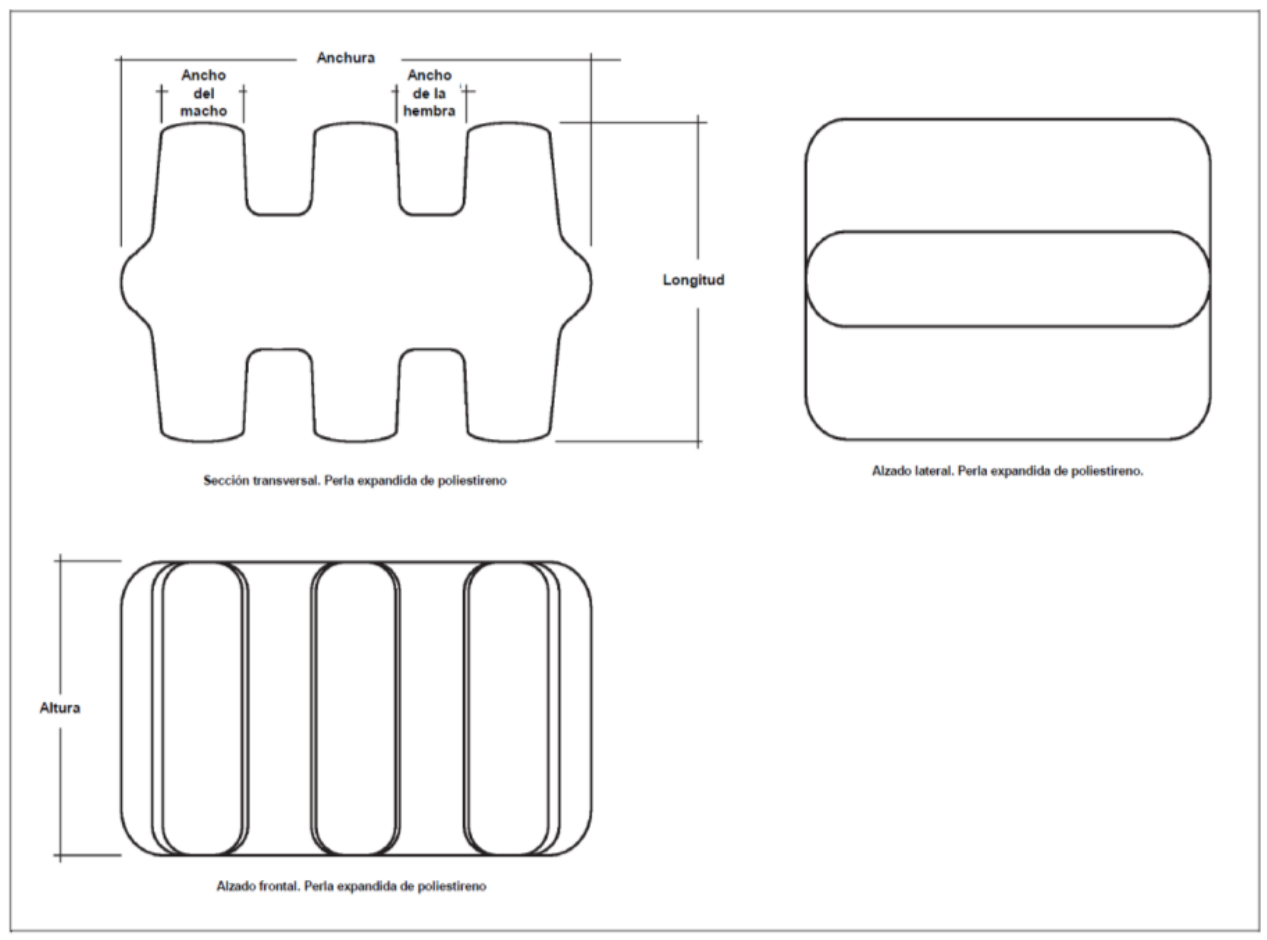

Imagen 2. Granulado de EPS

GRANULADO DE EPS
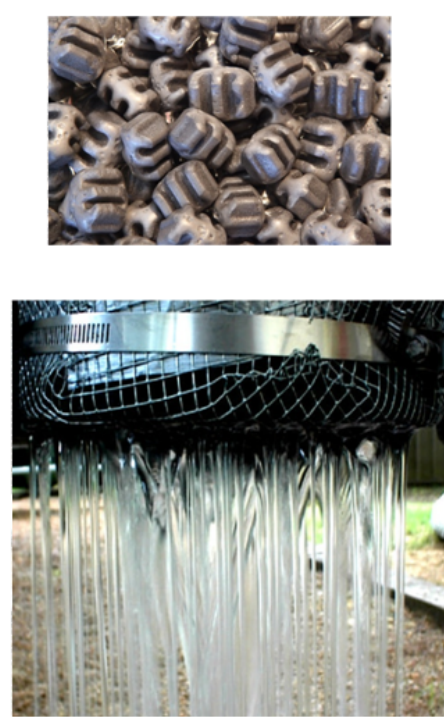

Caudal: 0,90 litros/segundo 30 veces más drenante que la gravilla 50 veces más drenante que la arena lavada
GRAVILLA
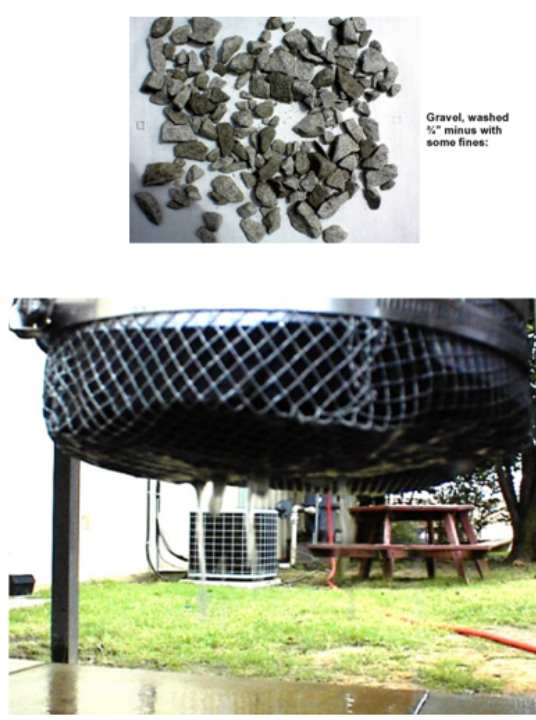

Caudal: 0,03 litros/segundo
ARENA LAVADA
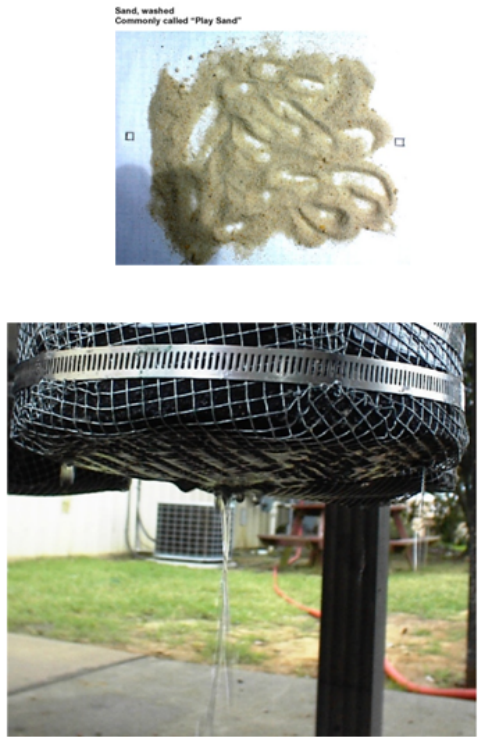

Caudal: 0,018 litros/segundo

Imagen 3. Comparativo de la conductividad hidráulica de materiales porosos para drenajes

\section{En cuanto a su instalación}

-Sistema modular para instalación manual con rendimiento de instalación $50 \%$ mejor.

-Sistema que proporciona máxima calidad y durabilidad, con el único compromiso de ejecutar la excavación según proyecto. Muy adecuado para agricultura pues tanto le vale a un particular como a un instalador. 


\section{2) Itinerario para alcanzar el CE de los productos innovadores}

Como producto innovador sin ningún precedente normativo armonizado a nivel europeo, la consecución del marcado CE para el drenaje francés prefabricado (DFP) implicó, según lo estipulado en el Artículo 21.1 c) del Reglamento 305/2011:

- La elaboración y aprobación europea de un DEE-Documento de Evaluación Europeo: este documento constituye la guía de evaluación europea de referencia para esta tipología de productos, que fue finalmente publicada en el DOUE (10/07/15). Este DEE 280001-00-0704 Preassembled line unit used for drainage or infiltration se encuentra a disposición de otros fabricantes de estos productos que deseen obtener el marcado CE.

- La elaboración del ETA 15/0201 para el drenaje certificado.

Esto permitió al fabricante realizar el marcado CE y Declaración de Prestaciones del producto. El marcado CE facilita el acceso del producto a los mercados europeos y da confianza técnica a los usuarios acerca de sus prestaciones.

A continuación se desarrollan con un poco más de detalle las bases y criterios conceptuales del Reglamento 305/2011 y se describe la metodología para alcanzar el marcado CE de un producto innovador.

\section{$\underline{\text { Introducción }}$}

Los productos de construcción se rigen por lo estipulado por el Reglamento de Productos de la Construcción (UE) 305/2011, que fija las condiciones para la comercialización de los productos de construcción y para la determinación según reglas armonizadas de las prestaciones de los productos y su posterior declaración.

Tiene por lo tanto la finalidad última de hacer posible un mercado único de productos de construcción en la Unión Europea, que comparta un lenguaje técnico único armonizado en cuanto a las prestaciones de los productos.

Se entiende como producto de construcción aquel que vaya a formar parte de las obras de construcción (lo cual incluye las obras de edificación y la ingeniería civil) de forma permanente y cuyas prestaciones influyan en las prestaciones de la obras relacionadas con los requisitos básicos de las mismas.

Los requisitos básicos de las obras contemplados por el Reglamento son:

(1) Resistencia mecánica y estabilidad

(2) Seguridad en caso de incendio

(3) Higiene, salud y medio ambiente

(4) Seguridad y accesibilidad de utilización

(5) Protección frente al ruido

(6) Ahorro de energía y aislamiento térmico

(7) Utilización sostenible de recursos naturales

Asimismo el Reglamento establece cuáles son los agentes económicos del proceso de comercialización (fabricantes, representantes autorizados, importadores, distribuidores) y las obligaciones de cada uno de ellos.

Todo ello se traduce en que los fabricantes deben proceder, siguiendo las metodologías armonizadas, al Marcado CE de sus productos y a la emisión de la Declaración de prestaciones (DoP) para la puesta en el mercado de sus productos.

Cabe no obstante diferenciar los dos casos siguientes: 
- Productos de construcción totalmente cubiertos por una norma armonizada existente: el fabricante está obligado a proceder al Marcado CE con arreglo a lo estipulado en la norma armonizada en cuestión.

- Productos de construcción innovadores, que carecen de norma armonizada o que se desvían de una norma armonizada existente: el fabricante no está obligado a proceder al Marcado CE. No obstante, si desea acceder al Marcado CE, esto es siempre posible por una de las vías que establece el artículo 21.1 cláusulas (b) y (c), es decir, por la vía de la elaboración de un documento ETE-Evaluación Técnica Europea. EI ETE podría definirse, en términos informales, como una "norma hecha a medida de los requisitos aplicables al producto y usos considerados", si bien, y a diferencia de una norma, el ETE es nominal (es para un producto comercial de un determinado fabricante).

La no obligatoriedad del marcado CE para estos productos innovadores y no normados no debe entenderse como que el fabricante de los mismos queda eximido de toda necesidad de demostrar las prestaciones de su producto. Por el contrario, debe demostrar frente al mercado y de forma fehaciente las prestaciones de su producto, máxime cuando éste puede ser un producto innovador que carece de precedentes técnicos y, por lo tanto, sus usuarios no disponen de referencias acerca de sus prestaciones y comportamiento técnico.

Para dar respuesta a esta necesidad de demostrar las prestaciones de su producto, el fabricante puede optar por un documento de evaluación de la idoneidad de ámbito nacional o puede optar por la certificación de ámbito europeo por la vía del Marcado CE basado en un ETE. De ahí que hablemos que el marcado CE vía ETE es voluntario para productos innovadores y no normados.

Naturalmente la certificación de ámbito europeo dará acceso a un mercado más amplio que una certificación de ámbito español, y sería la vía preferente en el caso que el fabricante se esté planteando comercializar el producto fuera de España.

\section{El marcado CE de productos innovadores y no normados por la vía del ETE}

Como ya se ha avanzado en la introducción, los productos huérfanos de norma europea armonizada pueden acceder al marcado CE por la vía de la elaboración de una Evaluación Técnica Europea-ETE, elaborada por parte de un Organismo de Evaluación Técnica-OET, oficialmente autorizado ${ }^{1}$.

Para la elaboración del ETE el fabricante se puede encontrar con los dos casos siguientes:

- El producto y usos objeto de la petición del ETE están cubiertos por una guía de evaluación europea ya existente, llamada DEE-Documento de Evaluación Europeo (caso b) del artículo 21.1 del Reglamento).

- El producto y usos objeto de la petición del ETE no están cubiertos por una guía de evaluación europea existente, por lo que es preciso desarrollar y consensuar a nivel europeo un DEE específico para la petición de ETE que formula el fabricante (caso c) del artículo 21.1 del Reglamento).

El primer caso implica la elaboración directa del ETE con arreglo al DEE existente, mientras que el segundo requiere de la elaboración previa de un DEE específico, hecho lo cual se aborda el ETE. Naturalmente el segundo caso implica un plazo de ejecución superior.

EI DEE lo desarrolla el OET que recibe la petición de ETE del fabricante, siendo este desarrollo llevado a cabo de forma colegiada con el resto de OETs miembros de la EOTA ${ }^{2}$ y

\footnotetext{
${ }^{1}$ El ITeC es un organismo autorizado desde el año 1997 para la emisión del ETE en todas las áreas de producto del Reglamento de Productos 305/2011.

${ }^{2}$ EOTA: European Organisation for Technical Assessment.
} 
según las directrices de la Comisión Europea, de acuerdo con la metodología del Anexo II del Reglamento.

En este DEE se tienen en cuenta los requisitos establecidos en las reglamentaciones nacionales de construcción aplicables al producto y uso en cuestión de los países europeos en los que el fabricante desea comercializar el producto en cuestión, así como los métodos armonizados para la verificación de dichos requisitos. Estos métodos pueden ser ensayos de laboratorio, verificaciones por cálculo o adopción de valores tabulados, en todos los casos tratándose de métodos que se han adoptado a nivel europeo como metodologías armonizadas.

EI DEE es un documento de carácter confidencial durante su elaboración y de carácter público una vez se aprueba el mismo, momento en el cual el DEE se publica en el DOUE (Diario Oficial de la Unión Europea) y pasa a estar disponible para otros fabricantes de productos incluidos en el alcance del DEE que deseen conseguir el marcado CE de sus productos.

\section{Las tareas de Verificación de la Constancia de Prestaciones}

Independientemente de si el producto dispone de norma armonizada o ha requerido de la elaboración de un ETE específico para él por carecer de norma armonizada de referencia, la última etapa para la consecución del marcado CE implica llevar a cabo las tareas de Verificación de la Constancia de Prestaciones (VCP).

En función del sistema de VCP que haya dictado la Comisión Europea para el producto (lo cual queda detallado en la norma o ETE de referencia), el grado de intervención de un organismo notificado será mayor o menor. Como regla general, en productos relacionados con el cumplimiento de requisitos de seguridad, el sistema VCP tiende a ser el más exigente (sistema $1 \circ 1+$ ), mientras que en el lado opuesto, para productos no relacionados 0 débilmente relacionados con el cumplimiento de requisitos de seguridad el sistema VCP tiende a ser el menos exigente (sistema 4).

Bajo cualquiera de los sistemas (desde el 1+ al 4) el fabricante debe implementar un sistema de control de producción en fábrica que asegure la constancia de las prestaciones del producto que el fabricante declarará frente al mercado.

La intervención de organismos notificados en tareas de certificación se limita a los sistemas $(1,1+$ y 2$)$, mientras que bajo el sistema 3 interviene un laboratorio notificado. Bajo el sistema 4 el fabricante puede llevar a cabo los ensayos por sus propios medios sin recurrir a un organismo notificado, siempre que estos medios respondan a los requisitos de la especificación armonizada de referencia.

Hechas estas tareas de VCP según el sistema que aplique en cada caso, el fabricante podrá:

- Marcar su producto CE.

- Emitir la Declaración de Prestaciones de su producto (DoP).

Esta DoP constituye el documento con carácter legal con el que el fabricante declara formalmente las prestaciones de su producto frente al mercado.

El marcado CE de los Drenajes franceses prefabricados (DFP) según el DEE 280001-000704 Preassembled line unit used for drainage or infiltration

EI DEE de referencia para el marcado CE de los DFP contempla la evaluación de los siguientes aspectos principales del comportamiento del producto drenante: 
- Deformación del producto frente a las cargas de uso (cargas permanentes del terreno y sobrecargas de uso debidas al tránsito de vehículos), así como deformación a largo plazo frente a las cargas permanentes (fluencia).

- Capacidad drenante del producto, tanto en situación de carga como en condiciones de ausencia de carga mecánica sobre el drenaje.

- Prestaciones del geotextil (resistencia al punzonamiento estático y dinámico).

- Durabilidad del drenaje.

En consecuencia, el marcado CE de un DFP ofrece al técnico usuario del producto la información técnica necesaria para poder valorar la adecuación del mismo a las condiciones de uso previstas en el proyecto, con arreglo a los requisitos reglamentarios que sean de aplicación al proyecto en cuestión.

\section{3) Conclusiones}

Un buen drenaje es tan importante o más que un buen riego, pero sigue siendo la asignatura pendiente en muchos lugares. Con el DFP el sector agrícola tiene la herramienta para mejorar las condiciones de la producción agrícola, desde poner a producir zonas no útiles por exceso de agua del terreno que provoca asfixia radicular a usos asociados a productividad como acortar tiempos tanto de siembra como de recolección, mejorar la aireación de la zona radicular contribuyendo a minimizar enfermedades y también para la remediación de suelos con exceso de agroquímicos o sales naturales.

La garantía de un buen drenaje no debe ser inferior a 25 años, el ETA 15/0201 asegura el cumplimiento de esta premisa.

El marcado CE, que es obligatorio para los productos que disponen de norma europea armonizada, es de carácter voluntario para los productos que carecen de norma. Para éstos, el marcado CE es siempre posible, y ofrece a los fabricantes una respuesta a los requisitos reglamentarios con los que se encuentran en Europa. Por ello el marcado CE facilita la entrada del producto innovador en estos mercados europeos, evitando llevar a cabo otras certificaciones nacionales país a país, necesarias en caso de carecer del marcado CE.

La inversión para alcanzar el marcado CE implica un notable esfuerzo financiero y técnico para la empresa; es muy importante anticiparse tanto como sea posible al requisito que se va a encontrar el producto en el mercado, para iniciar el procedimiento de certificación lo antes posible.

\section{4) Agradecimientos}

- La ASOCIACION ESPAÑOLA DE RIEGOS Y DRENAJES (AERYD), por su amabilidad y gran colaboración, permitiendo la presentación de este trabajo.

- Laboratorio AITEX (Asociación de Investigación de la Industria Textil), especialmente a los interlocutores durante las 2 fases de ensayos realizados Dña. Begoña Francés y D. Axel Ferrando.

- Laboratorio CECAM (centro de estudios de la construcción y análisis de materiales), por el trabajo de D. Lluís Rodríguez y la estrecha colaboración en desarrollar ensayos nuevos y la mejora continua obtenida.

- ITeC-Instituto de Tecnología de la Construcción de Cataluña, agente EOTA por su profesionalidad y enorme paciencia. D. Jordi Roher y D. Jordi Navarro. 


\section{5) Bibliografía}

- EOTA-European Organization for Technical Assessment (2014), Preassembled line unit used for drainage or infiltration, Official Journal of the European Union, Brussels.

- European Commission (2011), Regulation (EU) No 305/2011 of the European Parliament and the Council of 9 March 2011 laying down harmonised conditions for the marketing of construction products, Official Journal of the European Union 4.4.2011 L 88/5, Brussels.

- Flórez, P. (2015) Revista Aimcra n 121, 52-54

- Oderkirk, D. (2001). HYDRAULIC CONDUCTIVITY. An Evaluation of Drainage Media in Controlled Conditions, of BPI,pllc MEMPHIS, TENNESSEE 


\title{
D-05
}

\section{EVALUACIÓN DEL COSTE DE ELIMINAR LA SOBREEXPLOTACIÓN DEL ACUÍFERO "ALTO GUADALENTÍN" MEDIANTE UNA OFERTA PÚBLICA DE ADQUISICIÓN DE DERECHOS DE AGUA}

\author{
Martínez-Granados, D (1) (P), Calatrava, J (2)
}

\begin{abstract}
1 Investigador, E.T.S. de Ingeniería Agronómica, Universidad Politécnica de Cartagena, Paseo Alfonso XIII 48, 30203 Cartagena, david.martinez@upct.es

2 Profesor Titular de Universidad, E.T.S. de Ingeniería Agronómica, Universidad Politécnica de Cartagena, Paseo Alfonso XIII 48, 30203 Cartagena, j.calatrava@upct.es
\end{abstract}

\section{Resumen}

La sobreexplotación de acuíferos es uno de los principales problemas ambientales y de gestión del agua en el sureste de España. En algunas zonas, el reciente desarrollo de la desalinización supone una oportunidad para hacer frente a este problema a un menor coste social y económico. Este trabajo analiza el impacto económico de eliminar, mediante la adquisición pública de derechos de aguas subterráneas, la sobreexplotación en el acuífero Alto Guadalentín, uno de los casos más graves de degradación de recursos subterráneos de España. Dicho impacto se evalúa mediante un modelo de programación matemática que maximiza el margen neto derivado de utilizar las diferentes fuentes de suministro de agua disponibles en la zona para el regadío. Nuestros resultados muestran cómo la adquisición pública de derechos de aguas subterráneas tiene un impacto económico similar a la restricción de las extracciones del acuífero, si bien en el primer caso es la Administración la que soporta el coste de recuperación del acuífero, mientras que en el segundo éste coste recae sobre los agricultores, lo que convierte a esta última en una medida más impopular y con un mayor coste político. En ambos casos, la disponibilidad de recursos desalinizados reduce significativamente este impacto, ya que los agricultores pueden sustituir recursos subterráneos por desalinizados.

PALABRAS CLAVE: Aguas subterráneas, cuenca del Segura, economía del agua, demanda de agua, programación matemática, regadío.

\section{1- Introducción}

La sobreexplotación de acuíferos es uno de los principales problemas ambientales y de gestión del agua en el Mediterráneo. En el caso de la cuenca del Segura, una de las regiones agrícolas más productivas de España, la expansión de la horticultura intensiva durante las últimas décadas ha incrementado las presiones sobre los recursos subterráneos, una de las principales fuente de suministro de agua de la cuenca, haciendo que la sobreexplotación haya alcanzado proporciones alarmantes en muchos acuíferos, lo que pone en riesgo el cumplimiento con los objetivos medioambientales establecidos para 2027 en cumplimiento con la Directiva Marco del Agua (DMA). Uno de los casos más graves de sobreexplotación y degradación de los recursos subterráneos, no solo de España sino de toda Europa, es el acuífero Alto Guadalentín, situado en los municipios de Lorca y Puerto Lumbreras en el suroeste de la cuenca del Segura.

Aunque la DMA pone el acento en la tarificación como instrumento para la gestión de los recursos hídricos, en general, en situaciones de sobreexplotación de acuíferos, no suele 
recurrirse a establecer tarifas o tasas sobre el agua, sino a la ordenación de los recursos subterráneos mediante cuotas fijas de bombeo, restricciones o zonificaciones. Diversos trabajos han analizado otras opciones como la restricción de extracciones mediante planes de gestión que incluyen el establecimiento de cuotas y su intercambio en mercados o bancos de agua, los pagos por reducir el consumo, la compra de derechos o la cooperación entre los usuarios del recurso (Iglesias, 2002; Hellegers y van lerland, 2003; Albiac et al., 2006 y 2008; Carmona et al., 2011; Esteban y Albiac, 2011).

La compra de derechos de agua de riego ha sido uno de los instrumentos más aplicados en España, a través del Plan Especial del Alto Guadiana y los centros de intercambio de derechos de uso del agua de las cuencas del Júcar y Segura (Calatrava y Gómez-Ramos, 2009; Garrido et al., 2013). La reforma de 1999 de la Ley de Aguas (Ley 46/1999) contemplaba la posibilidad de que los organismos de cuenca creasen los denominados Centros de Intercambio de Derechos (CID). A través de estos, los organismos de cuenca podrían realizar ofertas públicas de adquisición de derechos (OPAD) a los titulares interesados en ceder temporal o permanentemente sus concesiones para proceder posteriormente a su cesión a otros titulares (Calatrava y Gómez-Ramos, 2009). En el espíritu inicial de la Ley 46/1999 estaba que los CID funcionasen como mecanismo para agregar y poner en contacto oferta y demanda de agua, a la manera de los Bancos de Agua que funcionan en los Estados Unidos (Garrido et al., 2013), no permitiéndose que pudiesen retener los derechos adquiridos y obligándoles a ofertar todos, limitándose por tanto su papel al de intermediarios.

Los primeros CID se crearon en las cuencas hidrográficas del Guadiana, Júcar y Segura en 2004. Pese a ello, no funcionaron hasta que, con el inicio de la sequía de 2005-2008, el RDL 9/2006 reforzó su eficacia para que pudiesen dar respuesta también a otras demandas, principalmente ambientales. En concreto, además de ceder recursos a otros usuarios (objetivo inicial), los CID podrían también dedicar derechos adquiridos para usos ambientales o cederlos a las Comunidades Autónomas. De hecho, todos los CID han funcionado solo como adquirientes de agua o de derechos que no han sido vendidos a otros usuarios (Garrido et al., 2013). Los recursos adquiridos se han cedido a otros usuarios en forma de nuevas concesiones (caso del Guadiana) o (casos del Segura y Júcar) se han utilizado para mantener caudales ecológicos en épocas de sequía (Rey et al., 2014). Por lo tanto, la principal utilidad de los CID ha sido la protección ambiental, de manera similar al caso de los bancos públicos del agua de California, Australia o Canadá (Garrido et al., 2013; Calatrava y Martínez-Granados, 2016).

En el caso de la cuenca del Segura, la CHS lanzó dos OPAD en 2007 y 2008 con el objetivo de crear una reserva estratégica para garantizar los caudales ambientales en los ríos Segura y Mundo, en la parte alta de la cuenca. En ambos casos, el presupuesto de la OPAD era de 700.000 euros y la compensación máxima a pagar por la cesión de derechos era 0,18 $€ / \mathrm{m}^{3}$. Todos los caudales adquiridos se destinaron a usos ambientales (Garrido et al., 2013). Al igual que en el caso del Júcar, el éxito de las OPAD del Segura fue moderado, ya que no se llegó a agotar el presupuesto inicialmente establecido por falta de suficientes oferentes (Garrido et al., 2013; Rey et al., 2014). En opinión de Calatrava y Martínez-Granados (2016), el precio no era lo suficientemente atractivo, ya que apenas supera el valor marginal del agua en la zona calculado por Calatrava y Martínez-Granados (2012).

La adquisición de derechos de agua tiene la ventaja de que permite reducir permanentemente las extracciones, además de ser menos conflictivo que establecer restricciones o cuotas de consumo u otras políticas de "mando y control". Sin embargo, tiene un elevado coste presupuestario para la Administración y, al reducir el uso del agua, puede tener un importante impacto sobre el empleo y la economía de las zonas rurales. Carmona et al. (2011) muestran como, para conseguir una recuperación parcial de los niveles de los acuíferos en la cuenca del Alto Guadiana, es necesario restringir la disponibilidad de agua a 
los agricultores y establecer un precio de compra de los derechos de agua elevado. Sin embargo, el cumplimiento de las restricciones de agua reducirá los ingresos agrícolas sino se adoptan medidas adicionales para compensar dichas pérdidas.

A diferencia de otras zonas en las que se ha utilizado este instrumento, como es el caso del Alto Guadiana, en el caso del Alto Guadalentín, el reciente desarrollo de recursos desalinizados supone una oportunidad para hacer frente a este problema a un menor coste social y económico. El uso de recursos desalinizados es una de las opciones barajadas por la Administración hidráulica para hacer frente a la escasez de agua en zonas del sureste de España (Downward y Taylor, 2007), siendo también una de las defendidas por Albiac et al. (2006 y 2008) por presentar menores costes privados y sociales que otras alternativas. Sin embargo, el uso de recursos desalinizados puede no suponer en la práctica una alternativa efectiva para reducir la sobreexplotación de los acuíferos, debido a que el coste de los recursos provenientes de la desalinización es muy superior al de los subterráneos. Incluso en zonas en las que la agricultura puede asumir el coste de la desalinización, existe un incentivo para optar por la extracción de aguas subterráneas a un menor coste.

En este sentido, el objetivo de este trabajo es evaluar el impacto económico de eliminar la sobreexplotación en el acuífero Alto Guadalentín mediante la compra pública de derechos de aguas subterráneas, teniendo en cuenta la futura disponibilidad de recursos procedentes de la desalinización de agua de mar. Se analiza también la opción de restringir las extracciones de recursos subterráneos a su fracción renovable mediante el establecimiento de cuotas, una opción que ha sido considerada por la Administración pero que por su complejidad institucional y por su elevado impacto económico ha sido aparcada en beneficio de la opción del aporte de nuevos recursos externos a la zona.

\section{2- Regadío y sobreexplotación en el acuífero Alto Guadalentín}

El acuífero Alto Guadalentín está situado en el Valle del Guadalentín que se ubica en el suroeste de la cuenca del Segura en torno al río Guadalentín, un río-rambla que es el afluente más grande de la margen derecha del río Segura (Figura 1). El Guadalentín constituye una de las regiones agrícolas más productivas del país. La importancia del sector agrario en la zona se debe en gran medida a sus características climáticas, entre el clima Mediterráneo y el semiárido, que la convierten en un marco idóneo para la producción agrícola temprana (Calatrava et al., 2011). Sin embargo, esta zona presenta unas precipitaciones escasas, con medias que no alcanzan los $350 \mathrm{~mm} / \mathrm{año}$, provocando un fuerte déficit hídrico y frecuentes periodos secos.

La escasez estructural de agua es especialmente grave en la zona. Aunque la cuenca del Segura recibe recursos externos a través del acueducto Tajo-Segura (ATS), la notable expansión de la superficie de regadío desde que el ATS comenzase a funcionar en 1980 ha ocasionado un déficit crónico de agua en la cuenca del Segura en general y en el Alto Guadalentín en particular.

De acuerdo con nuestras estimaciones a partir de información obtenida del Sistema de Información Geográfica de la Confederación Hidrográfica del Segura (https://www.chsegura.es), la superficie total de regadío sobre el acuífero Alto Guadalentín supone 36.026 hectáreas, de las cuales 21.107 pueden ser regadas. La demanda agraria de agua asciende a 116,42 $\mathrm{hm}^{3} / a n ̃ o$, mientras que la disponibilidad de agua teórica de las

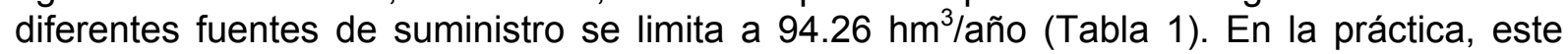
desequilibrio entre recursos y demandas es mayor. 


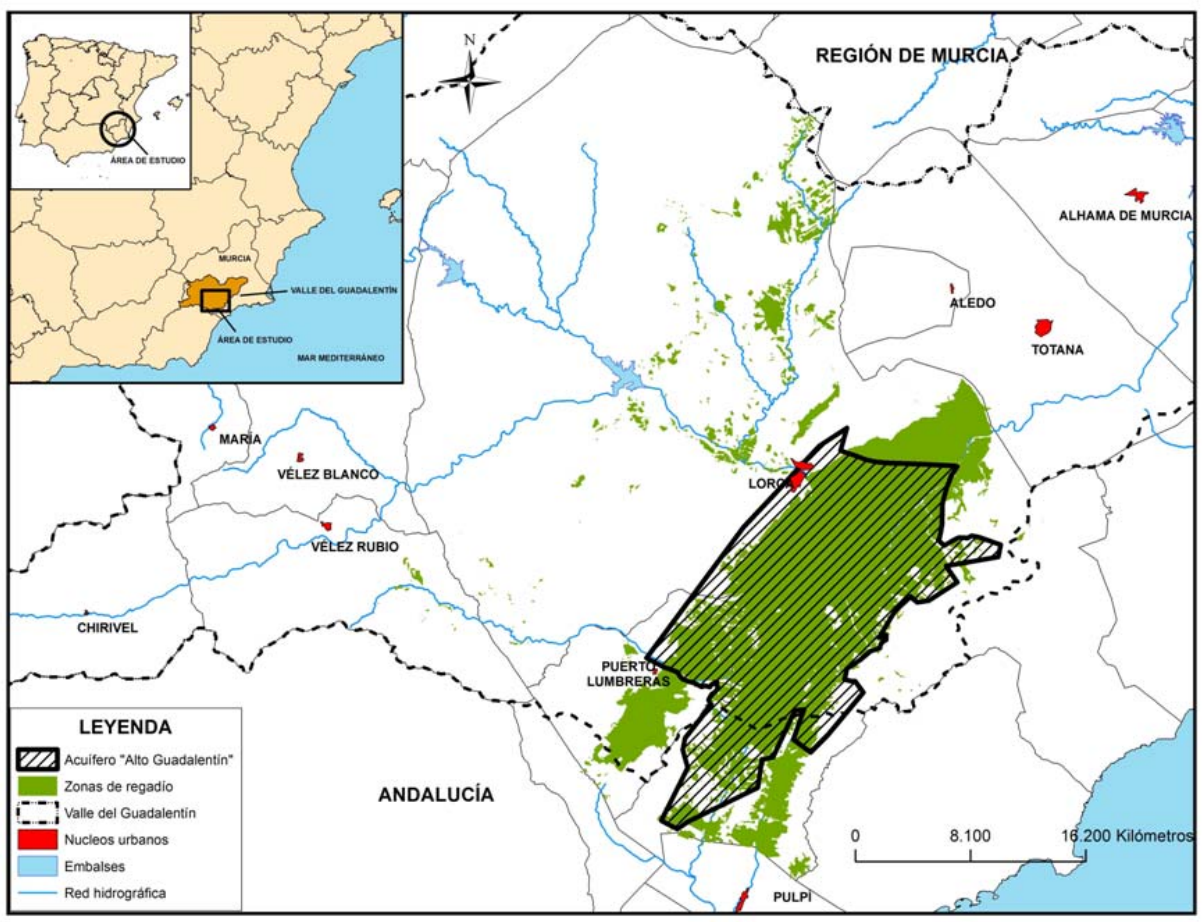

Figura 1. Ubicación y zonas regables del acuífero Alto Guadalentín.

Elaboración propia a partir del Sistema de Información Geográfica de la Confederación Hidrográfica del Segura (https://www.chsegura.es).

La disponibilidad teórica de agua se basa en los derechos y concesiones de agua existentes. En la práctica, la disponibilidad de recursos renovables se ha reducido desde los años ochenta del pasado siglo y el trasvase Tajo-Segura solo suministra una media del $60 \%$ de la cantidad anual máxima transferible para regadío. Por lo tanto, los recursos realmente disponibles se estiman en $74,35 \mathrm{hm}^{3} / a n ̃ o$, sin contar los recursos procedentes en un futuro próximo de la desalinizadora de Águilas (Tabla 1). Estos recursos actualmente utilizados cubren solo el $64 \%$ de la demanda agraria $\left(116,42 \mathrm{hm}^{3} / \mathrm{año}\right)$, lo que supone un déficit de

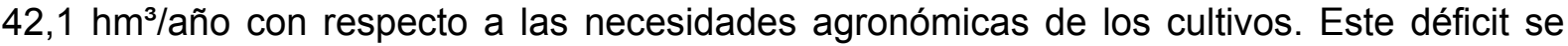
cubre en parte mediante la reducción de la superficie regada y en parte mediante la infradotación de los cultivos.

Tabla 1. Disponibilidad y coste de los recursos hídricos en el acuífero "Alto Guadalentín"

\begin{tabular}{|c|c|c|c|}
\hline Origen del recurso & $\begin{array}{l}\text { Derechos de agua } \\
\text { ( } \mathrm{hm}^{3} / \text { año) }\end{array}$ & $\begin{array}{l}\text { Recursos } \\
\text { disponibles } \\
\left(\mathrm{hm}^{3} / \text { año) }\right.\end{array}$ & $\begin{array}{c}\text { Coste del agua } \\
\left(€ / \mathrm{m}^{3}\right)\end{array}$ \\
\hline Superficiales & 13,90 & 11,10 & 0,050 \\
\hline Trasvase Tajo-Segura & 37,16 & 22,25 & 0.127 \\
\hline Reutilización & 4,70 & 4,70 & 0,080 \\
\hline Subterráneas & 38,50 & 36,30 & 0,240 \\
\hline Desalinización & - & 28,00 & 0,445 \\
\hline \multirow[t]{2}{*}{ Total } & $94,26^{*}$ & $74,35^{\star}$ & \\
\hline & renovables $\left(\mathrm{hm}^{3} / \mathrm{año}\right)$ & 27.60 & \\
\hline
\end{tabular}

Fuente: Elaboración propia a partir del Sistema de Información Geográfica de la Confederación Hidrográfica del Segura (https://www.chsegura.es) y de una encuesta realizada en 2012 a las comunidades de regantes de la zona. $\left.{ }^{*}\right)$ No incluye los recursos procedentes de la desalación. 
En estas circunstancias, y dada la elevada rentabilidad del regadío en la zona, existe un incentivo muy grande para explotar los recursos subterráneos de la zona de manera insostenible, hasta tal punto que las aportaciones de aguas subterráneas suponen 36,3 $\mathrm{hm}^{3} / a n ̃ o$, de los cuales $27,6 \mathrm{hm}^{3} /$ año son recursos no renovables (Tabla 1). Por lo tanto, si

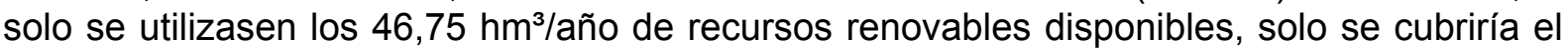
$40 \%$ de la demanda agraria de agua.

El uso masivo de recursos subterráneos durante las últimas décadas ha causado un serio problema de agotamiento del acuífero Alto Guadalentín, uno de los casos más graves de sobreexplotación de Europa. En base a la profundidad media del acuífero y a sus niveles piezométricos (CHS, 2008), estimamos que las extracciones no renovables acumuladas desde finales de los años setenta del pasado siglo suponen aproximadamente un $60 \%$ de la capacidad del acuífero. Además, el notable descenso de los niveles piezométricos ha incrementado los costes de bombeo en la zona y degradado la calidad del agua.

\section{3- Evaluación económica de los diferentes escenarios}

El impacto económico de los diferentes escenarios analizados se evalúa utilizando un modelo de programación matemática que maximiza el margen neto derivado de utilizar las diferentes fuentes de suministro de agua disponibles en la zona para el regadío y que permite simular el impacto económico de cada escenario.

La función objetivo del modelo es:

Sujeto a:

Donde o representa cada uno de los orígenes del agua disponible (superficial, trasvase Tajo-Segura, residual depurada, subterránea y desalinizada); wu es la cantidad de agua total utilizada en la zona contando todas las fuentes de suministro o ( $\left.\mathrm{hm}^{3} / a n ̃ o\right) ; M N(W u)$ es una función que relaciona la cantidad de agua utilizada en la zona con el margen neto generado en la misma (euros); $p w_{o}$ es el coste medio de cada fuente de suministro $o$ (euros $\left./ \mathrm{m}^{3} / a n ̃ o\right) ; ~ w u_{o}$ es la cantidad de agua utilizada en la zona de cada fuente de suministro $o$ ( $\mathrm{hm}^{3} / \mathrm{anno}$ ); dot $\mathrm{d}_{\mathrm{o}}$ es la cantidad de agua disponible de cada fuente de suministro o; $p c$ es el precio de compra de derechos de aguas subterráneas (euros $\left./ \mathrm{m}^{3} / a n ̃ o\right) ; ~ w v_{\text {subt }}$ es la cantidad de agua subterránea cuyos derechos son adquiridos por la administración ( $\left.\mathrm{hm}^{3} / a n ̃ o\right)$. Las variables de decisión del modelo son la cantidad de agua utilizada de cada fuente de suministro $w u_{o}$ (y por lo tanto $w u$ ) y la cantidad de derechos de aguas subterráneas adquiridas por la autoridad de cuenca ( $\left.w v_{\text {subt }}\right)$.

La función objetivo [1] maximiza el margen neto derivado de utilizar las diferentes fuentes de suministro de agua de regadío disponibles en la zona de estudio. La restricción [2] calcula la cantidad total de agua utilizada $\left(w_{u}\right)$ como la suma de las cantidades de agua utilizadas de 
cada origen $\left(w u_{0}\right)$. El conjunto de restricciones [3] restringe la cantidad de agua utilizada de cada origen $\left(w u_{0}\right)$ a su disponibilidad. La restricción [4] contabiliza las ventas de derechos de agua e impide que sean utilizados. Finalmente, las expresiones [5] y [6] son restricciones de no negatividad de las variables de decisión $\left(w u_{0}\right.$ y $\left.w v_{\text {subt }}\right)$.

El modelo se ejecuta para cada posible valor de $p c$ y se identifica el valor de dicho parámetro que permite eliminar los bombeos no renovables de agua. A partir de los valores óptimos de las variables de decisión $\left(w u_{0}{ }^{*}, w v_{\text {subt }}^{*}\right)$ obtenidos se calculan una serie de indicadores económicos (valor de la producción, margen neto, empleo agrario, coste para la Administración) que permitan evaluar los diferentes escenarios de gestión propuestos. Los indicadores económicos se han calculado de la siguiente forma:

- Valor de la producción agraria:

- Margen neto:

- Empleo agrario:

- Coste a asumir por la Administración:

Donde: $P F A(w u)$ es una función que liga la cantidad de agua utilizada en la zona con el valor de la producción agrícola de regadío generado en la misma (euros); $M N(w U)$ es una función que liga la cantidad de agua utilizada en la zona con el margen neto generado (euros); $M O(w u)$ es una función que liga la cantidad de agua utilizada en la zona con la mano de obra agraria utilizada (euros). Estas tres funciones provienen de un modelo no-lineal de optimización que simula las decisiones de asignación de tierra y agua entre cultivos en el regadío de la cuenca del Segura y genera indicadores económicos de uso del agua. Una descripción detallada de este modelo, incluyendo su estructura matemática, sus coeficientes técnicos y económicos y su calibración, puede verse en Martínez-Granados et al. (2011) y Calatrava y Martínez-Granados (2012).

En el caso del escenario de no intervención el modelo se modifica tomando valores nulos para el precio de compra del derecho y la cantidad de derechos adquiridos $\left(p c=0 ; w v_{\text {subt }}=\right.$ $0)$. En el caso del escenario de prohibición de extracciones, además de lo anterior, el uso de aguas subterráneas se restringe a su fracción renovable substituyendo la restricción [4] por: de recursos subterráneos $\left(\mathrm{hm}^{3} / \mathrm{año}\right)$. donde nonrenov son las extracciones medias no renovables

\section{4- Resultados}

En primer lugar, los resultados para el escenario de "no intervención" (segunda columna de la Tabla 2) muestran cómo, debido a la elevada demanda de agua de riego en la zona, se utilizarían aproximadamente la cuarta parte de los recursos desalinizados disponibles (en concreto, 7,44 de $28 \mathrm{hm}^{3}$ anuales), pese a que su precio es comparativamente superior (ver Tabla 1). Sin embargo, este incremento en el uso de recursos desalinizados no supondría una reducción en las extracciones del acuífero debido al notable grado de escasez de agua de la zona. En esta situación, el valor de la producción agraria es de aproximadamente 202 millones de euros/año, el margen neto de 64,6 millones de euros/año y el empleo agrario generado de 1,263 millones de jornales anuales.

Una opción para eliminar la sobreexplotación de acuíferos es limitar el uso de recursos subterráneos a la fracción renovable de los bombeos. En una situación de no disponibilidad de recursos desalinizados, el impacto económico sería notable, ya que los recursos subterráneos no renovables suponen más de una tercio de la disponibilidad media de agua 
para regadío en la zona. Sin embargo, puesto que en el futuro inmediato los regantes podrán disponer de recursos procedentes de la desalinización, el impacto de prohibir las extracciones no renovables se vería limitado, ya que los regantes podrían sustituir el agua subterránea por agua desalinizada y casi todos los recursos desalinizados disponibles se utilizarían pese a ser más caros que los subterráneos. Como se muestra en la tercera columna de la Tabla 2, en este escenario se reduce el valor de la producción agraria en 12,5 millones de euros/año (un 6,2\%), el margen neto agrario en 6 millones de euros/año (un $9,2 \%$ ) y el empleo agrario en 113.900 jornales al año (un 9,0\%). La disponibilidad de agua desalinizada compensa en parte el impacto negativo que la restricción de las extracciones de recursos subterráneos tendría para el sector agrario de la zona.

Tabla 2. Impacto económico de la eliminación de la sobreexplotación en el acuífero "Alto Guadalentín" mediante la restricción de bombeos y la compra pública de derechos

\begin{tabular}{|c|c|c|c|}
\hline & $\begin{array}{l}\text { No intervención } \\
\text { (situación actual) }\end{array}$ & $\begin{array}{l}\text { Prohibición de } \\
\text { extracciones no } \\
\text { renovables }\end{array}$ & $\begin{array}{l}\text { Adquisición de } \\
\text { derechos }(0,38 \\
\left.\text { euros } / \mathrm{m}^{3} / \mathrm{año}\right)\end{array}$ \\
\hline Uso total de agua ( $\left.\mathrm{hm}^{3} / a n ̃ o\right)$ & 81,88 & \multicolumn{2}{|c|}{$\begin{array}{c}74,44 \\
(-9,1 \%) \\
\end{array}$} \\
\hline $\begin{array}{l}\text { Uso de aguas subterráneas } \\
\left.\text { ( } \mathrm{hm}^{3} / a n ̃ o\right)\end{array}$ & 36,32 & \multicolumn{2}{|c|}{$\begin{array}{c}8,72 \\
(-76,0 \%)\end{array}$} \\
\hline $\begin{array}{l}\text { Reducción de extracciones } \\
\left(\mathrm{hm}^{3} / \mathrm{anno}\right)\end{array}$ & 0,00 & \multicolumn{2}{|c|}{27,60} \\
\hline $\begin{array}{l}\text { Uso de agua desalinizada } \\
\text { ( } \mathrm{hm}^{3} \text { /año) }\end{array}$ & 7,44 & \multicolumn{2}{|c|}{$\begin{array}{c}27,60 \\
(+271,0 \%) \\
\end{array}$} \\
\hline $\begin{array}{l}\text { Producción agraria (millones } \\
\text { de euros/año) }\end{array}$ & 201,97 & \multicolumn{2}{|c|}{$\begin{array}{l}189,51 \\
(-6,2 \%) \\
\end{array}$} \\
\hline $\begin{array}{l}\text { Margen neto agrario (millones } \\
\text { de euros/año) }\end{array}$ & 64,59 & $\begin{array}{c}58,62 \\
(-9,2 \%)\end{array}$ & $\begin{array}{c}69,11 \\
(+6,9 \%)\end{array}$ \\
\hline $\begin{array}{l}\text { Empleo agrario }\left(10^{4}\right. \\
\text { jornales/año) }\end{array}$ & 126,26 & \multicolumn{2}{|c|}{$\begin{array}{l}114,87 \\
(-9,0 \%) \\
\end{array}$} \\
\hline $\begin{array}{l}\text { Coste presupuestario público } \\
\text { (millones de euros/año) }\end{array}$ & 0,00 & 0,00 & 10,47 \\
\hline
\end{tabular}

Fuente: Elaboración propia. Cambio porcentual con respecto a la situación actual entre paréntesis.

De manera similar, la adquisición pública de derechos tendría un impacto menor de lo que sería esperado, al existir la posibilidad de sustituir derechos vendidos por recursos desalados (cuarta columna de la Tabla 2). La Figura 2 muestra cómo, a medida que se incrementa el precio de adquisición del derecho de agua subterránea, se reducen las extracciones (que son sustituidas en gran medida por recursos desalinizados) y, paralelamente, disminuye el valor de la producción agraria, mientras que se incrementan tanto el margen neto de los agricultores como el coste presupuestario soportado por la Administración derivado de la compra de los derechos. El empleo agrario evoluciona en paralelo al valor de la producción agraria, por lo que en la Figura 2 solo se muestra esta última para simplificar la figura.

La eliminación de la sobreexplotación en el acuífero Alto Guadalentín mediante la adquisición pública de derechos de agua exigiría alcanzar un precio de compra de 0,38 $€ / \mathrm{m}^{3} / a n ̃ o$, medido como una coste anual equivalente. Como consecuencia, el impacto en términos de producción y empleo agrario sería el mismo que en el escenario anterior. Por el contrario, en lugar de reducir el margen neto, la adquisición de derechos supondría un incremento de la rentabilidad privada de los agricultores de 4,5 millones de euros anuales (un 6,9\%), si bien a costa de un gasto público de 10,5 millones de euros anuales. Si se capitaliza dicho coste anual considerando un tipo de interés de entre 0,03 y 0,05 se obtiene un coste total de la OPAD de entre 210 y 350 millones de euros respectivamente. 


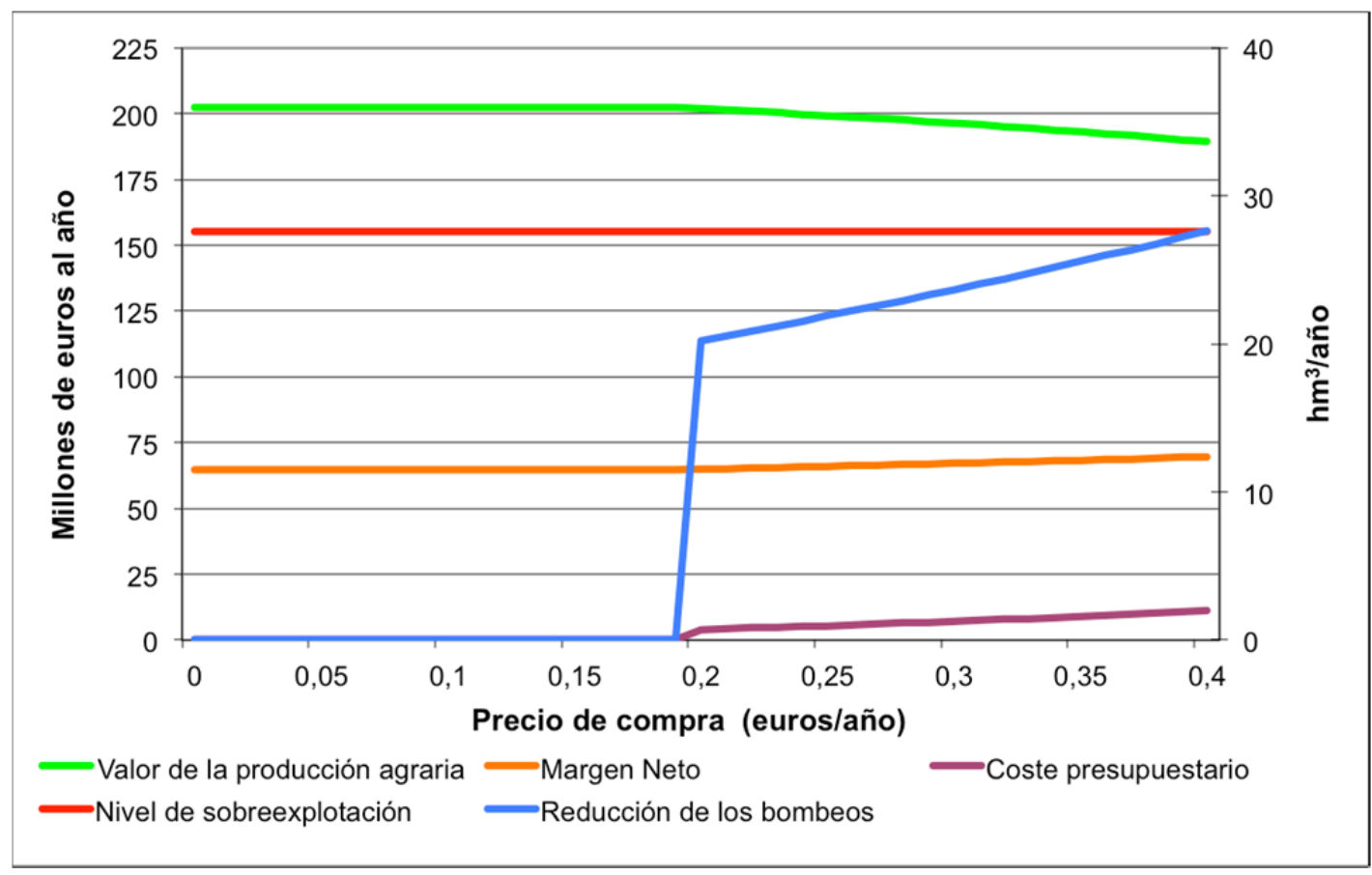

Figura 2. Impacto de la compra de derechos sobre las extracciones de aguas subterráneas, la producción, el margen neto y el coste presupuestario público. Elaboración propia.

\section{5- Conclusiones}

La sobreexplotación de acuíferos es uno de los principales problemas ambientales y de gestión del agua en el sureste Español, siendo especialmente grave en el acuífero Alto Guadalentín en la cuenca del Segura. Frente a medidas de mando y control basadas en la restricción de las extracciones, una de las alternativas utilizadas en España para hacer frente a este problema es la adquisición pública de derechos de aguas subterráneas. Este trabajo analiza el impacto económico de eliminar la sobreexplotación en el acuífero Alto Guadalentín mediante la adquisición de derechos de aguas subterráneas, en términos de rentabilidad de la actividad agraria, impacto social y coste presupuestario, y teniendo en cuenta la futura disponibilidad de recursos procedentes de la desalinización de agua de mar.

En primer lugar, nuestros resultados muestran como la eliminación de las extracciones no renovables tiene importantes efectos económicos sobre el sector agrario, aunque la disponibilidad de recursos desalinizados los reduce significativamente, si bien no los elimina totalmente, ya que los agricultores pueden sustituir recursos subterráneos por desalinizados.

Una primera opción analizada para eliminar la sobreexplotación de acuíferos es restringir las extracciones al nivel de recarga del acuífero mediante la prohibición del uso de los recursos subterráneos que corresponden a bombeos no renovables. En una situación como la actual, en la que el acuífero es una importante fuente de suministro y no existen todavía recursos alternativos, esta alternativa tendría importantes consecuencias negativas, tanto económicas como sociales, sobre el sector agrario al verse reducido el uso de agua. Sin embargo, si consideramos la inminente disponibilidad de recursos procedentes de la desalinización en la zona, el impacto negativo de la prohibición se vería reducido, ya que los agricultores podrían sustituir parcialmente los recursos subterráneos por desalinizados.

Por su parte, la opción de adquisición de derechos de agua de riego por parte de la Administración tiene cierto atractivo, ya que resuelve el problema de la sobreexplotación de manera definitiva y no supone merma alguna para la renta de los agricultores que son 
compensados. Sin embargo, se trata de una alternativa de elevado coste presupuestario y con un notable impacto social en términos de reducción del valor de la producción y el empleo agrarios (similar al de la restricción de las extracciones). De hecho, la diferencia entre ambas alternativas es que en el caso de la restricción de las extracciones el coste de eliminar la sobreexplotación es asumido por los agricultores, mientas que en el caso de la OPAD lo asumiría la Administración.

Aunque la restricción de las extracciones presenta un menor coste presupuestario, se trata de una medida impopular y hasta cierto punto difícil de materializar políticamente. Debe tenerse en cuenta que el éxito de cualquier intervención pública en materia de recursos hídricos depende en gran medida de la cooperación de los usuarios afectados. En este sentido, la adquisición de derechos de agua puede ser mejor recibida por los agricultores que la prohibición de las extracciones, máxime en una situación en la que existe la alternativa del recurso a la desalinización. Es improbable que pudiese aplicarse una medida restrictiva de este tipo sin establecer algún tipo de compensación para los agricultores, como la experiencia de otras cuencas española ha mostrado (Esteban and Albiac, 2011; Garrido et al., 2013). Pese a su elevado coste presupuestario, la adquisición de derechos tiene el mismo impacto sobre el sector agrario, pero es potencialmente menos conflictiva. Una solución intermedia podría ser la combinación de alternativas (incluyendo cierto grado de restricción de extracciones, compra de derechos y subvención a la desalinización) que permitiese repartir el coste de recuperación del acuífero entre agricultores y Administración.

\section{6- Agradecimientos}

La realización de este trabajo ha sido posible gracias a la financiación proporcionada por el Ministerio de Economía y Competitividad y el Fondo Europeo de Desarrollo Regional mediante el proyecto MERCAGUA (AGL2013-48080-C2-2-R).

\section{7- Referencias}

Albiac, J., Hanemann, M., Calatrava, J., Uche, J. \& Tapia, J. (2006). The rise and fall of the Ebro water transfer. Natural Resources Journal, 46(3), 727-757.

Albiac, J., Tapia, J., Meyer, A., Hanemann, M., Mema, M., Calatrava, J., Uche, J. \& Calvo, E. (2008). Los problemas económicos de la planificación hidrológica. Revista de Economía Aplicada, XVI(47), 25-50.

Calatrava, J. \& Gómez-Ramos, A. (2009). "El papel de los mercados de agua como instrumento de asignación de recursos hídricos en el regadío español"; en GómezLimón, J. A., Calatrava, J., Garrido, A., Sáez, F. J. \& Xabadia, À., eds.: La economía del agua de riego en España. Fundación Cajamar, Almería. pp 295-319.

Calatrava, J., Barberá, G.G. \& Castillo, V.M. (2011). Farming practices and policy measures for agricultural soil conservation in semi-arid Mediterranean areas: The case of the Guadalentín basin in southeast Spain. Land Degradation and Development, 22(1), 58-69.

Calatrava, J. \& Martínez-Granados, D. (2012). El valor de uso del agua en el regadío de la cuenca del Segura y en las zonas regables del trasvase Tajo-Segura. Economía Agraria y Recursos Naturales, 12(1), 5-32.

Calatrava, J. \& Martínez-Granados, D. (2016). "Los mercados formales de agua en la cuenca del Segura”. En: Gómez-Limón, J. A. y Calatrava, J. (editores) "Los mercados de agua en España: presente y perspectivas". Cajamar Caja Rural, Almería.

Carmona, G., Varela-Ortega, C. \& Bromley, J. (2011). The Use of Participatory ObjectOriented Bayesian Networks and Agro-Economic Models for Groundwater Management in Spain. Water Resources Management, 25(5),1509-1524.

CHS (2008). Esquema provisional de temas importantes de la Demarcación Hidrográfica del Segura. Confederación Hidrográfica del Segura, Murcia. 
Downward, S.R. \& Taylor, R. (2007). An assessment of Spain's Programa AGUA and its implications for sustainable water management in the province of Almería, southeast Spain. Journal of Environmental Management, 82(2), 277-289.

Esteban, E. \& Albiac, J. (2011). Groundwater and ecosystems damages: Questioning the Gisser-Sánchez effect. Ecological Economics, 70(11), 2062-2069.

Garrido, A., Rey, D. \& Calatrava, J. (2013): Water trading in Spain; en De Stefano, L. \& Llamas, M. R., eds.: Water, agriculture and the environment in Spain: Can we square the circle? Botín Foundation, CRC Press, Boca Raton (CA); pp. 205-216.

Hellegers, P. \& van lerland, E. (2003). Policy instruments for groundwater management in the Netherlands. Environmental and Resource Economics, 26(1), 163-172.

Iglesias, E. (2002). La gestión de las aguas subterráneas en el acuífero Mancha Occidental. Economía Agraria y Recursos Naturales, 2(1), 69-88.

Martínez-Granados, D., Maestre-Valero, J.F., Calatrava, J. \& Martínez-Álvarez, V. (2011). The economic impact of water evaporation losses from water reservoirs in the Segura basin, SE Spain. Water Resources Management, 25(13), 3153-3175.

Rey, D., Garrido, A. \& Calatrava, J. (2014). "Water markets in Spain: Meeting twenty-first century challenges with twentieth century regulations"; en Easter, K. W. \& Huang, Q., eds.: Water markets for the 21st. century: What have we learned? Global Issues in Water Policy Series Volume 11. Springer, Dordrecht, The Netherlands; pp. 127-147. 


\title{
D-06
}

\section{LA ACTIVIDAD DE LOS MERCADOS FORMALES DE AGUA EN LA CUENCA DEL SEGURA}

\author{
Calatrava, J (1) (P), Martínez-Granados, D (2)
}

\author{
${ }^{1}$ Profesor Titular de Universidad, E.T.S. de Ingeniería Agronómica, Universidad Politécnica \\ de Cartagena, Paseo Alfonso XIII 48, 30203 Cartagena, j.calatrava@upct.es \\ 2 Investigador, E.T.S. de Ingeniería Agronómica, Universidad Politécnica de Cartagena, \\ Paseo Alfonso XIII 48, 30203 Cartagena, david.martinez@upct.es
}

RESUMEN: La cuenca del Segura, en el sureste de España, es una de las zonas con mayor nivel de escasez de agua, no solo de España, sino de toda Europa. Entre las múltiples medidas tomadas por la Administración española para hacer frente a la escasez de agua en esta y otras cuencas del país, en 1999 se reformó la Ley de Aguas para introducir los mercados de agua en el ordenamiento jurídico español y regular su funcionamiento. El objetivo que se perseguía era flexibilizar el régimen concesional del agua en España para mejorar la reasignación de los recursos hídricos, incrementar la eficiencia económica en el uso del agua y reducir el impacto económico de la escasez. Las características de la economía del agua en la cuenca del Segura suponen unas muy favorables condiciones de inicio para la actividad de mercado, por lo que el potencial para su funcionamiento es notable. Sin embargo, y pese a concentrar la mayor actividad de mercados de agua de la España continental, el volumen de intercambios de agua en esta cuenca ha sido relativamente escaso. En este trabajo se describen las escasas experiencias de mercados formales de agua en la cuenca del Segura, tanto los realizados entre usuarios de la propia Demarcación, como los celebrados con usuarios de otras cuencas y las Ofertas Públicas de Adquisición de Derechos realizadas por la Administración.

\section{Introducción}

La cuenca del Segura es una de las áreas con mayor nivel de escasez de agua de Europa. En un contexto de creciente escasez estructural, el reparto del agua genera importantes conflictos entre usuarios que se agravan durante los periódicos episodios de sequía. Entre las múltiples medidas tomadas por el Gobierno de España para hacer frente a la escasez de agua en ésta y otras cuencas, en 1999 se reformó la Ley de Aguas (Ley 46/1999) para introducir los mercados de agua en el ordenamiento jurídico español y regular su funcionamiento. Se perseguía con ello flexibilizar el régimen concesional del agua para mejorar la reasignación de los recursos hídricos, incrementar la eficiencia económica en el uso del agua y reducir el impacto económico de la escasez (Rey et al., 2014).

La Ley 46/1999 permitió el intercambio voluntario de agua entre concesionarios que lleguen a un acuerdo privado para la cesión temporal de sus derechos de uso o propiedad del agua a cambio de una compensación, previa solicitud y autorización por parte del Organismo de Cuenca correspondiente. Estos contratos de cesión temporal de derechos pueden celebrarse entre usuarios situados dentro de una misma demarcación hidrográfica, y siempre hacia usos de igual o mayor orden de prelación. Aunque este mecanismo está pensado para asignar los recursos en períodos de sequía, su funcionamiento no está restringido a éstos. Posteriormente, durante la sequía de 2005-2008 el Ministerio de Medio Ambiente permitió, mediante el RDL 15/2005 y sus prórrogas anuales, los contratos de cesión entre usuarios de diferentes cuencas como medida excepcional para aliviar los 
problemas de disponibilidad de agua de las zonas más afectadas (Garrido et al., 2013b). En el caso del Segura, los volúmenes adquiridos a usuarios del Tajo durante 2006 superaron con creces a todos los contratos de cesión celebrados en la cuenca hasta ese año.

Además de la figura de los contratos de cesión entre usuarios, la Ley 46/1999 contemplaba la posibilidad de que los Organismos de Cuenca pudiesen crear los denominados Centros de Intercambio de Derechos (CID) de uso del agua, a través de los cuales realizar ofertas públicas de adquisición de derechos (OPAD) a los titulares de concesiones interesados en cederlas temporal o permanentemente para proceder posteriormente a su cesión a otros titulares (Calatrava y Gómez-Ramos, 2009). Los primeros CID se crearon en las cuencas hidrográficas del Guadiana, Júcar y Segura en 2004, aunque no funcionaron hasta que, con el inicio de la sequía de 2005-08, el RDL 9/2006 reforzó su eficacia para que pudiesen dar respuesta también a otras demandas (Garrido et al., 2013b). Por ejemplo, además de ceder recursos a otros usuarios (objetivo inicial), los CID podrían también destinar los derechos adquiridos a usos ambientales.

Las características de la economía del agua en la cuenca del Segura (escasez crónica, acentuada variabilidad en la oferta de agua, frecuentes episodios de sequía, distribución desigual de los recursos en favor del regadío tradicional, notables diferencias en el valor del agua y existencia de infraestructuras de transporte de agua entre las principales zonas de riego) constituyen unas favorables condiciones de inicio para la actividad de los mercados de agua, por lo que el potencial para su funcionamiento es notable. Sin embargo, el volumen de intercambios de agua en esta cuenca ha sido relativamente escaso. Pese a ello, concentra la mayoría de los contratos de cesión intra-cuenca de la España continental y más de la mitad de los celebrados entre usuarios de diferentes cuencas.

En este sentido, el objetivo de este trabajo es revisar las experiencias de mercados formales de agua en la cuenca del Segura desde 1999, tanto los realizados entre usuarios de la propia Demarcación, como los celebrados con usuarios de otras cuencas y las Ofertas Públicas de Adquisición de Derechos realizadas por la Administración. Para ello se han recopilado y clasificado las transacciones de las que se tiene conocimiento en base a la información primaria obtenida por los autores mediante entrevistas a comunidades de regantes, y a información secundaria procedente de fuentes públicas (Confederación Hidrográficas), privadas (asociaciones de regantes) y la bibliografía sobre el tema.

\section{Recursos y usos del agua en la cuenca del Segura}

Las estimaciones oficiales más recientes de recursos disponibles en la cuenca del Segura ascienden a una media de $1580 \mathrm{hm}^{3} /$ año, cifra que incluye las aguas superficiales y subterráneas, los recursos provenientes del Acueducto Tajo-Segura (ATS), la reutilización y la desalinización (CHS, 2014). Esta disponibilidad de recursos no basta para satisfacer la demanda bruta de agua de la cuenca que se estima en $1.841 \mathrm{hm}^{3} / a n ̃ o$, de los que 1.546 $\mathrm{hm}^{3} /$ año corresponden a los usos agrarios, $236 \mathrm{hm}^{3} / a n ̃ o$ al abastecimiento urbano, 20 $\mathrm{hm}^{3} /$ año a los usos industriales y $39 \mathrm{hm}^{3} /$ año a los ambientales. Además, para el cálculo del balance hídrico real de la cuenca no se consideran las extracciones de recursos subterráneos no renovables, por lo que los recursos renovables disponibles en la cuenca se estiman en $1.403 \mathrm{hm}^{3} /$ año, distribuidos en $1.113 \mathrm{hm}^{3} / a n ̃ o$ para las demandas agrarias, 236 $\mathrm{hm}^{3} /$ año para las urbanas, $15 \mathrm{hm}^{3} / a n ̃ o$ para las industriales y $39 \mathrm{hm}^{3} / a n ̃ o$ para las ambientales. Por lo tanto, considerando una demanda de $1.841 \mathrm{hm}^{3} / a n ̃ o$, se obtendría un déficit estructural de aproximadamente $438 \mathrm{hm}^{3} / a n ̃ o$. Este déficit se cubre mediante extracciones no renovables de recursos subterráneos $\left(237 \mathrm{hm}^{3} / a n ̃ o\right)$ y mediante una

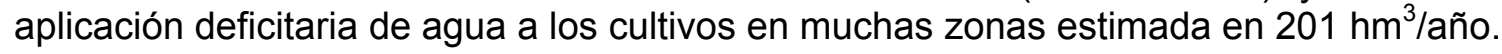

Como se ha mostrado, el principal usuario del agua en la cuenca del Segura es el regadío. La superficie regable de la cuenca asciende a 472.369 hectáreas, de las que 261.009 
hectáreas constituyen la superficie neta efectivamente regada (CHS, 2014). La superficie de regadío se ha multiplicado por dos desde los años 80 , lo que ha exacerbado la situación de escasez estructural de la cuenca y ha generado un grave problema de sobreexplotación en muchos acuíferos. Las zonas regables que se nutren del ATS, que incluyen algunas situadas en otras cuencas, comprenden un total de 152.488 hectáreas (CHS, 2015). La agricultura de regadío tiene gran importancia en la economía de la cuenca, tanto en términos del valor de la producción como del empleo y la actividad exportadora. MaestreValero et al. (2013) estiman que el valor medio de la producción agraria en el regadío de la cuenca del Segura asciende a 2.000 millones de euros anuales, lo que supone una rentabilidad para los agricultores en términos de margen neto de 865 millones de euros/año y genera un empleo anual equivalente a 58.500 Unidades de Trabajo Anual (UTA).

El valor de uso agrario del agua está entre los más altos del país. El valor marginal del agua en la cuenca es $0,52 € / \mathrm{m}^{3}$ y el valor medio $0,81 € / \mathrm{m}^{3}$, ambos medidos en términos de margen neto de explotación (Calatrava y Martínez-Granados, 2012). Sin embargo, estos valores presentan notables diferencias entre zonas, oscilando el valor marginal entre 0,13 y $0,97 € / \mathrm{m}^{3}$ y el valor medio entre 0,46 y $1,64 € / \mathrm{m}^{3}$. Los mayores valores corresponden a las zonas costeras de la cuenca y a las zonas regables que reciben agua del trasvase TajoSegura, debido a que en ellas se concentra la mayor parte de la horticultura intensiva y los invernaderos de la cuenca, además de tratarse generalmente de los regadíos más modernos y menos dotados en términos de disponibilidad de agua por hectárea.

En cuanto a las tarifas del agua, la tarifa media pagada en baja es casi $0,17 € / \mathrm{m}^{3}$ (CHS, 2014), muy por encima de la media de España (Calatrava et al., 2015). Por orígenes, las tarifas medias oscilan entre los $0,035 € / \mathrm{m}^{3}$ de los recursos superficiales y depurados, los $0,20 € / \mathrm{m}^{3}$ de los subterráneos y los $0,40 € / \mathrm{m}^{3}$ de los desalinizados. Estos valores medios son bastante homogéneos entre las diferentes áreas de la cuenca, con la excepción de las aguas subterráneas, cuyos costes de extracción varían entre $0,10-0,47 € / \mathrm{m}^{3}$ (CHS, 2014). A estas tarifas hay que añadir los costes de distribución del agua que los regantes pagan en forma de derramas a las comunidades de regantes, y que oscilan entre 0,04 y $0,075 € / \mathrm{m}^{3}$, con un valor medio de $0,06 € / \mathrm{m}^{3}$, según nuestras propias estimaciones en base a datos obtenidos de diversas comunidades de regantes. En el caso del abastecimiento urbano, el precio medio del agua potable suministrada a los municipios por la Mancomunidad de Canales del Taibilla (MCT), es de $0,6433 € / \mathrm{m}^{3}$.

\section{Contratos de cesión entre usuarios de la cuenca del Segura}

En la Figura 1 se muestran los volúmenes intercambiados y las compensaciones acordadas en los contratos de cesión autorizados en la cuenca entre 1999 y 2013, el período para el que se dispone de datos totales. El volumen medio anual es de casi $4 \mathrm{hm}^{3} / a n ̃ o$, lo que supone menos del $0,5 \%$ del agua utilizada en el regadío de la cuenca del Segura. Sin embargo, este valor medio es poco representativo, ya que solo se ha superado en tres de los trece años del período considerado, siendo el volumen intercambiado inferior a $2 \mathrm{hm}^{3}$ en la mitad de los años. Con algunas excepciones, el volumen medio anual intercambiado en cada contrato ha sido inferior a $0,4 \mathrm{hm}^{3} \mathrm{y}$, en muchos años, a $0,2 \mathrm{hm}^{3}$, si bien en el último lustro se han producido algunas operaciones superiores a los $4 \mathrm{hm}^{3}$.

En cuanto a las compensaciones acordadas, en primer lugar, la Figura 1 muestra un elevado grado de dispersión de los precios, lo que es de esperar dado el reducido nivel de concurrencia de este mercado. En segundo lugar, aunque las oscilaciones de los precios, tanto máximos como mínimos, son notables, se observan precios ligeramente superiores en los años de sequía. Finalmente, se observan menores precios en los primeros años del período, muy especialmente en los precios mínimos. Aclarar que todos los precios de intercambio citados en este trabajo son en origen y no incluyen ni el IVA ni los costes de transporte y distribución a los usuarios finales, salvo que se indique lo contrario. 


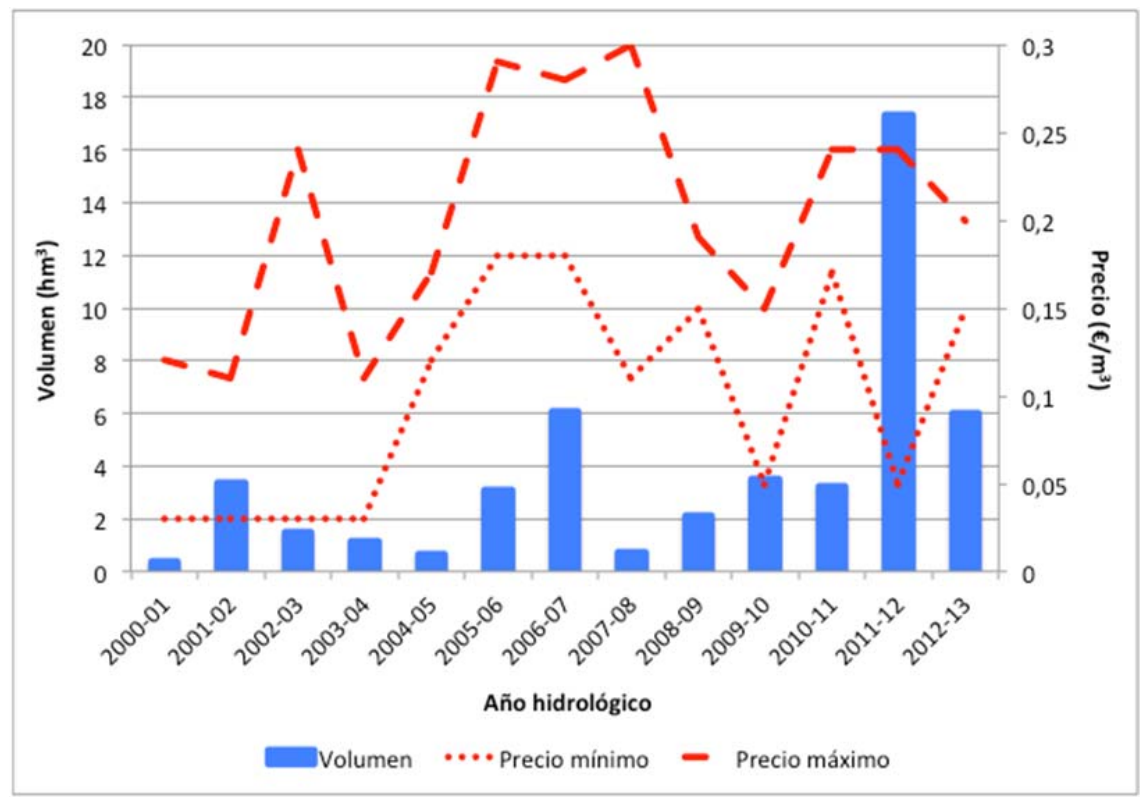

Figura 1. Volúmenes y precios en contratos de cesión en la cuenca del Segura (200013) Elaboración propia a partir de información proporcionada por la CHS.

De manera simplificada, las principales zonas de origen del agua intercambiada en contratos de cesión se localizan en la cabecera de la cuenca y a lo largo de la Vega del Río Segura. Las principales zonas de destino de los volúmenes adquiridos se localizan en el suroeste de la cuenca, más concretamente en las zonas del Alto Guadalentín, Águilas, Mazarrón y Bajo Almanzora, así como en las zonas regables del Acueducto Tajo-Segura. Esto no es óbice para que se hayan producido intercambios de ámbito espacial más restringido en otras zonas de la cuenca, aunque generalmente de menor volumen. El inusualmente elevado volumen de intercambios del año hidrológico 2011-12 se debe a la excepcional situación de abundancia de recursos superficiales propios en la cuenca en 2011 y 2012, lo que permitió una serie de operaciones de cierta importancia por parte de cedentes con exceso puntual de recursos y con destino principal en comunidades de regantes del suroeste de la cuenca.

Aunque no disponemos de información del volumen total intercambiado en los dos últimos años hidrológicos, la información disponible sobre algunos contratos recientes y de cierta relevancia, indica que los volúmenes intercambiados anualmente han sido superiores a la media de 2000-2013 y sugiere una tendencia creciente de los mismos, así como menores precios. Por ejemplo, en 2013-14 el Sindicato Central de Regantes del Acueducto TajoSegura (SCRATS) adquirió $1,2 \mathrm{hm}^{3}$ a la C.R. de Campotéjar y $4 \mathrm{hm}^{3}$ a la C.R. Riegos de Levante Margen Izquierda, ambas en la Vega del Segura. Por su parte, y también en 201314, las CC.RR. de Águilas y Mazarrón adquirieron $5 \mathrm{hm}^{3}$ de la Junta de Hacendados de la Huerta de Murcia, operación que se repitió en 2014-15. Este último acuerdo había sido denegado previamente por la imposibilidad física de medir los volúmenes consumidos por los cedentes, por lo que requirió de la instalación de un sistema de contadores volumétricos. El mismo problema ha frustrado otros acuerdos con el regadío tradicional, caso del alcanzado en 2015 por el SCRATS con el Juzgado Privativo de Aguas de Orihuela.

Algunos de estos acuerdos no han estado exentos de polémica. Las cesiones de agua de la Junta de Hacendados de la Huerta de Murcia a las CC.RR. de Águilas y Mazarrón en 2014 y 2015 fueron recurridas por la Asociación para la Conservación de la Huerta de Murcia (HUERMUR) ante la Confederación Hidrográfica del Segura (CHS), quien desestimó dicho recurso. Mayor oposición se ha encontrado el SCRATS en 2015 en su intento de adquirir agua a varias CC.RR. del regadío tradicional de la Vega Baja del Segura, que viene 
manteniendo a lo largo de los años una postura de oposición a las cesiones de agua desde la Vega del Segura a otras zonas de la cuenca. Más recientemente, ya en 2016, la propuesta de ceder $30 \mathrm{hm}^{3}$ del regadío tradicional de la cuenca al SCRATS ha desatado una tormenta política que ha requerido la intervención directa del MAGRAMA.

\section{Contratos de cesión con usuarios de la cuenca del Tajo}

La lógica de funcionamiento de los mercados de agua, que supone la transferencia de los recursos de usos de menor valor a otros de mayor valor, hace pensar en los usuarios urbanos como los primeros y principales compradores, como ocurre en muchas zonas del suroeste de los EE.UU. Sin embargo, la prioridad que los abastecimientos tienen en España sobre otros usos del agua, ha limitado en la práctica el recurso a los contratos de cesión. Aunque hay experiencias de acuerdos puntuales en las cuencas del Tajo, Segura y Júcar, algunos anteriores a la Ley de Aguas de 1999, la mayoría de los intercambios formales de agua en España han tenido lugar entre usuarios agrarios (Palomo-Hierro et al., 2015).

En el caso del Segura, la Mancomunidad de Canales del Taibilla (MCT) firmó durante la sequía de 2005-2008 tres convenios con la C.R. del Canal de Las Aves, situada en Aranjuez (Madrid), para la cesión de un máximo anual de $40 \mathrm{hm}^{3}$ (Tabla 1). Sin embargo, el objetivo real de estos convenios era crear una reserva estratégica en la cabecera del Tajo que asegurase el abastecimiento impidiendo que los niveles de los embalses de Entrepeñas y Buendía, de los que se nutre el ATS, cayesen por debajo del umbral crítico que imposibilita por ley el trasvase de recursos al Segura (Calatrava y Gómez-Ramos, 2009). En total, la MCT pagó 30,33 millones de euros por un volumen adquirido de $108,5 \mathrm{hm}^{3}$, equivalente a un precio medio de $0,2795 € / \mathrm{m}^{3}$, si bien en la práctica solo se trasvasaron $47,78 \mathrm{hm}^{3}\left(2,34 \mathrm{hm}^{3}\right.$

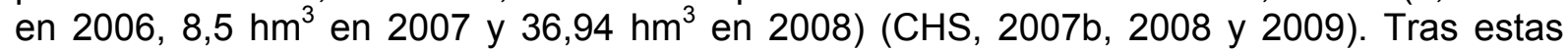
operaciones, y alguna compra puntual de pequeños volúmenes a usuarios de la propia cuenca durante la sequía de 2005-08, la entrada en funcionamiento de las desalinizadoras de San Pedro del Pinatar y Alicante, así como un mayor recurso a pozos de sequía de la $\mathrm{CHS}$, ha permitido que la MCT no haya vuelto a recurrir a las compras de agua.

Tabla 1. Contratos de cesión inter-cuencas entre usuarios del Segura y del Tajo

\begin{tabular}{cccccc}
\hline \multirow{2}{*}{ Comprador } & Cedente & $\begin{array}{c}\text { Año } \\
\text { hidrológico }\end{array}$ & $\begin{array}{c}\text { Volumen en } \\
\text { origen }\left(\mathbf{h m}^{3}\right)\end{array}$ & $\begin{array}{c}\text { Precio } \\
\left(\boldsymbol{\epsilon} / \mathbf{m}^{3}\right)\end{array}$ & $\begin{array}{c}\text { Compensación } \\
\text { (euros) }\end{array}$ \\
\hline \multirow{2}{*}{ MCT } & C.R. Canal de & $2005-2006$ & 35,52 & 0,2885 & 10.247 .520 \\
& las Aves & $2006-2007$ & 36,03 & 0,2364 & 8.517 .492 \\
& $2007-2008$ & 36,94 & 0,3130 & 11.562 .220 \\
\hline \multirow{3}{*}{ SCRATS } & $2005-2006$ & 31,05 & 0,1856 & 5.761 .700 \\
& & $2006-2007$ & 31,05 & 0,1881 & 5.839 .480 \\
& C.R. Canal de & $2007-2008$ & 31,05 & 0,1920 & 5.962 .097 \\
& Estremera & $2008-2009$ & 31,05 & 0,1920 & 5.962 .097 \\
& & $2013-2014$ & 5,560 & 0,06 & 333.600 \\
& & $2014-2015$ & 7,7 & 0,06 & 462.000 \\
\cline { 2 - 6 } & \multirow{2}{*}{ C.R. La Poveda } & $2013-2014$ & 1,4 & 0,06 & 84.000 \\
& $2014-2015$ & 1,4 & 0,06 & 84.000 \\
\hline
\end{tabular}

Fuente: Elaboración propia a partir de Claver (2013), SCRATS (2009 y 2015), las memorias anuales de la MCT (2007, 2008 y 2009), y de datos adicionales proporcionados por los compradores. Precios en origen sin incluir ni el I.V.A. ni la tarifa del trasvase Tajo-Segura correspondiente. 
Por su parte, el SCRATS estableció cuatro convenios sucesivos entre 2006 y 2009 con la C.R. del Canal de Estremera para la cesión anual de $31,05 \mathrm{hm}^{3}$ medidos en origen (Claver, 2013). Dicha comunidad de regantes renunciaba a utilizar la totalidad de su concesión en el período establecido en cada contrato de cesión, durante los cuales llevó a cabo la mejora y modernización de toda la zona regable. La compensación económica acordada el primer año fue de $0,1855 € / \mathrm{m}^{3}$, valor que fue incrementándose en una cuantía igual al $50 \%$ del valor del IPC de cada año, con excepción del cuarto contrato (Tabla 1). En la práctica, estos precios unitarios son mayores, ya que hay que considerar un $10 \%$ por pérdidas en el transporte a través del ATS y añadir el componente a) de la tarifa del trasvase $(0,013856$ $\left.€ / \mathrm{m}^{3}\right)$ y las cuotas del SCRATS $\left(0,002404 € / \mathrm{m}^{3}\right)$, lo que incrementa los precios medidos en las tomas de las CC.RR del ATS por encima de los $0,22 € / \mathrm{m}^{3}$ (Claver, 2013). A estos valores habría que añadir las derramas a pagar por los regantes a cada comunidad de regantes.

Los acuerdos entre el SCRATS y la C.R. del Canal de Estremera permitieron mitigar la escasez de agua en las zonas regables del ATS y fueron beneficiosos para ambas partes. Calatrava y Gómez-Limón (2016) valoran las ganancias brutas de este acuerdo plurianual en 89,9 millones de euros para los usuarios del ATS y 17,8 millones de euros para los de la C.R. del Canal de Estremera. Además, esta última utilizó los pagos por la cesión de derechos para financiar la modernización de sus infraestructuras. Sin embargo, estos acuerdos también dieron lugar a protestas por parte de usuarios aguas abajo en el Tajo (Garrido et al., 2013b). Cuando la situación de sequía se ha repetido en 2014 , se ha reactivado este acuerdo, aunque con diferentes condiciones.

Los dos casos de cesiones inter-cuencas de 2005-2009 recibieron el apoyo explícito del Ministerio de Medio Ambiente, que permitió dotaciones de agua intercambiadas muy elevadas (Calatrava y Gómez-Ramos, 2009), y se beneficiaron de exenciones en la tarifa del Acueducto Tajo-Segura, equivalentes a $0,085774 € / \mathrm{m}^{3}$, justificados por el Gobierno de España en base a la situación de extrema sequía existente (Garrido et al., 2013b). En concreto, quedaron exentos del pago de las cuotas correspondientes a los apartados b) y c) de la tarifa del trasvase, por lo que solo pagaron el apartado a) de la tarifa, que corresponde a la amortización del coste de las obras y cuyo importe va destinado a las CC.AA. por las que discurre el río Tajo. De hecho, puesto que estas exenciones se aplicaron tanto a los volúmenes procedentes de los contratos de cesión como a los volúmenes ordinarios trasvasados desde el Tajo, su cuantía económica superó el coste de adquisición por parte del SCRATS de los volúmenes de la C.R. del Canal de Estremera (Hernández-Mora y Del Moral, 2015). En el caso de los acuerdos entre la MCT y la C.R. del Canal de las Aves, el coste total de las compras $(30,687$ millones de euros) se compensó con la exención del peaje de los volúmenes ordinarios del trasvase durante la sequía de 2005-2008 (27,977 millones de euros) y de los propios volúmenes adquiridos (4,098 millones de euros).

Frente al apoyo del Gobierno Central, estos acuerdos de cesión recibieron fuerte oposición por parte del Gobierno de Castilla-La Mancha que recurrió sucesivamente en los tribunales los contratos de cesión de 2007, 2008 y 2009, habiendo sido desestimado hasta la fecha el primero de estos recursos. Es evidente que esta conflictividad supone un coste político de estos intercambios que no debe ser desdeñado. Menos clara es la evidencia sobre posibles efectos ambientales de los contratos inter-cuencas de 2005-2009, ya que la Ley 21/2013 solo exige una evaluación de impacto ambiental previa para trasvases superiores a $100 \mathrm{hm}^{3}$ pero no para cesiones temporales de derechos (Claver, 2013). Mientras que Yagüe (2008) y Claver (2013) mantienen que las cesiones entre el Tajo y el Segura no causaron problemas medioambientales, ya que se mantuvo el caudal ambiental mínimo en el tramo del río Tajo afectado, Hernández-Mora (2013) mantiene que los impactos fueron severos, ya que los caudales en Aranjuez cayeron por debajo de los $6 \mathrm{~m}^{3} / \mathrm{s}$ en diversas ocasiones.

Posteriormente, el mismo SCRATS firmó un acuerdo en 2011 con la C.R. de Illana-Leganiel en el Alto Tajo para la cesión total o parcial de su dotación durante 10 años (SCRATS, 
2012). La compensación económica pactada en el acuerdo tiene dos componentes: un pago anual fijo equivalente al canon de regulación de dicha comunidad de regantes (entre 13.000 $€$ y $17.000 €$ según el año) y un pago variable de $0,06 € / \mathrm{m}^{3}$ por el agua cedida en el caso de ser autorizada la cesión. Este contrato presenta notables semejanzas con un contrato de opción de suministro de agua, ya que la C.R. de Illana-Leganiel se compromete a ceder el volumen pactado cuando se den determinadas condiciones: una situación de sequía, que se active legalmente la posibilidad de celebrar cesiones inter-cuenca y que el SCRATS así lo solicite. En la práctica, cuando se han dado estas circunstancias en 2014 y 2015, la Dirección General del Agua ha denegado la solicitud de autorización de este contrato por considerar que la comunidad de regantes cedente no ha hecho uso de sus recursos en los últimos años, requisito previo para autorizar cualquier contrato de cesión (SCRATS, 2015).

Más recientemente, en 2014 y 2015 se han producido otros dos acuerdos entre el SCRATS y dos comunidades de regantes del Alto Tajo (Tabla 1). En primer lugar, se han firmado dos nuevos contratos con la C.R. del Canal de Estremera por un volumen de $9 \mathrm{hm}^{3}$ anuales, si bien la Dirección General del Agua solo ha autorizado la cesión de 5,56 hm en 2013-14 y $7,7 \mathrm{hm}^{3}$ en 2014-15. Estas denegaciones parciales se deben al hecho de que el consumo real acreditado por esta comunidad de regantes en 2013 y 2014 respectivamente es inferior al volumen solicitado. En los mismos años, el SCRATS firmó otros dos contratos de cesión con la C.R. de La Poveda (Madrid) que fueron autorizados por un volumen de 1,4 hm/año. Es de importancia recalcar que estos nuevos acuerdos no se han beneficiado de la exención de la tarifa del ATS, como en el caso de la anterior sequía, por lo que a los precios indicados en la Tabla 1 hay que añadir, además del IVA, $0,0984 € / \mathrm{m}^{3}$ en concepto de dicha tarifa.

\section{Ofertas públicas de adquisición de derechos}

Aunque el Centro de Intercambio de Derechos (CID) de agua del Segura se creó en 2004, no fue hasta 2007 cuando la CHS lanzó una primera OPAD con el objetivo de crear una reserva estratégica para garantizar los caudales ambientales en los ríos Segura y Mundo, en la cabecera de la cuenca (CHS, 2007a). El presupuesto de la OPAD era de 700.000 euros y la compensación máxima a pagar por la cesión de derechos era $0,18 € / \mathrm{m}^{3}$, siendo los costes del transporte del agua asumidos por la CHS. Finalmente, se aceptaron 41 ofertas de pequeños agricultores que sumaban un total de 371,5 hectáreas. El volumen adquirido fue $2,93 \mathrm{hm}^{3}$, a un precio medio de $0,168 € / \mathrm{m}^{3}$ y con un coste de 495.000 euros, y se destinó en si totalidad a usos ambientales (Garrido et al., 2013b). La OPAD se repitió en 2008 con idénticas condiciones y similares resultados (Calatrava y Gómez-Ramos, 2009).

Al igual que en las cuencas del Guadiana y del Júcar, el éxito de las OPAD del Segura fue moderado, ya que no se agotó el presupuesto inicial por falta de oferentes que cumplieran con los requisitos exigidos (Rey et al., 2014). Para Yagüe (2008), el precio máximo establecido era atractivo para los regantes, pero pudo más la "desconfianza que generan estos nuevos instrumentos entre los regantes y la cultura existente de mantener a ultranza los derechos de agua". En la práctica, muchos de los arroceros que participaron lo hicieron porque la disponibilidad de agua no les permitía completar sus ciclos de cultivo.

\section{Discusión}

Las experiencias de mercados de agua en la cuenca del Segura abarcan desde intercambios informales a nivel local, contratos de cesión entre usuarios de la Demarcación (amparados por la Ley 46/1999) o entre usuarios de diferentes cuencas (amparados por el Real Decreto 15/2005 y posteriores) y ofertas públicas de adquisición de derechos. Dejando a un lado los mercados informales por su casi imposible cuantificación, podemos afirmar que la actividad de los mercados formales de agua en el Segura ha sido menor de lo que se pudiera haber previsto dadas las condiciones hidrológicas y las características de la economía del agua en la cuenca, y que se ha limitado casi totalmente al ámbito agrario. 
Frente a los acuerdos intra-cuenca $\left(49,12 \mathrm{hm}^{3}\right)$, la mayoría de los volúmenes adquiridos en 2000-2013 proceden de acuerdos con usuarios del Tajo $\left(232,69 \mathrm{hm}^{3}\right)$.

Al igual que lo sucedido a nivel nacional, la actividad e impacto de los intercambios de agua en la cuenca del Segura durante los últimos tres lustros ha sido limitada y desigual. De manera resumida, podemos decir que en los últimos años los contratos de cesión se reducen a una o dos grandes operaciones puntuales $\left(3-6 \mathrm{hm}^{3}\right)$ cada año, casi siempre con las mismas zonas compradoras, y un número algo mayor, en torno a la decena, de pequeñas operaciones entre usuarios privados agrarios o pequeñas comunidades de regantes por volúmenes generalmente inferiores a $0,25 \mathrm{hm}^{3}$. Sin embargo, mientras que a nivel nacional la actividad de los mercados de agua ha estado concentrada en intercambios inter-cuencas en épocas de sequía, en el caso del Segura ésta se mantiene incluso en años de mayor disponibilidad de recursos, debido al desigual reparto de los recursos en la cuenca. El potencial de intercambio de agua en la cuenca no se limita por tanto a situaciones de escasez puntual, como tampoco es necesaria una situación coyuntural de sequía para que exista demanda de intercambios con los usuarios del Tajo, sino que dicha demanda existe también en años normales.

Otro aspecto de relevancia son las compensaciones acordadas en los intercambios. Se observa un notable grado de dispersión de los precios con mínimos en torno a $0,06 € / \mathrm{m}^{3}$ y $0,24 € / \mathrm{m}^{3}$ (incluso mayores en el caso de compras realizadas para usos urbanos), si bien no hay que olvidar que a estos valores hay que añadir los costes de transporte, elevación y distribución del agua que en algunos casos extremos han llegado a duplicar el coste final para el agricultor. Se observa también una evolución ligeramente decreciente de los precios hasta valores medios en la actualidad entorno a $0,15 € / \mathrm{m}^{3}$ (netos en origen). Sorprende también que los precios no guarden relación directa con el valor medio del recurso en las zonas de origen y/o destino, sino que parecen depender más de la capacidad de negociación y las circunstancias puntuales de escasez para ambas partes.

El elevado grado de dispersión de los precios, junto con el relativamente escaso número de transacciones de agua, apunta a la existencia de un mercado "estrecho" (thin market), típico de situaciones en las que el número de potenciales participantes en el mercado es reducido debido al limitado ámbito espacial del mercado, por ejemplo, porque existan restricciones físicas o legales al intercambio (Tisdell, 2011), lo que genera falta de competencia y dispersión en los precios (que dejan de ser un buen indicador de escasez).

En el caso de las OPAD, la experiencia del Segura es similar a la de otras cuencas, ya que no se agotó el presupuesto de adquisición. Los valores del agua en las zonas cedentes, en la parte castellano-manchega de la cuenca, sugieren que más que un problema de precios de oferta bajos, han primado otros comportamientos de tipo estratégico y/o colusivo, o que han existido presiones externas sobre los regantes para no participar en las OPAD (Calatrava y Gómez-Ramos, 2009).

Obviamente, un aspecto positivo es que los recursos se han reasignado a los usos de mayor valor. En el caso de los contratos inter-cuencas, los resultados obtenidos por Calatrava y Gómez-Limón (2016) sugieren que las ganancias de bienestar han sido cuantiosas y que pueden superar los posibles impactos ambientales negativos, a falta de una cuantificación de estos últimos. En este sentido, y a nivel de la cuenca, los volúmenes intercambiados y la denegación de determinadas solicitudes permite suponer que los posibles impactos ambientales han sido insignificantes, habiéndose producido incluso beneficios ambientales como consecuencia de las OPAD que, como en el resto de España, y de manera similar a los bancos públicos del agua de California o Australia (Wheeler at al., 2013), se han utilizado solo para la consecución de objetivos medioambientales (Garrido et al., 2013a). En el caso de los contratos de cesión inter-cuencas, la lógica sugiere que los impactos ambientales han debido ser mayores, si bien las opiniones al respecto son contradictorias. En cualquier caso, 
una de las debilidades más claras del marco legal de los mercados de agua en España es la no consideración de los efectos ambientales, positivos o negativos (Calatrava y GómezRamos, 2009), más que el impacto ambiental resultante de un intercambio concreto y puntual que seguramente no sea irreversible (Garrido et al., 2013c).

Pese al importante papel de la Administración como promotor de los intercambios intercuencas durante la sequía (Garrido et al., 2013a) y a las sucesivas reformas legales para ampliar el alcance de los intercambios (Hernández-Mora y Del Moral, 2015), no está clara la apuesta de la Administración por aprovechar las posibilidades de los centros de intercambios para facilitar los intercambios, agrupando la oferta, reduciendo los costes de transacción y promoviendo una mayor participación de los usuarios.

Las experiencias de mercados e agua en el Segura, con sus claroscuros, han sido positivas, ya que han permitido evitar importantes perjuicios económicos en zonas y momentos puntuales, facilitando incluso la consecución de objetivos medioambientales a través de las OPAD. Sin embargo, pese a sus beneficios, los mercados de agua no son la solución al problema de la escasez estructural en la cuenca, sino un instrumento más de los que pueden utilizarse, y, en ningún caso, pueden sustituir la acción de la Administración. Es más, lo limitado de su alcance en la práctica plantea dudas sobre su potencial real en épocas de sequía, en las que otras actuaciones, como la movilización de recursos subterráneos estratégicos y el recurso a la desalinización, han suministrado mayores volúmenes a los regantes.

\section{Agradecimientos}

La realización de este trabajo ha sido posible gracias a la financiación del Ministerio de Economía y Competitividad y el Fondo Europeo de Desarrollo Regional (FEDER) mediante el proyecto MERCAGUA (AGL2013-48080-C2-2-R) y del Programa de Apoyo a la Investigación de la Fundación Séneca-Agencia de Ciencia y Tecnología de la Región de Murcia mediante el proyecto 19280/PI/14.

\section{Referencias}

Calatrava, J., García-Valiñas, M.A., Garrido, A. y González-Gómez, F. (2015). Water pricing in Spain: Following the footsteps of somber climate change projections; en Dinar, A., Pochat, V. y Albiac, J., eds.: Water pricing experiences and innovations. Springer, Cham, Switzerland; pp. 313-340.

Calatrava, J. y Gómez-Ramos, A. (2009). El papel de los mercados de agua como instrumento de asignación de recursos hídricos en el regadío español; en Gómez-Limón, J. A., Calatrava, J., Garrido, A., Sáez, F. J. y Xabadia, À., eds.: La economía del agua de riego en España. Fundación Cajamar, Almería. pp 295-319.

Calatrava, J. y Gómez-Limón, J. A. (2016). Mercados de agua y eficiencia económica; en Gómez-Limón, J. A. y Calatrava, J., eds.: Los mercados de agua en España: Presente y perspectivas. Cajamar Caja Rural, Almería.

Calatrava, J. y Martínez-Granados, D. (2012). El valor de uso del agua en el regadío de la cuenca del Segura y en las zonas regables del trasvase Tajo-Segura. Economía Agraria y Recursos Naturales 12(1): 5-32.

CHS (2007a). Pliego de cláusulas administrativas particulares y prescripciones técnicas particulares que regirán en la oferta publica de la Confederación Hidrográfica del Segura para la adquisición de derechos de agua con destino a la cuenca del Segura por razones de garantía de los caudales ambientales y de abastecimiento de poblaciones. Confederación Hidrográfica del Segura, Murcia.

CHS (2007b). Memoria 2006. Confederación Hidrográfica del Segura, Murcia.

CHS (2008). Memoria 2007. Confederación Hidrográfica del Segura, Murcia. 
CHS (2009). Memoria 2008. Confederación Hidrográfica del Segura, Murcia.

CHS (2014). Borrador del Plan Hidrológico de la Cuenca del Segura 2015-2021. Confederación Hidrográfica de la Cuenca del Segura, Murcia.

CHS (2015). Estudio General sobre la Demarcación Hidrográfica del Segura. Confederación Hidrográfica del Segura, Murcia.

Claver, J. M. (2013). La experiencia de un contrato de cesión de derechos de aguas intercuencas (el derecho al aprovechamiento de las aguas trasvasadas); en Embid, A., ed.: Usos del agua (concesiones, autorizaciones y mercados de agua). AranzadiThomson Reuters, Cizur Menor (España).

Garrido, A., Maestu, J., Gomez-Ramos, A., Estrela, T., Yague, J., Segura, R., Calatrava, J., Arrojo, P. y Cubillo, F. (2013a). Voluntary water trading in Spain: A mixed approach of public and private initiatives; en Maestu, J., ed.: Water trading and global water scarcity: International experiences. Routledge, Abingdon, U.K. pp. 180-193.

Garrido, A., Rey, D. y Calatrava, J. (2013b). Water trading in Spain; en De Stefano, L. y Llamas, M. R., eds.; Water, agriculture and the environment in Spain: Can we square the circle? Botín Foundation, CRC Press, Boca Raton (CA); pp. 205-216.

Garrido A., Calatrava J. y Rey D. (2013c). La flexibilización del régimen de concesiones y el mercado de aguas en los usos de regadío; en Embid, A., ed.: Usos del agua (concesiones, autorizaciones y mercados de agua). Aranzadi-Thomson Reuters, Cizur Menor (España); pp. 177-197.

Hernández-Mora, N. (2013). El Tajo: Historia de un río ignorado. Fundación Nueva Cultura del Agua, Zaragoza.

Hernández-Mora, N. y Del Moral, L. (2015). Developing markets for water reallocation: Revisiting the experience of Spanish water mercantilización. Geoforum 62: 143-155.

Maestre-Valero, J. F., Martínez-Granados, D., Martínez-Alvarez, V. y Calatrava, J. (2013). Socio-economic impact of evaporation losses from reservoirs under past, current and future water availability scenarios in the semi-arid Segura basin. Water Resources Management 27(5): 1411-1426.

MCT (2007). La gestión del servicio 2006. Mancomunidad de los Canales del Taibilla, Ministerio de Medio Ambiente, Cartagena, España.

MCT (2008). La gestión del servicio 2007. Mancomunidad de los Canales del Taibilla, Ministerio de Medio Ambiente, Cartagena, España.

MCT (2009). La gestión del servicio 2008. Mancomunidad de los Canales del Taibilla, Ministerio de Medio Ambiente, Cartagena, España.

Palomo-Hierro, S., Gómez-Limón, J.A. y Riesgo, L. (2015). Water Markets in Spain: Performance and Challenges. Water 7: 652-678.

Rey D., Garrido A. y Calatrava J. (2014). Water markets in Spain: Meeting twenty-first century challenges with twentieth century regulations; en Easter, K. W. y Huang, Q., eds.; Water markets for the 21st. century: What have we learned? Springer, Dordrecht, The Netherlands; pp. 127-147.

SCRATS (2009): Memoria 2008. Sindicato Central de Regantes del Acueducto Tajo-Segura, Murcia.

SCRATS (2012): Memoria 2011. Sindicato Central de Regantes del Acueducto Tajo-Segura, Murcia.

SCRATS (2015): Memoria 2014. Sindicato Central de Regantes del Acueducto Tajo-Segura, Murcia.

Tisdell, J. G. (2011). Water markets in Australia: An experimental analysis of alternative market mechanisms. Australian Journal of Agricultural and Resource Economics 55(4): 500-517.

Wheeler, S., Garrick, D., Loch, A., y Bjornlund, H. (2013). Evaluating water market products to acquire water for the environment in Australia. Land Use Policy 30(1): 427-436.

Yagüe, J. (2008). Experiencia de los instrumentos de mercado en España; Thematic week seven: Economics and financing - The role of market instruments in integrated water management. Tribuna del Agua, Expo Agua 2008, Zaragoza. 


\title{
D-07
}

\section{ANÁLISIS DE LOS BENEFICIOS ECONÓMICOS DE UN SERVICIO DE ASESORAMIENTO AL REGANTE (SAR)}

\author{
Silva do Nascimento, A. K. ${ }^{1}$ Tarjuelo Martín-Benito, J. M. ${ }^{2}$ Ribeiro Vieira Lima, S. C. ${ }^{3}$ \\ Martinez-Romero, $A^{4}{ }^{4}$
}

${ }^{1}$ Estudiante de Doctorado, Universidad Castilla-la Mancha, anakelliane02@gmail.com

${ }^{2}$ Dr. Ingeniero Agrónomo, Catedrático de Universidad; Departamento de Producción Vegetal y Tecnología Agraria, UCLM; jose.tarjuelo@uclm.es

${ }^{3}$ Investigador, Instituto de Pesquisa e Inovação na Agricultura Irrigada (INOVAGRI), silviocarlos@inovagri.org.br

${ }^{4}$ Dr. Ingeniero Agrónomo, Profesor Asociado; ElIAB, Departamento de Mecánica Aplicada e Ingeniera de Proyectos, UCLM; angel.mromero@uclm.es

\section{Resumen}

Un Servicio de Asesoramiento al regante (SAR) tiene como objetivo principal la optimización del uso del agua en la agricultura, dando respuesta a las demandas tecnológicas de los regantes. El objetivo de este trabajo es analizar y cuantificar, para una parcela tipo de cebolla, los beneficios económicos de un Servicio de Asesoramiento al Regante (SAR), a través de un análisis comparativo de distintos manejos del riego en parcela. En el año 2015, en una parcela de cebolla ubicada en una Comunidad de Regantes (CCRR) de la provincia de Albacete se realizó el seguimiento del desarrollo fenológico del cultivo, y de la humedad en el suelo, que junto con los datos edáficos y climáticos permitió planificar la programación de riegos. Se plantearon cuatro escenarios comparativos: E1 (datos reales de manejo de riego en parcela), E2 (simulación tomando como referencia las recomendaciones semanales del SAR de Castilla-La Mancha (SIAR $\mathrm{CM}_{\mathrm{CM}}$ ), E3 (simulación con igual aporte que en el E1, variando la frecuencia y la dosis de riego) y E4 (simulación de riego optimizado realizando un Balance de agua en el suelo con el módulo de programación de riegos del programa MOPECO). Los costes de producción del cultivo se calcularon a partir de los datos facilitados por el agricultor, permitiendo interpretar indicadores tales como: el Suministro Relativo de Agua, Índice de Producción, Margen Bruto y la Productividad Agronómica del Agua. Los resultados indican que frente a un manejo sin seguir las recomendaciones de un SAR, los datos facilitados por el SIAR CM $_{\text {y }}$ una correcta programación pueden influir en un aumento de hasta $24 \%$ del rendimiento, una mayor Productividad Agronómica del Agua $\left(8,45 \mathrm{~kg} / \mathrm{m}^{3}\right.$ respecto a real obtenida de $7,14 \mathrm{~kg} / \mathrm{m}^{3}$ ) y un incremento del Margen Bruto de hasta un $50 \%$.

\section{1) Introducción}

El uso eficiente de agua y energía en la agricultura está ganando importancia debido a una tendencia limitante de la disponibilidad de agua para usos agrícolas, así como el aumento de los costes de energía. Estos aspectos condicionan la viabilidad de las actividades de riego en muchas zonas del mundo, entre ellas la región de Castilla-La Mancha (C-LM) (Ortega et al., 2004; Martínez-Valderrama et al., 2011).

A partir de la necesidad de una gestión adecuada de los cultivos que permite obtener producciones adecuadas y hacer un uso racional y eficiente de los recursos hídricos, los SAR se presentan como una herramienta adecuada para la optimización del uso del agua ofreciendo información para establecer una correcta programación de riegos.

Los SARs ofrecen apoyo técnico a los agricultores con el objetivo de conseguir un uso eficiente y racional de los medios de producción, especialmente de los fertilizantes, del agua, y 
de la energía, aumentando además la rentabilidad económica del regadío. Realizan una labor de transferencia tanto de información técnica, como de nuevas tecnologías que pueden aplicarse directamente en sus explotaciones, ayudando a optimizar su manejo, lo que repercute en beneficios de índole económicos y medioambientales.

La gestión óptima del riego en los cultivos implica la integración de diversos factores relacionados con la producción y calidad, que conducen al óptimo económico. Por ello es necesario definir y conocer las necesidades de agua de los cultivos, la interacción sueloplanta-atmósfera, efecto del déficit hídrico en la producción y calidad o el sistema de aplicación del agua de riego. El aumento de los costes de producción, especialmente los de la energía eléctrica asociada a los sistemas de riego presurizados, así como la limitación de las dotaciones de agua para el riego, está condicionando la implantación de cultivos y el manejo del riego en muchas zonas para hacer un uso más eficiente del agua. Uno de los principales problemas para que los SARs alcancen los objetivos potenciales, es conseguir que la información generada llegue a los usuarios a los que está destinada, así como que ésta, sea correctamente interpretada y aplicada para conseguir los objetivos perseguidos.

En general se asume la rentabilidad de los SARs, pero los trabajos que cuantifican los beneficios económicos de los mismos son limitados. El objetivo de este trabajo, que se engloba dentro de otro más amplio, es cuantificar y valorar los beneficios económicos de un SAR tomando como ejemplo un cultivo de cebolla, realizando un análisis comparativo de distintos manejos del riego en parcelas realizados por agricultores, comparándolo con un manejo en el que se tengan presentes las recomendaciones semanales de un SAR, y otro en el que se realice una programación de riegos más tecnificada, basada en un balance simplificado de agua en el suelo. Para ello se utilizan modelos de simulación de cultivo previamente calibrados experimentalmente tales como el modelo MOPECO (Domínguez et al., 2012).

\section{2) Materiales y métodos}

\section{1) Zona de Estudio}

Para la realización del estudio se realizó el seguimiento fenológico y manejo del riego en una parcela de cebolla de 2,48 ha durante la campaña de riegos de 2015, regada con cobertura total enterrada en marco 16,50m x 17,40m, dentro de una red colectiva de riego a la demanda ubicadas en el término municipal de Tarazona de la Mancha (Albacete) (Figura 1).

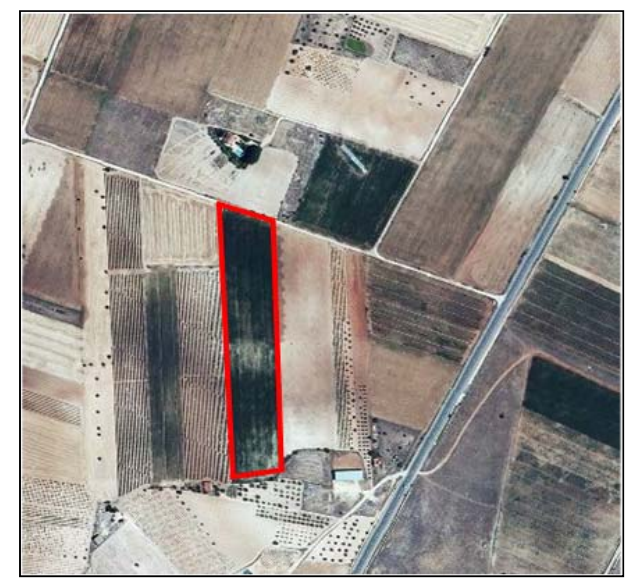

Figura 1. Parcela de seguimiento cultivada con cebolla; (Fuente: SigPac (http://sigpac.mapa.es/fega/visor/).

\section{2) Programación de Riego}

La programación de riegos se estableció siguiendo la metodología FAO del balance simplificado de agua en el suelo, contrastado con la medición de los valores del potencial 
hídrico en el suelo con sondas Watermark, estimando la equivalencia del contenido volumétrico de agua en el suelo en base a los valores medidos de densidad aparente del suelo y las curvas características de humedad con cámara de presión.

La evapotranspiración de referencia se estimó a partir de los datos registrados en la estación meteorológica de La Gineta integrada en la red del Servicio de Información Agroclimática para el Regadío por el método Penman Monteith (Allen et al., 1998). El balance hídrico se calculó mediante el módulo de programación de riegos del programa MOPECO que requiere datos sobre el suelo, clima y el cultivo. Los valores de Kc fueron obtenidos en base a las recomendaciones de FAO (Allen et al., 1998), adaptadas a los resultados de seguimiento realizados por el SIAR $R_{C M}$, para tener en cuenta las condiciones locales (Domínguez et al. 2012). Los valores de Kc utilizados en el cultivo fueron: en la etapa de establecimiento 0,65; en la Etapa de crecimiento vegetativo 0,65-1,20: en la etapa media 1,20 y en la etapa final $1,20-0,75$.

En la parcela del estudio se instaló, en un punto representativo de las condiciones medias de funcionamiento del sistema de riego, un transductor de presión para poder conocer el tiempo de riego, las condiciones de presión, y determinar la cantidad de agua aplicada. También se realizó al inicio de la campaña una evaluación en el sistema de riego.

Para analizar el posible efecto de distintos manejos, fueron considerados escenarios comparativos:

a) Escenario 1 (E1): este escenario presenta el riego real aplicado por el agricultor, basado en la experiencia.

b) Escenario 2 (E2): Simulación tomando como referencia las recomendaciones generales de consumos netos semanales ofrecidas por el SIAR $\mathrm{CM}_{\mathrm{M}}$. Los consumos publicados se refieren a valores de la semana anterior. Se ha establecido una frecuencia máxima de aplicación de 5 días (un riego a la semana) y mínima de 2 días (3 o 4 riegos por semana). El tiempo de riego utilizado varía entre $1 \mathrm{~h}(6 \mathrm{~mm})$ y $4 \mathrm{~h}(24 \mathrm{~mm})$.

c) Escenario 3 (E3): Simulación a partir del volumen real aplicado por el agricultor (E1), pero con intervalos entre riegos y dosis de riego distintos de los aplicados. El tiempo de riego para este manejo se ha establecido entre $1 \mathrm{~h}(6 \mathrm{~mm})$ y $3 \mathrm{~h}(18 \mathrm{~mm})$, con un intervalo entre riegos de entre 2 días y 4 días.

d) Escenario 4 (E4): Simulación aplicando un riego optimizado para la máxima producción, a partir de un balance de agua en el suelo, con ayuda del modelo MOPECO. El tiempo de riego para este manejo se ha establecido entre $1 \mathrm{~h}(6 \mathrm{~mm})$ y $5 \mathrm{~h}(30 \mathrm{~mm})$, con un intervalo entre riegos entre 1 días y 4 días.

MOPECO utiliza el modelo propuesto por Stewart et al. (1977) que estima el rendimiento del cultivo en función de la relación entre evapotranspiración real y la evapotranspiración máxima (ETa/ETm) en las diferentes etapas de crecimiento del cultivo. Cuando $\mathrm{ETa}<\mathrm{ETm}$ la planta sufre estrés hídrico que puede provocar un descenso en el rendimiento final (rendimiento real $(\mathrm{Ya})<$ rendimiento potencial $(\mathrm{Ym})$. El rendimiento potencial depende de la zona del estudio (Domínguez et al., 2012).

\section{3) Evaluación de los costes}

Los costes del SAR son muy distintos dependiendo de diversos factores, tales como los objetivos planteados, el nivel de información generada o la estructura y disposición de las explotaciones. En este trabajo los costes de producción del cultivo, para los distintos escenarios, se calcularon utilizando las informaciones facilitadas por los productores sobre la materia prima, abonos, labores y aplicación del agua. La metodología utilizada para calcular los costes fue la facilitada por de Juan et al. (2003). Los costes fueron clasificados en Costes externos, que se refieren a los costes como semillas, fertilizantes, fitosanitarios y agua; Costes calculados, que son los de mano de obra y maquinaria; Costes estimados, que son los seguros agrícolas y alquiler de maquinarias y Costes fijos, que hace referencia a una tasa fija por tratarse de una Comunidad de Regantes. La cuantificación de los ingresos fueron obtenidos a través de la multiplicación entre la producción y el precio de venta, que en este trabajo fue utilizado la cotización informada por el agricultor. Se agregó al resultado 
de los ingresos el valor de la PAC, que es una ayuda proporcionada por la Unión Europea a los agricultores. Toda esta información se analizó utilizando distintos indicadores para evaluar la repercusión económica de una correcta programación de riegos. Los indicadores planteados fueron:

e) Suministro Relativo de Agua (SRA): muestra la relación entre el agua que entra al sistema (precipitación y riego) y el agua requerida (evapotranspiración), indicando la relación entre la cantidad de agua disponible o utilizada y la cantidad de agua necesaria para la producción (Levine, 1982). Este indicador fue calculado por la Ecuación 1.

$$
S R A=(R G+P e) E T c^{-1}
$$

Donde SRA: suministro relativo de agua (\%); RG: agua de riego ( $\left.\mathrm{m}^{3} / \mathrm{ha}\right)$; Pe: precipitación efectiva ( $\left.\mathrm{m}^{3} / \mathrm{ha}\right)$. ETc: evapotranspiración de cultivo $\left(\mathrm{m}^{3} / \mathrm{ha}\right)$. La Precipitación efectiva $(\mathrm{Pe})$ se estima a través del USDA "metodología de la curva número 2" (SCS, 1972; NRCS, 2004).

La caracterización del riego aportado en función de si se ven satisfechas las necesidades de los cultivos, atiende al criterio presentado en la tabla 1:

Tabla 1. Criterio utilizado para clasificación de los escenarios según SRA

\begin{tabular}{|l|l|}
\hline Si SRA $(\%)>115 \%$ & Riego excesivo \\
\hline Si $115 \geq$ SRA $(\%) \geq 85 \%$ & Bien regado \\
\hline Si SRA $(\%)<85 \%$ & Riego insuficiente \\
\hline
\end{tabular}

f) Índice de Producción (IP), definido por Bos et. al (1994), relaciona la producción real (Cr) en $\mathrm{kg} / \mathrm{ha}$ con la producción máxima alcanzable por el cultivo $(\mathrm{Cp})$ en $\mathrm{kg} / \mathrm{ha}$. Los datos reales fueron facilitados por el agricultor y el rendimiento potencial, estimado en el modelo MOPECO. El indicador fue calculado por la Ecuación 2.

$$
\mathrm{IP}=\mathrm{Cr} / \mathrm{Cp}
$$

g) Margen Bruto de la producción (MB), El análisis de este indicador puede ser usado para comparar la utilidad de emplear diferentes tecnologías; en este caso, la tecnología ofrecida por el SIAR y la utilizada por el agricultor. El margen bruto (MB, en $€ /$ ha) fue calculado por la Ecuación 3, donde VP es el valor total de producción, incluyendo la Subvención ( $€ /$ ha) y GG son los gastos globales ( $€ /$ ha).

$$
M B=V P-G G
$$

h) Productividad Agronómica del Agua (PAA), que es claramente dependiente del cultivo, de las condiciones climáticas, y del manejo del riego llevado a cabo por el agricultor. Puede medirse mediante la relación entre la unidad de resultado conseguido y la unidad de insumo. En este caso el término productividad del agua (PA) es usado para poner de manifiesto la relación entre la cantidad del producto obtenido sobre el volumen o valor del agua aplicada (FAO, 2003). La PAA se obtuvo por la Ecuación 4.

$$
\mathrm{PAA}=\mathrm{RC} / \mathrm{Vr}
$$

En que PAA: Productividad Agronómica del Agua en $\mathrm{kg} / \mathrm{m}^{3}$; RC: rendimiento real del cultivo, en $\mathrm{kg} / \mathrm{ha}$; $\mathrm{Vt}=$ volumen de riego aplicado en $\mathrm{m}^{3} / \mathrm{ha}$, obtenido con base en la evaluación en campo.

\section{3) Resultados y discusión}




\section{1) Balance de agua en el suelo. Relaciones ETa/ETm en el cultivo}

Con respecto al E1 (manejo real en parcela), en la Figura 2 se muestra el gráfico de la evolución del contenido de agua en el suelo generado por el modelo MOPECO según la programación de riego seguida por el agricultor y las lluvias registradas en la parcela de estudio. Para facilitar la comprensión del gráfico cabe indicar que, la línea AW representa la evolución diaria de la cantidad de agua que hay disponible en el suelo para el cultivo durante su ciclo de crecimiento. Su magnitud depende de las características físicas y profundidad del suelo y la profundidad radicular alcanzada por el cultivo en cada etapa. La línea 1-p representa el nivel de agotamiento permisible de agua en el suelo. Representa el contenido de agua mínima en el suelo por encima del cual se evita el estrés hídrico en el cultivo que puede repercutir en el rendimiento del cultivo. Este valor depende del tipo de cultivo, su estado de desarrollo y de las condiciones climáticas (tomando como referencia la evapotranspiración de referencia, ETo). La línea ETa/ETm acumulada por etapa representa la relación entre evapotranspiración real del cultivo (ETa) y la evapotranspiración de un cultivo específico en condiciones de densidad y fertilización de suelo óptimas, es decir el máximo que podría evapotranspirar (Evapotranspiración máxima, ETm) en cada etapa. La línea $\mathrm{ETa} / \mathrm{ETm}$ diario representa la evolución de la relación diaria $\mathrm{ETa} / \mathrm{ETm}$; cuando este valor es inferior a 1 indica que el cultivo está sometido a estrés. Los puntos Pe indican la precipitación efectiva diaria registrada durante el ciclo del cultivo y los puntos Riego Neto recogen la altura de lamina de agua $(\mathrm{mm} \circ \mathrm{l} / \mathrm{m} 2)$ aplicada con los diferentes riegos.

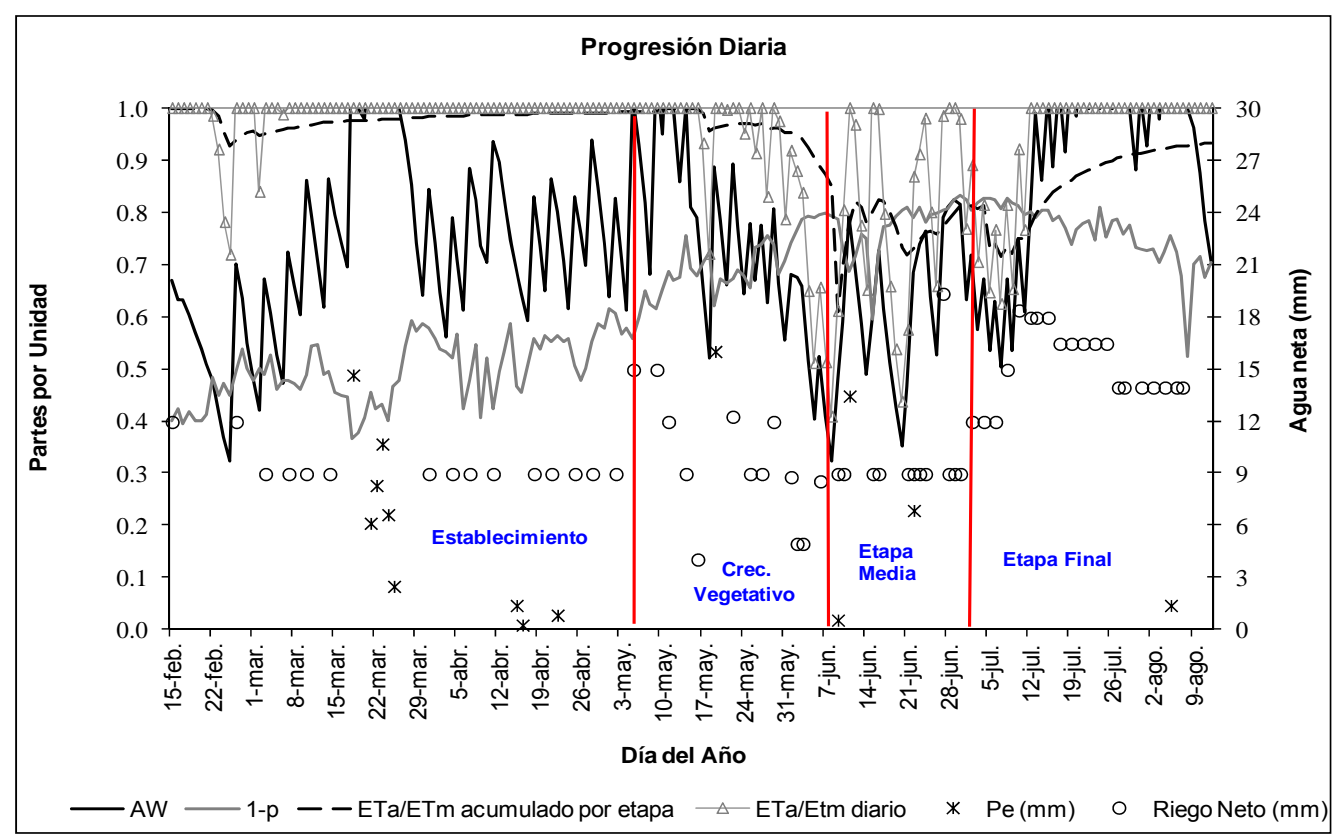

Figura 2. Evolución del contenido de agua aplicado para el cultivo de cebolla. Manejo real aplicado por agricultor (E1).

En este escenario, el riego bruto aportado se estimó en $7907 \mathrm{~m}^{3} /$ ha (estimado a partir horas de funcionamiento del sistema). La relación Evapotranspiración real /Evapotranspiración máxima del cultivo (ETa/ETm) del 90\%, indica que se realizó un manejo deficitario. Por etapas, las relaciones ETa/ETm fueron del $99 \%$ en la etapa de establecimiento, del $85 \%$ en la etapa de crecimiento vegetativo (estrés sufrido entre los días 21 de mayo hasta 6 de junio), del $81 \%$ en la etapa media (estrés observado en la Figura 2 entre los días 8 de junio hasta 03 de julio), y del 93\% en la etapa final (estrés moderado sufrido entre los días 4 hasta 12 de julio). La percolación estimada con MOPECO fue de 538 $\mathrm{m}^{3} / \mathrm{ha}$, de los que $226 \mathrm{~m}^{3} /$ ha se debieron a las lluvias ocurridas en el mes de marzo, (primera etapa del cultivo) y los $312 \mathrm{~m}^{3} /$ ha por el riego (Etapa Final). 
Las pautas del manejo del riego del agricultor fueron las siguientes: durante la etapa de establecimiento, riegos de $1 \mathrm{~h}(6 \mathrm{~mm}) 2$ veces a la semana. A partir de la etapa de crecimiento vegetativo hasta mitad de la etapa media, riegos de hasta $2 \mathrm{~h}(12 \mathrm{~mm})$, tres veces por semana. A partir de la mitad de la etapa media hasta el final del ciclo del cultivo, los riegos fueron de hasta $3 \mathrm{~h}$, con una frecuencia de 4 o 5 veces a la semana. El rendimiento final obtenido fue de $56.419 \mathrm{~kg} / \mathrm{ha}$ (Tabla 2), inferior a los $70.000 \mathrm{~kg} / \mathrm{ha}$ (rendimiento potencial considerado con base al obtenidos en otras parcelas en la misma zona en el año 2015). Este descenso del $24 \%$ respecto a producción máxima puede ser debido mayoritariamente al estrés de aproximadamente el $10 \%$ al que fue sometido el cultivo. En otras parcelas de seguimiento en la zona, para una relación ETa/ETm del 93\%, se obtuvieron rendimientos de $65682 \mathrm{~kg} / \mathrm{ha}$.

En el escenario E2, donde se utilizan las recomendaciones semanales de consumos del SIAR ${ }_{\mathrm{CM}}$, el aporte en forma de riego bruto estimado es de $8.724 \mathrm{~m}^{3} / \mathrm{ha}$, para una relación $\mathrm{ETa} / \mathrm{ETm}$ del $96 \%$. Por etapas, as relaciones $\mathrm{ETa} / \mathrm{ETm}$ fueron del $96 \%$ en la etapa de establecimiento, del $88 \%$ en la etapa de crecimiento vegetativo, $100 \%$ en la etapa media y $99 \%$ en la etapa final. Según los datos simulados por el programa MOPECO, la percolación estimada sería de $787 \mathrm{~m}^{3} / \mathrm{ha}$, de los que $323 \mathrm{~m}^{3} /$ ha se debieron a las lluvias ocurridas en el mes de marzo y los $464 \mathrm{~m}^{3} / \mathrm{ha}$ por el riego

Las pautas del manejo del riego basada en las recomendaciones semanales del SIAR ${ }_{C M}$ fueron: durante la etapa de establecimiento, riegos de hasta $3,5 \mathrm{~h}(21 \mathrm{~mm})$, una vez a la semana. En la etapa de crecimiento vegetativo, riegos de hasta $3 \mathrm{~h}(18 \mathrm{~mm})$ dos veces a la semana. En la etapa media, los riegos fueron de hasta $4 \mathrm{~h}(24 \mathrm{~mm})$, con una frecuencia de 2 o 3 veces a la semana y en la etapa final los riegos fueron de hasta $4 \mathrm{~h}(24 \mathrm{~mm}) 3$ veces a la semana. El rendimiento estimado fue de $67.150 \mathrm{~kg} / \mathrm{m}^{3}$ (Tabla 2), lo que representa un incremento de $19 \%$ con respecto a producción real obtenida.

En el escenario E3, el riego bruto aportado se estimó en $7907 \mathrm{~m}^{3} / \mathrm{ha}$ (aportando el mismo volumen de agua total que el agricultor (E1) variando la pauta de riegos) alcanzado una $\mathrm{ETa} / \mathrm{ETm}$ de $97 \%$, lo que conlleva un ligero estrés. Las relaciones ETa/ETm serían de $98 \%$ en la etapa de establecimiento, $92 \%$ en la etapa de crecimiento vegetativo, $97 \%$ en la etapa media y $99 \%$ en la etapa final. La percolación estimada con MOPECO fue de 158 $\mathrm{m}^{3} /$ ha, debido a las lluvias ocurridas en el mes de marzo (primera etapa del cultivo).

Las pautas del manejo del riego en este escenario fueron: durante la etapa de establecimiento riegos de hasta $1,5 \mathrm{~h}(9 \mathrm{~mm})$ dos veces a la semana (intervalo entre riegos de 4 días). Durante la mitad de la etapa de crecimiento vegetativo, riegos de hasta $2,5 \mathrm{~h}$ (15 $\mathrm{mm}) 2$ o 3 veces a la semana (intervalo de riegos de 3 días). A partir de la mitad de la segunda etapa (crecimiento vegetativo) hasta la primera semana de la etapa final, riegos de hasta $3 \mathrm{~h}$ (18 mm), con intervalo de 2 días ( 3 o 4 veces a la semana). En el resto de la etapa final riegos de hasta $2,1 \mathrm{~h}(13 \mathrm{~mm}) 3$ o 4 veces a la semana (intervalo de 2 días).

En la Figura 3 se representa la distribución del agua aplicada en las distintas etapas de desarrollo fenológico para los escenarios E1 y E3, donde el volumen total en el ciclo es el mismo. En la etapa de establecimiento y la etapa final el agricultor (E1) aplica un volumen superior al estimado en el E3, mientras que en la etapa de crecimiento vegetativo y etapa media el aporte fue inferior.

La principal diferencia entre ambos manejos, radica en el momento de aplicación del déficit, concentrado en el E3 durante la etapa de crecimiento vegetativo (ETa/ETm de 92\%) pues durante los periodos vegetativos y de maduración, el cultivo parece ser menos sensible al déficit de agua (Shock et al., 2000; Kadayifci et al., 2005; Bekele and Tilahun, 2007). En el E3, durante la etapa final, se reduce la aportación de agua, lo que limita la percolación (en E1 la percolación en esta etapa fue de $312 \mathrm{~m}^{3} / \mathrm{ha}$ ). Este manejo permite aumentar el aporte en la etapa de máxima sensibilidad al estrés (etapa media), aumentando el rendimiento en un $18,4 \%$ (66.801 kg/ha en el E3, frente a los $56.419 \mathrm{~kg} / \mathrm{ha}$ del E1). 


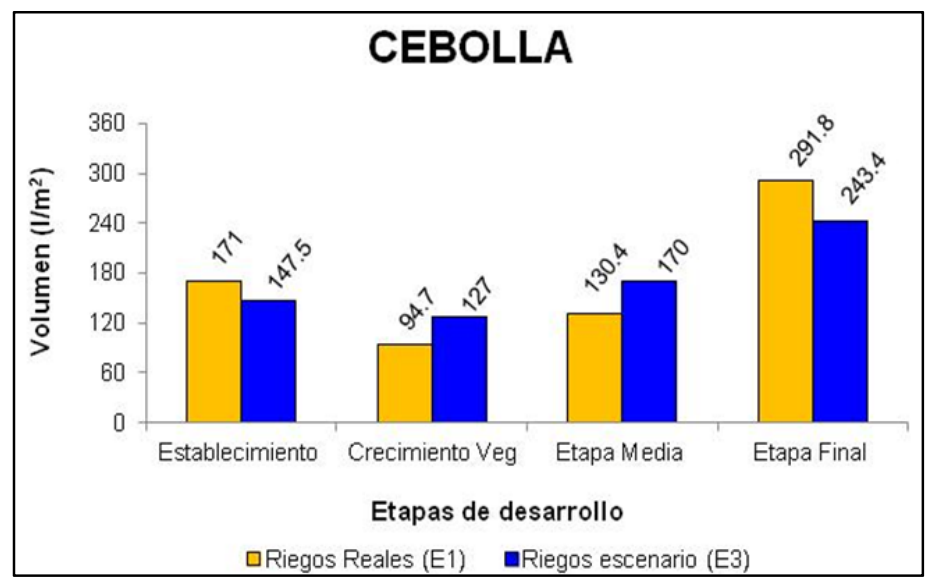

Figura 3: Distribución del agua aportada en las distintas etapas de cebolla para los los escenarios E1 y E3 (igual volumen total).

En el escenario 4, donde se simuló un manejo sin estrés, de máximo rendimiento, el programa estima un riego bruto de $8.256 \mathrm{~m}^{3} /$ ha con una ETa/ETm final y por etapas de $100 \%$. La percolación estimada con MOPECO fue de $138 \mathrm{~m}^{3} / \mathrm{ha}$, debido a las lluvias en el mes de marzo.

Las pautas del manejo del riego en este escenario fueron: durante la etapa de establecimiento riegos de hasta $1,5 \mathrm{~h}(9 \mathrm{~mm})$ aplicados con intervalo de riegos de 2 o 3 días. En la etapa de crecimiento vegetativo riegos de hasta $2,6 \mathrm{~h}(15,4 \mathrm{~mm}) 3$ veces a la semana. En la etapa media riegos de hasta $3,5 \mathrm{~h}(21,3 \mathrm{~mm}) 3$ veces a la semana y en la etapa final riegos de hasta $3,6 \mathrm{~h}(21,5 \mathrm{~mm}) 2$ a 4 veces a la semana. El rendimiento estimado fue de $69.769 \mathrm{~kg} / \mathrm{ha}$.

En la Figura 4 se representa los riegos semanales aplicados en el E1 y los propuestos en el resto de los distintos escenarios, así como la evolución del volumen acumulado por semanas. En la Figura 4a, el E1 frente al E2, durante la primera etapa los riegos aplicados por el agricultor fueron mayores que el recomendado en el E2. En la etapa de crecimiento vegetativo y la etapa media riega por debajo del E2 y en la etapa final los riegos, en su mayoría, fueron superiores al recomendado en E2.

La Figura 4b, se observa la comparación entre E1 y E3 que durante la etapa de establecimiento los riegos reales aplicados fueron superiores durante el período de 2 de marzo hasta 12 de abril. Durante la Etapa de crecimiento vegetativo y Etapa media el E3 recomienda regar más, sin embargo en la etapa final recomienda regar menos al aplicado en el E1.

La comparación entre E1 y E4 (Figura 4c), en la etapa de establecimiento el agricultor ha regado más que el propuesto en el período de 2 a 15 de marzo. Durante las etapas de crecimiento vegetativo y media hasta el día 12 de julio (inicio de la etapa final) ha regado por debajo del recomendado en E4. A partir de mediados de la etapa final ha regado por encima del indicado en E4.

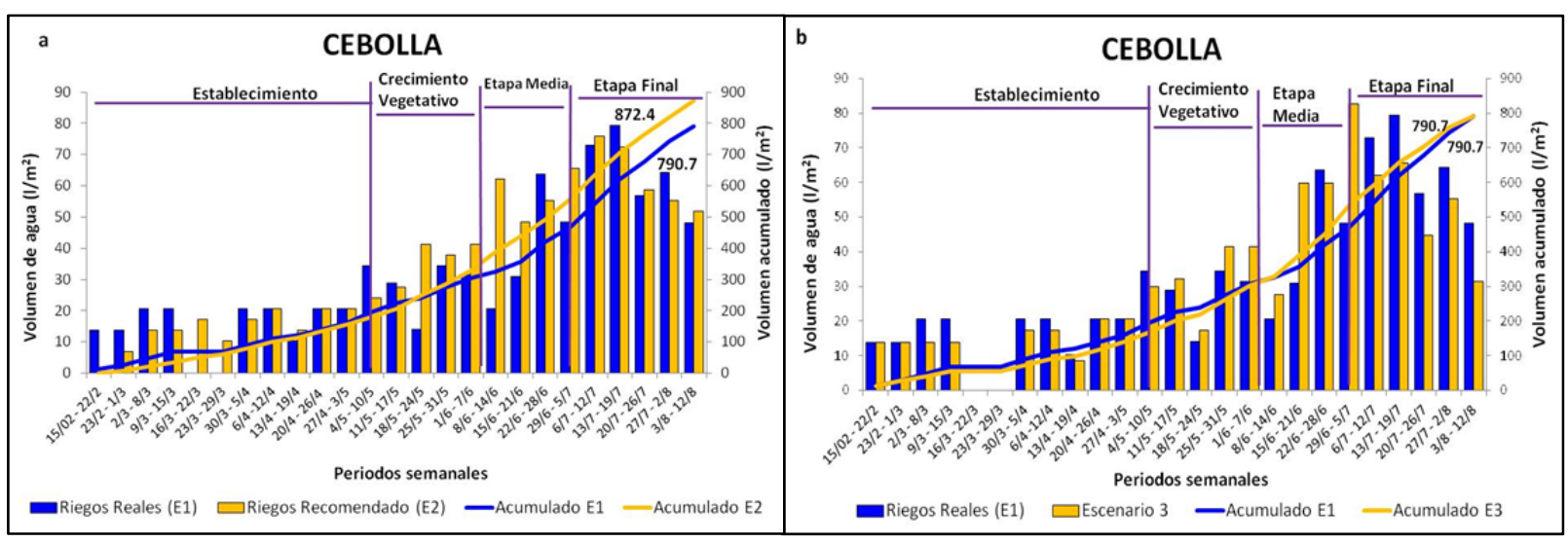




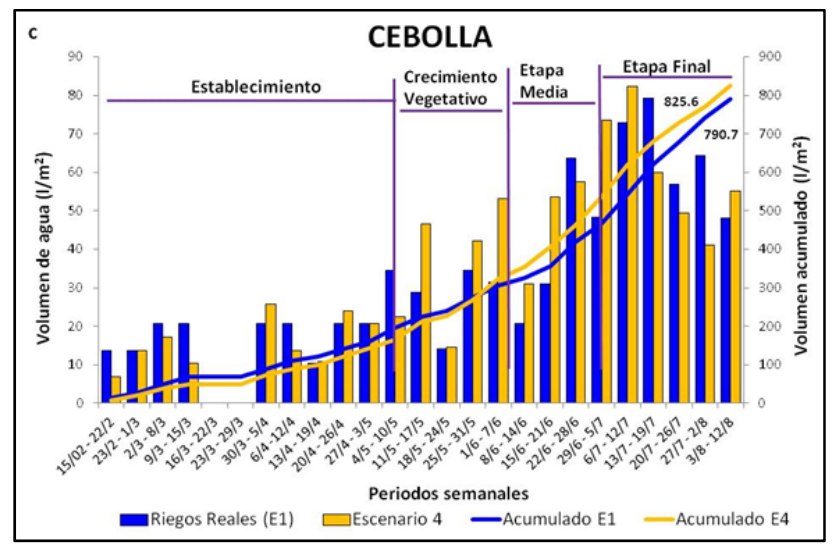

Figura 4. (a) Comparación entre los riegos semanales aplicados (E1) y los propuestos en la simulación del E2; (b) Comparación entre E1 y los propuestos en la simulación del E3; (c) Comparación entre E1 y los propuestos en la simulación del E4.

\section{2) Evaluación de los Costes}

En la Tabla 2 se presenta los ingresos y los costes para los cuatro escenarios: E1 (real), E2 (recomendación de consumos máximos semanales, SIAR $\mathrm{CLM}_{\mathrm{M}}$ ), E3 (mismo volumen del E1 aplicado con distinto intervalo y dosis de riego) y E4 (riego con máxima producción).

Tabla 2. Resumen de producción, Ingresos y los Costes para el cultivo de Cebolla en la parcela estudio.

\begin{tabular}{|c|c|c|c|c|}
\hline & E1 & E2 & E3 & E4 \\
\hline Producción (kg/ha) & 56419 & 67150 & 66801 & 69769 \\
\hline Ingresos + PAC (€/ha) & 8198,7 & 9701 & 9652,3 & 10067,8 \\
\hline Costes externos $(€ / \mathrm{ha})$ & 2489,8 & 2590,6 & 2489,8 & 2532,9 \\
\hline Costes calculados $(€ / \mathrm{ha})$ & 2134,6 & 2530,5 & 2134,5 & 2528,7 \\
\hline Costes estimados $(€ / \mathrm{ha})$ & 779,7 & 915 & 883 & 941,3 \\
\hline Coste Fijo $(€ / \mathrm{ha})$ & 130 & 130 & 130 & 130 \\
\hline Costes Totales $(€ / \mathrm{ha})$ & 5534,1 & 6166,2 & 5637,9 & 6132,9 \\
\hline
\end{tabular}

Para calcular los costes de los escenarios se utilizaron los mismos datos de materia prima y laboreos facilitados por el agricultor, y por lo tanto, la diferencia entre los costes es la cantidad de volumen bruto aportado en cada escenario y el incremento de los costes de mano de obra derivado del tiempo de funcionamiento del sistema de riego. El precio de venta informado por el agricultor fue de $0,14 € / \mathrm{kg}$. Se puede observar que los distintos manejos influyeron en la producción, donde E4 presenta mayor producción estimada $(69.769 \mathrm{~kg} / \mathrm{ha}), 24 \%$ más que la producción real y consecuentemente mayores ingresos, debido a la mayor producción estimada. El E2 presenta mayores costes por estimar un aporte mayor de volumen de riego bruto. Es importante destacar que en las simulaciones para E1 y E3, utiliza la misma cantidad de agua, sin embargo una mejor programación del manejo conlleva a un incremento en la producción de $18,4 \%$ en E3 $(66.801 \mathrm{~kg} / \mathrm{ha})$ respecto a producción real. El E2 presenta una producción estimada en $67150 \mathrm{~kg} / \mathrm{ha}$, lo que supone un incremento de $19 \%$ respecto a real obtenida.

\section{3) Indicadores}

La Tabla 3 presenta los valores de los indicadores de los cuatro escenarios estudiados. En los E1 y E3 se da el menor valor de SRA. En el escenario 1, el cultivo sufrió un estrés centrado en la Etapa de crecimiento vegetativo (ETa/ETm de 85\%) y en la Etapa media (ETa/ETm de $81 \%)$. En E3 el cultivo presenta estrés en la Etapa de crecimiento 
vegetativo (ETa/ETm de 92\%). En estos dos escenarios los valores de SRA son iguales al usar la misma cantidad de riego bruto aportado, pero con distribución distinta. A pesar del estrés mas fuerte, el manejo aplicado por el agricultor se clasifica a nivel global como bien regado, al igual que en el resto de los escenarios. Esa clasificación indica que las necesidades de los cultivos se ven satisfechas correctamente. El efecto del estrés sometido al cultivo en los escenarios E1 y E3 se puede observar más claramente al analizar el indicador IP, que presenta menor valor $(0,81)$ en el E1. EI menor valor de IP en E1 puede ser asignado al estrés sufrido en la tercera etapa, ya que esta es la etapa de mayor sensibilidad al estrés en el cultivo de la cebolla. En ésta la falta de agua puede repercutir más negativamente en el rendimiento final del cultivo. En el E2, ofrece un índice de producción alto $(0,96)$ al igual que el E3 y el E4 (IP de 0,95 y 1,00 respectivamente).

Tabla 3. Indicadores evaluados para los distintos escenarios en el cultivo de cebolla

\begin{tabular}{|l|c|c|c|c|}
\hline Indicador & E 1 & E 2 & E 3 & E 4 \\
\hline SRA (\%) & 0,98 & 1,07 & 0,98 & 1,01 \\
\hline IP & 0,81 & 0,96 & 0,95 & 1 \\
\hline MB $(€ / \mathrm{ha})$ & 2664,6 & 3534,8 & 4014,4 & 3934,8 \\
\hline PAA $\left(\mathrm{kg} / \mathrm{m}^{3}\right)$ & 7,14 & 7,70 & 8,45 & 8,45 \\
\hline
\end{tabular}

$\mathrm{SRA}=$ Suministro relativo de agua; IP, índice de producción; MB, margen bruto; PAA, productividad agronómica del agua.

Analizando el indicador Margen Bruto, (Tabla 3) se puede comprobar que el manejo aplicado por el agricultor derivó en un menor valor si se compara con el resto. En el E1 (riego bruto estimado en $7.907 \mathrm{~m}^{3} / \mathrm{ha}$ ) y E2, basada en las recomendaciones semanales del $\mathrm{SIAR}_{\mathrm{CM}}$, la programación recomienda aplicar un mayor valor de riego bruto $\left(8.724 \mathrm{~m}^{3} / \mathrm{ha}\right)$, que conlleva un aumento de los costes en $11,4 \%$, sin embargo aumenta la producción estimada en $67150 \mathrm{~kg} / \mathrm{ha}$ (19\% de incremento), y el MB en un $32 \%$.

Comparando el E1 con el E3, con aporte de riego bruto estimado en $7.907 \mathrm{~m}^{3} / \mathrm{ha}$, el coste total en el E3 es ligeramente mayor debido al seguro agrario, considerado en la metodología, como $1 \%$ del valor de la producción final. En eses escenarios se puede observar claramente el efecto del manejo aplicado, utilizando la misma cantidad de riego bruto de forma distinta, puede proporcionar aumento de la producción del 18,4\% (66.801 kg/ha), que repercute en un aumento del $50 \%$ del MB en el E3 (Tabla 3).

En el manejo propuesto en $\mathrm{E} 4$, con máxima producción, el riego bruto recomendado es de $8.256 \mathrm{~m}^{3} /$ ha, un $4,4 \%$ más que en el E1 $\left(7.907 \mathrm{~m}^{3} /\right.$ ha) que repercute en un incremento de los costes del $11 \%$, un aumento de producción del $24 \%$, que supone un $47,6 \%$ más en el MB (Tabla 3).

El indicador PAA se ha utilizado para analizar la diferencia entre el uso o no de las recomendaciones del SIAR $R_{C M}$. El E1 presenta una PAA de $7,14 \mathrm{~kg} / \mathrm{m}^{3}$, mientras que en el E3 y E4, se estima la mayor PAA, que asciende a $8,45 \mathrm{~kg} / \mathrm{m}^{3}$ en los dos escenarios. Para E2 el valor estimado sería menor que en el E3 y $\mathrm{E} 4$, con $7,70 \mathrm{~kg} / \mathrm{m}^{3}$. En un estudio similar, Montoro et. al (2008), estima un valor superior, con una media de PAA en la cebolla de $10,13 \mathrm{~kg} / \mathrm{m}^{3}$ para una producción media de $65.125 \mathrm{~kg} / \mathrm{ha}$ y $6.472 \mathrm{~m}^{3} / \mathrm{ha}$ de agua aplicada (media de los años de 2000 hasta 2005). Las condiciones climáticas del año 2015 con temperaturas más altas de los valores medios, pudo repercutir en los resultados, al requerir el cultivo un mayor volumen de agua para satisfacer las necesidades hídricas. Con los datos reales y los escenarios simulados se puede observar el efecto de distintos manejos en la producción, en los costes, el MB y a utilización de indicadores que posibilitan evaluar el posible beneficio de una correcta programación de riegos.

\section{4) Conclusiones}


La consideración de las recomendaciones semanales de carácter general de consumos máximos ofrecidas por el SIAR $\mathrm{CM}_{\mathrm{CM}}$, frente a un manejo del riego basado en la experiencia, repercute en un aumento del rendimiento del cultivo de cebolla cuya cuantificación dependerá del manejo que esté realizando. En el caso del estudio el aumento del rendimiento ha sido del $19 \%$, con una mejora en la eficiencia del uso de agua del $8 \%$ y del Margen Bruto estimado en $32 \%$. Una programación de riegos, basada en un balance de agua diario del suelo, permite ajustar el agua aplicada frente a la demandada por el cultivo, aproximando los rendimientos reales a los potenciales, limitando el agua perdida por percolación. En este caso el aumento del rendimiento ha sido del $18,4 \%$, con una mejora en la eficiencia del uso de agua del $18 \%$ y del Margen Bruto estimado en $50 \%$.

En una gran zona regable, la información general que proporcionan los SARs o la correcta programación de riegos basada en un balance de agua en el suelo a nivel de parcela mejora los rendimientos, el margen bruto y la eficiencia de los cultivos en distintos niveles.

\section{5) Agradecimientos}

Este trabajo fue realizado con el apoyo de CAPES, Coordinación de Perfeccionamiento de Personal de Nivel Superior - Brasil.

\section{6) Bibliografía}

Allen, R.G., Pereira, L.S., Raes, D., Smith, M., Crop evapotranspiration: guidelines for computing crop water requirements. Irrigation and Drainage. Paper 56. FAO, Rome, Italy, 1998.

Bekele, S., Tilahun, K., 2007. Regulated déficit irrigation scheduling of onion in a semiarid region of Ethiopia. Agricultural Water Management 89, 148-152.

Bos, M.G.; Murray-Rust, D.H.; Merrey, D.J.; Johnson, H. G. y Snellen, W.B. 1994. Methodologies for assessing performances of irrigation and drainage management. Irrigation and Drainage Systems, 7:231-261.

de Juan, J.A., Ortega, J.F., Tarjuelo, J.M., 2003. Sistemas de cultivo. Evaluación de itinerarios técnicos. Ediciones Mundi-Prensa, Madrid, Spain.

Domínguez A., Jiménez. M., Tarjuelo J.M., de Juan. J. A., Martínez-Romero A., Leite. K. N., 2012. Simulation of onion crop behavior under optimized regulated deficit irrigation using MOPECO model in a semi-arid enviroment. Agricultural Water Management. 113, 64-75 Q1.

FAO (Food and Agricultura Organization of the United Nations), 2003. Unlocking the Water Potencial of Agriculture. Roma, Italia.

Kadayifci, A., Tuylu, G.I., Ucar, Y., Cakmak, B., 2005. Crop water use of onion (Allium cepa L.) in Turkey. Agricultural Water Management 72, 59-68.

Levine G, 1982. Relative Water Supply: An explanatory variable for irrigation systems. Technichal Report No. 6. Cornell University. Ithaca, New York. EEUU.

Martín de Santa Olalla, F.J., Domínguez-Padilla, A., Lopez, R., 2004. Production and quality of the onion crop (Allium cepa L.) cultivated under controlled deficit irrigation conditions in a semi-arid climate. Agricultural Water Management 68, 77-89.

Martínez-Valderrama, J., Ibáñez, J., Alcalá, F.J., Domínguez, A., Yassin, M., Puigdefábregas, J., 2011. The use of a hydrological-economic model to assess sustainability in groundwater-dependent agriculture in drylands. Journal of Hydrology 402, 80-91.

NRCS, 2004. Part 630 Hydrology. National Engineering Handbook. Chapter 10. Estimation of Direct Runoff from Storm Rainfall. Natural Resources Conservation Service. United States Department of Agriculture.

SCS, 1972. Section 4: Hydrology. National Engineering Handbook. Soil Conservation Service, United States Department of Agriculture.

Shock,C. C. Feibert, E. B. G., Saunders, L. D. , 2000. Irrigation criteria for drip-irrigated onions. HortScience 35, 63-66.

Stewart, J. I., Hagan, R. M., Pruitt, W. O., Kanks, R. J., Riley, J. P., Danilson, R. E., Franklin, W. T., Jackson, E. B., 1977. Optimizing Crop Production Trough Control of Water and Salinity levels. Utah Water Res. Lab. PWRG 151-1, UT, USA. 


\title{
D-08
}

\section{INFLUENCIA DE LA EXPROPIACIÓN FORZOSA EN LA DISPONIBILIDAD DE TERRENOS PARA LA EJECUCIÓN DE OBRAS DE MODERNIZACIÓN DE REGADÍOS}

\author{
Martín de la Torre Martínez, C (1) (P); Serrano Bermejo, A (2);De la Fuente García, E (3)
}

${ }^{1}$ Responsable Unidad de Expropiaciones, Gerencia de Ingeniería y Edificación (Tragsatec), Julián Camarillo 6B, 28037, Madrid, cmam@tragsa.es

2 Profesor Titular, Universidad Politécnica de Madrid, Escuela Técnica Superior de Ingenieros Agrónomos, Departamento de Economía Agraria, Estadística y Gestión de Empresas, Av. Puerta de Hierro 2, 28040, Madrid, arturo.serrano@upm.es

3 Jefe de Actuaciones y Proyectos, Gerencia de Ingeniería y Edificación (Tragsatec), Julián Camarillo 6B, 28037, Madrid, emfg@tragsa.es

\section{Resumen}

La evolución de la economía del país, ha hecho que los tipos de interés hayan disminuido de manera continuada en los últimos años. El hecho de que la determinación del valor de expropiación desde el año 2.007 se lleve a cabo mediante capitalización de rentas y que, por lo tanto, el valor de indemnización dependa del tipo de interés, ha ocasionado un efecto económico difícil para las partes beneficiarias en una expropiación.

En este trabajo se estudia la evolución de la normativa, se cuantifican los resultados para el caso de una finca concreta de una explotación de algodón de regadío en el valle del Guadalquivir y se analizan los resultados.

En el estudio puede observarse que en los últimos ocho años, el valor de mercado de la tierra ha seguido una tendencia a la baja. Por el contrario, el valor de indemnización por expropiación de la misma se ha disparado, lo que hace inviable a las comunidades de regantes la participación en la modernización de regadíos, así como a la Administración la aplicación del Plan Hidrológico Nacional o Plan Nacional de Regadíos.

Estas circunstancias han hecho que, en octubre de 2.015 (Ley de carreteras) y noviembre de 2.015 (Texto refundido de Ley de Suelo), la legislación haya intentado paliar la situación, aunque sigue siendo insuficiente. Por ello se proponen algunas medidas a modo de conclusión al final del trabajo.

\section{Abstract}

The evolution of the country's economy has made that interest rates have decreased continuously in recent years. The fact that since the year 2007 the determination of the value of expropriation is being carried out through revenue capitalization, in which the indemnification value depends on the interest rate, has caused a difficult economic impact in the recipient parties of an expropriation.

In this paper we study the evolution of the expropriation regulations as well as the assessment of the amount of money corresponding to the expropriation of a farm dedicated the production of cotton in the Guadalquivir valley.

In the study it can be seen that over the last eight years the market value of the land has followed a downward trend. On the other hand, the value of compensation for land 
expropriation has been triggered, making infeasible to the irrigation communities their participation in the modernization of the irrigation systems and hinders the Administration the implementation of the National Hydrological Plan or the National Irrigation Plan.

These circumstances have led the Government to try to alleviate the situation with new regulations (road act of October 2015 and revised text of law of soil of November 2015) which remain insufficient. Therefore some legislative proposals are given as conclusions at the end of this work.

\section{1 - Introducción. Necesidad de Expropiación. Requisitos Previos.}

Con la modernización de regadíos, España promueve dirigir la agricultura hacia la competitividad, rentabilidad y sobre todo a la mejora de la eficiencia del uso del agua de riego. Supone un impulso positivo en la gestión y uso razonable del agua, que repercute directamente en la productividad de las explotaciones, y un valor añadido bruto de la zona modernizada.

De esta forma, los poderes públicos han acometido una planificación importante de reorientación para la mejora, la consolidación y la modernización de los regadíos españoles, que se recogen, entre otros, en el Plan Hidrológico Nacional, Plan Nacional de Regadíos, y en los distintos Planes de Choque para la Mejora y Modernización de los Regadíos.

El punto de partida necesario e ineludible para conseguir esta Modernización, radica en la obtención de la disponibilidad de los terrenos necesarios sobre los que se proyectan las actuaciones de mejora. Esta disponibilidad se encuentra ligada directamente al consentimiento o autorización de aquellas personas físicas o jurídicas que ostentan la titularidad de estos terrenos. Por tanto, la voluntad de los particulares puede incidir en la ejecución del planteamiento de modernización y, consecuentemente, subjetivizar el desarrollo de las obras.

Para evitar esta arbitrariedad en la obtención de la disposición de los terrenos necesarios, y conseguirlos de forma rápida y efectiva es conveniente iniciar por parte de la Administración competente el procedimiento expropiatorio correspondiente, mediante el cual se resuelve la confrontación existente entre el interés particular del expropiado y el interés general que conlleva la actuación, haciendo prevalecer éste último sobre la voluntad de los particulares, los que deberán de ser resarcidos o compensados siempre a cambio de una indemnización sustitutoria del bien o derecho expropiado a través de la figura del justoprecio.

El mecanismo legal por el que se desarrolla el procedimiento expropiatorio se encuentra en la Ley de Expropiación Forzosa, de 16 de diciembre de 1954, y en su Reglamento aprobado y desarrollado por Decreto de 26 de abril de 1957. Esta potestad expropiatoria sólo puede ser ejercida si existe una causa de utilidad pública o interés social que la legitime. Así se recoge en nuestra Carta Magna, en su artículo 33.3 cuando establece que "Nadie podrá ser privado de sus bienes y derechos sino por causa justificada de utilidad pública o interés social, mediante la correspondiente indemnización y de conformidad con lo dispuesto por las leyes". Por ello, la declaración de la causa que motiva la expropiación es indispensable para proceder a cualquier expropiación.

Por tanto, el objetivo principal de la incoación de un expediente expropiatorio es la obtención de la disponibilidad de los terrenos necesarios para la ejecución de obras de una forma rápida y efectiva. En la citada Ley de Expropiación Forzosa y su Reglamento se contemplan y desarrollan dos tipos de procedimientos en los expedientes de expropiación forzosa: el ordinario y el excepcional o de urgente ocupación, siendo éste último, el más 
usualmente aplicado por su rápida tramitación en la obtención y disposición de terrenos y, por tanto, en el que nos centramos en la presente exposición.

Para que la disponibilidad de los terrenos se haga efectiva mediante la tramitación de un expediente expropiatorio por la vía de urgencia, conforme establece el artículo 52 de la Ley de Expropiación forzosa, es necesario que las obras a ejecutar cumplan previamente con una serie de requisitos como son:

a) Que se encuentren declaradas de interés general, de utilidad pública y de urgente ocupación.

b) La existencia de un proyecto técnico, que contemple las obras a realizar, debidamente aprobado por la Administración competente, y que contenga un Anejo de expropiaciones donde se relacione de forma detallada todos los bienes y derechos necesarios para la ejecución de la obra.

Finalmente, en cuanto a la competencia para acordar la expropiación y los beneficiarios de la misma, la vigente Ley de Expropiación de 1954, establece en su artículo 2 que la expropiación puede ser acordada por el Estado, la provincia (actualmente la Comunidad Autónoma) y el municipio, pero amplía la causa de interés social de la expropiación a los particulares, en los que concurran los requisitos señalados por la Ley especial necesaria a estos efectos, que podrán ser beneficiarios de la expropiación. En el caso que nos ocupa, la expropiación tiene como beneficiario final a las comunidades de regantes, que pueden ostentar esta condición por su carácter de entidades de derecho público.

\section{2 - Expediente de Expropiación en Obras de Modernización de Regadíos.}

Como ya hemos comentado, en el contexto de obras de modernización de regadíos, el expediente expropiatorio se suele tramitar por el procedimiento de urgencia, regulado en el artículo 52 de la Ley de Expropiación Forzosa. Este procedimiento "excepcional", abrevia de manera sustancial la disponibilidad de los terrenos respecto al procedimiento ordinario, ya que posibilita que primeramente se efectúe la ocupación del bien expropiado y posteriormente se procede a tramitar la determinación del justiprecio, invirtiendo así el orden de actuación respecto al procedimiento ordinario. Es por ello, que este procedimiento de urgencia, ha ido convirtiéndose en la forma sistemática y generalizada del expediente expropiatorio por su mayor agilidad, rapidez y eficacia en los fines pretendidos, dejando en la práctica extinto el procedimiento ordinario, ya que en éste la ocupación del bien queda diferida a la entrega del justiprecio al expropiado.

Como resumen de la tramitación del expediente expropiatorio por el procedimiento de urgencia, se puede establecer el siguiente orden:

1. Declaración de interés general, de utilidad pública y declaración de urgente necesidad de ocupación.

2. Inicio y tramitación del expediente expropiatorio conforme al procedimiento establecido en el artículo 52 de la Ley de Expropiación Forzosa.

3. Ocupación y toma de posesión por la Administración de los terrenos expropiados.

4. Determinación del justiprecio.

5. Pago del bien o derecho expropiado

En lo referente a las obras de modernización de regadíos relacionadas tanto con el Plan Nacional de Regadíos como con el Plan de Choque, todas ellas han sido declaradas de interés general. Dichas obras llevan implícitas las declaraciones de utilidad pública a los 
efectos previstos en los artículos 9, 10 y 11 de la Ley de 16 de diciembre de 1954 de Expropiación Forzosa, y la de urgencia, a los efectos de ocupación de los bienes afectados a los que se refiere el art. 52 de dicha ley.

En relación al tipo de ocupación y privación del dominio de la propiedad, pueden establecerse tres tipos de afecciones: expropiación del pleno dominio, imposición de servidumbres, que suponen una limitación en el dominio o uso y disfrute de la cosa expropiada por parte de la propiedad, y ocupaciones temporales de los terrenos durante la duración de las obras.

Las grandes infraestructuras en obras de regadíos como la ejecución de balsas de riego, canales, estaciones de bombeo, filtrado y arquetas, entre otras, significan la privación total al titular del dominio del terreno ocupado por las mismas y, por tanto, su expropiación definitiva. Las conducciones de tubería, o tendidos eléctricos conllevan la imposición de servidumbres de acueducto, en el primer caso, y de vuelo, en el segundo, que suponen para el titular una limitación a su dominio pero no la pérdida total del mismo. Por último, la ocupación temporal de los terrenos necesarios durante el tiempo que dure la ejecución de la obra al objeto del tránsito de maquinaria, personal y zonas de acopio para la obra.

Conforme establece la Ley de Expropiación Forzosa y su Reglamento, en la valoración del justiprecio, se deberá valorar cada una de estas afecciones y siempre en directa relación a su extensión, cultivo, estado de la parcela, etc. Además habrá de tenerse en cuenta otro tipo de partidas indemnizatorias, complementarias a las principales afecciones, y que se concretan en los posibles deméritos ocasionados por restos de finca sin expropiar dejando una superficie que resulta antieconómica su explotación, o los derivados de la partición de finca, que suponen una anulación de la unidad de explotación, como también es necesario que se contemple la indemnización por rápida ocupación y el premio de afección.

Finalmente la Ley establece que a este justiprecio se puede llegar bien mediante acuerdo entre las partes, y en ausencia de este, establece un mecanismo de actuación hasta llegar a su fijación por el Jurado Provincial de Expropiación Forzosa.

\section{3 - Criterios para evaluar el impacto de la expropiación forzosa}

De lo comentado anteriormente puede deducirse que en obras importantes de modernización de regadíos, los costes derivados de la disponibilidad de terrenos tienen una significación importante dentro del cómputo total de la inversión a realizar. Requiere un análisis profundo tanto del trámite administrativo como del régimen jurídico de valoración de los terrenos que resulta de aplicación a la hora de fijar el justiprecio, un correcto dimensionamiento de las afecciones que concurren y una estimación del valor de los terrenos expropiados a nivel de anejo de expropiaciones del proyecto lo suficientemente aproximada al valor real de la totalidad de las afecciones y su posible variación a lo largo de la vida la tramitación del expediente expropiatorio.

El impacto económico de la expropiación refiere unívocamente a la fijación del precio unitario del suelo, en la instancia que corresponda, en tanto en cuanto todas las afecciones soportadas por el terreno tienen su origen estimativo en este valor. Así, cuando se determina el valor unitario de suelo, este será la referencia para valorar la expropiación permanente, la servidumbre, ocupaciones temporales, indemnización por rápida ocupación, deméritos y premio de afección.

A continuación se detalla con mayor profundidad aquellos aspectos legales y técnicos que influyen de una manera notoria en la fijación de este valor unitario de suelo en un procedimiento expropiatorio. 


\subsection{Desarrollo Normativo de Valoración}

La elección del método valorativo de una finca rústica viene determinada por la finalidad misma de la valoración. De este modo, el criterio a adoptar varía si se trata de una compraventa rústica o tiene una finalidad hipotecaria o expropiatoria.

Si bien la regulación expropiatoria atiende de manera general a la tasación de los terrenos expropiados, desde la Ley, de 12 de mayo de 1956, sobre régimen del suelo y ordenación urbana, la legislación del suelo ha venido conformando un régimen excepcional de valoración desplazando el criterio general contenido en la LEF y su Reglamento.

Para tener una idea ajustada a la actualidad valorativa a efectos expropiatorios, conviene destacar que desde el año 2007, fecha en la que entra en vigor La Ley 8/2007, de 28 de mayo, de suelo, se han sucedido numerosos cambios legislativos y normativos que han afectado principalmente y de manera significativa al criterio de valoración a adoptar para la fijación de los justiprecio. De este, como resumen del recorrido legislativo, se pueden citar:

- $\quad$ La Ley 8/2007, de 28 de mayo, de suelo

- Real Decreto Legislativo 2/2008, de 20 de junio, por el que se aprueba el texto refundido de la Ley de suelo

- Real Decreto 1492/2011, de 24 de octubre, por el que se aprueba el Reglamento de valoraciones de la Ley de Suelo

- Ley $37 / 2015$, de 29 de septiembre, de carreteras

- Real Decreto Legislativo 7/2015, de 30 de octubre, por el que se aprueba el texto refundido de la Ley de Suelo y Rehabilitación Urbana.

La Ley 8/2007, de 28 de mayo, de suelo, hoy derogada pero tuvo su vigencia hasta el 27 de junio de 2008, y la aprobación de su texto refundido en el Real Decreto Legislativo 2/2008 y la vigencia actual del Real Decreto Legislativo 7/2015 suponen un cambio definitivo tanto en la clasificación del suelo como en el criterio a adoptar para realizar las valoraciones de las afecciones a fincas rústicas en los procesos expropiatorios con respecto a la Ley 6/1998, de 13 de abril, sobre régimen del suelo y valoraciones, consolidando como método de valoración la capitalización de renta real o potencial.

A continuación, se desarrollan los aspectos fundamentales que inciden de una manera directa en la fijación del precio del suelo:

\subsubsection{Clasificación del suelo}

La Ley 6/1998 establecía tres clases de suelo atendiendo a su grado de transformación: urbano, no urbanizable y urbanizable. Se entiende por suelo urbano aquél que ya se encuentra totalmente transformado o en ejecución de un planeamiento y el suelo no urbanizable como aquel suelo en el que concurren situaciones concreta que impiden su transformación urbano, bien por la preservación de valores agrarios, forestales, ganaderos o aprovechamientos de riquezas naturales o bien por la inadecuación del mismo a ser urbano por condicionantes paisajísticos o regímenes especiales de protección. La Ley deja como suelo urbanizable aquél que no cumple ni con las condiciones de urbano ni no urbanizable.

La ley 8/2007, y siguientes desarrollos normativos lo mantienen, simplifica concepción de suelo y reduce el número de clase a dos: urbanizado y rural.

Define como suelo urbanizado aquél que se encuentra integrado de forma legal y efectiva en la red de dotaciones y servicios propios de los núcleos de población. Es decir, 
las parcelas, estén o no edificadas, que cuenten con las dotaciones y los servicios requeridos por la legislación urbanística o puedan llegar a contar con ellos sin otras obras que las de conexión de las parcelas a las instalaciones ya en funcionamiento.

\subsubsection{Método de valoración de finca en suelo rural}

Si bien la anterior norma jurídica, la Ley 6/1998, de 13 de abril, sobre régimen del suelo y valoraciones, establecía como criterio principal de valoración del suelo no urbanizable, el método de comparación a partir de fincas análogas, la ley del suelo de 2007 establece un criterio analítico de valoración en fincas ubicadas en suelo rural aplicando el método de capitalización de la renta anual o potencial, atendiendo al uso, disfrute o explotación. Es decir, es la capitalización de la renta generada por una explotación en el medio rural, entendida esta como un coste de oportunidad a un determinado interés la que genera el valor del suelo, en contraposición a la determinación del valor del suelo en base a criterios comparativos de fincas similares, en el espacio o en el tiempo, basados en los datos obtenidos de transmisiones de bienes inmuebles rústicos, principalmente operaciones de compraventa que se realizan en un determinada zona, término municipal o paraje.

La principal motivación que lleva al legislador a cambiar el criterio de valoración es el intento de eliminar o minimizar los fallos del mercado y las tensiones especulativas, atendiendo a un principio de tasación de la realidad y no estimación de las expectativas del suelo, cumpliendo, por tanto, con lo establecido en la LEF que determina que las tasaciones expropiatorias no han de tener en cuenta las plusvalías derivadas de las obras a acometer ni las previsibles para el futuro. Debe determinarse el valor del suelo atendiendo a lo que hay, independientemente de su clasificación futura y, para ello, la renta territorial se convierte en el factor principal en la formación del precio de la tierra.

Este cambio de criterio no está exento de controversia. El método de comparación, sumergido de lleno en las expectativas y en las tensiones concretas del mercado, atiende de una manera objetiva a factores que generan valor al suelo en una determinada zona o región, como pueden ser localización específica del paraje, climatología, factores edáficos concretos, tendencia futura de precios, etc... si la disponibilidad de datos para su cálculo es fiable, concreta y de calidad, que no siempre pueden ser dimensionados en el método de capitalización debido a que se corresponden con factores intangibles o en expectativas generadas, como puede ser la urbanística, no imputables a una explotación agraria. Sin embargo, el método de capitalización de rentas, en un principio atiende a la potencialidad productiva como factor exclusivo de generación del valor, aunque como se verá posteriormente, se introduzcan parámetros que intentan adaptar este valor a su entorno socio-económico desarrollados reglamentariamente. Por lo tanto, con este método, puede generalizarse que a mayor renta arrojada por la explotación mayor precio del suelo.

Se puede concluir pues, que el método comparativo tiene como pretensión estimar el valor de mercado con la dinámica de precios del mismo, atendiendo principalmente al destino del suelo y el método analítico atiende principalmente a la situación actual y real del suelo en base a la actividad productiva como generadora de su valor real y objetivo.

\subsubsection{El método de capitalización de rentas y su desarrollo reglamentario}

A grandes rasgos, el método analítico consiste en la capitalización de la renta de la tierra a un tipo de interés fijado legalmente.

La ley 8/2007 y el RD 2/2008 establece que "los terrenos se tasarán mediante la capitalización de la renta anual real o potencial, la que sea superior, de la explotación según su estado en el momento al que deba entenderse referida la valoración". 
Se define renta anual, potencial o real, como la diferencia entre ingresos y gastos anuales atendiendo al rendimiento del uso, disfrute o explotación de que sean susceptibles los terrenos conforme a la legislación que les sea aplicable. Este rendimiento del uso puede ser calculado a partir de las cuentas reales de una explotación en concreto o a partir de datos estadísticos significativos de una determinada zona, atendiendo a las prácticas comúnmente desarrolladas conformado el concepto de renta potencial.

Esta renta se capitaliza a un tipo de interés fijado inicialmente como la última referencia publicada por el Banco de España del rendimiento de la deuda pública del Estado en mercados secundarios a tres años corregido posteriormente, vía Ley de Presupuestos generales del Estado, al rendimiento de la deuda pública del Estado en mercados secundarios de dos a seis años, es decir, letras y bonos del Estado de dos a seis años.

Además, se incorpora el factor localización al valor obtenido por capitalización se podrá corregir al alza hasta un máximo del doble en función de factores objetivos de localización, como la accesibilidad a núcleos de población o a centros de actividad económica o la ubicación en entornos de singular valor ambiental o paisajístico.

Con la aprobación en el año 2011 del reglamento de Valoraciones definido en el Real Decreto 1492/2011, de 24 de octubre, por el que se aprueba el Reglamento de valoraciones de la Ley de Suelo se fija el método de cálculo de varios factores decisivos en el cálculo del valor del suelo que se habían quedado descritos pero no concretados. De este modo, como primera adecuación normativa del método, se establecen las fórmulas de cálculo de capitalización de la renta de explotación que con carácter general, en explotaciones constantes a lo largo del tiempo, se corresponde con la siguiente expresión:

$$
V=F . L \times R / r
$$

Siendo R la renta de explotación, $r$ el tipo de capitalización a aplicar y F.L el factor global de localización.

Sobre el tipo de capitalización a aplicar, fijándonos exclusivamente en explotaciones agropecuarias, el Real Decreto 1492/2011 establece:

a) Como tipo de capitalización aplicable con carácter general, $\mathrm{r} 1$, se utilizará el establecido en el apartado 1 de la Disposición adicional séptima del texto refundido de la Ley de Suelo, es decir el rendimiento de las letras y bonos del Tesoro de dos a seis años.

b) Cuando en el suelo rural se desarrollen actividades agropecuarias o forestales, se utilizará como tipo de capitalización, $\mathrm{r} 2$, el resultado de multiplicar el tipo de capitalización general $\mathrm{r} 1$ por el coeficiente corrector establecido en la tabla del Anexo I de este Reglamento según el tipo de cultivo o aprovechamiento.

Cabe mencionar la importancia del factor global de localización puesto que su aplicación ha sido motivo de controversia. El reglamento de valoraciones fija el criterio para su cálculo atendiendo a la localización, impacto demográfico y socio-económico y paisajístico y medioambiental, fijando su valor como máximo en 2 respetando así lo establecido en RD 2/2008. Esta limitación en la corrección por localización se declara inconstitucional y nula por Sentencia del TC 141/2014, de 11 de septiembre, y ya el RD 7/2015 elimina la limitación superior de este factor.

El actual y vigente RD $7 / 2015$, que aprueba el nuevo texto refundido de la ley del suelo, mantiene el criterio de valoración recogido en el Reglamento de Valoraciones pero introduce algunas modificaciones. Además de la ya comentada sobre el valor máximo del 
factor global de localización, introduce una modificación sobre el tipo de capitalización, en un intento por eliminar las distorsiones ocasionadas con el texto de la legislación anterior.

Por lo tanto, para fijar el valor unitario de suelo, es necesario estimar de una manera real o potencial la renta de explotación y aplicar el tipo de capitalización legal y el factor global de localización.

\subsubsection{Renta de la tierra}

Una vez analizado el método de valoración, es importante determinar el concepto de renta de la tierra en el planteamiento del método de capitalización. De una forma general, la renta de la tierra puede entenderse de dos formas: como el balance que arroja una finca teniendo en cuenta sus ingresos y gastos o como el canon de arrendamiento que se paga o que podría pagarse por el uso de la tierra en caso de arrendamiento.

De este modo se contempla el concepto de renta en el reglamento de valoraciones, pero no como territorial sino como renta de explotación y además, matiza el concepto de renta real y renta potencial. Por renta real se considera aquella que corresponde a la explotación del suelo rural de acuerdo con su estado y actividad en el momento de la valoración, ya sea la existente debidamente acreditada o la atribuible, de acuerdo con los cultivos y aprovechamientos implantados sobre la base de datos estadísticamente significativos. Por renta potencial se entiende aquella que pueda ser atribuible a la explotación de acuerdo con los usos y actividades más probables de que sean susceptibles, utilizando los medios técnicos normales para su producción. Los usos y actividades a los que se refiere la definición deben ser acreditados, bien porque haya una muestra estadística significativa de usos en su ámbito geográfico, es decir, que realmente se pueda destinar la explotación de la finca a cultivos y aprovechamientos comunes en la zona o porque se disponga de estudios económicos que justifiquen la viabilidad de la explotación que se quiere llevar a cabo.

Pero en un procedimiento expropiatorio, cuando se analiza y estudia la zona que va a ser afectada y se estiman los precios probables que la administración o la entidad beneficiaria va a proponer como justiprecio, no se dispone de los datos concretos de las explotaciones afectadas, de su análisis de ingresos y costes, ni de su particular "hacer" en su entorno productivo. De este modo y atendiendo a la norma, la manera de fijar la renta de explotación se realiza a partir de la información técnica y económica procedente de estudios y publicaciones realizadas por las Administraciones Públicas competentes en la materia sobre rendimientos, precios y costes, así como de las demás variables técnico-económicas de la zona. El propietario afectado sí posee información concreta de su explotación y, en caso de no estar de acuerdo con el precio ofrecido, podrá acreditar éstos en su hoja de aprecio y fundamentar de una manera robusta su valoración.

Por este motivo cobra especial importancia la información que las distintas Administraciones puedan suministrar de zonas de cultivo, cuanto más acotadas geográfica y técnicamente mejor, puesto que este aspecto redunda en una justa valoración del bien o derecho afectado. De hecho, cuando se analizan Resoluciones de justiprecio de los distintos Jurados de Expropiación, no existe un criterio unificado a la hora de distribuir ingresos y gastos para explotaciones análogas y tampoco una justificación motivada sobre el valor que se alcanza.

\subsubsection{Tipo de capitalización}

El tipo de capitalización a aplicar para valorar las fincas rústicas sometidas a un proceso expropiatorio quizás sea el factor más determinante en la fijación del precio y el que 
más dificultades y controversia ha generado desde que el método de capitalización de rentas está vigente como criterio legal de valoraciones.

Como se ha comentado anteriormente, el tipo de interés se fija legalmente. Atendiendo al Reglamento de Valoraciones del RD 1492/2011 el tipo a aplicar se corresponde con el producto de una capitalización general (r1) coincidente con el rendimiento de las letras y bonos del Tesoro de dos a seis años y una capitalización correctora (r2) según el tipo de cultivo o aprovechamiento.

De esta manera, el tipo $\mathrm{r} 1$ asemeja la rentabilidad agraria como un coste de oportunidad en los mercados financieros y el tipo $\mathrm{r} 2$ modula la rentabilidad concreta del cultivo. No todos los cultivos arrojan la misma renta ni tienen la misma rentabilidad. Se podría determinar de manera general que cultivos con mayor renta de explotación, como los de regadío, cultivos altamente tecnificados como hortícolas en invernadero, etc...obtienen mayor rentabilidad frente a cultivos como por ejemplo cultivos extensivos en secano y los aprovechamientos de pastos cuya renta en menor y su rentabilidad más baja.

Como ejemplo, en la siguiente tabla se exponen los valores de r2 para los cultivos y aprovechamientos más significativos, recogido en el anexo 1 del RD 1492/2011.

Tabla 1. Coeficientes correctores del tipo de capitalización en explotaciones agropecuarias y forestales

\begin{tabular}{|l|c|}
\hline Cultivo o aprovechamiento & Coeficiente corrector \\
\hline Tierras labor secano & 0,49 \\
\hline Tierras labor regadío & 0,78 \\
\hline Cultivos protegidos regadío & 0,78 \\
\hline Frutales cítricos & 0,61 \\
\hline Viñedo & 0,59 \\
\hline Olivar & 0,43 \\
\hline Pastizales & 0,51 \\
\hline Explotaciones forestales & 0,58 \\
\hline
\end{tabular}

La tierra entendida como una inversión, con respecto a inversiones financieras, tiene unas particularidades que hacen imposible su analogía: su liquidez es baja, la seguridad es alta por lo que el factor riesgo es mínimo y su rentabilidad es muy variable. Esta rentabilidad agraria se encuentra entre el $2 \%$ y el $5 \%$. Fijando legalmente, por tanto, el tipo de capitalización y adecuándolo a tipos de interés financiero, no existe ninguna garantía de que el valor de capitalización que se obtiene como resultado sea un estimador fiable del valor real del bien o del valor de mercado.

De hecho, establecer como tipo de capitalización base el rendimiento interno mercados secundarios entre 2 y 6 años, dato que se publica mensualmente en el BOE, se antojaba una solución adecuada para reflejar de una manera más o menos objetiva la rentabilidad agraria puesto que se suele encontrar en el umbral del $4 \%$. Pero analizando la evolución del mercado de deuda que ha estado sujeta durante un periodo largo de tiempo a las tensiones propias del escenario de recesión económica y crisis financiera que hemos sufrido, este indicador ha experimentado un desplome constante. Si a esta bajada de los rendimientos de deuda, le añadimos la aplicación de los factores correctores del tipo en función del cultivo, ha llevado a un aumento significativo y desproporcionado del valor indemnizatorio del suelo rústico y un alejamiento desmesurado de los valores de mercado.

Para facilitar la comprensión de este fenómeno, que ha ocasionado verdaderos problemas administrativos y judiciales, puesto que los organismos expropiantes han estado obligados a ofrecer justiprecios en consonancia con el imperativo legal para su cálculo, se 
expone el siguiente caso práctico de evolución temporal del valor de mercado y del valor de expropiación en euros por hectárea de un explotación media y representativa del cultivo de algodón en regadío en el Valle del Guadalquivir, considerando la variación del tipo de capitalización en el periodo comprendido de su aplicación (2.007-2.015). Para su ejemplificación se ha tomado el valor de $650 € /$ ha como referencia de renta de la tierra y un factor de localización medio de 1,5.

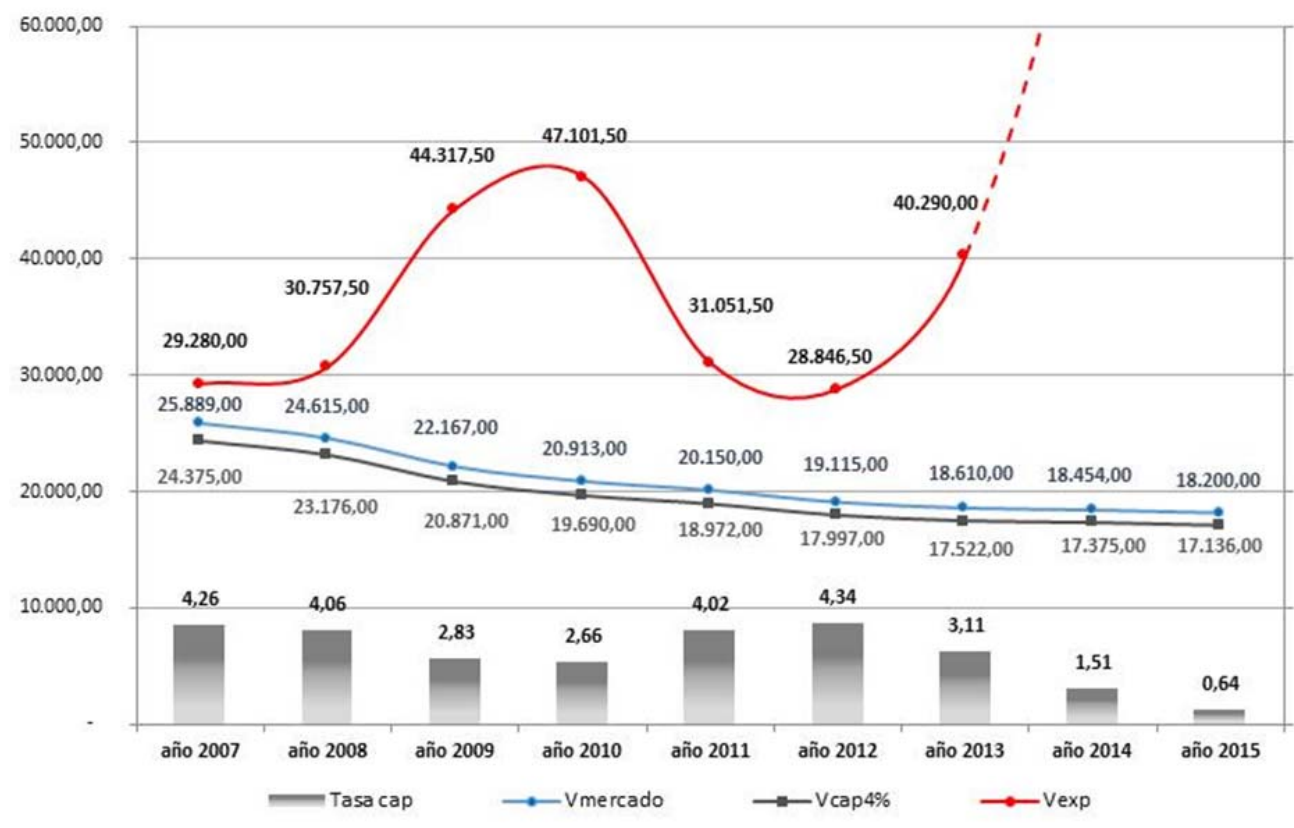

Figura 1. Evolución de los valores de la tierra en €/ha en cultivo de algodón en regadío en el Valle del Guadalquivir

Así pues, poniéndonos en el caso de una comunidad de regantes que tuviese que hacer frente a la expropiación de 16 hectáreas para la ejecución de balsas, de una primera estimación ajustándose a valor de mercado para el año 2013, que ronda los $300.000 €$, tendría que enfrentarse a una valor final de $650.000 €$ en la expropiación.

El efecto se agrava aún más en aquellos cultivos que tienen un factor de corrección más bajo, como por ejemplo labores de secano, en los que el tipo de capitalización a aplicar es la mitad del fijado anteriormente.

Ante esta situación en la que el tipo de interés dispara los precios de la tierra, se han sucedido diferentes mecanismos para minimizar su efecto. Los Jurados de Expropiación han tomado tipos medios anuales en lugar del mensual correspondiente para aumentar su valor; se han tomado valores de renta de la tierra más bajos e incluso se han tomado precios medios entre los valores estadísticos de mercado y valores analíticos calculados. Todo ello realizando interpretaciones de la norma contenida en el reglamento de valoraciones. Esto supone un conflicto jurídico puesto que esta situación favorece a los titulares afectados, comprometiendo muy gravemente la viabilidad del proyecto al no poder hacer frente al importe total de las expropiaciones del terreno por donde se va a ejecutar la obra prevista.

El primer intento de solución del problema ocasionado con el tipo de capitalización, se materializa en la Ley $37 / 2015$, de 29 de septiembre, de carreteras, que en su disposición final tercera, modificación del texto refundido de la Ley del suelo, estableciendo el tipo de capitalización como el valor promedio de los datos anuales publicados por el Banco de España de la rentabilidad de las Obligaciones del Estado a 30 años, correspondientes a los 
tres años anteriores a la fecha a la que deba entenderse referida la valoración. Este nuevo valor también se fija en el vigente el Texto refundido de la Ley de Suelo y Rehabilitación Urbana.

Esta modificación de la tasa o interés a aplicar soluciona, en parte, reflejando valores de capitalización más razonable; primero, porque la rentabilidad a largo plazo se comporta de una manera más estable y segundo, al tratarse de valores medios anuales establece, por lo menos, un comportamiento constante a lo largo de la tramitación del expediente expropiatorio. Pero, sin embargo, es un valor legal que sigue sometido a tensiones financieras sin ajustarse a la rentabilidad real agraria.

\subsubsection{Análisis de los justiprecios fijados por los Jurados de Expropiación.}

Los jurados de Expropiación, provinciales o territoriales, se han comportado de manera distinta ante esta situación como se ha dejado indicado anteriormente.

Por la propia naturaleza y composición de los Jurados, éstos pueden ponderar situaciones y establecer criterios, dentro de un ámbito legal común, que pueden no ser compartidos por las partes.

Como ejemplo y compendio de todo lo analizado en este trabajo, se expone el siguiente cuadro, en el cual se evalúan a lo largo de un periodo reciente de tiempo los justiprecios fijados por distintos Jurados provinciales de Castilla y León sobre actuaciones de modernización de regadíos análogas en zona territorial y precios medios para terrenos de labor regadío.

Tabla 2. Evolución de los Justiprecios fijados por Jurados de Expropiación para fincas de labor regadío en Castilla y león

\begin{tabular}{|l|l|c|c|}
\hline Jurado Provincial & \multicolumn{1}{|c|}{ Actuación } & $\begin{array}{c}\text { Fecha de } \\
\text { valoración }\end{array}$ & $\begin{array}{c}\text { Justiprecio } \\
\text { Fijado } \\
\text { (f/ha) }\end{array}$ \\
\hline PALENCIA & CANAL PISUERGA & Abril 2008 & 17.200 \\
\hline VALLADOLID & CANAL DE RIAZA & Abril 2008 & 19.200 \\
\hline BURGOS & CANAL DE RIAZA & Mayo 2008 & 14.400 \\
\hline VALLADOLID & CANAL DE TORDESILLAS & Abril 2009 & 23.700 \\
\hline BURGOS & CANAL DE GUMA & Mayo 2010 & 22.200 \\
\hline ZAMORA & CANAL DE TORO & Septiembre 2012 & 34.100 \\
\hline ZAMORA & CANAL DE TORO SECTOR III & Octubre 2013 & 34.700 \\
\hline ZAMORA & CANAL DE TORO SECTOR IV & Octubre 2013 & 39.600 \\
\hline
\end{tabular}

Se puede observar claramente la tendencia alcista de precios fijados como reflejo de la realidad cambiante a efectos valorativos. También se distingue los diferentes comportamientos de Jurados provinciales distintos sobre una misma realidad a valorar como ocurre en abril de 2008 para los territorios de Valladolid y Burgos.

\section{4 - Conclusiones}

Después de haber analizado los factores legales, económicos y técnicos, a través de la legislación que ha estado vigente sobre valoración de terrenos a efectos expropiatorios, para un correcto dimensionamiento de la partida de gasto en la que tienen que incurrir los beneficiarios de obras de modernización de regadíos, se proponen las siguientes conclusiones: 
1. A nivel de proyecto de ejecución de obras de modernización de regadíos, el Anejo de expropiaciones debe ser una herramienta objetiva y eficaz para establecer la horquilla de precios probable del procedimiento expropiatorio ajustándose a legislación vigente y a la realidad valorativa.

2. Establecer jurídicamente un régimen de valoración en el ámbito de las expropiaciones en las que el método de fijación de los precios del suelo no esté distanciado significativamente del valor de mercado de los terrenos, proponiendo para ello figuras mixtas entre métodos comparativos y métodos analíticos.

3. Disponer de información objetiva y fiable de las zonas territoriales específicas de explotación en el medio rural, atendiendo cuidadosamente a la diversidad de cultivos, gestión de la tierra y parámetros técnico-económicos para establecer unos valores medios reales en los que se establezca un umbral de precios invitando a los servicios de prospectiva, análisis y estadística de los organismos competentes en materia de precios y rendimientos a crear una base de datos de explotaciones tipo incluso a nivel de comarca. Esta herramienta sería de gran utilidad y convergencia para todos los agentes que intervienen en un procedimiento expropiatorio, desde el propietario afectado a los Jurados de Expropiación

4. El tipo de capitalización a aplicar legalmente debe ser reflejo de la rentabilidad de los mercados agrarios sin estar sujeto a tensiones impropias y coyunturales de los ciclos de la economía.

5. Dado que muchas de las valoraciones pasan por los Jurados de Valoración, estos deberían de homogeneizar más los criterios evaluatorios. 
Trabajos comerciales 


\title{
TC-01
}

\section{SISTEMA "NETVITC SYSTEM"}

\author{
Uribe, $J M^{1}{ }^{1}$ Salinas, J. $^{2}$
}

${ }^{1}$ Responsable de Dpto. Prescripción, Hidroten S.A. prescripcion@hidroten.es.

${ }^{2}$ Responsable de Dpto. Técnico, Hidroten S.A. tecnicocomercial@hidroten.es

\section{1- Introducción y Objetivos}

El objetivo de la ponencia es la presentación del Sistema "Netvitc System".

En el año 2.000, HIDROTEN S.A. lanza su primer producto aplicado al Sistema Netvitc System ${ }^{\circledR}$, un sistema que aporta soluciones eficaces y seguras en instalaciones.

\section{2- Materiales y Métodos}

El Sistema Netvitc System ${ }^{\circledR}$ (figura 1) es un revolucionario e innovador sistema modular de bridas de unión, desarrollado, fabricado y patentado por HIDROTEN S.A., para ejecución de instalaciones de tubería de PVC y PE polivalente, sencillo, versátil y seguro.

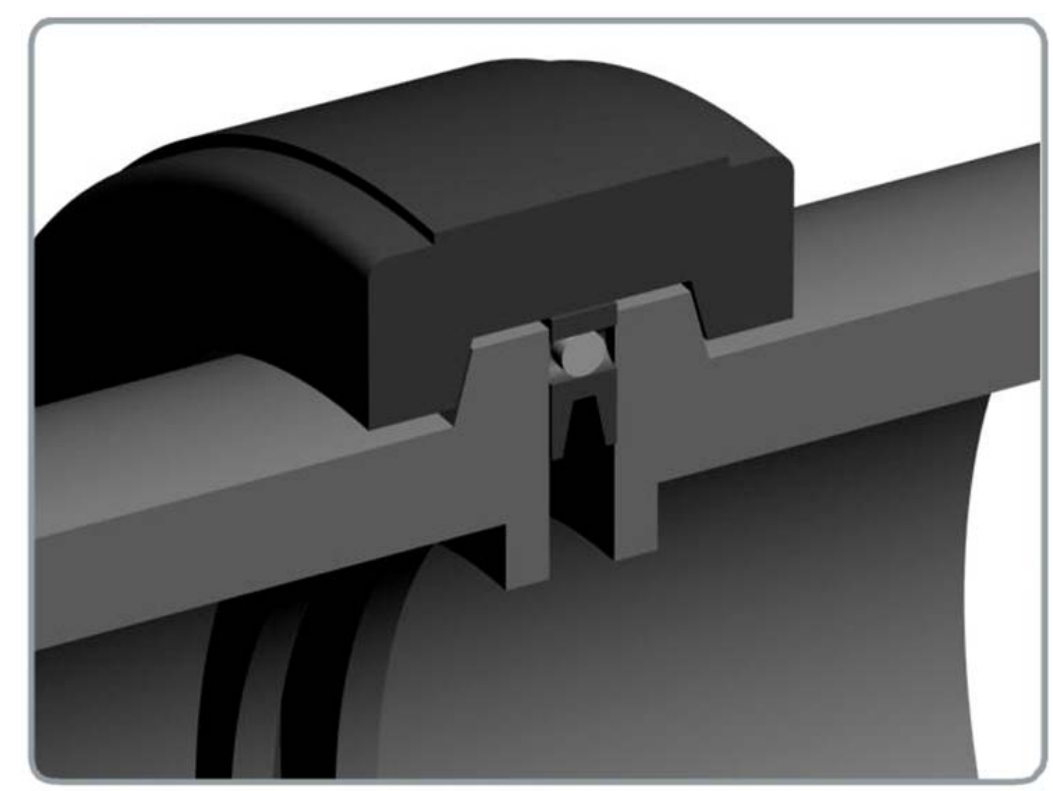

Figura 1. Detalle de unión del Sistema Netvitc System®. 


\section{3- Resultados y Discusión}

El Sistema Netvitc System ${ }^{\circledR}$ constituye la solución perfecta en sistemas de unión de tubería a presión para transporte de fluidos en diversos sectores como la industria, agricultura, depuración y Tratamiento de Aguas, Obra Civil...

El Sistema Netvitc System ${ }^{\circledR}$ aporta altos rendimientos en los procesos de instalación, consiguiendo una notable optimización de tiempo, mano de obra, materiales... frente a los sistemas tradicionales, permitiendo así un sencillo montaje y alta resistencia a la corrosión.

Este gran factor diferencial del Sistema Netvitc System ${ }^{\circledR}$ consiste en un sistema de bridas independientes. El sistema se aplica a una gran variedad de productos de HIDROTEN S.A., como válvulas de mariposa, válvulas de retención lineal, visores líquidos, filtros, accesorios PVC / P.P... permitiendo desmontar, por ejemplo, una línea de tubería sin necesidad de hacer descargas de fluidos.

La brida de unión del Sistema Netvitc System ${ }^{\circledR}$, ha sido diseñada aportando una gran diferencia importante con respecto al sistema tradicional de bridas por su sistema de unión independiente que reduce peso y tornillería.

La amplitud de gama permite hacer multitud de combinaciones y enlazar tuberías de diferentes materiales con el objetivo de encontrar la solución más adecuada para cualquier instalación.

El Sistema Netvitc System ${ }^{\circledR}$ por sus características ofrece soluciones a problemas ocasionados por otros sistemas tradicionales.

\section{CARACTERÍSTICAS GENERALES}

- Accesorios de Presión con unión Netvitc System ${ }^{\circledR}$ permiten por su diseño de bridas la posibilidad de rotación.

- Reduce de los sistemas el número de encoladuras y soldaduras.

- Permite rotación de accesorios.

- Los Accesorios Netvitc System ${ }^{\circledR}$ nos permiten ejecutar sistemas modulares combinando multitud de elementos en una instalación hidráulica tales como: válvulas, visores, filtros y diferentes materiales reduciendo el número de accesorios.

- Con su sistema de brida con dos tornillos permite realizar ampliaciones o limpiezas con la máxima comodidad y rapidez (figura 2).

- Máxima estanqueidad mediante la junta Netvitc System por su diseño bilabial con anillo reforzado de acero. 
- Su configuración de bridas y dos tornillos lo hace más ligero.

La gama de PVC-U Accesorios de Presión Netvitc System ${ }^{\circledR}$ está diseñada para tener la posibilidad de encolar el accesorio por la parte que sea necesario y hacer uniones mixtas Netvitc System ${ }^{\circledR}$-Encolar.

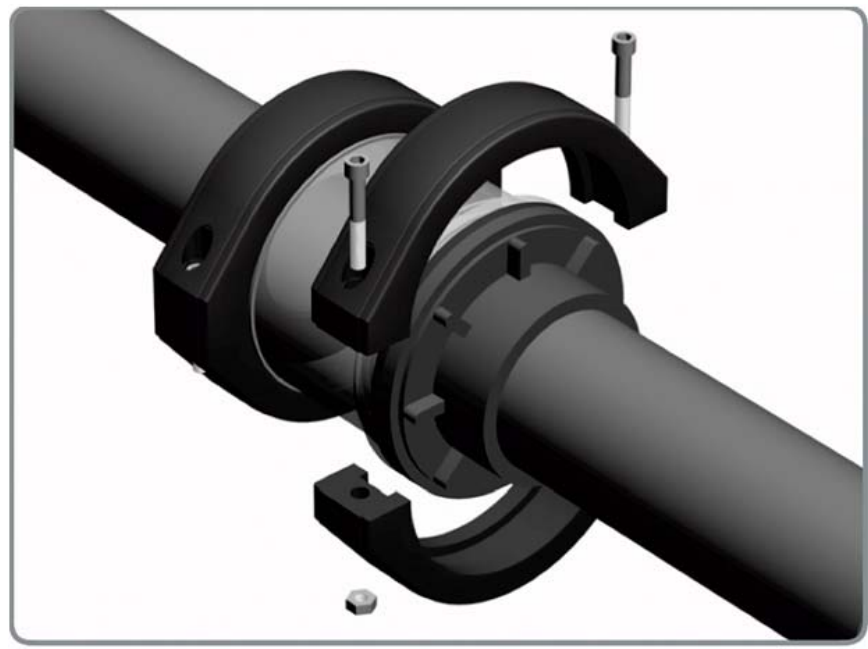

Figura 2. Esquema de montaje Netvitc System ${ }^{\circledR}$.

\section{APLICACIONES GENERALES}

Los Accesorios Netvitc System ${ }^{\circledR}$ son idóneos para instalar sistemas modulares

Prefabricados para tratamiento de agua, colectores de distribución de agua para sistemas de riego a presión e industria agroalimentaria.

Por su carácter desmontable es idóneo para instalaciones industriales que requieran efectuar frecuentes operaciones de limpieza.

También para hacer transiciones de materiales de PVC-U o PPFV con Fundición, PEAD, Acero, etc.

Sistema de distribución de agua en espacios reducidos como arquetas, estaciones de bombeo, armarios hidrantes.

\section{4- Conclusiones y Recomendaciones}

Gracias a su polivalencia, el Sistema Netvitc System ${ }^{\circledR}$, es capaz de unir diferentes materiales (PVC-U, PEAD, PP, Hierro) y elementos de unión, protección y maniobra 
(accesorios,

válvulas, filtros) con posibilidad de girar o rotar.

El Sistema Netvitc System ${ }^{\circledR}$ es perfecto en instalaciones hidráulicas interiores con poco espacio, tales como sala de bombas, cabezales de filtración, arquetas de maniobra y control, equipos de tratamiento de agua, plantas de desalación y depuración.

El Sistema Netvitc System ${ }^{\circledR}$ también es idóneo para ambientes húmedos y corrosivos, balnearios de agua salobre, aquariums, equipos de desalación, redes de distribución de agua de mar, industria agroalimentaria, líneas de salmuera, ya que el sistema reduce la tornillería en los enlaces (tornillería INOX).

\section{VENTAJAS CON RESPECTO A SISTEMAS TRADICIONALES}

- Capaz de unir diferentes materiales, aplicado a diferentes productos y con posibilidad de giro.

- Basado en bridas independientes que reduce tomillería, peso y posibilita el desmontaje.

- Rápido y sencillo generando alto rendimiento en obras e instalaciones.

- Resistente a ambientes corrosivos.

- Comparativo con el sistema ranurado.

- Reduce procesos de encoladura.

\section{Seguridad}

Netvitc System ${ }^{\circledR}$ es un sistema caracterizado básicamente por cuatro cualidades fundamentales; seguridad, operatividad, comodidad y rapidez.

Netvitc System ${ }^{\circledR}$ es un sistema fabricado con los últimos avances tecnológicos aplicados al sector, y con las máximas garantías en su respuesta al trabajo. Netvitc System cumple toda normativa aplicable al sector.

Otro aspecto importante es la minimización de puntos de unión, que ofrece una menor probabilidad de roturas de módulos en la instalación. Además, el diseño de su junta garantiza una total estanqueidad.

Otra ventaja frente a sistemas tradicionales es la mayor resistencia en ambientes corrosivos, gracias a la configuración de sus materiales.

\section{Operatividad}

Netvitc System ${ }^{\circledR}$ es un sistema operativo basado en bridas independientes que 
reduce tornillería, peso y ofrece una fácil posibilidad de montaje y desmontaje.

El sistema Netvitc System ${ }^{\circledR}$ ha sido ideado para ser desmontable, rotativo y con bridas independientes permitiendo gran operatividad y versatilidad a la hora de diseñar instalaciones en espacios reducidos.

Su operatividad queda vigente a la hora de poder adecuar los espacios, mediante giros gracias a las bridas independientes, a las necesidades que tengamos con tan solo aflojar y apretar dos tornillos.

\section{Comodidad}

El gran factor diferencial del sistema Netvitc System ${ }^{\circledR}$ consiste en un sistema de bridas, para las uniones, funcionando cada una de ellas de modo independiente con respecto a las otras utilizadas.

Si por ejemplo nos encontramos ante una rotura en una instalación, el sistema Netvitc System ${ }^{\circledR}$ nos permite desmontar una línea de tubería sin hacer descargas de fluidos, lo que conlleva a un ahorro de tiempo y de mano de obra considerable, pues una sola persona puede llevar a cabo la reparación. En un sistema tradicional, esto sería impensable, ya que no podríamos desmontar la línea y operar con las ventajas que nos ofrece el Netvitc System ${ }^{\circledR}$.

Es de destacar también la reducción de peso debido a la eliminación de tornillería y accesorios de conexión, lo cual facilita, por ejemplo, las instalaciones aéreas, donde el peso es algo fundamental.

\section{Rapidez}

El innovador diseño del sistema nos permite uniones directas entre accesorios, evitando encoladuras y posibilitando pruebas instantáneas, lo cual rompe con todas las normas de montaje y desmontaje tradicional y las innecesarias esperas.

El sistema Netvitc System ${ }^{\circledR}$ aporta celeridad en los montajes y desmontajes en sus instalaciones, pues en escasos segundos y apretando o aflojando dos tornillos manipulamos una brida de unión. Esto, a la larga, se convierte en un importante ahorro económico.

También es importante destacar el ahorro considerable de material, como podemos ver en el ejemplo (figura 3). 
AERYD XXXIV Congreso Nacional de Riegos, Sevilla 2016

\section{Sectores de aplicación}

Sistemas de riego a presión: captación, impulsión, filtración y distribución.

- Sistemas de tratamiento de agua y depuración.

- Piscinas, Balnearios, Spas.

- Industria: química, agroalimentaria y piscícola.

Obra civil: abastecimiento de agua.

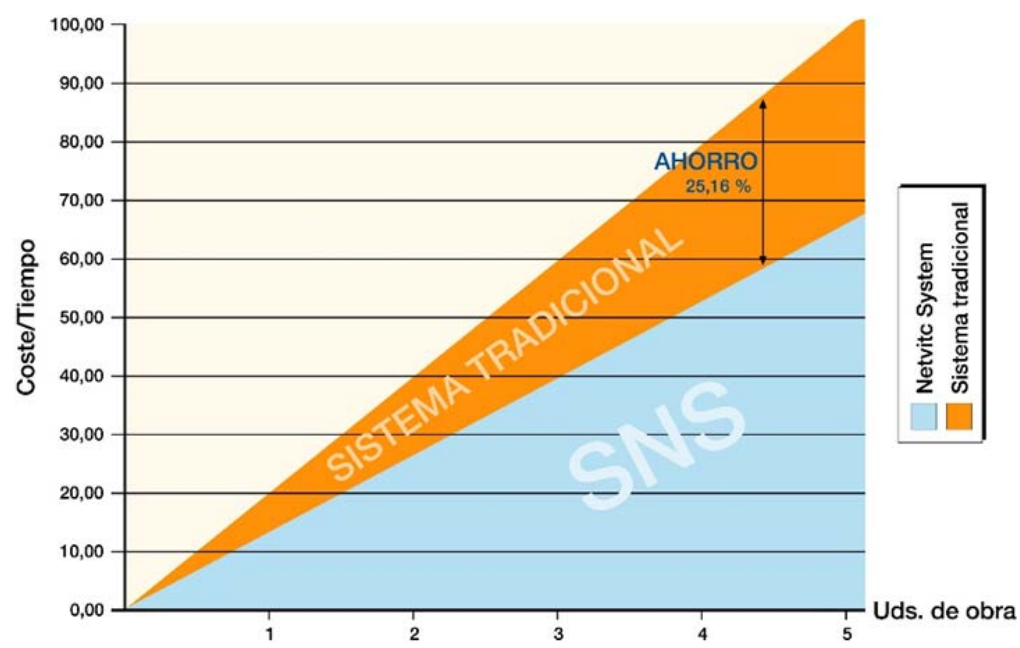

Figura 3. Ahorro de material respecto al sistema tradicional de bridas. 


\section{REUTILIZACIÓN DE AGUAS DEPURADAS EN RIEGO}

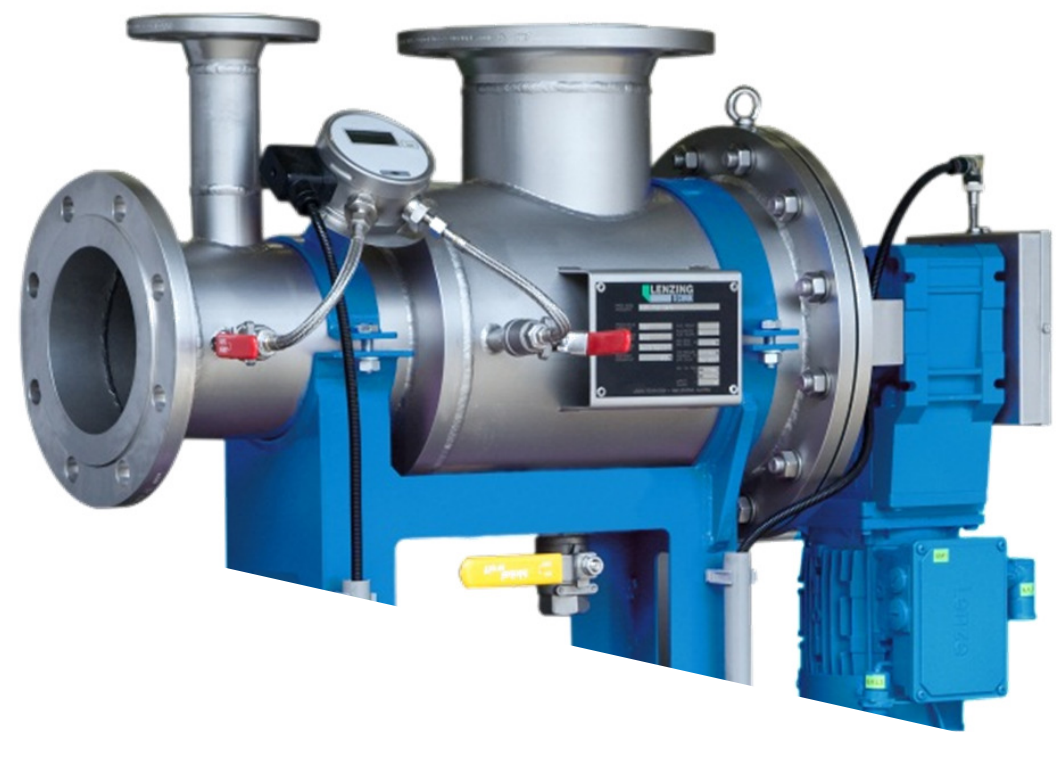

$$
\begin{aligned}
& \text { HAWLE-OPTIFIL } \\
& \text { HAWLE-CANFIL } \\
& \text { The new spirit of filtration }
\end{aligned}
$$




\section{RESUMEN}

\section{Visión general del filtrado}

\section{HAWLE-OPTIFIL}

»Visión general de la reutilización

» Simulación de funcionamiento

»Detalles de construcción

»Certificados

»Especificaciones Técnicas

》Referencias

»Planta Móvil de tratamiento de agua

\section{HAWLE-CANFIL}

»Áreas de aplicación

» Funcionamiento

»Dimensiones

»Especificaciones Técnicas

»Referencias 


\section{Visión general del filtrado}

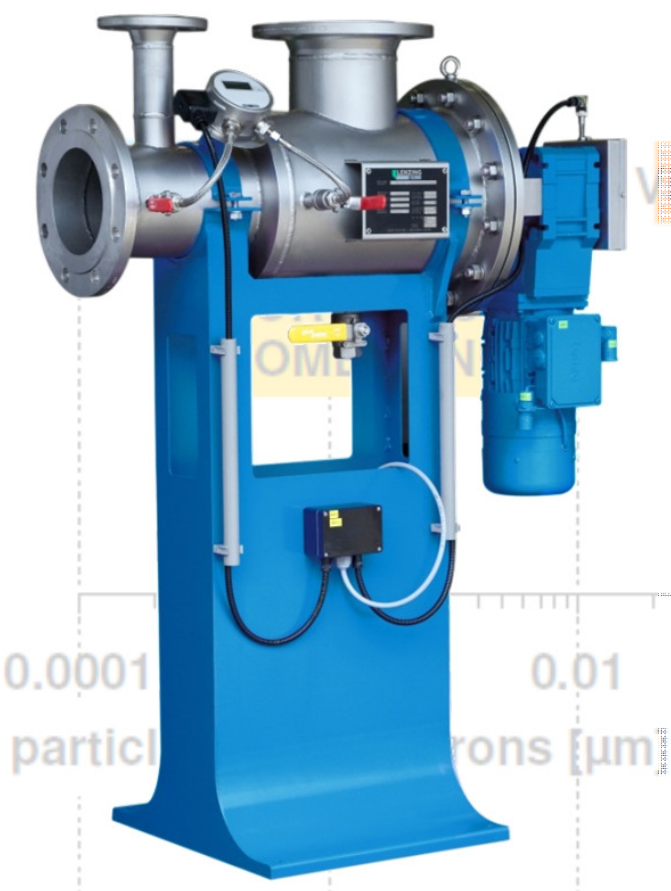

HAWLE-OPTIFIL

Tamaño de partículas $>0.001 \mathrm{~mm}=1 \mu \mathrm{m}$ !!!

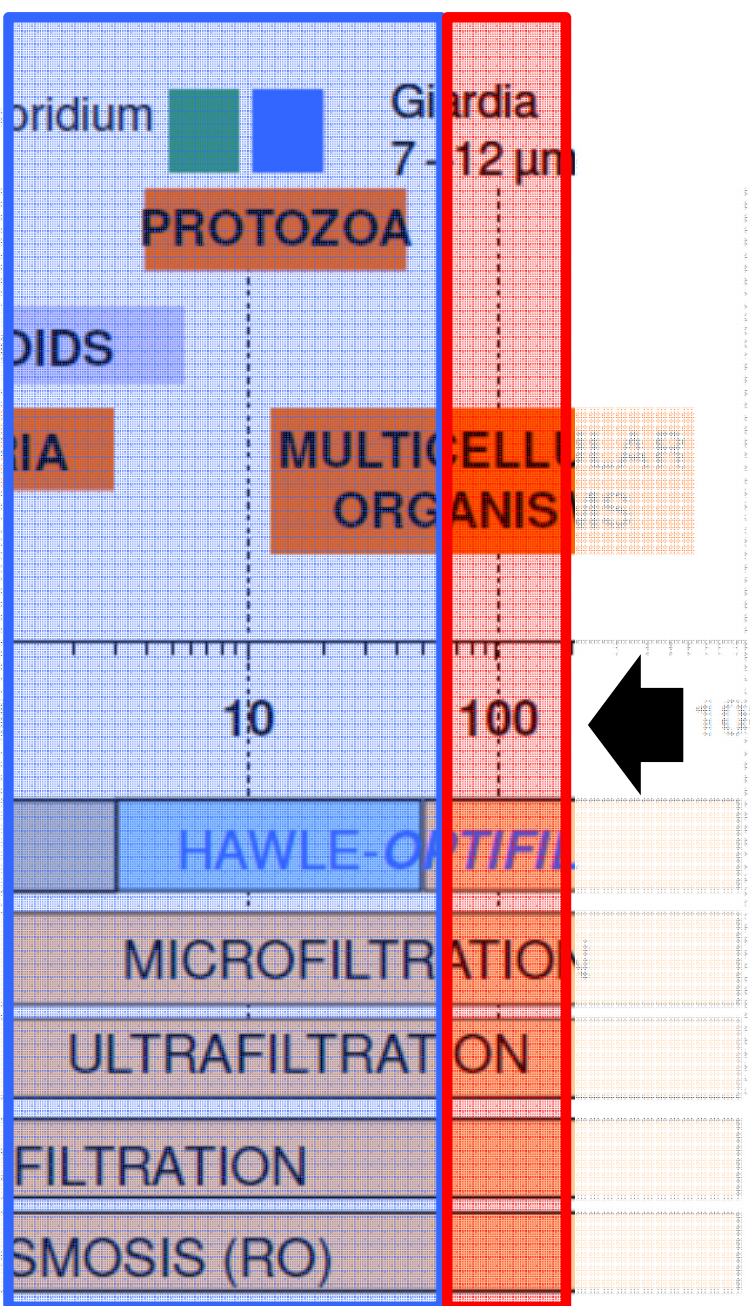

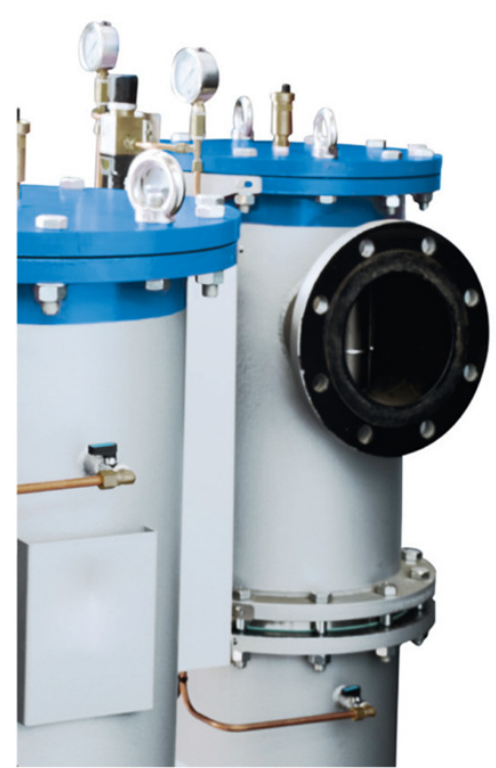

HAWLE-CANFIL

Tamaño de partículas $>0.05 \mathrm{~mm}=50 \mu \mathrm{m}$ !!! 


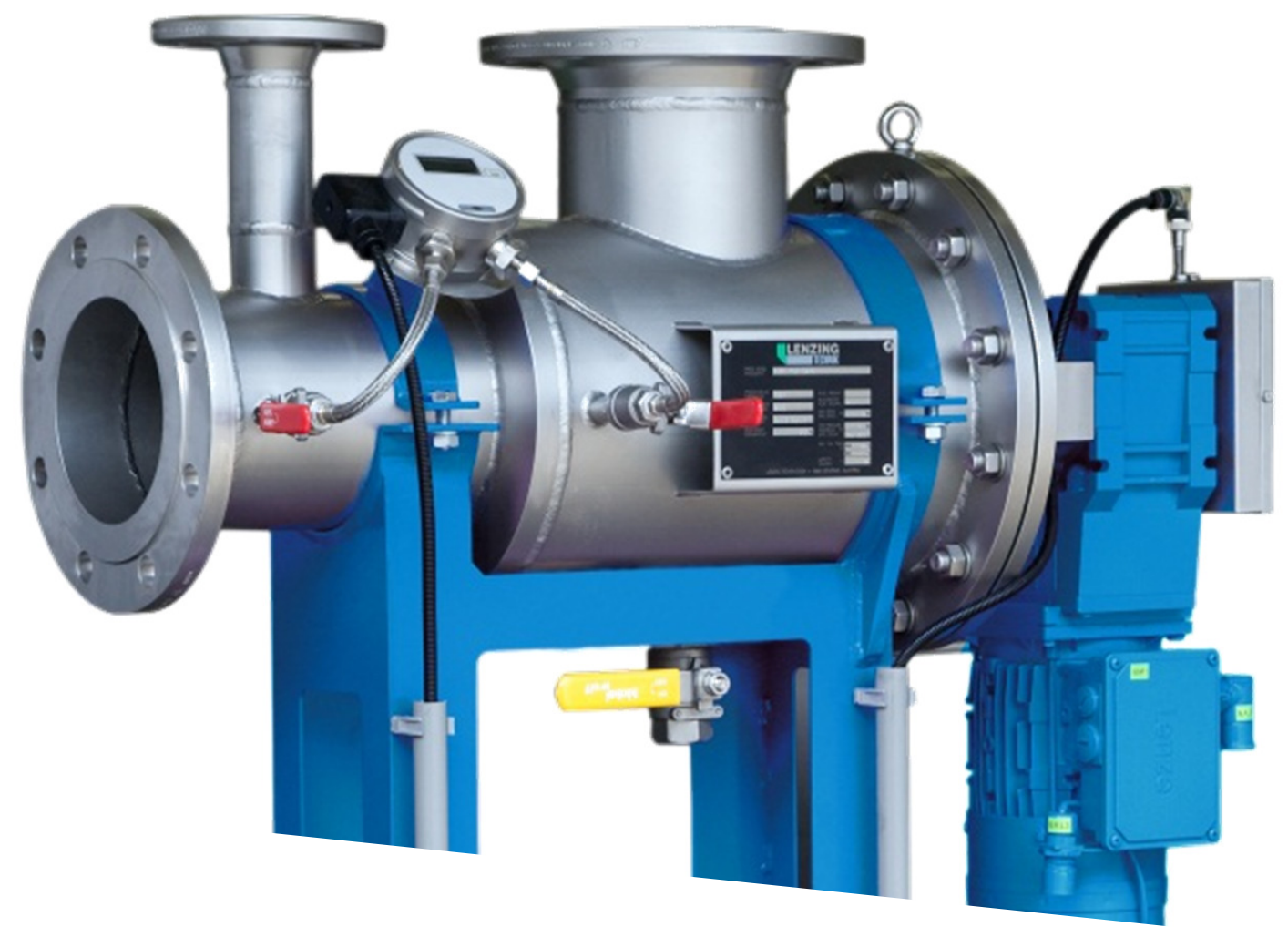

The new spirit of filtration 


\section{Visión general de la reutilización}

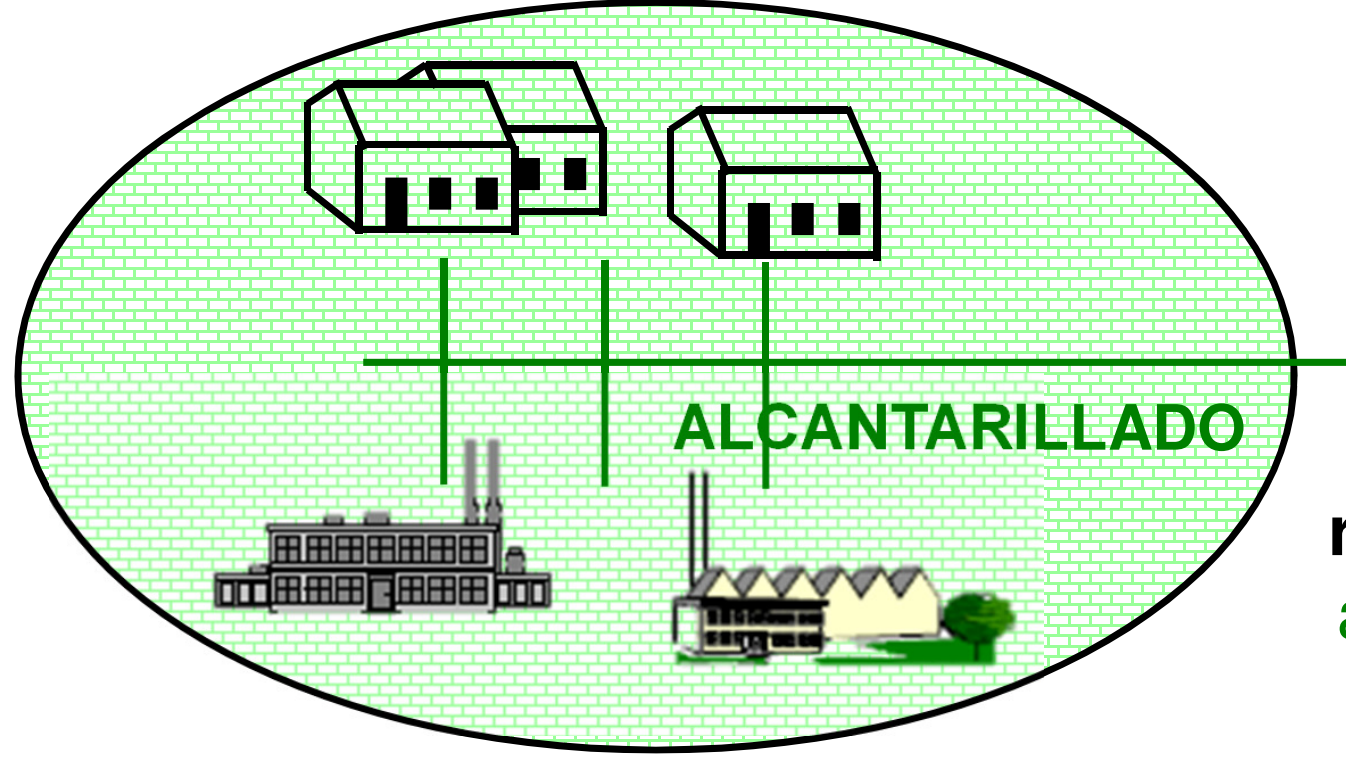

REUTILIZACIÓN EN REGADÍO

Real Decreto 1620/2007: Calidad 2.1

$><1$ huevo vivo de nematodo / 10 I

$><100$ U.F.C. $/ 100 \mathrm{ml}$

> Solidos en suspensión < 20 mg/l

$>$ Turbidez < 10 NTU

(*) Unidades Formadoras de Colonias

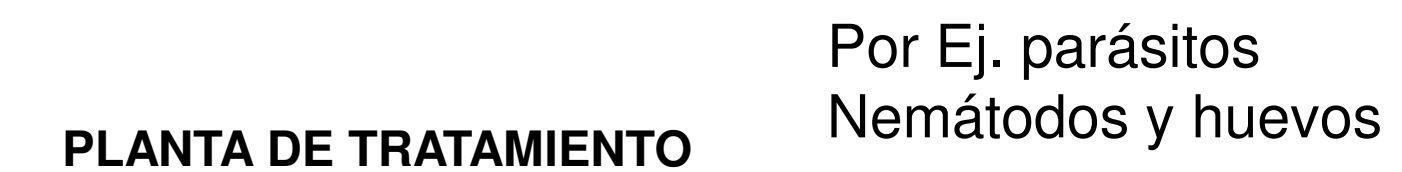
DE AGUA RESIDUAL

Nemátodos y huevos

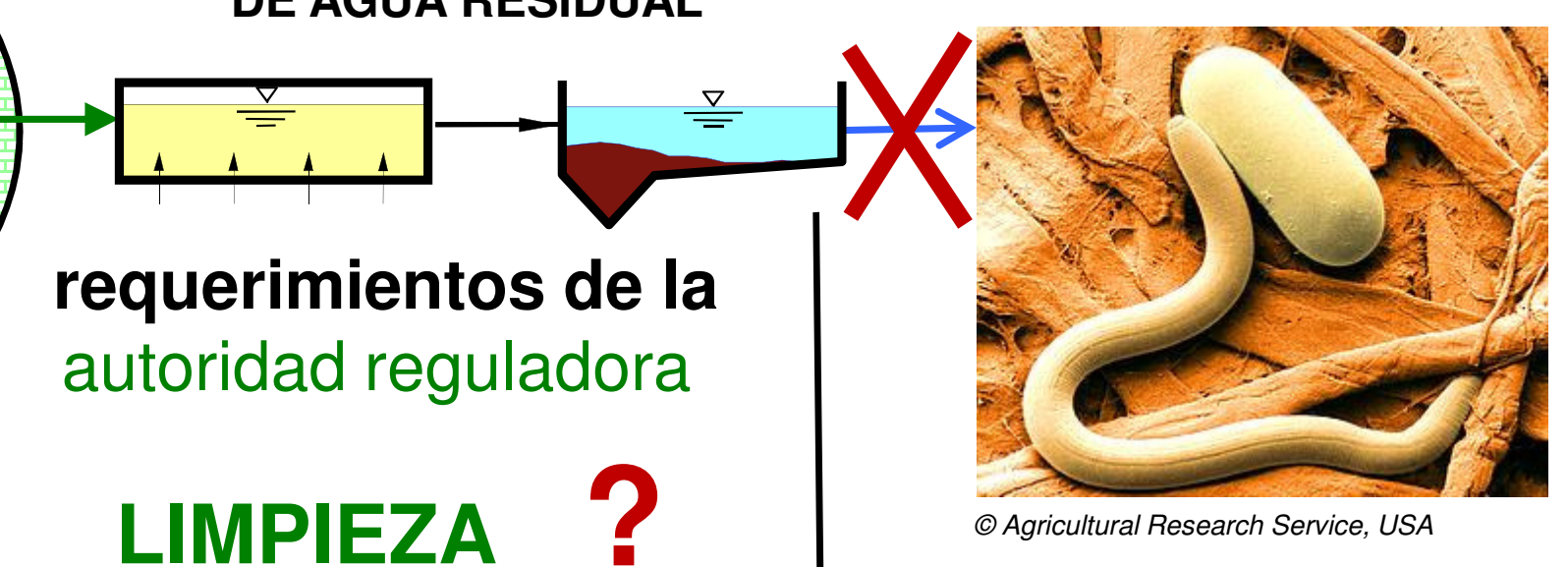

LIMPIEZA ?

(c) Agricultural Research Service, USA

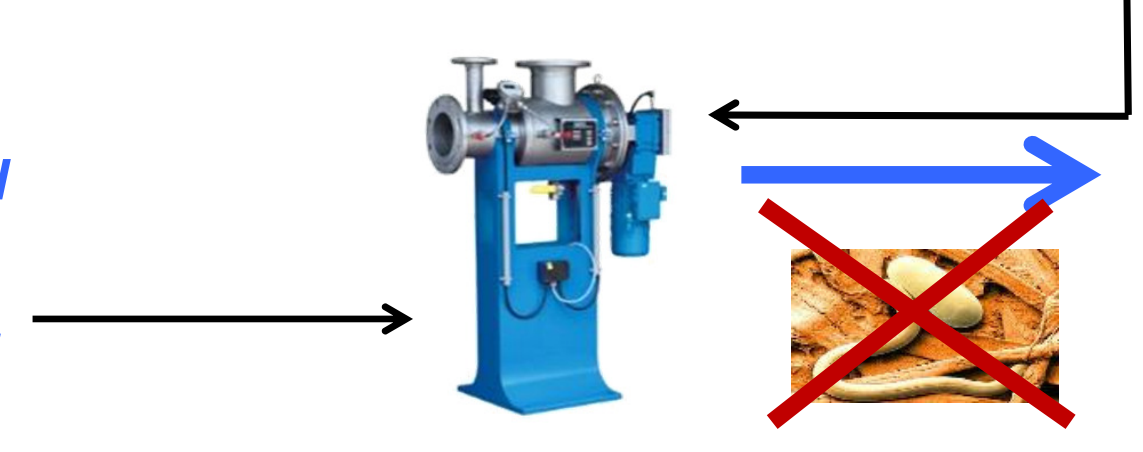

HAWLE-OPTIFIL

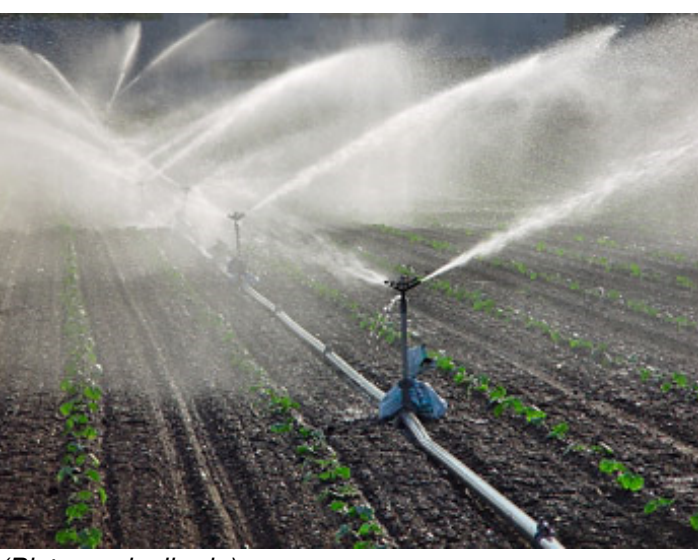

HAWLE. MADE FOR GENERATIONSS. 


\section{Detalle HAWLE-OPTIFIL}
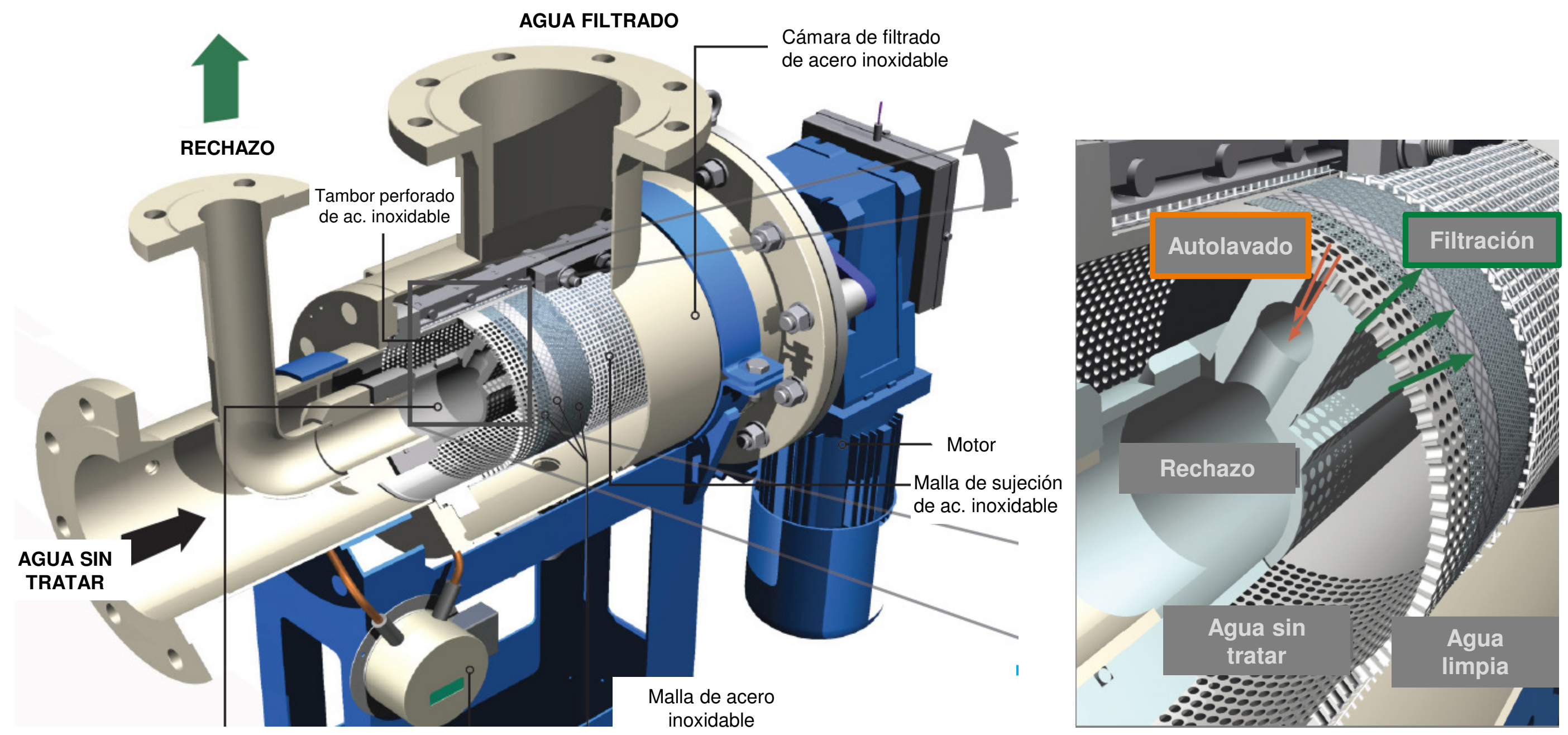

Dispositivo de autolavado
Sensor de presión diferencial

HAWLE. MADE FOR GENERATIONSSీ. 


\section{Detalle HAWLE-OPTIFIL}

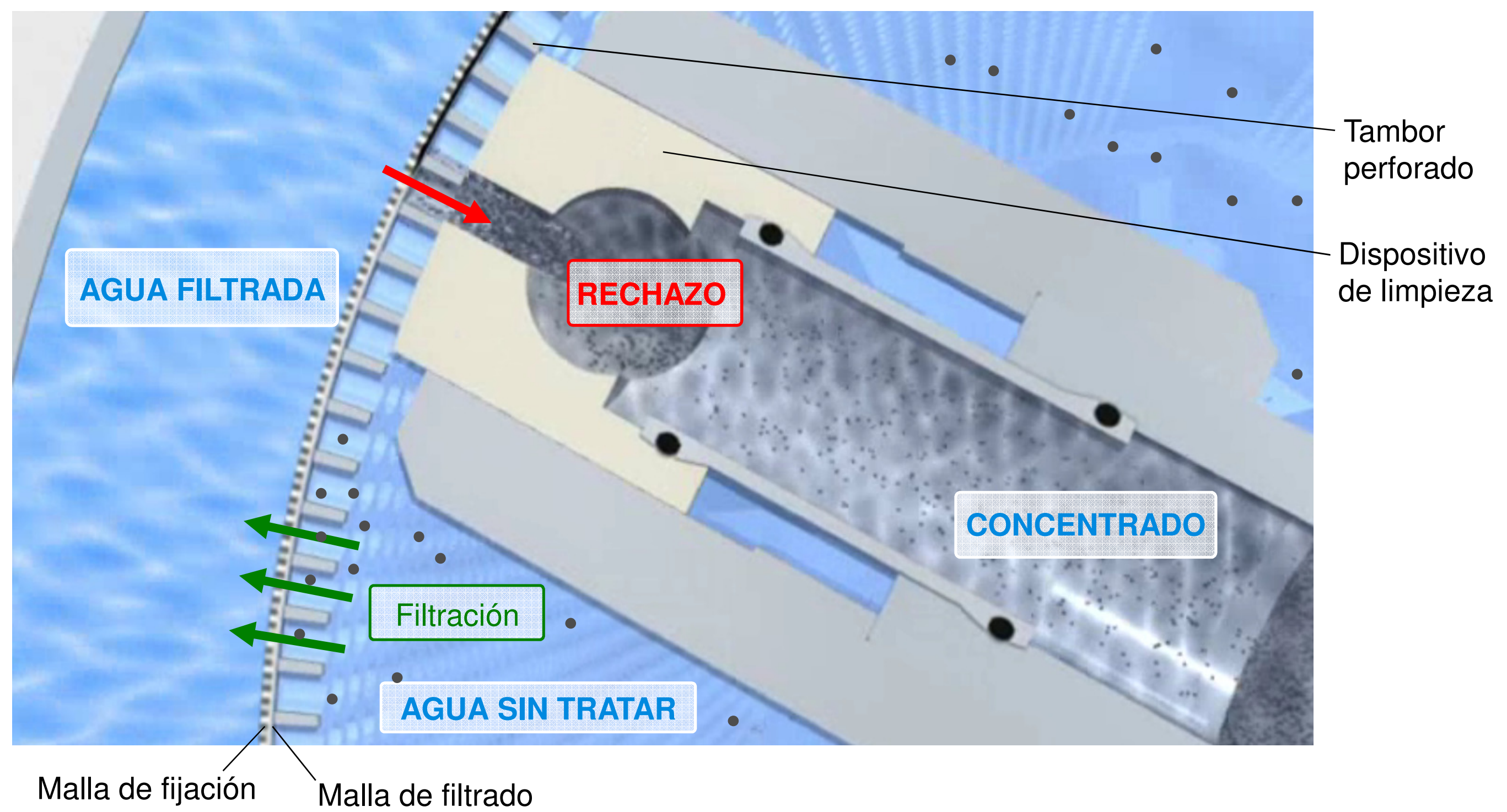




\section{Detalle HAWLE-OPTIFIL}

- Tipos de Malla disponibles

» $50 \mu \mathrm{m}$ - Acero Inoxidable 316

» $25 \mu \mathrm{m}$ - Acero Inoxidable 316

»10 $\mu \mathrm{m}$ - Acero Inoxidable 316

» $6 \mu \mathrm{m}$ - Poliamida (Agua salada)

» 5,5 $\mu \mathrm{m}$ - Acero Inoxidable recubierto con PFA (teflón)

» $3 \mu \mathrm{m}$ - Fibras comprimidas (fieltro)

» $2 \mu \mathrm{m}$ - Acero Inoxidable 316

» $1 \mu \mathrm{m}$ - Acero Inoxidable 316

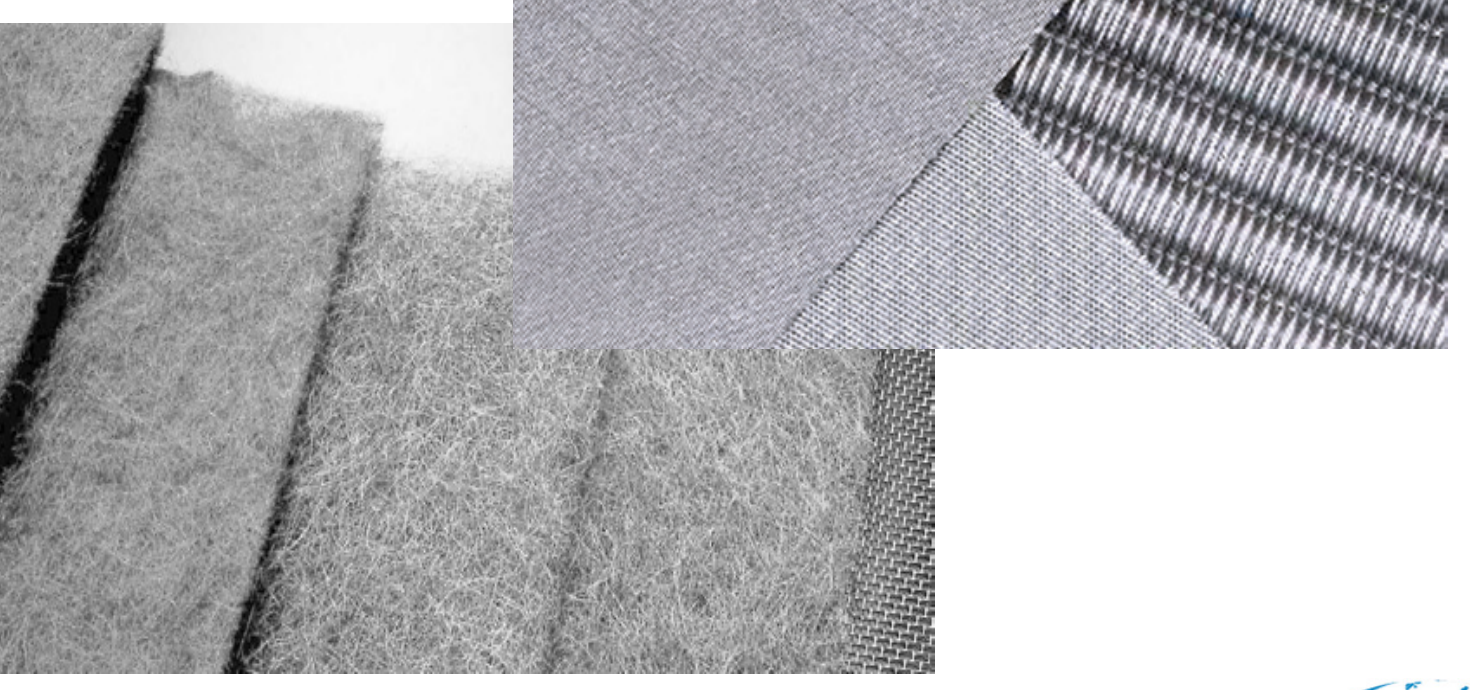




\section{Detalle HAWLE-OPTIFIL}

- Modelos de apertura rápida
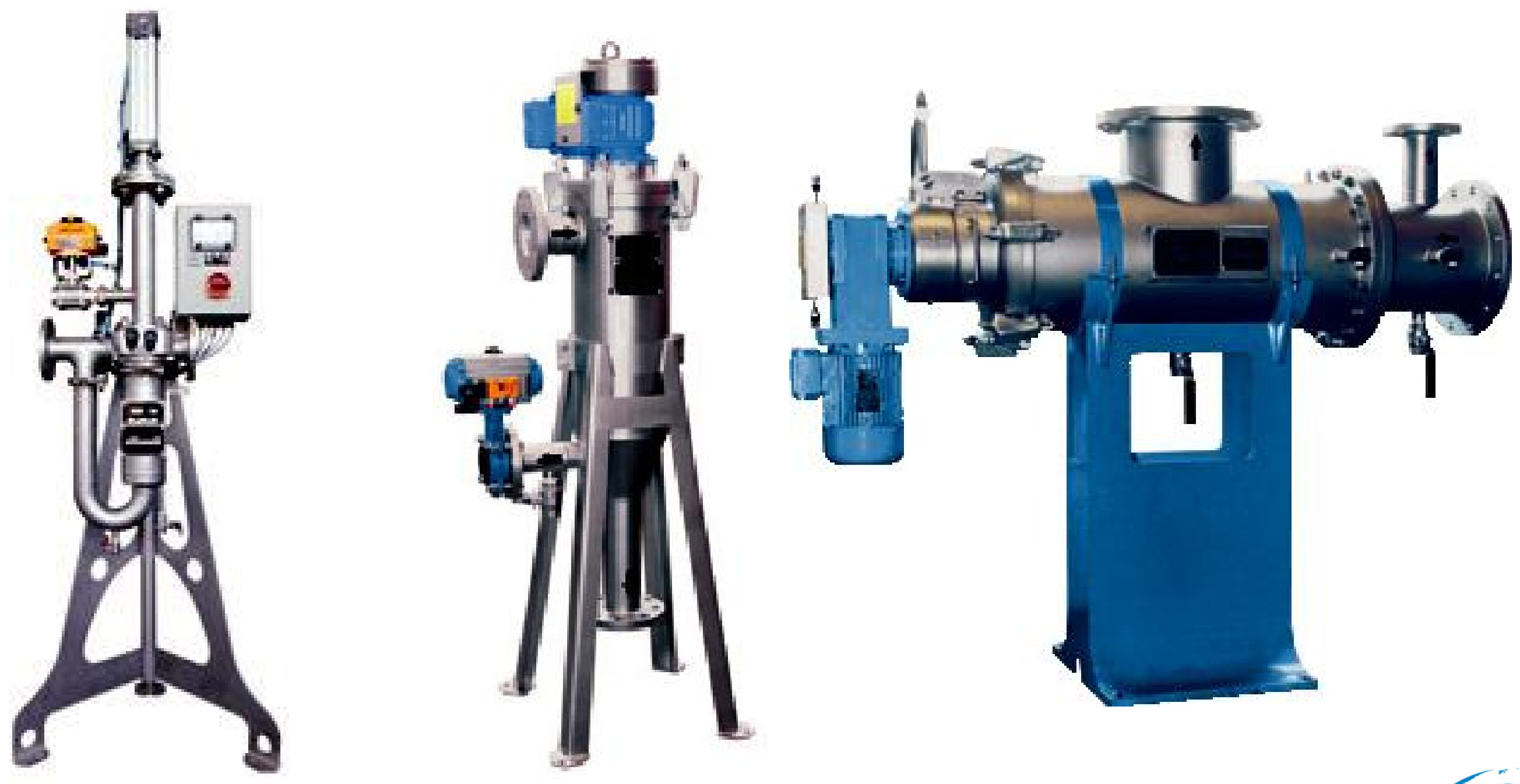

HAWLE. MADE FOR GENERATIONSS S. 


\section{Certificados HAWLE-OPTIFIL}

- Certificado para agua potable (ÖVGW)

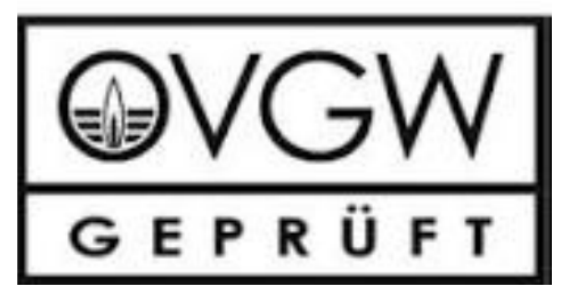

» Número de registro ÖVGW: W 1.680

- Está certificado el funcionamiento del filtro y el grado de filtración.

- Primer Certificado de un filtro automático por retrolavado en todo el mundo.

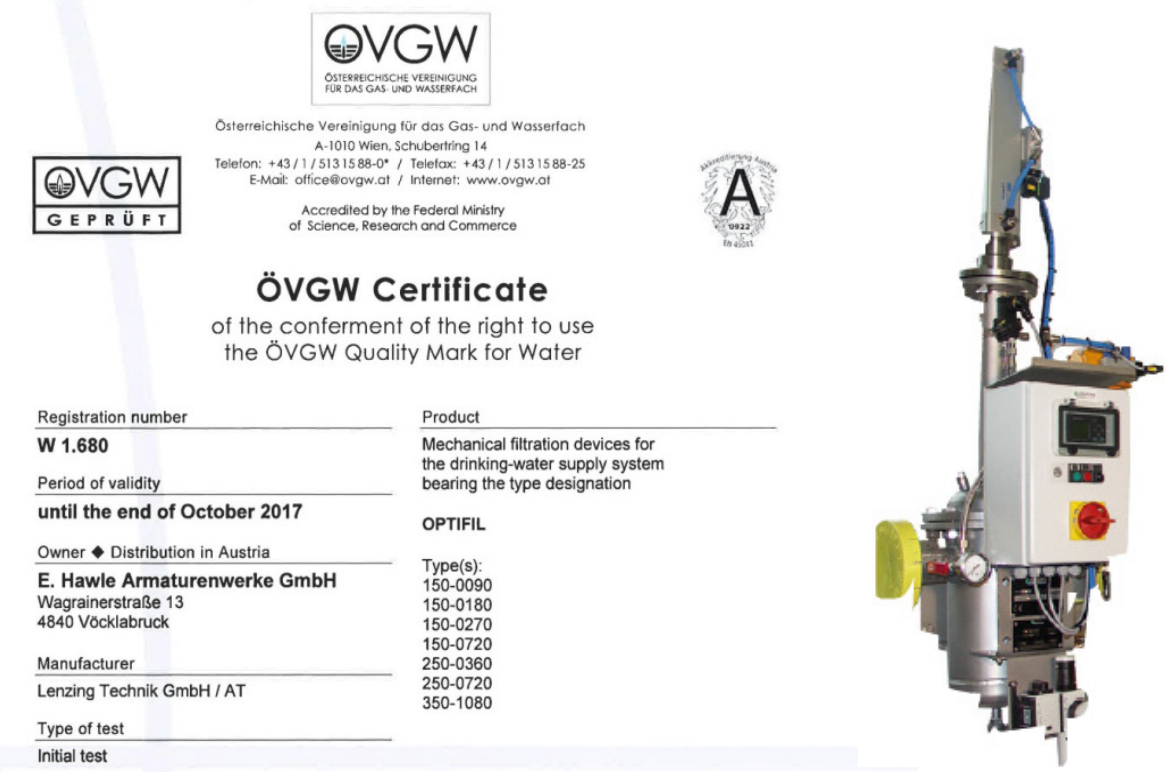

T12.320 dated 2 September 2014

Quality standards / Testing directives

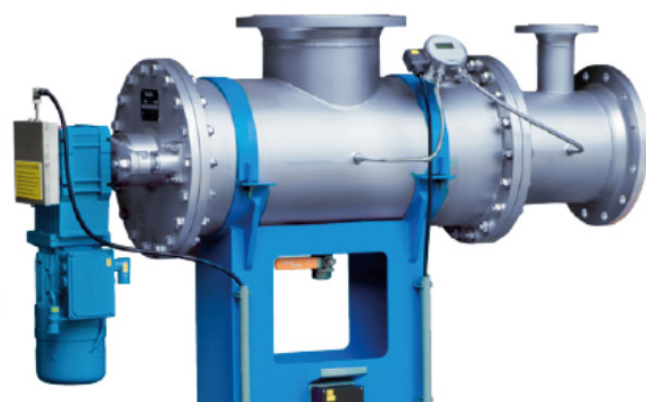




\section{Esp. Técnicas HAWLE-OPTIFIL}

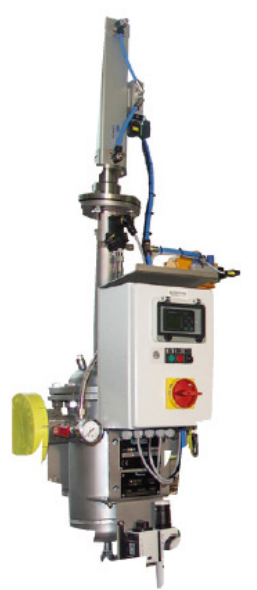

DN 50

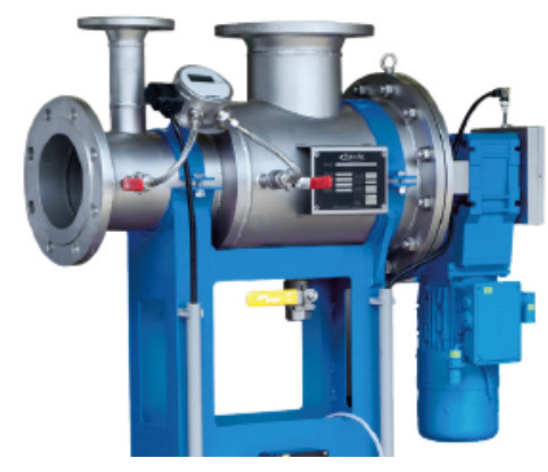

DN 150

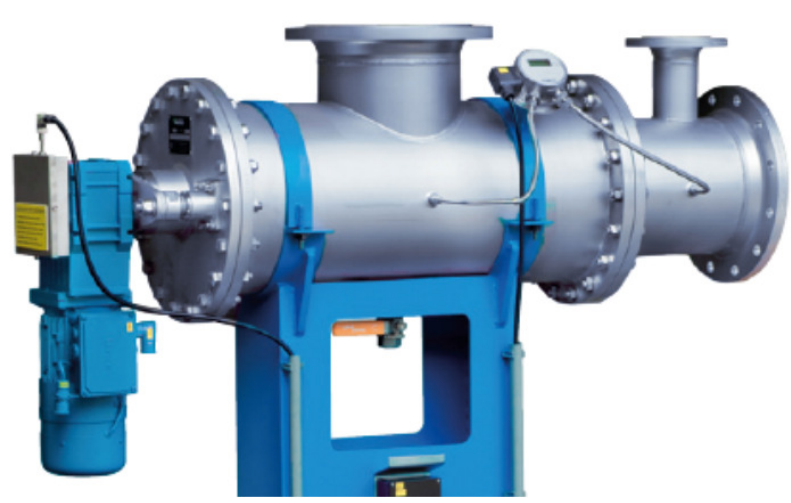

DN 250 / 350

\begin{tabular}{|c|c|c|c|c|c|c|c|c|}
\hline Modelo & $\begin{array}{c}\text { Presión } \\
\text { de trabajo } \\
\text { [bar] }\end{array}$ & $\begin{array}{c}\text { DN } \\
\text { Entrada y } \\
\text { salida } \\
\text { [mm/pulg.] }\end{array}$ & $\begin{array}{c}\text { DN } \\
\text { Salida de } \\
\text { limpieza } \\
\text { [mm/pulg.] }\end{array}$ & $\begin{array}{c}\text { Área de } \\
\text { filtrado } \\
\left.\qquad \mathrm{cm}^{2}\right]\end{array}$ & $\begin{array}{l}\text { Caudal } \\
\text { (3 pm) } \\
{\left[m^{3} / h\right]}\end{array}$ & $\begin{array}{c}\text { Caudal } \\
\text { (25 } \mu \mathrm{m}) \\
{\left[\mathrm{m}^{3} / \mathrm{h}\right]}\end{array}$ & 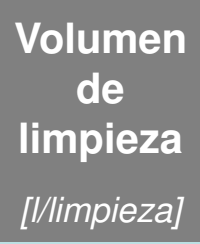 & $\begin{array}{c}\text { Duración } \\
\text { de la } \\
\text { limpieza } \\
\text { [seg/limpieza] }\end{array}$ \\
\hline 050-0200 & $10 / 16$ & 50 / 2" & 25 / 1" & 140 & 4.8 & 20 & 1.1 & 2 \\
\hline $100-0270$ & $10 / 16$ & 80 / 3" & 50 / 2" & 200 & 7 & 30 & 1.4 & 3 \\
\hline $150-0270$ & 10 & 150 / 6" & 50 / 2" & 570 & 19 & 100 & 4.3 & 3 \\
\hline $150-0720$ & 10 & 150 / 6" & 80 / 3" & 1520 & 50 & 140 & 5.6 & 3 \\
\hline $250-0720$ & 10 & 250 / 10" & 80 / 3" & 2500 & 85 & 380 & 19.0 & 4 \\
\hline $350-1080$ & 10 & 350 / 14" & 100 / 4" & 4800 & 163 & 600 & 36.5 & 5 \\
\hline
\end{tabular}

HAWLE. MADE FOR GENERATIONSS. 


\section{Dimensiones HAWLE-OPTIFIL}

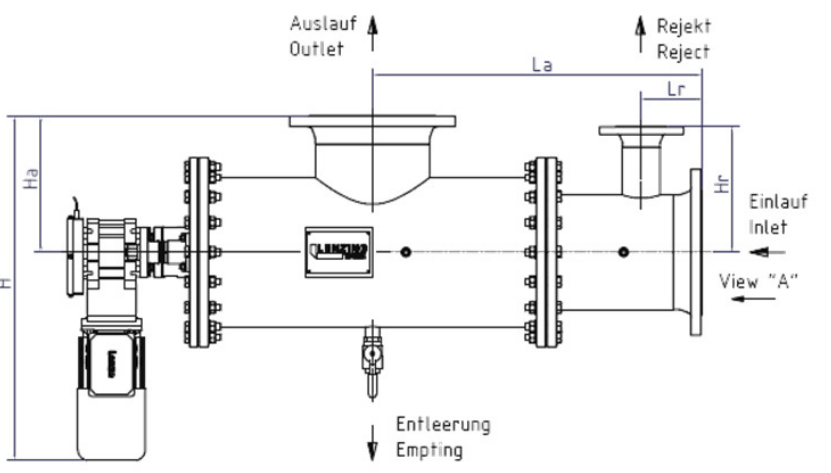

DN $250 / 350$

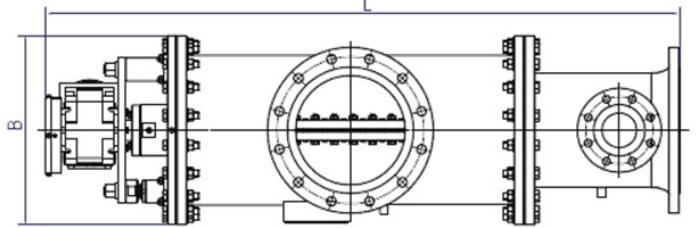

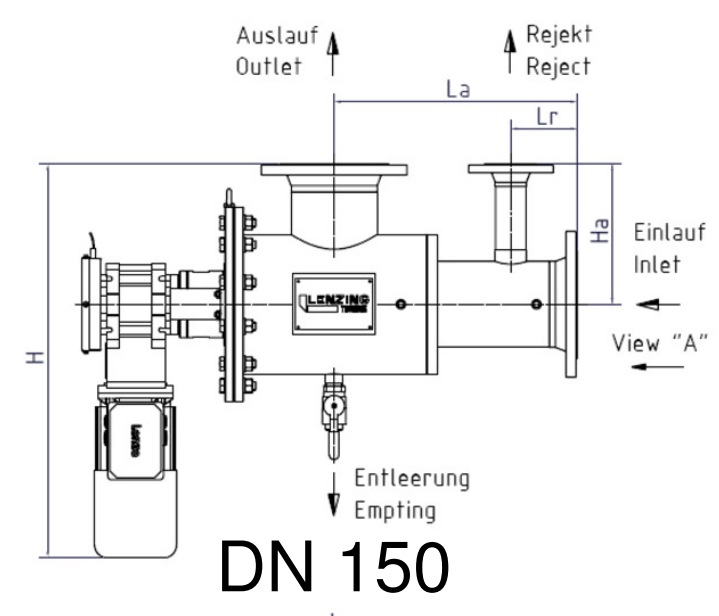

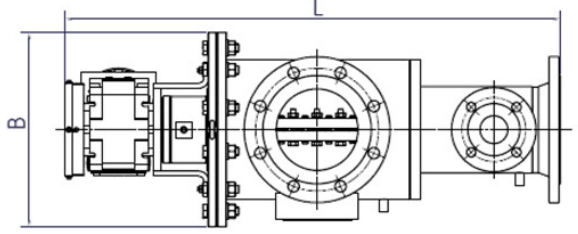

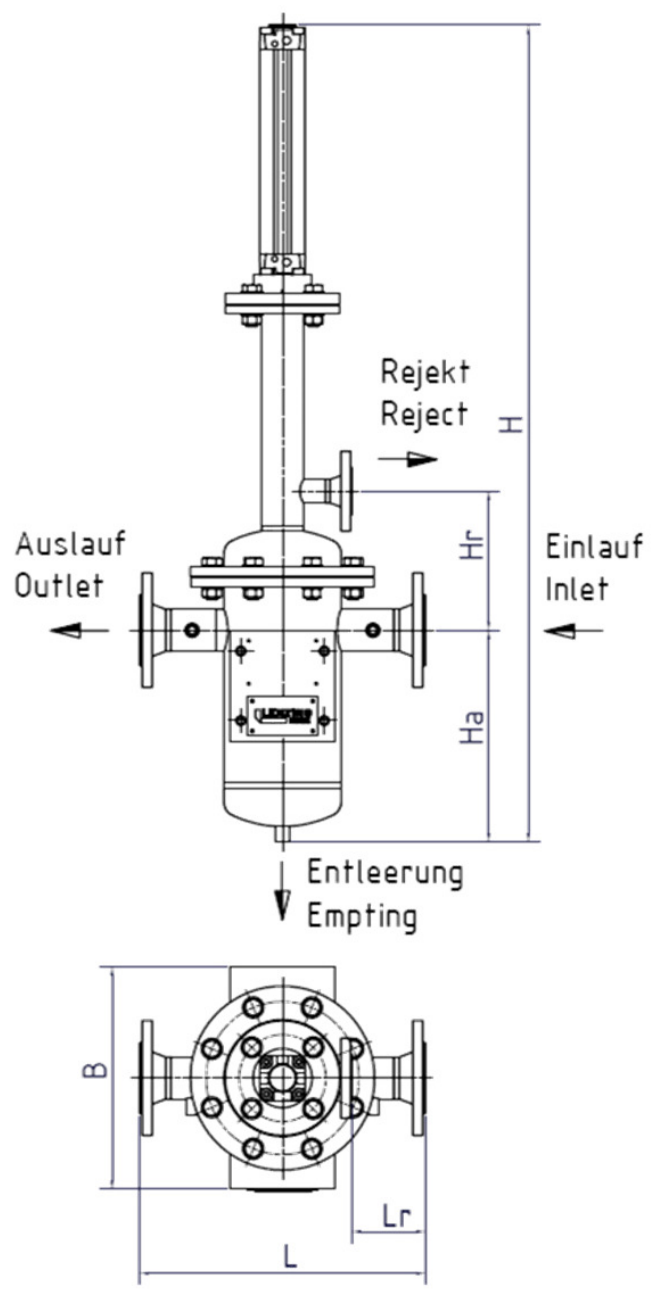

DN 50 


\section{Dimensiones HAWLE-OPTIFIL}
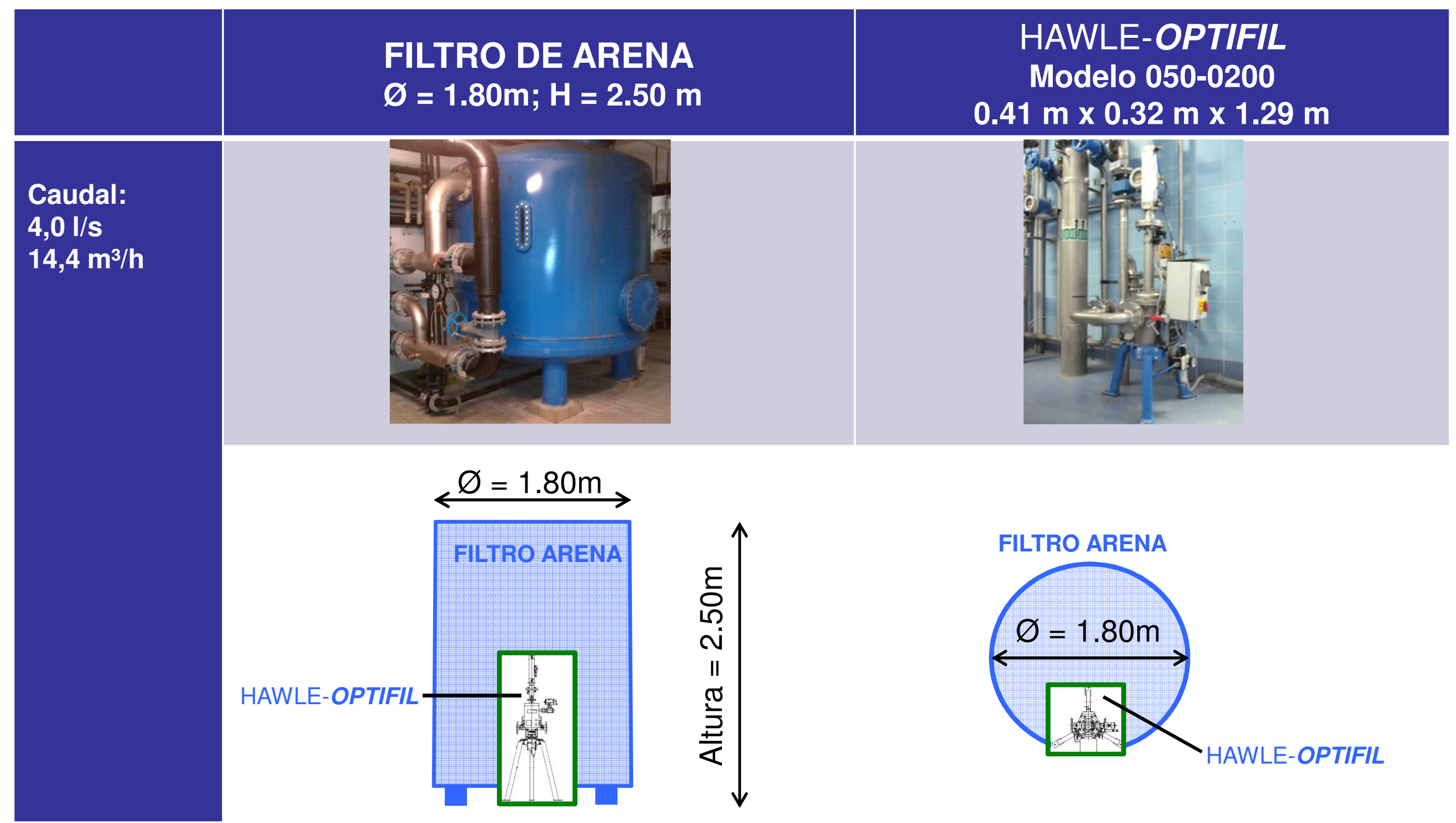

HAWLE. MADE FOR GENERATIOINS. 


\section{Referencias HAWLE-OPTIFIL}

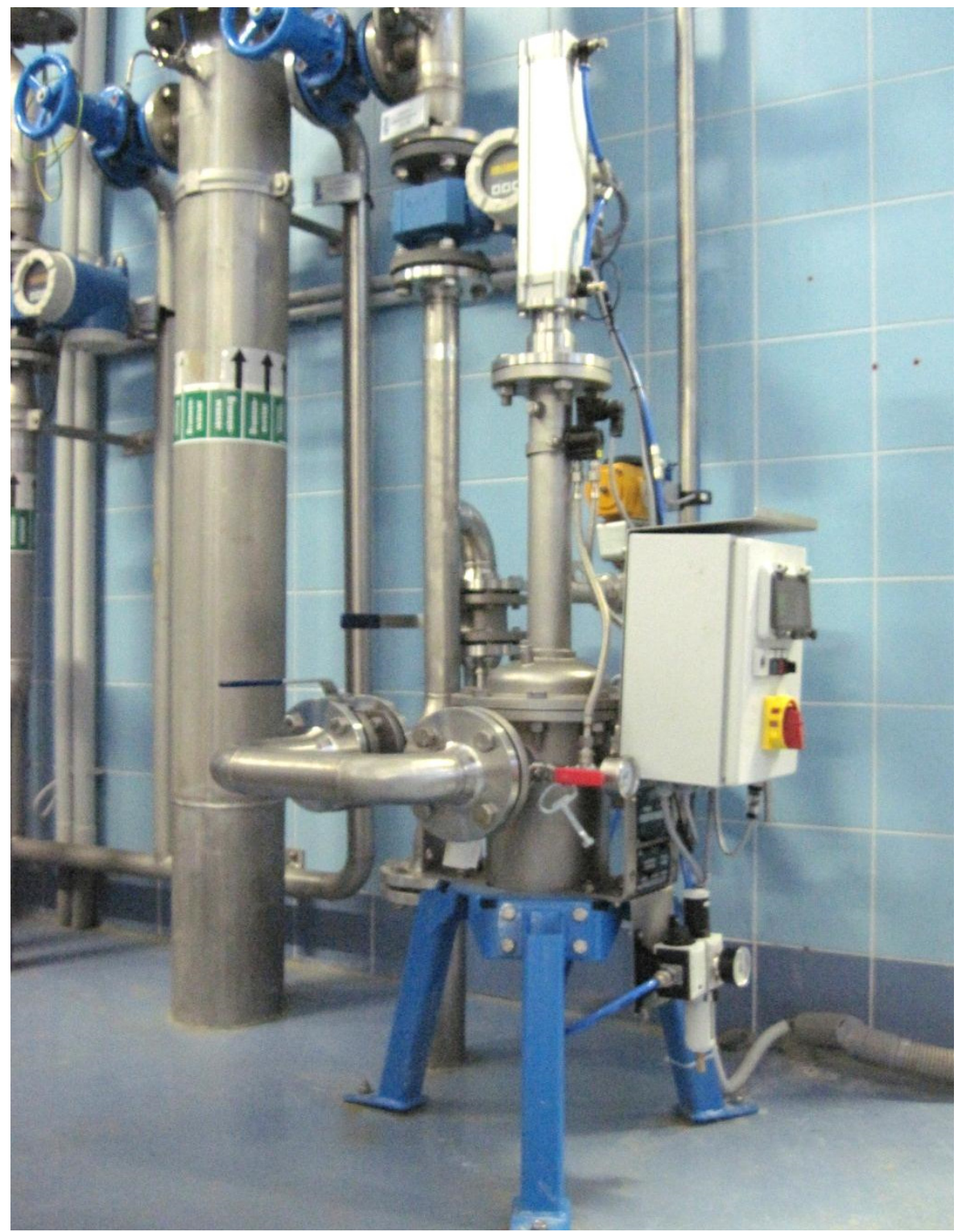

\begin{tabular}{|c|c|}
\hline Planta & Krottendorf DN 50 Asociación de aguas Unteres Lafnitztal \\
\hline Fuente agua sucia & pozo \\
\hline Caudal & $16 \mathrm{~m}^{3} / \mathrm{h}$ \\
\hline Objetivo & Eliminar partículas y reducir la turbidez (arena de cuarzo) \\
\hline Condiciones & $\begin{array}{l}\text { - Durante el arranque de la bomba una gran cantidad de } \\
\text { partículas es impulsada hacia el sistema } \\
\text { - Implementación en el sistema SCADA existente }\end{array}$ \\
\hline Solución & HAWLE-OPTIFIL con malla de $50 \mu \mathrm{m}$ de acero inoxidable \\
\hline
\end{tabular}




\section{Referencias HAWLE-OPTIFIL}

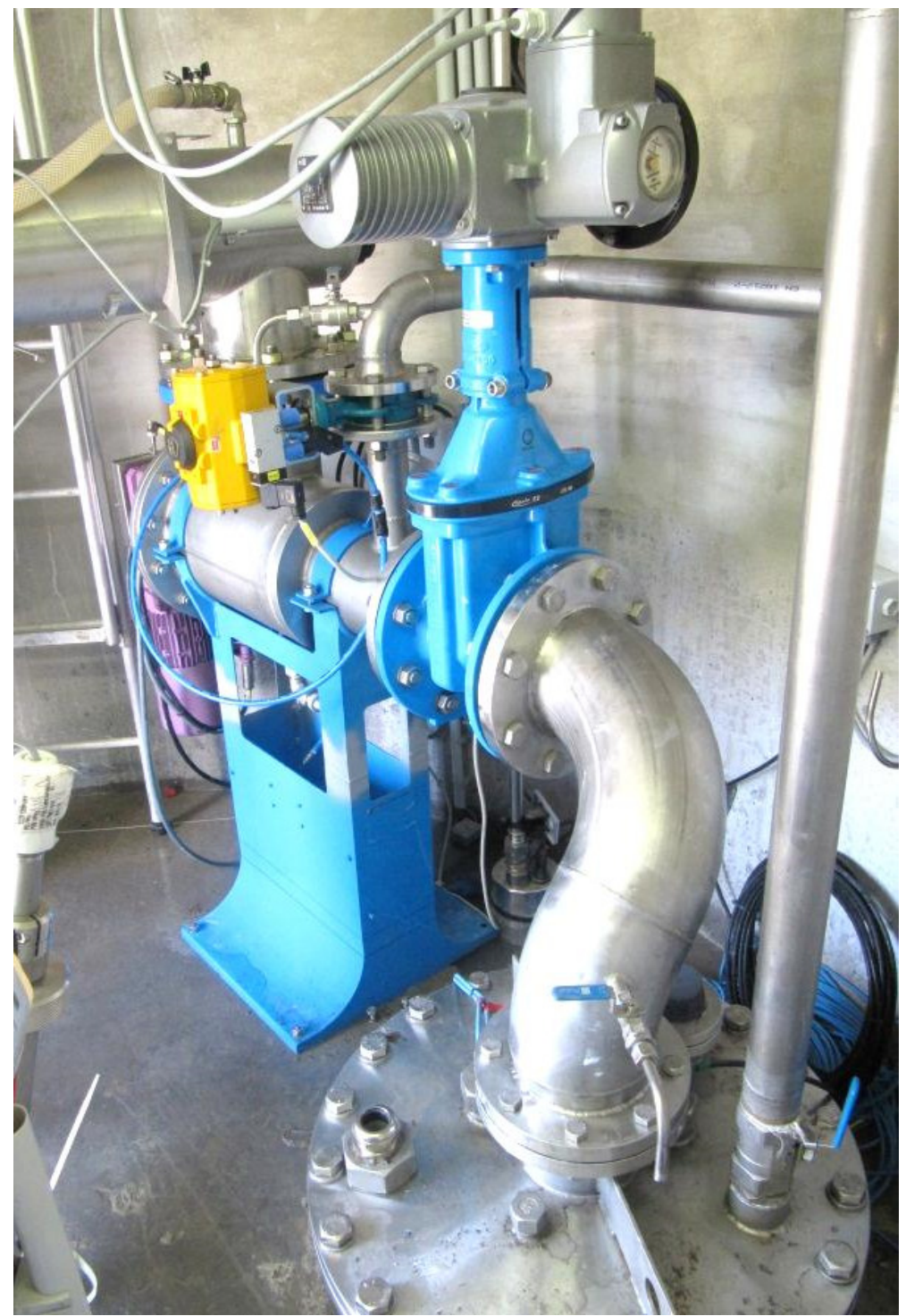

\begin{tabular}{|l|l|}
\hline Planta & Dobersdorf DN 150 Asociación de aguas Unteres \\
\hline Fuente agua & $\begin{array}{l}\text { Pozo de acuífero confinado } \\
57 \mathrm{~m}^{3} / \mathrm{h}\end{array}$ \\
\hline Caudal & $\begin{array}{l}\text { Eliminar partículas y reducir la turbidez (arena de cua } \\
\text { proteger el tratamiento UV }\end{array}$ \\
\hline Objetivo & $\begin{array}{l}\text { Espacio limitado para la instalación } \\
\text { - Implementación en el sistema SCADA existente }\end{array}$ \\
\hline Condiciones & HAWLE-OPTIFIL malla de 10 $10 \mathrm{~m}$ de acero inoxidable
\end{tabular}

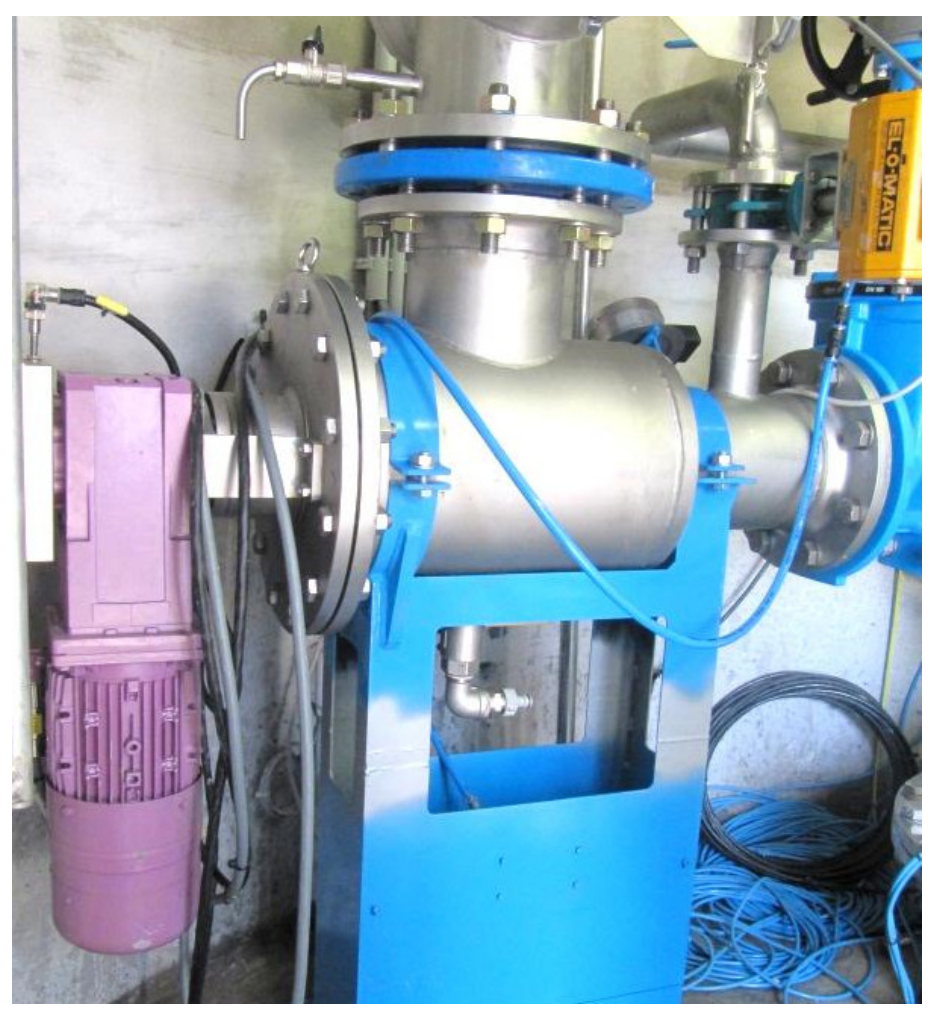




\section{Referencias HAWLE-OPTIFIL}

Ejemplo: Asociación de aguas "Unteres Lafnitztal"

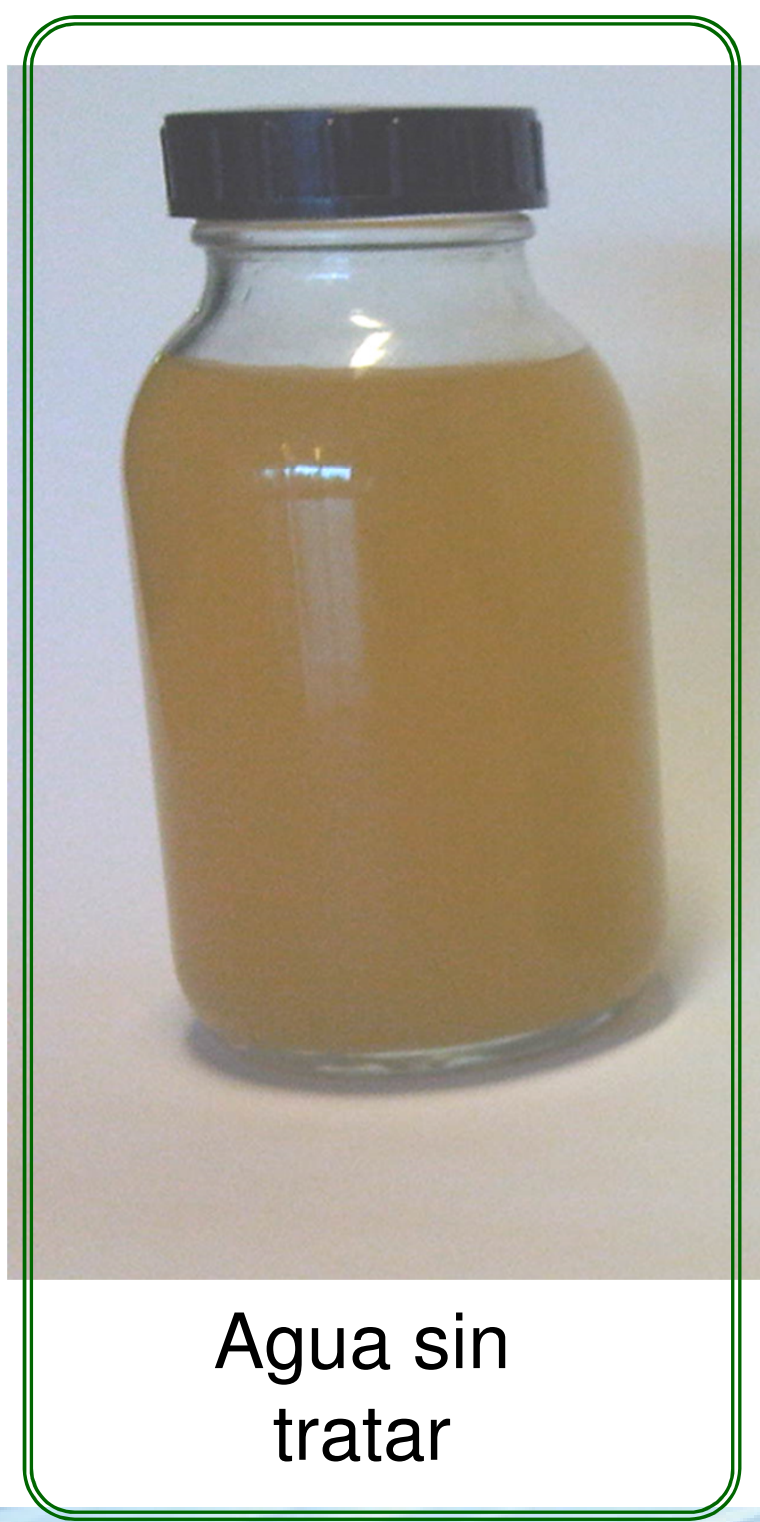

Filtrado;

Ahora, el agua puede ser desinfectada también mediante rayos UV. 


\section{Planta móvil de tratamiento de agua}
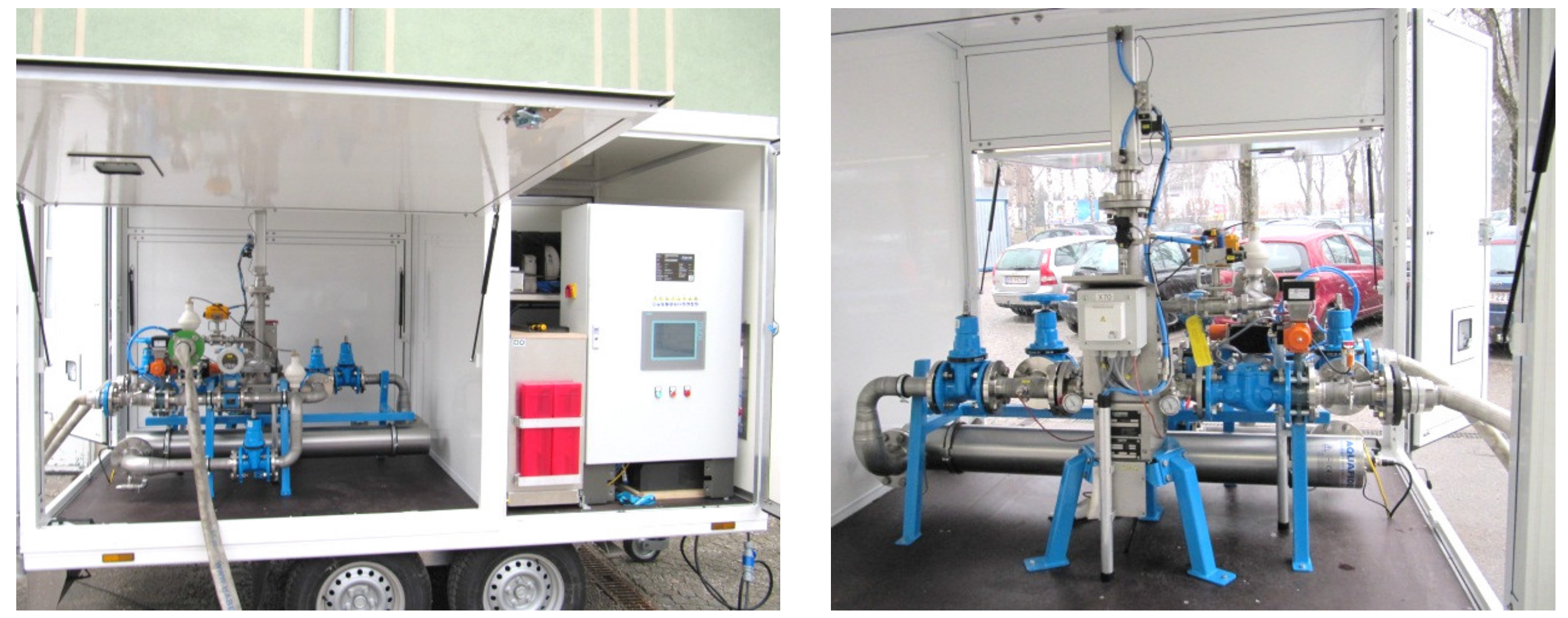

Remolque equipado con HAWLE-OPTIFIL DN 50 y tratamiento UV (opcional)

Funcionamiento:

Capacidad:

Aplicaciones:

Equipamiento:
- Eliminación de partículas, de turbidez y tratamiento UV

- De 5 a $20 \mathrm{~m}^{3} / \mathrm{h}$

- Distribución de emergencia de agua potable

- Ensayos piloto para los sistemas de filtrado

- Filtro autolimpiante automático HAWLE-OPTIFIL

- Tratamiento UV HAWLE-UV 


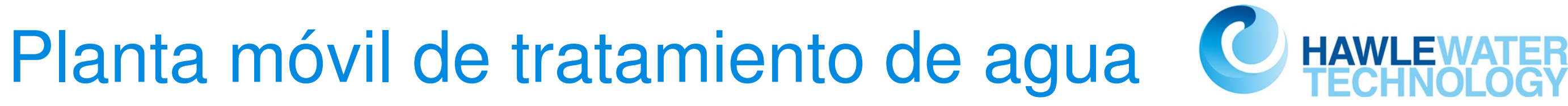

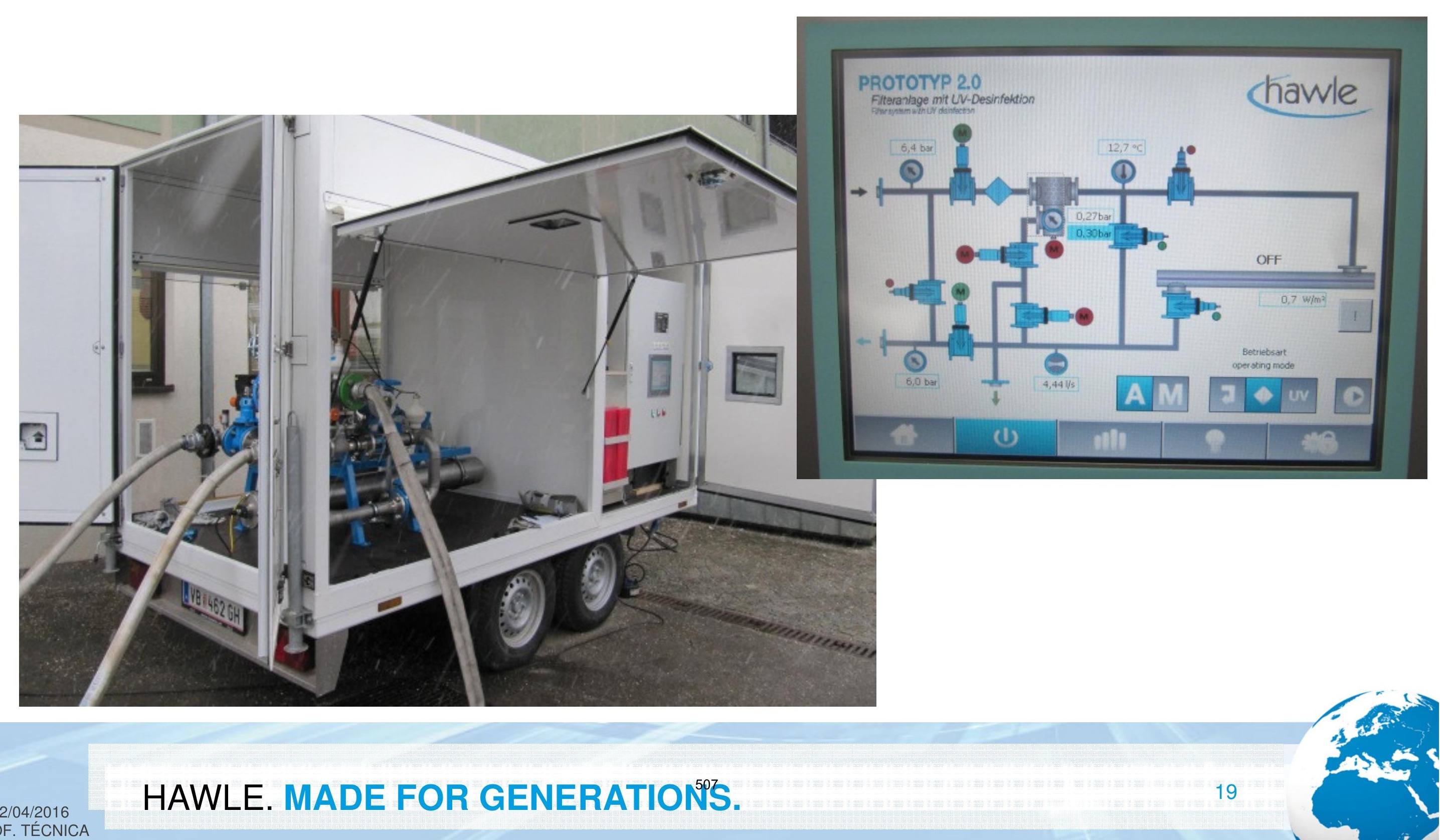


- Visión general de la reutilización

- Simulación de funcionamiento

- Detalles de construcción

- Certificados

- Especificaciones Técnicas

- Referencias

- Planta Móvil de tratamiento de agua 


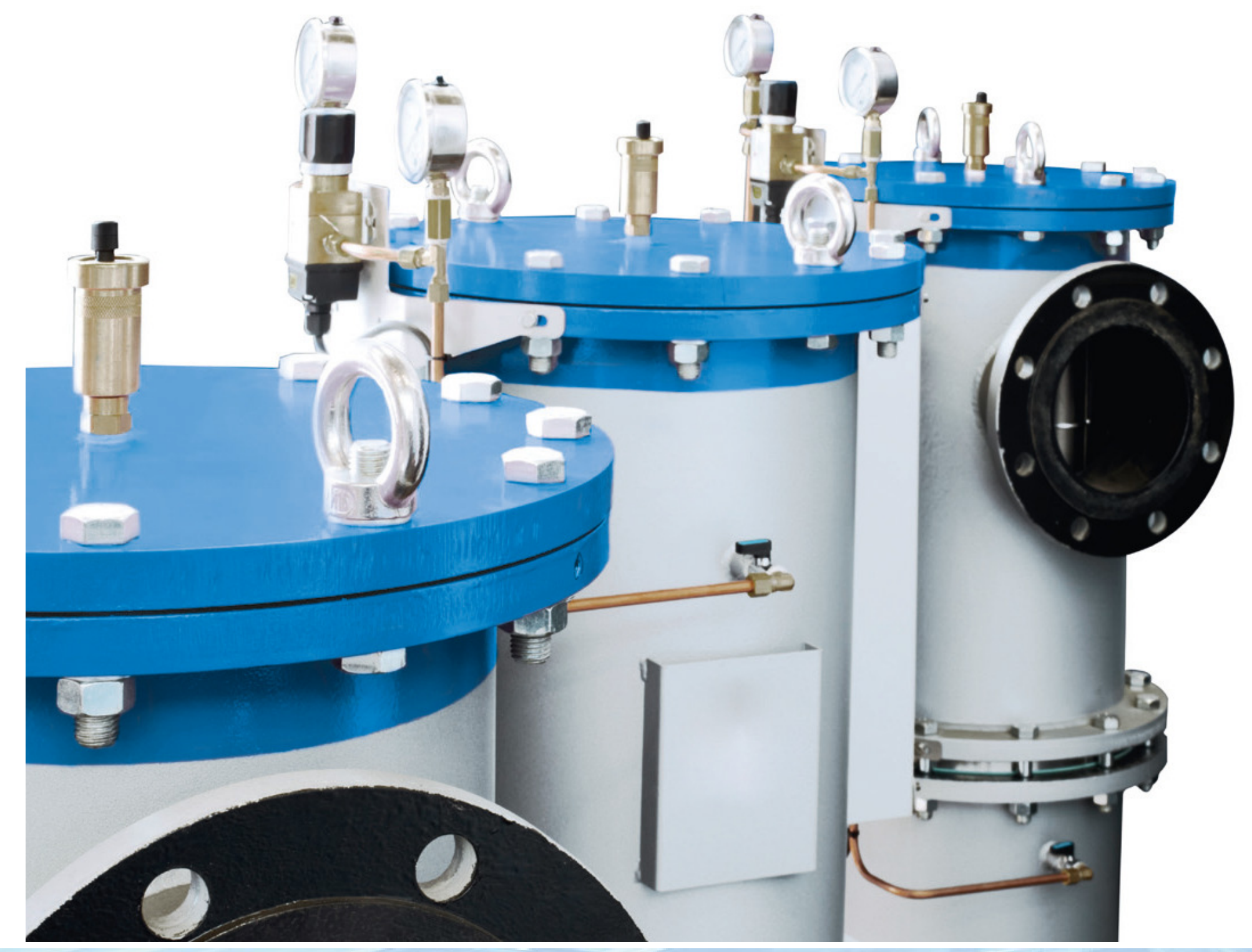




\section{ÁREAS DE APLICACIÓN}

- Filtrado de aguas para riego

- Tratamiento de aguas residuales

- Fabricación de nieve artificial

- Industria de celulosa y papel

- Fabricación de fibras

- Industria química y petroquímica

- Industria textil

- Industria siderúrgica

- Industria de la automoción

- Tratamiento de agua potable

- Plantas de producción de energía 


\section{Funcionamiento HAWLE-CANFIL

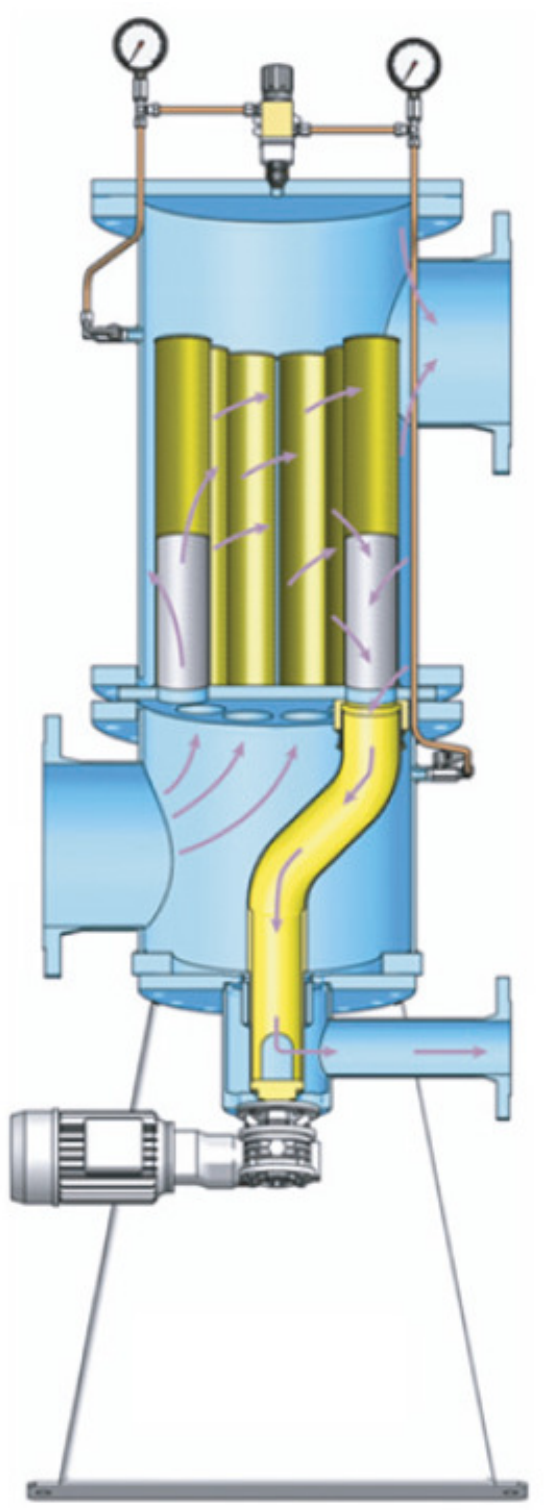

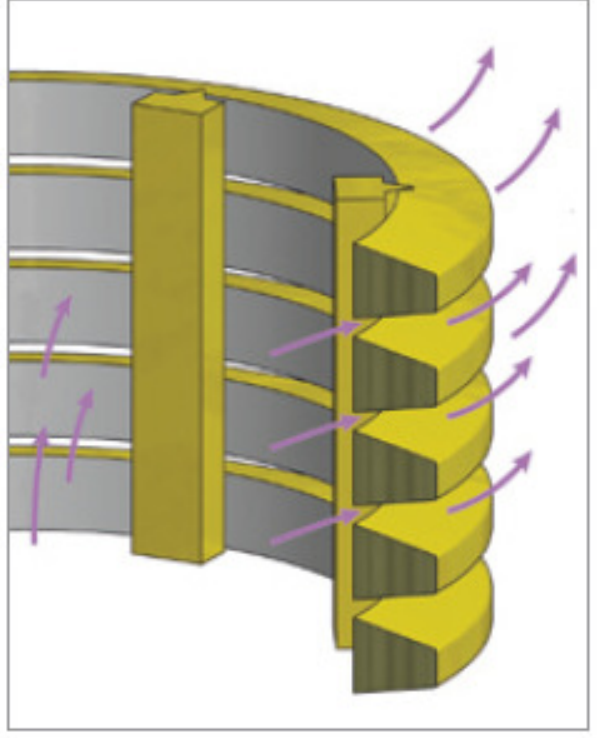

Estado: Filtrando

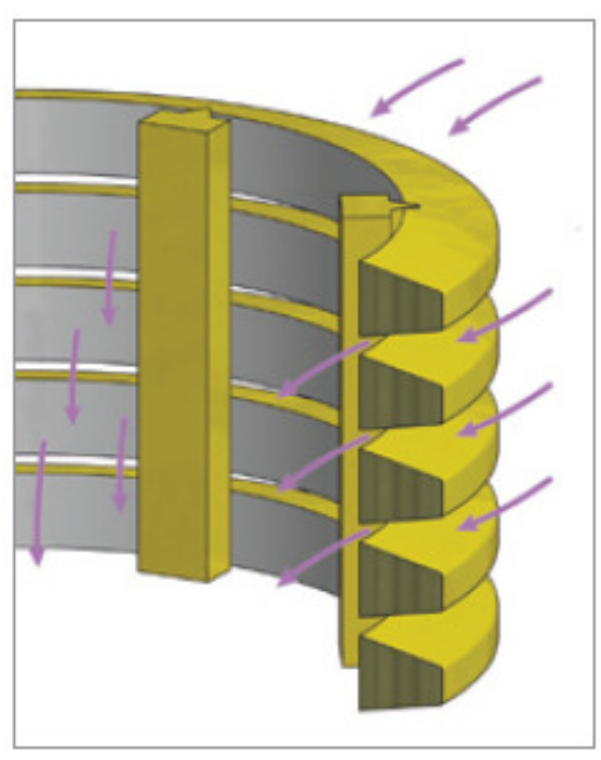

Estado: Limpiando

Principio de funcionamiento

HAWLE. MADE FOR GENERATIONS'S.

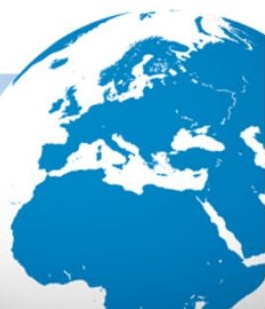




\section{Dimensiones HAWLE-CANFIL}

HAWLE-CANFIL 100 - 150

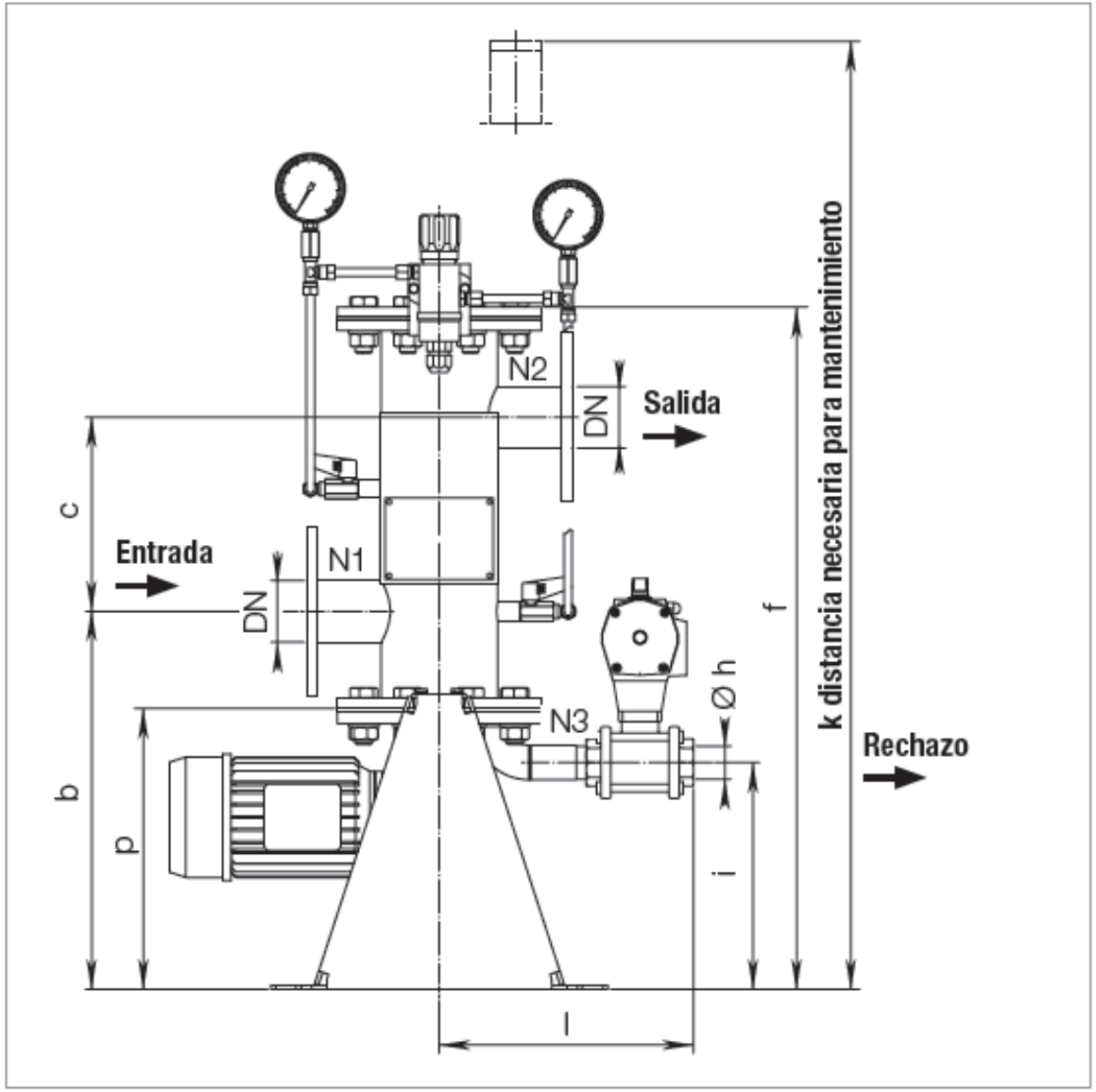

HAWLE-CANFIL 200 - 500

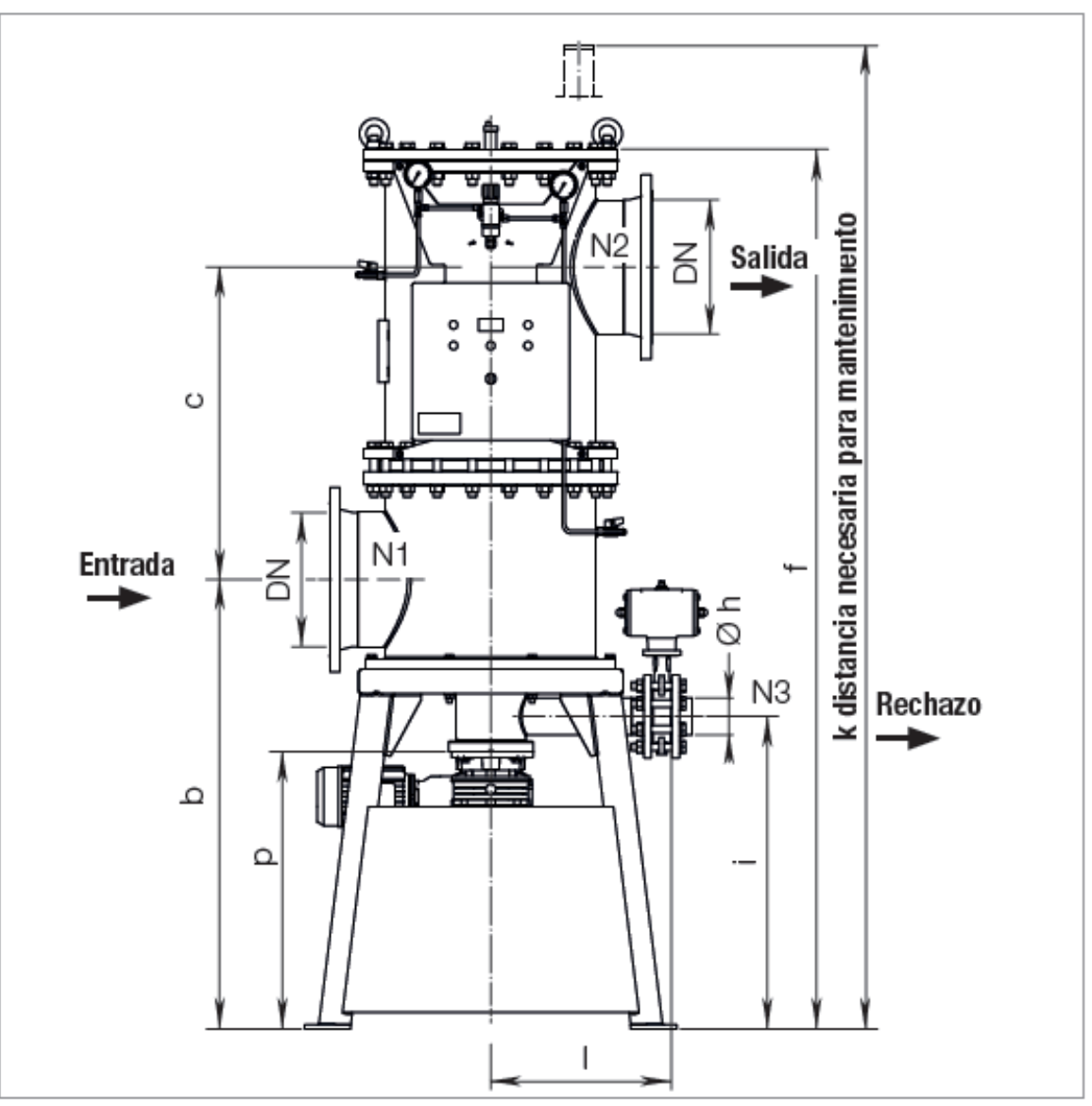




\section{Especificaciones HAWLE-CANFIL}

\begin{tabular}{|l|c|c|c|c|c|c|}
\cline { 2 - 7 } \multicolumn{1}{c|}{} & N1/N2 & \multicolumn{5}{c|}{ Caudal en m3/h } \\
\hline Tipo & DN & $\mathbf{5 0 \mu \mathrm { m }}$ & $\mathbf{7 5 \mu \mathrm { m }}$ & $\mathbf{1 0 0 \mu \mathrm { m }}$ & $\mathbf{1 5 0 \mu \mathrm { m }}$ & $\mathbf{2 0 0 \mu \mathrm { m }}$ \\
\hline CANFIL-100 & 50 & 7 & 10 & 13 & 18 & 20 \\
\hline CANFIL-150 & 80 & 25 & 36 & 47 & 53 & 53 \\
\hline CANFIL-200 & 100 & 55 & 81 & 105 & 115 & 115 \\
\hline CANFIL-300 & 150 & 119 & 174 & 227 & 251 & 251 \\
\hline CANFIL-350 & 200 & 170 & 248 & 324 & 388 & 388 \\
\hline CANFIL-400 & 250 & 279 & 408 & 523 & 523 & 523 \\
\hline CANFIL-500 & 300 & 454 & 665 & 866 & 948 & 948 \\
\hline
\end{tabular}




\section{Referencias HAWLE-CANFIL}

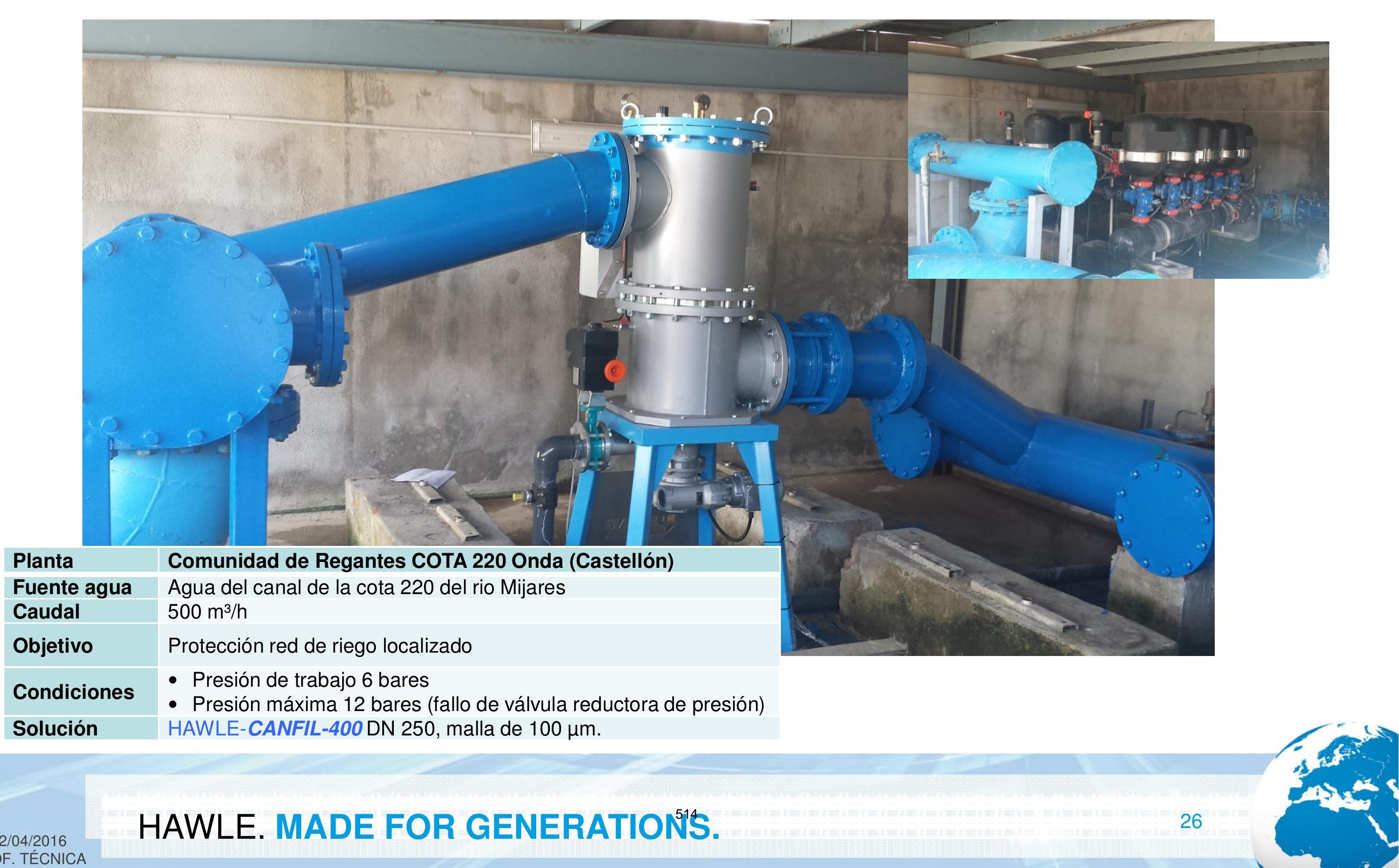




\section{Referencias HAWLE-CANFIL}

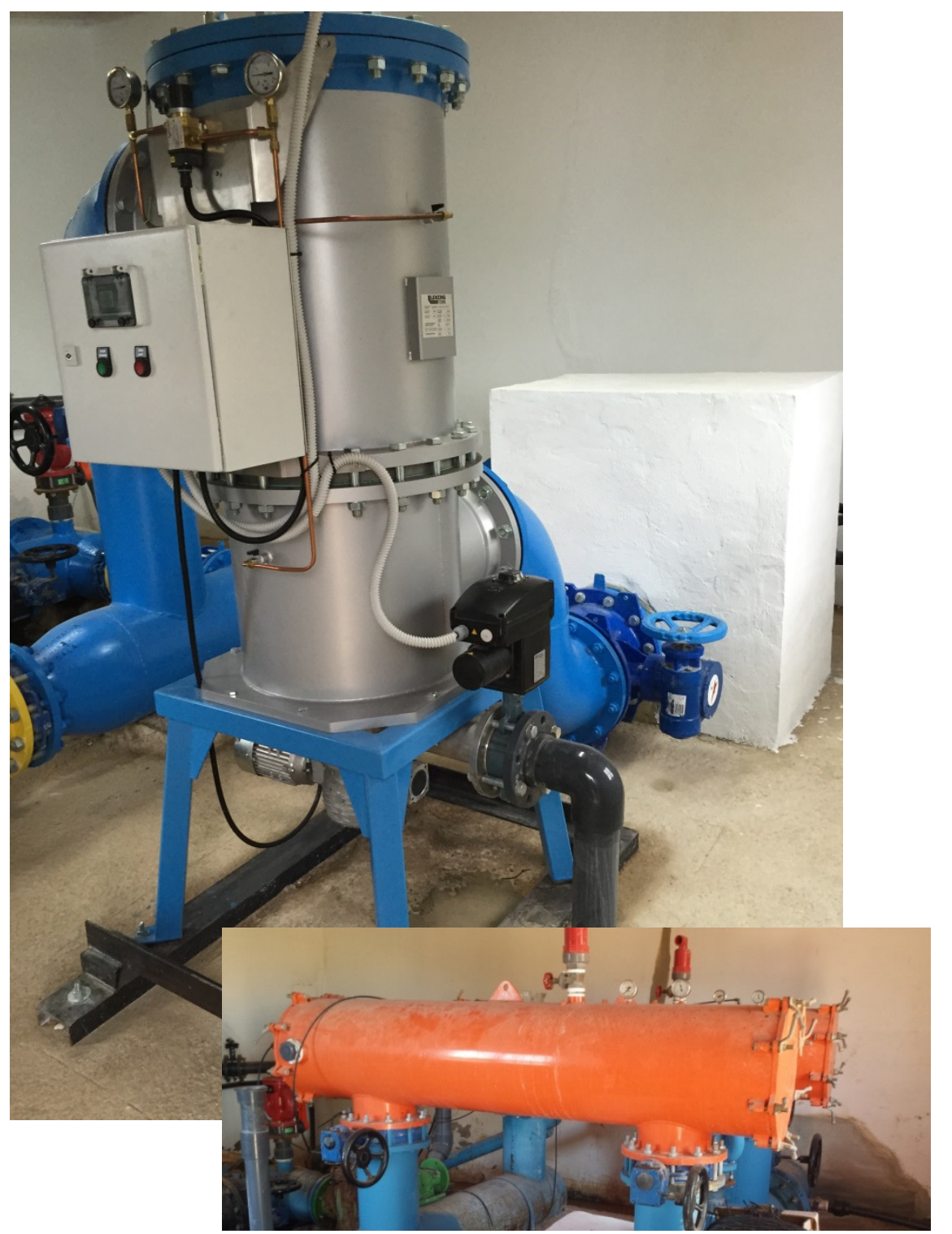

\begin{tabular}{|l|}
\hline Planta \\
\hline Fuente agua \\
\hline Caudal \\
\hline Objetivo \\
\hline Condiciones \\
\hline Solución \\
\hline
\end{tabular}

Comunidad de Regantes Pozo San Juan de Bugarra (Valencia)

Fuente agua Agua del río Turia $800 \mathrm{~m}^{3} / \mathrm{h}$

Protección red de riego localizado

- Presión de trabajo 2,4 bares

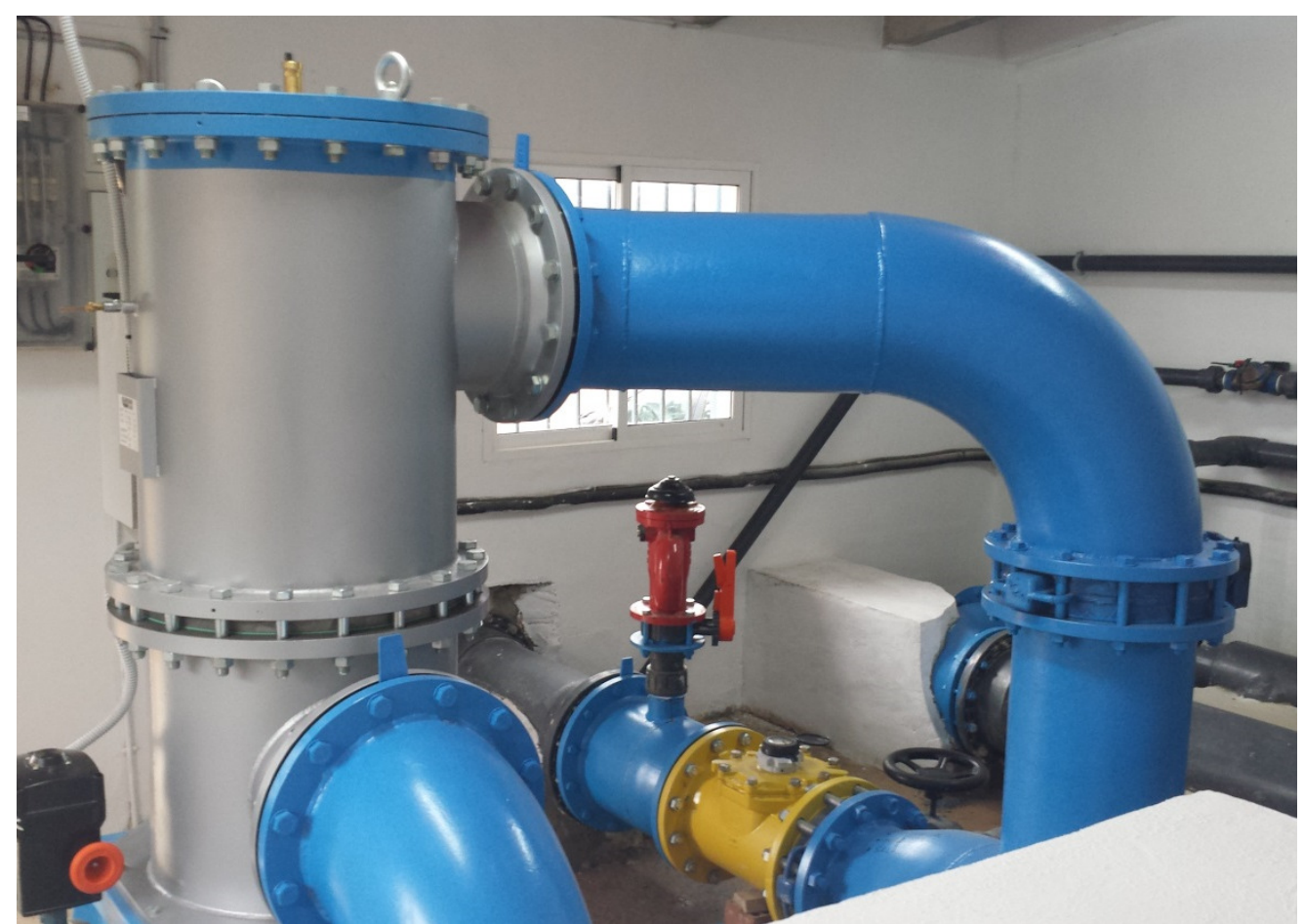

HAWLE. MADE FOR GENERATIONSSS. 


\section{HEMOS VISTO:}

\section{Visión general del filtrado}

\section{HAWLE-OPTIFIL}

»Visión general de la reutilización

» Simulación de funcionamiento

»Detalles de construcción

»Certificados

»Especificaciones Técnicas

》Referencias

»Planta Móvil de tratamiento de agua

\section{HAWLE-CANFIL}

»Áreas de aplicación

» Funcionamiento

»Dimensiones

»Especificaciones Técnicas

»Referencias 


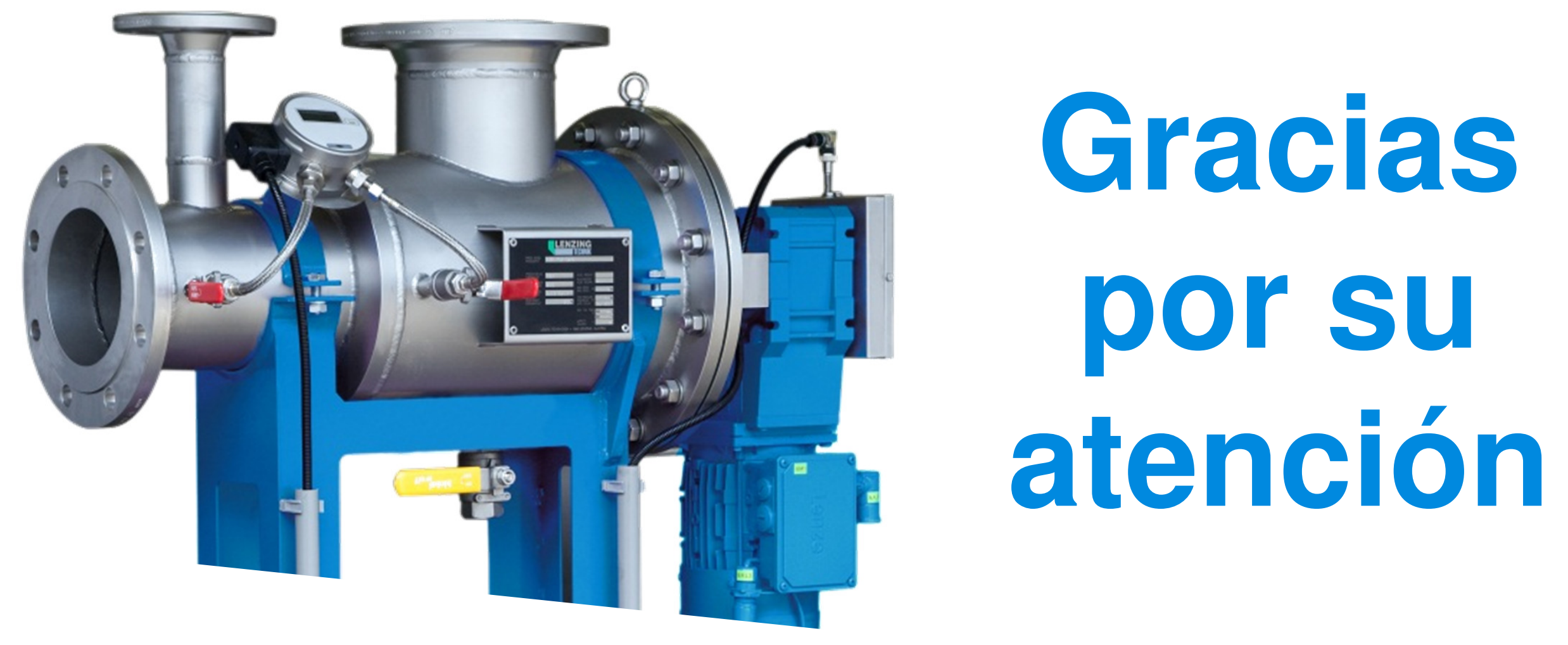

The new spirit of filtration 


\section{Gestión eficiente del agua con los contadores ultrasónicos inteligentes YZATEC}
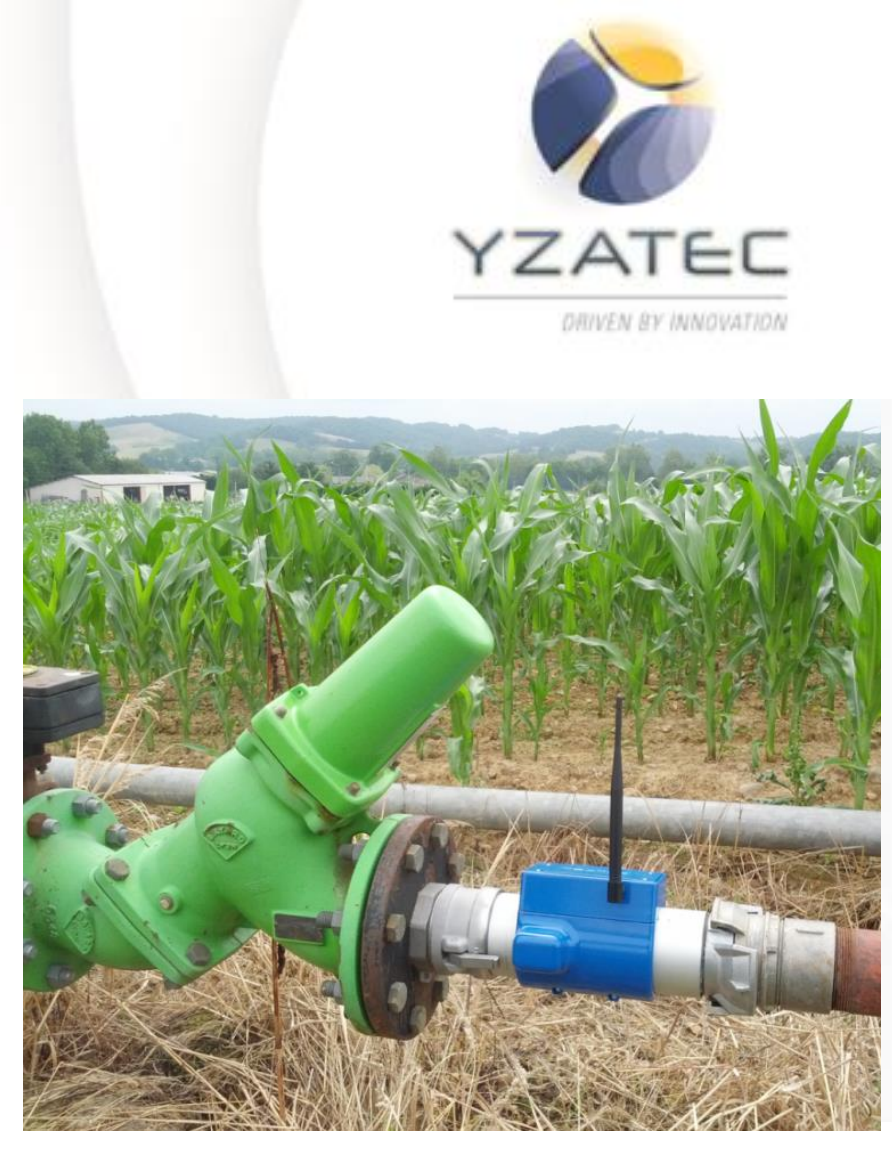

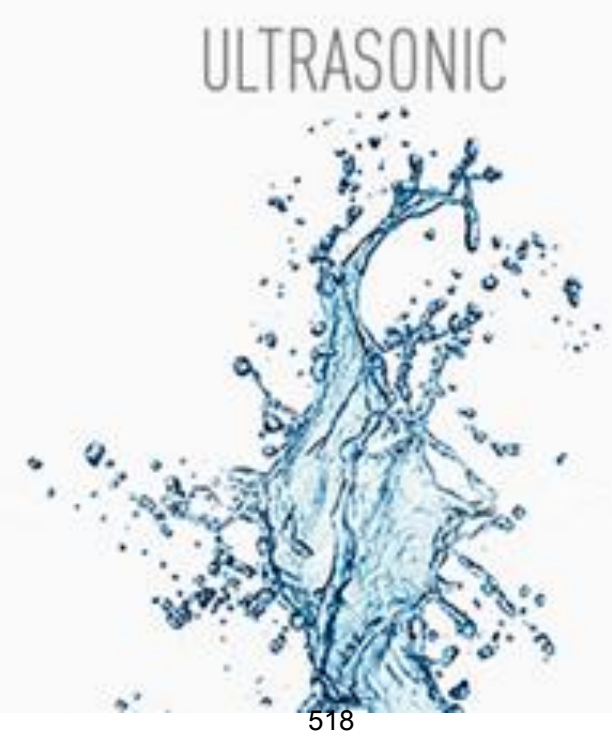

XXXIV CONGRESO NACIONAL DE RIEGOS

Sevilla, 7-9 de junio de 2016

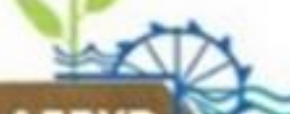

AERYD

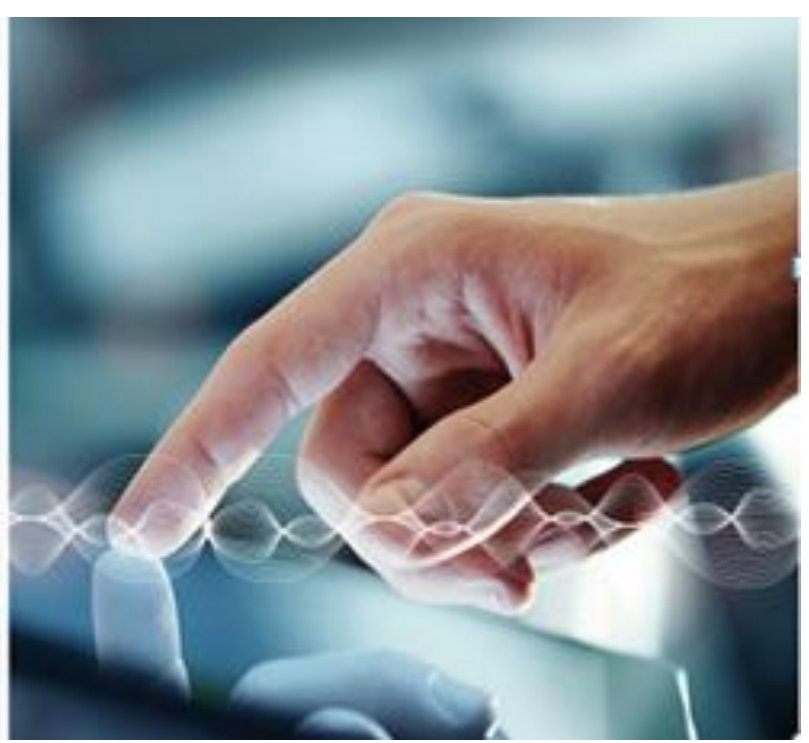

DOI: http://dx.doi.org/10.21151/CNRiegos.2016.TC3 
1/ Problemas en redes de distribución de agua

2/ Nueva gestión con los contadores ultrasónicos inteligentes

3/ Yzatec : simple desde la instalación hasta la gestión Como funciona

Como se instala

Como se gestiona

4/ Mejorar el rendimiento de su cultivo

Reducir los costes de mantenimiento

Gestión inteligente de su regadío

Facturar y pagar su consumo real de agua

5/ CACG, ejemplo de optimización de riego 
1- Problemas en redes de distribución de agua YZATEC DMINEN QY INNOVATION 


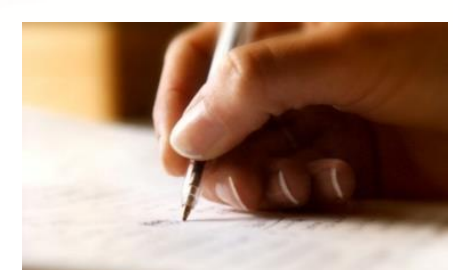

> Lectura manual o sistema poco compacto, varios interlocutores, costoso

$>$ Abono químicos corosivos $=>$ deterioro de los contadores

$>$ Elevada pérdida de carga => aumenta el coste energético

$>$ Pérdida de precisión por uso => información errónea del consumo

$>$ No miden caudales pequeños $=>$ consumo de agua no facturado

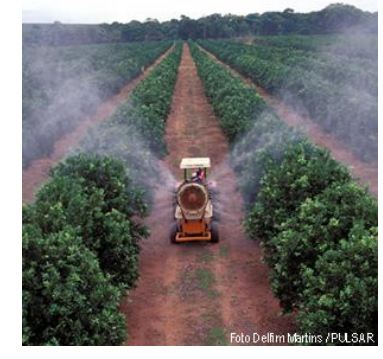

$>$ Obstrucción del contador $=>$ coste de mantenimiento

$>$ Funcionamiento erroneo en posición vertical

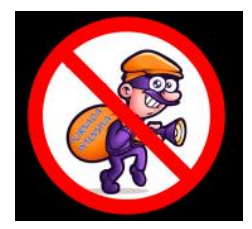

$>$ Robo de los contadores

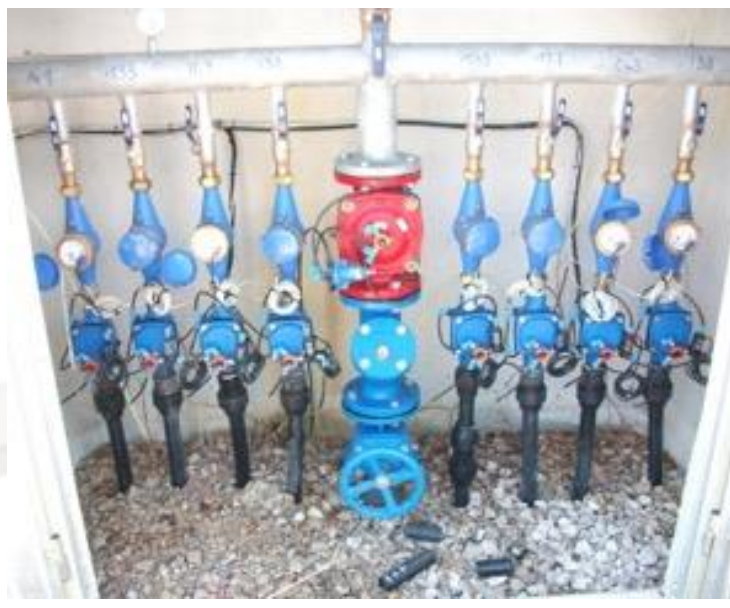


YZATEC 2- Nueva gestión con los contadores ultrasónicos 
Sin pérdida de carga, permiten obtener un significativo ahorro energético

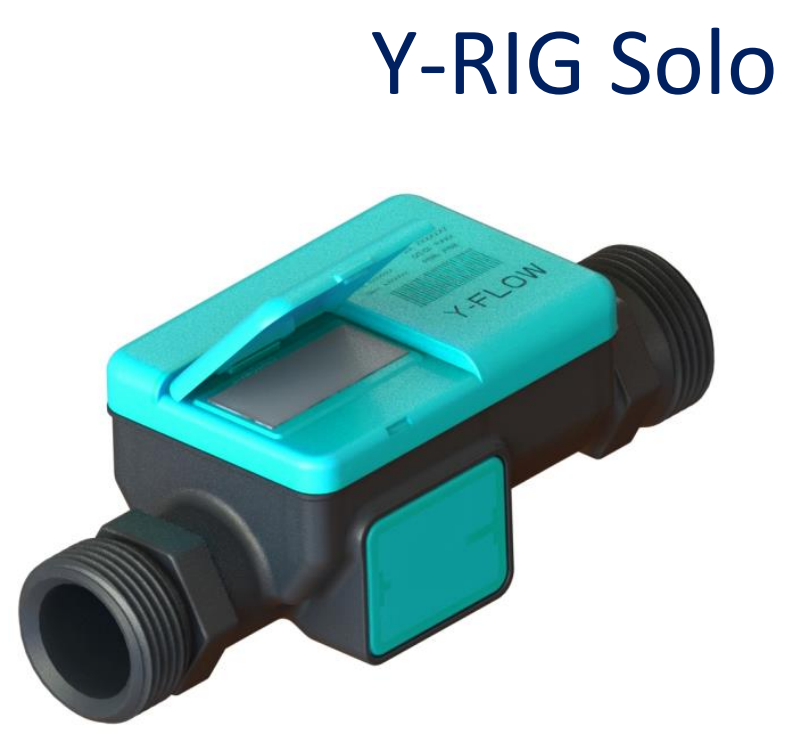

Medición no manipulable (con imanes u otros objetos)

Medición del consumo real del agua

Muy resistente y compacto

Instalación vertical y horizontal

Ahorro en coste de mantenimiento 
Sin pérdida de carga, permiten obtener un significativo ahorro energético

$$
\text { Y-RIG }
$$

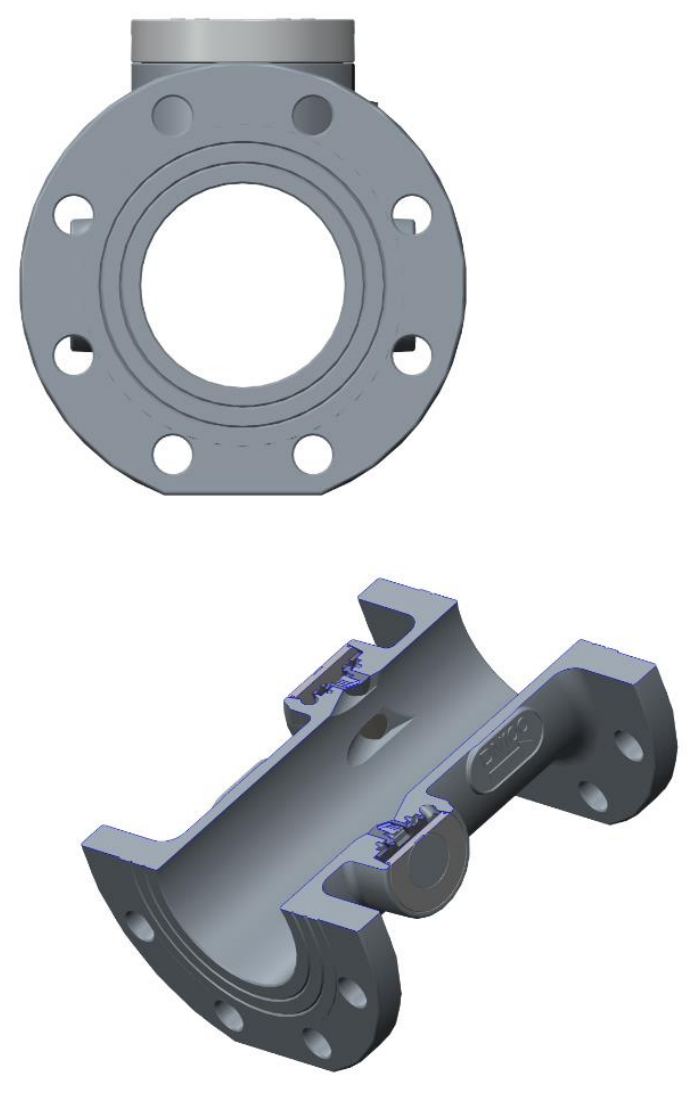

Medición no manipulable (con imanes u otros objetos)

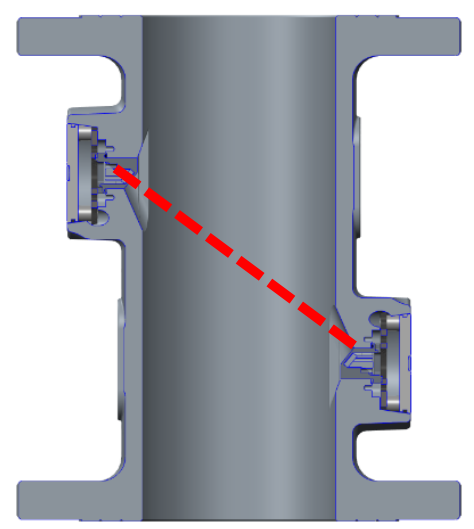

Medición del consumo real del agua

Muy resistente y compacto

Gestión de su consumo a distancia

Ahorro en coste de mantenimiento 
3- Yzatec : simple desde la instalación hasta la gestión YZATEC 


\section{Plug \& Play}
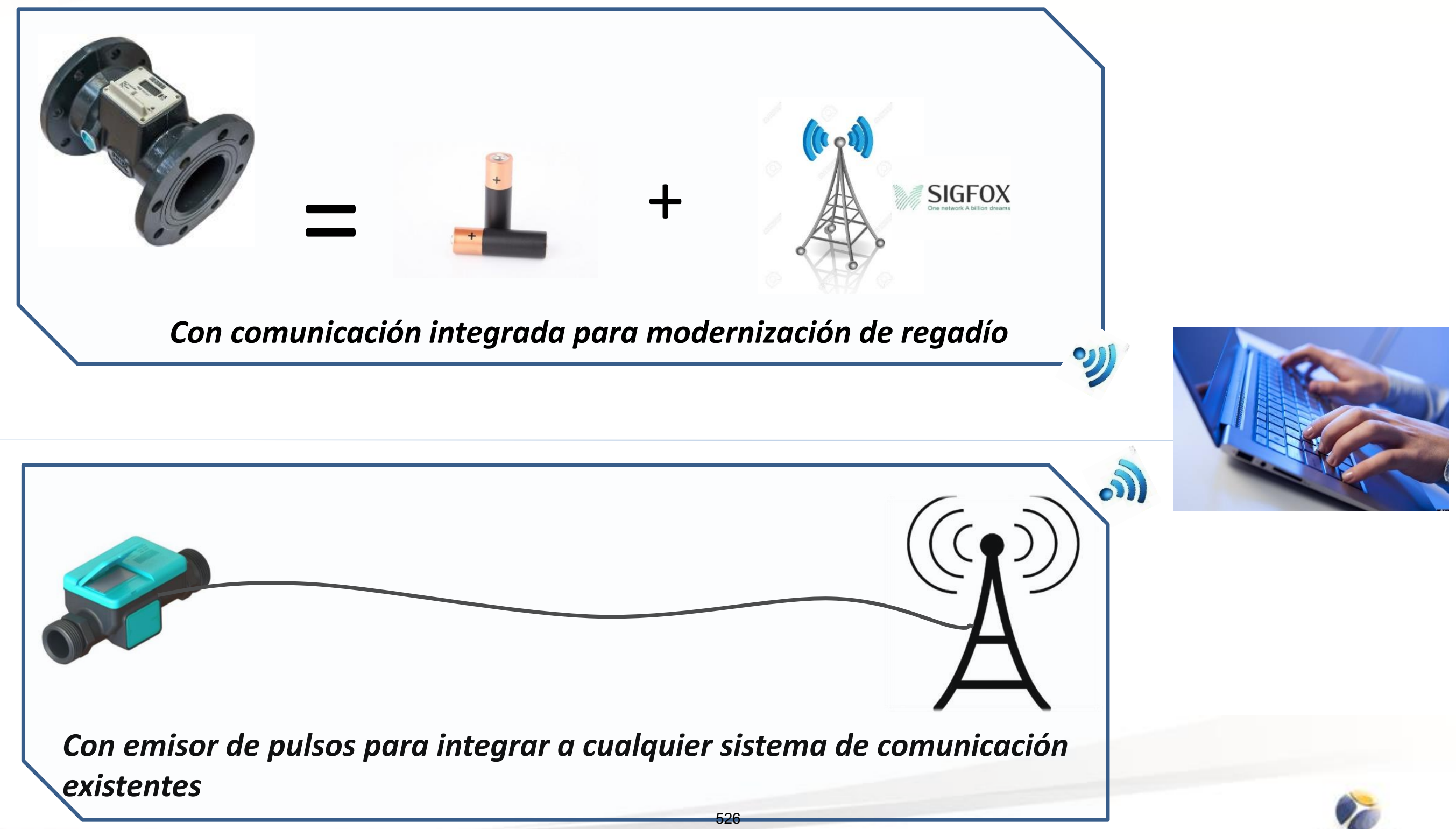


\section{Arquitectura Y-RIG con red SIGFOX}

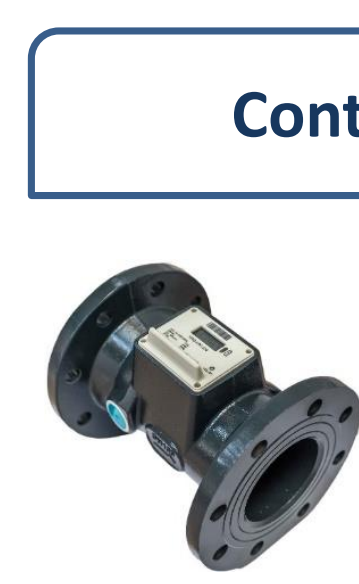

Y-RIG DN 100 Riego

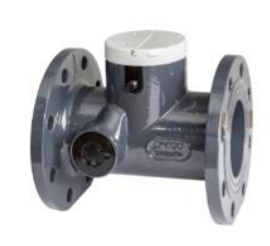

Y-RIG DN 50 Riego

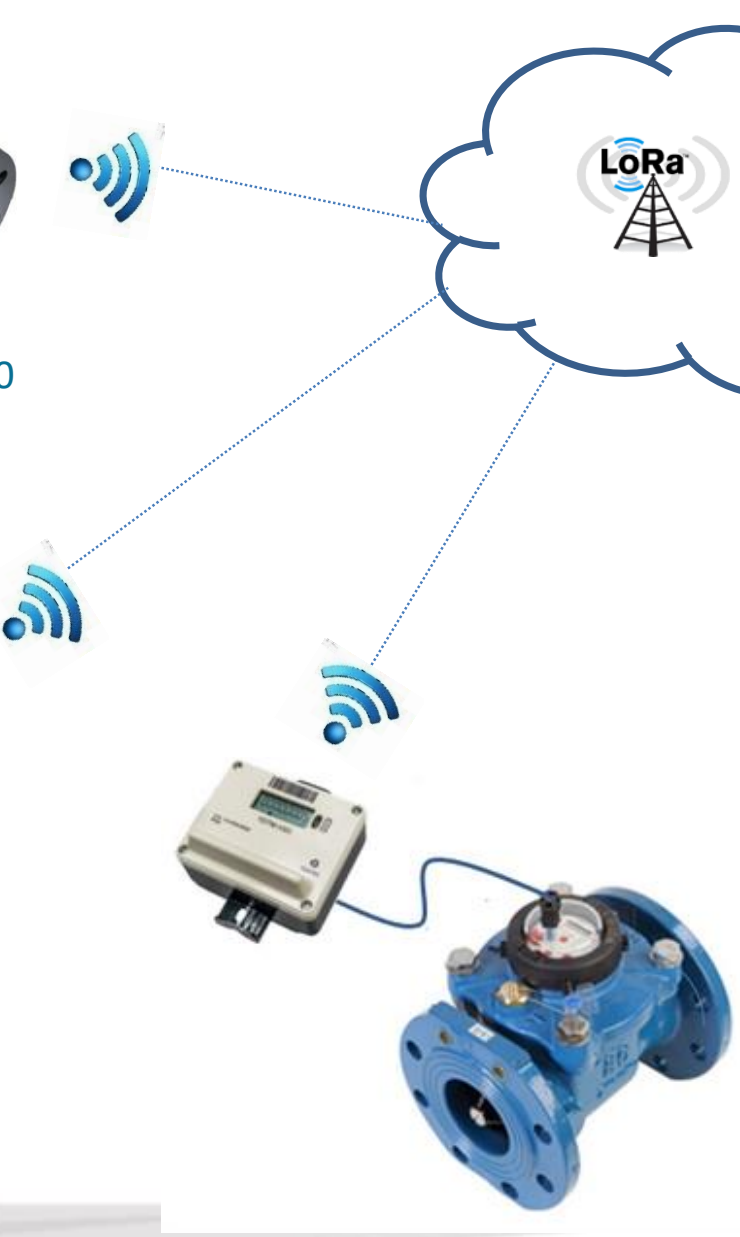

Red

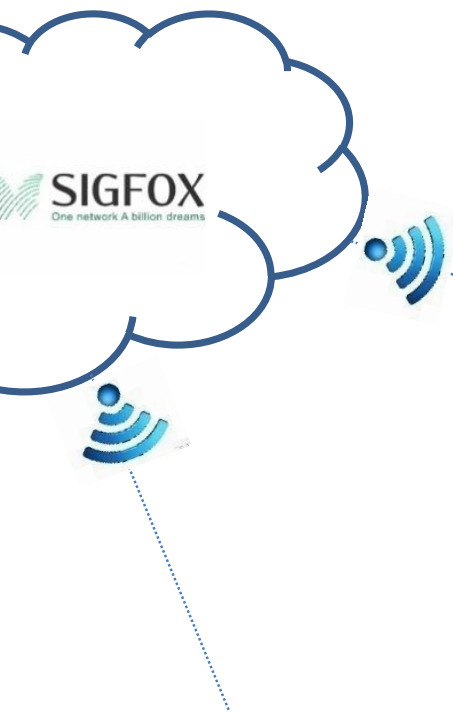

Plataforma web de telegestión

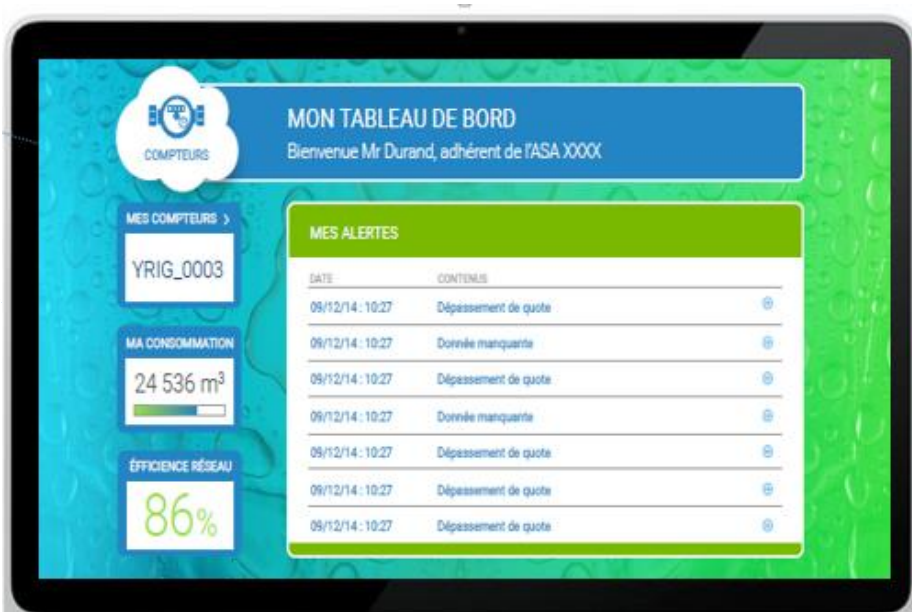

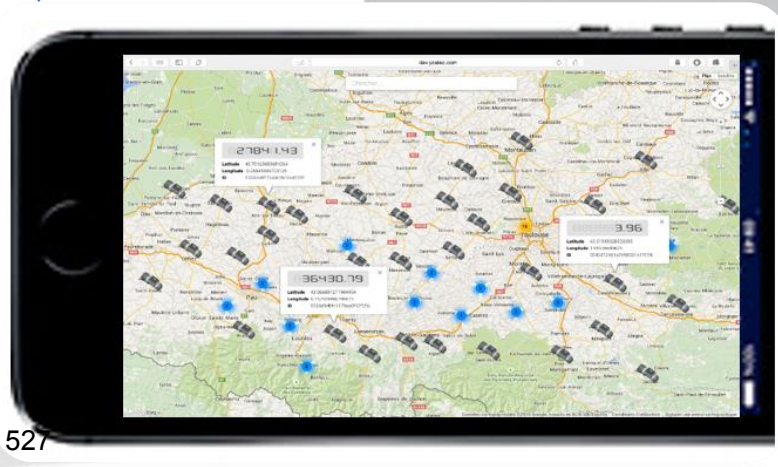

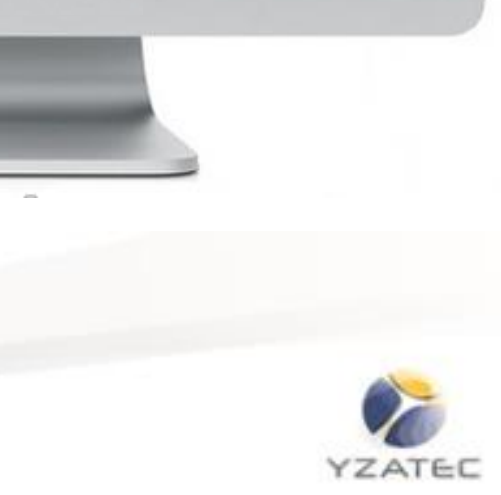




\section{Aceso simple a sus datos de consumo}
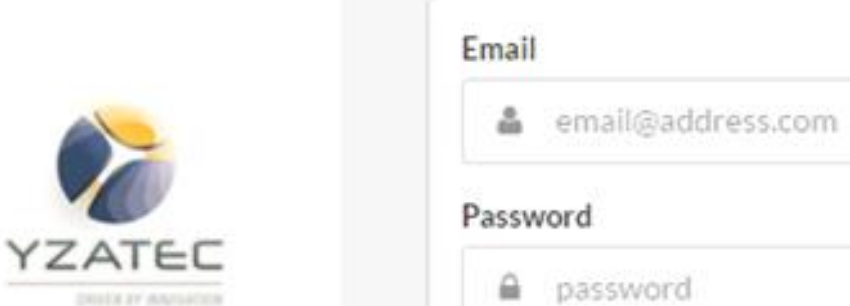


\section{Almacenamiento del historico de consumo}

6 demonstrator - 15-CCOl-c $x$

$\leftarrow \rightarrow C$

$\equiv$

Last messages 15-CC01-0063

\begin{tabular}{|c|c|c|c|c|c|}
\hline \# & 苗 & IIIII & 20 & ○ & 브 \\
\hline 2738 & 5/2/2016, 8:56:03 AM & $15-\mathrm{CC} 01-0063$ & 474.74 & $30: 41: 05$ & 21.89 \\
\hline 2737 & 5/2/2016, 7:55:05 AM & 15-CC01-0063 & 458.88 & $29: 57: 37$ & 0.00 \\
\hline 2736 & 5/2/2016,6:56:03 AM & 15-CC01-0063 & 458.88 & $29: 57: 37$ & 0.00 \\
\hline 2735 & 5/2/2016, 5:55:03 AM & $15-\mathrm{CCO} 1-0063$ & 458.88 & $29: 57: 37$ & 0.00 \\
\hline 2734 & $5 / 2 / 2016,4: 56: 03$ AM & $15-C C 01-0063$ & 458.88 & $29: 57: 37$ & 0.00 \\
\hline 2733 & 5/2/2016, 3:55:03 AM & $15-\mathrm{CC} 01-0063$ & 458.88 & $29: 57: 37$ & 0.00 \\
\hline 2732 & $5 / 2 / 2016,2: 56: 03 \wedge \mathrm{M}$ & $15-\mathrm{CCO1}-0063$ & 158.88 & $29: 57: 37$ & 0.00 \\
\hline 2731 & 5/2/2016, 1:55:03 AM & $15-\mathrm{CC} 01-0063$ & 458.88 & $29: 57: 37$ & 0.00 \\
\hline 2730 & 5/2/2016. 12:56:03 AM & $15-\mathrm{CC} 01-0063$ & 458.88 & $29: 57: 37$ & 0.00 \\
\hline 2729 & 5/1/2016, 11:55:03 PM & $15-\mathrm{CCO} 1-0063$ & 450.00 & $29: 57: 37$ & 0.00 \\
\hline 2728 & 5/1/2016, 10:56:03 PM & $15-C C 01-0063$ & 458.88 & $29: 57: 37$ & 0.00 \\
\hline 2727 & 5/1/2016, 9:55:03 PM & $15-$-С.০1-О0К.3 & 458.88 & $29: 57: 37$ & 0.00 \\
\hline 2726 & 5/1/2016, 8:56:04 PM & $15-C C 01-0063$ & 458.88 & $29: 57: 37$ & 0.00 \\
\hline 2725 & 5/1/2016, 7:55:04 PM & $15-\mathrm{CC} 01-0063$ & 458.88 & $29: 57: 37$ & 0.00 \\
\hline 2721 & 5/1/2016,6:56:01 PM & $15-\mathrm{CC} 01-0063$ & 158.88 & $29: 57: 37$ & 0.00 \\
\hline 2723 & 5/1/2016, 5:55:04 PM & $15-\mathrm{CC} 01-0063$ & 458.88 & $29: 57: 37$ & 0.00 \\
\hline 2722 & 5/1/2016. 4:56:04 PM & 15-CC01-0063 & 458.88 & $29: 57: 37$ & 0.00 \\
\hline 2721 & 5/1/2016, 3:55:03 PM & $15-C C 01-0063$ & 450.00 & $29: 57: 37$ & 0.00 \\
\hline
\end{tabular}




\section{Y-RIG}

\section{Gestión Diaría de su Regadío}

- Seguir su consumo a distancia

- Lectura global con el display

- Posibilidad de analizar los datos

\section{Poco Mantenimiento}

- Parte comunicante integrada

- Sin obstrucción

\section{Ahorro Agua e Energía}

- Sin pérdida de carga

- Detecta fugas

- Funciona con dos pilas (10 años)

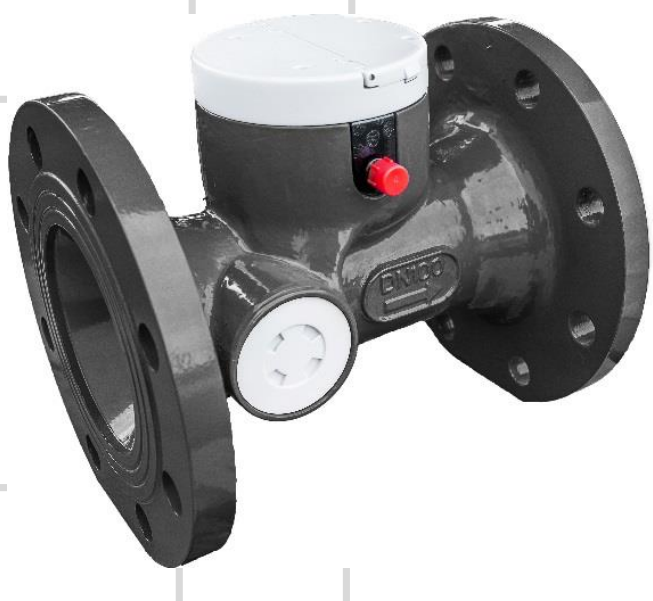

\section{Instalación}

- Se adapta a las instalaciones existentes

- Se pueden poner tubos simples

- Instalación UO DO 
4- Mejorar el rendimiento de su cultivo: Reducir los costes de mantenimiento Gestión inteligente de su regadío Facturar y pagar el consumo real de agua 
$\checkmark$ Instalación de la Comunicación + Fuente de Energía + Contador = en una Vez

$\checkmark$ Sin Parte Mecánica

$\checkmark$ Medición Precisa en Bajos y Altos Caudales

$\checkmark$ Resistente a las Condiciones de Uso Agrícola
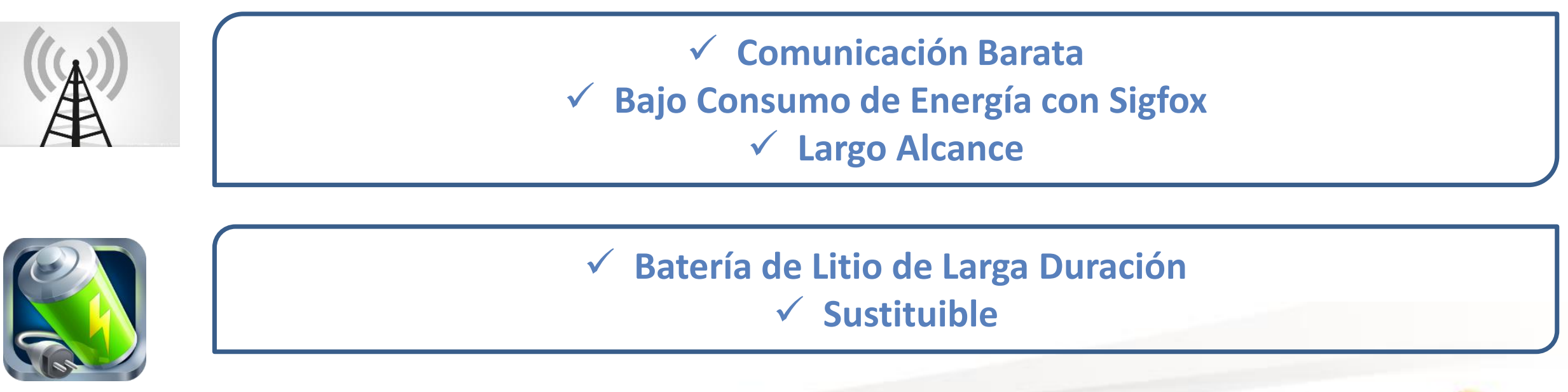

Batería de Litio de Larga Duración

$\checkmark$ Sustituible 


\section{Una gama completa en plástico y en fundición}

\section{DATOS DE RENDIMIENTO}

DN 50

DN 65

DN 80

DN 100

DN 125

DN 150

\begin{tabular}{|c|c|c|c|c|c|}
\hline DN & 50 & 65 & 80 & 100 & 125 \\
\hline Q4 Caudal máximo (m3/h) & 80 & 125 & 125 & 200 & 320 \\
\hline Q3 Caudal nominal (m3/h) & 63 & 100 & 100 & 160 & 250 \\
\hline Q2 Caudal de transición (m3/h) & 0,30 & 0,50 & 0,50 & 0,80 & 1,30 \\
\hline Q1 Caudal mínimo (m3/h) & 0,20 & 0,32 & 0,32 & 0,50 & 0,80 \\
\hline Ratio (Q3/01) & 250 & 250 & 250 & 250 & 250 \\
\hline Pérdida de presión en la Q3 (bar) & & & $<0.05$ & & \\
\hline
\end{tabular}

DN 20

DN 25

DN 32

DN 40 
5- CACG, ejemplo de optimización de riego 


\section{CACG}

\section{CONTEXTO}

CACG es la mayor comunidad de riegos en Francia

15.000 puntos de medición

Despliegue de Y-RIG 2015/2016

Diseñado para mejorar el control del consumo

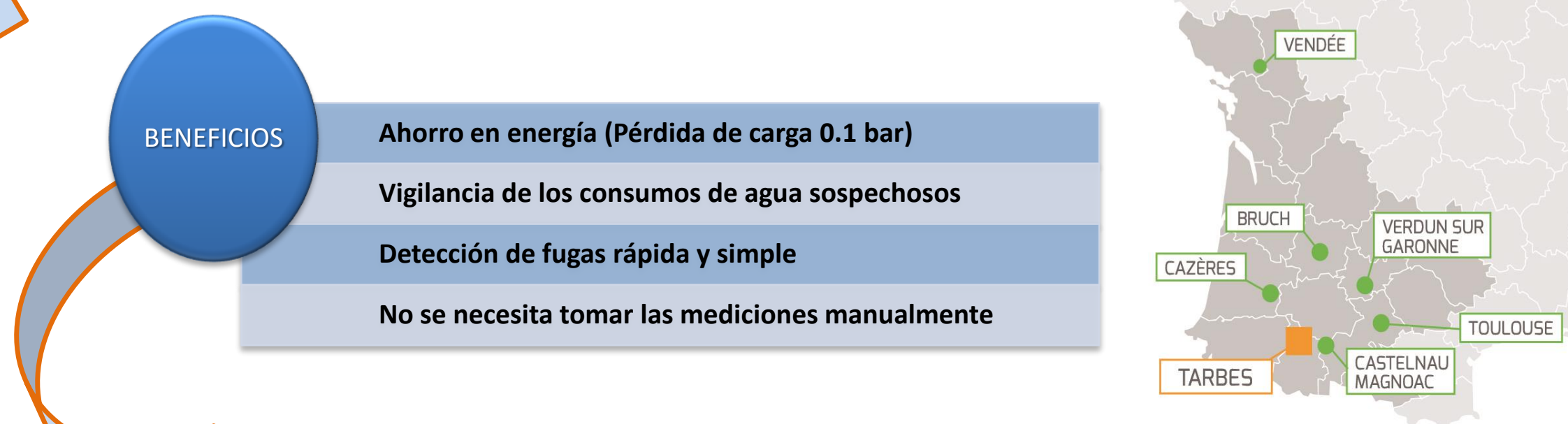

\section{Retorno de la inversión < 1 año}




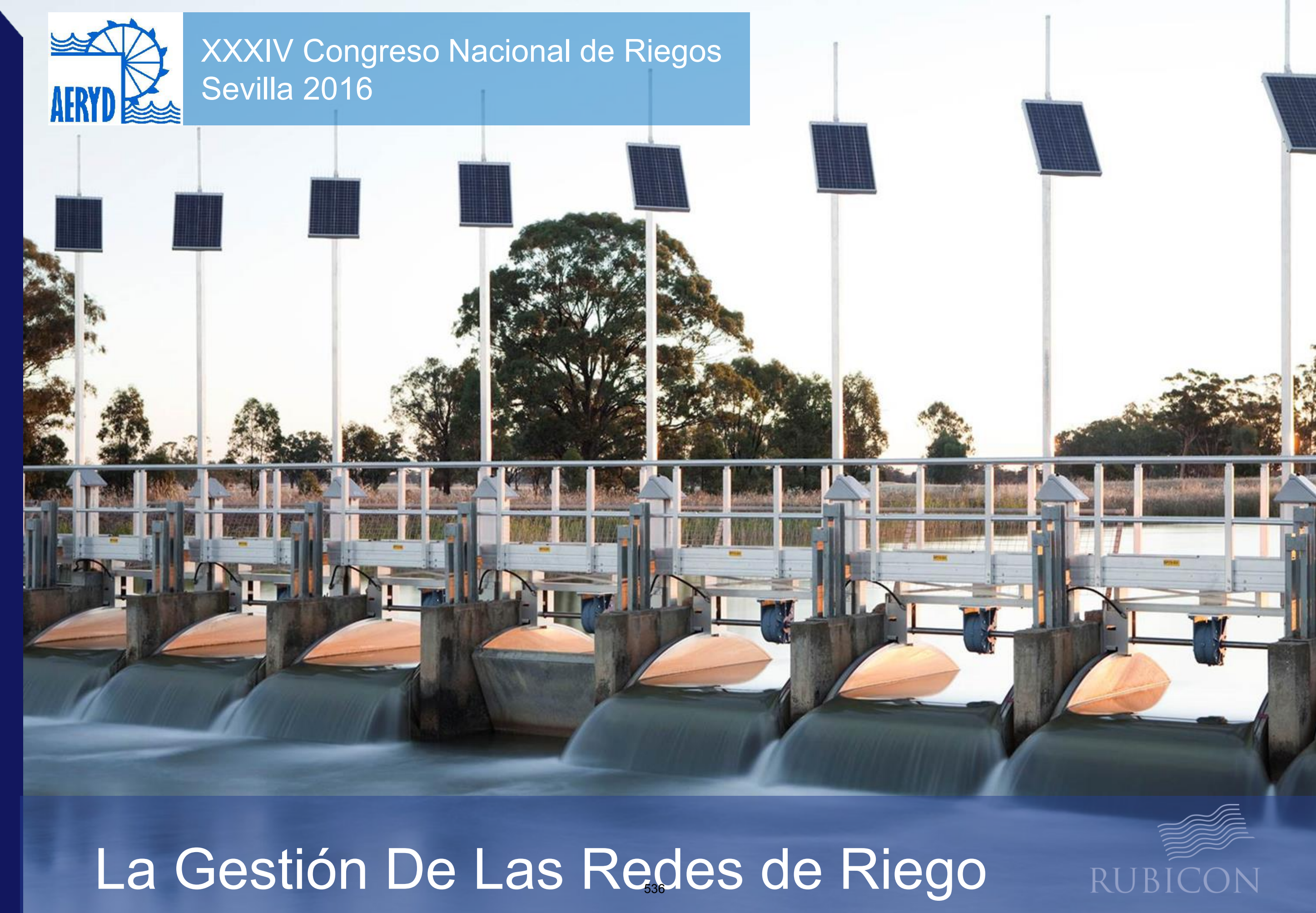




\section{Método tradicional del Riego por Gravedad}

Cuando hay recursos de agua en abundancia, se puede entregar caudales mayores que los pedidos, asegurando agua a todos los usuarios a lo largo del sistema.

- Grandes pérdidas por derrames

- Baja eficiencia

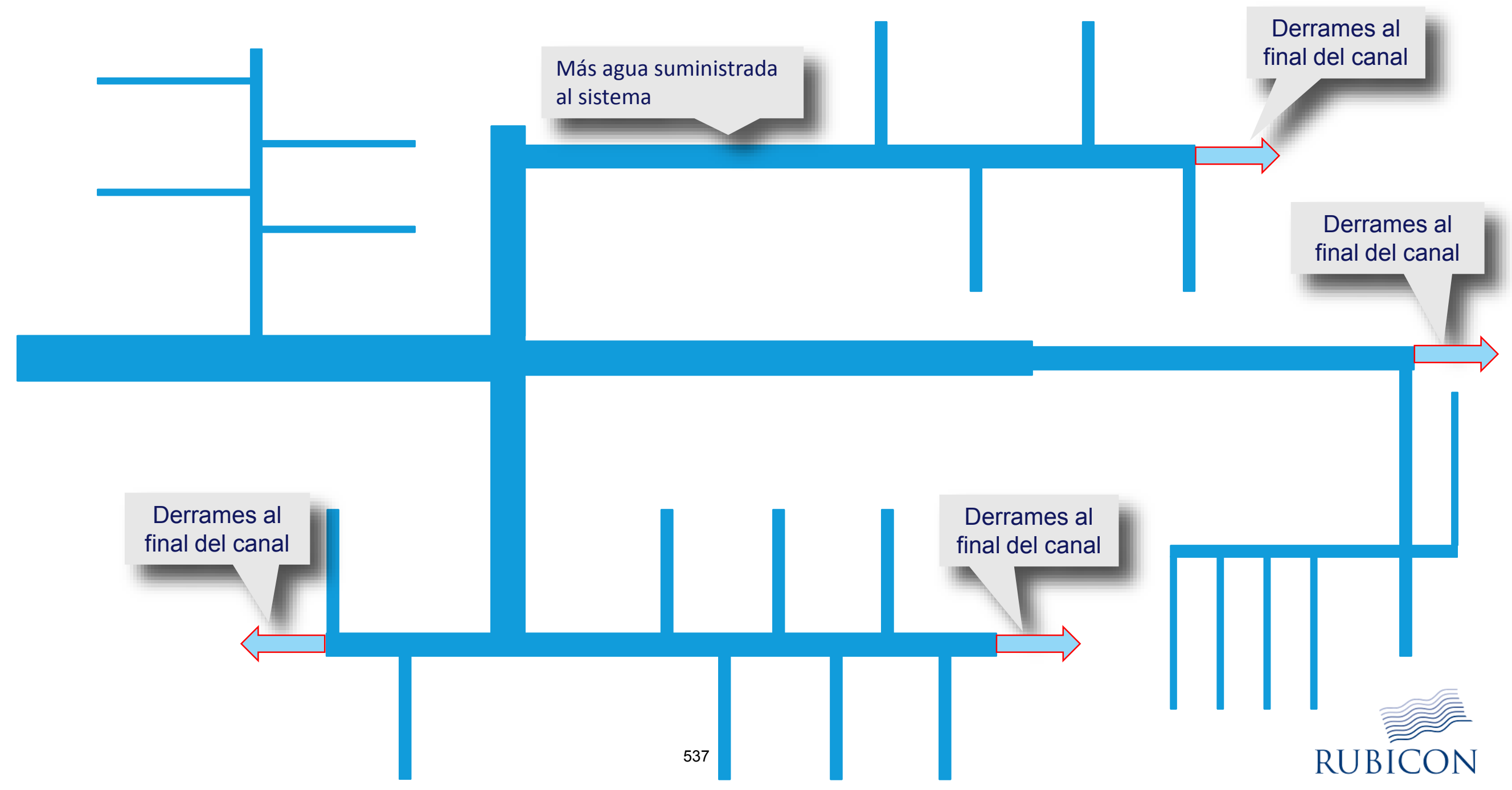




\section{Los turnos de riego son inflexibles y causan un uso excesivo del agua}

Los usuarios se ven forzados a utilizar toda el agua disponible, ya que sino hay que esperar al próximo turno.

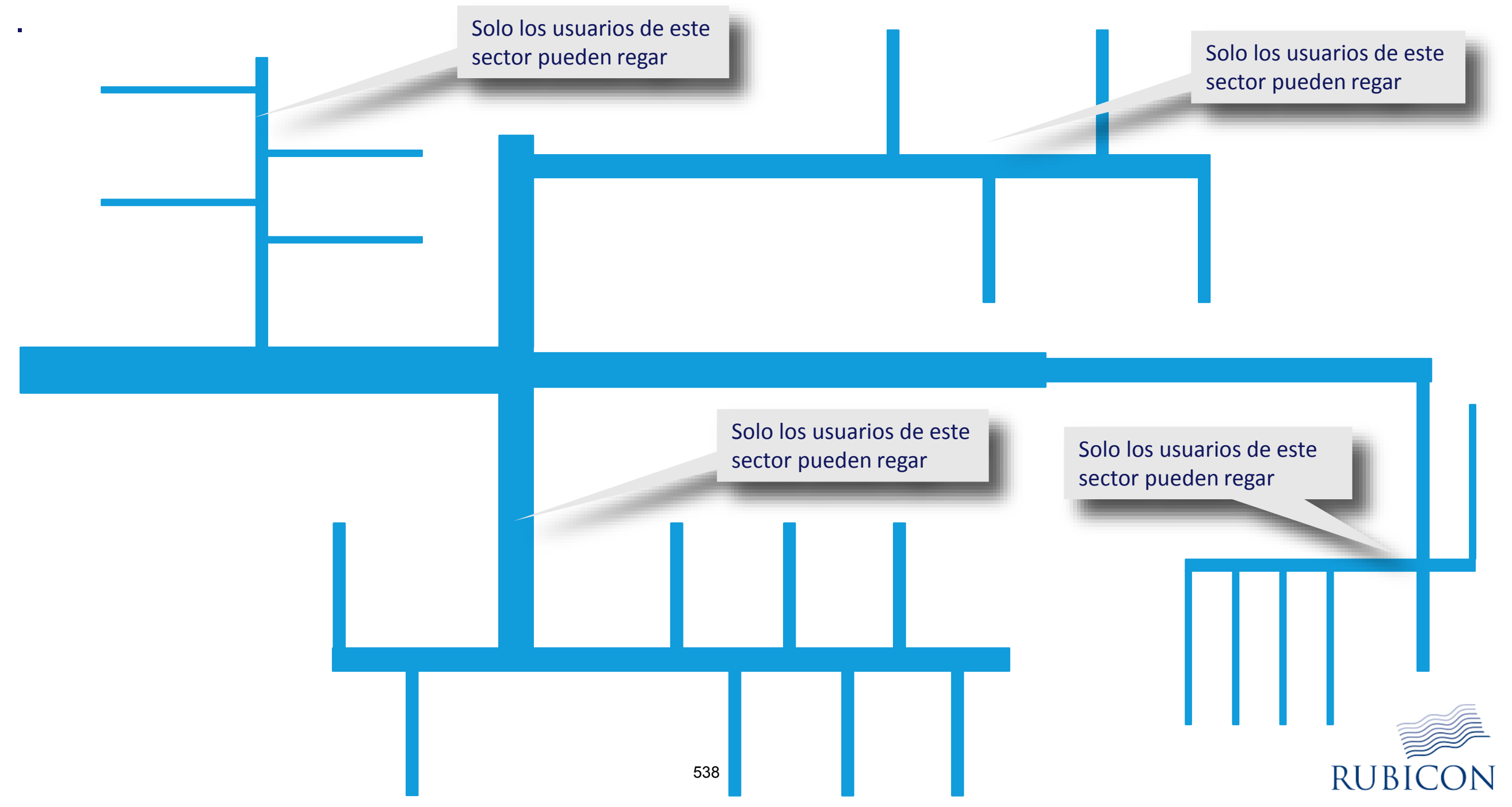




\section{Mejor Servicio $=$ Sistemas Presurizados}

Dado que los Sistemas de gravedad gestionados manualmente no proveen un servicio adecuado, la única respuesta es cambiar gravedad por presurización
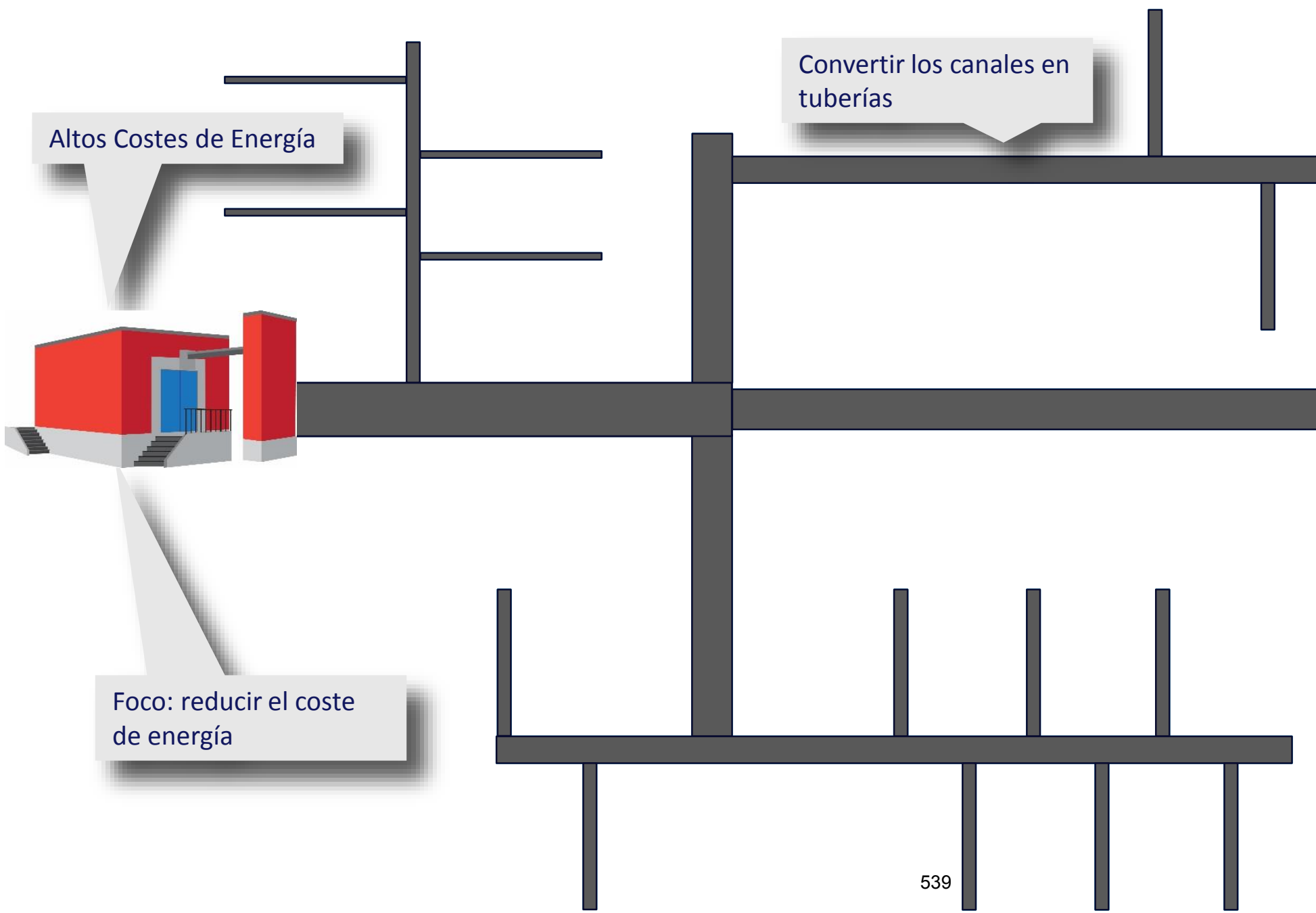

Convertir los canales en tuberías

Foco: reducir el coste 


\section{La Solución de Rubicon}

Rubicon ha desarrollado tecnología y software para aumentar la eficacia de los sistemas de gravedad
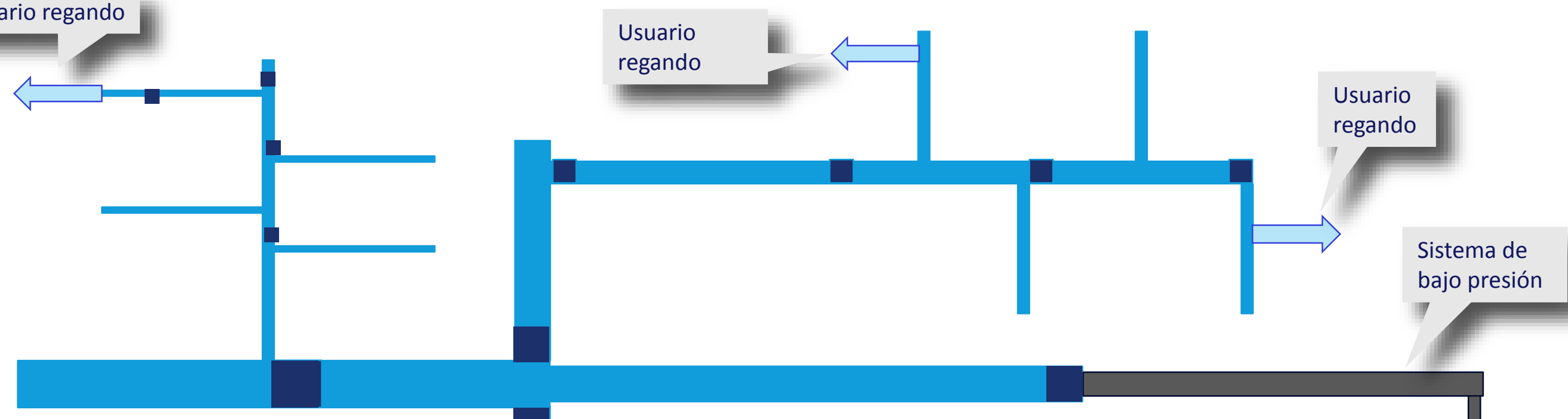


\section{El Mensaje Clave}

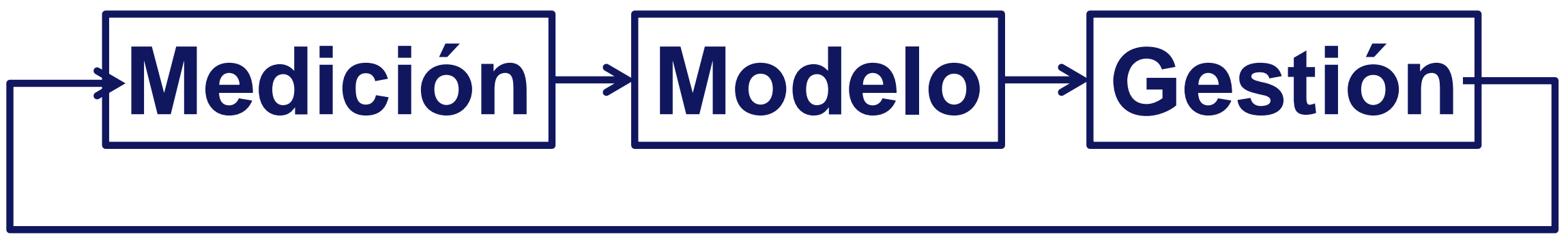

Ingeniería de sistemas para la gestión del canal

Utilizar toda la capacidad física del sistema de canal abierto

$\checkmark$ Aumentar la productividad del agua o el ahorro de agua

Proporcionar la rendición de cuentas del agua

Eliminar el riesgo de la agricultura de riego

Ahorre energía (menos / no bombeo)

$\checkmark$ Habilitar un mercado del agua (marco de política)

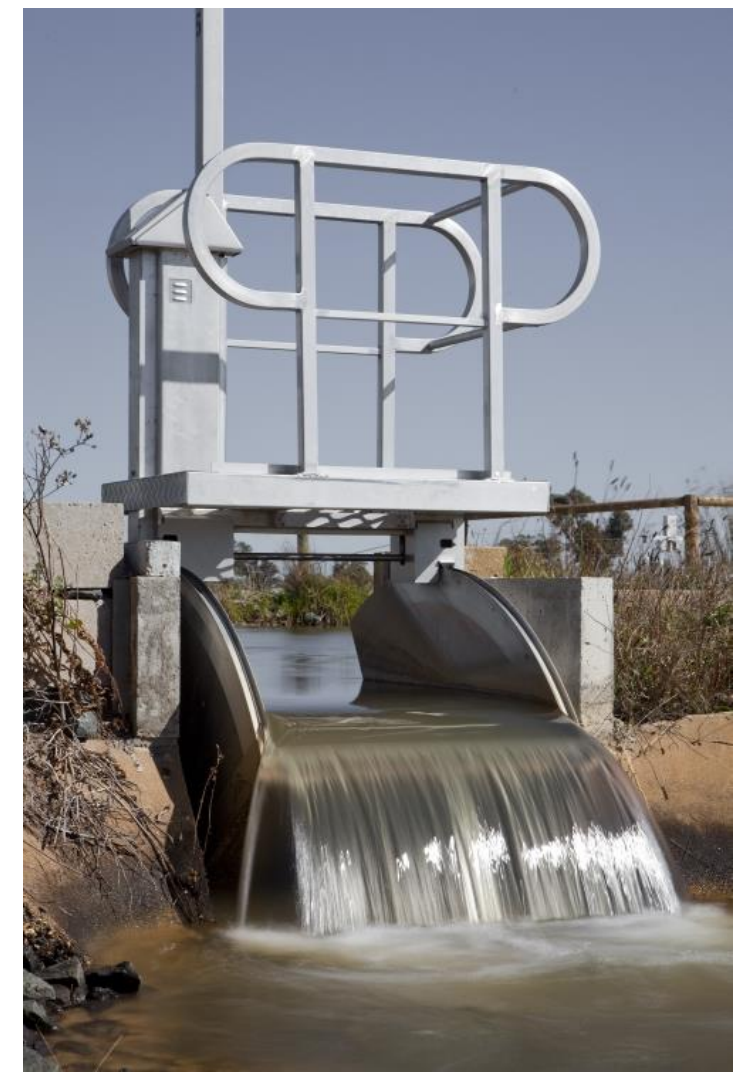




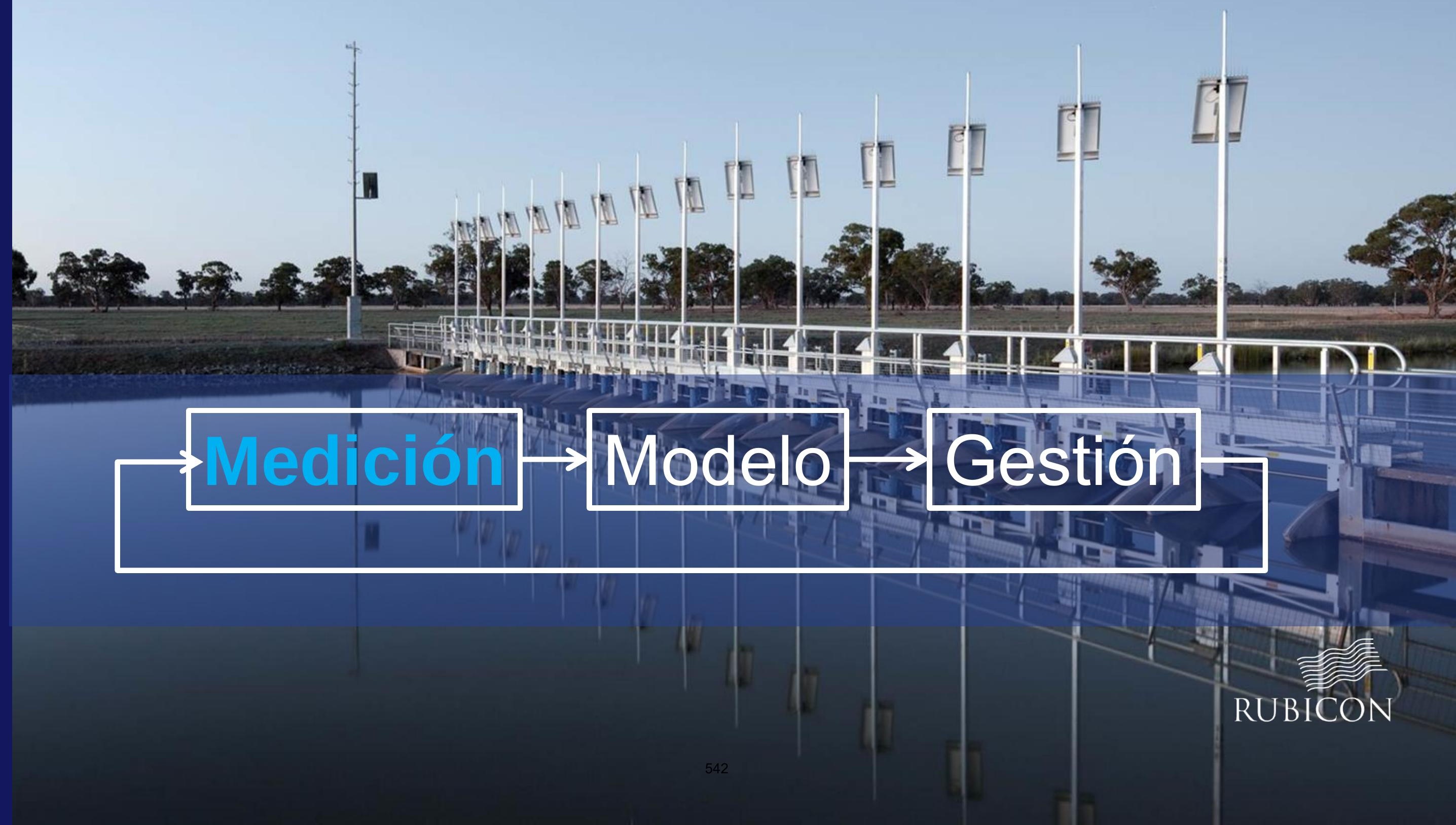




\section{Dispositivos innovadores}

FlumeGate $^{\mathrm{TM}}$

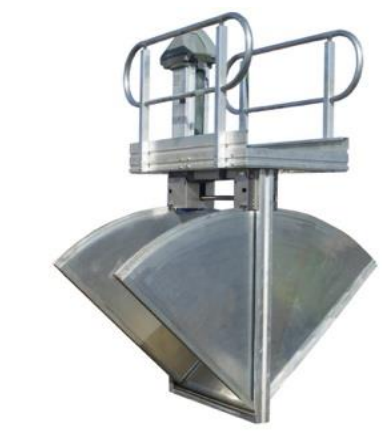

Medidor y control de caudal
SlipMeter ${ }^{\mathrm{TM}}$

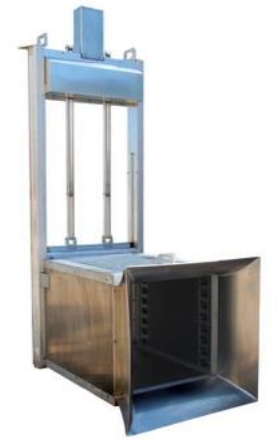

Medidor y control de caudal

FlumeMeter $^{\mathrm{TM}}$

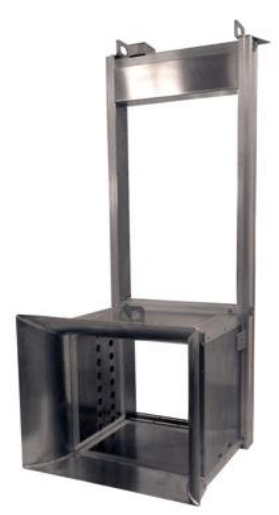

Medidor
BladeMeter $^{\mathrm{TM}}$

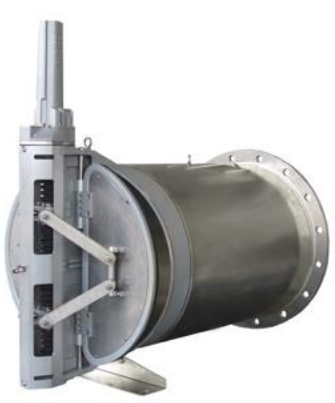

Medidor y control de caudal

Sonaray ${ }^{\circledR}$ Pipe Meter

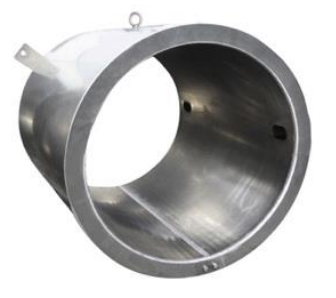

Medidor

Control de caudal 


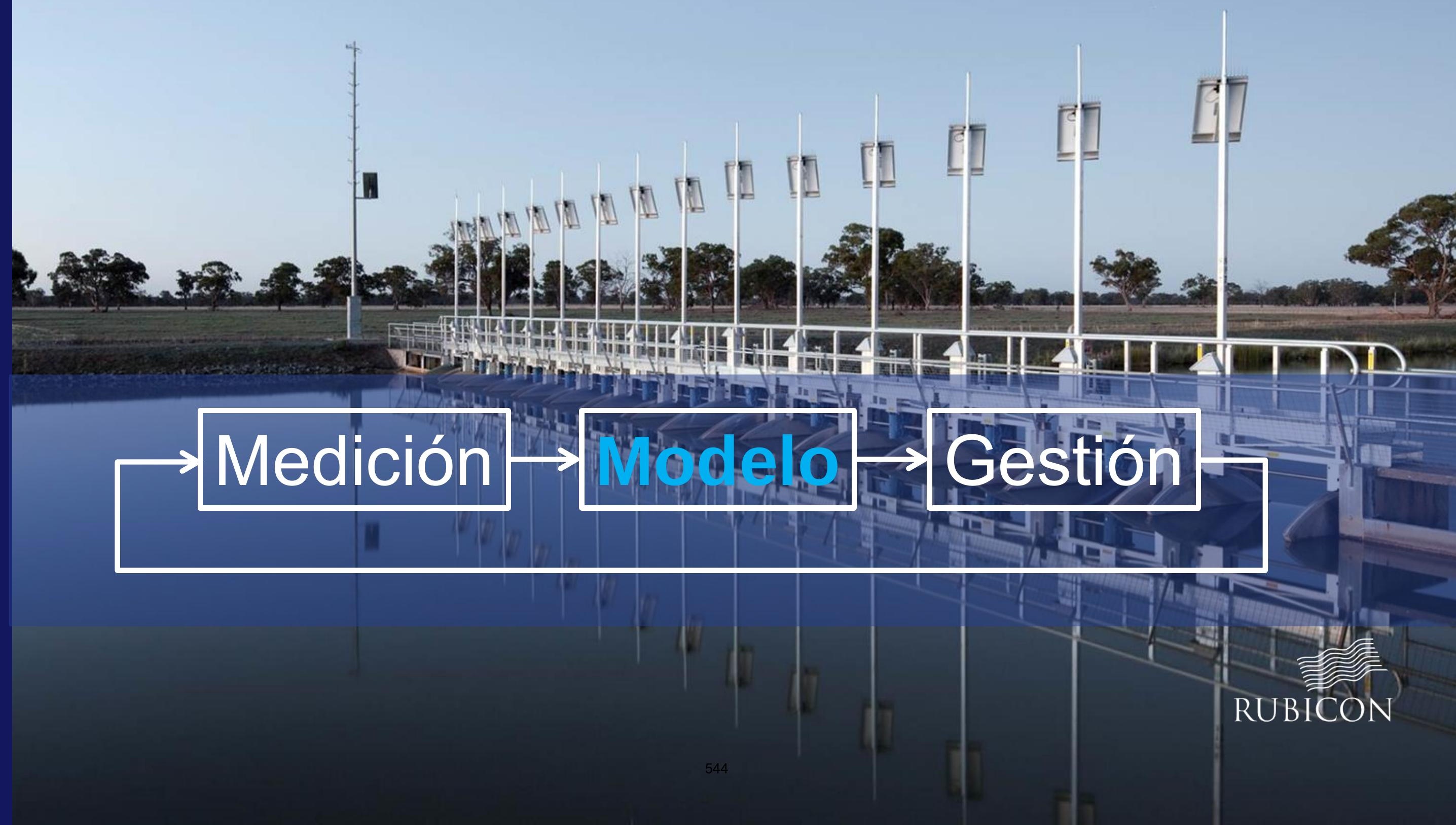




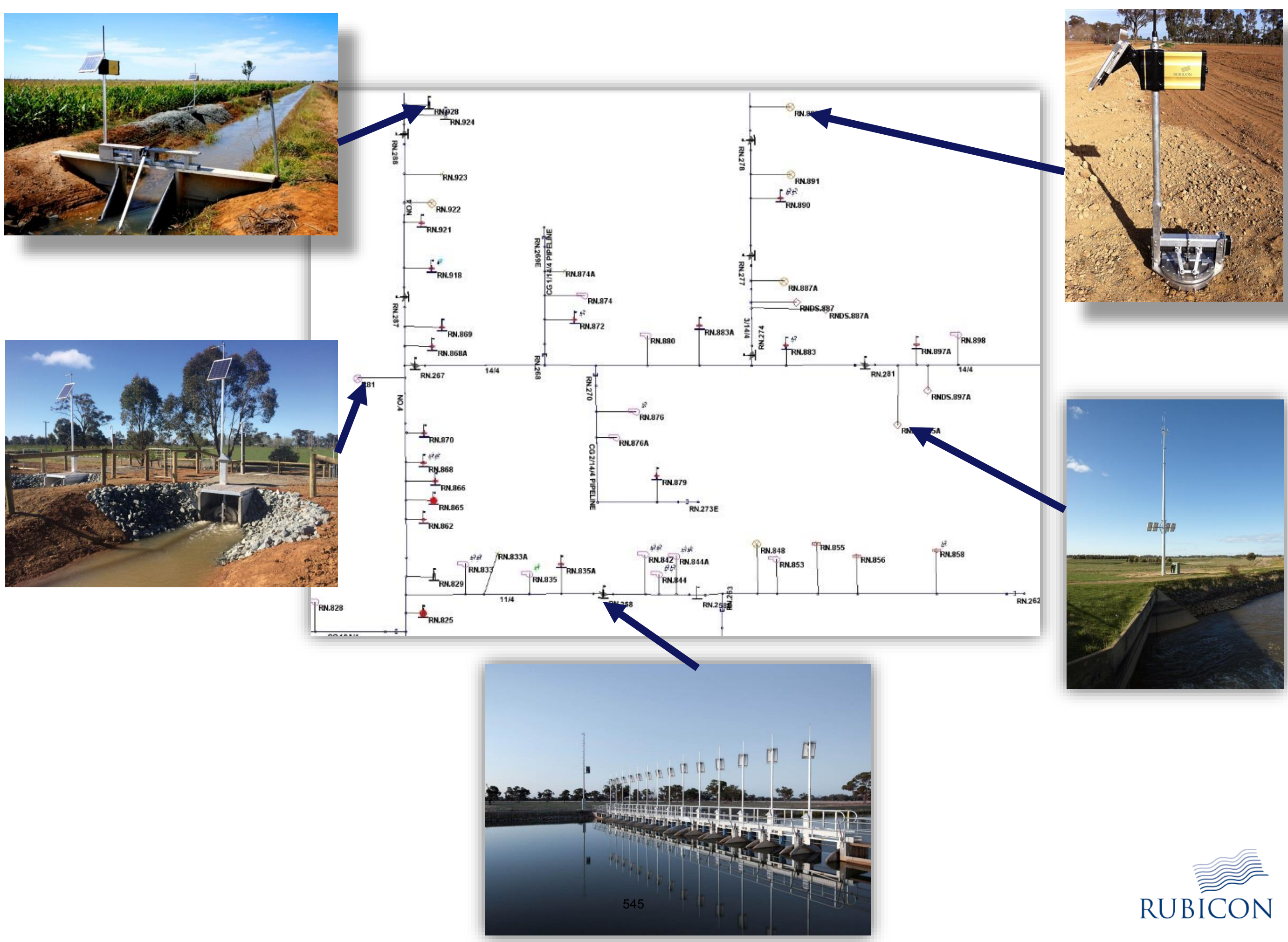




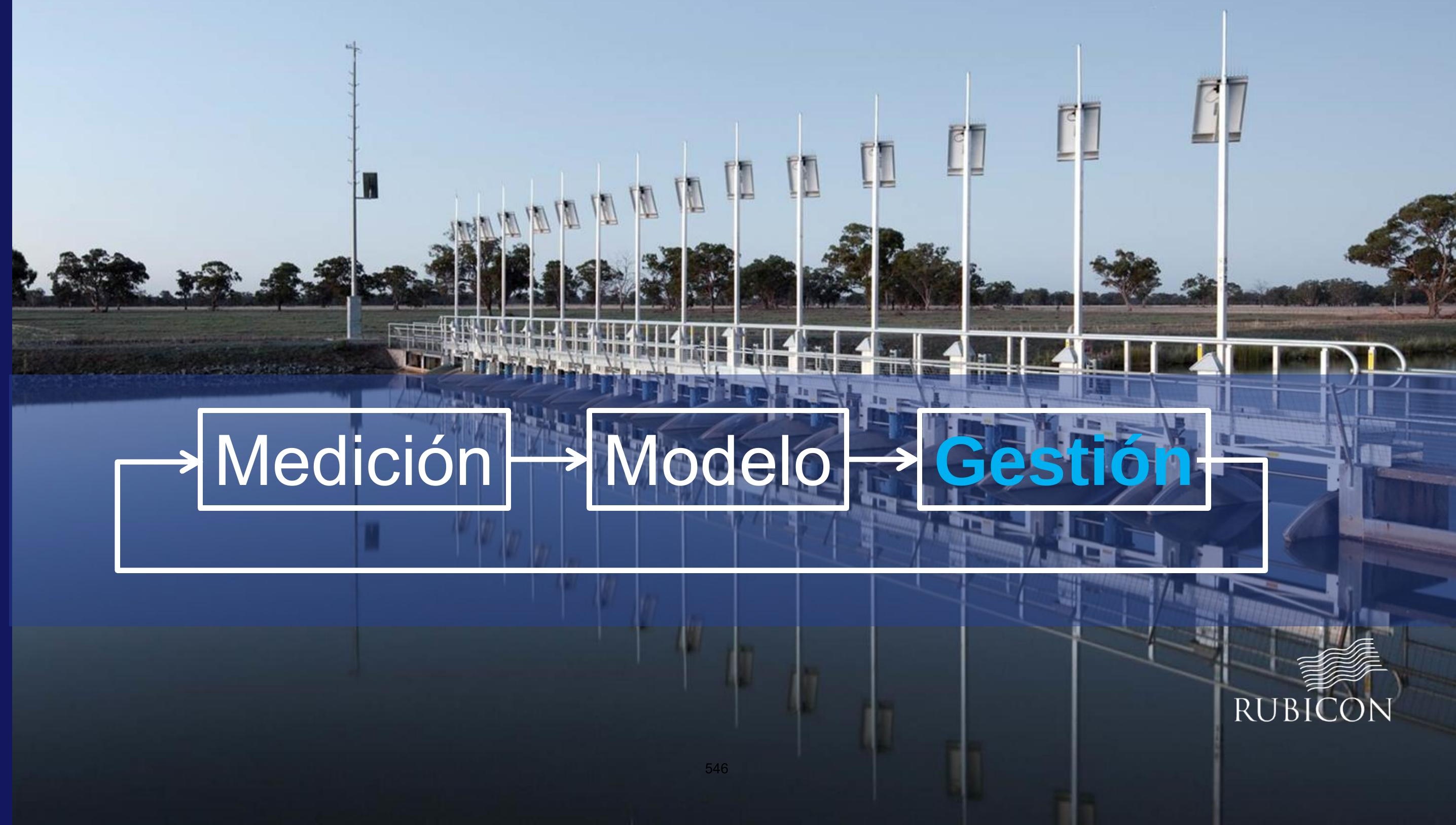




\section{La tecnología Total Channel Control (TCC)}

- Una idea de la complejidad del sistema

- GMW 6.000 kilómetros

- 15k Sitios agrícolas

- 20k sitios con medición del caudal

- 6k Restricciones de nivel de agua

- 20k estados modelo

- 300k estados de control

- 400k variables para definir el sistema

- 2,5 M seguido de variables;

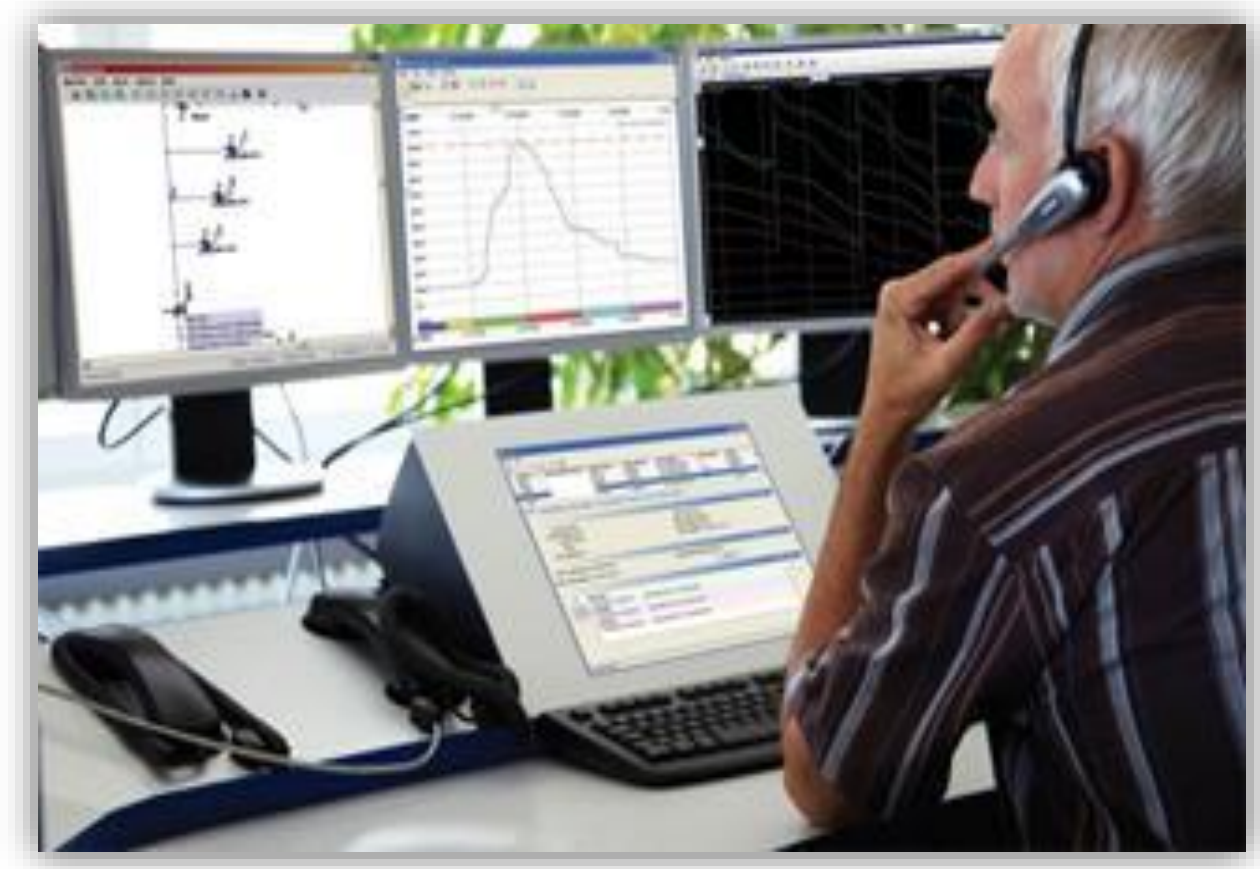

- 8 mensajes (basado en eventos) / por hora / por sitio? (700M mensajes durante una campaña, $\approx 200 \mathrm{~Gb}$ )

- Potencial del software $\approx 50 \%$ complejidad de SAP $\approx 100$ veces de Windows 


\section{G-MW's Modernised Irrigation Delivery System}

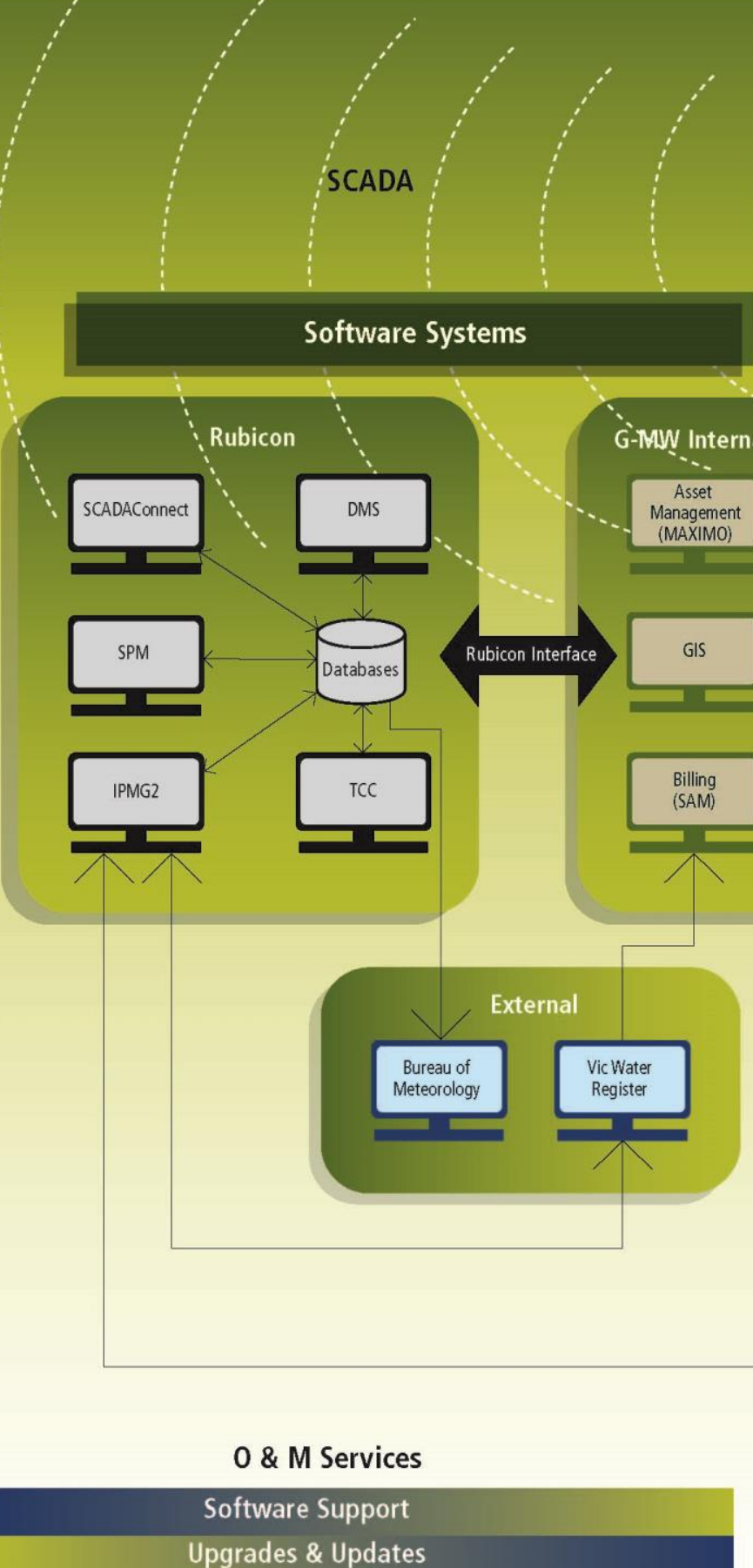

One of the world's largest SCADA systems 10,000 sites

1.2 million tags

500 million time series data points

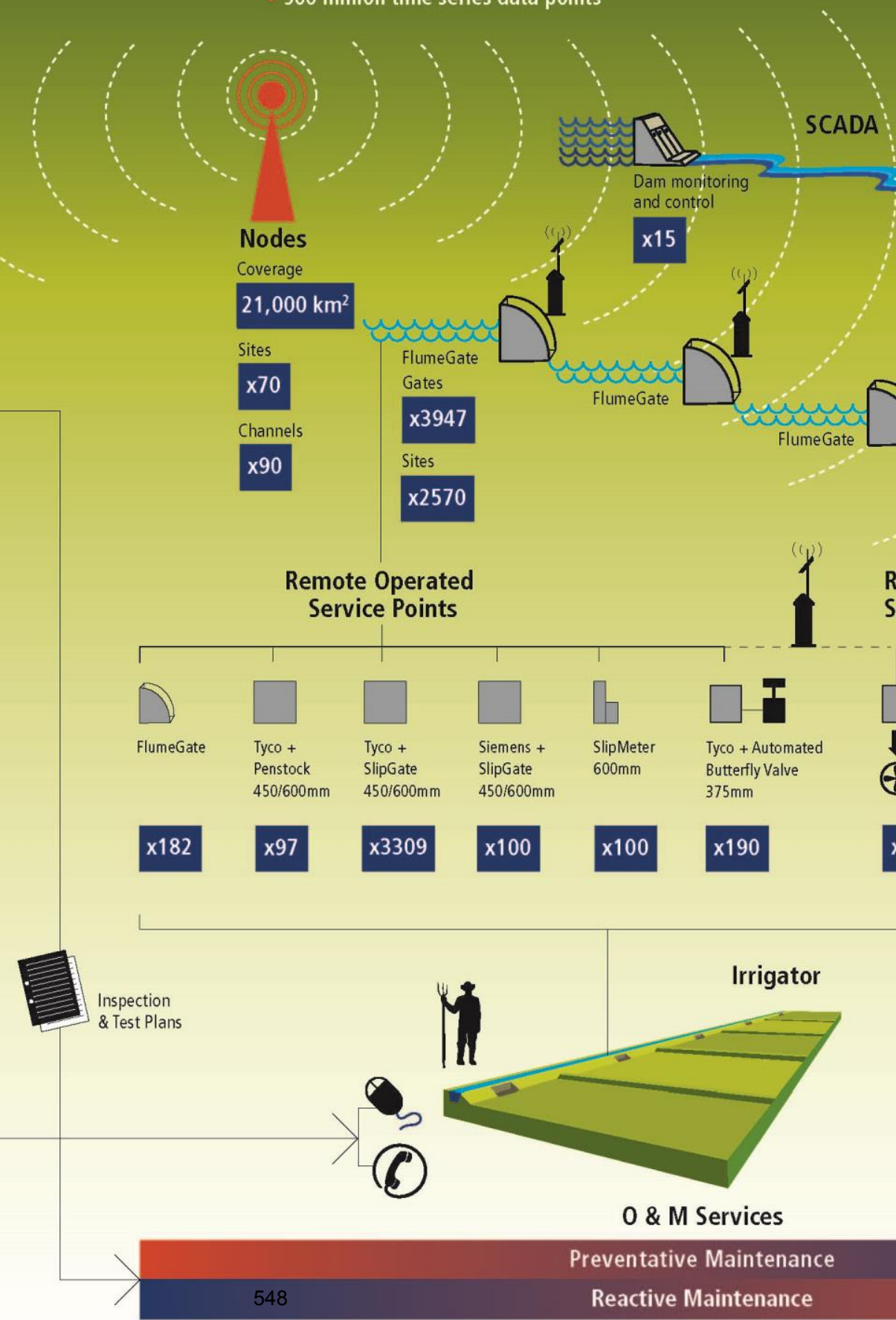




\section{KPMG - Software Size \& Complexity Report}

\subsection{INDUSTRY BENCHMARKS}

Estimated Size of Select Applications

\begin{tabular}{|l|l|}
\hline Application & Function Points \\
\hline US Air Traffic Control & 306,324 \\
\hline SAP & 296,764 \\
\hline Microsoft XP Operating System & 126,788 \\
\hline NSA Code Decryption & 35,897 \\
\hline FBI Fingerprint Analysis & 25,075 \\
\hline Nuclear Reactor Controls & 19,084 \\
\hline NASA Hubble Controls & 21,632 \\
\hline LINUX Operating System & 17,672 \\
\hline Oil Refinery Process Control & 17,203 \\
\hline ITT Systems 12 telecom & 17,002 \\
\hline Google Search Engine & 16,895 \\
\hline Patriot Missile Controls & 15,392 \\
\hline Soirce: “dpplied Sofnwre & \\
\hline
\end{tabular}

Source: "Applied Software Measurement" Caper Jones, 2008
September 2011

\section{Rubicon TCC Solution 70,000 Function Points}

Industry standard approach considered

- Executable lines of code

- Programming languages

- System complexity

Industry benchmarks are approximately

- \$20M for 10,000 Function Points

- \$240M for 100,000 Function Points

- Relationship not linear

Does not include value of IP \& Patents (2) RUBICON 


\section{La piedra angular de la solución de control de red de canales de Rubicon}

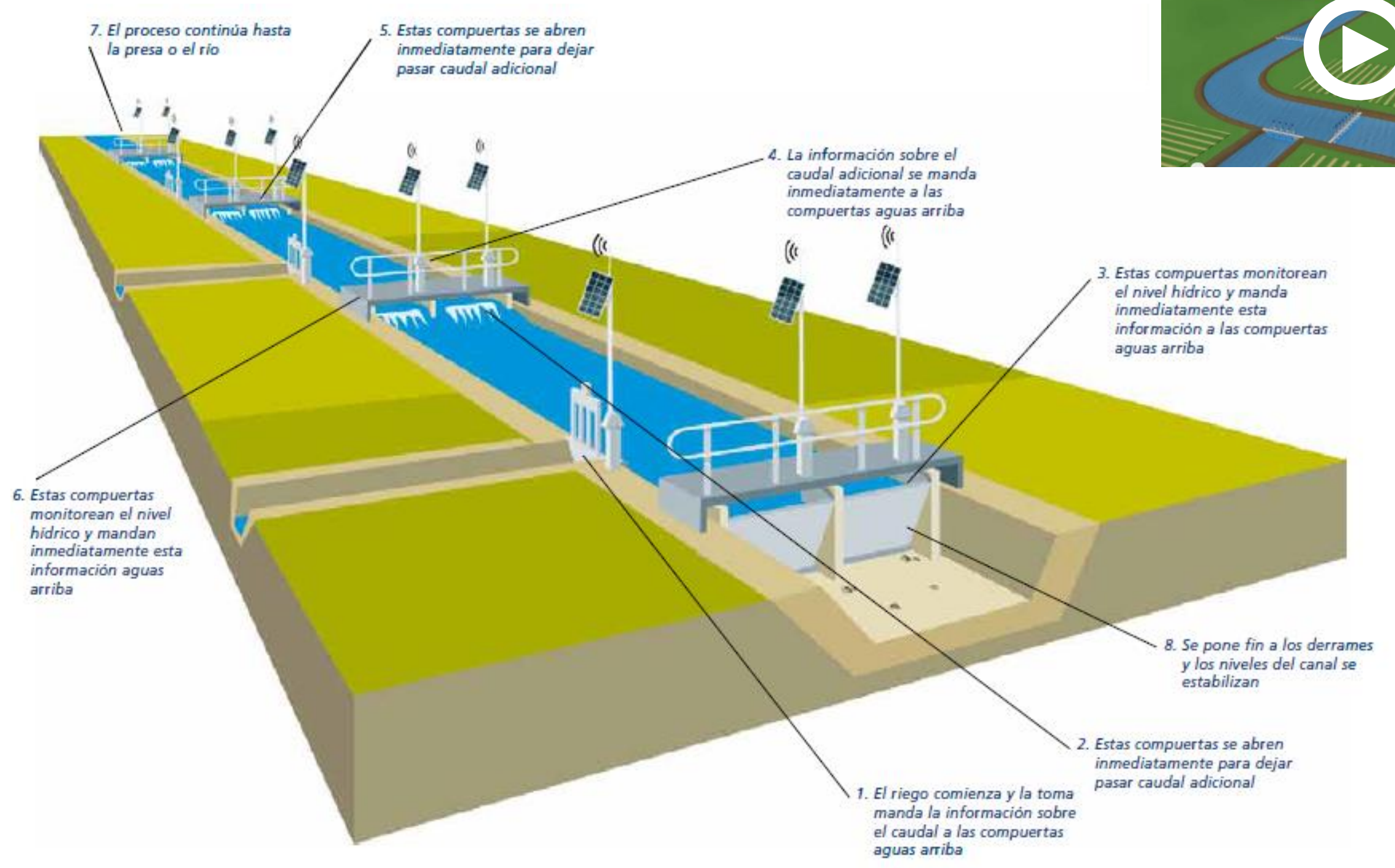




\section{Confluent: el software para la gestión integral}

Un base de datos que representa toda la información de una cuenca incluyendo los canales, las CR, los regantes, las parcelas, los cultivos, las peticiones, las dotaciones el uso de agua y varios módulos para procesar la información.

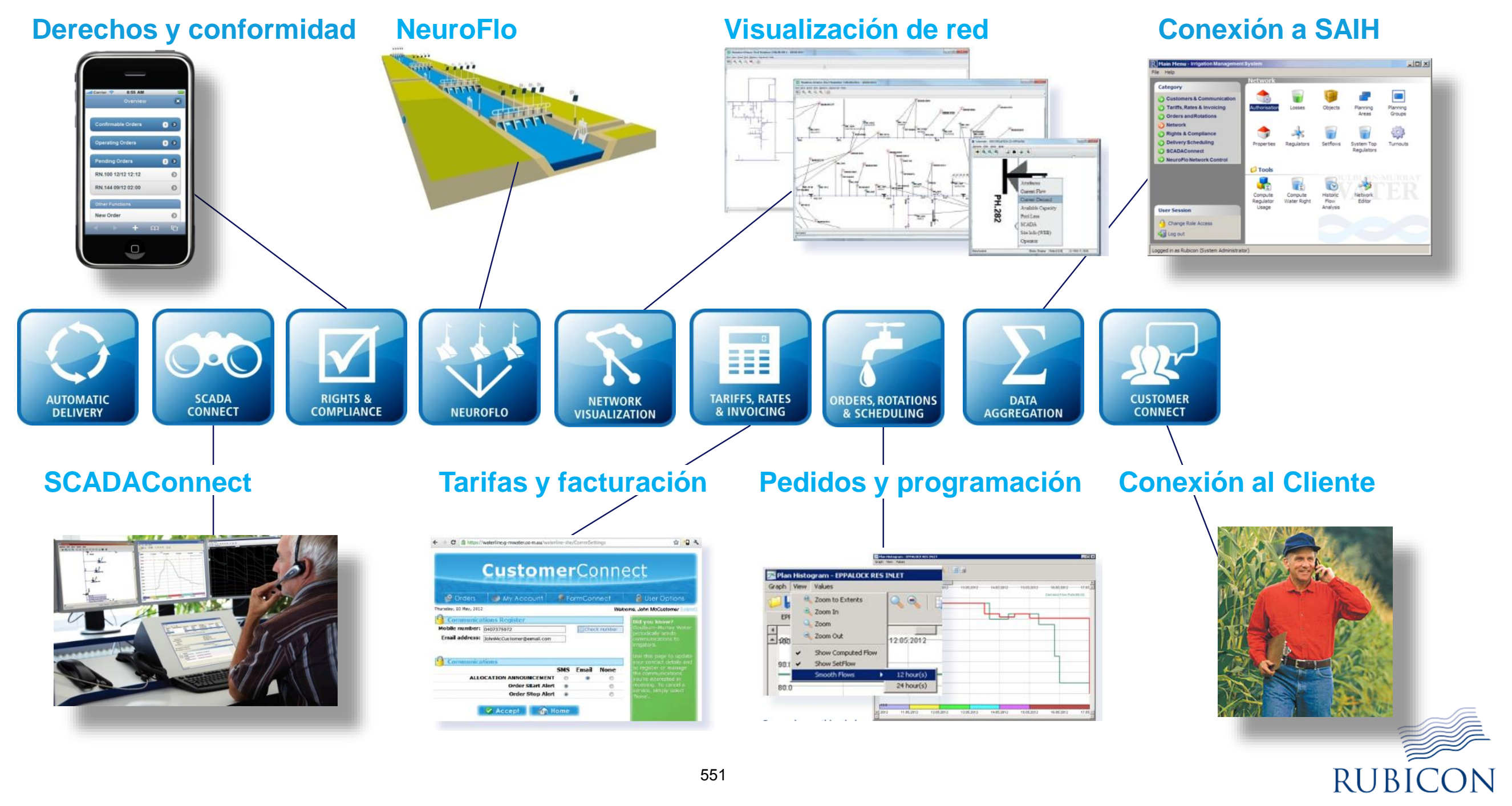




\section{Confluent gestiona la demanda sin exceder las limitaciones de los canales}

Se puede recibir peticiones en tiempo real y programarlas automáticamente para suministrar el agua a la demanda

Confluent

$\checkmark$ colecta peticiones vía telefónica, vía sistema de reconocimiento de voz o a través del internet;

$\checkmark$ programa las peticiones basadas en modelos hidráulicos de cada tramo

$\checkmark$ asegura que no se den desbordamientos

$\checkmark$ permite que el regante tenga flexibilidad y por ello utilice menos agua y produzca más

$\checkmark$ evita el coste de la construcción de balsas de regulación

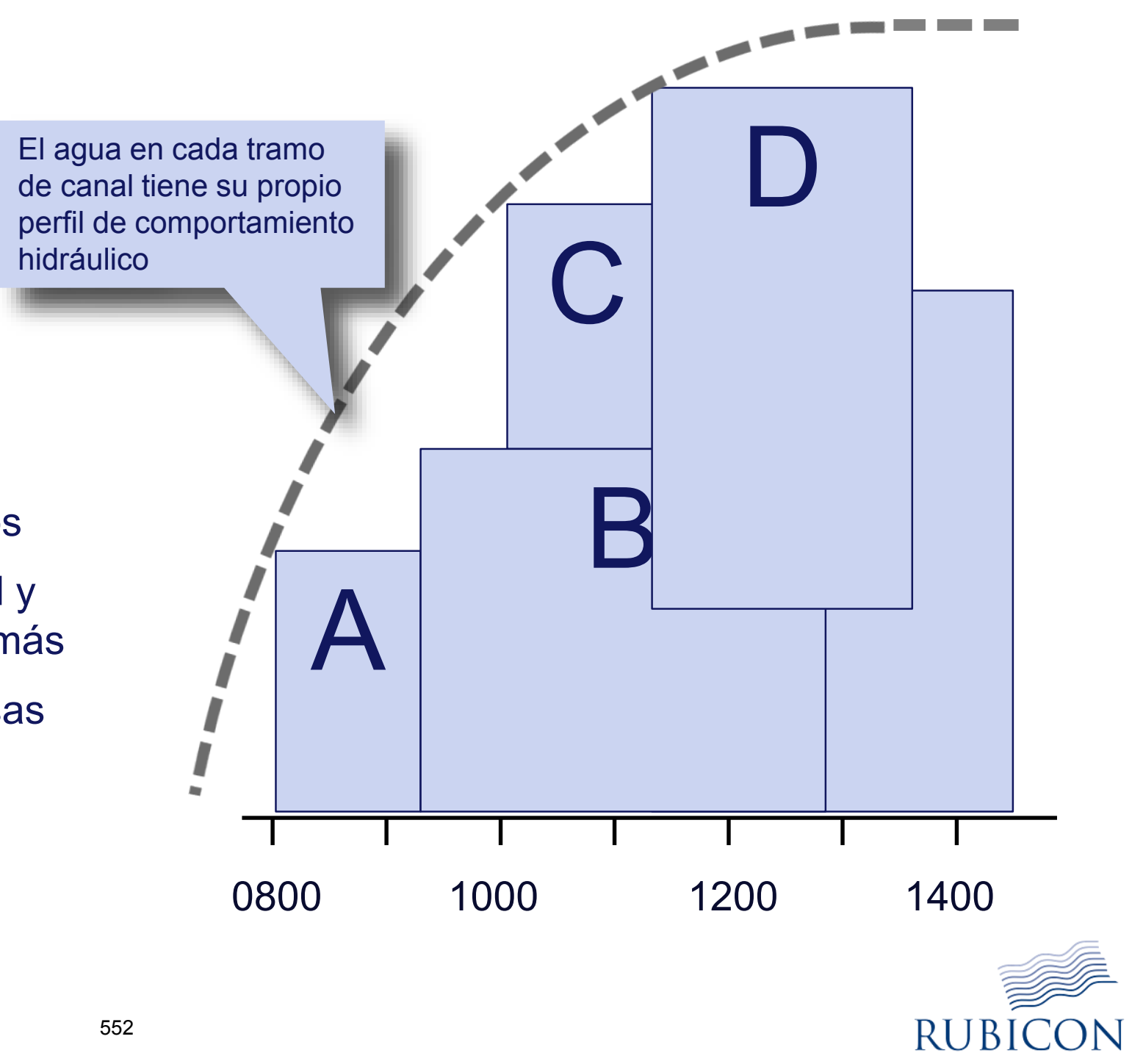




\section{Opción híbrida: Gravedad / bomba}

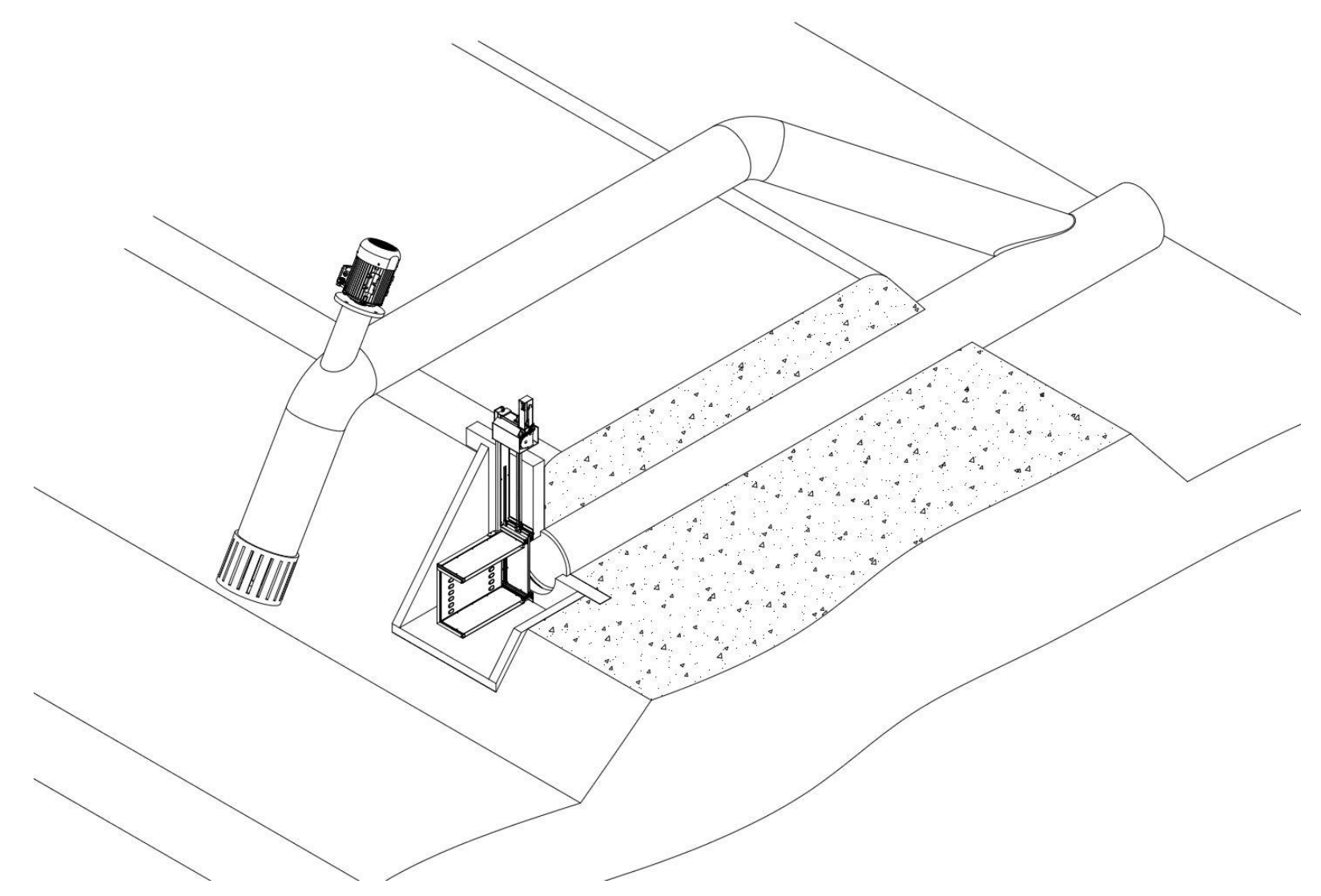

- Minimiza los costos de energía en comparación con la tubería a presión

$\checkmark$ Se puede establecer un régimen tarifario, donde los regantes pueden elegir la opción de bombeo en el pedido $\mathrm{Si}$ el caudal no disponible

$\checkmark$ La infraestructura de la bomba se puede añadir en cualquier etapa y a discreción los regantes 


\section{Opción híbrida: Gravedad / bomba}

La demanda supera la capacidad del sistema

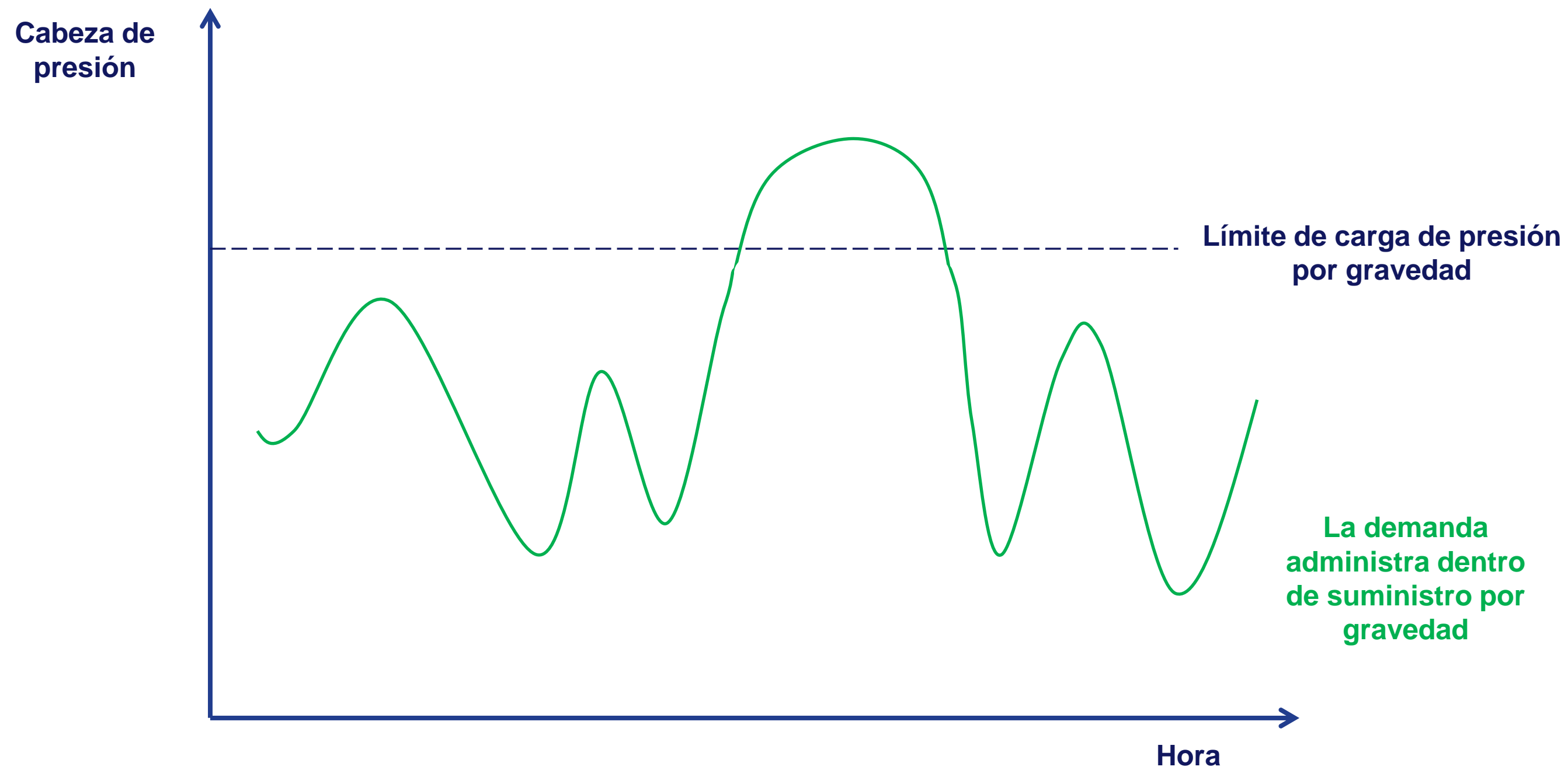




\section{Opción híbrida: Gravedad / bomba}

La demanda supera la capacidad del suministro por gravedad - reprogramar las solicitudes de entrega

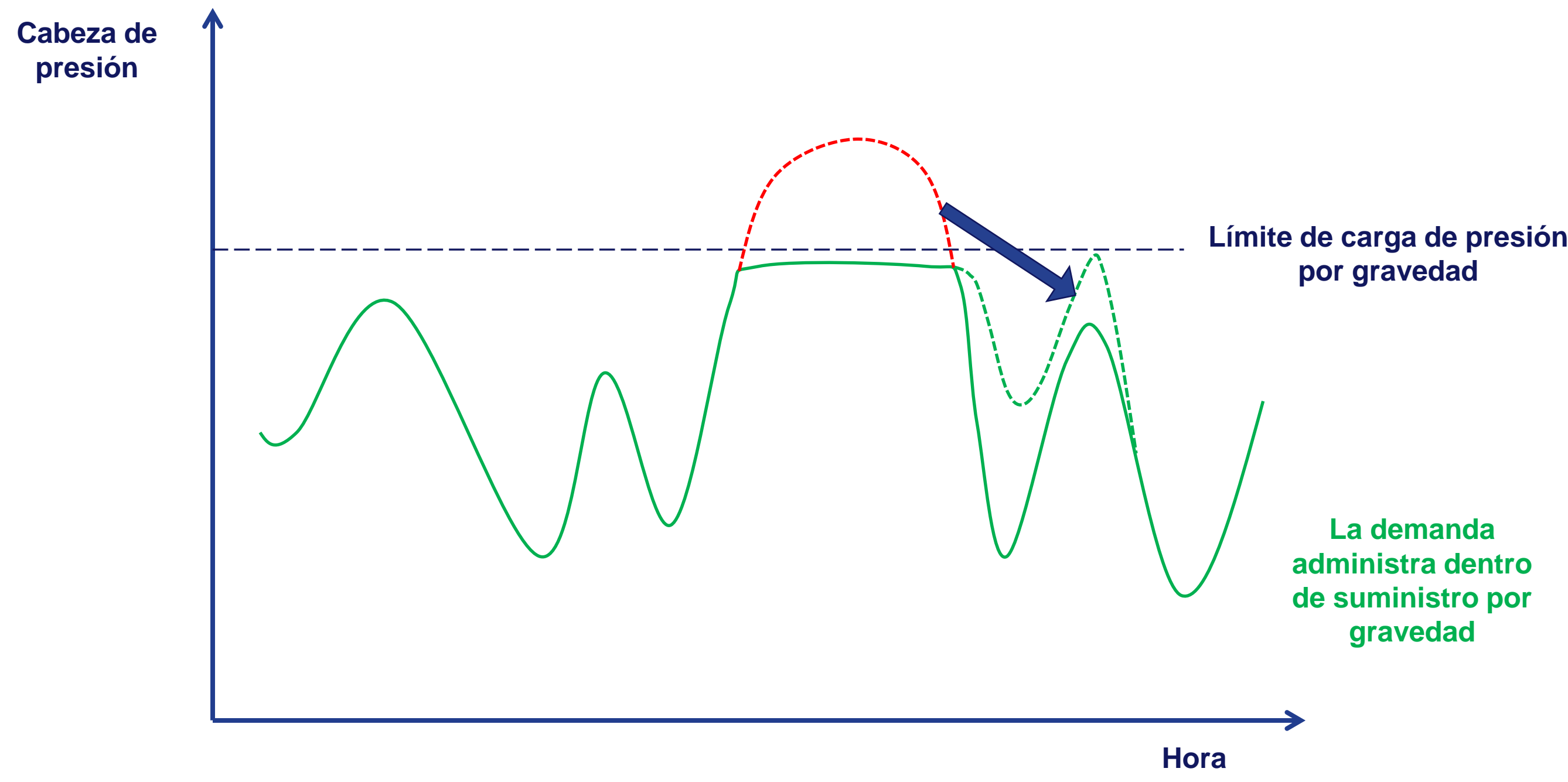




\section{Opción híbrida: Gravedad / bomba}

La demanda supera la capacidad del suministro por gravedad - bomba híbrida

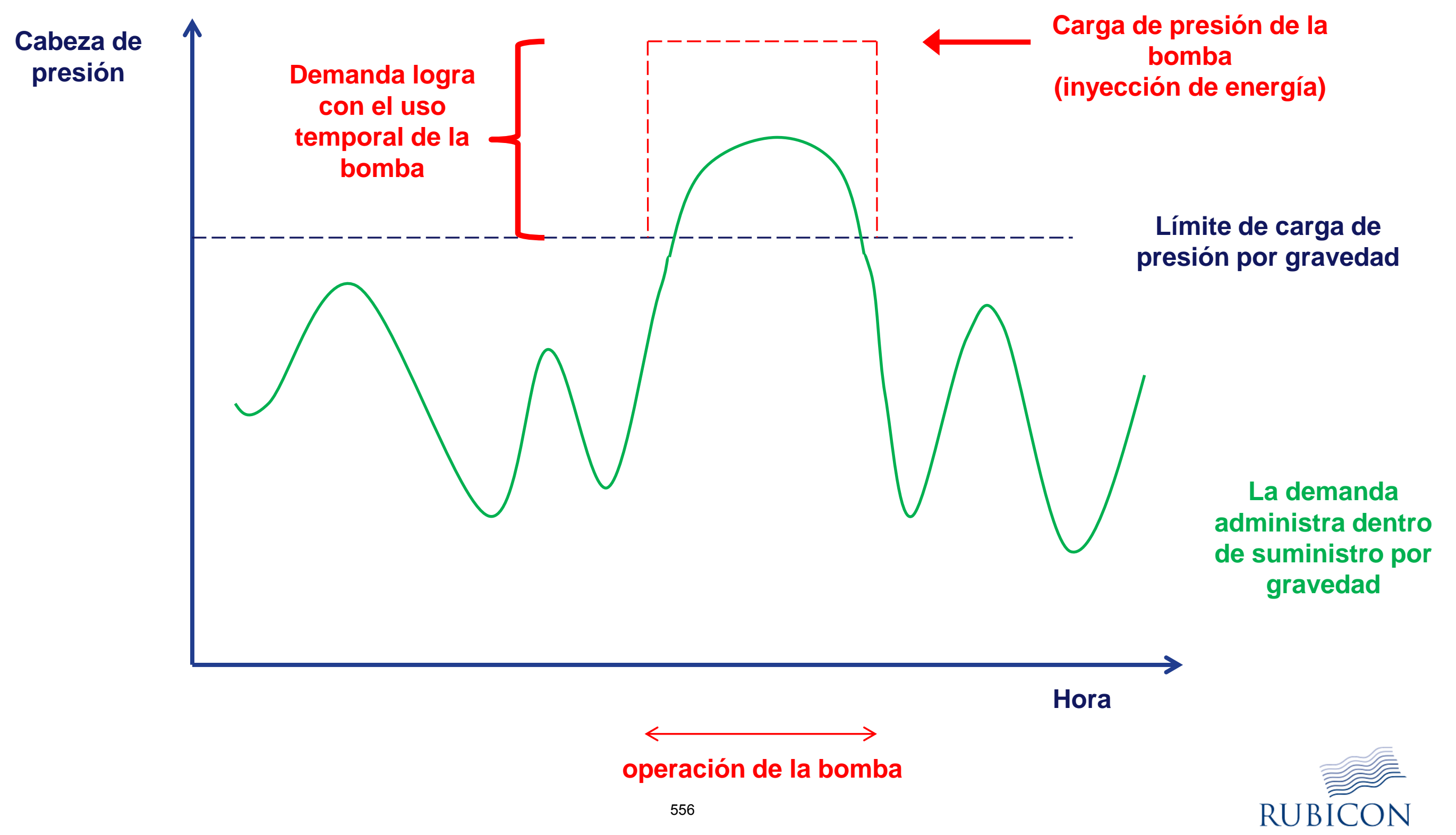




\section{Un caudal no fiable conlleva mayor consumo agua}

Si los niveles de los canales varían, los agricultores reciben de caudal inconsistente y de baja y así deben salir de su agua por más tiempo para cubrir sus tierras a menudo resulta en un exceso de infiltración
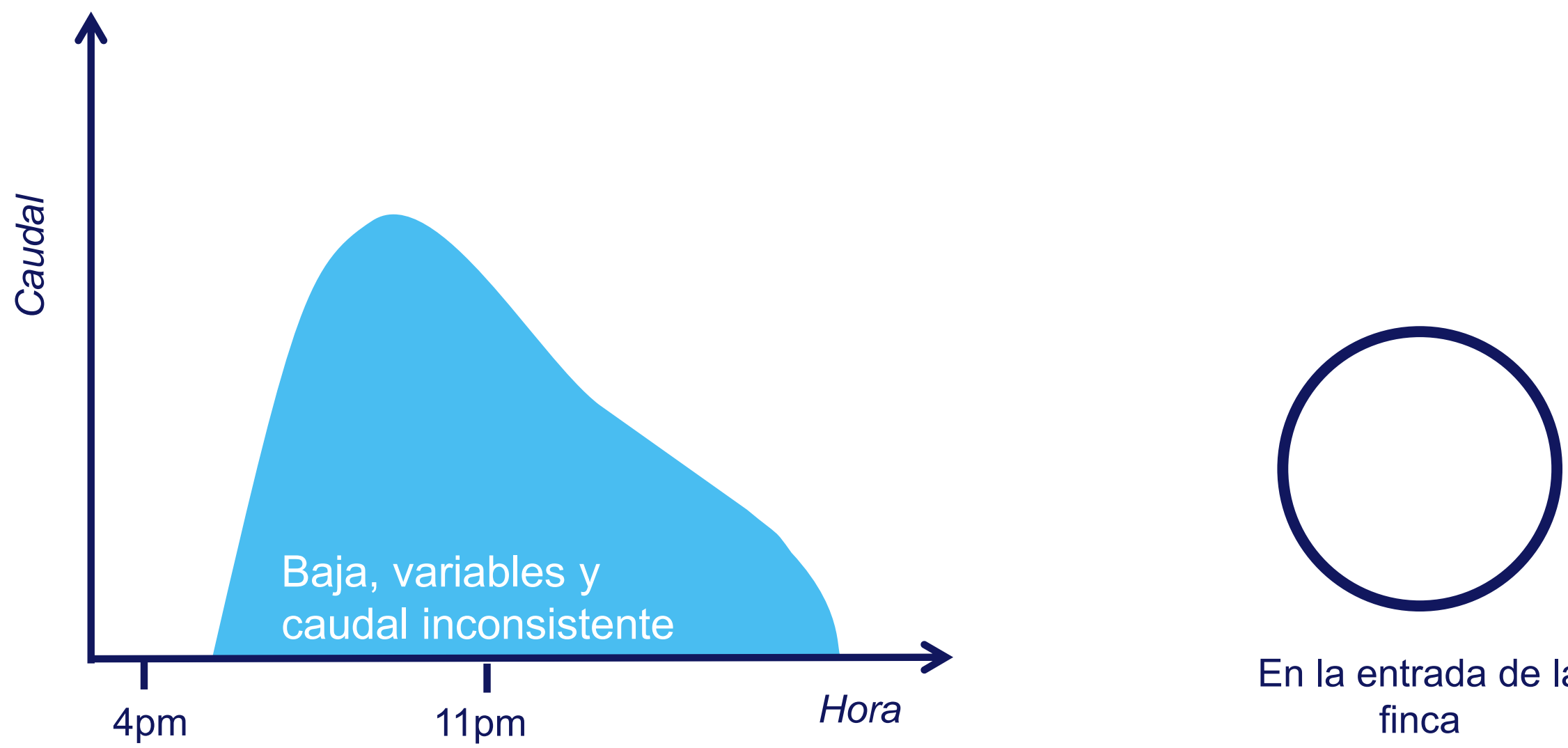

En la entrada de la finca 


\section{Caudal no fiable también se traduce en la baja productividad de los cultivos}

El agricultor debe regar en exceso para asegurar toda la cosecha se alcanza, a menudo también resulta en la escorrentía

$\checkmark$ El frente de la cosecha queda ahogado

$\checkmark$ Utilizando del agua en excesivos se resulta en la nitrificación del suelo (nutrientes NPK en solución y lixiviar de distancia) y salinización (eleva el nivel freático trayendo sales, que hace que la planta al estrés)

$\checkmark$ Cultivos estresados crecen menos y son más afectados por insectos y enfermedades......

Anegamiento y la infiltración

\section{en la parte delantera}

Nutrificación y / o salinización del suelo pueden resultar

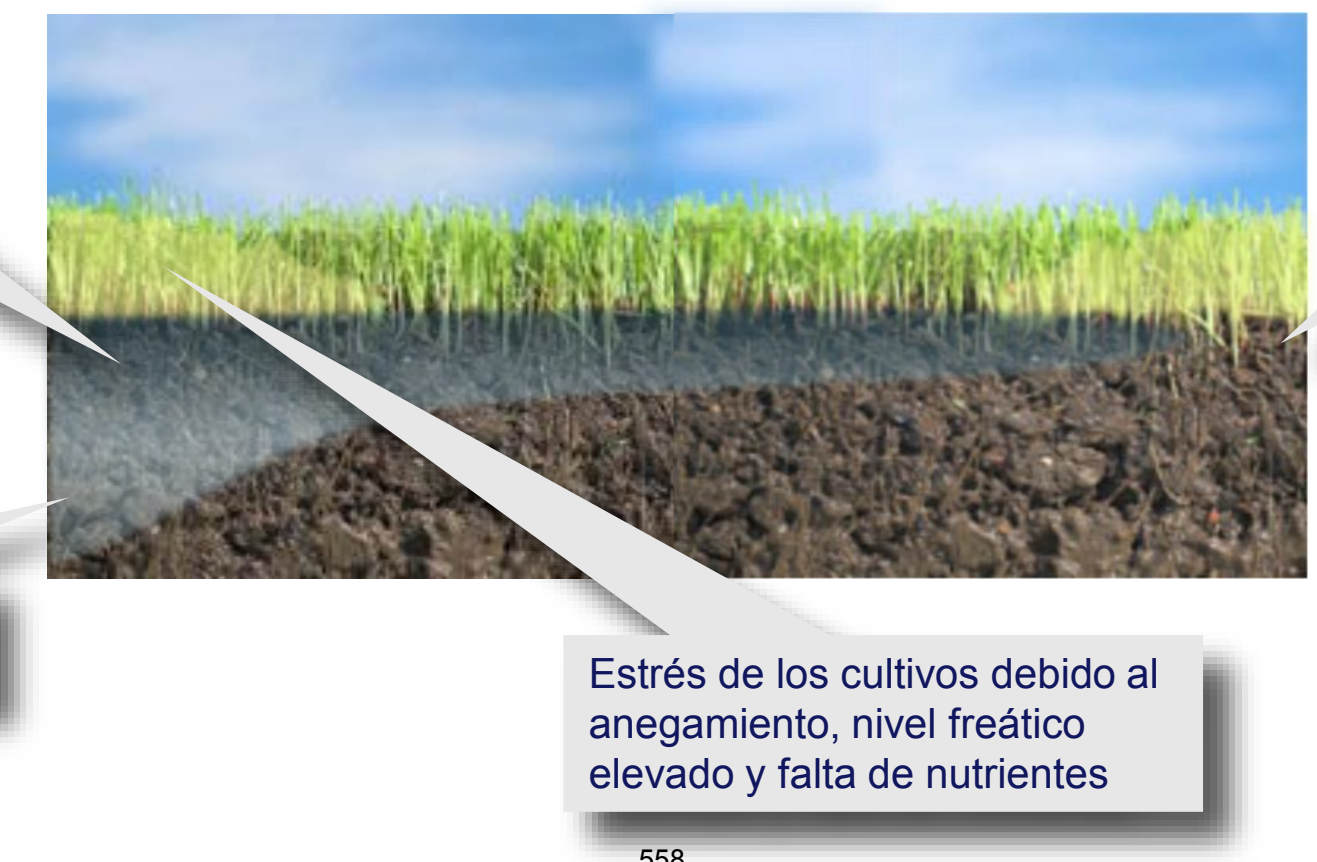

558
Estrés de los cultivos debido al anegamiento, nivel freático elevado y falta de nutrientes
La escorrentía (debido a la mala sincronización de corte) significa valioso fertilizante se elimina por lavado y puede contaminar los cursos de agua

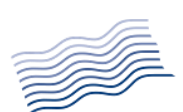

RUBICON 


\section{El control de la red asegura un alto caudal y constante}

Menos agua se utiliza y la productividad de los cultivos mejora porque los niveles de los canales se mantienen altos y estables para suministrar exactamente el agua que necesita el agricultor cuando necesitaban a caudal elevado y constante
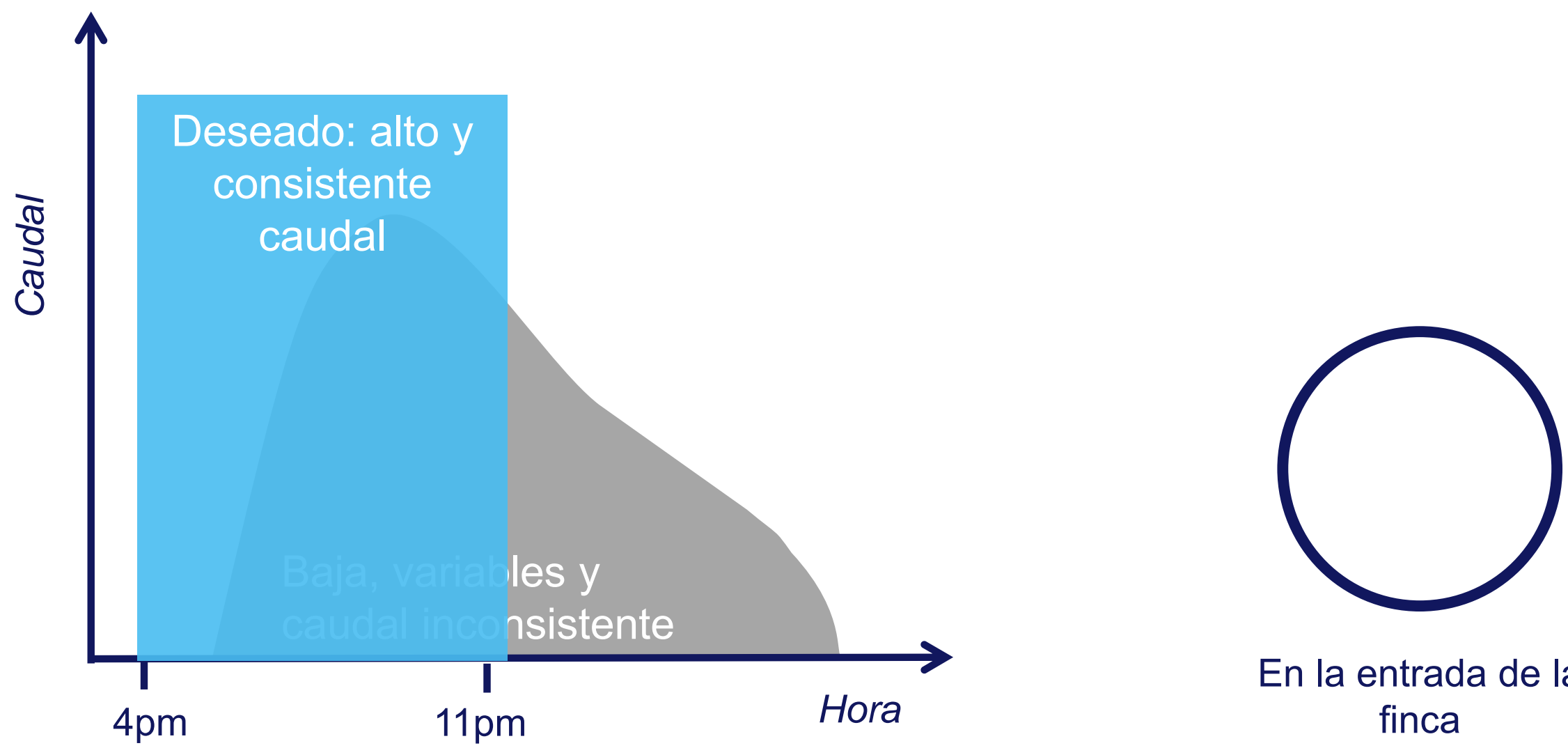

En la entrada de la finca 


\section{GMW - Australia}

$\checkmark$ Área de riego: $\mathbf{3 4 0 . 0 0 0 ~ h a}$

$6.300 \mathrm{Km}$. de canales de riego abierto

$\checkmark$ Instalación de 12.000 Compuertas Rubicon

$\checkmark$ Todo el red gestionado por Rubicon TCC software

$\checkmark$ La eficiencia de transporte y distribución mejoró de un $70 \%$ a un $85 \%$ y $90 \%=$ sistemas presurizados

$\checkmark$ No necesidad de balsas de regulación, ni bombeo, ni obra civil y entubado

$\checkmark$ Inversión MUCHO MENOR que en sistemas presurizados

$\checkmark$ SIN costes energéticos
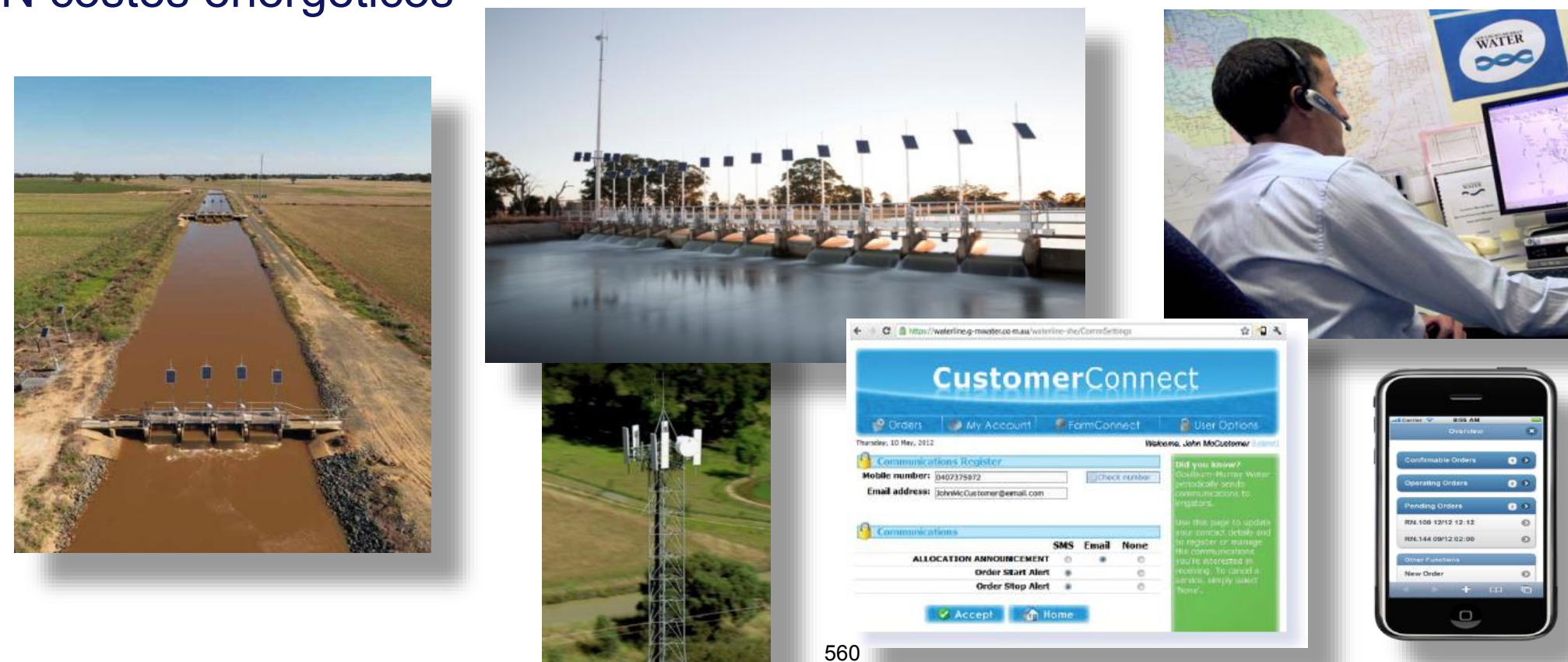


\section{Ejemplo: el poder de la automatización}

Gran precipitación el 5 Febrero 2011

$\checkmark$ Más de 330 agricultores decidieron cancelar su uso por medio de teléfono e internet

$\checkmark$ Como consecuencia la demanda disminuyó 4.000 litros por segundo ( $4 \mathrm{~m}^{3} / \mathrm{seg}$ )

$\checkmark$ Con cada disminución de la demanda, todas las compuertas en el canal principal cerraron un poquito para guardar el agua en los canales

$\checkmark$ En lugar de verterse al final del canal 200.000 litros, se vertieron solo 7.000 litros, es decir se ahorró $96.5 \%$

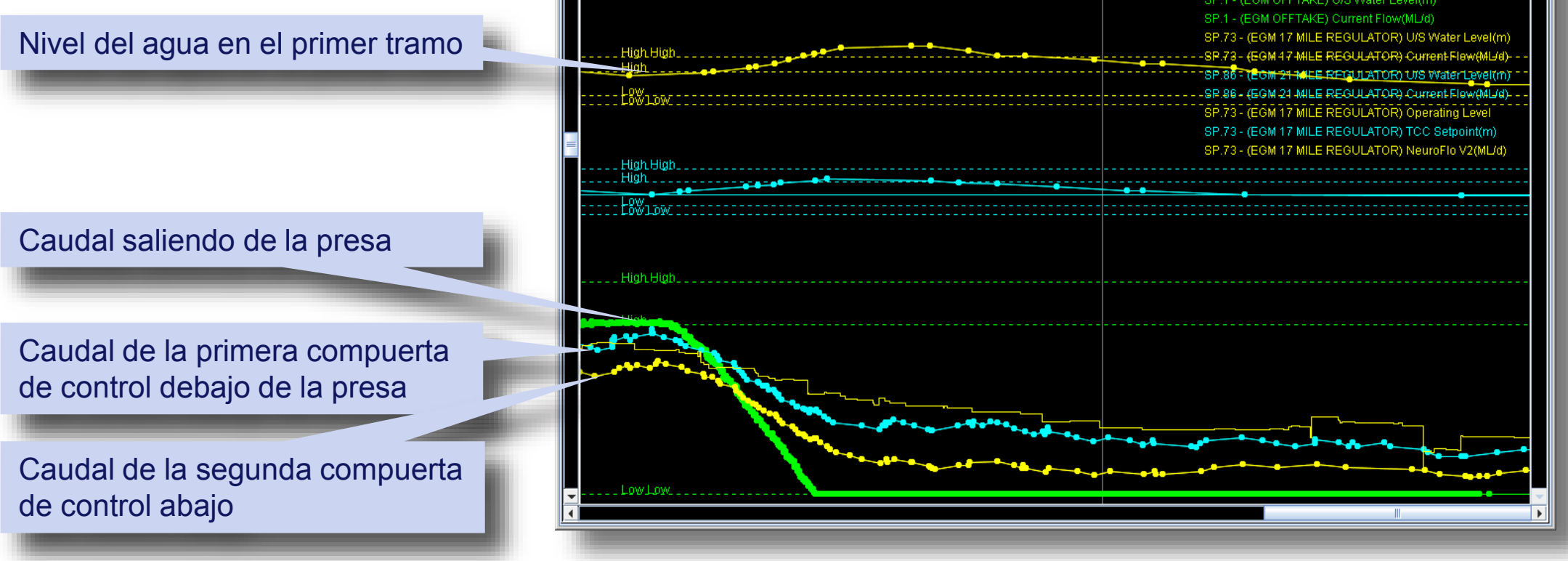




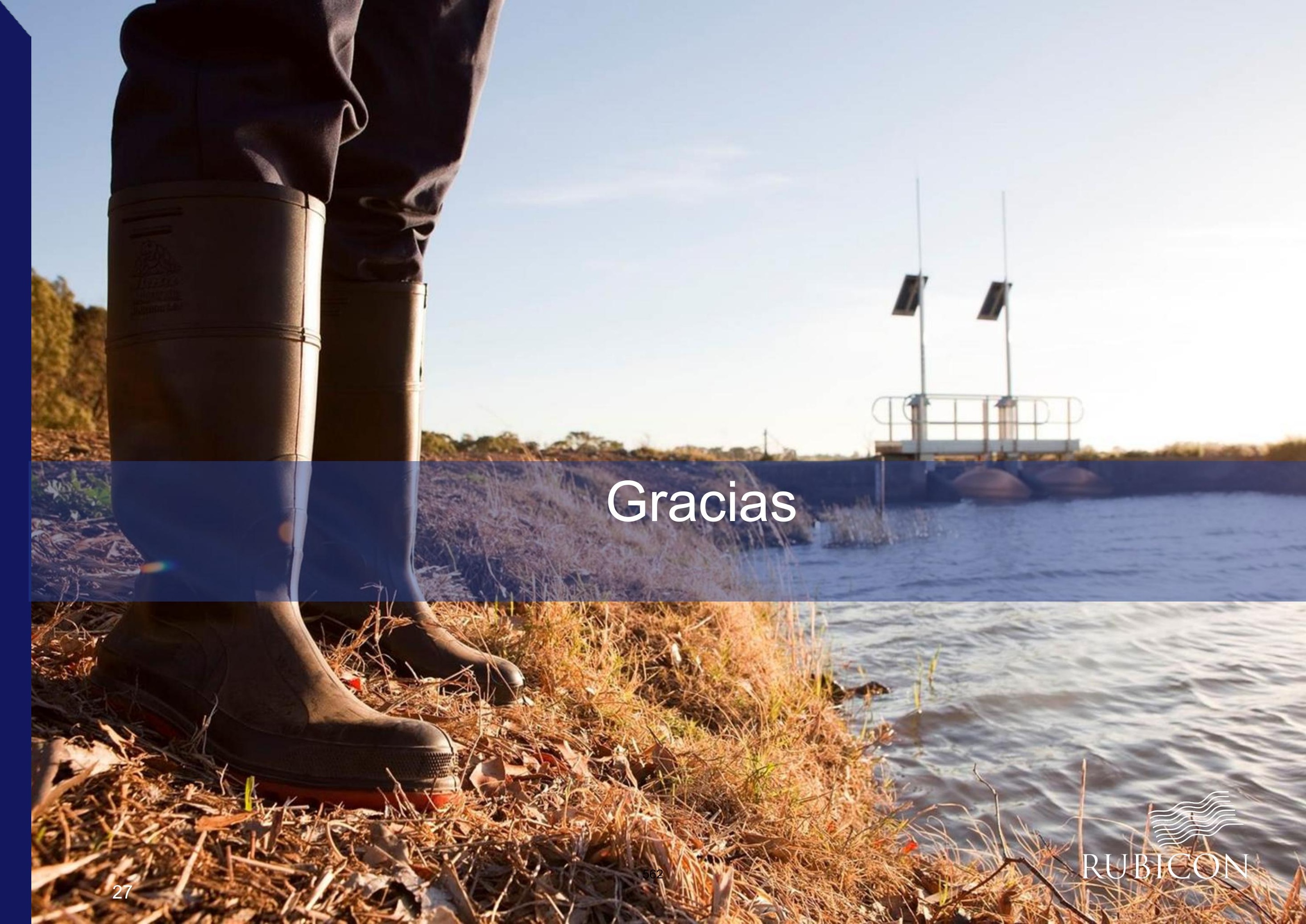




\section{COLABORAN}
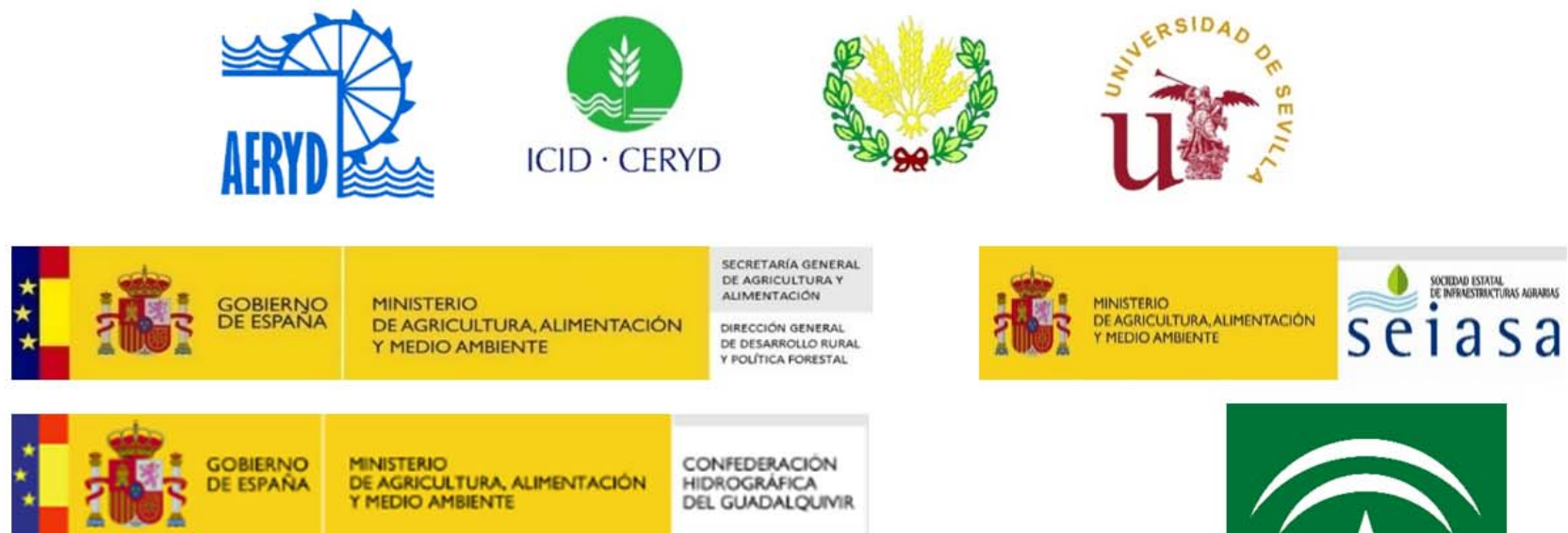

CONFEOERACION HIDROGRAFICA
DEL GUNDALQUMR

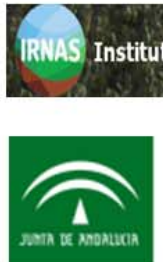

Instituto de Investigación y Formación Agraria y Pesquera CONSEJERIA DE AGRICULTURA, PESCA Y DESARROLLO RURAL

CSIC
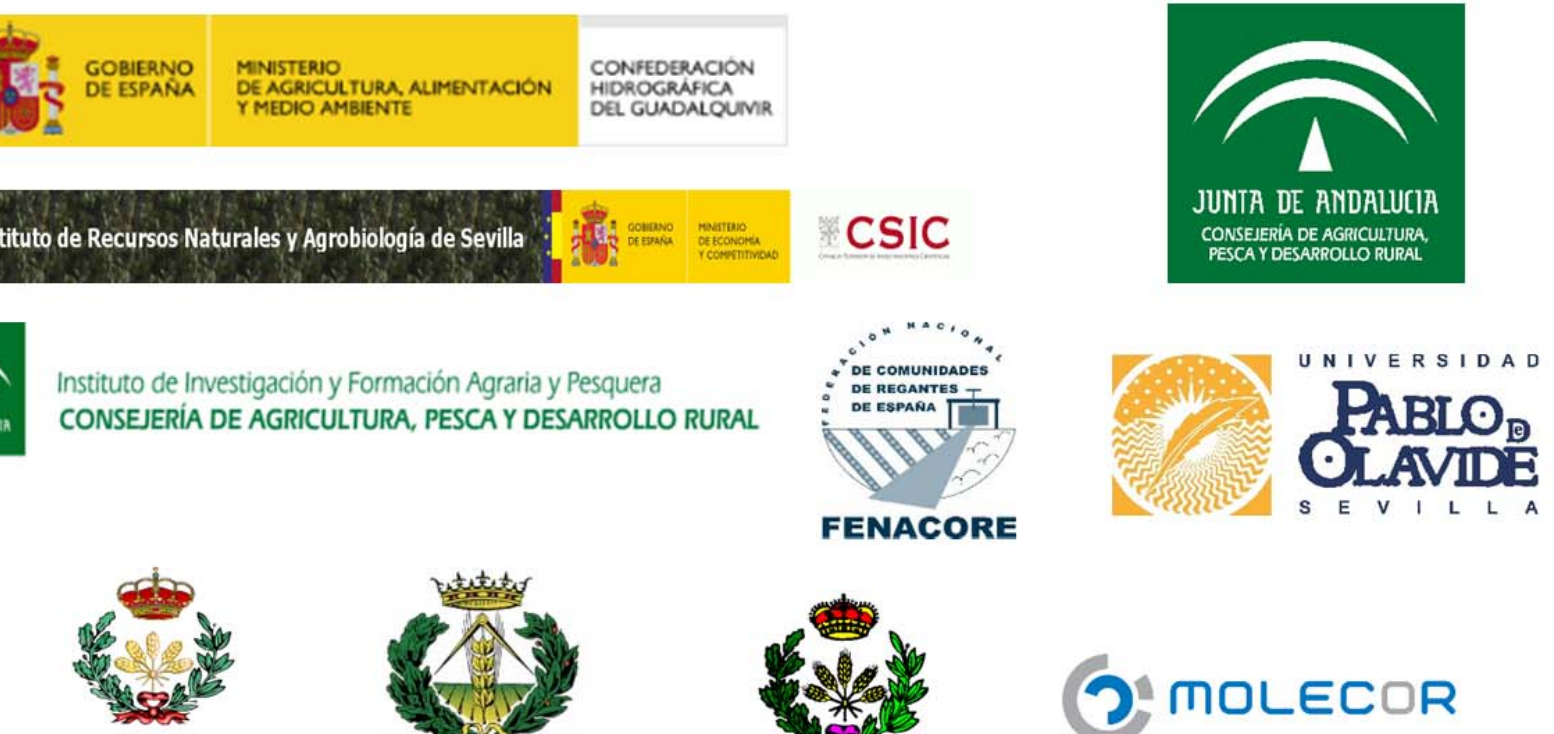

COLEGIO OFICIAL DE INGENIEROS AGRONOMOS DE ANDALUCIA
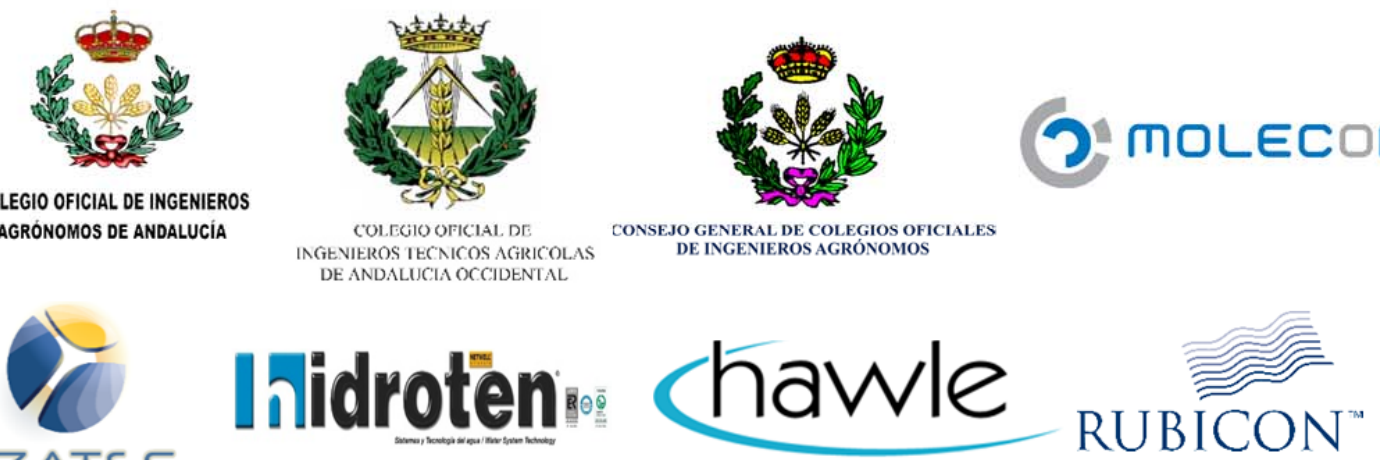